Prepared for the U.S. Department of Energy under Contract DE-AC05-76RL01830

\title{
Integrated Disposal Facility FY 2011 Glass Testing Summary Report
}

EM Pierce

DH Bacon

SN Kerisit

CF Windisch
KJ Cantrell

MM Valenta

SD Burton

JH Westsik Jr

September 2011

Pacific Northwest

NATIONAL LABORATORY

Proudly Operated by Battelle Since 1965 


\title{
DISCLAIMER
}

This report was prepared as an account of work sponsored by an agency of the United States Government. Neither the United States Government nor any agency thereof, nor Battelle Memorial Institute, nor any of their employees, makes any warranty, express or implied, or assumes any legal liability or responsibility for the accuracy, completeness, or usefulness of any information, apparatus, product, or process disclosed, or represents that its use would not infringe privately owned rights. Reference herein to any specific commercial product, process, or service by trade name, trademark, manufacturer, or otherwise does not necessarily constitute or imply its endorsement, recommendation, or favoring by the United States Government or any agency thereof, or Battelle Memorial Institute. The views and opinions of authors expressed herein do not necessarily state or reflect those of the United States Government or any agency thereof.

\author{
PACIFIC NORTHWEST NATIONAL LABORATORY \\ operated by \\ BATTELLE \\ for the \\ UNITED STATES DEPARTMENT OF ENERGY \\ under Contract DE-AC05-76RL01830
}

Printed in the United States of America
Available to DOE and DOE contractors from the
Office of Scientific and Technical Information,
P.O. Box 62, Oak Ridge, TN 37831-0062;
ph: (865) 576-8401
fax: $(\mathbf{8 6 5}) \mathbf{5 7 6 - 5 7 2 8}$
email: reports@adonis.osti.gov

Available to the public from the National Technical Information Service

5301 Shawnee Rd., Alexandria, VA 22312

ph: (800) 553-NTIS (6847)

email: orders@intis.gov $<$ http://www.ntis.gov/about/form.aspx $>$

Online ordering: http://www.ntis.gov

This document was printed on recycled paper. 


\title{
Integrated Disposal Facility Glass Testing FY 2011 Summary Report
}

\author{
EM Pierce $^{1}$ \\ KJ Cantrell \\ DH Bacon \\ MM Valenta \\ SN Kerisit \\ SD Burton \\ CF Windisch \\ JH Westsik Jr
}

September 2011

Prepared for

the U.S. Department of Energy

under Contract DE-AC05-76RL01830

Pacific Northwest National Laboratory

Richland, Washington 99352

\footnotetext{
${ }^{1}$ Oak Ridge National Laboratory, Oak Ridge, Tennessee.
} 


\section{Executive Summary}

Pacific Northwest National Laboratory (PNNL) was contracted by Washington River Protection Solutions, LLC to provide the technical basis for estimating radionuclide release from the engineered portion of the Integrated Disposal Facility (IDF) (e.g., source term). Vitrifying the low-activity waste (LAW) at Hanford is expected to generate over $1.6 \times 10^{5} \mathrm{~m}^{3}$ of glass (Certa and Wells 2010). The volume of immobilized low-activity waste (ILAW) at Hanford is the largest in the U.S. Department of Energy (DOE) complex and is one of the largest inventories (approximately $8.9 \times 10^{14} \mathrm{~Bq}$ total activity) of long-lived radionuclides, principally ${ }^{99} \mathrm{Tc}\left(\mathrm{t}_{1 / 2}=2.1 \times 10^{5}\right.$ years $)$, planned for disposal in a low-level waste (LLW) facility. Before the ILAW can be disposed, DOE must conduct a performance assessment (PA) for the IDF that describes the long-term impacts of the disposal facility on public health and environmental resources. As part of the ILAW glass testing program PNNL is implementing a strategy, consisting of experimentation and modeling, in order to provide the technical basis for estimating radionuclide release from the glass waste form in support of future IDF PAs. The purpose of this report is to summarize the progress made in fiscal year (FY) 2011 toward implementing the strategy with the goal of developing an understanding of the long-term corrosion behavior of LAW glasses.

The emphasis in FY 2011 was transitioning from the use of the Subsurface Transport Over Reactive Multi-phases (STORM) to the Subsurface Transport Over Multiple Phases (STOMP) computer code for near-field calculations. The STORM code was used in previous PAs, and STOMP-W-R has been validated as safety software through a rigorous testing program. In FY 2011, a STOMP simulation was developed that incorporates the geochemical reaction network needed to model the weathering of the glass. The reaction network includes the kinetic reactions, equilibrium reactions, mineral species, and aqueous species used previously in the STORM sensitivity analysis base case. A one-dimensional, hightemperature simulation was used for the initial STOMP modeling framework development. This onedimensional model was successfully benchmarked against the previous STORM model. The modifications must now be incorporated into the parallel-processing mode for the more complex modeling required for the PA work.

The IDF PA modeling work must account for the long-term corrosion rate of the ILAW glasses. The pressurized unsaturated flow (PUF) tests are being conducted to simulate and accelerate the glass weathering process. PUF experiments were conducted on three prototypic ILAW glasses: ORPLG9, ORPLB2, and ORPLF7. Chemical compositions of the aqueous effluents from the PUF tests are available through 107, 57, and 185 days, respectively. The ORPLG9 test is continuing. At the conclusion of the test, the weathered glasses will be characterized.

The STOMP code needs as input a series of reaction networks leading to the secondary phases that form during the weathering of the ILAW glasses. Geochemical modeling using Geochemist's Workbench ${ }^{\circledR}$ is being conducted to determine the reaction network. Product Consistency Test (PCT) data for 128 glasses were used in the geochemical modeling effort. For a majority of these glasses, a secondary-phase reaction network previously developed for ILAW glass LAWA44 produced good model fits for the major glass components. Notable exceptions were for $\mathrm{K}$ and $\mathrm{Li}$ and for glasses that contained relatively high concentrations of $\mathrm{Ca}$ and $\mathrm{Li}$ and relatively low concentrations of Na. Alternative secondary-phase reaction networks are proposed for these cases, with the exception of Li, which proved problematic. 
A Monte Carlo simulation tool is being developed to predict the composition, extent, and morphology of the weathered glass hydration layer as a function of glass composition. The developed simulation tool will then be used to provide input data for geochemical modeling of secondary phase formation to be used in PA analyses. In FY 2011, the capability was added to model condensation reactions whereby dissolved silicon atoms can deposit back on the glass surface. The code was also transformed from a single-processor to a multiple-processor code to accelerate the simulations. The updated Monte Carlo code was then used to simulate the dissolution of a series of borosilicate glasses under static and flowthrough test conditions. These simulations predict three main dissolution regimes as a function of flow rate: 1) congruent, or near-congruent, dissolution with a thin hydration layer at high flow rates; 2) the rapid formation of a blocking layer at low flow rates with slow release of the accumulated dissolved B; and 3) an intermediate regime in which the hydration layer thickens significantly and a thin blocking layer, which water can occasionally penetrate, forms at the glass-water interface.

The Monte Carlo simulations use as input glass compositions, glass structure, and the reactivity of the glass components. Magic-angle spinning nuclear magnetic resonance (MAS-NMR) spectroscopy, Raman spectroscopy and x-ray photoelectron spectroscopy (XPS) were used to characterize the glass structure. A number of simple and complex glasses were characterized with the MAS-NMR to gain a more detailed understanding of the local coordination around the Al, B, and Si atoms in the glass. Deep-UV Raman spectroscopy provided good structure/property correlation for simple borosilicate glasses but the Raman spectra of ILAW glasses were nonspecific, precluding reliable structure/property correlation for these more complex glasses. The hydration layer on the weathered ILAW glasses could not be characterized with Raman spectroscopy because the reaction layer was too thin. 


\title{
Acronyms and Abbreviations
}

\author{
1-D one-dimensional \\ 2-D two-dimensional \\ ANSI \\ American National Standards Institute \\ AREST-CT \\ Analyzer for RadionuclidE Source-Term with Chemical Transport \\ $\mathrm{BBO}$ \\ beta barium borate \\ CMP \\ Configuration Management Plan \\ $\mathrm{CP}$ \\ cross-polarization \\ DIW \\ deionized water \\ DOE \\ U.S. Department of Energy \\ EBS \\ engineered barrier system \\ ECKEChem \\ Equilibrium-Conservation-Kinetic Equation Chemistry and Reactive Transport \\ (part of STOMP computer code) \\ EDS \\ energy dispersive spectroscopy \\ EM \\ Office of Environmental Management (DOE) \\ FY \\ fiscal year \\ HDI \\ "How do I...?" (PNNL’s standards-based management system) \\ HLW \\ high-level waste \\ HR \\ high resolution \\ IDF \\ Integrated Disposal Facility \\ ILAW \\ immobilized low-activity waste \\ JY \\ Jobin Yvon \\ LabRAM \\ Laboratory Raman System \\ LAW \\ low-activity waste \\ LLW \\ low-level waste \\ MAS-NMR \\ magic-angle spinning nuclear magnetic resonance \\ $\mathrm{MC}$ \\ Monte Carlo \\ NQA \\ nuclear quality assurance \\ ORP \\ Office of River Protection \\ PA \\ performance assessment \\ PCT \\ Product Consistency Test \\ PNNL \\ Pacific Northwest National Laboratory \\ PUF \\ Pressurized Unsaturated Flow Test \\ $\mathrm{Q}^{n}$ \\ $\mathrm{SiO}_{4}$ tetrahedra with $\mathrm{n}$ non-bridging oxygen sites \\ QA \\ quality assurance \\ QC \\ quality control \\ SEM \\ scanning electron microscopy
}


SI

$\mathrm{SiO}_{4}$

SPFT

STOMP

STORM

TST

UV

VHT

VSL/CUA

WTP

$\mathrm{XRD}$ saturation index

structural representation of the silicate tetrahedral in the glass

single-pass flow-through

Subsurface Transport Over Multiple Phases (computer model)

Subsurface Transport Over Reactive Multiphases (computer code)

transition state theory

ultraviolet

Vapor Hydration Test

Vitreous State Laboratory at The Catholic University of America

Hanford Tank Waste Treatment and Immobilization Plant

X-ray diffraction 


\section{Units of Measure}

$\begin{array}{ll}{ }^{\circ} \mathrm{C} & \text { temperature in degrees Celsius }\left[\mathrm{T}\left({ }^{\circ} \mathrm{C}\right)=\mathrm{T}(\mathrm{K})-273.15\right] \\ \mathrm{cm} & \text { centimeter } \\ \mathrm{g} & \text { gram } \\ \mu & \text { micro }\left(\text { prefix, } 10^{-6}\right) \\ \mu \mathrm{m} & \text { micrometer } \\ \mathrm{mW} & \text { milliwatt } \\ \mathrm{m} & \text { meter } \\ \mathrm{M} & \text { molarity, mole/Liter } \\ \mathrm{mL} & \text { milliliter } \\ \mathrm{mol} & \text { mole } \\ \mathrm{nm} & \text { nanometers } \\ \mathrm{s} & \text { second } \\ \mathrm{R}^{2} & \text { r-squared - statistical measure of how well a data fit analysis approximates actual } \\ & \text { data points } \\ \mathrm{wt} \% & \text { weight percent }\end{array}$




\section{Contents}

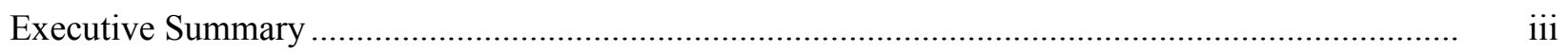

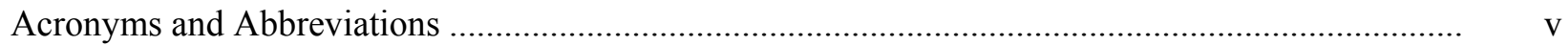

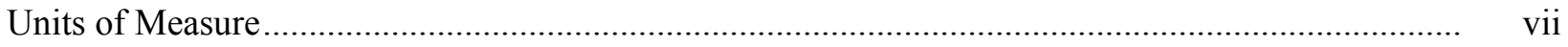

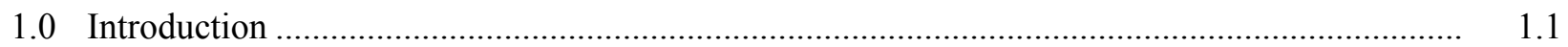

1.1 Overview_-ILAW Glass Disposal at Hanford................................................................

1.2 Purpose and Report Contents and Organization............................................................. 1.2

2.0 Theoretical Considerations for Glass......................................................................................

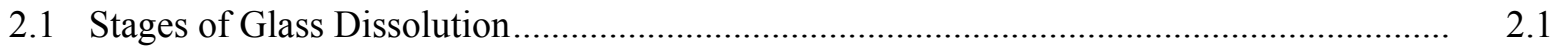

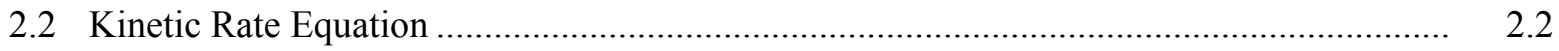

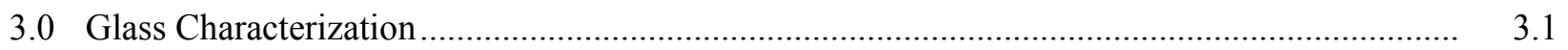

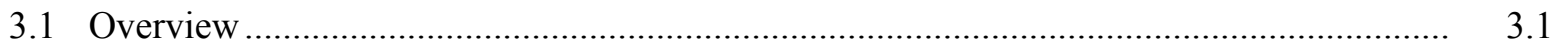

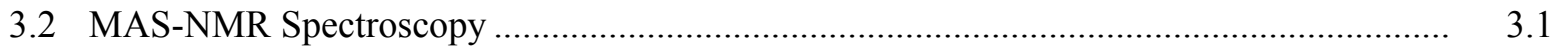

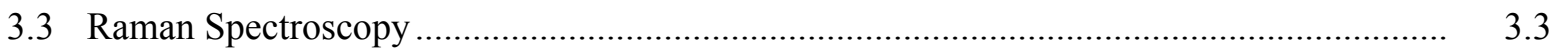

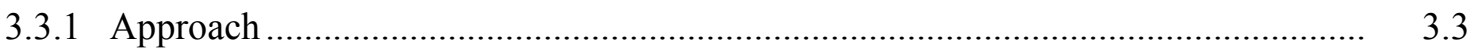

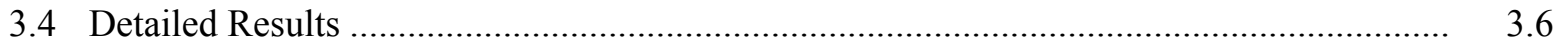

3.4.1 Deep-UV Raman of Simple Glass Compositions .............................................. 3.6

3.4.2 Deep-UV Raman Spectra of ILAW Glasses ......................................................... 3.6

3.4.3 Application of Other Techniques to ILAW Glasses............................................. 3.11

3.4.4 Current Assessment of Raman Spectra Based on XPS and EDS

3.5 Summary of Results and Conclusions........................................................................ 3.15

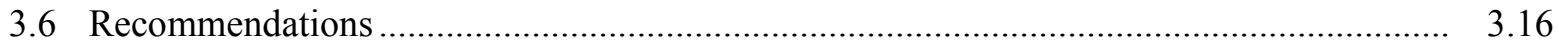

4.0 Pressurized Unsaturated Flow Experiments ....................................................................... 4.1

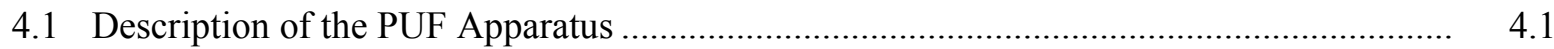

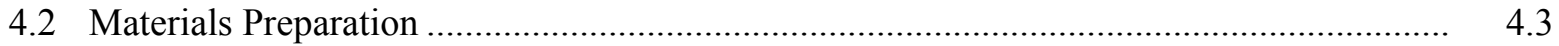

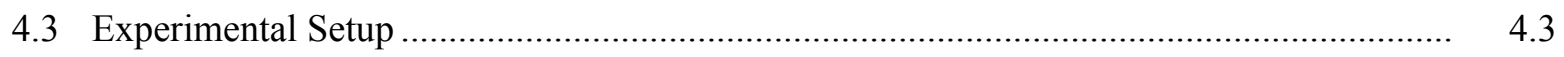

4.4 Normalized Concentration Calculation ........................................................................... 4.3

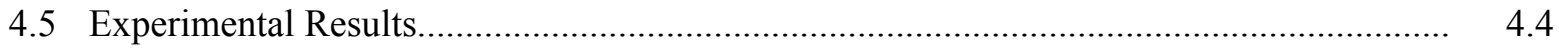

4.5.1 ORPLF7 Glass Results ......................................................................... 4.4

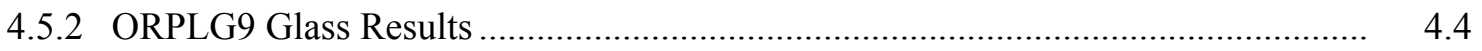

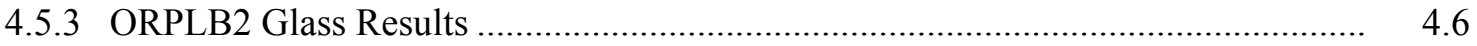

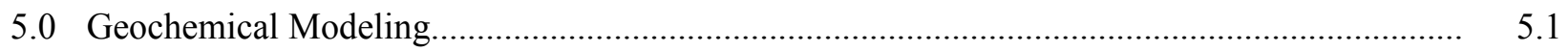

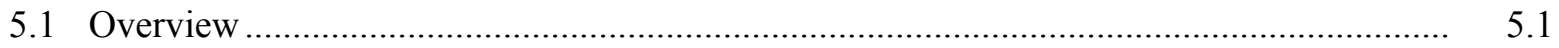

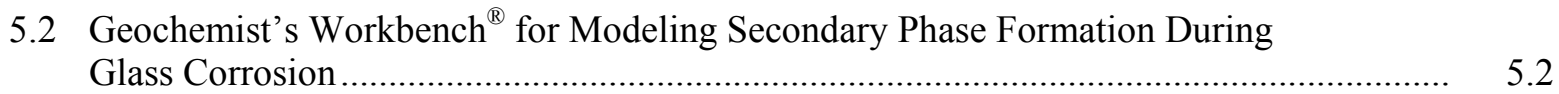

5.3 Description of Geochemical Modeling Approach for Determining Secondary

Phase Formation During Glass Corrosion 
5.4 Geochemical Modeling Results ............................................................................ 5.3

5.5 Solid-Phase Characterization Results......................................................................... 5.4

5.6 Alternative Secondary Phase Reaction Networks .......................................................... 5.6

5.7 Summary of Geochemical Modeling ........................................................................... 5.9

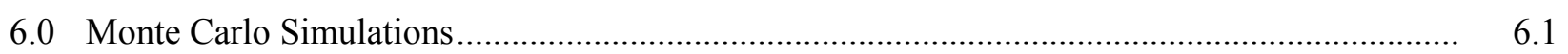

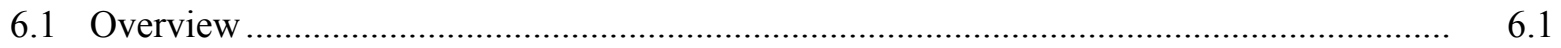

6.2 Monte Carlo Code Development..................................................................................... 6.3

6.3 Dissolution of Borosilicate Glasses in Near-Equilibrium Conditions................................ 6.4

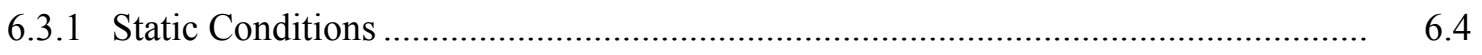

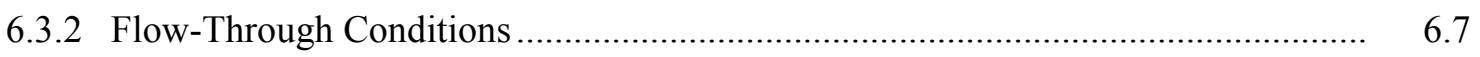

6.4 Summary of Monte Carlo Modeling Results ................................................................ 6.10

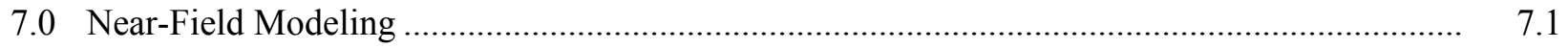

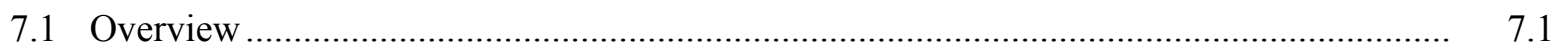

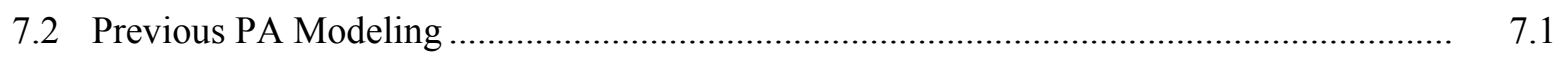

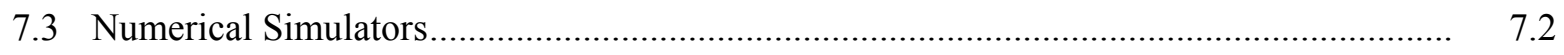

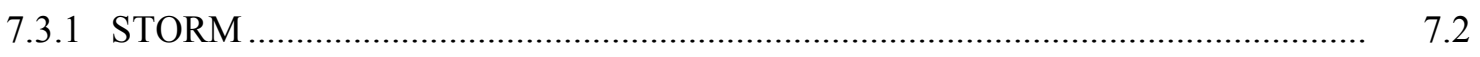

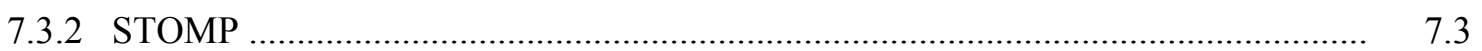

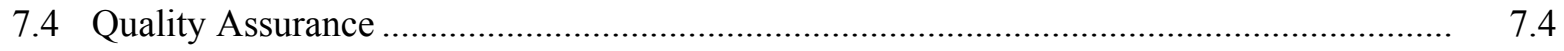

7.4.1 Description of STOMP Quality Assurance/Quality Control Program ..................... 7.4

7.4.2 Modes Compliant with NQA-1-2000 Software Requirements and DOE Order 414.1c................................................................................ $\quad 7.5$

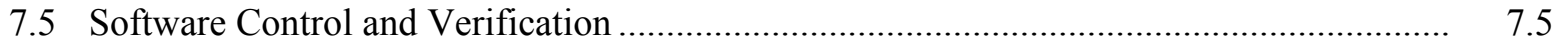

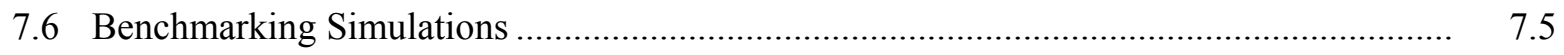

7.6.1 Base-Case Model Setup and Parameterization................................................... 7.5

7.6.2 Initial and Boundary Conditions .................................................................... 7.17

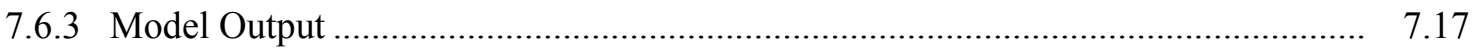

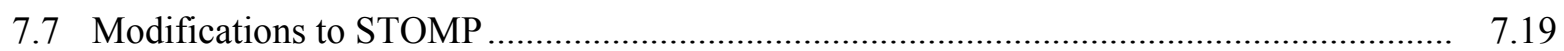

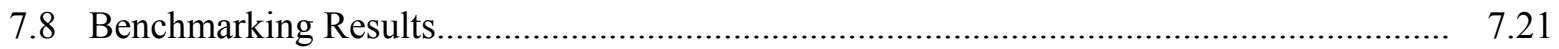

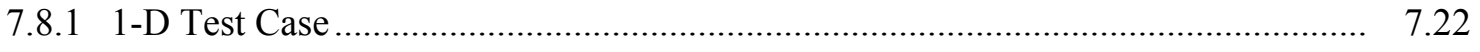

7.8.2 2-D Test Case ........................................................................................... 7.24

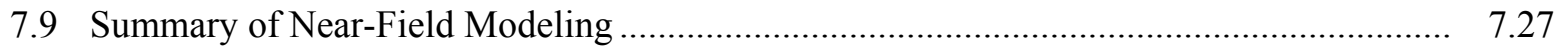

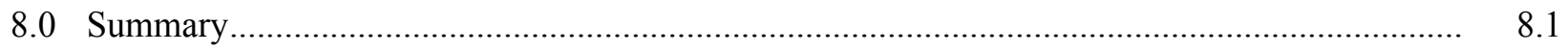

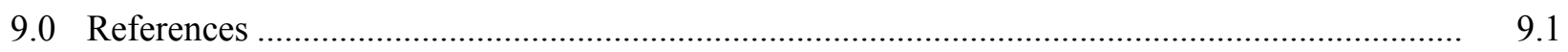

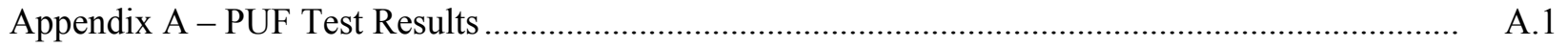

Appendix B - Glass Compositions Used for Geochemical Modeling Input ................................... B. 1

Appendix C - PCT $\left(90^{\circ} \mathrm{C}\right)$ Modeling Results ......................................................................... C.1 


\section{Figures}

2.1 General Schematic of the Stages of Glass-Water Reaction ................................................... 2.1

3.1 Boron-11 MAS-NMR for RD33, RD66, and RE100 ........................................................... 3.2

3.2 Deep-UV Raman Spectrum of LB45-45 Glass with No Post-Acquisition Correction or Modification

3.3 Deep-UV Raman Spectra of Tris Hydroxymethyl Aminomethane Buffer Crystals.

3.4 Raman Spectrum of an ILAW Glass Obtained on Another Spectrometer Using a HigherPower Visible-Light Laser....

3.5 Comparison of Deep-UV Raman Spectra of the Washed ILAW Glasses: Unreacted vs. Reacted Under Various Conditions.

4.1 Picture of PUF System Hardware

4.2 Normalized Concentration as a Function of Time for the PUF Experiment on ORPLF7 Glass.

4.3 Normalized Concentration as a Function of Time for the PUF Experiment on ORPLG9 Glass.

4.4 Normalized Concentration as a Function of Time for the PUF Experiment on ORPLB2 Glass

5.1 Schematic Representation of Data Inputs Needed for Geochemical Modeling to Develop the Chemical Reaction Network of Secondary Phases that Form During Glass Corrosion, Which is Subsequently Used in STOMP Calculation to Model the Weathering of ILAW Glasses for the IDF PA

5.2 Measured Solution Concentrations in PCT for K and Model Results Using the Secondary Reaction Network Listed in Table 3.1 and Model Results with the Addition of K-Analcime to the Network as a Function of Reaction Progress Determined for Glass Sample LAWA126

6.1 Comparison of the Time Evolution of the $\mathrm{Si}$ and $\mathrm{B}$ Concentrations in Solution for a Glass of Composition $70 \% \mathrm{SiO}_{2}, 15 \% \mathrm{~B}_{2} \mathrm{O}_{3}, 15 \% \mathrm{Na}_{2} \mathrm{O}$ and Leached at $2000 \mathrm{~m}^{-1}$ with $\left\{\mathrm{w}_{1}, \mathrm{w}_{2}, \mathrm{w}_{3}, \mathrm{w}_{\mathrm{c}}\right\}=\left\{10^{-2}, 10^{-3}, 10^{-4}, 10\right\}$ Obtained with the MC Model versus that Published by Devreux et al. in 2004 .

6.2 Si and B Concentrations as Functions of Time for a Glass of Composition $70 \% \mathrm{SiO}_{2}$, $15 \% \mathrm{~B}_{2} \mathrm{O}_{3}, 15 \% \mathrm{Na}_{2} \mathrm{O}$ and Leached at $2000 \mathrm{~m}^{-1}$ with $\left\{\mathrm{w}_{1}, \mathrm{w}_{2}, \mathrm{w}_{3}, \mathrm{w}_{\mathrm{c}}\right\}=\left\{10^{-2}, 10^{-3}, 10^{-4}, 10\right\} \ldots \ldots \ldots$

6.3 Snapshots of the Si Density as a Function of Depth from the Initial Glass-Water Interface for a Glass of Composition $70 \% \mathrm{SiO}_{2}, 15 \% \mathrm{~B}_{2} \mathrm{O}_{3}, 15 \% \mathrm{Na}_{2} \mathrm{O}$ and Leached at $2000 \mathrm{~m}^{-1}$ with $\left\{\mathrm{w}_{1}, \mathrm{w}_{2}, \mathrm{w}_{3}, \mathrm{w}_{\mathrm{c}}\right\}=\left\{10^{-2}, 10^{-3}, 10^{-4}, 10\right\}$

6.4 Total Si Density as a Function of Depth from the Initial Glass-Water Interface after 20,000 Simulation Steps

6.5 Silicon and Boron Dissolution Rates as a Function of Flow Rate for a Glass of Composition $70 \% \mathrm{SiO}_{2}, 15 \% \mathrm{~B}_{2} \mathrm{O}_{3}, 15 \% \mathrm{Na}_{2} \mathrm{O}$ and Leached at $2000 \mathrm{~m}^{-1}$ with $\left\{\mathrm{w}_{1}, \mathrm{w}_{2}, \mathrm{w}_{3}, \mathrm{w}_{\mathrm{c}}\right\}=\left\{10^{-2}, 10^{-3}, 10^{-4}, 10\right\}$

6.6 Surface Area Exposed to the Main Solution as a Function of Simulated Time as Obtained from Simulations of the Dissolution of a Glass of Composition $65 \% \mathrm{SiO}_{2}$, $17.5 \% \mathrm{~B}_{2} \mathrm{O}_{3}, 17.5 \% \mathrm{Na}_{2} \mathrm{O}$ Leached at $2000 \mathrm{~m}^{-1}$ Under a Range of Simulated Flow Rates. 
6.7 Cumulative Number of Si Atoms in the Effluent as a Function of Simulated Time for a Glass of Composition $65 \% \mathrm{SiO}_{2}, 17.5 \% \mathrm{~B}_{2} \mathrm{O}_{3}, 17.5 \% \mathrm{Na}_{2} \mathrm{O}$ Under a Range of Simulated Flow Rates

6.8 Cumulative Number of B Atoms in the Effluent as a Function of Simulated Time for a Glass of Composition $65 \% \mathrm{SiO}_{2}, 17.5 \% \mathrm{~B}_{2} \mathrm{O}_{3}, 17.5 \% \mathrm{Na}_{2} \mathrm{O}$ Under a Range of Simulated Flow Rates

6.9 Dissolution Rate Based on Silicon Release as a Function of Si Concentration in the Aqueous Solution for Three Glasses in the Composition Range (80- $x) \% \mathrm{SiO}_{2}$, $(10+x / 2) \% \mathrm{~B}_{2} \mathrm{O}_{3},(10+x / 2) \% \mathrm{Na}_{2} \mathrm{O}$, with $5<x<30 \%$.

7.1 Lithographic Units for WTP Glass Waste Form Release Simulations

7.2 Comparison of Porosity Change Predicted by STOMP and STORM

7.3 Comparison of Permeability Change Predicted by STOMP and STORM

7.4 Comparison of Effective Aqueous Diffusion Coefficients Calculated by STOMP and STORM using Campbell's Power Law Model

7.5 Comparison of Water and Tc Fluxes Across Bottom Model Boundary Predicted by STOMP and STORM 1-D Models.

7.6 Comparison of Tc Concentrations vs. Depth and Time Predicted by STOMP and STORM 1-D Models

7.7 Comparison of LAWA44 Glass Dissolution Rate Predicted by STOMP and STORM 1-D Models

7.8 Comparison of Secondary Mineral Analcime Precipitation Predicted by STOMP and STORM 1-D Models.

7.9. Comparison of Water and Te Flux Across Bottom Model Boundary for STOMP and STORM

7.10. Comparison of Tc Concentration at 300 Years Predicted by STOMP and STORM 2-D Models

7.11. Comparison of LAWA44 Glass Dissolution Rate at 300 Years Predicted by STOMP and STORM 2-D Models

7.12. Comparison of Analcime Precipitated at 300 Years Predicted by STOMP and STORM 2-D Models 


\section{Tables}

3.1 Summary of Percentages of B(III) to B(IV) for Various Unreacted and Reacted Glass Samples, Collected with an 850-MHz NMR Spectrometer ................................................... 3.3

3.2 Summary of Compositions of Unreacted ILAW Glasses ...........................................................

3.3 Reaction Conditions for Reacted ILAW Glasses.............................................................. 3.5

3.4 ILAW Glass Bulk Compositions in Terms of Atom Ratios Calculated from Mass

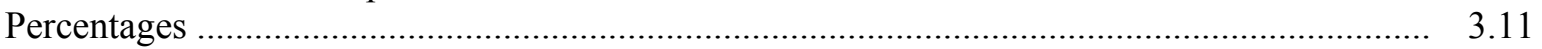

3.5 Atom Percentages and Atom Ratios Calculated from XPS Measurements of the Indicated ILAW Glasses...

3.6 Atom Ratios Calculated from EDS Measurements of the Indicated ILAW Glasses ................ 3.13

4.1 Composition of Glass Used in Simulations ...................................................................... 4.1

5.1 Secondary Phase Reaction Network Used for Initial Modeling of PCT Results ..................... 5.4

5.2 Mineral Phases Identified in PCT Glass Samples by XRD ................................................... 5.5

5.3 Mineral Phases Identified in PCT Glass Samples by SEM/EDS and XRD ............................ 5.6

6.1 Timing and Speedups Obtained from the Dissolution of a Borosilicate Glass with

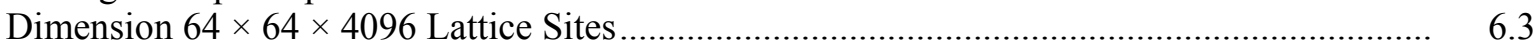

7.1 Relative Volume of Solid Species in Material Zones ...........................................................

7.2 Specific Surface Area of Solid Species in Material Zones .................................................. 7.7

7.3 Material Hydraulic Properties Used in Simulations...............................................................

7.4 Key Aqueous Species Produced by the Dissolution of Waste Glass ...................................... 7.11

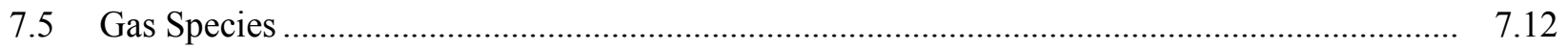

7.6 Composition and Particle Density for the Glass Specimen Used in Simulations ...................... 7.12

7.7 LAWA44 Composition in Mole Fraction Used in STORM Simulations ................................. 7.13

7.8 Composition of Native and Surrounding Materials Used in Simulations ................................. 7.13

7.9 Compositions of Secondary Minerals Used in Simulations ...................................................... 7.14

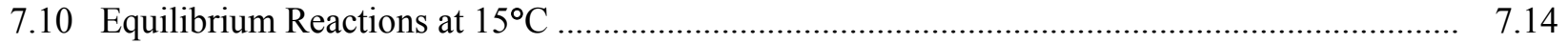

7.11 Summary of Kinetic Rate Parameters Used for Glass ....................................................... 7.16

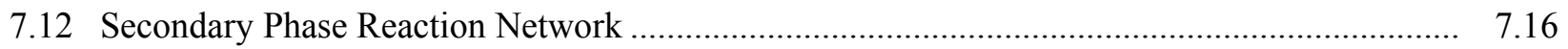

7.13 Initial Aqueous Concentrations Used in Simulations ....................................................... 7.17 


\subsection{Introduction}

The federal facilities located on the Hanford Site in southeastern Washington State have been used extensively by the U.S. government to produce nuclear materials for the U.S. strategic defense arsenal. Currently, the Hanford Site is under the stewardship of the U.S. Department of Energy (DOE) Office of Environmental Management (EM). A large inventory of radioactive and mixed waste resulting from the production of nuclear materials has accumulated, mainly in 177 underground single- and double-shell tanks located in the central plateau of the Hanford Site (Mann et al. 2001). The DOE EM Office of River Protection (ORP) is proceeding with plans to immobilize and permanently dispose of the low-activity waste (LAW) fraction onsite in a shallow subsurface disposal facility (the Integrated Disposal Facility [IDF]). Pacific Northwest National Laboratory (PNNL) was contracted to provide the technical basis for estimating radionuclide release from the engineered portion of the IDF (the source term) as part of an immobilized low-activity waste (ILAW) glass testing program to support future IDF performance assessments (PAs).

\subsection{Overview—ILAW Glass Disposal at Hanford}

Currently, DOE plans to dispose of the glasses made from nuclear waste stored in underground tanks at Hanford at two U.S. locations: 1) the ILAW glass will be stored onsite at the IDF and 2) the high-level waste (HLW) glass will be disposed of at a geologic repository (previously Yucca Mountain, Nevada). The solid and liquid waste recovered from the tanks will be pretreated to separate the low-activity fraction from the high-level and transuranic waste fractions. The LAW and HLW fractions will be immobilized into a vitrified matrix (i.e., glass). Vitrifying the LAW is expected to generate over $1.6 \times 10^{5} \mathrm{~m}^{3}$ of glass (Certa and Wells 2010). The volume of ILAW at Hanford is the largest in the DOE complex and is one of the largest inventories (approximately $8.9 \times 10^{14} \mathrm{~Bq}$ total activity) of long-lived radionuclides, principally ${ }^{99} \mathrm{Tc}\left(\mathrm{t}_{1 / 2}=2.1 \times 10^{5}\right.$ years), planned for disposal in a low-level waste (LLW) facility.

Before the ILAW can be disposed of, DOE must conduct a performance assessment (PA) for the IDF that describes the long-term impacts of the disposal facility on public health and environmental resources. One of the inputs to the PA is estimates of radionuclide release rates from the engineered portion of the disposal facility (source term). These estimates are expected to be based on chemical reactions that occur in the near field and are controlled by the dissolution of the vitrified matrix. Therefore, to provide credible estimates, a mechanistic understanding of the basic physical and geochemical processes that control glass dissolution and hence, radionuclide release, must be understood and incorporated into models to effectively simulate the glass-water reaction over the period of regulatory concern (approximately 10000 years). Apart from glass composition, the dissolution rate is a function of temperature, $\mathrm{pH}$, and solution composition of the liquid contacting the glass. The temperature of the IDF is a known constant, $15^{\circ} \mathrm{C}$. However, both the $\mathrm{pH}$ and the composition of the liquid contacting the glass are variables that are affected by flow rate, reactions with other engineered materials, gas-water equilibria, secondary-phase precipitation, alkali-ion exchange, and dissolution of the glass itself. Consequently, glass dissolution rates vary both in time and as a function of position in the disposal system. There is no physical constant such as a "leach rate" or radionuclide release rate parameter that can be assigned to the glass waste form in such a dynamic system.

A model based on empirical release behavior of the glass cannot provide feedback regarding the effects of design options on the disposal-system performance. Therefore, the source-term analysis 
requires the use of a reactive-chemical transport modeling framework that takes into account the coupled effects of fluid flow and glass-water reactions on the chemistry of liquids percolating through the disposal facility. The fluid chemistry is coupled with kinetic rate equations that describe the response of the glass corrosion rate to changes in liquid composition in the disposal facility or repository, all computed as functions of time and space. These kinetic rate equations assume that 1) the dependence of dissolution and precipitation rates on departure from equilibrium are based on arguments and assumptions of Transition State Theory (TST) and 2) the driving force for the transformation of unstable to stable silicate materials is governed principally by the magnitude of displacement from thermodynamic equilibrium. This technical strategy (McGrail et al. 1998, 2001a, 2003; Mann et al. 2001) requires the use of a reactive chemical transport code (e.g., Subsurface Transport Over Reactive Multi-phases [STORM]) that integrates the results obtained from bench-scale laboratory test methods and from long-term accelerated weathering tests to simulate and model glass weathering. For the IDF PA program, data collection has been focused on measuring and quantifying the effects of environmentally relevant and sensitive parameters (e.g., effect of $\mathrm{pH}$, temperature, and solution composition) that are needed to simulate and model, with a high level of confidence, the long-term behavior of glass. This methodology is similar to the strategy being used to analyze the Drigg LLW site in the United Kingdom (Abraitis et al. 2000; Small et al. 2000).

\subsection{Purpose and Report Contents and Organization}

The purpose of this report is to summarize the progress made in fiscal year (FY) 2011 toward implementing the strategy with the goal of developing an understanding of the long-term corrosion behavior of LAW glasses. Work completed in FY 2010 is documented in the 2010 annual report (Pierce et al. 2010b).

Section 2.0 of this report provides a brief introduction to the theoretical aspects of glass weathering, modeling the glass-water reaction. Section 3.0 discusses the glass characterization results using a combination of magic-angle spinning nuclear magnetic resonance spectroscopy (MAS-NMR), ultra violet (UV) Raman spectroscopy, and X-ray photoelectron spectroscopy to determine the relationships between local molecular structure and glass dissolution kinetics and to characterize the weathered hydration layer on leached glasses. The experimental results collected to date for pressurized unsaturated flow (PUF) test experiments conducted on three ILAW glasses are discussed in Section 4.0. Section 5.0 discusses the results from geochemical modeling calculations performed with long-term product consistency test (PCT) data on ILAW glasses to define the reaction network as input to near-field modeling calculations for performance assessment analyses. Further development of the Monte Carlo modeling code to predict the composition, extent, and morphology of the glass hydration layer as a function of glass composition is described in Section 6.0. Also included in Section 6 is a description of the application of the Monte Carlo simulation to dissolution of borosilicate glass under static and flow-through test conditions. Section 7.0 discusses the progress that has been made in transitioning from the use of STORM to STOMP for the near-field modeling calculations. Finally, a brief summary of the information contained in this report is provided in Section 8.0. 


\subsection{Theoretical Considerations for Glass}

This section briefly discusses the stages of glass dissolution, the application of a kinetic rate equation to model the glass-water reaction, how rate-law parameters vary with composition, and the numerical computer code used to simulate the glass weathering process over geologic time scales. We also discuss the technical basis for several of the assumptions used to define the base-case simulations.

\subsection{Stages of Glass Dissolution}

A large amount of information on the glass-water reaction collected over the past 25 years has been summarized in the "glass compendium" (Cunnane et al. 1994a,b) and numerous reviews (Barkatt et al. 1986; Hench et al. 1986; Bunker et al. 1988; Casey and Bunker 1990; Werme et al. 1990; Bourcier 1991, 1994; Vernaz and Dussossoy 1992; McGrail et al. 1997; Strachan and Croak 2000; Vernaz et al. 2001; Icenhower et al. 2004; Van Iseghem et al. 2004). Based on these reviews, the glass dissolution reaction can be divided into five regimes or stages (Figure 2.1) that occur as the reaction proceeds (e.g., Stage I, II, III, IV, and V).

- Stage I-Initial diffusion or interdiffusion

- Stage II-Initial or forward rate, $r_{0}$

- Stage III-Decreasing rate, $r(\mathrm{t})$

- Stage IV-Residual rate, $r_{\mathrm{r}}$

- Stage V-Alteration renewal.

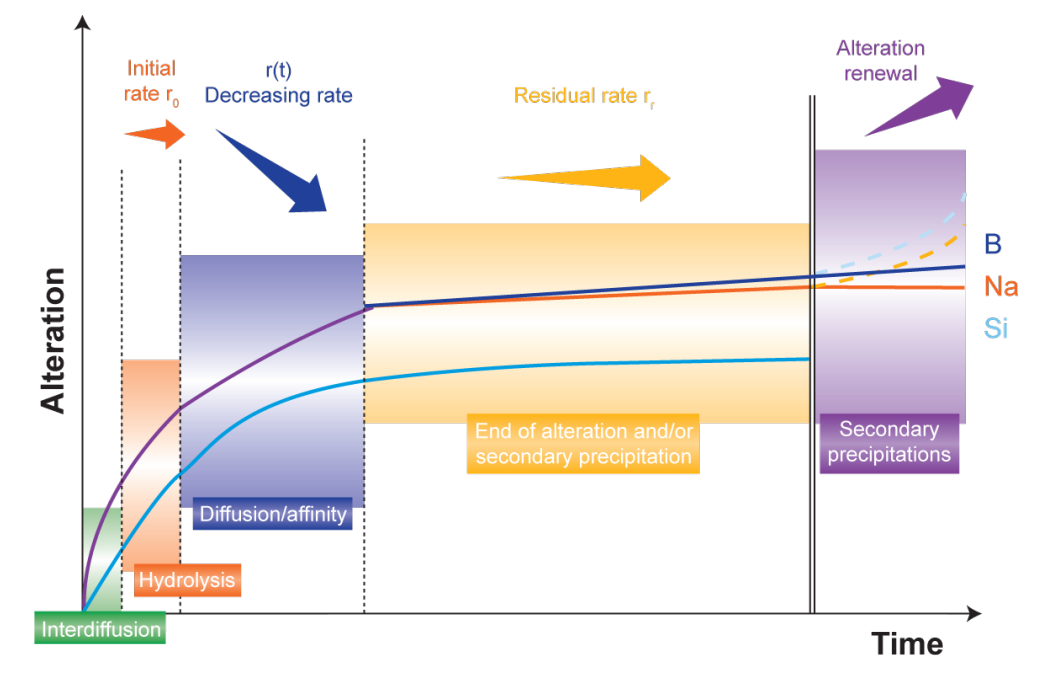

Figure 2.1. General Schematic of the Stages of Glass-Water Reaction

The initial stage (Stage I) of glass weathering begins when network-modifying cations and protons in solution are exchanged, a process referred to as interdiffusion. This mechanism has been identified experimentally during the leaching of numerous glasses, especially in acidic media (Doremus 1975). The process of interdiffusion is followed by two simultaneous reactions: hydration and dissolution of the glass 
network, commonly referred to as the initial or forward rate (Stage II). In dilute solutions, the TST-based model successfully accounts for silicate dissolution in terms of temperature, $\mathrm{pH}$, and reactive surface area. Stage III is reached as the concentration of dissolved components increases and the build-up of these components approaches the formation of a thermodynamically unstable phase (hydrated surface layer).

During Stage III, the matrix dissolution rate becomes dependent on the solution saturation state (concentration of elements in solution). Therefore, the process of ion exchange reaches a relatively constant rate in accordance with a diffusion-controlled process as a hydrated surface layer (e.g., gel layer) develops on the surface of the glass over time. The hydrated surface layer forms when relatively insoluble glass components (i.e., $\mathrm{Al}, \mathrm{Fe}$, and $\mathrm{Si}$ ) accumulate in the bulk solution and condense at the glass-water interface. Unlike the rate of ion exchange, the dissolution rate of the glass network decreases because of the common-ion effect (i.e., as the solution becomes more concentrated in glass components). The difference in chemical potential between the glass and the aqueous phase decreases, which decreases the dissolution rate - corresponding to an incongruent release of $\mathrm{B}, \mathrm{Na}$, and $\mathrm{Si}$. This decrease in the rate of matrix dissolution is partially caused by the effect silicic acid $\left(\mathrm{H}_{4} \mathrm{SiO}_{4}(\mathrm{aq})\right)$ has on the dissolution rate and the formation of the hydrated surface layer (Abraitis et al. 2000; Pierce et al. 2004a, 2008a,b). In other words, as the activity of $\mathrm{H}_{4} \mathrm{SiO}_{4}(\mathrm{aq})$ increases in the aqueous solution, the rate of glass dissolution decreases. It is important to note that in the case of glass, the dissolution rate cannot become zero because silicate glasses are thermodynamically unstable in water.

During Stage IV, the solution becomes saturated, and secondary minerals begin to form. The alteration phase is often a clay mineral, such as a smectite or chlorite (Pierce et al. 2007). The precipitation kinetics associated with these phases can be complex, but in general, the rate of secondary phase growth increases in response to the increase in magnitude of supersaturation (Nagy and Lasaga 1993; Nagy 1995). Depending on the type of alteration phase, the glass-water reaction can increase from the residual rate and return to a rate consistent with the saturation and $\mathrm{pH}$ conditions observed during Stage II (e.g., Stage V-alteration rate renewal). This type of behavior has been observed in accelerated weathering experiments and may be associated with the $\mathrm{Al} / \mathrm{Fe}$ ratio of the glass formulation (Jantzen et al. 2008).

\subsection{Kinetic Rate Equation}

A mathematical model that describes glass reactivity is needed to predict the long-term fate of glass in the subsurface over the period of regulatory concern. Over the last few decades, a general rate equation has been developed to describe the dissolution of glass (and more ordered materials) into aqueous solution. As described below, the equation is based upon the TST of chemical kinetics, in which the overall reaction rate is governed by the slowest elementary reaction. Elementary reactions have simple stoichiometry and can be combined as an overall reaction. In many cases, the elementary reactions can only be inferred. As an example of the elementary reaction, consider the dissolution of $\mathrm{SiO}_{2}$ polymorphs to form silicic acid:

$$
\mathrm{SiO}_{2}(s)+2 \mathrm{H}_{2} \mathrm{O} \leftrightarrow \mathrm{SiO}_{2} \cdot 2 \mathrm{H}_{2} \mathrm{O}^{\ddagger} \rightarrow \mathrm{H}_{4} \mathrm{SiO}_{4}(a q)
$$


in which $\mathrm{SiO}_{2} \cdot 2 \mathrm{H}_{2} \mathrm{O}^{\ddagger}$ represents an activated complex. Note that a double-headed arrow, symbolizing a reversible reaction, links the reactants and the activated complex in Equation (2.1). Equation (2.1) also illustrates that the TST formulation assumes that the decay of the activated complex is an irreversible reaction.

Previous studies have established that the corrosion rate of silicate waste glasses is a complex process that depends strongly on temperature, $\mathrm{pH}$, and the chemical composition of the aqueous solution contacting the glass (Cunnane et al. 1994a,b and the references contained therein). When the aqueous solution is dilute, the glass dissolves at a characteristic forward rate that depends only on glass composition, temperature, and solution $\mathrm{pH}$ (McGrail et al. 1997). In static systems, or where the rates of mass transport by fluid flow are slow, dissolution releases glass components into the aqueous solution, and the concentrations of these elements in the contacting fluid increase. The buildup of these dissolved components leads to slower glass corrosion rates as the contacting solution becomes more concentrated. As solution concentrations of dissolved elements continue to increase, solubility limits with respect to secondary phase(s) are reached, and these phases may begin to precipitate. Because silicate glasses are metastable solids, thermodynamics dictates that the glass will continue to dissolve or transform into more stable alteration phases. The key factor controlling long-term durability of waste glasses is the rate at which this process proceeds.

The rate law that appears to best describe this overall dissolution behavior developed by Aagaard and Helgeson (1982) and applied to glass by Grambow (1985) is presented as follows:

$$
r_{i}=\vec{k}_{o} v_{i} a_{H^{+}}^{\eta} \exp \left(\frac{E_{a}}{R T}\right)\left[1-\left(\frac{Q}{K_{g}}\right)^{\sigma}\right] \prod_{j} a_{j}
$$

where

$$
\begin{aligned}
r_{i} & =\text { dissolution rate, } \mathrm{g} \mathrm{m}^{-2} \mathrm{~d}^{-1} \\
\vec{k}_{0} & =\text { intrinsic rate constant, } \mathrm{g} \mathrm{m}^{-2} \mathrm{~d}^{-1} \\
v_{i} & =\text { mass fraction of component } i \text {, unitless } \\
a_{\mathrm{H}^{+}} & =\text {hydrogen ion activity (variable to be calculated by STOMP) } \\
E_{a} & =\text { activation energy, } \mathrm{kJ} / \mathrm{mol} \\
R & =\text { gas constant, } \mathrm{kJ} /(\mathrm{mol} \cdot \mathrm{K}) \\
T & =\text { temperature, } \mathrm{K}\left(\text { assumed constant at } 15^{\circ} \mathrm{C} \text { or } 288 \mathrm{~K}\right) \\
Q & =\text { ion activity product for glass (variable to be calculated by STOMP) } \\
K_{g} & =\text { pseudo-equilibrium constant } \\
\eta & =\text { pH power law coefficient } \\
\sigma & =\text { Temkin coefficient }(\sigma=1 \text { assumed). }
\end{aligned}
$$

The chief virtue of Equation (2.2) is that it can be directly input into reaction-transport codes for simulating the dissolution behavior of glass under specific storage conditions. Another benefit of Equation (2.2) is that it is solidly based on the TST of chemical kinetics, in which a series of reaction rates are governed by the slowest elementary reaction. Therefore, it is simply necessary to ascertain the rate-limiting step in dissolution rather than attempt to fully understand all of the possible reactions and kinetic pathways that can occur during the reaction of glass with aqueous solution. Because this 
rate-limiting step is an "elementary reaction," the stoichiometry of the reaction is typically simple and can be easily defined in a reactive transport model.

In addition, test results with ILAW and bulk vitrification glasses show that these high-sodium containing glasses are susceptible to a secondary reaction mechanism, alkali ion exchange. This reaction results in the selective extraction of $\mathrm{Na}$ via the reaction:

$$
\text { LAWA44-Na }+\mathrm{H}^{+} \rightarrow \text { LAWA44-H }+\mathrm{Na}^{+}
$$

where LAWA44-Na represents the unreacted glass containing $\mathrm{Na}$, and LAWA44-H represents a hydrated glass where the $\mathrm{Na}$ has been replaced with an equimolar amount of hydrogen. The rate of this ionexchange reaction, referred to hereafter as $r_{I E X}$, has been determined from single-pass flow-through (SPFT) experiments (Pierce et al. 2004a, 2005). In the STOMP code, the ion exchange reaction is taken into account as the amount of hydrated glass is formed via Equation (2.3), and that hydrated glass is allowed to dissolve according to the same kinetic rate law, Equation (2.2), as the parent glass. 


\subsection{Glass Characterization}

\subsection{Overview}

The objectives of the glass characterization task are to 1) determine relationships between local molecular structures in ILAW glasses and dissolution kinetics and 2) characterize the remnant of the gel layer on glasses that had undergone dissolution testing. To accomplish this task, a combination of MAS-NMR, Raman spectroscopy and x-ray photoelectron spectroscopy (XPS) were used. During FY 2011, the MAS-NMR analyses focused on conducting experiments required to gain insight into the $\mathrm{Al}, \mathrm{B}$, and Si coordination in unreacted and reacted glass samples. An overview of the results is provided below along with a few general observations. It is expected that a more detailed analysis of these data will be provided in FY 2012. A significant amount of Raman data was obtained on unreacted chemically simple glasses in FY 2010, and a summary of the results is provided below along with the data collected in FY 2011. Lastly, XPS was also used to gain insight into the composition of the surface of reacted glass samples in FY 2011 and the results are discussed in the following sections. The results from these characterization measurements will provide key information for the development of the Monte Carlo code discussed in Section 6.0.

\subsection{MAS-NMR Spectroscopy}

MAS-NMR spectroscopy was conducted with subsamples of unreacted glass powder to gain a more detailed understanding of the relationship between local coordination geometry around the Al, B, and $\mathrm{Si}$ atoms and the effect this has on glass dissolution. In addition to unreacted glass samples, reacted glass powder samples were also analyzed to gain insight into the structure of the gel layer, which develops on the glass surface during weathering.

The local coordination geometry around the $\mathrm{Al}$ and $\mathrm{Si}$ atoms contained in the glass structure was investigated at room temperature for a variety of chemically simple, three- to four-component glasses, and chemically complex, 10 - to 20 - component glasses, with ${ }^{27} \mathrm{Al},{ }^{11} \mathrm{~B}$, and ${ }^{29} \mathrm{Si}$ MAS-NMR. The ${ }^{27} \mathrm{Al}$ and ${ }^{11} \mathrm{~B}$ spectra for each glass were collected at high field using a combination of $850-\mathrm{MHz}$ and $900-\mathrm{MHz} \mathrm{NMR}$ spectrometers. The data acquired on higher-field instruments allow for the separation of the anticipated boron species, especially in the more chemically complex ILAW glass samples. The increased resolution provides better data for determining the percentage of boron moieties. The high-field spectrometers also provide dependable data with regard to accounting for the Al species (four-coordinate or six-coordinate).

The ${ }^{29} \mathrm{Si}$ cross-polarization (CP) MAS-NMR spectra for each glass sample were collected on a $300-\mathrm{MHz}$ NMR spectrometer. Spectra were referenced to tetrakis(trimethylsilyl)silane $\left(\mathrm{Si}\left[\mathrm{Si}\left(\mathrm{CH}_{3}\right)_{3}\right]_{4}\right.$, $9.8 \mathrm{ppm})$. The Si data was taken for two sets of glasses to ascertain changes in Si-O linkage populations, specifically looking for changes in population in $\mathrm{Q} 4-\mathrm{Q} 1\left[\mathrm{Si}(\mathrm{O})_{4}\right.$ to $\mathrm{Si}(\mathrm{O})$ ] groups. The chemical shift of ${ }^{29} \mathrm{Si}$ moves downfield from Q4 to Q1 with changes in the silica polymerization. It has also been documented that the peak position shifts downfield with increasing aluminum content, which results in significantly more $\mathrm{Si}-\mathrm{O}-\mathrm{Al}$ moieties versus $\mathrm{Si}-\mathrm{O}-\mathrm{Si}$.

The results collected to date suggest that for all of the glass samples tested, the fourfold-coordinated $\mathrm{Si}$ is present with a variety of Q species and the distribution of these Q species changes with glass composition. For example, CP MAS-NMR results reveal that the distribution of Q species in unreacted 
Hf glasses shifts to lower values with an increase in the Hf content, suggesting that the polymerized Si network ( $\mathrm{Si}-\mathrm{O}-\mathrm{Si}$ linkages) is being disrupted by the formation of $\mathrm{Hf}-\mathrm{O}-\mathrm{Si}$ linkages (Lobanova et al. 2001; Zhange et al. 2001; Davis et al. 2003). The effect of Hf on glass dissolution is consistent with other high-valence cations (HVC) such as $\mathrm{Zr}$, which tend to increase the overall glass durability as $\mathrm{Hf}-\mathrm{O}-\mathrm{Si}$ or $\mathrm{Zr}-\mathrm{O}-\mathrm{Si}$ linkages increase, because these linkages are much stronger than the typical $\mathrm{Si}-\mathrm{O}-\mathrm{Si}$ or $\mathrm{Si}-\mathrm{O}-\mathrm{Al}$ linkages. In addition to changing the unaltered glass structure, HVCs, such as $\mathrm{Zr}$, also affect the rate of dissolution by changing the morphology and pore size of the gel layer formed during the glass dissolution process under near-saturated conditions (Lobanova et al. 2001; Bergeron et al. 2010).

In addition to unreacted glass samples, Si CP MAS-NMR spectra of leached NeB series and LAWA44, LAWB45, and LAWC22 glasses were also analyzed. A few general observations can be ascertained from these results. The median ${ }^{29} \mathrm{Si}$ chemical shift moves from -86 to $-95 \mathrm{ppm}$, suggesting the surface is becoming more polymerized with respect to $\mathrm{Si}-\mathrm{O}-\mathrm{Si}$ linkages. This observation is consistent with the Raman and XPS results discussed in the next section.

Similar to $\mathrm{Si}$ in unreacted glass samples, the $\mathrm{Al}$ is fourfold coordinated, whereas the $\mathrm{B}$ coordination alternates between three- and fourfold coordination. An example of this for a chemically simple glass sample is shown in Figure 3.1. The results are also summarized in Table 3.1. The downfield peaks (10 to $20 \mathrm{ppm}$ ) are consistent with threefold or trigonal coordination, while the upfield resonance ( 2 to $-1 \mathrm{ppm})$ is consistent with fourfold or tetrahedral coordination. These results show the fourfold-coordinated $\mathrm{B}$ increases with $\mathrm{B}$ content for the RE series glasses. The relationship between the effect of glass composition on B speciation in unaltered glass samples is not unexpected and has been observed previously; see Pierce et al. (2010a) and the references contained therein. Additional information on the percentage of ring versus non-ring threefold-coordinated B is also contained in the downfield peak. Analysis of the MAS-NMR data will continue in FY 2012.

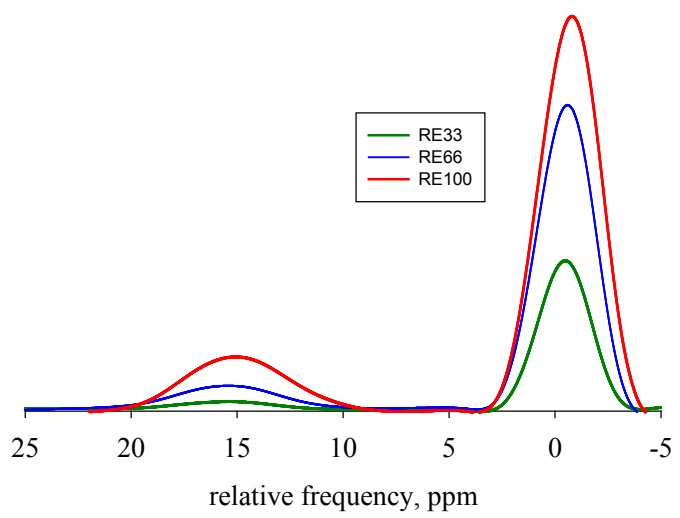

Figure 3.1. Boron-11 MAS-NMR for RD33, RD66, and RE100 (from bottom to top). All spectra were collected on a 750-MHz spectrometer. The downfield peaks (10 to $20 \mathrm{ppm}$ ) are consistent with trigonal coordination, while the upfield resonance ( 2 to $-1 \mathrm{ppm})$ is consistent with tetrahedral coordination. 
Table 3.1. Summary of Percentages of B(III) to B(IV) for Various Unreacted and Reacted Glass Samples, Collected with an 850-MHz NMR Spectrometer

\begin{tabular}{cccc}
\hline Unreacted Glasses & B(III) & B(IV) & \\
\hline BOJ-1 & 1.4 & 98.6 & \\
BOJ-2 & 4.62 & 95.38 & \\
LAW290A & 42.63 & 57.37 & \\
LAW44 fines & 43.24 & 56.76 & \\
LAW95A & 45.07 & 54.93 & \\
Hf 0\% & 25.06 & 74.94 & \\
Hf 10\% & 27.46 & 72.54 & \\
Hf 15\% & 30.56 & 69.44 & \\
Hf 20\% & 37.08 & 62.92 & \\
RD100 & 22.11 & 77.89 & \\
Reacted Glasses & B(III) & B(IV) & Percent Silicic Acid \\
\hline NeB1 & 89.85 & 10.15 & \\
NeB2 & 53.89 & 46.11 & \\
LAWB45-45 & 53.24 & 46.76 & 40 \\
LAWB45-46 & 53.1 & 46.9 & 60 \\
LAWB45-47 & 53.61 & 46.39 & 80 \\
LAWB45-48 & 55.01 & 44.99 & 100 \\
LAWA44-27 & 51 & 49 & 0 \\
LAWA44-32 & 49.35 & 50.65 & 80 \\
\hline & & &
\end{tabular}

\subsection{Raman Spectroscopy}

The objectives of this Task were to apply deep-UV Raman spectroscopy to 1) determine relationships between local molecular structures in the ILAW glasses and dissolution kinetics and 2) characterize the remnant of the gel layer on glasses that had undergone dissolution testing.

\subsubsection{Approach}

\subsubsection{Raman Spectroscopy}

Raman spectroscopy was chosen as the preferred method to identify local molecular structures in the ILAW glasses and reaction layer composition for several reasons. First, the technique was successfully applied for this purpose on bulk glass samples with "simple" composition (compared to the ILAW glasses) that were the focus of study in previous years of this program (Pierce et al. 2010a,b). Windisch et al. (2011) confirmed the advantages of Raman spectroscopy in studying glasses that, although simpler in composition, were related to the ILAW glasses. The technique could distinguish different local molecular structures, including silicate tetrahedra with different numbers of non-bridging oxygen atoms, and borate groups, and also identified devitrification if it occurred. Additionally, there exists a significant database in the literature of the Raman spectra of glasses, along with protocol for deconvoluting bands in these spectra. The open literature was used to help correlate Raman spectra with local molecular 
structures. Finally, Raman spectroscopy is usually more easily adapted to in-situ study, which was considered an advantage over other techniques if there were future interest and resources to monitor the gel layer as it formed during dissolution testing.

The use of deep- $\boldsymbol{U} \boldsymbol{V}$ Raman spectroscopy was the focus of research in FY 2011. Deep-UV excitation, specifically at $244 \mathrm{~nm}$, is a special type of Raman spectroscopy with advantageous that are particularly suited to the ILAW glasses. Moreover, deep-UV Raman spectroscopy had not been previously applied to ILAW glass compositions. There are three distinct advantages to deep-UV Raman spectroscopy. First, primarily because of reduced dispersion, there is virtually no fluorescence interference when acquiring Raman spectra of condensed-phase materials when using excitation wavelengths shorter than approximately $260 \mathrm{~nm}$. This is important for the ILAW glass samples we tested because the samples were in the form of powders or fines. High-surface-area silicate glass samples produce a large amount of fluorescence from surface hydroxides and defects that can easily overwhelm Raman scattering. This phenomenon and the success of using deep-UV excitation are discussed in "Detailed Results," Section 3.4 below. Second, deep-UV Raman excitation results in an enhancement of Raman scattering intensity, scaling with the fourth power of the frequency of excitation. Finally, surface sensitivity is greater when using shorter wavelengths, which was considered advantageous when identifying the remnant of the gel layer.

Raman spectra were collected using a Horiba JY (Jobin Yvon) (Edison, New Jersey) LabRAM HR (high-resolution) Raman (confocal) microscope system. With a focal length of $0.8 \mathrm{~m}$ and dual gratings with groove density of 2400 grooves $/ \mathrm{mm}$, the instrument can achieve a nominal spectral resolution of 1-2 $\mathrm{cm}^{-1}$. Excitation was provided by the deep-UV 244-nm line of a Lexel (Fremont, California) Model 85-SHG frequency-doubled $\mathrm{Ar}^{+}$-ion laser equipped with a nonlinear beta barium borate crystal. Laser power was $25 \mathrm{~mW}$ at the source and approximately $2 \mathrm{~mW}$ at the sample. A $40 \times \mathrm{UV}$-compatible microscope objective (numerical aperture $=0.75$ ) was used. The spectrometer pinhole was kept fairly large, at $400 \mu \mathrm{m}$, resulting in less-than-optimal depth and lateral resolution. However, laser throughput was improved with the larger pinhole, giving exceptionally high Raman intensities, in some cases tens of thousands of counts, when collected with a relatively short exposure time (100-200 s). The spectral range was restricted to Raman shift above $450 \mathrm{~cm}^{-1}$. Measurements at lower frequencies were not possible because of the presence of a factory-installed edge filter for eliminating the exciting line. Consequently, Raman bands associated with deformation modes, commonly observed below $500 \mathrm{~cm}^{-1}$, were not observable in this study. Instead, emphasis was on the stretching modes, both network and those that involve non-bridging oxygen, which occur at higher frequencies. Spectral analysis, including curve fitting, was performed using Thermo Scientific (Waltham, Massachusetts) GRAMS/32 AI software. Grams/32 AI uses the Levenberg-Marquardt nonlinear peak fitting method (Levenberg 1944). It was applied here using Gaussian peak functions and restricted to the $710-1325 \mathrm{~cm}^{-1}$ region of the spectrum. Prior to curve fitting, a weak exponential baseline correction was used to remove the small amount of background that persists in this region even with deep-UV excitation.

\subsubsection{Glass Samples}

Three ILAW glasses were also studied in this research and their compositions are given below in Table 3.2. The ILAW glasses were studied both before and after reaction in SPFT tests. The intention was to use the Raman spectra of the glasses before dissolution testing to identify the principal molecular structures in the glasses. By comparing these spectra to spectra taken after testing, the goal was to 
determine which, if any, of the structures were affected by the dissolution tests and to identify new phases that might be part of the remnant of the gel layer on the reacted glass surface. The most important variables for the SPFT tests on the three ILAW glasses are given in Table 3.3. Note that part of the sample names correlates with the corresponding untested ILAW glass (LB=LAWB; LC=LAWC;

LW=LAWA). Also, Si refers to composition of the flow-through stream in terms of percent silicate acid with respect to saturation.

Table 3.2. Summary of Compositions of Unreacted ILAW Glasses

\begin{tabular}{lccc}
\hline \multicolumn{1}{c}{ Oxide } & LAWA44 & LAWB45 & LAWC22 \\
\hline $\mathrm{Al}_{2} \mathrm{O}_{3}$ & $6.20 \%$ & $6.13 \%$ & $6.08 \%$ \\
$\mathrm{~B}_{2} \mathrm{O}_{3}$ & $8.90 \%$ & $12.34 \%$ & $10.06 \%$ \\
$\mathrm{CaO}$ & $1.99 \%$ & $6.63 \%$ & $5.12 \%$ \\
$\mathrm{Cl}$ & $0.65 \%$ & $0.01 \%$ & $0.09 \%$ \\
$\mathrm{Cr}_{2} \mathrm{O}_{3}$ & $0.02 \%$ & $0.07 \%$ & $0.02 \%$ \\
$\mathrm{~F}$ & $0.01 \%$ & $0.08 \%$ & $0.16 \%$ \\
$\mathrm{Fe}_{2} \mathrm{O}_{3}$ & $6.98 \%$ & $5.26 \%$ & $5.43 \%$ \\
$\mathrm{~K}_{2} \mathrm{O}$ & $0.50 \%$ & $0.26 \%$ & $0.10 \%$ \\
$\mathrm{Li}_{2} \mathrm{O}$ & - & $4.62 \%$ & $2.51 \%$ \\
$\mathrm{MgO}$ & $1.99 \%$ & $2.97 \%$ & $1.51 \%$ \\
$\mathrm{MnO}$ & - & - & $0.04 \%$ \\
$\mathrm{MoO}_{3}$ & $0.01 \%$ & - & - \\
$\mathrm{Na}_{2} \mathrm{O}$ & $20.00 \%$ & $6.50 \%$ & $14.40 \%$ \\
$\mathrm{NiO}$ & - & - & $0.03 \%$ \\
$\mathrm{P}_{2} \mathrm{O}_{5}$ & $0.03 \%$ & $0.03 \%$ & $0.17 \%$ \\
$\mathrm{PbO}_{2}$ & - & - & $0.02 \%$ \\
$\mathrm{Re}_{2} \mathrm{O}_{7}$ & $0.10 \%$ & $0.01 \%$ & $0.01 \%$ \\
$\mathrm{SO}_{3}$ & $0.10 \%$ & $0.84 \%$ & $0.34 \%$ \\
$\mathrm{SiO}_{2}$ & $44.55 \%$ & $47.86 \%$ & $46.67 \%$ \\
$\mathrm{TiO}_{2}$ & $1.99 \%$ & - & $1.14 \%$ \\
$\mathrm{ZnO}_{\mathrm{ZrO}_{2}}$ & $2.96 \%$ & $3.15 \%$ & $3.07 \%$ \\
\hline & $2.99 \%$ & $3.15 \%$ & $3.03 \%$ \\
\hline
\end{tabular}

Table 3.3. Reaction Conditions for Reacted ILAW Glasses

\begin{tabular}{cccc}
\hline Glass & $\mathrm{pH}$ & Temperature & Percent Silicate Acid \\
\hline LB45-43 & 9.0 & $90^{\circ} \mathrm{C}$ & 0.0 \\
LB45-44 & 9.0 & $90^{\circ} \mathrm{C}$ & 20 \\
LB45-45 & 9.0 & $90^{\circ} \mathrm{C}$ & 40 \\
LB45-46 & 9.0 & $90^{\circ} \mathrm{C}$ & 60 \\
LB45-47 & 9.0 & $90^{\circ} \mathrm{C}$ & 80 \\
LB45-48 & 9.0 & $90^{\circ} \mathrm{C}$ & 100 \\
LC22-43 & 9.0 & $90^{\circ} \mathrm{C}$ & 0 \\
LC22-47 & 9.0 & $90^{\circ} \mathrm{C}$ & 80 \\
LW44-27 & 9.0 & $90^{\circ} \mathrm{C}$ & 0 \\
LW44-32 & 9.0 & $90^{\circ} \mathrm{C}$ & $80 \%$ \\
\hline
\end{tabular}




\subsection{Detailed Results}

\subsubsection{Deep-UV Raman of Simple Glass Compositions}

These results collected on the simple glass compositions were discussed in the FY 2010 summary report and published as a journal article in FY 2011 (Windisch et al. 2011). Therefore, we will only provide a brief summary of the conclusions of the work here.

Conclusions from simple glass study. Deep-UV Raman spectroscopy employing 244-nm excitation was advantageous over visible Raman spectroscopy when applied to glasses in finely powdered form. In particular, both reduced fluorescence background and improved signal-to-noise were realized, the latter approaching a magnitude consistent with the fourth-power scattering law. Raman spectra acquired this way on silica-rich borosilicate glass powders with compositions at or above the trisilicate composition were successfully curve fit using a protocol similar to that previously discussed in the literature. The results demonstrated a systematic variation of $Q^{3}$ units in the glass as a function of both $\mathrm{Na}_{2} \mathrm{O}$ and $\mathrm{B}_{2} \mathrm{O}_{3}$ content. Increasing $\mathrm{Na}_{2} \mathrm{O}$ was found to raise the fraction of $\mathrm{Q}^{3}$ units in the glasses systematically, in agreement with studies on related glasses, and, as long as the value of the $\mathrm{Na}_{2} \mathrm{O} / \mathrm{B}_{2} \mathrm{O}_{3}$ ratio was sufficiently high, to contribute to higher rates of dissolution in SPFT testing. In contrast, dissolution rates appeared less strongly determined by the $\mathrm{Q}^{3}$ fraction when $\mathrm{Na}_{2} \mathrm{O} / \mathrm{B}_{2} \mathrm{O}_{3}$ was near unity and appeared to grow larger upon further reduction of the $\mathrm{Q}^{3}$ fraction. The results were interpreted to indicate the increasingly important role of network hydrolysis in the glass dissolution mechanism in compositions where a $\mathrm{BO}_{4}$ tetrahedron supplants the $\mathrm{Q}^{3}$ unit as the charge-compensating structure for $\mathrm{Na}^{+}$ions.

\subsubsection{Deep-UV Raman Spectra of ILAW Glasses}

Preliminary assessment of spectra. Deep-UV Raman spectra of the reacted ILAW glasses in Table 3.2 before SPFT testing and after testing under conditions in Table 3.3 showed characteristics similar to those illustrated by LB45-45 in Figure 3.2. Several points need to be made regarding these spectra. First, the intensities of the Raman bands were uncharacteristically weak, compared to spectra of the "simple" glasses discussed previously in this report. Intensities of the bands were only a few hundred counts. This holds for both the unreacted and reacted samples. Consequently, signal-to-noise was also relatively poor. This can be attributed to a number of factors, including the large number of components in these glasses including several different network formers and modifiers (giving rise to even more disorder in the structure than realized in a simple glass composition), as well as the coloring (tan to green) that results in more absorption and less scattering. Also, the form of the glass fines was irregular, so that Raman spectra of varying quality were obtained at different positions around the sample. The best spectrum for each sample was obtained only after significant time spent taking trial-and-error measurements at different points on the sample. The spectra in Figure 3.2 (obtained at two locations) correspond to those with the highest signal-to-noise ratio for LB45-45. The additional time associated with obtaining several spectra to get the best result increased the "typical acquisition time" for a sample significantly. 


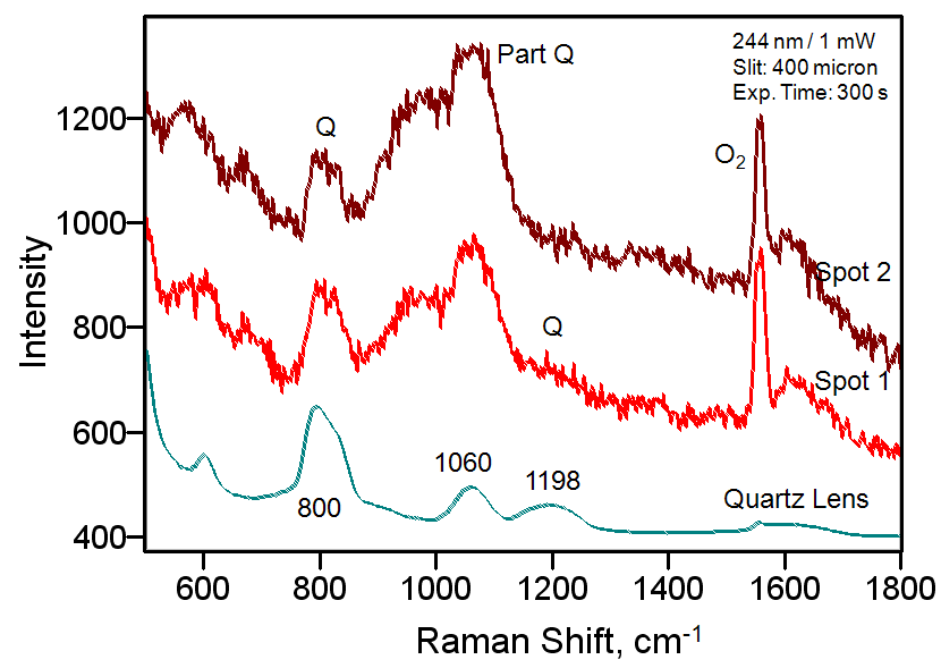

Figure 3.2. Deep-UV Raman Spectrum of LB45-45 Glass with No Post-Acquisition Correction or Modification

As shown in Figure 3.2, the spectra also contained significant interference from the spectrum of the quartz objective lens. This happens with our instrument when the signals from the sample are very weak, as they are in this case. The contribution of the quartz peaks varies from sample to sample, position to position, and with the quality of the sample spectrum. The spectra of the ILAW glasses discussed below were all corrected for the contribution from the quartz lens by performing spectral subtraction.

There are additional extraneous peaks in the spectra, typified by Figure 3.2, that need to be noted. The peak at $1552 \mathrm{~cm}^{-1}$ is due to atmospheric oxygen. A more disturbing interference is from amorphous carbon whose broad and strong peaks are at approximately $1380 \mathrm{~cm}^{-1}$ and $1605 \mathrm{~cm}^{-1}$ (stronger). We were initially uncertain about the source of carbon but ultimately concluded it came from the photodecomposition (under the UV laser light) of residual organic buffer compound present in solutions used in the SPFT studies. As shown in Figure 3.3, the residual buffer compound on the samples decomposes to carbon under UV light $(1 \mathrm{~mW})$, similarly giving rise to amorphous carbon peaks, including the strong peak at approximately $1600 \mathrm{~cm}^{-1}$.

These results indicated that a significant amount of the residual buffer compound remained on the reacted ILAW glass samples and needed to be "washed off" before taking the Raman spectra. Consequently, the ILAW glass samples were rinsed carefully with deionized water (DIW), using an ultrasonic cleaner, followed by a final washing/drying step with ethanol.

In the meantime, we also obtained Raman spectra of some of the reacted glass samples using visible light, i.e., 488-nm excitation, employing another Raman spectrometer. Earlier attempts to use this spectrometer with visible light on other samples were unsuccessful because of fluorescence interference. Nevertheless, visible Raman spectra were never measured on the current ILAW glass samples and, given the much higher laser powers possible with our visible laser and that quartz from a lens would not contribute, we deemed it wise to "recheck" the visible Raman approach for the ILAW glass samples. The decision was also prompted by the unexpected weakness of the signals we were observing with UV. The 
results of this work were in line with our previous attempts to use visible light. Most of the samples gave too much fluorescence to discern Raman spectra when using visible light. A best case is shown in Figure 3.4 for ILAW glass LB45-45. As observed, the Raman bands from the glass are very weak and broad, and confounded by the presence of a strong fluorescence background that increases toward higher Raman shift. The fluorescence is believed to arise from defects on the finely ground glass surface, but is also probably exacerbated here by the formation of carbon-containing decomposition products from the residual organic buffer compound.
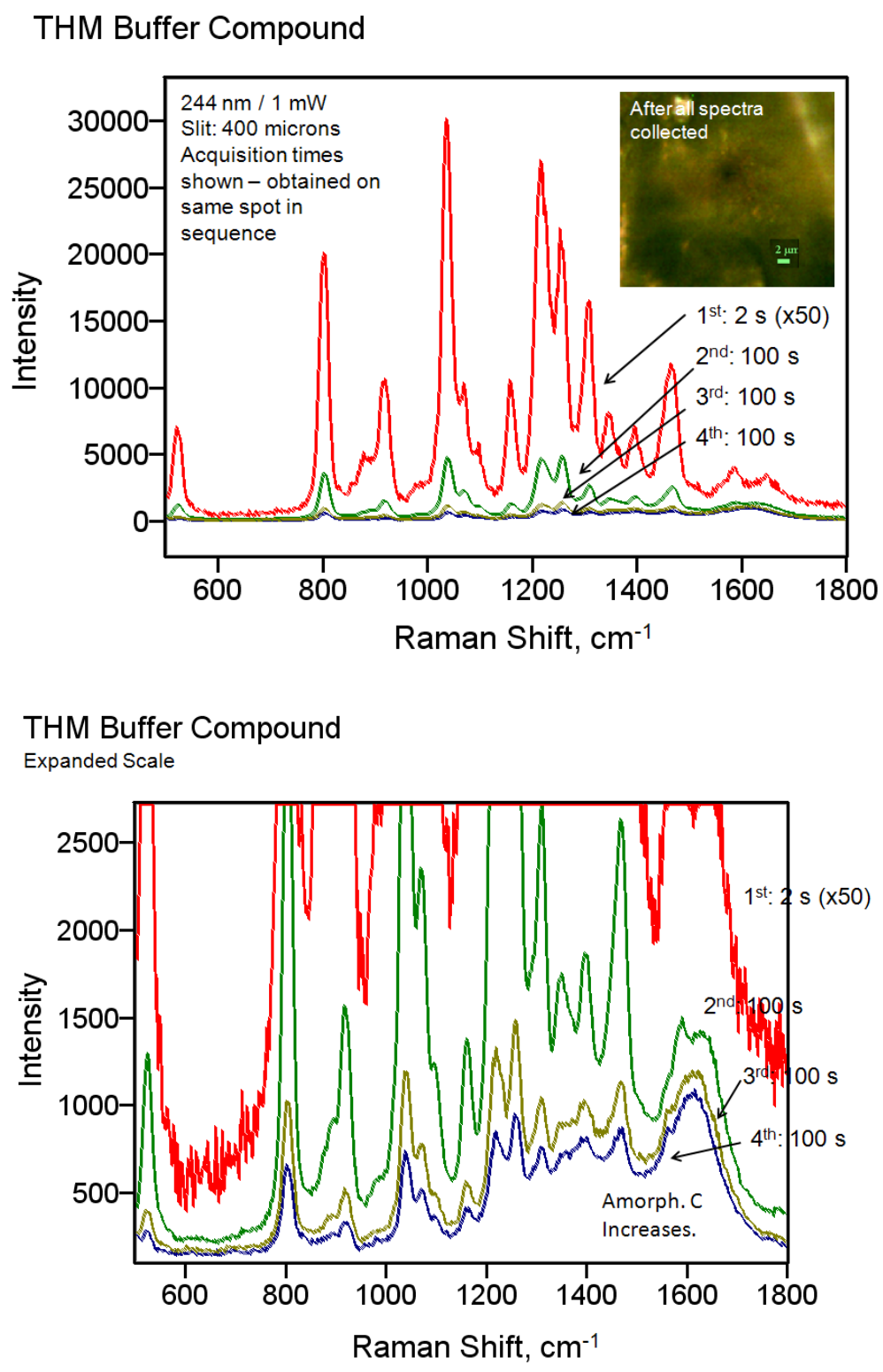

Figure 3.3. Deep-UV Raman Spectra of Tris Hydroxymethyl Aminomethane (THM) Buffer Crystals. Spectra were taken as a function of time. Lower image shows an expansion of the same spectra, revealing growth of the amorphous carbon bands at approximately 1380 and $1605 \mathrm{~cm}^{-1}$. Evidence for laser burning is also seen in the microscope (as a burn spot) under white light illumination. 
LB45-45

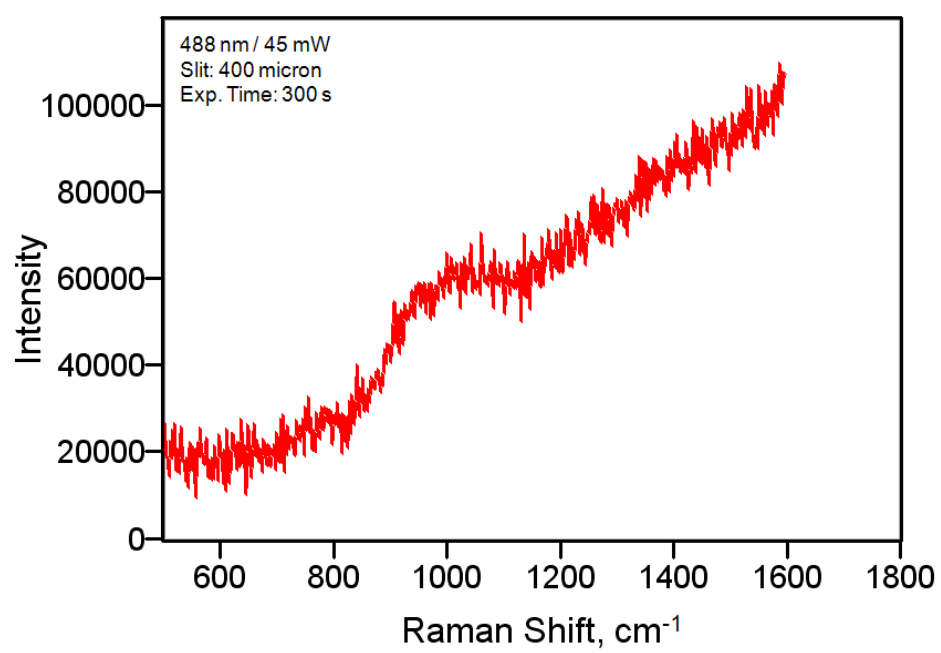

Figure 3.4. Raman Spectrum of an ILAW Glass Obtained on Another Spectrometer Using a HigherPower Visible-Light (488 nm) Laser

Deep-UV Raman spectra of ILAW glass after correction for interferences. The deep-UV Raman spectra of the ILAW glass samples before and after SPFT testing are shown in Figure 3.5. In each case, spectra of the reacted glass are compared to the spectrum of the unreacted glass with the same composition. The unreacted samples are LAWA44, LAWB45, and LAWC22. Their compositions are listed in Table 3.2. The reacted glasses were subjected to reaction conditions also reported previously, but the key conditions are listed in Table 3.3. The reacted samples were washed to remove residual buffer compound as discussed above, and the resulting spectra were corrected for the presence of peaks due to quartz from the microscope objective lens, also discussed above. The resulting spectra shown in Figure 3.5 are therefore the most accurate versions of the deep-UV Raman spectra of the ILAW glasses obtained to date.

As shown in Figure 3.5, the spectra of all of the glasses, both reacted and unreacted, are very similar. In particular, they contain an envelope of bands in the $800-1200 \mathrm{~cm}^{-1}$ region arising primarily from stretching modes of the glass network formers, mainly Si-O groups, some B-O and/or Al-O, and possibly $\mathrm{Ti}-\mathrm{O}$ and $\mathrm{Zr}-\mathrm{O}$ contribution. Most of the remaining glass components act as network modifiers, perturbing the frequency, intensity, and width of these bands. As silicate glasses, broad features below $600 \mathrm{~cm}^{-1}$ are also expected, arising from bending/deformation modes of the Si-O network. While evidence for the low-frequency modes is apparent below $600 \mathrm{~cm}^{-1}$ in the spectra in Figure 3.5, the peaks are difficult to analyze because the spectral cutoff of the UV-Raman spectrometer (due to filters for attenuating the Rayleigh line) reduces all intensities below around $500 \mathrm{~cm}^{-1}$. Peaks between $600 \mathrm{~cm}^{-1}$ and $800 \mathrm{~cm}^{-1}$, previously reported in the literature for borosilicate glasses and assigned to rings, are not strongly evident in any of the spectra acquired in this work. One possibility for the absence of ring modes in the spectra of the ILAW glasses is that the structural complexity of the LAW compositions is greater than those of borate and borosilicate systems previously studied. The presence of several different modifier cations could introduce enough disorder in the glass structure that the ring bands, usually weak at these borate concentrations to begin with, are broadened to the extent that they are indiscernible from the background in our spectra. Another possibility is that the ring population is simply much lower in 
glasses with the LAW compositions. Weak, broad, bands above $1200 \mathrm{~cm}^{-1}$ have also been observed in borate and borosilicate glasses (arising from B-O stretch in groups containing non-bridging oxygen atoms), and there is some indication of the presence of bands in this region in the spectra in Figure 3.5. However, attribution of these peaks (at least partly) to residual amorphous carbon cannot be discounted. Carbon gives rise to peaks at approximately $1360 \mathrm{~cm}^{-1}$ and $1600 \mathrm{~cm}^{-1}$ (Note that these peaks frequencies for carbon are commonly reported for spectra with visible light excitation. In Raman spectra using UV light, the peaks can be shifted to slightly higher frequencies.). Given the presence of carbon confirmed in unwashed samples, it would appear unwise to rule out its presence in small, but detectable, amounts in the these samples. The sharp peak at approximately $1552 \mathrm{~cm}^{-1}$ in all of the spectra is due to atmospheric oxygen.
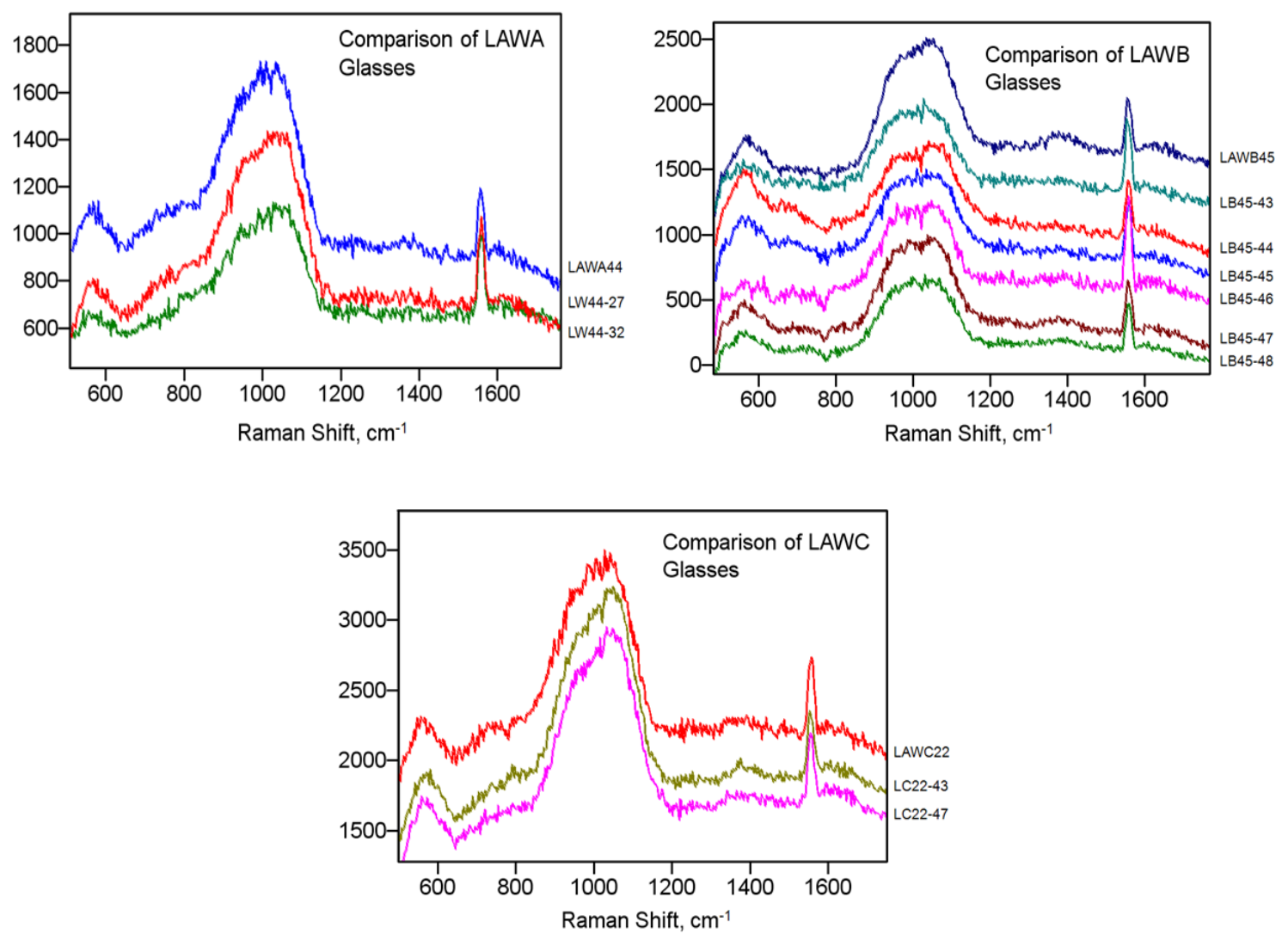

Figure 3.5. Comparison of Deep-UV Raman Spectra of the Washed ILAW Glasses: Unreacted vs. Reacted Under Various Conditions. Spectra were corrected for contribution from the quartz lens. Glasses LAWA44, LAWB45, and LAWC22 are the unreacted samples for each composition. Spectral acquisition parameters were the same as those reported for the simple glass studies.

Several conclusions can be drawn from the discussion in the above paragraph. First, the analysis of the deep-UV Raman spectra in this work is largely restricted to the $800-1200 \mathrm{~cm}^{-1}$ region. Second, the features in this region are remarkably similar for all of the glasses studied, both reacted and unreacted. There are some minor differences, but the broad and overlapping nature of the bands in the region make unambiguous curve fitting and assignment of components virtually impossible. For example, careful scrutiny of the spectrum of glass LAWB45 and spectra of this same glass after several reaction conditions 
reveals minor variation of the spectral envelope in the Si-O stretching region. In particular, the symmetry of the envelope appears to change. The spectrum of the unreacted glass has more intensity on the highfrequency side (ca. $1050 \mathrm{~cm}^{-1}$ ) than on the low-frequency side, compared to the reacted glasses. This same trend does not seem to be the case for LAWA44 and LAWC22. Unfortunately, without more quantitative information (that would have been forthcoming if curve fitting were reliable) and without the support of information from other techniques, definitive conclusions regarding the structural differences between the glasses and changes related to the effect of dissolution reactions cannot be made from the Raman spectra at this time.

Given the similarity of the Raman spectra of the ILAW glasses under study, all of the glasses were submitted for XPS analysis to determine whether compositional changes had occurred during the dissolution studies (consistent with previous measurements) in those particular samples being analyzed by Raman spectroscopy and, if so, what these changes were. A few samples were also submitted for scanning electron microscopy/energy dispersive spectroscopy (SEM/EDS) analysis in cross-section. The use of NMR is also considered and is part of the experimental plan for this program, but results were not available at the time of this writing.

\subsubsection{Application of Other Techniques to ILAW Glasses}

Observations regarding bulk composition of ILAW glasses. Melt compositions of the unreacted bulk ILAW glasses, shown in Table 3.2 in mass percentages, were used to calculate the following atomic ratios: $\mathrm{B} / \mathrm{Si}, \mathrm{Al} / \mathrm{Si}, \mathrm{Na} / \mathrm{Si}$, and $\mathrm{Fe} / \mathrm{Si}$. These ratios, listed in Table 3.4, were used (instead of mass or atom percentages) in subsequent analysis for the following two reasons.

First, for EDS in particular, absolute concentrations are semiquantitative. Slight volatility of $\mathrm{Na}$ under electron bombardment is possible, and B cannot even be measured. Since complete accounting of elements (with oxygen as difference) is suspect, only the ratios of elements are meaningful, and these need to be considered carefully. Nevertheless, significant differences in these ratios between reacted and unreacted glasses would provide a sound assessment of the relative changes of glass components as a result of reaction/dissolution. Moreover, both XPS and initial compositions are available, along with the EDS data, for corroboration.

Second, B, Al, and Na were the primary focus of this analysis, since they were shown to be affected most in previous SPFT studies. Fe was also analyzed because of the varied chemistry associated with its multiple oxidation states and relevance to groundwater chemistry. XPS and EDS results for the ILAW glasses, with compositions noted in Table 3.2 and Table 3.4, are given in Table 3.5 and Table 3.6, respectively.

Table 3.4. ILAW Glass Bulk Compositions in Terms of Atom Ratios Calculated from Mass Percentages

\begin{tabular}{cccccc}
\hline Glass & Bulk Al/Si & Bulk B/Si & Bulk Na/Si & Bulk Na/B & Bulk Fe/Si \\
\hline LAWA44-unreacted & 0.16 & 0.34 & 0.86 & 2.0 & 0.12 \\
LAWB45-unreacted & 0.15 & 0.44 & 0.26 & 0.59 & 0.04 \\
LAWC22-unreacted & 0.15 & 0.37 & 0.60 & 1.62 & 0.09 \\
\hline
\end{tabular}


Table 3.5. Atom Percentages and Atom Ratios Calculated from XPS Measurements of the Indicated ILAW Glasses. Three ILAW composition glasses were studied. Data are for both the unreacted sample of each glass and samples of the same glass reacted under different conditions.

\begin{tabular}{|c|c|c|c|c|c|c|c|c|c|c|c|c|c|c|c|}
\hline Glass & $\mathrm{Al}$ & B & $\mathrm{Ca}$ & $\mathrm{Fe}$ & $\mathrm{Mg}$ & $\mathrm{Na}$ & $\mathrm{Si}$ & $\mathrm{Zn}$ & $\mathrm{Zr}$ & $\mathrm{C}$ & $\mathrm{Al} / \mathrm{Si}$ & $\mathrm{B} / \mathrm{Si}$ & $\mathrm{Na} / \mathrm{Si}$ & $\mathrm{Na} / \mathrm{B}$ & $\mathrm{Fe} / \mathrm{Si}$ \\
\hline LAWA44-unreacted & 3.9 & 4.9 & 0.7 & 3.5 & 1.0 & 20.9 & 25.2 & 1.1 & 0.8 & 37.9 & 0.15 & 0.19 & 0.83 & 4.27 & 0.14 \\
\hline LW44-32 & 1.2 & 1.1 & 0.4 & 1.6 & 0.4 & 1.5 & 55.7 & 0.7 & 0.2 & 37.2 & 0.02 & 0.02 & 0.03 & 1.36 & 0.03 \\
\hline LB45-43 & 4.6 & 1.2 & 3.1 & 9.8 & 4.2 & 0.6 & 24.9 & 5.0 & 3.8 & 42.7 & 0.18 & 0.05 & 0.02 & 0.50 & 0.39 \\
\hline LB45-44 & 5.1 & 0.4 & 2.3 & 6.6 & 8.2 & 0.5 & 37.5 & 5.1 & 1.4 & 32.7 & 0.14 & 0.01 & 0.01 & 1.25 & 0.18 \\
\hline LB45-45 & 3.0 & 0.5 & 1.2 & 7.2 & 12.3 & 0.4 & 39.3 & 7.3 & 0.5 & 28.5 & 0.08 & 0.01 & 0.01 & 0.80 & 0.18 \\
\hline LB45-47 & 0.7 & 0.9 & 0.3 & 1.9 & 12.2 & 0.1 & 37.3 & 7.2 & 0.1 & 39.3 & 0.02 & 0.02 & - & 0.10 & 0.05 \\
\hline LB45-48 & 1.0 & 0.5 & 0.5 & 1.7 & 14.1 & 0.2 & 43.2 & 8.1 & 0.3 & 30.6 & 0.02 & 0.01 & - & 0.40 & 0.04 \\
\hline LAWC22-unreacted & 4.1 & 6.3 & 3.0 & 2.9 & 1.0 & 14.3 & 29.1 & 1.5 & 0.9 & 36.9 & 0.14 & 0.22 & 0.49 & 2.27 & 0.10 \\
\hline LC22-43 & 4.9 & 3.5 & 2.7 & 4.3 & 0.7 & 4.2 & 29.8 & 2.2 & 1.9 & 45.8 & 0.16 & 0.12 & 0.14 & 1.20 & 0.14 \\
\hline LC22-47 & 0.5 & 0.0 & 0.6 & 2.7 & 5.5 & 0.7 & 48.4 & 5.0 & 0.0 & 36.5 & 0.01 & - & 0.01 & - & 0.06 \\
\hline
\end{tabular}


Table 3.6. Atom Ratios Calculated from EDS Measurements of the Indicated ILAW Glasses. Two ILAW glass compositions were studied with EDS, including an unreacted sample and one of the reacted specimens. For all samples, EDS measurements were performed both in the center of a 100-micron-size fine and near an edge. Measurement of B was not possible with EDS.

\begin{tabular}{lccccc}
\hline \multicolumn{1}{c}{ Glass } & Bulk Al/Si & Bulk B/Si & $\mathrm{Bulk} \mathrm{Na/Si}$ & $\mathrm{Bulk} \mathrm{Na/B}$ & $\mathrm{Bulk} \mathrm{Fe/Si}$ \\
\hline $\begin{array}{l}\text { LAWA44-unreacted } \\
\text { (center) }\end{array}$ & 0.13 & - & 0.73 & - & 0.10 \\
$\begin{array}{l}\text { LAWA44-unreacted } \\
\text { (edge) }\end{array}$ & 0.15 & - & 0.64 & - & 0.11 \\
$\begin{array}{l}\text { LW44-32 } \\
\text { (center) }\end{array}$ & 0.16 & - & 0.77 & - & 0.10 \\
$\begin{array}{l}\text { LW44-32 } \\
\text { (edge) }\end{array}$ & 0.15 & - & 0.69 & - & 0.11 \\
$\begin{array}{l}\text { LAWB45-unreacted } \\
\text { (center) }\end{array}$ & 0.15 & - & 0.29 & - & 0.07 \\
$\begin{array}{l}\text { LAWB45-unreacted } \\
\text { (edge) }\end{array}$ & 0.15 & - & 0.29 & - & 0.07 \\
$\begin{array}{l}\text { LB45-43 } \\
\text { (center) }\end{array}$ & 0.14 & - & 0.32 & - & 0.07 \\
$\begin{array}{l}\text { LB45-43 } \\
\text { (edge) }\end{array}$ & 0.15 & - & 0.31 & - & 0.07 \\
\hline
\end{tabular}

Comparing the $\mathrm{B} / \mathrm{Si}, \mathrm{Al} / \mathrm{Si}, \mathrm{Na} / \mathrm{Si}$ and $\mathrm{Fe} / \mathrm{Si}$ ratios for the three unreacted glasses (LAWA44, LAWB45, and LAWC22) as calculated from the melt compositions and as determined by XPS (Table 3.5) and EDS (Table 3.6) led to the following observations:

1. Calculations based on XPS measurements reproduced the bulk melt compositions within $1 \%$ for the $\mathrm{Al} / \mathrm{Si}$ ratio for all three glasses. The $\mathrm{B} / \mathrm{Si}$ ratios followed the right trend for the three glass compositions (B/Si: LAWB45 > LAWC22 > LAWA44), but the values were about half of the melt composition values. The trend was also correct for $\mathrm{Na} / \mathrm{Si}(\mathrm{Na} / \mathrm{Si}$ : LAWA44 $>$ LAWC22 > LAWB45) with some error, but the error was less than that for B/Si. In the case of LAWA44, the difference between the XPS measurements of $\mathrm{Na} / \mathrm{Si}$ and the melt composition was only $1 \%$. The $\mathrm{Fe} / \mathrm{Si}$ values form the XPS measurements were reasonably close to those from the melt compositions, given that their magnitude was much smaller than the other ratios.

2. Ratios for $\mathrm{Al} / \mathrm{Si}, \mathrm{Na} / \mathrm{Si}$, and $\mathrm{Fe} / \mathrm{Si}$ were also calculated from the EDS data obtained from the two glasses LAWA44 and LAWB45, with EDS measurements obtained both in the center (interior) of a 100-micron-size glass fine of each glass (imaged in cross-section) and within a few microns of the surface. Results for all of the ratios were similar for both positions within the glass fine and for both of the unreacted glasses studied. The Al/Si ratios were within $3 \%$ of the values of the bulk compositions; the $\mathrm{Na} / \mathrm{Si}$ ratios deviated slightly from the bulk compositions but differently from the XPS data (closer for LAWB45, but farther away for LAWA44). The Fe/Si values were consistent with the melt compositions.

The overall assessment for measurements of the bulk unreacted specimens is that both techniques gave $\mathrm{Al} / \mathrm{Si}$ and $\mathrm{Fe} / \mathrm{Si}$ values acceptably close to the melt compositions. The $\mathrm{B} / \mathrm{Si}$ and $\mathrm{Na} / \mathrm{Si}$ values, on the other hand, deviated somewhat, with the error for $\mathrm{B} / \mathrm{Si}$ being greater. Three possible explanations for the 
deviation are: 1) element volatility induced by the electron beams (in the case of EDS), 2) a true difference in the composition ( $\mathrm{Na}$ and $\mathrm{B}$ deficiency) of the surface of the glass, even when unreacted (indicated by the XPS data), and 3) volatility in the melt with bulk glass composition being slightly different from values predicted from gravimetric analysis of the starting materials. All three of these factors probably contribute. The most significant deviations in the cases of B and $\mathrm{Na}$ in the XPS data, however, strongly argue for an important role of explanation 2) for some glass compositions.

Assessment of reactions based on XPS data. The following three observations concern the concentration of species on the surface of reacted glasses as determined by XPS. (See Table 3.3 for values of one of the important reaction conditions, i.e., Si concentration in solution.) The observations are made by comparing the $\mathrm{B} / \mathrm{Si}, \mathrm{Na} / \mathrm{Si}, \mathrm{Al} / \mathrm{Si}$, and $\mathrm{Fe} / \mathrm{Si}$ ratios of the bulk glasses with those of surfaces of the reacted glasses. The assumption in our analysis is that, for the reacted glass, these surfaces are remnants of chemical transformations of the original glass. An alternate viewpoint is that they are remnants of a precipitation layer formed during reaction. There is no way to distinguish these two possibilities using the ex-situ data. Consequently, if the results relate to a precipitation layer, interpretation, i.e., regarding loss of species during reaction, will need to be modified accordingly.

1. XPS shows significant depletion of $\mathrm{B}$ and $\mathrm{Na}$ from surfaces (note $\mathrm{B} / \mathrm{Si}$ and $\mathrm{Na} / \mathrm{Si}$ ratios) of all three compositions (LAWA44, LAWB45, and LAWC22) as a result of all conditions of the reactions. The depletion of both $\mathrm{B}$ and $\mathrm{Na}$ appeared more severe when Si content in the solution was higher (especially going from $0 \% \mathrm{Si}$ to $20 \% \mathrm{Si}$; differences between $20 \% \mathrm{Si}$ and higher were less).

2. XPS also showed significant depletion of $\mathrm{Al}$ on the surface (note $\mathrm{Al} / \mathrm{Si}$ ratios) but only when the Si concentration in the solution was greater than $20 \%$. When Si concentration was $20 \%$ or less, the concentration of $\mathrm{Al}$ on the surface either increased or stayed the same. This trend for $\mathrm{Al}$ was clearest for LAWB45 because more glasses of this composition were tested, although the same trend is suggested by the limited data for LAWA44 and LAWC22.

3. XPS showed behavior for $\mathrm{Fe}$ that was similar to that of $\mathrm{Al}$ for all the glasses, i.e., significant loss from the surface when Si concentration in solution was high (e.g., 80\%). However, at lower concentrations of $\mathrm{Si}$, the Fe actually appears to build up on the surface. In the case of LAWB45 exposed to solution with no $\mathrm{Si}$, the amount of $\mathrm{Fe}$ on the surface increased by more than a factor of four. Fe concentrations were also elevated on the surface (but not as much) when Si concentrations were between $20 \%$ and $60 \% \mathrm{Si}$.

The principal overall assessment of surface reactions based on the XPS data is similar to analysis made in previous reports on borosilicate glass dissolution: both $\mathrm{B}$ and $\mathrm{Na}$ are depleted at the glass surface during dissolution. In the present analysis, the extent of this depletion appeared more significant when Si concentration in the solution was higher. Al was also found to be depleted but not as much as B and $\mathrm{Na}$, especially when Si concentration in solution was low. Finally, Fe was depleted when Si concentration in solution was very high, but increased or was unaffected at lower Si concentrations.

EDS assessment of bulk vs. surface chemistry. EDS measurements were performed on some of the ILAW glass samples that were also studied with XPS. The reason for the EDS measurements was to determine whether changes in composition indicated by the XPS measurements were restricted to the surface or involved the bulk of the glass fines as well. In the EDS measurements, glass fines were mounted in epoxy, cut, polished, and then studied in cross-section. This permitted quantification of components both in the center of a glass fine as well as within a few microns of the surface, depending on 
where the probe beam was positioned. The same procedure was used in the present study on unreacted samples of LAWA44 and LAWB45, and on these same glasses reacted under one set of conditions. EDS measurements were performed on both unreacted and reacted glasses, with the probe beam position in the center of a glass fine and near its surface. The results are shown in Table 3.6. The principal result is that the measurements were essentially identical for a glass with the same bulk composition, regardless of whether the glass was reacted or unreacted. The results were also the same regardless of where on the sample the probe beam was positioned (i.e., within the bulk or near the surface). The changes in composition detected by XPS are apparently confined to the surface of the glass fines. Since no evidence of a reaction layer was apparent in the SEM (obtained in conjunction with the EDS), it can be concluded that this layer is significantly less than a micron in thickness.

\subsubsection{Current Assessment of Raman Spectra Based on XPS and EDS Measurements}

As discussed above, the deep-UV Raman spectra of ILAW glasses with three different compositions looked very similar. The spectra of the unreacted glasses were all similar, and spectra of the reacted glasses mostly were the same as those of the reacted glasses with the same bulk composition. Based on the results of the XPS and EDS measurements, the result can be understood in terms of the relationship between the thickness of the reaction layer and the depth resolution of the measurements. XPS is a true surface analysis technique, with depth resolution on the order of nanometers. In contrast, Raman spectroscopy interrogates depths that vary with the optical properties of the material and the optical configuration of the instrument. Despite the higher-surface sensitivity typically afforded by confocal microscopy coupled with deep-UV (short wavelength) excitation, the weak Raman bands of the ILAW glasses required us to obtain spectra with relatively large pinhole settings. This decreased the depth resolution significantly. Realistically, with the present setup, our ability to discriminate composition applies to phases with thicknesses of 0.5 microns or greater. If reaction layers are significantly thinner than this, as suggested by comparing the XPS, EDS and melt compositions, then the Raman spectra will largely reflect the bulk composition. It is our belief that this is the case in the present study. With the single exception of glass LAWB45, whose spectrum shows a slight difference after reaction, the Raman spectra appear to be dominated by features arising from bulk constituents and not the thin reaction layers. Even in the case of LAWB45, there is insufficient surface sensitivity to identify phase/ composition changes in this study without ambiguity. Nevertheless, the results for LAWB45 indicate a minor difference when the glass is reacted that may shed light on the reaction chemistry if/when information from other techniques such as NMR is available.

\subsection{Summary of Results and Conclusions}

- Deep-UV Raman spectra were successfully obtained from glass samples with "simple" compositions and from complex ILAW glasses, both before and after reaction in SPFT tests.

- Deep-UV Raman spectroscopy showed distinct advantages, particularly the reduction of fluorescence interference on powdered glass samples.

- Good structure/property correlation was achieved on a series of borosilicate glasses with "simple" composition. In particular, a combination of the amount of $\mathrm{Q}^{3}$ structures in the glass and the $\mathrm{Na}_{2} \mathrm{O} / \mathrm{B}_{2} \mathrm{O}_{3}$ ratio was related to the dissolution rate measured in SPFT tests. The results of this work were published. 
- Raman spectra of the ILAW glasses were non-specific, precluding reliable structure/property correlation.

- The remnant of the gel layer on the reacted ILAW glasses could not be characterized with Raman spectroscopy because it was too thin.

- Preliminary application of techniques with greater surface sensitivity, such as XPS, was found to be more promising in characterizing the remnant of the gel layer and the underlying glass. XPS results were consistent with analytical data from SPFT tests. However, electron spectroscopic techniques like XPS are more "elemental" compared to Raman spectroscopy, which has greater molecular specificity.

\subsection{Recommendations}

1. Discontinue or postpone further Raman spectroscopy analysis of the ILAW glasses unless one or more of the following conditions is satisfied.

a. Detailed molecular structure information on the ILAW glasses is derived from using other methods. For example, if NMR shows a preponderance of a particular $\mathrm{Q}^{\mathrm{n}}$ structure in one ILAW glass composition over another, then the Raman spectra of these two glasses can be scrutinized in terms of this difference. As it stands, differences between the Raman spectra are too subtle to analyze without the assistance of results from other methods.

b. If other glass compositions are considered that have much greater differences in composition than the series of ILAW glasses studied in this work.

c. If glass dissolution studies are performed that generate reaction layers or remnants of gel layers with significantly greater thicknesses than the ILAW glasses studied in this work. Reaction layer thicknesses would have to be on the order of hundreds of nanometers (minimum) to characterize them under conditions similar to those used in this study.

2. Other techniques should be explored to characterize molecular structure in the ILAW glasses. The techniques should be pursued either as stand-alone or in terms of their potential for generating results that could be used to interpret the Raman spectra.

3. If Raman spectroscopy is to be continued, use of deep-UV Raman excitation is recommended. This work showed distinct advantages of deep-UV excitation. Despite the ambiguities associated with interpretation, it is unlikely that Raman spectra of the finely divided, high-surface-area ILAW glass samples could have been obtained at all using conventional visible excitation.

The deep-UV Raman spectra collected in this work should serve as a potential database of information on the ILAW glasses in the event results from other techniques ultimately facilitate band assignments and interpretation. 


\subsection{Pressurized Unsaturated Flow Experiments}

IDF PA models must account for the long-term corrosion rate of a range of ILAW glass formulations. The corrosion rate, a key parameter in PA calculations, affects the overall performance of the ILAW source term and ultimately the IDF. As water migrates through the IDF and contacts the waste package, the solution in contact with the dissolving glass becomes more and more concentrated in glass components, until solubility limits for alteration phases begin to be exceeded. Once formed, these metastable, amorphous, and/or crystalline alteration phases begin to control the overall dissolution of the glass waste form. Therefore, to predict the long-term corrosion of these glasses in the disposal system environment, information on the glass transformation into a paragenetic assemblage of alteration products or minerals must be known. Although the suite of weathering products that will form as a consequence of the glass-water reactions cannot be determined a priori at this time, as discussed by McGrail et al. (2000b, 2003), PUF Tests can be used to simulate and accelerate the weathering process. PUF experiments were conducted on three prototypic ILAW glasses; ORPLG9, ORPLB2, and ORPLF7. The compositions in weight percent for the ILAW glasses are shown below in Table 4.1.

Table 4.1. Composition of Glass Used in Simulations

\begin{tabular}{cccc}
\hline Oxides & ORPLB2 & ORPLG9 & ORPLF7 \\
\hline $\mathrm{Al}_{2} \mathrm{O}_{3}$ & 10.00 & 6.74 & 8.60 \\
$\mathrm{~B}_{2} \mathrm{O}_{3}$ & 7.30 & 8.49 & 9.50 \\
$\mathrm{CaO}$ & 1.10 & 2.69 & 9.72 \\
$\mathrm{Fe}_{2} \mathrm{O}_{3}$ & 1.10 & 0.28 & 0.30 \\
$\mathrm{~K}_{2} \mathrm{O}$ & 0.12 & 5.75 & 0.50 \\
$\mathrm{Li} 2 \mathrm{O}$ & 0.00 & 0.00 & 4.35 \\
$\mathrm{MgO}$ & 1.10 & 0.95 & 0.98 \\
$\mathrm{Na}_{2} \mathrm{O}$ & 25.00 & 21.00 & 12.00 \\
$\mathrm{SiO}_{2}$ & 39.98 & 40.75 & 42.14 \\
$\mathrm{SnO}_{2}$ & 1.08 & 2.83 & 0.00 \\
$\mathrm{TiO}_{2}$ & 0.00 & 0.00 & 0.00 \\
$\mathrm{~V}_{2} \mathrm{O}_{5}$ & 2.00 & 0.00 & 2.50 \\
$\mathrm{ZnO} \mathrm{ro}$ & 3.65 & 3.39 & 2.91 \\
$\mathrm{ZrO}_{2}$ & 5.44 & 5.66 & 3.88 \\
$\mathrm{Others}$ & 2.13 & 1.48 & 2.62 \\
$\mathrm{Sum}^{2}$ & 100.0 & 100.0 & 100.0 \\
\hline
\end{tabular}

\subsection{Description of the PUF Apparatus}

The PUF apparatus (Figure 4.1) allows accelerated weathering experiments to be conducted under hydraulically unsaturated conditions, thereby mimicking the vadose zone environment while allowing the corroding glass to achieve a final reaction state. The PUF apparatus provides the capability to vary the volumetric water content from saturation to $20 \%$ of saturation or less, minimize the flow rate to increase liquid residence time, and operate at a maximum temperature of $100^{\circ} \mathrm{C}$. The PUF column operates under 
a hydraulically unsaturated condition by creating a steady-state vertical water flow, while maintaining uniform water content throughout the column, and by using gravity to assist in drainage.
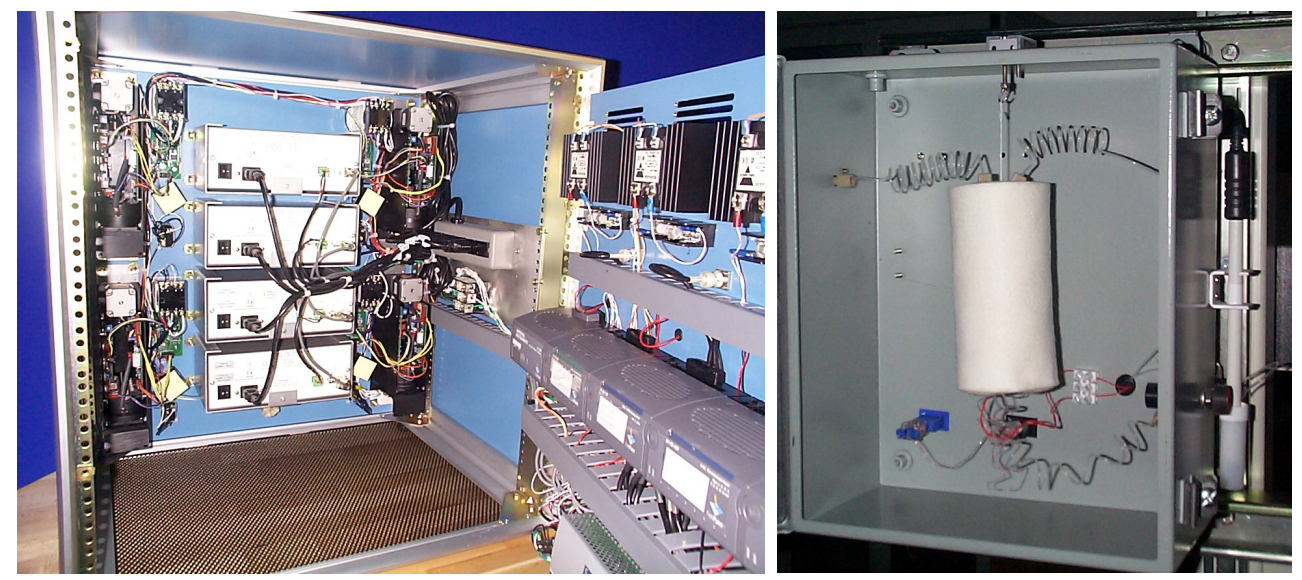

Figure 4.1. Picture of PUF System Hardware (Patent \#5974859)

The underlying principle for creating such conditions is Darcy's Law as modified by Richards (1931)

$$
J_{w}=-K\left(\psi_{m}\right) \frac{\delta \Psi}{\delta z}
$$

where $\quad J_{\mathrm{w}}=$ the volumetric flux density $(\mathrm{m} / \mathrm{s})$,

$\psi=$ the water potential; which is equal to the matrix potential $\left(\psi_{\mathrm{m}}\right)+$ gravitational potential $\left(\psi_{\mathrm{g}}\right)(\mathrm{m})$,

$K\left(\psi_{\mathrm{m}}\right)=$ the conductivity as a function of matrix potential $\left(\mathrm{m} \mathrm{s}^{-1}\right)$, and

$z=$ the length of the column (m).

It can be easily shown that if uniform moisture content is established throughout the column, Equation (4.1) reduces to:

$$
J_{w}=K\left(\psi_{m}\right)
$$

Equation (4.2) simply states that under uniform water content conditions, the volumetric flux density of water is equal to the unsaturated hydraulic conductivity.

This system has been previously described in other publications (McGrail et al. 2000c, 2001b; Pierce et al. 2004a), and an interested reader should consult these references, as well as the references contained therein, for more detail. Only a general description will be provided within this document. In general, the PUF system consists of a column (7.62-cm length and 1.91-cm diameter) fabricated from a chemically inert material, polyether ether ketone, so that dissolution reactions are not influenced by interaction with the column material. A porous titanium plate with nominal pore size of $0.2 \mu \mathrm{m}$ is sealed in the bottom of the column to ensure an adequate pressure differential for the conductance of fluid while operating under unsaturated conditions (Wierenga et al., 1993). Titanium was chosen because it is highly resistant to corrosion and has excellent wetting properties. Once the porous titanium plate is water saturated, water but not air is allowed to flow through the $0.2-\mu \mathrm{m}$ pores, as long as the applied pressure differential does 
not exceed the air-entry relief pressure or "bubble pressure" of the Ti plate. If the pressure differential is exceeded, air will escape through the plate and compromise the ability to maintain unsaturated flow conditions in the column. The computer control system runs LabVIEW ${ }^{\mathrm{TM}}$ (National Instruments Corporation) software for logging test data to disk from several thermocouples, pressure sensors, in-line sensors for effluent $\mathrm{pH}$ and conductivity, and column weight from an electronic strain gauge to accurately track water mass balance and saturation level. The column also includes a "PUF port," which is an electronically actuated valve that periodically vents the column gases. The purpose of column venting is to prevent reduction in the partial pressure of important gases, especially $\mathrm{O}_{2}$ and $\mathrm{CO}_{2}$, which may be consumed in a variety of chemical reactions.

\subsection{Materials Preparation}

The glass samples used for the PUF tests were crushed using a ball mill or mortar and pestle. The crushed glass was sieved to obtain the -40 to +60 mesh ( 420 - to $250-\mu \mathrm{m}$ diameter) size fraction. The sample was then washed in DIW, sonicated, rinsed using ethanol, and then dried in an oven at $90^{\circ} \mathrm{C}$.

\subsection{Experimental Setup}

As previously described in Section 4.1, the basic PUF apparatus consists of a column in which glass particles (or other material) of a known size and density are compacted to a known bulk density $\left(\mathrm{g} \mathrm{m}^{-3}\right)$. The remaining void space (which is not filled by glass) represents the porosity $(\varepsilon)$. Volumetric water content $(\theta)$ is the percent volume of water within the total fixed column volume. For example, when a $20-\mathrm{cm}^{3}$ column is packed with glass leaving a $50 \%$ void space $(\varepsilon)$, the column is considered fully saturated when $10 \mathrm{ml}$ of water $(\theta=50 \%)$ is in the column at any given point in time. Using these same parameters, a column is considered unsaturated when $\theta<\varepsilon$. The rate of water flow through the column is the pore water velocity $\left(\mathrm{U}_{\mathrm{p}}, \mathrm{m} \mathrm{s}^{-1}\right)$, which is simply the influent flux $\left(\mathrm{m}^{3} \mathrm{~s}^{-1}\right)$ divided by the cross-sectional area of the column $\left(\mathrm{m}^{2}\right)$ divided by $\theta$. To determine the residence time for an aliquot of water to move through the column, the length $(\mathrm{m})$ of the column is divided by $\mathrm{U}_{\mathrm{p}}$.

DIW is used in PUF experiments because it is assumed that the chemistry of the water in the IDF will be determined by the corroding glass. This is a valid assumption because the volume of glass contained in the IDF is much larger than the volume of water percolating through the system.

\subsection{Normalized Concentration Calculation}

The results from chemical analyses on collected effluent samples will be used to calculate a normalized release rate for each major glass component according to Equation (4.3).

$$
N C_{i}=\frac{\left(C_{i \mathrm{~L}}-\bar{C}_{i b}\right)}{f_{i}}
$$

where $\quad N C_{i}=$ the normalized concentration of element $i$

$C_{i}=$ the concentration of element $i$ contained in the effluent solution

$C_{i, b}=$ the background concentration of element $i$

$f_{i}=$ is the mass fraction of element $i$ contained in the glass. 
In the testing here, DIW was used and the background concentration was therefore assumed to be zero in Equation (4.3).

\subsection{Experimental Results}

The PUF test results are presented on each of the three glasses. It is important to note that boron is used as an indicator of matrix dissolution because this element serves as a network former in the glass structure and is not retained in the formation of the alteration layer. Less-soluble elements, such as aluminum (Al) and silicon ( $\mathrm{Si}$ ) which can also serve as network formers, are often sequestered in alteration layers during the glass-water reaction. Alkali cations, such as sodium (Na) and lithium (Li), can be released from the glass as a result of two distinct processes: matrix dissolution and/or alkali-ion exchange. Alkali-ion exchange is an important process because it can cause localized $\mathrm{pH}$ increases in the samples, which can then increase dissolution rates. Detailed results are in Appendix A.

\subsubsection{ORPLF7 Glass Results}

Results comparing the normalized concentration for the major components contained in ORPLF7 (also referred to as IDF3F7) are shown in Figure 4.2. The experiment ran for approximately 185 days. Over the 185-day duration, the normalized concentration of the sodium in the effluent was 1 to 2 times higher than the release of boron, which indicates that $\mathrm{Na}$ is being released by a combination of matrix dissolution and alkali-ion exchange. This glass contains approximately $12 \mathrm{wt} \% \mathrm{Na}$ in the target composition, which is approximately $9-13 \mathrm{wt} \%$ lower than the higher Na-loaded glasses (which contain approximately $21 \%$ to $25 \% \mathrm{Na}$ ). Lithium is being released from the glass at approximately the same rate as boron, which indicates that $\mathrm{Li}$ is being released from the glass by matrix dissolution. The concentrations of $\mathrm{Al}$ and $\mathrm{Si}$ in the effluent are 1 to 2 orders of magnitude lower than that of B indicating that these elements are being sequestered by the formation of alteration phases. Over the entire 185 days, this experiment continuously experienced some difficulties, which resulted in the water mass balance being lower than usual. Because of these difficulties, a new PUF experiment on this glass was recently initiated and will be monitored over the next several months to confirm the results obtained for the 185-day experiment. After termination of the PUF test with ORPLF7 glass, the solid material was subsampled from the column in 1- to 5-mm intervals. The moisture content of these samples was measured by drying the samples in a vacuum desiccator. The dry solid material will be retained for potential future analyses, including X-ray diffraction (XRD) and SEM, to identify secondary alteration phases.

\subsubsection{ORPLG9 Glass Results}

Results comparing the normalized release rates for the major components contained in ORPLG9 (also referred to as IDF2G9) are shown in Figure 4.3. The experiment ran for approximately 107 days. Over the 107-day duration, the normalized concentration of the sodium in the effluent was 1 to 1.8 times higher than the release of boron, which indicates that $\mathrm{Na}$ is being released by a combination of matrix dissolution and alkali-ion exchange. This glass contains approximately $21 \mathrm{wt} \% \mathrm{Na}$ in the target composition, which is between the target Na compositions contained in the other two ILAW glasses. Al and Si are being released from the glass at a much lower rate than $\mathrm{B}$, indicating that these elements are being sequestered by the formation of alteration phases. Additional insight on the long-term weathering products will be determined after the experiment has been terminated and samples of the weathered glass are removed and analyzed. 


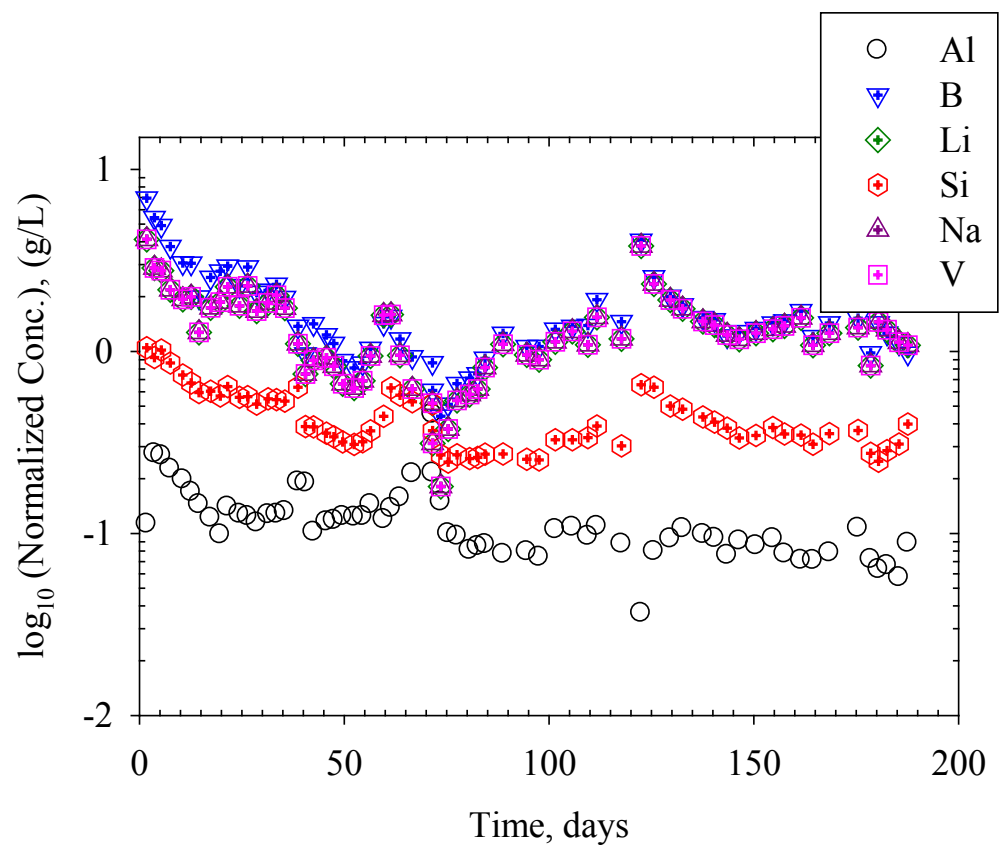

Figure 4.2. Normalized Concentration as a Function of Time for the PUF Experiment on ORPLF7 Glass (also referred to as IDF3F7)

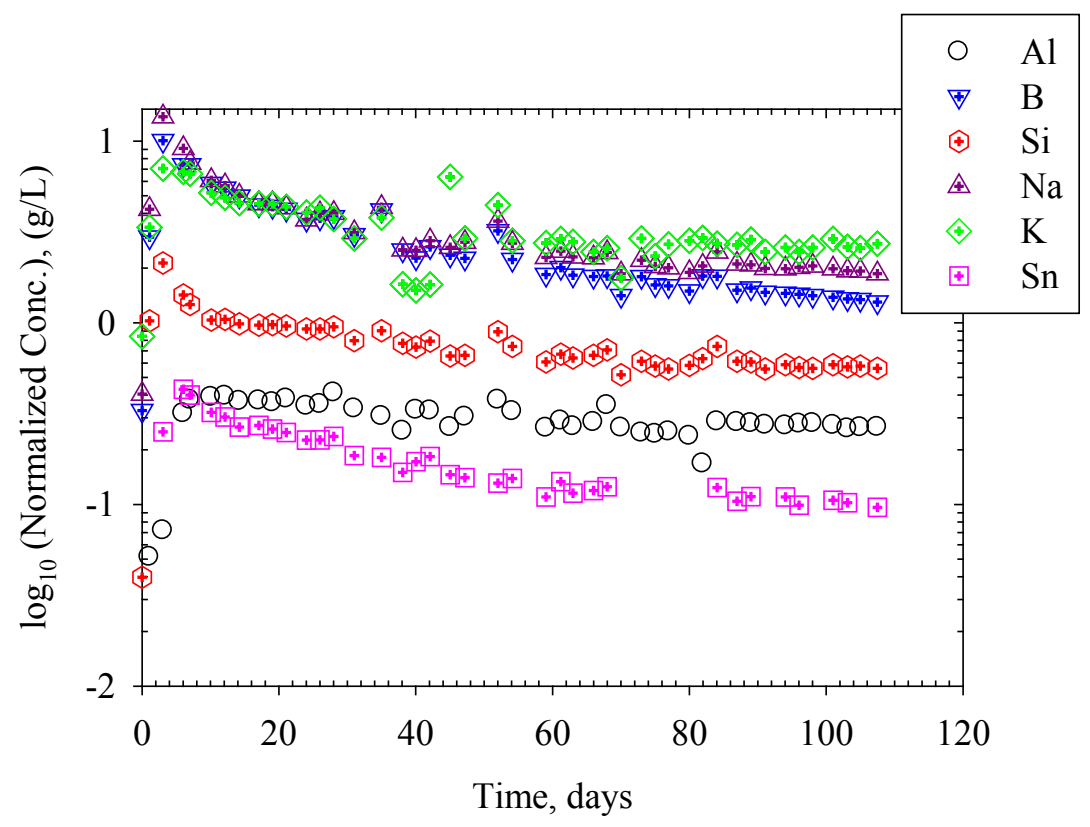

Figure 4.3. Normalized Concentration as a Function of Time for the PUF Experiment on ORPLG9 Glass (also referred to as IDF2G9) 


\subsubsection{ORPLB2 Glass Results}

Results comparing the normalized release rates for the major components contained in ORPLB2 (also referred to as IDF1B2) are shown in Figure 4.4. The experiment ran for approximately 57 days. Over the 57-day duration, the normalized concentration of the sodium in the effluent was 1 to 1.2 times higher than the release of boron, which indicates that $\mathrm{Na}$ is being released primarily by matrix dissolution with some alkali-ion exchange occurring. This glass contains approximately $25 \mathrm{wt} \% \mathrm{Na}$ in the target composition, which is the glass with the highest Na composition. Similarly to the other two ILAW glasses, Al and Si are being released from the glass at a lower rate than $\mathrm{B}$, indicating that these elements are being sequestered by the formation of alteration phases. Additional insight on the long-term weathering products will be determined after the experiment has been terminated and samples of the weathered glass are removed and analyzed.

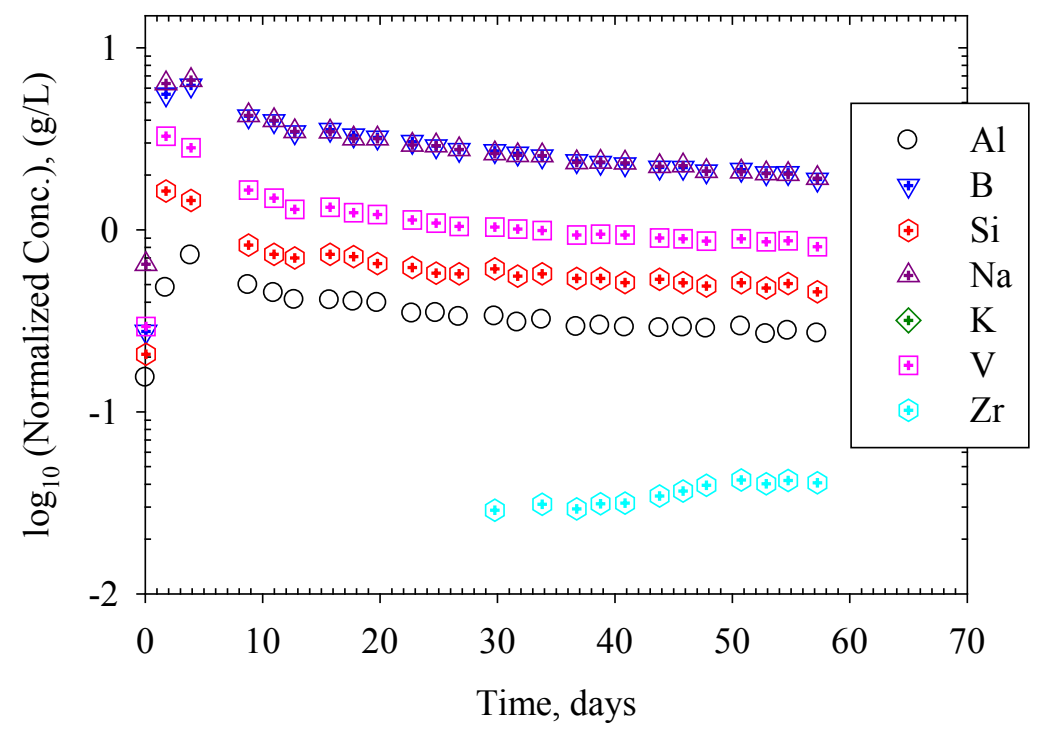

Figure 4.4. Normalized Concentration as a Function of Time for the PUF Experiment on ORPLB2 Glass (also referred to as IDF1B2) 


\subsection{Geochemical Modeling}

\subsection{Overview}

Low-activity waste PA models must account for the long-term corrosion rate of a range of ILAW glass formulations. The corrosion rate, a key parameter in PA calculations, affects the overall performance of the ILAW source term. As water migrates through the IDF and contacts the waste package, the solution in contact with the dissolving glass becomes more and more concentrated in glass components, until solubility limits for alteration phases begin to be exceeded. Once formed, these metastable, amorphous, and/or crystalline alteration phases begin to affect the overall dissolution of the glass waste form by incorporating key aqueous species, such as silicic acid. Therefore, to predict the long-term corrosion of these glasses in the disposal system environment, information on the paragenetic assemblage of alteration products or minerals resulting from the glass-water reaction must be known. Because the suite of weathering products that will form as a consequence of the glass-water reactions cannot be determined a priori at this time, as discussed by McGrail et al. (2000, 2003), results from existing (CUA/VSL and PNNL) long-term product consistency tests (PCT) conducted at $90^{\circ} \mathrm{C}$ were used to simulate and accelerate the weathering process. The chemical reaction network of secondary phases determined for ILAW glasses will be used as input for STOMP simulations of the IDF for ILAW. The STOMP code will be used to provide the near-field radionuclide-release source term for the future IDF PAs.

This section describes results of modeling performed at PNNL for Washington River Protection Solutions, Inc. (WRPS) to develop a series of chemical reaction networks of secondary phases that form during the weathering of ILAW glasses for the next iteration of the IDF PA. Figure 5.1 illustrates schematically how geochemical modeling is used to develop a chemical reaction network of secondary phases based upon inputs that include initial glass composition, analytical results from PCT, PUF, and vapor hydration (VHT) tests, and solid-phase characterization results of reaction products formed during the PCT, PUF, and VHT tests. This work is needed to accurately model corrosion (weathering) of new glass formulations anticipated to be produced by the Hanford Tank Waste Treatment and Immobilization Plant (WTP). The Phase I work scope focuses on acquiring this information for specific glass formulations to support the next iteration of the IDF PA. In Phase I, chemical reaction networks of secondary phases will be developed using currently available data on newer glass formulations collected by PNNL since the 2001 PA. The Phase II work scope supports the development of a technical basis that relates glass compositional ranges to a specific chemical reaction network of secondary phases. The intent is to reduce the amount of experimental and modeling work required when new glass formulations are developed. The work discussed below will incorporate experimental data (VHT, PCT, etc.) on new and existing glass formulations collected by the VSL/CUA. 


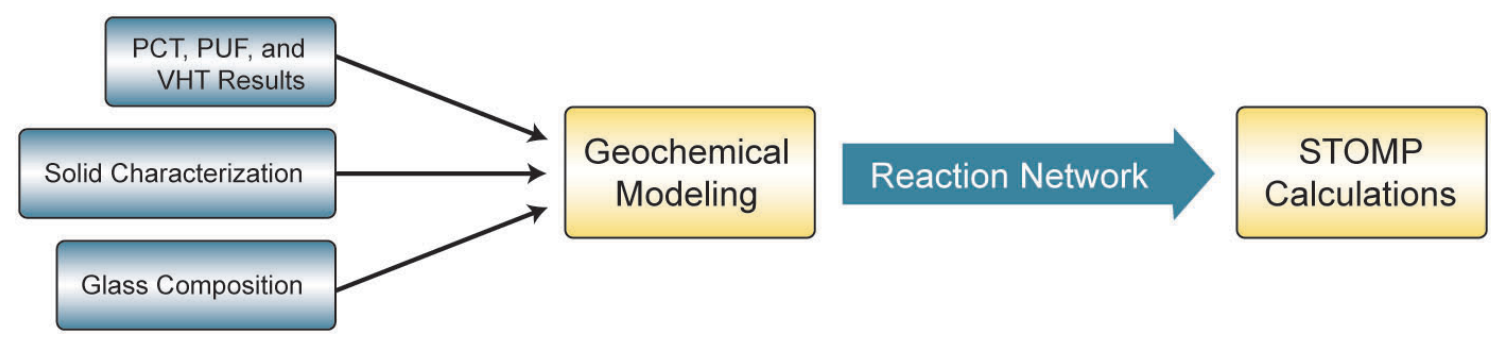

Figure 5.1. Schematic Representation of Data Inputs Needed for Geochemical Modeling to Develop the Chemical Reaction Network of Secondary Phases that Form During Glass Corrosion, Which is Subsequently Used in STOMP Calculation to Model the Weathering of ILAW Glasses for the IDF PA

\subsection{Geochemist's Workbench ${ }^{\circledR}$ for Modeling Secondary Phase Formation During Glass Corrosion}

In the previous ILAW studies, the geochemical modeling program EQ3/EQ6 (Wolery and Daveler 1992) was used to model experimental ILAW glass weathering data for determining chemical reaction networks of secondary phases that form during glass weathering. Beginning this year, it is anticipated that the program Geochemist's Workbench (Bethke and Yeakel 2009) will also be used for reasons of convenience, which include convenient input and output interfaces and user-friendly graphical data presentation capabilities. The same thermodynamic database used previously for geochemical modeling of ILAW data with EQ3/EQ6 is also included in the suite of thermodynamic databases available in Geochemist's Workbench. To confirm that Geochemist's Workbench was computationally equivalent to EQ3/EQ6, a validation and verification exercise was completed using the same input data set (from LAWA44) and the same thermodynamic data file. The details of the approach and results of the validation and verification exercise were documented in a Validation and Verification Plan and Validation and Verification Report, which has been added to the project records. The conclusions of the report indicated that the Geochemist's Workbench and EQ3/EQ6 are computationally equivalent.

\subsection{Description of Geochemical Modeling Approach for Determining Secondary Phase Formation During Glass Corrosion}

To determine the suite of secondary phases that form during corrosion of a particular glass sample, the React Module of Geochemist's Workbench (Bethke and Yeakel 2009) is used to trace a reaction path that takes place as a particular sample of glass dissolves in water. To set up the model, the glass composition is placed in an input file in terms of its component metal oxide composition, e.g., $\mathrm{SiO}_{2}, \mathrm{~B}_{2} \mathrm{O}_{3}$, $\mathrm{Al}_{2} \mathrm{O}_{3}$, and $\mathrm{Na}_{2} \mathrm{O}$. In the case of the halides, these components are added as their elemental gases, e.g., $\mathrm{F}_{2}$ and $\mathrm{Cl}_{2}$. The quantity of material included in the input file is set to equal one mole of glass. This is done so that when one mole of glass dissolves, the reaction progress equals $100 \%$. The input file is also set up so that the solution in which the glass dissolves is in equilibrium with air (the oxygen fugacity is set to 0.21 atmospheres, and the $\mathrm{CO}_{2}$ fugacity is set to $10^{-3.5}$ atmospheres). As an increment of reactant (glass, in our case) is added to water, its components are initially completely dissolved in the water and are then allowed to come to equilibrium. The model accounts for all possible aqueous species that could potentially form, redox reactions that could occur, and mineral species that could precipitate at 
equilibrium (based upon the thermodynamic database that is used). If the saturation index (SI) of a particular mineral phase exceeds 1.0, it will precipitate until the solution attains an equilibrium status ( $\mathrm{SI}=1.0$ or less for all minerals considered). The program keeps track of how much glass has dissolved, which phases and quantities of minerals have precipitated, and the solution composition and speciation in equilibrium with the suite of minerals that have dissolved or precipitated.

To develop the correct mineral phases for the chemical reaction network, it is necessary to eliminate a large number of the phases from consideration for the following reasons: 1) the formation of some phases is kinetically inhibited at the disposal system temperature of $\left.15^{\circ} \mathrm{C}, 2\right)$ the selection of some phases will violate the Gibbs phase rule, 3) simulations will be compared with experiments, and phases will be eliminated that generated solution compositions that were inconsistent with the experiments, or 4) phase stability will be considered over the range of chemical conditions expected for the ILAW disposal system. The bulk of the final set of phases appropriate for each glass type will be determined by simulating the solution chemistry observed in product consistency test (PCT) experiments.

In addition to the computer simulations, characterization of alteration products is used to identify key secondary phases that are required to constrain the computer simulations. Alteration products formed at the surfaces of the glass in the PUF test and the VHT, and PCT experiments are characterized by XRD, $\mathrm{SEM} / \mathrm{EDS}$, and transmission electron microscopy.

\subsection{Geochemical Modeling Results}

Initial modeling of the PCT results for the 128 glass samples was conducted using the secondaryphase reaction network listed in Table 5.1. This secondary-phase reaction network is the same as that developed for LAWA44 by Pierce et al. (2004b). All PCTs were conducted at $90^{\circ} \mathrm{C}$. In a number of cases, adjustments were made to the $\log \mathrm{K}$ values from the original database to get the values shown in Table 5.1 in order to adequately reproduce the PCT solution concentration data. For analcime, 3.00 was added to the original $\log \mathrm{K}$ value. For anatase, the original database contains a $\log \mathrm{K}$ value only for $25^{\circ} \mathrm{C}$; a value of 2.00 was added to the $25^{\circ} \mathrm{C}$ value for use at $90^{\circ} \mathrm{C}$. For baddeleyite, 2.50 was added to the original $\log \mathrm{K}$ value. For chalcedony, 0.30 was added to the original $\log \mathrm{K}$ value. $\mathrm{For} \mathrm{Fe}(\mathrm{OH})_{3}(\mathrm{~s})$, a value of 3.50 was added to the original $\log \mathrm{K}$ value. For sepiolite, a value of 15.00 was added to the original $\log \mathrm{K}$ value. For $\mathrm{Zn}(\mathrm{OH})_{2}-\gamma$, a value of 3.50 was added to the original $\log \mathrm{K}$ value. When necessary, the upward adjustments of the $\log \mathrm{K}$ values were the consequence of the fact that amorphous phases rather than their crystalline analogs often form in laboratory experiments with waste glasses. Amorphous solids are typically much more soluble than their crystalline analogs, which is reflected in the higher equilibrium constants.

Glass compositions used as input for the modeling are compiled in Appendix B (from Papathanassiu et al. 2011). The measured compositions of the solutions contacting the glass in the PCT tests are reported by Papathanassiu et al. (2011). Results of the PCT modeling results are presented in terms of the secondary phases calculated to form as a function of reaction progress (mol-glass $/ \mathrm{kg}$ ) and as comparisons with the measured solution concentrations $(\mathrm{mg} / \mathrm{L})$ versus model results for selected elements as a function of reaction progress. These results are presented for each glass sample in Appendix C. The agreement between the experimental solution concentrations and the model results are in general quite good, particularly for the major glass components. Notable exceptions to this general condition include results for the components $\mathrm{K}, \mathrm{Li}, \mathrm{Fe}, \mathrm{Ti}$, and $\mathrm{Zr}$. Calculated concentrations for $\mathrm{K}$ and $\mathrm{Li}$ determined by the 
model for these two components are generally significantly higher than measured concentrations. This suggests that additional phases occur that are not included in the secondary-phase reaction network used for these calculations (Table 5.1). Alternative secondary-phase reaction networks that include possible phases that result in better model fits for these components are discussed in Section 5.6. Solid-phase characterization results (summarized in Section 5.5) were used to provide the basis for inclusion of additional phases not initially included in the secondary-phase reaction network (Table 5.1) to obtain better agreement between model results and experimental data. PCT modeling results for $\mathrm{Fe}$, Ti, and $\mathrm{Zr}$ were typically much lower than measured values. Under oxidizing conditions, these metals tend to form relatively insoluble hydroxide/oxide precipitates whose dissolved species are not effectively separated from colloidally dispersed forms by routine filtration techniques (Cho et al. 2005; Rajh et al. 1992; Fox 1988). This can result in measured concentrations that are significantly higher than the true dissolved concentrations. As a result no attempt was made to obtain better fits for these three components.

Table 5.1. Secondary Phase Reaction Network Used for Initial Modeling of PCT Results

\begin{tabular}{lcc}
\hline \multicolumn{1}{c}{ Phase } & Reaction & Log K $\left(90^{\circ} \mathrm{C}\right)$ \\
\hline Analcime & analcime $+3.84 \mathrm{H}^{+} \leftrightarrow 0.96 \mathrm{Al}^{3+}+0.96 \mathrm{Na}^{+}+$ & 3.40 \\
$\left(\mathrm{Na}_{0.96} \mathrm{Al}_{0.96} \mathrm{Si}_{2.04} \mathrm{O}_{6} \cdot \mathrm{H}_{2} \mathrm{O}\right)$ & $2.04 \mathrm{SiO}_{2}(\mathrm{aq})+2.92 \mathrm{H}_{2} \mathrm{O}$ & \\
Anatase $\left(\mathrm{TiO}_{2}\right)$ & $\mathrm{TiO}_{2}+2 \mathrm{H}_{2} \mathrm{O} \leftrightarrow \mathrm{Ti}(\mathrm{OH})_{4}(\mathrm{aq})$ & -6.56 \\
Baddeleyite $\left(\mathrm{ZrO}_{2}\right)$ & $\mathrm{ZrO}_{2}+2 \mathrm{H}^{+} \leftrightarrow \mathrm{Zr}^{2+}(\mathrm{OH})_{2}{ }_{2}$ & -5.20 \\
Calcite $\left(\mathrm{CaCO}_{3}\right)$ & $\mathrm{CaCO}_{3}+\mathrm{H}^{+} \leftrightarrow \mathrm{Ca}^{2+}+\mathrm{HCO}_{3}{ }^{-}$ & 0.91 \\
Chalcedony $\left(\mathrm{SiO}_{2}\right)$ & $\mathrm{SiO}_{2} \leftrightarrow \mathrm{SiO}_{2}(\mathrm{aq})$ & -2.65 \\
$\mathrm{Fe}(\mathrm{OH})_{3}(\mathrm{~s})$ & $\mathrm{Fe}(\mathrm{OH})_{3}(\mathrm{am})+3 \mathrm{H}^{+} \leftrightarrow \mathrm{Fe}^{3+}+3 \mathrm{H}_{2} \mathrm{O}$ & 3.04 \\
Gibbsite $\left[\mathrm{Al}(\mathrm{OH})_{3}\right]$ & $\mathrm{Al}(\mathrm{OH})_{3}+3 \mathrm{H}^{+} \leftrightarrow \mathrm{Al}^{3+}+3 \mathrm{H}_{2} \mathrm{O}$ & 4.46 \\
Sepiolite & sepiolite $+8 \mathrm{H}^{+} \leftrightarrow 4 \mathrm{Mg}^{+}+6 \mathrm{SiO}_{2}(\mathrm{aq})+11 \mathrm{H}_{2} \mathrm{O}$ & 39.72 \\
{$\left[\mathrm{Mg}_{4} \mathrm{Si}_{6} \mathrm{O}_{15}(\mathrm{OH})_{2} \cdot 6 \mathrm{H}_{2} \mathrm{O}\right]$} & & \\
$\mathrm{Zn}(\mathrm{OH})_{2}-\gamma$ & $\mathrm{Zn}(\mathrm{OH})_{2}-\gamma+2 \mathrm{H}^{+} \leftrightarrow \mathrm{Zn}^{2+}+2 \mathrm{H}_{2} \mathrm{O}$ & 11.88 \\
\hline
\end{tabular}

\subsection{Solid-Phase Characterization Results}

To establish that the selected secondary-phase reaction network is correct, selected glass samples from the PCT tests were characterized with XRD and SEM/EDS. Phases identified by XRD analyses are shown in Table 5.2. Note that a crystalline phase must be present at greater than $\sim 5-10 \mathrm{wt} . \%$ of the total sample mass (greater than $1 \mathrm{wt} . \%$ under optimum conditions) to be readily detected by XRD. The XRD spectra for each of these samples along with the SEM/EDS results are reported by Papathatassiu et al. (2011).

The most common phase identified in the samples was analcime $\left[\mathrm{Na}\left(\mathrm{AlSi}_{2} \mathrm{O}_{6}\right)\left(\mathrm{H}_{2} \mathrm{O}\right)\right]$. This phase was frequently the second most abundant phase predicted to occur in the reaction progress modeling (after chalcedony). Using the initial secondary-phase reaction network, analcime was predicted to occur in the PCTs for all samples in Table 5.2. Gobbinsite $\left[\mathrm{Na}_{5}\left(\mathrm{Si}_{11} \mathrm{Al}_{5}\right) \mathrm{O}_{32} \cdot 11 \mathrm{H}_{2} \mathrm{O}\right]$, which is compositionally very similar to analcime, was identified in samples A1-AN105R2 and A1C1-1. Stevensite $\left[(\mathrm{Ca}, \mathrm{Na})_{\mathrm{x}} \mathrm{Mg}_{3-}\right.$ $\left.{ }_{x} \mathrm{Si}_{4} \mathrm{O}_{10}(\mathrm{OH})_{2}\right]$ was identified in 7 of the 24 samples analyzed. Hectorite-15a $\left[\mathrm{Na}_{0.2}(\mathrm{Mg}, \mathrm{Li})_{3} \mathrm{Si}_{4} \mathrm{O}_{10}(\mathrm{OH})_{2} \cdot 4 \mathrm{H}_{2} \mathrm{O}\right]$ was found only in sample A1C1-1. Phillipsite-Na $\left[\mathrm{Na}_{4} \mathrm{KAl}_{5} \mathrm{Si}_{11} \mathrm{O}_{32}\left(\mathrm{H}_{2} \mathrm{O}\right)_{10}\right]$ was also identified in just one of the samples (A1C1-2). Chabazite $\left[\mathrm{Ca}_{2} \mathrm{Al}_{4} \mathrm{Si}_{8} \mathrm{O}_{24} \cdot 12 \mathrm{H}_{2} \mathrm{O}\right]$ was determined to occur in three of the samples (A2-AP101, LAWA126, and PNLA126CC). Herschelite $\left[\mathrm{NaAlSi}_{2} \mathrm{O}_{6} \cdot 3 \mathrm{H}_{2} \mathrm{O}\right]$ was identified in two samples (A2-AP101 and 
LAWA126). Saponite-15 $\left.\AA \mathrm{Ca}_{0.2} \mathrm{Mg}_{3}(\mathrm{SiAl})_{4} \mathrm{O}_{10}(\mathrm{OH})_{2} \cdot 4 \mathrm{H}_{2} \mathrm{O}\right]$ was found in one sample (LAWB60). Swinfordite-13 $\left.\AA \mathrm{Ca}_{0.1}(\mathrm{Li}, \mathrm{Al})_{3} \mathrm{Si}_{4} \mathrm{O}_{10}(\mathrm{OH})_{2} \cdot 2 \mathrm{H}_{2} \mathrm{O}\right]$ was identified in three samples (LAWB73, LAWB81, LAWC32). Foshagite $\left[\mathrm{Ca}_{4}\left(\mathrm{SiO}_{3}\right)_{3}(\mathrm{OH})_{2}\right]$ was identified in sample LAWB90. Of the phases in Table 5.2 identified by XRD, thermodynamic data are available only for analcime, saponite, and foshagite.

Table 5.2. Mineral Phases Identified in PCT Glass Samples by XRD

\begin{tabular}{|c|c|}
\hline Sample ID & Phases Identified \\
\hline A1-AN105R2 & analcime $-\mathrm{c}-\mathrm{Na}\left(\mathrm{Si}_{2} \mathrm{Al}\right) \mathrm{O}_{6} \cdot \mathrm{H}_{2} \mathrm{O}$, gobbinsite $-\mathrm{Na}_{5}\left(\mathrm{Si}_{11} \mathrm{Al}_{5}\right) \mathrm{O}_{32} \cdot 11 \mathrm{H}_{2} \mathrm{O}$ \\
\hline A1C1-1 & $\begin{array}{l}\text { analcime }-\mathrm{c}-\mathrm{Na}\left(\mathrm{Si}_{2} \mathrm{Al}\right) \mathrm{O}_{6} \cdot \mathrm{H}_{2} \mathrm{O} \text {, gobbinsite }-\mathrm{Na}_{5}\left(\mathrm{Si}_{11} \mathrm{Al}_{5}\right) \mathrm{O}_{32} \cdot 11 \mathrm{H}_{2} \mathrm{O} \\
\text { hectorite-15a- } \mathrm{Na}_{0.2}(\mathrm{Mg}, \mathrm{Li})_{3} \mathrm{Si}_{4} \mathrm{O}_{10}(\mathrm{OH})_{2} \cdot 4 \mathrm{H}_{2} \mathrm{O} \text {, stevensite }-(\mathrm{Ca}, \mathrm{Na})_{\mathrm{x}} \mathrm{Mg}_{3-\mathrm{x}} \mathrm{Si}_{4} \mathrm{O}_{10}(\mathrm{OH})_{2}\end{array}$ \\
\hline A1C1-2 & $\begin{array}{l}\text { analcime }-\mathrm{c}-\mathrm{Na}\left(\mathrm{Si}_{2} \mathrm{Al}\right) \mathrm{O}_{6} \cdot \mathrm{H}_{2} \mathrm{O} \text {, phillipsite- } \mathrm{Na}-\mathrm{Na}_{4} \mathrm{KAl}_{5} \mathrm{Si}_{11} \mathrm{O}_{32}\left(\mathrm{H}_{2} \mathrm{O}\right)_{10} \\
\text { stevensite }-(\mathrm{Ca}, \mathrm{Na})_{\mathrm{x}} \mathrm{Mg}_{3-\mathrm{x}} \mathrm{Si}_{4} \mathrm{O}_{10}(\mathrm{OH})_{2}\end{array}$ \\
\hline A2-AP101 & chabazite $-\mathrm{Ca}_{2} \mathrm{Al}_{4} \mathrm{Si}_{8} \mathrm{O}_{24} \cdot 12 \mathrm{H}_{2} \mathrm{O}$, herschelite $-\mathrm{NaAlSi}_{2} \mathrm{O}_{6} \cdot 3 \mathrm{H}_{2} \mathrm{O}$ \\
\hline A88AP101R1 & analcime $-\mathrm{Na}\left(\mathrm{AlSi}_{2} \mathrm{O}_{6}\right)\left(\mathrm{H}_{2} \mathrm{O}\right)$ \\
\hline A88Si-15 & None \\
\hline C100GCC & analcime $-\mathrm{NaAl}\left(\mathrm{Si}_{2} \mathrm{O}_{6}\right) \mathrm{H}_{2} \mathrm{O}$, stevensite $-(\mathrm{Ca}, \mathrm{Na})_{x} \mathrm{Mg}_{3-\mathrm{x}} \mathrm{Si}_{4} \mathrm{O}_{10}(\mathrm{OH})_{2}$ \\
\hline LAWA44R10 & analcime $-\mathrm{Na}\left(\mathrm{AlSi}_{2} \mathrm{O}_{6}\right)\left(\mathrm{H}_{2} \mathrm{O}\right)$ \\
\hline LAWA53 & analcime $-\mathrm{NaAl}\left(\mathrm{Si}_{2} \mathrm{O}_{6}\right) \mathrm{H}_{2} \mathrm{O}$ \\
\hline LAWA88R1 & analcime $-\mathrm{NaAl}\left(\mathrm{Si}_{2} \mathrm{O}_{6}\right) \mathrm{H}_{2} \mathrm{O}$ \\
\hline LAWA126 & chabazite $-\mathrm{Ca}_{1.96} \mathrm{Al}_{3.9} \mathrm{Si}_{8.1} \mathrm{O}_{24}\left(\mathrm{H}_{2} \mathrm{O}\right)_{13}$, herschelite $-\mathrm{NaAlSi}_{2} \mathrm{O}_{6} \cdot 3 \mathrm{H}_{2} \mathrm{O}$ \\
\hline LAWB31 & None \\
\hline LAWB32 & None \\
\hline LAWB35 & None \\
\hline LAWB60 & saponite- $15 \AA-\mathrm{Ca}_{0.2} \mathrm{Mg}_{3}(\mathrm{SiAl})_{4} \mathrm{O}_{10}(\mathrm{OH})_{2} \cdot 4 \mathrm{H}_{2} \mathrm{O}$, stevensite $-\mathrm{Ca}_{0.2} \mathrm{Mg}_{2.9} \mathrm{Si}_{4} \mathrm{O}_{10}(\mathrm{OH})_{2} \cdot 4 \mathrm{H}_{2} \mathrm{O}$ \\
\hline LAWB73 & 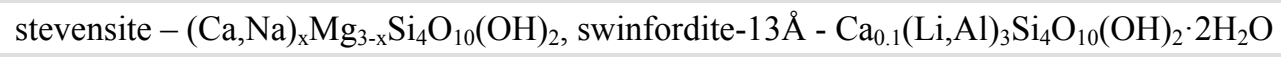 \\
\hline LAWB81 & swinfordite- $13 \mathrm{a}-\mathrm{Ca}_{0.1}(\mathrm{Li}, \mathrm{Al})_{3} \mathrm{Si}_{4} \mathrm{O}_{10}(\mathrm{OH})_{2} \cdot 2 \mathrm{H}_{2} \mathrm{O}$ \\
\hline LAWB89 & None \\
\hline LAWB90 & foshagite $-\mathrm{Ca}_{4}\left(\mathrm{SiO}_{3}\right)_{3}(\mathrm{OH})_{2}$ \\
\hline LAWC23 & None \\
\hline LAWC27 & None \\
\hline LAWC31 & analcime $-\mathrm{NaAl}\left(\mathrm{Si}_{2} \mathrm{O}_{6}\right) \mathrm{H}_{2} \mathrm{O}$, stevensite $-(\mathrm{Ca}, \mathrm{Na})_{\mathrm{x}} \mathrm{Mg}_{3-\mathrm{x}} \mathrm{Si}_{4} \mathrm{O}_{10}(\mathrm{OH})_{2}$ \\
\hline LAWC32 & $\begin{array}{l}\text { analcime }-\mathrm{NaAl}\left(\mathrm{Si}_{2} \mathrm{O}_{6}\right) \mathrm{H}_{2} \mathrm{O} \text {, stevensite }-\left(\mathrm{Ca}, \mathrm{Na}_{\mathrm{x}} \mathrm{Mg}_{3-\mathrm{x}} \mathrm{Si}_{4} \mathrm{O}_{10}(\mathrm{OH})_{2},\right. \\
\text { swinfordite- } 13 \AA-\mathrm{Ca}_{0.1}(\mathrm{Li}, \mathrm{Al})_{3} \mathrm{Si}_{4} \mathrm{O}_{10}(\mathrm{OH})_{2} \cdot 2 \mathrm{H}_{2} \mathrm{O}\end{array}$ \\
\hline PNLA126CC & analcime $-\mathrm{NaAl}\left(\mathrm{Si}_{2} \mathrm{O}_{6}\right) \mathrm{H}_{2} \mathrm{O}$, chabazite $-\mathrm{Ca}_{1.96} \mathrm{Al}_{3.9} \mathrm{Si}_{8.1} \mathrm{O}_{24}\left(\mathrm{H}_{2} \mathrm{O}\right)_{13}$ \\
\hline
\end{tabular}

A summary of SEM/EDS analysis results in terms of likely phases present based upon elemental composition and morphology are compared with phases identified by XRD in Table 5.3. Elemental compositions determined by EDS and crystal morphology apparent from the SEM images provide compelling evidence for the presence of analcime in a majority of the samples (13 out of 24). Elemental compositions and crystal morphology provide credible evidence for the presence of chabazite in many of the samples (10 out of 24). Evidence supporting the possible presence of a number of phases (saponite, $\mathrm{Fe}(\mathrm{OH})_{3}, \mathrm{Zn}(\mathrm{OH})_{2}, \mathrm{Zr}(\mathrm{OH})_{4}$, phillipsite, and stevensite) is less certain and is based primarily on analysis of locations that could be mixtures of some of the indicated phases. EDS analyses for LAWB60, LAWB73, LAWB90, and LAWC27 indicate the likely presence of a calcium silicate phase. EDS 
analyses for LAWB89, LAWB90, and LAWC27, indicate the likely presence of a calcium carbonate phase. This information will be used in Section 5.6 to rationalize the inclusion of additional phases to the secondary-phase reaction network to achieve better model fits of the PCT solution data.

Table 5.3. Mineral Phases Identified in PCT Glass Samples by SEM/EDS and XRD

\begin{tabular}{|c|c|c|}
\hline Sample ID & $\begin{array}{c}\text { Possible Secondary Mineral Phase Compositions } \\
\text { Based on SEM/EDS }\end{array}$ & Phases Identified by XRD \\
\hline A1-AN105R2 & analcime, saponite, $\mathrm{Fe}(\mathrm{OH})_{3}, \mathrm{Zn}(\mathrm{OH})_{2}, \mathrm{Zr}(\mathrm{OH})_{4}$ & analcime, gobbinsite \\
\hline A1C1-1 & analcime, saponite, $\mathrm{Fe}(\mathrm{OH})_{3}, \mathrm{Zn}(\mathrm{OH})_{2}, \mathrm{Zr}(\mathrm{OH})_{4}$ & analcime, gobbinsite, hectorite, stevensite \\
\hline $\mathrm{A} 1 \mathrm{C} 1-2$ & analcime, saponite, $\mathrm{Fe}(\mathrm{OH})_{3}, \mathrm{Zn}(\mathrm{OH})_{2}$ & analcime, phillipsite, stevensite \\
\hline A2-AP101 & chabazite, phillipsite & chabazite, herschelite \\
\hline A88AP101R1 & $\begin{array}{l}\text { analcime, chabazite, phillipsite, } \mathrm{Fe}(\mathrm{OH})_{3} \text {, } \\
\mathrm{Zn}(\mathrm{OH})_{2}, \mathrm{Zr}(\mathrm{OH})_{4}\end{array}$ & analcime \\
\hline A88Si-15 & analcime, chabazite, saponite & None \\
\hline C100GCC & $\begin{array}{l}\text { analcime, chabazite, saponite, } \mathrm{Fe}(\mathrm{OH})_{3}, \mathrm{Zn}(\mathrm{OH})_{2} \text {, } \\
\mathrm{Zr}(\mathrm{OH})_{4}\end{array}$ & analcime, stevensite \\
\hline LAWA44R10 & analcime, saponite & analcime \\
\hline LAWA53 & analcime, chabazite, saponite & analcime \\
\hline LAWA88R1 & analcime, chabazite, saponite, $\mathrm{Fe}(\mathrm{OH})_{3}, \mathrm{Zn}(\mathrm{OH})_{2}$ & analcime \\
\hline LAWA126 & analcime, chabazite, phillipsite, saponite & chabazite, herschelite \\
\hline LAWB31 & none & None \\
\hline LAWB32 & none & None \\
\hline LAWB35 & saponite, $\mathrm{Zr}(\mathrm{OH})_{4}$ & None \\
\hline LAWB60 & chabazite, calcium silicate, stevensite, $\mathrm{Zr}(\mathrm{OH})_{4}$ & saponite- $15 \AA$, stevensite \\
\hline LAWB73 & calcium silicate, stevensite, $\mathrm{Zn}(\mathrm{OH})_{2}, \mathrm{Zr}(\mathrm{OH})_{4}$ & stevensite, swinfordite- $13 \AA$ \\
\hline LAWB81 & saponite, $\mathrm{Fe}(\mathrm{OH})_{3}, \mathrm{Zn}(\mathrm{OH})_{2}, \mathrm{Zr}(\mathrm{OH})_{4}$ & swinfordite- $13 \AA$ \\
\hline LAWB89 & calcium carbonate & None \\
\hline LAWB90 & calcium carbonate, calcium silicate & foshagite \\
\hline LAWC23 & chabazite, saponite, $\mathrm{Fe}(\mathrm{OH})_{3}, \mathrm{Zn}(\mathrm{OH})_{2}$ & None \\
\hline LAWC27 & $\begin{array}{l}\text { analcime, calcium carbonate, calcium silicate, } \\
\text { saponite, stevensite }\end{array}$ & None \\
\hline LAWC31 & stevensite, $\mathrm{Zn}(\mathrm{OH})_{2}$ & analcime, stevensite \\
\hline LAWC32 & $\begin{array}{l}\text { analcime, saponite, stevensite, } \mathrm{Fe}(\mathrm{OH})_{3}, \mathrm{Zn}(\mathrm{OH})_{2} \text {, } \\
\mathrm{Zr}(\mathrm{OH})_{4}\end{array}$ & analcime, stevensite, swinfordite- $13 \AA$ \\
\hline PNLA126CC & analcime, chabazite, saponite, $\mathrm{Fe}(\mathrm{OH})_{3}, \mathrm{Zr}(\mathrm{OH})_{4}$, & analcime, chabazite \\
\hline
\end{tabular}

\subsection{Alternative Secondary Phase Reaction Networks}

A certain fraction of the ILAW glass sample PCT results did not fit well with model predictions. In these cases the original secondary-phase reaction network (Table 5.1) was augmented with additional phases to achieve better agreement between the model results and the experimental PCT data. Samples selected for further discussion in this section are confined to those for which XRD and SEM/EDS analyses were conducted. This was done because only these samples have solid-phase characterization data that can be used to support arguments for the occurrence of additional phases not included in the 
original secondary-phase reaction network. The most frequent discrepancies between measured and model results occurred with $\mathrm{K}$ and $\mathrm{Li}$. Possible phases that could account for the lower $\mathrm{K}$ concentrations relative to model fits of PCT data include an analcime phase in which $\mathrm{Na}$ is partially replaced with $\mathrm{K}$ (Savage et al. 2001) or a K-rich chabazite $\left(\mathrm{Ca}_{0.5}, \mathrm{Na}, \mathrm{K}\right)_{4}\left[\mathrm{Al}_{4} \mathrm{Si}_{8} \mathrm{O}_{24}\right] \cdot 12 \mathrm{H}_{2} \mathrm{O}$. Analogous phases could potentially account for the lower Li concentrations as well. For example, Li chabazite is a stable phase that can be readily synthesized (e.g., Singh and Webley 2005). Accounting for these phases in the model is problematic because thermodynamic data for these phases is not currently available and the exact compositions of these phases in the PCT tests is unknown. For example, the distribution of exchangeable cations in chabazite is variable and will depend on their concentrations in the glass and the solution in contact with the glass. To determine whether $\mathrm{K}$ - and Li-rich forms of analcime or chabazite could potentially explain the discrepancies between the initial modeling results and the PCT data, further modeling was conducted in which the hypothetical phases $\mathrm{K}$-analcime $\left[\mathrm{K}\left(\mathrm{AlSi}_{2} \mathrm{O}_{6}\right)\left(\mathrm{H}_{2} \mathrm{O}\right)\right]$ and Li-analcime $\left[\mathrm{Li}\left(\mathrm{AlSi}_{2} \mathrm{O}_{6}\right)\left(\mathrm{H}_{2} \mathrm{O}\right)\right]$ are assumed to control $\mathrm{K}$ and $\mathrm{Li}$ concentrations. These hypothetical phases were used for the modeling because analcime and chabazite have similar composition, with ratios of exchangeable cation charge to $\mathrm{Al}, \mathrm{Si}$, and $\mathrm{O}$ that are equal (only the degree of hydration is different).

An example of this approach is presented here for glass sample LAWA126. This sample was selected for illustration because it did not contain any $\mathrm{Li}$ and only one additional phase was required to improve the fit for K. The modeling was conducted iteratively, by manually adjusting the log $\mathrm{K}$ values for $\mathrm{K}$-analcime until the best fit of the PCT data was obtained. Figure 5.2 shows K concentrations measured in the PCT solutions as a function of reaction progress determined for glass sample LAWA126, model results determined using the original secondary-phase reaction network listed in Table 5.1, and model results with the addition of $\mathrm{K}$-analcime to the network. The results indicate that significantly better fits for $\mathrm{K}$ occur when $\mathrm{K}$-analcime is included in the model. The best fit was obtained using $\log \mathrm{K}=5.304$ for $\mathrm{K}$-analcime. The $\log \mathrm{K}$ used for Na-analcime in the model was 6.404 at $90^{\circ} \mathrm{C}$, indicating that the hypothetical K-analcime has a lower solubility than that of Na-analcime. Results for the other elements are not shown because any change in the model results for these elements was nearly imperceptible. These model results do not prove that K-analcime did precipitate during the LAWA126 PCT; however, the results do indicate that precipitation of a phase with this composition is a reasonable explanation for the K concentrations determined for the PCTs. Based upon the XRD and SEM/EDS results from Papathanassiu et al. (2011), it is likely that rather than formation of a pure K-analcime phase, a chabazite phase in which $\mathrm{K}$ substitutes for other cations in the framework of the phase is what actually occurs. The solid-phase characterization results for LAWA126 support this assertion. The XRD results confirm the presence of chabazite, and the SEM/EDS results illustrate the occurrence of a crystalline phase consistent with the crystal morphology and composition of chabazite with an exchangeable cation composition dominated by $\mathrm{Na}$ but with a significant fraction of $\mathrm{K}$.

For some glass samples containing Li, it was possible to get better model fits of the PCT data by including both the hypothetical K-analcime phase and a hypothetical Li-analcime phase. However, because XRD analysis indicates the presence of other Li-containing phases including hectorite-15a$\mathrm{Na}_{0.2}(\mathrm{Mg}, \mathrm{Li})_{3} \mathrm{Si}_{4} \mathrm{O}_{10}(\mathrm{OH})_{2} \cdot 4 \mathrm{H}_{2} \mathrm{O}$ (sample A1C1-1) and swinfordite-13 $\AA-\mathrm{Ca}_{0.1}\left(\mathrm{Li}, \mathrm{Al}_{3} \mathrm{Si}_{4} \mathrm{O}_{10}(\mathrm{OH})_{2} \cdot 2 \mathrm{H}_{2} \mathrm{O}\right.$ (samples LAWB73, LAWB81, and LAWC32), these results cannot be considered a reliable indication that a Li-analcime-type phase actually occurs. Because thermodynamic data for hectorite and swinfordite are not available, modeling cannot be used to test the applicability of these phases. Because of these factors, reliable and unambiguous modeling of glasses with significant Li content is problematic. 


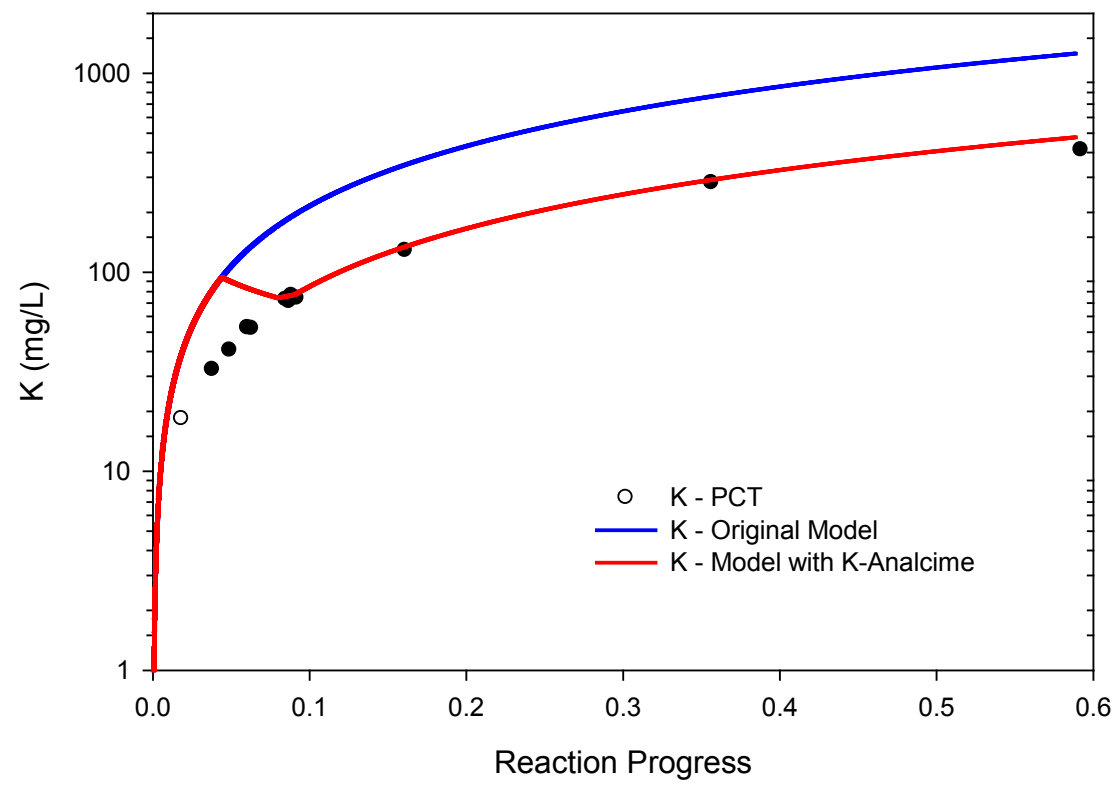

Figure 5.2. Measured Solution Concentrations in PCT for $\mathrm{K}(\mathrm{mg} / \mathrm{L})$ and Model Results Using the Secondary Reaction Network Listed in Table 3.1 and Model Results with the Addition of K-Analcime to the Network as a Function of Reaction Progress (mol-glass $/ \mathrm{kg}$ ) Determined for Glass Sample LAWA126 (PCT conducted at $90^{\circ} \mathrm{C}$ )

For glass samples that had relatively high concentrations of $\mathrm{Ca}$ and $\mathrm{Li}$ and relatively low concentrations of $\mathrm{Na}$, modeling conducted with the reaction network in Table 5.1 resulted in particularly poor fits. For samples LAWB60 and LAWB73, the model fits for Ca were especially poor and the fits for $\mathrm{Al}$ and Si were poorer than typically observed. For samples LAWB89 and LAWB90, model fits for Ca, $\mathrm{Al}$, and $\mathrm{Si}$ were all quite poor. For these samples, the measured calcium concentrations were significantly higher than model results when the solubility of calcite was assumed to control Ca concentrations (Table 5.1). Significant improvements to the model fits for $\mathrm{Ca}$ could be made by assuming the solubility of either monohydrocalcite $\left(\mathrm{CaCO}_{3} \cdot \mathrm{H}_{2} \mathrm{O}\right)$ or gyrolite $\left(\mathrm{Ca}_{2} \mathrm{Si}_{3} \mathrm{O}_{7}(\mathrm{OH})_{2} \cdot 1.5 \mathrm{H}_{2} \mathrm{O}\right)$ controlled $\mathrm{Ca}$ concentrations. Using SEM/EDS a calcium carbonate phase was identified in samples LAWB89 and LAWB90 and a calcium silicate phase was identified in samples LAWB60, LAWB73, and LAWB90, suggesting that monohydrocalcite and gyrolite are plausible phases. Foshagite $\left(\mathrm{Ca}_{4} \mathrm{Si}_{3} \mathrm{O}_{9}(\mathrm{OH})_{2} \cdot 0.5 \mathrm{H}_{2} \mathrm{O}\right)$ was identified in LAWB90 by XRD. It is possible that gyrolite controlled Ca concentrations in solution for the LAWB90 PCT but that this phase subsequently transformed to foshagite as a result of sample dehydration prior to XRD analysis. Depending on the sample, model fits for $\mathrm{Al}, \mathrm{Si}$, and $\mathrm{Na}$ concentrations could be improved by suppressing gibbsite and allowing boehmite, diaspore or kaolinite to control the aluminum concentrations and reducing the chalcedony $\log \mathrm{K}$ by $0.3 \log$ units. No consistent approach was identified that would improve the model fits for each of these samples. It is suspected that the inability to identify and appropriately model the Li phase may have contributed to this problem. As a result, further efforts to improve the model fits of samples that were not adequately described by the secondary-phase reaction network in Table 5.1 and the hypothetical K-analcime phase were abandoned. 


\subsection{Summary of Geochemical Modeling}

It was determined that for the majority of the 128 glass samples that were modeled, a secondaryphase reaction network previously developed for ILAW glass sample LAWA44 produced good model fits for the major glass components. Notable exceptions were K and Li. Model fits for glass samples that contained relatively high concentrations of $\mathrm{Ca}$ and $\mathrm{Li}$ and relatively low concentrations of $\mathrm{Na}$ also had relatively poor fits for $\mathrm{Ca}, \mathrm{Al}$, and $\mathrm{Si}$. For samples that did not contain $\mathrm{Li}$, significantly better model fits for $\mathrm{K}$ were attained assuming that $\mathrm{K}$ concentrations were controlled by the solubility of a hypothetical $\mathrm{K}$-analcime phase. Solid-phase characterization results indicated that rather than a pure K-analcime phase, a K-rich chabazite phase is more likely the phase that actually occurs. XRD results confirmed the presence of chabazite and SEM/EDS results verified the presence of a crystalline phase consistent with the crystal morphology and composition of chabazite. EDS results indicated that the exchangeable cation composition for the chabazite was dominated by $\mathrm{Na}$ but with significant fractions of $\mathrm{K}$. Because the hypothetical K-analcime phase and K-chabazite have an equivalent compositional stoichiometry for the structural elements (chabazite has more waters of hydration), the good model fits for K are consistent with chabazite being the phase that controls K concentrations during corrosion of ILAW glasses.

Modeling Li proved to be problematic due to an inability to identify the specific composition(s) of Li-containing phase(s) and a lack of thermodynamic data for such phases. For glass samples that contained relatively high concentrations of $\mathrm{Ca}$ and $\mathrm{Li}$ and relatively low concentrations of $\mathrm{Na}$, it was determined that monohydrocalcite $\left(\mathrm{CaCO}_{3} \cdot \mathrm{H}_{2} \mathrm{O}\right)$ and/or gyrolite $\left(\mathrm{Ca}_{2} \mathrm{Si}_{3} \mathrm{O}_{7}(\mathrm{OH})_{2} \cdot 1.5 \mathrm{H}_{2} \mathrm{O}\right)$ could potentially control $\mathrm{Ca}$ concentrations rather than calcite, as was the case for more typical glass compositions. Better model fits of the experimental PCT data for these types of glasses could be obtained by suppressing gibbsite precipitation and assuming that $\mathrm{Al}$ concentrations were controlled by boehmite, diaspore, or kaolinite (depending upon the specific sample). Developing a consistent reaction network of secondary phases for these types of glass was not feasible, probably due to the inability to identify and model the phase(s) that control Li concentrations and the lack of actual thermodynamic data for K-chabazite. 


\subsection{Monte Carlo Simulations}

\subsection{Overview}

The primary objective of the Monte Carlo (MC) simulations is to predict the composition, extent, and morphology of the hydration layer as a function of glass composition and thus provide input data for geochemical modeling of secondary-phase formation.

In the MC model, the glass framework is mapped onto a cubic array, which allows for high computing efficiency. Each lattice site initially represents a glass-former cation (e.g., Si, Al, or B) and its first oxygen coordination shell. Glass-modifier cations (e.g., $\mathrm{Na}$ ) are placed in interstitial positions. When a site is dissolved, it is considered to be replaced by water. Connections between nearest-neighbor sites represent $\mathrm{X}-\mathrm{O}-\mathrm{X}$ linkages, where $\mathrm{X}$ is a glass-former cation. To represent the fourfold connectivity of the glass-former cations, two connections are removed at each lattice site. The volume of the contacting solution can be considered either to be infinite to mimic a SPFT test conducted under dilute conditions or to have a fixed surface-area-to-volume ratio $\left(\right.$ in $^{-1}$ ). Four elements have been considered so far, namely, silicon, boron, aluminum, and sodium. Silicon atoms are in tetrahedral coordination and therefore form four connections with nearest-neighbor sites. If associated with a non-bridging oxygen, a silicon site is considered to form only three connections with nearest-neighbor sites and is charge compensated by a sodium ion. Boron atoms can be in either tetrahedral or trigonal coordination environments. When in tetrahedral coordination, boron sites are charge compensated by sodium ions. Additionally, three trigonal borons can form a boroxol ring. Boroxol rings can also polymerize. Aluminum atoms are always considered to be in tetrahedral coordination, are charge compensated by sodium, and cannot be associated with a non-bridging oxygen. Sodium atoms are used to charge compensate tetrahedral boron and aluminum sites as well as non-bridging oxygen sites. Sodium ions are assumed to dissolve with the site they are charge compensating.

Each simulation step of the MC algorithm comprises five stages: 1) a dissolution evaluation and execution stage, in which each surface site is evaluated for dissolution using dissolution probabilities determined using the approach described below; 2) a glass connectivity evaluation stage, in which the new glass configuration is evaluated to determine whether clusters of lattice sites not connected to the main glass slab are present and therefore should also be dissolved; 3) a condensation stage, in which silicon atoms can deposit back at surface sites; 4) a liquid connectivity evaluation stage, in which the connectivity of the main aqueous solution is determined; and finally, 5) a coordination evaluation stage, in which the coordination of each site in the final glass configuration is recalculated.

Boron atoms are considered to dissolve instantaneously once in contact with the aqueous solution and therefore their dissolution probability is set to 1 regardless of their coordination. Silicon sites, however, have a probability for dissolution dependent on their coordination. Probabilities $w_{1}, w_{2}$, and $w_{3}$ are used for sites with one, two, or three connections to nearest neighbors. The MC program also includes aluminum, and therefore $\mathrm{Si}$ and $\mathrm{Al}$ can find themselves in a number of possible bonding environments. 
To minimize the number of reactivity parameters used to describe all possible bonding environments, we employed the formulation introduced by Ledieu et al. (2006), which defines the Si and Al dissolution probabilities as follows:

$$
w_{d}(\mathrm{Si}, n, m)=\frac{w_{n}}{r^{m}}
$$

and

$$
w_{d}(\mathrm{Al}, n, m)=\frac{w_{n}}{r^{m+1}}
$$

where $\quad w_{\mathrm{d}}=$ the dissolution probability for Si or $\mathrm{Al}$

$n=$ the total number of connections

$m=$ the number of connections with $\mathrm{Al}$

$r=$ the relative strength between Si-O-Al and Si-O-Si linkages.

Furthermore, silicon atoms can recondense at surface sites with probability

$$
w_{r}=w_{c} c_{\mathrm{Si}}
$$

where $w_{\mathrm{c}}$ is the condensation probability and $c_{\mathrm{Si}}$ is the concentration of silicon in the aqueous solution.

In FY 2010, initial developments of the MC code were implemented. In addition, the MC code was used to evaluate the effects of different structural features (presence of non-bridging oxygen, the formation and polymerization of boroxol rings, and the aluminum avoidance rule) on the rates and mechanisms of dissolution of borosilicate and alumino-borosilicate glasses. This study led to the following conclusions: 1) the dependence of the dissolution rate on the amount of non-bridging oxygen was found to be linear at all $\mathrm{Si} / \mathrm{B}$ ratios and the accelerating effect of non-bridging oxygen was shown to increase with increasing Si/B ratio. 2) The formation of boroxol rings and of clusters of boroxol rings resulted in an increase of the dissolution rate at all $\mathrm{Si} / \mathrm{B}$ ratios, and again, the extent of the rate increase was strongly dependent on the Si/B ratio. 3) For aluminosilicate glasses, the implementation of the aluminum avoidance rule was found to increase the rate of dissolution relative to that obtained for a random distribution.

Moreover, the MC code was used to model the dissolution of the NeB glasses studied by Pierce et al. (2010a). The simulations showed that at low B/Al ratios, the rupture of both Al-O-Si and Si-O-Si linkages contributed to the dissolution rate, whereas at high $\mathrm{B} / \mathrm{Al}$ ratios, the dissolution rate was independent of the rupture of Al-O-Si linkages and was controlled by $\mathrm{S}^{1}$ sites (silicon sites at the glasswater interface with one connection to nearest-neighbor sites). This work resulted in the publication of a research article (Kerisit and Pierce 2011) in the international scientific journal Geochimica et Cosmochimica Acta. Importantly, the work performed in FY 2010 focused on the dissolution of glasses in dilute conditions only and, therefore, the work carried out in FY 2011 was focused on the dissolution of glasses in near-saturated conditions. 
The progress made in FY 2011 can be divided into two areas, namely development of the MC code and $\mathrm{MC}$ computational study of the dissolution of borosilicate glasses under near-saturated conditions. Therefore, this section has been divided into the aforementioned subsections.

\subsection{Monte Carlo Code Development}

The principal change to the MC code completed this year was the implementation of condensation reactions whereby dissolved silicon atoms can deposit back on the glass surface. These calculations are much more demanding computationally than those performed last year under dilute conditions because they require the code to keep track of the connectivity of the aqueous solution in addition to that of the glass, and they also result in thicker hydration layers, which require thicker glass slabs and longer times to be simulated. Therefore, in order to significantly accelerate the MC simulations, the MC code was transformed from a single-processor to a multiple-processor code. Communications between processors are performed with Message Passing Interface (MPI). Despite an initial setback, whereby for subroutines that required extensive communication (e.g., the connectivity subroutine), the added burden due to communication between processors increased the overall computational cost, satisfactory speedup of the code with the increasing number of processors was eventually obtained by optimizing the size of the main arrays passed between processors. An example of the speedup obtained for the principal subroutines is shown in Table 6.1.

Table 6.1. Timing and Speedups Obtained from the Dissolution of a Borosilicate Glass with Dimension $64 \times 64 \times 4096$ Lattice Sites. Timings are in seconds per computer step.

\begin{tabular}{ccccccc}
\hline Number of CPUs & Coordination & Speedup & Connectivity & Speedup & Dissolution & Speedup \\
\hline 1 & 0.806 & 1.0 & 0.913 & 1.0 & 0.664 & 1.0 \\
2 & 0.401 & 2.0 & 0.462 & 2.0 & 0.345 & 1.9 \\
4 & 0.210 & 3.8 & 0.269 & 3.4 & 0.173 & 3.8 \\
8 & 0.127 & 6.3 & 0.187 & 4.9 & 0.088 & 7.5 \\
\hline
\end{tabular}

The new parallel implementation yielded very good agreement with the results obtained by Devreux et al. (2004) with a similar MC algorithm, as shown in Figure 6.1. The use of random numbers in the $\mathrm{MC}$ algorithm will cause fluctuations from one simulation to another, which could explain the small differences between the absolute values of the silicon and boron concentrations calculated here and those of Devreux et al. (2004). 


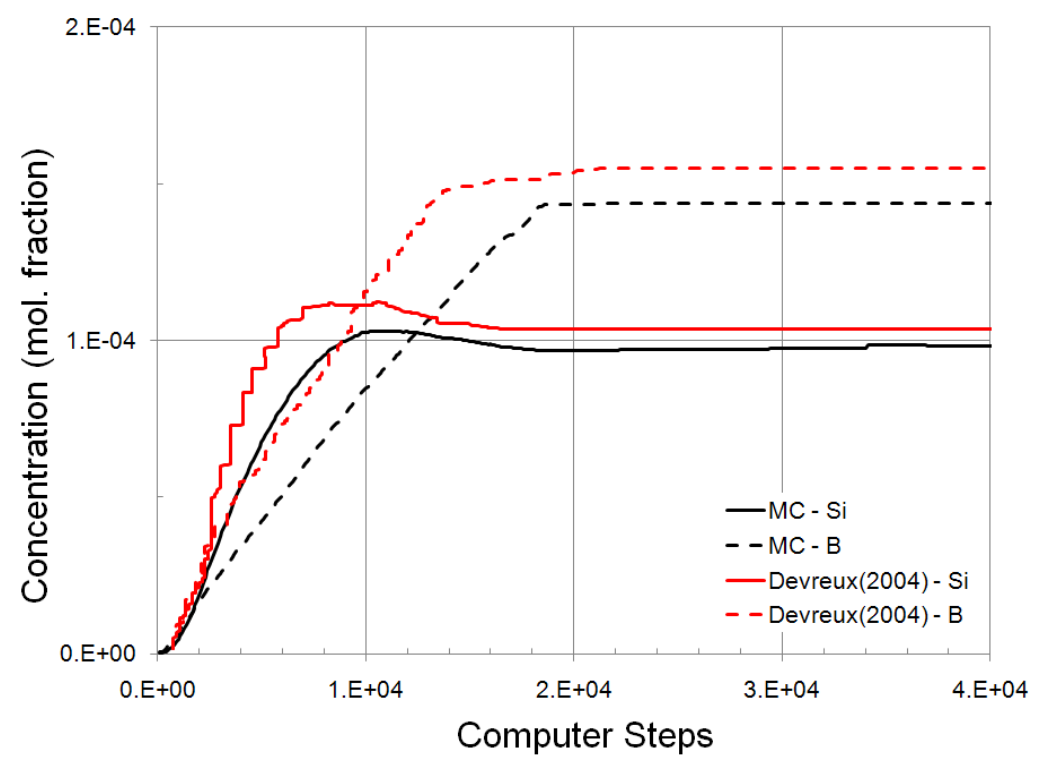

Figure 6.1. Comparison of the Time Evolution of the Si and B Concentrations in Solution for a Glass of Composition $70 \% \mathrm{SiO}_{2}, 15 \% \mathrm{~B}_{2} \mathrm{O}_{3}, 15 \% \mathrm{Na}_{2} \mathrm{O}$ and Leached at $2000 \mathrm{~m}^{-1}$ with $\left\{\mathrm{w}_{1}, \mathrm{w}_{2}, \mathrm{w}_{3}, \mathrm{w}_{\mathrm{c}}\right\}$ $=\left\{10^{-2}, 10^{-3}, 10^{-4}, 10\right\}$ Obtained with the MC Model versus that Published by Devreux et al. in 2004

\subsection{Dissolution of Borosilicate Glasses in Near-Equilibrium Conditions}

To determine how changes in solution composition affect the dissolution of borosilicate glasses and to study their dissolution behavior as the equilibrium is approached, two types of MC simulations were performed, namely $\mathrm{MC}$ simulations under static and flow-through test conditions, specifically Product Consistency Test method B (PCT-B) (ASTM-C1285-02) and the SPFT test method (ASTM-C1662-10), respectively.

\subsubsection{Static Conditions}

In static test conditions (e.g., PCT-B), a pristine glass is placed in contact with an initially pure aqueous solution at a fixed surface-area-to-volume ratio. In these conditions, as shown in Figure 6.2 for a model glass of composition $70 \% \mathrm{SiO}_{2}, 15 \% \mathrm{~B}_{2} \mathrm{O}_{3}$, and $15 \% \mathrm{Na}_{2} \mathrm{O}$, leached at $2000 \mathrm{~m}^{-1}$ with probability set $\left\{\mathrm{w}_{1}, \mathrm{w}_{2}, \mathrm{w}_{3}, \mathrm{w}_{\mathrm{c}}\right\}=\left\{10^{-2}, 10^{-3}, 10^{-4}, 10\right\}$, the Si and $\mathrm{B}$ concentrations in solution initially increase before reaching a plateau at the same time. Figure 6.3 shows snapshots of the Si density as a function of depth during the MC simulation. In Figure 6.3, the initial glass-water interface is on the right at a depth of 1024. Initially, the glass-water interface retreats in a uniform fashion. After approximately 8,000 computer steps, the Si density profile displays an inflection point at the interface between the leaching solution and the surface of the pristine glass. As the glass-water interface retreats further, $\mathrm{Si}$ begins to accumulate in that region, which transforms into a distinct peak as a result. Eventually, that region of the interface displays a Si peak that is denser than the original glass itself. After approximately 20,000 computer steps, as the Si concentration in solution reaches its plateau, the Si density profile does not change significantly. Figure 6.2 reveals that, at this point in the simulation, the deepest layer in 
contact with the main solution increases from the position of the interface with the pristine glass to the position of the main peak in Si density. This suggests that the development of the Si peak leads to the formation of a blocking layer through which water does not percolate. This lack of percolation needs to be confirmed by experiment to determine whether the MC model includes all the relevant mechanisms of glass alteration.

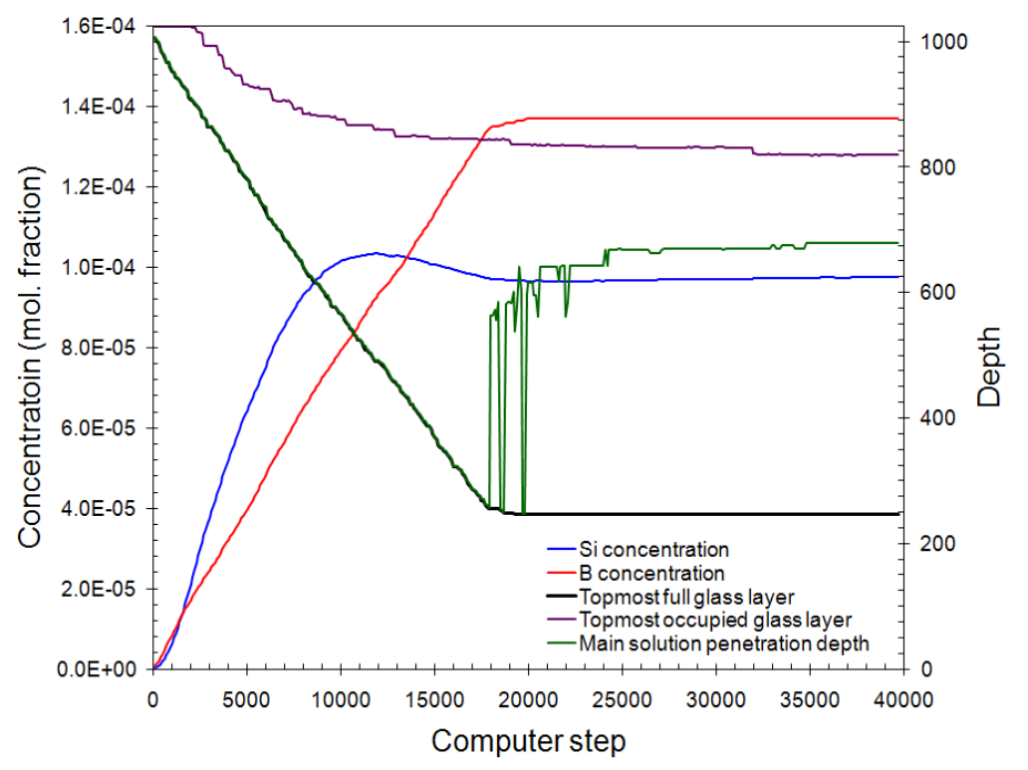

Figure 6.2. $\mathrm{Si}$ and $\mathrm{B}$ Concentrations as Functions of Time for a Glass of Composition $70 \% \mathrm{SiO}_{2}$, $15 \% \mathrm{~B}_{2} \mathrm{O}_{3}, 15 \% \mathrm{Na}_{2} \mathrm{O}$ and Leached at $2000 \mathrm{~m}^{-1}$ with $\left\{\mathrm{w}_{1}, \mathrm{w}_{2}, \mathrm{w}_{3}, \mathrm{w}_{\mathrm{c}}\right\}=\left\{10^{-2}, 10^{-3}, 10^{-4}, 10\right\}$. Also shown are the topmost full glass layer, topmost occupied glass layer and main solution penetration depth.

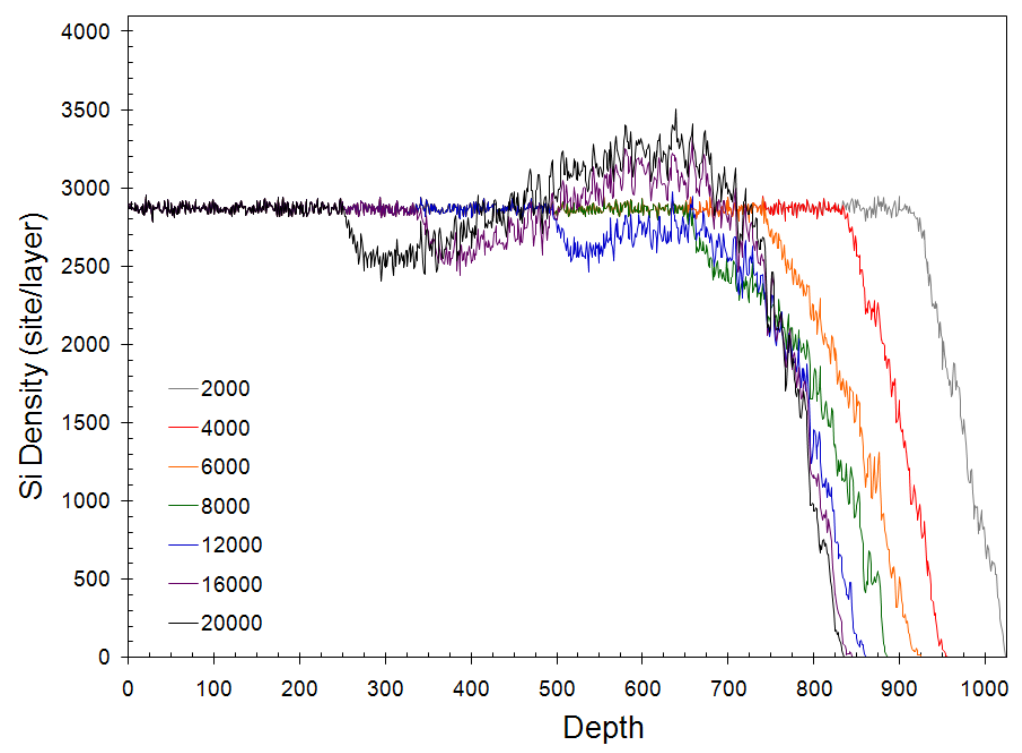

Figure 6.3. Snapshots of the Si Density as a Function of Depth from the Initial Glass-Water Interface for a Glass of Composition $70 \% \mathrm{SiO}_{2}, 15 \% \mathrm{~B}_{2} \mathrm{O}_{3}, 15 \% \mathrm{Na}_{2} \mathrm{O}$ and Leached at $2000 \mathrm{~m}^{-1}$ with $\left\{\mathrm{w}_{1}, \mathrm{w}_{2}, \mathrm{w}_{3}, \mathrm{w}_{\mathrm{c}}\right\}=\left\{10^{-2}, 10^{-3}, 10^{-4}, 10\right\}$. The initial glass-water interface is to the right at a depth of 1024. 
Analysis of the total Si density as a function of depth and simulated time together with the contributions from Si sites with zero, one, two, three, and four connections with nearest-neighbor Si sites indicates that the peak in the Si density stems from the formation of a network of Si sites fully coordinated to nearest-neighbor Si sites.

A new feature implemented in the MC code was used to visualize the history of the Si sites in the reacted glass, i.e., whether they were originally present in the glass or whether they recondensed at the interface, as shown in Figure 6.4. Figure 6.4 indicates that, after 20,000 computer steps, the blocking layer is roughly composed in its thickest section (depth of 600-700) of 1/3 original Si sites and 2/3 Si sites present due to recondensation. Although the MC model cannot predict whether recondensed Si sites polymerize in an amorphous or crystalline structure, it does give an indication of the potential heterogeneity of the hydration layer. In other words, the present simulation suggests that, for this glass composition, $1 / 3$ of the blocking layer retains the original glass structure, whereas the remaining $2 / 3$ can potentially adopt a different structure.

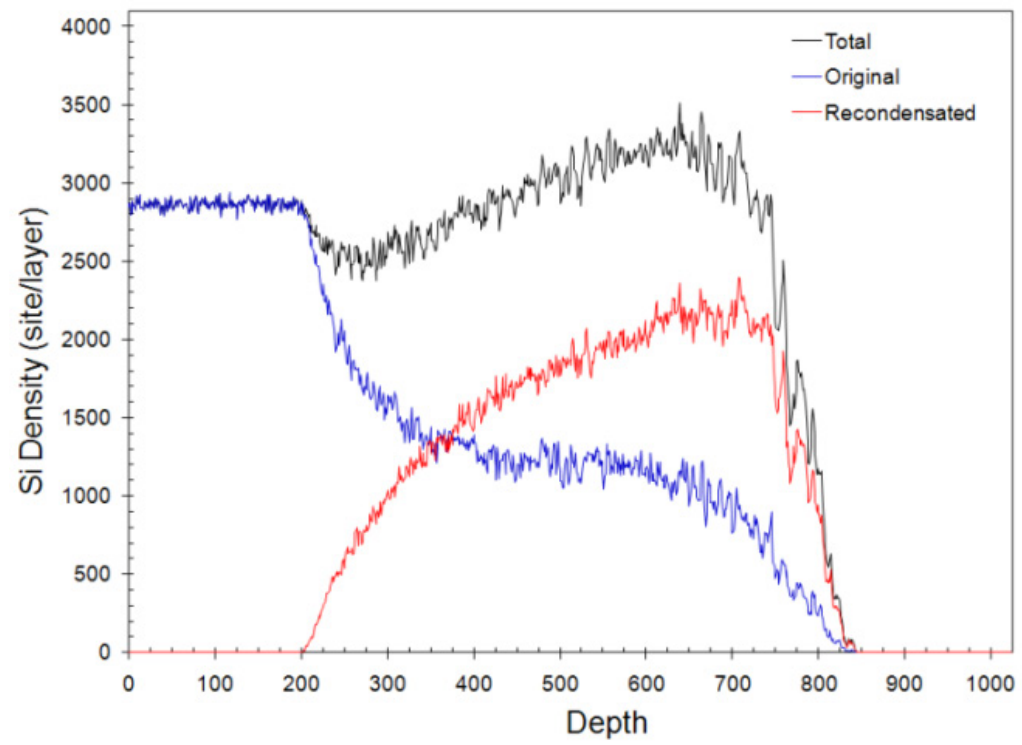

Figure 6.4. Total Si Density as a Function of Depth from the Initial Glass-Water Interface after 20,000 Simulation Steps. Also shown are the contributions from Si sites originally present in the glass and from those that are present at the interface due to recondensation. The initial glass-water interface is to the right at a depth of 1024.

Integrating all the information discussed in the above, the following picture of the time evolution of the glass-water interface in static conditions emerges. Initially, the glass dissolves into a very dilute solution and, therefore, the morphology of the glass-water interface is similar to that obtained in last year's simulations (Pierce et al. 2010b). As the Si concentration in solution increases, recondensation reactions become more prominent. The dynamics of dissolution-recondensation reactions lead to the preferred removal of low-coordination sites and the formation of a denser Si network. When the Si concentration becomes high enough, recondensation reactions cause the formation of nuclei of highly coordinated Si sites at the position of the interface with the pristine glass. These nuclei then continue to grow and begin to merge as the interface with the pristine glass recedes further. Eventually, the growth of the dense Si layer prevents percolation of water through the hydration layer. At this point, the dissolution 
rate of the sites exposed to the main solution matches the condensation rate from the main solution and the Si concentration in solution becomes constant. Additionally, because of the blocking Si layer, B is released at a much lower rate.

\subsubsection{Flow-Through Conditions}

In flow-through conditions, the simulations also begin with a pristine glass in contact with a pure aqueous solution of fixed volume but a flow is applied to the aqueous solution, which removes some fraction of the dissolved species from the system at each computer step.

Initially, a glass of composition $70 \% \mathrm{SiO}_{2}, 15 \% \mathrm{~B}_{2} \mathrm{O}_{3}$, and $15 \% \mathrm{Na}_{2} \mathrm{O}$ leached at $2000 \mathrm{~m}^{-1}$ with $\left\{\mathrm{w}_{1}, \mathrm{w}_{2}, \mathrm{w}_{3}, \mathrm{w}_{\mathrm{c}}\right\}=\left\{10^{-2}, 10^{-3}, 10^{-4}, 10\right\}$ was used as a model glass to study the glass dissolution behavior as a function of flow rate (Figure 6.5). The general trends shown in Figure 6.5 (i.e., increasing dissolution rate with increasing flow rate, linear dependence on log-log plot, plateau values at high flow rates that correspond to dilute case) are in agreement with measurements of dissolution rates as a function of flow rates carried out by Pierce and co-workers for several glass compositions (Pierce et al. 2008a, 2010a). In addition, as seen experimentally in those same studies, the MC model predicts incongruent dissolution at low flow rates and congruent dissolution when the dissolution rate reaches a plateau (Figure 6.5).

Next, the dissolution of a series of borosilicate glasses with composition range (80-x) $\% \mathrm{SiO}_{2}$, $(10+x / 2) \% \mathrm{~B}_{2} \mathrm{O}_{3},(10+x / 2) \% \mathrm{Na}_{2} \mathrm{O}$, where $5<x<30 \%$, was investigated as a function of simulated flow rate. All the glasses were leached at $2000 \mathrm{~m}^{-1}$ with $\left\{\mathrm{w}_{1}, \mathrm{w}_{2}, \mathrm{w}_{3}, \mathrm{w}_{\mathrm{c}}\right\}=\left\{10^{-2}, 10^{-3}, 10^{-4}, 10\right\}$. The glass slabs had an initial surface area of $64 \times 64$ lattice sites and a thickness of 8192 lattice sites. Calculations were run for 100,000 computer steps or until the glass had completely dissolved, whichever came first.

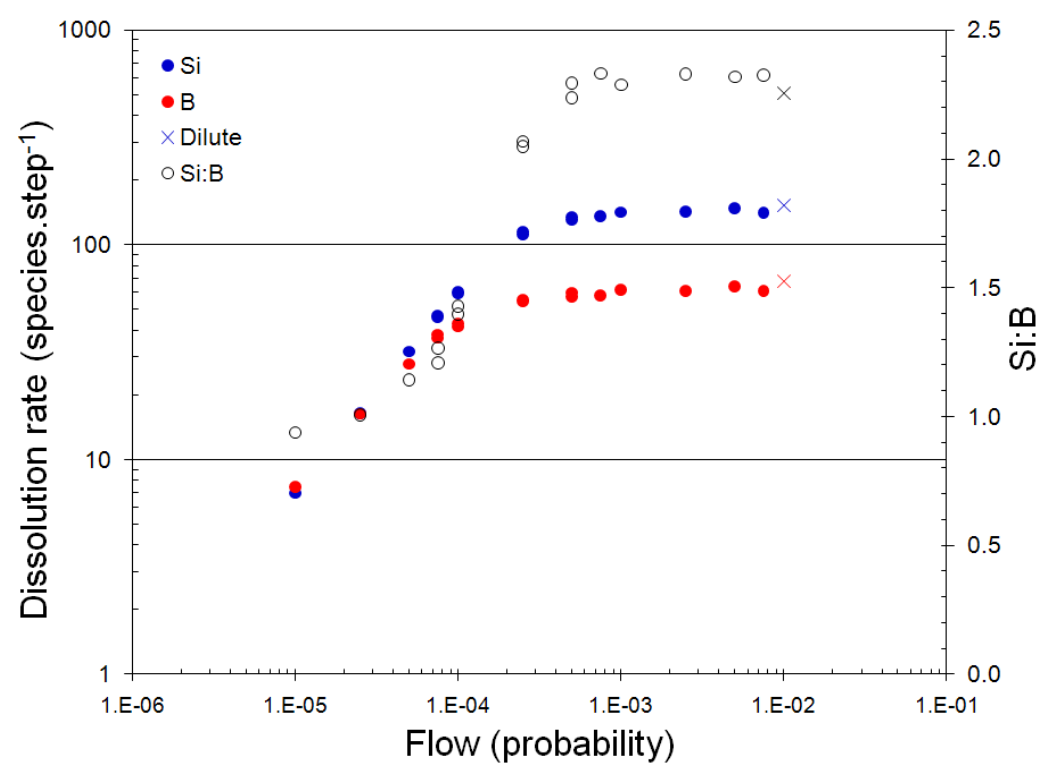

Figure 6.5. Silicon and Boron Dissolution Rates as a Function of Flow Rate for a Glass of Composition $70 \% \mathrm{SiO}_{2}, 15 \% \mathrm{~B}_{2} \mathrm{O}_{3}, 15 \% \mathrm{Na}_{2} \mathrm{O}$ and Leached at $2000 \mathrm{~m}^{-1}$ with $\left\{\mathrm{w}_{1}, \mathrm{w}_{2}, \mathrm{w}_{3}, \mathrm{w}_{\mathrm{c}}\right\}$ $=\left\{10^{-2}, 10^{-3}, 10^{-4}, 10\right\}$. Also shown is the silicon-to-boron ratio in solution. The results obtained in dilute conditions are shown as crosses. 
As discussed above, the MC model predicted the formation of a blocking layer, through which water does not percolate, during the dissolution under static conditions of a glass with composition $70 \% \mathrm{SiO}_{2}$, $15 \% \mathrm{~B}_{2} \mathrm{O}_{3}$, and $15 \% \mathrm{Na}_{2} \mathrm{O}$. Therefore, in the light of these results, the dissolution of the borosilicate glass series was examined to determine at which composition and flow rate combinations the MC model predicts the formation of a blocking layer. The glass of composition $65 \% \mathrm{SiO}_{2}, 17.5 \% \mathrm{~B}_{2} \mathrm{O}_{3}$, and $17.5 \%$ $\mathrm{Na}_{2} \mathrm{O}$ illustrates well the different dissolution regimes predicted as a function of flow rate. Figure 6.6 shows the glass surface area exposed to the main aqueous solution for this glass and for a range of simulated flow rates. At low flow rates, a blocking layer forms rapidly, as shown by the sudden decrease in exposed surface area. As the flow rate increases, the onset of the formation of the blocking layer is delayed. Interestingly, the calculations at simulated flow rates of 0.00003 and 0.0001 suggest that the blocking layer can be thin enough for water to occasionally break through it, which results in large fluctuations in the exposed surface area. Figure 6.6 also shows that the exposed glass surface area, which is directly correlated with the hydration layer thickness, initially increases with flow rate but significantly decreases when the flow rate is high enough for the glass to dissolve congruently.

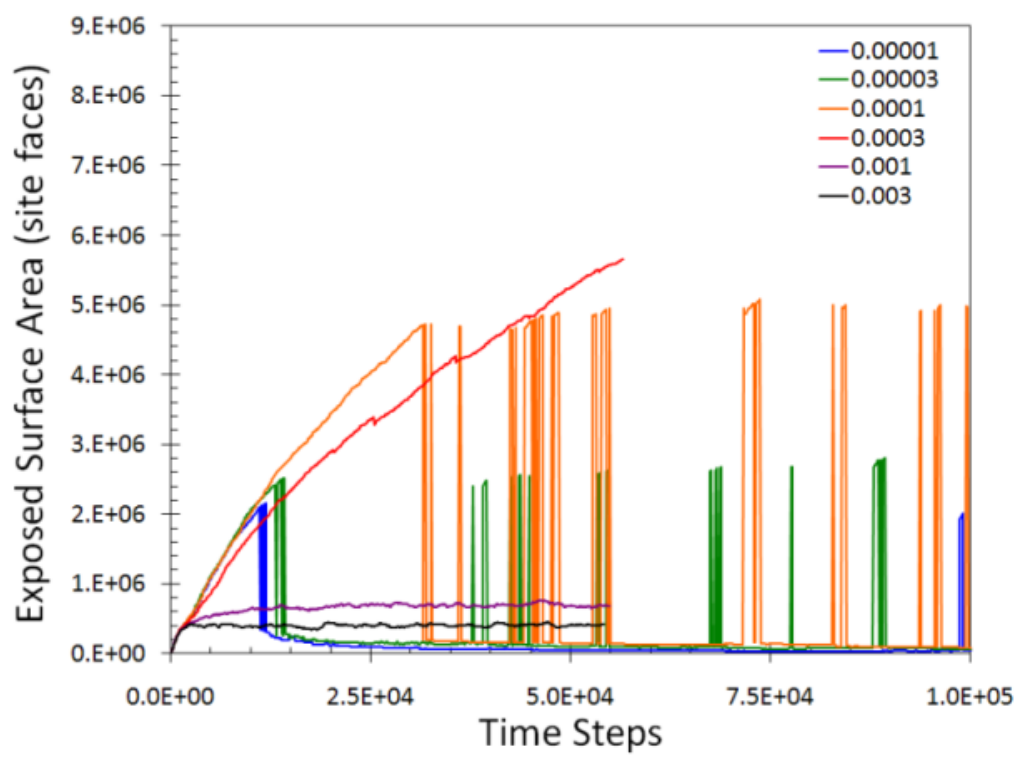

Figure 6.6. Surface Area Exposed to the Main Solution (in exposed site faces) as a Function of Simulated Time as Obtained from Simulations of the Dissolution of a Glass of Composition $65 \% \mathrm{SiO}_{2}, 17.5 \% \mathrm{~B}_{2} \mathrm{O}_{3}, 17.5 \% \mathrm{Na}_{2} \mathrm{O}$ Leached at $2000 \mathrm{~m}^{-1}$ Under a Range of Simulated Flow Rates.

Figure 6.7 and Figure 6.8 show the cumulative number of Si and $\mathrm{B}$ atoms, respectively, in the effluent as dissolution proceeds for the glass of composition $65 \% \mathrm{SiO}_{2}, 17.5 \% \mathrm{~B}_{2} \mathrm{O}_{3}$, and $17.5 \% \mathrm{Na}_{2} \mathrm{O}$. For $\mathrm{Si}$, a linear behavior is observed once steady state has been reached or the blocking layer has been formed.

The effect of the formation of the blocking layer is more noticeable for $\mathrm{B}$, whereby a significant decrease in slope is observed at the onset of the blocking layer formation, which is especially clear for a simulated flow rate of 0.0001 . However, despite the formation of the blocking layer, B continues to be released in the effluent. This phenomenon is due to two reasons. Firstly, as shown in Figure 6.6, water can occasionally break through the blocking layer, which leads to intermittent B release. Secondly, at these low flow rates, the flow rate is not high enough to rapidly remove B that has accumulated in the overlying aqueous solution and therefore B continues to be slowly released in the effluent. 
Lastly, the dissolution rate based on silicon release is plotted, in Figure 6.9, as a function of the $\mathrm{Si}$ steady-state concentration in the solution in contact with the dissolving glass. Interestingly, the general behavior, whereby the dissolution rate is first fairly constant and then drops abruptly with increasing concentration, is in excellent agreement with experimental measurements made by Pierce et al. (2008a) on three prototypic LAW glasses.

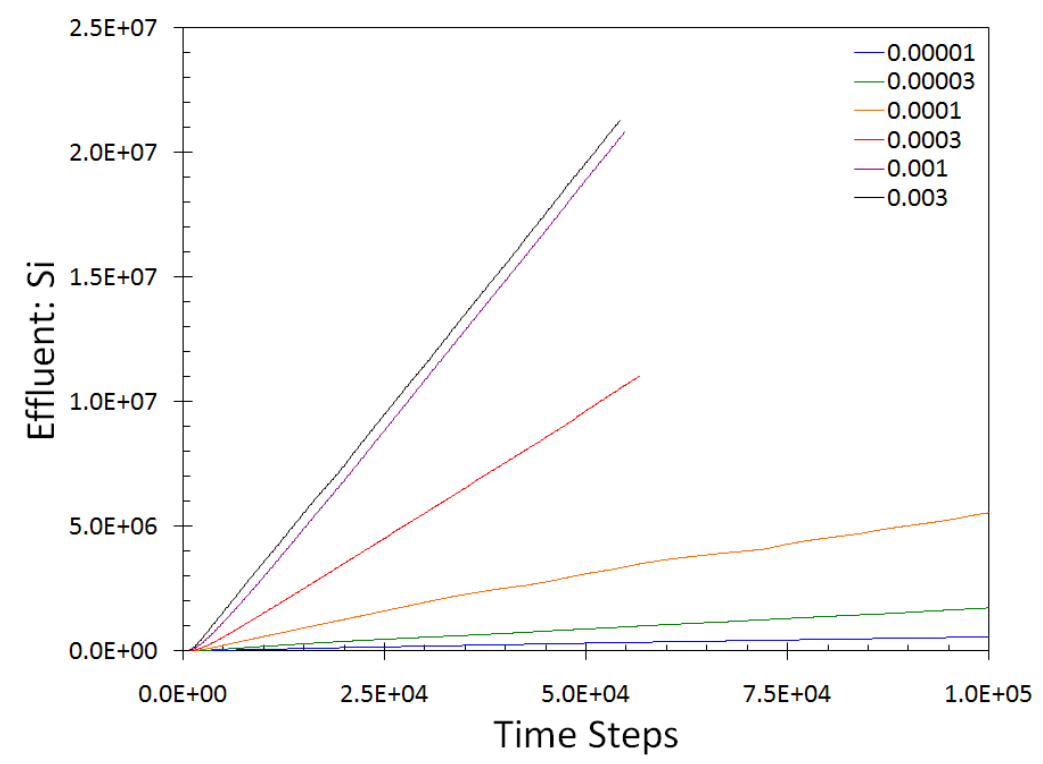

Figure 6.7. Cumulative Number of Si Atoms in the Effluent as a Function of Simulated Time for a Glass of Composition $65 \% \mathrm{SiO}_{2}, 17.5 \% \mathrm{~B}_{2} \mathrm{O}_{3}, 17.5 \% \mathrm{Na}_{2} \mathrm{O}$ Under a Range of Simulated Flow Rates

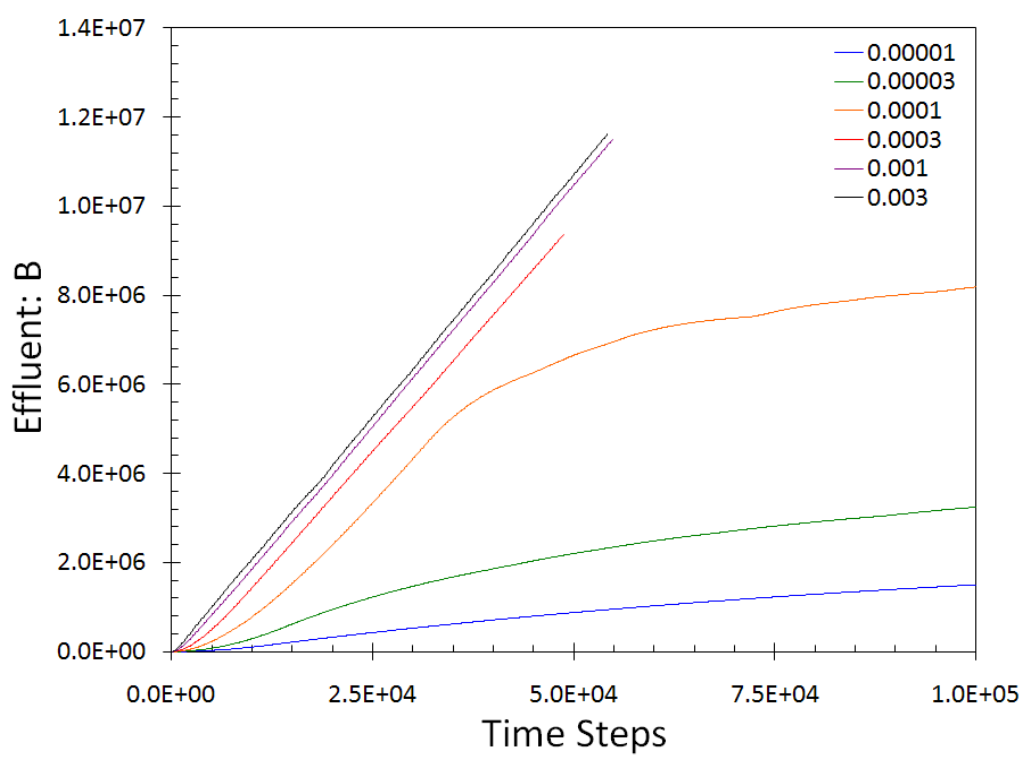

Figure 6.8. Cumulative Number of B Atoms in the Effluent as a Function of Simulated Time for a Glass of Composition $65 \% \mathrm{SiO}_{2}, 17.5 \% \mathrm{~B}_{2} \mathrm{O}_{3}, 17.5 \% \mathrm{Na}_{2} \mathrm{O}$ Under a Range of Simulated Flow Rates 


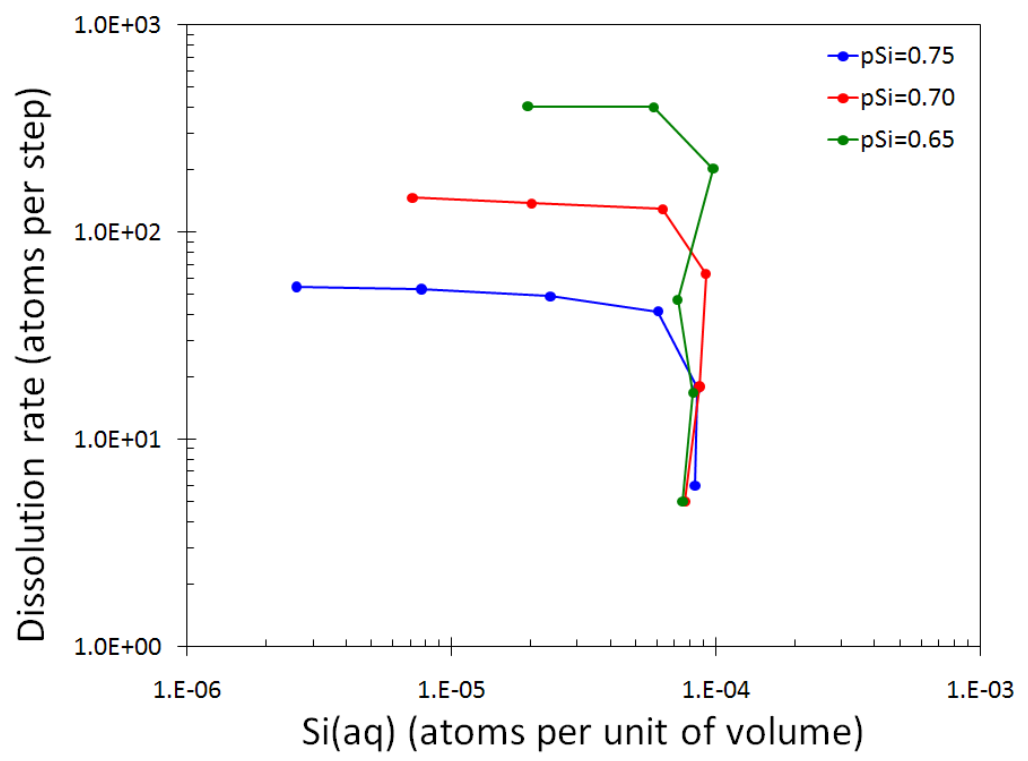

Figure 6.9. Dissolution Rate Based on Silicon Release as a Function of Si Concentration in the Aqueous Solution for Three Glasses in the Composition Range $(80-x) \% \mathrm{SiO}_{2},(10+x / 2) \% \mathrm{~B}_{2} \mathrm{O}_{3}$, $(10+x / 2) \% \mathrm{Na}_{2} \mathrm{O}$, with $5<x<30 \%$

\subsection{Summary of Monte Carlo Modeling Results}

In summary, the $\mathrm{MC}$ simulations predict three main dissolution regimes as a function of flow rate: 1) congruent, or near-congruent, dissolution with a thin hydration layer at high flow rates; 2) the rapid formation of a blocking layer at low flow rates with slow release of the accumulated dissolved B; and 3 ) an intermediate regime in which the hydration layer thickens significantly and a thin blocking layer, which water can occasionally penetrate, forms at the glass-water interface. 


\subsection{Near-Field Modeling}

\subsection{Overview}

A primary goal of the Near-Field Modeling task was to transition from STORM, which was used in previous PAs, to STOMP-W-R, which has been validated as safety software through a rigorous testing program. A description of previous PA modeling is given in Section 7.2, and a description of the STORM and STOMP simulators is given in Section 7.3.

For the IDF PA, the following modes of STOMP have been tested to be compliant with Nuclear Quality Assurance (NQA)-1-2000 Software Requirements and DOE Order 414.1C: STOMP-W (water), STOMP-W-T (water with transport), and STOMP-W-R (water with reactions). The STOMP quality assurance program is described in Section 7.4.

Creating the near-field modeling framework has progressed through developing a STOMP simulation that incorporates the geochemical reaction network needed to model the weathering of waste glass. The reaction network includes all kinetic reactions, equilibrium reactions, mineral species, and aqueous species used in STORM simulations for the Sensitivity Analysis base-case simulation at $99^{\circ} \mathrm{C}$. Kinetic reactions include glass dissolution, sodium hydrogen-ion exchange, and secondary mineral precipitation. A one-dimensional (1-D), high-temperature simulation was chosen for the first STOMP/STORM benchmark to speed the development of the modeling framework because a 1-D simulation at high temperature requires a much shorter time to achieve a significant change in simulation output than a twodimensional (2-D) field-scale simulation at low temperature and low water flux. This was described in a report regarding the sensitivity of glass kinetic rate law parameters (Bacon and Pierce 2010). This initial STOMP/STORM benchmark is described in Section 7.6.

\subsection{Previous PA Modeling}

A critical component of the PA will be to provide quantitative estimates of radionuclide release rates from the engineered portion of the disposal facilities (source terms). Computer models are essential for this purpose because effects on groundwater resources must be projected out 10,000 years and longer. Details on the recommended technical strategy for developing this source term have been published (McGrail et al. 2003) and have undergone review by an international panel of experts.

The 2001 ILAW PA (Mann et al. 2001) showed that a key variable was the waste-form release rate, calculated over thousands of years. In this PA, the waste-form release rate was evaluated by modeling the basic physical and chemical processes that are known to control the waste-form dissolution behavior instead of using empirical extrapolations from laboratory "leaching" experiments commonly used in other PAs. This methodology was adopted for the following reasons:

- The radionuclide release rate from dissolving silicate glass or grout cannot be determined independently of other system variables. For example, neglecting the waste-form composition, the glass dissolution rate is a function of three variables: temperature, $\mathrm{pH}$, and composition of the fluid contacting the glass (McGrail et al. 2001). The temperature of the ILAW disposal system is assumed to be known and constant. However, both $\mathrm{pH}$ and composition of the fluid contacting the glass are variables affected by flow rate, reactions with other engineered materials, gas-water equilibria, 
secondary phase precipitation, alkali ion exchange, and the glass-dissolution, classic-feedback mechanism. Consequently, glass-dissolution rates vary both in time and as a function of position in the disposal system. A "leach rate" or radionuclide release rate parameter cannot be assigned to a waste form in such a dynamic system.

- One of the principal purposes of the IDF PA is to provide feedback to engineers regarding the effects of design options on disposal-system performance. A model based on empirical release rates for different waste forms is inadequate for this task. Unfortunately, the robust methodology we used comes with additional requirements. First, detailed information is needed on the reaction mechanisms controlling the dissolution behavior of the waste form. Laboratory experiments are required to obtain the rate-law parameters needed for the models used for our simulations. Second, the model now being used (described in the next section) is markedly more complex than a model based on empirical release rates because of its capability to simulate reactive transport coupled with heterogeneous, unsaturated flow. Execution times with today's most sophisticated massively parallel computers can be two weeks for the 2-D simulations presented in this report. The benefits, however, particularly with regard to the technical defensibility of the methodology and results, far outweigh the penalties.

For the 2005 IDF PA, a variety of waste-form materials were simulated, including three WTP glasses (LAWA44, LAWB45, and LAWC22), grout, and two bulk-vitrification glasses, a six-tank composite, and S-109 (Bacon and McGrail 2005).

\subsection{Numerical Simulators}

\subsubsection{STORM}

STORM has been used to simulate the corrosion of waste forms containing radioactive glass at the Hanford Site in Richland, Washington (Bacon and McGrail 2005). STORM was developed by coupling STOMP, a non-isothermal multiphase flow simulator (White and Oostrom 2006), with Analyzer for RadionuclidE Source-Term with Chemical Transport (AREST-CT) Version 1.1, a reactive transport and porous medium alteration simulator (Chen et al. 1995, 1997). The underlying mathematics in STORM are contained in a set of coupled, nonlinear, partial differential equations. They describe the rate of change of the solute concentrations of pore water in a variably saturated, non-isothermal porous medium. STORM capabilities include kinetic dissolution of glass, kinetic precipitation and dissolution of secondary phases, aqueous equilibrium speciation, gas-aqueous equilibria, two-phase flow (water and air), and dynamic hydraulic properties.

STORM has the capability to simulate the special glass kinetic reaction in which many aqueous species are released, but equilibrium depends only on a few of these species, such as silica and aluminum. Also, reactive transport in STORM is fully coupled with unsaturated flow; the unsaturated flow field may be altered by mineral dissolution and precipitation reactions. STORM runs efficiently in parallel on multi-core workstations and supercomputers, shortening execution times. The verification studies for STORM are documented in the STORM user's guide (Bacon et al. 2004).

However, STORM has certain limitations that limit its usefulness for the present work. Due to lack of funding, STORM has not been updated for five years and has never been graded as Class C Safety and 
Hazard Analysis and Design Software. Therefore, under DOE Order 414.1C, STORM cannot be used for PAs. Also, reactive transport in STORM is limited to two dimensions.

\subsubsection{STOMP}

The STOMP code has been graded as Class C Safety and Hazard Analysis and Design Software under DOE Order 414.1C (see Section 7.4.1), making it applicable to PAs. The flow modules in STORM were derived from STOMP. The main difference between STOMP and STORM is that STORM uses the AREST-CT reactive transport solver, and STOMP uses the Equilibrium-Conservation-Kinetic Equation Chemistry and Reactive Transport (ECKEChem) reaction solver (White and McGrail 2005). AREST-CT uses a global implicit solution scheme in which the transport and reaction equations are solved simultaneously. ECKEChem uses an operator split solution scheme in which the transport equations and reaction equations are solved sequentially.

The STOMP simulator (White and McGrail 2005) has been developed by PNNL for modeling subsurface flow and transport systems and remediation technologies. The STOMP simulator's fundamental purpose is to produce numerical predictions of thermal and hydrogeologic flow and transport phenomena in variably saturated subsurface environments. The STOMP simulator is written in the FORTRAN 77 and 90 languages, following American National Standards Institute (ANSI) standards. The simulator uses a variable source code configuration, which allows the execution memory and speed to be tailored to the problem specifics and essentially requires that the source code be assembled and compiled through a software maintenance utility. Auxiliary applications include numerical predictions of solute transport processes, including reactive transport. Quantitative predictions from the STOMP simulator are generated from the numerical solution of partial differential equations that describe subsurface environment transport phenomena. The description of the contaminated subsurface environment is founded on governing conservation equations and constitutive functions. Governing coupled flow equations are partial differential equations for the conservation of water mass, air mass, and thermal energy. Constitutive functions relate primary variables to secondary variables. The governing partial differential equations are solved with the integral volume finite-difference method. The governing equations that describe thermal and hydrogeological flow processes are solved simultaneously using Newton-Raphson iteration to resolve the nonlinearities in the governing equations. Governing transport equations are partial differential equations for the conservation of solute mass. Governing equations for solute mass conservation are solved sequentially, following the solution of the coupled flow equations.

Version 4.0 of STOMP includes the recently PNNL-developed batch geochemistry solution module ECKEChem (White and McGrail 2005). The ECKEChem batch-chemistry module was developed in a fashion that would allow its implementation into all operational modes of the STOMP simulator, making it a more versatile chemistry component. Additionally, this approach allows for verification of the ECKEChem module against more classical reactive transport problems involving aqueous systems. Currently, the ECKEChem package has been implemented in the STOMP-W-R and STOMP-WCS-R modes. The fundamental objective in developing the ECKEChem module was to embody a systematic procedure for converting geochemical systems for mixed equilibrium and kinetic reactions into a system of nonlinear equations. This objective has been realized through a recently developed general paradigm for modeling reactive chemicals in batch systems, which has been coded into a preprocessor for BIOGEOCHEM (Fang et al. 2003). To couple this processor to the STOMP simulator, a conversion program, BioGeoChemTo, was written in Perl that reads the preprocessor output and converts it into 
STOMP simulator input format. This addition has been incorporated in accord with the STOMP simulator quality assurance and control program; see Section 7.4 and the associated references for more detail.

\subsection{Quality Assurance}

The quality of the work will be verified through compliance with the ILAW Glass Testing for Disposal at IDF Quality Assurance Project Plan (QAPP-EED-58762), which contains hyperlinks to the applicable requirements sections of PNNL's standards-based management system called "How Do I...?" (HDI). Computer software procedures were followed for the use of STORM reactive transport software and STOMP software. All staff members contributing to the work described in this report have received proper technical and quality assurance training in the use and operation of the STORM and STOMP codes.

\subsubsection{Description of STOMP Quality Assurance/Quality Control (QA/QC) Program}

The STOMP simulator is software custom-developed at PNNL that meets NQA-1-2000 software requirements as well as the requirements specified under DOE Order 414.1C for Safety Software. Specifically, STOMP management follows the PNNL HDI Safety Software Subject Area that is written to meet those requirements. To this end, STOMP development is managed under a Configuration Management Plan (CMP) (White and Freedman 2007) in conjunction with a Software Test Plan (Freedman and White 2007) that detail the procedures used to test, document, and archive modifications to the source code. Formal procedures for software problem reporting and corrective actions for software errors and updates are maintained and rigorously implemented (Nichols and White 2007a). Documentation of all verification and validation testing is publicly available.

Managing STOMP software includes maintaining both internal and external STOMP user lists. PNNL STOMP users are trained in the design, use, and evaluation of the software. Internal users are also trained to the problem reporting and corrective action procedures that are outlined in the CMP.

STOMP software is also supported by a Software Requirement Specification (Zhang et al. 2007) and a Software Design Document (Nichols and White 2007b), which are essential for developing quality software and life cycle maintenance. In addition to the documentation used to manage and document software development, STOMP is supported by user and theory guides. The User Guide (White and Oostrom 2006) is frequently updated to document input requirements for new capabilities. Updates to the theory guide (White and Oostrom 2000) are supported by addenda (Ward et al. 2005; White and McGrail 2005).

STOMP software can be used in a variety of different applications, including the analysis of nuclear facilities. Hence, under DOE Order 414.1C, STOMP software has been generically graded as Class C Safety and Hazard Analysis and Design Software. This classification was selected because results from STOMP-based analyses may affect regulatory permitting requirements for nuclear facilities. The classification of the software, however, will be application dependent, and the classification is evaluated on a project basis. 


\subsubsection{Modes Compliant with NQA-1-2000 Software Requirements and DOE Order 414.1c}

- STOMP-W

- STOMP-WA

- STOMP-WAE

- STOMP-WAE-B

- STOMP-WOA

- STOMP-WO

- STOMP-W-R

- STOMP-W-Sc

\subsection{Software Control and Verification}

After the modifications described in this report were made to STOMP, Modes STOMP-W (water), STOMP-W-T (water with transport), and STOMP-W-R (water with reactive transport, used for these results) were run against the suite of test problems (Freedman and White 2007) used previously to validate STOMP as Class C Safety and Hazard Analysis and Design Software. Based on the results of these simulations, it was determined that these modifications did not change the results of the test suite problems. Then, the modified serial version of STOMP used to achieve these results was put under configuration management (White and Freedman 2007), meaning it is now part of the version-controlled code base. A simplified glass dissolution test case, described in Section 7.8.1, was added to the QA test suite for STOMP to make sure that future modifications to the code do not adversely affect waste glass PA calculations. Detailed checking of QA test suite results for all of the modes listed in Section 7.4.2 and preparation of test logs is underway as part of another project in order to re-validate the current version of STOMP as Class C Safety and Hazard Analysis and Design Software.

\subsection{Benchmarking Simulations}

This report describes the development of a framework for near-field modeling of radionuclide release from WTP glass waste packages. The simulation of LAWA44 waste packages using STORM is used as a base case (Bacon and McGrail 2005). Section 7.6.1 describes in detail the model input required for either STORM or STOMP. An input file for STOMP will then be developed for the same base case, and the outputs from STOMP and STORM will be compared. In other words, by using this base case, which has been used in previous STORM simulations, we will verify that STOMP simulations provide results equivalent to previous STORM simulations. This process will validate the use of STOMP for future IDF PAs. Therefore, simulations for additional waste glasses for future IDF PAs will be developed using STOMP.

\subsubsection{Base-Case Model Setup and Parameterization}

This section details the data required for the STORM code input data file (Bacon et al. 2004). Input data to STORM can be divided into 1) unsaturated flow and transport and 2) chemistry. Entries for 
unsaturated flow and transport include 1) lithographic units, 2) hydraulic properties, and 3) hydraulic initial and boundary conditions. STORM was used to compute the flow field in the near-field region based on hydraulic properties for the materials and specified initial and boundary conditions. Chemistry input to STORM consists of entries for aqueous, gas, and solid species; equilibrium reactions; kinetic reactions; and geochemical initial and boundary conditions. These are described below.

Several waste glasses will be simulated, including three WTP glasses, the properties of which are being tested at VSL/CUA. For the purposes of this work, LAWA44 glass will be used to exemplify the data requirements. Data on this waste glass and near- and far-field materials were defined principally from facility design documents (Puigh 2004), the near-field hydraulic properties data package (Meyer et al. 2004), or the far-field hydraulic properties data package (Khaleel 2004). The properties of these materials are detailed below.

\subsubsection{Unsaturated Flow and Transport Input}

\section{Lithographic Units}

To establish a consistent framework for overlaying a computational grid on the spatial domain of interest, a set of material zones or lithographic units is defined for units with similar hydrogeological and geochemical properties. These zones are usually related to disposal design components, geologic formations, or geologic facies determined from borehole analyses. However, because there are practical limits to the resolution of the model grid, material zones may also include combinations of materials that are assigned uniform hydraulic and/or chemical properties. These materials were classified into appropriate zones as a part of the near-field hydraulics data package (Meyer et al. 2004).

The WTP glass simulations encompass a 2-D vertical stack of four waste packages near the center of a single trench (Figure 7.1). The WTP glass waste packages are $2.3 \mathrm{~m}$ tall, $1.22 \mathrm{~m}$ wide, and filled with glass to a height of $1.96 \mathrm{~m}$. The layers in the IDF trench were assumed to be $1 \mathrm{~m}$ apart vertically, while waste packages were spaced $30 \mathrm{~cm}$ apart horizontally. It is not likely that the waste packages will be perfectly aligned horizontally, so to more realistically simulate flow, the waste packages are offset horizontally $10 \mathrm{~cm}$ relative to the waste package above or below.

For each lithographic unit, a list of the solid species that make up the unit is required. For each solid, the relative volume and the specific surface area are needed. Initial values for these variables for each lithographic unit are listed in Table 7.1 and Table 7.2. For Hanford sands and backfill soil, petrologic and particle-size data were obtained from the near-field hydrology data package (Meyer et al. 2004). The specific surface area was inferred from the particle-size data. Assuming spherical grains, the specific surface area $A_{m}$ is related to the particle radius $R_{m}$ by

$$
A_{m}=\frac{3 V_{r}}{R_{m}\left(1-\theta_{T}\right)}
$$

where $V_{r}$ is the relative volume, and $\theta_{T}$ is the total porosity. 


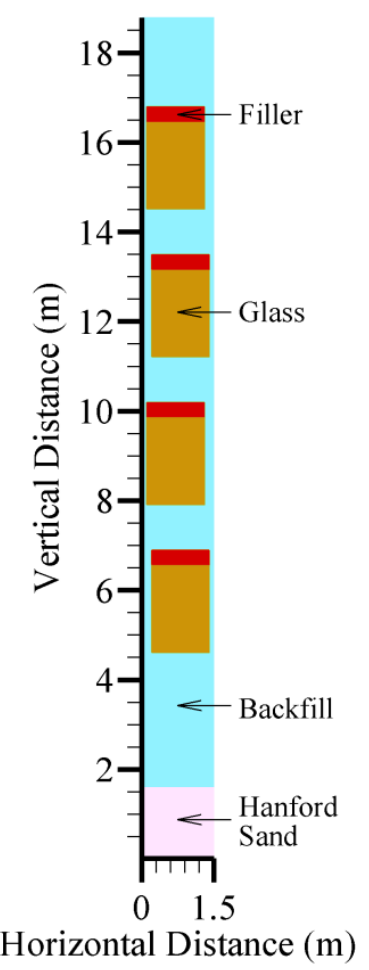

Figure 7.1. Lithographic Units for WTP Glass Waste Form Release Simulations

Table 7.1. Relative Volume of Solid Species in Material Zones

\begin{tabular}{lccccc}
\hline & Glass & Quartz & Albite & K-Feldspar & Illite \\
\hline Hanford Sand & 0 & 0.4 & 0.4 & 0.1 & 0.1 \\
Backfill & 0 & 0.4 & 0.4 & 0.1 & 0.1 \\
Glass & 1 & 0 & 0 & 0 & 0 \\
Filler & 0 & 0.4 & 0.4 & 0.1 & 0.1 \\
\hline
\end{tabular}

Table 7.2. Specific Surface Area $\left(\mathrm{m}^{2} / \mathrm{m}^{3}\right)$ of Solid Species in Material Zones

\begin{tabular}{lcccc}
\hline & Glass & Quartz & Albite & K-Feldspar \\
\hline Hanford Sand & 0 & 8200 & 8,200 & 2,050 \\
Backfill & 0 & 8200 & 8,200 & 2,050 \\
Glass & 50 & 0 & 0 & 0 \\
Filler & 0 & 8200 & 8,200 & 2,050 \\
\hline
\end{tabular}

The assumed specific surface area for Hanford sediments and backfill soil is consistent with petrologic and particle-size data obtained from laboratory-measured values (Serne et al. 1993). The specific surface area of the filler material in the WTP waste packages is assumed to be the same as the backfill. 
The surface area assumed for the glass is consistent with the expected sparse degree of glass fracturing in the waste package based on previous experience with HLW glasses (Farnsworth et al. 1985; Peters and Slate 1981). Fracturing is expected to increase the glass surface area no more than 10 times its geometric surface area.

\section{Computational Grid}

The computational grid was set at $2 \mathrm{~cm}$ in vertical resolution; this is smaller than the 5 -cm grid spacing used in the 2001 ILAW PA. The smaller grid spacing was used to resolve the details in the backfill material between waste packages. The time step used in the calculations was calculated automatically by the code, given a convergence criterion of $1 \times 10^{-6}$. This verifies that predicted values of aqueous species concentrations and mineral volumes are accurate between iterations for a given time step. If this cannot be achieved within a certain number of iterations, the time step is automatically reduced. Numerous simulations were conducted to verify that the grid spacing and convergence criteria chosen for the simulations were small enough for accuracy yet large enough to allow the simulations to finish in a reasonable amount of time. For comparison, the base-case, remote-handled trench simulation was run with a grid spacing of $1 \mathrm{~cm}$ and a convergence criterion of $5 \times 10^{-7}$. Results from these simulations were not significantly different from those with the grid spacing and convergence criterion used in the simulations reported in this document (Bacon and McGrail 2005).

\section{Material Hydraulic Properties}

The hydraulic properties for each lithographic unit in the simulation (Table 7.3) were determined in the near-field hydraulics data package (Meyer et al. 2004) or the far-field hydraulic properties data package (Khaleel 2004).

Table 7.3. Material Hydraulic Properties Used in Simulations

\begin{tabular}{lcccccc}
\hline Material & $\begin{array}{c}\text { Particle } \\
\text { Density } \\
\left(\mathrm{g} / \mathrm{cm}^{3}\right)\end{array}$ & $\begin{array}{c}\text { Saturated } \\
\text { Water } \\
\text { Content }\end{array}$ & $\begin{array}{c}\text { Residual } \\
\text { Water } \\
\text { Content }\end{array}$ & $\begin{array}{c}\text { van Genuchten } \\
\alpha\left(\mathrm{cm}^{-1}\right)\end{array}$ & $\begin{array}{c}\text { Saturated Hydraulic } \\
\text { vanuchten } \\
\text { Conductivity } \\
(\mathrm{cm} / \mathrm{s})\end{array}$ \\
\hline Hanford Sand & 2.63 & 0.394 & 0.049 & $6.31 \times 10^{-2}$ & 2.05 & $4.15 \times 10^{-3}$ \\
Backfill & 2.71 & 0.350 & $3.00 \times 10^{-2}$ & $6.50 \times 10^{-2}$ & 1.70 & $4.91 \times 10^{-3}$ \\
Glass & 2.68 & 0.020 & $4.60 \times 10^{-4}$ & $2.00 \times 10^{-1}$ & 3.00 & $1.00 \times 10^{-2}$ \\
Filler & 2.71 & 0.316 & $3.00 \times 10^{-2}$ & $6.50 \times 10^{-2}$ & 1.70 & $4.91 \times 10^{-3}$ \\
\hline
\end{tabular}

\section{Hydraulic Initial Conditions}

Initial hydraulic conditions for each lithographic unit include the following parameters:

- water content

- water flux

- dissolved gas content of aqueous phase

- gas pressure 
- relative humidity of gas phase

- temperature.

The initial conditions were calculated by assuming a steady-state water flux at the upper boundary, which results in a steady-state water content distribution consistent with the hydraulic properties defined for each material. A spectrum of water flux rates ranging from 0.1 to $4.2 \mathrm{~mm} / \mathrm{yr}$ were used for different sensitivity cases. A constant subsurface temperature equal to the average ambient temperature of $15^{\circ} \mathrm{C}$ was assumed. The dissolved gas content of the aqueous phase was assumed to be negligible with respect to flow. The relative humidity of the gas phase was assumed to be $100 \%$.

\section{Hydraulic Boundary Conditions}

The following data are needed as a function of time and space along each boundary:

- water flux

- dissolved gas content of aqueous phase

- gas pressure

- relative humidity of gas phase

- temperature.

The upper boundary is located just beneath the engineered barrier system and was assigned a specified flux. A range of water flux rates, from $0.1 \mathrm{~mm} / \mathrm{yr}$ to $4.2 \mathrm{~mm} / \mathrm{yr}$, may be used for different sensitivity cases. The lower bound of the recharge rates $(0.1 \mathrm{~mm} / \mathrm{yr})$ was determined as a part of the recharge data package (Fayer and Szecsody 2004). The highest recharge rate $(4.2 \mathrm{~mm} / \mathrm{yr})$ was implemented in the previous PA (Mann et al. 2001) and is provided here for comparison.

The location of the lower model boundary was selected so that horizontal gradients are small. The lower boundary is a free drainage boundary $4.5 \mathrm{~m}$ below the lowest layer of backfill. For hydraulic boundary conditions at this lower boundary, free drainage under gravity will be assumed. Also, the side boundaries are placed at axes of symmetry so that no-flow boundaries can be assumed.

A constant subsurface temperature, equal to the average ambient temperature of $15^{\circ} \mathrm{C}$, was assumed. The dissolved gas content of the aqueous phase was assumed to be negligible with respect to flow. The relative humidity of the gas phase was assumed to be $100 \%$.

\section{Solute Transport Coefficients}

The following data are needed for each gaseous and aqueous species:

- aqueous diffusion coefficient $\left(\mathrm{m}^{2} / \mathrm{s}\right)$ and

- gas diffusion coefficient $\left(\mathrm{m}^{2} / \mathrm{s}\right)$ or an assumption that the gas partial pressure is fixed. 
The aqueous molecular diffusion coefficient was calculated using a Power Law model (Campbell 1985), as recommended in the Near-Field Hydrology Data Package (Meyer et al. 2004). This model has the form

$$
D_{i}=a D_{f} \Theta^{b}
$$

where $\quad D_{i}=$ the diffusion coefficient in a porous medium

$D_{f}=$ the free-water diffusion coefficient

$\Theta=$ the water content of the porous medium

$a$ and $b=$ empirical fitting parameters.

In this case, $D_{f}$ was determined to be $1.84 \mathrm{E}-5 \mathrm{~cm}^{2} / \mathrm{s}, a=1.486$, and $b=1.956$ by fitting to ultracentrifuge data for Hanford sediments.

The gas partial pressure for $\mathrm{CO}_{2}$ was fixed at an atmospheric value of $3 \times 10^{-4}$ atm, so no gaseous diffusion coefficient needed to be specified.

\subsubsection{Chemistry Input}

\section{Aqueous Species}

Aqueous species are the cations, anions, or neutral complexes present in the aqueous phase. For each aqueous species, the following data are needed:

- molecular weight $(\mathrm{g} / \mathrm{mol})$

- charge (unitless)

- hard-core diameter (unitless)

- number of elements in aqueous species (unitless)

- stoichiometric coefficient of each element (mol).

The aqueous species listed in Table 7.4 were identified by simulating the dissolution of waste glass in DIW at $15^{\circ} \mathrm{C}$ with the EQ3/6 code package (Wolery and Daveler 1992). All data were obtained from the EQ3/6 data0.com.R8 database (Daveler and Wolery 1992). The EQ3/6 software was used to extract a subset of aqueous (and solid) species from the large thermodynamic database that were relevant for the reactive transport simulations.

\section{Gas Species}

Gas species are components such as $\mathrm{CO}_{2}$ and $\mathrm{O}_{2}$ that make up the gas phase. For each gas species, the following data are needed:

- molecular weight (g/mol)

- hard-core diameter (unitless) 
No redox reactions were considered in the current simulations, so only $\mathrm{CO}_{2}(\mathrm{~g})$ was considered (Table 7.5).

Table 7.4. Key Aqueous Species Produced by the Dissolution of Waste Glass

\begin{tabular}{|c|c|c|}
\hline Species & Mol. Wt. & Hard-Core Diameter \\
\hline $\mathrm{AlO}_{2}^{-}$ & 58.98 & 4.0 \\
\hline $\mathrm{B}(\mathrm{OH})_{3}(\mathrm{aq})$ & 61.83 & 3.0 \\
\hline $\mathrm{BO}_{2}^{-}$ & 42.81 & 3.0 \\
\hline $\mathrm{Ca}^{2+}$ & 40.08 & 6.0 \\
\hline $\mathrm{CO}_{2}(\mathrm{aq})$ & 44.01 & 3.0 \\
\hline $\mathrm{CO}_{3}^{2-}$ & 60.01 & 5.0 \\
\hline $\mathrm{CrO}_{4}^{2-}$ & 115.99 & 4.0 \\
\hline $\mathrm{Fe}(\mathrm{OH})_{3}(\mathrm{aq})$ & 106.87 & 3.0 \\
\hline $\mathrm{H}_{2} \mathrm{O}$ & 18.01 & 3.0 \\
\hline $\mathrm{H}_{2} \mathrm{SiO}_{4}{ }^{2-}$ & 94.10 & 4.0 \\
\hline $\mathrm{H}^{+}$ & 1.01 & 9.0 \\
\hline $\mathrm{HCO}_{3}^{-}$ & 61.02 & 4.0 \\
\hline $\mathrm{HCrO}_{4}^{-}$ & 117.00 & 4.0 \\
\hline $\mathrm{HSiO}_{3}^{-}$ & 77.09 & 4.0 \\
\hline $\mathrm{K}^{+}$ & 39.10 & 3.0 \\
\hline $\mathrm{KOH}(\mathrm{aq})$ & 56.10 & 0.0 \\
\hline $\mathrm{La}^{3+}$ & 138.91 & 9.0 \\
\hline $\mathrm{Mg}^{2+}$ & 24.31 & 8.0 \\
\hline $\mathrm{MgB}(\mathrm{OH})_{4}^{+}$ & 103.15 & 4.0 \\
\hline $\mathrm{MgCO}_{3}(\mathrm{aq})$ & 84.31 & 0.0 \\
\hline $\mathrm{MgHCO}_{3}^{+}$ & 85.32 & 4.0 \\
\hline $\mathrm{Na}^{+}$ & 22.99 & 4.0 \\
\hline $\mathrm{NaB}(\mathrm{OH})_{4}(\mathrm{aq})$ & 101.83 & 3.0 \\
\hline $\mathrm{NaCO}_{3}^{-}$ & 83.00 & 4.0 \\
\hline $\mathrm{NaHCO}_{3}(\mathrm{aq})$ & 84.01 & 3.0 \\
\hline $\mathrm{NaHSiO}_{3}(\mathrm{aq})$ & 100.08 & 0.0 \\
\hline $\mathrm{NaOH}(\mathrm{aq})$ & 40.00 & 3.0 \\
\hline $\mathrm{Ni}^{2+}$ & 58.69 & 4.5 \\
\hline $\mathrm{OH}^{-}$ & 17.01 & 3.0 \\
\hline $\mathrm{SiO}_{2}(\mathrm{aq})$ & 60.08 & 3.0 \\
\hline $\mathrm{TcO}_{4}^{-}$ & 162.00 & 4.0 \\
\hline $\mathrm{Ti}(\mathrm{OH})_{4}(\mathrm{aq})$ & 115.91 & 3.0 \\
\hline $\mathrm{Zn}(\mathrm{OH})_{3}^{-}$ & 116.41 & 4.0 \\
\hline $\mathrm{Zn}^{2+}$ & 65.39 & 6.0 \\
\hline $\mathrm{ZnOH}^{+}$ & 82.40 & 4.0 \\
\hline $\mathrm{Zr}(\mathrm{OH})_{4}(\mathrm{aq})$ & 159.25 & 3.0 \\
\hline
\end{tabular}


Table 7.5. Gas Species

\begin{tabular}{ccc}
\hline Species & Mol. Wt. & Hard-Core Diameter \\
\hline $\mathrm{CO}_{2}(\mathrm{~g})$ & 44.01 & 3.0 \\
\hline
\end{tabular}

\section{Solid Species}

The mass density $\left(\mathrm{g} / \mathrm{cm}^{3}\right)$ and the stoichiometric coefficient of each element are needed for each solid species, including any secondary minerals that precipitate from supersaturated conditions. The simulations will reference several WTP glasses; the composition of LAWA44 glass is given as an example (Table 7.6). The mole fraction of each of the elements in the waste glass is required as input to STOMP/STORM and is shown in Table 7.7.

Table 7.6. Composition (Mass\%) and Particle Density for the Glass Specimen Used in Simulations

\begin{tabular}{cc}
\hline Oxide & LAWA44 \\
\hline $\mathrm{Al}_{2} \mathrm{O}_{3}$ & 6.20 \\
$\mathrm{~B}_{2} \mathrm{O}_{3}$ & 8.90 \\
$\mathrm{CaO}$ & 1.99 \\
$\mathrm{Fe}_{2} \mathrm{O}_{3}$ & 6.98 \\
$\mathrm{MgO}$ & 1.99 \\
$\mathrm{Na} \mathrm{O}_{2}$ & 20.0 \\
$\mathrm{SiO}_{2}$ & 44.55 \\
$\mathrm{TiO}_{2}$ & 1.99 \\
$\mathrm{ZnO}$ & 2.96 \\
$\mathrm{ZrO}_{2}$ & 2.99 \\
$\mathrm{Others}^{(\mathrm{a})}$ & 1.42 \\
$\mathrm{Total}$ & 100.0 \\
& 66.96 \\
& $(2.698 \pm 0.008) \times 10^{6}$ \\
\hline Formula $\mathrm{Weight}_{2} \mathrm{~g} / \mathrm{mol}^{2}$ & \\
Density, $\mathrm{g} / \mathrm{m}^{3}$ &
\end{tabular}

The compositions of materials that make up the backfill, filler, and Hanford sand are listed in Table 7.8 (Serne et al. 1993). The mass density is obtained by dividing the molecular weight by the molar volume of the compound.

Secondary phases are solids that precipitate from a supersaturated aqueous solution. A list of potential secondary phases that form from long-term weathering experiments with the various waste glass formulations and from modeling the solution chemistry observed in experiments with the EQ3/6 code is provided in (Pierce et al. 2004a,b). A large number of phases were eliminated from consideration because 1) formation of the phase is kinetically prohibited at the disposal system temperature of $15^{\circ} \mathrm{C}$, 2) selection of the phase would violate the Gibbs phase rule, 3) simulations show that allowing the phase 
to form is inconsistent with a large body of laboratory test data with borosilicate glasses, or 4) the phase is unstable over the range of chemical environments expected for the IDF system.

Table 7.7. LAWA44 Composition in Mole Fraction Used in STORM Simulations

\begin{tabular}{lc}
\hline \multicolumn{1}{r}{ Element } & LAWA44 \\
\hline $\mathrm{Al}$ & $8.15 \mathrm{E}-02$ \\
$\mathrm{~B}$ & $1.71 \mathrm{E}-01$ \\
$\mathrm{Ca}$ & $2.38 \mathrm{E}-02$ \\
$\mathrm{Cl}$ & $1.23 \mathrm{E}-02$ \\
$\mathrm{Cr}$ & $1.76 \mathrm{E}-04$ \\
$\mathrm{~F}$ & $3.53 \mathrm{E}-04$ \\
$\mathrm{Fe}$ & $5.86 \mathrm{E}-02$ \\
$\mathrm{~K}$ & $7.11 \mathrm{E}-03$ \\
$\mathrm{Mg}$ & $3.31 \mathrm{E}-02$ \\
$\mathrm{Mo}$ & $4.65 \mathrm{E}-05$ \\
$\mathrm{Na}$ & $4.32 \mathrm{E}-01$ \\
$\mathrm{O}$ & $1.83 \mathrm{E}+00$ \\
$\mathrm{P}$ & $2.83 \mathrm{E}-04$ \\
$\mathrm{~S}$ & $8.37 \mathrm{E}-04$ \\
$\mathrm{Si}$ & $4.97 \mathrm{E}-01$ \\
$\mathrm{Tc}$ & $2.77 \mathrm{E}-04$ \\
$\mathrm{Ti}$ & $1.67 \mathrm{E}-02$ \\
$\mathrm{Zn}$ & $2.44 \mathrm{E}-02$ \\
$\mathrm{Zr}$ & $1.63 \mathrm{E}-02$ \\
\hline
\end{tabular}

Table 7.8. Composition of Native and Surrounding Materials Used in Simulations

\begin{tabular}{llcc}
\hline \multicolumn{1}{c}{ Species } & \multicolumn{1}{c}{ Formula } & $\begin{array}{c}\text { Mol. Wt. } \\
\text { g/mol }\end{array}$ & $\begin{array}{c}\text { Molar Volume, } \\
\mathrm{cm}^{3} / \mathrm{mol}\end{array}$ \\
\hline Albite & $\mathrm{NaAlSi}_{3} \mathrm{O}_{8}$ & 262.2 & 100.4 \\
Illite & $\mathrm{K}_{0.6} \mathrm{Mg}_{0.25} \mathrm{Al}_{1.8} \mathrm{Al}_{0.5} \mathrm{Si}_{3.5} \mathrm{O}_{10}(\mathrm{OH})_{2}$ & 383.9 & 500.0 \\
K-Feldspar & $\mathrm{KAlSi}_{3} \mathrm{O}_{8}$ & 278.3 & 108.8 \\
Quartz & $\mathrm{SiO}_{2}$ & 60.1 & 22.6 \\
\hline
\end{tabular}

The final phase assemblage used in STORM simulations (see Table 7.9) was further constrained because preliminary runs showed that the phase never formed or formed in such small amounts that the effects were insignificant. The compositions of the secondary minerals used in the simulations are listed in Table 7.9. The mass density is obtained by dividing the molecular weight by the molar volume of the solid. 
Table 7.9. Compositions of Secondary Minerals Used in Simulations

\begin{tabular}{lccc}
\hline \multicolumn{1}{c}{ Species } & Formula & Mol. Wt. & Molar Volume \\
\hline Analcime & $\mathrm{Na}_{0.96} \mathrm{Al}_{0.96} \mathrm{Si}_{2.04} \mathrm{O}_{6}$ & 201.2 & 96.8 \\
Anatase & $\mathrm{TiO}_{2}$ & 79.8 & 20.5 \\
Baddeleyite & $\mathrm{ZrO}_{2}$ & 123.2 & 21.9 \\
Calcite & $\mathrm{CaCO}_{3}$ & 100.1 & 36.9 \\
Chalcedony & $\mathrm{SiO}_{2}$ & 60.1 & 22.7 \\
Clinochlore-14A & $\mathrm{Mg}_{5} \mathrm{Al}_{2} \mathrm{Si}_{3} \mathrm{O}_{10}(\mathrm{OH})_{8}$ & 555.8 & 207.1 \\
Fe(OH $)_{3}(\mathrm{am})$ & $\mathrm{Fe}(\mathrm{OH})_{3}$ & 106.9 & 34.4 \\
Gibbsite & $\mathrm{Al}(\mathrm{OH})_{3}$ & 78.0 & 31.9 \\
Zn $(\mathrm{OH})_{2}$ (gamma) & $\mathrm{Zn}(\mathrm{OH})_{2}$ & 99.4 & 30.0 \\
\hline
\end{tabular}

\section{Equilibrium Reactions}

For each equilibrium reaction, the stoichiometric coefficient of each aqueous species in each reaction and the equilibrium constant at a temperature of $15^{\circ} \mathrm{C}$ are needed. The equilibrium reactions in Table 7.10 were identified by simulating the dissolution of the waste glasses and grout in DIW at $15^{\circ} \mathrm{C}$ with the EQ3/6 code package (Wolery and Daveler 1992) and the data0.com.R8 database (Daveler and Wolery 1992; Wolery and Daveler 1992). A significant number of secondary aqueous species were excluded from the simulations because their concentrations were extremely small over the range of chemical conditions anticipated for the ILAW disposal system.

Table 7.10. Equilibrium Reactions at $15^{\circ} \mathrm{C}$

\begin{tabular}{|c|c|}
\hline Reaction & $\log \mathrm{K}$ \\
\hline $\mathrm{BO}_{2}^{-}+\mathrm{H}_{2} \mathrm{O}+\mathrm{H}^{+}=\mathrm{B}(\mathrm{OH})_{3}(\mathrm{aq})$ & 9.35 \\
\hline $\mathrm{CO}_{2}(\mathrm{aq})+\mathrm{H}_{2} \mathrm{O}=\mathrm{H}^{+}+\mathrm{HCO}_{3}^{-}$ & -6.42 \\
\hline $\mathrm{CO}_{3}^{2-}+\mathrm{H}^{+}=\mathrm{HCO}_{3}^{-}$ & 10.43 \\
\hline $\mathrm{H}_{2} \mathrm{SiO}_{4}{ }^{2-}+\mathrm{H}^{+}=2 \mathrm{H}_{2} \mathrm{O}+\mathrm{SiO}_{2}(\mathrm{aq})$ & 22.96 \\
\hline $\mathrm{HCrO}_{4}^{-}=\mathrm{CrO}_{4}^{2-}+\mathrm{H}^{+}$ & -6.49 \\
\hline $\mathrm{HSiO}_{3}^{-}+\mathrm{H}^{+}=\mathrm{SiO}_{2}(\mathrm{aq})+\mathrm{H}_{2} \mathrm{O}$ & 10.10 \\
\hline $\mathrm{KOH}(\mathrm{aq})+\mathrm{H}^{+}=\mathrm{H}_{2} \mathrm{O}+\mathrm{K}^{+}$ & 14.46 \\
\hline $\mathrm{MgB}(\mathrm{OH})_{4}^{+}+\mathrm{H}^{+}=\mathrm{H}_{2} \mathrm{O}+\mathrm{B}(\mathrm{OH})_{3}(\mathrm{aq})+\mathrm{Mg}^{2+}$ & 7.35 \\
\hline $\mathrm{MgCO}_{3}(\mathrm{aq})+\mathrm{H}^{+}=\mathrm{HCO}_{3}^{-}+\mathrm{Mg}^{2+}$ & 7.50 \\
\hline $\mathrm{MgHCO}_{3}^{+}=\mathrm{HCO}_{3}^{-}+\mathrm{Mg}^{2+}$ & -1.04 \\
\hline $\mathrm{NaB}(\mathrm{OH})_{4}(\mathrm{aq})+\mathrm{H}^{+}=\mathrm{B}(\mathrm{OH})_{3}(\mathrm{aq})+\mathrm{Na}^{+}+\mathrm{H}_{2} \mathrm{O}$ & 8.97 \\
\hline $\mathrm{NaCO}_{3}^{-}+\mathrm{H}^{+}=\mathrm{HCO}_{3}^{-}+\mathrm{Na}^{+}$ & 9.82 \\
\hline $\mathrm{NaHCO}_{3}(\mathrm{aq})=\mathrm{HCO}_{3}^{-}+\mathrm{Na}^{+}$ & -0.24 \\
\hline $\mathrm{NaHSiO}_{3}(\mathrm{aq})+\mathrm{H}^{+}=\mathrm{Na}^{+}+\mathrm{SiO}_{2}(\mathrm{aq})+\mathrm{H}_{2} \mathrm{O}$ & 8.36 \\
\hline $\mathrm{NaOH}(\mathrm{aq})+\mathrm{H}^{+}=\mathrm{Na}^{+}+\mathrm{H}_{2} \mathrm{O}$ & 15.12 \\
\hline $\mathrm{OH}^{-}+\mathrm{H}^{+}=\mathrm{H}_{2} \mathrm{O}$ & 14.34 \\
\hline $\mathrm{Zn}(\mathrm{OH})_{2}(\mathrm{aq})=2 \mathrm{OH}^{-}+\mathrm{Zn}^{2+}+2 \mathrm{H}_{2} \mathrm{O}$ & -11.36 \\
\hline $\mathrm{ZnOH}^{+}=\mathrm{OH}^{-}+\mathrm{H}_{2} \mathrm{O}+\mathrm{Zn}^{2+}$ & -5.05 \\
\hline
\end{tabular}




\section{Kinetic Reactions}

For each kinetic reaction, the following data are needed:

- mass-action law type: 1. full, 2. reduced, or 3. glass

- stoichiometric coefficient of aqueous species in each reaction

- equilibrium constant at a temperature of $15^{\circ} \mathrm{C}$

- rate constant of reaction.

A full mass-action law type will be used for each solid phase except the waste glass. A special massaction law type will be used for the glass. A full mass-action law type allows a solid species to both dissolve and precipitate; a reduced mass-action law type allows a solid species to either dissolve or precipitate, but not both. For both full and reduced mass action, equilibrium depends on all aqueous species released by the kinetic reaction. A glass mass-action law type allows the glass to dissolve, but not precipitate, and equilibrium of the rate equation depends only on aqueous silica.

Compilations of kinetic rate constants equivalent to thermodynamic databases for important mineral phases are not available. Also, the available mineral dissolution/precipitation kinetics data are much more limited than thermodynamic data. Consequently, sufficiently large rate constants will be used to approximate equilibrium conditions, that is, to make certain that the phase will precipitate rapidly if the local chemical environment at a grid node is saturated with respect to the particular phase.

For a dissolution reaction involving glass, parameters associated with the following kinetic rate law are needed:

$$
r_{g}=\vec{k} a_{\mathrm{H}^{+}}^{-\eta} e \frac{-E_{a}}{\mathrm{RT}}\left[1-\left(\frac{Q}{K_{g}}\right)^{\sigma}\right]
$$

where

$$
\begin{aligned}
r_{g} & =\text { dissolution rate, } \mathrm{g} /\left(\mathrm{m}^{2} \mathrm{~d}\right) \\
\vec{k} & =\text { intrinsic rate constant, } \mathrm{g} /\left(\mathrm{m}^{2} \mathrm{~d}\right) \\
a_{\mathrm{H}^{+}} & =\text {hydrogen ion activity }(\text { variable to be calculated by STORM }) \\
E_{a} & =\text { activation energy, } \mathrm{kJ} / \mathrm{mol} \\
R & =\text { gas constant, } \mathrm{kJ} /(\mathrm{mol} \cdot \mathrm{K}) \\
T & =\text { temperature, } \mathrm{K}\left(\text { assumed constant at } 15^{\circ} \mathrm{C}\right) \\
Q & =\text { ion activity product for glass (variable to be calculated by STORM) } \\
K_{g} & =\text { pseudo-equilibrium constant } \\
\eta & =\text { pH power law coefficient } \\
\sigma & =\text { Temkin coefficient }(\sigma=1 \text { assumed }) .
\end{aligned}
$$

Equation 6.3 is an approximation for glass because glass is metastable, and the reaction proceeds one way (i.e., glass dissolves). The unknown parameters in Equation $6.3\left(\vec{k}, \mathrm{E}_{a}, \mathrm{Kg}\right.$, and $\eta$ ) have been determined for ILAW glasses (Pierce et al. 2004a) and bulk-vitrification glasses (Pierce et al. 2004b); these values are given in Table 7.11. 
Table 7.11. Summary of Kinetic Rate Parameters Used for Glass

\begin{tabular}{llc}
\hline \multicolumn{1}{c}{ Parameter } & \multicolumn{1}{c}{ Meaning } & LAWA44 \\
\hline$\vec{k}$ & Intrinsic rate constant, $\mathrm{mol} /\left(\mathrm{m}^{2} \mathrm{~s}\right)$ & $2.2 \times 10^{-3}$ \\
$K_{g}$ & $\begin{array}{l}\text { Apparent equilibrium constant } \\
\text { for glass based on activity of }\end{array}$ & $10^{-3.26}$ \\
& $\begin{array}{l}\mathrm{SiO}_{2}(\mathrm{aq}) \\
\mathrm{pH} \text { power law coefficient }\end{array}$ & 0.49 \\
$\eta$ & $\begin{array}{l}\text { Activation energy of glass } \\
\text { dissolution reaction, } \mathrm{kJ} / \mathrm{mol}\end{array}$ & 60 \\
$E_{a}$ & Na ion-exchange rate, $\mathrm{mol} /\left(\mathrm{m}^{2} \mathrm{~s}\right)$ & $5.3 \times 10^{-11}$ \\
\hline
\end{tabular}

Test results with ILAW and bulk vitrification glasses (excluding LAWB45) show that it is susceptible to a secondary reaction mechanism, alkali-ion exchange. This reaction results in the selective extraction of $\mathrm{Na}$ via the reaction:

$$
\text { LAWA44-Na }+\mathrm{H}^{+} \rightarrow \text { LAWA44-H }+\mathrm{Na}^{+}
$$

where LAWA44-Na represents the unreacted glass containing $\mathrm{Na}$, and LAWA44-H represents a hydrated glass where the $\mathrm{Na}$ has been replaced with an equimolar amount of hydrogen. The rate of this reaction has been determined from SPFT experiments (Pierce et al. 2004a,b). STORM keeps track of the amount of hydrated glass formed via reaction (Equation 7.4) and then allows it to dissolve according to the same kinetic rate law (Equation 7.3) as the parent glass.

Pierce et al. (2004a,b) describe the methods used to develop a solubility product for the key secondary phases identified from laboratory testing and from simulations with the EQ3/6 code. For convenience, the $\log \mathrm{K}$ they derived for each secondary phase given in Table 7.9 is reproduced in Table 7.12. For the secondary phases, where a $\log \mathrm{K}$ was not available or could not be estimated, the reaction was not included in the STORM simulations.

Table 7.12. Secondary Phase Reaction Network

\begin{tabular}{lc}
\hline \multicolumn{1}{c}{ Reaction } & Log K \\
\hline Analcime $\leftrightarrow 0.96 \mathrm{AlO}_{2}^{-}+0.96 \mathrm{Na}^{+}+2.04 \mathrm{SiO}_{2}(\mathrm{aq})$ & -16.47 \\
Anatase $+2 \mathrm{H}_{2} \mathrm{O} \leftrightarrow \mathrm{Ti}(\mathrm{OH})_{4}(\mathrm{aq})$ & -6.56 \\
Baddeleyite $+2 \mathrm{H}_{2} \mathrm{O} \leftrightarrow \mathrm{Zr}(\mathrm{OH})_{4}(\mathrm{aq})$ & -6.79 \\
Calcite $+\mathrm{H}^{+} \leftrightarrow \mathrm{Ca}^{2+}+\mathrm{HCO}_{3}^{-}$ & 2.00 \\
Chalcedony $\leftrightarrow \mathrm{SiO}_{2}(\mathrm{aq})$ & -3.94 \\
$\mathrm{Clinochlore}-14 \mathrm{~A}+8 \mathrm{H}^{+} \leftrightarrow 3 \mathrm{SiO}_{2}(\mathrm{aq})+5 \mathrm{Mg}^{2+}+8 \mathrm{H}_{2} \mathrm{O}+2 \mathrm{AlO}_{2}^{-}$ & 22.93 \\
$\mathrm{Fe}(\mathrm{OH})_{3}(\mathrm{am})+\mathrm{H}_{2} \mathrm{O} \leftrightarrow \mathrm{Fe}(\mathrm{OH})_{3}(\mathrm{aq})$ & -11.09 \\
$\mathrm{Gibbsite} \leftrightarrow \mathrm{AlO}_{2}^{-}+\mathrm{H}_{2} \mathrm{O}$ & -13.10 \\
$\mathrm{Zn}(\mathrm{OH})_{2}(\mathrm{gamma})+2 \mathrm{H}^{+} \leftrightarrow 2 \mathrm{H}_{2} \mathrm{O}+\mathrm{Zn}^{2+}$ & 11.88 \\
\hline
\end{tabular}




\subsubsection{Initial and Boundary Conditions}

For each specified gas species concentration, the partial pressure of gaseous species is needed. The gas partial pressures for $\mathrm{CO}_{2}$ and $\mathrm{O}_{2}$ were fixed at atmospheric values of $3 \times 10^{-4}$ and $2.1 \times 10^{-1} \mathrm{~atm}$, respectively.

For each specified aqueous species, the specified total concentration and the stoichiometric coefficient of each aqueous species are needed. Aqueous-species concentrations at the upper boundary, and for initial conditions, were specified as a part of the near-field geochemistry data package (Krupka et al. 2004) and are given in Table 7.13. Total aqueous species concentrations were specified at the upper boundary, and a no-diffusion condition was imposed across the lower boundary. The contaminant flux across the lower boundary was therefore limited to advection:

$$
f=c \rho_{w} v
$$

where $c$ is the concentration $(\mathrm{mol} / \mathrm{kg}), \rho_{w}$ is the density of water $\left(\mathrm{kg} / \mathrm{m}^{3}\right)$, and $v$ is the specific discharge $(\mathrm{m} / \mathrm{s})$.

Table 7.13. Initial Aqueous Concentrations Used in Simulations

\begin{tabular}{lc}
\hline \multicolumn{1}{c}{ Species } & $\begin{array}{c}\text { Initial Concentration } \\
(\mathrm{mol} / \mathrm{kg})\end{array}$ \\
\hline $\mathrm{AlO}_{2}{ }^{-}$ & $10^{-6}$ \\
$\mathrm{~B}(\mathrm{OH})_{3}(\mathrm{aq})$ & $10^{-10}$ \\
$\mathrm{Ca}^{2+}$ & $10^{-7}$ \\
$\mathrm{Cr}($ total $)$ & $10^{-10}$ \\
$\mathrm{Fe}(\mathrm{OH})_{3}(\mathrm{aq})$ & $10^{-10}$ \\
$\mathrm{H}_{2} \mathrm{O}$ & 1 \\
$\mathrm{H}^{+}$ & $10^{-7}$ \\
$\mathrm{~K}^{+}$ & $10^{-6}$ \\
$\mathrm{Mg}^{2+}$ & $10^{-10}$ \\
$\mathrm{Na}^{+}$ & $10^{-6}$ \\
$\mathrm{Si}_{(\text {total })}$ & $10^{-5}$ \\
$\mathrm{TcO}_{4}^{-}$ & $10^{-10}$ \\
$\mathrm{Ti}^{2}(\mathrm{OH})_{4}(\mathrm{aq})$ & $10^{-10}$ \\
$\mathrm{Zn}{ }^{2+}$ & $10^{-10}$ \\
$\mathrm{Zr}(\mathrm{OH})_{4}(\mathrm{aq})$ & $10^{-10}$ \\
\hline
\end{tabular}

\subsubsection{Model Output}

The normalized flux to the vadose zone is calculated by summing the flux at each node across the bottom boundary of the model and normalizing the total flux according to the amount of each 
radionuclide in all the waste packages at the start of the simulation. The normalized flux across the lower boundary, $F$, in units of $\mathrm{M} / \mathrm{yr}$, was calculated using

$$
F=\frac{\sum_{i=1}^{N} f_{i} \Delta x_{i} \Delta y_{i}}{I_{j}} \zeta
$$

where $\quad f_{i}=$ flux across the bottom of an individual grid block (mole $\left./ \mathrm{m}^{2}-\mathrm{s}\right)$

$\Delta x_{i} \Delta y_{i}=$ cross-sectional area of an individual grid block $\left(\mathrm{m}^{2}\right)$

$\zeta=\frac{3.1558 \times 10^{13} \mathrm{~s}}{\mathrm{Myr}}$

$I_{j}=$ inventory of $j^{\text {th }}$ radionuclide in the simulated waste packages (mol),

where

$$
I_{j}=V_{w p}\left(1-\theta_{T}\right) \rho_{G} \gamma_{j}
$$

where $\quad V_{w p}=$ volume of the waste packages $\left(\mathrm{m}^{3}\right)$

$\theta_{T}=$ total porosity of the material representing the waste packages $\left(\mathrm{m}^{3} / \mathrm{m}^{3}\right)$

$\rho_{G}=$ molar density of the material representing the waste packages $\left(\mathrm{mol} / \mathrm{m}^{3}\right)$

$\gamma_{j}=$ mole fraction of $j^{\text {th }}$ radionuclide in the material representing the waste packages $(\mathrm{mol} / \mathrm{mol})$.

The volume of the four simulated waste packages, $V_{w p}$, was $11.2 \mathrm{~m}^{3}$ for the WTP glass simulations. The cross-sectional area of each grid block was $0.02 \mathrm{~m}^{2}$.

The units of M/yr (pronounced "per million years") are equivalent to units of "ppm/yr," which were used in previous PAs (Mann et al. 1998, 2001). The term ppm was used to express the fraction of radionuclide released from the waste packages per year in "per millionth," similar to the commonly used "percent" term. However, the unit ppm, when used in environmental science for expressing levels of pollutants in water, has the specific meaning of $\mathrm{mg} /$ liter ( $\mathrm{mg}$ of contaminant per liter of water). Using ppm to mean "per millionth," while correct, may be confusing in this context and has been replaced with units of $\mathrm{M} / \mathrm{yr}$.

The radionuclide concentrations, for instance Tc, are also normalized by the inventory,

$$
\mathrm{Tc}_{\text {normalized }}=\frac{\mathrm{Tc}}{I_{\mathrm{Tc}}}
$$




\subsection{Modifications to STOMP}

Several modifications were made to the STOMP code so that model assumptions and results could be consistent with those used in STORM. Test cases were run after each modification to make sure that 1) STOMP and STORM gave similar results and 2) modifications to the input file did not impact previous simulations.

Fixed gas concentrations are a common option in many geochemical codes, including STORM. This feature was implemented in STOMP by adding the character string "fix" to a given species name. ECKEChem checks for this string in each species name, and if present, does not update that species concentration at each time step. This modification was tested by checking to verify that the $\mathrm{CO}_{2}(\mathrm{~g})$ partial pressure remained fixed at $3.0 \times 10^{-4}$.

Dissolution and precipitation reactions can change the volume fractions of solids as a function of time, thus changing the porosity. Porosity changes as a function of mineral precipitation and dissolution had previously been implemented in STOMP, but not documented. This option may be invoked by including the phrase "w/ porosity" in the second line of the solution control card. This modification was tested by running a simulation of a PUF test at $99^{\circ} \mathrm{C}$, as described in another report (Bacon and Pierce 2010), which displayed measureable changes in porosity over a short amount of time. Agreement between STOMP and STORM is good for an increase in porosity over seven days (Figure 7.2).

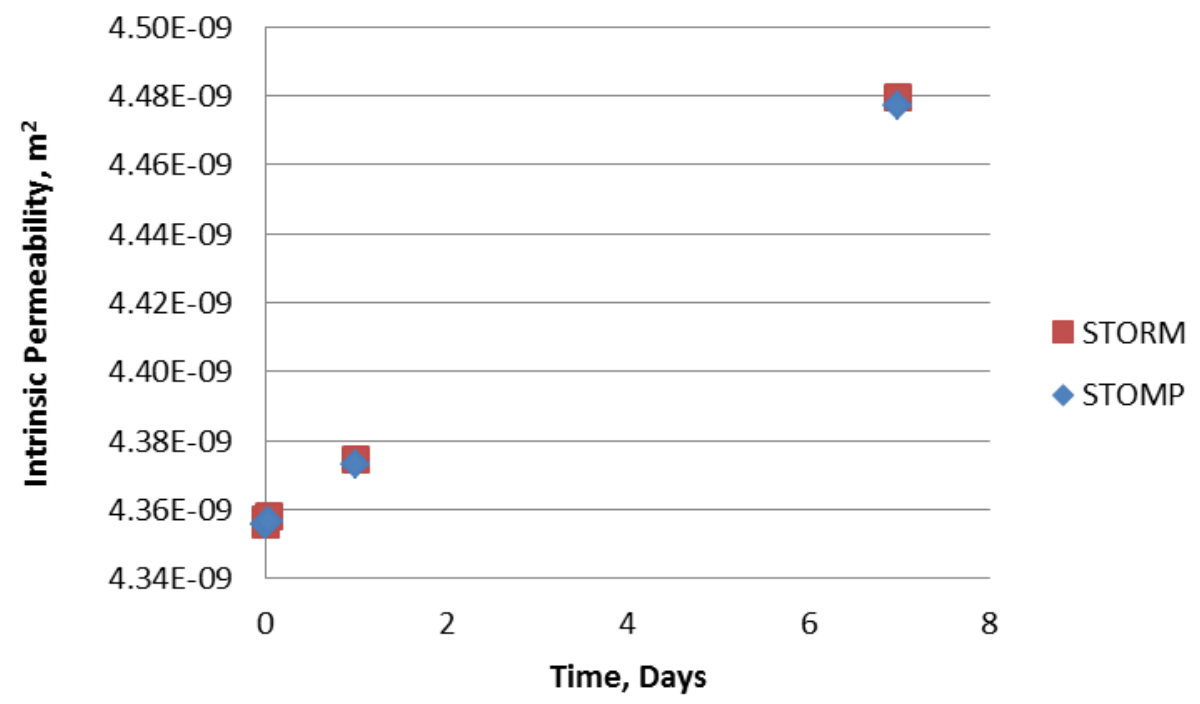

Figure 7.2. Comparison of Porosity Change Predicted by STOMP and STORM

Furthermore, intrinsic permeability varies as a function of porosity. One option for modeling this relationship, the Kozeny-Carman equation, has been added to STOMP. The Kozeny-Carman equation was obtained from a theoretical derivation of Darcy's law and includes numerical coefficients that must be determined empirically:

$$
k=C_{0} \frac{\phi_{T}^{3}}{\left(1-\phi_{T}\right)^{2} M_{S}^{2}},
$$


where $M_{S}$ is the specific surface area of the porous matrix (defined per unit volume of solid), and $C_{0}$ is the coefficient for which Carman (1937) suggested the value of $1 / 5$. This option may be invoked by adding the string "kozeny", followed by a comma, to the end of a Rock/Soil Hydraulic Properties Card input line for a particular material.

This modification was tested by running a simulation of a PUF test at $99^{\circ} \mathrm{C}$, as described in another report (Bacon and Pierce 2010), which displayed measureable changes in permeability over a short amount of time. Agreement between STOMP and STORM is good for an increase in permeability over seven days (Figure 7.3).

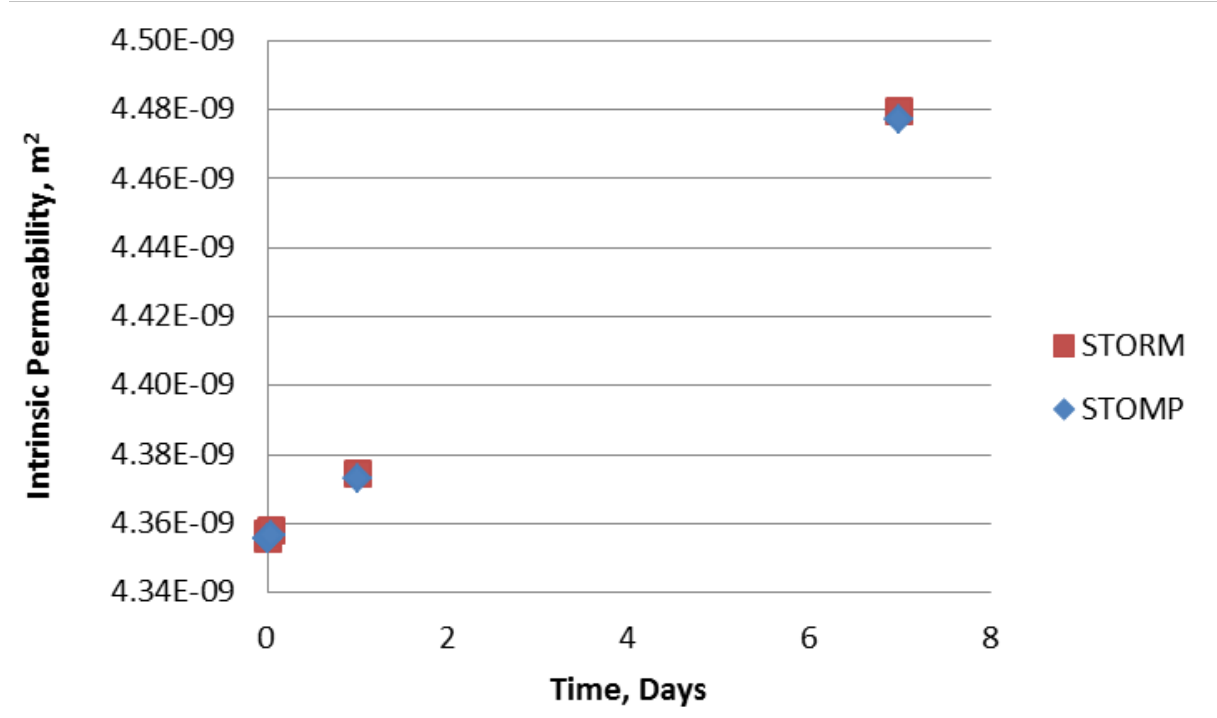

Figure 7.3. Comparison of Permeability Change Predicted by STOMP and STORM

Faulty logic in the ECKEChem subroutines allowed minerals to precipitate when they were marked as "toward reactants," which means that they should only be allowed to dissolve. In particular, this bug allowed the glass to precipitate, and so was fixed. This code change may affect previous ECKEChem simulations not related to this project.

Previously, the only diffusion model available for aqueous species transport in STOMP was the conventional model. STORM utilized the complete set of molecular diffusion models available for solute transport for species transport as well. Therefore, the complete set of molecular diffusion models available for solutes was also implemented for aqueous species in STOMP, with the addition of the Power Law model (Campbell 1985). The conventional model for molecular diffusion in STOMP assumes that diffusion decreases linearly with a decrease in water content. In contrast, the power law model assumes diffusion is proportional to the water content raised to a specified coefficient. In the case of the $2005 \mathrm{PA}$ simulations (Bacon and McGrail 2005), this coefficient was close to 2, which means that the conventional model in STOMP would predict higher diffusion coefficients than the power law model at low water contents. After this modification was implemented, effective aqueous diffusion coefficients calculated by both STOMP and STORM for the benchmarking problem described herein were compared and found to be identical (Figure 7.4). 


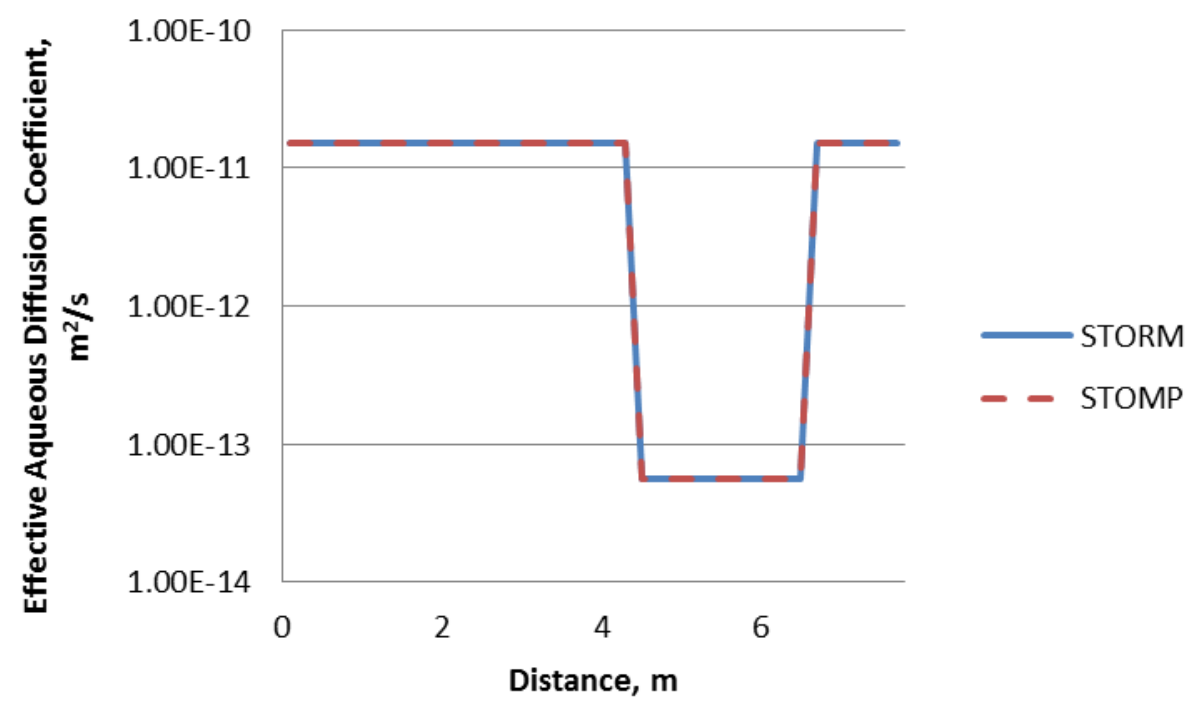

Figure 7.4. Comparison of Effective Aqueous Diffusion Coefficients Calculated by STOMP and STORM using Campbell's Power Law Model

Previously, STOMP assumed a default initial surface area for secondary minerals that was significantly higher than that calculated by STORM, resulting in faster secondary mineral precipitation. The capability to specify initial surface area of secondary minerals was added to STOMP. In the Lithology Card, if the surface area of a mineral is specified with an initial volume fraction of 0 , the specified surface area will be used rather than the default value. If the secondary mineral is not listed in the Lithology Card, the default surface area will be used.

The new variables SP_RATE and SP_AREA were added to store mineral rate and surface area for output. The user may now list these output variables in the reference-node and plot-file sections of the Output Control Card, as shown here:

Species Mineral Rate, LAWA44-H, mol/s,

Species Mineral Area,Albite-high, $\mathrm{m}^{\wedge} 2$,

An option was added to scale reactive surface area linearly with water saturation, as in STORM. This option may be invoked by including the phrase "w/ area" in the second line of the solution control card.

Ultimately, these changes to STOMP were tested by running the benchmarking simulations described in the following section.

\subsection{Benchmarking Results}

Output from both STOMP and STORM are compared for identical test cases, including aqueous species concentrations, glass dissolution rate, amounts of secondary minerals precipitated, and Tc flux across the lower model boundary. This comparison provides the technical basis for using the STOMP code in future IDF PAs by validating that the results from STORM and STOMP are comparable. 


\subsubsection{1-D Test Case}

A simplified test case was developed to be added to the QA test suite for STOMP. STOMP is being revalidated as safety software using the QA test suite as part of another project. STOMP and STORM were compared using a test case similar to the base case described in Section 7.6.1. Differences are:

- 1-D vs. 2-D

- one waste package, rather than four

- a shortened vertical domain, $7.8 \mathrm{~m}$ rather than $17.8 \mathrm{~m}$

- a coarser variable grid spacing of $20 \mathrm{~cm}$ rather than $2 \mathrm{~cm}$

- shorter time steps of 1 day rather than 1 year.

Tc release rates from the bottom of the repository (Figure 7.5) differ by $3.8 \%$ at the end of a 200 -year simulation. Agreement between Tc concentrations over time surrounding the waste packages (Figure 7.6), glass dissolution rate (Figure 7.7), and secondary mineral precipitation (Figure 7.8) is very good. Better agreement between STORM and STOMP can be achieved by using smaller time steps in STOMP. STOMP's operator split reactive transport scheme requires much smaller time steps to achieve an accurate answer for this complex problem.

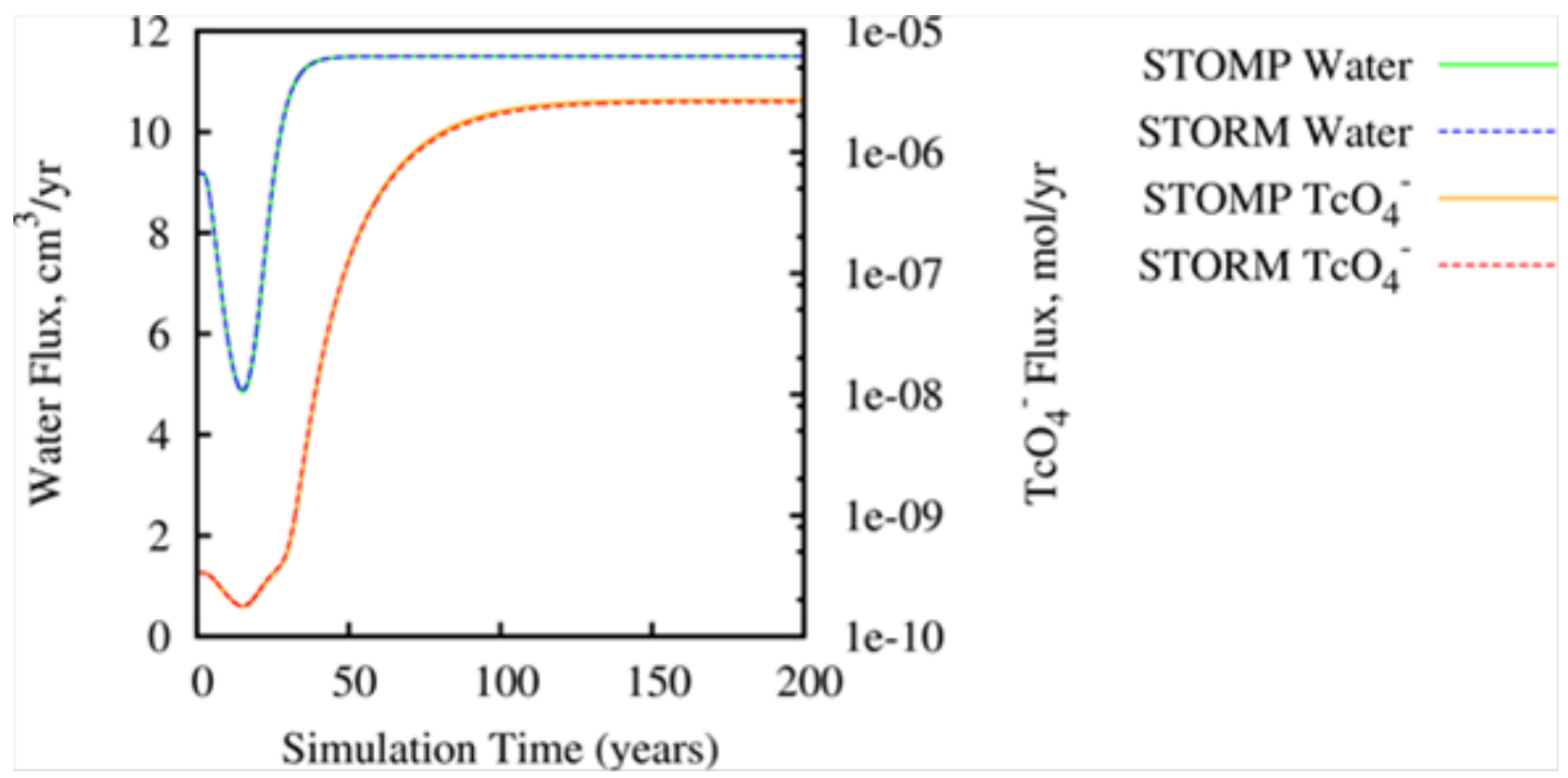

Figure 7.5. Comparison of Water and Tc Fluxes Across Bottom Model Boundary Predicted by STOMP and STORM 1-D Models 

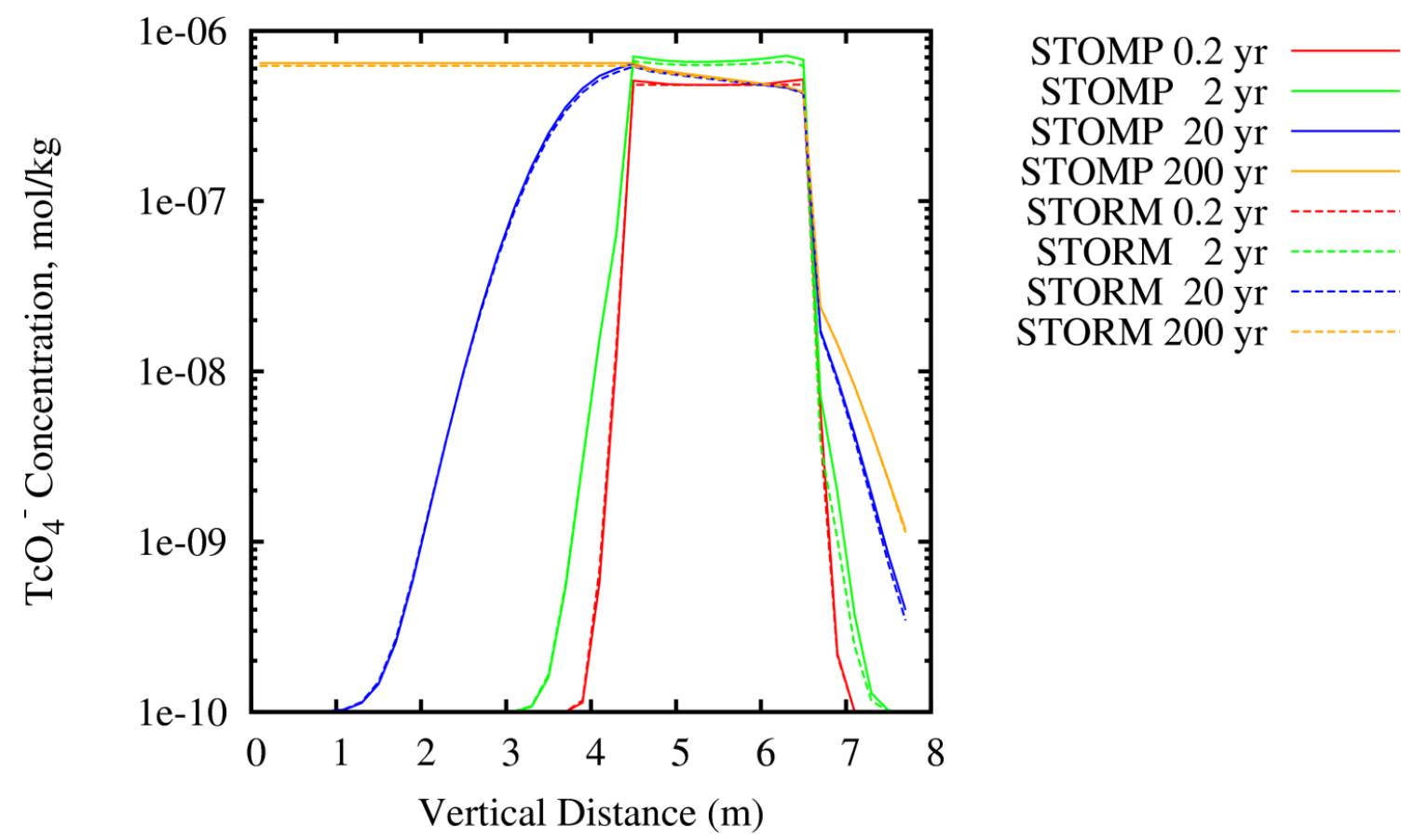

Figure 7.6. Comparison of Tc Concentrations vs. Depth and Time Predicted by STOMP and STORM 1-D Models
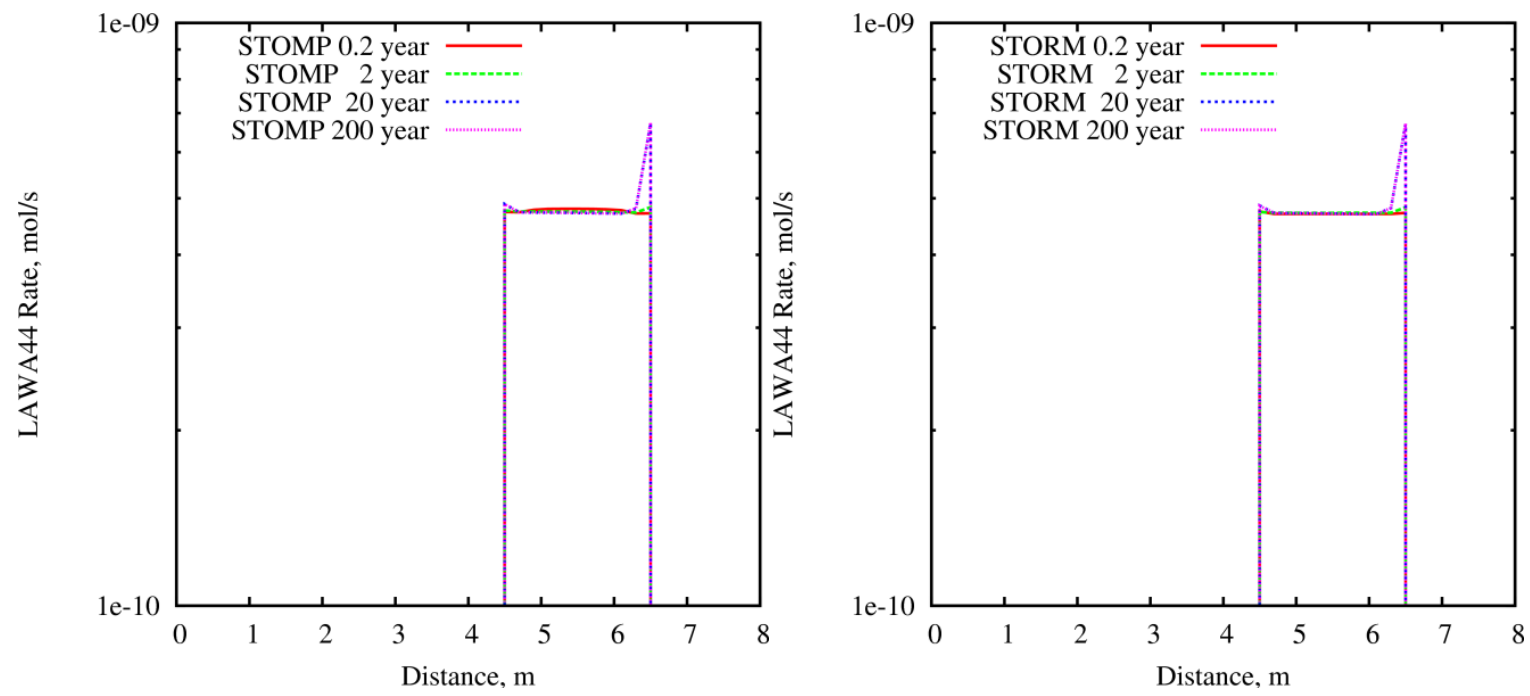

Figure 7.7. Comparison of LAWA44 Glass Dissolution Rate Predicted by STOMP (left) and STORM (right) 1-D Models 

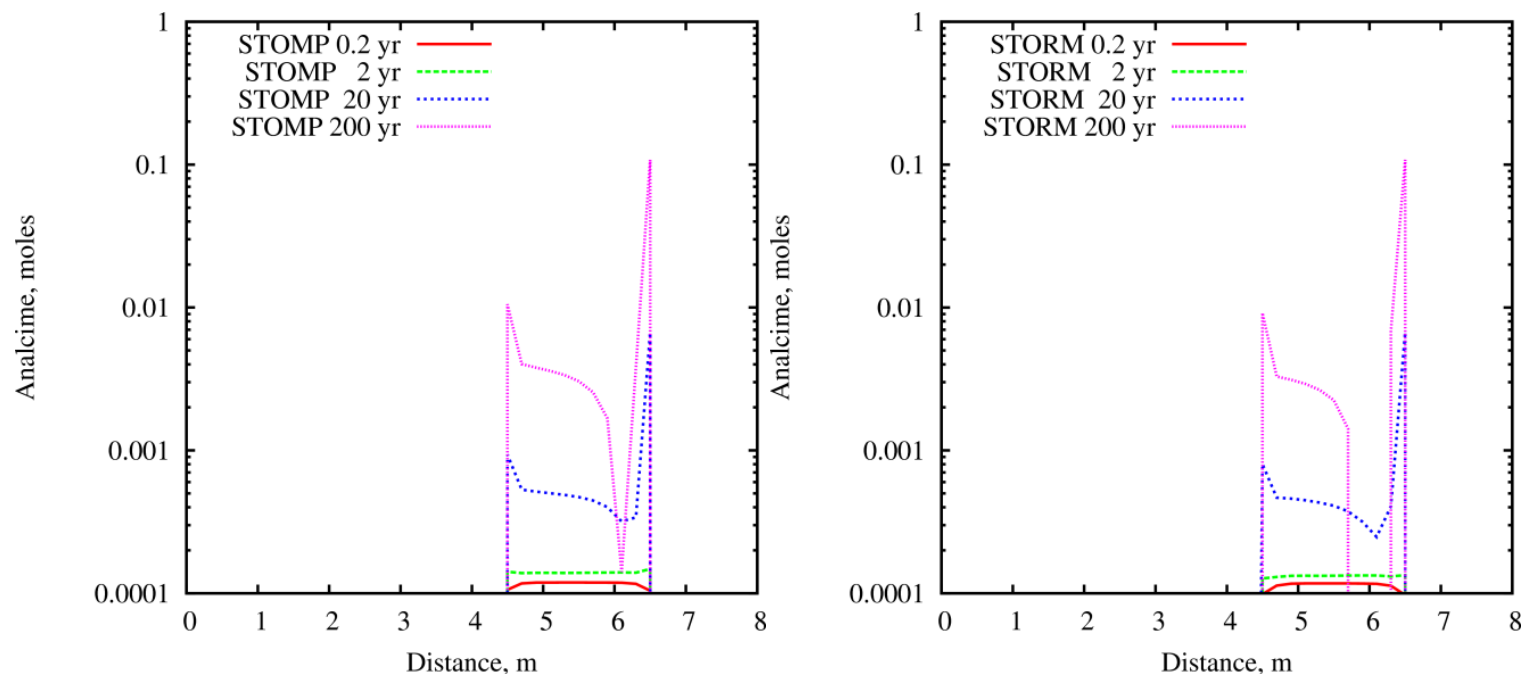

Figure 7.8. Comparison of Secondary Mineral Analcime Precipitation Predicted by STOMP (left) and STORM (right) 1-D Models

\subsubsection{2-D Test Case}

The input parameters detailed in Section 7.6.1 were used as a basis to develop input files for STORM and STOMP. However, due to budget constraints, only the serial version of STOMP could be modified in FY 2011. A simplified version of the base-case simulation was used for comparison. STOMP and STORM were compared using a test case similar to the base case described in Section 7.6.1. Differences are:

- one waste package, rather than four

- a shortened vertical domain, $4.3 \mathrm{~m}$ rather than $17.8 \mathrm{~m}$

- a coarser variable grid spacing of 10 to $20 \mathrm{~cm}$ rather than $2 \mathrm{~cm}$

- shorter time steps of 1.5 days rather than 1 year.

Tc release rates from the bottom of the repository differ by $1.5 \%$ for a 300 -year simulation (Figure 7.9). Agreement between Tc concentrations surrounding the waste packages (Figure 7.10), glass dissolution rate (Figure 7.11), and secondary mineral precipitation (Figure 7.12) is very good. The contrast in hydraulic properties between the glass and backfill is much more significant in a 2-D simulation than in the 1-D simulation previously shown. The fractured glass drains more easily than the porous backfill material, resulting in water flow around the waste packages, rather than directly through them. Peclet numbers are close to 10 in the glass, making this an advection-dominated problem in which STORM displays more numerical dispersion due to its upwind global implicit reactive-transport scheme. STOMP's Total-Variation-Diminishing operator split scheme displays less numerical dispersion, but requires much smaller time steps to achieve convergence. STORM required 15 minutes to complete this simulation, whereas STOMP required 1 hour and 45 minutes due to the smaller time steps taken. 


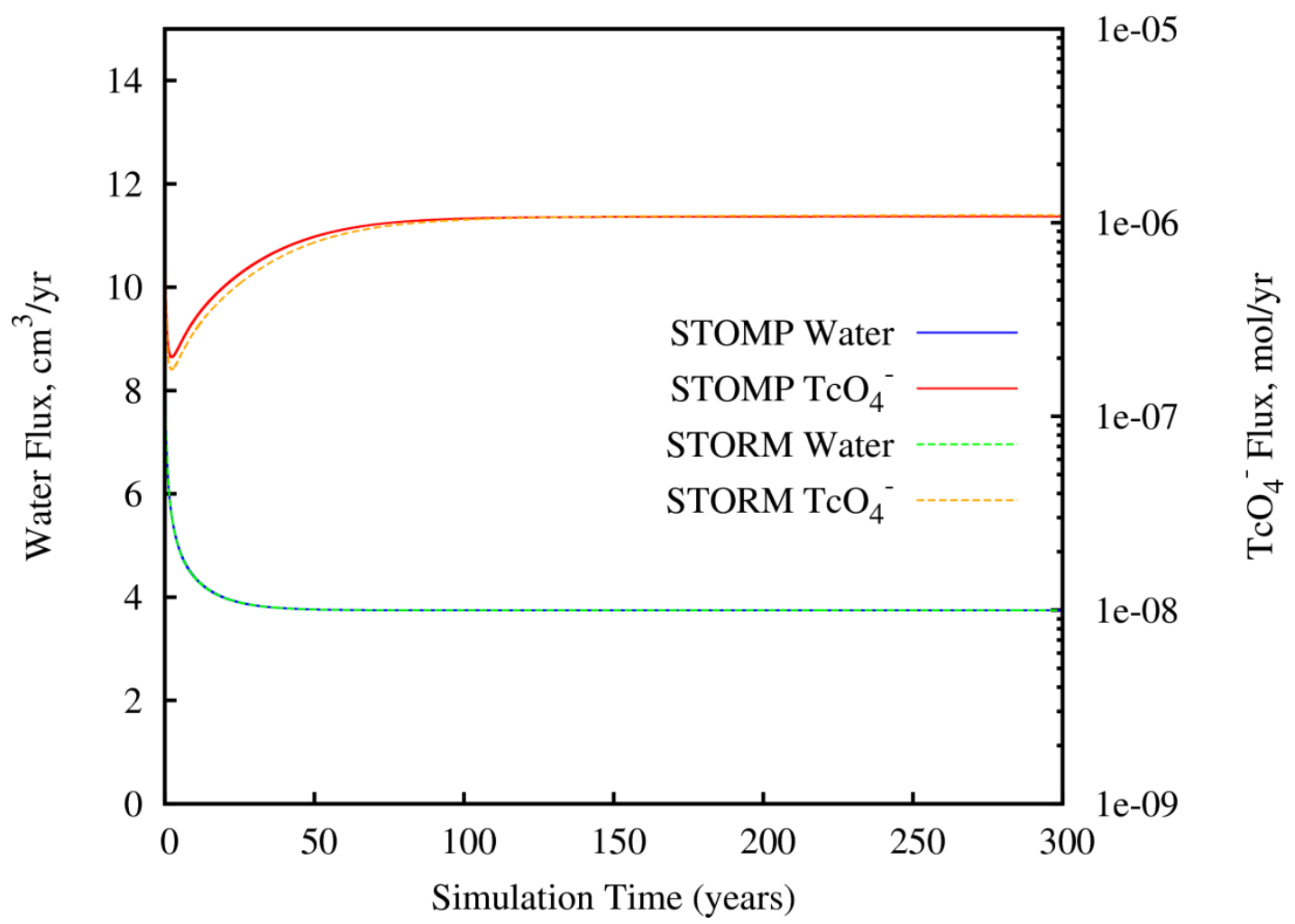

Figure 7.9. Comparison of Water and Tc Flux Across Bottom Model Boundary for STOMP and STORM
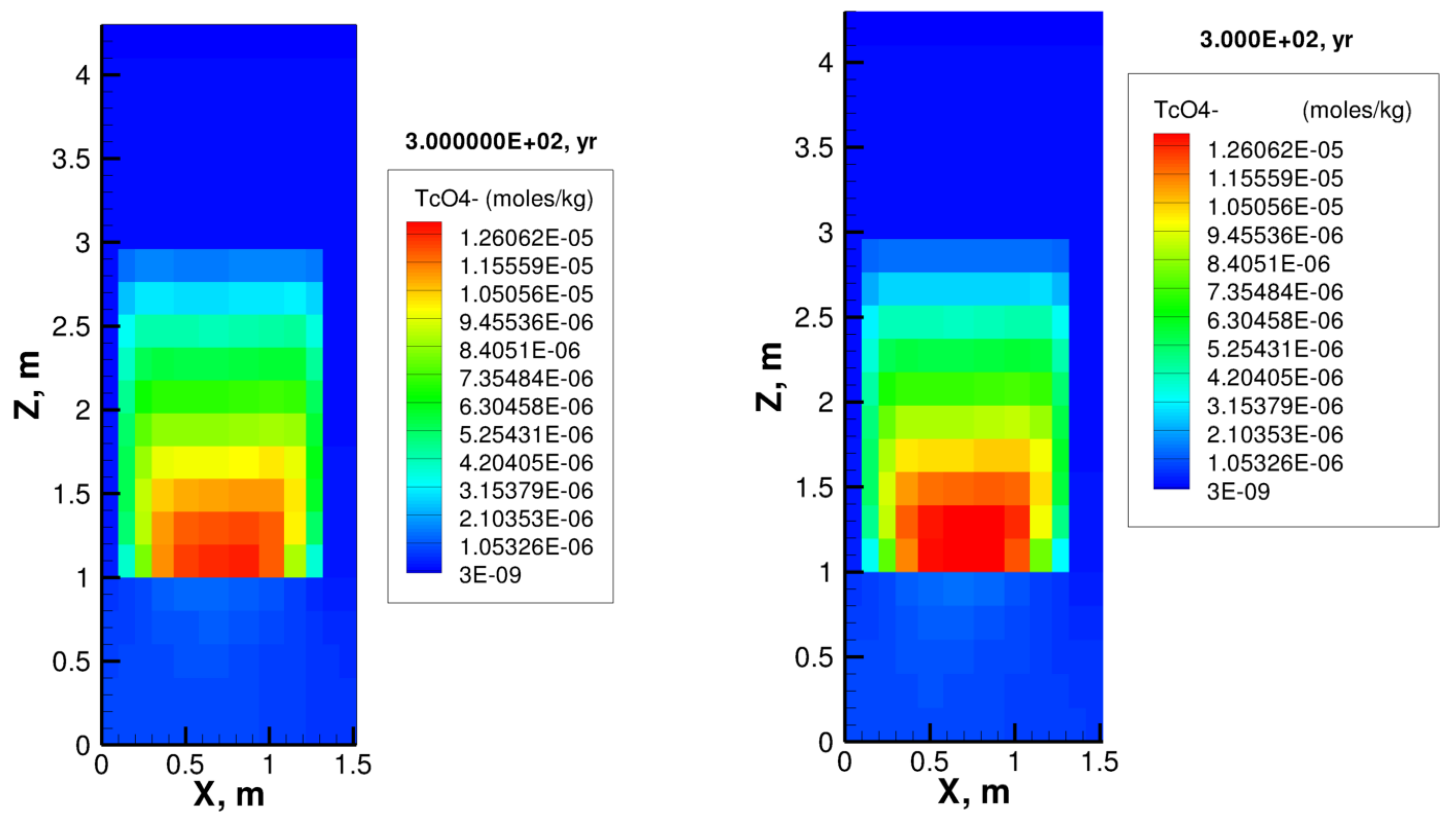

Figure 7.10. Comparison of Tc Concentration at 300 Years Predicted by STOMP and STORM 2-D Models 

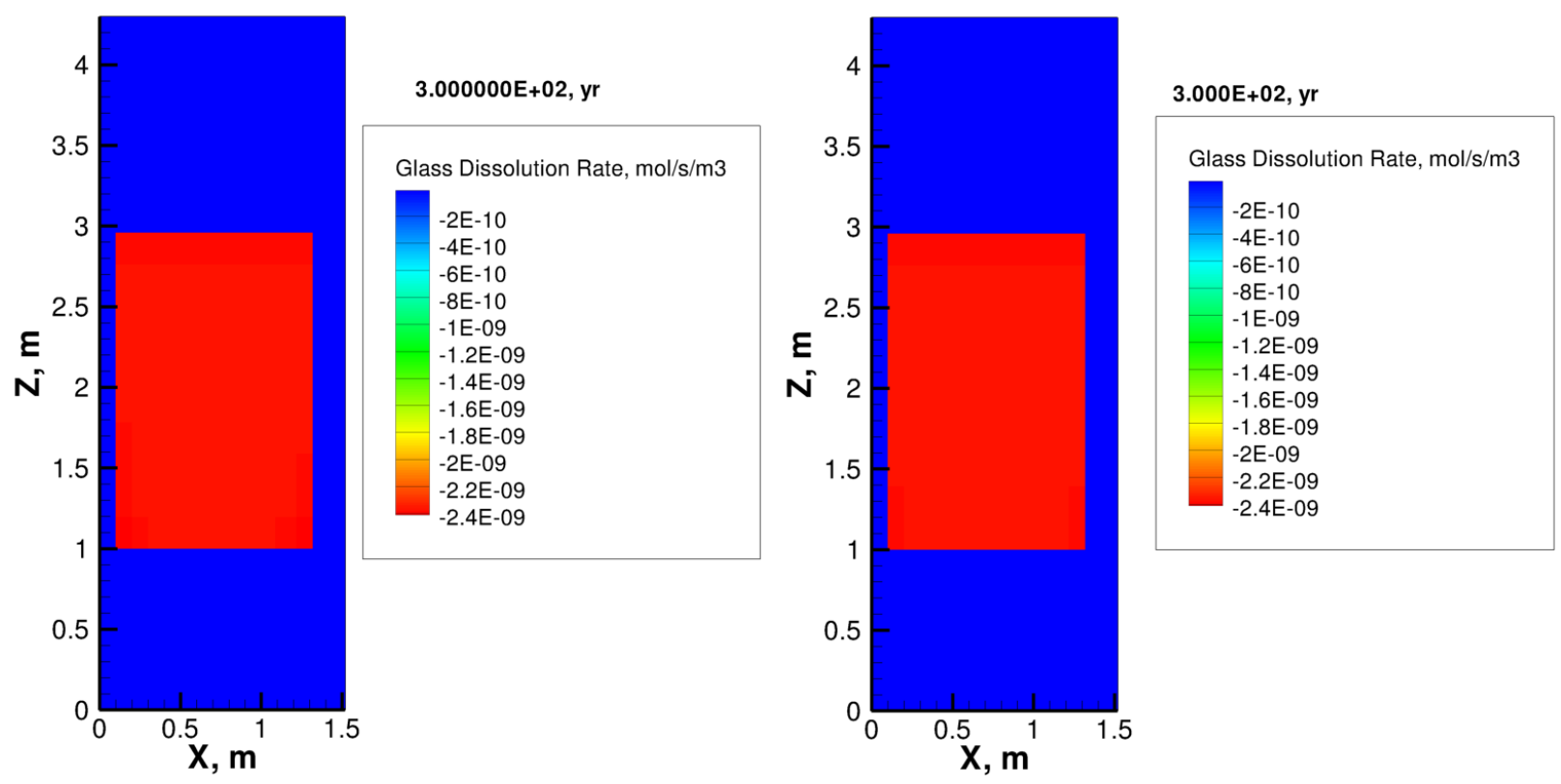

Figure 7.11. Comparison of LAWA44 Glass Dissolution Rate at 300 Years Predicted by STOMP (left) and STORM (right) 2-D Models
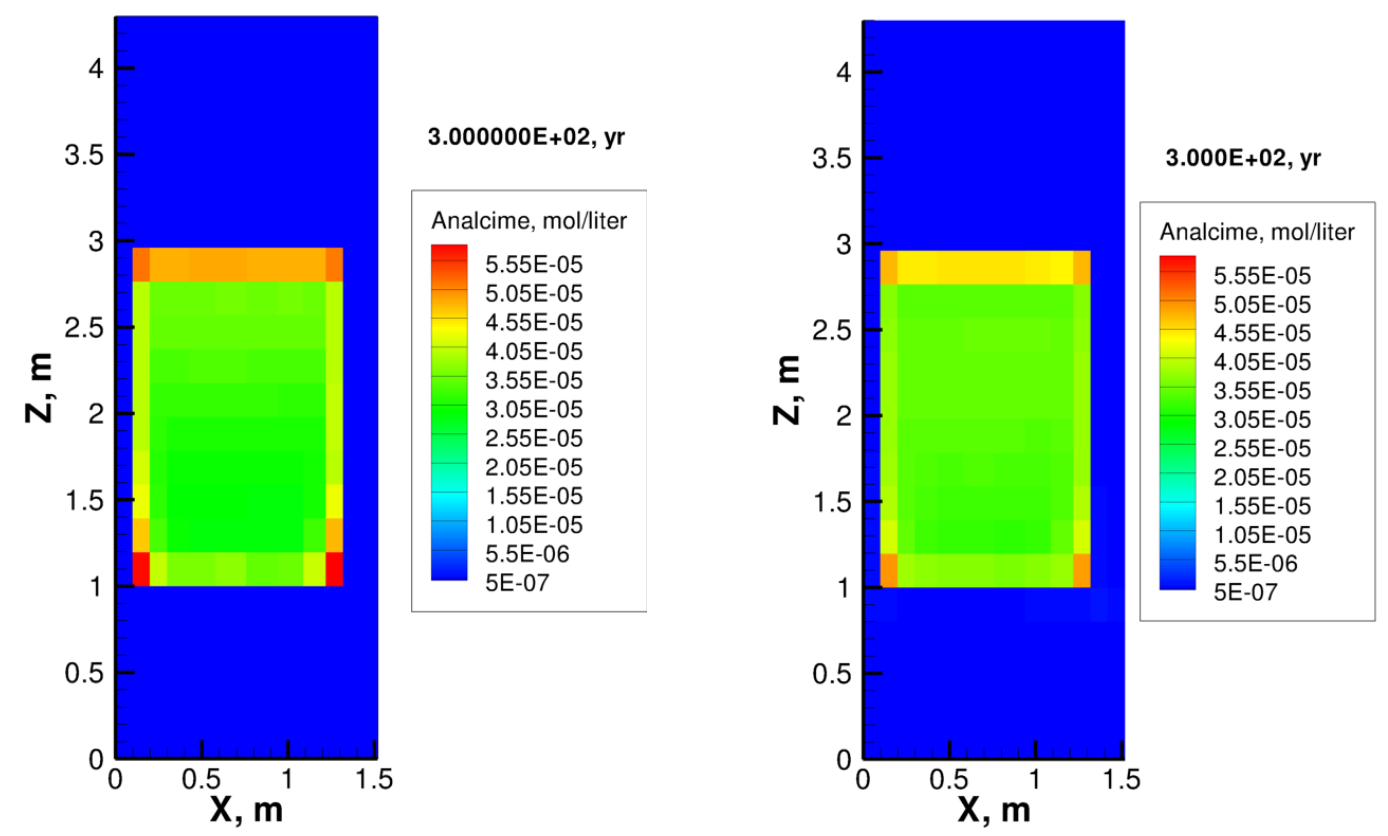

Figure 7.12. Comparison of Analcime Precipitated at 300 Years Predicted by STOMP (left) and STORM (right) 2-D Models 


\subsection{Summary of Near-Field Modeling}

The STORM code traditionally has been used to conduct near-field simulations for the IDF PA. A simulation using LAWA44 glass was used to benchmark STORM against an updated version of the STOMP code with the ECKEChem reactive transport code, which is currently being re-validated as safety software.

Results for STOMP and STORM compare well, despite the fact that each code uses different reactive transport schemes. STORM uses a global implicit solution scheme in which the transport and reaction equations are solved simultaneously. STOMP uses an operator split solution scheme in which the transport equations and reaction equations are solved sequentially. The operator split solution scheme used by STOMP requires smaller time steps in order to achieve an accurate solution for the benchmark test case, and results in a significantly longer run time than STORM. Work in FY 2012 should include a task to determine whether the efficiency of the operator split reactive-transport scheme in STOMP can be improved.

The serial version of STOMP was used to obtain these benchmarking results. In order to compare STOMP against the full simulation presented in the 2005 PA in a reasonable amount of time, the parallel version of STOMP is needed. All of the modifications made to the serial version of STOMP in FY 2011 are planned to be made on a parallel version of STOMP in FY 2012. 


\subsection{Summary}

A combined experimental and computational approach is being used to predict the long-term performance of ILAW glass in a near-surface disposal facility. This report highlights the activities toward this end that were performed at PNNL during FY 2011. In brief, the STORM code has traditionally been used to conduct near-field simulations for the IDF PA. The input parameters for a base-case simulation using LAWA44 glass were used to benchmark STORM against an updated version of the STOMP code with the ECKEChem reactive transport code, which is being validated as safety software. Results for STOMP and STORM compare well, despite the fact that each code uses different reactive transport schemes. The operator split solution scheme used by STOMP requires smaller time steps to achieve an accurate solution for the benchmark test case, and results in a significantly longer run time than STORM. A parallel-processing version of STOMP will be needed before PA calculations can be performed.

In addition to improving the continuum scale simulations of glass weathering, geochemical modeling was performed on 128 ILAW glass compositions that have been undergoing long-term weathering experiments using the PCT method. These results suggest that of the 128 glass samples that were modeled, a secondary-phase reaction network previously developed for ILAW glass sample LAWA44 produced good model fits for the major glass components. Notable exceptions were $\mathrm{K}$ and Li. This is probably because of the lack of thermodynamic data for phases that are enriched in $\mathrm{K}$ or Li. For example, in the absence of Li significantly better model fits for $\mathrm{K}$ were attained assuming $\mathrm{K}$ concentrations were controlled by the solubility of a hypothetical K-analcime phase. On the other hand, modeling Li proved to be problematic due to an inability to identify the specific composition(s) of Li-containing phase(s) and a lack of thermodynamic data for such phases. For glass samples that contained relatively high concentrations of $\mathrm{Ca}$ and $\mathrm{Li}$ and relatively low concentrations of $\mathrm{Na}$, it was determined that monohydrocalcite $\left(\mathrm{CaCO}_{3} \cdot \mathrm{H}_{2} \mathrm{O}\right)$ and/or gyrolite $\left(\mathrm{Ca}_{2} \mathrm{Si}_{3} \mathrm{O}_{7}(\mathrm{OH})_{2} \cdot 1.5 \mathrm{H}_{2} \mathrm{O}\right)$ could potentially control Ca concentrations rather than calcite, as was the case for more typical glass compositions. Better model fits of the experimental PCT data for these types of glass could be obtained by suppressing gibbsite precipitation and assuming that $\mathrm{Al}$ concentrations were controlled by boehmite, diaspore or kaolinite (depending upon the specific sample). Developing a consistent reaction network of secondary phases for these types of glasses was not feasible, probably due to the inability to identify and model the phase(s) that control Li concentrations and the lack of actual thermodynamic data for K-chabazite

In addition to the geochemical and STOMP code simulations, advances in the development of the MC simulations have resulted in the addition of condensation processes at the glass-water interface. These condensation reactions are the precursor steps to alteration-phase development. In support of the MC simulations, additional characterization of the altered glass surface (hydrated surface layer) was performed with a combination of MAS NMR, Raman, and X-ray photoelectron spectroscopy techniques. The remnant of the gel layer on the reacted ILAW glasses could not be characterized with Raman spectroscopy because it was too thin. Although the Raman analyses of unreacted and reacted ILAW glasses were unsuccessful in providing the detailed information required for MC modeling, XPS analyses provide significant information on the composition of the surface of reacted ILAW glasses. Preliminary application of techniques with greater surface sensitivity, such as XPS, was found to be more promising in characterizing the remnant of the gel layer and the underlying glass. In addition to XPS measurements, MAS-NMR results of reacted and unreacted glasses have been providing some interesting results. Analysis of these results will continue in FY 2012. 
Pressurized unsaturated flow experiments are ongoing on the new ILAW glass compositions. The PUF tests will be terminated in FY 2012 and the solid-phase characterization results will be included in future geochemical modeling simulations. 


\subsection{References}

Aagaard P and HC Helgeson. 1982. "Thermodynamic and Kinetic Constraints on Reaction Rates among Minerals and Aqueous Solutions. I. Theoretical Considerations." American Journal of Science 282:237-285.

Abraitis PK, FR Livens, JE Monteith, JS Small, DP Trivedi, DJ Vaughan and RA Wogelius. 2000. "The Kinetics and Mechanisms of Simulated British Magnox Waste Glass Dissolution as a Function of pH, Silicic Acid Activity, and Time in Low-Temperature Aqueous Systems.” Applied Geochemistry 15:1399-1416.

ASTM-American Society for Testing and Materials. 2008. Standard Test Methods for Determining Chemical Durability of Nuclear, Hazardous, and Mixed Waste Glasses and Multiphase Glass Ceramics: The Product Consistency Test (PCT). ASTM C1285-02, West Conshohocken, Pennsylvania.

ASTM-American Society for Testing and Materials. 2010. Standard Practice for Measurement of the Glass Dissolution Rate Using the Single-Pass Flow-Through Test Method. ASTM C1662-10, West Conshohocken, Pennsylvania.

Bacon DH and BP McGrail. 2005. Waste Form Release Calculations for the 2005 Integrated Disposal Facility Performance Assessment. PNNL-15198, Pacific Northwest National Laboratory, Richland, Washington.

Bacon DH and EM Pierce. 2010. Sensitivity Analysis of Kinetic Rate-Law Parameters Used to Simulate Long-Term Weathering of ILAW Glass. PNNL-19472, Pacific Northwest National Laboratory, Richland, Washington.

Bacon DH, MD White, and BP McGrail. 2004. Subsurface Transport Over Reactive Multiphases (STORM): A Parallel, Coupled, Nonisothermal Multiphase Flow, Reactive Transport, and Porous Medium Alteration Simulator, Version 3.0, User's Guide. PNNL-14783, Pacific Northwest National Laboratory, Richland, Washington.

Barkatt A, BC Gibson, PB Macedo, CJ Montrose, W Sousanpour, A Barkatt, MA Boroomand, V Rogers, and M Penafiel. 1986. "Mechanisms of Defense Waste Glass Dissolution." Nuclear Technology $73: 140-164$.

Bergeron, B, L Galoisy, P Jollivet, F. Angeli, T. Charpentier, G. Calas, and S. Gin. 2010. "First Investigations of the Influence of IVB Elements (Ti, Zr, and Hf) on the Chemical Durability of SodaLime Borosilicate Glasses.” Journal of Non-Crystalline Solids 356:2315-2322.

Bethke CM and S Yeakel. 2009. The Geochemist's Workbench ${ }^{\circledR}$, Release 8.0, Reference Manual. Hydrogeology Program, University of Illinois, Urbana, Illinois.

Bourcier WL. 1991. “Overview of Chemical Modeling of Nuclear Waste Glass Dissolution.” Material Research Symposium Proceedings 212:3-17. 
Bourcier WL. 1994. "Waste Glass Corrosion Modeling: Comparison with Experimental Results." Materials Research Symposium Proceedings 333:69-81.

Bunker BC, DR Tallant, TJ Headley, GL Turner and RJ Kirkpatrick. 1988. "The Structure of Leached Sodium Borosilicate Glass.” Physics and Chemistry of Glasses 29(3):106-120.

Campbell GS. 1985. Soil Physics with BASIC: Transport Models for Soil-Plant Systems. Elsevier, New York.

Carman PC. 1937. "Fluid Flow through a Granular Bed." Transactions of the Institution of Chemical Engineers (London) 15:150-156.

Casey WH and BC Bunker. 1990. "Leaching of Mineral and Glass Surfaces During Dissolution." Mineral-Water Interface Geochemistry. MF Hochella, Jr. and AF White (eds.), Mineralogical Society of America 23:397-426.

Certa PJ and MN Wells. 2010. River Protection Project System Plan. ORP-11242, Rev. 5, U.S. Department of Energy, Office of River Protection, Richland, Washington.

Chen Y, DW Engel, BP McGrail, and KS Lessor. 1995. AREST-CT V1.0 Software Verification. PNL-10692, Pacific Northwest Laboratory, Richland, Washington.

Chen Y, BP McGrail, and DW Engel. 1997. "Source-Term Analysis for Hanford Low-Activity Tank Waste using the Reaction-Transport Code AREST-CT.” In Scientific Basis for Nuclear Waste Management XX, Pittsburgh, Pennsylvania.

Cho HR, C Walther, J Rothe, V Neck, MA Denecke, K Dardenne, and T Fanghanel. 2005. "Combined LIBD and XAFS Investigation of the Formation and Structure of $\mathrm{Zr}(\mathrm{IV})$ Colloids." Analytical and Bioanalytical Chemistry 383:28-40.

Cunnane JC, JK Bates, and CR Bradley. 1994a. High-level Borosilicate Waste Glass: A Compendium of Corrosion Characteristics, Vol. 1. DOE-EM-0177, U.S. Department of Energy, Office of Waste Management, Springfield, Virginia.

Cunnane JC, JK Bates, and CR Bradley. 1994b. High-Level Waste Borosilicate Glass: A Compendium of Corrosion Characteristics, Vol. 2. DOE-EM-0177, U.S. Department of Energy, Office of Waste Management, Springfield, Virginia.

Daveler SA and TJ Wolery. 1992. EQPT, A Data File Preprocessor for the EQ3/6 Software Package: User's Guide and Related Documentation (Version 7.0). UCRL-MA-110662 PT II, Lawrence Livermore National Laboratory, Livermore, California.

Davis LL, JG Darab, M Qian, D Zhao, CS Palenik, H Li, DM Strachan, and L Li. 2003. "Hafnium in Peralkaline and Peraluminous Boro-aluminosilicate Glass and Glass Sub-Components: A Solubility Study." Journal of Non-Crystalline Solids 328:102-122.

Devreux F, A Ledieu, P Barboux, and Y Minet. 2004. "Leaching of Borosilicate Glasses. II. Model and Monte-Carlo Simulations." Journal of Non-Crystalline Solids 343:13-25. 
DOE Order 414.1C. 2005. “Quality Assurance.” U.S. Department of Energy, Washington, D.C.

Doremus RH. 1975. "Interdiffusion of Hydrogen and Alkali Ions in a Glass Surface." Journal of NonCrystalline Solids 19:137-144.

Fang YL, GT Yeh, and WD Burgos. 2003. "A General Paradigm to Model Reaction-based Biogeochemical Processes in Batch Systems." Water Resources Research 39(4): Art. No. 1083.

Farnsworth RK, MKW Chan, and SC Slate. 1985. "The Effect of Radial Temperature Gradients on Glass Fracture in Simulated High-Level Waste Canisters." Materials Research Society Symposium Proceedings 44:831-838.

Fayer MJ and JE Szecsody. 2004. Recharge Data Package for the 2005 Integrated Disposal Facility Performance Assessment. PNNL-14744, Pacific Northwest National Laboratory, Richland, Washington.

Fox LE. 1988. "The Solubility of Colloidal Ferric Hydroxide and its Relevance to Iron Concentrations in River Water." Geochimica et Cosmochimica Acta 53(3):771-777.

Freedman VL and MD White. 2007. STOMP Software Test Plan. PNNL-SA-54022, Pacific Northwest National Laboratory, Richland, Washington.

Grambow B. 1985. “A General Rate Equation For Nuclear Waste Glass Corrosion.” In: Materials Research Society Symposium Proceedings 44:15-27.

Hench LL, DE Clark, and AB Harker. 1986. "Nuclear Waste Solids.” Journal of Materials Science 21:1457-1478.

Icenhower JP, S Samson, A Luttge and BP McGrail. 2004. "Towards a Consistent Rate Law: Glass Corrosion Kinetics Near Saturation." In Energy, Waste, and the Environment: A Geochemical Perspective, R Giere and P Stille (eds.), Geological Society of London 236:579-594.

Jantzen CM, DI Kaplan, NE Bibler, DK Peeler and MJ Plodinec. 2008. "Performance of a Buried Radioactive High-Level Waste (HLW) Glass after 24 Years." Journal of Nuclear Materials 378:244-256.

Kerisit S and EM Pierce. 2011. "Monte Carlo Simulations of the Dissolution of Borosilicate and Aluminoborosilicate Glasses in Dilute Conditions." Geochimica et Cosmochimica Acta 75:5296-5309.

Khaleel R. 2004. Far-Field Hydrology Data Package for the Integrated Disposal Facility Performance Assessment. RPP-20621, Rev. 0, CH2M HILL Hanford Group, Inc., Richland, Washington.

Krupka KM, RJ Serne, and DI Kaplan. 2004. Geochemical Data Package for the 2005 Hanford Integrated Disposal Facility Performance Assessment. PNNL-13037 Rev. 2, Pacific Northwest National Laboratory, Richland, Washington.

Ledieu A, F Devreux, P Barboux, and Y Minet. 2006. "Contribution of Monte Carlo Modeling to Understanding the Alteration of Nuclear Glasses by Water." Nuclear Science Engineering 153:285-300. 
Levenberg K. 1944. "A Method for the Solution of Certain Problems in Least Squares." Quarterly Journal of Applied Mathematics 2:164-168.

Lobanova M, L Maurer, P Barboux, F Devreux, and Y Minet. 2001. "Monte Carlo Modelling of Glass Dissolution: Comparison with Experiments." Materials Research Society Symposium Proceedings: Scientific Basis for Nuclear Waste Management XXIV, August 27-31, 2000, Sydney, Australia, KP Hart and GR Lumpkin (eds.), 663:237-245, Materials Research Society, Warrendale, Pennsylvania.

Mann FM, KC Burgard, WR Root, RJ Puigh, SH Finfrock, R Khaleel, DH Bacon, EJ Freeman, BP McGrail, SK Wurstner, and PE Lamont. 2001. Hanford Immobilized Low-Activity Waste Performance Assessment: 2001 Version. DOE/ORP-2000-24 Rev. 0, U.S. Department of Energy, Office of River Protection, Richland, Washington.

Mann FM, RJ Puigh, II, CR Eiholzer, Y Chen, NW Kline, AH Lu, BP McGrail, PD Rittmann, GF Williamson, NR Brown, and PE LaMont. 1998. Hanford Immobilized Low Activity Tank Waste Performance Assessment. DOE/RL-97-69 Rev. B, Project Hanford Management Contractor, Richland, Washington.

McGrail BP, WL Ebert, AJ Bakel and DK Peeler. 1997. "Measurement of Kinetic Rate Law Parameters on a Na-Ca-Al Borosilicate Glass for Low-Activity Waste." Journal of Nuclear Materials 249(2-3):175-189.

McGrail BP, DH Bacon, WL Ebert and KP Saripalli. 1998. A Strategy to Conduct an Analysis of the Long-Term Performance of Low-Activity Waste Glass in a Shallow Subsurface Disposal System at Hanford. PNNL-11834, Pacific Northwest National Laboratory, Richland, Washington.

McGrail BP, PF Martin, HT Schaef, CW Lindenmeier, and AT Owen. 2000a. "Glass/Ceramic Interactions in The Can-in-Canister Configuration for Disposal of Excess Weapons Plutonium." In Material Research Symposium Proceedings Scientific Basis for Nuclear Waste; Management XXIII, 2000; RW Smith and DW Shoesmith (eds), Material Research Society, pp. 345-352.

McGrail BP, JP Icenhower, PF Martin, DR Rector, HT Schaef, EA Rodriguez, and JL Steele. 2000b. Low-Activity Waste Glass Studies: FY2000 Summary Report. PNNL-13381, Pacific Northwest National Laboratory, Richland, Washington.

McGrail BP, DH Bacon, WL Ebert, and KP Saripalli. 2000c. A Strategy to Conduct an Analysis of the Long-Term Performance of Low-Activity Waste Glass in a Shallow Subsurface Disposal System at Hanford. PNNL-11834 Rev. 1, Pacific Northwest National Laboratory, Richland, Washington.

McGrail BP, DH Bacon, JP Icenhower, FM Mann, RJ Puigh, HT Schaef, and SV Mattigod. 2001a. "Near-Field Performance Assessment for a Low-Activity Waste Glass Disposal System: Laboratory Testing to Modeling Results." Journal of Nuclear Materials 298:95-111.

McGrail BP, JP Icenhower, PF Martin, HT Schaef, MJ O’Hara, EA Rodriguez, and JL Steele. 2001b. Waste Form Release Data Package for the 2001 Immobilized Low-Activity Waste Performance Assessment. PNNL-13043, Rev. 2, Pacific Northwest National Laboratory, Richland, Washington.

McGrail BP, DH Bacon, RJ Serne, and EM Pierce. 2003. A Strategy to Assess Performance of Selected Low-Activity Waste Forms in an Integrated Disposal Facility. PNNL-14362, Pacific Northwest National Laboratory, Richland, Washington. 
Meyer PD, KP Saripalli, and VL Freedman. 2004. Near-Field Hydrology Data Package for the Integrated Disposal Facility 2005 Performance Assessment. PNNL-14700, Pacific Northwest National Laboratory, Richland, Washington.

Nagy KL and AC Lasaga. 1993. "Letter: Simultaneous Precipitation Kinetics of Kaolinite and Gibbsite at $80^{\circ} \mathrm{C}$ and $\mathrm{pH}$ 3." Geochimica et Cosmochimica Acta 57:4329-4335.

Nagy KL. 1995. "Dissolution and Precipitation Kinetics of Sheet Silicates." Chapter 5 in Chemical Weathering Rates of Silicate Minerals. Reviews in Mineralogy, AF White and SL Brantley (eds.), 31:173-233. Mineralogical Society of America, Washington, D.C.

Nichols WE and MD White. 2007a. Project Management Plan for Subsurface Transport Over Multiple Phases (STOMP) Software Maintenance and Development. PNNL-SA-54024, Pacific Northwest National Laboratory, Richland, Washington.

Nichols WE and MD White. 2007b. Software Design Description For Subsurface Transport Over Multiple Phases (STOMP) Software. PNNL-SA-54078, Pacific Northwest National Laboratory, Richland, Washington.

NQA-1-2000. 2001. Quality Assurance Requirements for Nuclear Facility Applications. The American Society of Mechanical Engineers, New York, New York.

Papathanassiu A, IS Muller, M Brandys, K Gilbo, A Barkatt, I Joseph, and IL Pegg. 2011. ILAW Glass Testing for Disposal at IDF: Phase 1 Testing. VSL-11R2270-1, Vitreous State Laboratory, The Catholic University of America, Washington, D.C.

Peters RD and SC Slate. 1981. "Fracturing of Simulated High-Level Waste Canisters." Nuclear Engineering Design 67:425-445.

Pierce EM, BP McGrail, EA Rodriguez, HT Schaef, KP Saripalli, RJ Serne, KM Krupka, PF Martin, SR Baum, KN Geiszler, LR Reed, and WJ Shaw. 2004a. Waste Form Release Data Package for the 2005 Integrated Disposal Facility Performance Assessment. PNNL-14805, Pacific Northwest National Laboratory, Richland, Washington.

Pierce EM, BP McGrail, EA Rodriguez, DM Wellman, LR Reed, DH Bacon, HT Schaef, and SR Baum. 2004b. Laboratory Testing of Bulk Vitrified Low-Activity Waste Form to Support the 2005 Integrated Disposal Facility Performance Assessment. PNNL-15126, Pacific Northwest National Laboratory, Richland, Washington.

Pierce EM, JP Icenhower, RJ Serne, and J Catalano. 2005. "Experimental Determination of $\mathrm{UO}_{2}(\mathrm{cr})$ Dissolution Kinetics: Effects of Solution Saturation State and pH." Journal of Nuclear Materials 345:206-218.

Pierce EM, BP McGrail, J Marra, PF Martin, BW Arey, and KN Geiszler. 2007. “Accelerated Weathering of a High-Level and Pu-bearing Lanthanide Borosilicate Waste Glass in a Can-in-Canister Configuration." Applied Geochemistry 22:1841-1859. 
Pierce EM, EL Richards, AM Davis, LR Reed and EA Rodriguez. 2008a. "Aluminoborosilicate Waste Glass Dissolution under Alkaline Conditions at $40^{\circ} \mathrm{C}$ : Implications for a Chemical Affinity-based Rate Equation." Environmental Chemistry 5:1-13.

Pierce EM, EA Rodriguez, LJ Calligan, WJ Shaw, and BP McGrail. 2008b. "An Experimental Study of the Dissolution Rates of Simulated Aluminoborosilicate Waste Glasses as a Function of $\mathrm{pH}$ and Temperature under Dilute Conditions.” Applied Geochemistry 23:2559-2573.

Pierce EM, LR Reed, WJ Shaw, BP McGrail, JP Icenhower, CF Windisch, EA Cordova, and J Broady. 2010a. "Experimental Determination of the Effect of the Ratio of B/Al on Glass Dissolution Along the Nepheline $\left(\mathrm{NaAlSiO}_{4}\right)$ - Malinkoite $\left(\mathrm{NaBSiO}_{4}\right)$ Join." Geochimica et Cosmochimica Acta 74:2634-2654.

Pierce EM, DH Bacon, SN Kerisit, CF Windisch, KJ Cantrell, MM Valenta, SD Burton, RJ Serne, SV Mattigod. 2010b. Integrated Disposal Facility Glass Testing FY2010 Summary Report.

PNNL-19736, Pacific Northwest National Laboratory, Richland, Washington.

Puigh RJ. 2004. Facility Data for the Hanford Integrated Disposal Facility Performance Assessment. RPP-20691, Rev. 0, Fluor Government Group, Richland, Washington.

Rajh T, ZV Saponjic, and OI Micic. 1992. "Reactions of Hydrous Titanium Oxide Colloids with Strong Oxidizing Agents.” Langmuir 8:1265-1270.

Richards LA. 1931. "Capillary Conduction of Liquids through Porous Mediums.” Physics 1:318-333.

Savage B, D Rochelle, Y Moore, A Milodowski, K Bateman, D Bailey, and M Mihara. 2001. "Analcime Reactions at $25-90^{\circ} \mathrm{C}$ in Hyperalkaline Fluids." Mineralogical Magazine 65(5):571-587.

Serne RJ, JL Conca, VL LeGore, KJ Cantrell, CW Lindenmeier, JA Campbell, JE Amonette, and MI Wood. 1993. Solid-Waste Leach Characteristics and Contaminant-Sediment Interactions.

Volume 1: Batch Leach and Adsorption Tests and Sediment Characterization. PNL-8889 Vol. 1, Pacific Northwest Laboratory, Richland, Washington.

Singh RK and P Webley. 2005. "Adsorption of $\mathrm{N}_{2}, \mathrm{O}_{2}$, and $\mathrm{Sr}$ in Potassium Chabazite." Adsorption 11:173-177.

Small JS, PN Humphrey, TL Johnstone, R Plant, MG Randall and DP Trivedi. 2000. "Results of an Aqueous Source Term Model for a Radiological Risk Assessment of the Drigg LLW Site, UK." In Scientific Basis for Nuclear Waste Management XXIII, Materials Research Society, Boston, Massachusetts.

Strachan DM and TL Croak. 2000. "Compositional Effects on Long-term Dissolution of Borosilicate Glass." Journal of Non-Crystalline Solids 272:22-33. 
Van Iseghem P, M Aetsens, K Lemmens, S Gin, D Deneele, B Grambow, BP McGrail, DM Strachan, G Wicks, and T McMenamin. 2004. "GLAMOR--A Critical Evaluation of the Dissolution Mechanisms of High-level Waste Glasses in Conditions of Relevance for Geological Disposal." In Euradwaste '04: Radioactive Waste Management: Community Policy and Research Initiatives: Proceedings of the Sixth European Commission Conference on the Management and Disposal of Radioactive Waste. C Davies (ed.), March 29-31, Luxembourg. Directorate-General for Research, European Commission, Luxembourg.

Vernaz EY and JL Dussossoy. 1992. "Current State of Knowledge of Nuclear Waste Glass Corrosion Mechanisms - The Case of R7T7 Glass." Applied Geochemistry 1:13-22.

Vernaz E, S Gin, C Jegou, and I Ribet. 2001. "Present Understanding of R7T7 Glass Alteration Kinetics and their Impact on Long-term Behavior Modeling." Journal of Nuclear Materials 298:27-36.

Ward AL, MD White, EJ Freeman, and ZF Zhang. 2005. STOMP Subsurface Transport Over Multiple Phases Version 1.0 Addendum: Sparse Vegetation Evapotranspiration Model for the Water-Air-Energy Operational Mode. PNNL-15465, Pacific Northwest National Laboratory, Richland, Washington.

Werme LO, IK Bjorner, G Bart, HU Zwicky, B Grambow, W Lutze, RC Ewing and C Magrabi. 1990. "Chemical Corrosion of Highly Radioactive Borosilicate Nuclear Waste Glass under Simulated Repository Conditions.” Journal of Materials Research 5(5):1130-1146.

White MD and M Oostrom. 2000. STOMP: Subsurface Transport Over Multiple Phases Version 2.0 Theory Guide. PNNL-12030 UC-2010, Pacific Northwest National Laboratory, Richland, Washington.

White MD and BP McGrail. 2005. STOMP, Subsurface Transport Over Multiple Phases, Version 1.0, Addendum: ECKEChem, Equilibrium-Conservation-Kinetic Equation Chemistry and Reactive Transport. PNNL-15482, Pacific Northwest National Laboratory, Richland, Washington.

White MD and M Oostrom. 2006. STOMP: Subsurface Transport Over Multiple Phases, Version 4.0, User's Guide. PNNL-15782, Pacific Northwest National Laboratory, Richland, Washington.

White MD and VL Freedman. 2007. STOMP Software Configuration Management Plan. PNNL-SA-54023, Pacific Northwest National Laboratory, Richland, Washington.

Windisch Jr CF, EM Pierce, SD Burton, and CC Bovaird. 2011. "Deep-UV Raman Spectroscopic Analysis of Structure and Dissolution Rates of Silica-rich Sodium Borosilicate Glasses." Journal of NonCrystalline Solids 357(10):2170-2177.

Wierenga PJ, MH Young, GW Gee, RG Hills, CT Kincaid, TJ Nicholson, and RE Cady. 1993. Soil Characterization Methods for Unsaturated Low-Level Waste Sites. PNL-8480, Pacific Northwest Laboratory, Richland, Washington.

Wolery TJ and SA Daveler. 1992. EQ6, A Computer Program for Reaction Path Modeling of Aqueous Geochemical Systems: Theoretical Manual, User's Guide and Related Documentation. UCRL-MA-110662 PT IV, Lawrence Livermore National Laboratory, Livermore, California. 
Zhang ZF, VL Freedman, and MD White. 2007. Requirements for STOMP Subsurface Transport Over Multiple Phases. PNNL-SA-54079, Pacific Northwest National Laboratory, Richland, Washington. 
Appendix A

\section{PUF Test Results}




\section{Appendix A}

\section{PUF Test Results}

Table A.1. PUF Results for ORPLF7

\begin{tabular}{|c|c|c|c|c|c|c|c|c|}
\hline Vial \# & $\begin{array}{c}\text { Time } \\
\text { (days) }\end{array}$ & $\begin{array}{c}\mathrm{Al} \\
(\mu \mathrm{g} / \mathrm{L})\end{array}$ & $\begin{array}{c}\mathrm{B} \\
(\mu \mathrm{g} / \mathrm{L})\end{array}$ & $\begin{array}{c}\mathrm{Ca} \\
(\mu \mathrm{g} / \mathrm{L})\end{array}$ & $\begin{array}{c}\mathrm{Cr} \\
(\mu \mathrm{g} / \mathrm{L})\end{array}$ & $\begin{array}{c}\mathrm{Li} \\
(\mu \mathrm{g} / \mathrm{L})\end{array}$ & $\begin{array}{c}\mathrm{K} \\
(\mu \mathrm{g} / \mathrm{L}) \\
\end{array}$ & $\begin{array}{c}\mathrm{Si} \\
(\mu \mathrm{g} / \mathrm{L})\end{array}$ \\
\hline 1 & 1.77 & $5.1 \mathrm{E}+03$ & $2.1 \mathrm{E}+05$ & ND & $3.8 \mathrm{E}+03$ & $1.2 \mathrm{E}+05$ & $7.3 \mathrm{E}+04$ & $2.1 \mathrm{E}+05$ \\
\hline 2 & 3.67 & $1.3 \mathrm{E}+04$ & $1.6 \mathrm{E}+05$ & ND & $2.9 \mathrm{E}+03$ & $9.1 \mathrm{E}+04$ & $1.1 \mathrm{E}+05$ & $1.8 \mathrm{E}+05$ \\
\hline 3 & 5.33 & $1.2 \mathrm{E}+04$ & $1.5 \mathrm{E}+05$ & ND & $2.6 \mathrm{E}+03$ & $9.4 \mathrm{E}+04$ & $6.6 \mathrm{E}+04$ & $2.0 \mathrm{E}+05$ \\
\hline 4 & 7.52 & $1.0 \mathrm{E}+04$ & $1.1 \mathrm{E}+05$ & ND & $1.9 \mathrm{E}+03$ & $8.2 \mathrm{E}+04$ & $6.6 \mathrm{E}+04$ & $1.7 \mathrm{E}+05$ \\
\hline 5 & 10.58 & $9.0 \mathrm{E}+03$ & $9.0 \mathrm{E}+04$ & ND & $1.5 \mathrm{E}+03$ & $6.7 \mathrm{E}+04$ & $9.6 \mathrm{E}+04$ & $1.5 \mathrm{E}+05$ \\
\hline 6 & 12.61 & $7.7 \mathrm{E}+03$ & $9.0 \mathrm{E}+04$ & ND & $1.6 \mathrm{E}+03$ & $6.3 \mathrm{E}+04$ & $9.3 \mathrm{E}+04$ & $1.3 \mathrm{E}+05$ \\
\hline 7 & 14.55 & $6.6 \mathrm{E}+03$ & $5.9 \mathrm{E}+04$ & ND & $1.0 \mathrm{E}+03$ & $4.6 \mathrm{E}+04$ & $3.6 \mathrm{E}+04$ & $1.2 \mathrm{E}+05$ \\
\hline 8 & 17.40 & $5.5 \mathrm{E}+03$ & $7.5 \mathrm{E}+04$ & ND & $1.3 \mathrm{E}+03$ & $5.9 \mathrm{E}+04$ & $1.7 \mathrm{E}+05$ & $1.2 \mathrm{E}+05$ \\
\hline 9 & 19.73 & $4.5 \mathrm{E}+03$ & $8.1 \mathrm{E}+04$ & ND & $1.4 \mathrm{E}+03$ & $6.7 \mathrm{E}+04$ & $1.8 \mathrm{E}+05$ & $1.1 \mathrm{E}+05$ \\
\hline 10 & 21.54 & $6.4 \mathrm{E}+03$ & $8.7 \mathrm{E}+04$ & ND & $1.7 \mathrm{E}+03$ & $6.2 \mathrm{E}+04$ & $2.1 \mathrm{E}+05$ & $1.3 \mathrm{E}+05$ \\
\hline 11 & 24.41 & $5.8 \mathrm{E}+03$ & $6.8 \mathrm{E}+04$ & ND & $1.4 \mathrm{E}+03$ & $5.0 \mathrm{E}+04$ & $1.4 \mathrm{E}+05$ & $1.1 \mathrm{E}+05$ \\
\hline 12 & 26.40 & $5.7 \mathrm{E}+03$ & $8.6 \mathrm{E}+04$ & ND & $1.7 \mathrm{E}+03$ & $6.4 \mathrm{E}+04$ & $1.9 \mathrm{E}+05$ & $1.1 \mathrm{E}+05$ \\
\hline 13 & 28.63 & $5.2 \mathrm{E}+03$ & $6.2 \mathrm{E}+04$ & ND & $1.3 \mathrm{E}+03$ & $5.0 \mathrm{E}+04$ & $1.8 \mathrm{E}+05$ & $1.0 \mathrm{E}+05$ \\
\hline 14 & 31.40 & $5.8 \mathrm{E}+03$ & $6.4 \mathrm{E}+04$ & ND & $1.5 \mathrm{E}+03$ & $4.7 \mathrm{E}+04$ & $1.8 \mathrm{E}+05$ & $1.1 \mathrm{E}+05$ \\
\hline 15 & 33.47 & $5.8 \mathrm{E}+03$ & $6.9 \mathrm{E}+04$ & ND & $1.8 \mathrm{E}+03$ & $5.2 \mathrm{E}+04$ & $2.4 \mathrm{E}+05$ & $1.1 \mathrm{E}+05$ \\
\hline 16 & 35.48 & $6.0 \mathrm{E}+03$ & $5.8 \mathrm{E}+04$ & ND & $1.6 \mathrm{E}+03$ & $4.5 \mathrm{E}+04$ & $1.8 \mathrm{E}+05$ & $1.1 \mathrm{E}+05$ \\
\hline 17 & 38.69 & $8.8 \mathrm{E}+03$ & $4.1 \mathrm{E}+04$ & ND & $1.0 \mathrm{E}+03$ & $3.9 \mathrm{E}+04$ & ND & $1.3 \mathrm{E}+05$ \\
\hline 18 & 40.56 & $8.6 \mathrm{E}+03$ & $2.9 \mathrm{E}+04$ & ND & ND & $3.2 \mathrm{E}+04$ & $1.3 \mathrm{E}+05$ & $7.6 \mathrm{E}+04$ \\
\hline 19 & 42.51 & $4.6 \mathrm{E}+03$ & $4.2 \mathrm{E}+04$ & ND & $8.8 \mathrm{E}+02$ & $4.4 \mathrm{E}+04$ & $1.2 \mathrm{E}+05$ & $7.6 \mathrm{E}+04$ \\
\hline 20 & 45.65 & $5.3 \mathrm{E}+03$ & $3.6 \mathrm{E}+04$ & ND & $1.0 \mathrm{E}+03$ & $2.5 \mathrm{E}+04$ & $8.7 \mathrm{E}+04$ & $7.0 \mathrm{E}+04$ \\
\hline 21 & 47.48 & $5.4 \mathrm{E}+03$ & $3.3 \mathrm{E}+04$ & ND & $9.5 \mathrm{E}+02$ & $2.3 \mathrm{E}+04$ & $7.4 \mathrm{E}+04$ & $6.7 \mathrm{E}+04$ \\
\hline 22 & 49.63 & $5.7 \mathrm{E}+03$ & $2.6 \mathrm{E}+04$ & ND & $6.9 \mathrm{E}+02$ & $1.7 \mathrm{E}+04$ & $9.4 \mathrm{E}+04$ & $6.3 \mathrm{E}+04$ \\
\hline 23 & 52.41 & $5.6 \mathrm{E}+03$ & $2.4 \mathrm{E}+04$ & ND & $7.0 \mathrm{E}+02$ & $1.7 \mathrm{E}+04$ & $4.9 \mathrm{E}+04$ & $6.1 \mathrm{E}+04$ \\
\hline 24 & 54.51 & $5.7 \mathrm{E}+03$ & $2.5 \mathrm{E}+04$ & ND & $8.6 \mathrm{E}+02$ & $1.8 \mathrm{E}+04$ & $1.2 \mathrm{E}+05$ & $6.3 \mathrm{E}+04$ \\
\hline 25 & 56.41 & $6.6 \mathrm{E}+03$ & $3.1 \mathrm{E}+04$ & ND & $1.1 \mathrm{E}+03$ & $2.3 \mathrm{E}+04$ & $1.7 \mathrm{E}+05$ & $7.2 \mathrm{E}+04$ \\
\hline 26 & 59.60 & $5.4 \mathrm{E}+03$ & $4.2 \mathrm{E}+04$ & ND & $1.5 \mathrm{E}+03$ & $3.2 \mathrm{E}+04$ & $1.8 \mathrm{E}+05$ & $8.7 \mathrm{E}+04$ \\
\hline 27 & 61.42 & $6.3 \mathrm{E}+03$ & $4.6 \mathrm{E}+04$ & ND & $1.3 \mathrm{E}+03$ & $4.4 \mathrm{E}+04$ & $1.3 \mathrm{E}+05$ & $1.2 \mathrm{E}+05$ \\
\hline 28 & 63.61 & $7.2 \mathrm{E}+03$ & $3.5 \mathrm{E}+04$ & $1.1 \mathrm{E}+04$ & $8.5 \mathrm{E}+02$ & $3.8 \mathrm{E}+04$ & $2.2 \mathrm{E}+05$ & $1.1 \mathrm{E}+05$ \\
\hline 29 & 66.64 & $9.7 \mathrm{E}+03$ & $2.8 \mathrm{E}+04$ & ND & $5.9 \mathrm{E}+02$ & $3.0 \mathrm{E}+04$ & $2.3 \mathrm{E}+05$ & $1.0 \mathrm{E}+05$ \\
\hline 30 & 71.54 & $2.1 \mathrm{E}+04$ & $2.6 \mathrm{E}+04$ & ND & ND & $2.8 \mathrm{E}+04$ & $4.1 \mathrm{E}+05$ & $1.0 \mathrm{E}+05$ \\
\hline 31 & 71.57 & $9.8 \mathrm{E}+03$ & $1.8 \mathrm{E}+04$ & ND & ND & $2.2 \mathrm{E}+04$ & $4.2 \mathrm{E}+04$ & $7.2 \mathrm{E}+04$ \\
\hline 32 & 73.56 & $6.8 \mathrm{E}+03$ & $1.3 \mathrm{E}+04$ & ND & ND & $1.4 \mathrm{E}+04$ & $6.6 \mathrm{E}+04$ & $5.3 \mathrm{E}+04$ \\
\hline 33 & 75.39 & $4.6 \mathrm{E}+03$ & $1.5 \mathrm{E}+04$ & ND & ND & $1.4 \mathrm{E}+04$ & $5.3 \mathrm{E}+04$ & $4.9 \mathrm{E}+04$ \\
\hline 34 & 77.54 & $4.4 \mathrm{E}+03$ & $2.0 \mathrm{E}+04$ & ND & ND & $1.6 \mathrm{E}+04$ & $4.8 \mathrm{E}+04$ & $5.3 \mathrm{E}+04$ \\
\hline
\end{tabular}


Table A.1. (contd)

\begin{tabular}{|c|c|c|c|c|c|c|c|c|}
\hline Vial \# & $\begin{array}{l}\text { Time } \\
\text { (days) }\end{array}$ & $\begin{array}{c}\mathrm{Al} \\
(\mu \mathrm{g} / \mathrm{L})\end{array}$ & $\begin{array}{c}\text { B } \\
(\mu \mathrm{g} / \mathrm{L})\end{array}$ & $\begin{array}{c}\mathrm{Ca} \\
(\mu \mathrm{g} / \mathrm{L})\end{array}$ & $\begin{array}{c}\mathrm{Cr} \\
(\mu \mathrm{g} / \mathrm{L})\end{array}$ & $\begin{array}{c}\mathrm{Li} \\
(\mu \mathrm{g} / \mathrm{L})\end{array}$ & $\begin{array}{c}\mathrm{K} \\
(\mu \mathrm{g} / \mathrm{L})\end{array}$ & $\begin{array}{c}\mathrm{Si} \\
(\mu \mathrm{g} / \mathrm{L})\end{array}$ \\
\hline 35 & 80.60 & $3.7 \mathrm{E}+03$ & $2.1 \mathrm{E}+04$ & ND & $7.1 \mathrm{E}+02$ & $1.5 \mathrm{E}+04$ & $9.8 \mathrm{E}+04$ & $5.1 \mathrm{E}+04$ \\
\hline 36 & 82.56 & $3.9 \mathrm{E}+03$ & $2.2 \mathrm{E}+04$ & ND & $6.9 \mathrm{E}+02$ & $1.5 \mathrm{E}+04$ & $4.2 \mathrm{E}+04$ & $5.2 \mathrm{E}+04$ \\
\hline 37 & 84.39 & $4.0 \mathrm{E}+03$ & $2.7 \mathrm{E}+04$ & ND & $1.1 \mathrm{E}+03$ & $1.8 \mathrm{E}+04$ & $1.3 \mathrm{E}+05$ & $5.4 \mathrm{E}+04$ \\
\hline 38 & 88.79 & $3.5 \mathrm{E}+03$ & $3.7 \mathrm{E}+04$ & ND & $1.4 \mathrm{E}+03$ & $2.3 \mathrm{E}+04$ & $2.3 \mathrm{E}+05$ & $5.4 \mathrm{E}+04$ \\
\hline 39 & 94.57 & $3.6 \mathrm{E}+03$ & $3.1 \mathrm{E}+04$ & ND & $1.2 \mathrm{E}+03$ & $1.8 \mathrm{E}+04$ & $1.8 \mathrm{E}+05$ & $5.0 \mathrm{E}+04$ \\
\hline 40 & 97.60 & $3.4 \mathrm{E}+03$ & $3.1 \mathrm{E}+04$ & ND & $1.1 \mathrm{E}+03$ & $1.8 \mathrm{E}+04$ & $2.2 \mathrm{E}+05$ & $5.0 \mathrm{E}+04$ \\
\hline 41 & 101.52 & $4.8 \mathrm{E}+03$ & $3.9 \mathrm{E}+04$ & ND & $1.4 \mathrm{E}+03$ & $2.3 \mathrm{E}+04$ & $2.1 \mathrm{E}+05$ & $6.4 \mathrm{E}+04$ \\
\hline 42 & 105.70 & $4.9 \mathrm{E}+03$ & $4.0 \mathrm{E}+04$ & ND & $1.5 \mathrm{E}+03$ & $2.5 \mathrm{E}+04$ & $1.6 \mathrm{E}+05$ & $6.4 \mathrm{E}+04$ \\
\hline 43 & 109.50 & $4.4 \mathrm{E}+03$ & $4.1 \mathrm{E}+04$ & ND & $1.2 \mathrm{E}+03$ & $2.3 \mathrm{E}+04$ & $2.5 \mathrm{E}+05$ & $6.6 \mathrm{E}+04$ \\
\hline 44 & 111.69 & $5.0 \mathrm{E}+03$ & $5.7 \mathrm{E}+04$ & ND & $1.8 \mathrm{E}+03$ & $3.0 \mathrm{E}+04$ & $2.9 \mathrm{E}+05$ & $7.7 \mathrm{E}+04$ \\
\hline 45 & 117.71 & $4.0 \mathrm{E}+03$ & $4.3 \mathrm{E}+04$ & ND & $1.5 \mathrm{E}+03$ & $2.4 \mathrm{E}+04$ & $1.9 \mathrm{E}+05$ & $6.0 \mathrm{E}+04$ \\
\hline 46 & 122.50 & $1.7 \mathrm{E}+03$ & $1.2 \mathrm{E}+05$ & $2.6 \mathrm{E}+03$ & $3.8 \mathrm{E}+03$ & $7.1 \mathrm{E}+04$ & $2.9 \mathrm{E}+05$ & $1.3 \mathrm{E}+05$ \\
\hline 47 & 125.61 & $3.6 \mathrm{E}+03$ & $7.6 \mathrm{E}+04$ & ND & $2.2 \mathrm{E}+03$ & $5.3 \mathrm{E}+04$ & $1.2 \mathrm{E}+05$ & $1.3 \mathrm{E}+05$ \\
\hline 48 & 129.61 & $4.3 \mathrm{E}+03$ & $5.9 \mathrm{E}+04$ & ND & $1.9 \mathrm{E}+03$ & $4.3 \mathrm{E}+04$ & $1.4 \mathrm{E}+05$ & $9.9 \mathrm{E}+04$ \\
\hline 49 & 132.62 & $4.9 \mathrm{E}+03$ & $5.3 \mathrm{E}+04$ & ND & $1.7 \mathrm{E}+03$ & $4.1 \mathrm{E}+04$ & $1.3 \mathrm{E}+05$ & $9.5 \mathrm{E}+04$ \\
\hline 50 & 137.60 & $4.5 \mathrm{E}+03$ & $4.5 \mathrm{E}+04$ & ND & $1.4 \mathrm{E}+03$ & $3.2 \mathrm{E}+04$ & $1.3 \mathrm{E}+05$ & $8.6 \mathrm{E}+04$ \\
\hline 51 & 140.41 & $4.3 \mathrm{E}+03$ & $4.4 \mathrm{E}+04$ & ND & $1.3 \mathrm{E}+03$ & $3.3 \mathrm{E}+04$ & $9.8 \mathrm{E}+04$ & $8.1 \mathrm{E}+04$ \\
\hline 52 & 143.48 & $3.5 \mathrm{E}+03$ & $3.6 \mathrm{E}+04$ & ND & $1.1 \mathrm{E}+03$ & $3.1 \mathrm{E}+04$ & $1.7 \mathrm{E}+05$ & $7.5 \mathrm{E}+04$ \\
\hline 53 & 146.46 & $4.2 \mathrm{E}+03$ & $3.8 \mathrm{E}+04$ & ND & $1.1 \mathrm{E}+03$ & $2.6 \mathrm{E}+04$ & $1.9 \mathrm{E}+05$ & $6.6 \mathrm{E}+04$ \\
\hline 54 & 150.56 & $3.9 \mathrm{E}+03$ & $3.9 \mathrm{E}+04$ & ND & $1.2 \mathrm{E}+03$ & $2.7 \mathrm{E}+04$ & $1.9 \mathrm{E}+05$ & $6.8 \mathrm{E}+04$ \\
\hline 55 & 154.66 & $4.3 \mathrm{E}+03$ & $4.2 \mathrm{E}+04$ & ND & $1.4 \mathrm{E}+03$ & $2.8 \mathrm{E}+04$ & $1.7 \mathrm{E}+05$ & $7.5 \mathrm{E}+04$ \\
\hline 56 & 157.51 & $3.5 \mathrm{E}+03$ & $4.3 \mathrm{E}+04$ & ND & $1.3 \mathrm{E}+03$ & $2.9 \mathrm{E}+04$ & $1.8 \mathrm{E}+05$ & $6.9 \mathrm{E}+04$ \\
\hline 57 & 161.52 & $3.3 \mathrm{E}+03$ & $4.9 \mathrm{E}+04$ & ND & $1.6 \mathrm{E}+03$ & $3.4 \mathrm{E}+04$ & $1.9 \mathrm{E}+05$ & $6.8 \mathrm{E}+04$ \\
\hline 58 & 164.46 & $3.2 \mathrm{E}+03$ & $3.6 \mathrm{E}+04$ & ND & $1.0 \mathrm{E}+03$ & $2.5 \mathrm{E}+04$ & $9.8 \mathrm{E}+04$ & $6.1 \mathrm{E}+04$ \\
\hline 59 & 168.46 & $3.6 \mathrm{E}+03$ & $4.2 \mathrm{E}+04$ & ND & $1.2 \mathrm{E}+03$ & $2.8 \mathrm{E}+04$ & $1.2 \mathrm{E}+05$ & $7.0 \mathrm{E}+04$ \\
\hline 61 & 175.44 & $4.9 \mathrm{E}+03$ & $4.5 \mathrm{E}+04$ & ND & $1.4 \mathrm{E}+03$ & $2.9 \mathrm{E}+04$ & $1.0 \mathrm{E}+05$ & $7.2 \mathrm{E}+04$ \\
\hline 62 & 178.52 & $3.3 \mathrm{E}+03$ & $2.9 \mathrm{E}+04$ & ND & $8.4 \mathrm{E}+02$ & $2.0 \mathrm{E}+04$ & $2.0 \mathrm{E}+04$ & $5.4 \mathrm{E}+04$ \\
\hline 63 & 180.47 & $2.9 \mathrm{E}+03$ & $4.2 \mathrm{E}+04$ & $3.9 \mathrm{E}+03$ & $1.2 \mathrm{E}+03$ & $2.3 \mathrm{E}+04$ & ND & $4.9 \mathrm{E}+04$ \\
\hline 64 & 182.55 & $3.0 \mathrm{E}+03$ & $3.7 \mathrm{E}+04$ & $2.7 \mathrm{E}+03$ & $8.3 \mathrm{E}+02$ & $2.4 \mathrm{E}+04$ & ND & $5.6 \mathrm{E}+04$ \\
\hline 65 & 185.46 & $2.6 \mathrm{E}+03$ & $3.3 \mathrm{E}+04$ & ND & $7.3 \mathrm{E}+02$ & $2.5 \mathrm{E}+04$ & $2.8 \mathrm{E}+05$ & $6.1 \mathrm{E}+04$ \\
\hline 66 & 187.62 & $4.0 \mathrm{E}+03$ & $2.9 \mathrm{E}+04$ & ND & $8.2 \mathrm{E}+02$ & $2.6 \mathrm{E}+04$ & $7.8 \mathrm{E}+04$ & $7.9 \mathrm{E}+04$ \\
\hline
\end{tabular}


Table A.1. (contd)

\begin{tabular}{|c|c|c|c|c|c|c|c|}
\hline Vial \# & $\begin{array}{l}\text { Time } \\
\text { (days) }\end{array}$ & $\begin{array}{c}\mathrm{Na} \\
(\mu \mathrm{g} / \mathrm{L})\end{array}$ & $\begin{array}{c}\mathrm{V} \\
(\mu \mathrm{g} / \mathrm{L})\end{array}$ & $\begin{array}{c}\mathrm{Zn} \\
(\mu \mathrm{g} / \mathrm{L})\end{array}$ & $\begin{array}{c}\mathrm{Zr} \\
(\mu \mathrm{g} / \mathrm{L})\end{array}$ & $\begin{array}{c}\text { Cs } \\
(\mu \mathrm{g} / \mathrm{L})\end{array}$ & $\begin{array}{c}\mathrm{Re} \\
(\mu \mathrm{g} / \mathrm{L})\end{array}$ \\
\hline 1 & 1.77 & $1.4 \mathrm{E}+06$ & $5.8 \mathrm{E}+04$ & ND & ND & NM & NM \\
\hline 2 & 3.67 & $7.6 \mathrm{E}+05$ & $4.0 \mathrm{E}+04$ & ND & ND & NM & NM \\
\hline 3 & 5.33 & $6.2 \mathrm{E}+05$ & $3.9 \mathrm{E}+04$ & ND & ND & NM & NM \\
\hline 4 & 7.52 & $4.7 \mathrm{E}+05$ & $3.1 \mathrm{E}+04$ & ND & ND & NM & NM \\
\hline 5 & 10.58 & $3.8 \mathrm{E}+05$ & $2.7 \mathrm{E}+04$ & ND & ND & NM & NM \\
\hline 6 & 12.61 & $3.8 \mathrm{E}+05$ & $2.8 \mathrm{E}+04$ & ND & ND & NM & NM \\
\hline 7 & 14.55 & $2.4 \mathrm{E}+05$ & $1.8 \mathrm{E}+04$ & ND & ND & NM & NM \\
\hline 8 & 17.40 & $3.2 \mathrm{E}+05$ & $2.4 \mathrm{E}+04$ & ND & ND & NM & NM \\
\hline 9 & 19.73 & $6.5 \mathrm{E}+05$ & $2.6 \mathrm{E}+04$ & ND & ND & NM & NM \\
\hline 10 & 21.54 & $4.1 \mathrm{E}+05$ & $3.2 \mathrm{E}+04$ & ND & ND & NM & NM \\
\hline 11 & 24.41 & $3.0 \mathrm{E}+05$ & $2.5 \mathrm{E}+04$ & ND & ND & NM & NM \\
\hline 12 & 26.40 & $3.8 \mathrm{E}+05$ & $3.2 \mathrm{E}+04$ & ND & ND & NM & NM \\
\hline 13 & 28.63 & $2.8 \mathrm{E}+05$ & $2.3 \mathrm{E}+04$ & ND & ND & NM & NM \\
\hline 14 & 31.40 & $2.8 \mathrm{E}+05$ & $2.6 \mathrm{E}+04$ & ND & ND & NM & NM \\
\hline 15 & 33.47 & $3.2 \mathrm{E}+05$ & $2.8 \mathrm{E}+04$ & ND & ND & NM & NM \\
\hline 16 & 35.48 & $2.6 \mathrm{E}+05$ & $2.4 \mathrm{E}+04$ & ND & ND & NM & NM \\
\hline 17 & 38.69 & $1.8 \mathrm{E}+05$ & $1.5 \mathrm{E}+04$ & ND & ND & NM & NM \\
\hline 18 & 40.56 & $1.5 \mathrm{E}+05$ & $1.1 \mathrm{E}+04$ & ND & ND & $\mathrm{NM}$ & $\mathrm{NM}$ \\
\hline 19 & 42.51 & $1.6 \mathrm{E}+05$ & $1.3 \mathrm{E}+04$ & ND & ND & $2.3 \mathrm{E}-01$ & $8.1 \mathrm{E}+02$ \\
\hline 20 & 45.65 & $1.6 \mathrm{E}+05$ & $1.3 \mathrm{E}+04$ & ND & ND & $1.7 \mathrm{E}-01$ & $7.7 \mathrm{E}+02$ \\
\hline 21 & 47.48 & $1.5 \mathrm{E}+05$ & $1.2 \mathrm{E}+04$ & ND & ND & $1.7 \mathrm{E}-01$ & $7.6 \mathrm{E}+02$ \\
\hline 22 & 49.63 & $1.1 \mathrm{E}+05$ & $9.3 \mathrm{E}+03$ & ND & ND & $1.6 \mathrm{E}-01$ & $6.0 \mathrm{E}+02$ \\
\hline 23 & 52.41 & $1.1 \mathrm{E}+05$ & $8.8 \mathrm{E}+03$ & ND & ND & $9.4 \mathrm{E}-02$ & $5.8 \mathrm{E}+02$ \\
\hline 24 & 54.51 & $1.2 \mathrm{E}+05$ & $9.6 \mathrm{E}+03$ & ND & ND & $2.0 \mathrm{E}-01$ & $6.6 \mathrm{E}+02$ \\
\hline 25 & 56.41 & $1.5 \mathrm{E}+05$ & $1.3 \mathrm{E}+04$ & ND & ND & $2.5 \mathrm{E}-01$ & $8.1 \mathrm{E}+02$ \\
\hline 26 & 59.60 & $1.8 \mathrm{E}+05$ & $2.2 \mathrm{E}+04$ & ND & ND & $2.3 \mathrm{E}-01$ & $7.5 \mathrm{E}+02$ \\
\hline 27 & 61.42 & $2.1 \mathrm{E}+05$ & $2.2 \mathrm{E}+04$ & ND & ND & $1.8 \mathrm{E}-01$ & $8.6 \mathrm{E}+02$ \\
\hline 28 & 63.61 & $1.9 \mathrm{E}+05$ & $1.3 \mathrm{E}+04$ & ND & ND & $3.0 \mathrm{E}-01$ & $6.4 \mathrm{E}+02$ \\
\hline 29 & 66.64 & $1.5 \mathrm{E}+05$ & $8.7 \mathrm{E}+03$ & ND & ND & 2.4E-01 & $5.0 \mathrm{E}+02$ \\
\hline 30 & 71.54 & $1.5 \mathrm{E}+05$ & $7.3 \mathrm{E}+03$ & ND & ND & 4.1E-01 & $3.5 \mathrm{E}+02$ \\
\hline 31 & 71.57 & $1.0 \mathrm{E}+05$ & $4.4 \mathrm{E}+03$ & ND & ND & $1.6 \mathrm{E}-01$ & $2.1 \mathrm{E}+02$ \\
\hline 32 & 73.56 & $6.9 \mathrm{E}+04$ & $2.5 \mathrm{E}+03$ & ND & ND & $1.1 \mathrm{E}-01$ & $1.4 \mathrm{E}+02$ \\
\hline 33 & 75.39 & $6.6 \mathrm{E}+04$ & $5.2 \mathrm{E}+03$ & ND & ND & 8.7E-02 & $3.3 \mathrm{E}+02$ \\
\hline 34 & 77.54 & $8.4 \mathrm{E}+04$ & $7.5 \mathrm{E}+03$ & ND & ND & 8.8E-02 & $4.6 \mathrm{E}+02$ \\
\hline 35 & 80.60 & $8.4 \mathrm{E}+04$ & $8.1 \mathrm{E}+03$ & ND & ND & $1.1 \mathrm{E}-01$ & $5.6 \mathrm{E}+02$ \\
\hline 36 & 82.56 & $8.7 \mathrm{E}+04$ & $8.7 \mathrm{E}+03$ & ND & ND & 7.1E-02 & $6.5 \mathrm{E}+02$ \\
\hline 37 & 84.39 & $1.2 \mathrm{E}+05$ & $1.1 \mathrm{E}+04$ & ND & ND & $1.4 \mathrm{E}-01$ & $7.6 \mathrm{E}+02$ \\
\hline 38 & 88.79 & $1.5 \mathrm{E}+05$ & $1.5 \mathrm{E}+04$ & ND & ND & 2.4E-01 & $9.4 \mathrm{E}+02$ \\
\hline 39 & 94.57 & $1.2 \mathrm{E}+05$ & $1.3 \mathrm{E}+04$ & ND & ND & $1.8 \mathrm{E}-01$ & $7.6 \mathrm{E}+02$ \\
\hline 40 & 97.60 & $1.2 \mathrm{E}+05$ & $1.3 \mathrm{E}+04$ & ND & ND & 1.9E-01 & $1.0 \mathrm{E}+03$ \\
\hline
\end{tabular}


Table A.1. (contd)

\begin{tabular}{|c|c|c|c|c|c|c|c|}
\hline Vial \# & $\begin{array}{c}\text { Time } \\
\text { (days) }\end{array}$ & $\begin{array}{c}\mathrm{Na} \\
(\mu \mathrm{g} / \mathrm{L})\end{array}$ & $\begin{array}{c}\mathrm{V} \\
(\mu \mathrm{g} / \mathrm{L})\end{array}$ & $\begin{array}{c}\mathrm{Zn} \\
(\mu \mathrm{g} / \mathrm{L})\end{array}$ & $\begin{array}{c}\mathrm{Zr} \\
(\mu \mathrm{g} / \mathrm{L})\end{array}$ & $\begin{array}{c}\text { Cs } \\
(\mu \mathrm{g} / \mathrm{L})\end{array}$ & $\begin{array}{c}\mathrm{Re} \\
(\mu \mathrm{g} / \mathrm{L})\end{array}$ \\
\hline 41 & 101.52 & $1.5 \mathrm{E}+05$ & $1.6 \mathrm{E}+04$ & ND & ND & $1.5 \mathrm{E}-01$ & $9.8 \mathrm{E}+02$ \\
\hline 42 & 105.70 & $1.5 \mathrm{E}+05$ & $1.8 \mathrm{E}+04$ & ND & ND & $1.3 \mathrm{E}-01$ & $9.1 \mathrm{E}+02$ \\
\hline 43 & 109.50 & $1.6 \mathrm{E}+05$ & $1.5 \mathrm{E}+04$ & ND & ND & $1.8 \mathrm{E}-01$ & $9.9 \mathrm{E}+02$ \\
\hline 44 & 111.69 & $1.9 \mathrm{E}+05$ & $2.2 \mathrm{E}+04$ & ND & ND & 2.2E-01 & $1.4 \mathrm{E}+03$ \\
\hline 45 & 117.71 & $1.5 \mathrm{E}+05$ & $1.6 \mathrm{E}+04$ & ND & ND & 2.0E-01 & $1.1 \mathrm{E}+03$ \\
\hline 46 & 122.50 & $2.7 \mathrm{E}+05$ & $5.3 \mathrm{E}+04$ & ND & ND & $1.6 \mathrm{E}-01$ & $2.1 \mathrm{E}+03$ \\
\hline 47 & 125.61 & $2.6 \mathrm{E}+05$ & $3.3 \mathrm{E}+04$ & ND & ND & 7.6E-02 & $1.3 \mathrm{E}+03$ \\
\hline 48 & 129.61 & $2.3 \mathrm{E}+05$ & $2.7 \mathrm{E}+04$ & ND & ND & $1.2 \mathrm{E}-01$ & $1.2 \mathrm{E}+03$ \\
\hline 49 & 132.62 & $2.1 \mathrm{E}+05$ & $2.4 \mathrm{E}+04$ & ND & ND & 9.9E-02 & $1.1 \mathrm{E}+03$ \\
\hline 50 & 137.60 & $1.6 \mathrm{E}+05$ & $2.0 \mathrm{E}+04$ & ND & ND & 7.9E-02 & $9.3 \mathrm{E}+02$ \\
\hline 51 & 140.41 & $1.6 \mathrm{E}+05$ & $2.0 \mathrm{E}+04$ & ND & ND & $9.4 \mathrm{E}-02$ & $8.7 \mathrm{E}+02$ \\
\hline 52 & 143.48 & $1.5 \mathrm{E}+05$ & $1.7 \mathrm{E}+04$ & ND & ND & $1.1 \mathrm{E}-01$ & $7.1 \mathrm{E}+02$ \\
\hline 53 & 146.46 & $1.4 \mathrm{E}+05$ & $1.6 \mathrm{E}+04$ & ND & ND & $1.2 \mathrm{E}-01$ & $7.2 \mathrm{E}+02$ \\
\hline 54 & 150.56 & $1.4 \mathrm{E}+05$ & $1.8 \mathrm{E}+04$ & ND & ND & $1.2 \mathrm{E}-01$ & $8.3 \mathrm{E}+02$ \\
\hline 55 & 154.66 & $1.4 \mathrm{E}+05$ & $1.9 \mathrm{E}+04$ & ND & ND & $1.0 \mathrm{E}-01$ & $8.9 \mathrm{E}+02$ \\
\hline 56 & 157.51 & $1.4 \mathrm{E}+05$ & $1.9 \mathrm{E}+04$ & ND & ND & $1.1 \mathrm{E}-01$ & $9.0 \mathrm{E}+02$ \\
\hline 57 & 161.52 & $1.6 \mathrm{E}+05$ & $2.1 \mathrm{E}+04$ & ND & ND & $1.3 \mathrm{E}-01$ & $1.0 \mathrm{E}+03$ \\
\hline 58 & 164.46 & $1.2 \mathrm{E}+05$ & $1.5 \mathrm{E}+04$ & ND & ND & $1.2 \mathrm{E}-01$ & $7.0 \mathrm{E}+02$ \\
\hline 59 & 168.46 & $1.4 \mathrm{E}+05$ & $1.8 \mathrm{E}+04$ & ND & ND & 2.0E-01 & $8.6 \mathrm{E}+02$ \\
\hline 61 & 175.44 & $1.5 \mathrm{E}+05$ & $1.9 \mathrm{E}+04$ & ND & ND & $1.0 \mathrm{E}-01$ & $9.1 \mathrm{E}+02$ \\
\hline 62 & 178.52 & $9.2 \mathrm{E}+04$ & $1.2 \mathrm{E}+04$ & ND & ND & $6.9 \mathrm{E}-02$ & $5.7 \mathrm{E}+02$ \\
\hline 63 & 180.47 & $1.1 \mathrm{E}+05$ & $2.0 \mathrm{E}+04$ & ND & ND & $1.0 \mathrm{E}-01$ & $7.2 \mathrm{E}+02$ \\
\hline 64 & 182.55 & $1.0 \mathrm{E}+05$ & $1.8 \mathrm{E}+04$ & ND & ND & $1.1 \mathrm{E}-01$ & $5.4 \mathrm{E}+02$ \\
\hline 65 & 185.46 & $1.2 \mathrm{E}+05$ & $1.6 \mathrm{E}+04$ & ND & ND & 3.0E-01 & $5.1 \mathrm{E}+02$ \\
\hline 66 & 187.62 & $1.2 \mathrm{E}+05$ & $1.5 \mathrm{E}+04$ & ND & ND & ND & $5.8 \mathrm{E}+02$ \\
\hline
\end{tabular}

ND indicates "not detected" below quantification level.

NM indicates analyte concentration was not measured. 
Table A.2. PUF Results for ORPLG9

\begin{tabular}{|c|c|c|c|c|c|c|c|}
\hline Vial \# & $\begin{array}{c}\text { Time } \\
\text { (days) }\end{array}$ & $\begin{array}{c}\mathrm{Al} \\
(\mu \mathrm{g} / \mathrm{L})\end{array}$ & $\begin{array}{c}\text { B } \\
(\mu \mathrm{g} / \mathrm{L})\end{array}$ & $\begin{array}{c}\mathrm{Ca} \\
(\mu \mathrm{g} / \mathrm{L}) \\
\end{array}$ & $\begin{array}{c}\mathrm{Cr} \\
(\mu \mathrm{g} / \mathrm{L})\end{array}$ & $\begin{array}{c}\mathrm{K} \\
(\mu \mathrm{g} / \mathrm{L}) \\
\end{array}$ & $\begin{array}{c}\mathrm{Si} \\
(\mu \mathrm{g} / \mathrm{L})\end{array}$ \\
\hline 1 & 0.00 & ND & $8.7 \mathrm{E}+03$ & ND & ND & $4.0 \mathrm{E}+04$ & $7.6 \mathrm{E}+03$ \\
\hline 2 & 1.09 & $1.8 \mathrm{E}+03$ & $7.8 \mathrm{E}+04$ & ND & $1.5 \mathrm{E}+03$ & $1.6 \mathrm{E}+05$ & $2.0 \mathrm{E}+05$ \\
\hline 3 & 3.05 & $2.6 \mathrm{E}+03$ & $2.7 \mathrm{E}+05$ & ND & $5.1 \mathrm{E}+03$ & $3.4 \mathrm{E}+05$ & $4.1 \mathrm{E}+05$ \\
\hline 4 & 6.03 & $1.1 \mathrm{E}+04$ & $2.0 \mathrm{E}+05$ & ND & $2.8 \mathrm{E}+03$ & $3.2 \mathrm{E}+05$ & $2.7 \mathrm{E}+05$ \\
\hline 5 & 7.01 & $1.3 \mathrm{E}+04$ & $2.0 \mathrm{E}+05$ & ND & $2.3 \mathrm{E}+03$ & $3.2 \mathrm{E}+05$ & $2.4 \mathrm{E}+05$ \\
\hline 6 & 10.12 & $1.4 \mathrm{E}+04$ & $1.5 \mathrm{E}+05$ & ND & $1.7 \mathrm{E}+03$ & $2.5 \mathrm{E}+05$ & $2.0 \mathrm{E}+05$ \\
\hline 7 & 12.12 & $1.4 \mathrm{E}+04$ & $1.5 \mathrm{E}+05$ & ND & $1.5 \mathrm{E}+03$ & $2.3 \mathrm{E}+05$ & $2.0 \mathrm{E}+05$ \\
\hline 8 & 14.22 & $1.3 \mathrm{E}+04$ & $1.3 \mathrm{E}+05$ & ND & $1.4 \mathrm{E}+03$ & $2.2 \mathrm{E}+05$ & $1.9 \mathrm{E}+05$ \\
\hline 9 & 17.07 & $1.3 \mathrm{E}+04$ & $1.2 \mathrm{E}+05$ & ND & $1.2 \mathrm{E}+03$ & $2.2 \mathrm{E}+05$ & $1.9 \mathrm{E}+05$ \\
\hline 10 & 19.08 & $1.3 \mathrm{E}+04$ & $1.2 \mathrm{E}+05$ & ND & $1.2 \mathrm{E}+03$ & $2.2 \mathrm{E}+05$ & $1.9 \mathrm{E}+05$ \\
\hline 11 & 21.09 & $1.4 \mathrm{E}+04$ & $1.1 \mathrm{E}+05$ & ND & $1.2 \mathrm{E}+03$ & $2.1 \mathrm{E}+05$ & $1.8 \mathrm{E}+05$ \\
\hline 12 & 24.03 & $1.2 \mathrm{E}+04$ & $9.8 \mathrm{E}+04$ & ND & $1.0 \mathrm{E}+03$ & $1.9 \mathrm{E}+05$ & $1.8 \mathrm{E}+05$ \\
\hline 13 & 26.00 & $1.3 \mathrm{E}+04$ & $9.9 \mathrm{E}+04$ & ND & $1.1 \mathrm{E}+03$ & $2.1 \mathrm{E}+05$ & $1.8 \mathrm{E}+05$ \\
\hline 14 & 28.03 & $1.5 \mathrm{E}+04$ & $1.0 \mathrm{E}+05$ & ND & $1.1 \mathrm{E}+03$ & $1.8 \mathrm{E}+05$ & $1.8 \mathrm{E}+05$ \\
\hline 15 & 31.01 & $1.2 \mathrm{E}+04$ & $8.0 \mathrm{E}+04$ & ND & $8.7 \mathrm{E}+02$ & $1.4 \mathrm{E}+05$ & $1.5 \mathrm{E}+05$ \\
\hline 16 & 35.01 & $1.1 \mathrm{E}+04$ & $1.1 \mathrm{E}+05$ & ND & $1.2 \mathrm{E}+03$ & $1.8 \mathrm{E}+05$ & $1.7 \mathrm{E}+05$ \\
\hline 17 & 38.09 & $9.0 \mathrm{E}+03$ & $6.6 \mathrm{E}+04$ & ND & $7.1 \mathrm{E}+02$ & $7.8 \mathrm{E}+04$ & $1.5 \mathrm{E}+05$ \\
\hline 18 & 40.04 & $1.2 \mathrm{E}+04$ & $6.0 \mathrm{E}+04$ & ND & $6.5 \mathrm{E}+02$ & $7.2 \mathrm{E}+04$ & $1.4 \mathrm{E}+05$ \\
\hline 19 & 42.12 & $1.2 \mathrm{E}+04$ & $6.9 \mathrm{E}+04$ & ND & $7.7 \mathrm{E}+02$ & $7.8 \mathrm{E}+04$ & $1.5 \mathrm{E}+05$ \\
\hline 20 & 45.03 & $9.5 \mathrm{E}+03$ & $6.2 \mathrm{E}+04$ & ND & $7.1 \mathrm{E}+02$ & $3.0 \mathrm{E}+05$ & $1.3 \mathrm{E}+05$ \\
\hline 21 & 47.19 & $1.1 \mathrm{E}+04$ & $6.0 \mathrm{E}+04$ & ND & $8.2 \mathrm{E}+02$ & $1.4 \mathrm{E}+05$ & $1.3 \mathrm{E}+05$ \\
\hline 22 & 52.01 & $1.3 \mathrm{E}+04$ & $8.5 \mathrm{E}+04$ & ND & $1.1 \mathrm{E}+03$ & $2.1 \mathrm{E}+05$ & $1.7 \mathrm{E}+05$ \\
\hline 23 & 54.14 & $1.2 \mathrm{E}+04$ & $5.9 \mathrm{E}+04$ & ND & $8.0 \mathrm{E}+02$ & $1.4 \mathrm{E}+05$ & $1.4 \mathrm{E}+05$ \\
\hline 24 & 59.04 & $9.4 \mathrm{E}+03$ & $4.9 \mathrm{E}+04$ & ND & $6.3 \mathrm{E}+02$ & $1.3 \mathrm{E}+05$ & $1.2 \mathrm{E}+05$ \\
\hline 25 & 61.21 & $1.0 \mathrm{E}+04$ & $5.3 \mathrm{E}+04$ & ND & $7.1 \mathrm{E}+02$ & $1.4 \mathrm{E}+05$ & $1.3 \mathrm{E}+05$ \\
\hline 26 & 62.98 & $9.6 \mathrm{E}+03$ & $4.8 \mathrm{E}+04$ & ND & $6.4 \mathrm{E}+02$ & $1.3 \mathrm{E}+05$ & $1.2 \mathrm{E}+05$ \\
\hline 27 & 65.98 & $1.0 \mathrm{E}+04$ & $4.7 \mathrm{E}+04$ & ND & $6.5 \mathrm{E}+02$ & $1.2 \mathrm{E}+05$ & $1.3 \mathrm{E}+05$ \\
\hline 28 & 67.98 & $1.3 \mathrm{E}+04$ & $4.8 \mathrm{E}+04$ & ND & $6.3 \mathrm{E}+02$ & $1.2 \mathrm{E}+05$ & $1.4 \mathrm{E}+05$ \\
\hline 29 & 70.02 & $9.4 \mathrm{E}+03$ & $3.7 \mathrm{E}+04$ & ND & $4.8 \mathrm{E}+02$ & $8.4 \mathrm{E}+04$ & $9.9 \mathrm{E}+04$ \\
\hline 30 & 72.99 & $8.9 \mathrm{E}+03$ & $4.7 \mathrm{E}+04$ & ND & $5.8 \mathrm{E}+02$ & $1.4 \mathrm{E}+05$ & $1.2 \mathrm{E}+05$ \\
\hline 31 & 75.01 & $8.7 \mathrm{E}+03$ & $4.3 \mathrm{E}+04$ & ND & $5.8 \mathrm{E}+02$ & $1.1 \mathrm{E}+05$ & $1.1 \mathrm{E}+05$ \\
\hline 32 & 76.97 & $9.0 \mathrm{E}+03$ & $4.2 \mathrm{E}+04$ & ND & $5.2 \mathrm{E}+02$ & $1.3 \mathrm{E}+05$ & $1.1 \mathrm{E}+05$ \\
\hline 33 & 80.01 & $8.5 \mathrm{E}+03$ & $3.9 \mathrm{E}+04$ & ND & $5.5 \mathrm{E}+02$ & $1.4 \mathrm{E}+05$ & $1.1 \mathrm{E}+05$ \\
\hline 34 & 81.96 & $6.0 \mathrm{E}+03$ & $4.8 \mathrm{E}+04$ & ND & $6.7 \mathrm{E}+02$ & $1.4 \mathrm{E}+05$ & $1.2 \mathrm{E}+05$ \\
\hline 35 & 84.05 & $1.0 \mathrm{E}+04$ & $4.8 \mathrm{E}+04$ & ND & $6.8 \mathrm{E}+02$ & $1.3 \mathrm{E}+05$ & $1.4 \mathrm{E}+05$ \\
\hline 36 & 86.97 & $1.0 \mathrm{E}+04$ & $4.0 \mathrm{E}+04$ & ND & $5.5 \mathrm{E}+02$ & $1.3 \mathrm{E}+05$ & $1.2 \mathrm{E}+05$ \\
\hline 37 & 89.01 & $1.0 \mathrm{E}+04$ & $4.1 \mathrm{E}+04$ & ND & $5.9 \mathrm{E}+02$ & $1.4 \mathrm{E}+05$ & $1.2 \mathrm{E}+05$ \\
\hline 38 & 91.09 & $9.8 \mathrm{E}+03$ & $3.9 \mathrm{E}+04$ & ND & $5.0 \mathrm{E}+02$ & $1.2 \mathrm{E}+05$ & $1.1 \mathrm{E}+05$ \\
\hline 39 & 94.03 & $9.7 \mathrm{E}+03$ & $3.8 \mathrm{E}+04$ & ND & $5.0 \mathrm{E}+02$ & $1.2 \mathrm{E}+05$ & $1.1 \mathrm{E}+05$ \\
\hline 40 & 96.04 & $9.9 \mathrm{E}+03$ & $3.8 \mathrm{E}+04$ & ND & $5.4 \mathrm{E}+02$ & $1.2 \mathrm{E}+05$ & $1.1 \mathrm{E}+05$ \\
\hline
\end{tabular}


Table A.2. (contd)

\begin{tabular}{cccccccc}
\hline Vial \# & $\begin{array}{c}\text { Time } \\
(\text { days })\end{array}$ & $\begin{array}{c}\mathrm{Al} \\
(\mu \mathrm{g} / \mathrm{L})\end{array}$ & $\begin{array}{c}\mathrm{B} \\
(\mu \mathrm{g} / \mathrm{L})\end{array}$ & $\begin{array}{c}\mathrm{Ca} \\
(\mu \mathrm{g} / \mathrm{L})\end{array}$ & $\begin{array}{c}\mathrm{Cr} \\
(\mu \mathrm{g} / \mathrm{L})\end{array}$ & $\begin{array}{c}\mathrm{K} \\
(\mu \mathrm{g} / \mathrm{L})\end{array}$ & $\begin{array}{c}\mathrm{Si} \\
(\mu \mathrm{g} / \mathrm{L})\end{array}$ \\
\hline 41 & 98.03 & $1.0 \mathrm{E}+04$ & $3.7 \mathrm{E}+04$ & $\mathrm{ND}$ & $4.8 \mathrm{E}+02$ & $1.2 \mathrm{E}+05$ & $1.1 \mathrm{E}+05$ \\
42 & 101.00 & $9.7 \mathrm{E}+03$ & $3.6 \mathrm{E}+04$ & $\mathrm{ND}$ & $5.1 \mathrm{E}+02$ & $1.4 \mathrm{E}+05$ & $1.1 \mathrm{E}+05$ \\
43 & 103.12 & $9.3 \mathrm{E}+03$ & $3.6 \mathrm{E}+04$ & $\mathrm{ND}$ & $4.8 \mathrm{E}+02$ & $1.3 \mathrm{E}+05$ & $1.1 \mathrm{E}+05$ \\
44 & 104.99 & $9.5 \mathrm{E}+03$ & $3.5 \mathrm{E}+04$ & ND & $5.3 \mathrm{E}+02$ & $1.2 \mathrm{E}+05$ & $1.1 \mathrm{E}+05$ \\
45 & 107.48 & $9.5 \mathrm{E}+03$ & $3.4 \mathrm{E}+04$ & ND & $5.0 \mathrm{E}+02$ & $1.3 \mathrm{E}+05$ & $1.1 \mathrm{E}+05$ \\
\hline \multicolumn{7}{l}{ ND indicates "not detected" below quantification level. } \\
NM indicates analyte concentration was not measured.
\end{tabular}

Table A.2. (contd)

\begin{tabular}{|c|c|c|c|c|c|c|c|}
\hline Vial \# & $\begin{array}{c}\text { Time } \\
\text { (days) }\end{array}$ & $\begin{array}{c}\mathrm{Na} \\
(\mu \mathrm{g} / \mathrm{L})\end{array}$ & $\begin{array}{c}\mathrm{Sn} \\
(\mu \mathrm{g} / \mathrm{L})\end{array}$ & $\begin{array}{c}\mathrm{Zn} \\
(\mu \mathrm{g} / \mathrm{L})\end{array}$ & $\begin{array}{c}\mathrm{Zr} \\
(\mu \mathrm{g} / \mathrm{L})\end{array}$ & $\begin{array}{c}\text { Cs } \\
(\mu \mathrm{g} / \mathrm{L}) \\
\end{array}$ & $\begin{array}{c}\mathrm{Re} \\
(\mu \mathrm{g} / \mathrm{L})\end{array}$ \\
\hline 1 & 0.00 & $6.3 \mathrm{E}+04$ & ND & ND & ND & $3.7 \mathrm{E}-01$ & $1.0 \mathrm{E}+02$ \\
\hline 2 & 1.09 & $6.6 \mathrm{E}+05$ & ND & ND & ND & $4.0 \mathrm{E}+00$ & $1.9 \mathrm{E}+03$ \\
\hline 3 & 3.05 & $2.1 \mathrm{E}+06$ & $5.6 \mathrm{E}+03$ & ND & ND & $6.6 \mathrm{E}+00$ & $4.6 \mathrm{E}+03$ \\
\hline 4 & 6.03 & $1.4 \mathrm{E}+06$ & $9.6 \mathrm{E}+03$ & ND & ND & $3.5 \mathrm{E}+00$ & $2.4 \mathrm{E}+03$ \\
\hline 5 & 7.01 & $1.2 \mathrm{E}+06$ & $8.9 \mathrm{E}+03$ & ND & ND & $2.8 \mathrm{E}+00$ & $1.9 \mathrm{E}+03$ \\
\hline 6 & 10.12 & $9.5 \mathrm{E}+05$ & $7.2 \mathrm{E}+03$ & ND & ND & $2.1 \mathrm{E}+00$ & $1.5 \mathrm{E}+03$ \\
\hline 7 & 12.12 & $8.9 \mathrm{E}+05$ & $6.8 \mathrm{E}+03$ & ND & ND & $1.9 \mathrm{E}+00$ & $1.4 \mathrm{E}+03$ \\
\hline 8 & 14.22 & $7.8 \mathrm{E}+05$ & $5.9 \mathrm{E}+03$ & ND & ND & $1.6 \mathrm{E}+00$ & $1.2 \mathrm{E}+03$ \\
\hline 9 & 17.07 & $7.1 \mathrm{E}+05$ & $6.1 \mathrm{E}+03$ & ND & ND & $1.4 \mathrm{E}+00$ & $1.1 \mathrm{E}+03$ \\
\hline 10 & 19.08 & $7.1 \mathrm{E}+05$ & $5.8 \mathrm{E}+03$ & ND & ND & $1.4 \mathrm{E}+00$ & $1.1 \mathrm{E}+03$ \\
\hline 11 & 21.09 & $6.7 \mathrm{E}+05$ & $5.6 \mathrm{E}+03$ & ND & ND & $1.3 \mathrm{E}+00$ & $1.1 \mathrm{E}+03$ \\
\hline 12 & 24.03 & $5.8 \mathrm{E}+05$ & $5.0 \mathrm{E}+03$ & ND & ND & $1.1 \mathrm{E}+00$ & $9.3 \mathrm{E}+02$ \\
\hline 13 & 26.00 & $6.2 \mathrm{E}+05$ & $5.1 \mathrm{E}+03$ & ND & ND & $1.3 \mathrm{E}+00$ & $1.0 \mathrm{E}+03$ \\
\hline 14 & 28.03 & $6.2 \mathrm{E}+05$ & $5.3 \mathrm{E}+03$ & ND & ND & $1.3 \mathrm{E}+00$ & $1.1 \mathrm{E}+03$ \\
\hline 15 & 31.01 & $4.9 \mathrm{E}+05$ & $4.1 \mathrm{E}+03$ & ND & ND & $1.2 \mathrm{E}+00$ & $8.3 \mathrm{E}+02$ \\
\hline 16 & 35.01 & $6.7 \mathrm{E}+05$ & $4.1 \mathrm{E}+03$ & ND & ND & $1.4 \mathrm{E}+00$ & $1.2 \mathrm{E}+03$ \\
\hline 17 & 38.09 & $3.9 \mathrm{E}+05$ & $3.4 \mathrm{E}+03$ & ND & ND & 8.3E-01 & $7.3 \mathrm{E}+02$ \\
\hline 18 & 40.04 & $3.9 \mathrm{E}+05$ & $3.8 \mathrm{E}+03$ & ND & ND & 8.5E-01 & $6.5 \mathrm{E}+02$ \\
\hline 19 & 42.12 & $4.4 \mathrm{E}+05$ & $4.1 \mathrm{E}+03$ & ND & ND & $9.5 \mathrm{E}-01$ & $7.6 \mathrm{E}+02$ \\
\hline 20 & 45.03 & $4.1 \mathrm{E}+05$ & $3.3 \mathrm{E}+03$ & ND & ND & $1.0 \mathrm{E}+00$ & $7.0 \mathrm{E}+02$ \\
\hline 21 & 47.19 & $4.3 \mathrm{E}+05$ & $3.1 \mathrm{E}+03$ & ND & ND & $6.9 \mathrm{E}-01$ & $7.2 \mathrm{E}+02$ \\
\hline 22 & 52.01 & $5.7 \mathrm{E}+05$ & $2.9 \mathrm{E}+03$ & ND & ND & $1.0 \mathrm{E}+00$ & $5.1 \mathrm{E}+02$ \\
\hline 23 & 54.14 & $4.3 \mathrm{E}+05$ & $3.1 \mathrm{E}+03$ & ND & ND & ND & $7.4 \mathrm{E}+02$ \\
\hline 24 & 59.04 & $3.6 \mathrm{E}+05$ & $2.5 \mathrm{E}+03$ & ND & ND & $1.4 \mathrm{E}+00$ & $6.0 \mathrm{E}+02$ \\
\hline 25 & 61.21 & $3.9 \mathrm{E}+05$ & $3.0 \mathrm{E}+03$ & ND & ND & 7.5E-01 & $6.6 \mathrm{E}+02$ \\
\hline 26 & 62.98 & $3.6 \mathrm{E}+05$ & $2.6 \mathrm{E}+03$ & ND & ND & $6.6 \mathrm{E}-01$ & $6.0 \mathrm{E}+02$ \\
\hline 27 & 65.98 & $3.6 \mathrm{E}+05$ & $2.7 \mathrm{E}+03$ & ND & ND & $6.9 \mathrm{E}-01$ & $6.2 \mathrm{E}+02$ \\
\hline 28 & 67.98 & $3.8 \mathrm{E}+05$ & $2.8 \mathrm{E}+03$ & ND & ND & $6.6 \mathrm{E}-01$ & $5.9 \mathrm{E}+02$ \\
\hline
\end{tabular}


Table A.2. (contd)

\begin{tabular}{cccccccc}
\hline Vial \# & $\begin{array}{c}\text { Time } \\
(\text { days })\end{array}$ & $\begin{array}{c}\mathrm{Na} \\
(\mu \mathrm{g} / \mathrm{L})\end{array}$ & $\begin{array}{c}\mathrm{Sn} \\
(\mu \mathrm{g} / \mathrm{L})\end{array}$ & $\begin{array}{c}\mathrm{Zn} \\
(\mu \mathrm{g} / \mathrm{L})\end{array}$ & $\begin{array}{c}\mathrm{Zr} \\
(\mu \mathrm{g} / \mathrm{L})\end{array}$ & $\begin{array}{c}\mathrm{Cs} \\
(\mu \mathrm{g} / \mathrm{L})\end{array}$ & $\begin{array}{c}\mathrm{Re} \\
(\mu \mathrm{g} / \mathrm{L})\end{array}$ \\
\hline 29 & 70.02 & $2.9 \mathrm{E}+05$ & $\mathrm{ND}$ & $\mathrm{ND}$ & $\mathrm{ND}$ & $5.3 \mathrm{E}-01$ & $4.6 \mathrm{E}+02$ \\
30 & 72.99 & $3.4 \mathrm{E}+05$ & $\mathrm{ND}$ & $\mathrm{ND}$ & $\mathrm{ND}$ & $6.9 \mathrm{E}-01$ & $6.0 \mathrm{E}+02$ \\
31 & 75.01 & $3.2 \mathrm{E}+05$ & $\mathrm{ND}$ & $\mathrm{ND}$ & $\mathrm{ND}$ & $5.6 \mathrm{E}-01$ & $5.7 \mathrm{E}+02$ \\
32 & 76.97 & $3.1 \mathrm{E}+05$ & $\mathrm{ND}$ & $\mathrm{ND}$ & $\mathrm{ND}$ & $6.3 \mathrm{E}-01$ & $5.7 \mathrm{E}+02$ \\
33 & 80.01 & $3.0 \mathrm{E}+05$ & $\mathrm{ND}$ & $\mathrm{ND}$ & $\mathrm{ND}$ & $6.0 \mathrm{E}-01$ & $5.5 \mathrm{E}+02$ \\
34 & 81.96 & $3.2 \mathrm{E}+05$ & $\mathrm{ND}$ & $\mathrm{ND}$ & $\mathrm{ND}$ & $5.7 \mathrm{E}-01$ & $6.1 \mathrm{E}+02$ \\
35 & 84.05 & $3.8 \mathrm{E}+05$ & $2.8 \mathrm{E}+03$ & $\mathrm{ND}$ & $\mathrm{ND}$ & $6.5 \mathrm{E}-01$ & $6.0 \mathrm{E}+02$ \\
36 & 86.97 & $3.3 \mathrm{E}+05$ & $2.3 \mathrm{E}+03$ & $\mathrm{ND}$ & $\mathrm{ND}$ & $6.5 \mathrm{E}-01$ & $5.3 \mathrm{E}+02$ \\
37 & 89.01 & $3.3 \mathrm{E}+05$ & $2.5 \mathrm{E}+03$ & $\mathrm{ND}$ & $\mathrm{ND}$ & $5.3 \mathrm{E}-01$ & $5.3 \mathrm{E}+02$ \\
38 & 91.09 & $3.1 \mathrm{E}+05$ & $\mathrm{ND}$ & $\mathrm{ND}$ & $\mathrm{ND}$ & $4.9 \mathrm{E}-01$ & $5.2 \mathrm{E}+02$ \\
39 & 94.03 & $3.1 \mathrm{E}+05$ & $2.5 \mathrm{E}+03$ & $\mathrm{ND}$ & $\mathrm{ND}$ & $5.5 \mathrm{E}-01$ & $5.1 \mathrm{E}+02$ \\
40 & 96.04 & $3.2 \mathrm{E}+05$ & $2.2 \mathrm{E}+03$ & $\mathrm{ND}$ & $\mathrm{ND}$ & $4.4 \mathrm{E}-01$ & $5.2 \mathrm{E}+02$ \\
41 & 98.03 & $3.2 \mathrm{E}+05$ & $\mathrm{ND}$ & $\mathrm{ND}$ & $\mathrm{ND}$ & $5.3 \mathrm{E}-01$ & $5.2 \mathrm{E}+02$ \\
42 & 101.00 & $3.1 \mathrm{E}+05$ & $2.4 \mathrm{E}+03$ & $\mathrm{ND}$ & $\mathrm{ND}$ & $5.6 \mathrm{E}-01$ & $5.0 \mathrm{E}+02$ \\
43 & 103.12 & $3.0 \mathrm{E}+05$ & $2.3 \mathrm{E}+03$ & $\mathrm{ND}$ & $\mathrm{ND}$ & $4.6 \mathrm{E}-01$ & $4.9 \mathrm{E}+02$ \\
44 & 104.99 & $3.0 \mathrm{E}+05$ & $\mathrm{ND}$ & $\mathrm{ND}$ & $\mathrm{ND}$ & $5.2 \mathrm{E}-01$ & $5.1 \mathrm{E}+02$ \\
45 & 107.48 & $2.9 \mathrm{E}+05$ & $2.2 \mathrm{E}+03$ & ND & ND & $4.7 \mathrm{E}-01$ & $4.9 \mathrm{E}+02$ \\
\hline ND indicates "not detected" below quantification level. & & & & \\
NM indicates analyte concentration was not measured. & & & & \\
\hline
\end{tabular}


Table A.3. PUF Results for ORPLB2

\begin{tabular}{cccccccc}
\hline Vial \# & $\begin{array}{c}\text { Time } \\
(\text { days })\end{array}$ & $\begin{array}{c}\mathrm{Al} \\
(\mu \mathrm{g} / \mathrm{L})\end{array}$ & $\begin{array}{c}\mathrm{B} \\
(\mu \mathrm{g} / \mathrm{L})\end{array}$ & $\begin{array}{c}\mathrm{Ca} \\
(\mu \mathrm{g} / \mathrm{L})\end{array}$ & $\begin{array}{c}\mathrm{Cr} \\
(\mu \mathrm{g} / \mathrm{L})\end{array}$ & $\begin{array}{c}\mathrm{K} \\
(\mu \mathrm{g} / \mathrm{L})\end{array}$ & $\begin{array}{c}\mathrm{Si} \\
(\mu \mathrm{g} / \mathrm{L})\end{array}$ \\
\hline 1 & 0.07 & $8.1 \mathrm{E}+03$ & $6.3 \mathrm{E}+03$ & $\mathrm{ND}$ & $\mathrm{ND}$ & $\mathrm{ND}$ & $3.9 \mathrm{E}+04$ \\
2 & 1.77 & $2.5 \mathrm{E}+04$ & $1.3 \mathrm{E}+05$ & $\mathrm{ND}$ & $3.9 \mathrm{E}+03$ & $1.3 \mathrm{E}+05$ & $3.1 \mathrm{E}+05$ \\
3 & 3.90 & $3.8 \mathrm{E}+04$ & $1.4 \mathrm{E}+05$ & $\mathrm{ND}$ & $2.8 \mathrm{E}+03$ & $1.6 \mathrm{E}+05$ & $2.7 \mathrm{E}+05$ \\
4 & 8.80 & $2.6 \mathrm{E}+04$ & $9.5 \mathrm{E}+04$ & ND & $1.5 \mathrm{E}+03$ & $1.3 \mathrm{E}+05$ & $1.5 \mathrm{E}+05$ \\
5 & 10.97 & $2.4 \mathrm{E}+04$ & $9.0 \mathrm{E}+04$ & ND & $1.3 \mathrm{E}+03$ & $1.4 \mathrm{E}+05$ & $1.4 \mathrm{E}+05$ \\
6 & 12.74 & $2.2 \mathrm{E}+04$ & $7.8 \mathrm{E}+04$ & ND & $1.1 \mathrm{E}+03$ & $9.7 \mathrm{E}+04$ & $1.3 \mathrm{E}+05$ \\
7 & 15.74 & $2.2 \mathrm{E}+04$ & $8.1 \mathrm{E}+04$ & ND & $1.1 \mathrm{E}+03$ & $1.3 \mathrm{E}+05$ & $1.4 \mathrm{E}+05$ \\
8 & 17.74 & $2.1 \mathrm{E}+04$ & $7.5 \mathrm{E}+04$ & ND & $1.0 \mathrm{E}+03$ & $1.3 \mathrm{E}+05$ & $1.3 \mathrm{E}+05$ \\
9 & 19.78 & $2.1 \mathrm{E}+04$ & $7.3 \mathrm{E}+04$ & ND & $9.6 \mathrm{E}+02$ & $1.2 \mathrm{E}+05$ & $1.2 \mathrm{E}+05$ \\
10 & 22.75 & $1.8 \mathrm{E}+04$ & $6.9 \mathrm{E}+04$ & ND & $9.1 \mathrm{E}+02$ & $1.7 \mathrm{E}+05$ & $1.2 \mathrm{E}+05$ \\
11 & 24.77 & $1.8 \mathrm{E}+04$ & $6.5 \mathrm{E}+04$ & ND & $8.9 \mathrm{E}+02$ & $1.1 \mathrm{E}+05$ & $1.1 \mathrm{E}+05$ \\
12 & 26.73 & $1.8 \mathrm{E}+04$ & $6.2 \mathrm{E}+04$ & ND & $8.2 \mathrm{E}+02$ & $1.6 \mathrm{E}+05$ & $1.1 \mathrm{E}+05$ \\
13 & 29.77 & $1.8 \mathrm{E}+04$ & $6.2 \mathrm{E}+04$ & ND & $8.0 \mathrm{E}+02$ & $1.8 \mathrm{E}+05$ & $1.1 \mathrm{E}+05$ \\
14 & 31.72 & $1.6 \mathrm{E}+04$ & $6.0 \mathrm{E}+04$ & ND & $8.1 \mathrm{E}+02$ & $1.4 \mathrm{E}+05$ & $1.0 \mathrm{E}+05$ \\
15 & 33.81 & $1.7 \mathrm{E}+04$ & $5.8 \mathrm{E}+04$ & ND & $7.9 \mathrm{E}+02$ & $1.6 \mathrm{E}+05$ & $1.1 \mathrm{E}+05$ \\
16 & 36.74 & $1.5 \mathrm{E}+04$ & $5.4 \mathrm{E}+04$ & ND & $7.6 \mathrm{E}+02$ & $1.8 \mathrm{E}+05$ & $1.0 \mathrm{E}+05$ \\
17 & 38.78 & $1.6 \mathrm{E}+04$ & $5.3 \mathrm{E}+04$ & ND & $7.5 \mathrm{E}+02$ & $1.7 \mathrm{E}+05$ & $1.0 \mathrm{E}+05$ \\
18 & 40.85 & $1.5 \mathrm{E}+04$ & $5.2 \mathrm{E}+04$ & ND & $7.3 \mathrm{E}+02$ & $1.9 \mathrm{E}+05$ & $9.6 \mathrm{E}+04$ \\
19 & 43.80 & $1.5 \mathrm{E}+04$ & $5.0 \mathrm{E}+04$ & ND & $7.2 \mathrm{E}+02$ & $1.9 \mathrm{E}+05$ & $1.0 \mathrm{E}+05$ \\
20 & 45.80 & $1.5 \mathrm{E}+04$ & $5.0 \mathrm{E}+04$ & ND & $7.0 \mathrm{E}+02$ & $1.7 \mathrm{E}+05$ & $9.6 \mathrm{E}+04$ \\
21 & 47.79 & $1.5 \mathrm{E}+04$ & $4.8 \mathrm{E}+04$ & ND & $6.8 \mathrm{E}+02$ & $1.9 \mathrm{E}+05$ & $9.2 \mathrm{E}+04$ \\
22 & 50.76 & $1.6 \mathrm{E}+04$ & $4.9 \mathrm{E}+04$ & ND & $7.0 \mathrm{E}+02$ & $2.0 \mathrm{E}+05$ & $9.6 \mathrm{E}+04$ \\
23 & 52.88 & $1.4 \mathrm{E}+04$ & $4.7 \mathrm{E}+04$ & ND & $7.1 \mathrm{E}+02$ & $1.8 \mathrm{E}+05$ & $9.0 \mathrm{E}+04$ \\
24 & 54.75 & $1.5 \mathrm{E}+04$ & $4.7 \mathrm{E}+04$ & ND & $6.8 \mathrm{E}+02$ & $1.8 \mathrm{E}+05$ & $9.5 \mathrm{E}+04$ \\
25 & 57.24 & $1.4 \mathrm{E}+04$ & $4.3 \mathrm{E}+04$ & ND & $6.6 \mathrm{E}+02$ & $2.0 \mathrm{E}+05$ & $8.5 \mathrm{E}+04$ \\
\hline & & & & & &
\end{tabular}

ND indicates "not detected" below quantification level. 
Table A.3. (contd)

\begin{tabular}{|c|c|c|c|c|c|c|c|}
\hline Vial \# & $\begin{array}{l}\text { Time } \\
\text { days }\end{array}$ & $\begin{array}{r}\mathrm{Na} \\
(\mu \mathrm{g} / \mathrm{L})\end{array}$ & $\begin{array}{r}\mathrm{V} \\
(\mu \mathrm{g} / \mathrm{L})\end{array}$ & $\begin{array}{r}\mathrm{Zn} \\
(\mu \mathrm{g} / \mathrm{L})\end{array}$ & $\begin{array}{r}\mathrm{Zr} \\
(\mu \mathrm{g} / \mathrm{L})\end{array}$ & $\begin{array}{r}\text { Cs } \\
(\mu \mathrm{g} / \mathrm{L})\end{array}$ & $\begin{array}{r}\operatorname{Re} \\
(\mu \mathrm{g} / \mathrm{L})\end{array}$ \\
\hline 1 & 0.07 & $1.2 \mathrm{E}+05$ & $3.3 \mathrm{E}+03$ & ND & ND & $9.5 \mathrm{E}+01$ & $2.6 \mathrm{E}+02$ \\
\hline 2 & 1.77 & $1.2 \mathrm{E}+06$ & $3.7 \mathrm{E}+04$ & ND & ND & $3.0 \mathrm{E}+03$ & $3.8 \mathrm{E}+03$ \\
\hline 3 & 3.90 & $1.2 \mathrm{E}+06$ & $3.2 \mathrm{E}+04$ & ND & ND & $2.6 \mathrm{E}+03$ & $3.1 \mathrm{E}+03$ \\
\hline 4 & 8.80 & $7.9 \mathrm{E}+05$ & $1.9 \mathrm{E}+04$ & ND & ND & $1.2 \mathrm{E}+03$ & $1.6 \mathrm{E}+03$ \\
\hline 5 & 10.97 & $7.4 \mathrm{E}+05$ & $1.7 \mathrm{E}+04$ & ND & ND & $1.0 \mathrm{E}+03$ & $1.3 \mathrm{E}+03$ \\
\hline 6 & 12.74 & $6.4 \mathrm{E}+05$ & $1.5 \mathrm{E}+04$ & ND & ND & $8.6 \mathrm{E}+02$ & $1.1 \mathrm{E}+03$ \\
\hline 7 & 15.74 & $6.4 \mathrm{E}+05$ & $1.5 \mathrm{E}+04$ & ND & ND & $8.0 \mathrm{E}+02$ & $1.1 \mathrm{E}+03$ \\
\hline 8 & 17.74 & $5.9 \mathrm{E}+05$ & $1.4 \mathrm{E}+04$ & ND & ND & $8.2 \mathrm{E}+02$ & $1.1 \mathrm{E}+03$ \\
\hline 9 & 19.78 & $5.9 \mathrm{E}+05$ & $1.4 \mathrm{E}+04$ & ND & ND & $7.3 \mathrm{E}+02$ & $1.0 \mathrm{E}+03$ \\
\hline 10 & 22.75 & $5.4 \mathrm{E}+05$ & $1.3 \mathrm{E}+04$ & ND & ND & $7.0 \mathrm{E}+02$ & $9.3 \mathrm{E}+02$ \\
\hline 11 & 24.77 & $5.4 \mathrm{E}+05$ & $1.2 \mathrm{E}+04$ & ND & ND & $6.8 \mathrm{E}+02$ & $9.1 \mathrm{E}+02$ \\
\hline 12 & 26.73 & $5.1 \mathrm{E}+05$ & $1.2 \mathrm{E}+04$ & ND & ND & $6.4 \mathrm{E}+02$ & $8.9 \mathrm{E}+02$ \\
\hline 13 & 29.77 & $4.9 \mathrm{E}+05$ & $1.2 \mathrm{E}+04$ & ND & $1.2 \mathrm{E}+03$ & $5.7 \mathrm{E}+02$ & $8.3 \mathrm{E}+02$ \\
\hline 14 & 31.72 & $4.8 \mathrm{E}+05$ & $1.1 \mathrm{E}+04$ & ND & ND & $6.0 \mathrm{E}+02$ & $8.5 \mathrm{E}+02$ \\
\hline 15 & 33.81 & $4.7 \mathrm{E}+05$ & $1.1 \mathrm{E}+04$ & ND & $1.3 \mathrm{E}+03$ & $5.7 \mathrm{E}+02$ & $8.0 \mathrm{E}+02$ \\
\hline 16 & 36.74 & $4.4 \mathrm{E}+05$ & $1.1 \mathrm{E}+04$ & ND & $1.2 \mathrm{E}+03$ & $5.0 \mathrm{E}+02$ & $7.7 \mathrm{E}+02$ \\
\hline 17 & 38.78 & $4.4 \mathrm{E}+05$ & $1.1 \mathrm{E}+04$ & ND & $1.3 \mathrm{E}+03$ & $5.5 \mathrm{E}+02$ & $7.8 \mathrm{E}+02$ \\
\hline 18 & 40.85 & $4.3 \mathrm{E}+05$ & $1.1 \mathrm{E}+04$ & ND & $1.3 \mathrm{E}+03$ & $4.5 \mathrm{E}+02$ & $7.6 \mathrm{E}+02$ \\
\hline 19 & 43.80 & $4.1 \mathrm{E}+05$ & $1.0 \mathrm{E}+04$ & ND & $1.4 \mathrm{E}+03$ & $4.9 \mathrm{E}+02$ & $7.3 \mathrm{E}+02$ \\
\hline 20 & 45.80 & $4.2 \mathrm{E}+05$ & $1.0 \mathrm{E}+04$ & ND & $1.5 \mathrm{E}+03$ & $4.9 \mathrm{E}+02$ & $7.3 \mathrm{E}+02$ \\
\hline 21 & 47.79 & $3.9 \mathrm{E}+05$ & $9.7 \mathrm{E}+03$ & ND & $1.6 \mathrm{E}+03$ & $5.0 \mathrm{E}+02$ & $7.3 \mathrm{E}+02$ \\
\hline 22 & 50.76 & $3.9 \mathrm{E}+05$ & $1.0 \mathrm{E}+04$ & ND & $1.7 \mathrm{E}+03$ & $4.2 \mathrm{E}+02$ & $7.2 \mathrm{E}+02$ \\
\hline 23 & 52.88 & $3.8 \mathrm{E}+05$ & $9.6 \mathrm{E}+03$ & ND & $1.6 \mathrm{E}+03$ & $4.1 \mathrm{E}+02$ & $7.2 \mathrm{E}+02$ \\
\hline 24 & 54.75 & $3.8 \mathrm{E}+05$ & $9.8 \mathrm{E}+03$ & ND & $1.7 \mathrm{E}+03$ & $4.5 \mathrm{E}+02$ & $7.1 \mathrm{E}+02$ \\
\hline 25 & 57.24 & $3.6 \mathrm{E}+05$ & $9.0 \mathrm{E}+03$ & ND & $1.6 \mathrm{E}+03$ & $4.6 \mathrm{E}+02$ & $6.6 \mathrm{E}+02$ \\
\hline
\end{tabular}




\section{Appendix B}

Glass Compositions Used for Geochemical

Modeling Input (from Papathanassiu et al. 2011) 
Table B.1. Glass Compositions Used in Geochemical Modeling (g/mol-glass)

\begin{tabular}{|c|c|c|c|c|c|c|c|c|c|}
\hline Glass ID & A100CC & A100G115A & A1-AN105R2 & A1C1-1 & A1C1-2 & A1C1-3 & A2-AP101 & A2B1-1 & $\mathrm{A} 2 \mathrm{~B} 1-2$ \\
\hline $\mathrm{Al}_{2} \mathrm{O}_{3}$ & 6.064 & 6.063 & 6.101 & 6.088 & 6.073 & 6.057 & 5.622 & 5.758 & 5.895 \\
\hline $\mathrm{B}_{2} \mathrm{O}_{3}$ & 10.007 & 10.005 & 8.841 & 9.126 & 9.415 & 9.701 & 9.824 & 9.883 & 9.919 \\
\hline $\mathrm{CaO}$ & 5.064 & 5.063 & 1.960 & 2.742 & 3.521 & 4.299 & 1.991 & 3.184 & 4.374 \\
\hline $\mathrm{Fe}_{2} \mathrm{O}_{3}$ & 5.414 & 5.413 & 6.871 & 6.501 & 6.135 & 5.766 & 5.532 & 5.477 & 5.405 \\
\hline $\mathrm{K}_{2} \mathrm{O}$ & 0.260 & 0.260 & 0.440 & 0.347 & 0.255 & 0.161 & 3.812 & 2.904 & 2.002 \\
\hline $\mathrm{Li}_{2} \mathrm{O}$ & 2.502 & 2.501 & 0.000 & 0.623 & 1.247 & 1.871 & 0.000 & 1.071 & 2.152 \\
\hline $\mathrm{MgO}$ & 1.491 & 1.491 & 1.960 & 1.850 & 1.735 & 1.619 & 1.481 & 1.852 & 2.232 \\
\hline $\mathrm{Na}_{2} \mathrm{O}$ & 14.470 & 14.467 & 20.662 & 19.167 & 17.673 & 16.170 & 18.467 & 15.230 & 11.981 \\
\hline $\mathrm{SO}_{3}$ & 0.36 & 0.38 & 0.18 & 0.21 & 0.23 & 0.29 & 0.35 & 0.35 & 0.42 \\
\hline $\mathrm{SiO}_{2}$ & 46.613 & 46.603 & 43.824 & 44.480 & 45.142 & 45.787 & 44.008 & 45.179 & 46.292 \\
\hline $\mathrm{TiO}_{2}$ & 1.141 & 1.141 & 1.960 & 1.759 & 1.554 & 1.348 & 1.991 & 1.842 & 1.692 \\
\hline $\mathrm{ZnO}$ & 3.072 & 3.072 & 2.920 & 2.951 & 2.984 & 3.017 & 2.941 & 3.414 & 3.894 \\
\hline $\mathrm{ZrO}_{2}$ & 3.032 & 3.032 & 2.940 & 2.956 & 2.974 & 2.991 & 2.961 & 3.014 & 3.063 \\
\hline $\mathrm{Cl}$ & 0.330 & 0.330 & 1.170 & 0.913 & 0.654 & 0.395 & 0.420 & 0.320 & 0.220 \\
\hline $\mathrm{Cr}_{2} \mathrm{O}_{3}$ & 0.020 & 0.020 & 0.020 & 0.015 & 0.013 & 0.011 & 0.020 & 0.020 & 0.030 \\
\hline $\mathrm{Cs}_{2} \mathrm{O}$ & - & - & 0.150 & 0.147 & 0.148 & 0.148 & 0.150 & 0.150 & 0.150 \\
\hline $\mathrm{F}$ & 0.030 & 0.030 & - & 0.086 & 0.169 & 0.252 & 0.350 & 0.280 & 0.220 \\
\hline
\end{tabular}


Table B.1. (contd)

\begin{tabular}{|c|c|c|c|c|c|c|c|c|c|}
\hline Glass ID & A2B1-3 & A88AP101R1 & $\mathrm{A} 88 \mathrm{Si}+15$ & A88Si-15 & B1-AZ101 & C100-G-136B & C100GCC & C1-AN107 & C22AN107 \\
\hline $\mathrm{Al}_{2} \mathrm{O}_{3}$ & 6.037 & 6.102 & 6.141 & 6.055 & 6.180 & 6.127 & 6.127 & 6.066 & 6.106 \\
\hline $\mathrm{B}_{2} \mathrm{O}_{3}$ & 9.971 & 9.834 & 9.481 & 10.218 & 10.026 & 10.092 & 10.092 & 10.031 & 10.079 \\
\hline $\mathrm{CaO}$ & 5.576 & 1.999 & 1.930 & 2.072 & 6.771 & 6.408 & 6.408 & 5.098 & 5.115 \\
\hline $\mathrm{Fe}_{2} \mathrm{O}_{3}$ & 5.346 & 5.552 & 5.351 & 5.765 & 5.278 & 6.478 & 6.478 & 5.421 & 5.585 \\
\hline $\mathrm{K}_{2} \mathrm{O}$ & 1.091 & 2.136 & 2.370 & 1.882 & 0.180 & 0.150 & 0.150 & 0.069 & 0.090 \\
\hline $\mathrm{Li}_{2} \mathrm{O}$ & 3.224 & 0.000 & 0.000 & 0.000 & 4.307 & 2.733 & 2.733 & 2.506 & 2.512 \\
\hline $\mathrm{SO}_{3}$ & 0.47 & 0.23 & 0.29 & 0.19 & 0.49 & 0.40 & 0.40 & 0.29 & 0.27 \\
\hline $\mathrm{SiO}_{2}$ & 47.432 & 44.153 & 42.554 & 45.867 & 48.578 & 46.726 & 46.726 & 46.636 & 46.612 \\
\hline $\mathrm{TiO}_{2}$ & 1.542 & 1.999 & 1.930 & 2.072 & 1.392 & 1.121 & 1.121 & 1.147 & 1.141 \\
\hline $\mathrm{ZnO}$ & 4.365 & 2.961 & 2.850 & 3.072 & 4.848 & 3.014 & 3.014 & 3.062 & 3.063 \\
\hline $\mathrm{ZrO}_{2}$ & 3.113 & 2.998 & 2.890 & 3.112 & 3.165 & 3.024 & 3.024 & 3.020 & 3.023 \\
\hline $\mathrm{Cl}$ & 0.120 & 0.130 & 0.140 & 0.120 & 0.020 & 0.120 & 0.120 & 0.065 & 0.080 \\
\hline $\mathrm{Cr}_{2} \mathrm{O}_{3}$ & 0.030 & 0.016 & 0.020 & 0.010 & 0.030 & 0.020 & 0.020 & 0.009 & 0.020 \\
\hline $\mathrm{Cs}_{2} \mathrm{O}$ & 0.150 & - & - & - & 0.150 & - & - & 0.149 & - \\
\hline $\mathrm{F}$ & 0.150 & 0.227 & 0.250 & 0.200 & 0.080 & 0.060 & 0.060 & 0.283 & 0.140 \\
\hline
\end{tabular}


Table B.1. (contd)

\begin{tabular}{|c|c|c|c|c|c|c|c|c|c|}
\hline Glass ID & $\mathrm{C} 22 \mathrm{Si}+15$ & $\mathrm{C} 22 \mathrm{Si}-15$ & LAWA102R1 & LAWA104 & LAWA105 & LAWA112B14 & LAWA112B15 & LAWA125 & LAWA126 \\
\hline $\mathrm{Al}_{2} \mathrm{O}_{3}$ & 6.043 & 6.160 & 6.040 & 6.614 & 7.027 & 6.095 & 6.154 & 5.637 & 5.637 \\
\hline $\mathrm{B}_{2} \mathrm{O}_{3}$ & 9.837 & 10.291 & 9.968 & 8.591 & 8.281 & 9.861 & 9.801 & 9.545 & 9.815 \\
\hline $\mathrm{CaO}$ & 4.994 & 5.218 & 5.044 & 1.924 & 1.854 & 7.643 & 7.603 & 1.939 & 1.989 \\
\hline $\mathrm{Fe}_{2} \mathrm{O}_{3}$ & 5.358 & 5.555 & 5.383 & 6.735 & 6.490 & 0.000 & 0.000 & 5.387 & 5.537 \\
\hline $\mathrm{K}_{2} \mathrm{O}$ & 0.095 & 0.076 & 0.259 & 0.551 & 0.602 & 1.888 & 2.408 & 4.208 & 3.878 \\
\hline $\mathrm{Li}_{2} \mathrm{O}$ & 2.459 & 2.572 & 2.492 & 0.000 & 0.000 & 0.000 & 0.000 & 0.000 & 0.000 \\
\hline $\mathrm{MgO}$ & 1.484 & 1.551 & 1.485 & 1.924 & 1.854 & 1.479 & 1.479 & 1.439 & 1.479 \\
\hline $\mathrm{Na}_{2} \mathrm{O}$ & 16.197 & 12.812 & 14.503 & 22.001 & 24.006 & 19.982 & 19.982 & 19.990 & 18.451 \\
\hline $\mathrm{SO}_{3}$ & 0.31 & 0.23 & 0.67 & 0.10 & 0.09 & 0.16 & 0.11 & 0.31 & 0.31 \\
\hline $\mathrm{SiO}_{2}$ & 45.581 & 47.680 & 46.350 & 42.989 & 41.430 & 44.220 & 43.980 & 42.888 & 44.098 \\
\hline $\mathrm{TiO}_{2}$ & 1.121 & 1.175 & 1.136 & 1.924 & 1.854 & 1.998 & 1.988 & 1.939 & 1.999 \\
\hline $\mathrm{ZnO}$ & 3.001 & 3.139 & 3.050 & 2.861 & 2.757 & 2.967 & 2.947 & 2.879 & 2.959 \\
\hline $\mathrm{ZrO}_{2}$ & 2.960 & 3.096 & 3.010 & 2.886 & 2.782 & 3.007 & 2.987 & 2.909 & 2.989 \\
\hline $\mathrm{Cl}$ & 0.090 & 0.071 & 0.329 & 0.717 & 0.782 & 0.380 & 0.310 & 0.220 & 0.200 \\
\hline $\mathrm{Cr}_{2} \mathrm{O}_{3}$ & 0.020 & 0.017 & 0.020 & 0.022 & 0.024 & 0.020 & 0.010 & 0.020 & 0.020 \\
\hline $\mathrm{Cs}_{2} \mathrm{O}$ & - & - & - & 0.001 & 0.002 & - & - & 0.180 & 0.160 \\
\hline $\mathrm{F}$ & 0.160 & 0.129 & 0.030 & 0.011 & 0.012 & 0.100 & 0.090 & 0.320 & 0.300 \\
\hline
\end{tabular}


Table B.1. (contd)

\begin{tabular}{|c|c|c|c|c|c|c|c|c|c|}
\hline Glass ID & LAWA127R1 & LAWA127R2 & LAWA128 & LAWA129 & LAWA130 & LAWA133 & LAWA134 & LAWA135 & LAWA136 \\
\hline $\mathrm{Al}_{2} \mathrm{O}_{3}$ & 5.651 & 5.658 & 6.027 & 7.466 & 6.025 & 6.204 & 5.647 & 5.655 & 5.655 \\
\hline $\mathrm{B}_{2} \mathrm{O}_{3}$ & 10.205 & 10.217 & 7.066 & 8.515 & 8.943 & 8.901 & 9.964 & 10.092 & 10.092 \\
\hline $\mathrm{CaO}$ & 2.068 & 2.069 & 2.079 & 3.528 & 2.078 & 5.485 & 2.019 & 2.048 & 3.048 \\
\hline $\mathrm{Fe}_{2} \mathrm{O}_{3}$ & 5.758 & 5.768 & 5.787 & 0.000 & 2.858 & 3.487 & 5.627 & 5.695 & 5.695 \\
\hline $\mathrm{K}_{2} \mathrm{O}$ & 3.430 & 3.429 & 3.878 & 3.878 & 3.877 & 0.430 & 3.728 & 3.577 & 3.577 \\
\hline $\mathrm{Li}_{2} \mathrm{O}$ & 0.000 & 0.000 & 0.000 & 0.000 & 0.000 & 0.000 & 0.000 & 0.000 & 0.000 \\
\hline $\mathrm{MgO}$ & 1.536 & 1.540 & 1.179 & 1.179 & 1.179 & 1.998 & 1.499 & 1.519 & 1.519 \\
\hline $\mathrm{Na}_{2} \mathrm{O}$ & 16.312 & 16.305 & 18.451 & 18.449 & 18.445 & 19.980 & 17.729 & 17.016 & 17.016 \\
\hline $\mathrm{SO}_{3}$ & 0.18 & 0.21 & 0.30 & 0.31 & 0.33 & 0.20 & 0.28 & 0.27 & 0.27 \\
\hline $\mathrm{SiO}_{2}$ & 45.828 & 45.886 & 46.067 & 47.511 & 46.053 & 44.535 & 44.753 & 45.304 & 44.304 \\
\hline $\mathrm{TiO}_{2}$ & 2.073 & 2.079 & 2.089 & 2.089 & 2.088 & 1.998 & 2.029 & 2.048 & 2.048 \\
\hline $\mathrm{ZnO}$ & 3.071 & 3.079 & 3.088 & 3.088 & 4.137 & 2.967 & 2.998 & 3.038 & 3.038 \\
\hline $\mathrm{ZrO}_{2}$ & 3.110 & 3.119 & 3.128 & 3.128 & 3.127 & 2.997 & 3.038 & 3.078 & 3.078 \\
\hline $\mathrm{Cl}$ & 0.181 & 0.180 & 0.200 & 0.200 & 0.200 & 0.559 & 0.200 & 0.190 & 0.190 \\
\hline $\mathrm{Cr}_{2} \mathrm{O}_{3}$ & 0.019 & 0.020 & 0.020 & 0.020 & 0.020 & 0.020 & 0.020 & 0.020 & 0.020 \\
\hline $\mathrm{Cs}_{2} \mathrm{O}$ & 0.145 & - & 0.160 & 0.160 & 0.160 & - & - & - & - \\
\hline $\mathrm{F}$ & 0.265 & 0.270 & 0.300 & 0.300 & 0.300 & 0.040 & 0.290 & 0.280 & 0.280 \\
\hline
\end{tabular}


Table B.1. (contd)

\begin{tabular}{|c|c|c|c|c|c|c|c|c|c|}
\hline Glass ID & LAWA41 & LAWA42 & LAWA43-1 & LAWA44 & LAWA44R10 & LAWA45 & LAWA49 & LAWA50 & LAWA51 \\
\hline $\mathrm{Al}_{2} \mathrm{O}_{3}$ & 6.203 & 6.204 & 12.002 & 6.202 & 6.202 & 6.201 & 6.203 & 6.201 & 6.203 \\
\hline $\mathrm{B}_{2} \mathrm{O}_{3}$ & 7.501 & 9.034 & 7.391 & 8.903 & 8.903 & 11.901 & 8.904 & 8.902 & 11.976 \\
\hline $\mathrm{CaO}$ & 2.000 & 2.404 & 1.967 & 1.991 & 1.991 & 0.000 & 0.000 & 0.000 & 0.000 \\
\hline $\mathrm{Fe}_{2} \mathrm{O}_{3}$ & 6.983 & 8.411 & 6.881 & 6.982 & 6.982 & 6.980 & 9.982 & 11.981 & 6.998 \\
\hline $\mathrm{K}_{2} \mathrm{O}$ & 3.101 & 3.101 & 3.101 & 0.500 & 0.500 & 0.501 & 0.501 & 0.501 & 0.451 \\
\hline $\mathrm{Li}_{2} \mathrm{O}$ & 0.000 & 0.001 & 0.001 & 0.000 & 0.000 & 0.000 & 0.000 & 0.000 & 0.000 \\
\hline $\mathrm{MgO}$ & 1.995 & 2.402 & 1.965 & 1.991 & 1.991 & 1.477 & 1.478 & 1.477 & 1.484 \\
\hline $\mathrm{Na}_{2} \mathrm{O}$ & 20.002 & 20.004 & 20.004 & 20.006 & 20.006 & 20.000 & 20.005 & 20.000 & 18.003 \\
\hline $\mathrm{SO}_{3}$ & 0.10 & 0.10 & 0.10 & 0.10 & 0.09 & 0.10 & 0.07 & 0.10 & 0.07 \\
\hline $\mathrm{SiO}_{2}$ & 43.414 & 38.007 & 38.007 & 44.563 & 44.563 & 44.552 & 44.565 & 42.550 & 46.579 \\
\hline $\mathrm{TiO}_{2}$ & 1.995 & 2.403 & 1.966 & 1.991 & 1.991 & 1.994 & 1.995 & 1.994 & 1.996 \\
\hline $\mathrm{ZnO}$ & 2.993 & 3.605 & 2.949 & 2.971 & 2.971 & 2.477 & 2.478 & 2.477 & 2.488 \\
\hline $\mathrm{ZrO}_{2}$ & 2.995 & 3.607 & 2.951 & 2.991 & 2.991 & 2.992 & 2.992 & 2.992 & 2.998 \\
\hline $\mathrm{Cl}$ & 0.580 & 0.579 & 0.579 & 0.650 & 0.650 & 0.652 & 0.652 & 0.652 & 0.587 \\
\hline $\mathrm{Cr}_{2} \mathrm{O}_{3}$ & 0.017 & 0.017 & 0.017 & 0.020 & 0.020 & 0.020 & 0.020 & 0.020 & 0.018 \\
\hline $\mathrm{Cs}_{2} \mathrm{O}$ & - & - & - & - & - & - & 0.001 & - & 0.001 \\
\hline $\mathrm{F}$ & 0.040 & 0.036 & 0.036 & 0.010 & 0.010 & 0.010 & 0.010 & 0.010 & 0.009 \\
\hline
\end{tabular}


Table B.1. (contd)

\begin{tabular}{|c|c|c|c|c|c|c|c|c|c|}
\hline Glass ID & LAWA52 & LAWA53 & LAWA56 & LAWA60 & LAWA65 & LAWA76 & LAWA81 & LAWA82 & LAWA83 \\
\hline $\mathrm{Al}_{2} \mathrm{O}_{3}$ & 6.179 & 6.145 & 6.151 & 8.528 & 6.155 & 6.132 & 6.201 & 6.201 & 6.201 \\
\hline $\mathrm{B}_{2} \mathrm{O}_{3}$ & 6.191 & 6.165 & 12.050 & 11.228 & 6.167 & 10.916 & 8.902 & 8.902 & 8.902 \\
\hline $\mathrm{CaO}$ & 7.882 & 7.840 & 1.970 & 4.321 & 3.289 & 7.822 & 3.989 & 0.000 & 1.994 \\
\hline $\mathrm{Fe}_{2} \mathrm{O}_{3}$ & 7.505 & 7.467 & 7.474 & 0.000 & 7.476 & 7.448 & 6.980 & 6.980 & 4.986 \\
\hline $\mathrm{K}_{2} \mathrm{O}$ & 0.501 & 0.494 & 0.495 & 0.501 & 0.499 & 0.497 & 0.501 & 0.501 & 0.501 \\
\hline $\mathrm{Li}_{2} \mathrm{O}$ & 0.000 & 0.000 & 0.000 & 0.000 & 0.000 & 4.985 & 0.000 & 0.000 & 0.000 \\
\hline $\mathrm{MgO}$ & 1.477 & 1.473 & 1.475 & 1.994 & 6.034 & 1.466 & 1.994 & 1.994 & 1.994 \\
\hline $\mathrm{Na}_{2} \mathrm{O}$ & 19.999 & 19.898 & 19.918 & 19.999 & 19.924 & 10.098 & 20.000 & 20.000 & 20.000 \\
\hline $\mathrm{SO}_{3}$ & 0.10 & 0.62 & 0.52 & 0.10 & 0.48 & 0.86 & 0.10 & 0.10 & 0.10 \\
\hline $\mathrm{SiO}_{2}$ & 42.247 & 42.036 & 42.079 & 44.551 & 42.087 & 41.919 & 44.552 & 44.552 & 44.552 \\
\hline $\mathrm{TiO}_{2}$ & 1.108 & 1.100 & 1.101 & 1.994 & 1.104 & 1.100 & 0.000 & 3.989 & 1.994 \\
\hline $\mathrm{ZnO}$ & 2.994 & 2.977 & 2.980 & 2.965 & 2.983 & 2.971 & 2.965 & 2.965 & 2.965 \\
\hline $\mathrm{ZrO}_{2}$ & 2.992 & 2.977 & 2.980 & 2.992 & 2.980 & 2.969 & 2.992 & 2.992 & 2.992 \\
\hline $\mathrm{Cl}$ & 0.652 & 0.646 & 0.646 & 0.652 & 0.649 & 0.647 & 0.652 & 0.652 & 0.652 \\
\hline $\mathrm{Cr}_{2} \mathrm{O}_{3}$ & 0.020 & 0.020 & 0.020 & 0.020 & 0.020 & 0.019 & 0.020 & 0.020 & 0.020 \\
\hline $\mathrm{Cs}_{2} \mathrm{O}$ & 0.001 & - & - & 0.001 & - & - & - & - & - \\
\hline $\mathrm{F}$ & 0.010 & 0.010 & 0.010 & 0.010 & 0.010 & 0.010 & 0.010 & 0.010 & 0.010 \\
\hline
\end{tabular}


Table B.1. (contd)

\begin{tabular}{|c|c|c|c|c|c|c|c|c|c|}
\hline Glass ID & LAWA84 & LAWA87 & LAWA88 & LAWA88R1 & LAWA89 & LAWA90 & LAWA93 & LAWA96 & LAWB30 \\
\hline $\mathrm{Al}_{2} \mathrm{O}_{3}$ & 6.201 & 4.481 & 6.082 & 6.082 & 6.082 & 6.082 & 6.179 & 6.201 & 8.604 \\
\hline $\mathrm{B}_{2} \mathrm{O}_{3}$ & 8.902 & 8.874 & 9.700 & 9.700 & 9.700 & 9.700 & 11.095 & 7.904 & 10.039 \\
\hline $\mathrm{CaO}$ & 1.994 & 1.992 & 1.992 & 1.991 & 0.000 & 3.983 & 7.882 & 3.989 & 7.235 \\
\hline $\mathrm{Fe}_{2} \mathrm{O}_{3}$ & 2.992 & 6.971 & 5.533 & 5.532 & 5.533 & 5.533 & 7.505 & 2.992 & 8.276 \\
\hline $\mathrm{K}_{2} \mathrm{O}$ & 0.501 & 2.583 & 2.583 & 2.581 & 2.583 & 2.583 & 0.501 & 0.501 & 0.323 \\
\hline $\mathrm{Li}_{2} \mathrm{O}$ & 0.000 & 0.000 & 0.000 & 0.000 & 0.000 & 0.000 & 5.067 & 0.000 & 4.070 \\
\hline $\mathrm{MgO}$ & 1.994 & 1.992 & 1.475 & 1.475 & 1.475 & 1.475 & 1.477 & 1.994 & 3.075 \\
\hline $\mathrm{Na}_{2} \mathrm{O}$ & 20.000 & 20.005 & 20.005 & 20.006 & 20.005 & 20.005 & 10.027 & 20.000 & 7.902 \\
\hline $\mathrm{SO}_{3}$ & 0.10 & 0.19 & 0.19 & 0.19 & 0.19 & 0.19 & 0.10 & 0.10 & 0.18 \\
\hline $\mathrm{SiO}_{2}$ & 44.552 & 44.467 & 44.002 & 44.004 & 44.002 & 44.002 & 42.247 & 43.555 & 42.730 \\
\hline $\mathrm{TiO}_{2}$ & 1.994 & 1.992 & 1.992 & 1.991 & 3.983 & 0.000 & 1.108 & 1.994 & 0.000 \\
\hline $\mathrm{ZnO}$ & 2.965 & 2.958 & 2.951 & 2.951 & 2.951 & 2.951 & 2.994 & 2.965 & 4.115 \\
\hline $\mathrm{ZrO}_{2}$ & 2.992 & 2.988 & 2.988 & 2.987 & 2.988 & 2.988 & 2.992 & 2.992 & 3.120 \\
\hline $\mathrm{Cl}$ & 0.652 & 0.329 & 0.329 & 0.330 & 0.329 & 0.329 & 0.652 & 0.652 & 0.007 \\
\hline $\mathrm{Cr}_{2} \mathrm{O}_{3}$ & 0.020 & 0.009 & 0.009 & 0.010 & 0.009 & 0.009 & 0.020 & 0.020 & 0.086 \\
\hline $\mathrm{Cs}_{2} \mathrm{O}$ & - & - & - & - & - & - & 0.001 & - & 0.002 \\
\hline $\mathrm{F}$ & 0.010 & - & - & - & - & - & 0.010 & 0.010 & 0.097 \\
\hline
\end{tabular}


Table B.1. (contd)

\begin{tabular}{|c|c|c|c|c|c|c|c|c|c|}
\hline Glass ID & LAWB31 & LAWB32 & LAWB33 & LAWB34 & LAWB35 & LAWB37 & LAWB38 & LAWB40 & LAWB41 \\
\hline $\mathrm{Al}_{2} \mathrm{O}_{3}$ & 6.183 & 6.180 & 6.175 & 6.178 & 6.178 & 6.166 & 6.156 & 6.137 & 6.145 \\
\hline $\mathrm{B}_{2} \mathrm{O}_{3}$ & 12.141 & 15.146 & 12.125 & 12.131 & 12.132 & 12.108 & 12.088 & 12.052 & 12.067 \\
\hline $\mathrm{CaO}$ & 4.047 & 4.045 & 4.042 & 6.065 & 4.044 & 4.709 & 4.746 & 4.687 & 6.481 \\
\hline $\mathrm{Fe}_{2} \mathrm{O}_{3}$ & 7.195 & 4.180 & 5.164 & 5.167 & 5.167 & 5.157 & 5.149 & 5.133 & 5.140 \\
\hline $\mathrm{K}_{2} \mathrm{O}$ & 0.320 & 0.320 & 0.320 & 0.320 & 0.320 & 0.319 & 0.319 & 0.318 & 0.318 \\
\hline $\mathrm{Li}_{2} \mathrm{O}$ & 2.968 & 2.966 & 2.964 & 2.965 & 2.966 & 2.960 & 3.806 & 6.294 & 4.514 \\
\hline $\mathrm{SO}_{3}$ & 0.63 & 0.68 & 0.76 & 0.71 & 0.70 & 0.90 & 1.06 & 1.36 & 1.23 \\
\hline $\mathrm{SiO}_{2}$ & 47.101 & 47.077 & 47.039 & 47.063 & 47.067 & 46.973 & 46.897 & 46.755 & 46.816 \\
\hline $\mathrm{TiO}_{2}$ & 0.000 & 0.000 & 0.000 & 0.000 & 0.000 & 0.000 & 0.000 & 0.000 & 0.000 \\
\hline $\mathrm{ZnO}$ & 3.103 & 3.101 & 3.099 & 3.100 & 3.100 & 3.094 & 3.089 & 3.080 & 3.084 \\
\hline $\mathrm{ZrO}_{2}$ & 3.103 & 3.101 & 3.099 & 3.100 & 3.100 & 3.094 & 3.089 & 3.080 & 3.084 \\
\hline $\mathrm{Cl}$ & 0.007 & 0.007 & 0.007 & 0.007 & 0.007 & 0.007 & 0.007 & 0.007 & 0.007 \\
\hline $\mathrm{Cr}_{2} \mathrm{O}_{3}$ & 0.089 & 0.089 & 0.089 & 0.089 & 0.089 & 0.089 & 0.088 & 0.088 & 0.088 \\
\hline $\mathrm{Cs}_{2} \mathrm{O}$ & 0.002 & 0.002 & 0.002 & 0.002 & 0.002 & 0.002 & 0.002 & 0.002 & 0.002 \\
\hline $\mathrm{F}$ & 0.099 & 0.099 & 0.099 & 0.099 & 0.099 & 0.099 & 0.099 & 0.098 & 0.099 \\
\hline
\end{tabular}


Table B.1. (contd)

\begin{tabular}{|c|c|c|c|c|c|c|c|c|c|}
\hline Glass ID & LAWB60 & LAWB61 & LAWB62 & LAWB63 & LAWB64 & LAWB65 & LAWB66 & LAWB67 & LAWB68 \\
\hline $\mathrm{Al}_{2} \mathrm{O}_{3}$ & 6.143 & 6.205 & 6.194 & 6.579 & 6.207 & 6.188 & 6.203 & 6.189 & 6.192 \\
\hline $\mathrm{B}_{2} \mathrm{O}_{3}$ & 12.366 & 9.966 & 9.948 & 9.953 & 9.969 & 9.939 & 9.963 & 9.940 & 8.440 \\
\hline $\mathrm{CaO}$ & 11.905 & 6.708 & 11.996 & 9.351 & 6.710 & 6.690 & 8.214 & 5.186 & 8.199 \\
\hline $\mathrm{Fe}_{2} \mathrm{O}_{3}$ & 0.000 & 5.310 & 0.000 & 0.000 & 3.300 & 5.295 & 5.308 & 5.296 & 5.299 \\
\hline $\mathrm{K}_{2} \mathrm{O}$ & 0.261 & 0.261 & 0.261 & 0.261 & 0.262 & 0.261 & 0.261 & 0.261 & 0.261 \\
\hline $\mathrm{Li}_{2} \mathrm{O}$ & 4.630 & 5.823 & 5.812 & 5.052 & 5.825 & 4.303 & 4.313 & 4.303 & 4.305 \\
\hline $\mathrm{MgO}$ & 2.976 & 2.977 & 2.971 & 2.973 & 2.978 & 2.969 & 2.976 & 2.969 & 2.970 \\
\hline $\mathrm{Na}_{2} \mathrm{O}$ & 6.514 & 5.501 & 5.491 & 5.494 & 5.503 & 5.476 & 5.489 & 5.487 & 5.479 \\
\hline $\mathrm{SO}_{3}$ & 0.64 & 0.71 & 0.89 & 0.84 & 0.68 & 0.89 & 0.65 & 0.97 & 0.83 \\
\hline $\mathrm{SiO}_{2}$ & 47.961 & 48.624 & 48.536 & 48.942 & 48.639 & 48.492 & 48.609 & 48.497 & 48.521 \\
\hline $\mathrm{TiO}_{2}$ & 0.000 & 1.398 & 1.395 & 1.396 & 1.398 & 1.394 & 1.397 & 1.394 & 1.395 \\
\hline $\mathrm{ZnO}$ & 3.157 & 3.168 & 3.162 & 5.815 & 5.181 & 4.664 & 3.167 & 3.160 & 4.666 \\
\hline $\mathrm{ZrO}_{2}$ & 3.157 & 3.168 & 3.162 & 3.164 & 3.169 & 3.159 & 3.167 & 3.160 & 3.161 \\
\hline $\mathrm{Cl}$ & 0.010 & - & - & - & - & - & - & - & - \\
\hline $\mathrm{Cr}_{2} \mathrm{O}_{3}$ & 0.070 & 0.101 & 0.100 & 0.100 & 0.101 & 0.100 & 0.101 & 0.100 & 0.100 \\
\hline $\mathrm{Cs}_{2} \mathrm{O}$ & - & - & - & - & - & - & - & - & - \\
\hline $\mathrm{F}$ & 0.080 & 0.070 & 0.070 & 0.070 & 0.070 & 0.070 & 0.070 & 0.070 & 0.070 \\
\hline
\end{tabular}


Table B.1. (contd)

\begin{tabular}{|c|c|c|c|c|c|c|c|c|c|}
\hline Glass ID & LAWB69 & LAWB70 & LAWB71 & LAWB72 & LAWB73 & LAWB74 & LAWB75 & LAWB76 & LAWB77 \\
\hline $\mathrm{Al}_{2} \mathrm{O}_{3}$ & 6.151 & 6.159 & 6.162 & 6.154 & 6.193 & 6.218 & 6.187 & 6.186 & 6.160 \\
\hline $\mathrm{B}_{2} \mathrm{O}_{3}$ & 12.332 & 12.347 & 10.802 & 12.339 & 9.947 & 10.108 & 11.792 & 11.790 & 12.350 \\
\hline $\mathrm{CaO}$ & 10.462 & 6.629 & 6.633 & 7.125 & 9.345 & 8.728 & 8.684 & 8.682 & 6.631 \\
\hline $\mathrm{Fe}_{2} \mathrm{O}_{3}$ & 0.000 & 3.255 & 3.257 & 3.252 & 1.907 & 1.915 & 1.905 & 1.905 & 2.204 \\
\hline $\mathrm{K}_{2} \mathrm{O}$ & 0.230 & 0.230 & 0.230 & 0.230 & 0.261 & 0.262 & 0.261 & 0.261 & 0.230 \\
\hline $\mathrm{Li}_{2} \mathrm{O}$ & 4.611 & 4.616 & 4.619 & 4.113 & 5.049 & 5.331 & 5.304 & 5.805 & 4.117 \\
\hline $\mathrm{MgO}$ & 2.971 & 2.974 & 2.976 & 2.972 & 2.971 & 2.983 & 1.504 & 1.504 & 2.975 \\
\hline $\mathrm{Na}_{2} \mathrm{O}$ & 6.621 & 6.629 & 6.633 & 6.625 & 5.490 & 5.513 & 5.485 & 5.484 & 6.631 \\
\hline $\mathrm{SO}_{3}$ & 0.65 & 0.54 & 0.48 & 0.61 & 0.90 & 0.77 & 1.00 & 1.02 & 0.52 \\
\hline $\mathrm{SiO}_{2}$ & 47.960 & 48.018 & 48.047 & 47.984 & 48.531 & 48.728 & 48.482 & 49.365 & 48.027 \\
\hline $\mathrm{TiO}_{2}$ & 0.000 & 0.000 & 1.553 & 0.000 & 1.395 & 1.401 & 1.394 & 0.000 & 1.552 \\
\hline $\mathrm{ZnO}$ & 4.571 & 5.157 & 5.160 & 5.154 & 4.667 & 4.686 & 4.663 & 4.662 & 5.158 \\
\hline $\mathrm{ZrO}_{2}$ & 3.151 & 3.154 & 3.156 & 3.152 & 3.162 & 3.175 & 3.159 & 3.158 & 3.155 \\
\hline $\mathrm{Cl}$ & 0.010 & 0.010 & 0.010 & 0.010 & - & - & - & - & 0.010 \\
\hline $\mathrm{Cr}_{2} \mathrm{O}_{3}$ & 0.050 & 0.050 & 0.050 & 0.050 & 0.100 & 0.101 & 0.100 & 0.100 & 0.050 \\
\hline $\mathrm{Cs}_{2} \mathrm{O}$ & - & - & - & - & - & - & - & - & - \\
\hline $\mathrm{F}$ & 0.080 & 0.080 & 0.080 & 0.080 & 0.070 & 0.071 & 0.070 & 0.070 & 0.080 \\
\hline
\end{tabular}


Table B.1. (contd)

\begin{tabular}{|c|c|c|c|c|c|c|c|c|c|}
\hline Glass ID & LAWB78 & LAWB79 & LAWB80 & LAWB81 & LAWB82 & LAWB83 & LAWB84 & LAWB85 & LAWB86 \\
\hline $\mathrm{Al}_{2} \mathrm{O}_{3}$ & 6.161 & 6.156 & 6.156 & 6.155 & 6.162 & 6.183 & 6.187 & 6.184 & 6.188 \\
\hline $\mathrm{B}_{2} \mathrm{O}_{3}$ & 12.351 & 12.342 & 12.341 & 12.340 & 10.100 & 10.035 & 10.041 & 11.527 & 12.426 \\
\hline $\mathrm{CaO}$ & 7.132 & 7.127 & 7.126 & 7.126 & 7.134 & 6.783 & 6.687 & 5.283 & 5.737 \\
\hline $\mathrm{Fe}_{2} \mathrm{O}_{3}$ & 3.256 & 3.253 & 3.253 & 3.253 & 9.519 & 5.293 & 5.296 & 5.293 & 5.297 \\
\hline $\mathrm{K}_{2} \mathrm{O}$ & 0.230 & 0.230 & 1.992 & 0.230 & 0.230 & 0.190 & 0.190 & 0.190 & 0.190 \\
\hline $\mathrm{Li}_{2} \mathrm{O}$ & 3.055 & 3.514 & 3.513 & 4.263 & 4.269 & 4.312 & 4.405 & 4.313 & 4.356 \\
\hline $\mathrm{MgO}$ & 2.975 & 2.973 & 2.973 & 2.972 & 1.483 & 2.971 & 2.973 & 2.972 & 2.974 \\
\hline $\mathrm{Na}_{2} \mathrm{O}$ & 9.797 & 8.629 & 6.626 & 6.625 & 6.633 & 5.473 & 5.476 & 5.473 & 5.477 \\
\hline $\mathrm{SO}_{3}$ & 0.51 & 0.58 & 0.58 & 0.60 & 0.48 & 0.49 & 0.44 & 0.49 & 0.43 \\
\hline $\mathrm{SiO}_{2}$ & 47.080 & 47.748 & 47.993 & 47.989 & 45.532 & 48.624 & 48.654 & 48.629 & 48.664 \\
\hline $\mathrm{TiO}_{2}$ & 0.000 & 0.000 & 0.000 & 0.000 & 0.000 & 1.391 & 1.392 & 1.391 & 0.000 \\
\hline $\mathrm{ZnO}$ & 4.007 & 4.004 & 4.004 & 5.004 & 5.010 & 4.842 & 4.845 & 4.843 & 4.846 \\
\hline $\mathrm{ZrO}_{2}$ & 3.155 & 3.153 & 3.153 & 3.153 & 3.156 & 3.162 & 3.163 & 3.162 & 3.164 \\
\hline $\mathrm{Cl}$ & 0.010 & 0.010 & 0.010 & 0.010 & 0.010 & 0.010 & 0.010 & 0.010 & 0.010 \\
\hline $\mathrm{Cr}_{2} \mathrm{O}_{3}$ & 0.050 & 0.050 & 0.050 & 0.050 & 0.050 & 0.040 & 0.040 & 0.040 & 0.040 \\
\hline $\mathrm{Cs}_{2} \mathrm{O}$ & - & - & - & - & - & - & - & - & - \\
\hline $\mathrm{F}$ & 0.080 & 0.080 & 0.080 & 0.080 & 0.080 & 0.060 & 0.060 & 0.060 & 0.060 \\
\hline
\end{tabular}


Table B.1. (contd)

\begin{tabular}{|c|c|c|c|c|c|c|c|c|c|}
\hline Glass ID & LAWB87 & LAWB88 & LAWB89 & LAWB90 & LAWB91 & LAWB92 & LAWB93 & LAWB94 & LAWB95 \\
\hline $\mathrm{Al}_{2} \mathrm{O}_{3}$ & 6.495 & 6.488 & 6.186 & 6.192 & 6.191 & 6.187 & 6.186 & 6.186 & 6.189 \\
\hline $\mathrm{B}_{2} \mathrm{O}_{3}$ & 13.020 & 13.006 & 10.040 & 10.050 & 10.047 & 10.041 & 10.039 & 10.031 & 10.035 \\
\hline $\mathrm{CaO}$ & 6.114 & 7.990 & 6.787 & 6.794 & 6.792 & 6.787 & 6.786 & 6.780 & 6.783 \\
\hline $\mathrm{Fe}_{2} \mathrm{O}_{3}$ & 5.032 & 2.203 & 5.295 & 5.301 & 5.299 & 5.296 & 5.295 & 5.295 & 5.297 \\
\hline $\mathrm{K}_{2} \mathrm{O}$ & 0.200 & 0.200 & 0.190 & 0.190 & 0.190 & 0.190 & 0.190 & 0.194 & 0.194 \\
\hline $\mathrm{Li}_{2} \mathrm{O}$ & 4.701 & 4.696 & 5.005 & 3.617 & 2.925 & 2.222 & 4.664 & 5.359 & 5.761 \\
\hline $\mathrm{MgO}$ & 1.413 & 1.412 & 2.973 & 2.976 & 2.975 & 2.973 & 2.973 & 2.972 & 2.973 \\
\hline $\mathrm{Na}_{2} \mathrm{O}$ & 5.012 & 5.006 & 4.084 & 6.884 & 8.735 & 10.121 & 4.784 & 3.385 & 2.457 \\
\hline $\mathrm{SO}_{3}$ & 0.57 & 0.68 & 0.44 & 0.34 & 0.37 & 0.43 & 0.45 & 0.50 & 0.46 \\
\hline $\mathrm{SiO}_{2}$ & 49.214 & 50.101 & 49.350 & 47.996 & 46.820 & 46.101 & 48.984 & 49.662 & 50.211 \\
\hline $\mathrm{TiO}_{2}$ & 0.000 & 0.000 & 1.391 & 1.393 & 1.392 & 1.392 & 1.391 & 1.393 & 1.394 \\
\hline $\mathrm{ZnO}$ & 4.891 & 4.886 & 4.845 & 4.850 & 4.848 & 4.845 & 4.844 & 4.839 & 4.841 \\
\hline $\mathrm{ZrO}_{2}$ & 3.197 & 3.194 & 3.163 & 3.166 & 3.165 & 3.163 & 3.163 & 3.158 & 3.159 \\
\hline $\mathrm{Cl}$ & 0.010 & 0.010 & 0.010 & 0.010 & 0.010 & 0.010 & 0.010 & 0.007 & 0.007 \\
\hline $\mathrm{Cr}_{2} \mathrm{O}_{3}$ & 0.060 & 0.060 & 0.040 & 0.040 & 0.040 & 0.040 & 0.040 & 0.039 & 0.039 \\
\hline $\mathrm{Cs}_{2} \mathrm{O}$ & - & - & - & - & - & - & - & - & - \\
\hline $\mathrm{F}$ & 0.050 & 0.050 & 0.060 & 0.060 & 0.060 & 0.060 & 0.060 & 0.064 & 0.064 \\
\hline
\end{tabular}


Table B.1. (contd)

\begin{tabular}{|c|c|c|c|c|c|c|c|c|c|}
\hline Glass ID & LAWC12 & LAWC15 & LAWC21 & LAWC21rev2 & LAWC22 & LAWC23 & LAWC24 & LAWC25 & LAWC26 \\
\hline $\mathrm{Al}_{2} \mathrm{O}_{3}$ & 11.989 & 6.221 & 6.139 & 6.125 & 6.076 & 6.118 & 5.955 & 5.784 & 6.121 \\
\hline $\mathrm{B}_{2} \mathrm{O}_{3}$ & 9.142 & 8.929 & 10.104 & 10.058 & 10.056 & 10.076 & 9.808 & 9.526 & 13.263 \\
\hline $\mathrm{CaO}$ & 1.596 & 2.006 & 6.419 & 6.415 & 5.110 & 6.401 & 6.231 & 6.052 & 6.411 \\
\hline $\mathrm{Fe}_{2} \mathrm{O}_{3}$ & 5.716 & 7.007 & 6.489 & 6.435 & 5.426 & 6.470 & 6.297 & 6.116 & 0.010 \\
\hline $\mathrm{K}_{2} \mathrm{O}$ & 0.141 & 0.142 & 0.150 & 0.140 & 0.083 & 2.881 & 5.558 & 8.079 & 0.140 \\
\hline $\mathrm{Li}_{2} \mathrm{O}$ & 0.000 & 0.000 & 2.744 & 2.732 & 2.506 & 0.000 & 0.000 & 0.000 & 2.731 \\
\hline $\mathrm{MgO}$ & 1.387 & 2.009 & 1.512 & 1.501 & 1.514 & 1.507 & 1.467 & 1.425 & 1.500 \\
\hline $\mathrm{Na}_{2} \mathrm{O}$ & 20.026 & 19.963 & 11.897 & 11.970 & 14.408 & 11.856 & 11.541 & 11.209 & 11.962 \\
\hline $\mathrm{SO}_{3}$ & 0.18 & 0.23 & 0.29 & 0.29 & 0.29 & 0.35 & 0.34 & 0.53 & 0.35 \\
\hline $\mathrm{SiO}_{2}$ & 39.384 & 44.713 & 46.766 & 46.778 & 46.642 & 46.763 & 45.429 & 44.122 & 49.960 \\
\hline $\mathrm{TiO}_{2}$ & 3.416 & 2.001 & 1.122 & 1.121 & 1.144 & 1.122 & 1.090 & 1.058 & 1.120 \\
\hline $\mathrm{ZnO}$ & 4.274 & 2.990 & 3.024 & 3.022 & 3.071 & 3.014 & 2.934 & 2.850 & 3.021 \\
\hline $\mathrm{ZrO}_{2}$ & 2.458 & 3.005 & 3.024 & 3.022 & 3.028 & 3.017 & 2.937 & 2.852 & 3.021 \\
\hline $\mathrm{Cl}$ & 0.119 & 0.078 & 0.120 & 0.110 & 0.048 & 0.123 & 0.120 & 0.117 & 0.110 \\
\hline $\mathrm{Cr}_{2} \mathrm{O}_{3}$ & 0.017 & 0.003 & 0.020 & 0.020 & 0.012 & 0.020 & 0.019 & 0.019 & 0.020 \\
\hline $\mathrm{Cs}_{2} \mathrm{O}$ & - & - & - & - & - & 0.000 & 0.000 & 0.000 & - \\
\hline $\mathrm{F}$ & 0.009 & 0.469 & 0.060 & 0.050 & 0.336 & 0.060 & 0.058 & 0.057 & 0.050 \\
\hline
\end{tabular}


Table B.1. (contd)

\begin{tabular}{|c|c|c|c|c|c|c|c|c|c|}
\hline Glass ID & LAWC27 & LAWC28 & LAWC29 & LAWC30 & LAWC31 & LAWC32 & LAWC33 & PNLA126CC & TFA-BASE \\
\hline $\mathrm{Al}_{2} \mathrm{O}_{3}$ & 6.117 & 6.117 & 6.551 & 6.122 & 6.119 & 6.490 & 6.146 & 5.652 & 6.999 \\
\hline $\mathrm{B}_{2} \mathrm{O}_{3}$ & 12.183 & 10.045 & 10.049 & 10.053 & 10.048 & 10.047 & 10.100 & 9.854 & 9.999 \\
\hline $\mathrm{CaO}$ & 8.544 & 12.814 & 9.617 & 6.412 & 7.409 & 9.038 & 6.947 & 2.001 & 0.010 \\
\hline $\mathrm{Fe}_{2} \mathrm{O}_{3}$ & 0.009 & 0.010 & 0.009 & 4.101 & 4.429 & 2.424 & 4.444 & 5.562 & 5.499 \\
\hline $\mathrm{K}_{2} \mathrm{O}$ & 0.136 & 0.140 & 0.136 & 0.140 & 0.140 & 0.136 & 0.140 & 3.882 & 0.410 \\
\hline $\mathrm{Li}_{2} \mathrm{O}$ & 2.733 & 2.729 & 2.734 & 2.731 & 2.729 & 2.734 & 2.753 & 0.000 & 0.000 \\
\hline $\mathrm{MgO}$ & 1.500 & 1.499 & 1.501 & 1.500 & 1.500 & 1.501 & 1.512 & 1.481 & 1.500 \\
\hline $\mathrm{Na}_{2} \mathrm{O}$ & 11.953 & 11.954 & 11.958 & 11.964 & 11.958 & 11.956 & 12.012 & 18.467 & 19.998 \\
\hline $\mathrm{SO}_{3}$ & 0.41 & 0.43 & 0.37 & 0.34 & 0.39 & 0.38 & 0.37 & 0.29 & 0.08 \\
\hline $\mathrm{SiO}_{2}$ & 48.868 & 46.717 & 47.181 & 46.754 & 46.731 & 46.744 & 46.977 & 44.238 & 49.065 \\
\hline $\mathrm{TiO}_{2}$ & 1.121 & 1.119 & 1.121 & 1.120 & 1.120 & 1.121 & 1.131 & 2.001 & 3.000 \\
\hline $\mathrm{ZnO}$ & 3.018 & 3.018 & 5.365 & 5.352 & 4.019 & 4.019 & 4.044 & 2.961 & 1.500 \\
\hline $\mathrm{ZrO}_{2}$ & 3.018 & 3.018 & 3.019 & 3.021 & 3.019 & 3.019 & 3.033 & 3.001 & 1.500 \\
\hline $\mathrm{Cl}$ & 0.111 & 0.110 & 0.112 & 0.110 & 0.110 & 0.111 & 0.110 & 0.200 & 0.280 \\
\hline $\mathrm{Cr}_{2} \mathrm{O}_{3}$ & 0.018 & 0.020 & 0.018 & 0.020 & 0.020 & 0.018 & 0.020 & 0.020 & - \\
\hline $\mathrm{Cs}_{2} \mathrm{O}$ & - & - & - & - & - & - & - & - & - \\
\hline $\mathrm{F}$ & 0.054 & 0.050 & 0.054 & 0.050 & 0.050 & 0.054 & 0.050 & 0.300 & 0.010 \\
\hline
\end{tabular}


Table B.1. (contd)

\begin{tabular}{lccc}
\hline \multicolumn{1}{c}{ Glass ID } & WVF-G-21B & WVH-G-57B & WVJ-G-109D \\
\hline $\mathrm{Al}_{2} \mathrm{O}_{3}$ & 6.079 & 6.102 & 6.174 \\
$\mathrm{~B}_{2} \mathrm{O}_{3}$ & 9.799 & 10.023 & 10.022 \\
$\mathrm{CaO}$ & 1.990 & 7.392 & 6.775 \\
$\mathrm{Fe}_{2} \mathrm{O}_{3}$ & 5.539 & 4.421 & 5.282 \\
$\mathrm{~K}_{2} \mathrm{O}$ & 2.130 & 0.140 & 0.190 \\
$\mathrm{Li}_{2} \mathrm{O}$ & 0.000 & 2.731 & 4.310 \\
$\mathrm{MgO}$ & 1.480 & 1.500 & 2.977 \\
$\mathrm{Na}_{2} \mathrm{O}$ & 20.008 & 11.934 & 5.472 \\
$\mathrm{SO}_{3}$ & 0.33 & 0.43 & 0.43 \\
$\mathrm{SiO}_{2}$ & 43.996 & 46.644 & 48.577 \\
$\mathrm{TiO}_{2}$ & 1.990 & 1.120 & 1.393 \\
$\mathrm{ZnO}_{2}$ & 2.950 & 4.011 & 4.841 \\
$\mathrm{ZrO}_{2}$ & 2.990 & 3.011 & 3.157 \\
$\mathrm{Cl}$ & 0.130 & 0.110 & 0.010 \\
$\mathrm{Cr}_{2} \mathrm{O}_{3}$ & 0.020 & 0.020 & 0.040 \\
$\mathrm{Cs}_{2} \mathrm{O}$ & 0.150 & 0.150 & 0.150 \\
$\mathrm{~F}$ & 0.230 & 0.050 & 0.060 \\
\hline
\end{tabular}




\section{Appendix C}

\section{PCT $\left(90^{\circ} \mathrm{C}\right)$ Modeling Results}




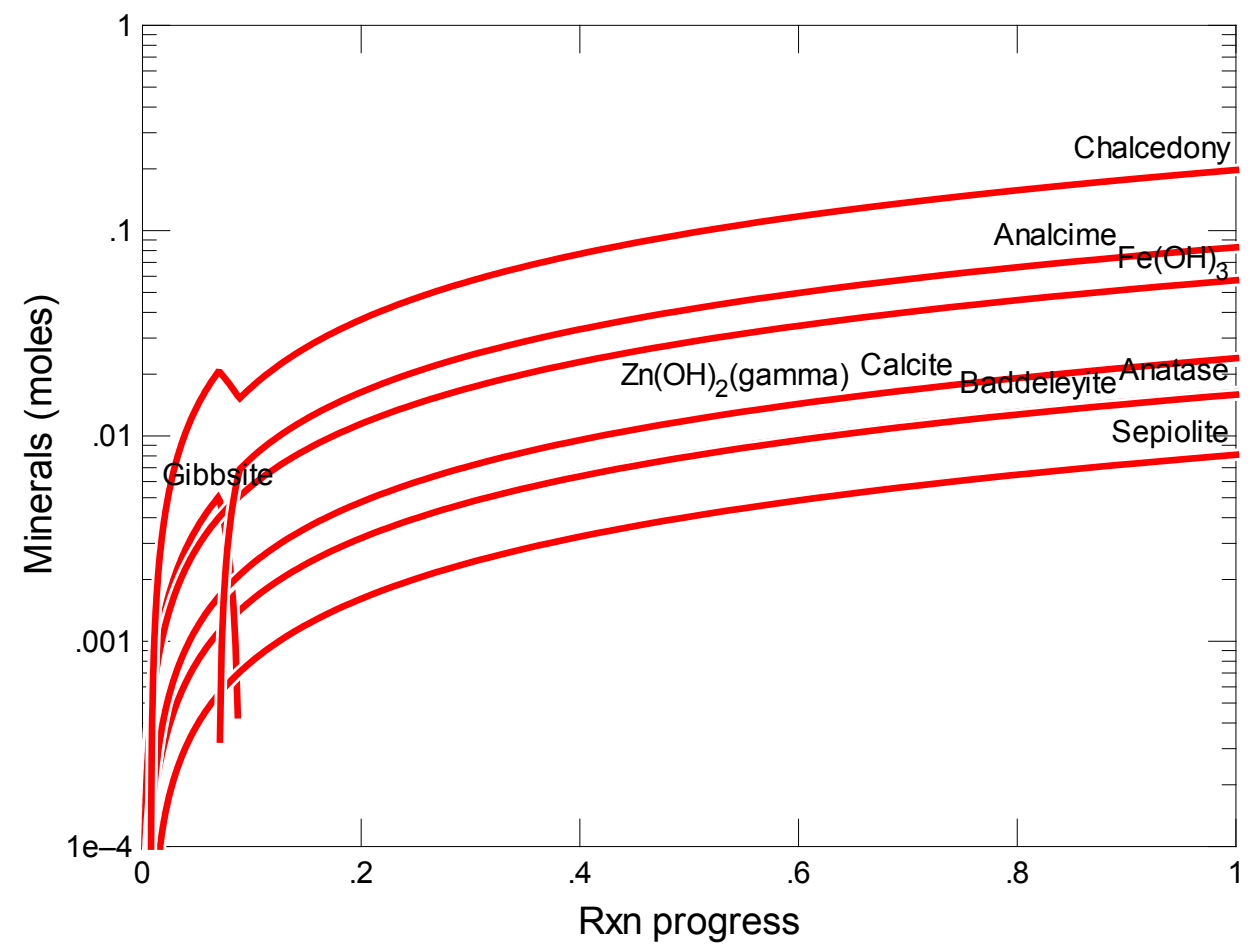

Figure C.1. Secondary Phases Calculated to Form as a Function of Reaction Progress (mol-glass $/ \mathrm{kg}$ ) Determined for Glass Sample A1-AN105R2

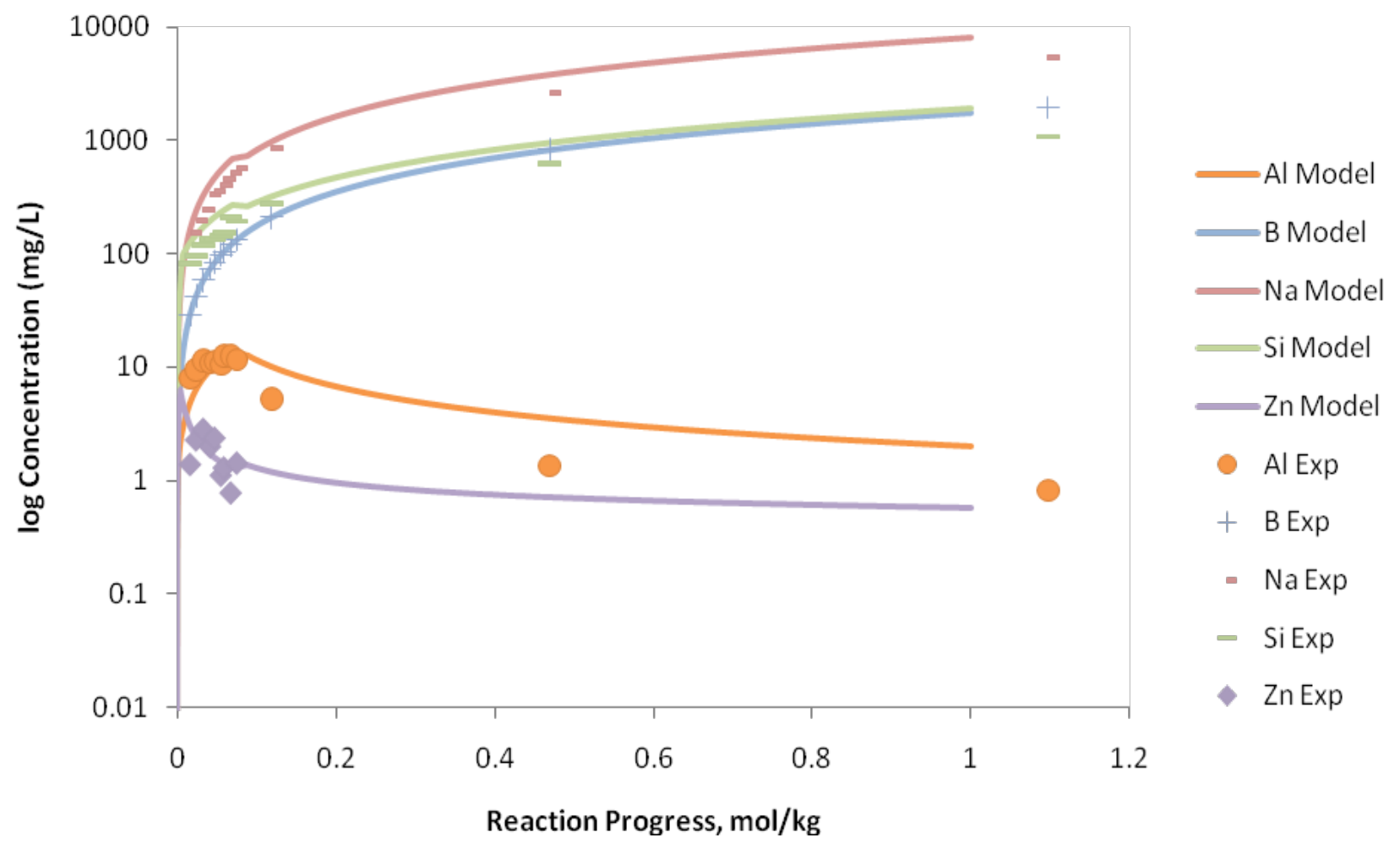

Figure C.2. Measured Solution Concentrations (mg/L) and Model Results for Al, B, Na, Si, and Zn, as a Function of Reaction Progress (mol-glass/kg) Determined for Glass Sample A1-AN105R2 


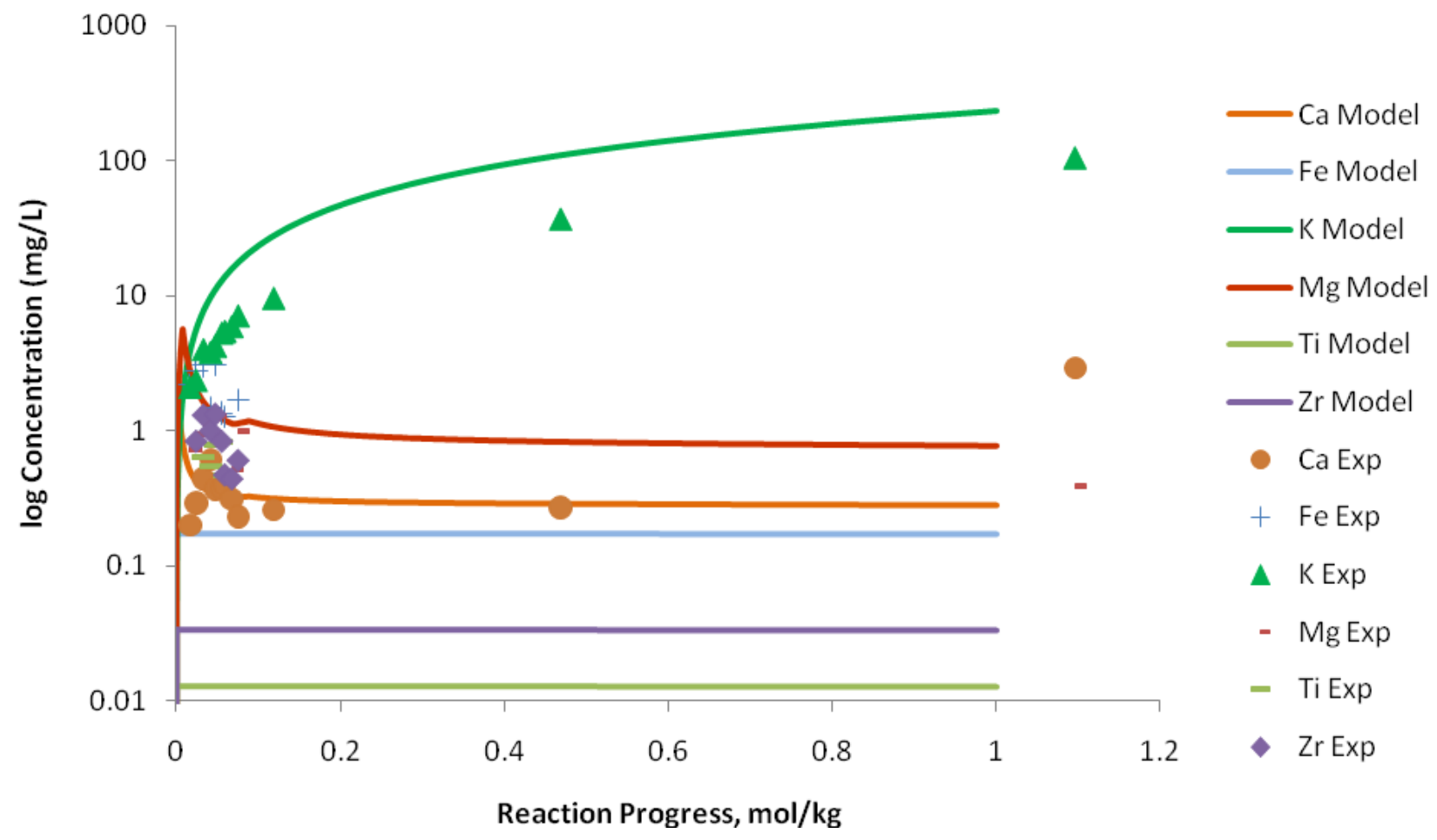

Figure C.3. Measured Solution Concentrations (mg/L) and Model Results for Ca, Fe, K, Li, Mg, Ti, and $\mathrm{Zr}$, as a Function of Reaction Progress (mol-glass/kg) Determined for Glass Sample A1-AN105R2

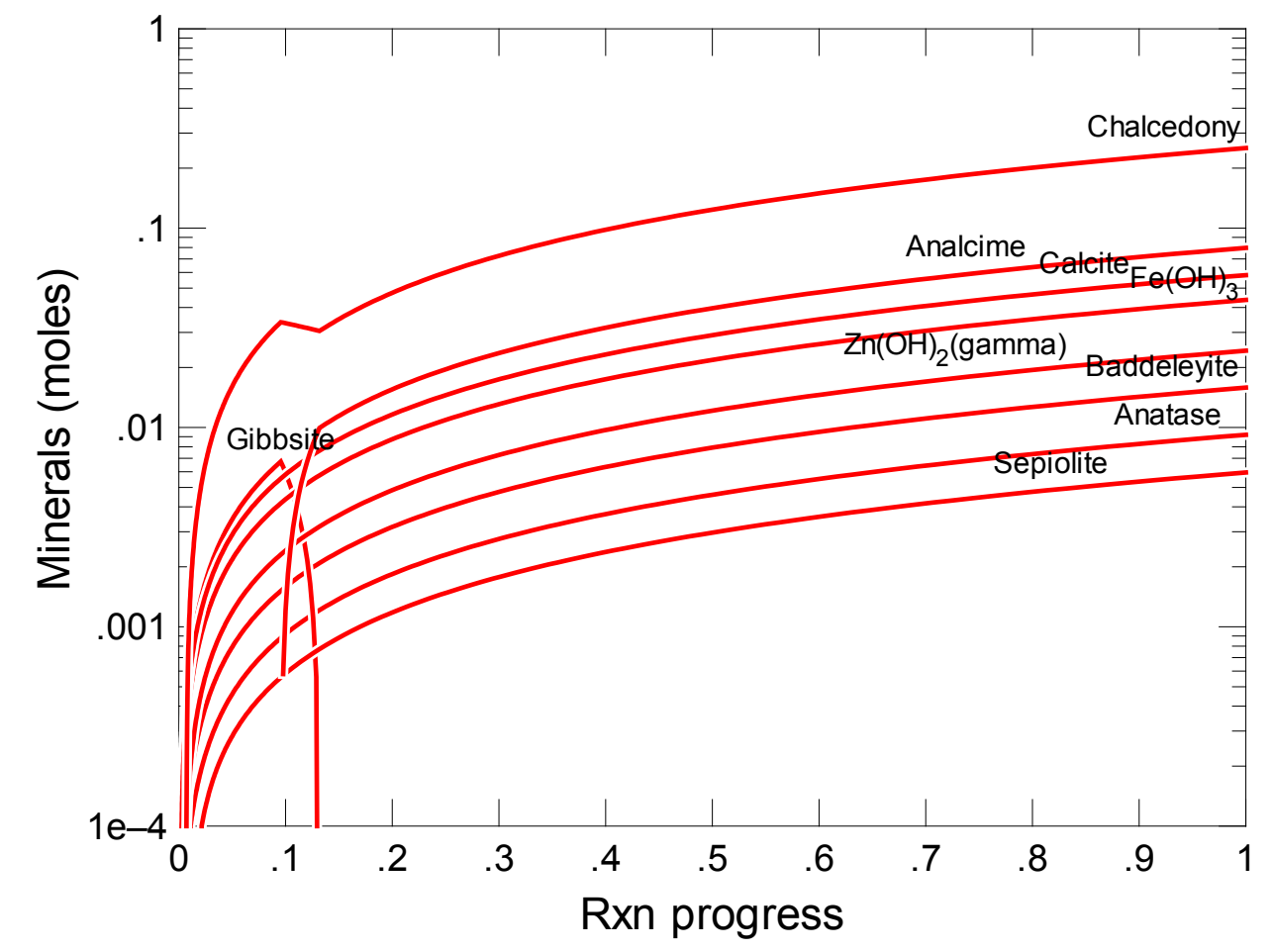

Figure C.4. Secondary Phases Calculated to Form as a Function of Reaction Progress (mol-glass/kg) Determined for Glass Sample A100CC 


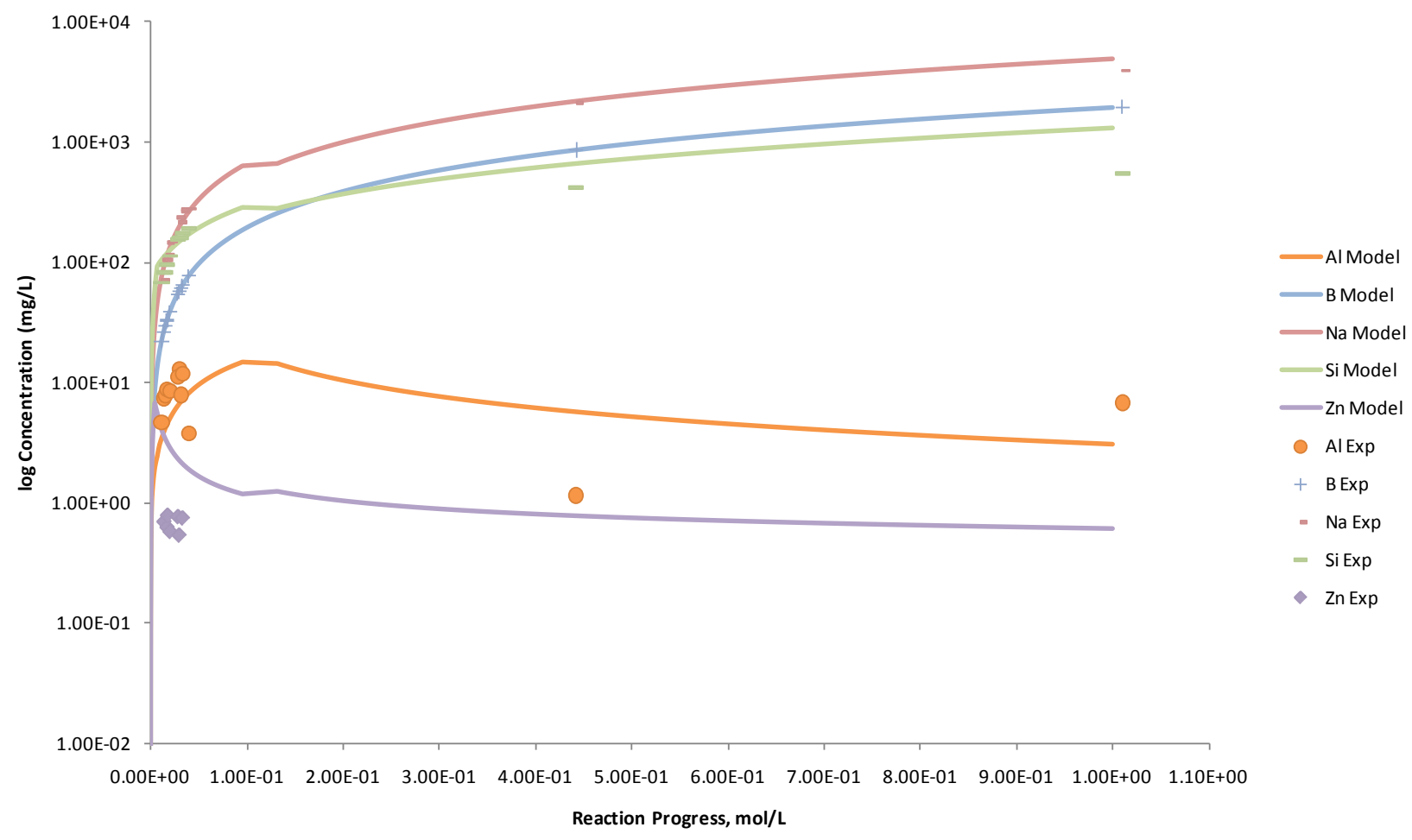

Figure C.5. Measured Solution Concentrations (mg/L) and Model Results for Al, B, Na, Si, and Zn, as a Function of Reaction Progress (mol-glass $/ \mathrm{kg}$ ) Determined for Glass Sample A100CC

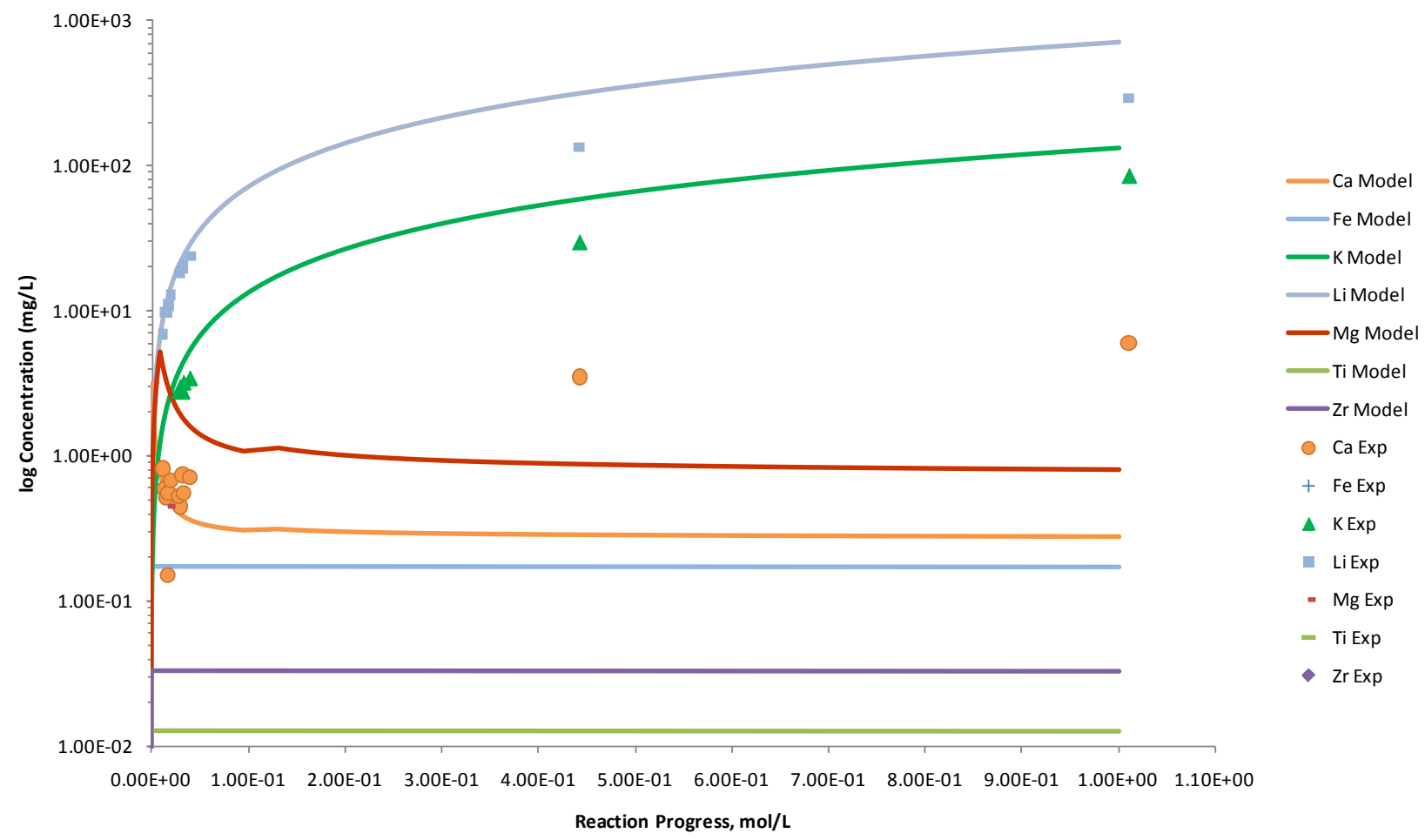

Figure C.6. Measured Solution Concentrations (mg/L) and Model Results for $\mathrm{Ca}, \mathrm{Fe}, \mathrm{K}, \mathrm{Li}, \mathrm{Mg}$, Ti, and $\mathrm{Zr}$, as a Function of Reaction Progress (mol-glass $/ \mathrm{kg}$ ) Determined for Glass Sample A100CC 


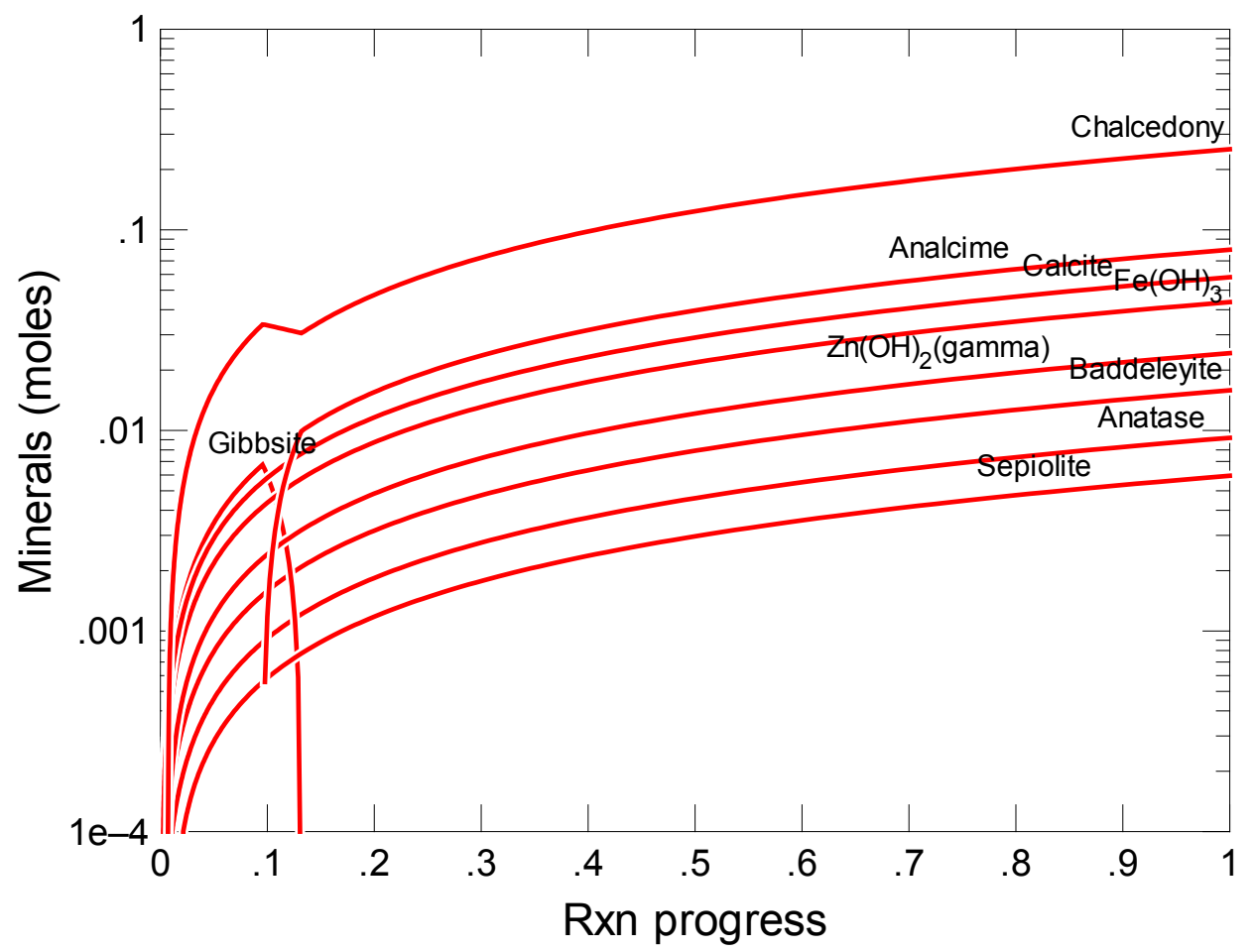

Figure C.7. Secondary Phases Calculated to Form as a Function of Reaction Progress (mol-glass/kg) Determined for Glass Sample A100G115A

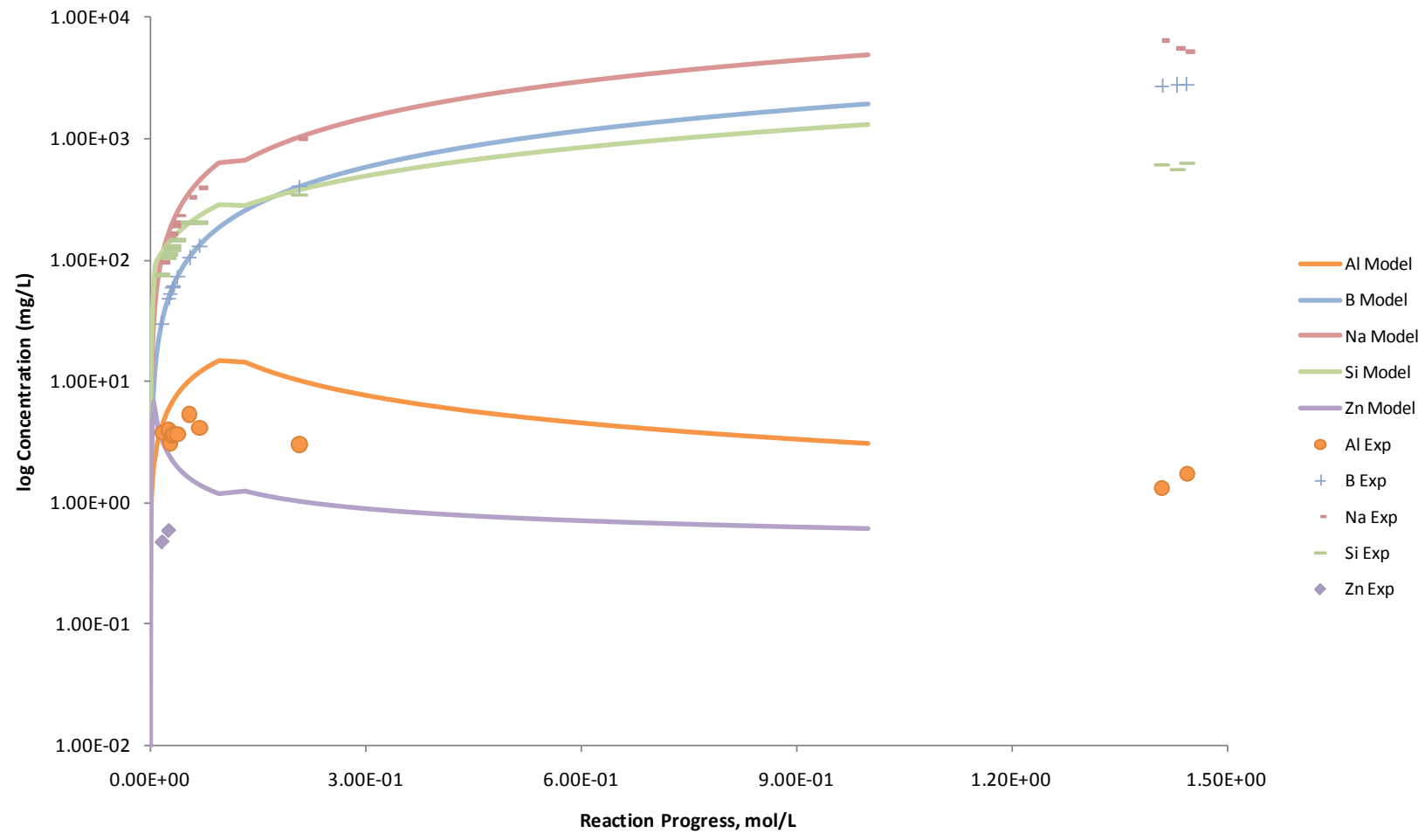

Figure C.8. Measured Solution Concentrations (mg/L) and Model Results for Al, B, Na, Si, and Zn, as a Function of Reaction Progress (mol-glass $/ \mathrm{kg}$ ) Determined for Glass Sample A100G115A 


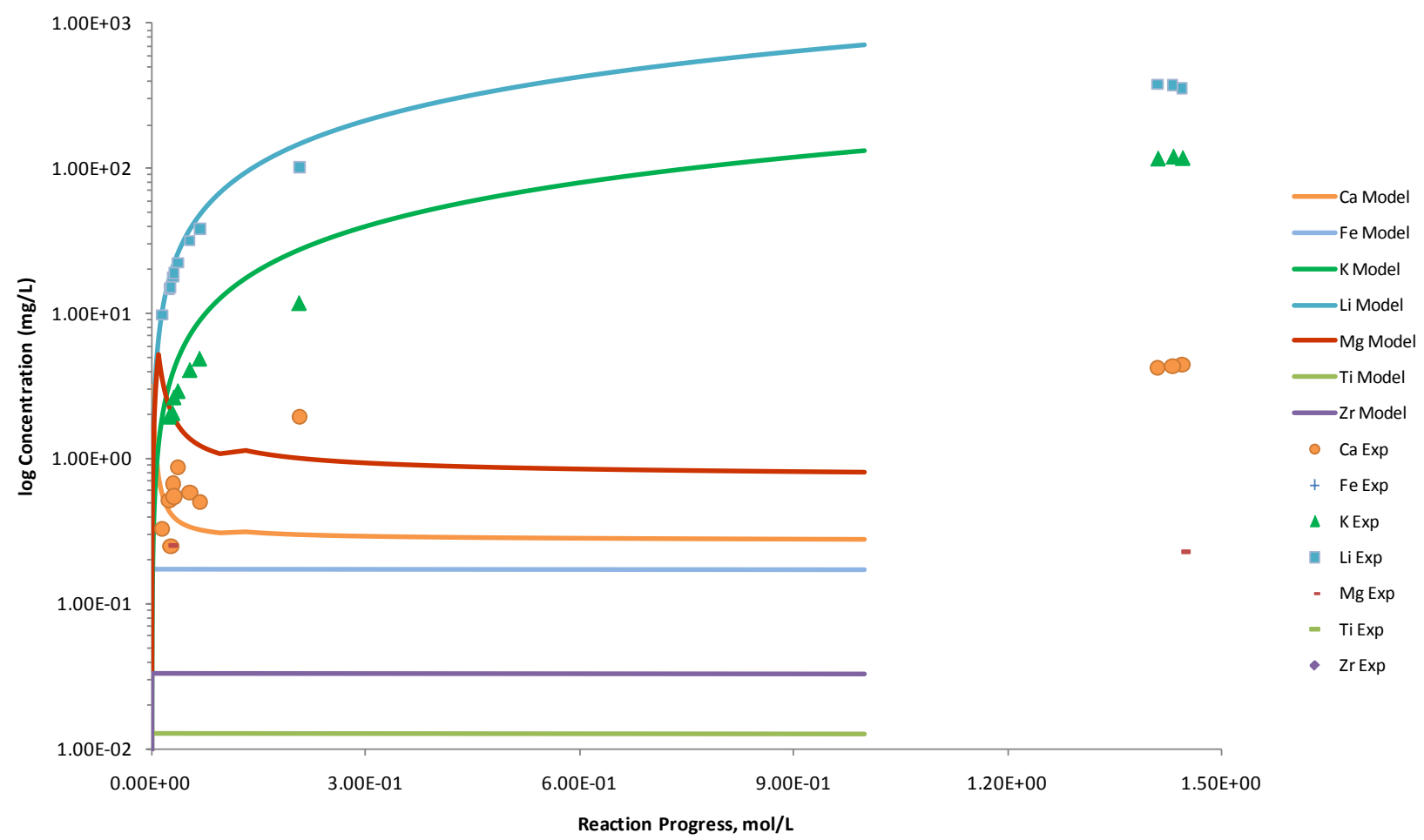

Figure C.9. Measured Solution Concentrations (mg/L) and Model Results for $\mathrm{Ca}, \mathrm{Fe}, \mathrm{K}, \mathrm{Li}, \mathrm{Mg}$, Ti, and $\mathrm{Zr}$, as a Function of Reaction Progress (mol-glass $/ \mathrm{kg}$ ) Determined for Glass Sample A100G115A

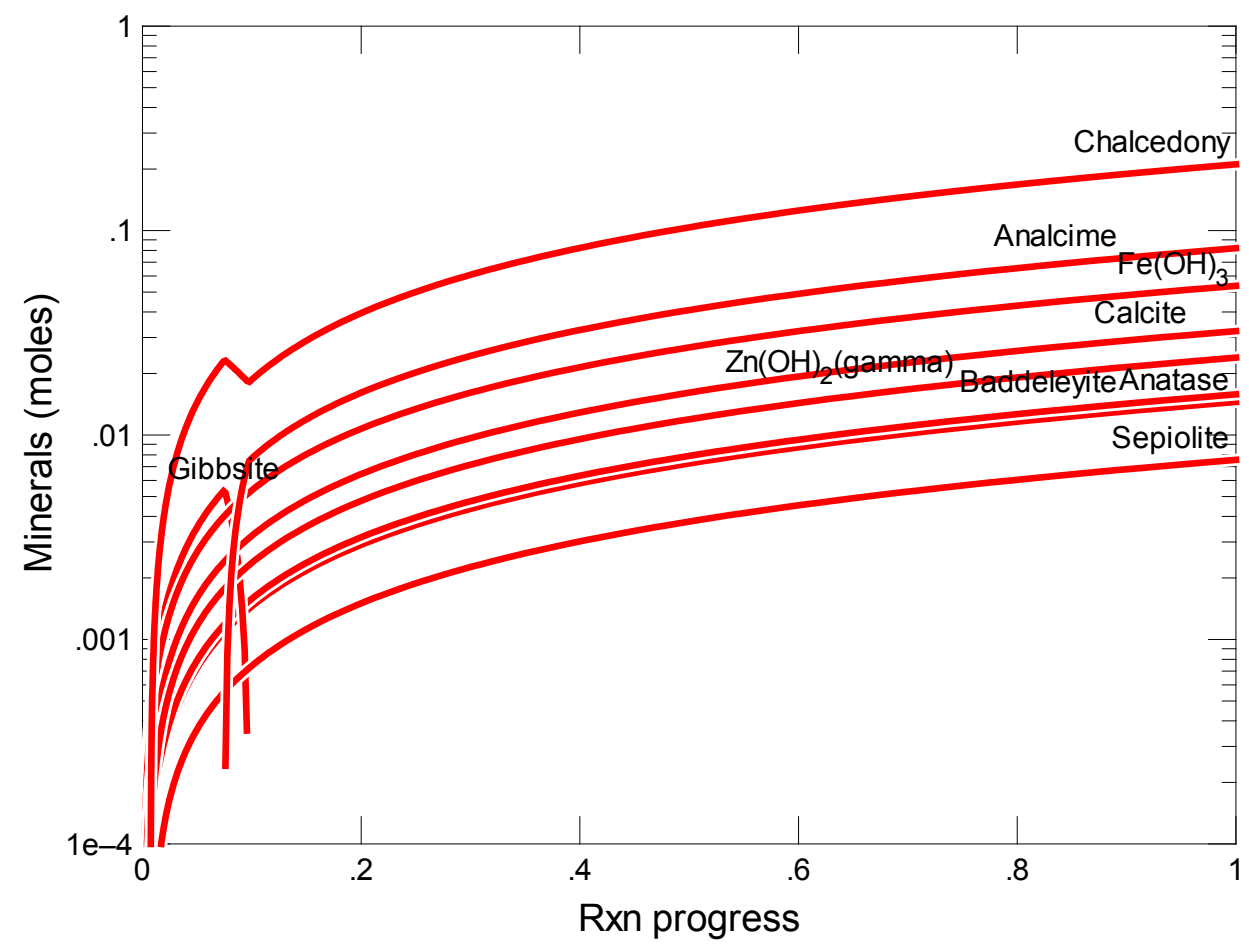

Figure C.10. Secondary Phases Calculated to Form as a Function of Reaction Progress (mol-glass $/ \mathrm{kg}$ ) Determined for Glass Sample A1C1-1 


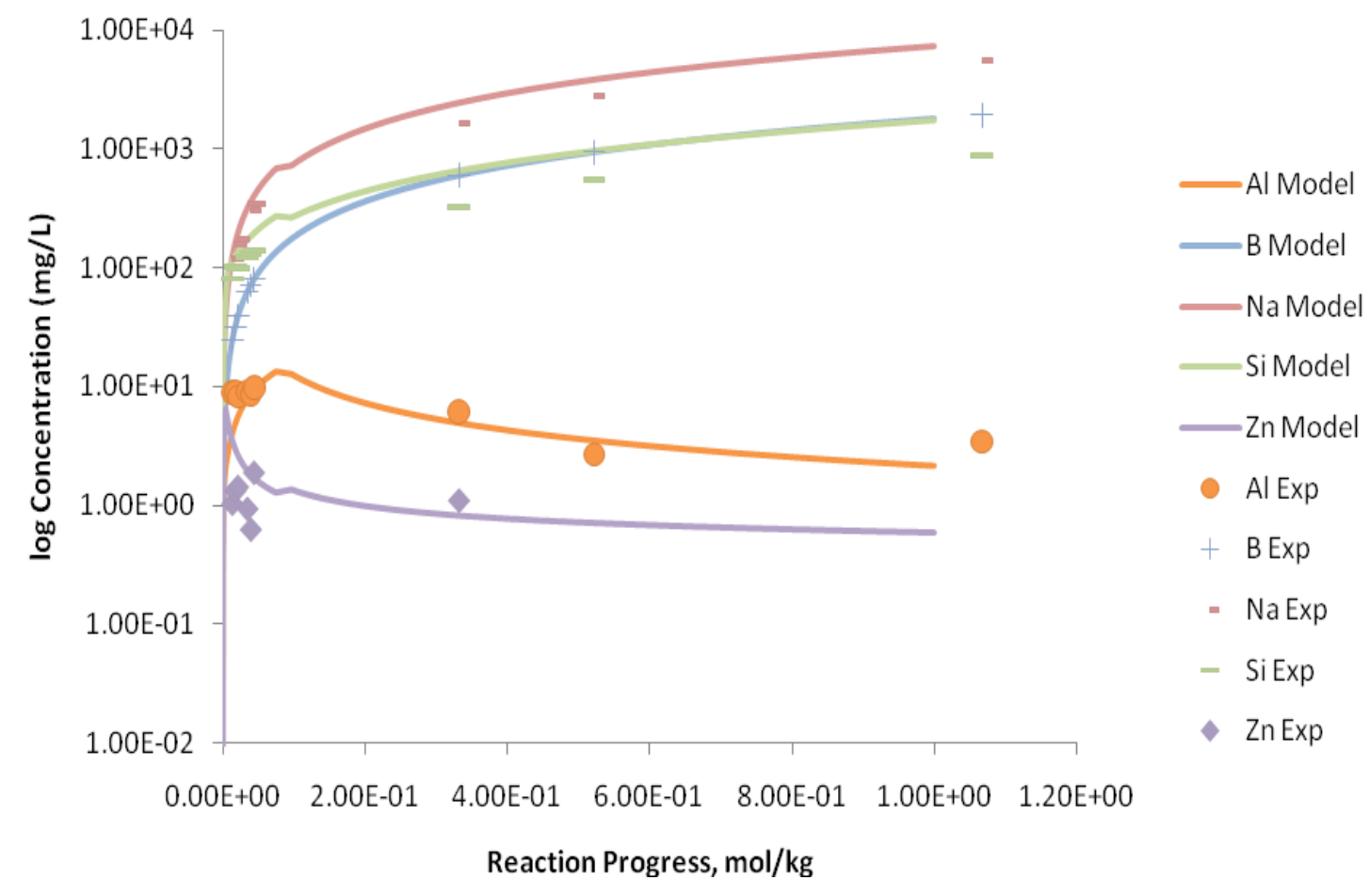

Figure C.11. Measured Solution Concentrations (mg/L) and Model Results for Al, B, Na, Si, and Zn, as a Function of Reaction Progress (mol-glass $/ \mathrm{kg}$ ) Determined for Glass Sample A1C1-1

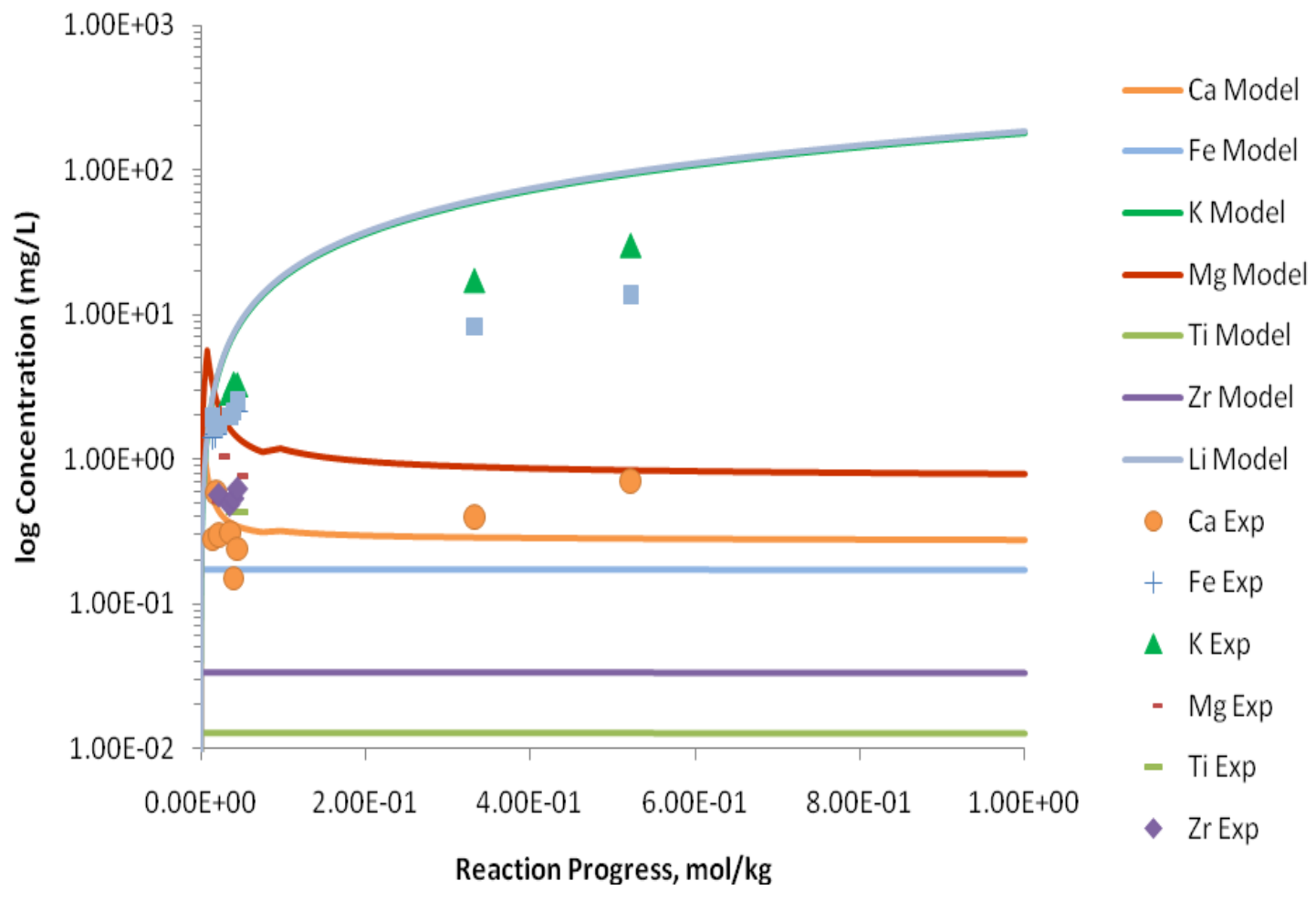

Figure C.12. Measured Solution Concentrations (mg/L) and Model Results for Ca, Fe, K, Li, Mg, Ti, and $\mathrm{Zr}$, as a Function of Reaction Progress (mol-glass/kg) Determined for Glass Sample A1C1-1 


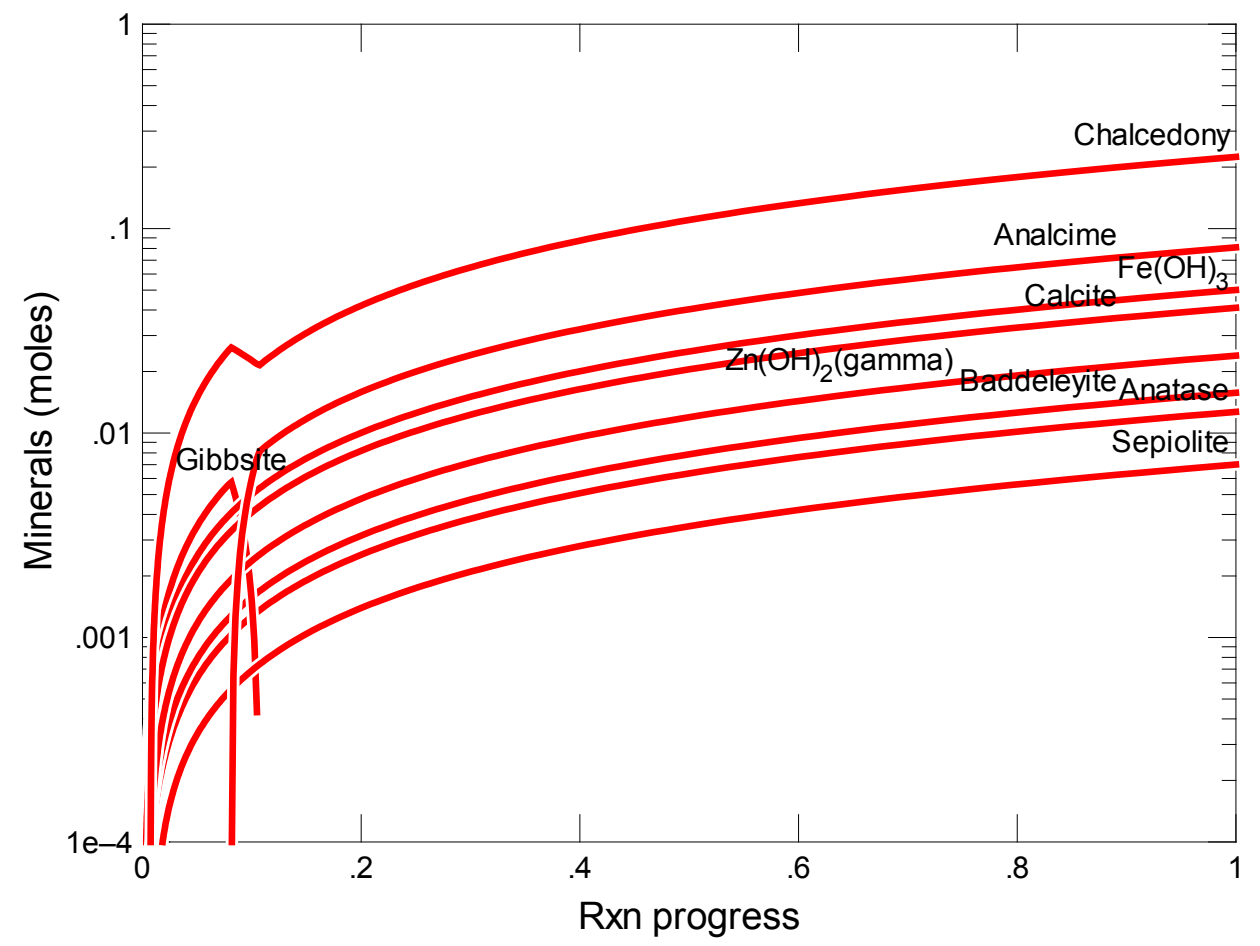

Figure C.13. Secondary Phases Calculated to Form as a Function of Reaction Progress (mol-glass/kg) Determined for Glass Sample A1C1-2

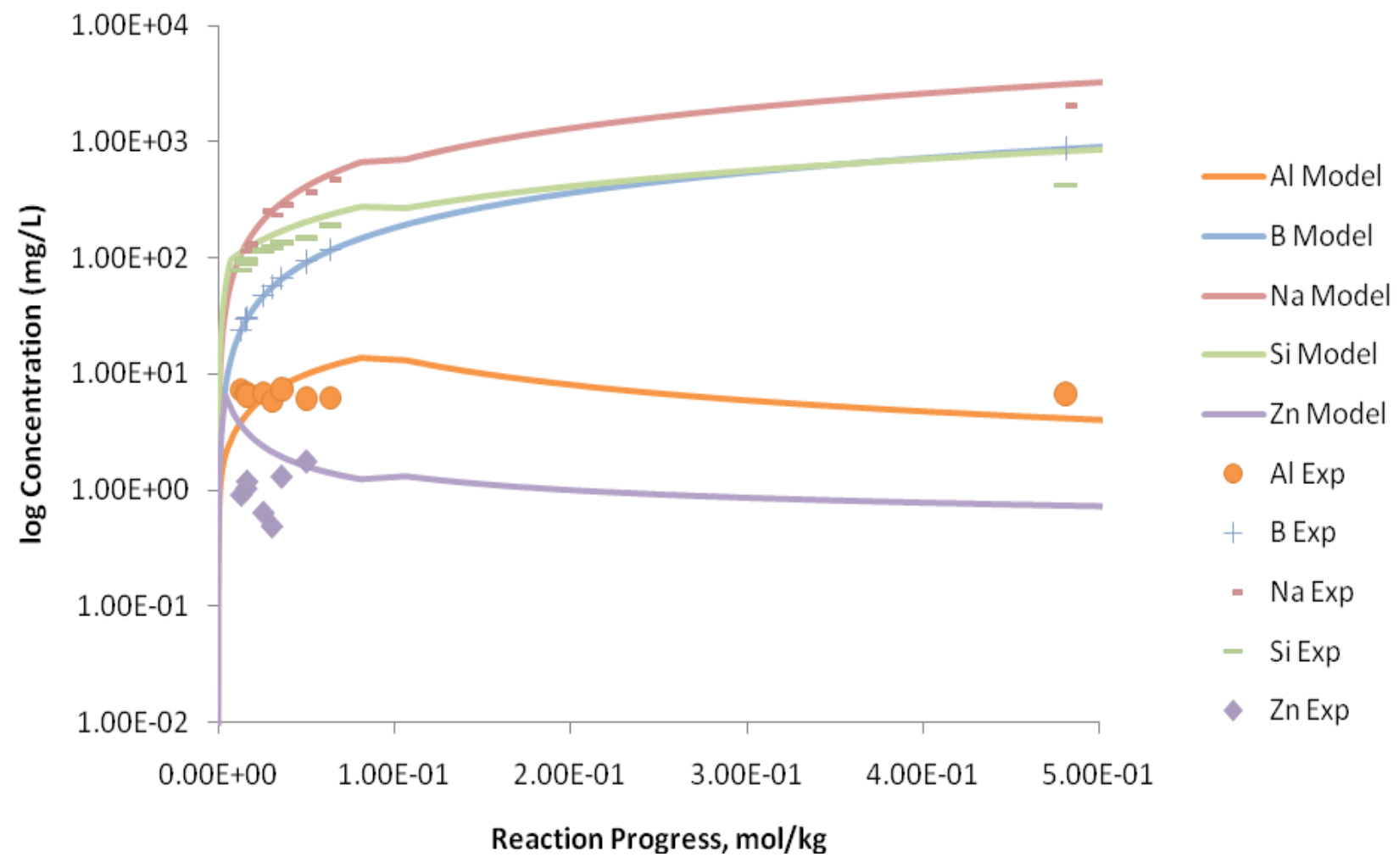

Figure C.14. Measured Solution Concentrations (mg/L) and Model Results for Al, B, Na, Si, and Zn, as a Function of Reaction Progress (mol-glass $/ \mathrm{kg}$ ) Determined for Glass Sample A1C1-2 


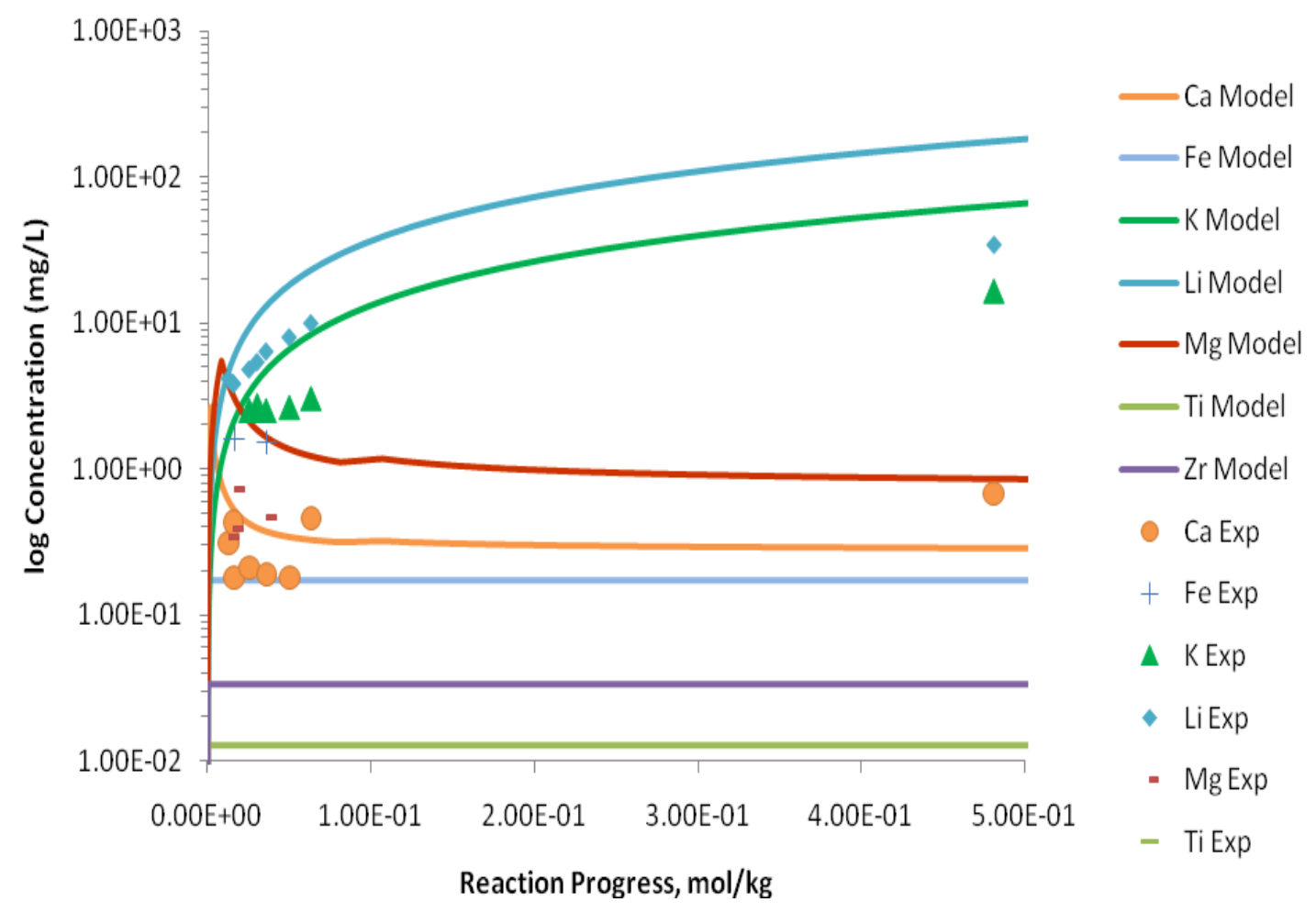

Figure C.15. Measured Solution Concentrations (mg/L) and Model Results for Ca, Fe, K, Li, Mg, Ti, and $\mathrm{Zr}$, as a Function of Reaction Progress (mol-glass/kg) Determined for Glass Sample A1C1-2

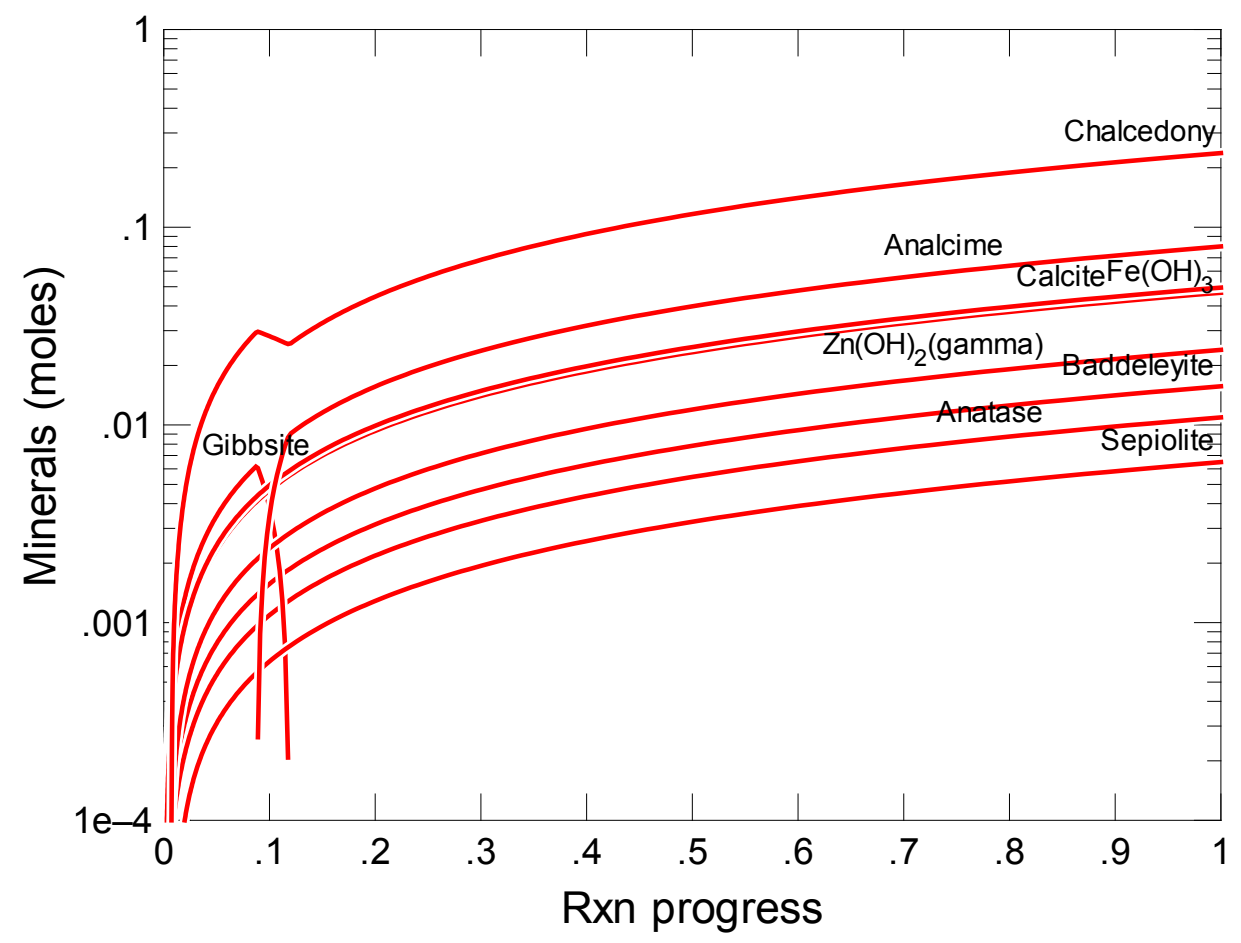

Figure C.16. Secondary Phases Calculated to Form as a Function of Reaction Progress (mol-glass $/ \mathrm{kg}$ ) Determined for Glass Sample A1C1-3 


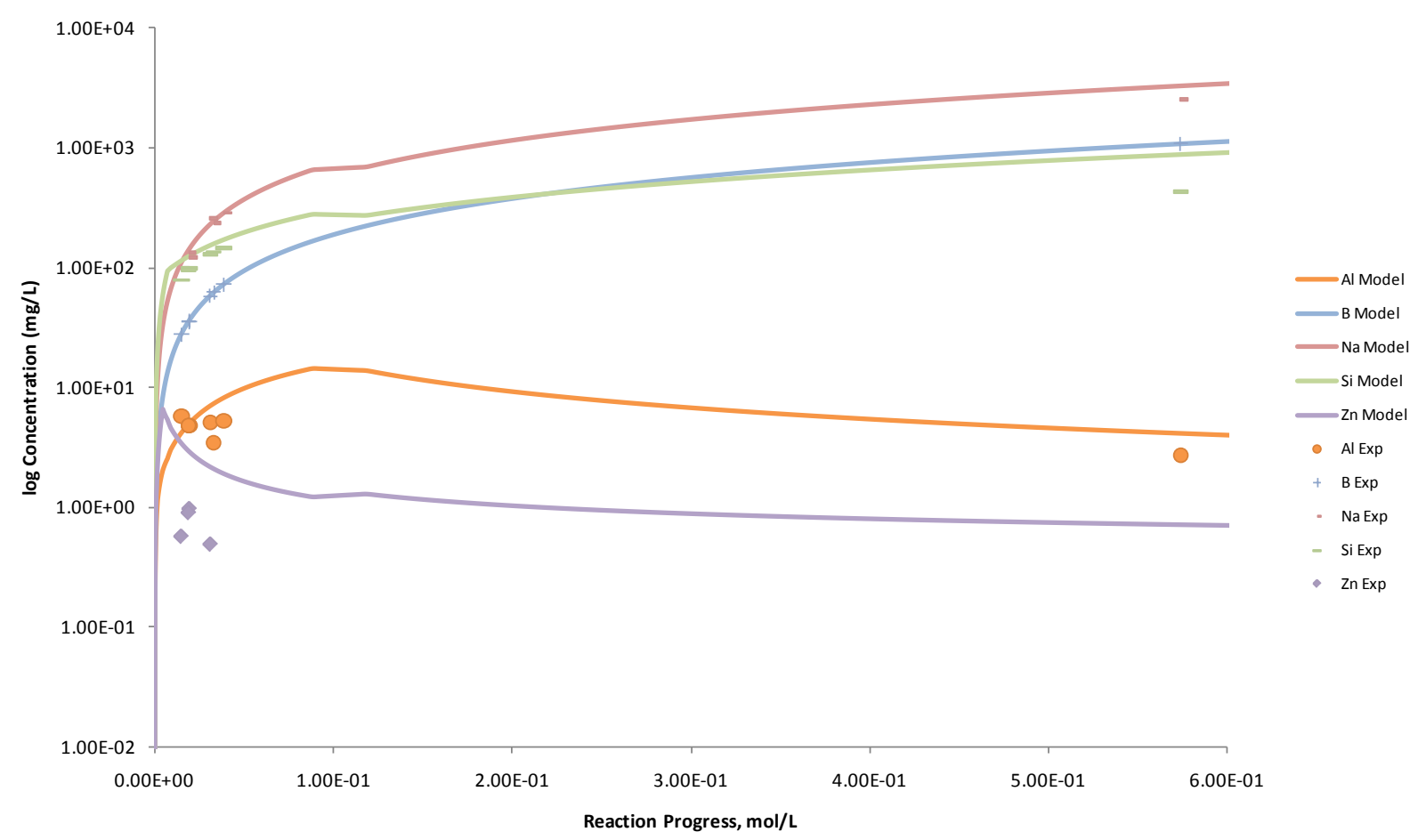

Figure C.17. Measured Solution Concentrations (mg/L) and Model Results for Al, B, Na, Si, and Zn, as a Function of Reaction Progress (mol-glass $/ \mathrm{kg}$ ) Determined for Glass Sample A1C1-3

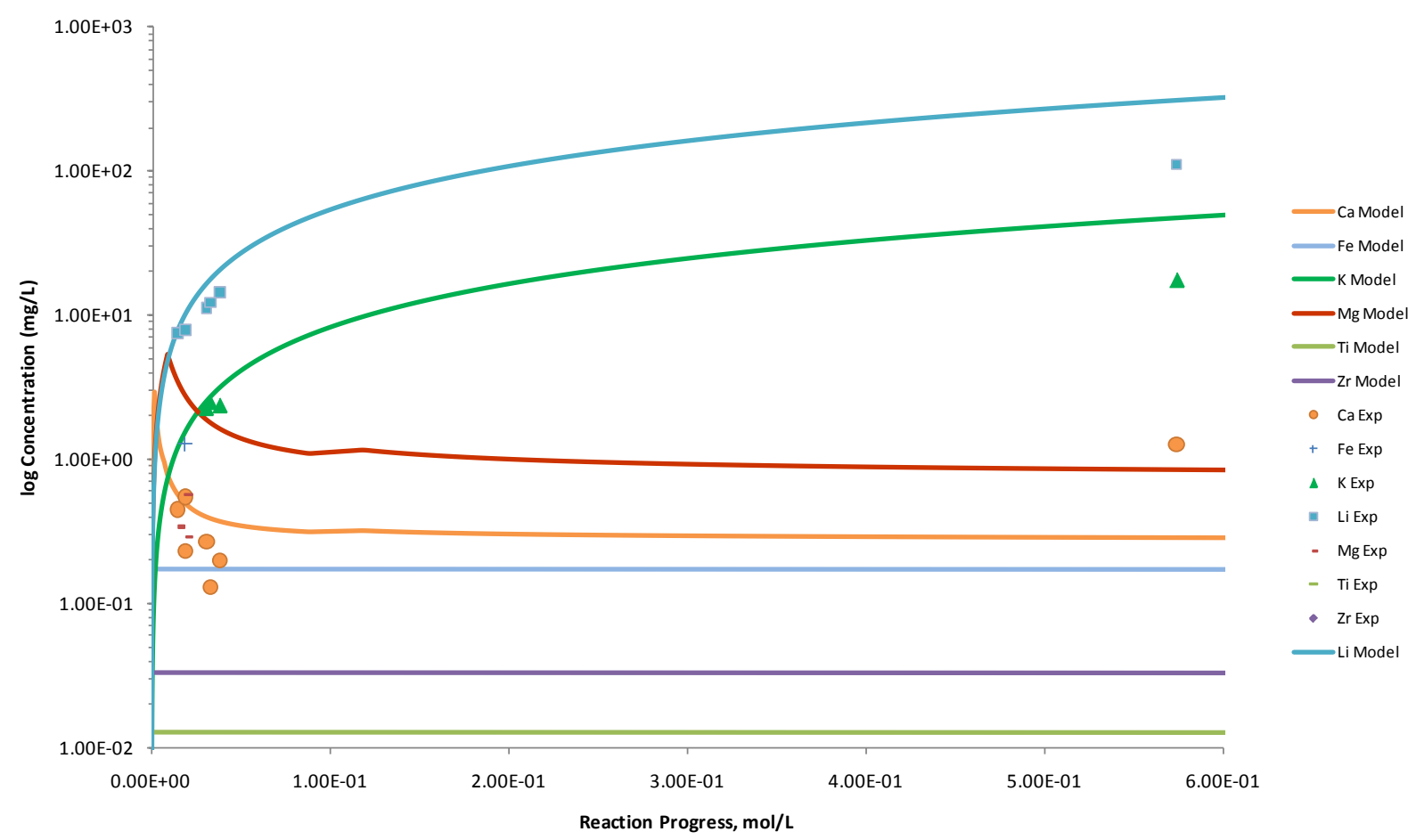

Figure C.18. Measured Solution Concentrations (mg/L) and Model Results for Ca, Fe, K, Li, Mg, Ti, and $\mathrm{Zr}$, as a Function of Reaction Progress (mol-glass/kg) Determined for Glass Sample $\mathrm{A} 1 \mathrm{C} 1-3$ 


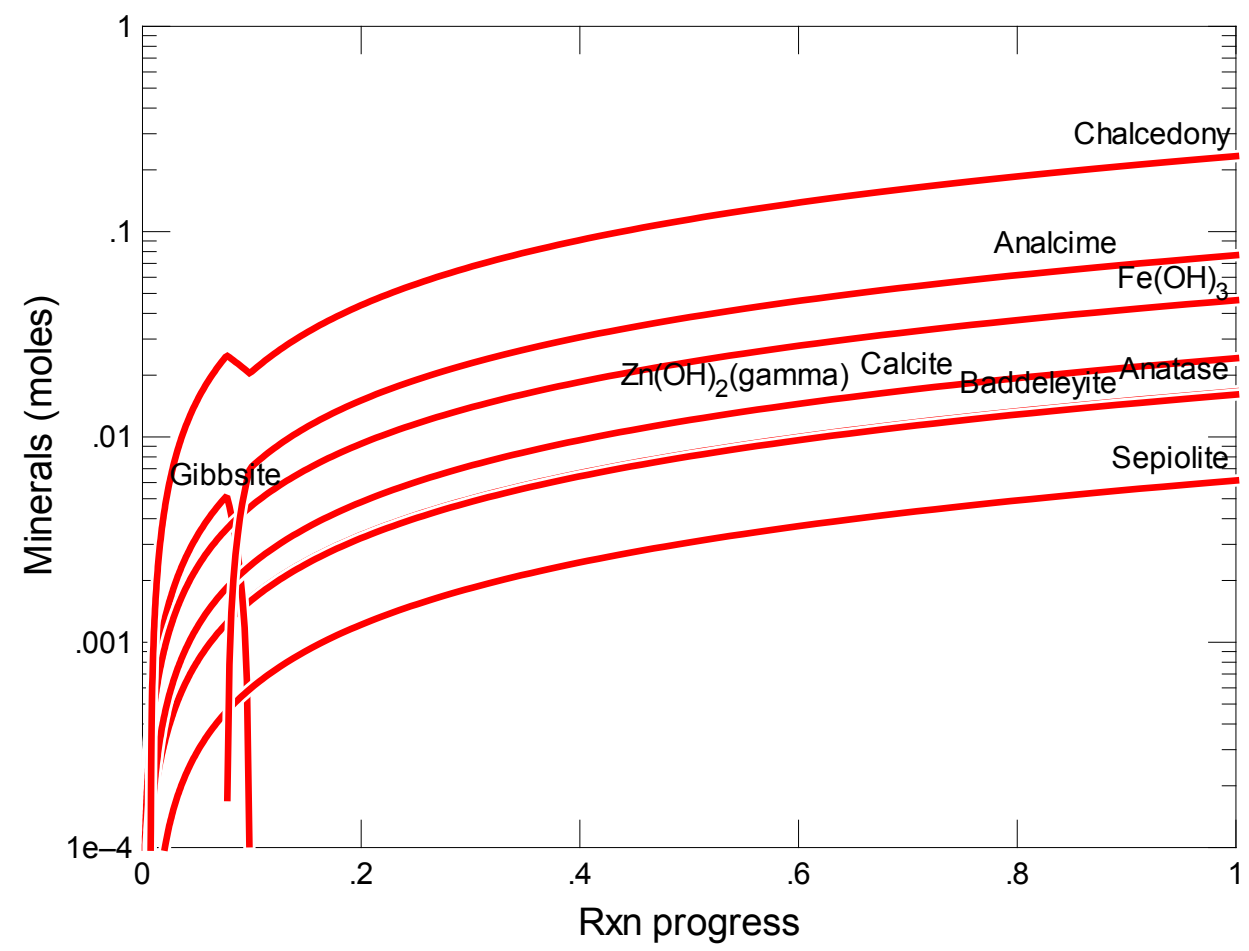

Figure C.19. Secondary Phases Calculated to Form as a Function of Reaction Progress (mol-glass/kg) Determined for Glass Sample A2-AP101

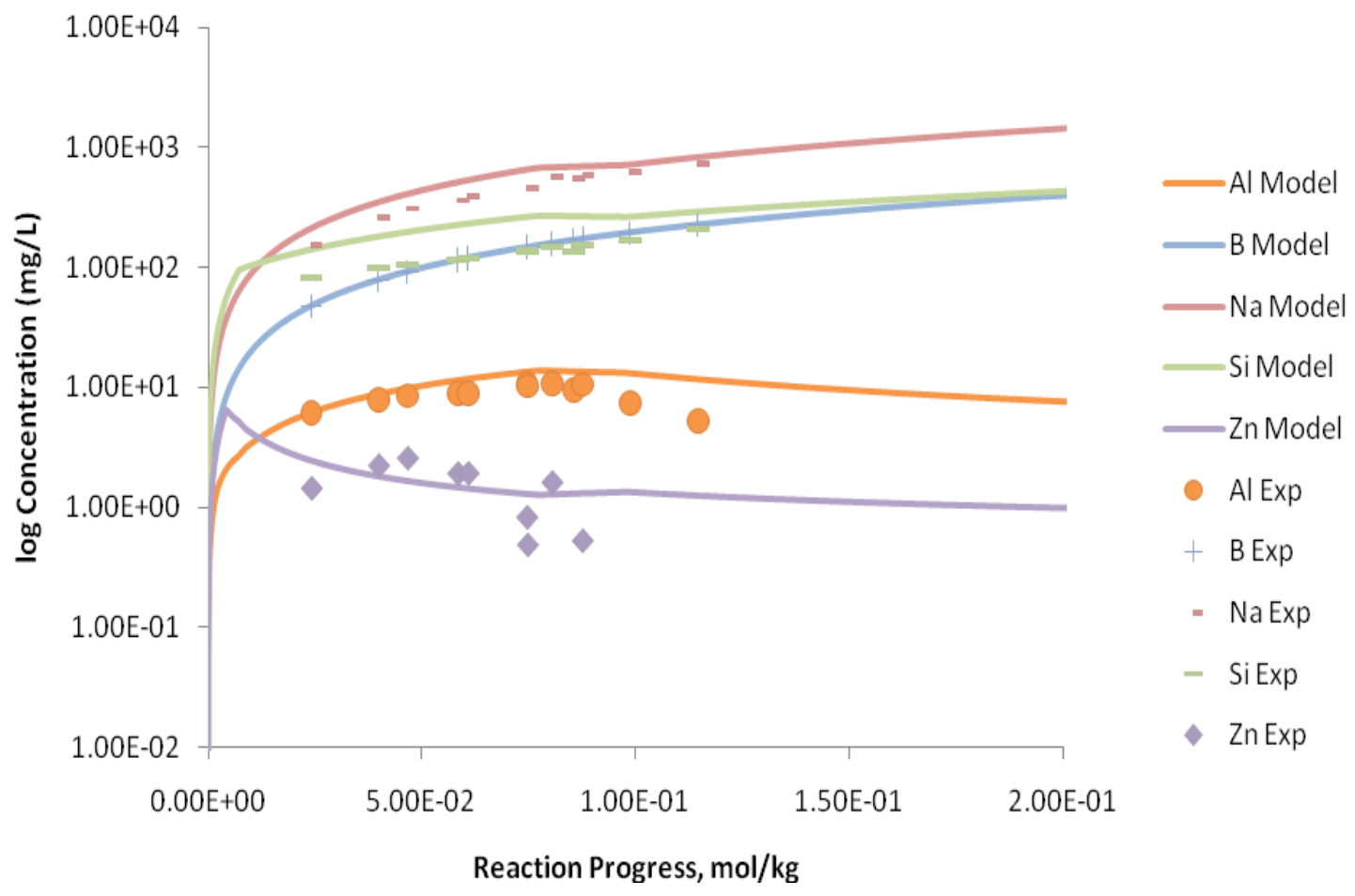

Figure C.20. Measured Solution Concentrations (mg/L) and Model Results for Al, B, Na, Si, and Zn, as a Function of Reaction Progress (mol-glass $/ \mathrm{kg}$ ) Determined for Glass Sample A2-AP101 


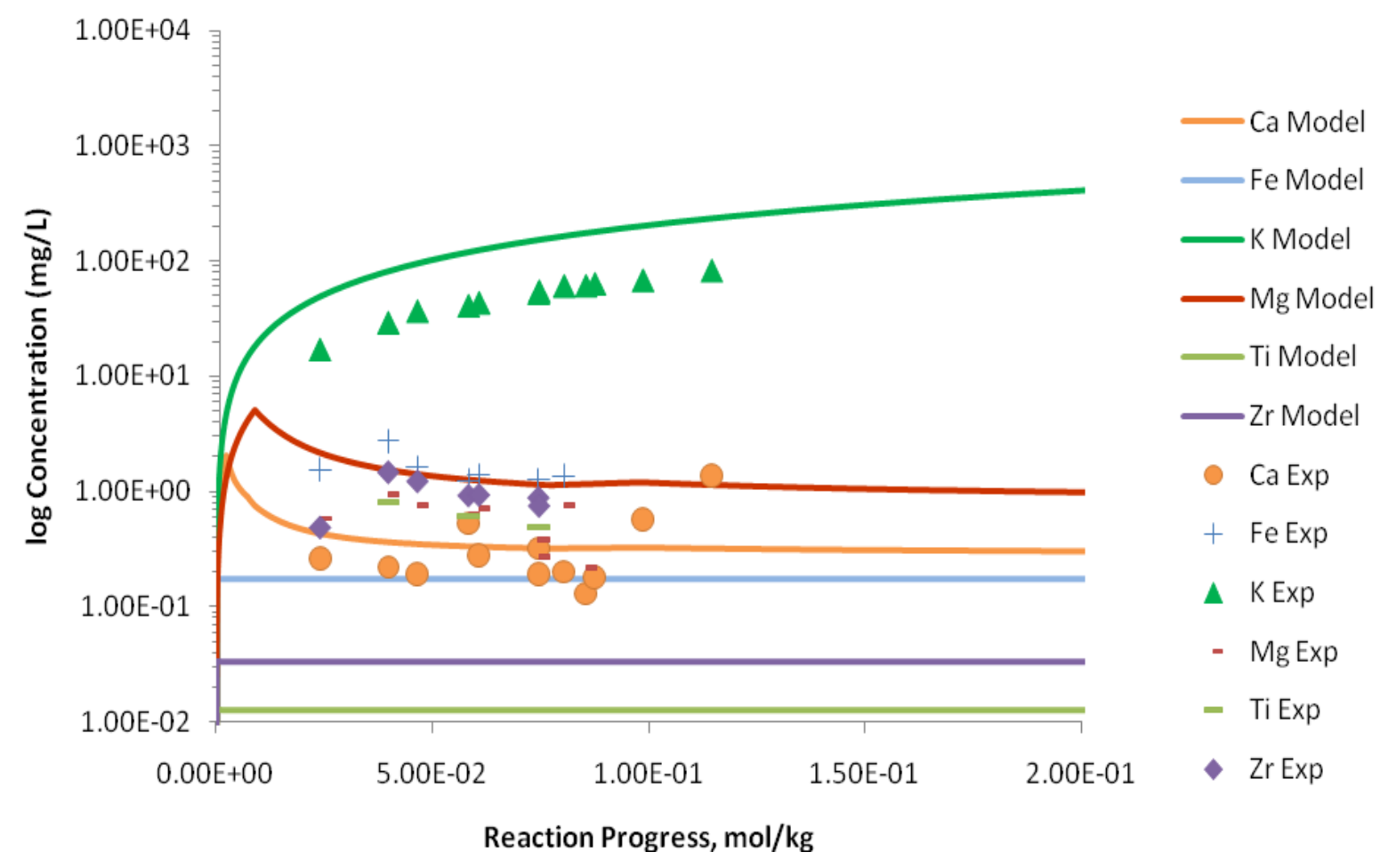

Figure C.21. Measured Solution Concentrations (mg/L) and Model Results for Ca, Fe, K, Li, $\mathrm{Mg}, \mathrm{Ti}$, and $\mathrm{Zr}$, as a Function of Reaction Progress (mol-glass $/ \mathrm{kg}$ ) Determined for Glass Sample A2-AP101

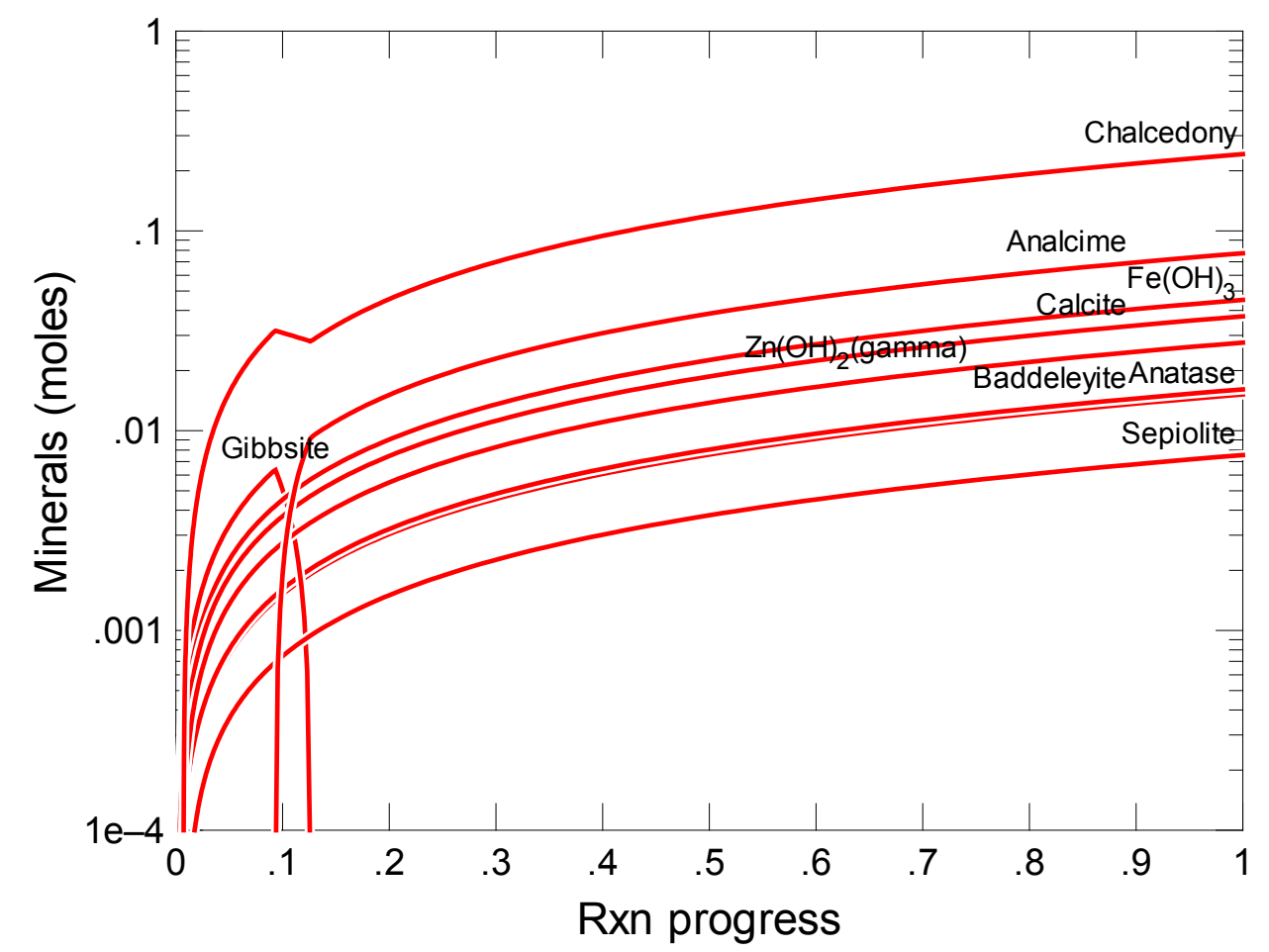

Figure C.22. Secondary Phases Calculated to Form as a Function of Reaction Progress (mol-glass/kg) Determined for Glass Sample A2B1-1 


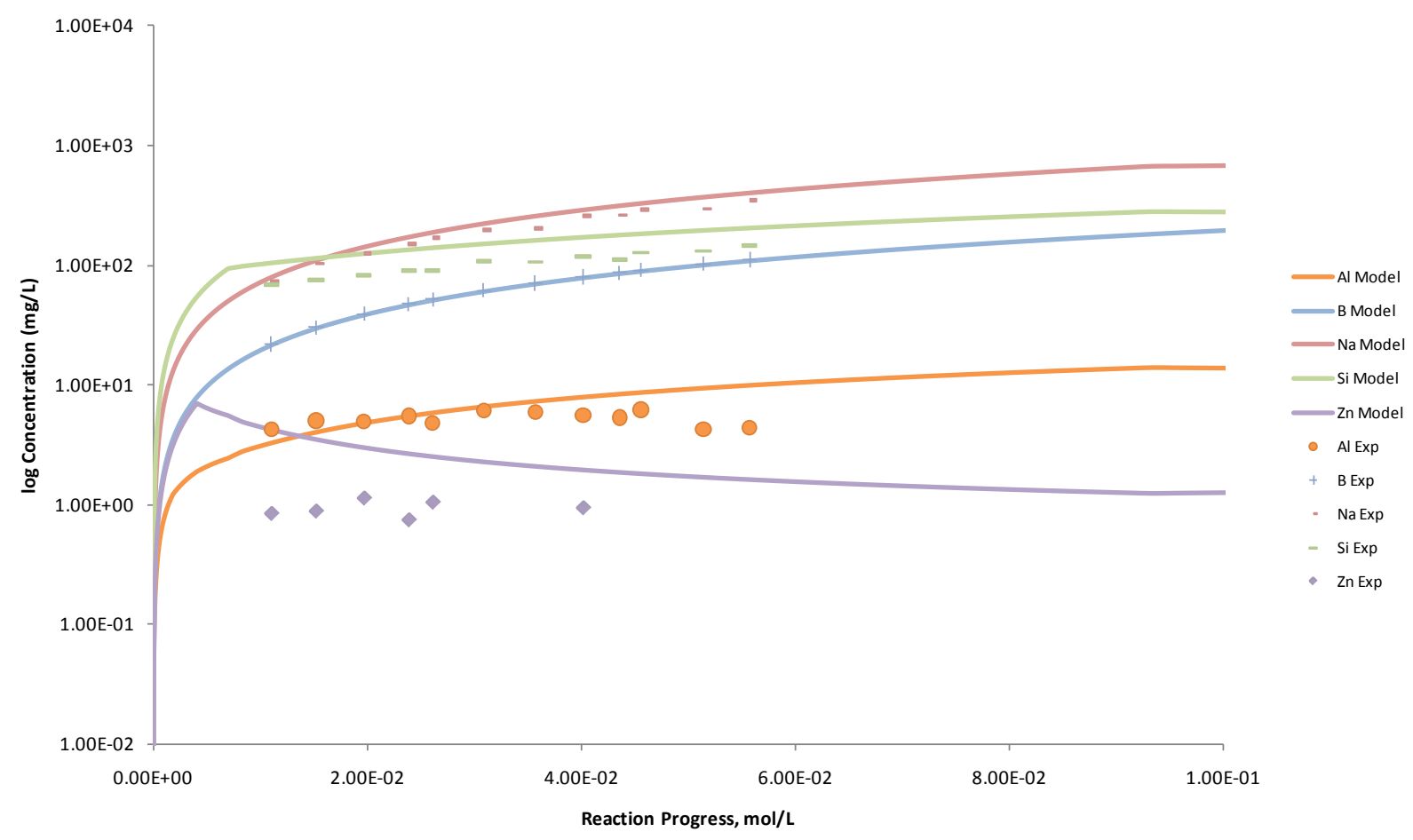

Figure C.23. Measured Solution Concentrations (mg/L) and Model Results for Al, B, Na, Si, and Zn, as a Function of Reaction Progress (mol-glass $/ \mathrm{kg}$ ) Determined for Glass Sample A2B1-1

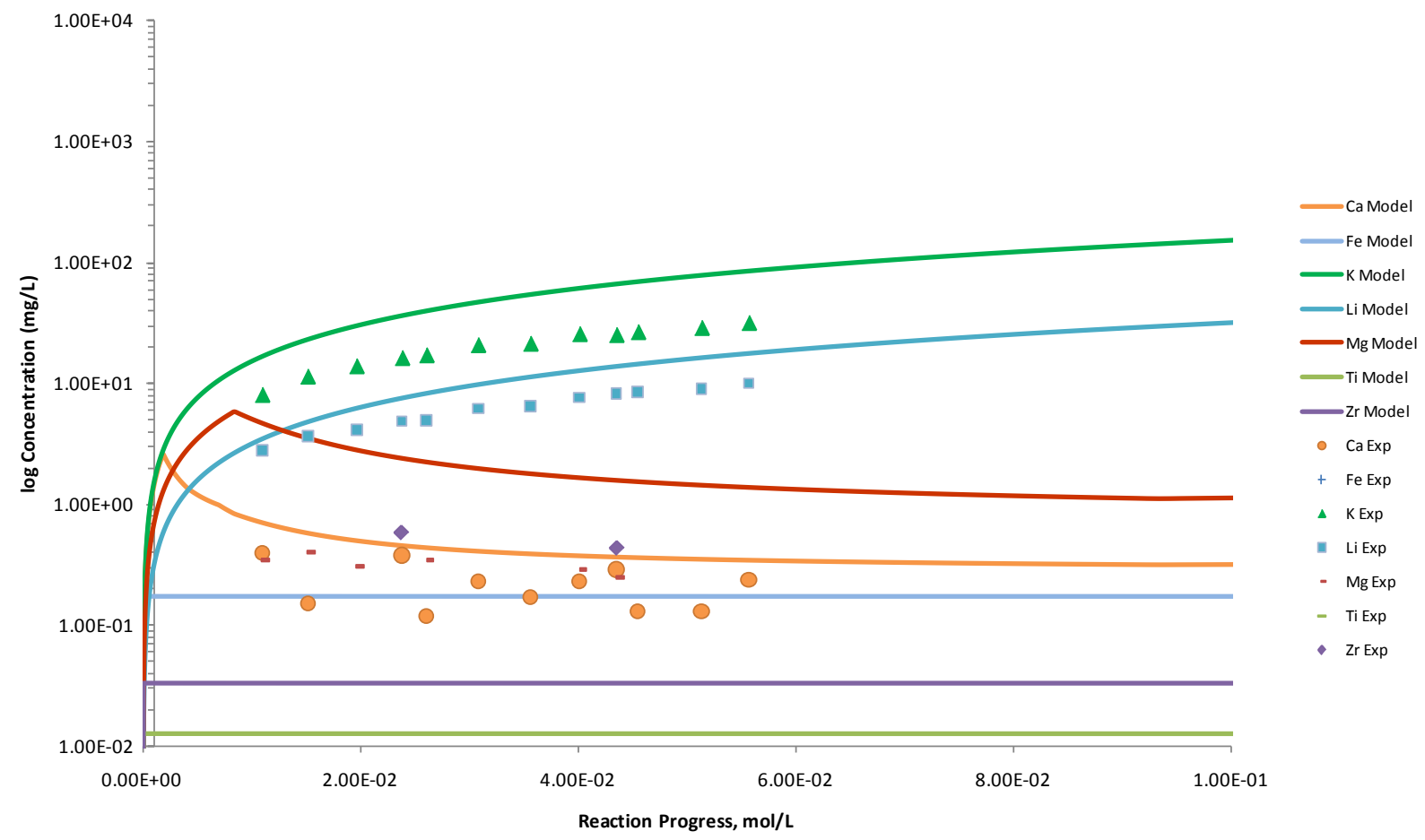

Figure C.24. Measured Solution Concentrations (mg/L) and Model Results for Ca, Fe, K, Li, Mg, Ti, and $\mathrm{Zr}$, as a Function of Reaction Progress (mol-glass/kg) Determined for Glass Sample A2B1-1 


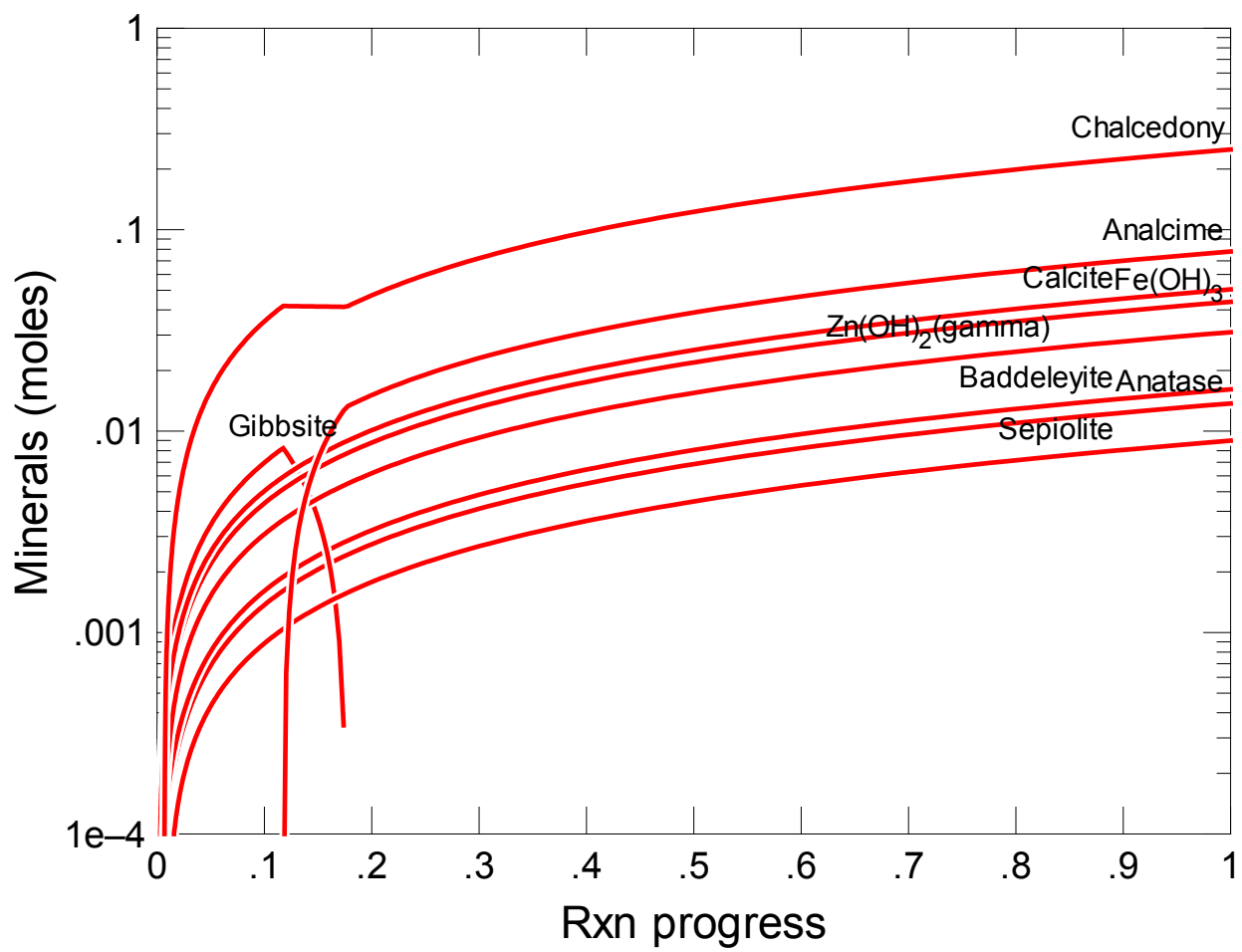

Figure C.25. Secondary Phases Calculated to Form as a Function of Reaction Progress (mol-glass/kg) Determined for Glass Sample A2B1-2

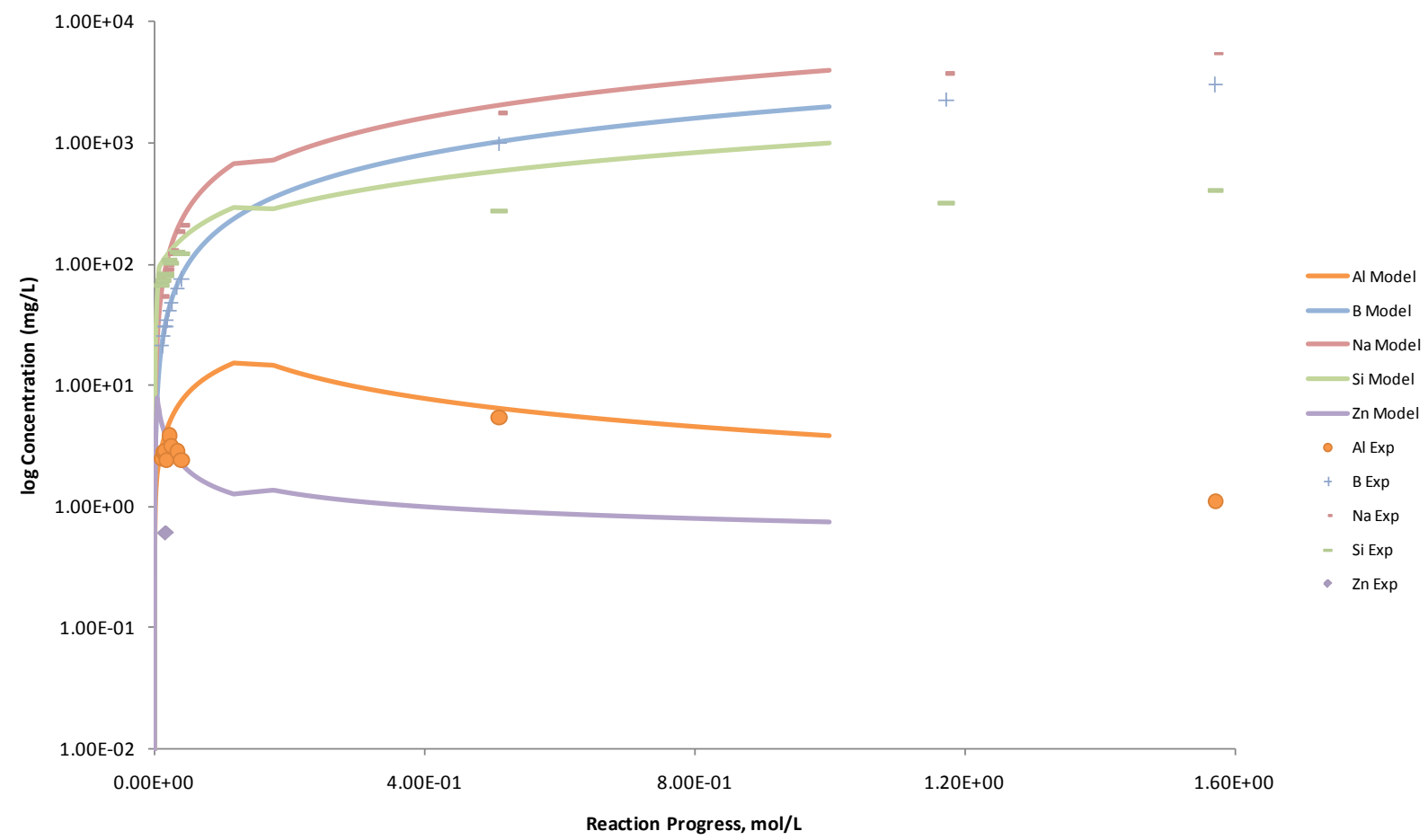

Figure C.26. Measured Solution Concentrations (mg/L) and Model Results for Al, B, Na, Si, and Zn, as a Function of Reaction Progress (mol-glass $/ \mathrm{kg}$ ) Determined for Glass Sample A2B1-2 


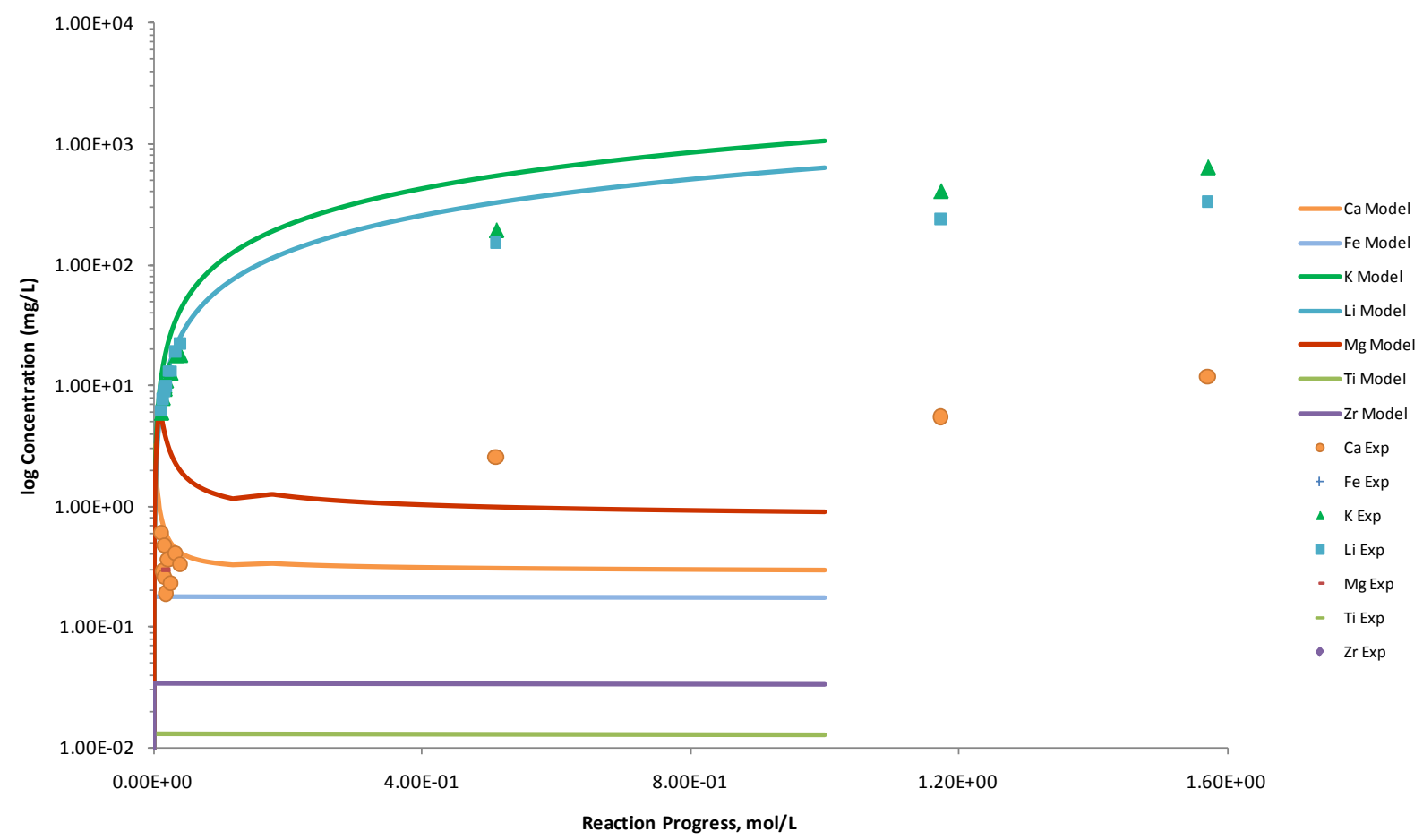

Figure C.27. Measured Solution Concentrations (mg/L) and Model Results for $\mathrm{Ca}, \mathrm{Fe}, \mathrm{K}, \mathrm{Li}, \mathrm{Mg}, \mathrm{Ti}$, and $\mathrm{Zr}$, as a Function of Reaction Progress (mol-glass/kg) Determined for Glass Sample A2B1-2

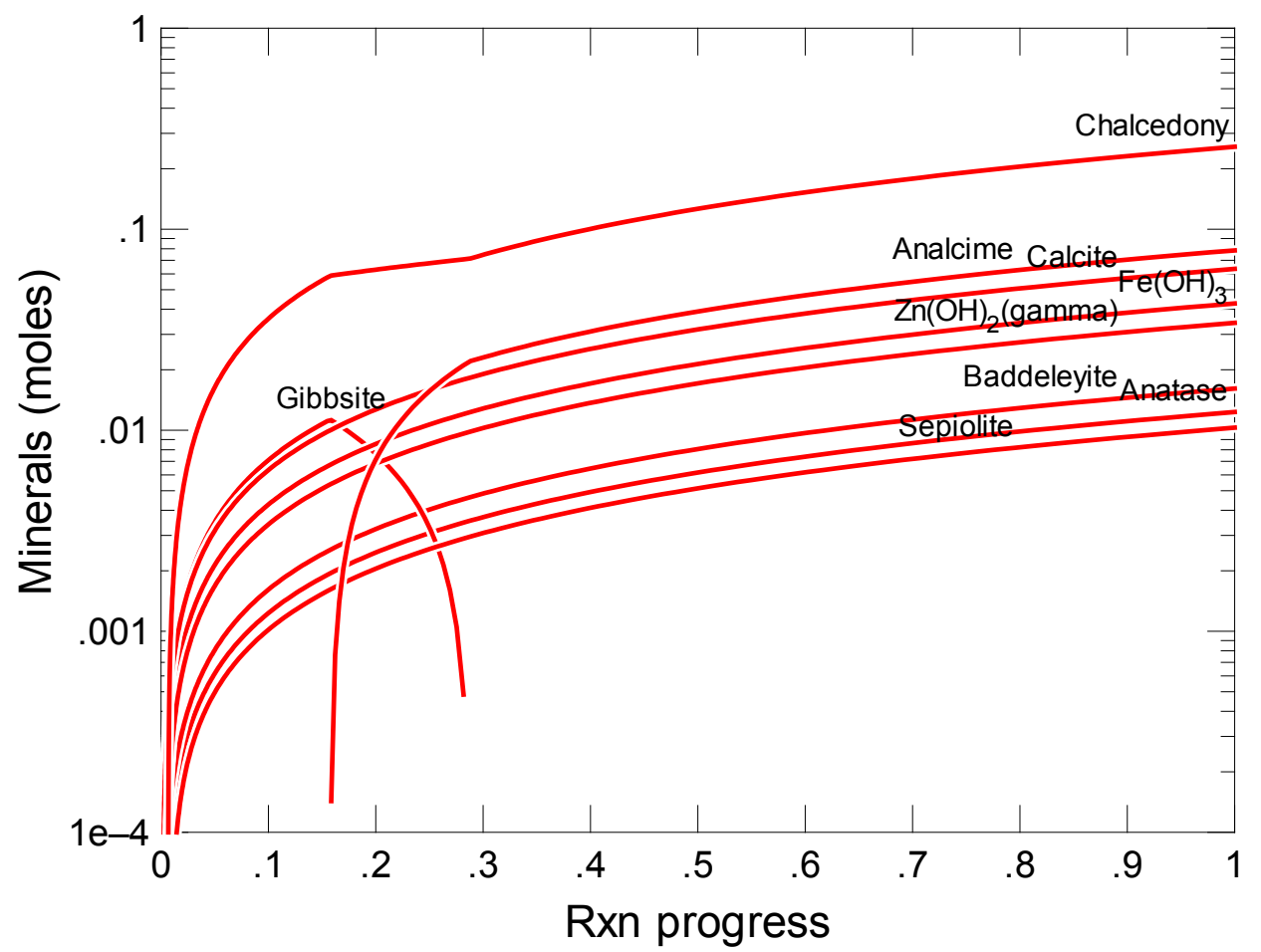

Figure C.28. Secondary Phases Calculated to Form as a Function of Reaction Progress (mol-glass $/ \mathrm{kg}$ ) Determined for Glass Sample A2B1-3 


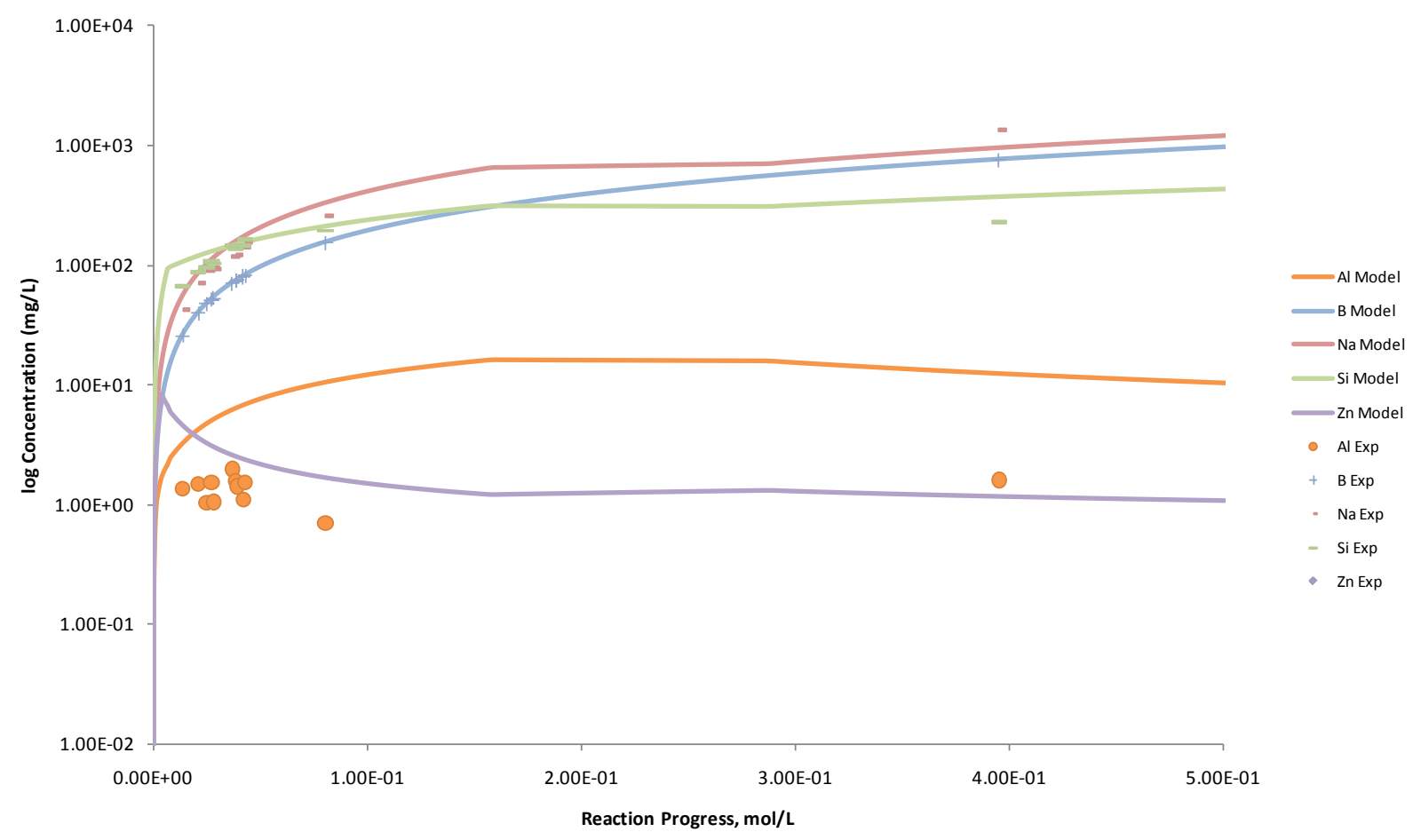

Figure C.29. Measured Solution Concentrations (mg/L) and Model Results for Al, B, Na, Si, and Zn, as a Function of Reaction Progress (mol-glass $/ \mathrm{kg}$ ) Determined for Glass Sample A2B1-3

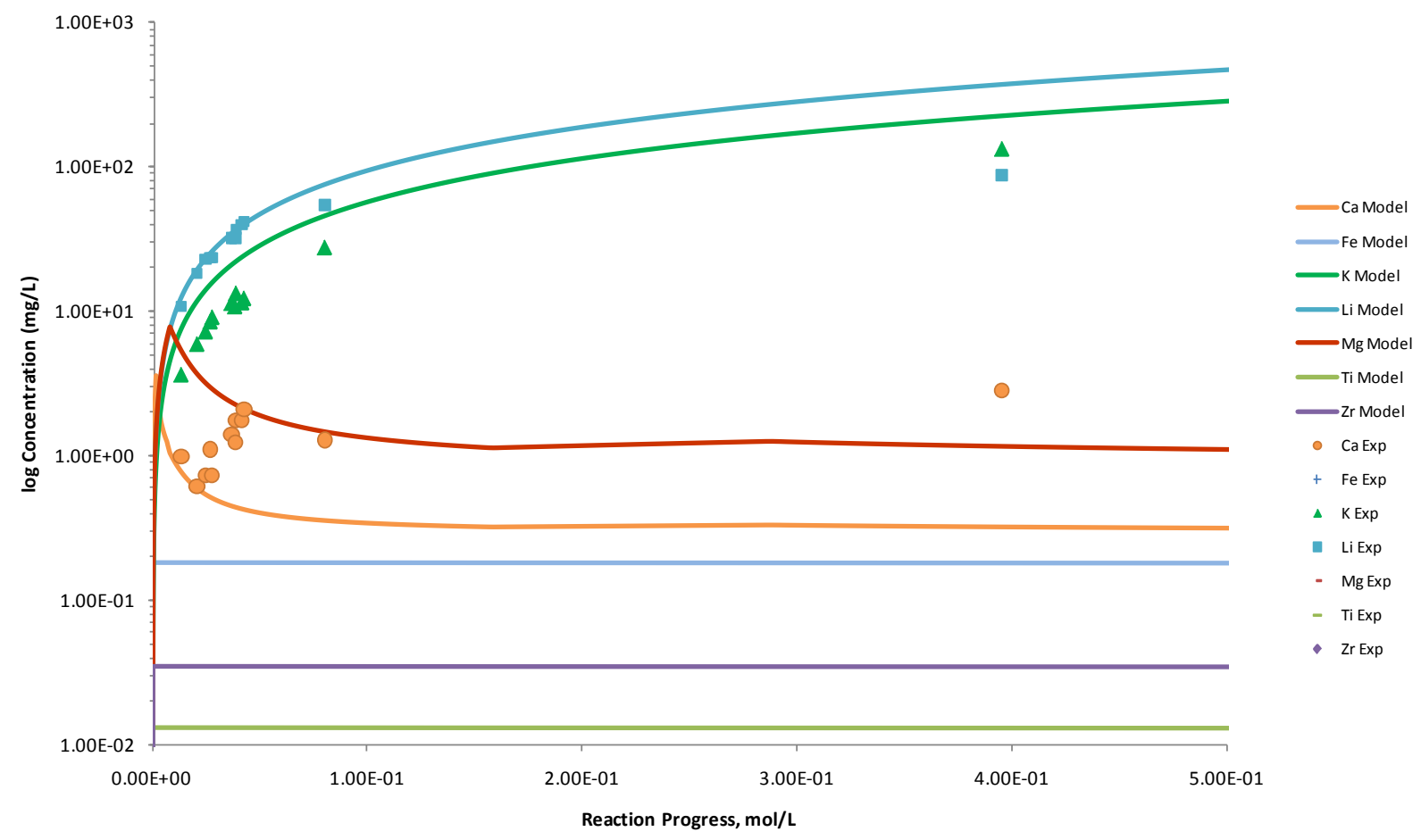

Figure C.30. Measured Solution Concentrations (mg/L) and Model Results for Ca, Fe, K, Li, Mg, Ti, and $\mathrm{Zr}$, as a Function of Reaction Progress (mol-glass/kg) Determined for Glass Sample A2B1-3 


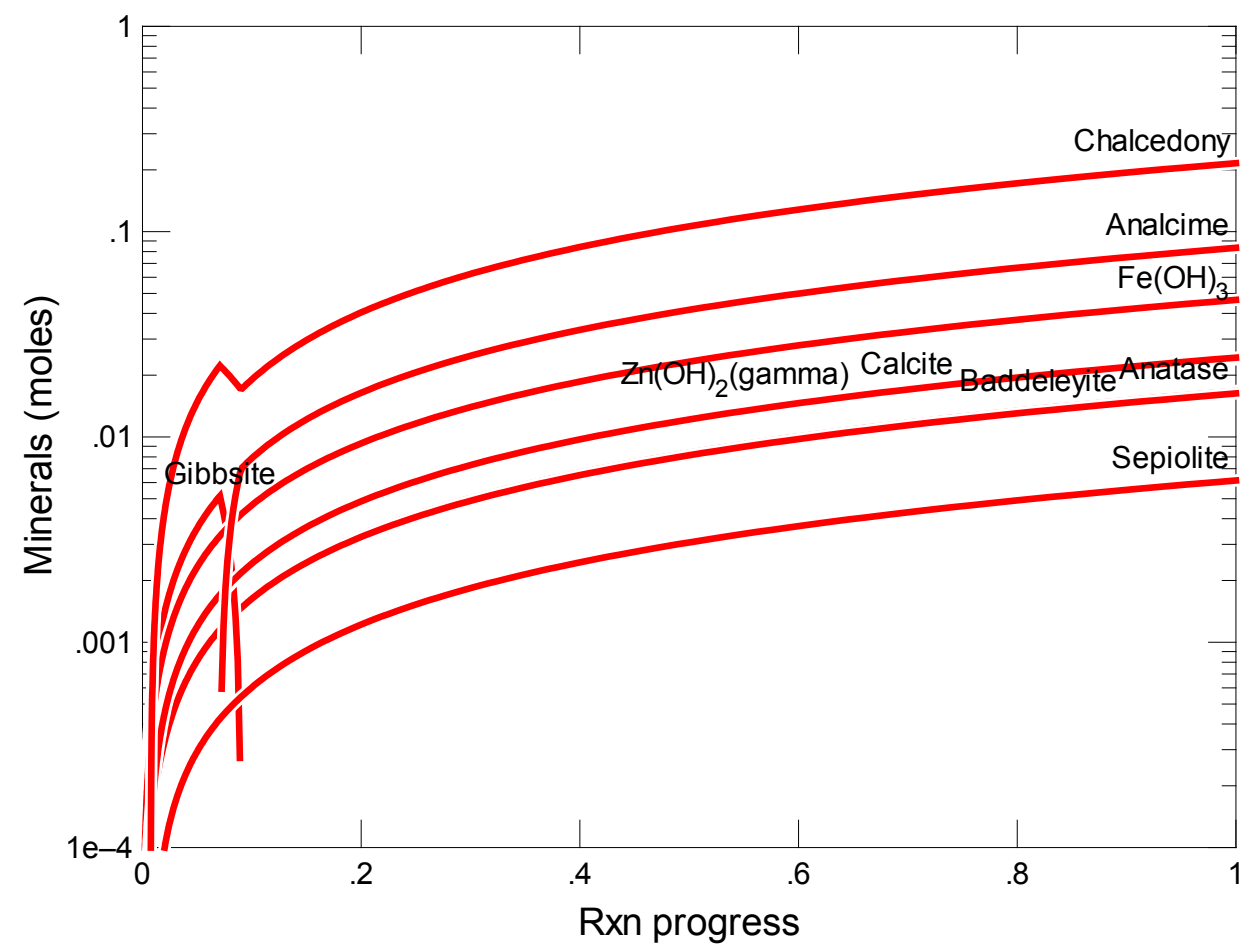

Figure C.31. Secondary Phases Calculated to Form as a Function of Reaction Progress (mol-glass/kg) Determined for Glass Sample A88AP101R1

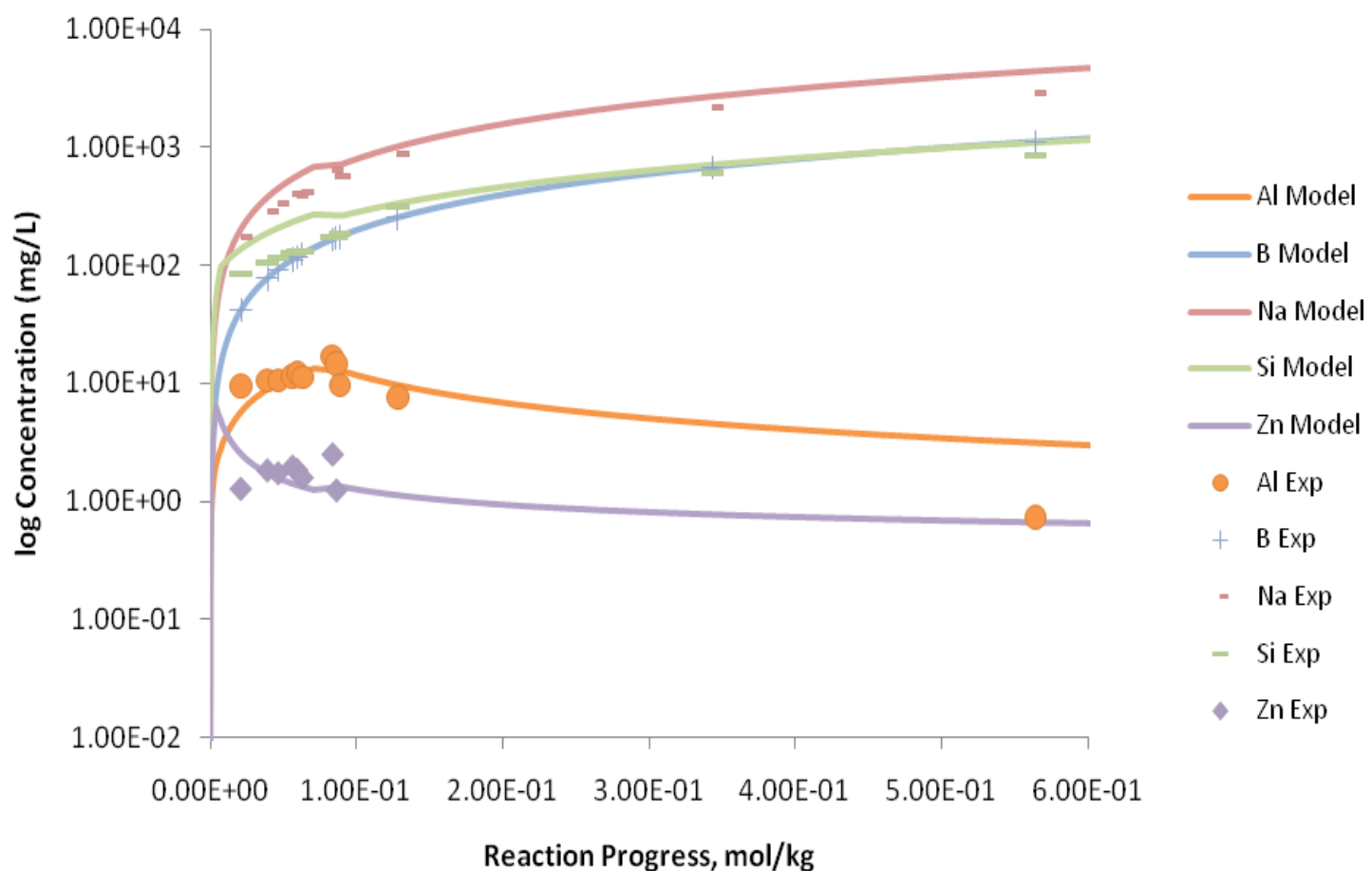

Figure C.32. Measured Solution Concentrations (mg/L) and Model Results for Al, B, Na, Si, and Zn, as a Function of Reaction Progress (mol-glass $/ \mathrm{kg}$ ) Determined for Glass Sample A88AP101R1 


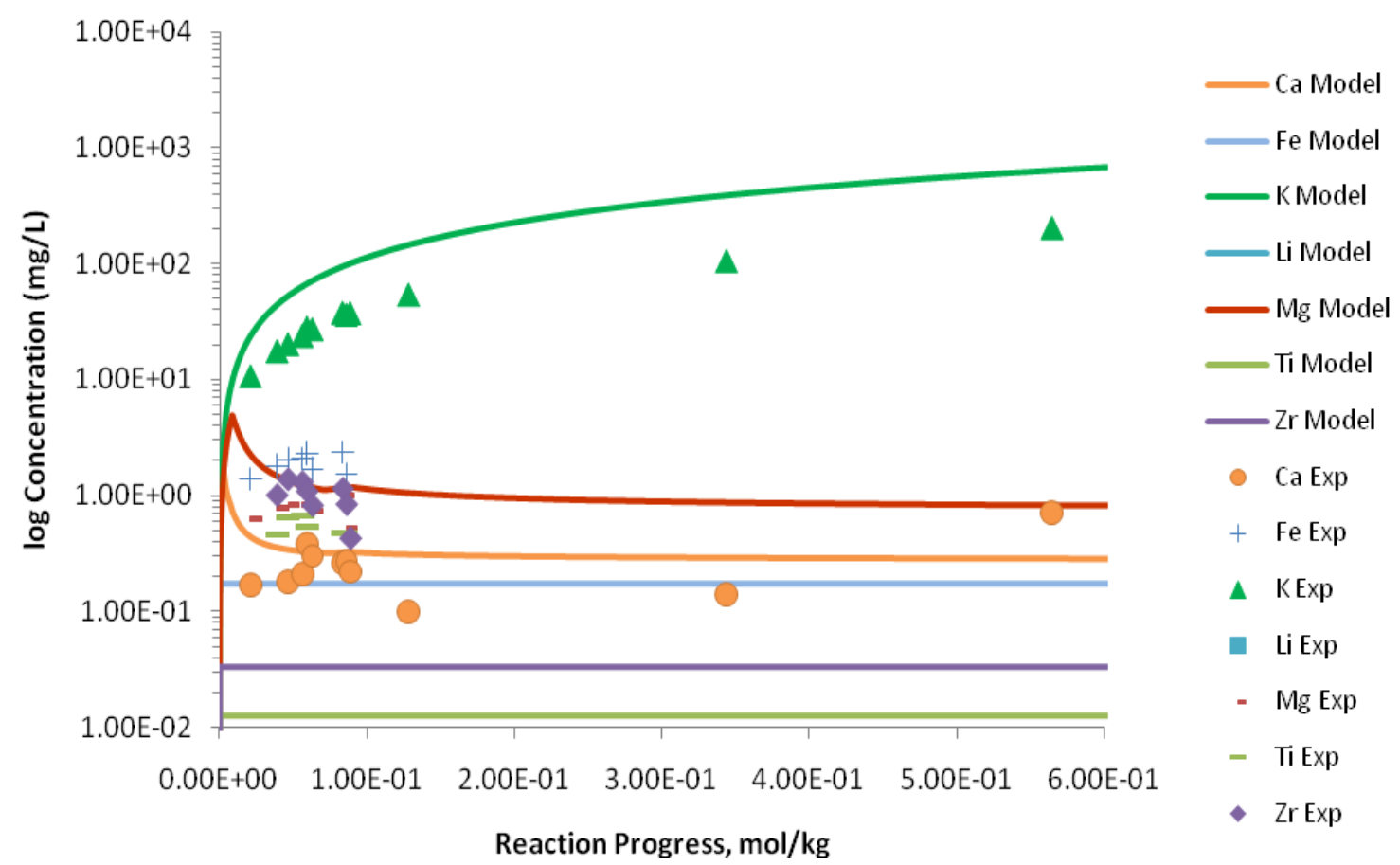

Figure C.33. Measured Solution Concentrations (mg/L) and Model Results for $\mathrm{Ca}, \mathrm{Fe}, \mathrm{K}, \mathrm{Li}, \mathrm{Mg}, \mathrm{Ti}$, and $\mathrm{Zr}$, as a Function of Reaction Progress (mol-glass $/ \mathrm{kg}$ ) Determined for Glass Sample A88AP101R1

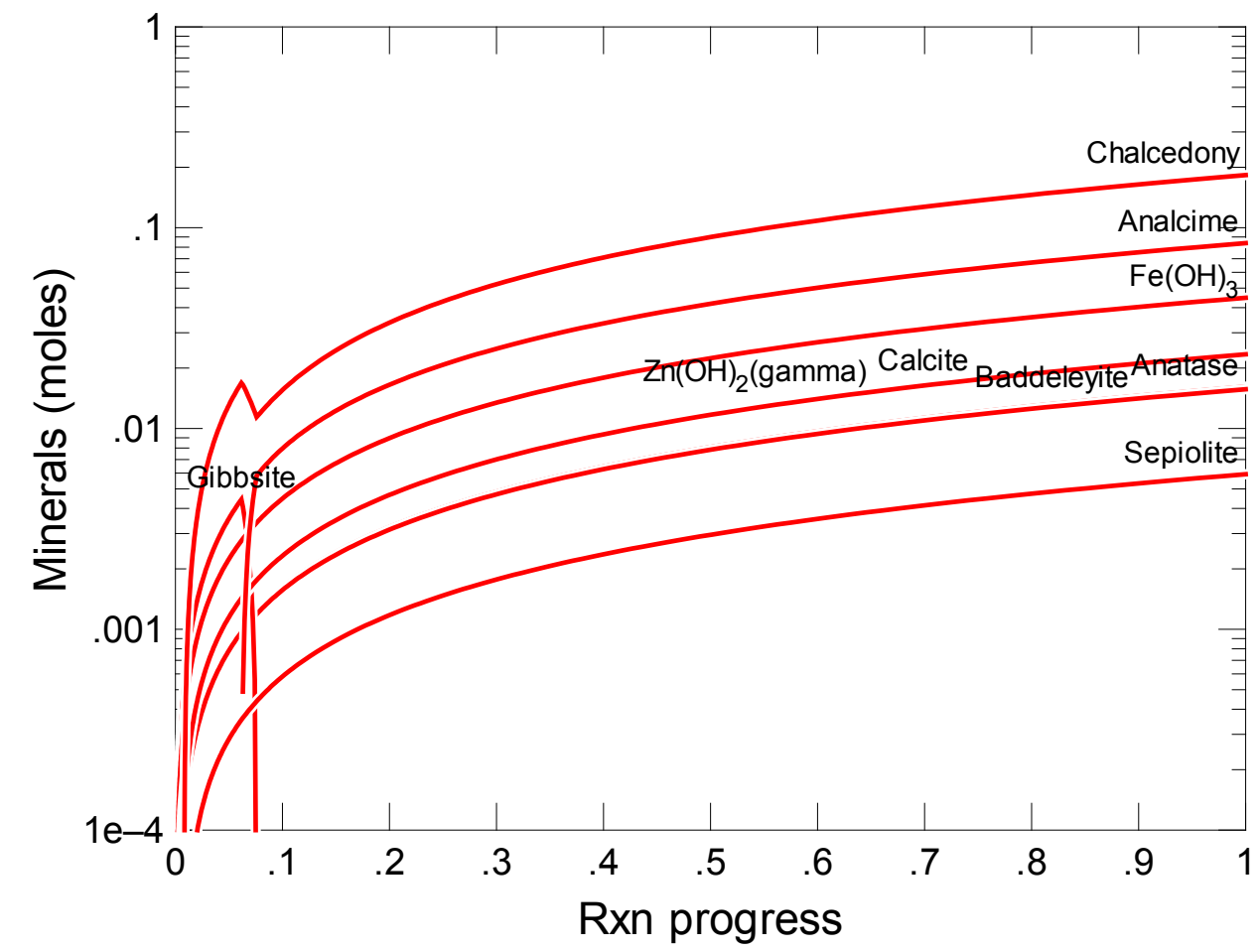

Figure C.34. Secondary Phases Calculated to Form as a Function of Reaction Progress (mol-glass/kg) Determined for Glass Sample A88Si+15 


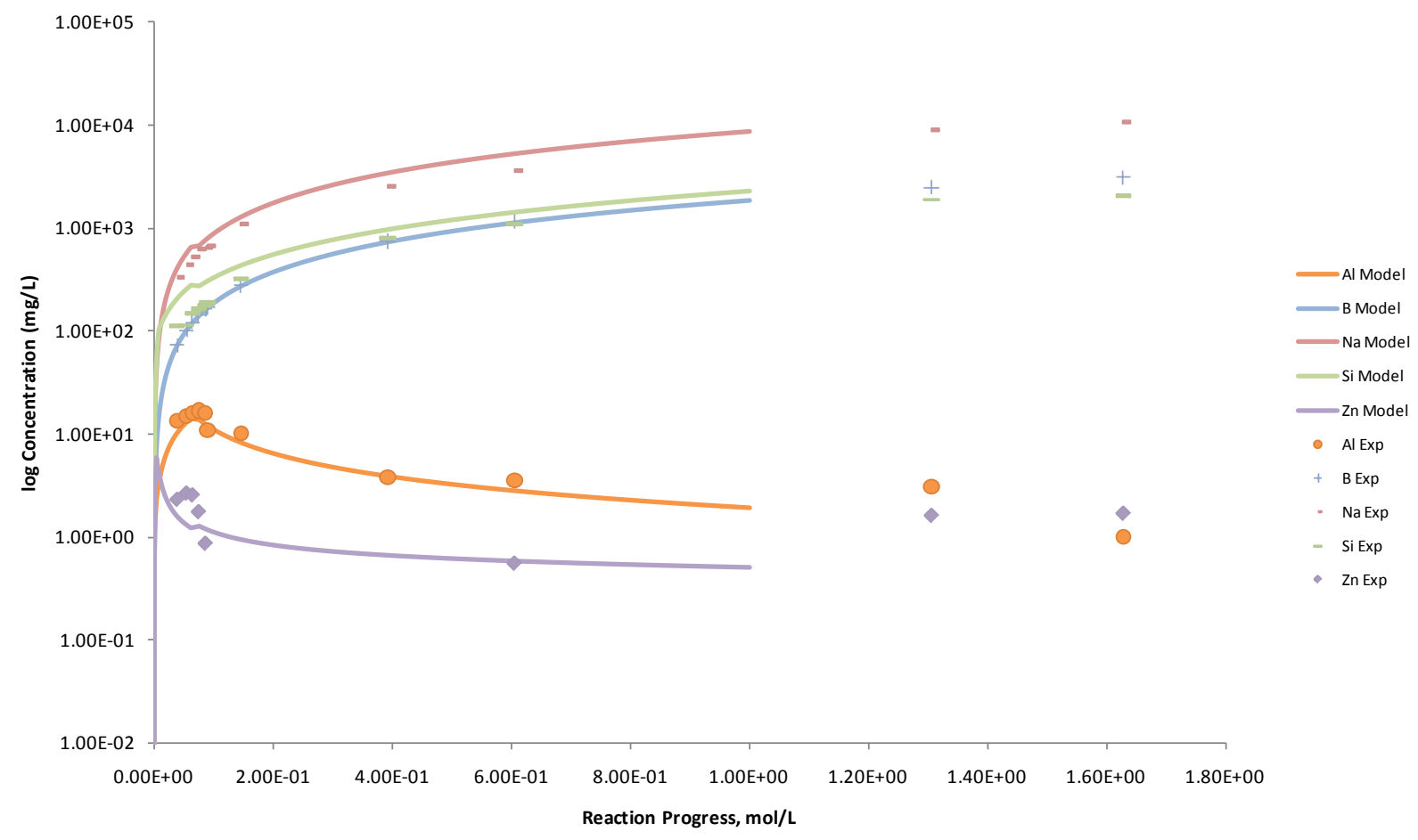

Figure C.35. Measured Solution Concentrations (mg/L) and Model Results for Al, B, Na, Si, and Zn, as a Function of Reaction Progress (mol-glass $/ \mathrm{kg}$ ) Determined for Glass Sample A88Si+15

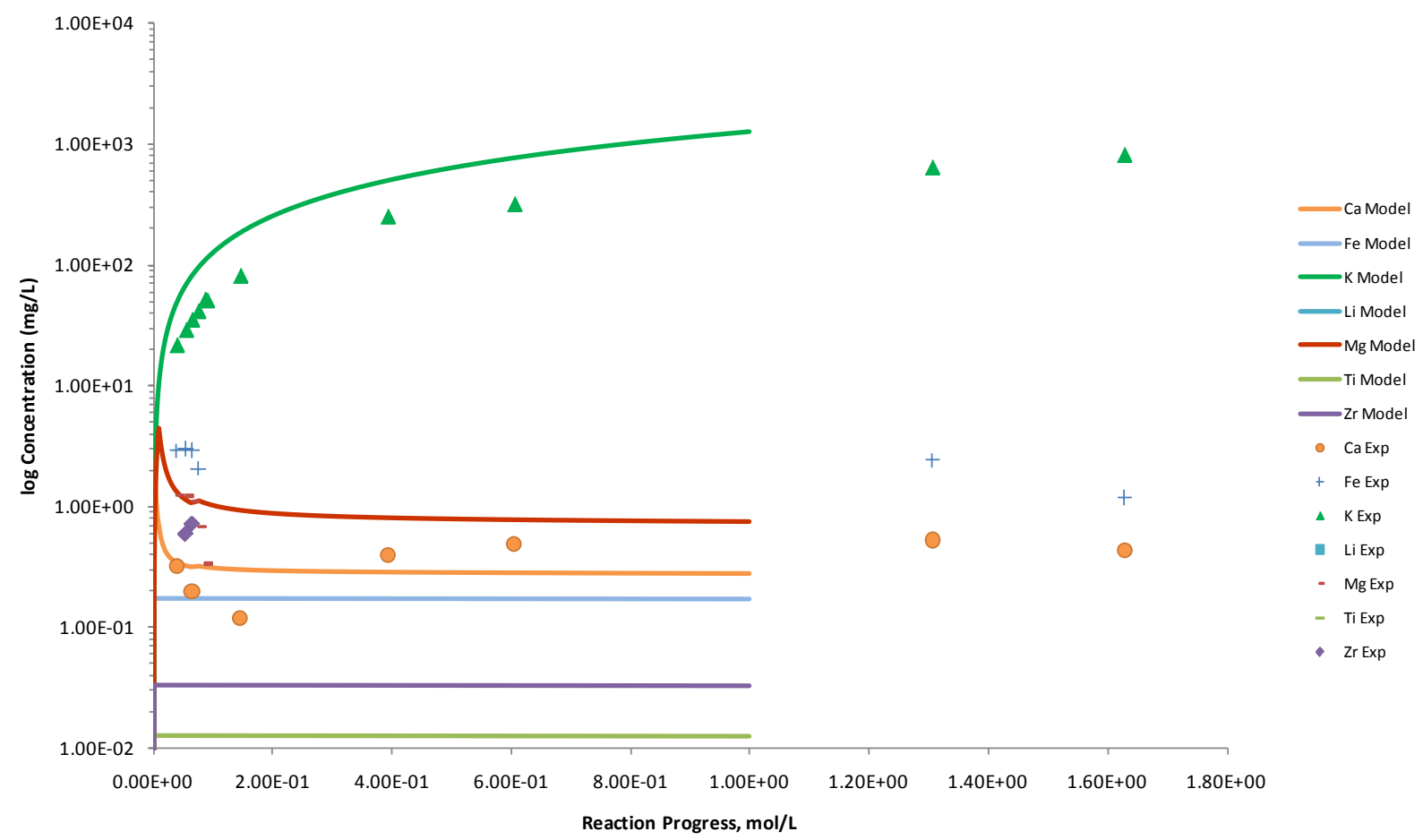

Figure C.36. Measured Solution Concentrations (mg/L) and Model Results for Ca, Fe, K, Li, Mg, Ti, and $\mathrm{Zr}$, as a Function of Reaction Progress (mol-glass/kg) Determined for Glass Sample $\mathrm{A} 88 \mathrm{Si}+15$ 


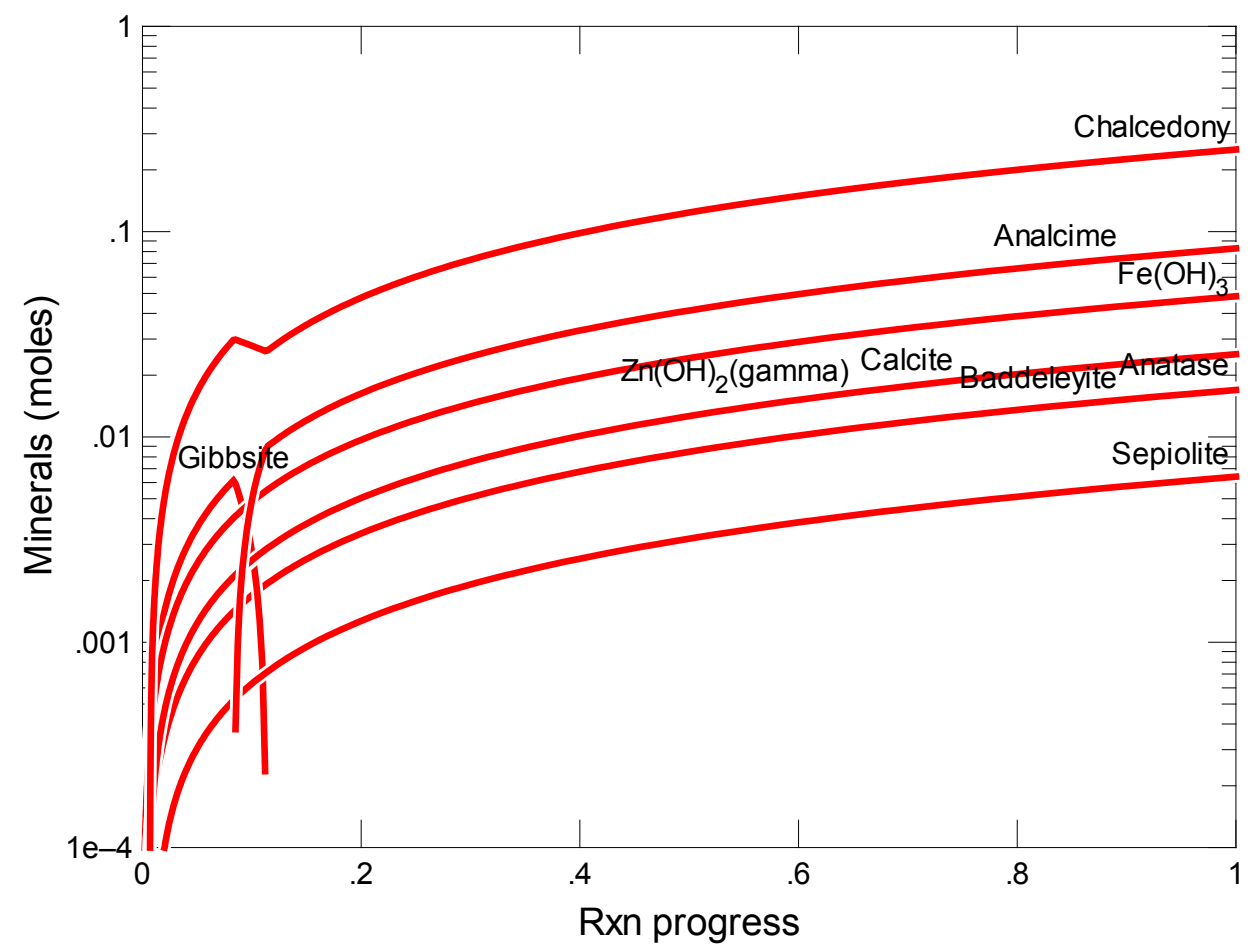

Figure C.37. Secondary Phases Calculated to Form as a Function of Reaction Progress (mol-glass/kg) Determined for Glass Sample A88Si-15

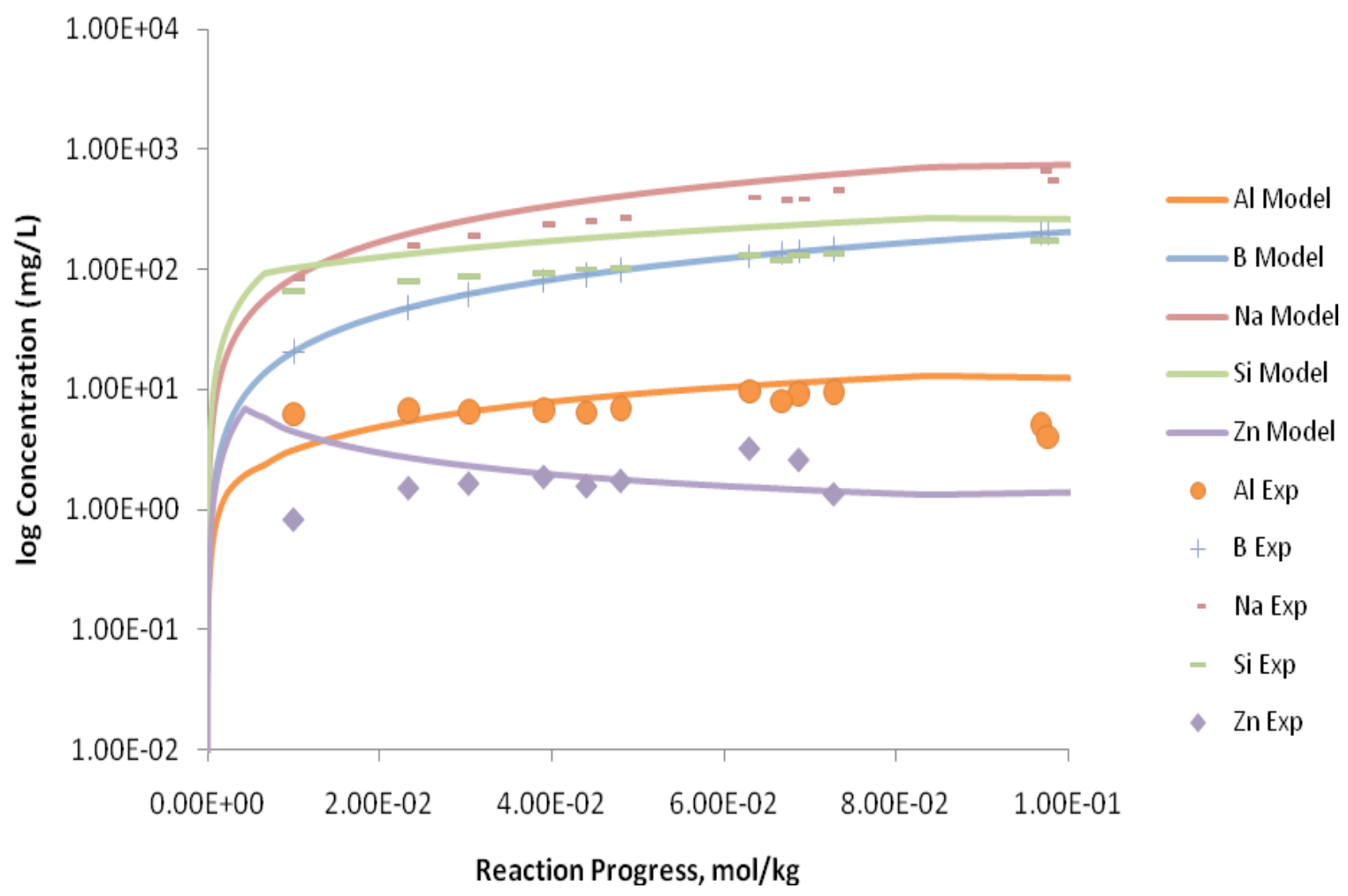

Figure C.38. Measured Solution Concentrations (mg/L) and Model Results for Al, B, Na, Si, and Zn, as a Function of Reaction Progress (mol-glass $/ \mathrm{kg}$ ) Determined for Glass Sample A88Si-15 


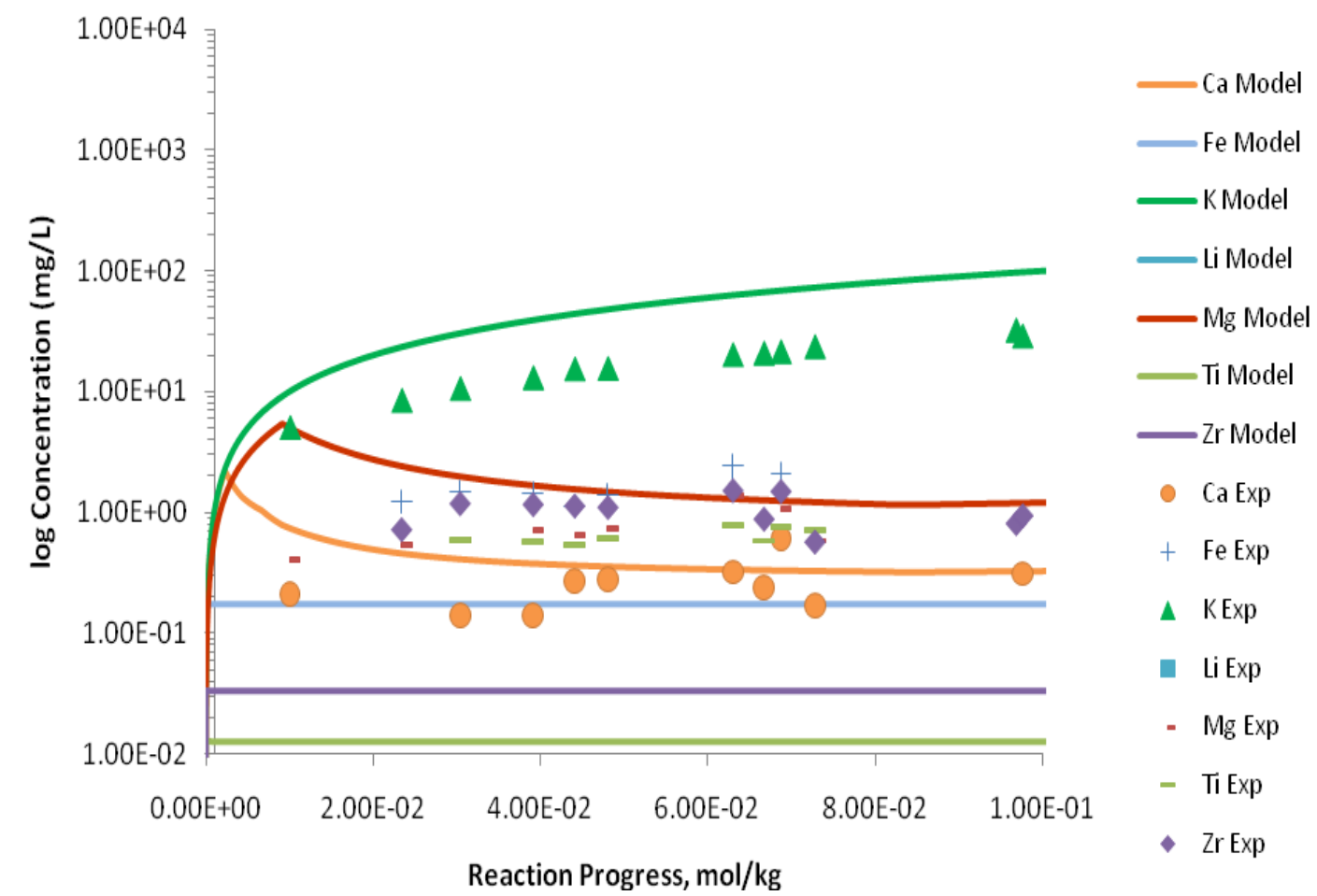

Figure C.39. Measured Solution Concentrations (mg/L) and Model Results for $\mathrm{Ca}, \mathrm{Fe}, \mathrm{K}, \mathrm{Li}, \mathrm{Mg}, \mathrm{Ti}$, and $\mathrm{Zr}$, as a Function of Reaction Progress (mol-glass/kg) Determined for Glass Sample A88Si-15

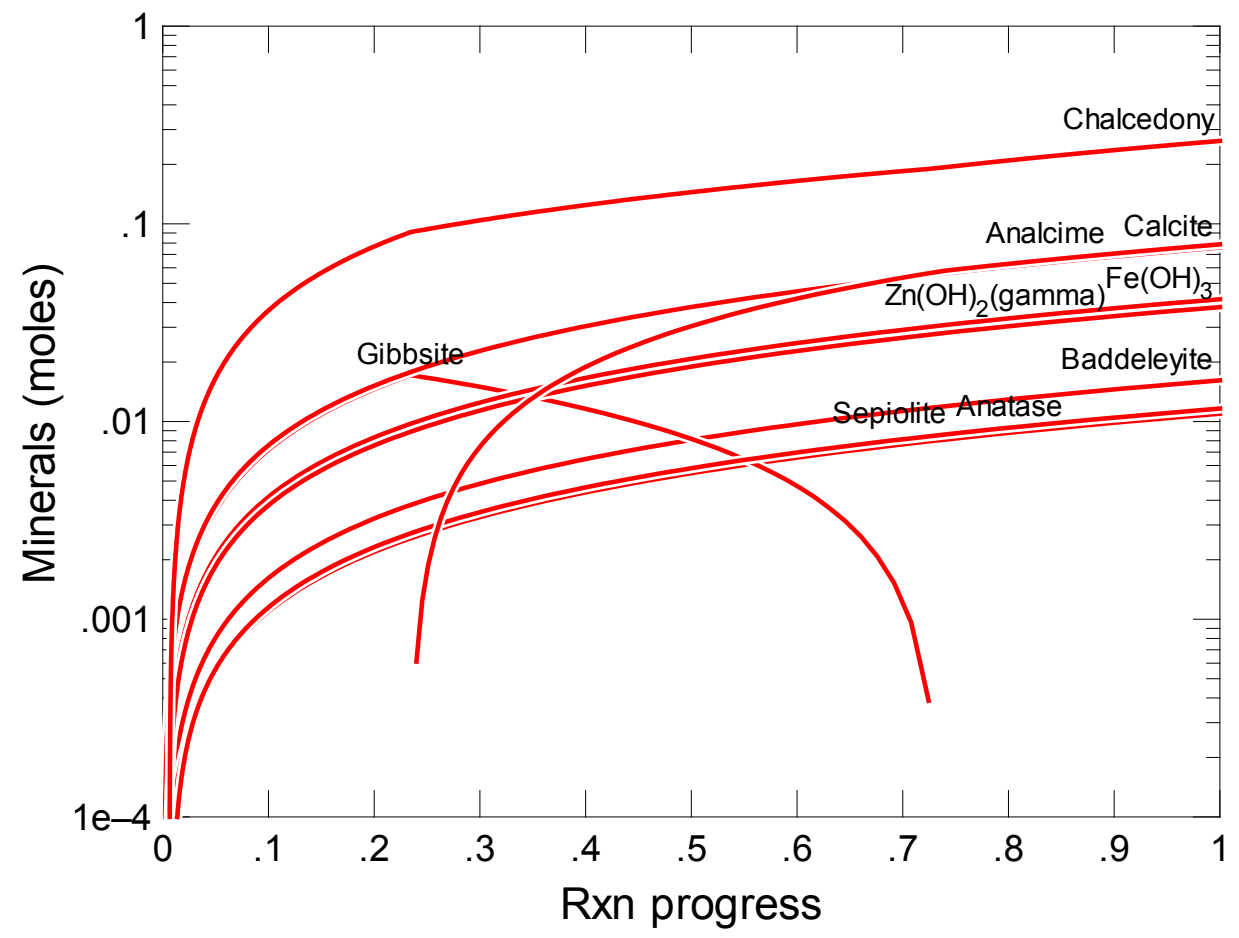

Figure C.40. Secondary Phases Calculated to Form as a Function of Reaction Progress (mol-glass $/ \mathrm{kg}$ ) Determined for Glass Sample B1-AZ101 


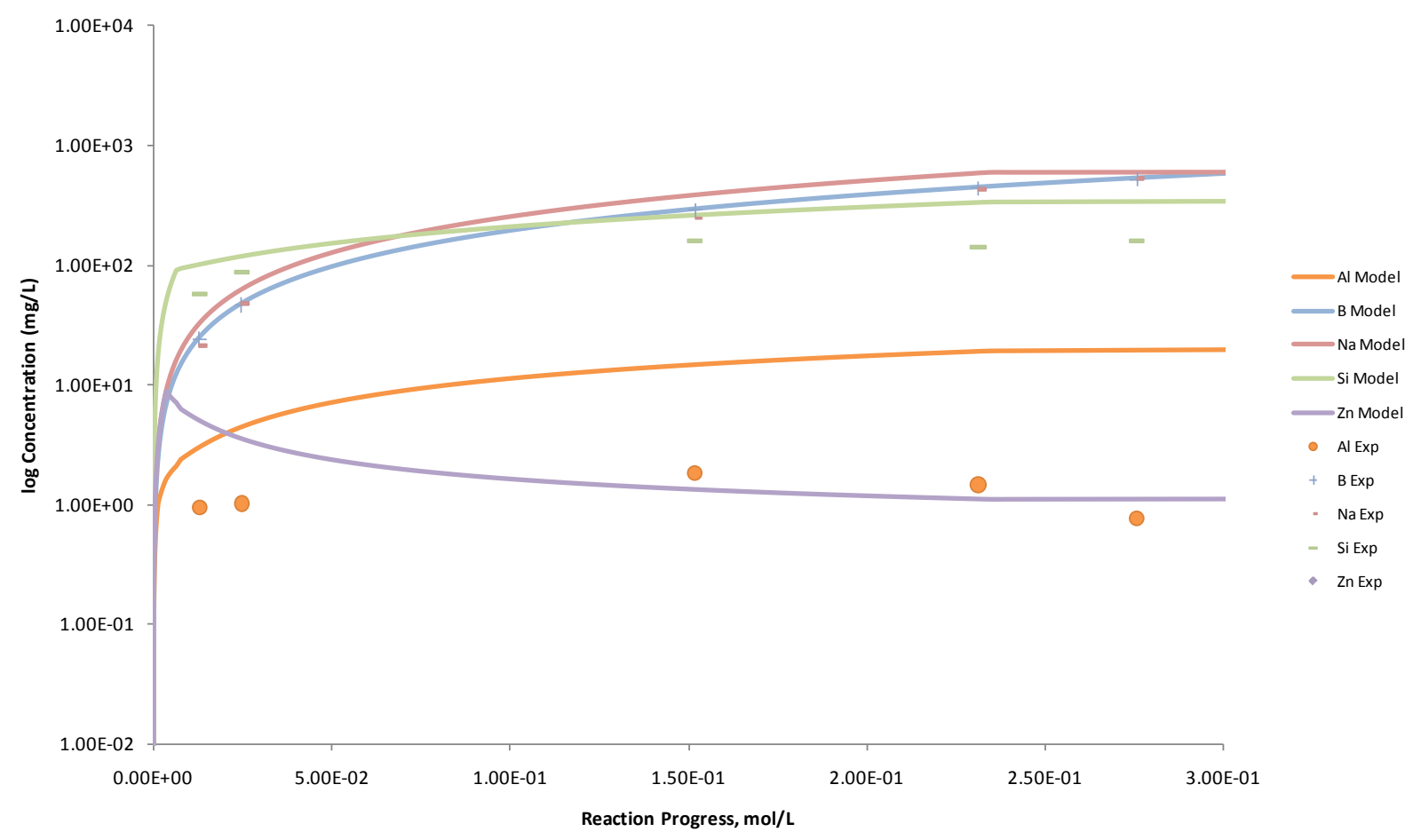

Figure C.41. Measured Solution Concentrations (mg/L) and Model Results for Al, B, Na, Si, and Zn, as a Function of Reaction Progress (mol-glass $/ \mathrm{kg}$ ) Determined for Glass Sample B1-AZ101

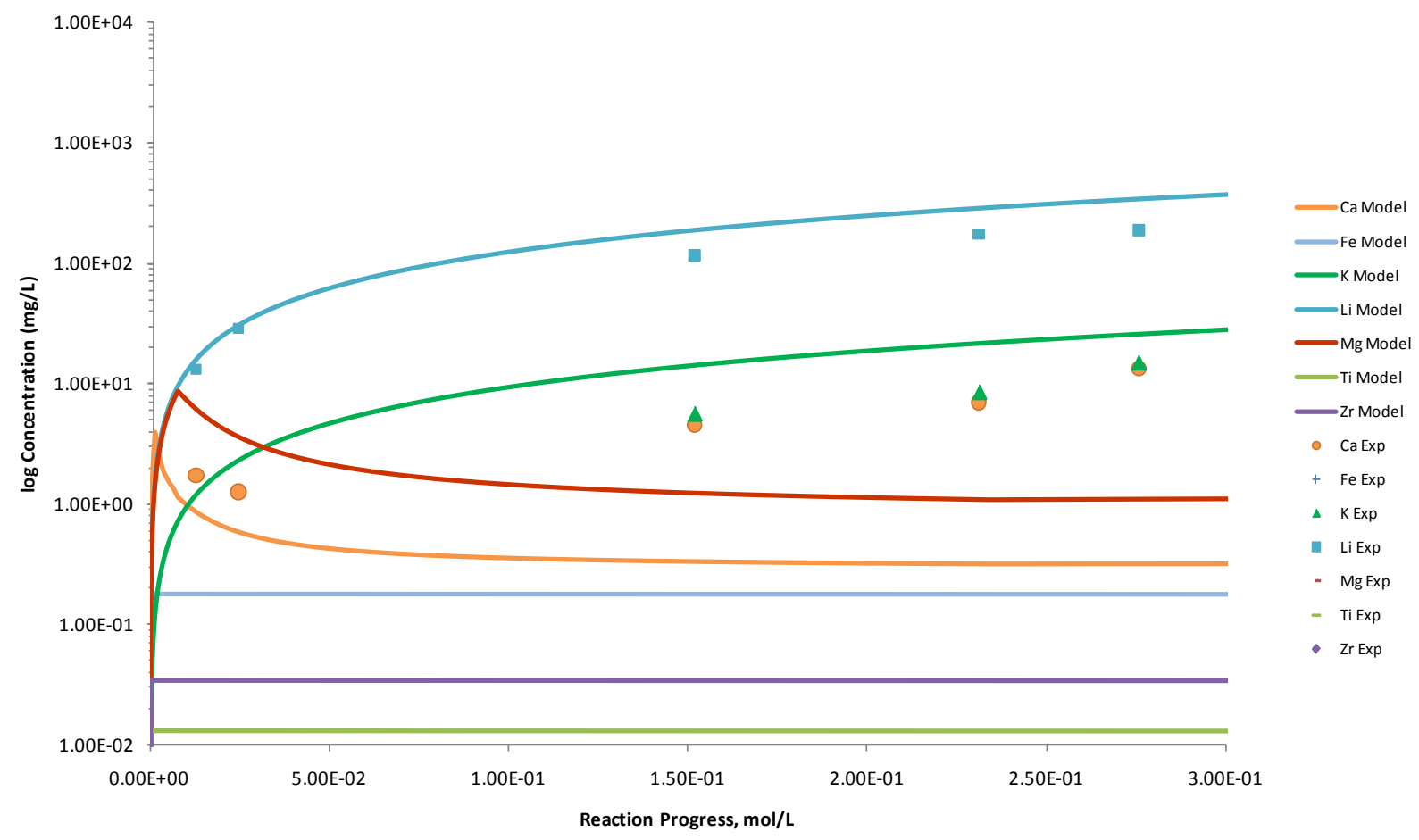

Figure C.42. Measured Solution Concentrations (mg/L) and Model Results for Ca, Fe, K, Li, Mg, Ti, and $\mathrm{Zr}$, as a Function of Reaction Progress (mol-glass $/ \mathrm{kg}$ ) Determined for Glass Sample $\mathrm{B} 1-\mathrm{AZ101}$ 


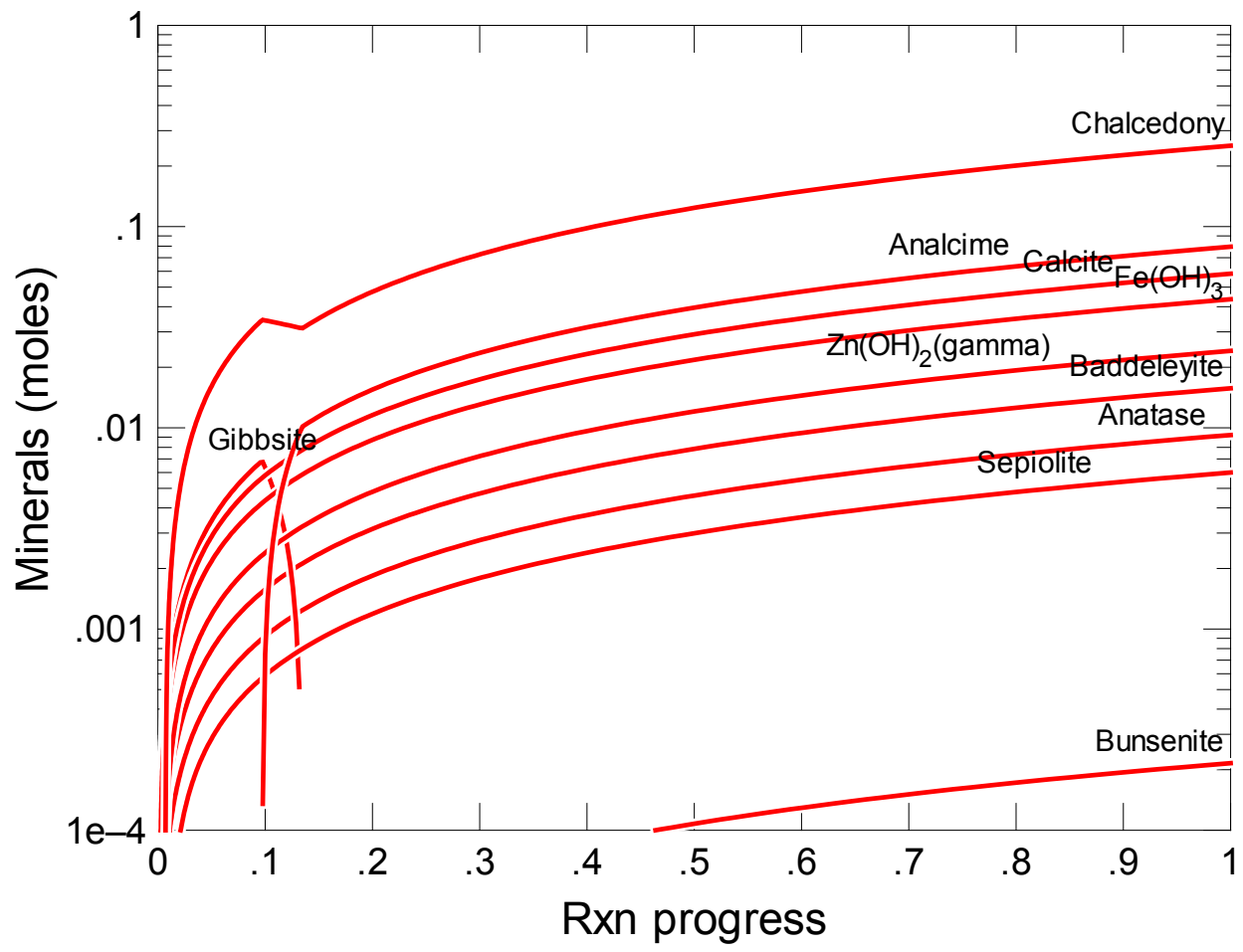

Figure C.43. Secondary Phases Calculated to Form as a Function of Reaction Progress (mol-glass/kg) Determined for Glass Sample C1-AN107

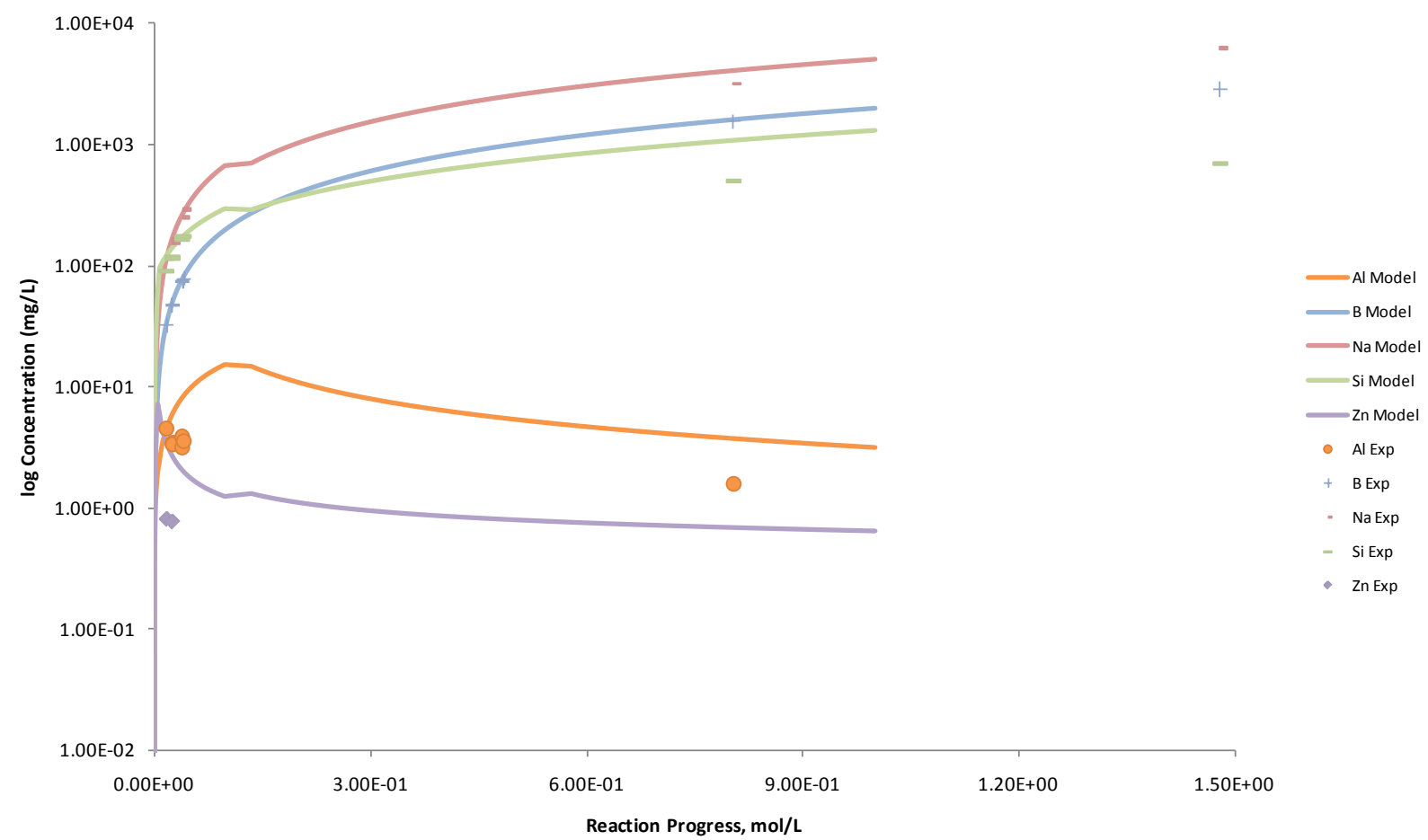

Figure C.44. Measured Solution Concentrations (mg/L) and Model Results for Al, B, Na, Si, and Zn, as a Function of Reaction Progress (mol-glass/kg) Determined for Glass Sample C1-AN107 


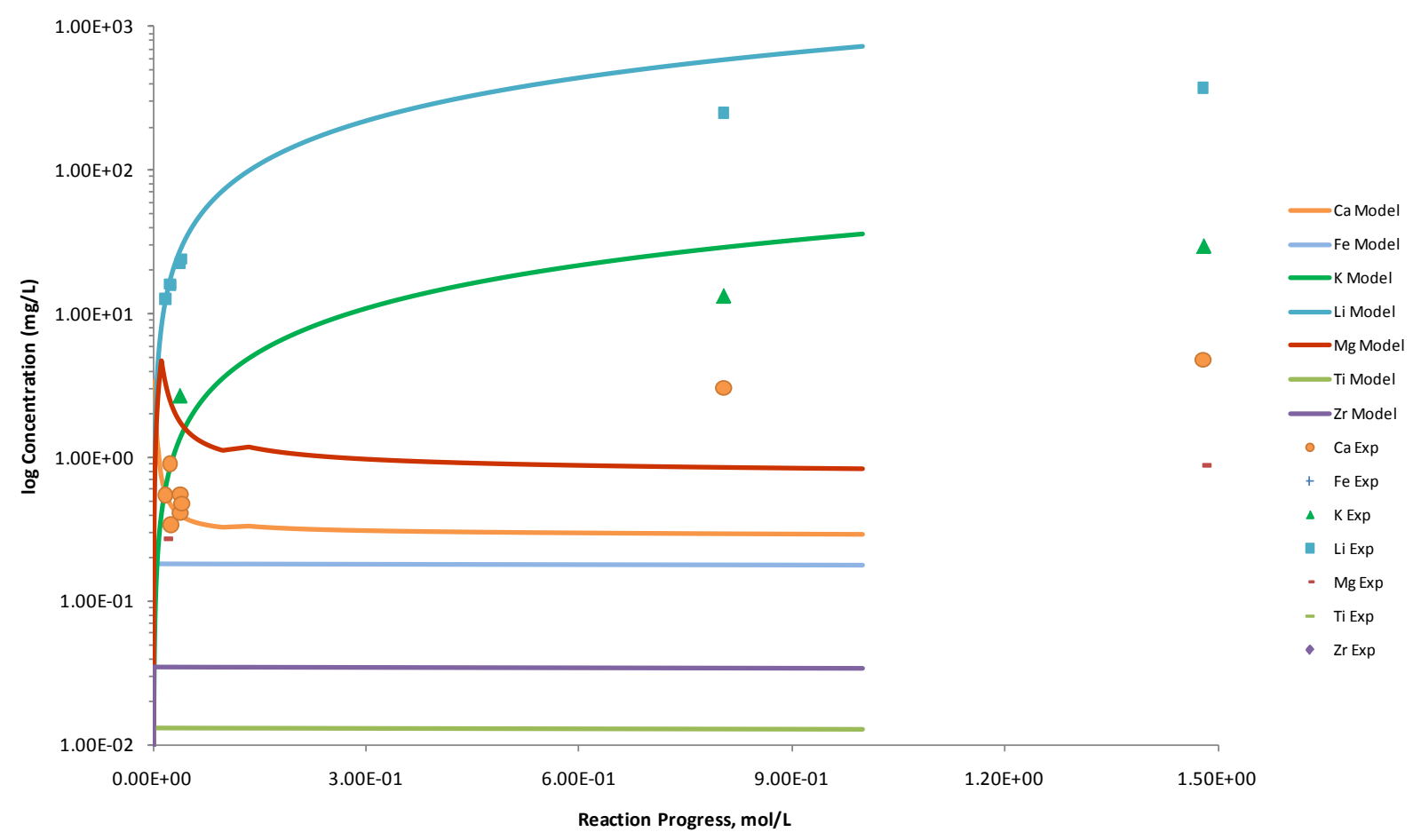

Figure C.45. Measured Solution Concentrations (mg/L) and Model Results for $\mathrm{Ca}, \mathrm{Fe}, \mathrm{K}, \mathrm{Li}, \mathrm{Mg}, \mathrm{Ti}$, and $\mathrm{Zr}$, as a Function of Reaction Progress (mol-glass/kg) Determined for Glass Sample C1-AN107

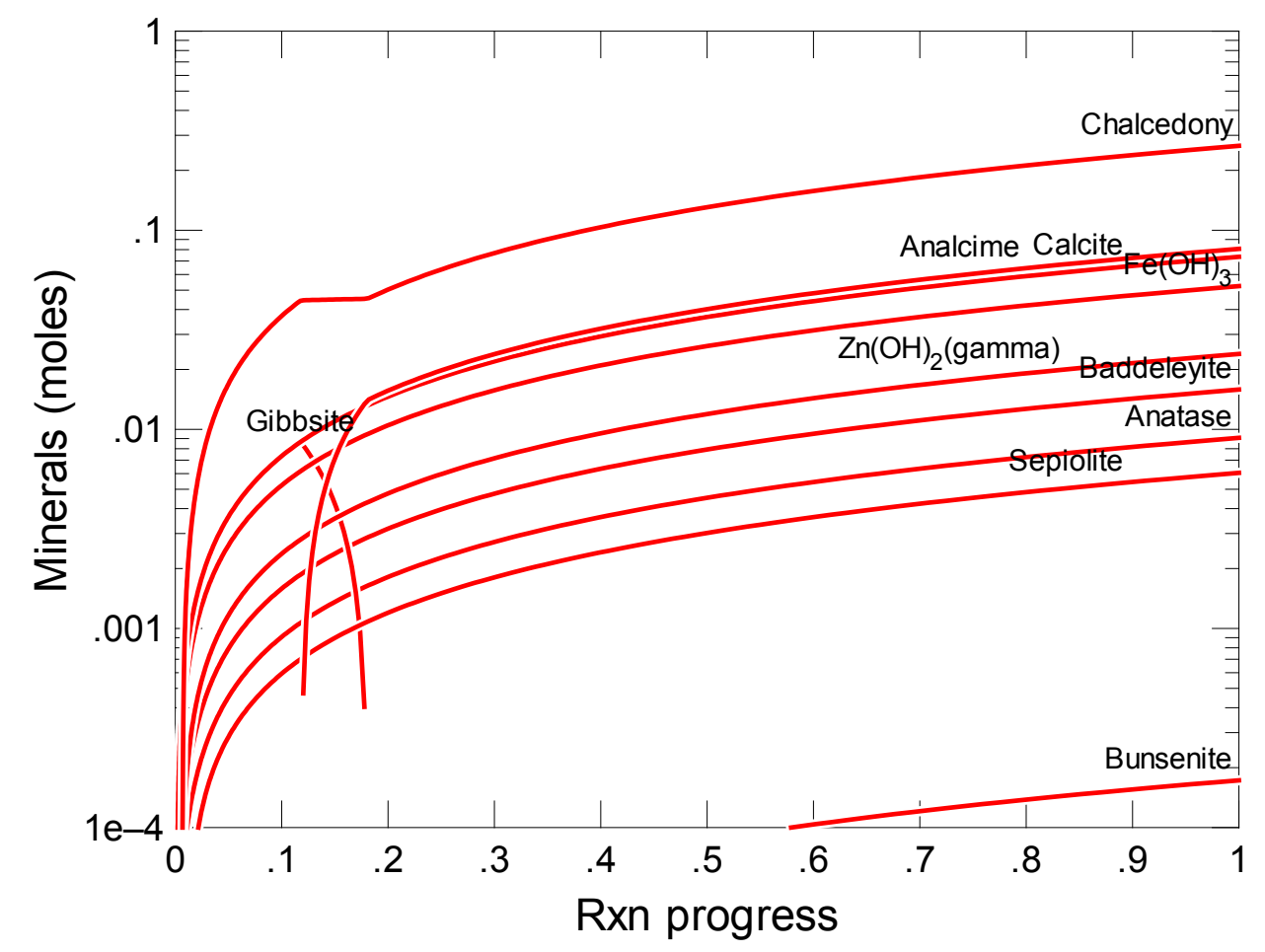

Figure C.46. Secondary Phases Calculated to Form as a Function of Reaction Progress (mol-glass/kg) Determined for Glass Sample C100-G-136B 


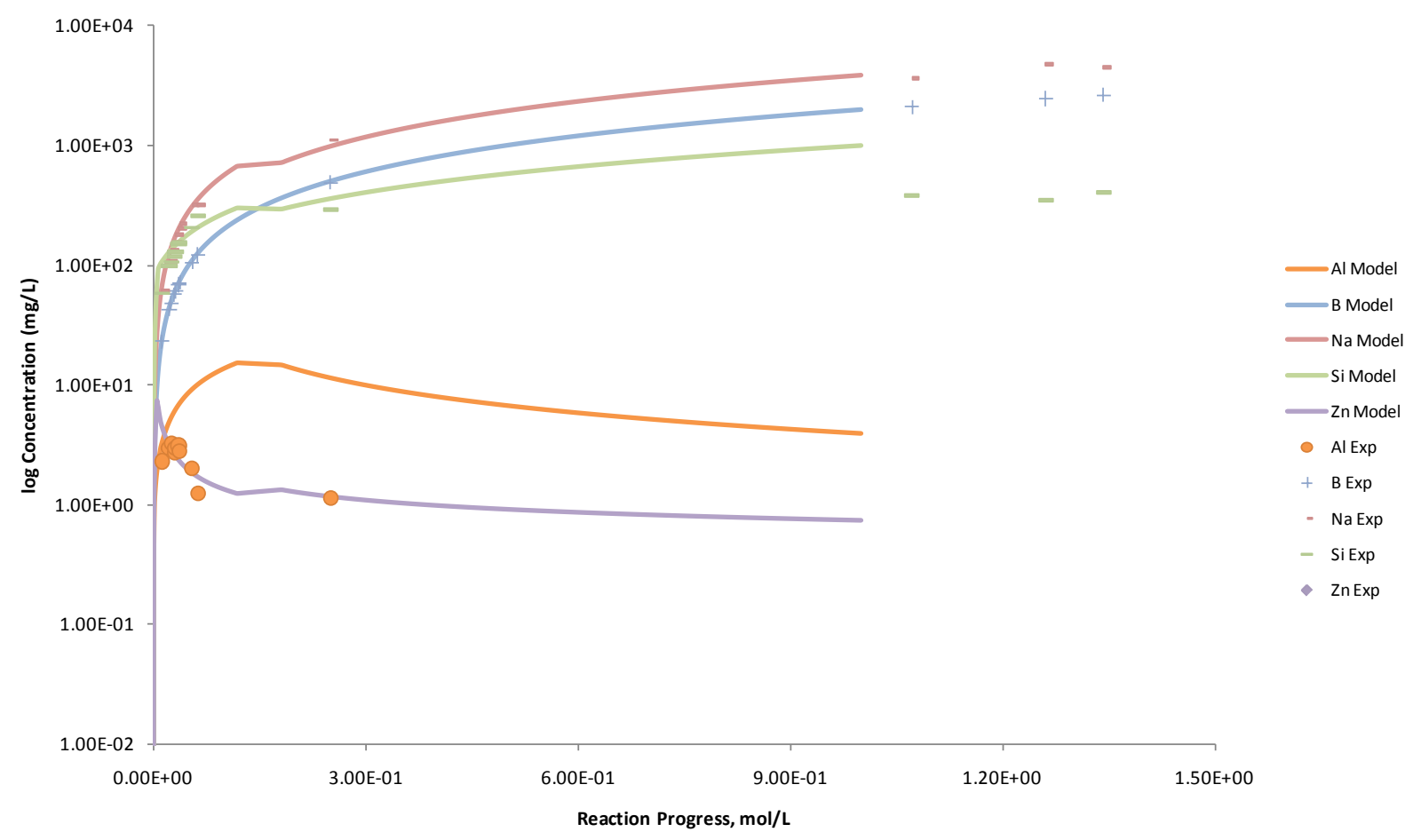

Figure C.47. Measured Solution Concentrations (mg/L) and Model Results for Al, B, Na, Si, and Zn, as a Function of Reaction Progress (mol-glass $/ \mathrm{kg}$ ) Determined for Glass Sample C100-G-136B

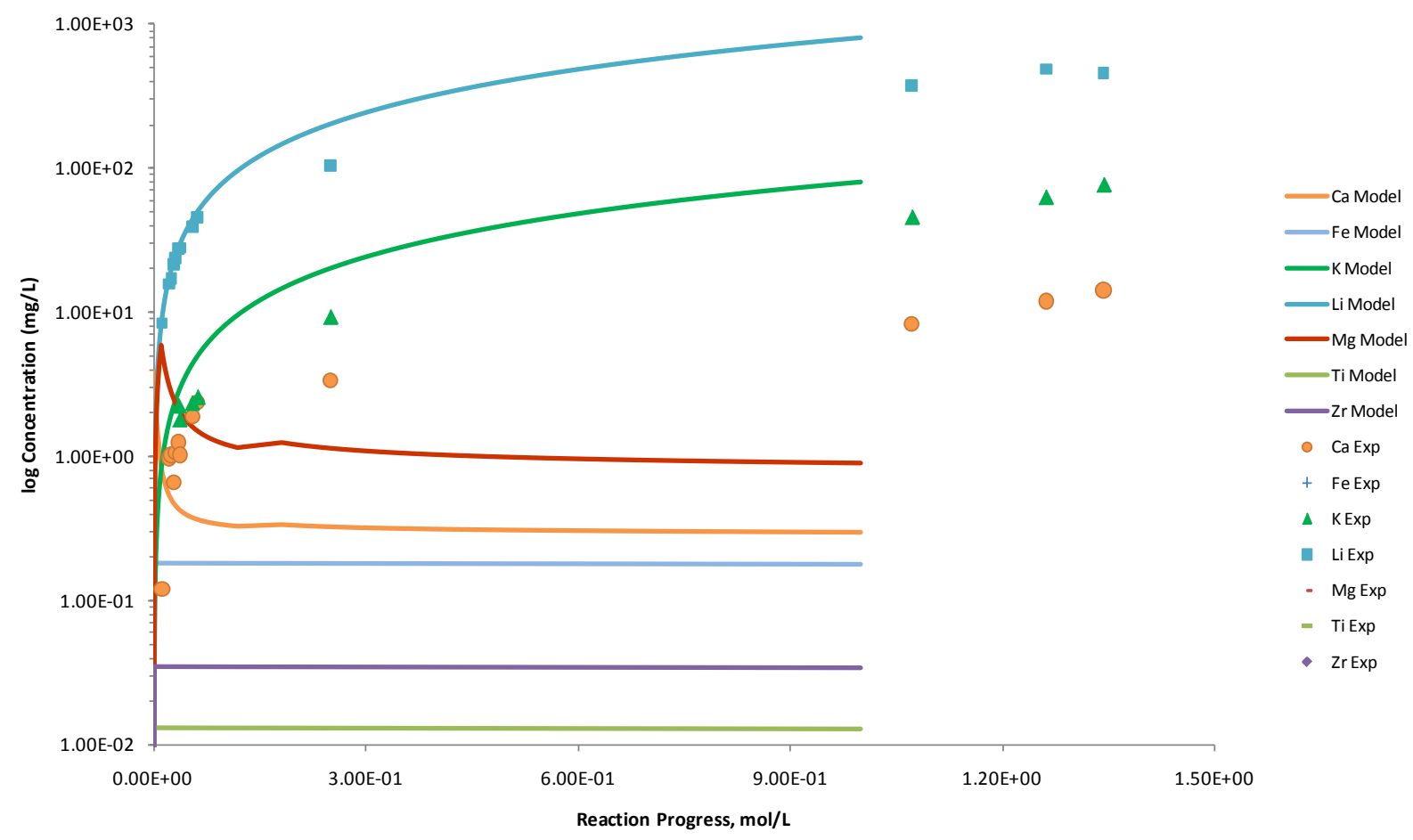

Figure C.48. Measured Solution Concentrations (mg/L) and Model Results for $\mathrm{Ca}, \mathrm{Fe}, \mathrm{K}, \mathrm{Li}, \mathrm{Mg}, \mathrm{Ti}$, and $\mathrm{Zr}$, as a Function of Reaction Progress (mol-glass/kg) Determined for Glass Sample C100-G-136B 


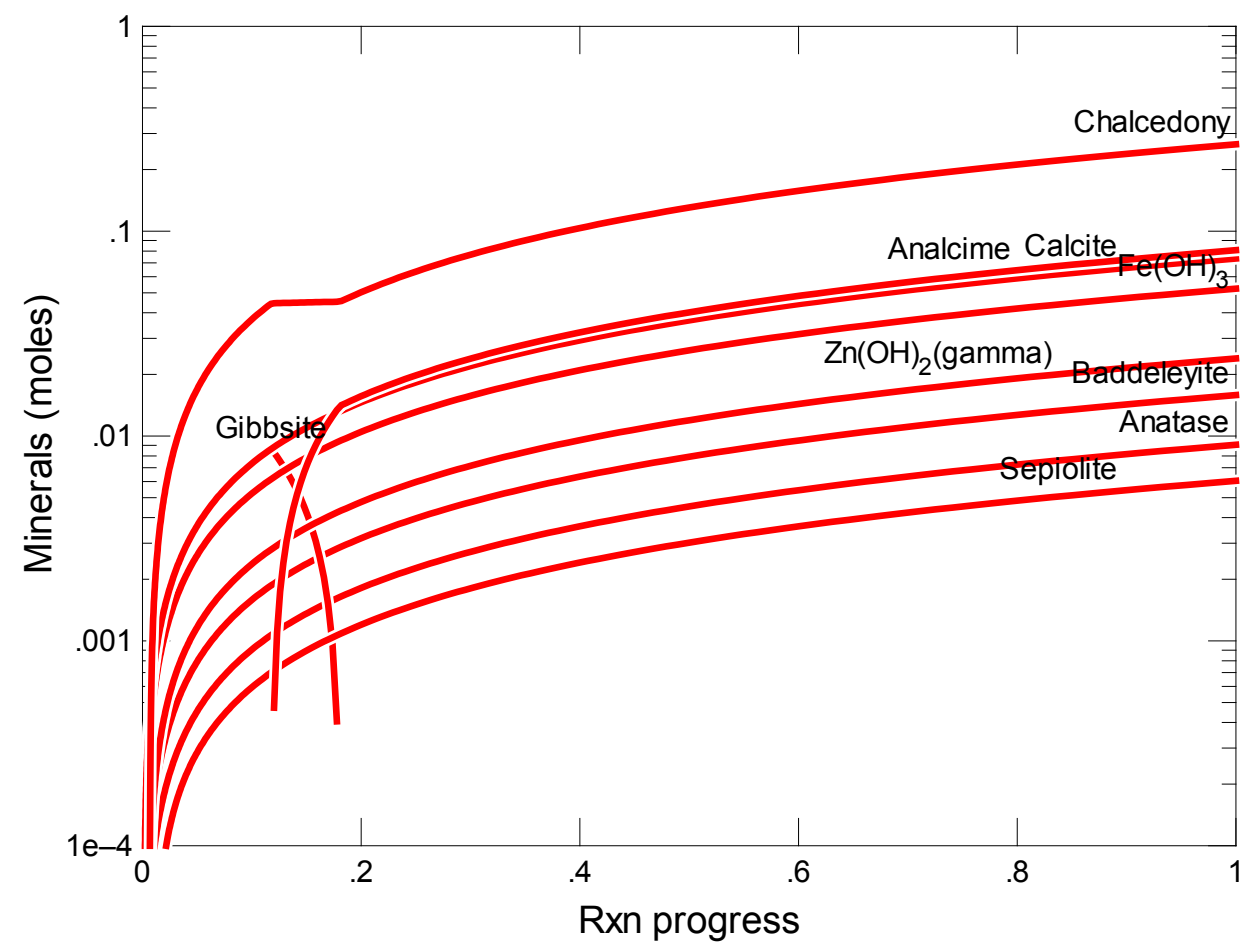

Figure C.49. Secondary Phases Calculated to Form as a Function of Reaction Progress (mol-glass $/ \mathrm{kg}$ ) Determined for Glass Sample C100GCC

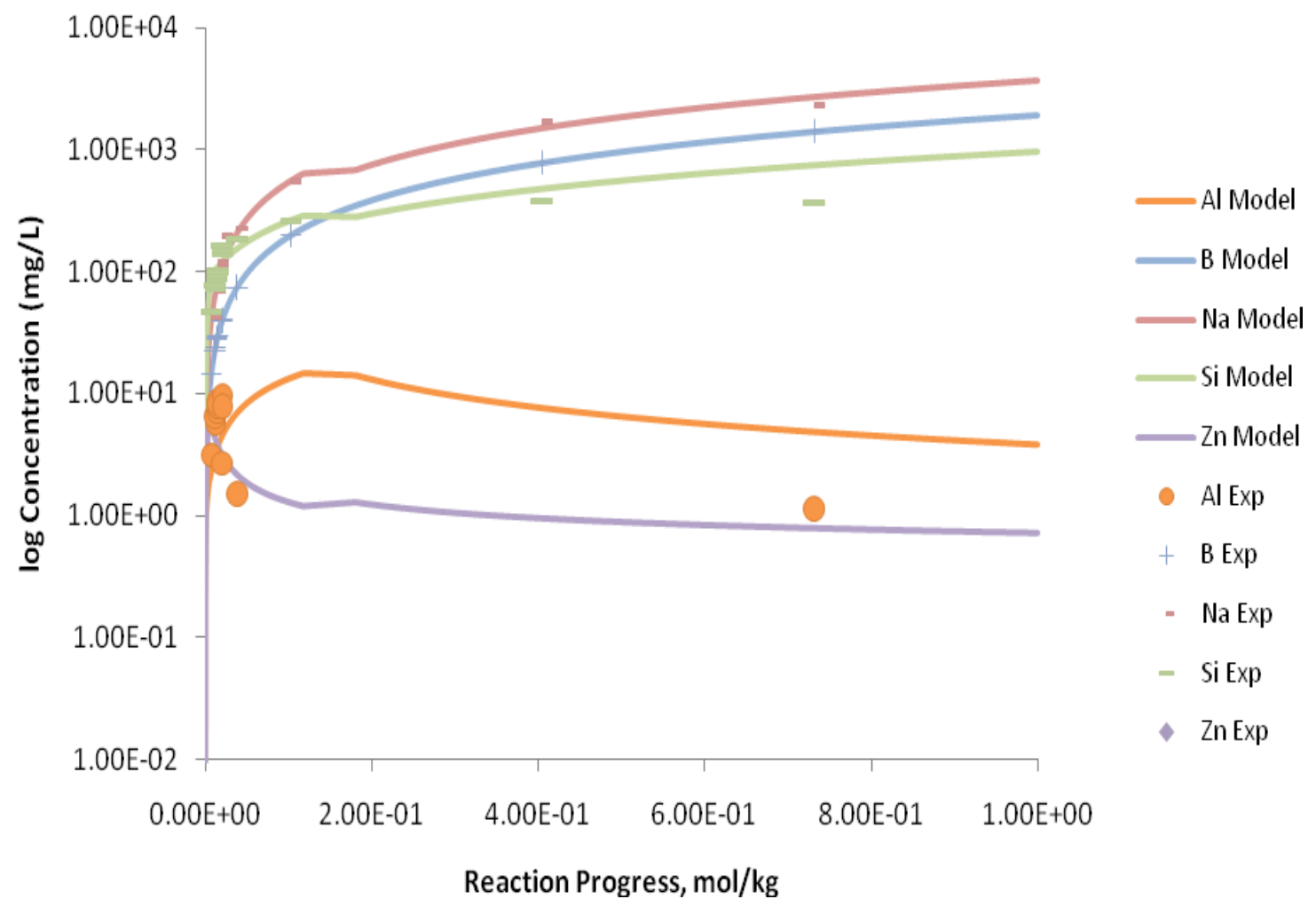

Figure C.50. Measured Solution Concentrations (mg/L) and Model Results for Al, B, Na, Si, and Zn, as a Function of Reaction Progress (mol-glass/kg) Determined for Glass Sample C100GCC 


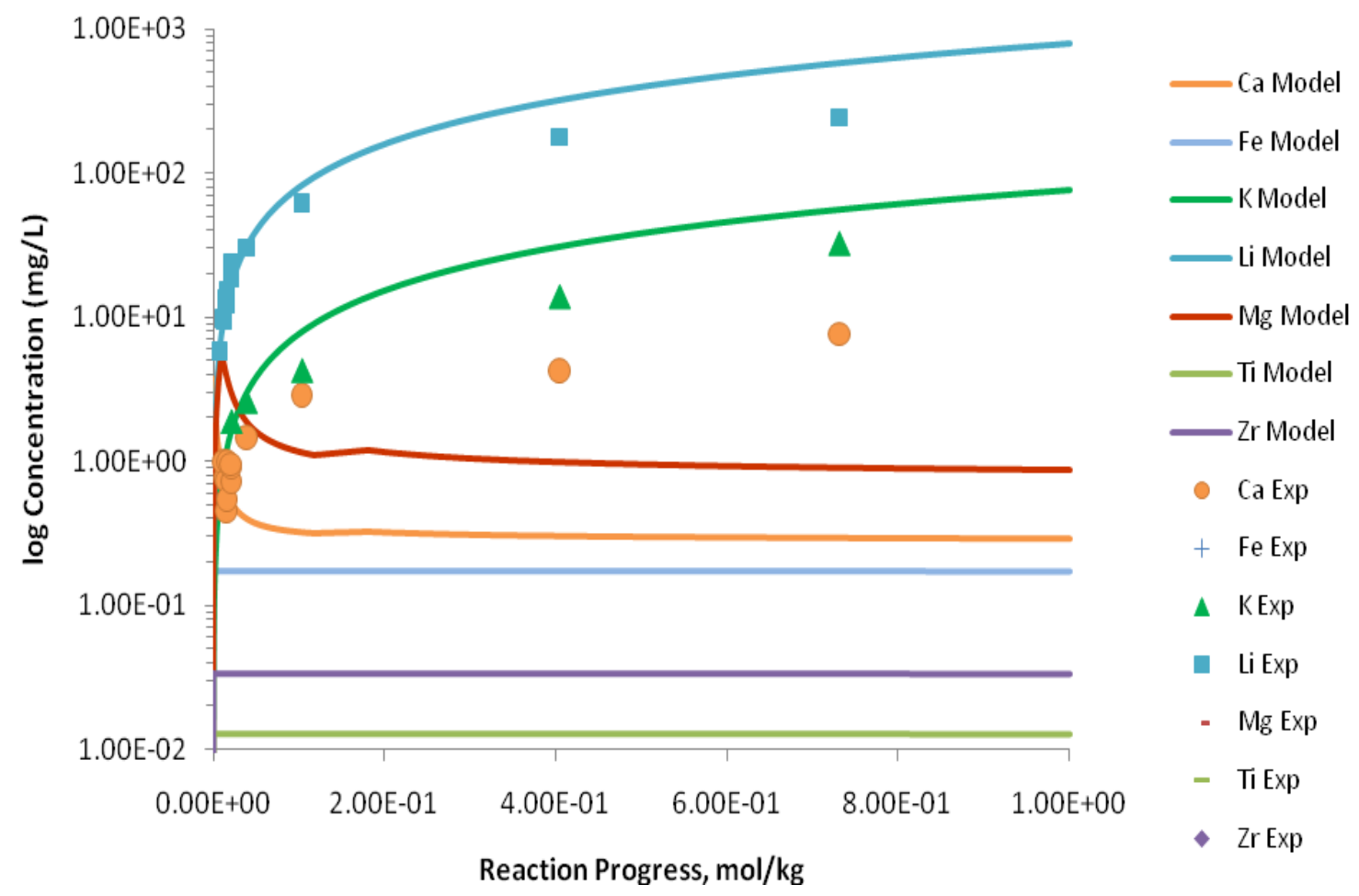

Figure C.51. Measured Solution Concentrations (mg/L) and Model Results for $\mathrm{Ca}, \mathrm{Fe}, \mathrm{K}, \mathrm{Li}, \mathrm{Mg}$, Ti, and $\mathrm{Zr}$, as a Function of Reaction Progress (mol-glass $/ \mathrm{kg}$ ) Determined for Glass Sample C100GCC

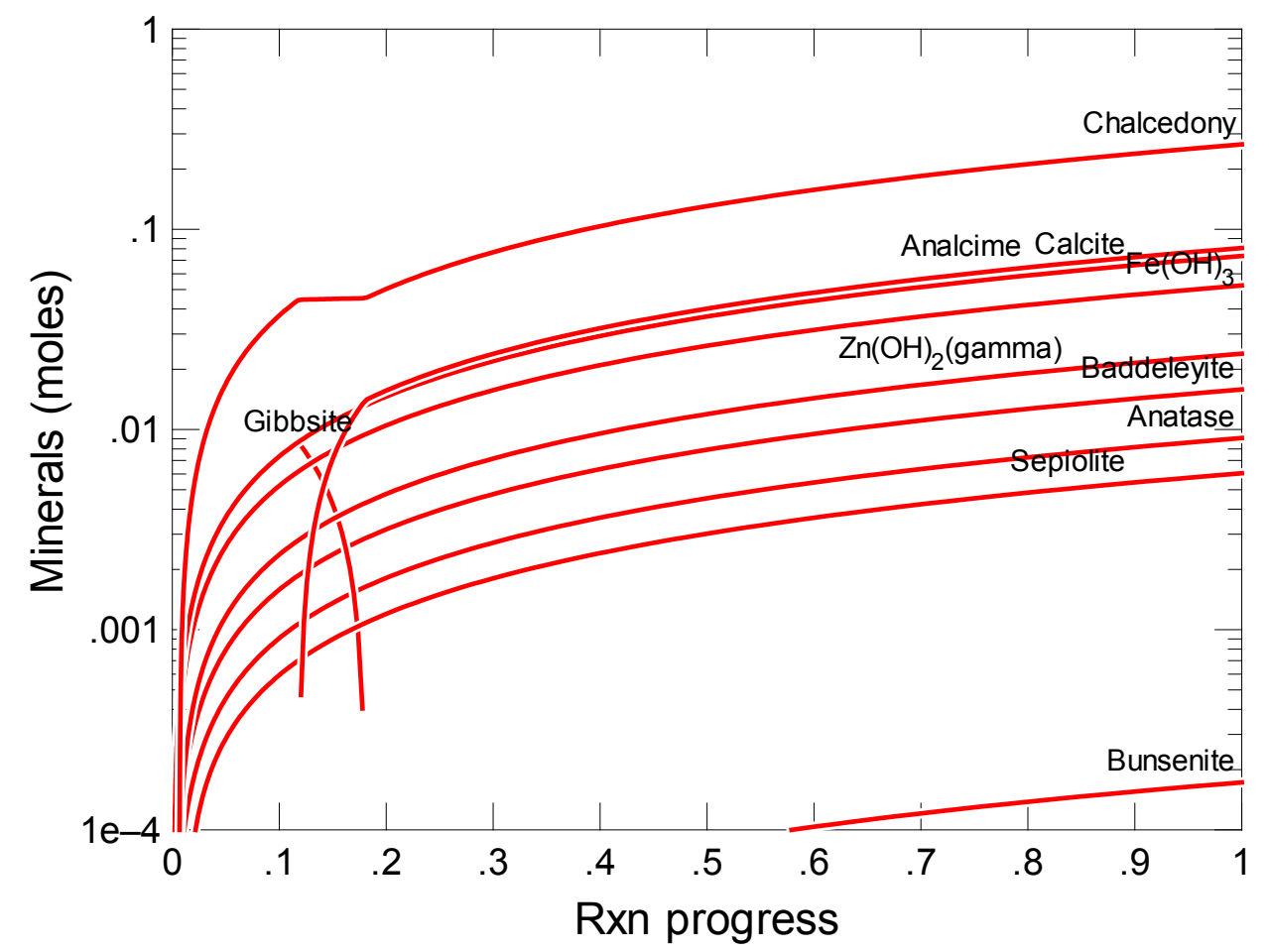

Figure C.52. Secondary Phases Calculated to Form as a Function of Reaction Progress (mol-glass/kg) Determined for Glass Sample C22AN107 


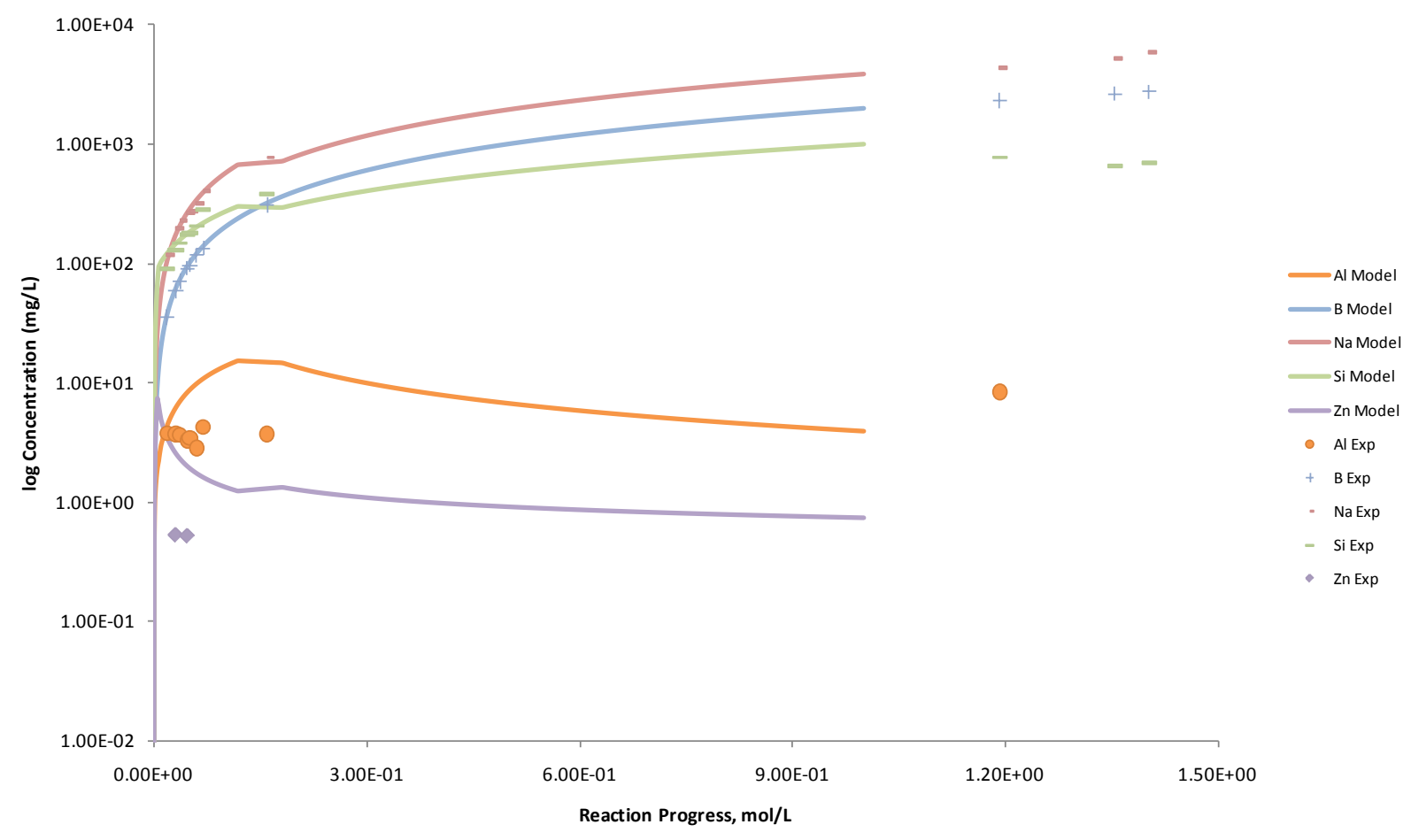

Figure C.53. Measured Solution Concentrations (mg/L) and Model Results for Al, B, Na, Si, and Zn, as a Function of Reaction Progress (mol-glass/kg) Determined for Glass Sample C22AN107

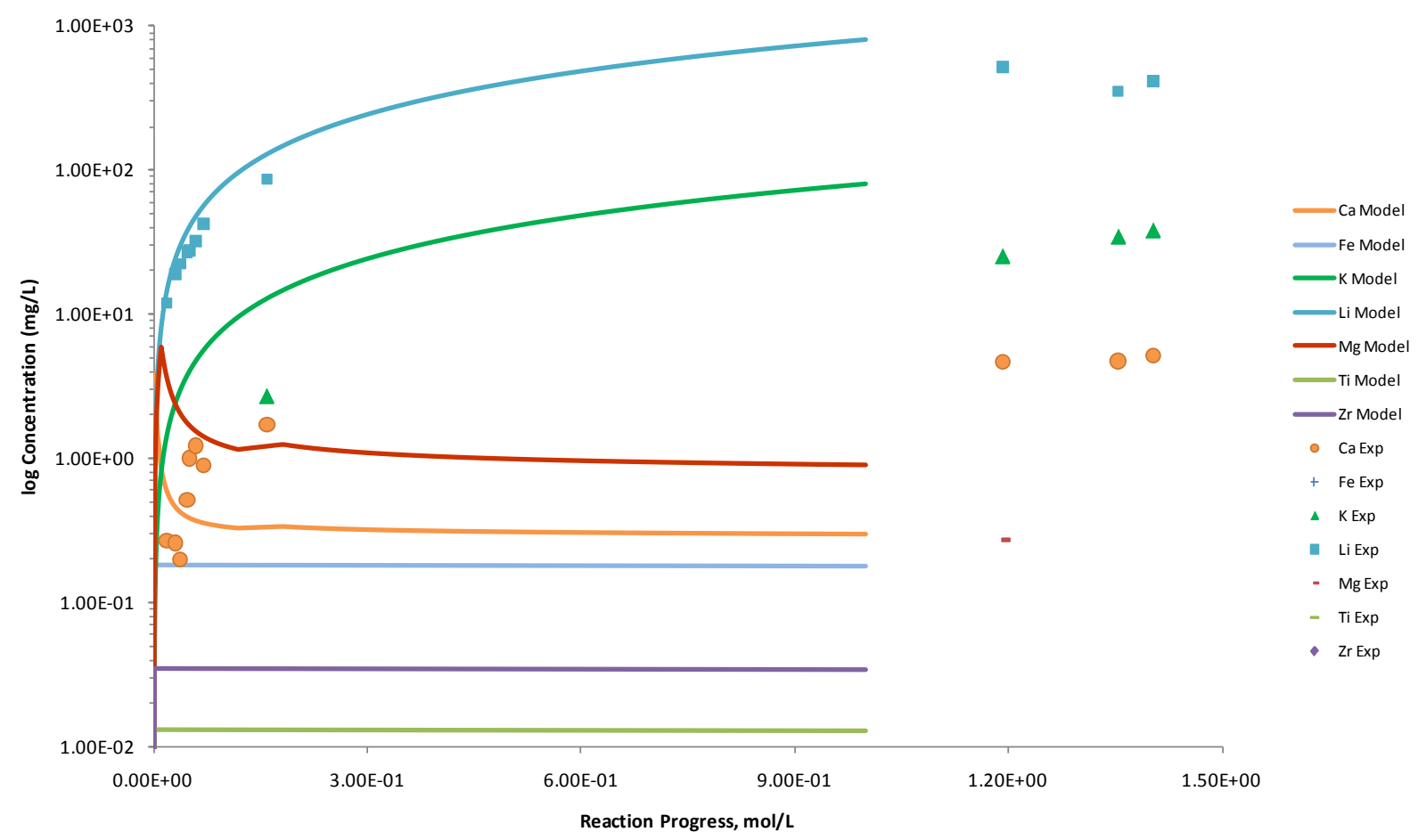

Figure C.54. Measured Solution Concentrations (mg/L) and Model Results for Ca, Fe, K, Li, Mg, Ti, and $\mathrm{Zr}$, as a Function of Reaction Progress (mol-glass/kg) Determined for Glass Sample C22AN107 


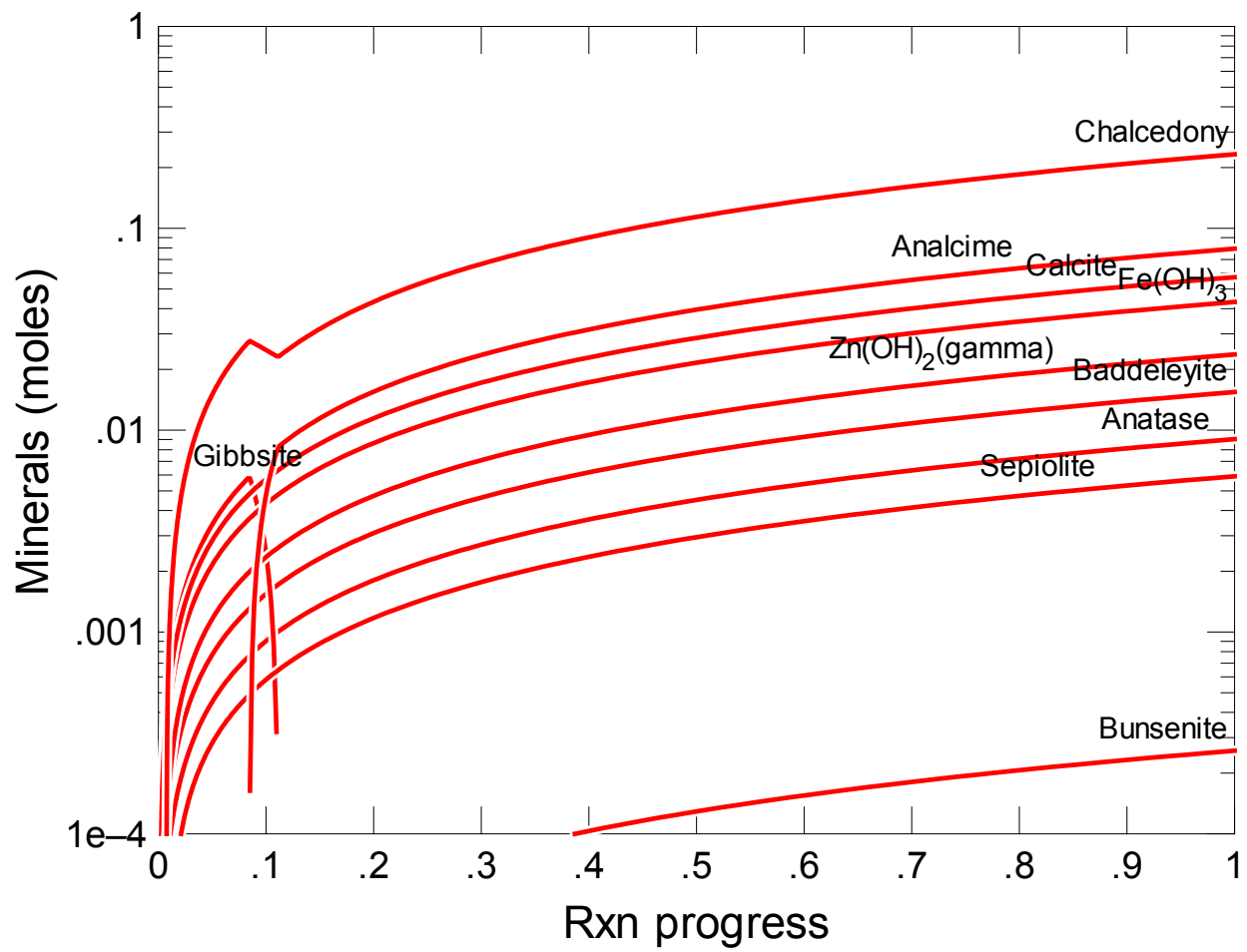

Figure C.55. Secondary Phases Calculated to Form as a Function of Reaction Progress (mol-glass/kg) Determined for Glass Sample C22Si+15

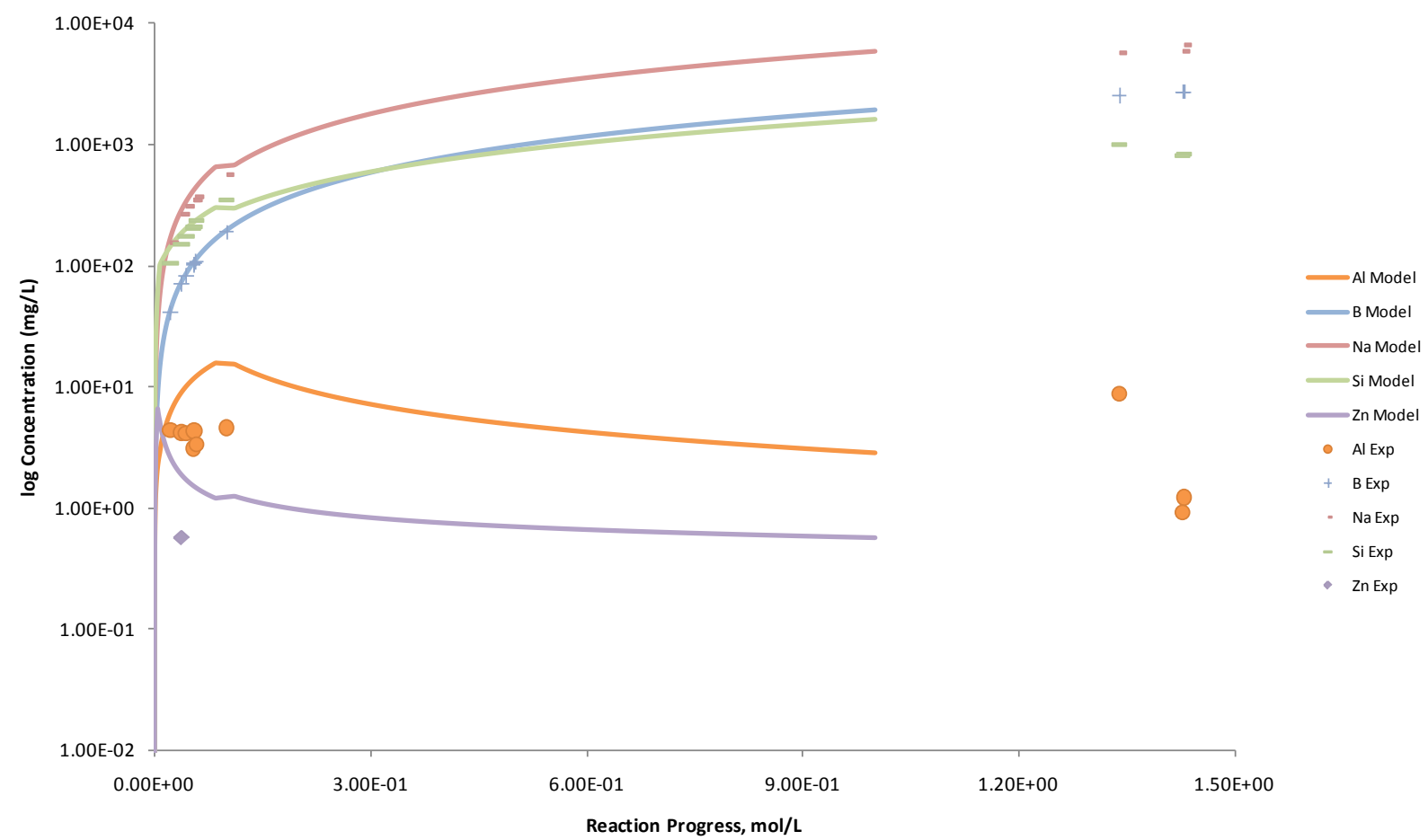

Figure C.56. Measured Solution Concentrations (mg/L) and Model Results for Al, B, Na, Si, and Zn, as a Function of Reaction Progress (mol-glass $/ \mathrm{kg}$ ) Determined for Glass Sample C22Si+15 


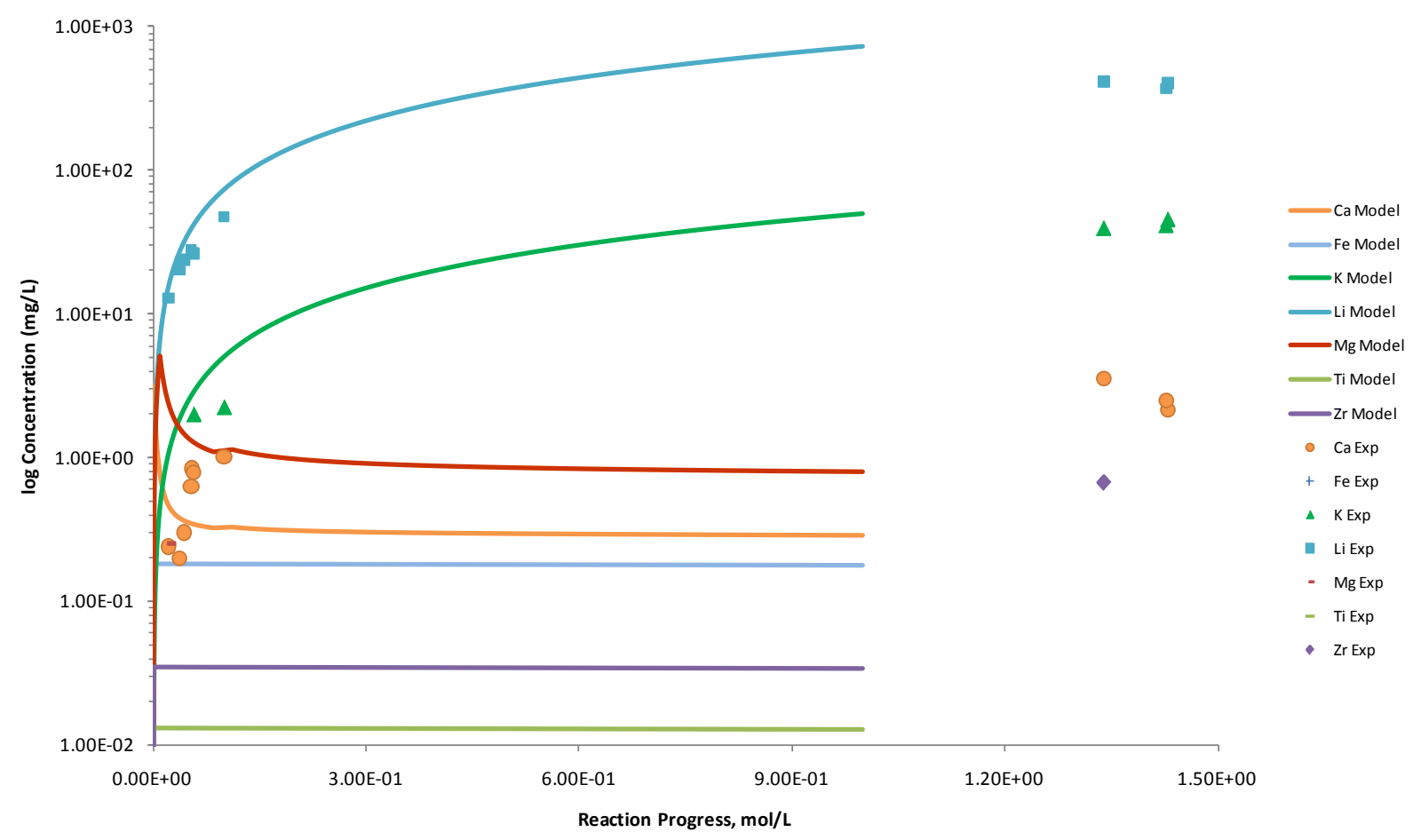

Figure C.57. Measured Solution Concentrations (mg/L) and Model Results for $\mathrm{Ca}, \mathrm{Fe}, \mathrm{K}, \mathrm{Li}, \mathrm{Mg}, \mathrm{Ti}$, and $\mathrm{Zr}$, as a Function of Reaction Progress (mol-glass/kg) Determined for Glass Sample $\mathrm{C} 22 \mathrm{Si}+15$

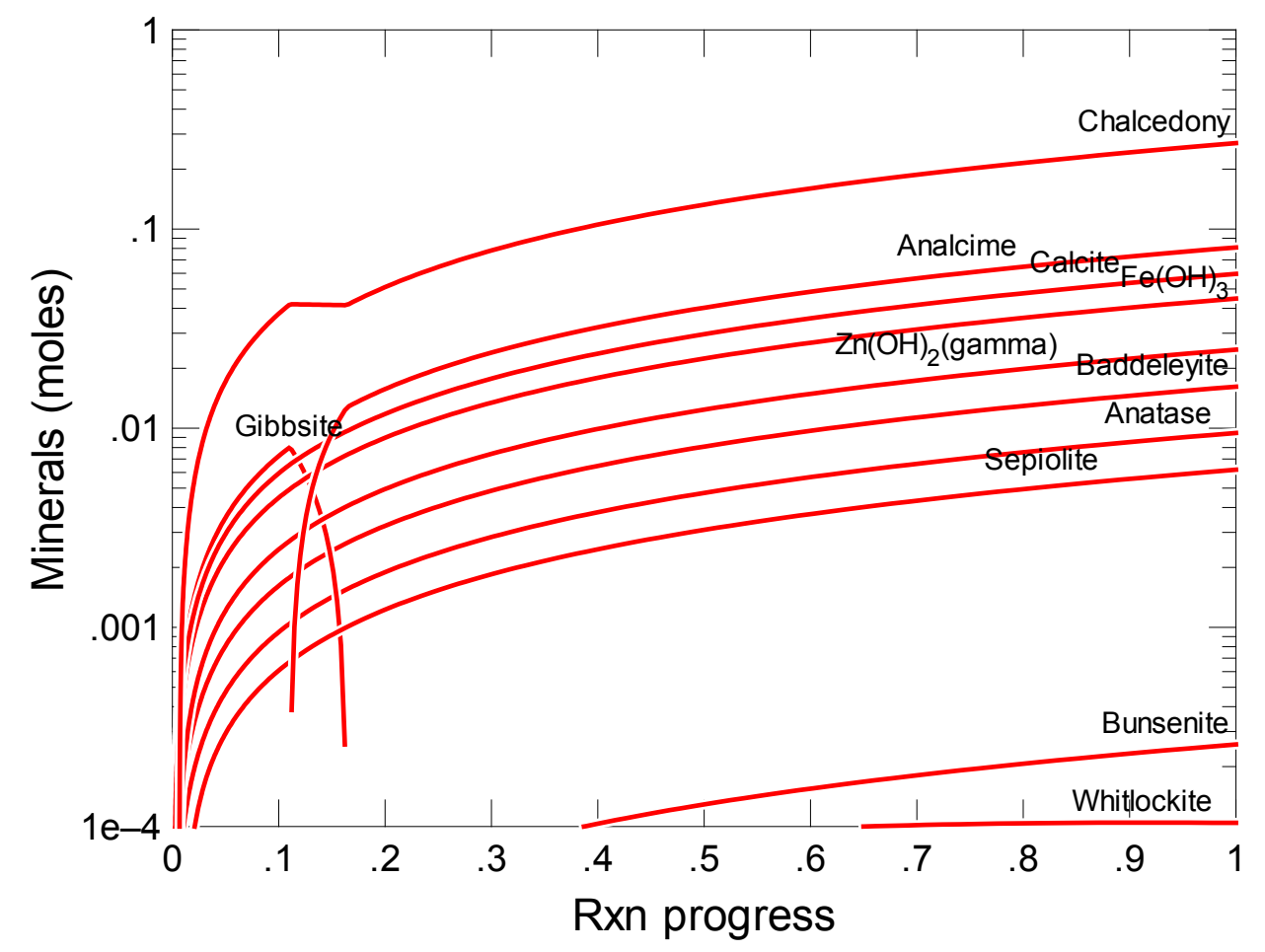

Figure C.58. Secondary Phases Calculated to Form as a Function of Reaction Progress (mol-glass/kg) Determined for Glass Sample C22Si-15 


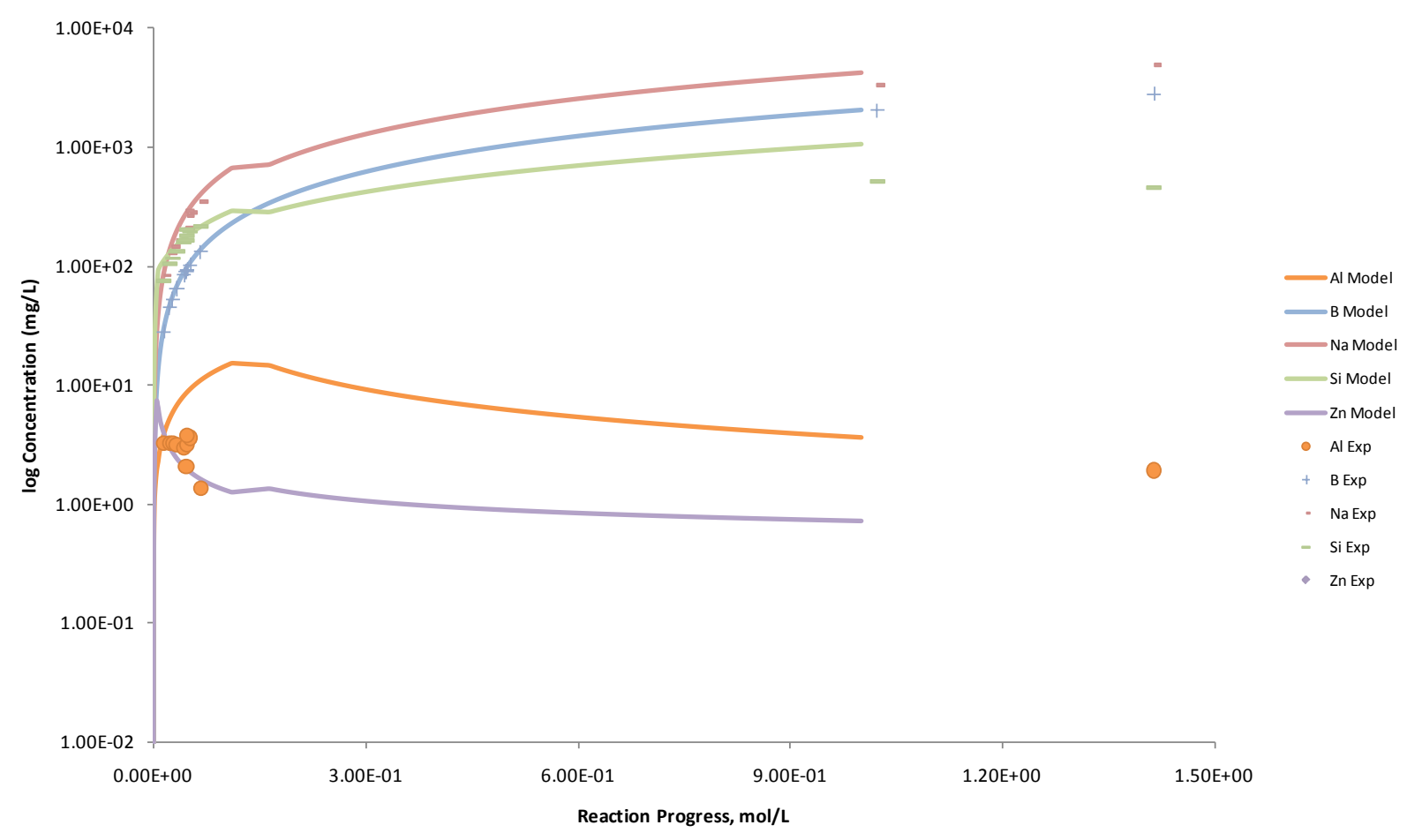

Figure C.59. Measured Solution Concentrations (mg/L) and Model Results for Al, B, Na, Si, and Zn, as a Function of Reaction Progress (mol-glass/kg) Determined for Glass Sample C22Si-15

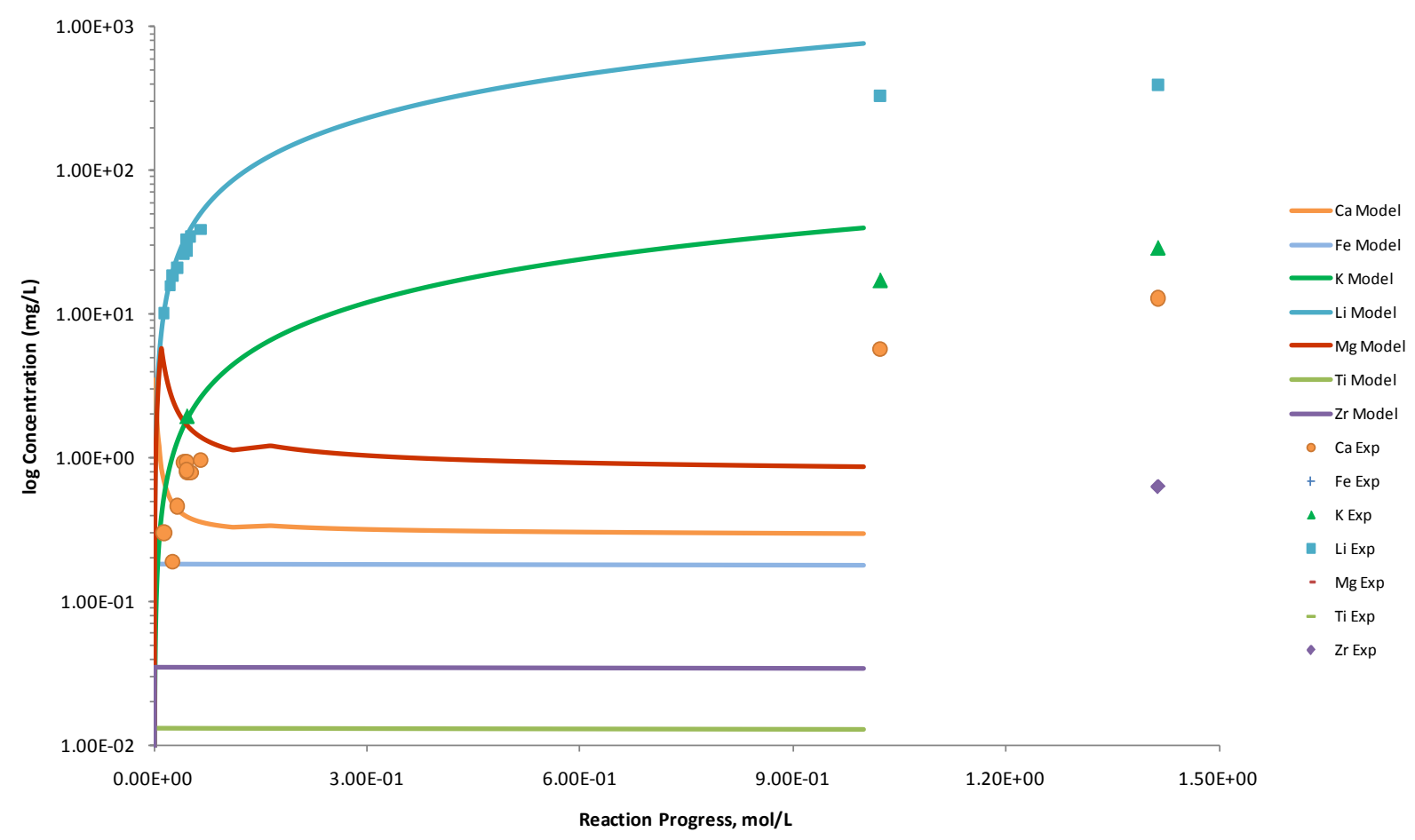

Figure C.60. Measured Solution Concentrations (mg/L) and Model Results for Ca, Fe, K, Li, Mg, Ti, and $\mathrm{Zr}$, as a Function of Reaction Progress (mol-glass/kg) Determined for Glass Sample C22Si-15 


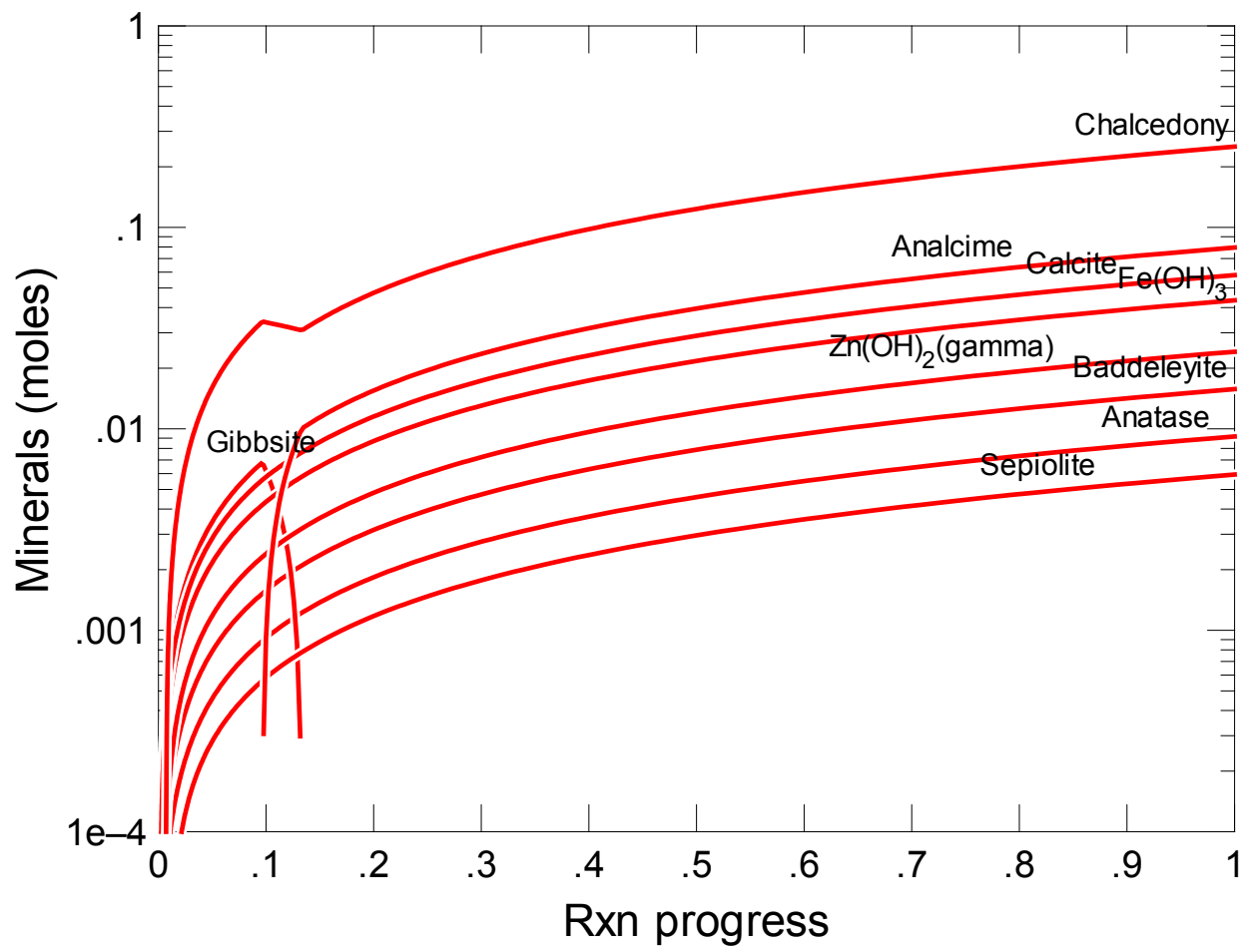

Figure C.61. Secondary Phases Calculated to Form as a Function of Reaction Progress (mol-glass $/ \mathrm{kg}$ ) Determined for Glass Sample LAWA102R1

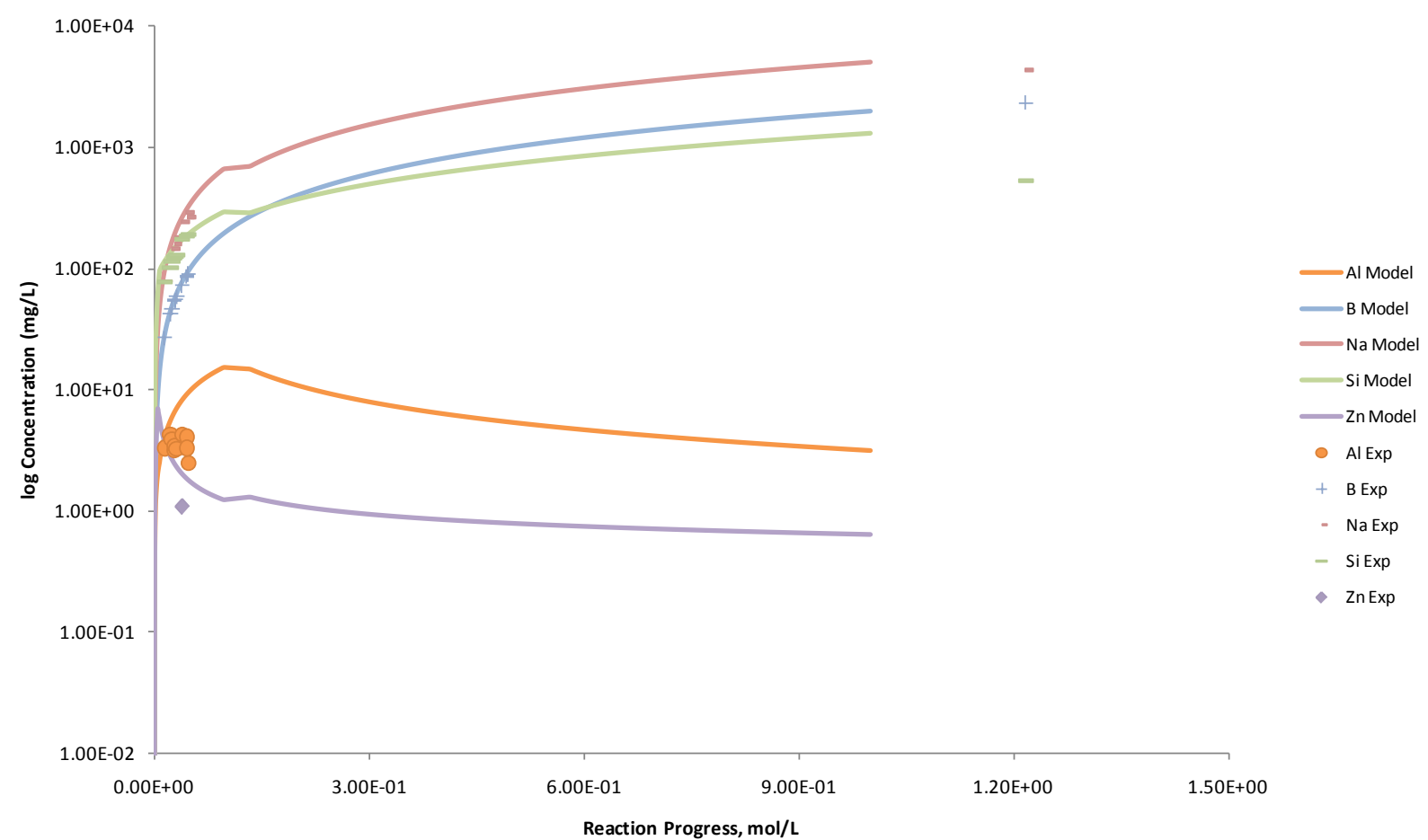

Figure C.62. Measured Solution Concentrations (mg/L) and Model Results for Al, B, Na, Si, and Zn, as a Function of Reaction Progress (mol-glass $/ \mathrm{kg}$ ) Determined for Glass Sample

LAWA102R1 


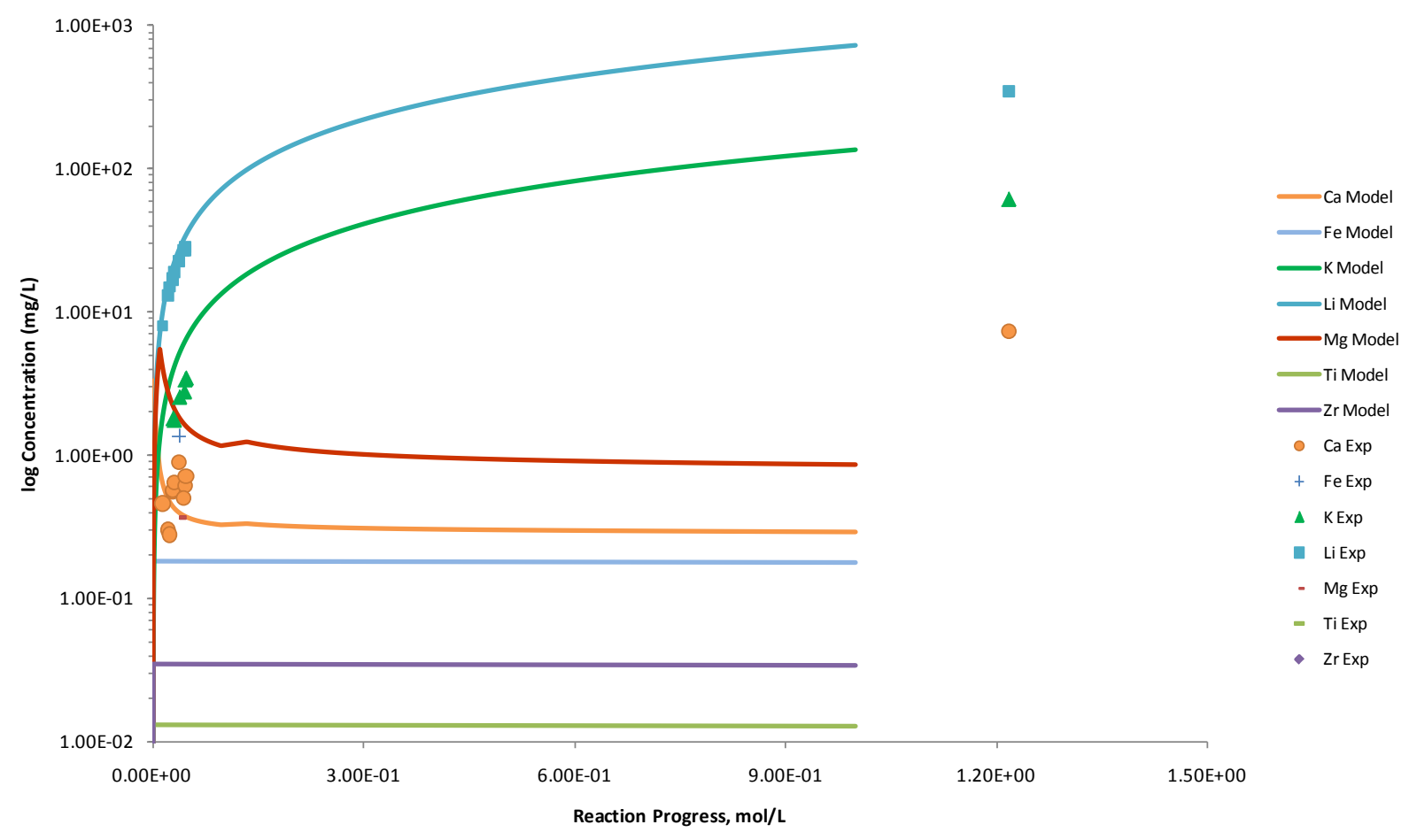

Figure C.63. Measured Solution Concentrations (mg/L) and Model Results for $\mathrm{Ca}, \mathrm{Fe}, \mathrm{K}, \mathrm{Li}, \mathrm{Mg}, \mathrm{Ti}$, and Zr, as a Function of Reaction Progress (mol-glass/kg) Determined for Glass Sample LAWA102R1

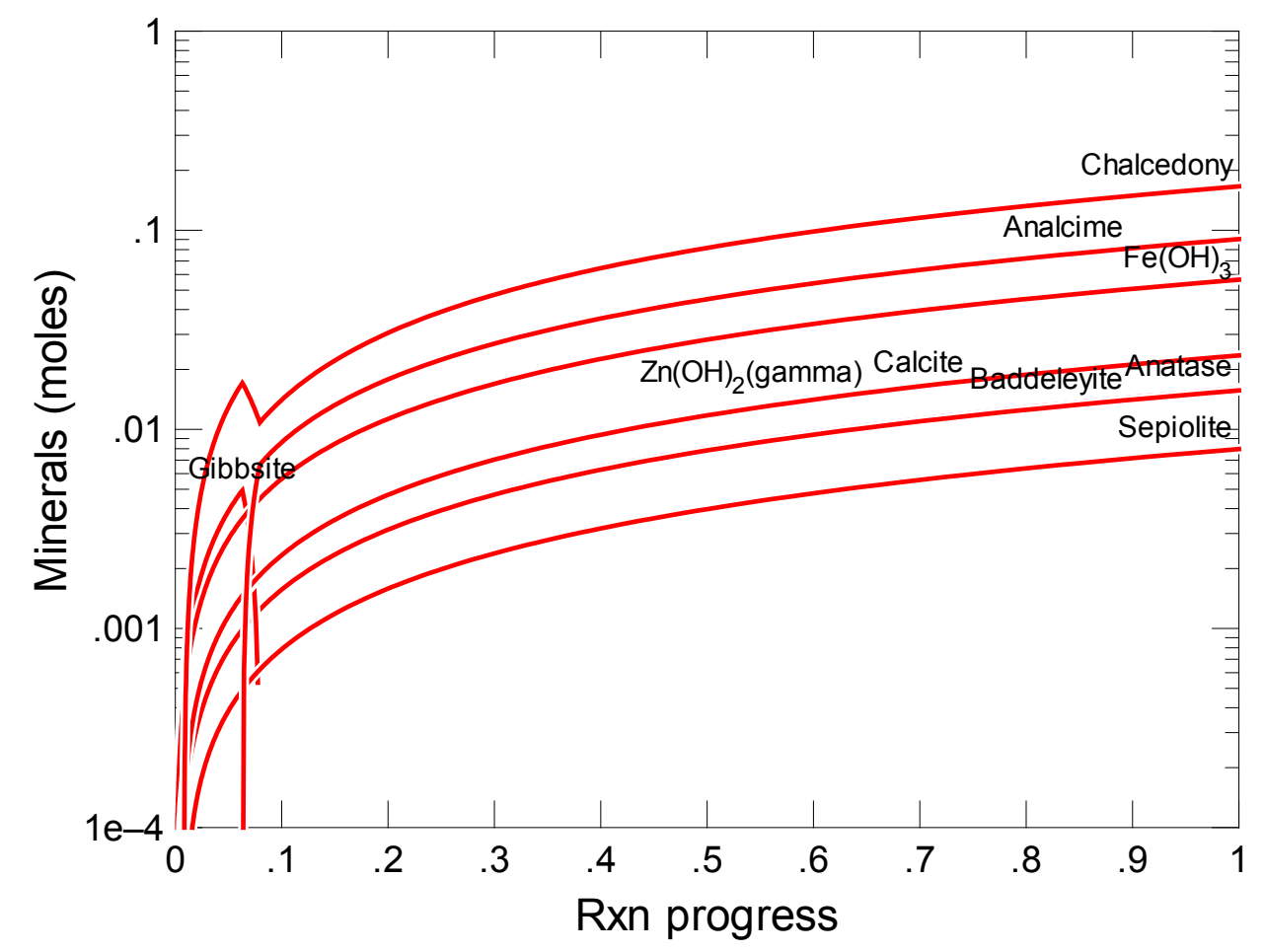

Figure C.64. Secondary Phases Calculated to Form as a Function of Reaction Progress (mol-glass/kg) Determined for Glass Sample LAWA104 


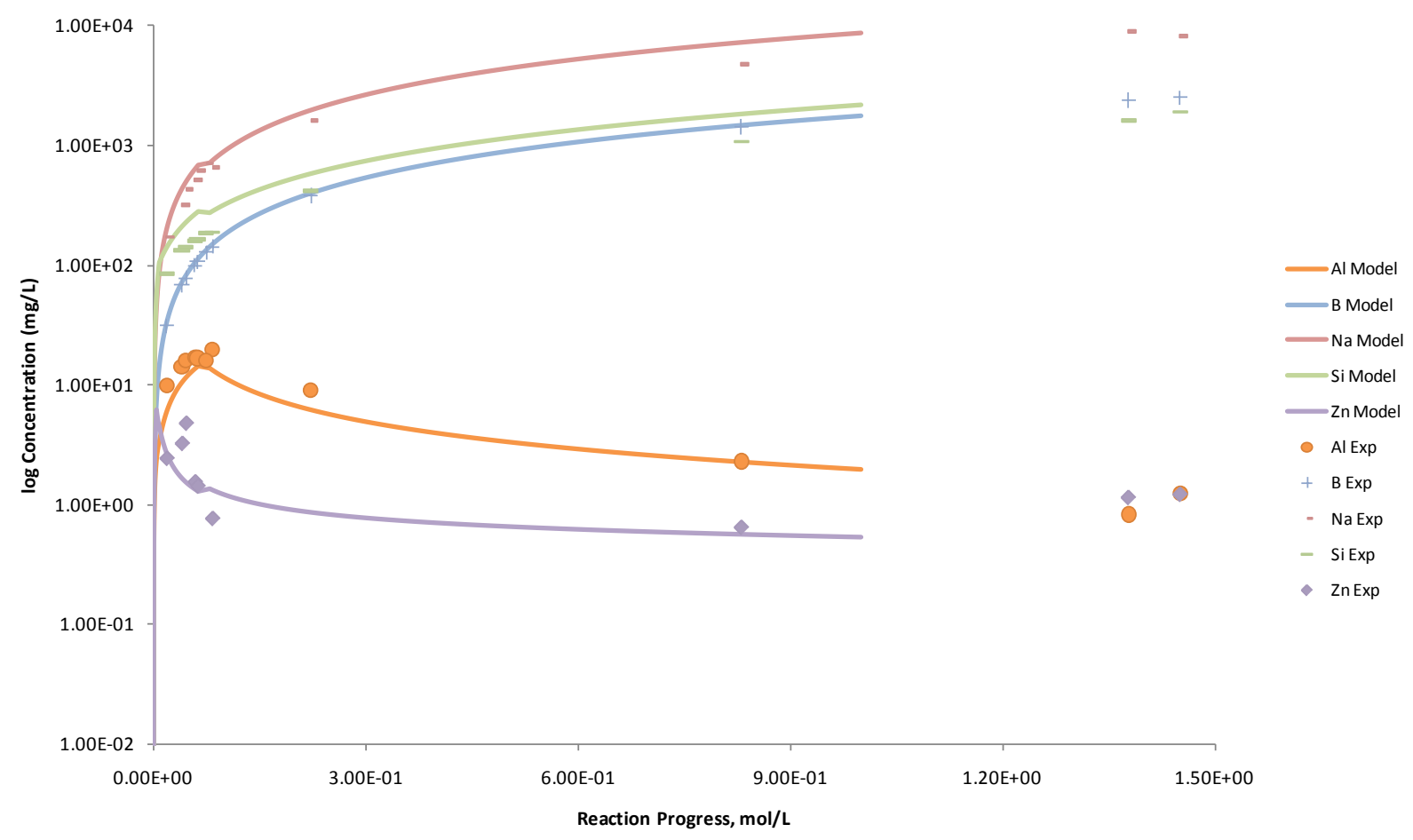

Figure C.65. Measured Solution Concentrations (mg/L) and Model Results for Al, B, Na, Si, and Zn, as a Function of Reaction Progress (mol-glass/kg) Determined for Glass Sample LAWA104

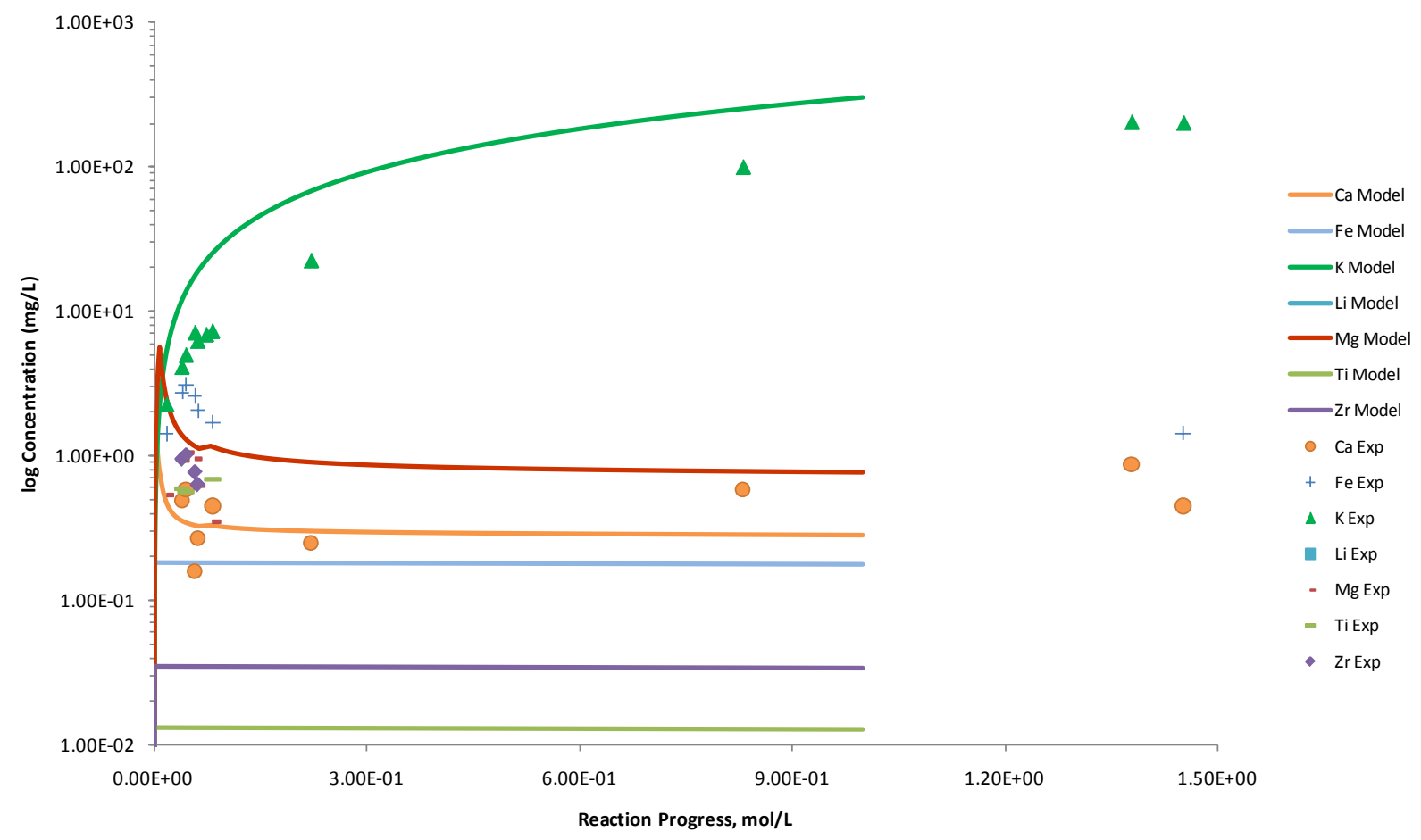

Figure C.66. Measured Solution Concentrations (mg/L) and Model Results for Ca, Fe, K, Li, Mg, Ti, and Zr, as a Function of Reaction Progress (mol-glass $/ \mathrm{kg}$ ) Determined for Glass Sample LAWA104 


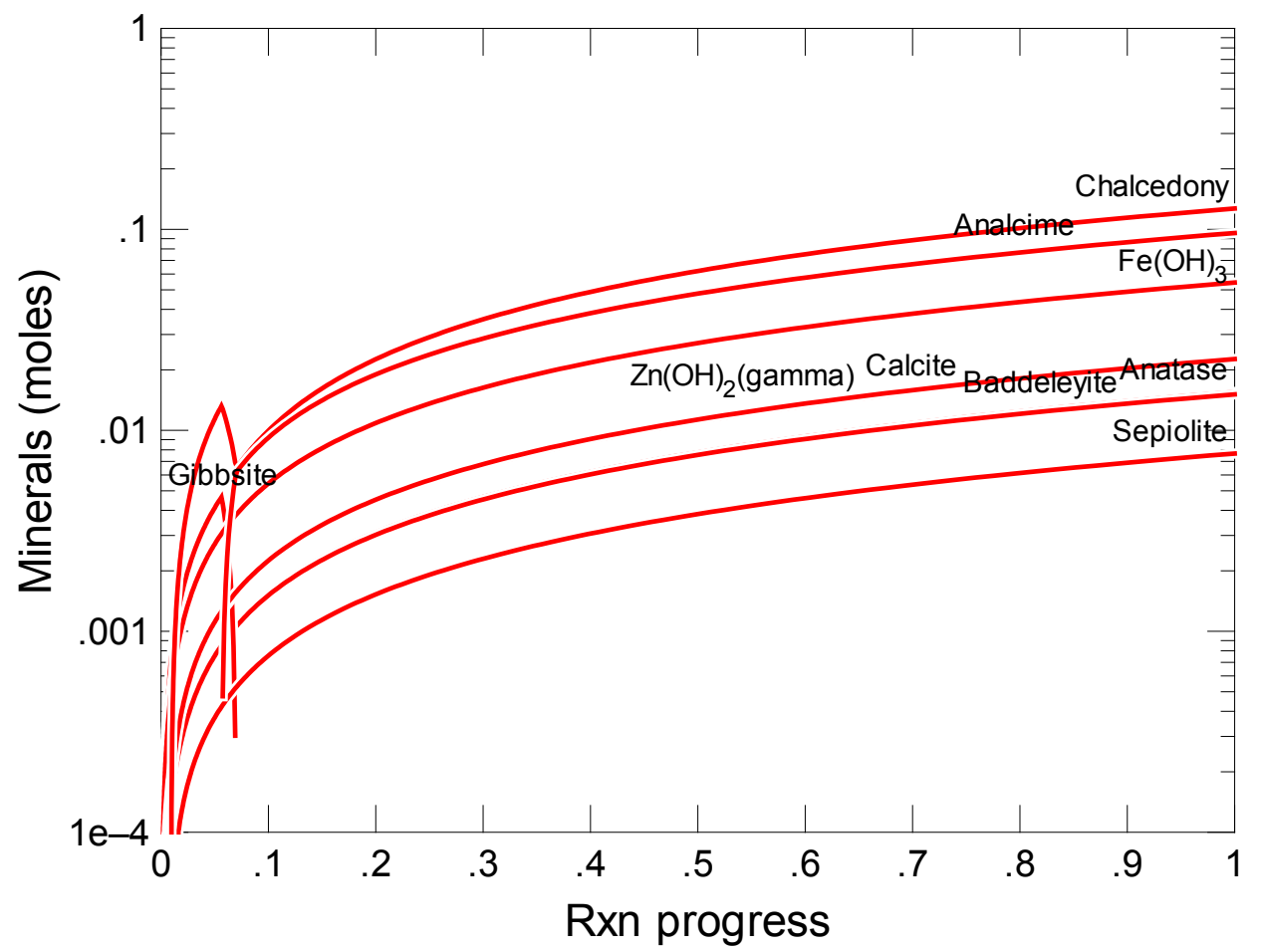

Figure C.67. Secondary Phases Calculated to Form as a Function of Reaction Progress (mol-glass/kg) Determined for Glass Sample LAWA105

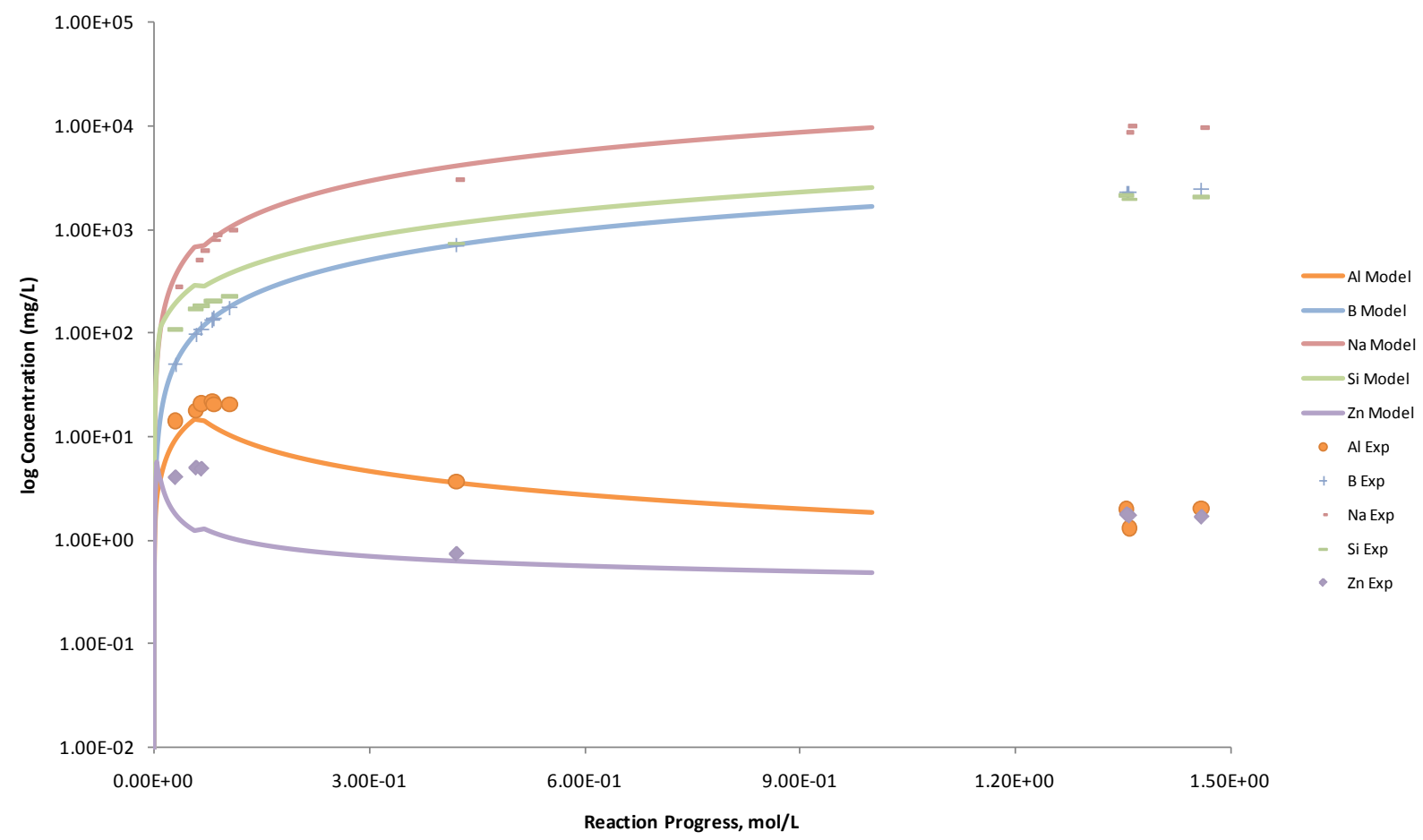

Figure C.68. Measured Solution Concentrations (mg/L) and Model Results for Al, B, Na, Si, and Zn, as a Function of Reaction Progress (mol-glass/kg) Determined for Glass Sample LAWA105 


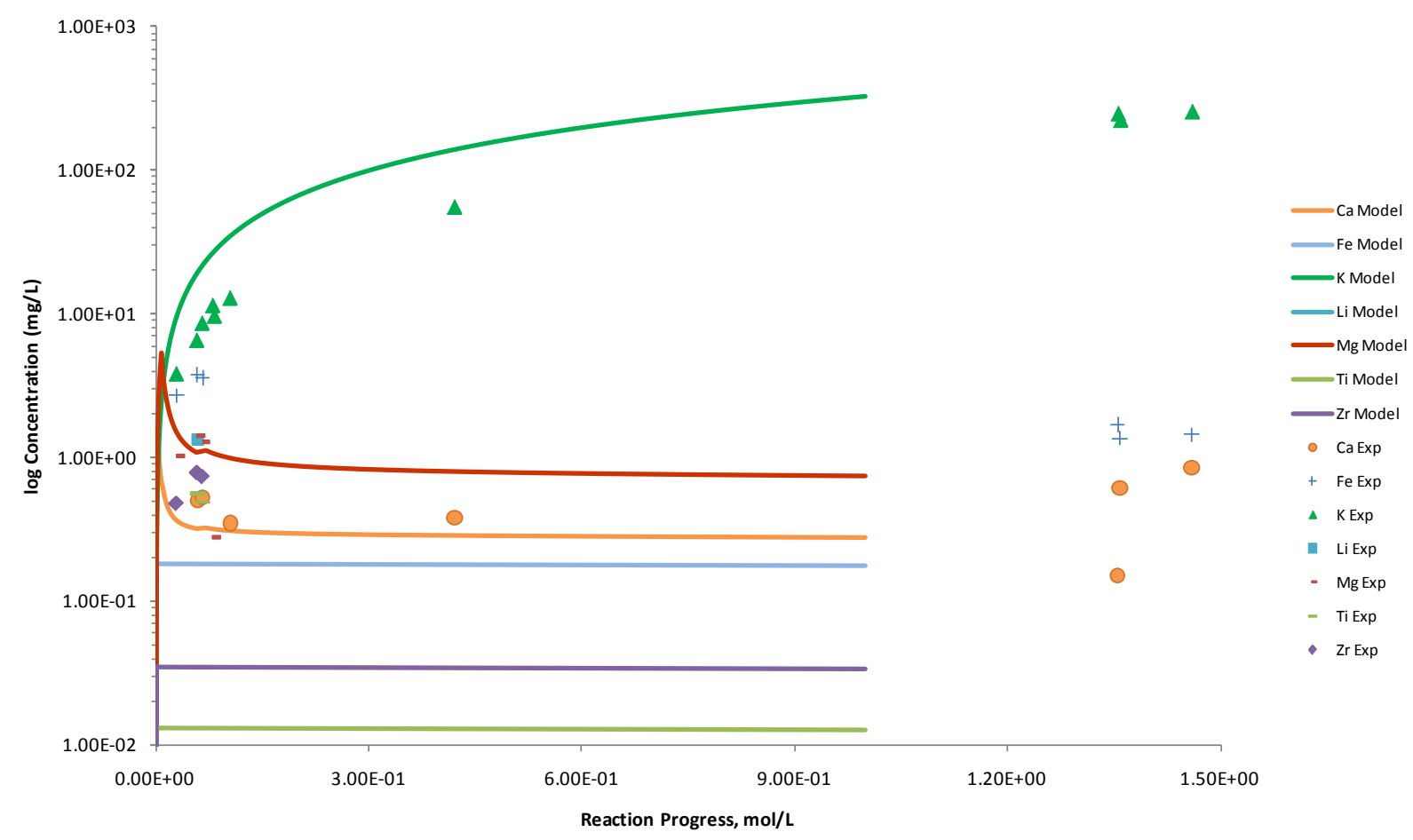

Figure C.69. Measured Solution Concentrations (mg/L) and Model Results for $\mathrm{Ca}, \mathrm{Fe}, \mathrm{K}, \mathrm{Li}, \mathrm{Mg}, \mathrm{Ti}$, and Zr, as a Function of Reaction Progress (mol-glass/kg) Determined for Glass Sample LAWA105

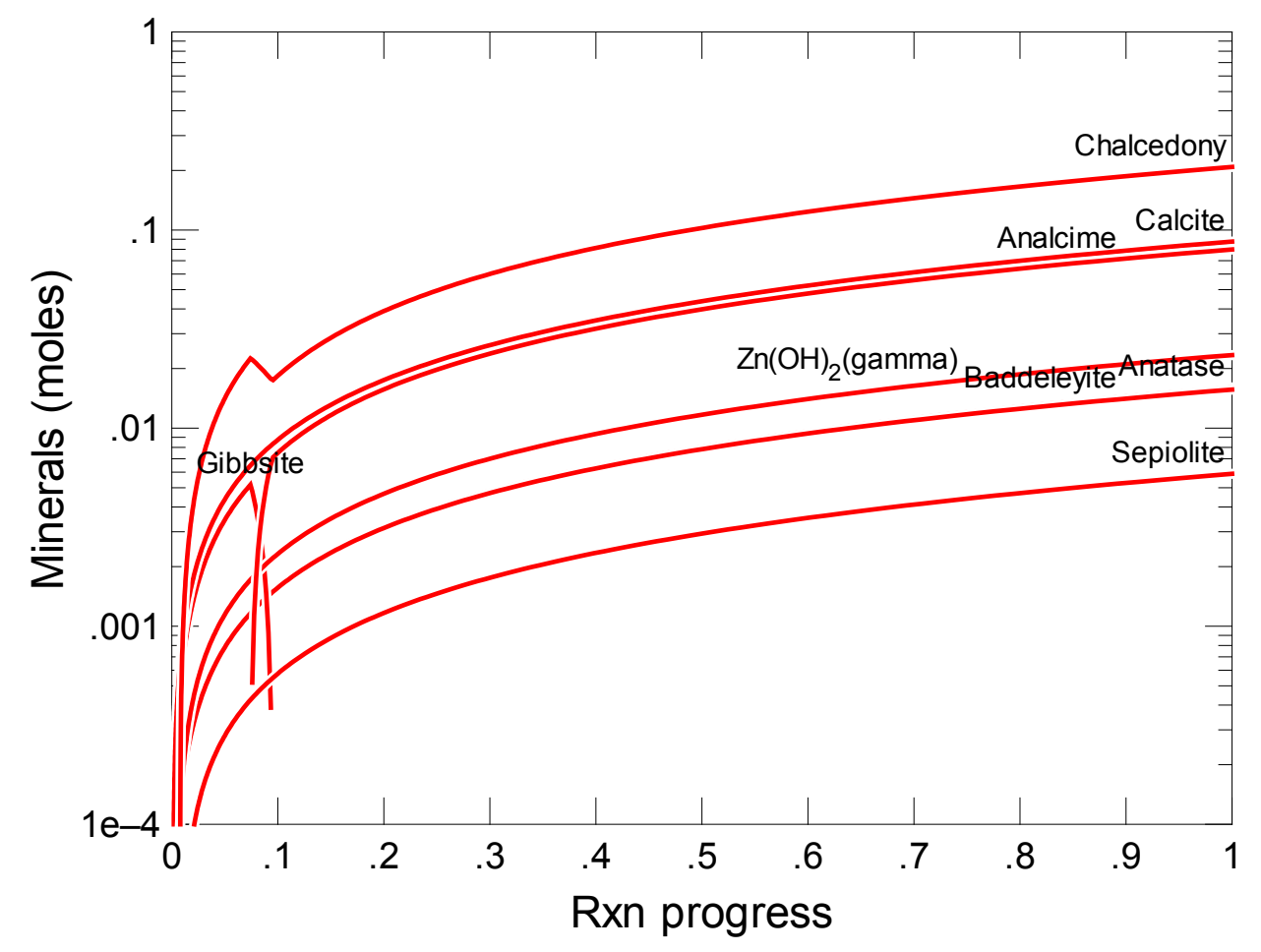

Figure C.70. Secondary Phases Calculated to Form as a Function of Reaction Progress (mol-glass/kg) Determined for Glass Sample LAWA112B14 


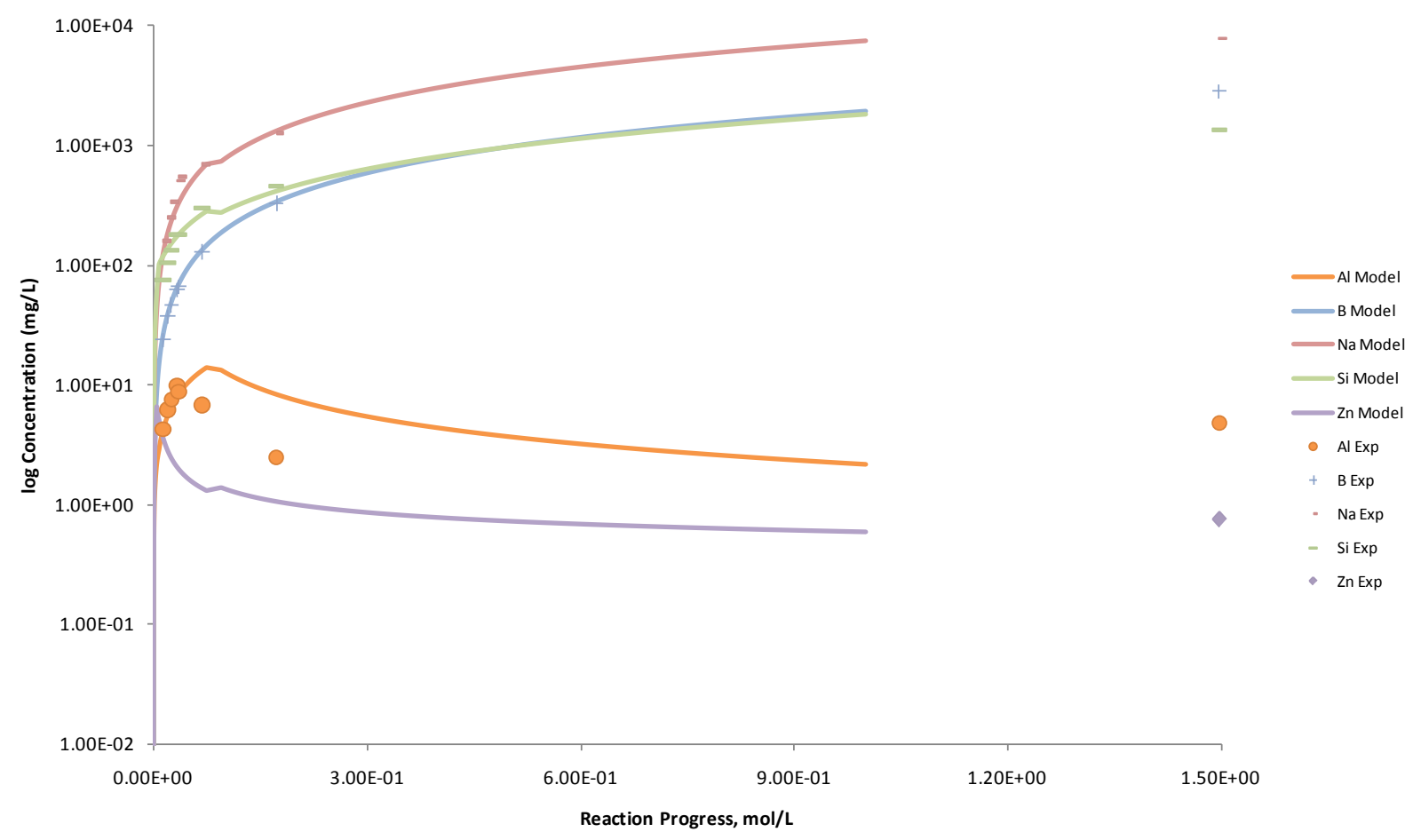

Figure C.71. Measured Solution Concentrations (mg/L) and Model Results for Al, B, Na, Si, and Zn, as a Function of Reaction Progress (mol-glass $/ \mathrm{kg}$ ) Determined for Glass Sample LAWA112B14

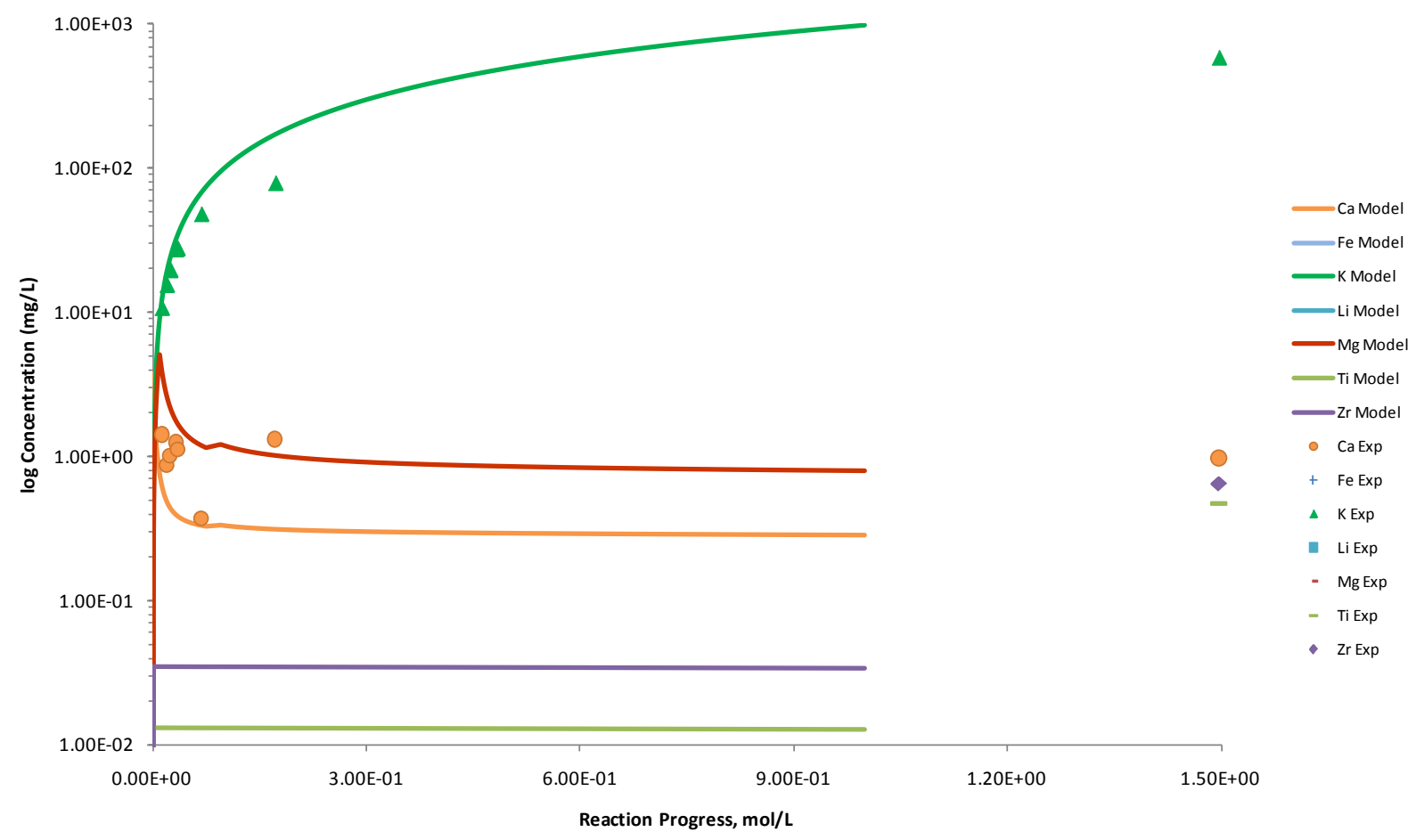

Figure C.72. Measured Solution Concentrations (mg/L) and Model Results for Ca, Fe, K, Li, Mg, Ti, and $\mathrm{Zr}$, as a Function of Reaction Progress (mol-glass $/ \mathrm{kg}$ ) Determined for Glass Sample LAWA112B14 


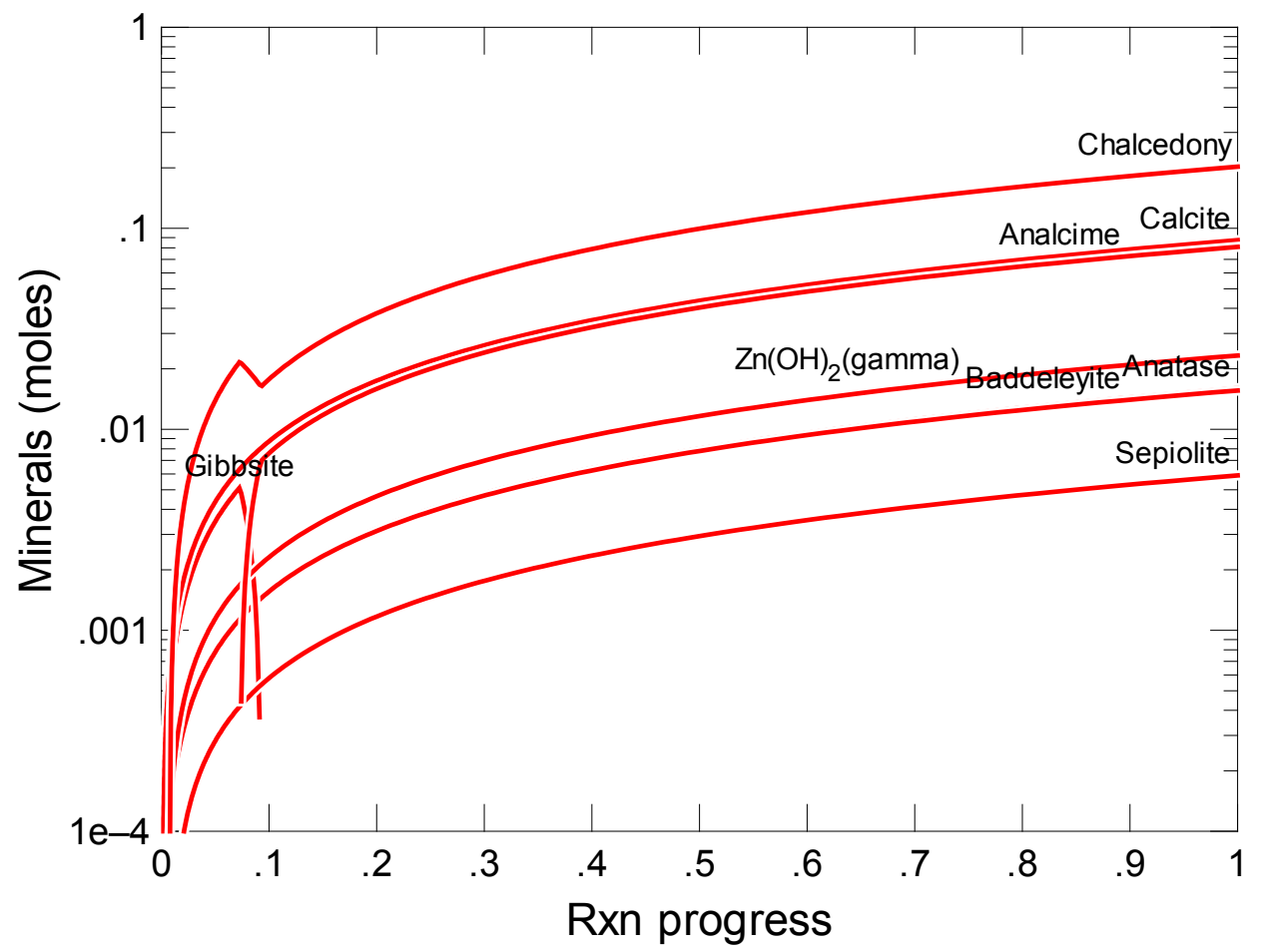

Figure C.73. Secondary Phases Calculated to Form as a Function of Reaction Progress (mol-glass/kg) Determined for Glass Sample LAWA112B15

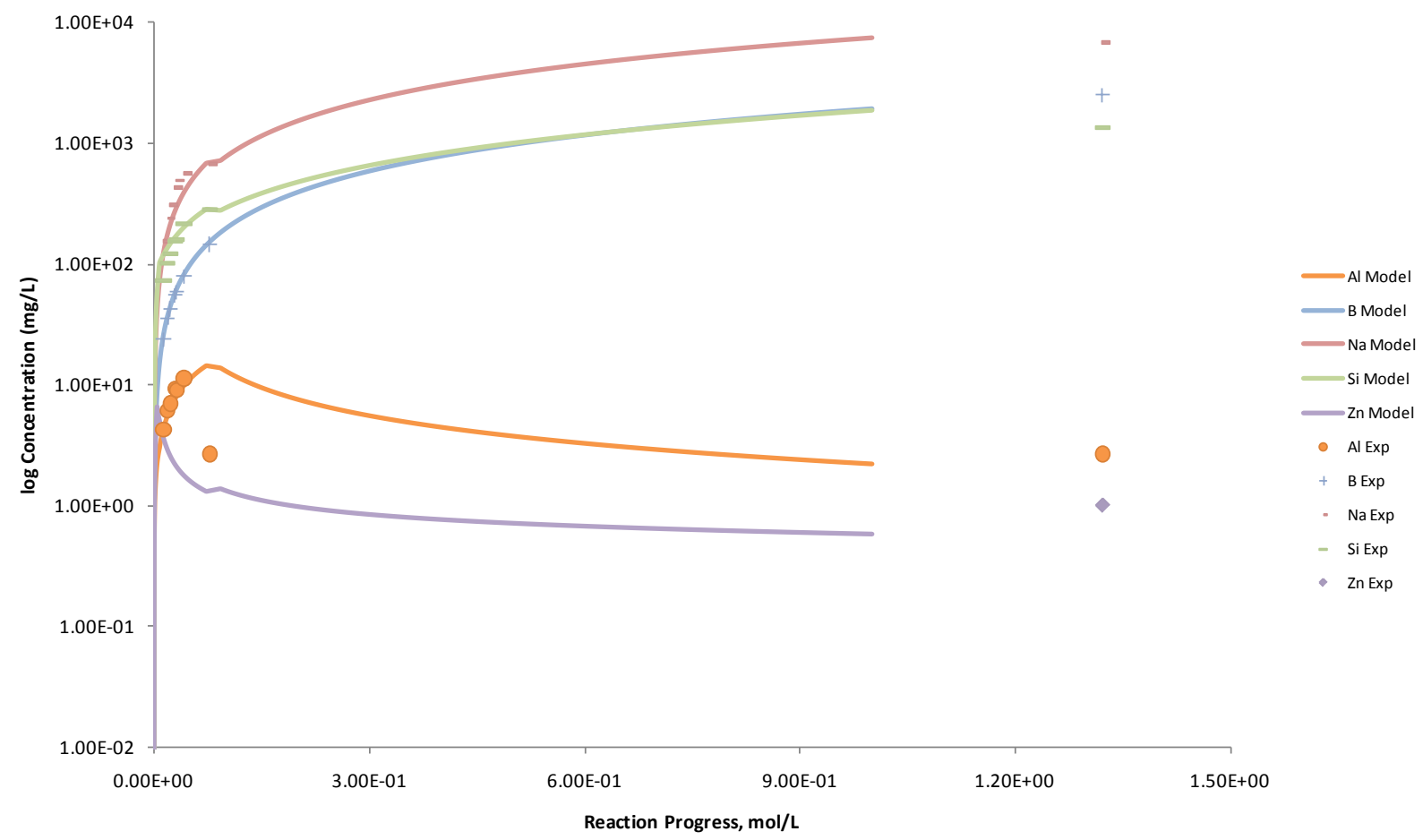

Figure C.74. Measured Solution Concentrations (mg/L) and Model Results for Al, B, Na, Si, and Zn, as a Function of Reaction Progress (mol-glass $/ \mathrm{kg}$ ) Determined for Glass Sample LAWA112B15 


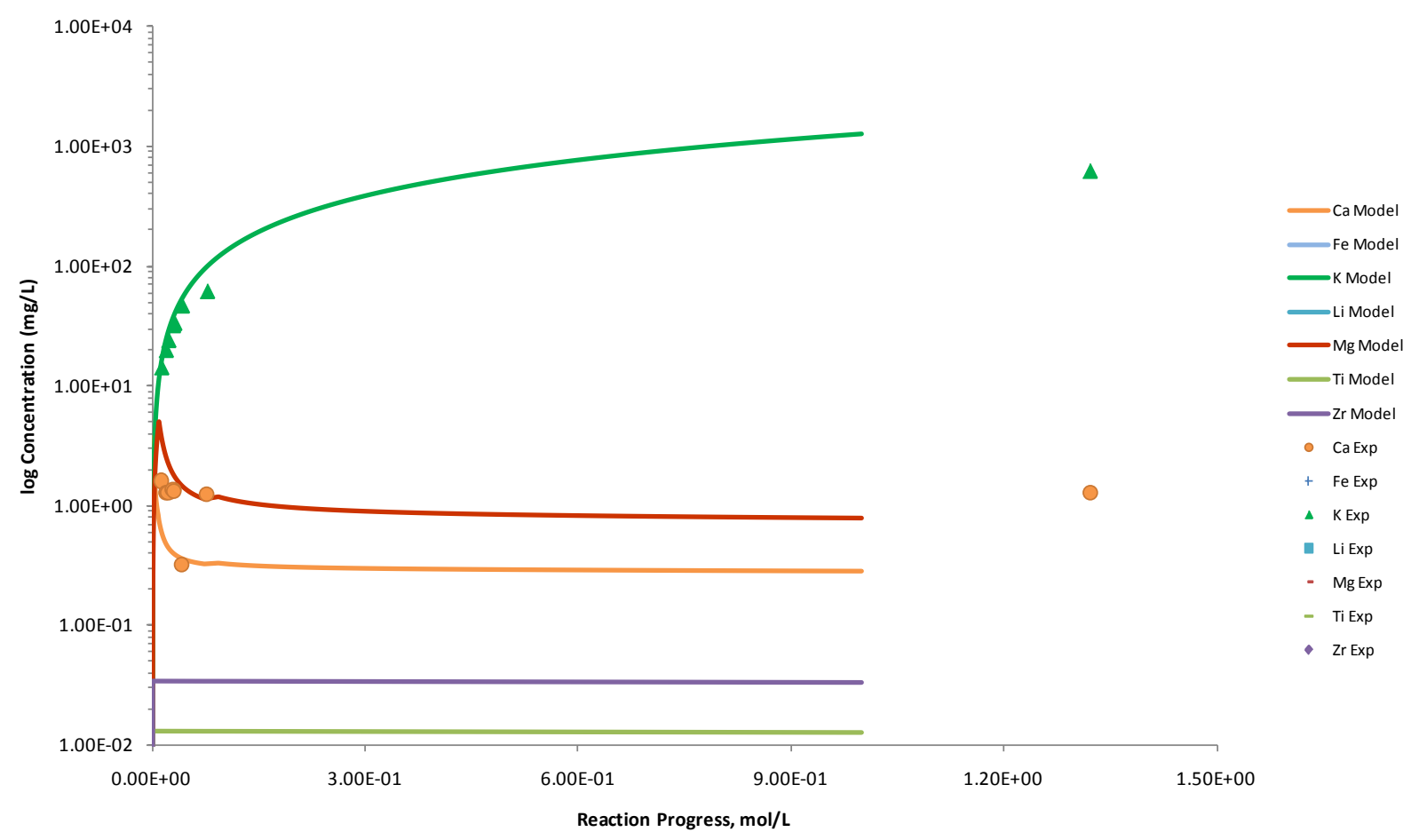

Figure C.75. Measured Solution Concentrations (mg/L) and Model Results for $\mathrm{Ca}, \mathrm{Fe}, \mathrm{K}, \mathrm{Li}, \mathrm{Mg}, \mathrm{Ti}$, and $\mathrm{Zr}$, as a Function of Reaction Progress (mol-glass/kg) Determined for Glass Sample LAWA112B15

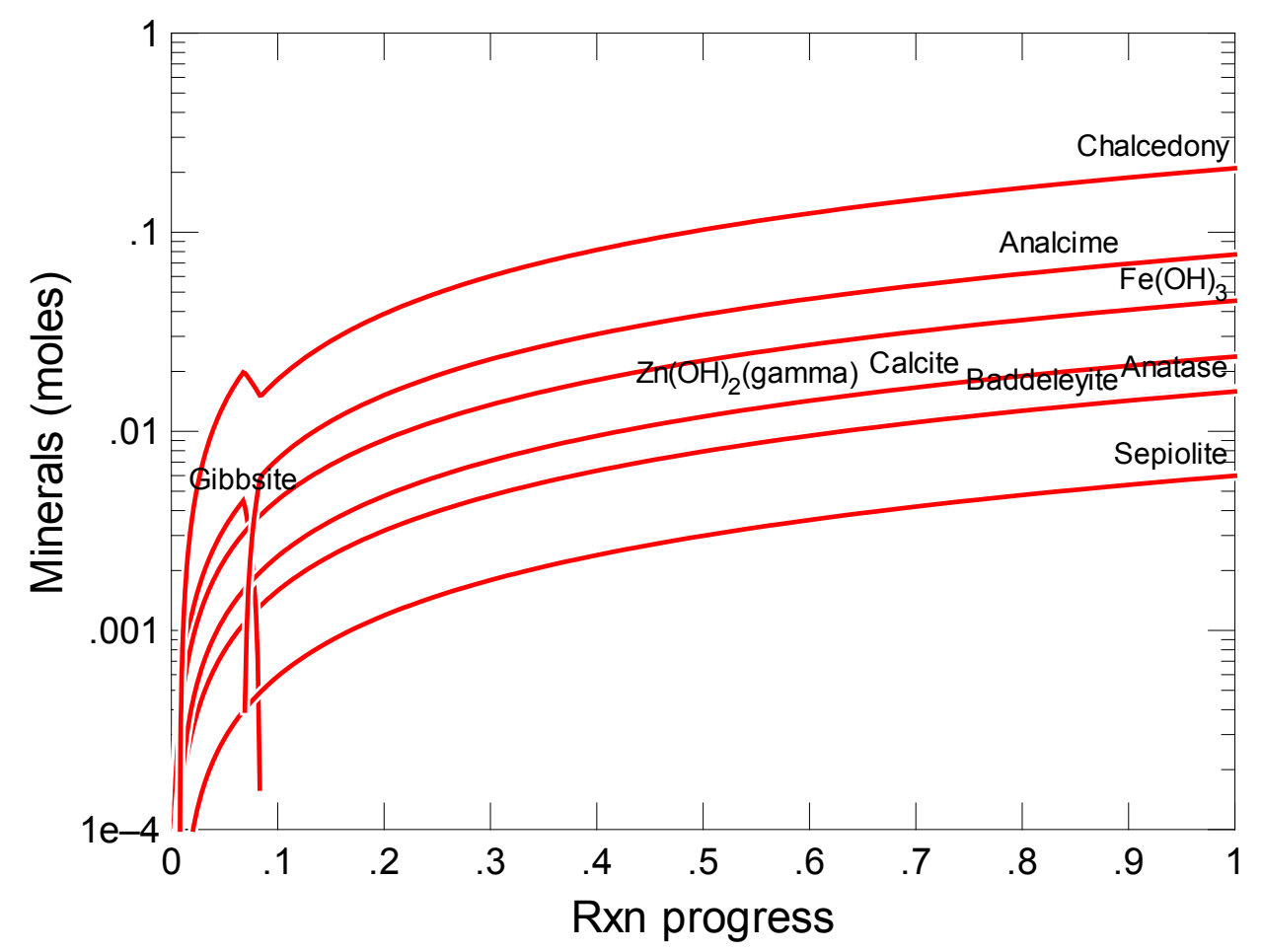

Figure C.76. Secondary Phases Calculated to Form as a Function of Reaction Progress (mol-glass/kg) Determined for Glass Sample LAWA125 


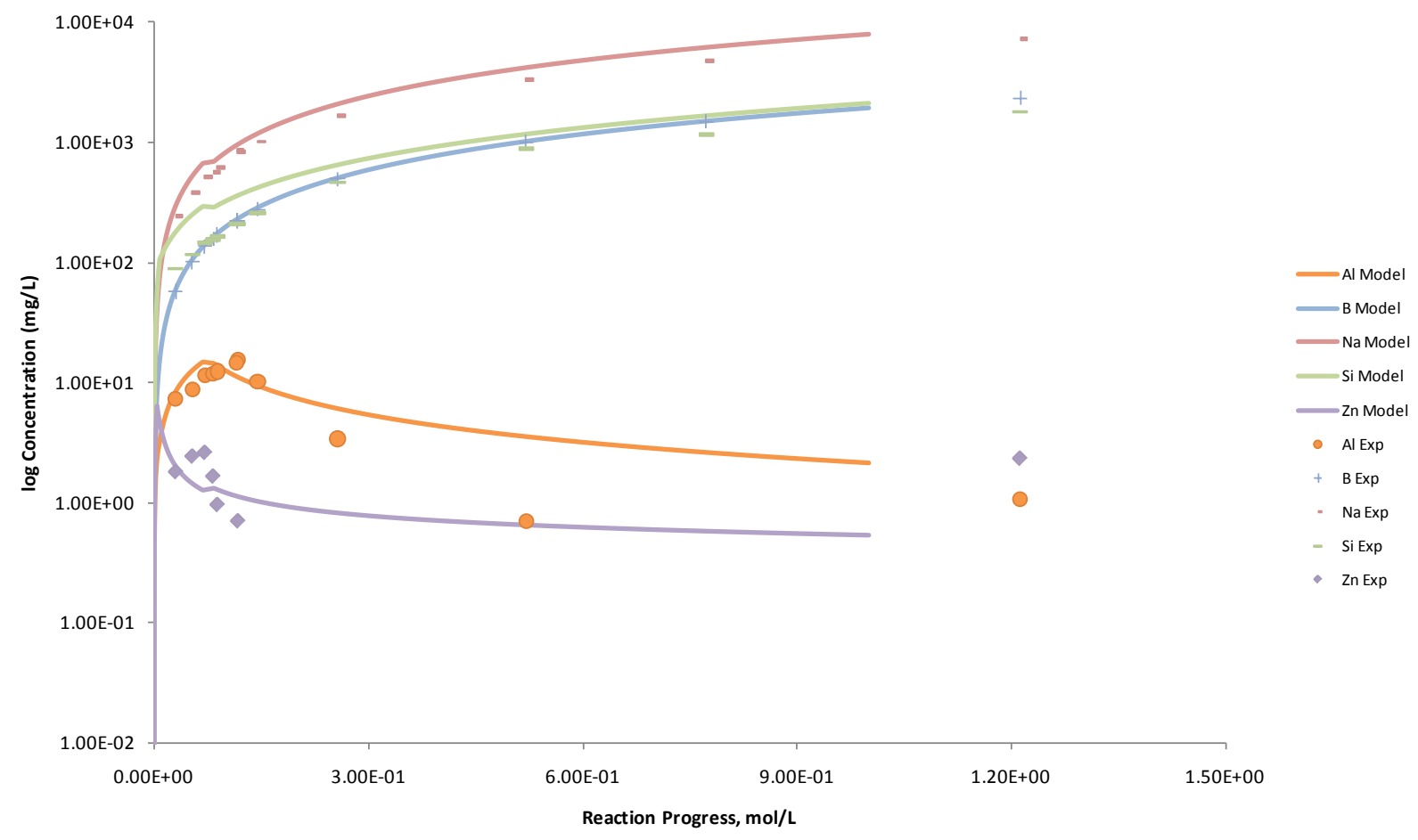

Figure C.77. Measured Solution Concentrations (mg/L) and Model Results for Al, B, Na, Si, and Zn, as a Function of Reaction Progress (mol-glass/kg) Determined for Glass Sample LAWA125

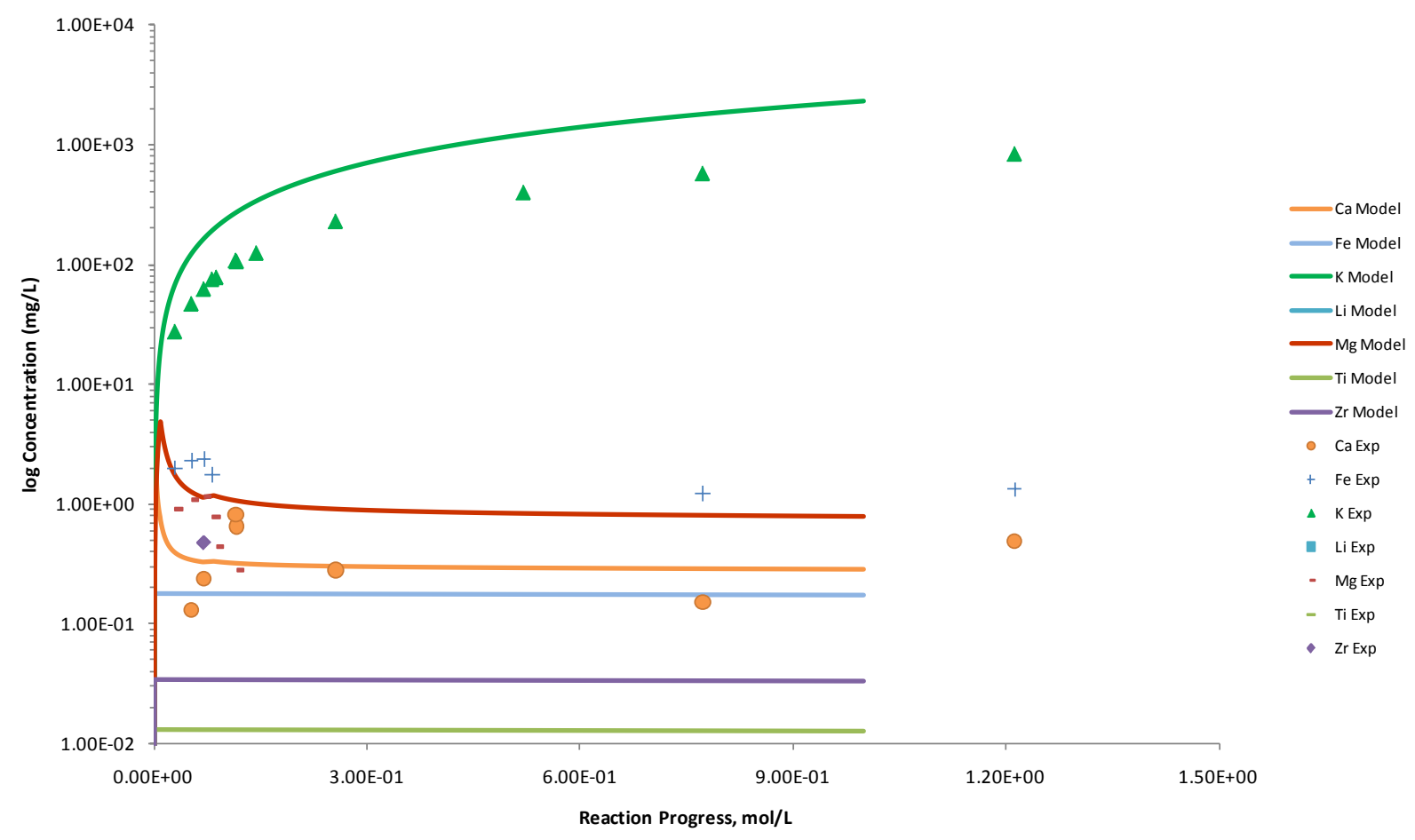

Figure C.78. Measured Solution Concentrations (mg/L) and Model Results for Ca, Fe, K, Li, Mg, Ti, and $\mathrm{Zr}$, as a Function of Reaction Progress (mol-glass/kg) Determined for Glass Sample LAWA125 


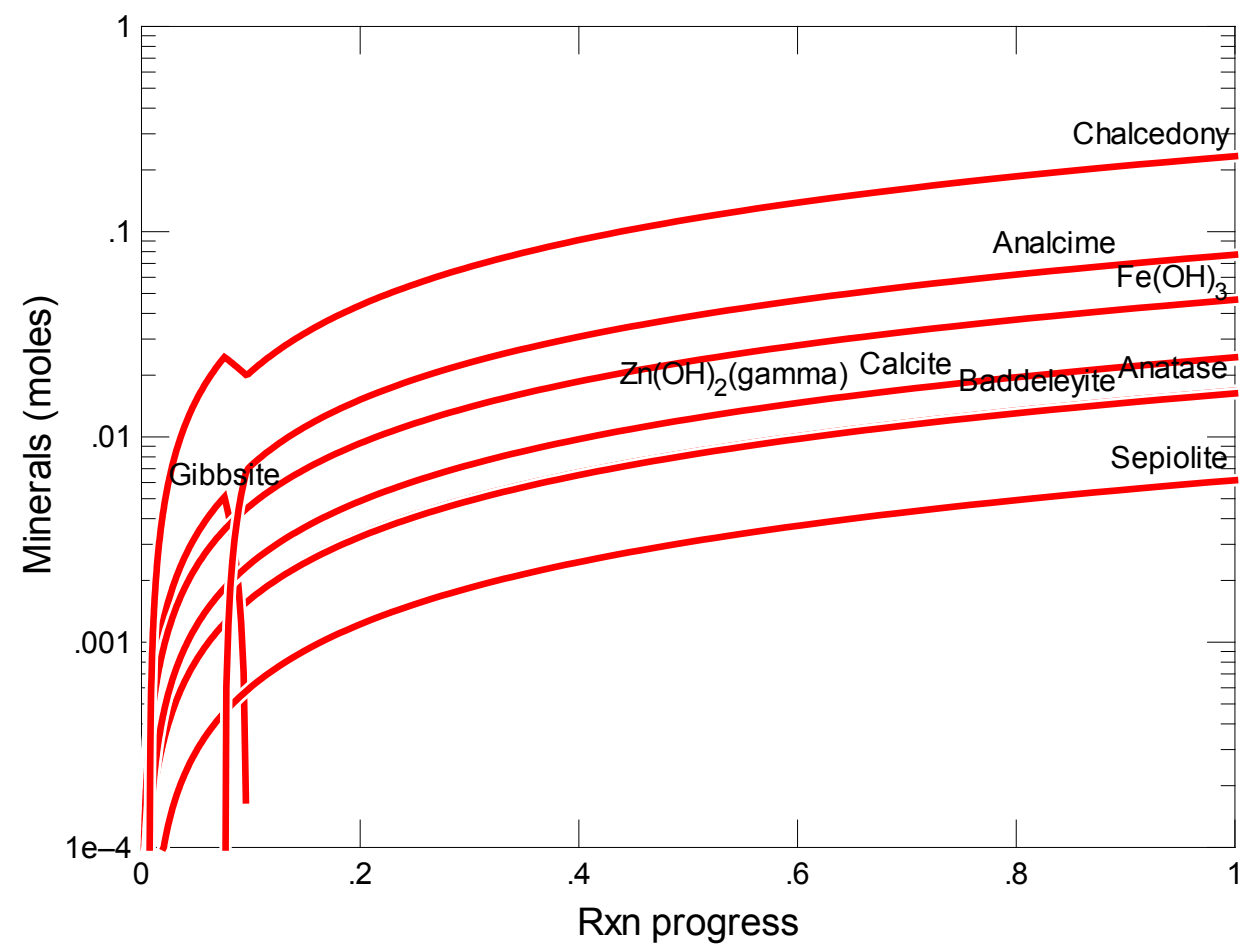

Figure C.79. Secondary Phases Calculated to Form as a Function of Reaction Progress (mol-glass/kg) Determined for Glass Sample LAWA126

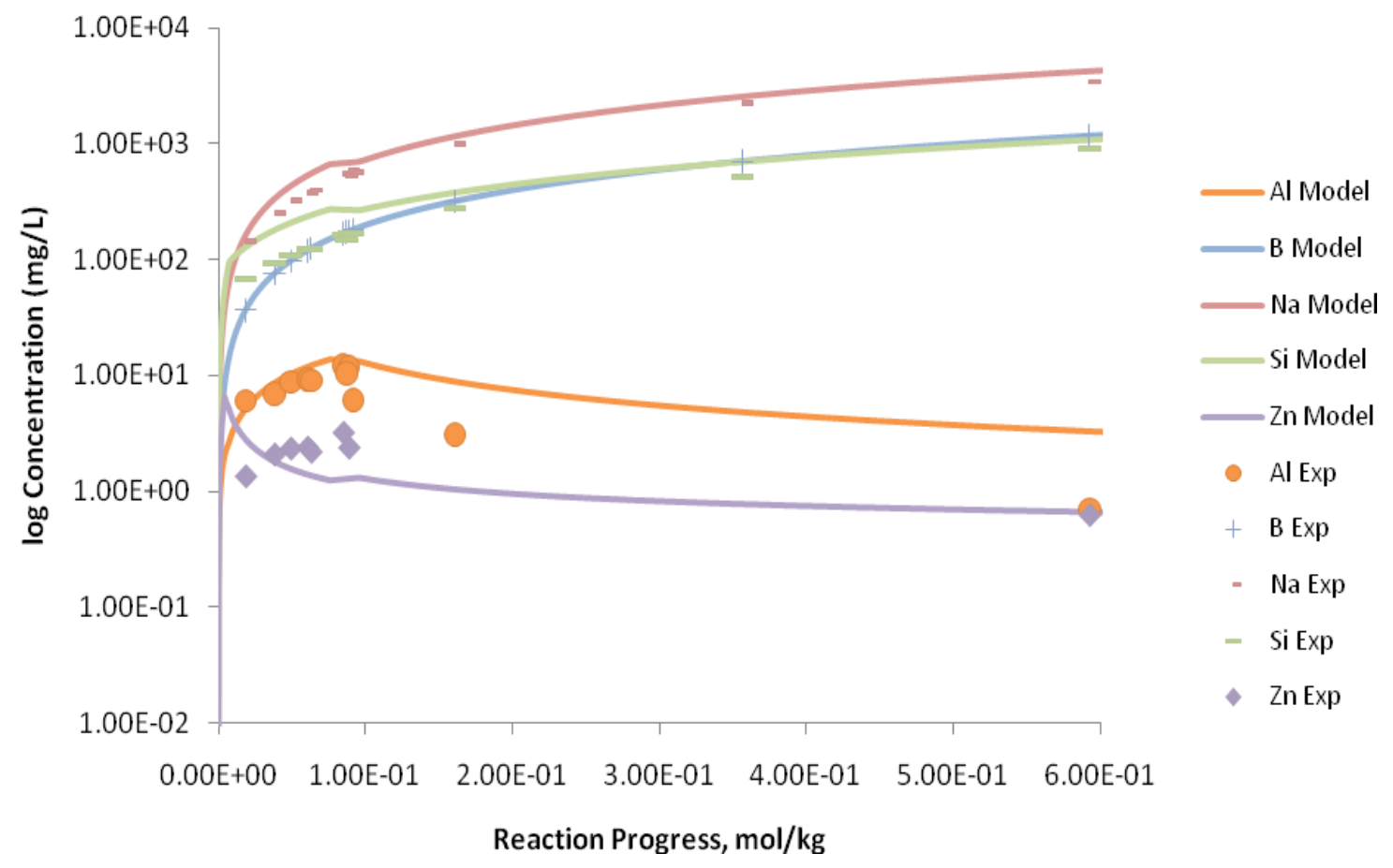

Figure C.80. Measured Solution Concentrations (mg/L) and Model Results for Al, B, Na, Si, and Zn, as a Function of Reaction Progress (mol-glass/kg) Determined for Glass Sample LAWA126 


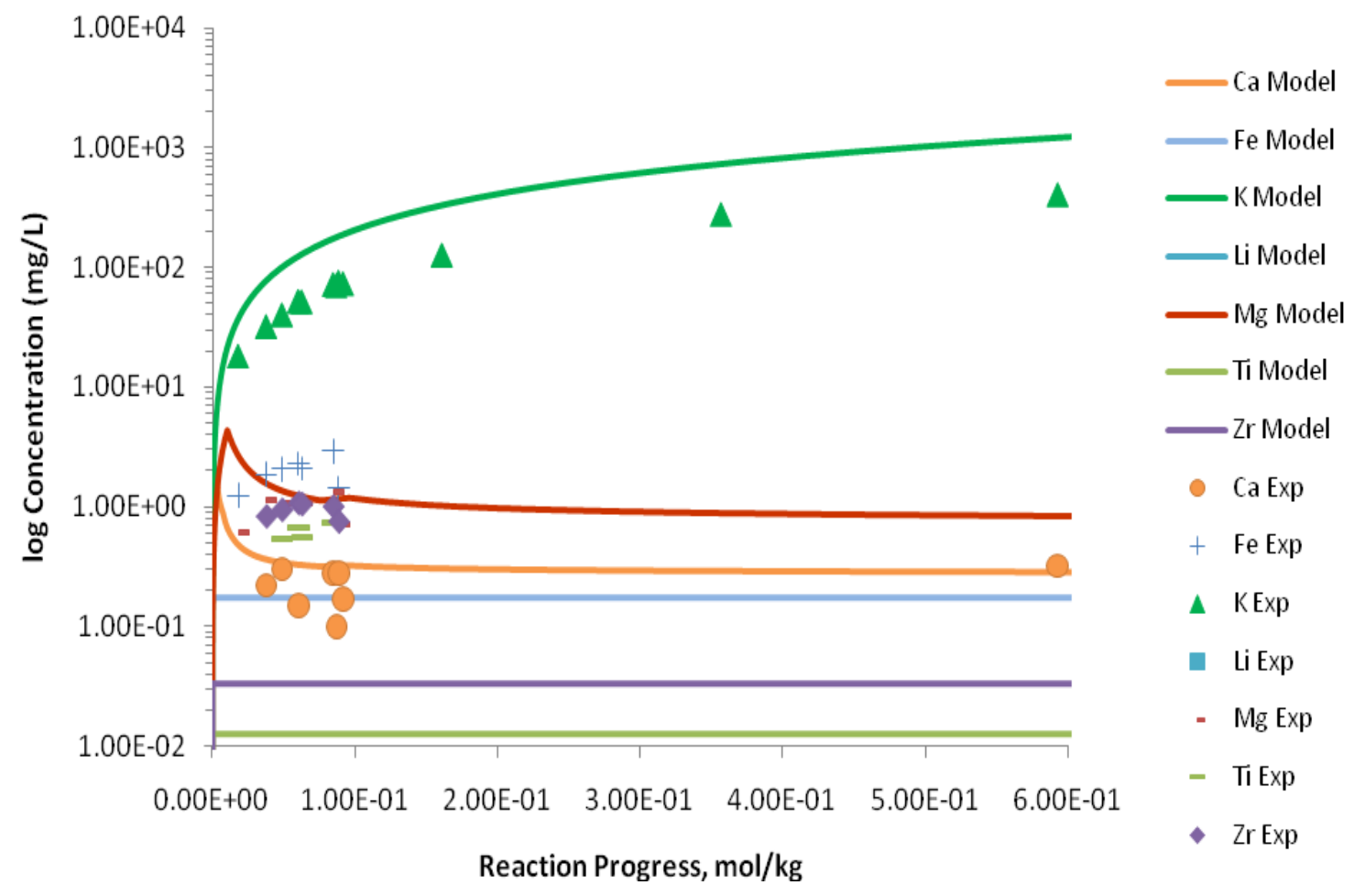

Figure C.81. Measured Solution Concentrations (mg/L) and Model Results for $\mathrm{Ca}, \mathrm{Fe}, \mathrm{K}, \mathrm{Li}, \mathrm{Mg}, \mathrm{Ti}$, and $\mathrm{Zr}$, as a Function of Reaction Progress (mol-glass $/ \mathrm{kg}$ ) Determined for Glass Sample LAWA126

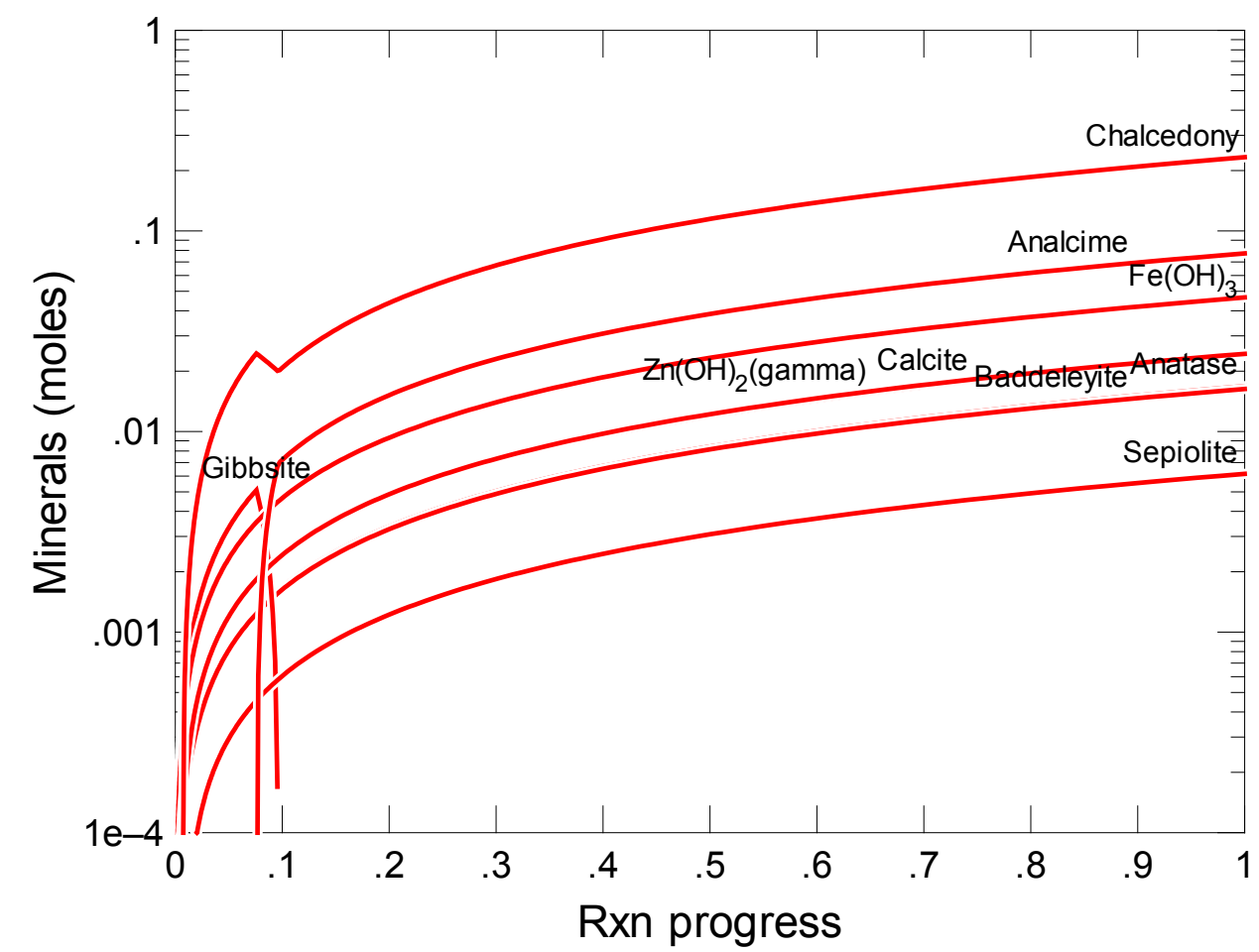

Figure C.82. Secondary Phases Calculated to Form as a Function of Reaction Progress (mol-glass/kg) Determined for Glass Sample LAWA127R1 


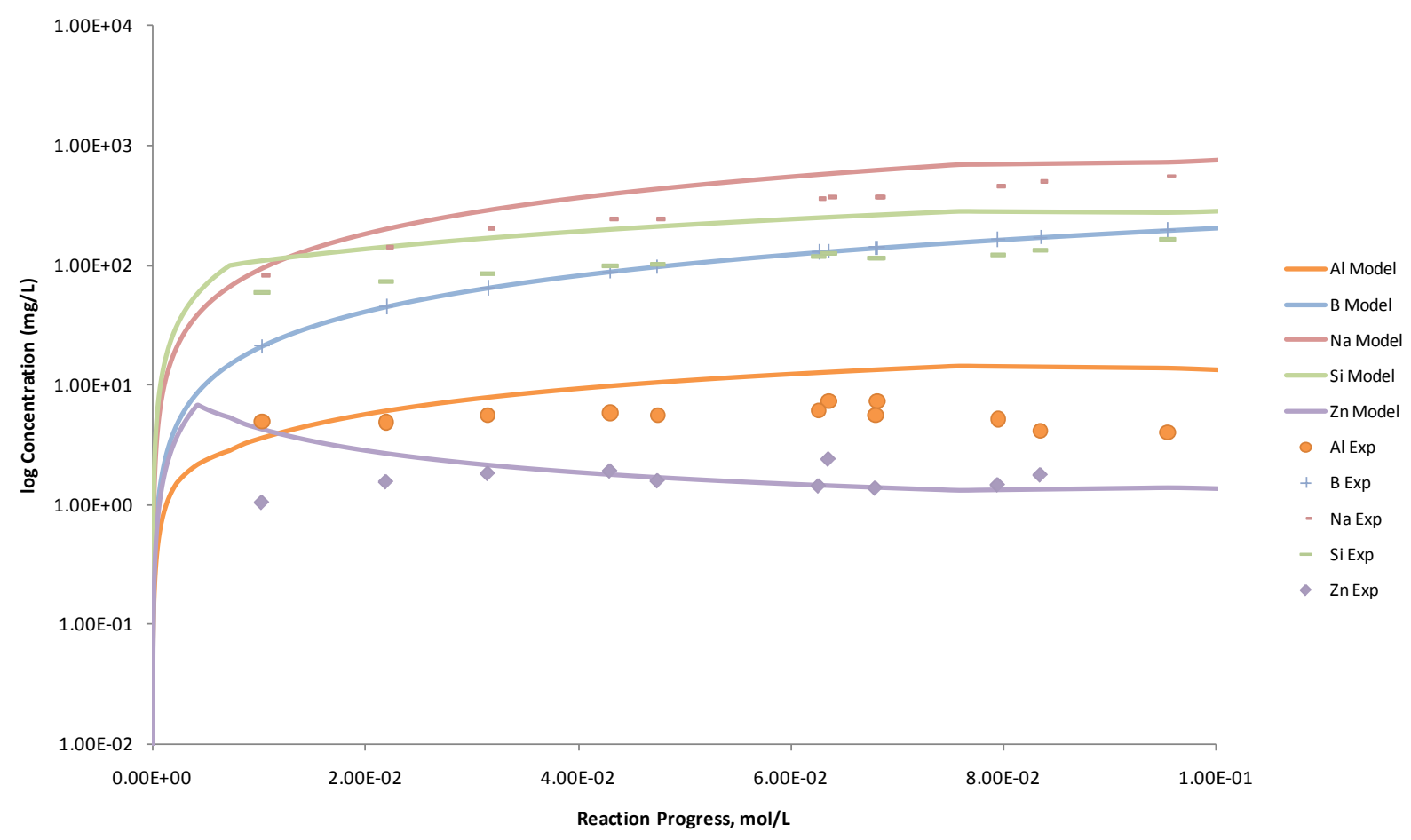

Figure C.83. Measured Solution Concentrations (mg/L) and Model Results for Al, B, Na, Si, and Zn, as a Function of Reaction Progress (mol-glass $/ \mathrm{kg}$ ) Determined for Glass Sample LAWA127R1

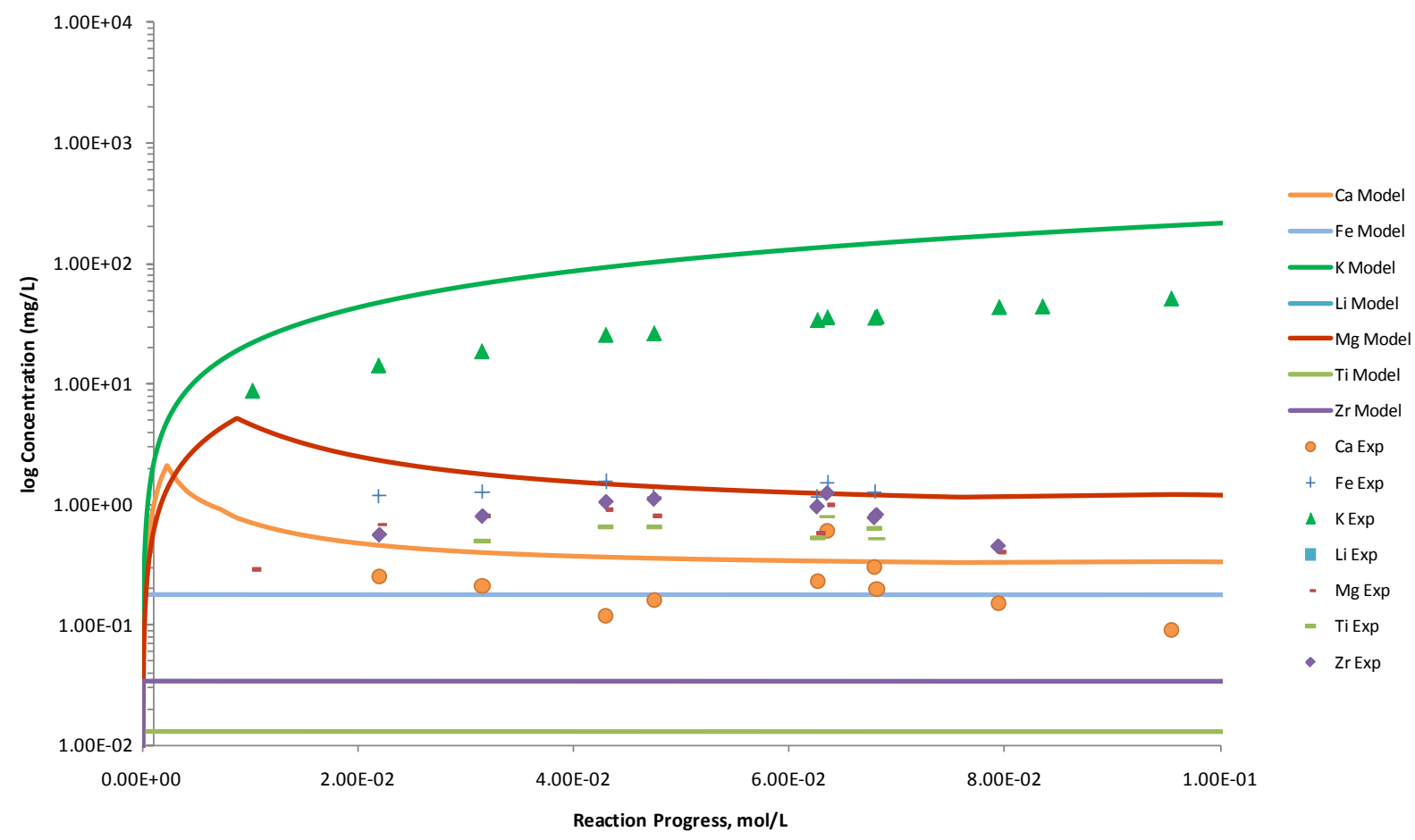

Figure C.84. Measured Solution Concentrations (mg/L) and Model Results for $\mathrm{Ca}, \mathrm{Fe}, \mathrm{K}, \mathrm{Li}, \mathrm{Mg}, \mathrm{Ti}$, and $\mathrm{Zr}$, as a Function of Reaction Progress (mol-glass/kg) Determined for Glass Sample LAWA127R1 


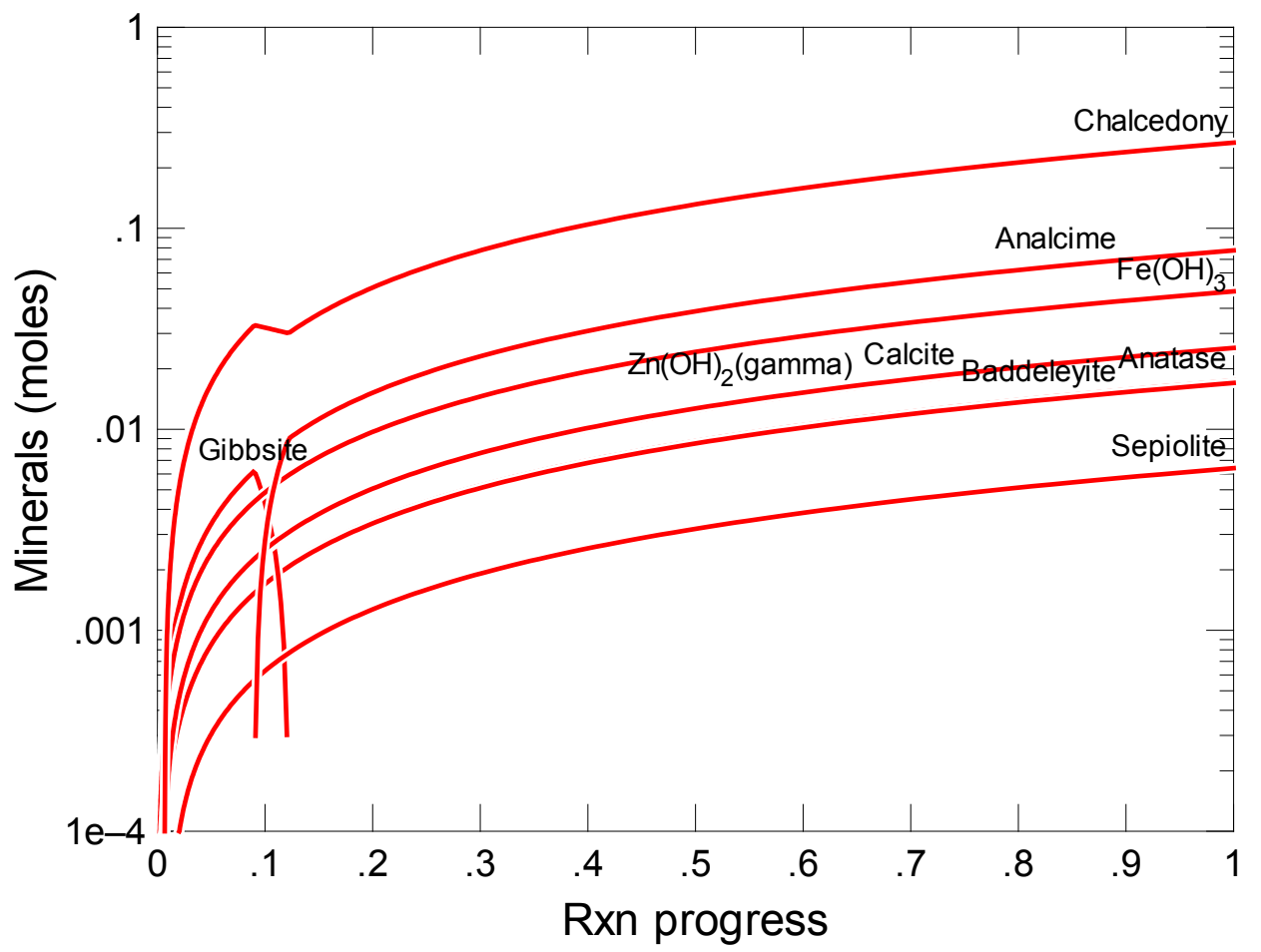

Figure C.85. Secondary Phases Calculated to Form as a Function of Reaction Progress (mol-glass/kg) Determined for Glass Sample LAWA127R2

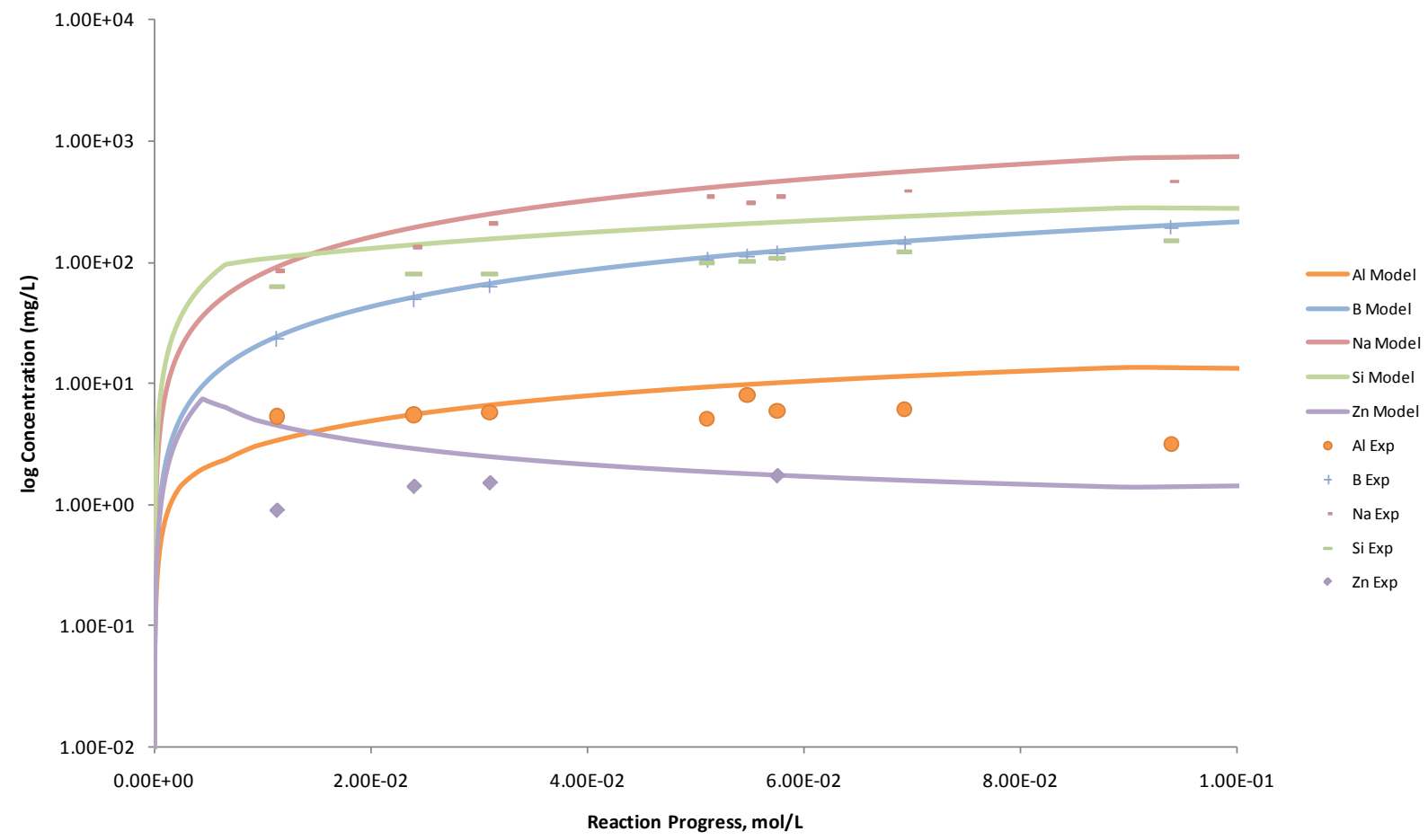

Figure C.86. Measured Solution Concentrations (mg/L) and Model Results for Al, B, Na, Si, and Zn, as a Function of Reaction Progress (mol-glass $/ \mathrm{kg}$ ) Determined for Glass Sample LAWA127R2 


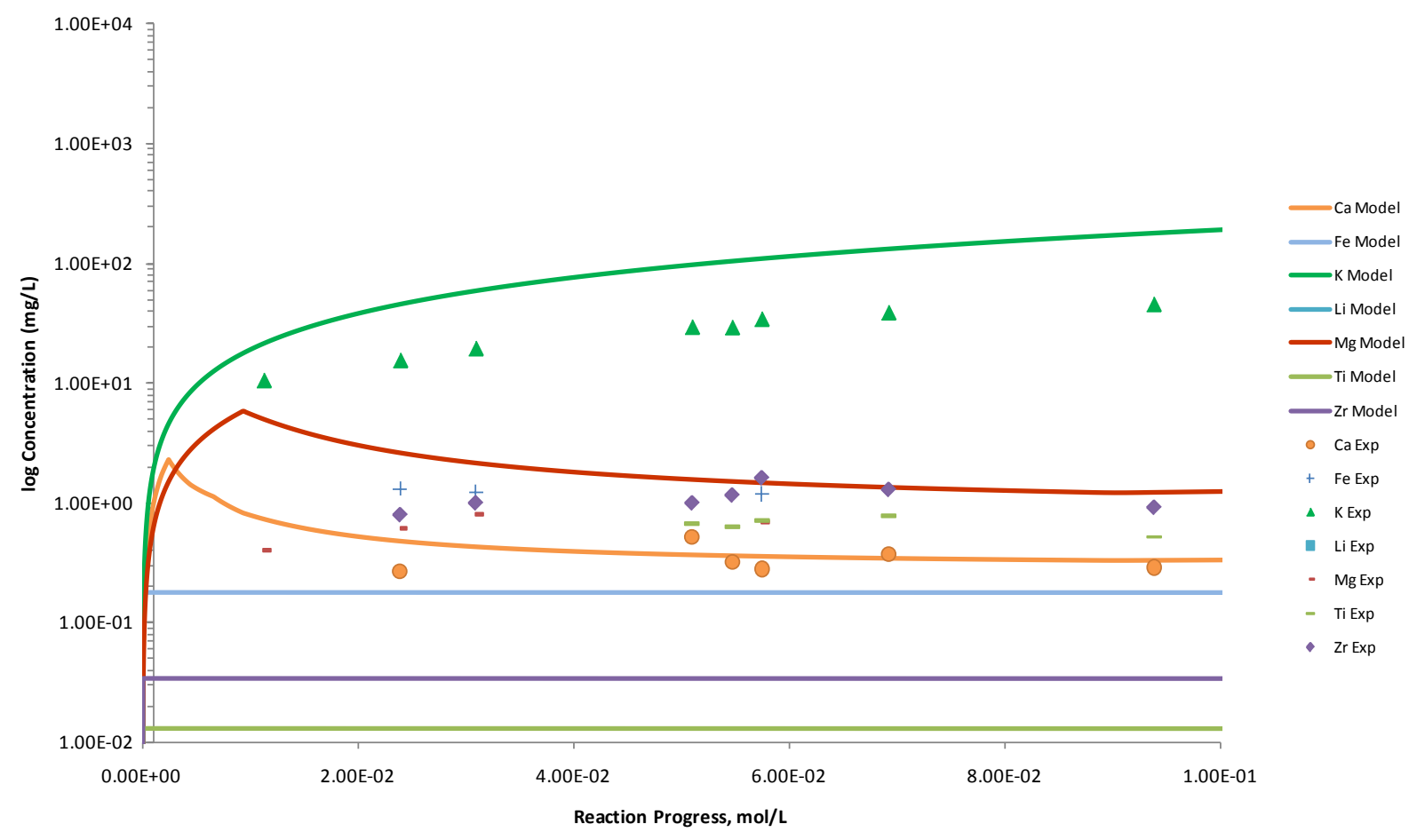

Figure C.87. Measured Solution Concentrations (mg/L) and Model Results for $\mathrm{Ca}, \mathrm{Fe}, \mathrm{K}, \mathrm{Li}, \mathrm{Mg}, \mathrm{Ti}$, and $\mathrm{Zr}$, as a Function of Reaction Progress (mol-glass/kg) Determined for Glass Sample LAWA127R2

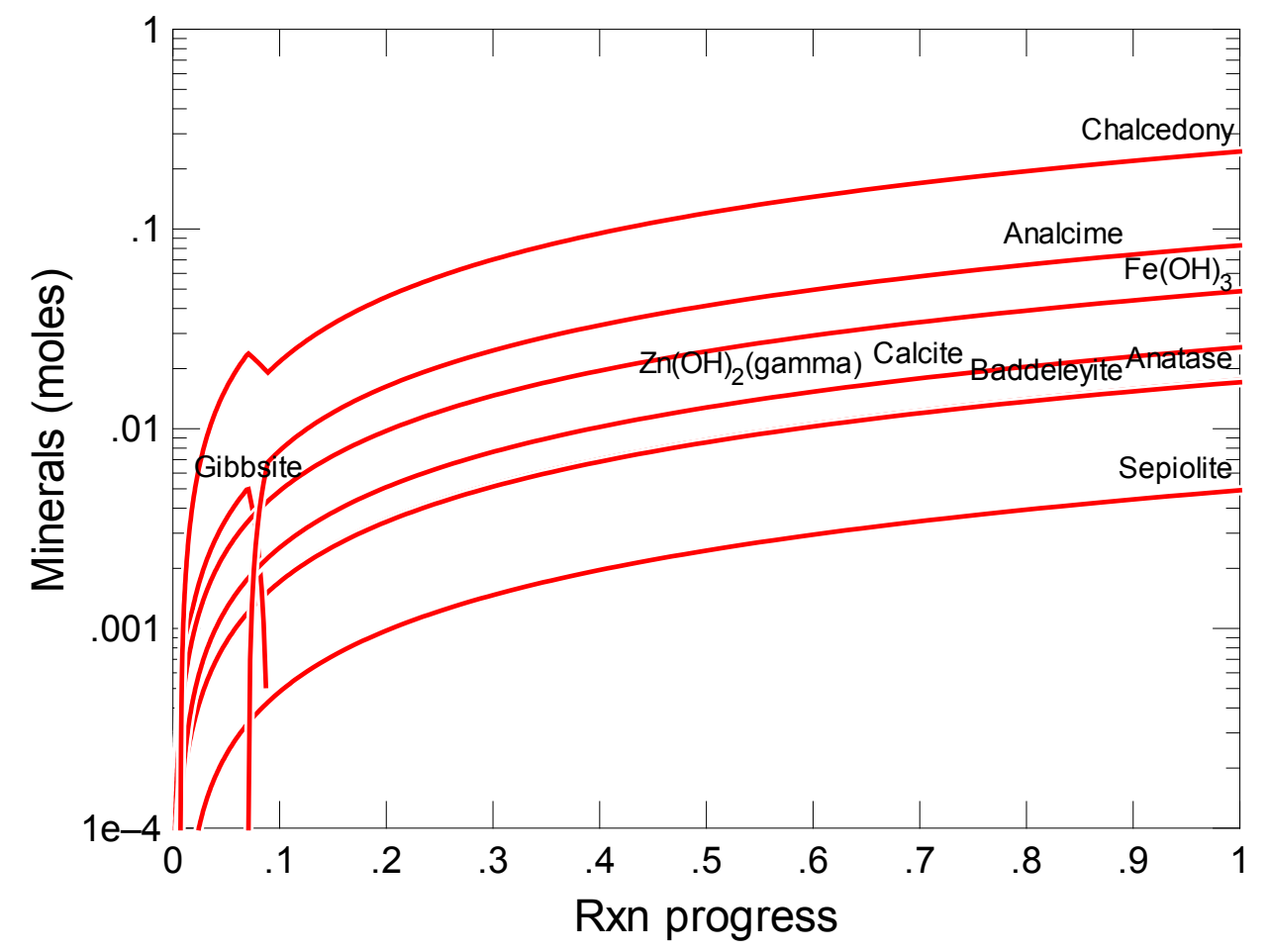

Figure C.88. Secondary Phases Calculated to Form as a Function of Reaction Progress (mol-glass $/ \mathrm{kg}$ ) Determined for Glass Sample LAWA128 


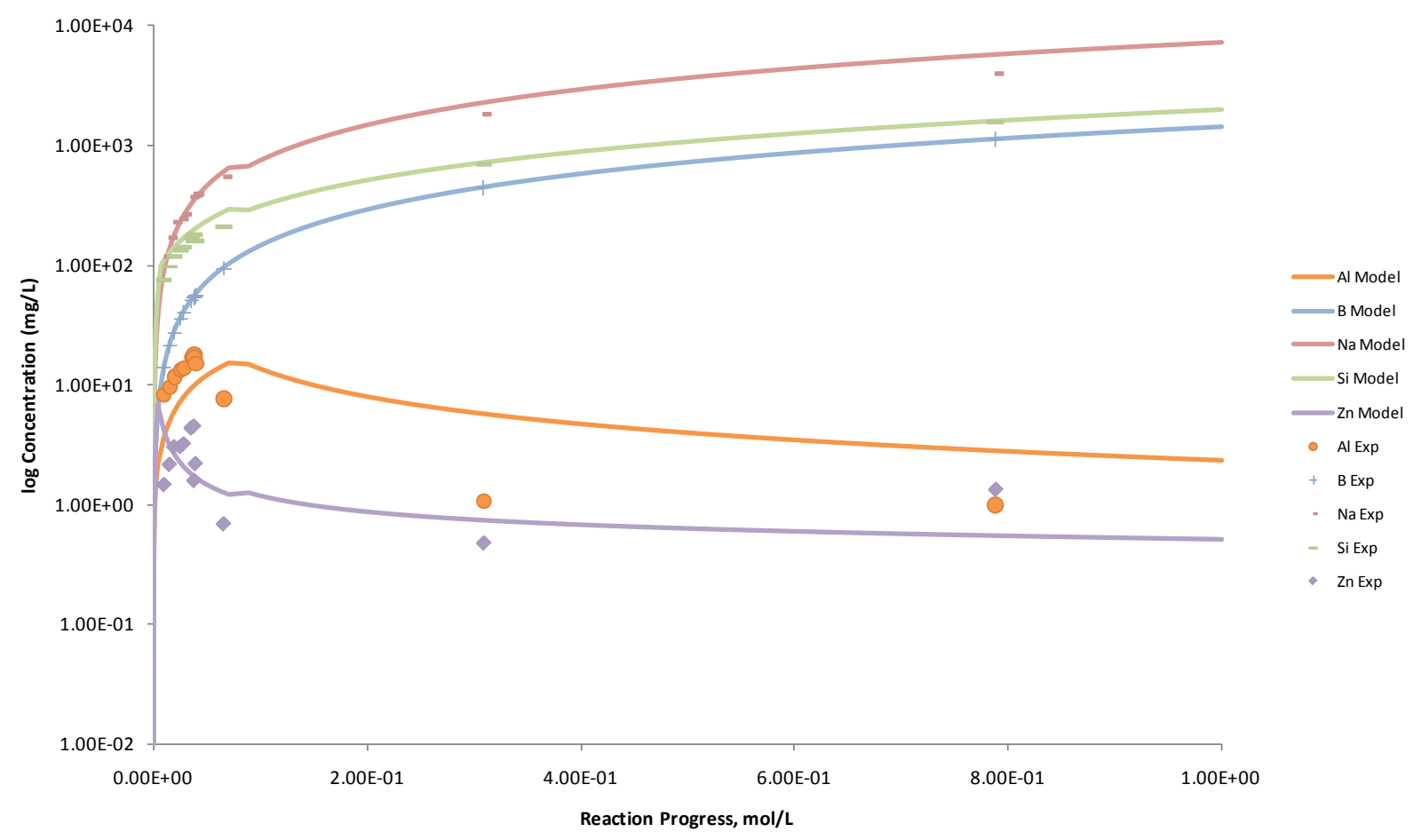

Figure C.89. Measured Solution Concentrations (mg/L) and Model Results for Al, B, Na, Si, and Zn, as a Function of Reaction Progress (mol-glass/kg) Determined for Glass Sample LAWA128

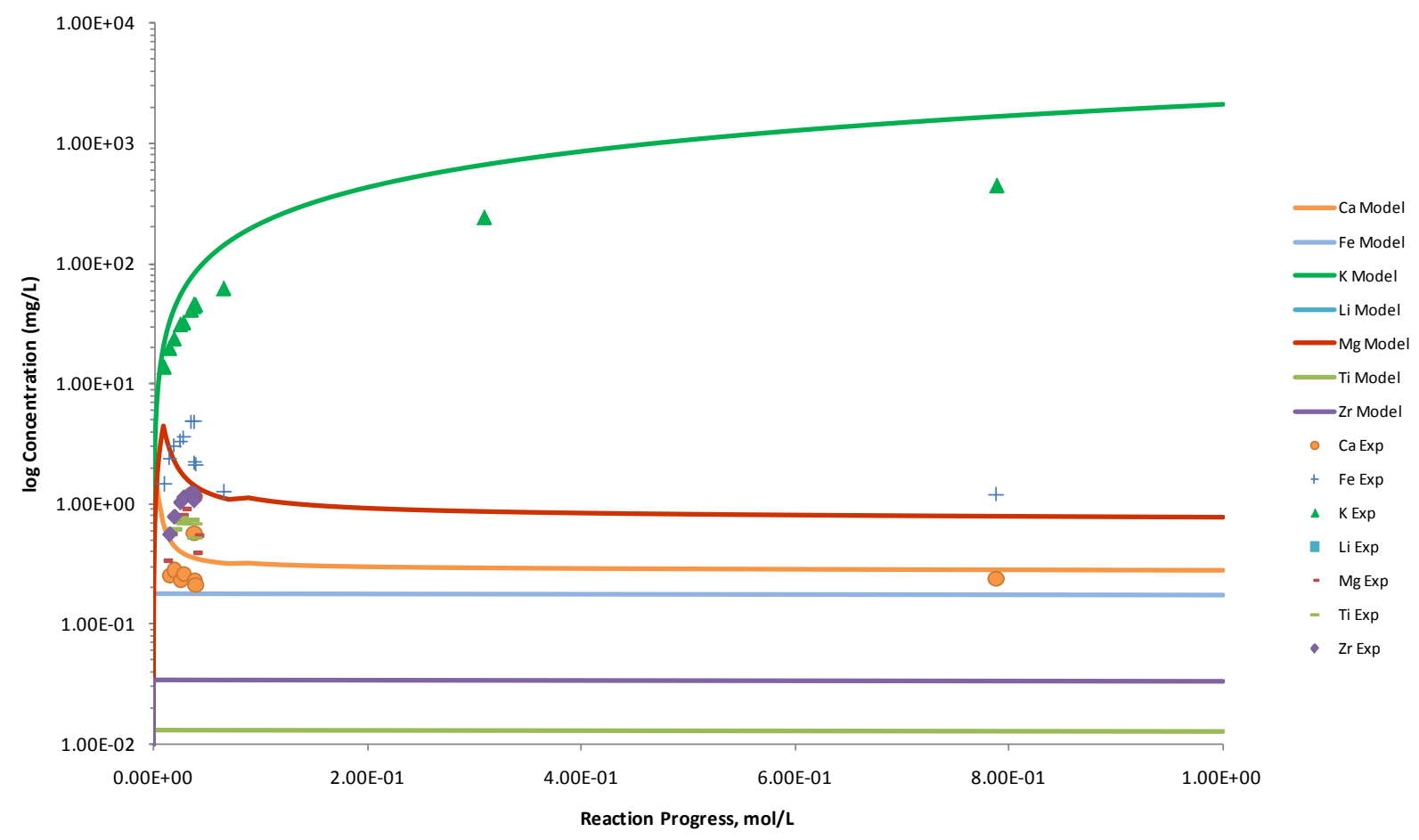

Figure C.90. Measured Solution Concentrations (mg/L) and Model Results for Ca, Fe, K, Li, Mg, Ti, and $\mathrm{Zr}$, as a Function of Reaction Progress (mol-glass $/ \mathrm{kg}$ ) Determined for Glass Sample LAWA128 


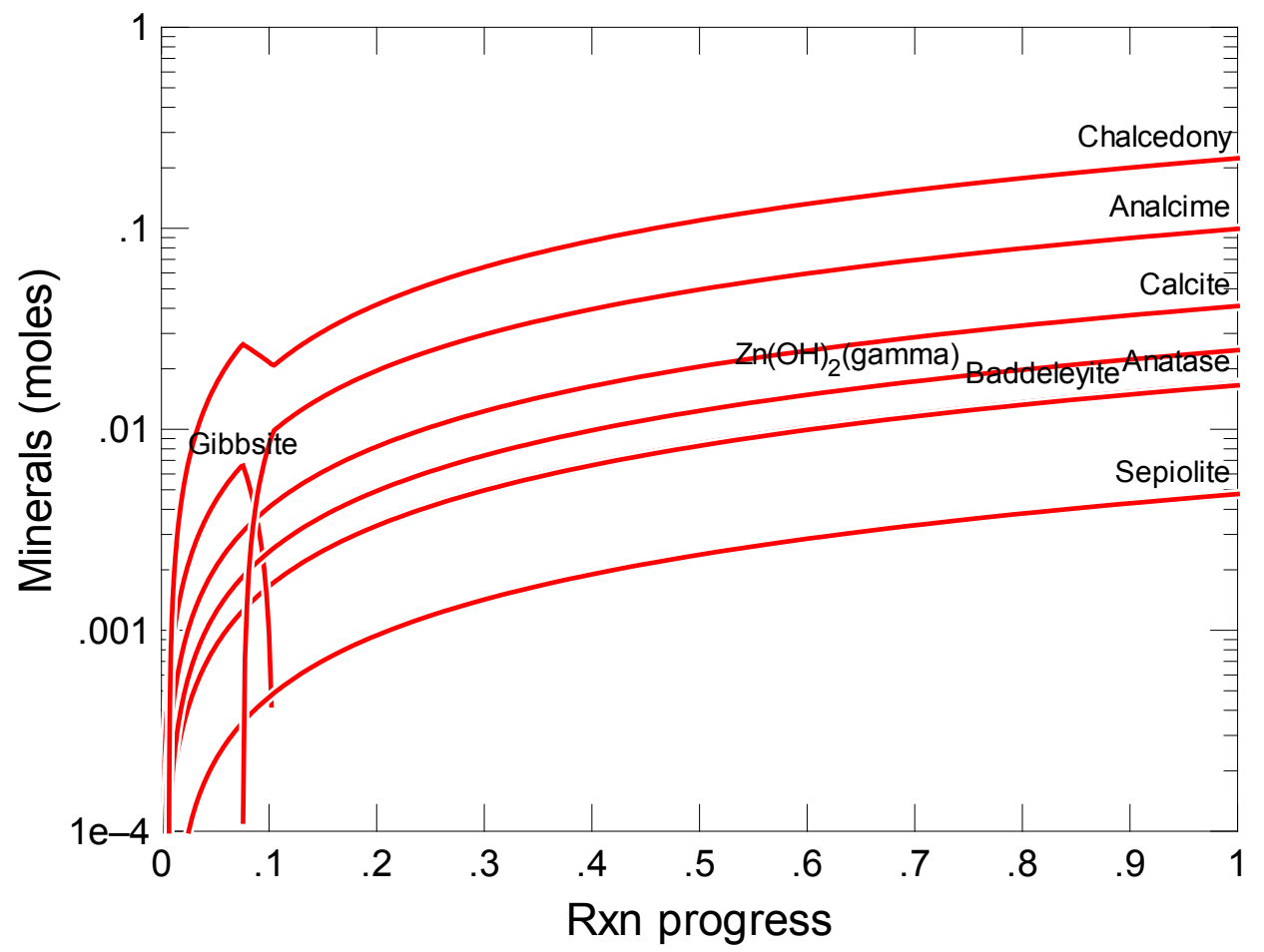

Figure C.91. Secondary Phases Calculated to Form as a Function of Reaction Progress (mol-glass/kg) Determined for Glass Sample LAWA129

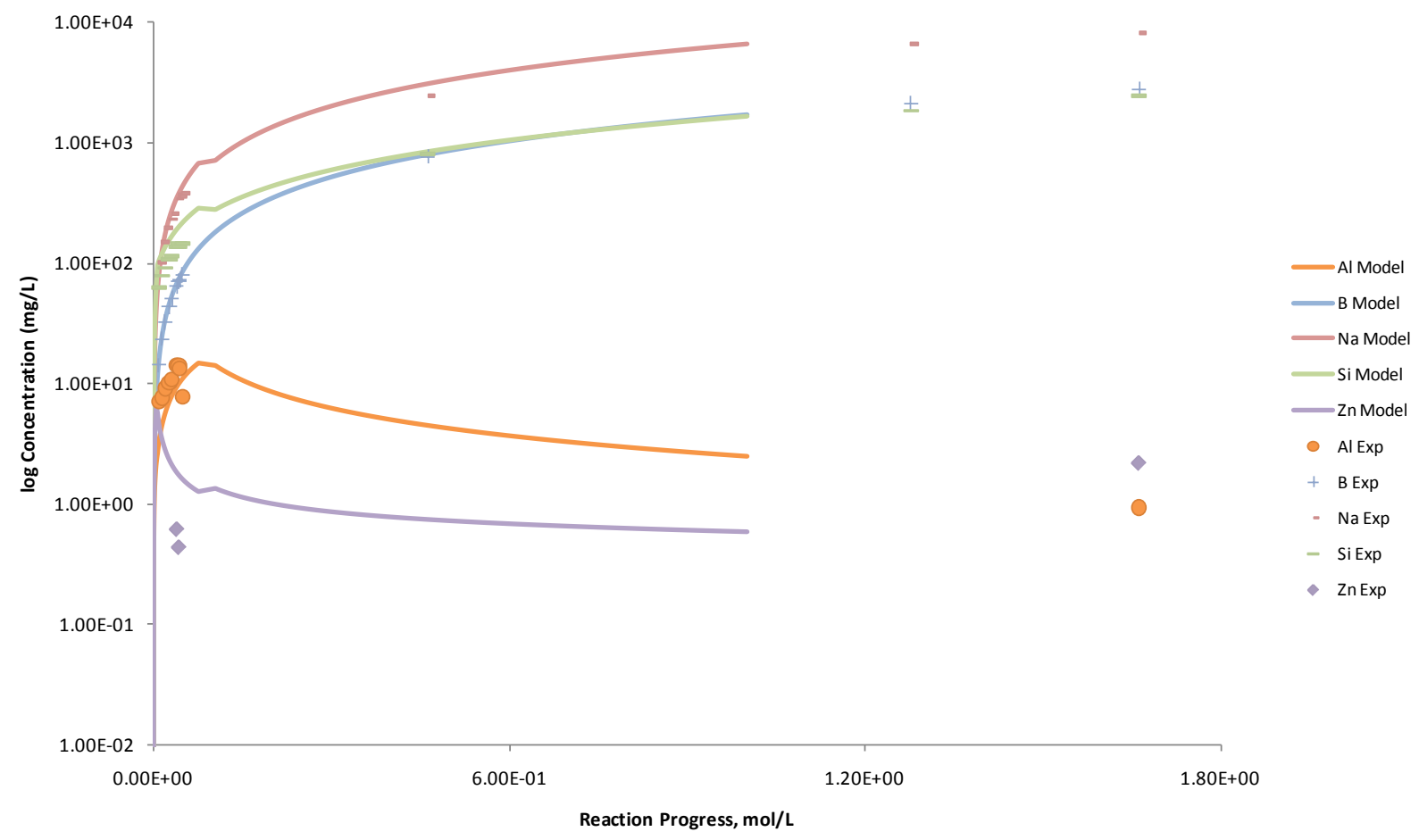

Figure C.92. Measured Solution Concentrations (mg/L) and Model Results for Al, B, Na, Si, and Zn, as a Function of Reaction Progress (mol-glass $/ \mathrm{kg}$ ) Determined for Glass Sample LAWA129 


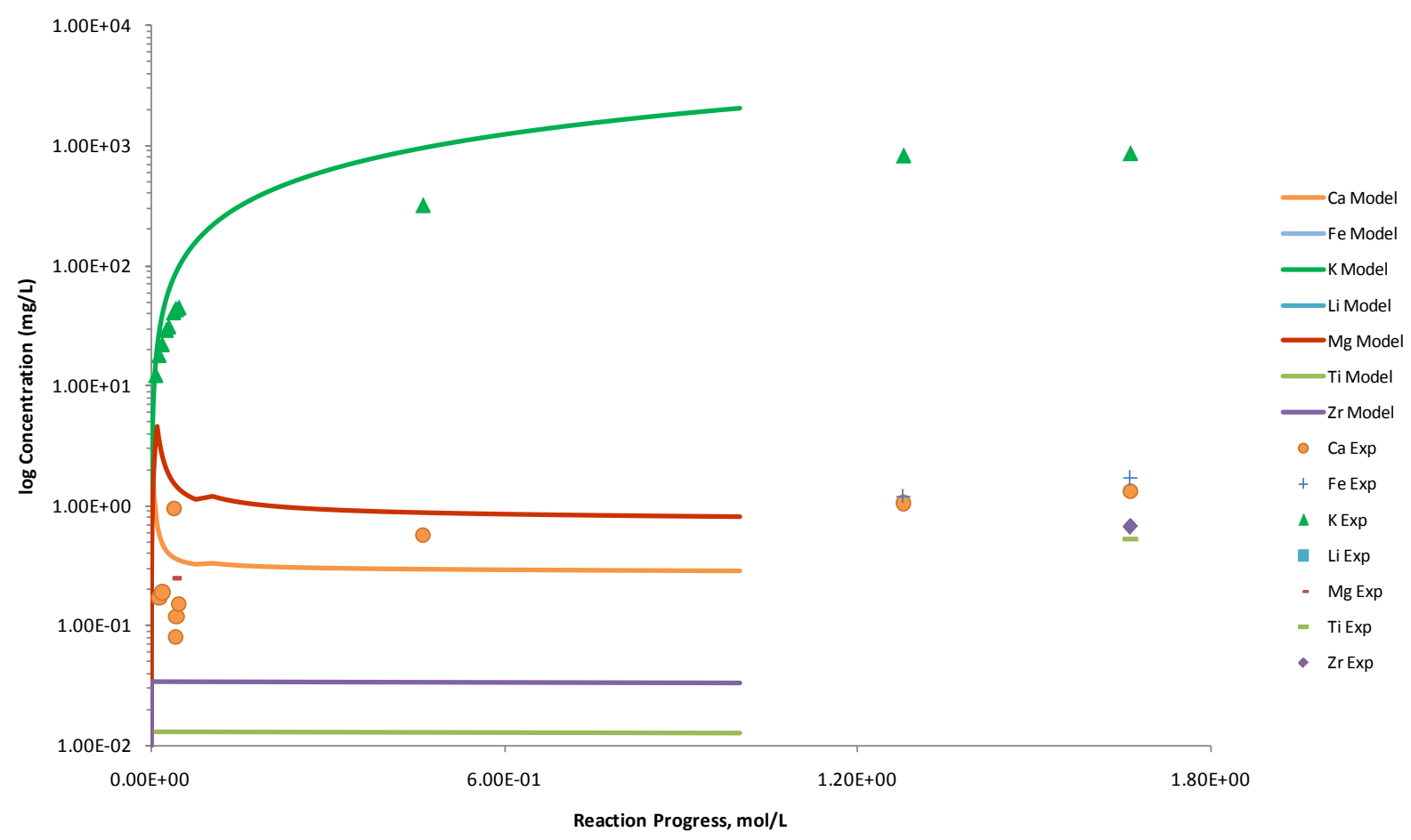

Figure C.93. Measured Solution Concentrations (mg/L) and Model Results for $\mathrm{Ca}, \mathrm{Fe}, \mathrm{K}, \mathrm{Li}, \mathrm{Mg}$, Ti, and $\mathrm{Zr}$, as a Function of Reaction Progress (mol-glass/kg) Determined for Glass Sample LAWA129

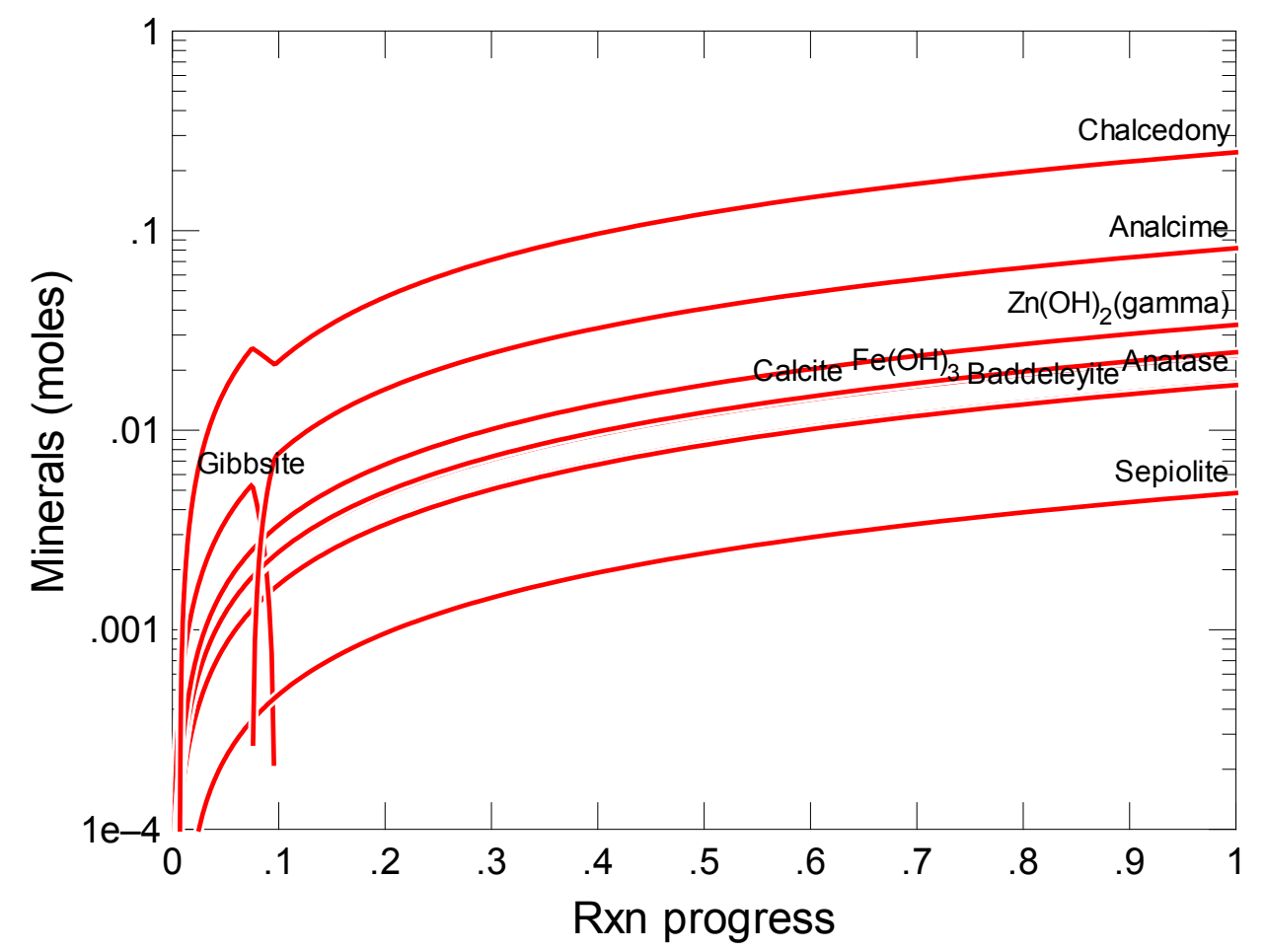

Figure C.94. Secondary Phases Calculated to Form as a Function of Reaction Progress (mol-glass/kg) Determined for Glass Sample LAWA130 


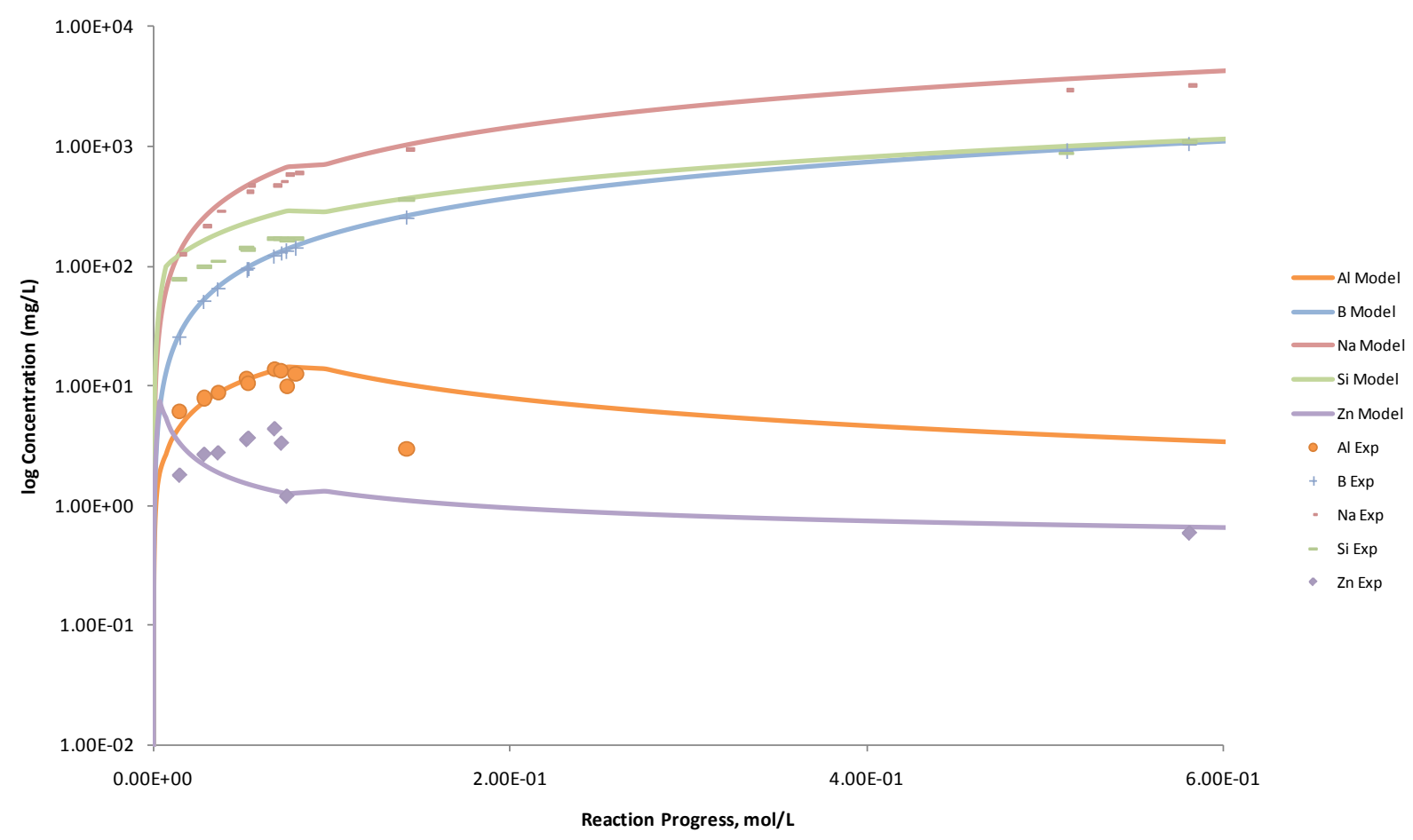

Figure C.95. Measured Solution Concentrations (mg/L) and Model Results for Al, B, Na, Si, and Zn, as a Function of Reaction Progress (mol-glass/kg) Determined for Glass Sample LAWA130

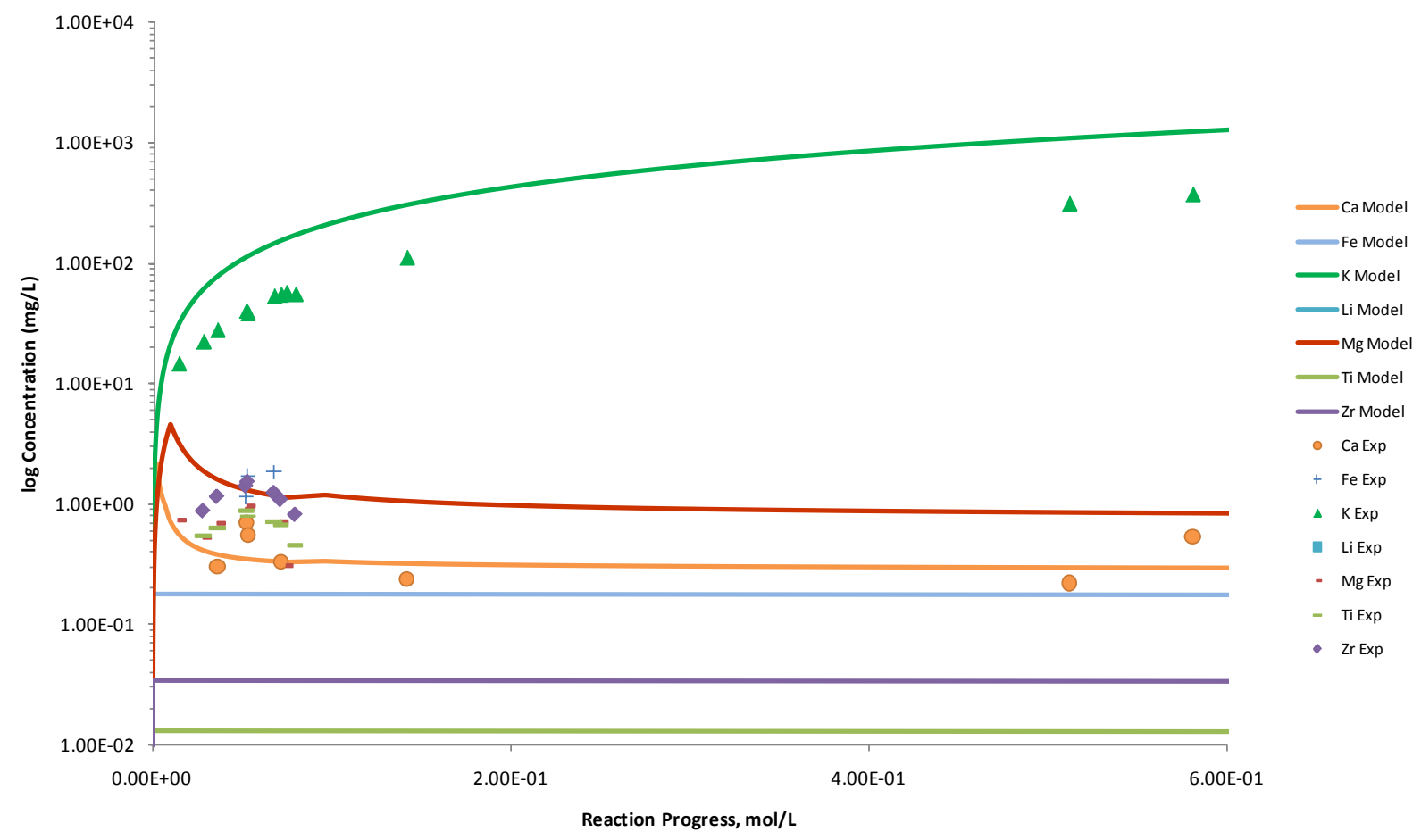

Figure C.96. Measured Solution Concentrations (mg/L) and Model Results for Ca, Fe, K, Li, Mg, Ti, and Zr, as a Function of Reaction Progress (mol-glass $/ \mathrm{kg}$ ) Determined for Glass Sample LAWA130 


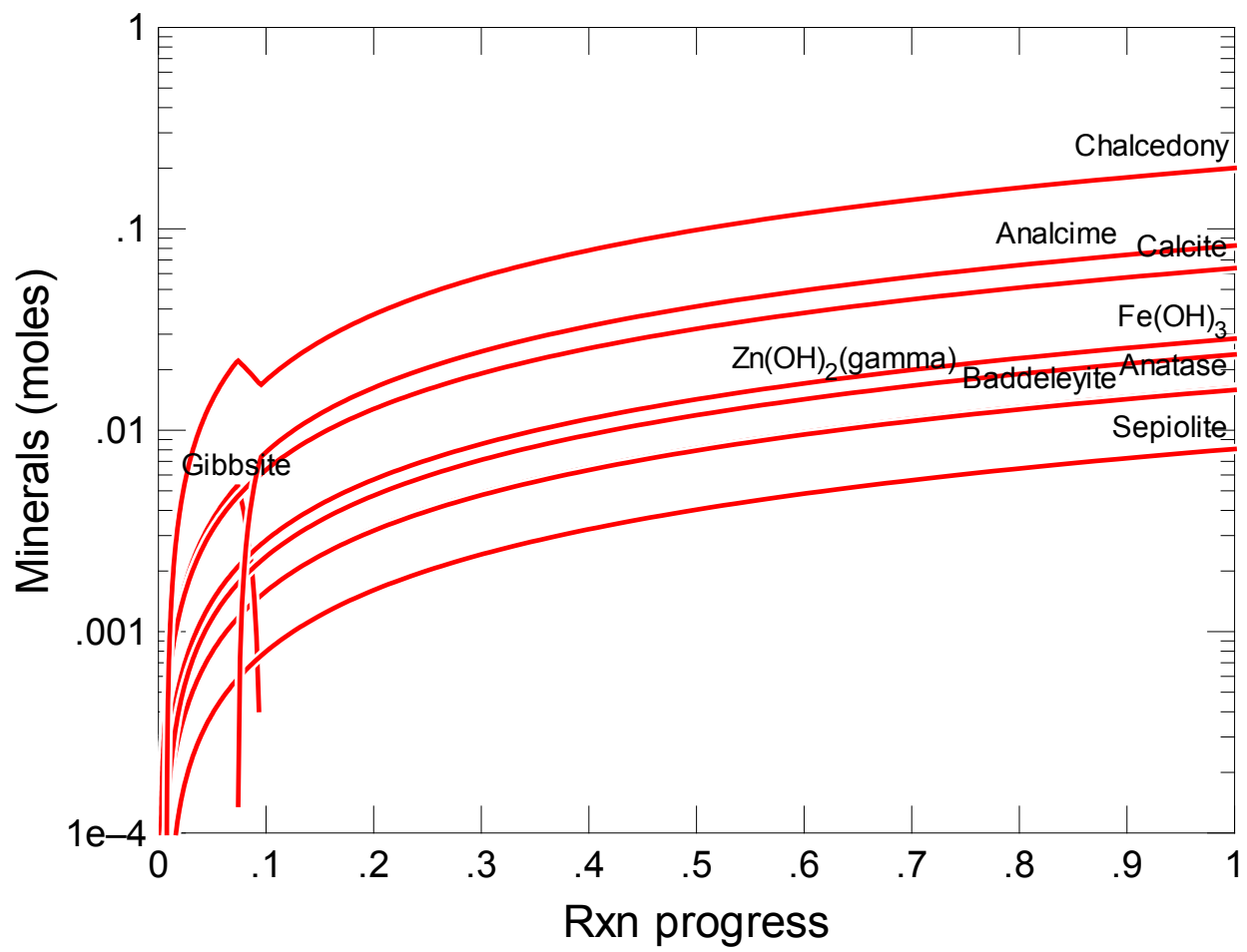

Figure C.97. Secondary Phases Calculated to Form as a Function of Reaction Progress (mol-glass/kg) Determined for Glass Sample LAWA133

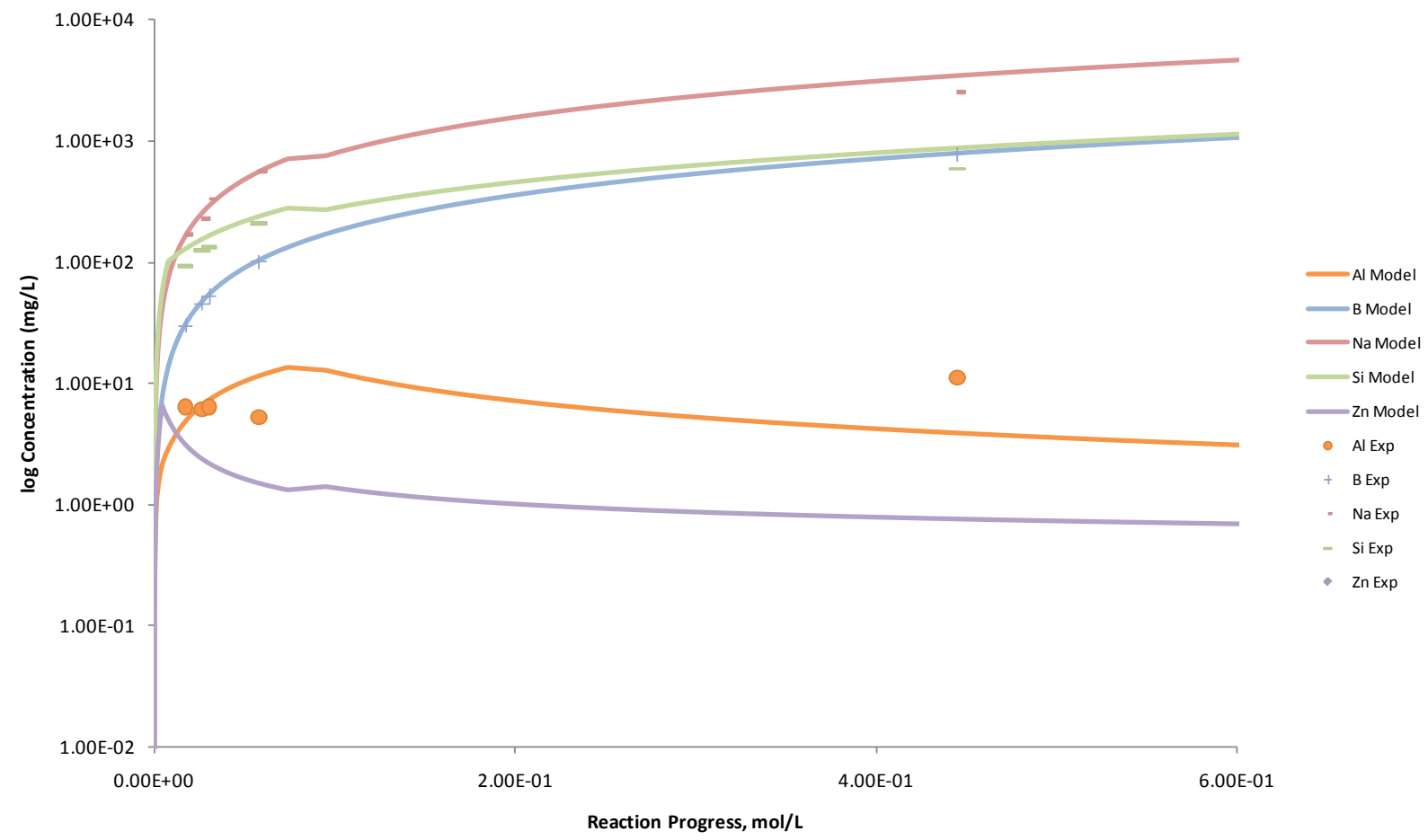

Figure C.98. Measured Solution Concentrations (mg/L) and Model Results for Al, B, Na, Si, and Zn, as a Function of Reaction Progress (mol-glass/kg) Determined for Glass Sample LAWA133 


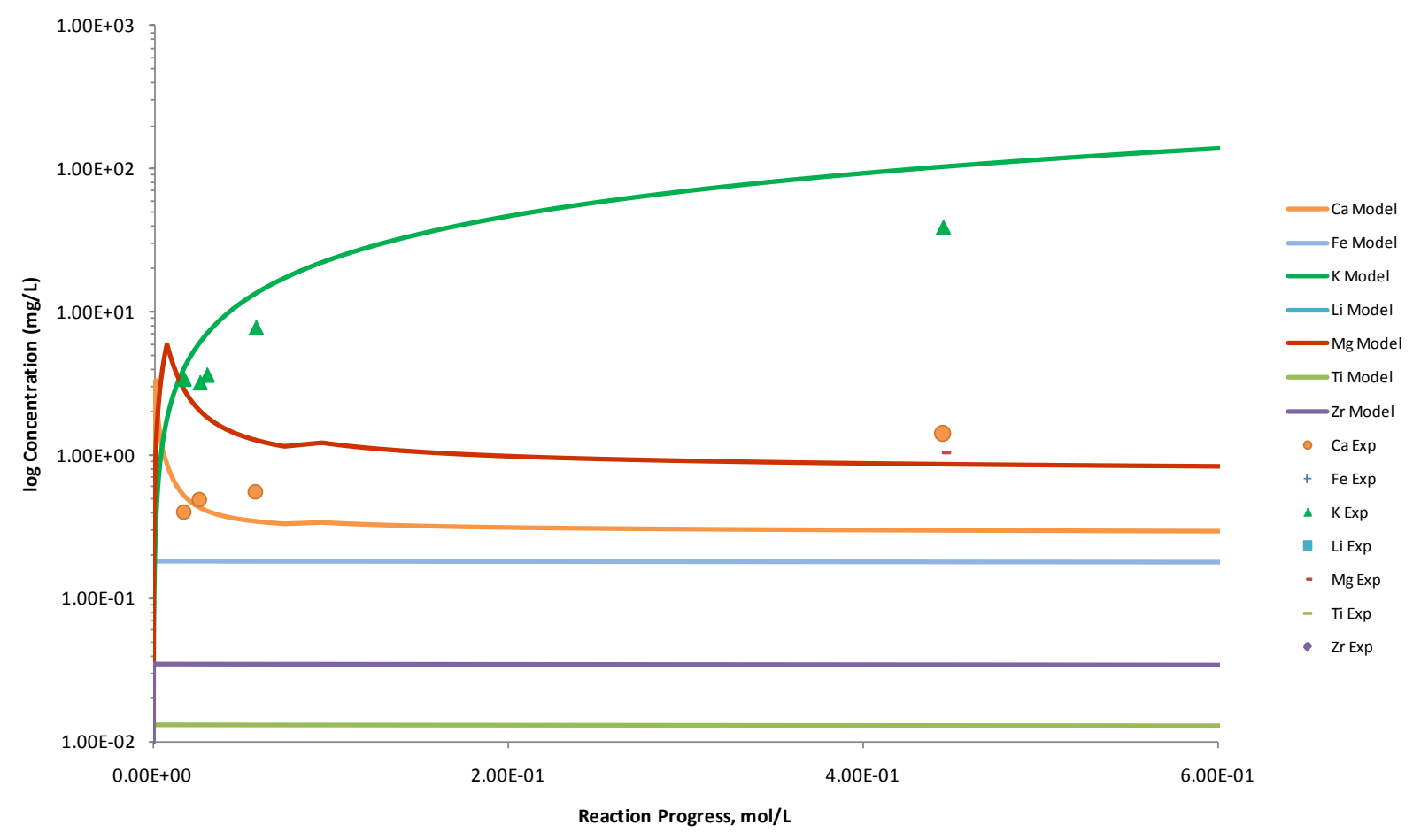

Figure C.99. Measured Solution Concentrations (mg/L) and Model Results for $\mathrm{Ca}, \mathrm{Fe}, \mathrm{K}, \mathrm{Li}, \mathrm{Mg}, \mathrm{Ti}$, and Zr, as a Function of Reaction Progress (mol-glass/kg) Determined for Glass Sample LAWA133

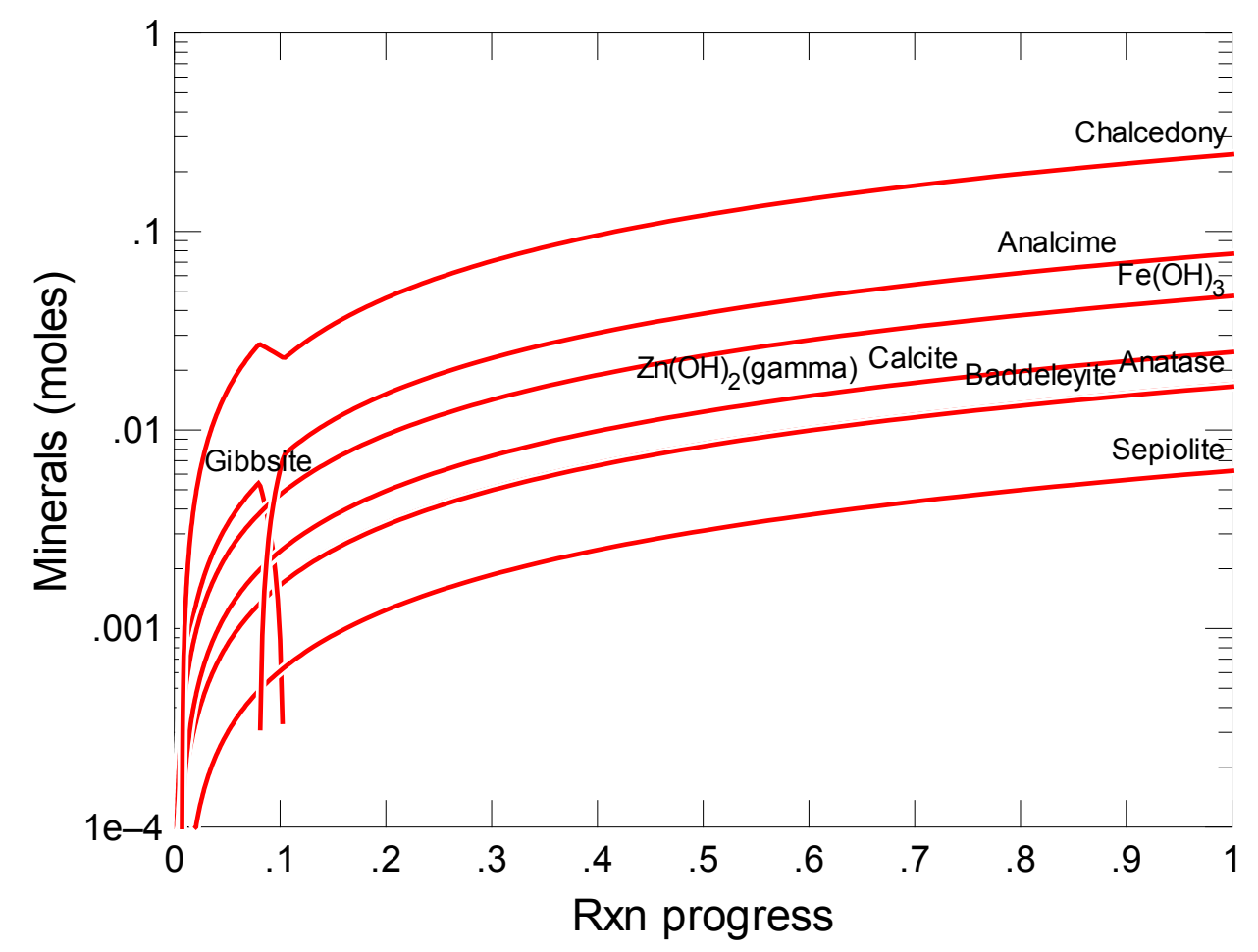

Figure C.100. Secondary Phases Calculated to Form as a Function of Reaction Progress (mol-glass $/ \mathrm{kg}$ ) Determined for Glass Sample LAWA134 


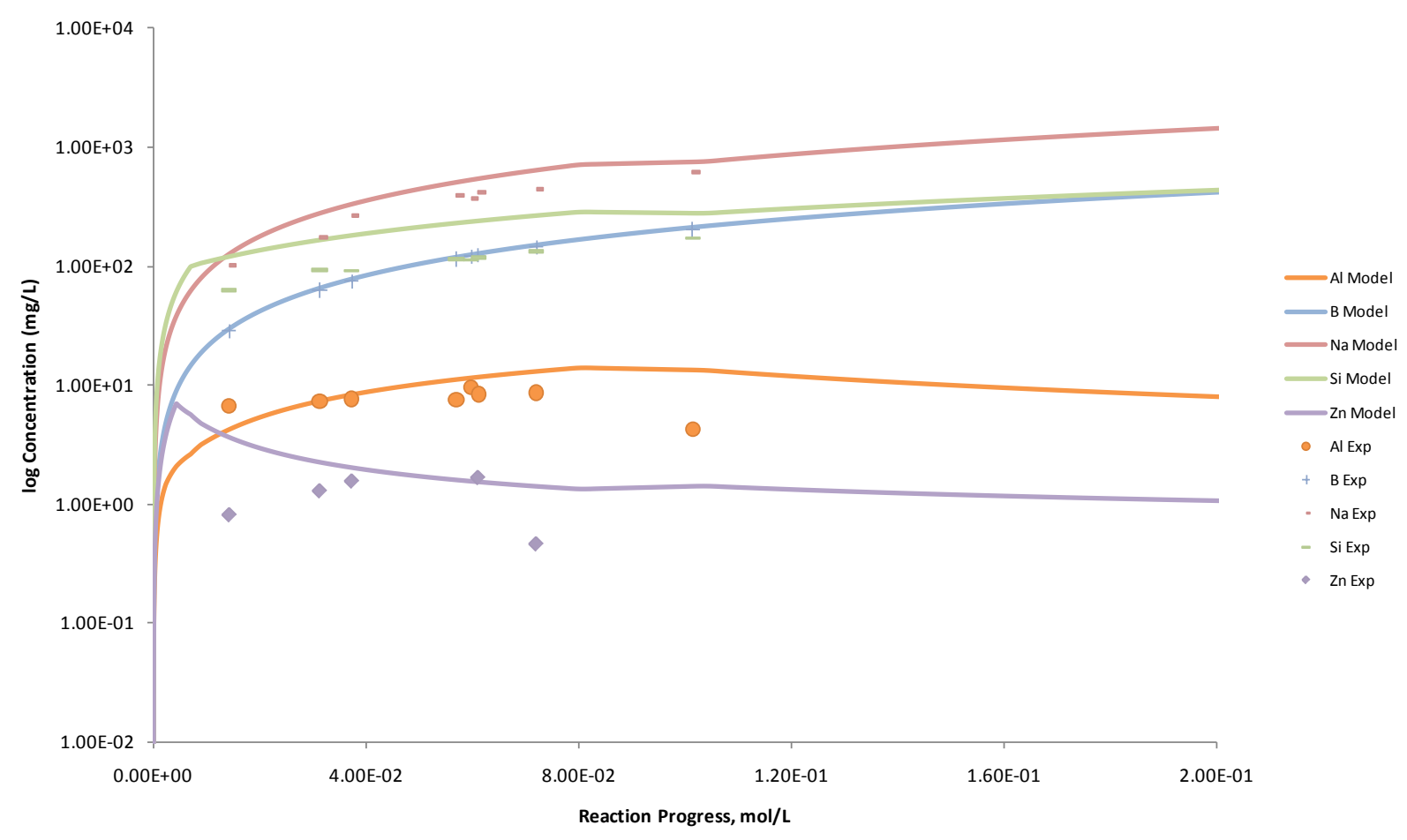

Figure C.101. Measured Solution Concentrations (mg/L) and Model Results for Al, B, Na, Si, and Zn, as a Function of Reaction Progress (mol-glass $/ \mathrm{kg}$ ) Determined for Glass Sample LAWA134

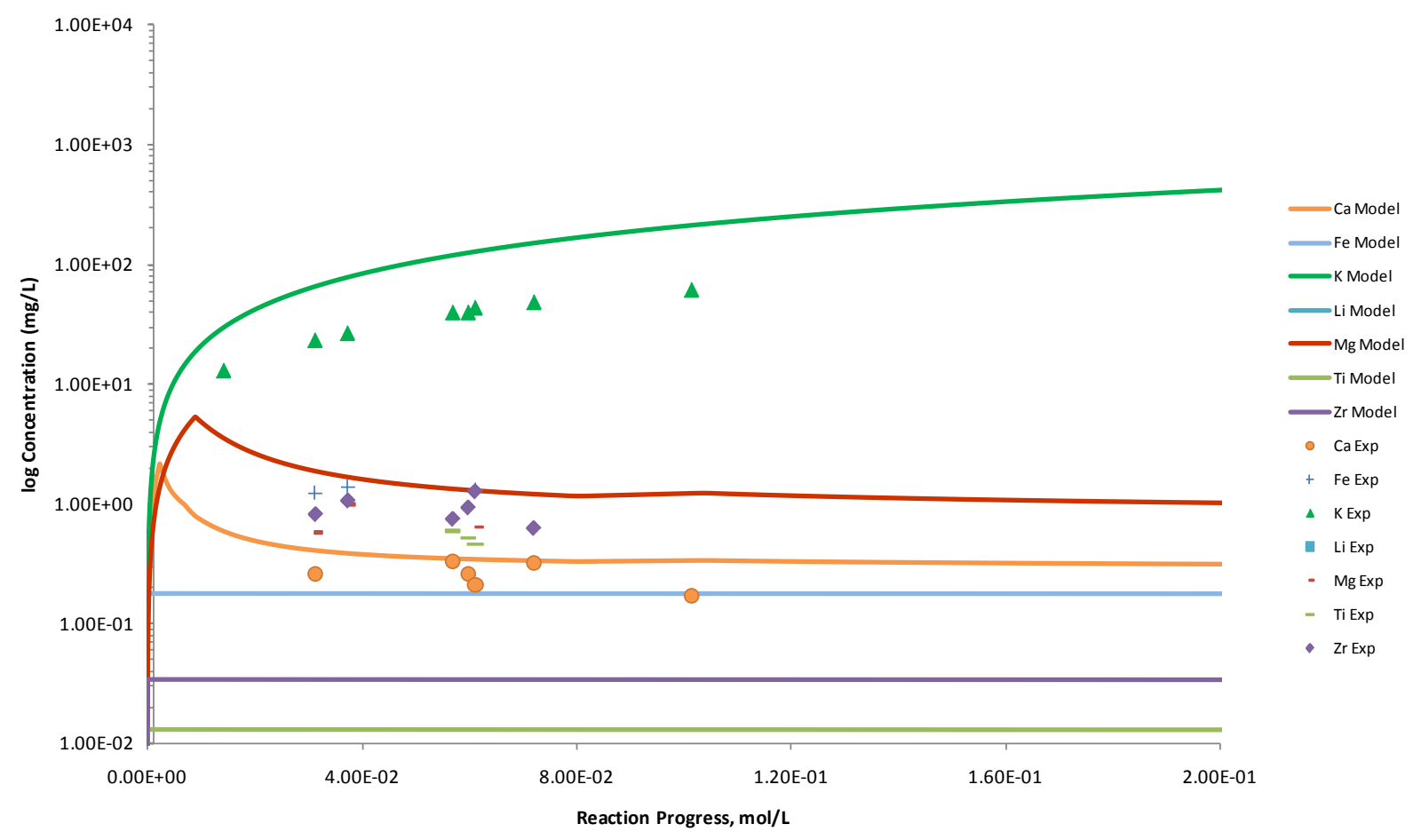

Figure C.102. Measured Solution Concentrations (mg/L) and Model Results for $\mathrm{Ca}, \mathrm{Fe}, \mathrm{K}, \mathrm{Li}, \mathrm{Mg}, \mathrm{Ti}$, and $\mathrm{Zr}$, as a Function of Reaction Progress (mol-glass/kg) Determined for Glass Sample LAWA134 


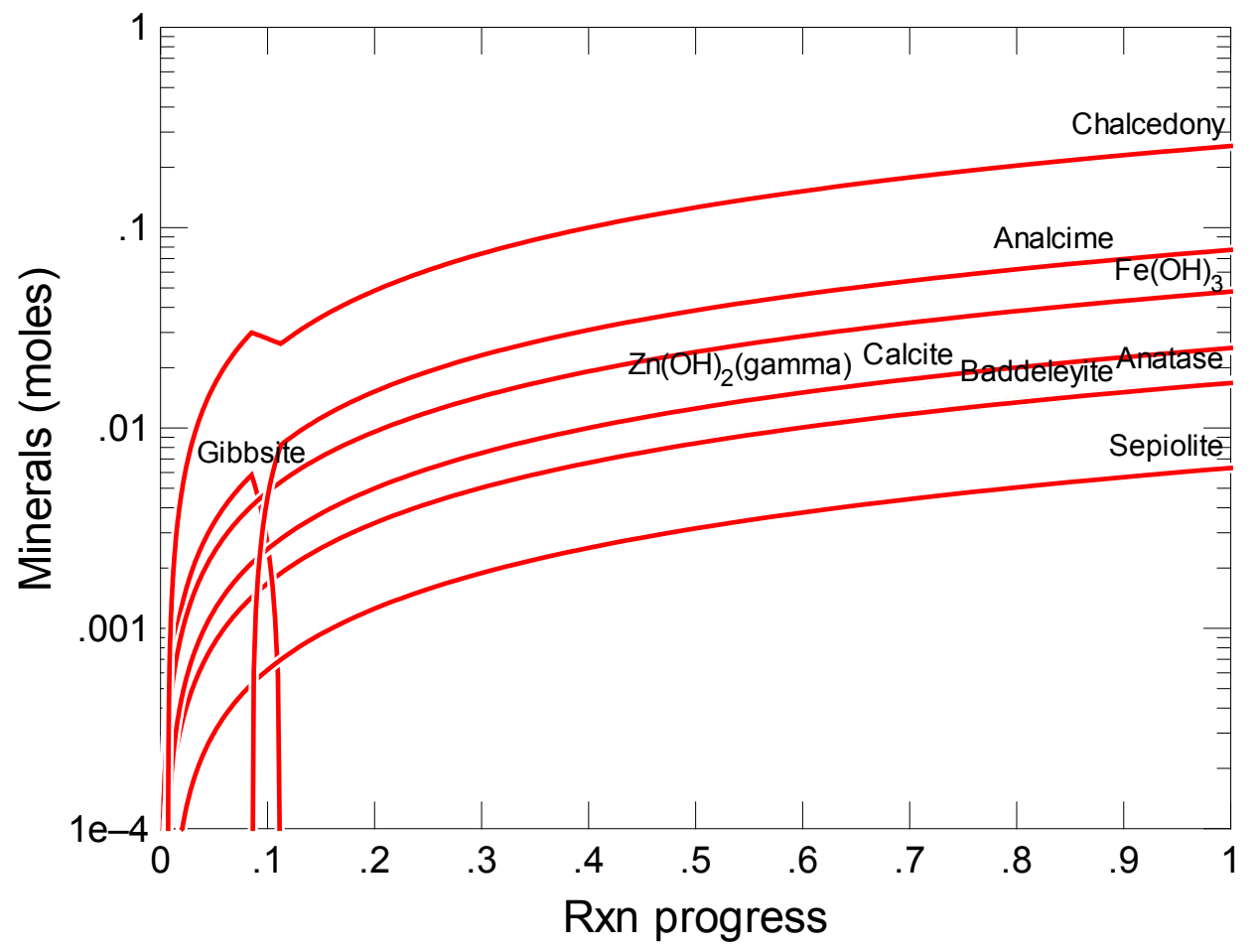

Figure C.103. Secondary Phases Calculated to Form as a Function of Reaction Progress (mol-glass $/ \mathrm{kg}$ ) Determined for Glass Sample LAWA135

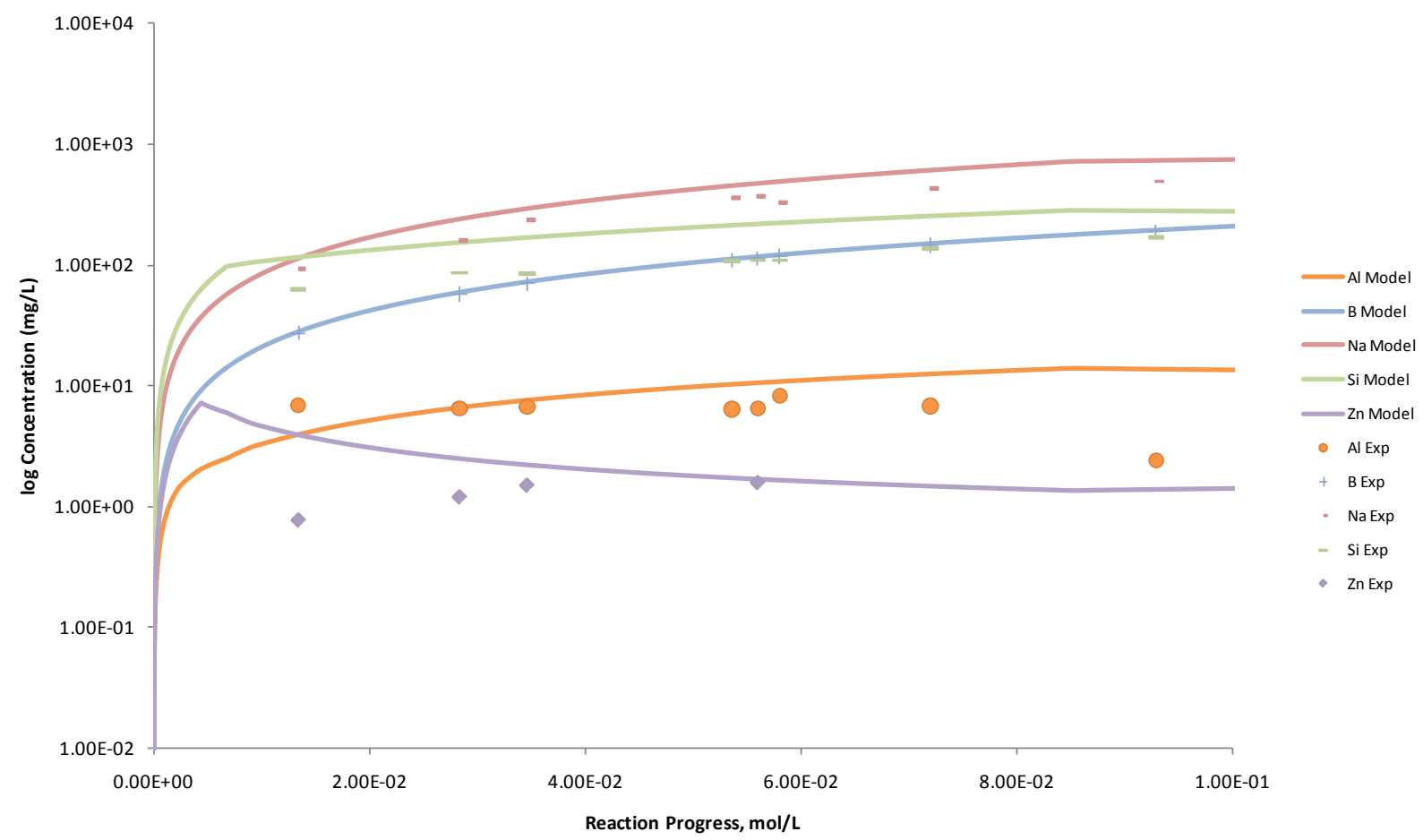

Figure C.104. Measured Solution Concentrations (mg/L) and Model Results for Al, B, Na, Si, and Zn, as a Function of Reaction Progress (mol-glass $/ \mathrm{kg}$ ) Determined for Glass Sample LAWA135 


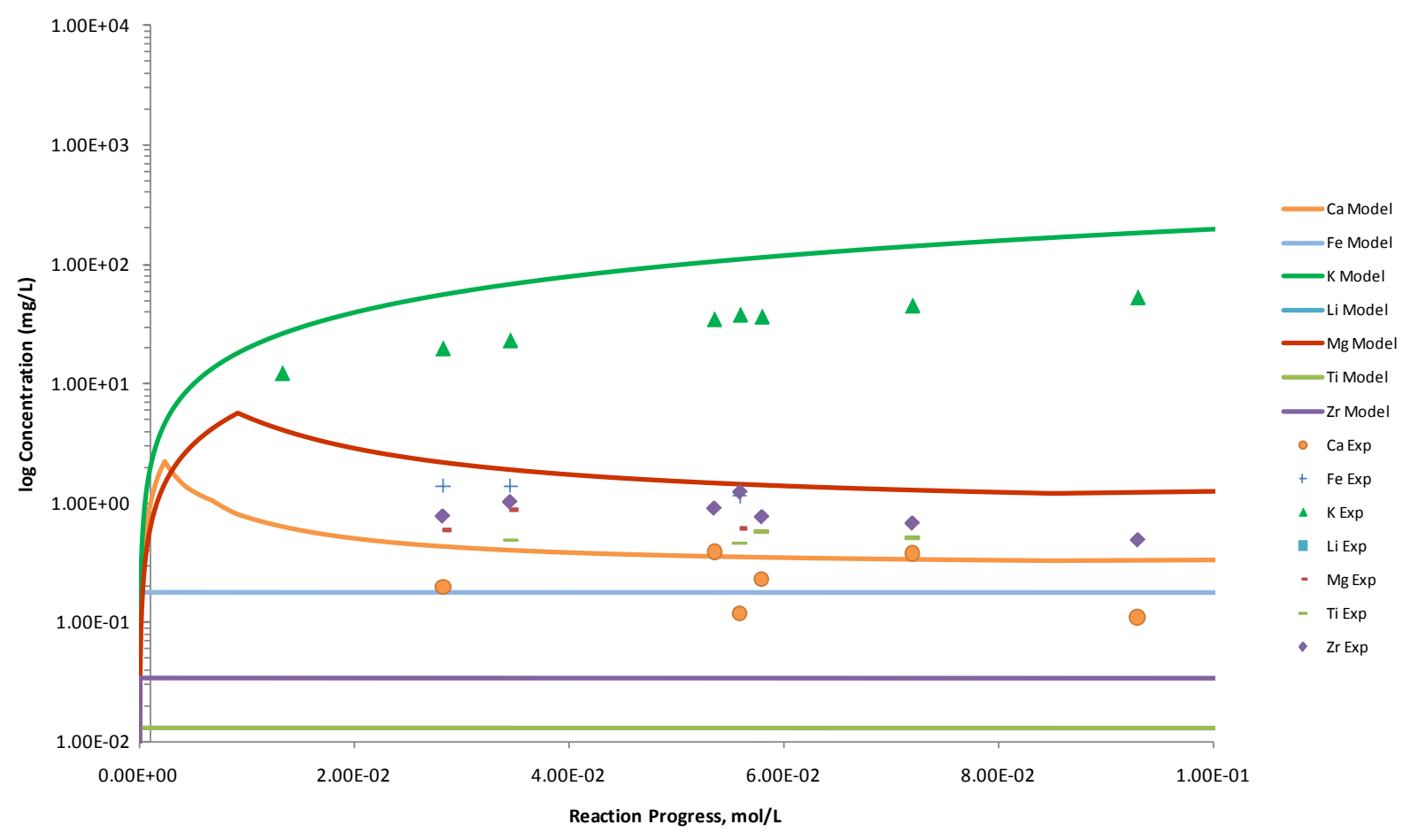

Figure C.105. Measured Solution Concentrations (mg/L) and Model Results for $\mathrm{Ca}, \mathrm{Fe}, \mathrm{K}, \mathrm{Li}, \mathrm{Mg}, \mathrm{Ti}$, and Zr, as a Function of Reaction Progress (mol-glass/kg) Determined for Glass Sample LAWA135

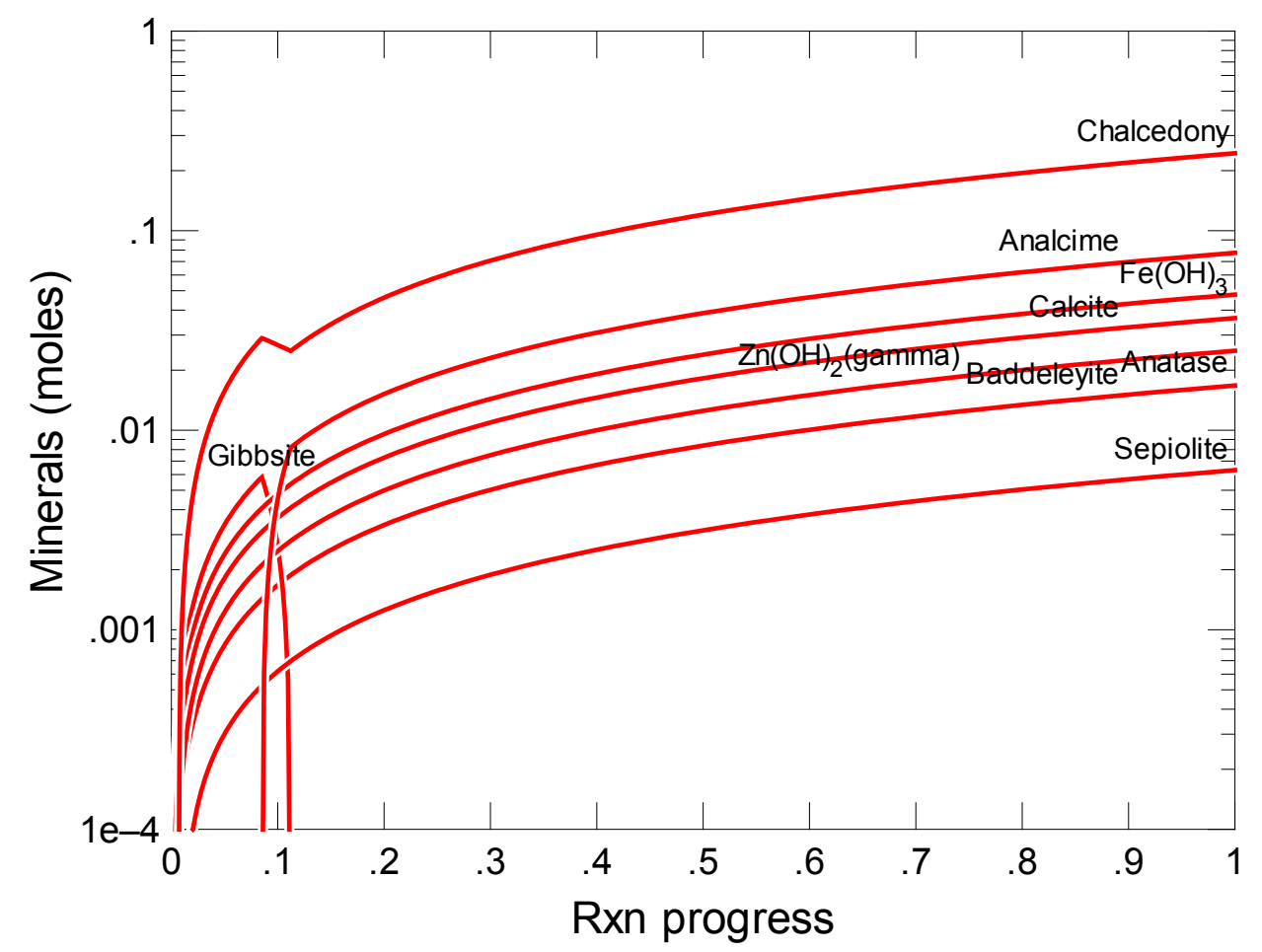

Figure C.106. Secondary Phases Calculated to Form as a Function of Reaction Progress (mol-glass $/ \mathrm{kg}$ ) Determined for Glass Sample LAWA136 


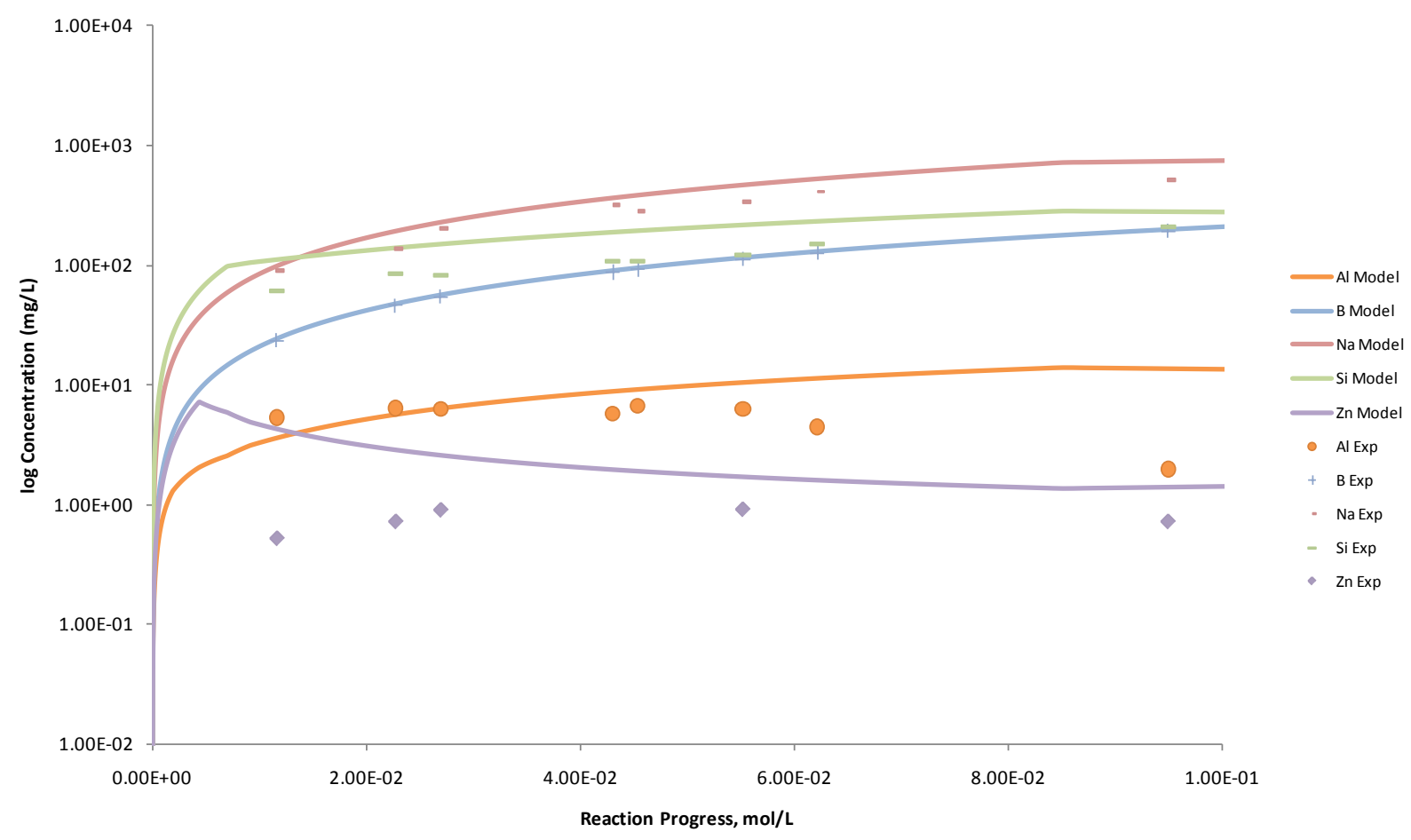

Figure C.107. Measured Solution Concentrations (mg/L) and Model Results for Al, B, Na, Si, and Zn, as a Function of Reaction Progress (mol-glass $/ \mathrm{kg}$ ) Determined for Glass Sample LAWA136

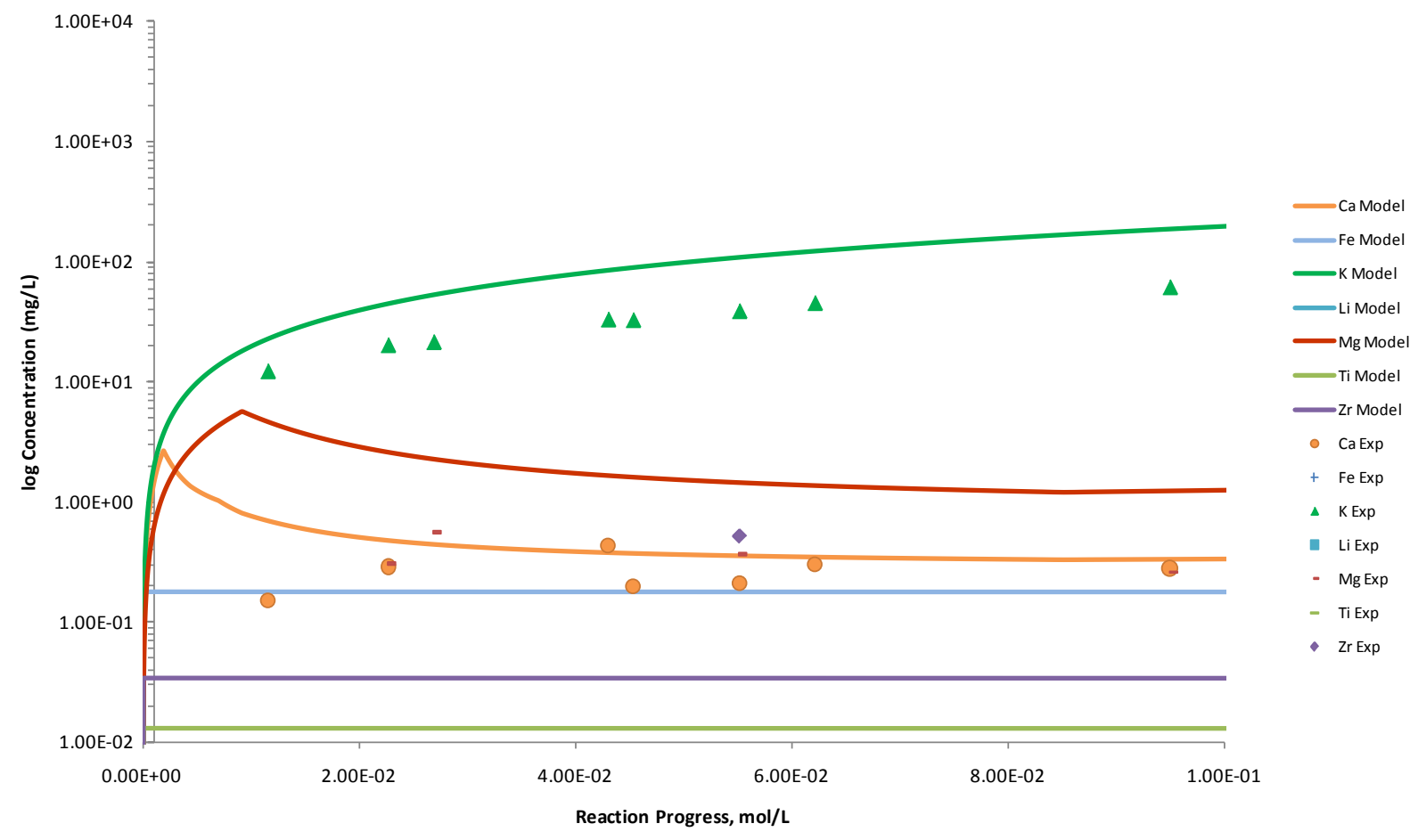

Figure C.108. Measured Solution Concentrations (mg/L) and Model Results for $\mathrm{Ca}, \mathrm{Fe}, \mathrm{K}, \mathrm{Li}, \mathrm{Mg}, \mathrm{Ti}$, and $\mathrm{Zr}$, as a Function of Reaction Progress (mol-glass/kg) Determined for Glass Sample LAWA136 


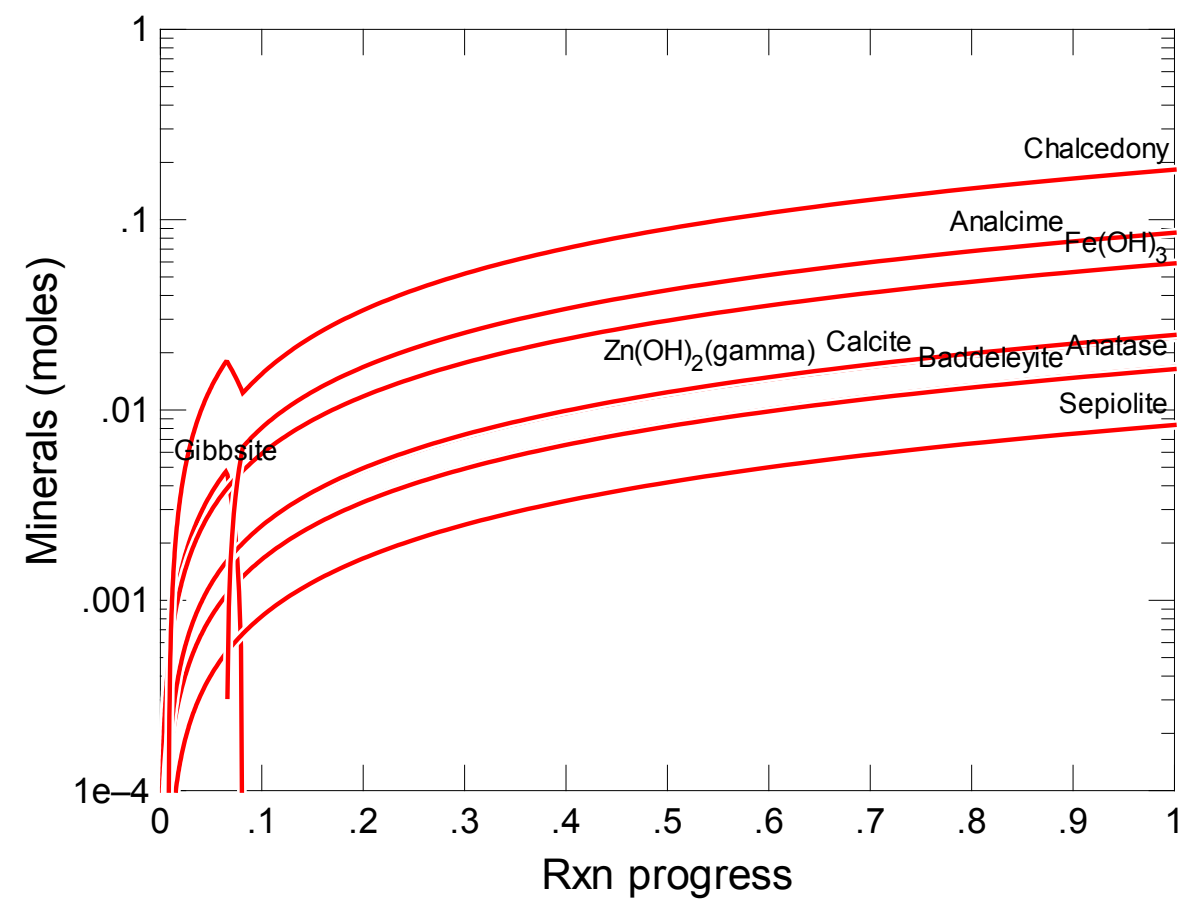

Figure C.109. Secondary Phases Calculated to Form as a Function of Reaction Progress (mol-glass/kg) Determined for Glass Sample LAWA41

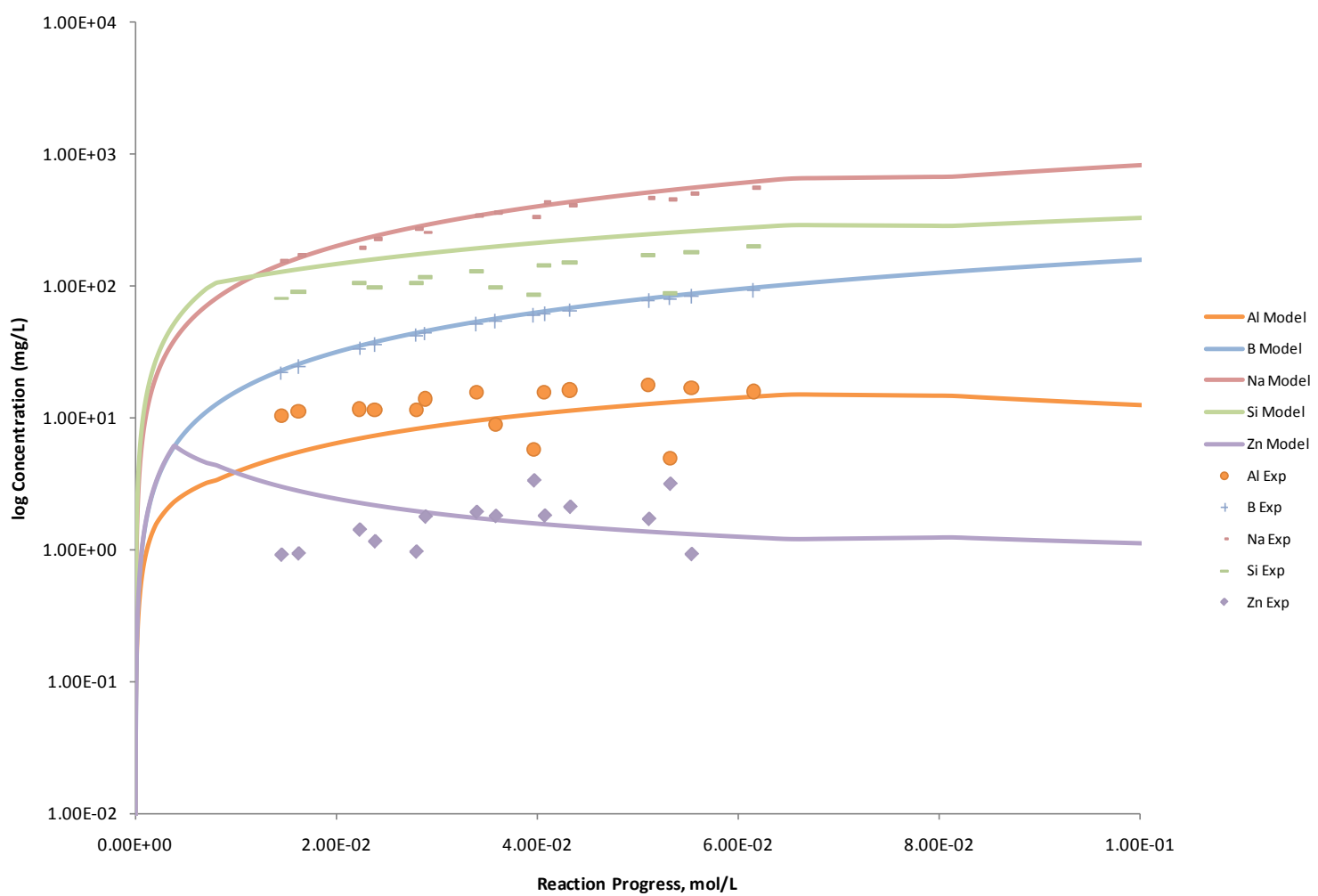

Figure C.110. Measured Solution Concentrations (mg/L) and Model Results for $\mathrm{Al}, \mathrm{B}, \mathrm{Na}$, $\mathrm{Si}$, and $\mathrm{Zn}$, as a Function of Reaction Progress (mol-glass $/ \mathrm{kg}$ ) Determined for Glass Sample LAWA41 


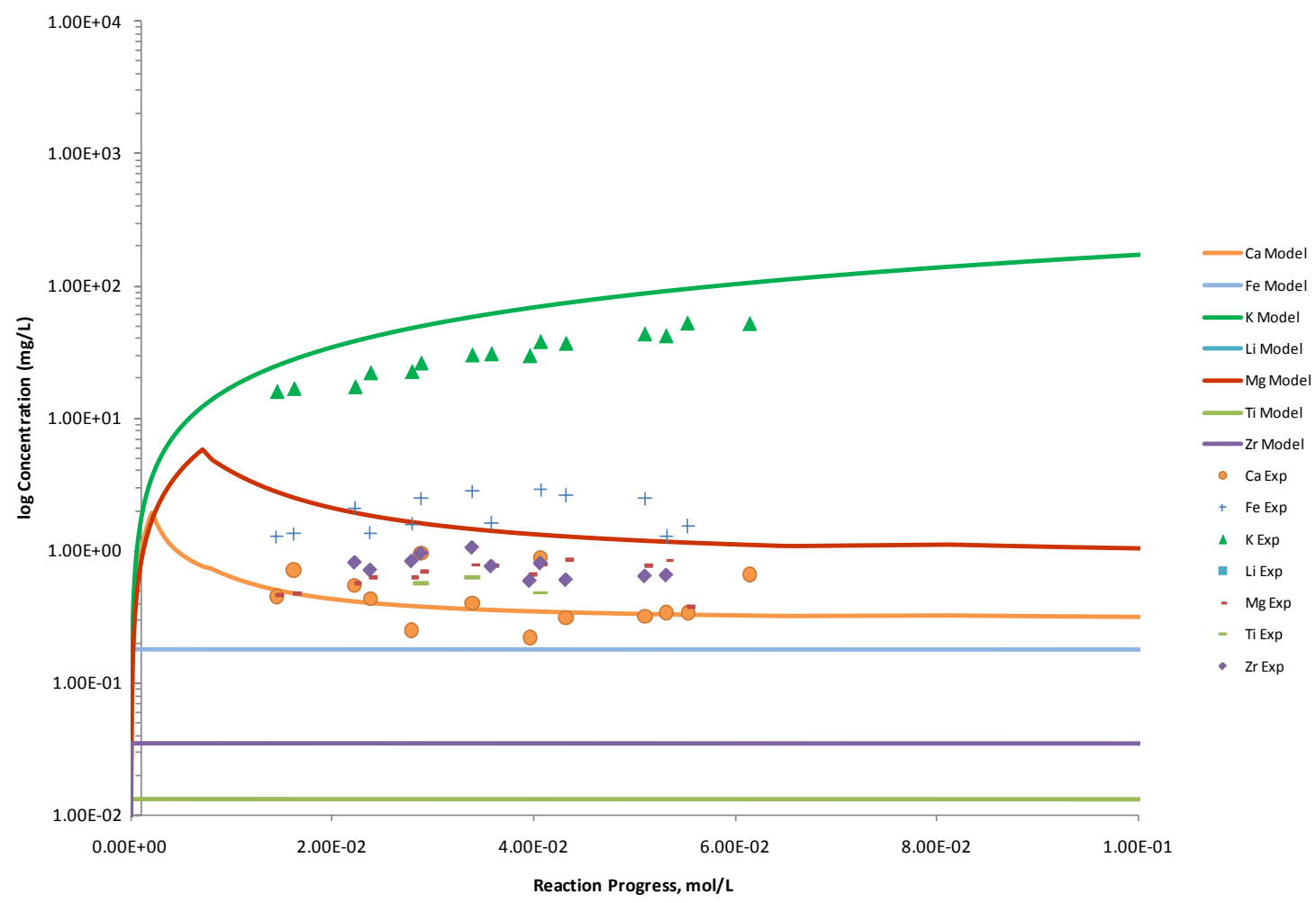

Figure C.111. Measured Solution Concentrations (mg/L) and Model Results for $\mathrm{Ca}, \mathrm{Fe}, \mathrm{K}, \mathrm{Li}, \mathrm{Mg}$, Ti, and $\mathrm{Zr}$, as a Function of Reaction Progress (mol-glass/kg) Determined for Glass Sample LAWA41

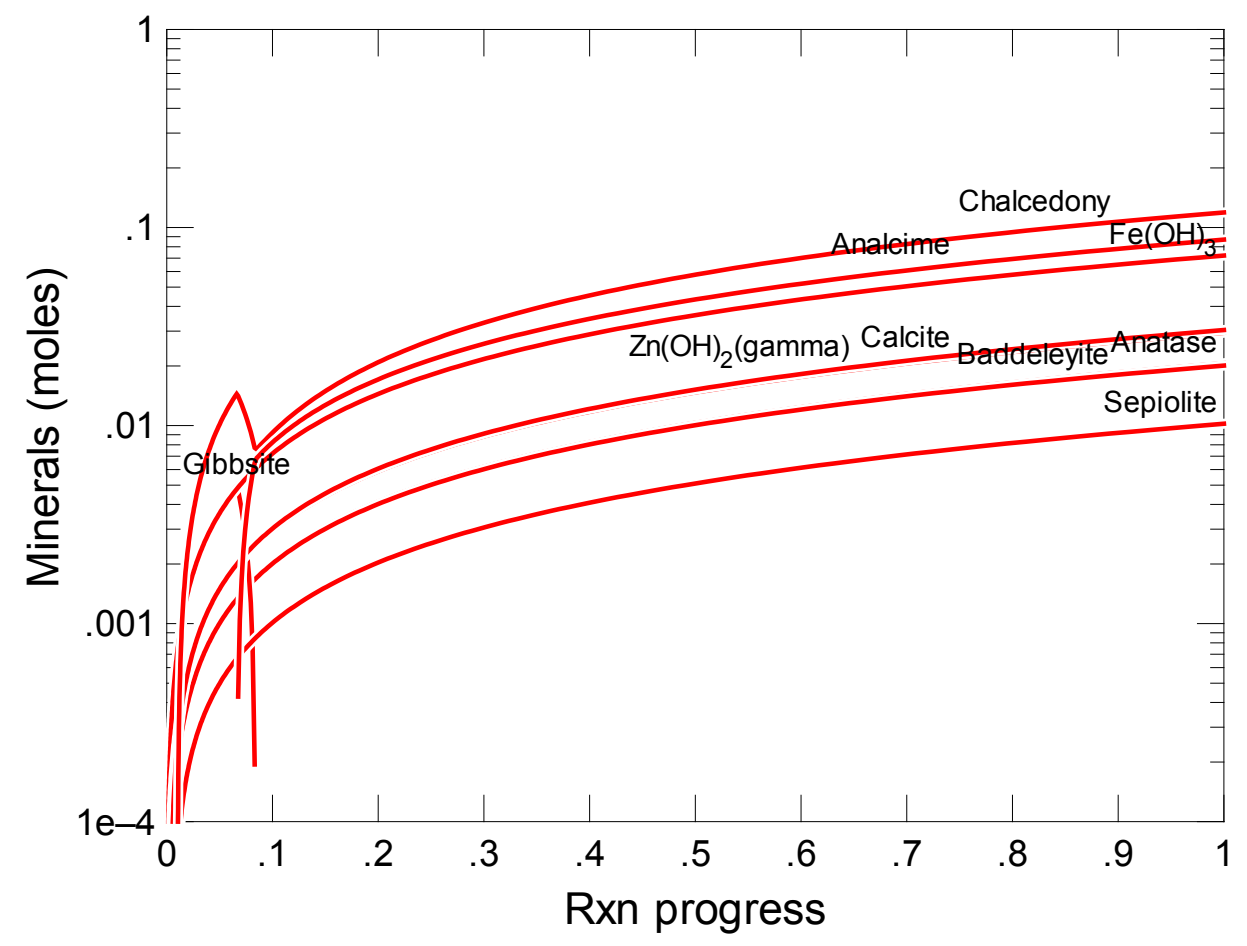

Figure C.112. Secondary Phases Calculated to Form as a Function of Reaction Progress (mol-glass/kg) Determined for Glass Sample LAWA42 


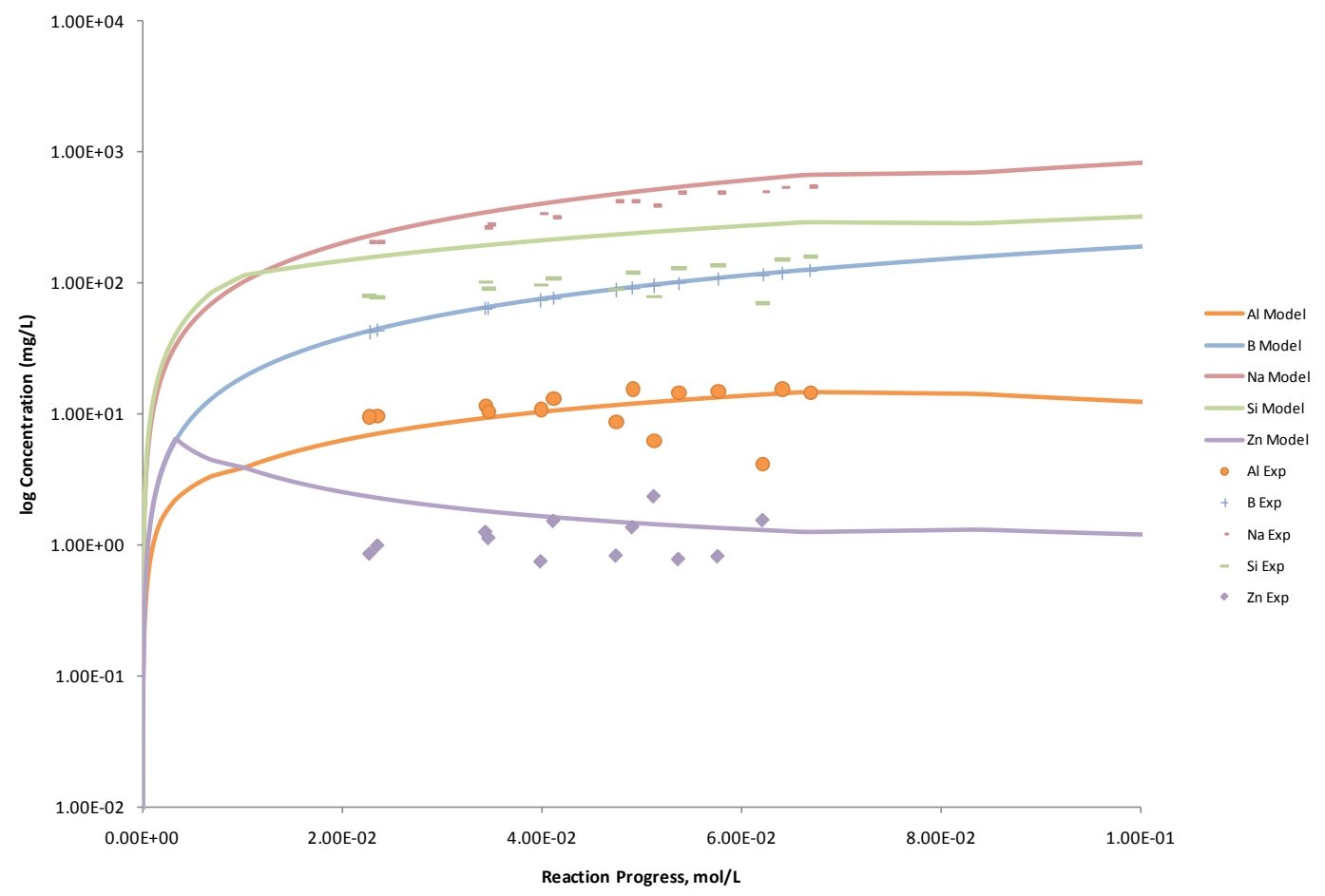

Figure C.113. Measured Solution Concentrations (mg/L) and Model Results for Al, B, Na, Si, and Zn, as a Function of Reaction Progress (mol-glass $/ \mathrm{kg}$ ) Determined for Glass Sample LAWA42

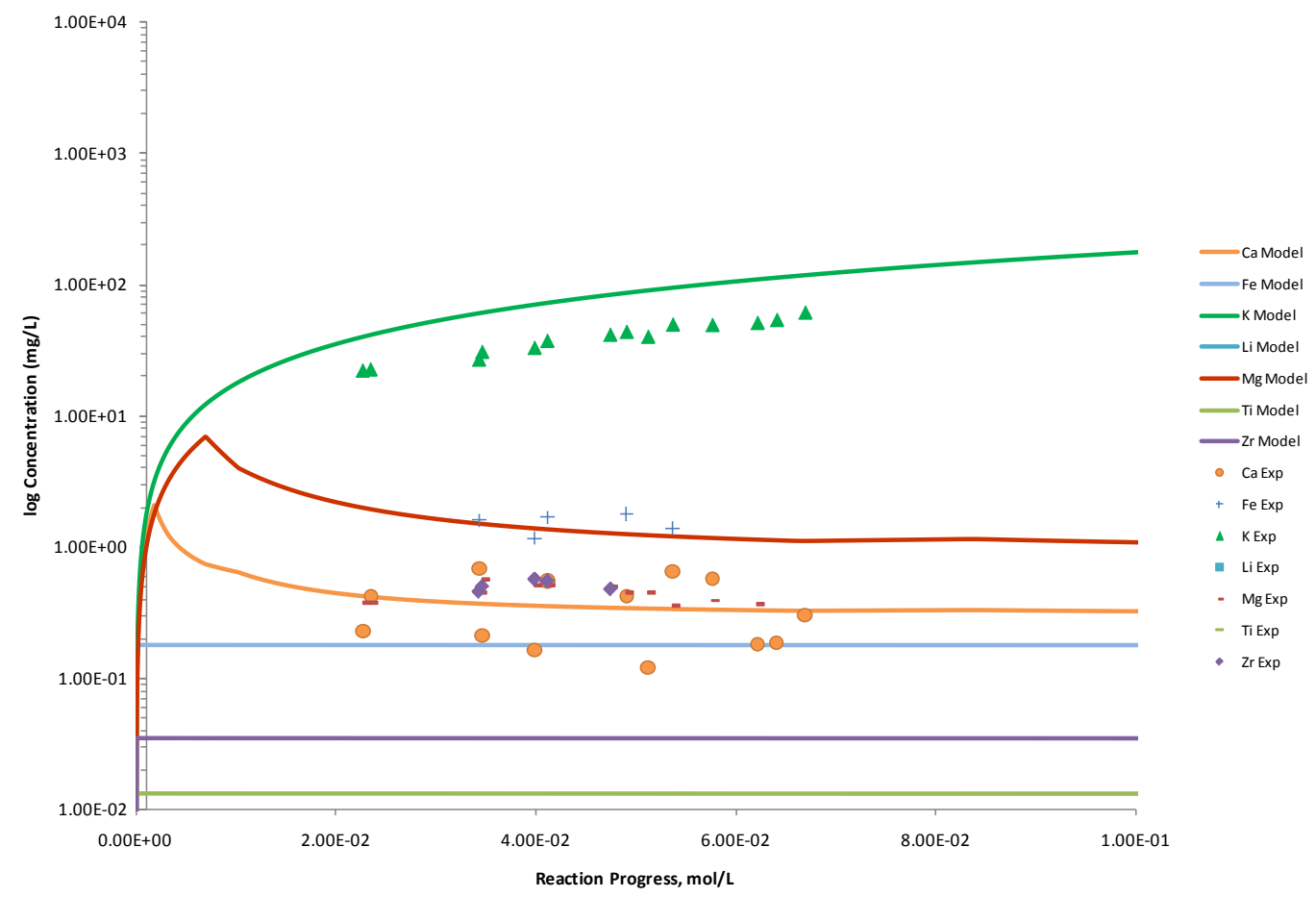

Figure C.114. Measured Solution Concentrations (mg/L) and Model Results for $\mathrm{Ca}, \mathrm{Fe}, \mathrm{K}, \mathrm{Li}, \mathrm{Mg}$, Ti, and $\mathrm{Zr}$, as a Function of Reaction Progress (mol-glass/kg) Determined for Glass Sample LAWA42 


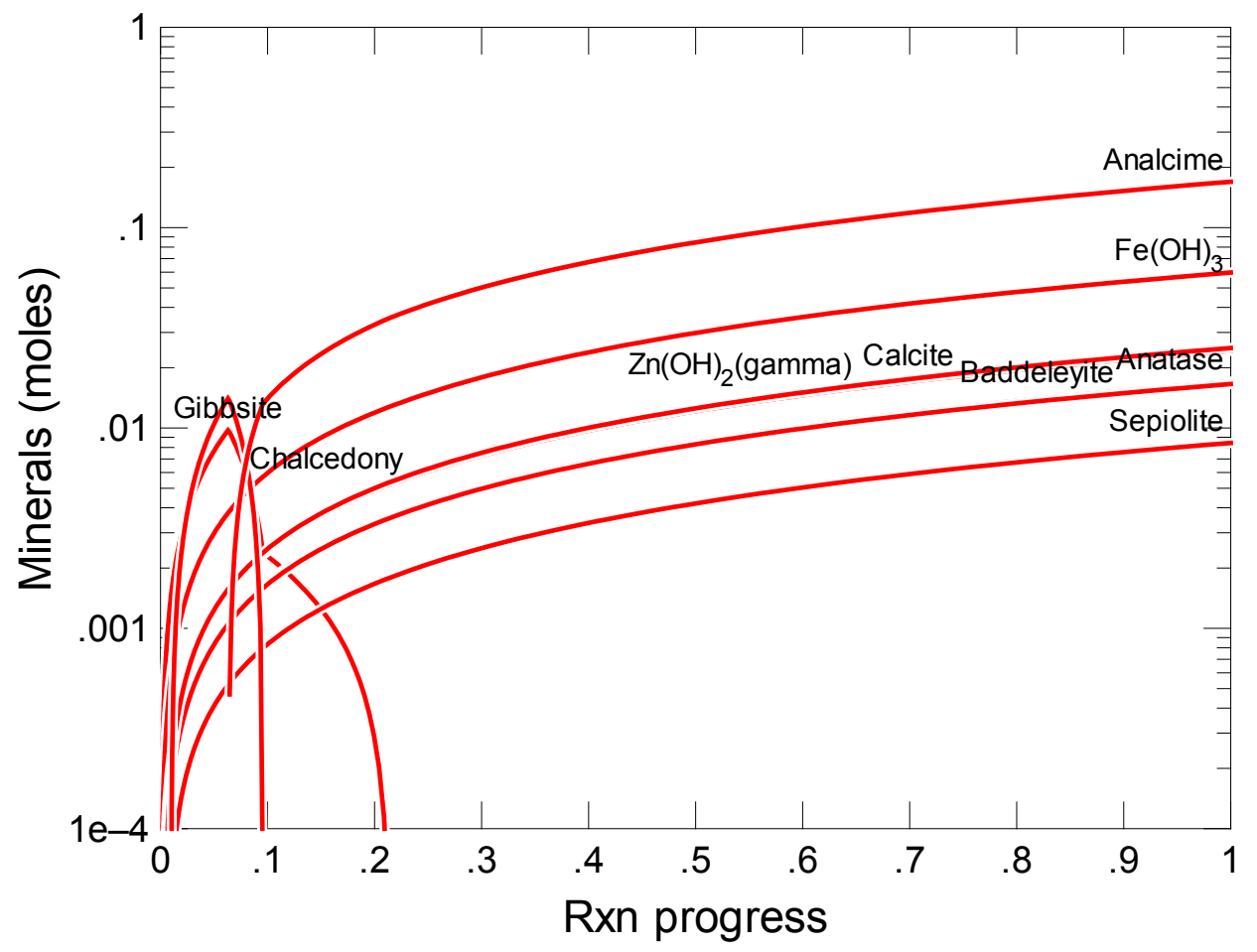

Figure C.115. Secondary Phases Calculated to Form as a Function of Reaction Progress (mol-glass $/ \mathrm{kg}$ ) Determined for Glass Sample LAWA43-1

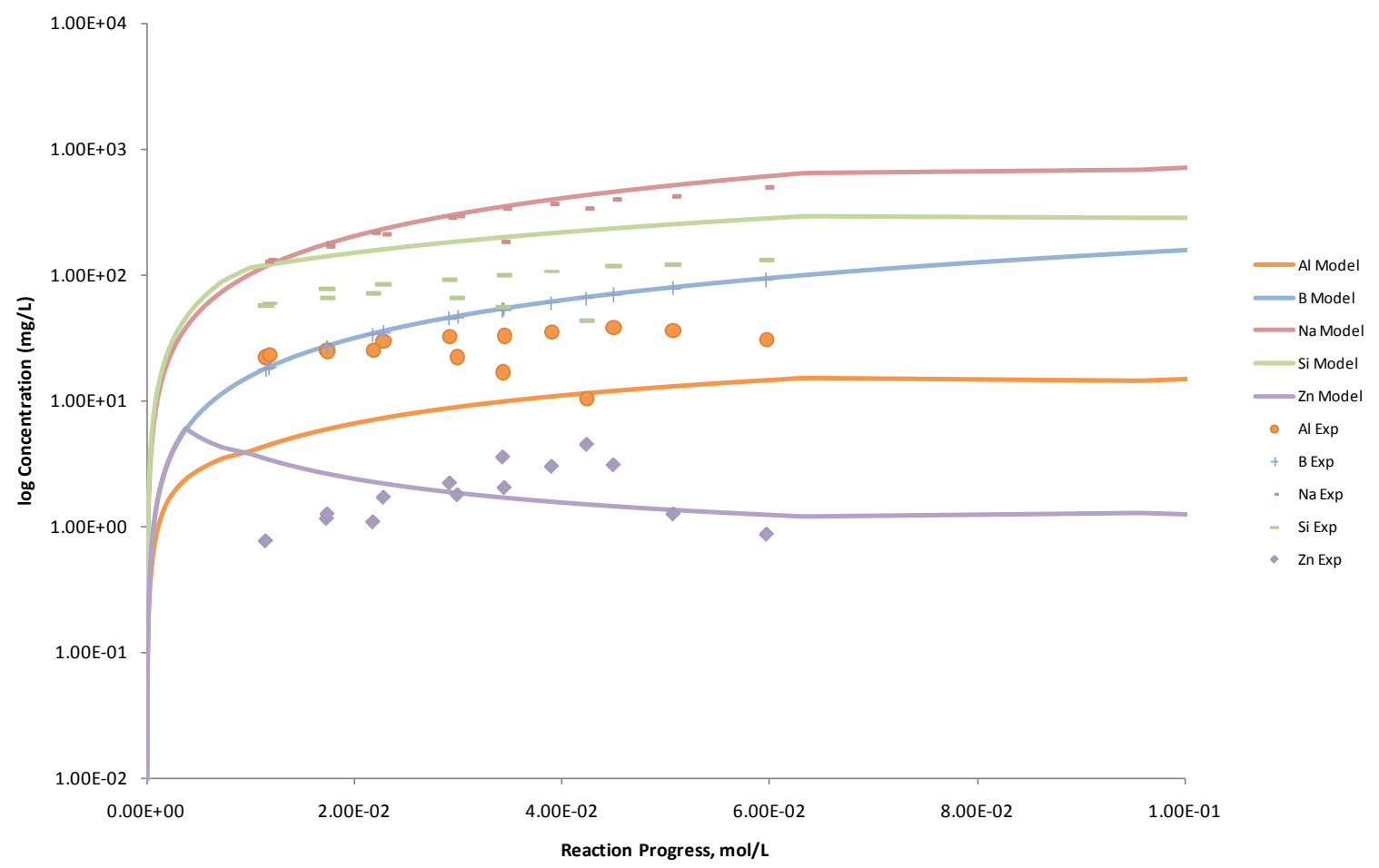

Figure C.116. Measured Solution Concentrations (mg/L) and Model Results for Al, B, Na, Si, and Zn, as a Function of Reaction Progress (mol-glass $/ \mathrm{kg}$ ) Determined for Glass Sample LAWA43-1 


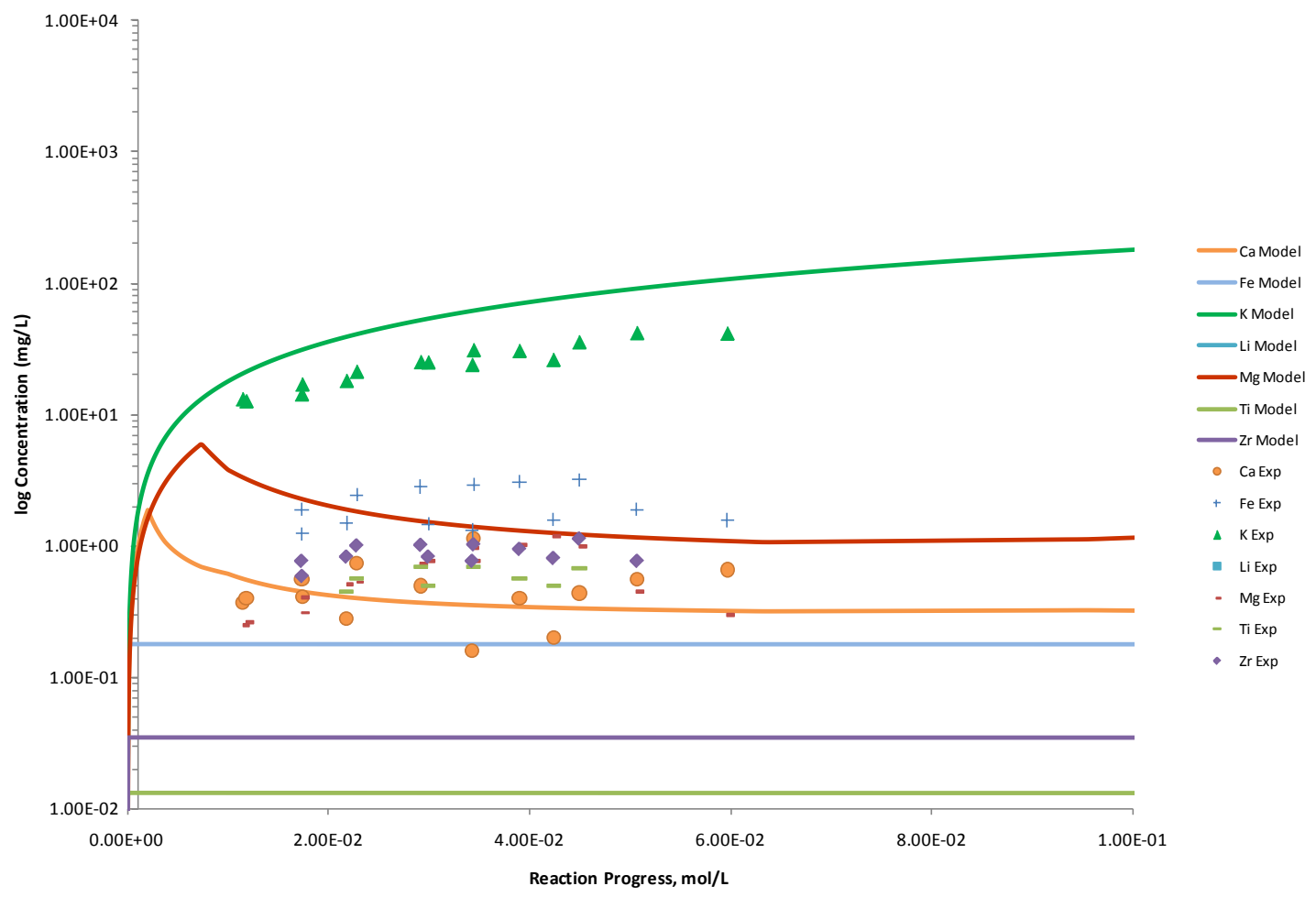

Figure C.117. Measured Solution Concentrations (mg/L) and Model Results for $\mathrm{Ca}, \mathrm{Fe}, \mathrm{K}, \mathrm{Li}, \mathrm{Mg}$, Ti, and $\mathrm{Zr}$, as a Function of Reaction Progress (mol-glass/kg) Determined for Glass Sample LAWA43-1

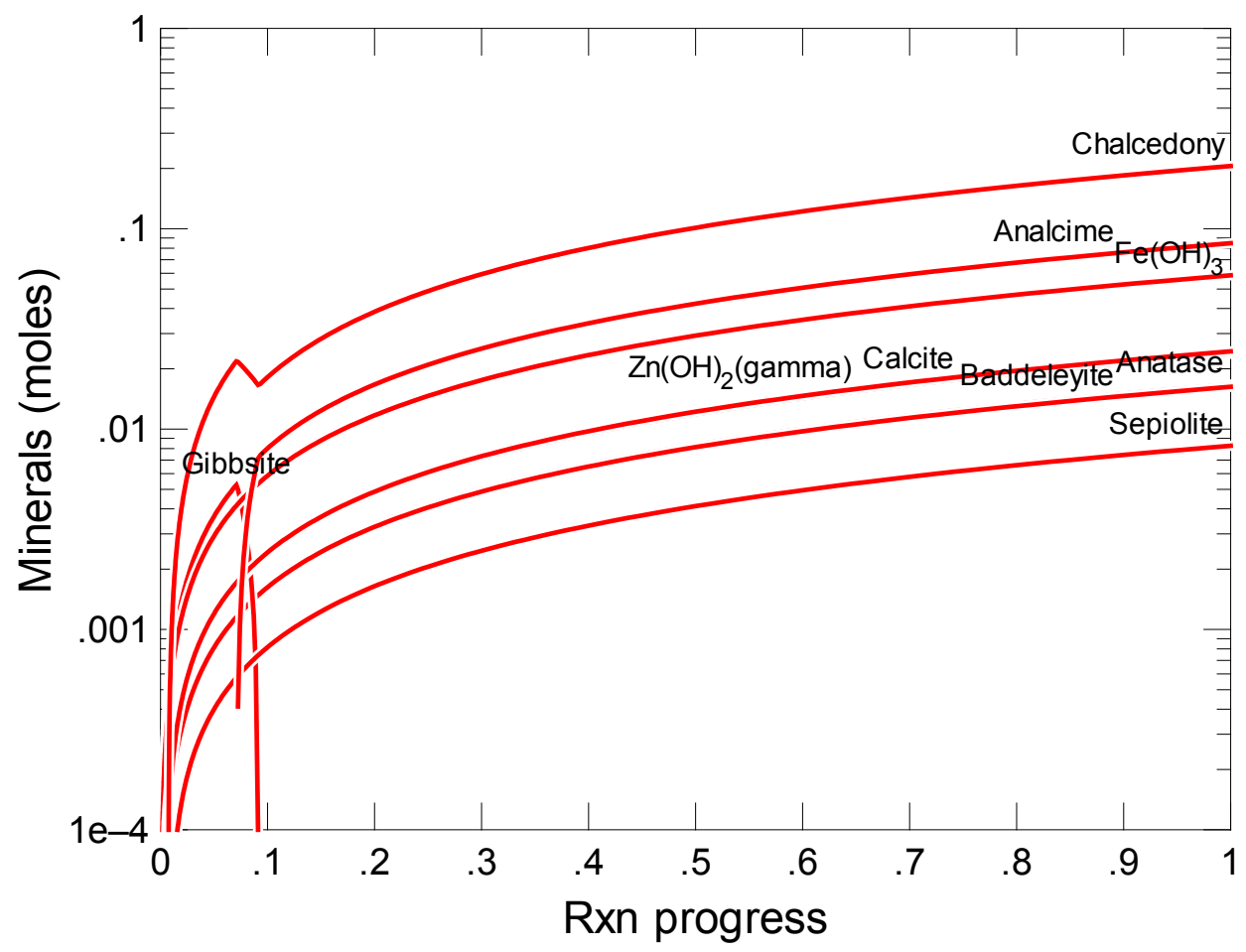

Figure C.118. Secondary Phases Calculated to Form as a Function of Reaction Progress (mol-glass $/ \mathrm{kg}$ ) Determined for Glass Sample LAWA44 


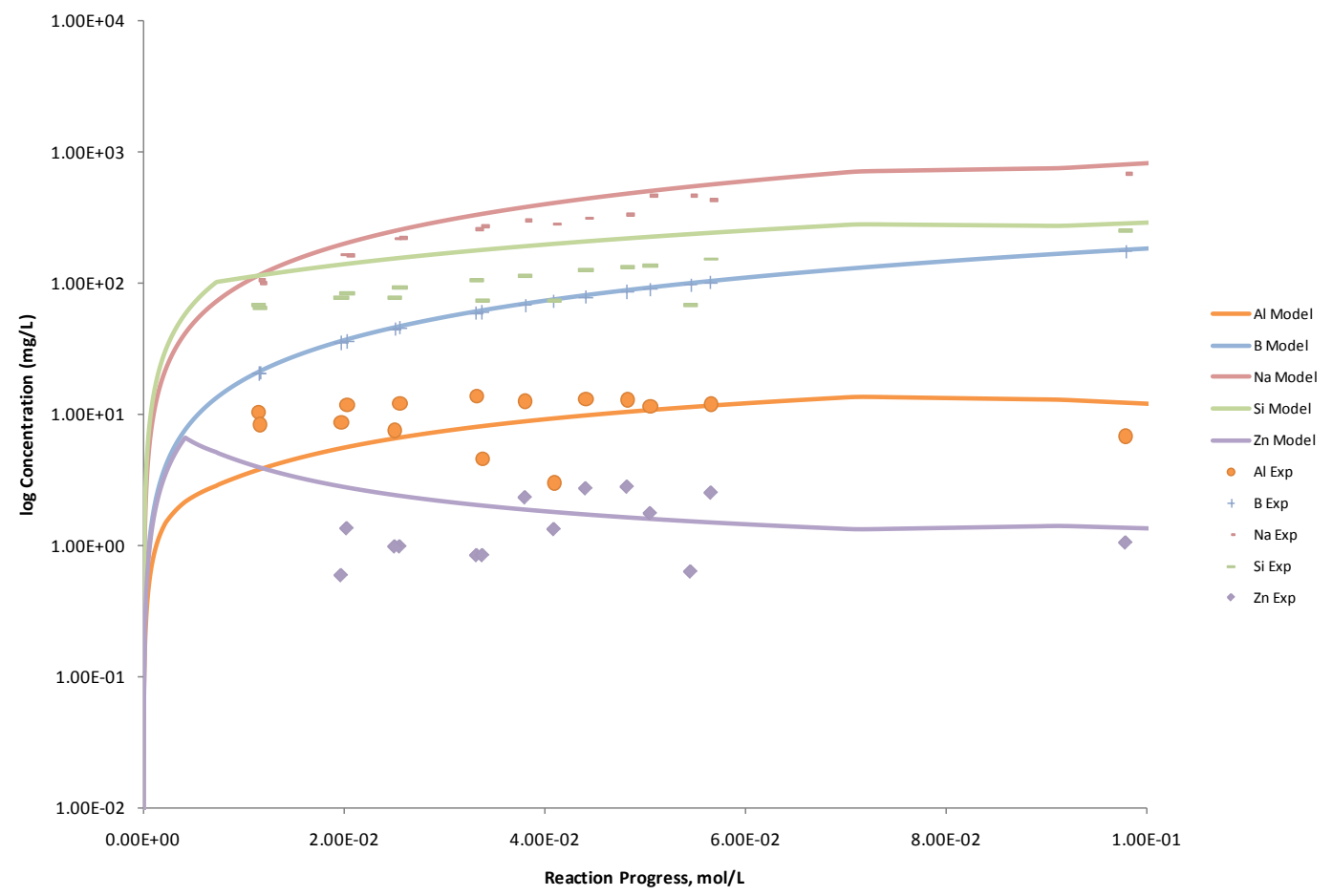

Figure C.119. Measured Solution Concentrations (mg/L) and Model Results for $\mathrm{Al}, \mathrm{B}, \mathrm{Na}$, Si, and $\mathrm{Zn}$, as a Function of Reaction Progress (mol-glass $/ \mathrm{kg}$ ) Determined for Glass Sample LAWA44

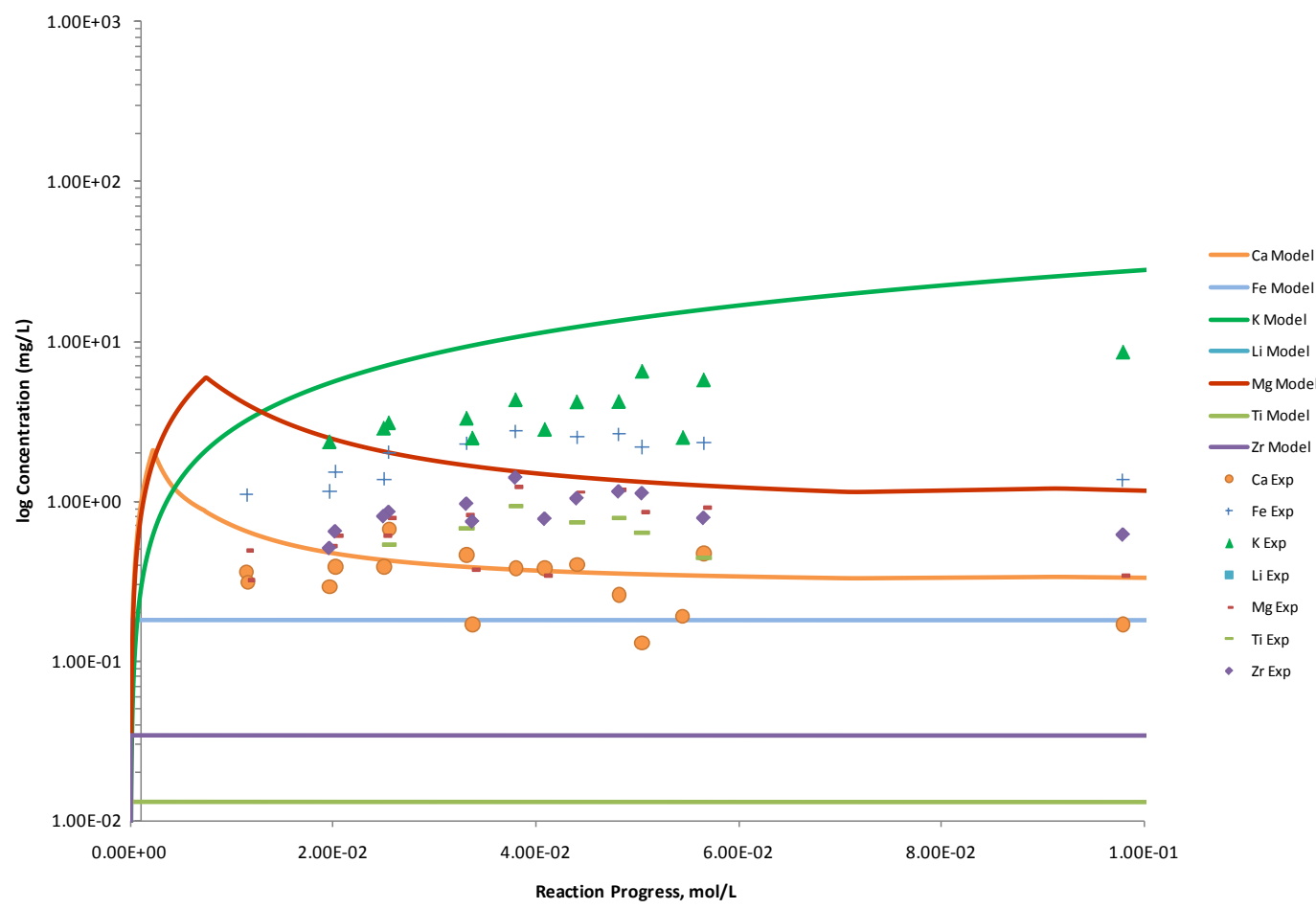

Figure C.120. Measured Solution Concentrations (mg/L) and Model Results for $\mathrm{Ca}, \mathrm{Fe}, \mathrm{K}, \mathrm{Li}, \mathrm{Mg}, \mathrm{Ti}$, and $\mathrm{Zr}$, as a Function of Reaction Progress (mol-glass/kg) Determined for Glass Sample LAWA44 


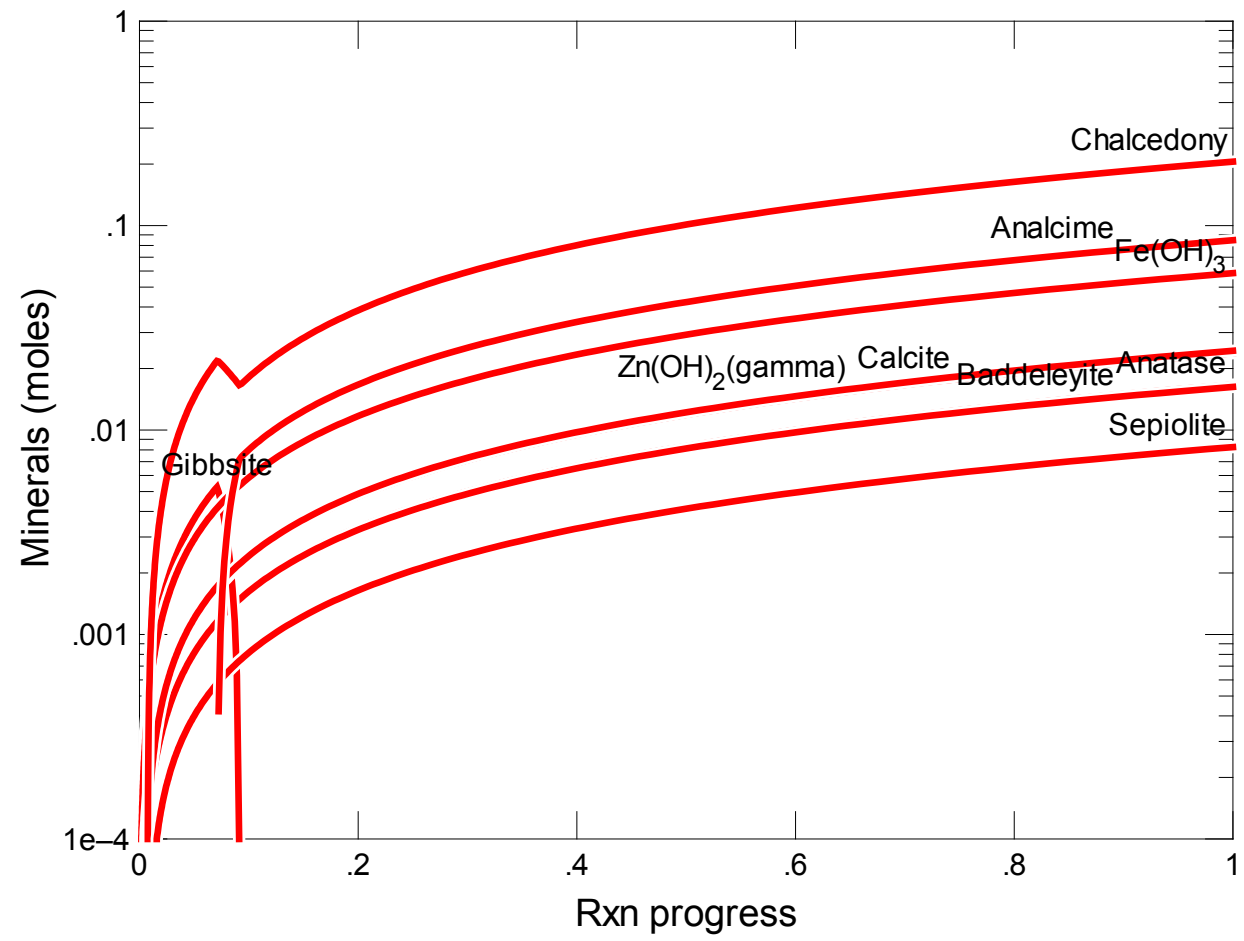

Figure C.121. Secondary Phases Calculated to Form as a Function of Reaction Progress (mol-glass $/ \mathrm{kg}$ ) Determined for Glass Sample LAWA44R10

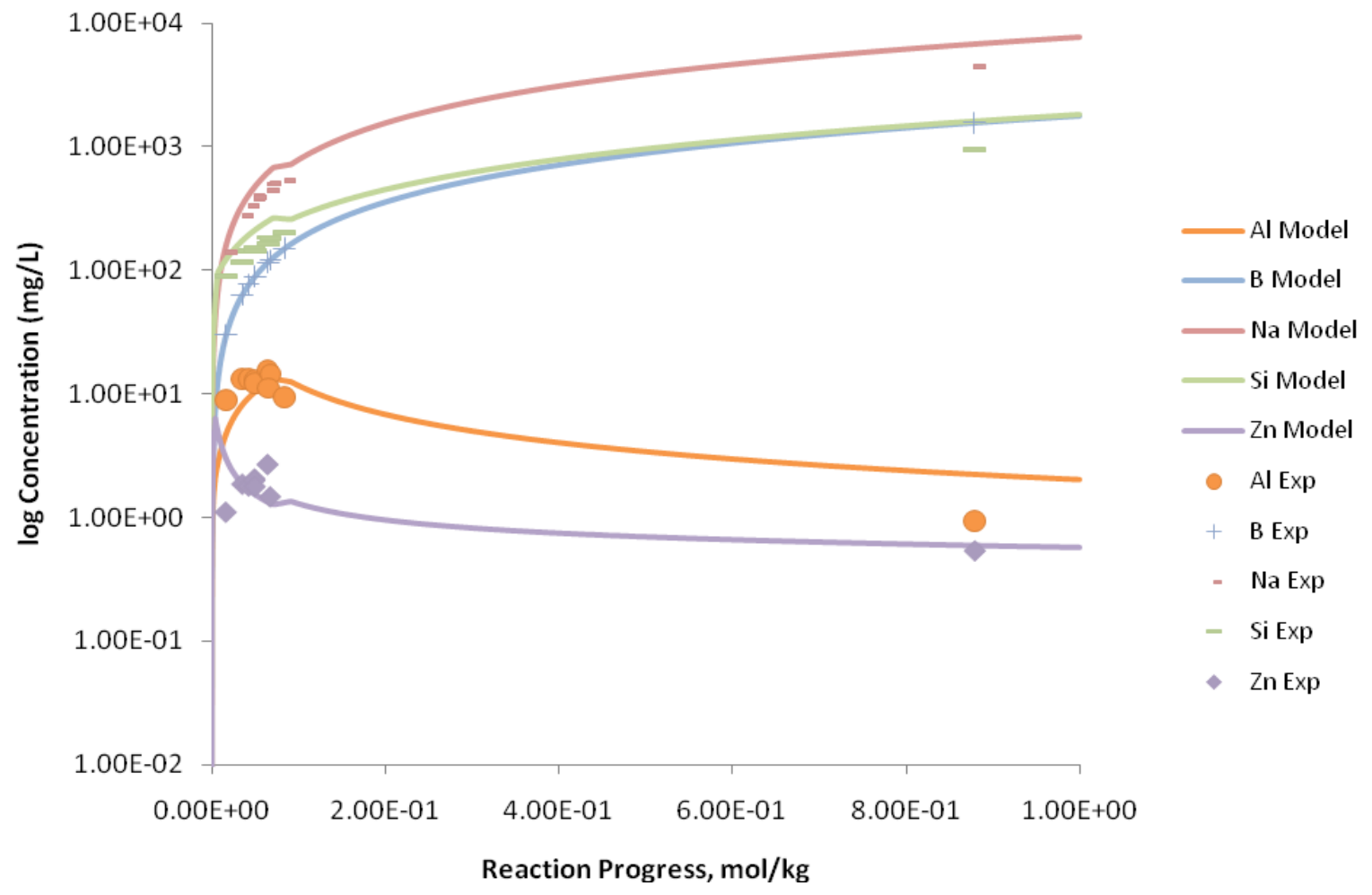

Figure C.122. Measured Solution Concentrations (mg/L) and Model Results for Al, B, Na, Si, and Zn, as a Function of Reaction Progress (mol-glass $/ \mathrm{kg}$ ) Determined for Glass Sample LAWA44R10 


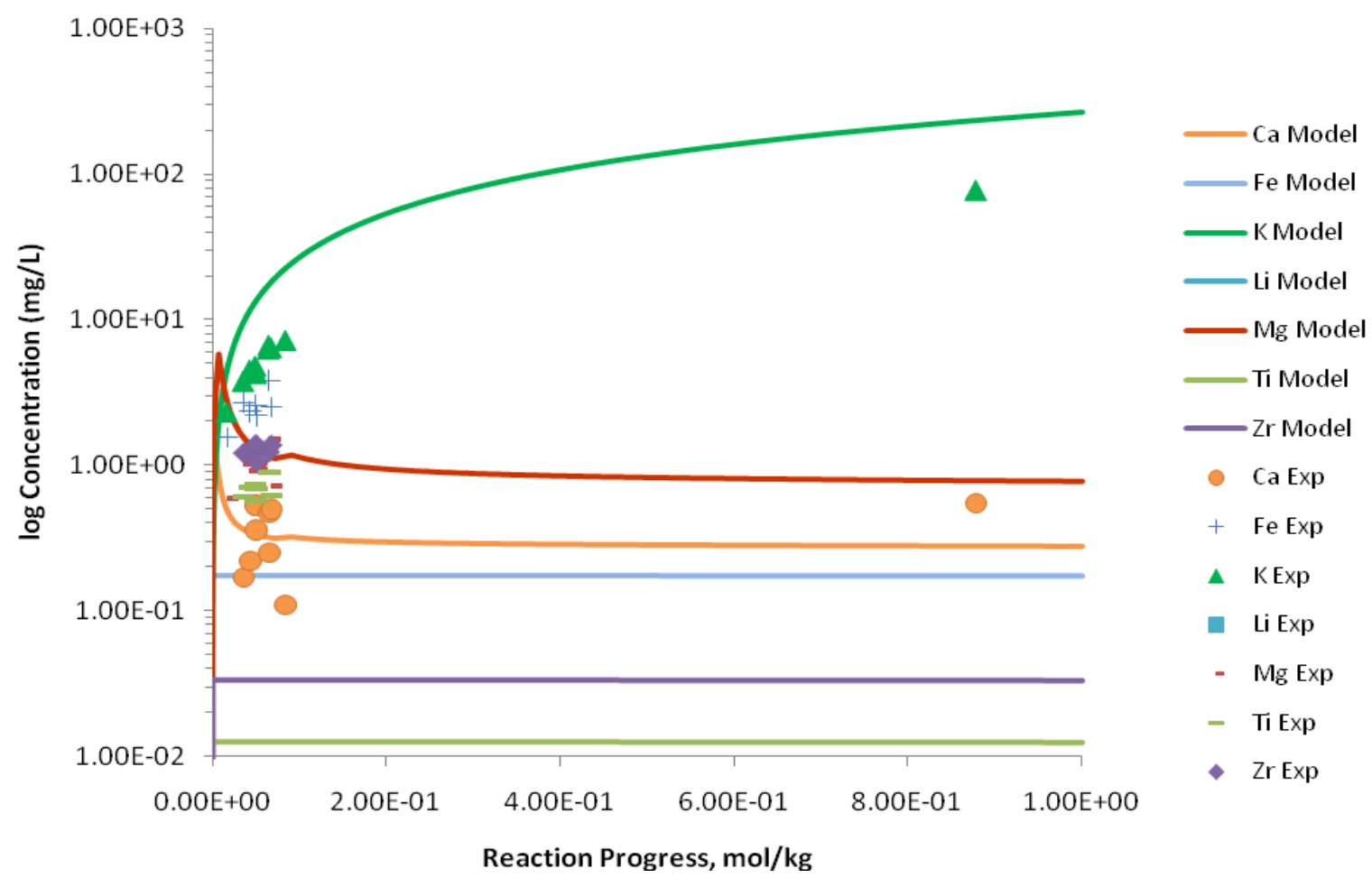

Figure C.123. Measured Solution Concentrations (mg/L) and Model Results for Ca, Fe, K, Li, Mg, Ti, and $\mathrm{Zr}$, as a Function of Reaction Progress (mol-glass/kg) Determined for Glass Sample LAWA44R10

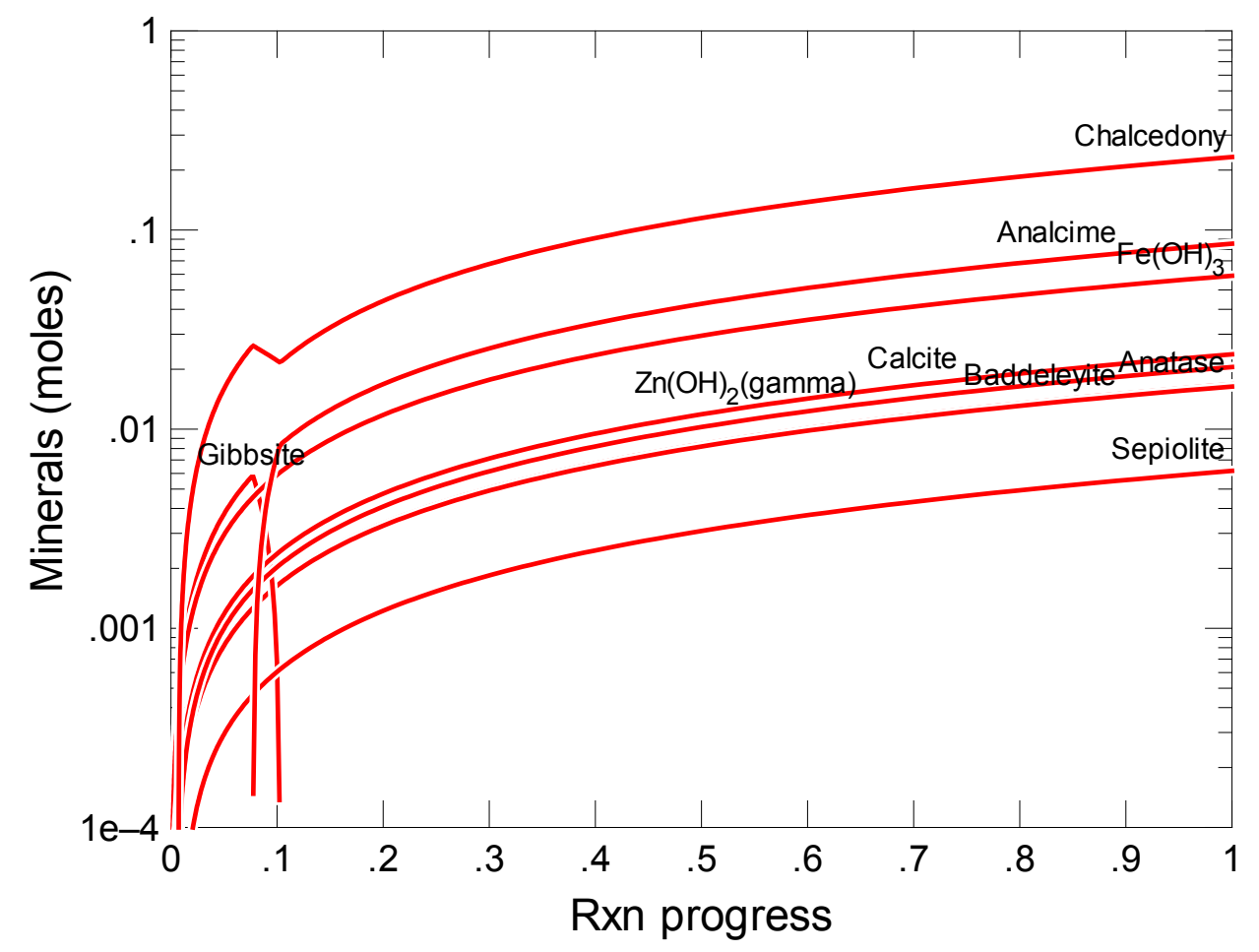

Figure C.124. Secondary Phases Calculated to Form as a Function of Reaction Progress (mol-glass $/ \mathrm{kg}$ ) Determined for Glass Sample LAWA45 


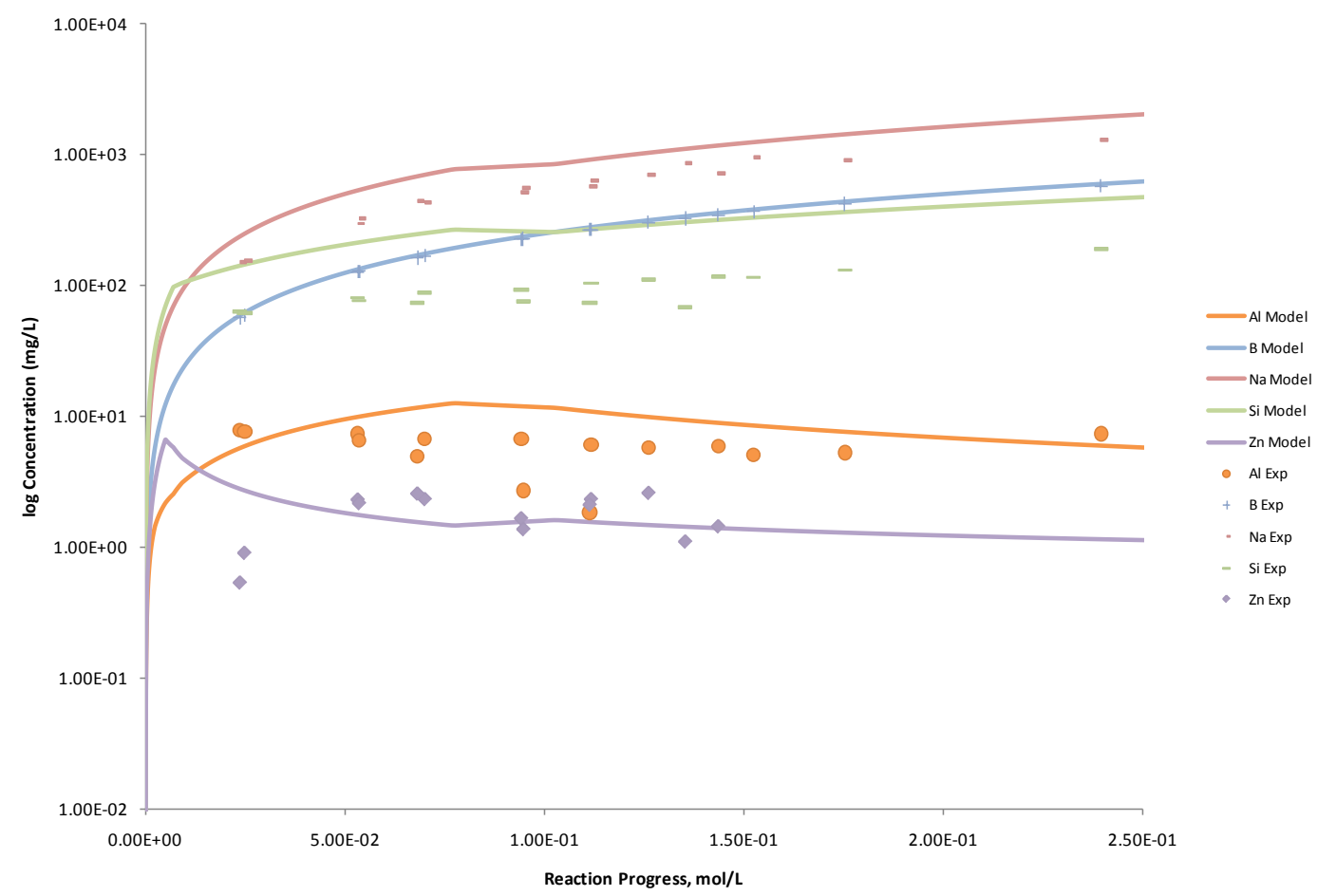

Figure C.125. Measured Solution Concentrations (mg/L) and Model Results for Al, B, Na, Si, and Zn, as a Function of Reaction Progress (mol-glass $/ \mathrm{kg}$ ) Determined for Glass Sample LAWA45

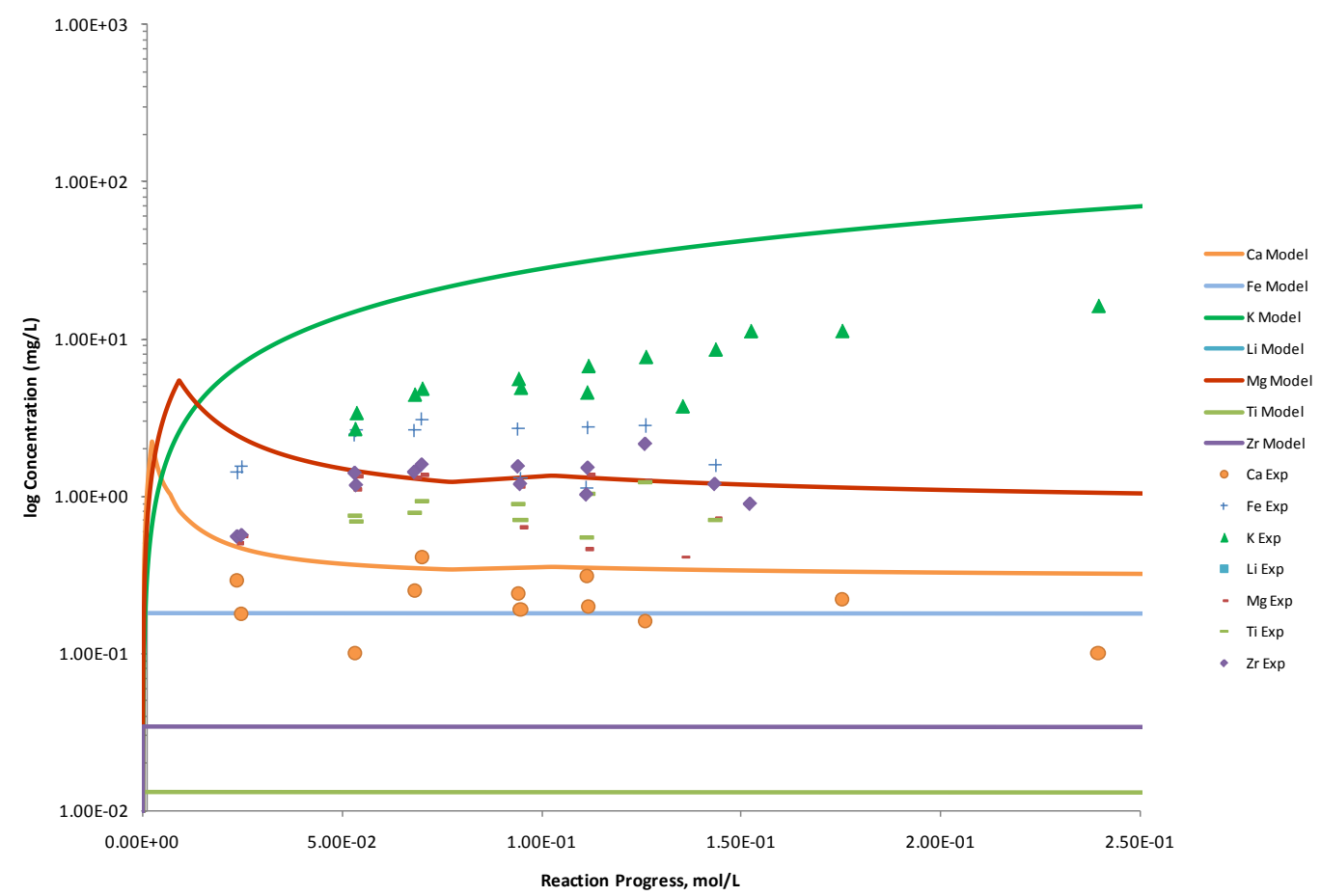

Figure C.126. Measured Solution Concentrations (mg/L) and Model Results for $\mathrm{Ca}, \mathrm{Fe}, \mathrm{K}, \mathrm{Li}, \mathrm{Mg}$, Ti, and $\mathrm{Zr}$, as a Function of Reaction Progress (mol-glass $/ \mathrm{kg}$ ) Determined for Glass Sample LAWA45 


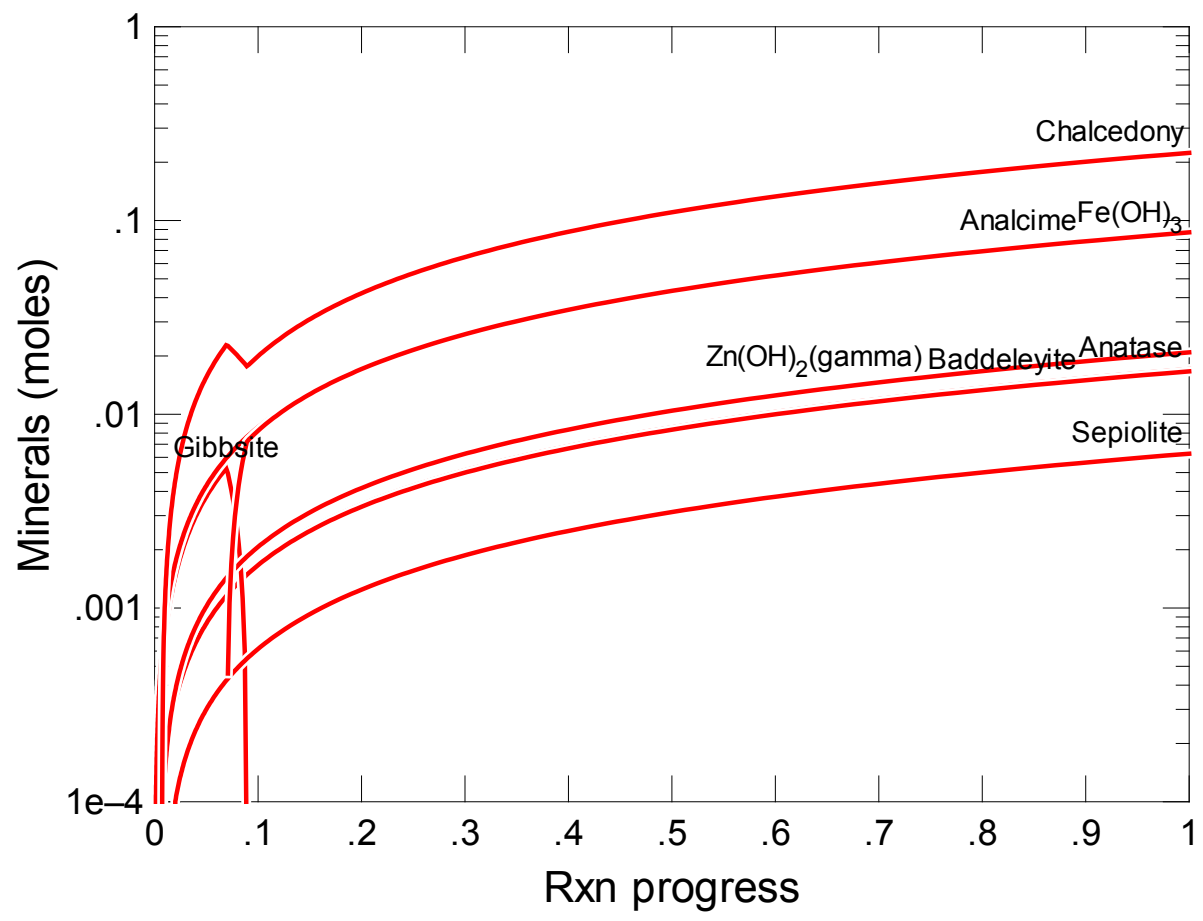

Figure C.127. Secondary Phases Calculated to Form as a Function of Reaction Progress (mol-glass/kg) Determined for Glass Sample LAWA49

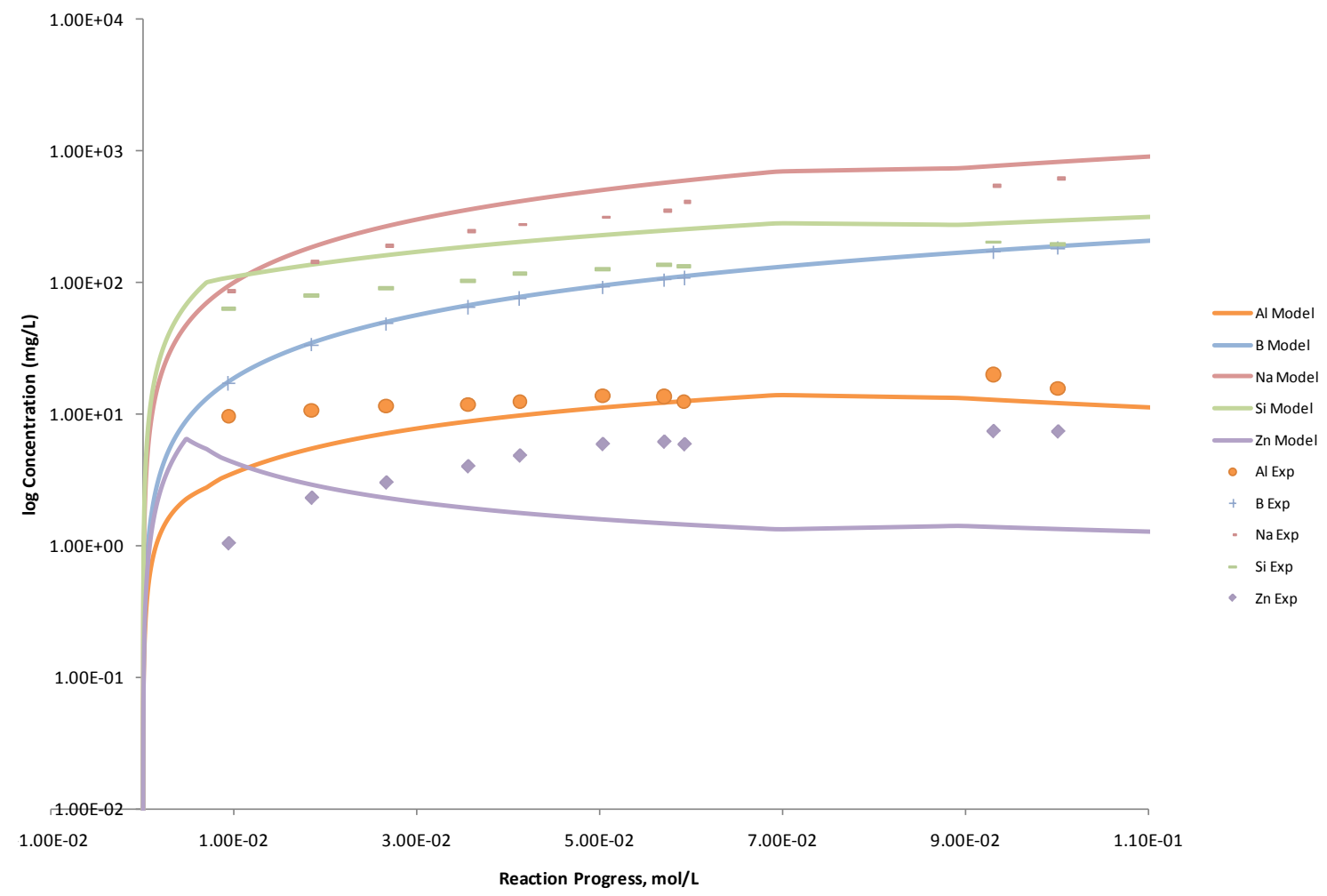

Figure C.128. Measured Solution Concentrations (mg/L) and Model Results for Al, B, Na, Si, and Zn, as a Function of Reaction Progress (mol-glass $/ \mathrm{kg}$ ) Determined for Glass Sample LAWA49 


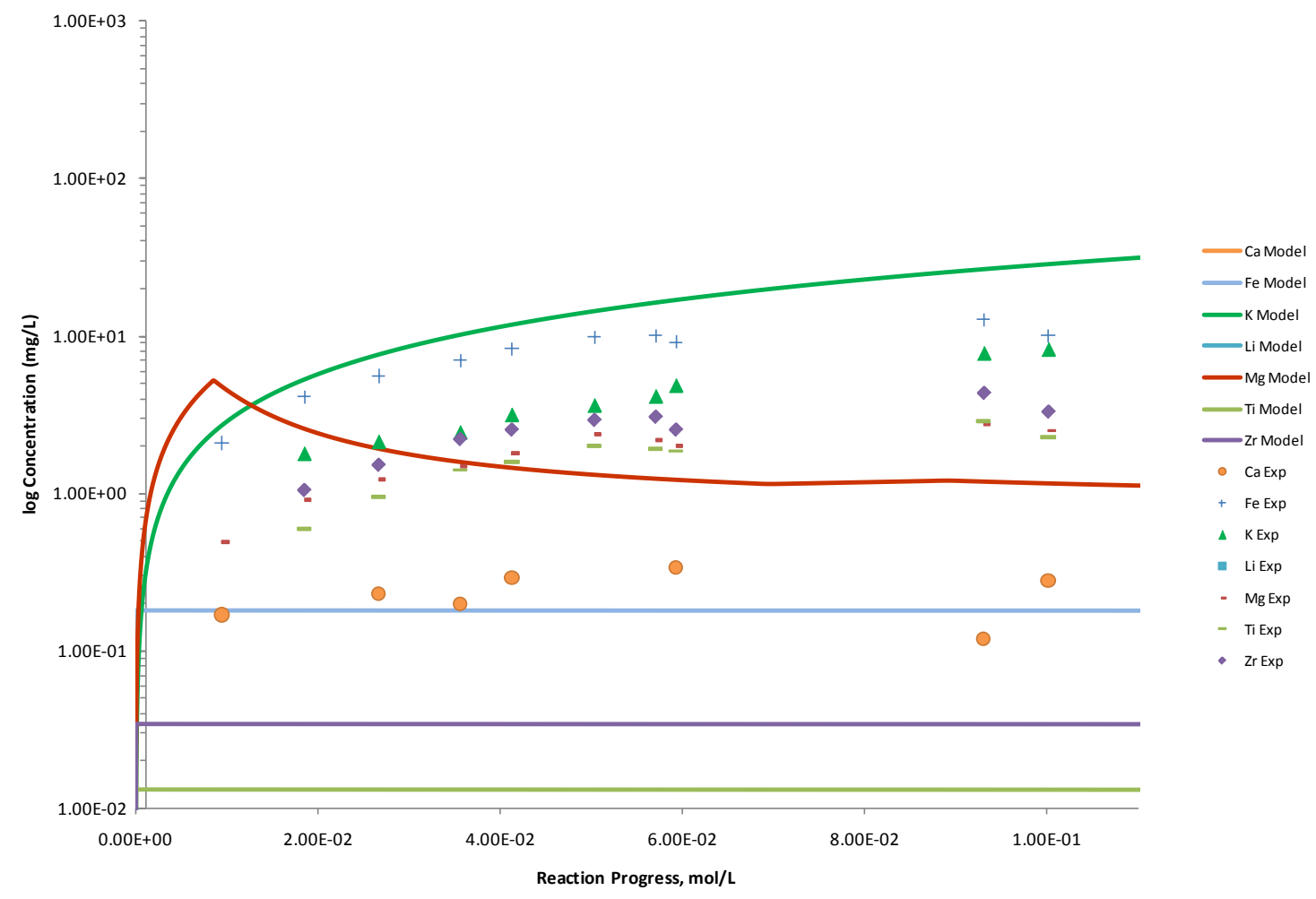

Figure C.129. Measured Solution Concentrations (mg/L) and Model Results for $\mathrm{Ca}, \mathrm{Fe}, \mathrm{K}, \mathrm{Li}, \mathrm{Mg}, \mathrm{Ti}$, and $\mathrm{Zr}$, as a Function of Reaction Progress (mol-glass/kg) Determined for Glass Sample LAWA49

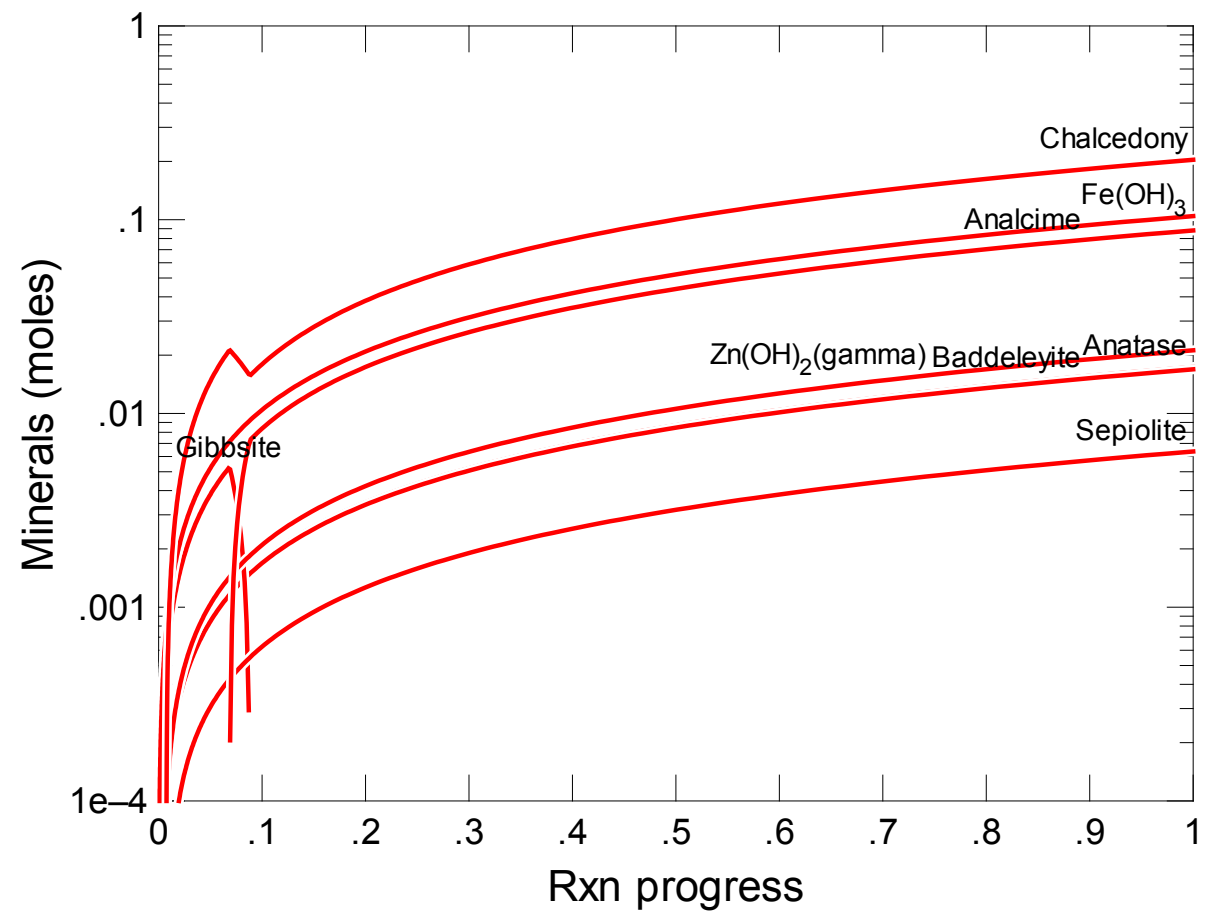

Figure C.130. Secondary Phases Calculated to Form as a Function of Reaction Progress (mol-glass $/ \mathrm{kg}$ ) Determined for Glass Sample LAWA50 


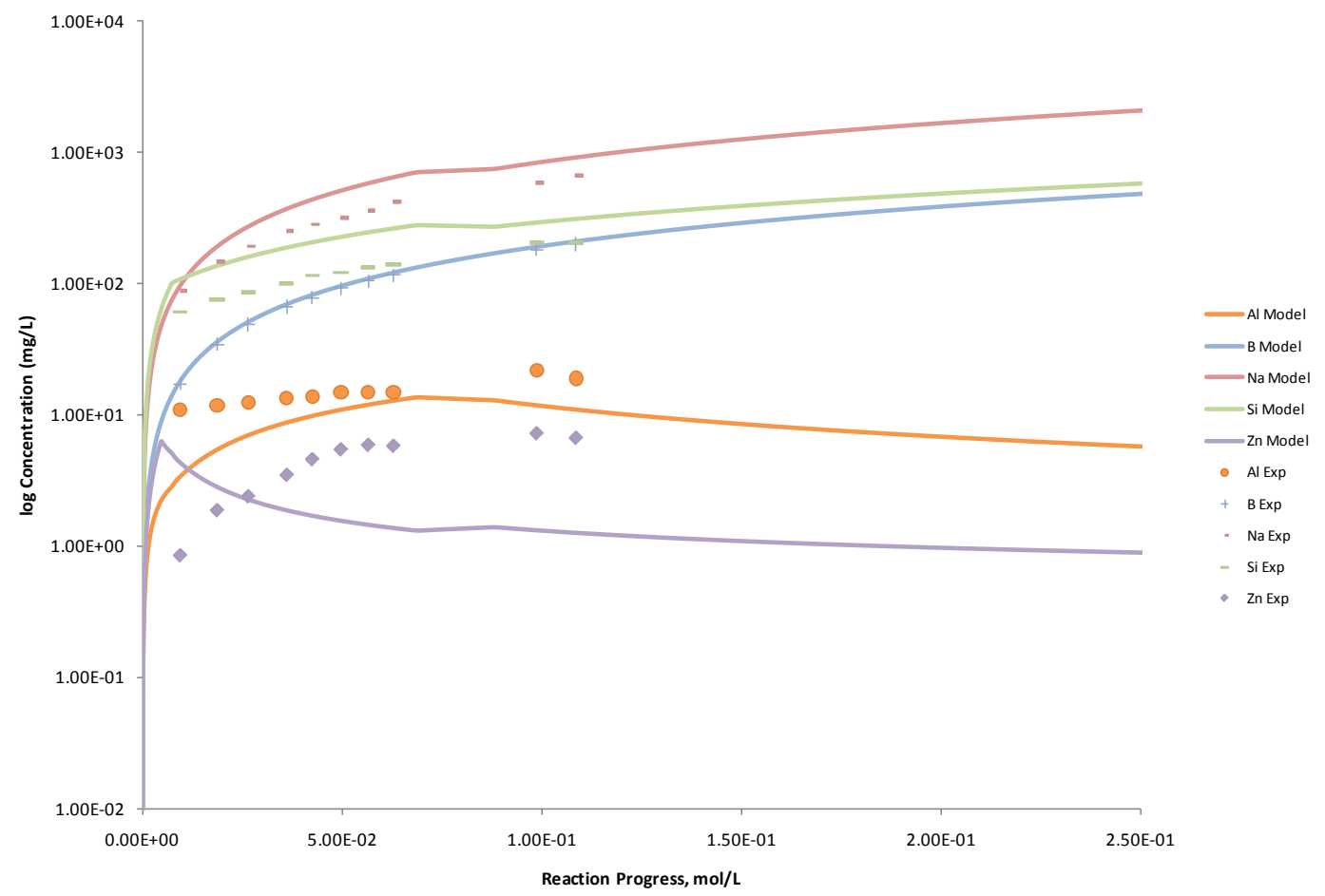

Figure C.131. Measured Solution Concentrations (mg/L) and Model Results for Al, B, Na, Si, and Zn, as a Function of Reaction Progress (mol-glass $/ \mathrm{kg}$ ) Determined for Glass Sample LAWA50

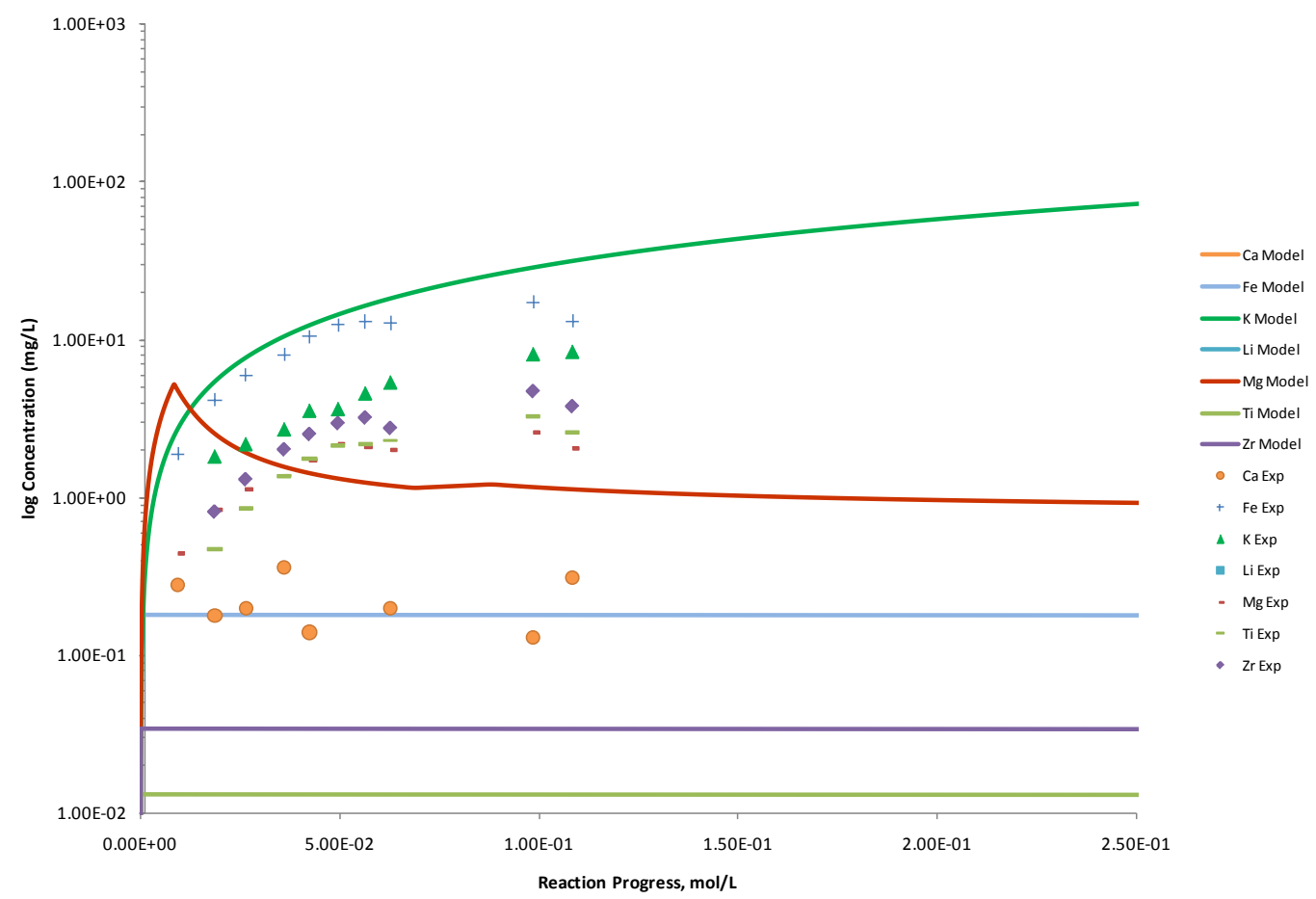

Figure C.132. Measured Solution Concentrations (mg/L) and Model Results for $\mathrm{Ca}, \mathrm{Fe}, \mathrm{K}, \mathrm{Li}, \mathrm{Mg}, \mathrm{Ti}$, and Zr, as a Function of Reaction Progress (mol-glass/kg) Determined for Glass Sample LAWA50 


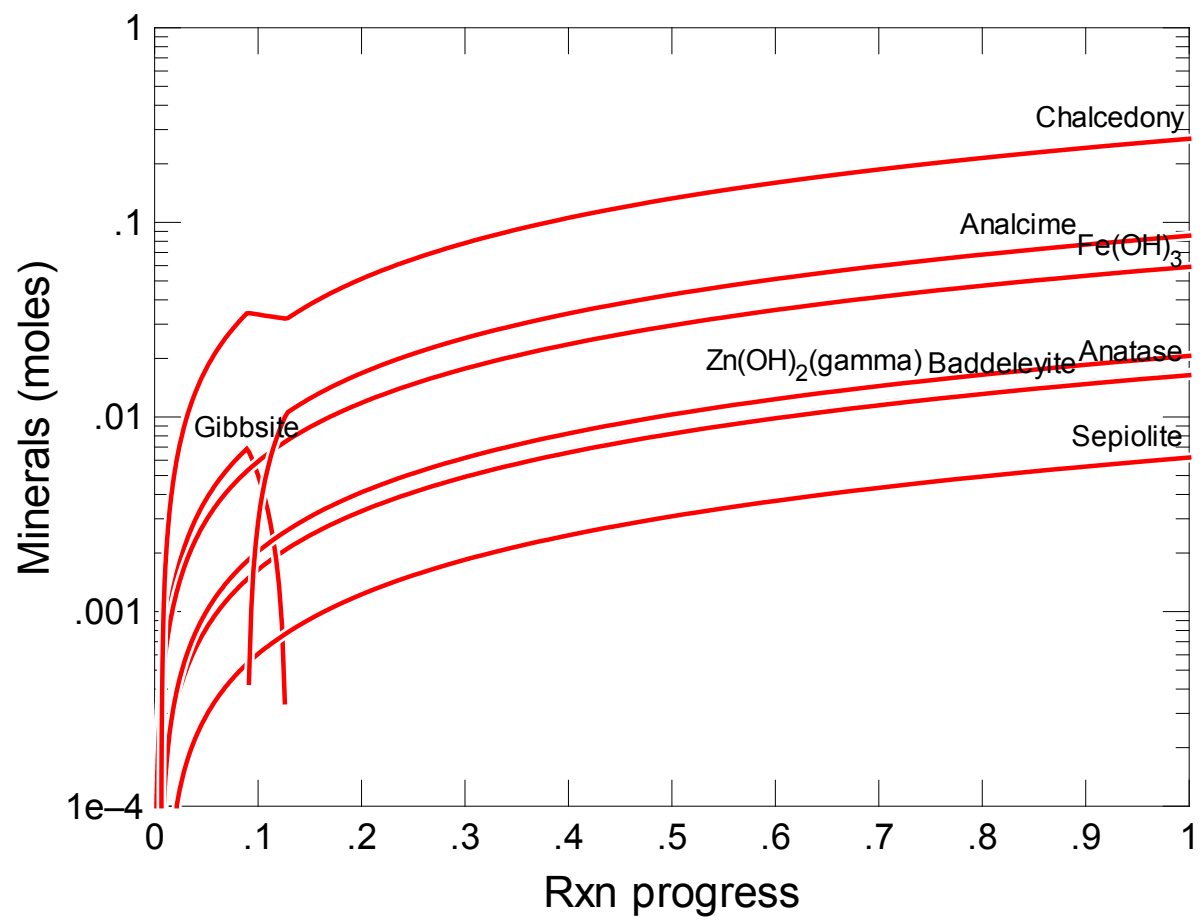

Figure C.133. Secondary Phases Calculated to Form as a Function of Reaction Progress (mol-glass/kg) Determined for Glass Sample LAWA51

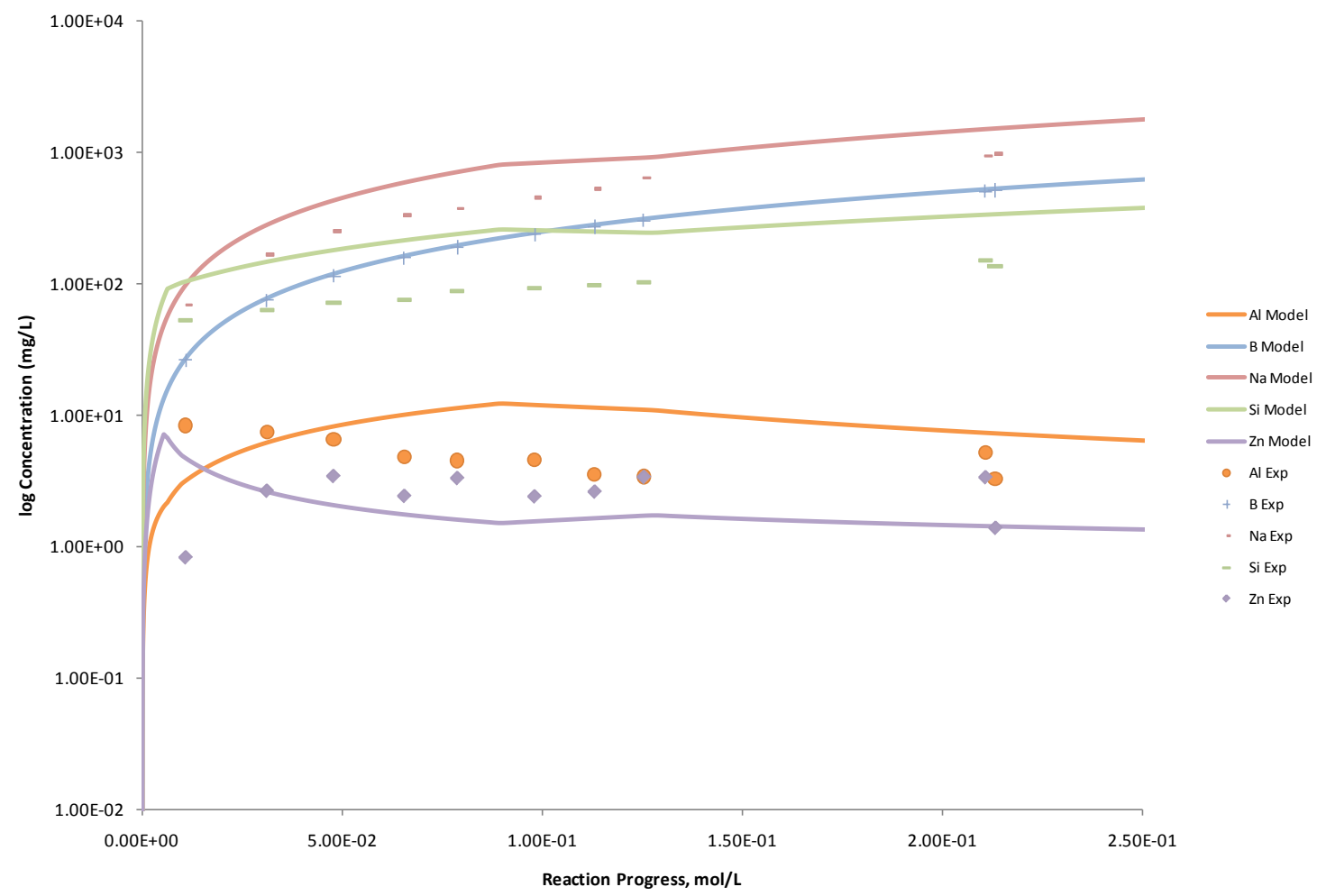

Figure C.134. Measured Solution Concentrations (mg/L) and Model Results for Al, B, Na, Si, and Zn, as a Function of Reaction Progress (mol-glass $/ \mathrm{kg}$ ) Determined for Glass Sample LAWA51 


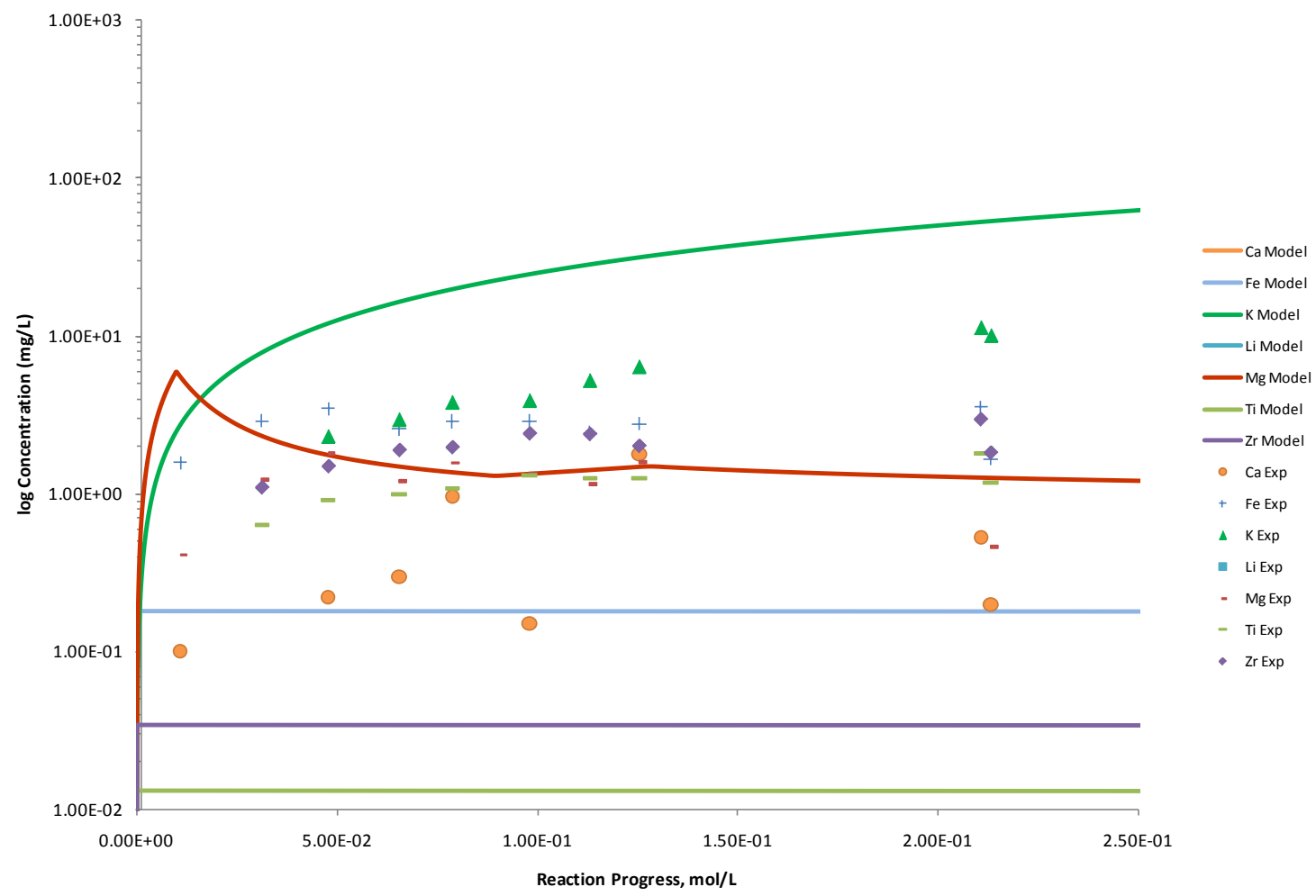

Figure C.135. Measured Solution Concentrations (mg/L) and Model Results for $\mathrm{Ca}, \mathrm{Fe}, \mathrm{K}, \mathrm{Li}, \mathrm{Mg}, \mathrm{Ti}$, and $\mathrm{Zr}$, as a Function of Reaction Progress (mol-glass/kg) Determined for Glass Sample LAWA51

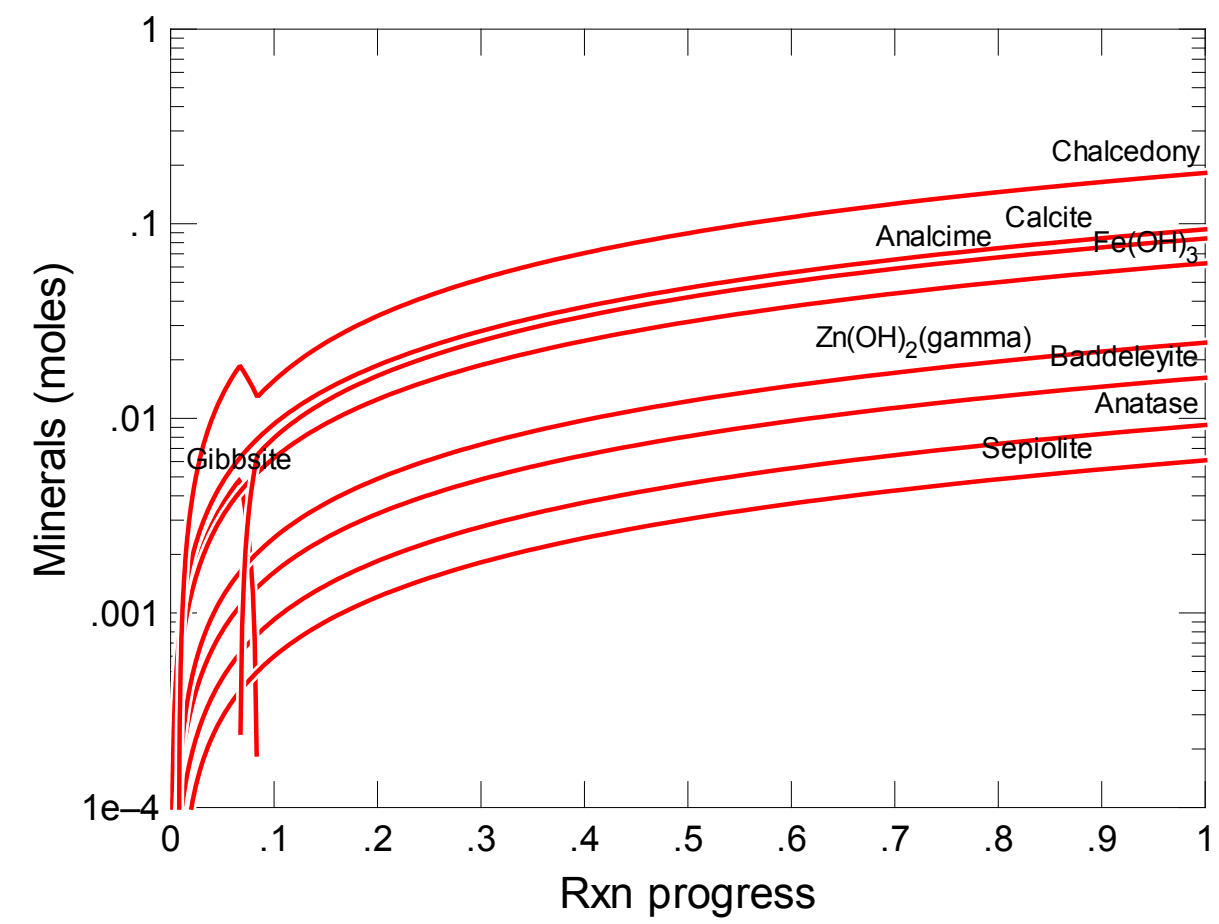

Figure C.136. Secondary Phases Calculated to Form as a Function of Reaction Progress (mol-glass/kg) Determined for Glass Sample LAWA52 


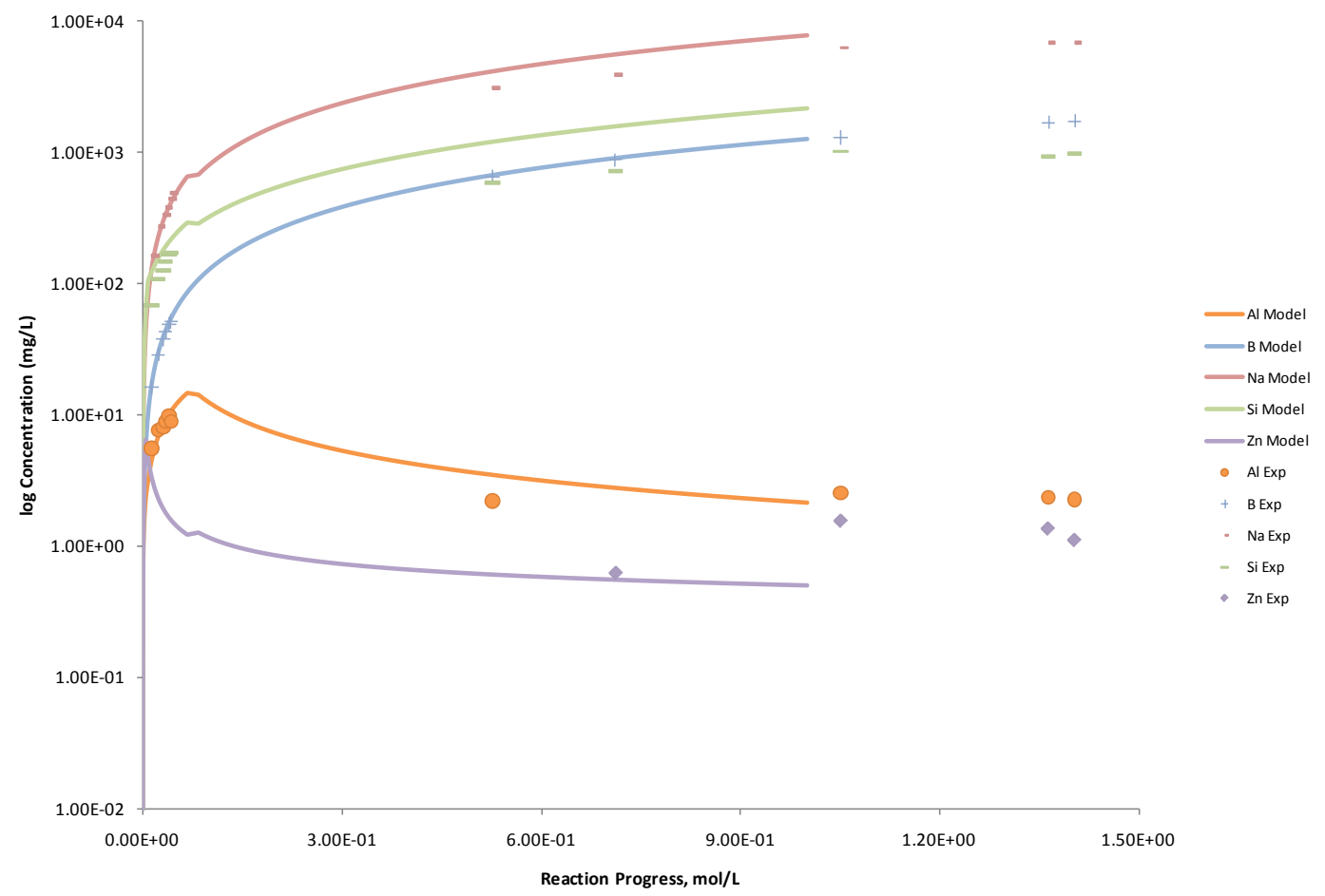

Figure C.137. Measured Solution Concentrations (mg/L) and Model Results for Al, B, Na, Si, and Zn, as a Function of Reaction Progress (mol-glass $/ \mathrm{kg}$ ) Determined for Glass Sample LAWA52

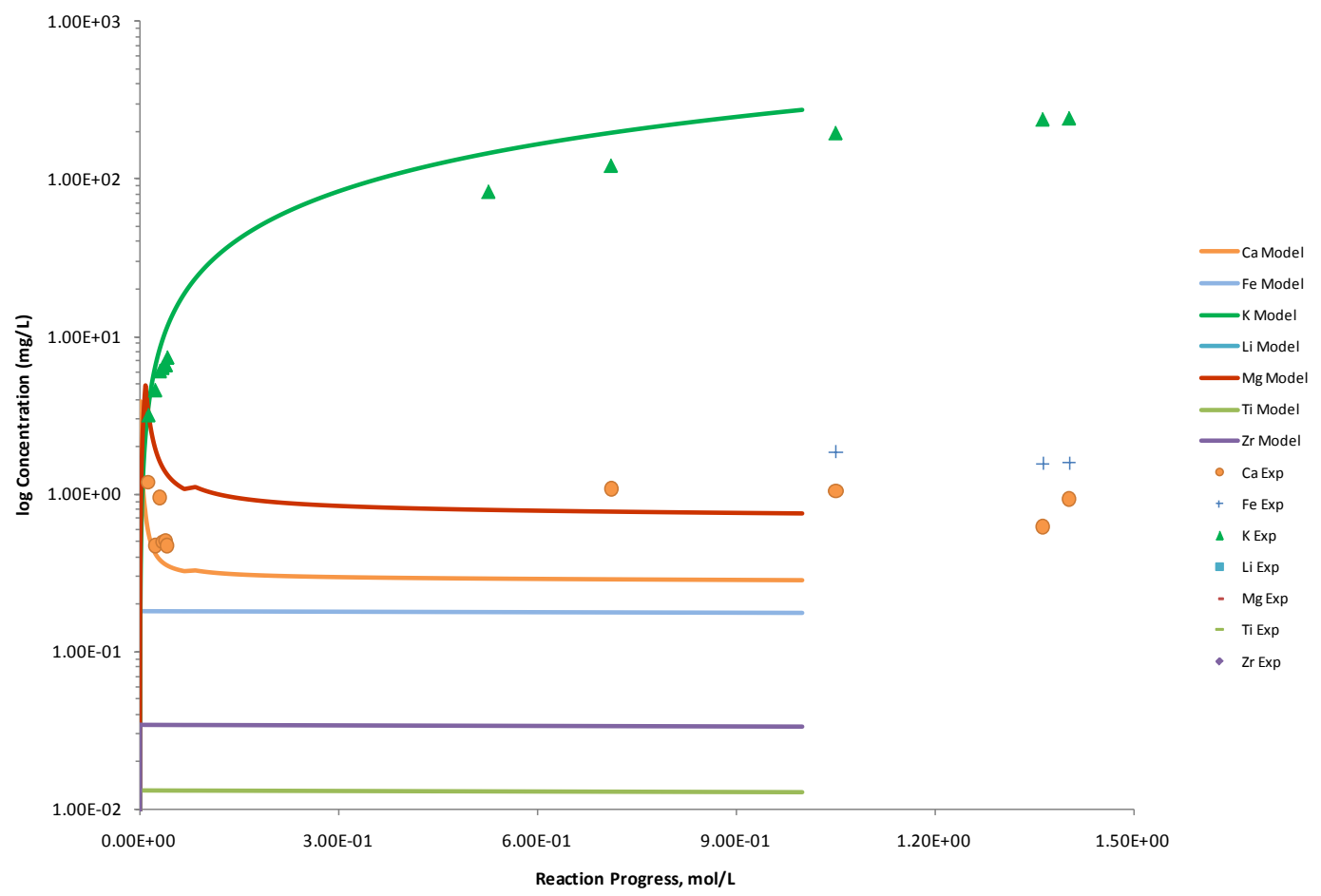

Figure C.138. Measured Solution Concentrations (mg/L) and Model Results for $\mathrm{Ca}, \mathrm{Fe}, \mathrm{K}, \mathrm{Li}, \mathrm{Mg}, \mathrm{Ti}$, and $\mathrm{Zr}$, as a Function of Reaction Progress (mol-glass/kg) Determined for Glass Sample LAWA52 


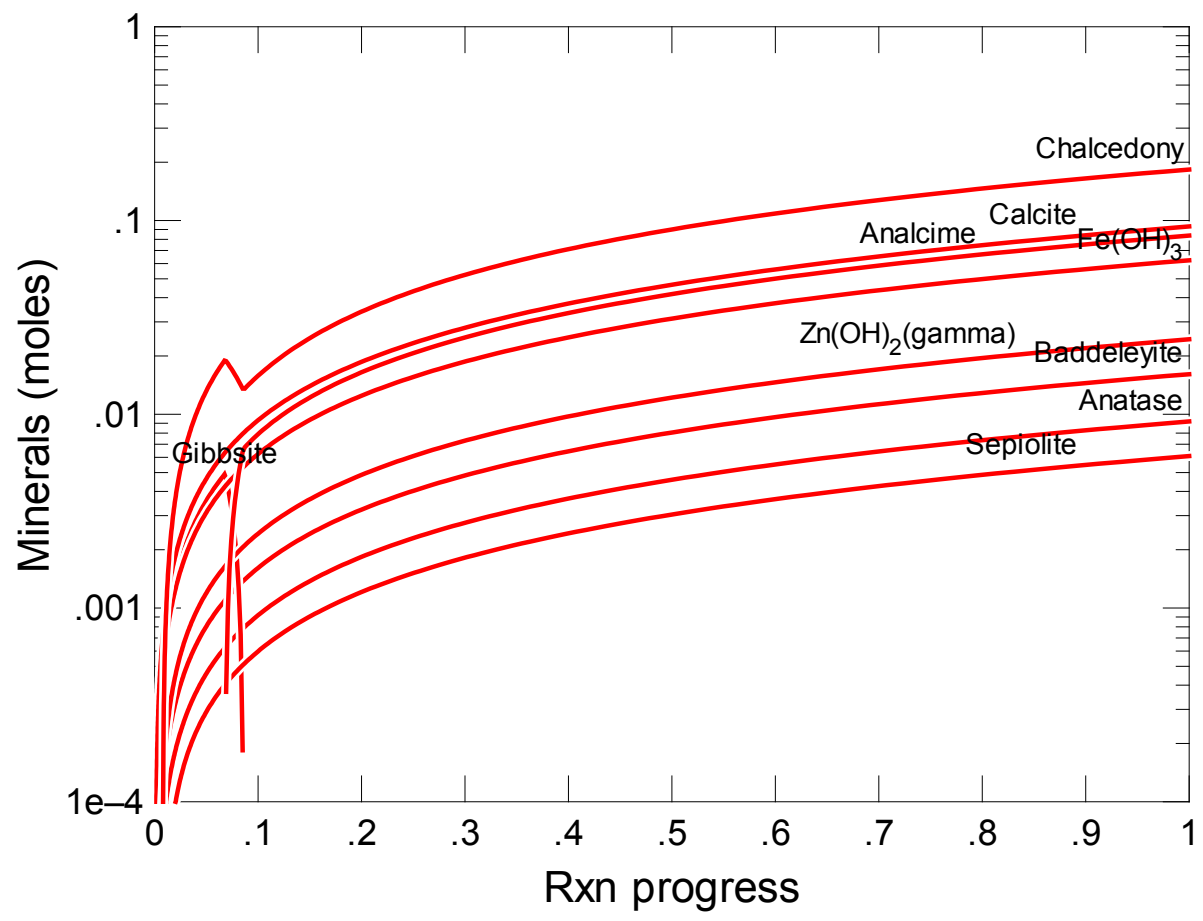

Figure C.139. Secondary Phases Calculated to Form as a Function of Reaction Progress (mol-glass $/ \mathrm{kg}$ ) Determined for Glass Sample LAWA53

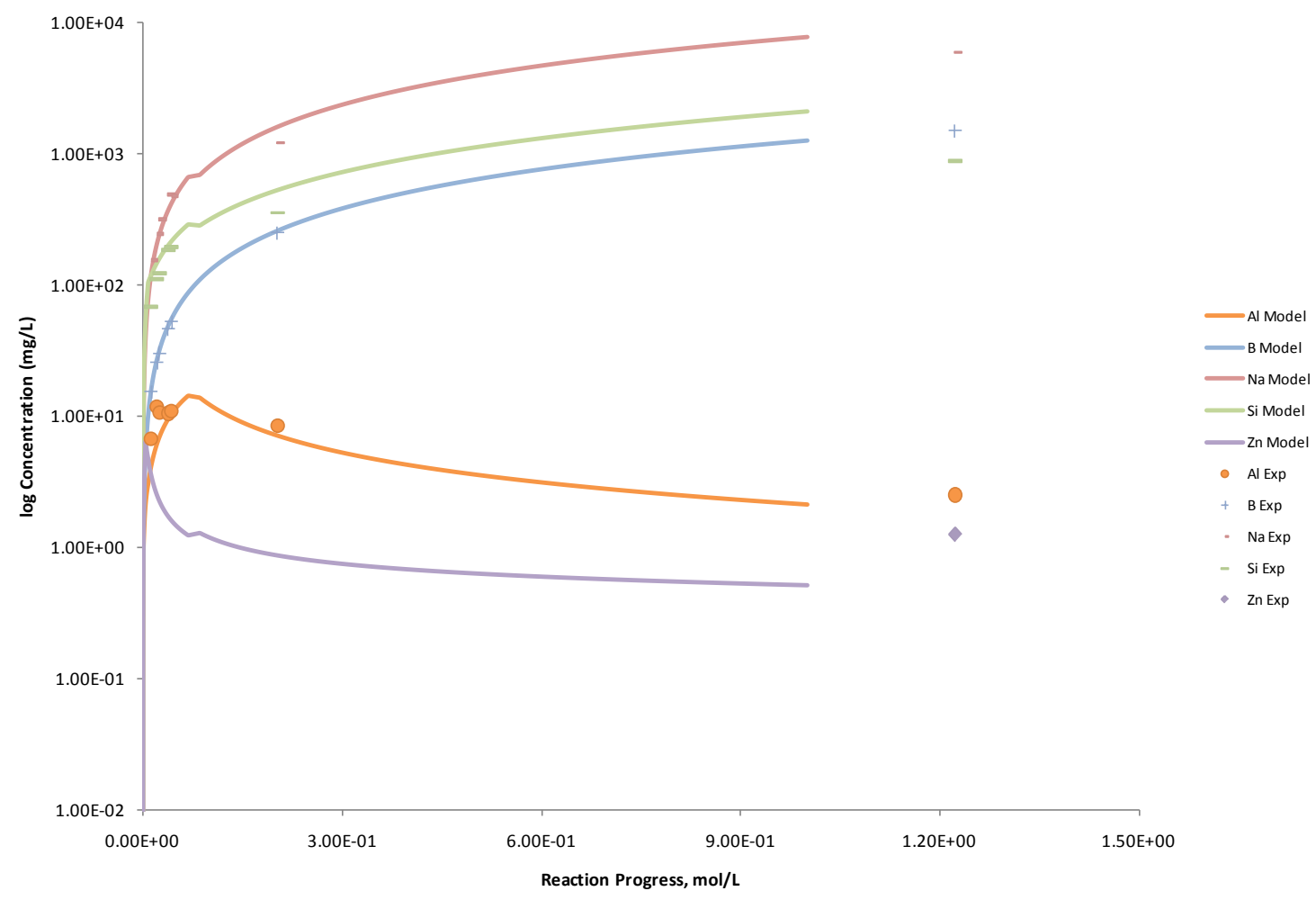

Figure C.140. Measured Solution Concentrations (mg/L) and Model Results for $\mathrm{Al}, \mathrm{B}, \mathrm{Na}$, $\mathrm{Si}$, and $\mathrm{Zn}$, as a Function of Reaction Progress (mol-glass $/ \mathrm{kg}$ ) Determined for Glass Sample LAWA53 


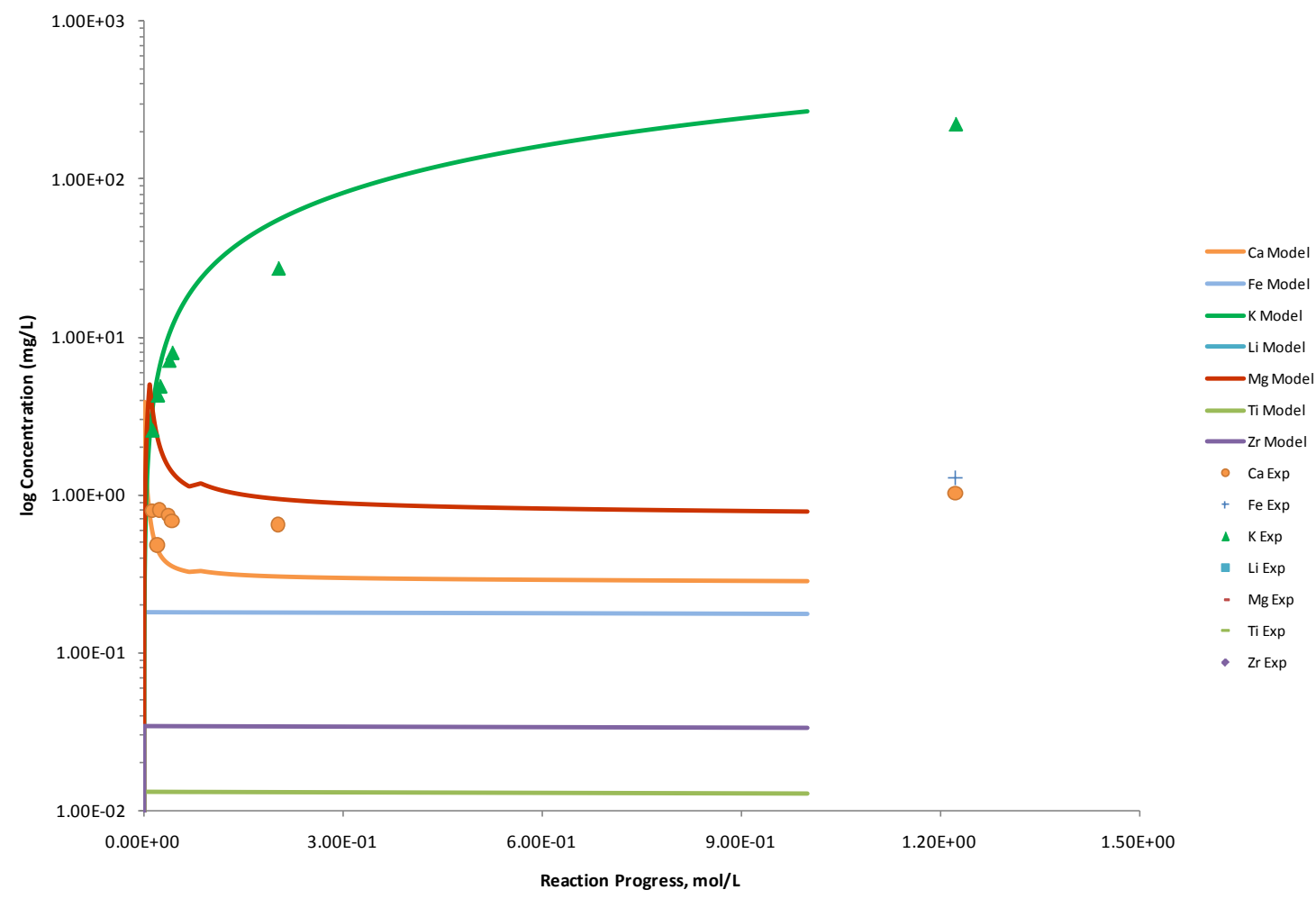

Figure C.141. Measured Solution Concentrations (mg/L) and Model Results for $\mathrm{Ca}, \mathrm{Fe}, \mathrm{K}, \mathrm{Li}, \mathrm{Mg}, \mathrm{Ti}$, and $\mathrm{Zr}$, as a Function of Reaction Progress (mol-glass/kg) Determined for Glass Sample LAWA53

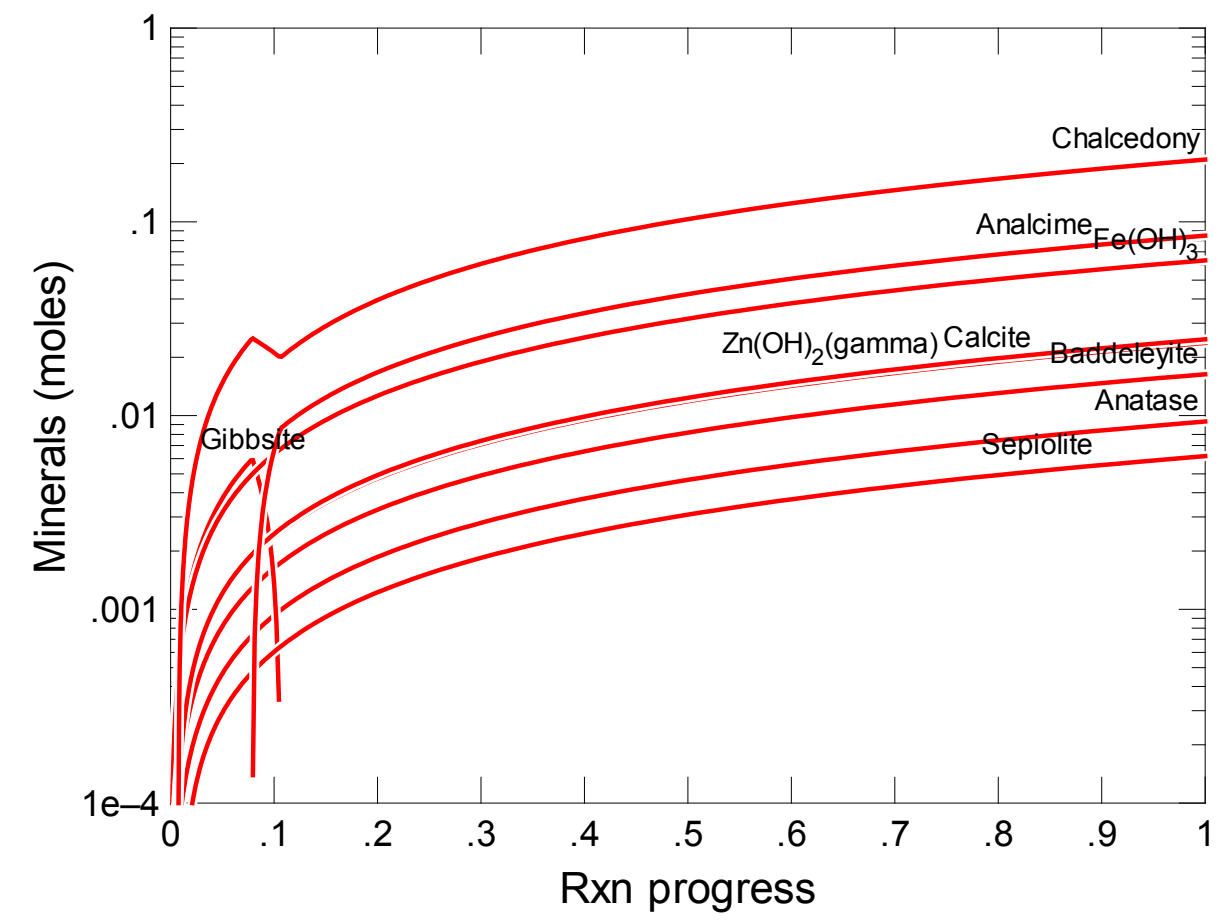

Figure C.142. Secondary Phases Calculated to Form as a Function of Reaction Progress (mol-glass $/ \mathrm{kg}$ ) Determined for Glass Sample LAWA56 


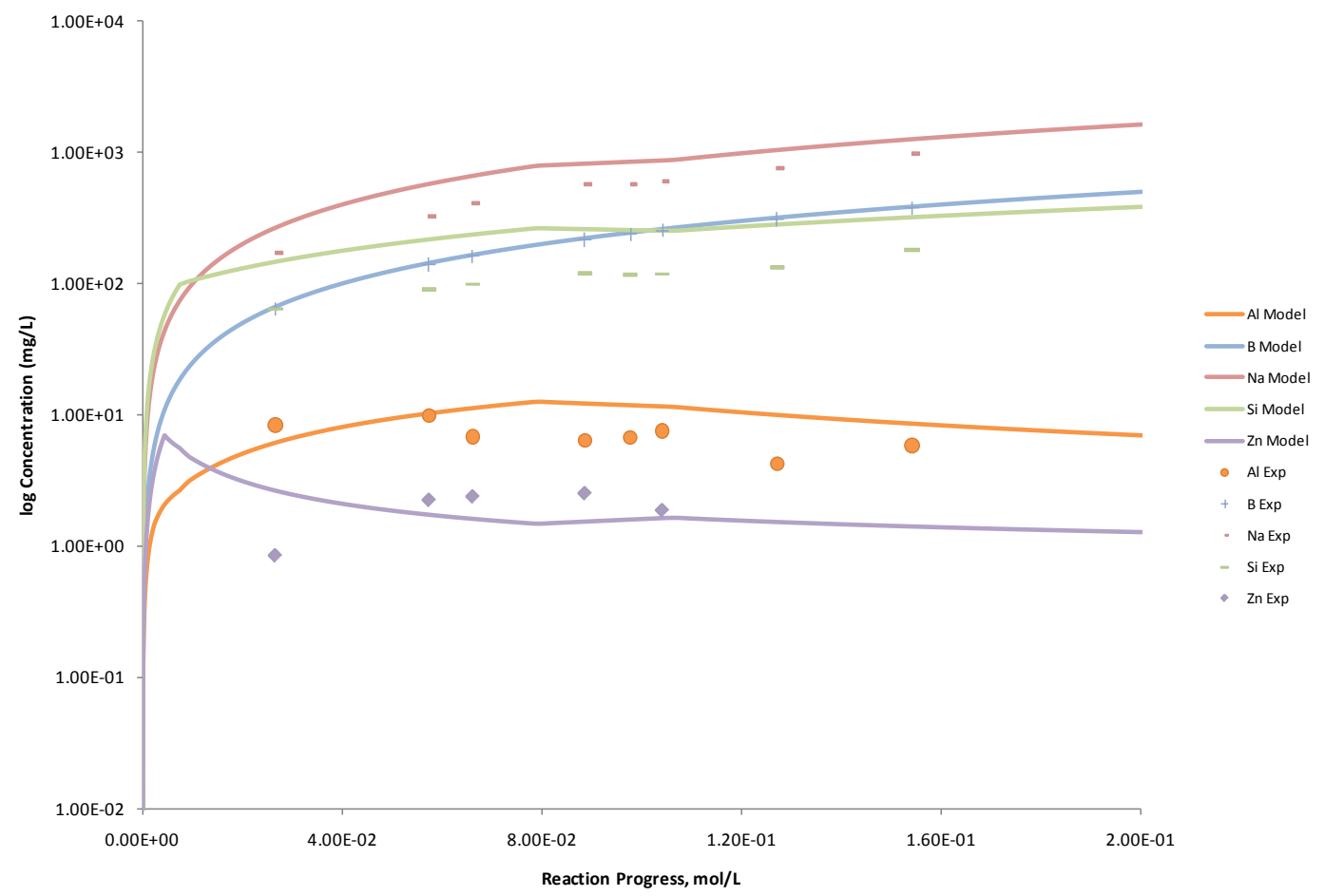

Figure C.143. Measured Solution Concentrations (mg/L) and Model Results for Al, B, Na, Si, and Zn, as a Function of Reaction Progress (mol-glass $/ \mathrm{kg}$ ) Determined for Glass Sample LAWA56

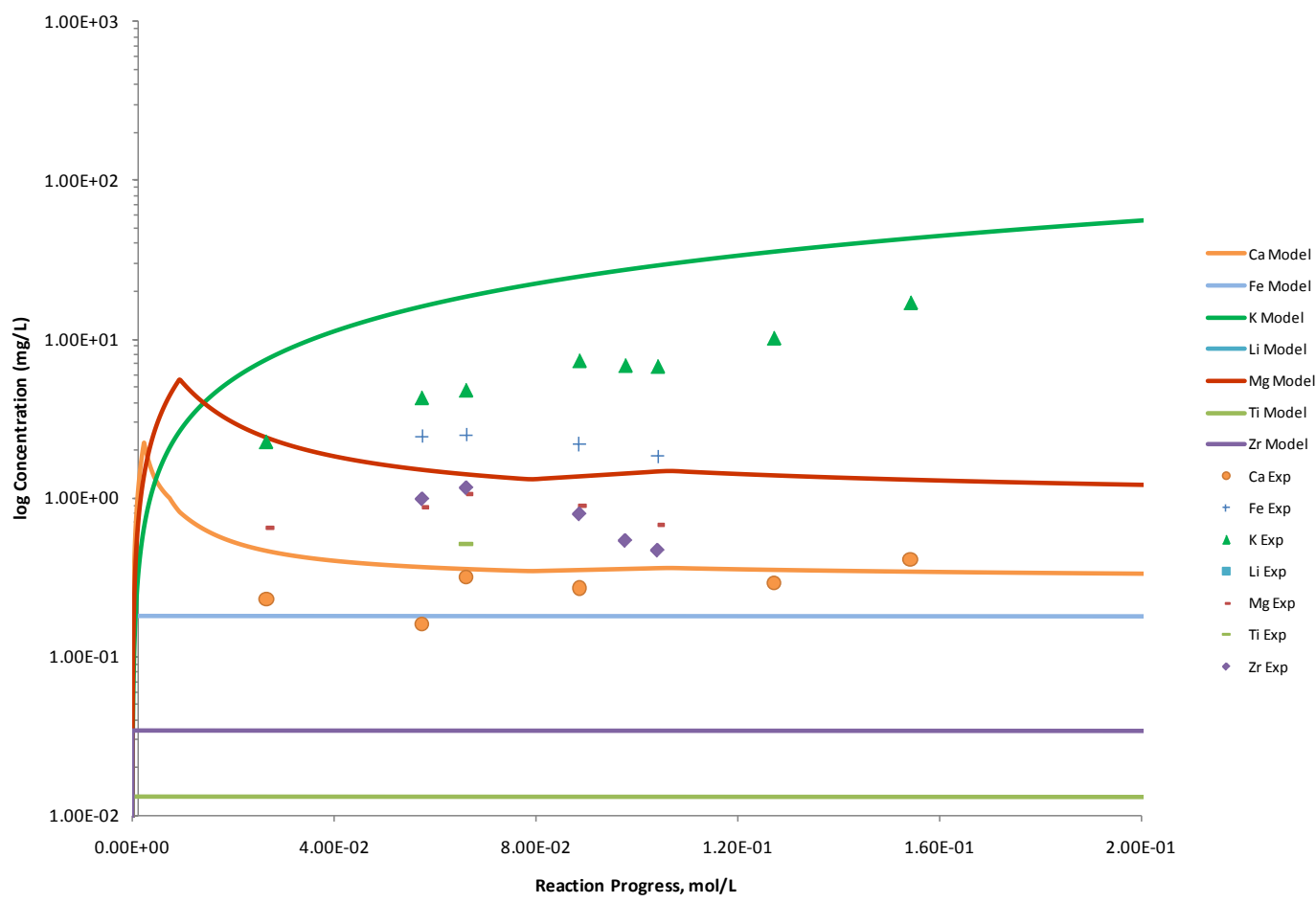

Figure C.144. Measured Solution Concentrations (mg/L) and Model Results for $\mathrm{Ca}, \mathrm{Fe}, \mathrm{K}, \mathrm{Li}, \mathrm{Mg}$, Ti, and $\mathrm{Zr}$, as a Function of Reaction Progress (mol-glass $/ \mathrm{kg}$ ) Determined for Glass Sample LAWA56 


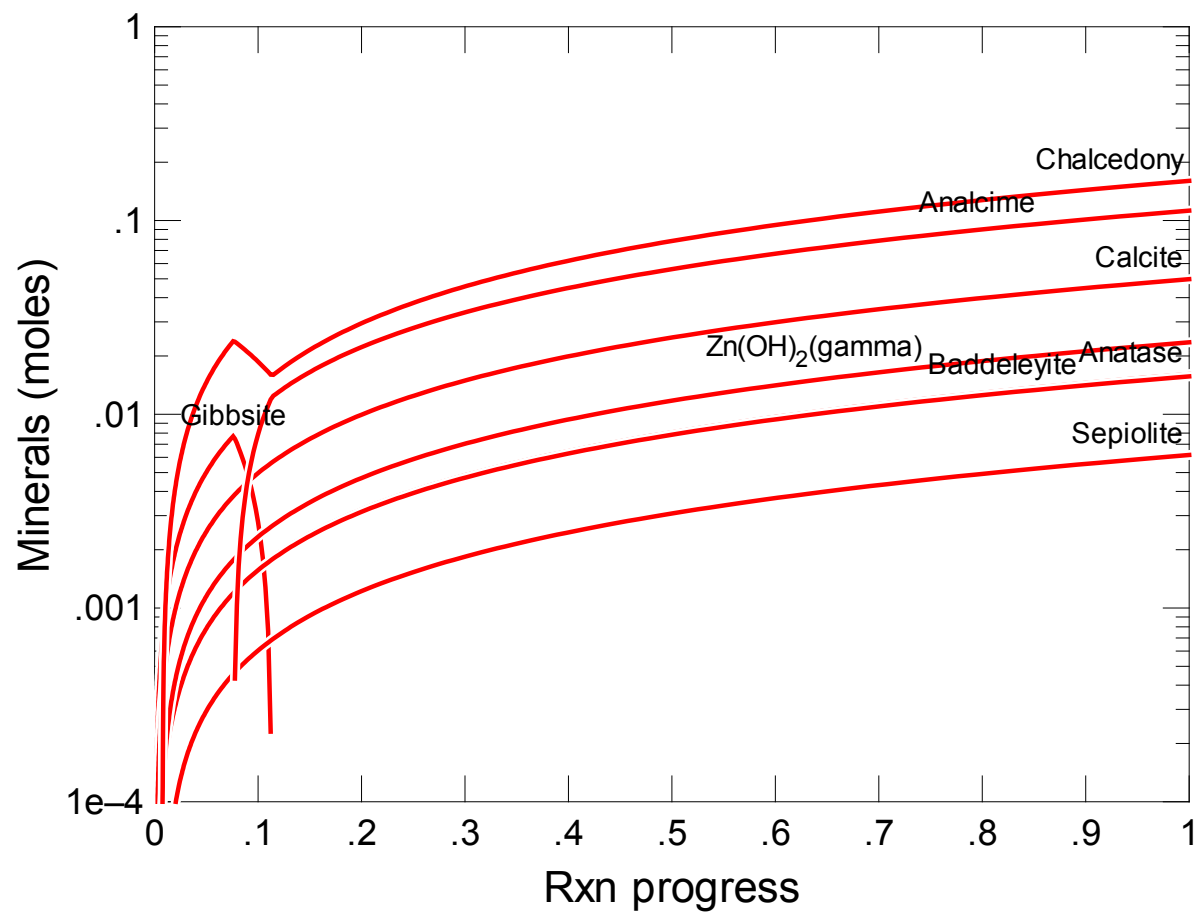

Figure C.145. Secondary Phases Calculated to Form as a Function of Reaction Progress (mol-glass/kg) Determined for Glass Sample LAWA60

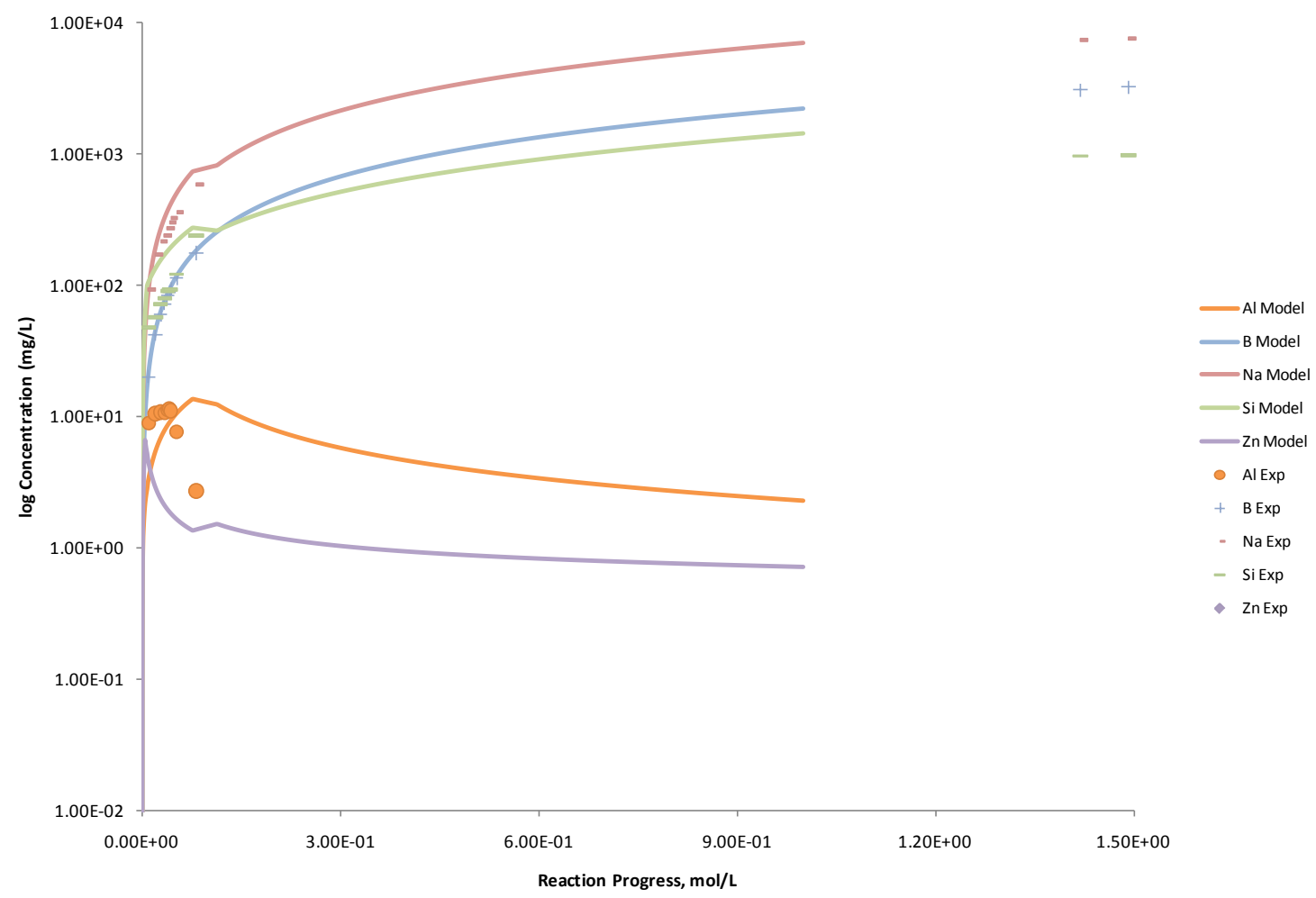

Figure C.146. Measured Solution Concentrations (mg/L) and Model Results for $\mathrm{Al}, \mathrm{B}, \mathrm{Na}$, $\mathrm{Si}$, and $\mathrm{Zn}$, as a Function of Reaction Progress (mol-glass $/ \mathrm{kg}$ ) Determined for Glass Sample LAWA60 


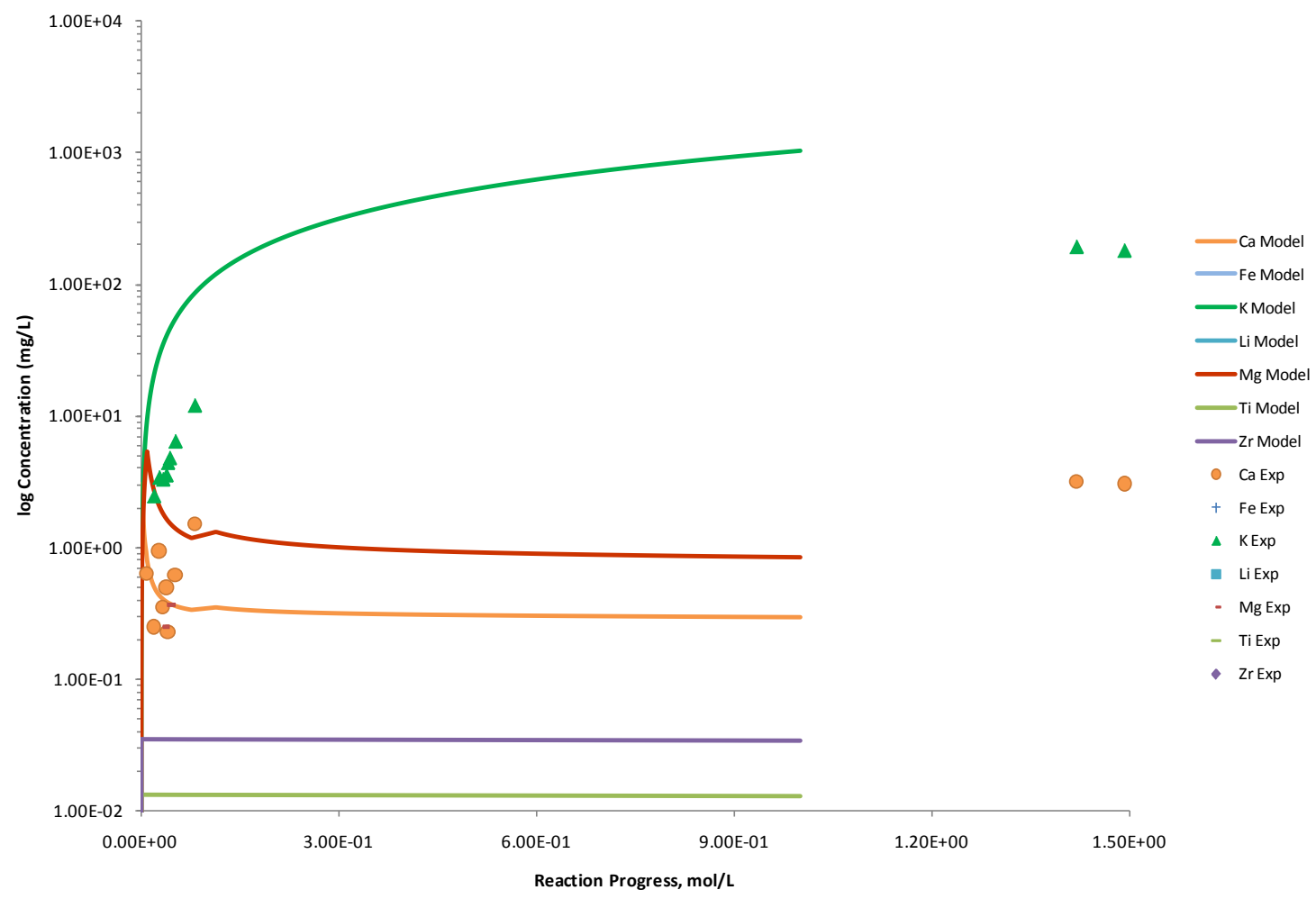

Figure C.147. Measured Solution Concentrations (mg/L) and Model Results for $\mathrm{Ca}, \mathrm{Fe}, \mathrm{K}, \mathrm{Li}, \mathrm{Mg}, \mathrm{Ti}$, and Zr, as a Function of Reaction Progress (mol-glass/kg) Determined for Glass Sample LAWA60

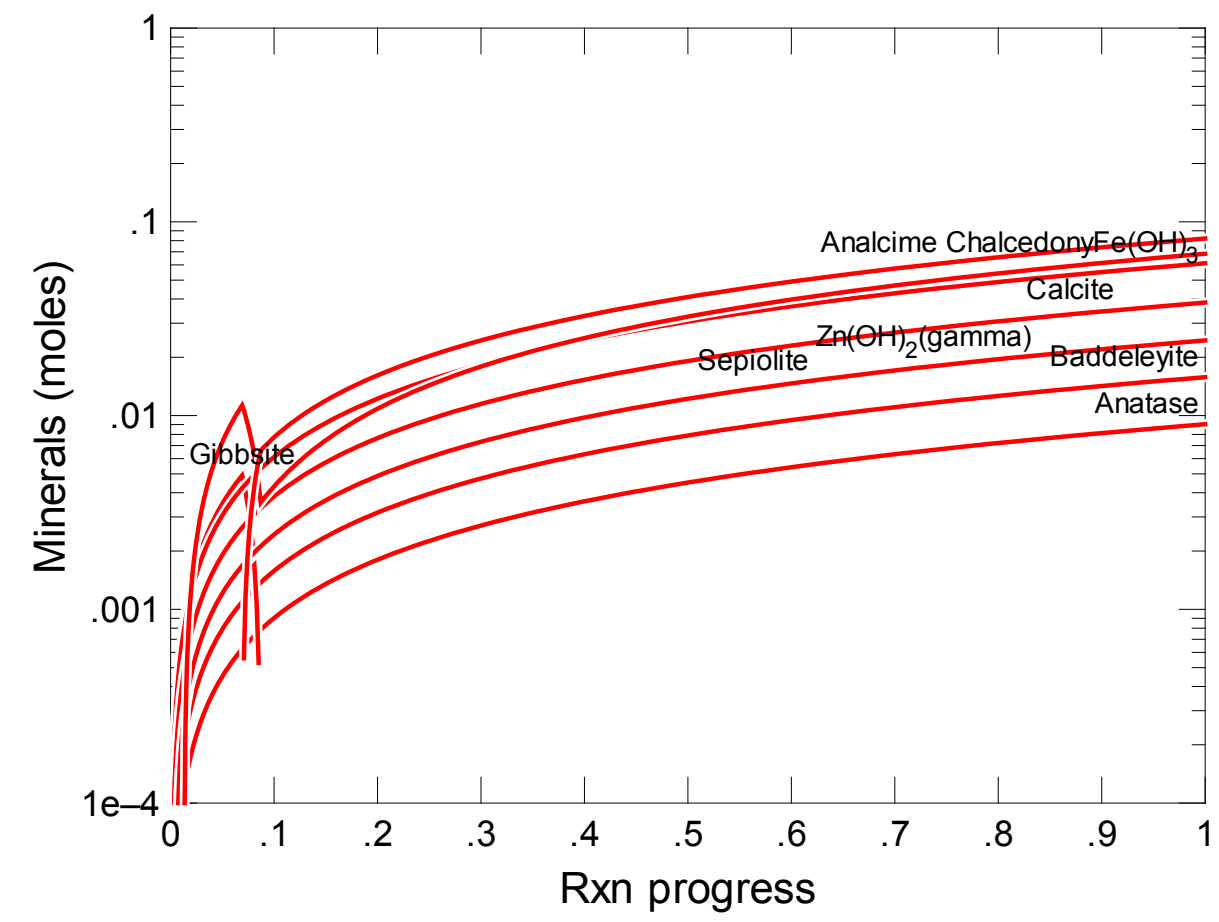

Figure C.148. Secondary Phases Calculated to Form as a Function of Reaction Progress (mol-glass $/ \mathrm{kg}$ ) Determined for Glass Sample LAWA65 


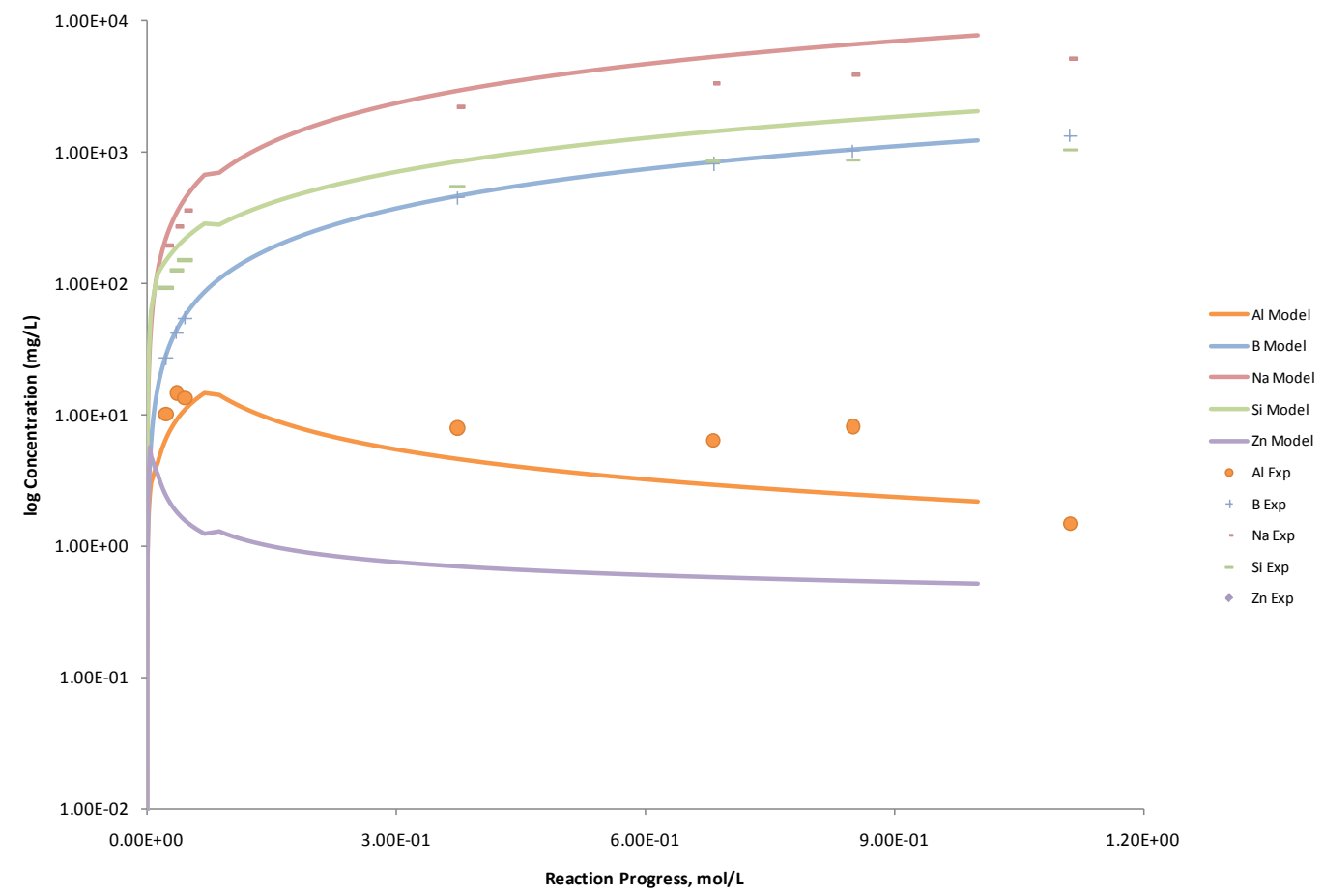

Figure C.149. Measured Solution Concentrations (mg/L) and Model Results for Al, B, Na, Si, and Zn, as a Function of Reaction Progress (mol-glass $/ \mathrm{kg}$ ) Determined for Glass Sample LAWA65

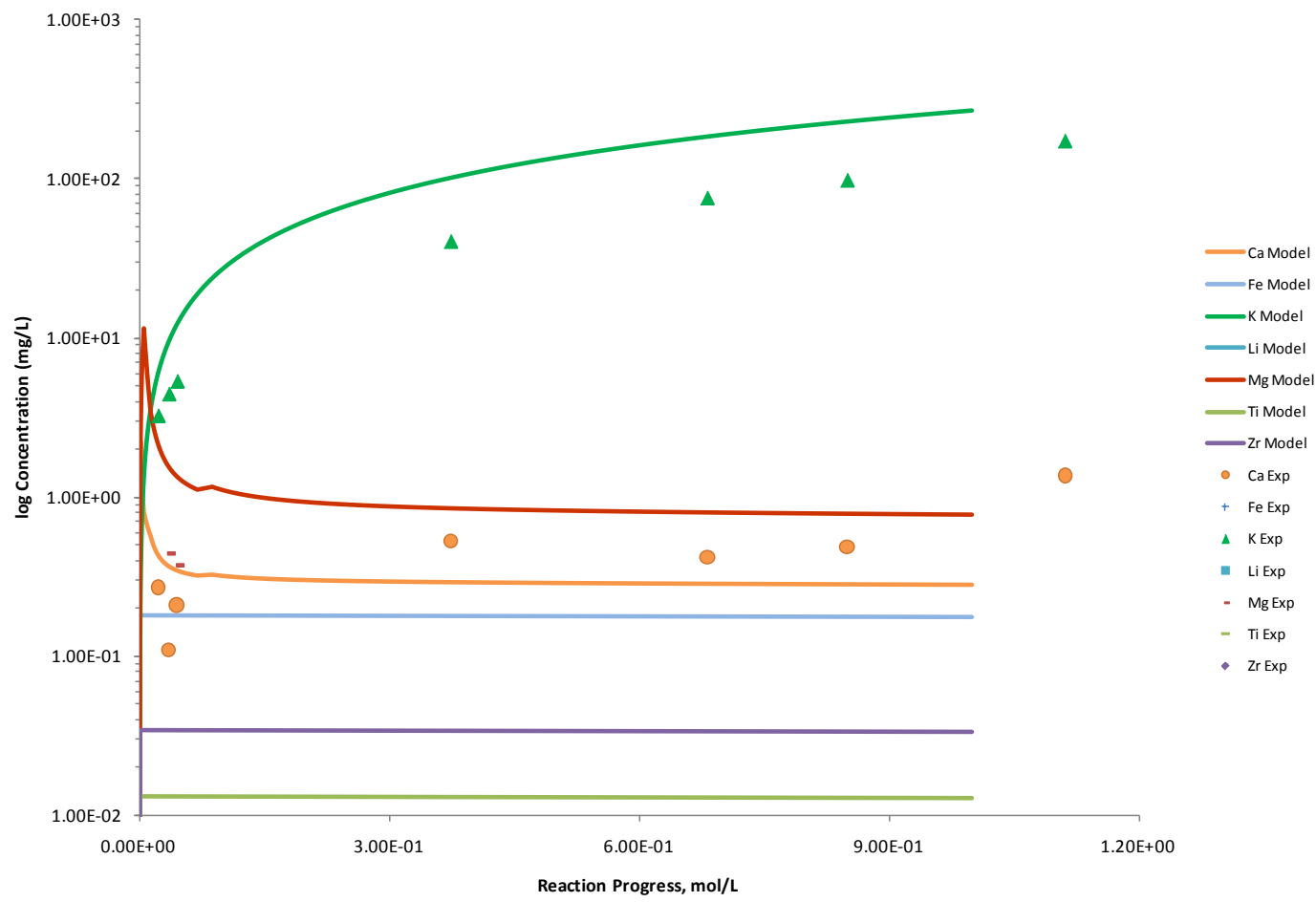

Figure C.150. Measured Solution Concentrations (mg/L) and Model Results for $\mathrm{Ca}, \mathrm{Fe}, \mathrm{K}, \mathrm{Li}, \mathrm{Mg}$, Ti, and $\mathrm{Zr}$, as a Function of Reaction Progress (mol-glass/kg) Determined for Glass Sample LAWA65 


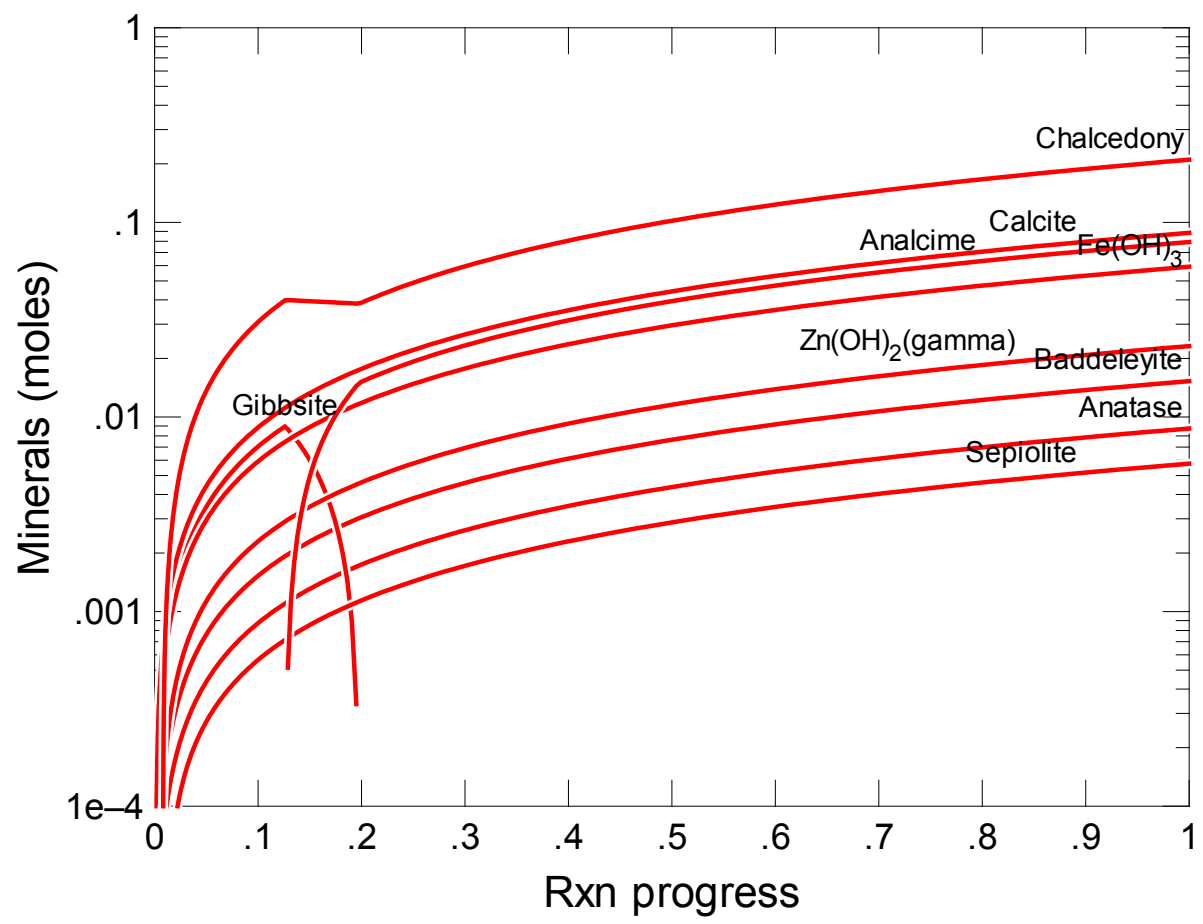

Figure C.151. Secondary Phases Calculated to Form as a Function of Reaction Progress (mol-glass/kg) Determined for Glass Sample LAWA76

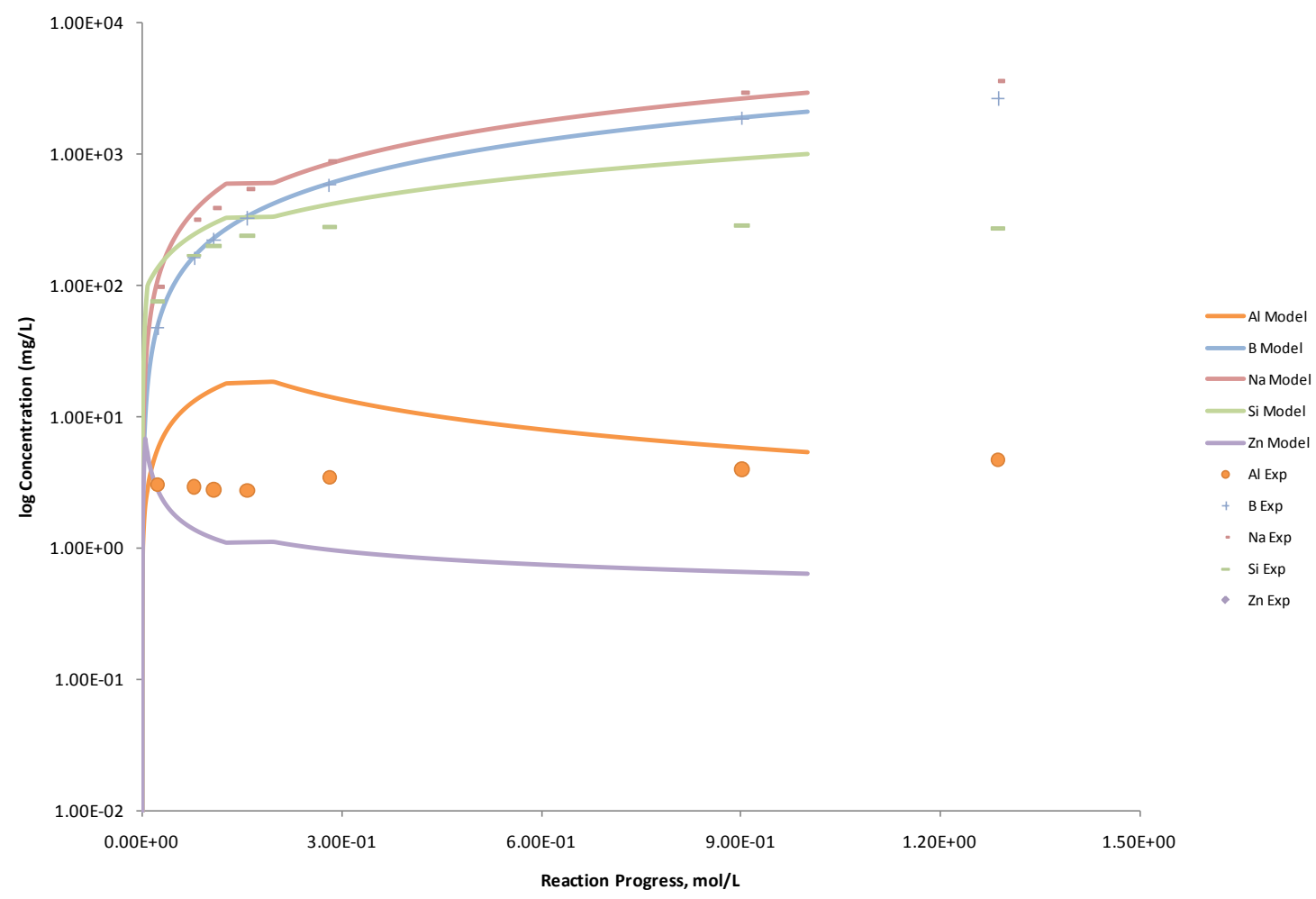

Figure C.152. Measured Solution Concentrations (mg/L) and Model Results for Al, B, Na, Si, and Zn, as a Function of Reaction Progress (mol-glass $/ \mathrm{kg}$ ) Determined for Glass Sample LAWA76 


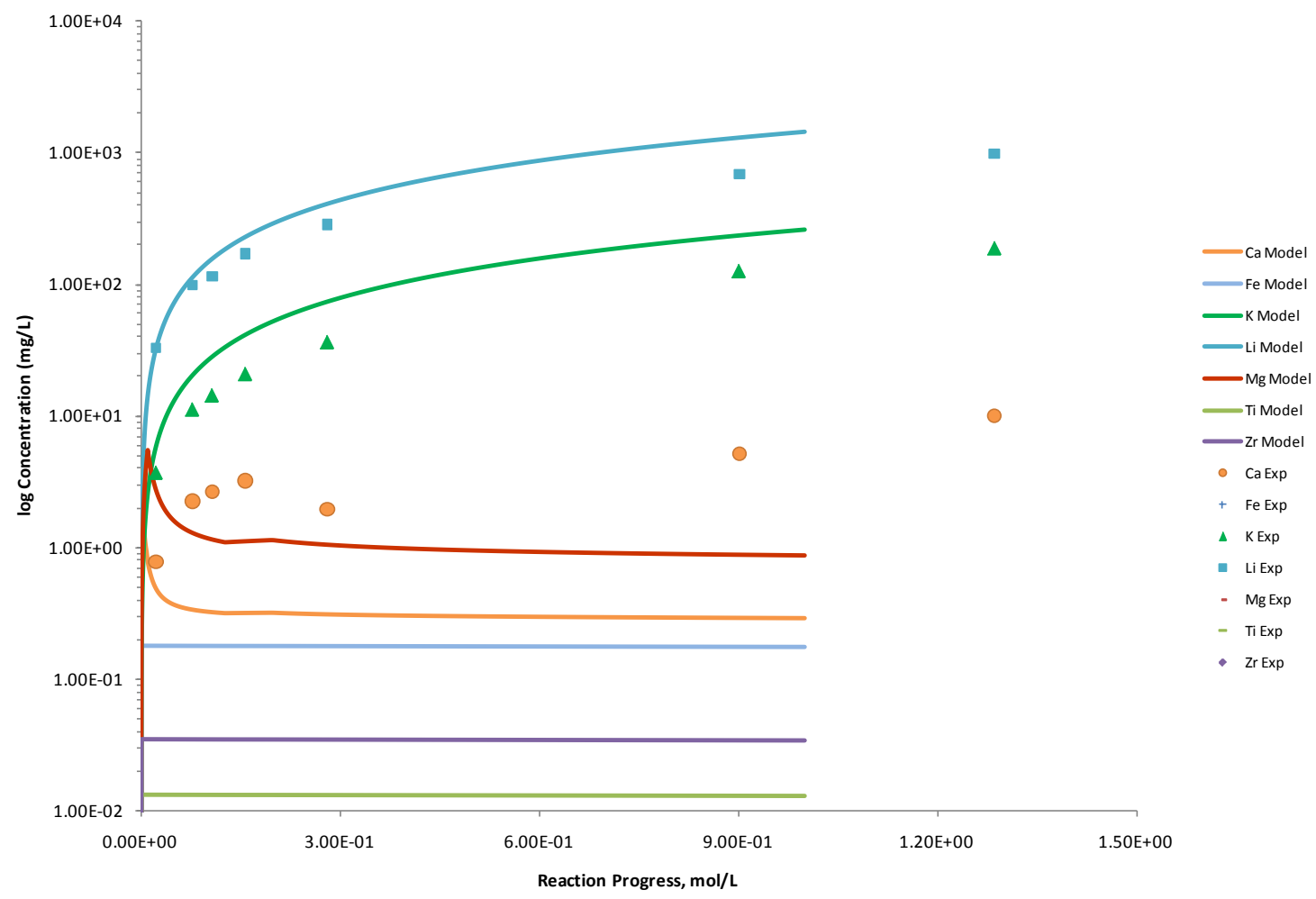

Figure C.153. Measured Solution Concentrations (mg/L) and Model Results for $\mathrm{Ca}, \mathrm{Fe}, \mathrm{K}, \mathrm{Li}, \mathrm{Mg}, \mathrm{Ti}$, and $\mathrm{Zr}$, as a Function of Reaction Progress (mol-glass/kg) Determined for Glass Sample LAWA76

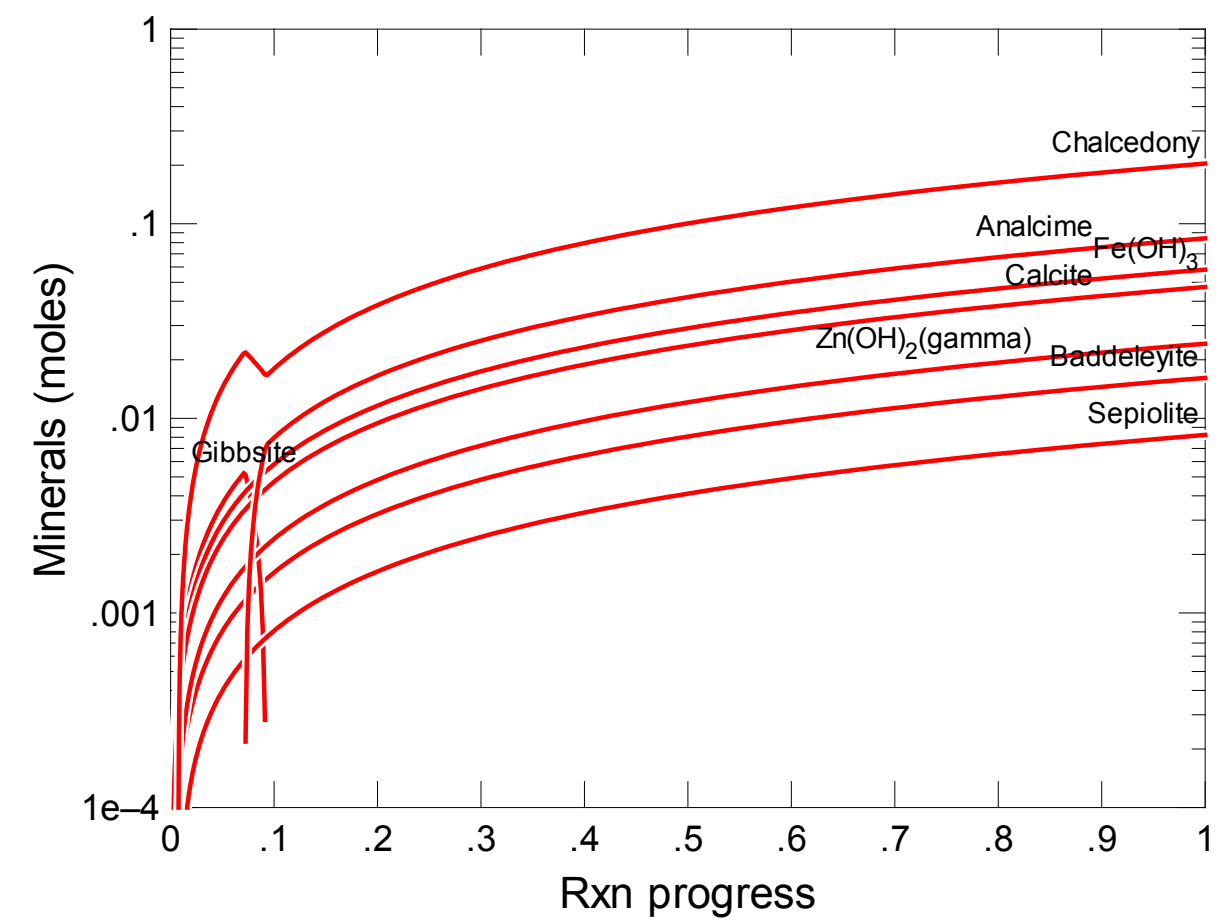

Figure C.154. Secondary Phases Calculated to Form as a Function of Reaction Progress (mol-glass/kg) Determined for Glass Sample LAWA81 


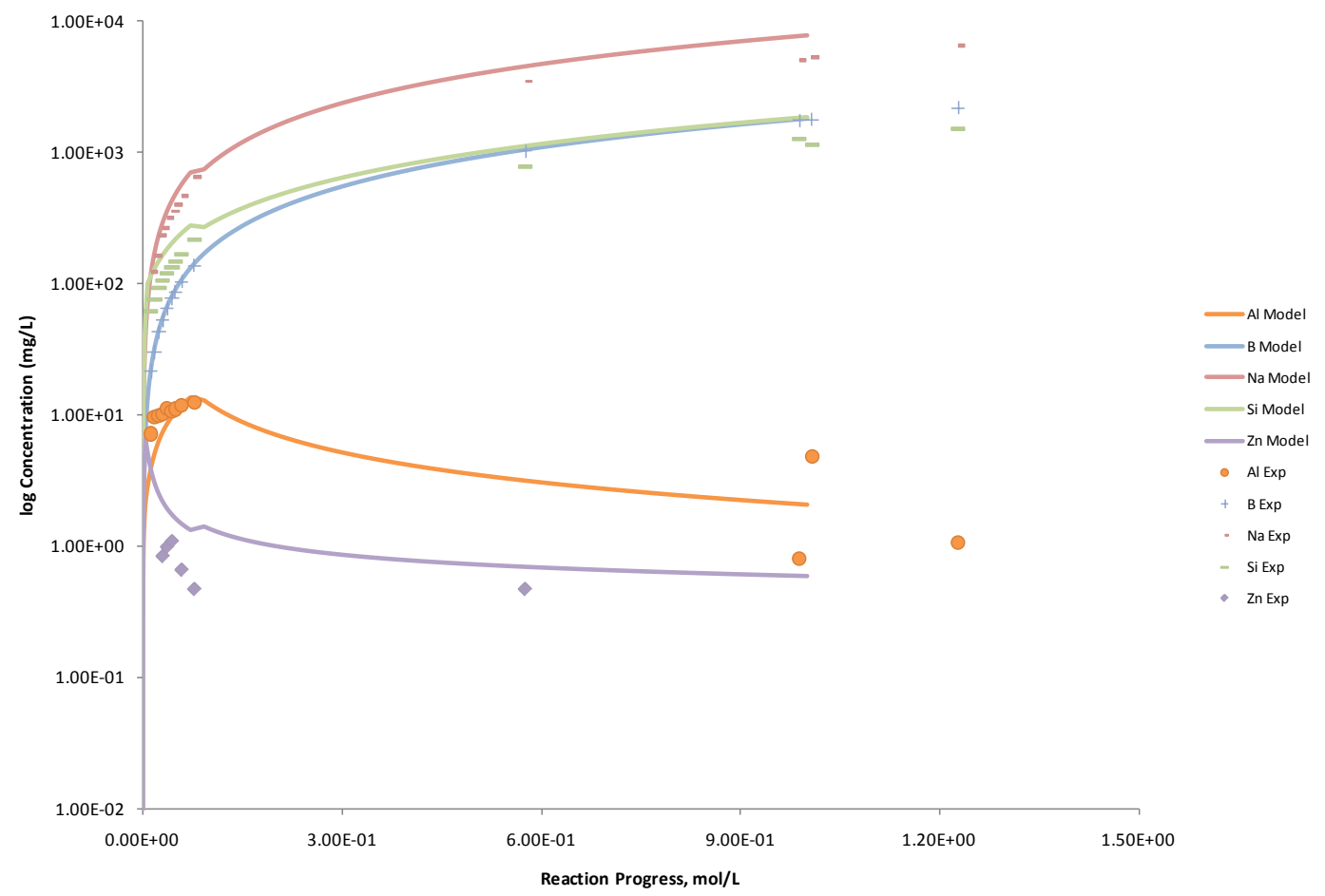

Figure C.155. Measured Solution Concentrations (mg/L) and Model Results for Al, B, Na, Si, and Zn, as a Function of Reaction Progress (mol-glass $/ \mathrm{kg}$ ) Determined for Glass Sample LAWA81

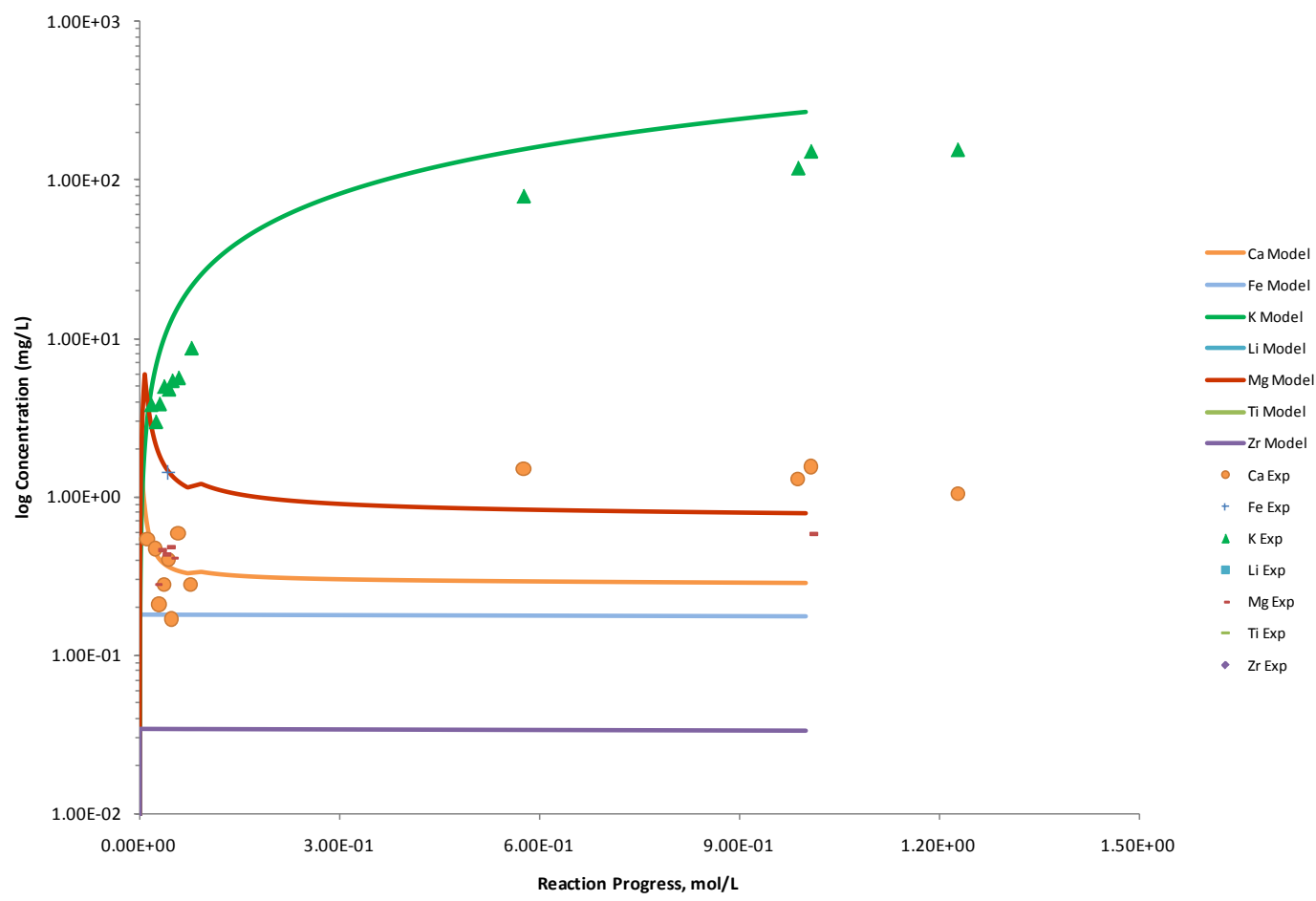

Figure C.156. Measured Solution Concentrations (mg/L) and Model Results for $\mathrm{Ca}, \mathrm{Fe}, \mathrm{K}, \mathrm{Li}, \mathrm{Mg}$, Ti, and $\mathrm{Zr}$, as a Function of Reaction Progress (mol-glass/kg) Determined for Glass Sample LAWA81 


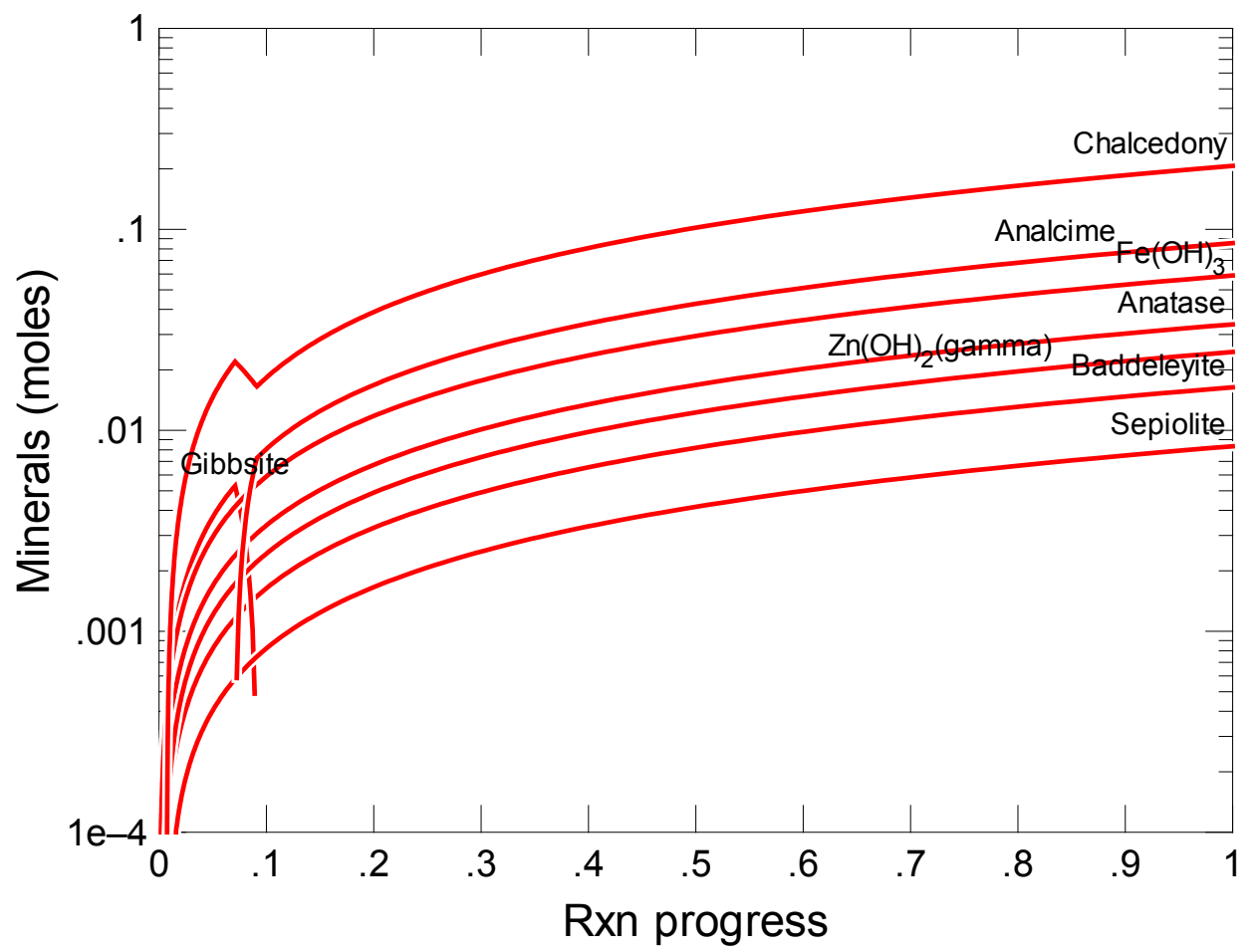

Figure C.157. Secondary Phases Calculated to Form as a Function of Reaction Progress (mol-glass $/ \mathrm{kg}$ ) Determined for Glass Sample LAWA82

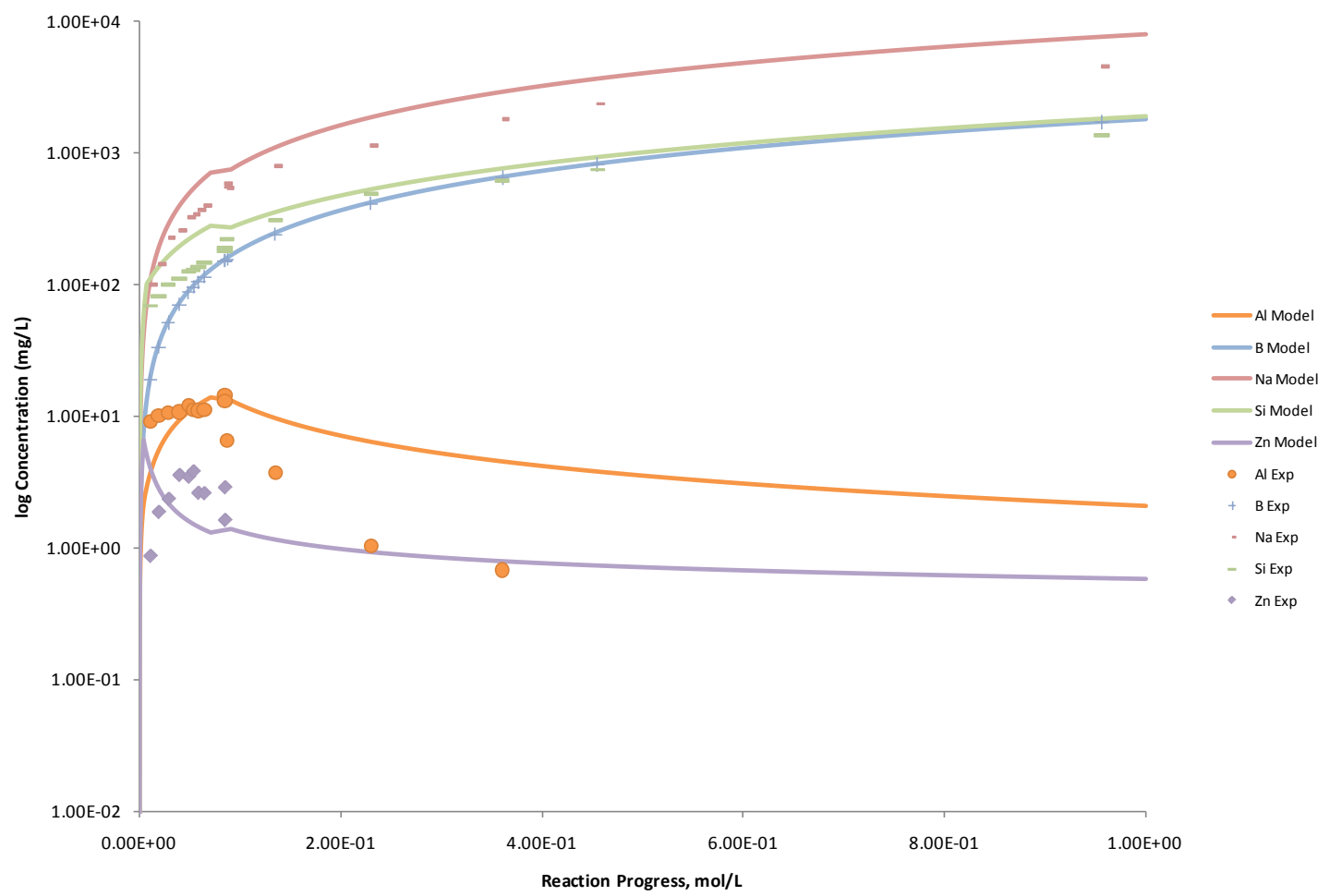

Figure C.158. Measured Solution Concentrations (mg/L) and Model Results for Al, B, Na, Si, and Zn, as a Function of Reaction Progress (mol-glass $/ \mathrm{kg}$ ) Determined for Glass Sample LAWA82 


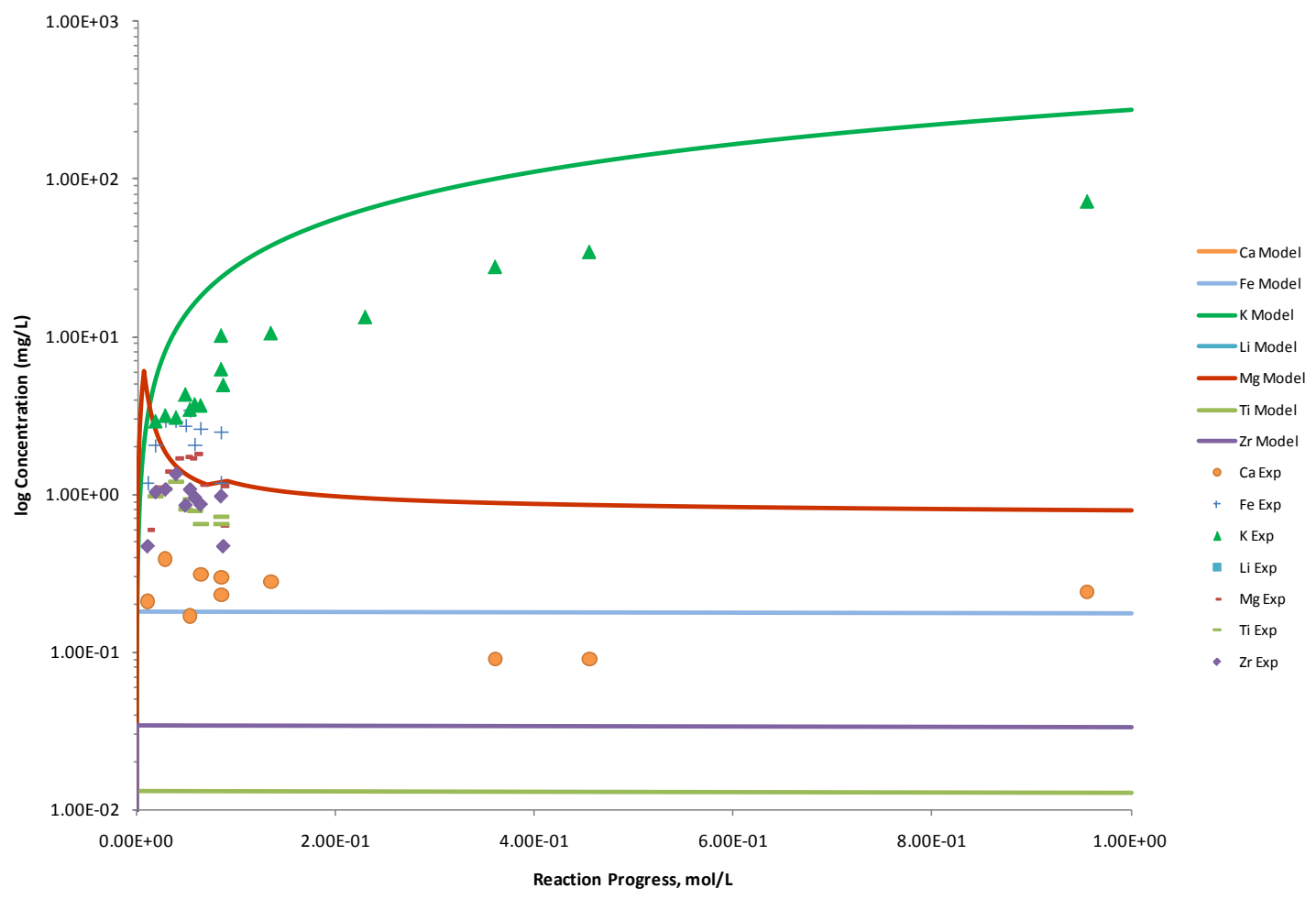

Figure C.159. Measured Solution Concentrations (mg/L) and Model Results for $\mathrm{Ca}, \mathrm{Fe}, \mathrm{K}, \mathrm{Li}, \mathrm{Mg}$, Ti, and $\mathrm{Zr}$, as a Function of Reaction Progress (mol-glass/kg) Determined for Glass Sample LAWA82

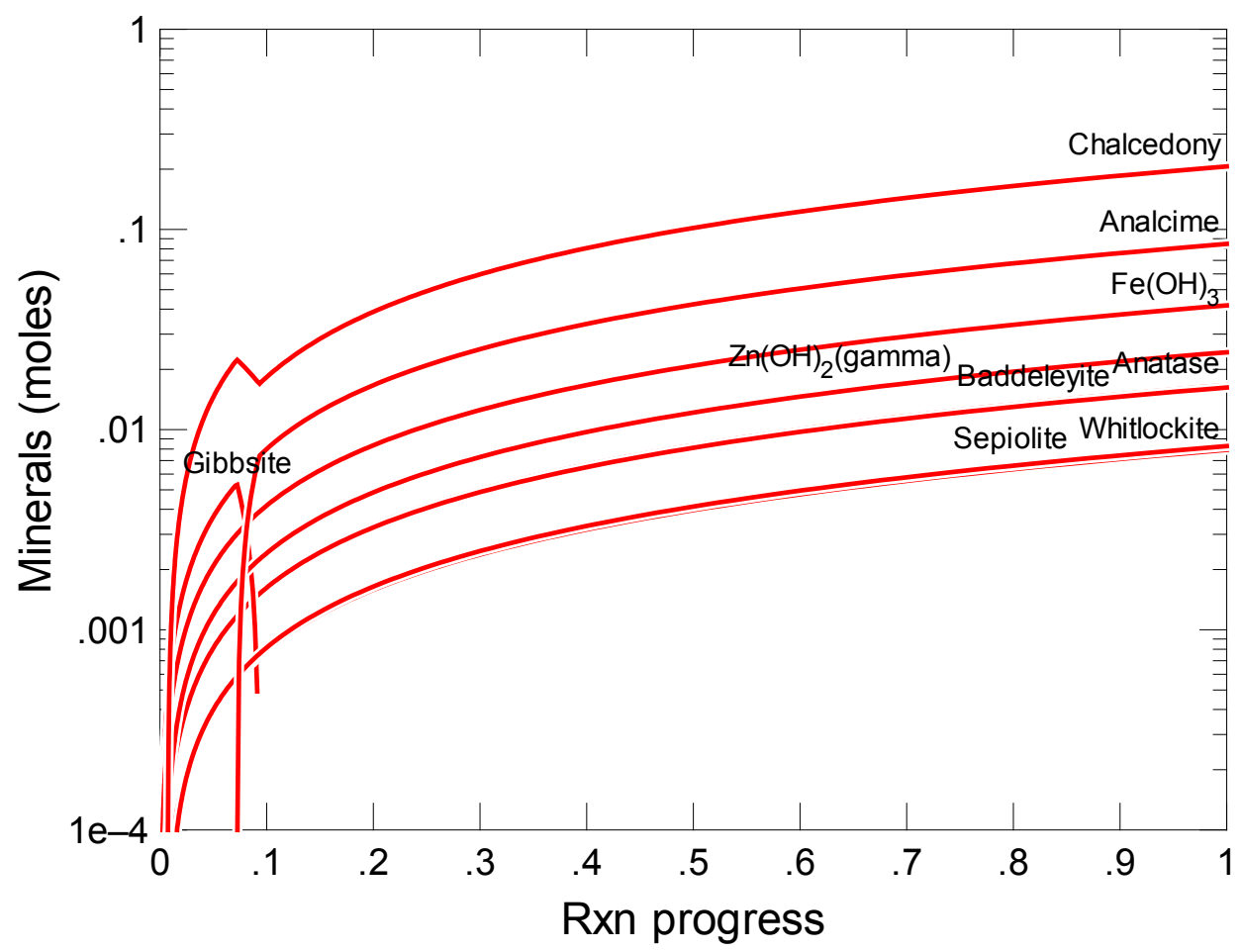

Figure C.160. Secondary Phases Calculated to Form as a Function of Reaction Progress (mol-glass/kg) Determined for Glass Sample LAWA83 


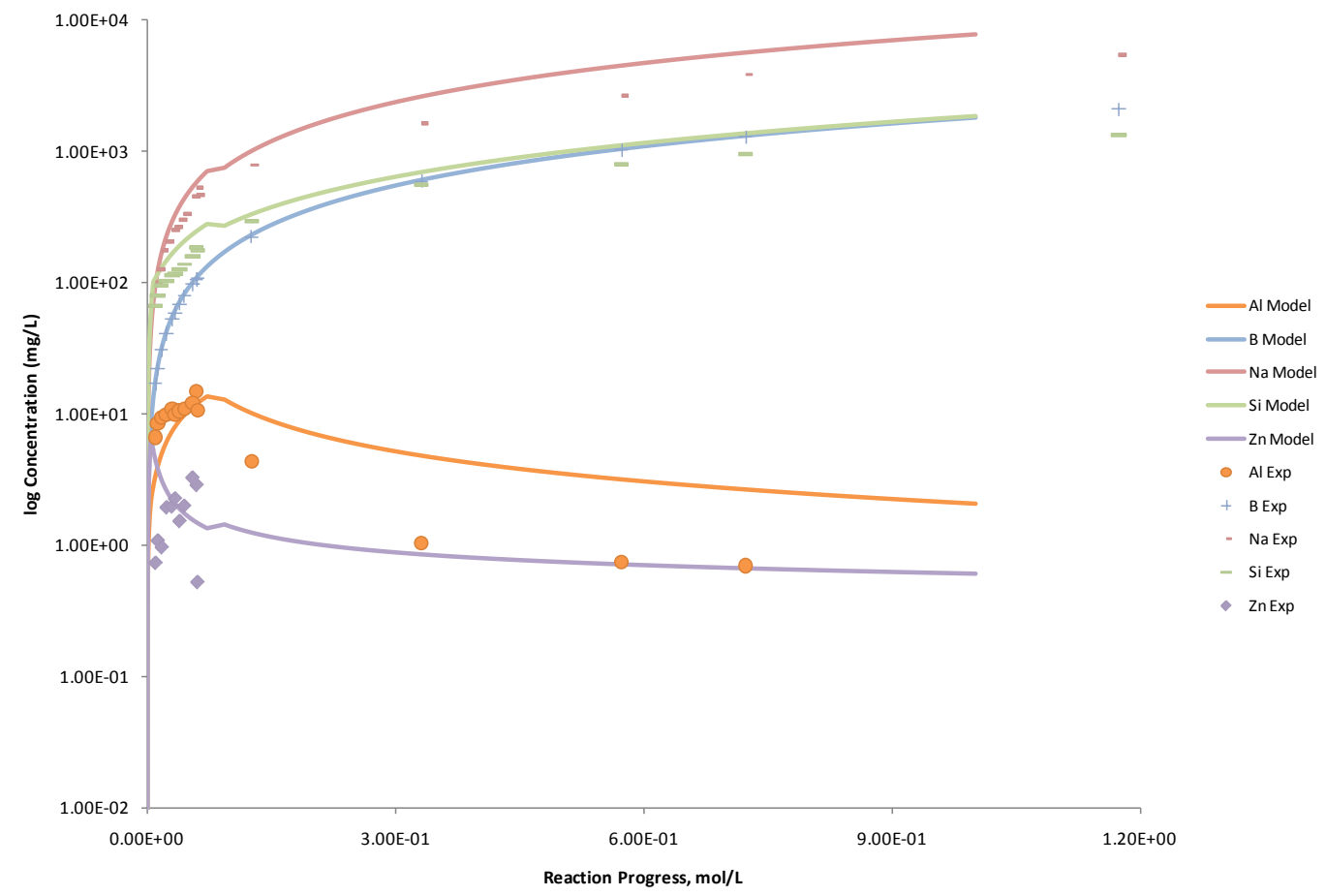

Figure C.161. Measured Solution Concentrations (mg/L) and Model Results for Al, B, Na, Si, and Zn, as a Function of Reaction Progress (mol-glass $/ \mathrm{kg}$ ) Determined for Glass Sample LAWA83

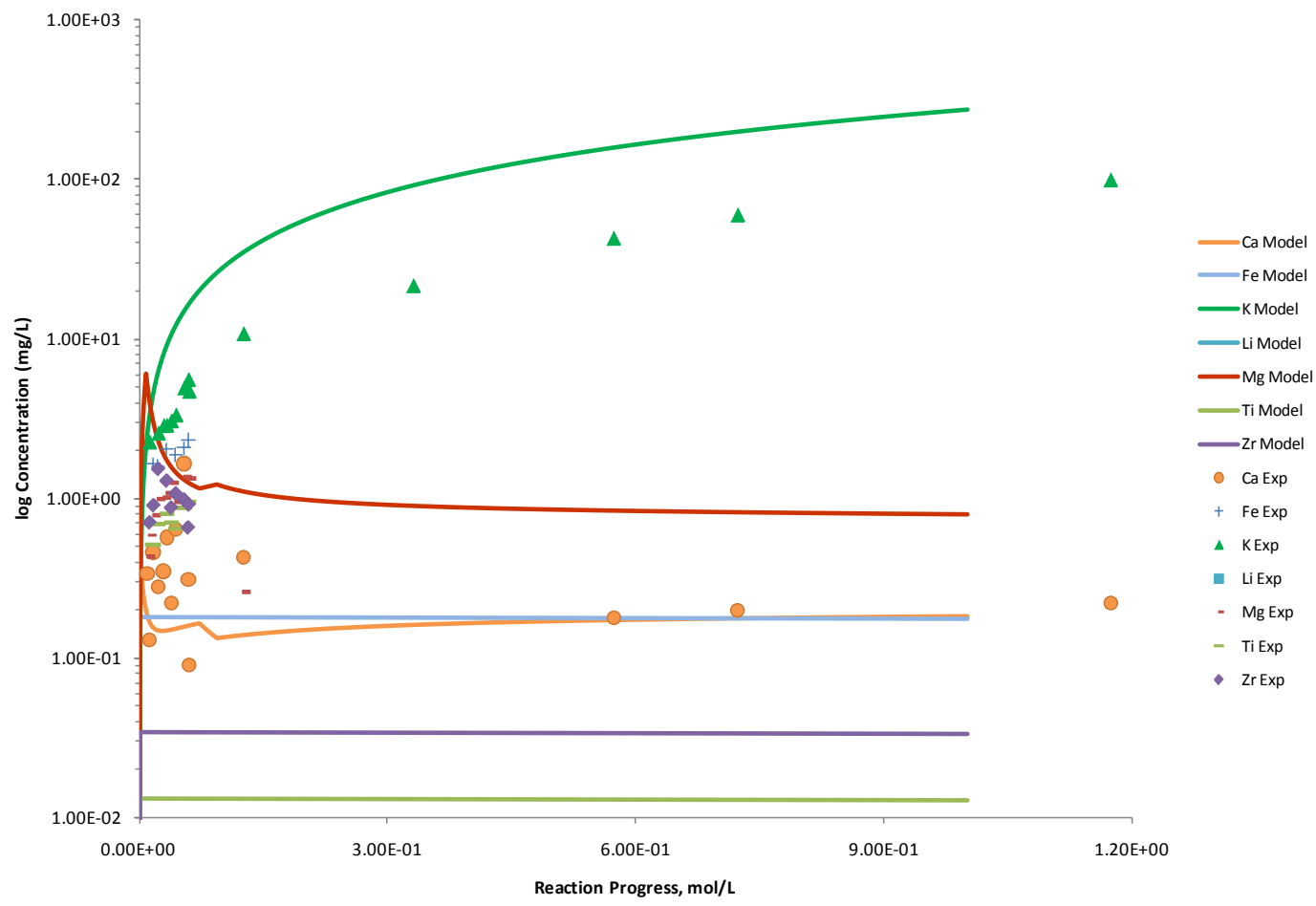

Figure C.162. Measured Solution Concentrations (mg/L) and Model Results for $\mathrm{Ca}, \mathrm{Fe}, \mathrm{K}, \mathrm{Li}, \mathrm{Mg}, \mathrm{Ti}$, and $\mathrm{Zr}$, as a Function of Reaction Progress (mol-glass/kg) Determined for Glass Sample LAWA83 


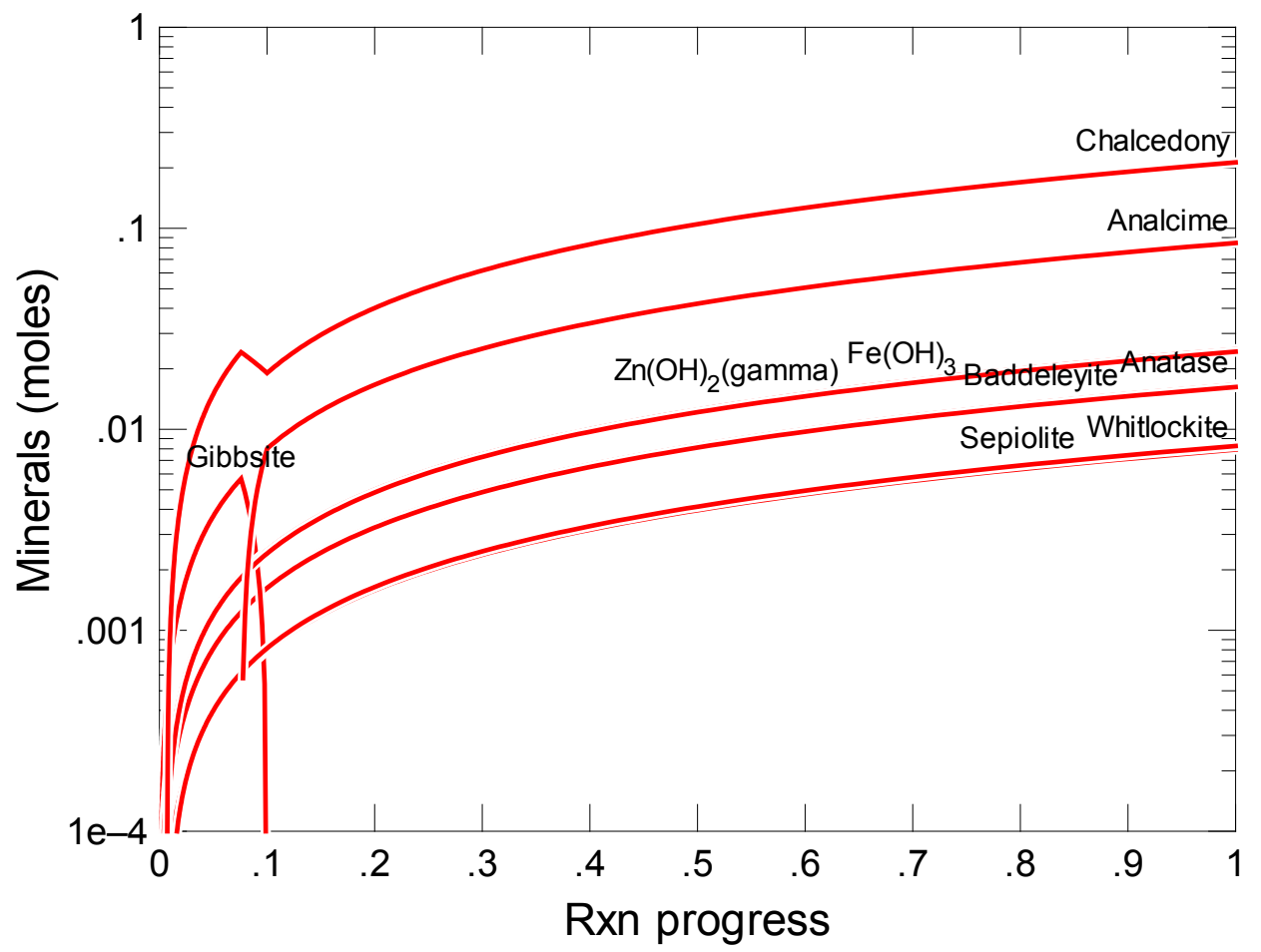

Figure C.163. Secondary Phases Calculated to Form as a Function of Reaction Progress (mol-glass $/ \mathrm{kg}$ ) Determined for Glass Sample LAWA84

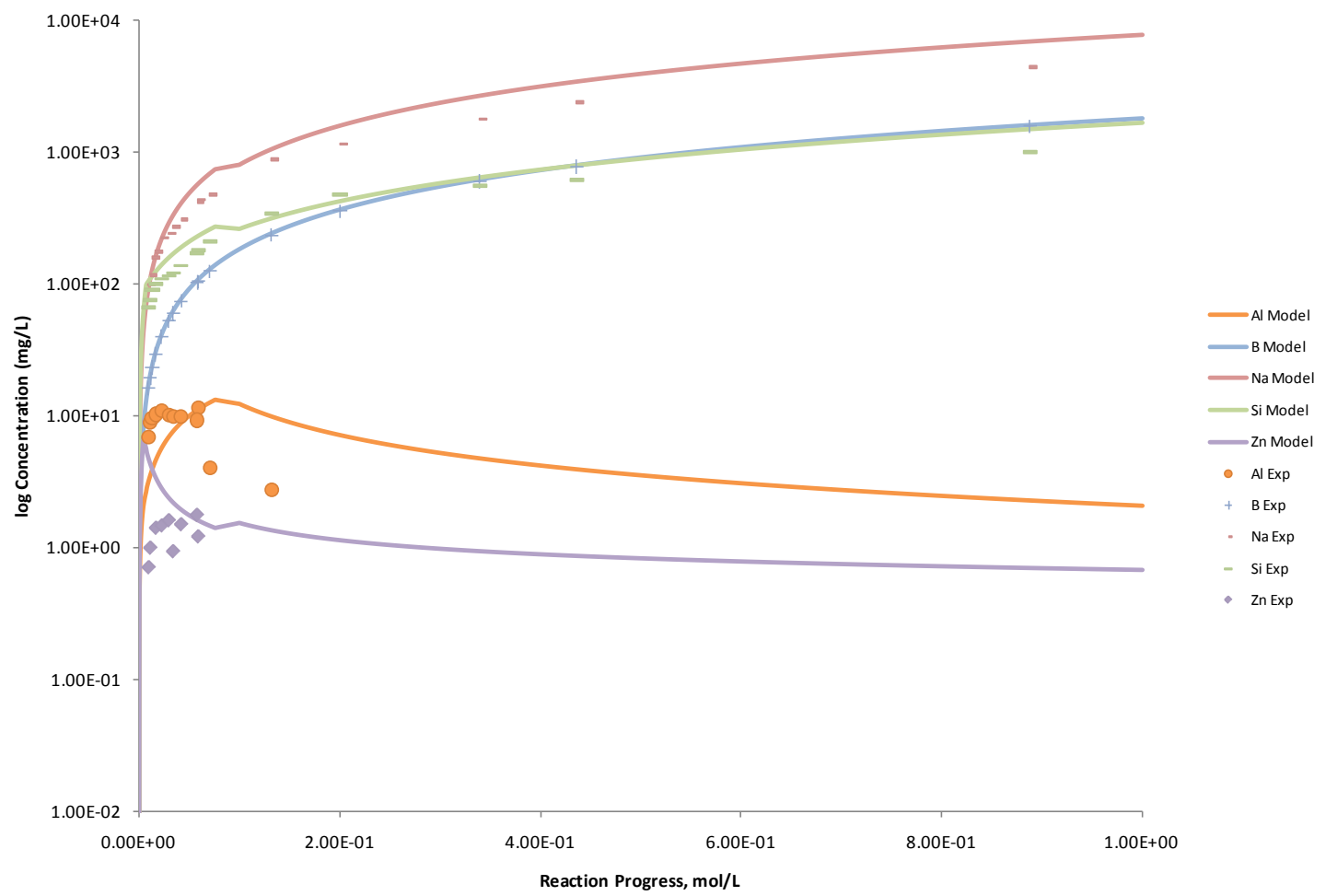

Figure C.164. Measured Solution Concentrations (mg/L) and Model Results for Al, B, Na, Si, and Zn, as a Function of Reaction Progress (mol-glass $/ \mathrm{kg}$ ) Determined for Glass Sample LAWA84 


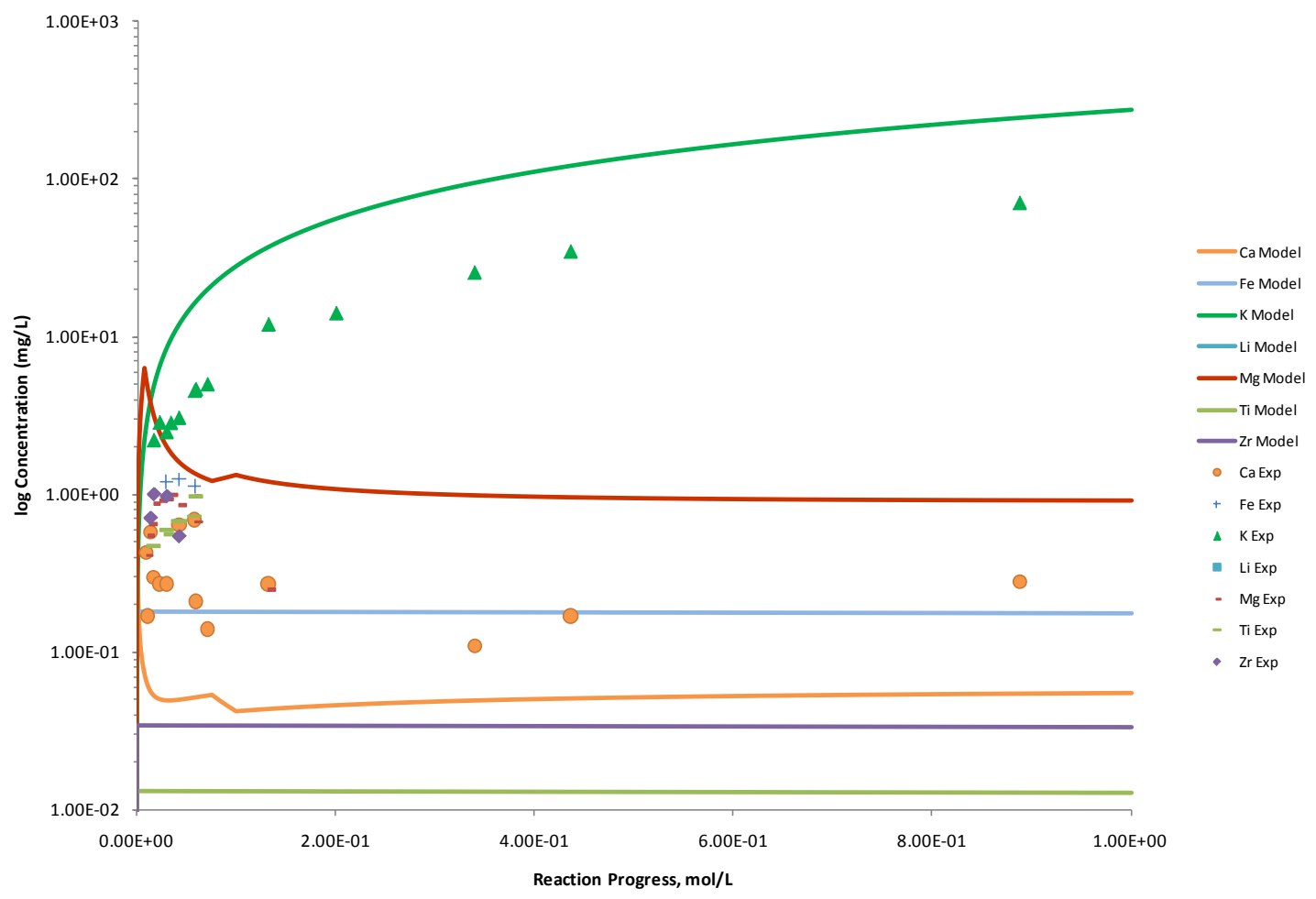

Figure C.165. Measured Solution Concentrations (mg/L) and Model Results for $\mathrm{Ca}, \mathrm{Fe}, \mathrm{K}, \mathrm{Li}, \mathrm{Mg}$, Ti, and $\mathrm{Zr}$, as a Function of Reaction Progress (mol-glass/kg) Determined for Glass Sample LAWA84

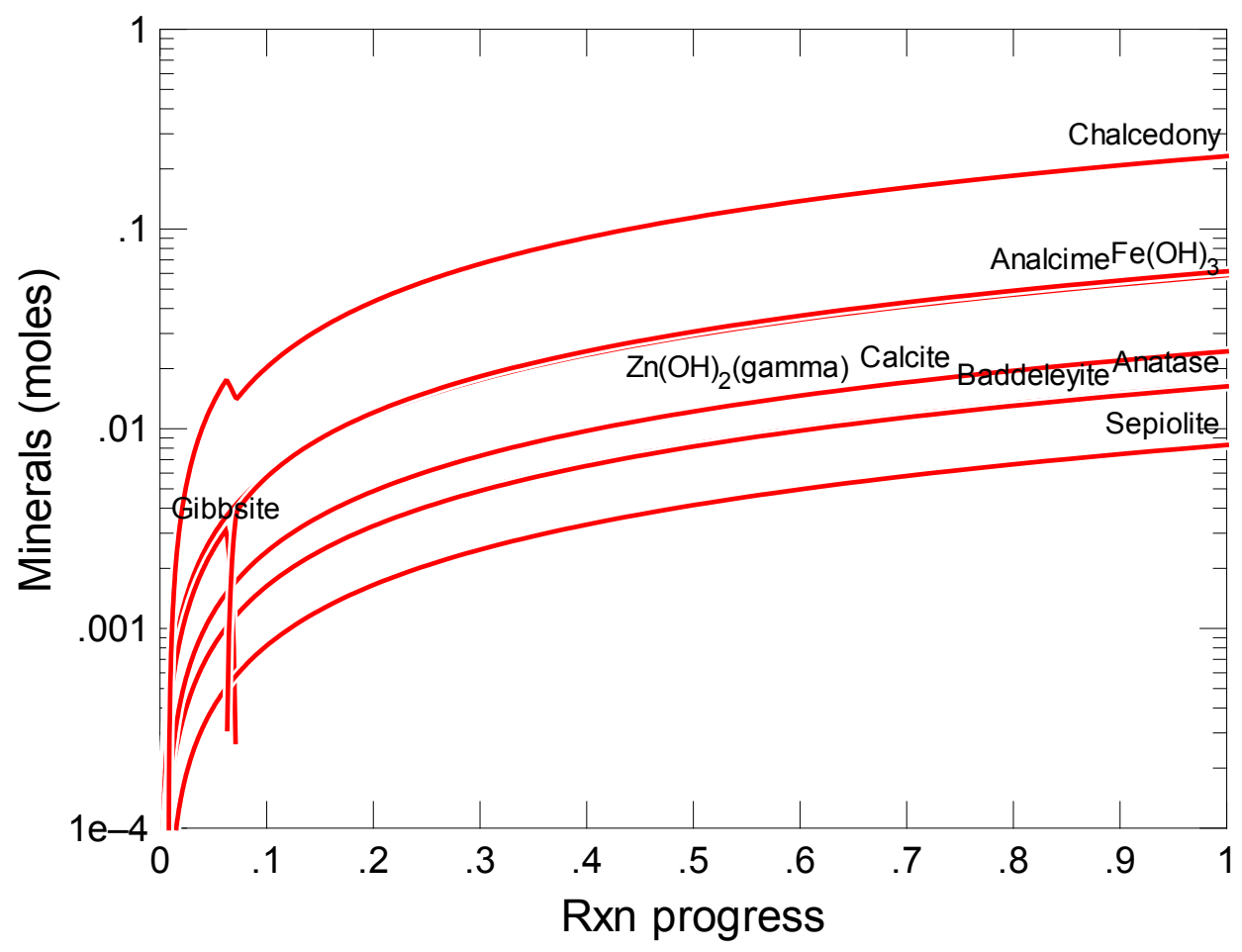

Figure C.166. Secondary Phases Calculated to Form as a Function of Reaction Progress (mol-glass $/ \mathrm{kg}$ ) Determined for Glass Sample LAWA87 


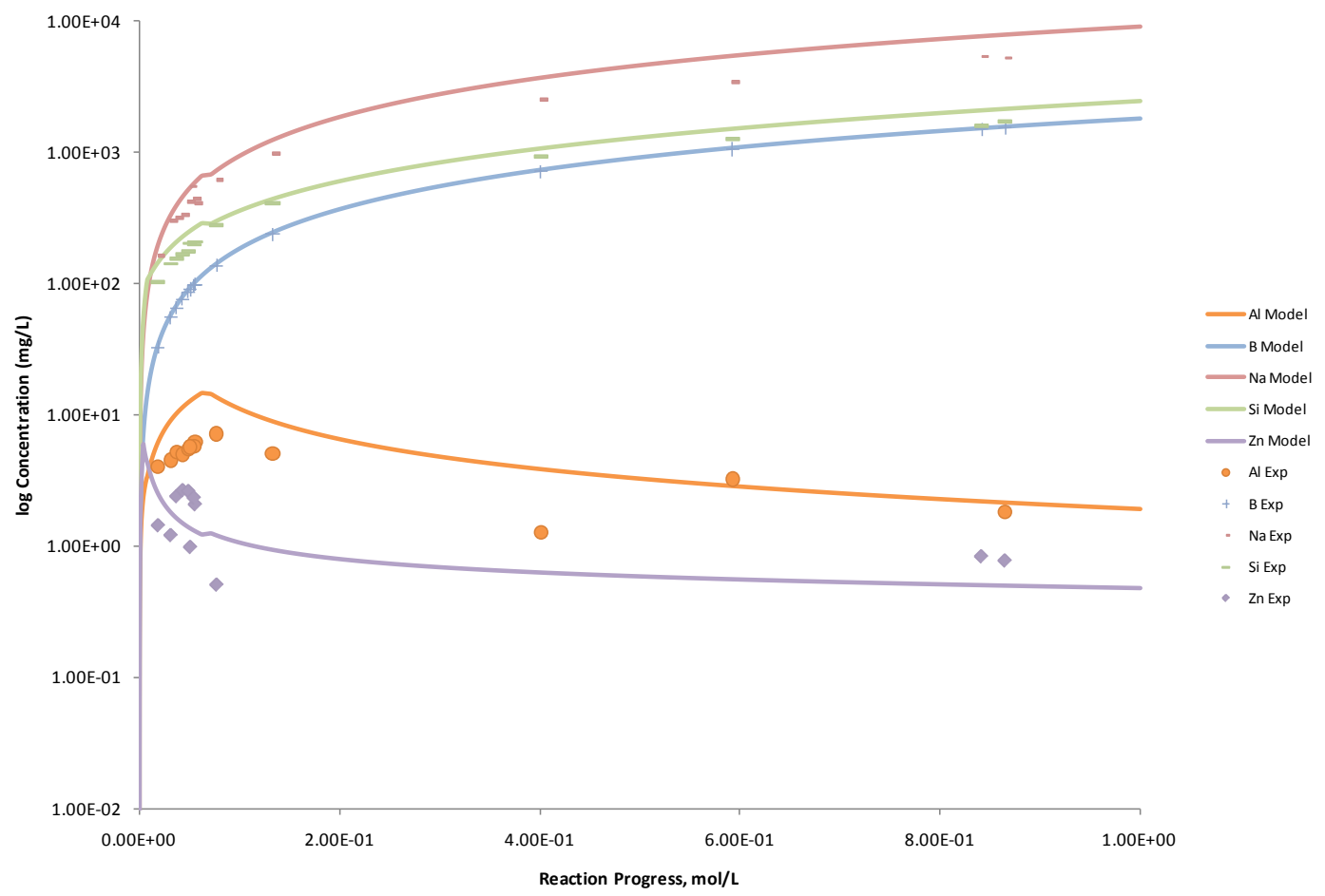

Figure C.167. Measured Solution Concentrations (mg/L) and Model Results for Al, B, Na, Si, and Zn, as a Function of Reaction Progress (mol-glass $/ \mathrm{kg}$ ) Determined for Glass Sample LAWA87

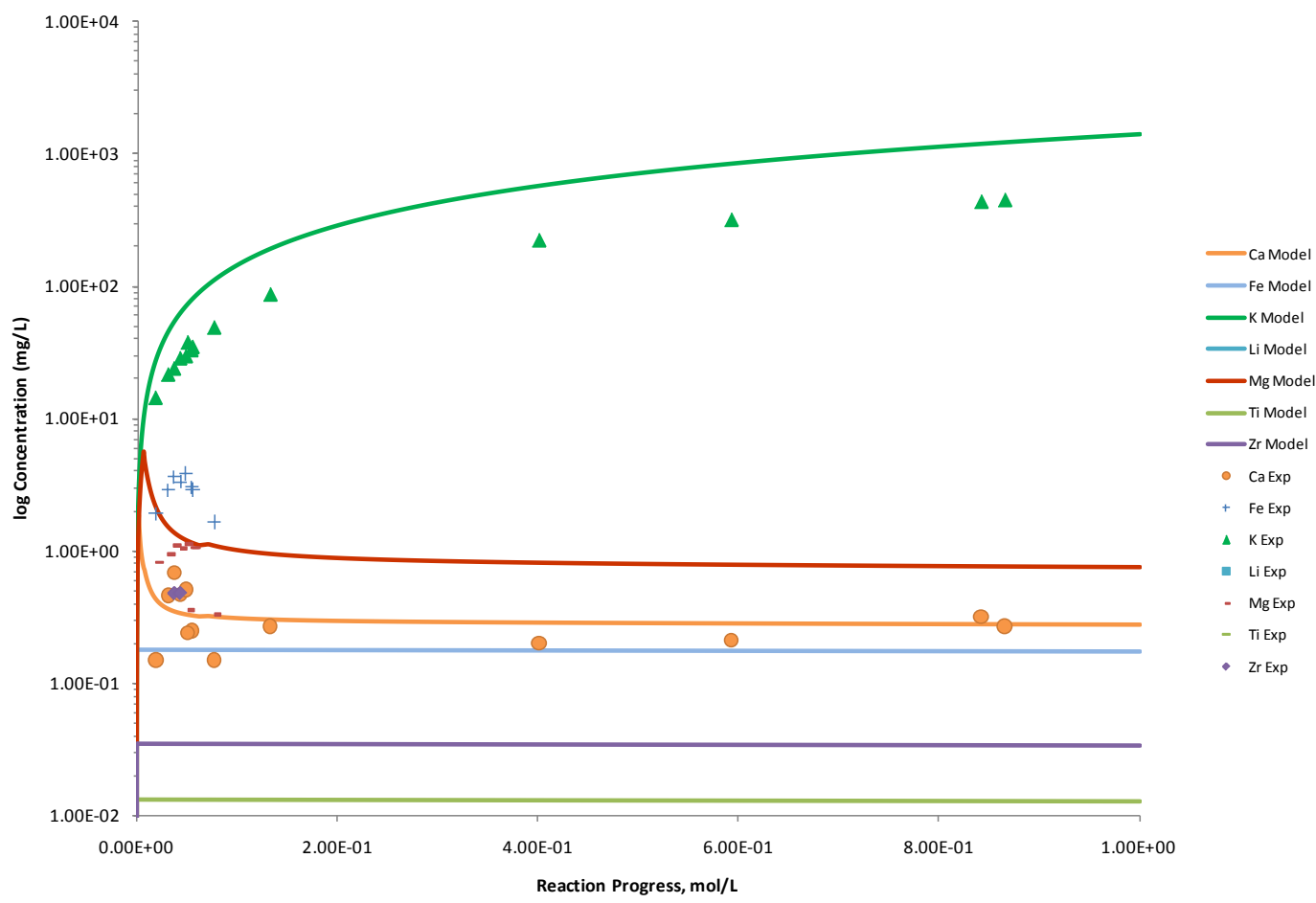

Figure C.168. Measured Solution Concentrations (mg/L) and Model Results for $\mathrm{Ca}, \mathrm{Fe}, \mathrm{K}, \mathrm{Li}, \mathrm{Mg}, \mathrm{Ti}$, and $\mathrm{Zr}$, as a Function of Reaction Progress (mol-glass/kg) Determined for Glass Sample LAWA87 


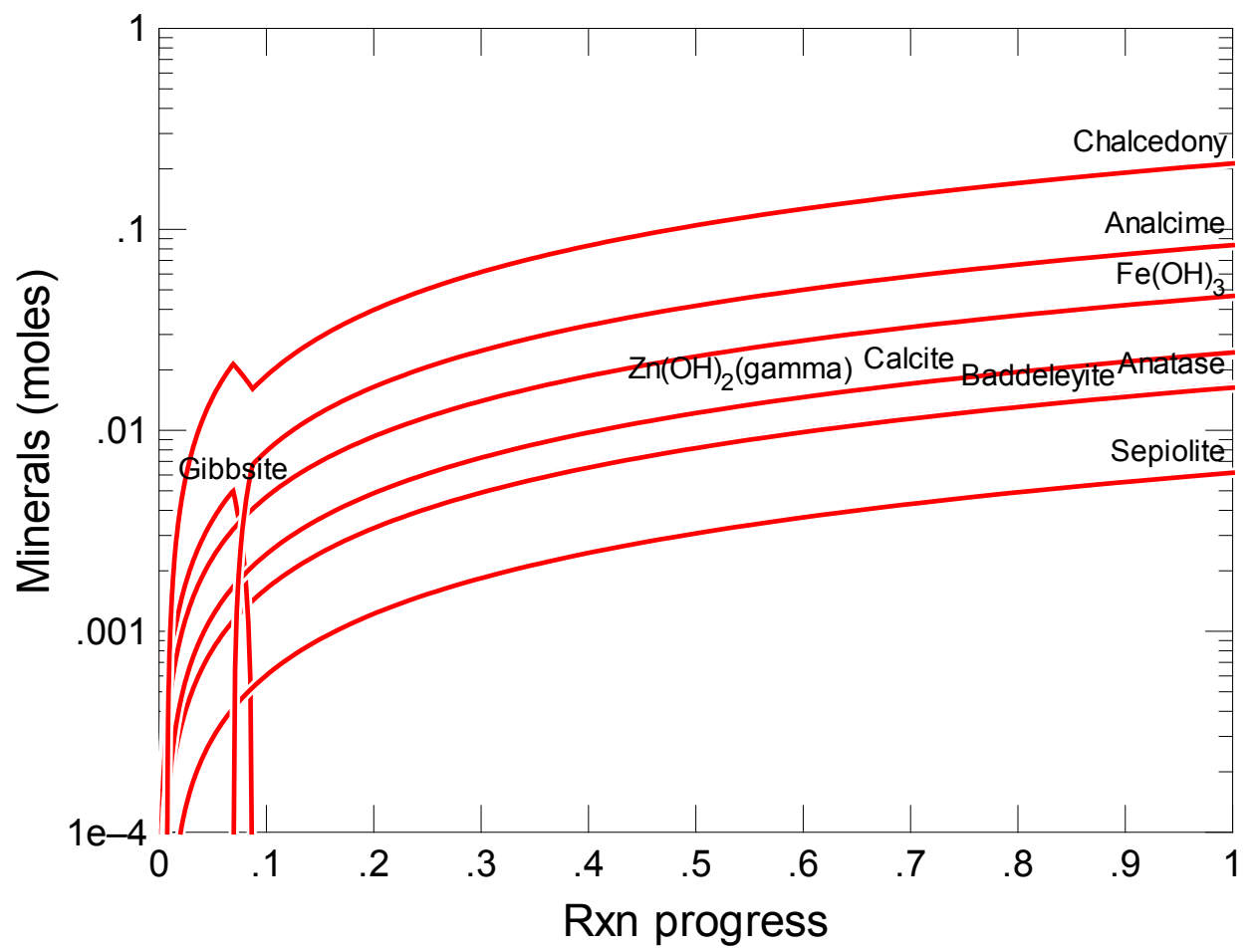

Figure C.169. Secondary Phases Calculated to Form as a Function of Reaction Progress (mol-glass $/ \mathrm{kg}$ ) Determined for Glass Sample LAWA88

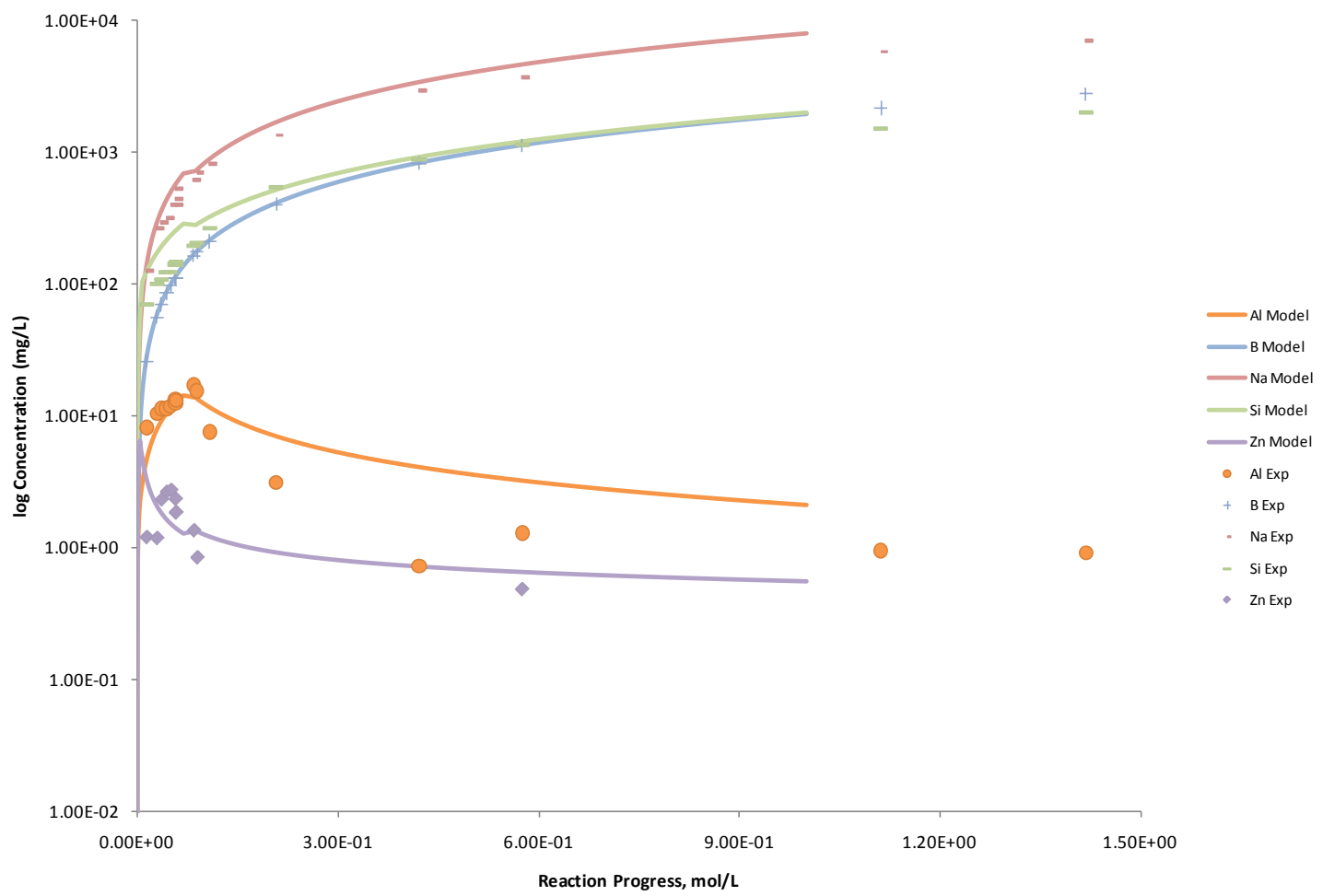

Figure C.170. Measured Solution Concentrations (mg/L) and Model Results for Al, B, Na, Si, and Zn, as a Function of Reaction Progress (mol-glass $/ \mathrm{kg}$ ) Determined for Glass Sample LAWA88 


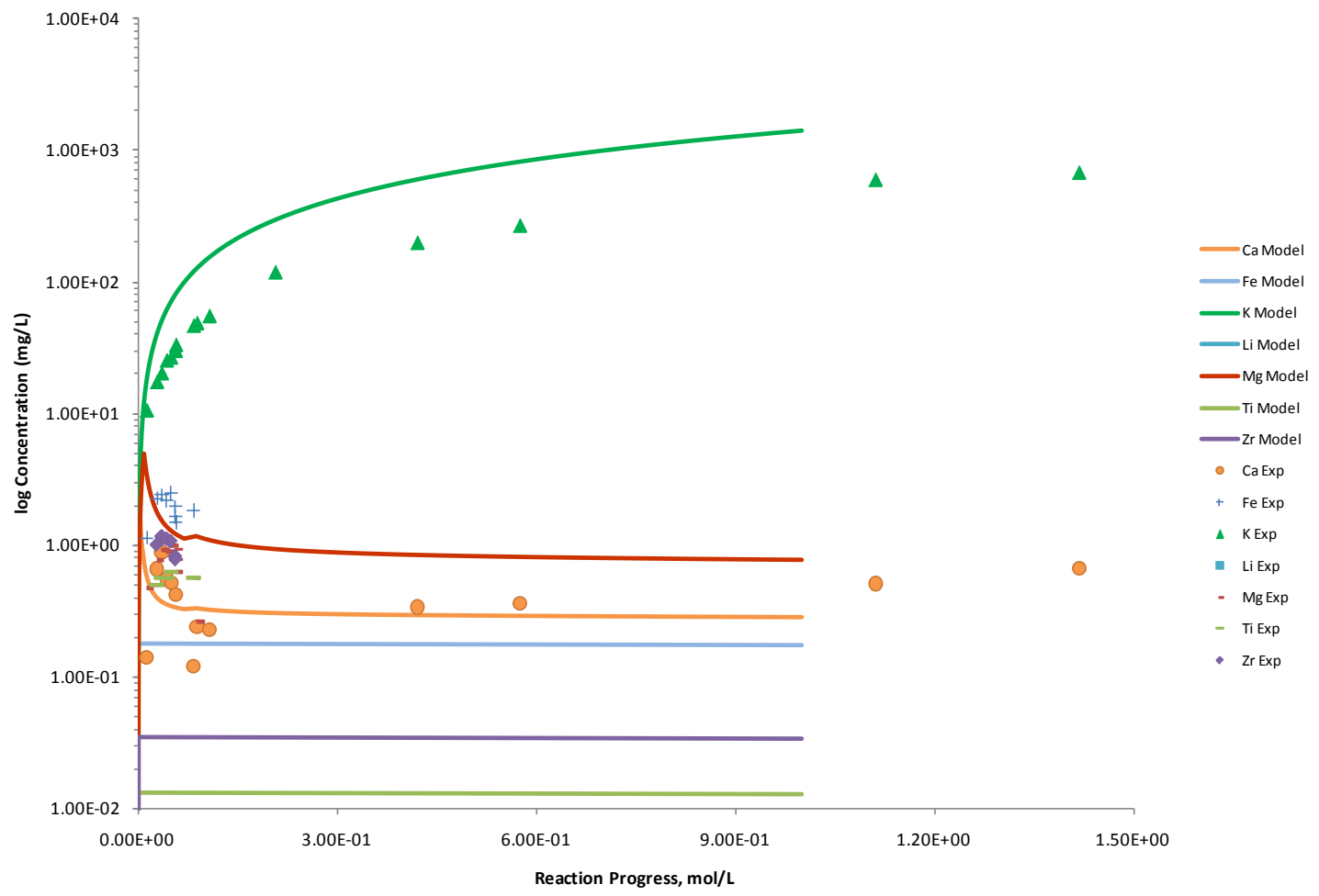

Figure C.171. Measured Solution Concentrations (mg/L) and Model Results for $\mathrm{Ca}, \mathrm{Fe}, \mathrm{K}, \mathrm{Li}, \mathrm{Mg}$, Ti, and $\mathrm{Zr}$, as a Function of Reaction Progress (mol-glass/kg) Determined for Glass Sample LAWA88

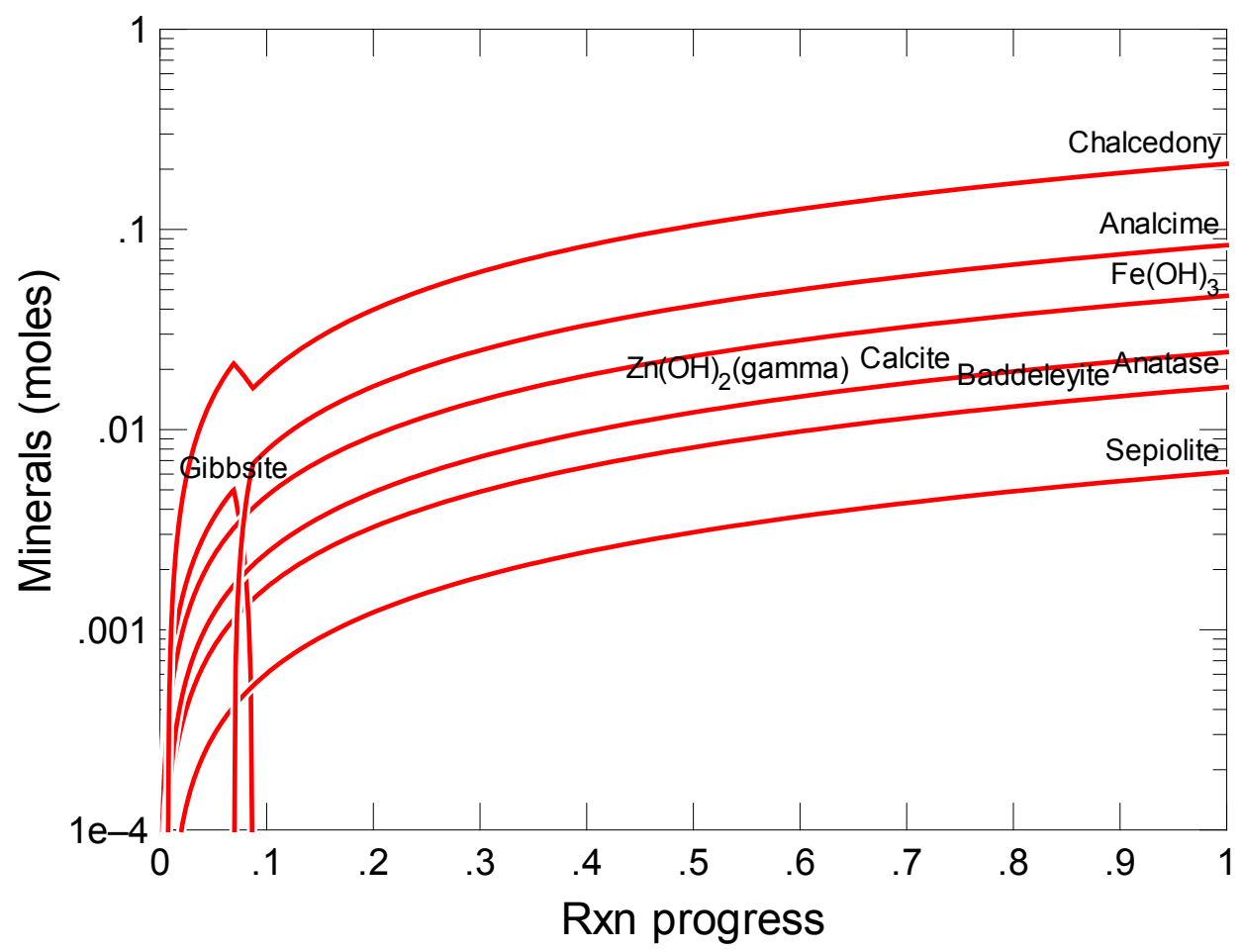

Figure C.172. Secondary Phases Calculated to Form as a Function of Reaction Progress (mol-glass/kg) Determined for Glass Sample LAWA88R1 


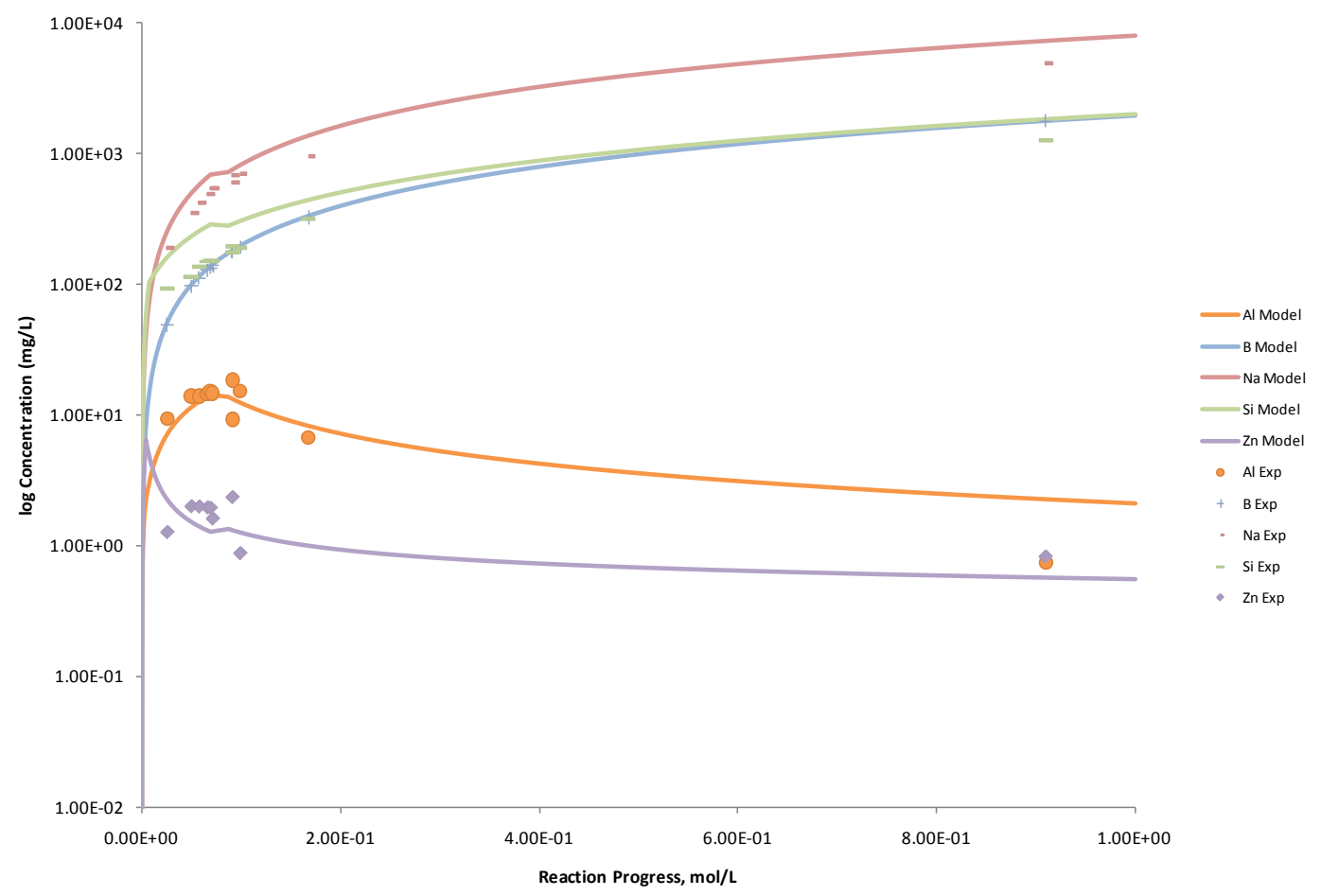

Figure C.173. Measured Solution Concentrations (mg/L) and Model Results for Al, B, Na, Si, and Zn, as a Function of Reaction Progress (mol-glass $/ \mathrm{kg}$ ) Determined for Glass Sample LAWA88R1

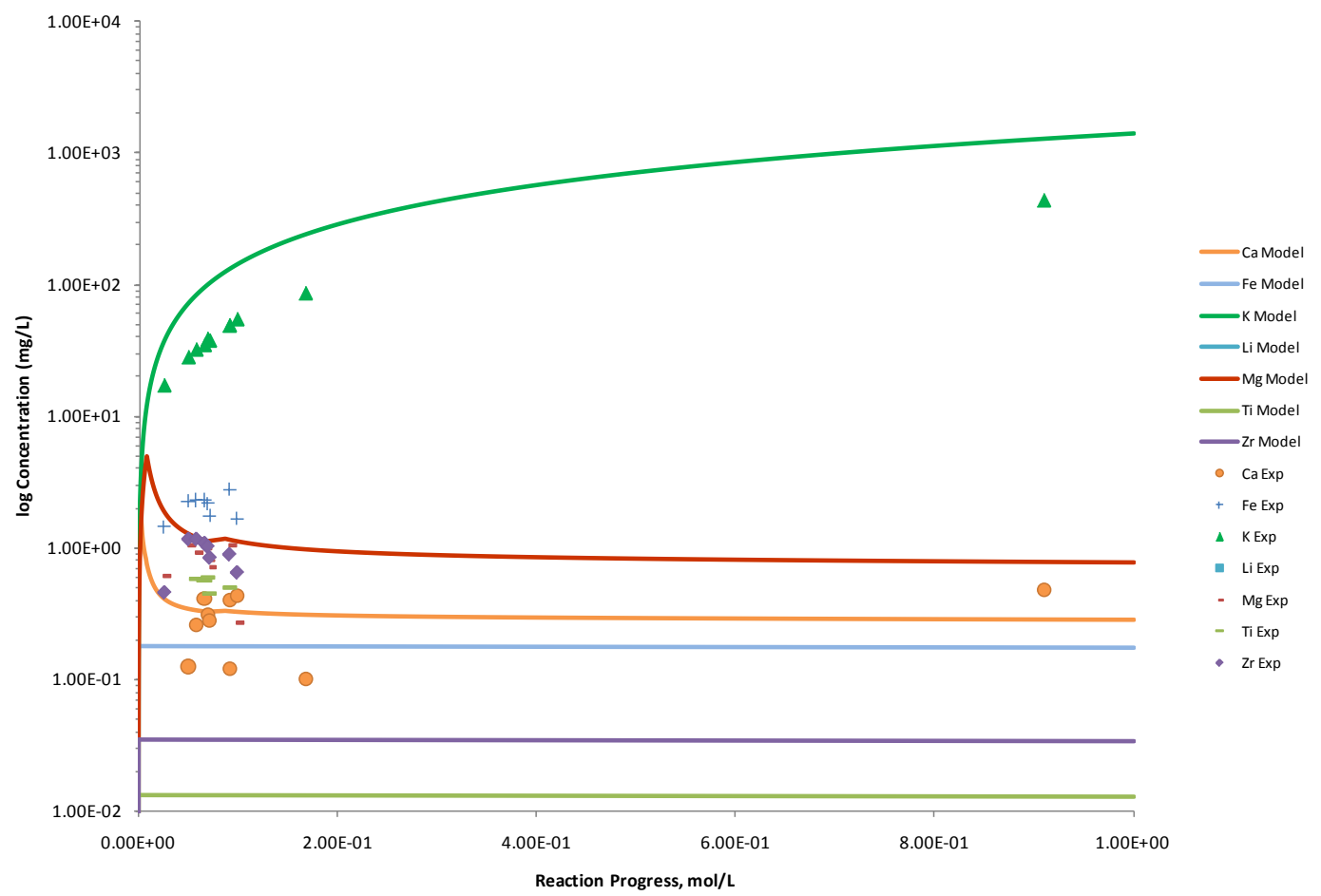

Figure C.174. Measured Solution Concentrations (mg/L) and Model Results for Ca, Fe, K, Li, Mg, Ti, and $\mathrm{Zr}$, as a Function of Reaction Progress (mol-glass/kg) Determined for Glass Sample LAWA88R1 


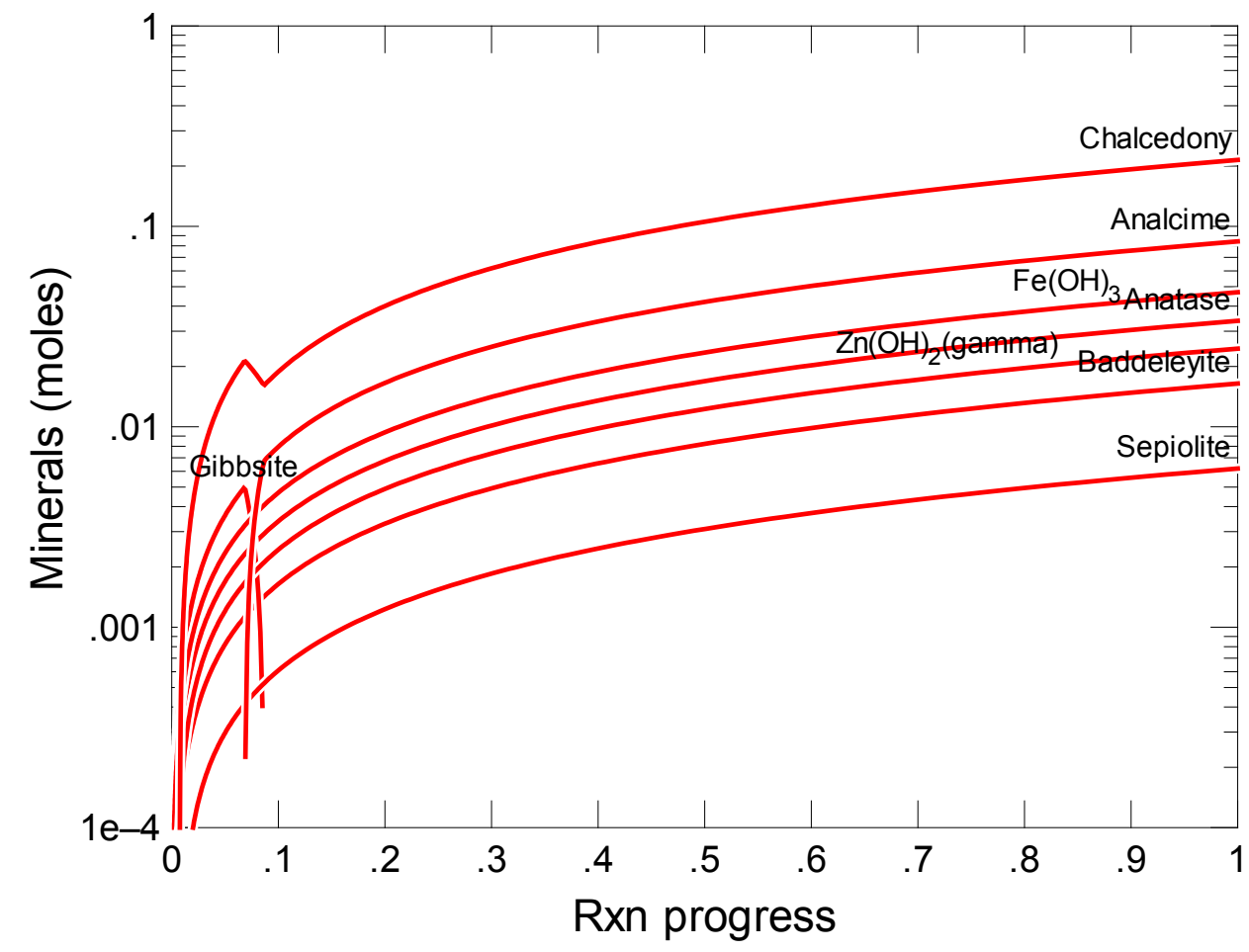

Figure C.175. Secondary Phases Calculated to Form as a Function of Reaction Progress (mol-glass $/ \mathrm{kg}$ ) Determined for Glass Sample LAWA89

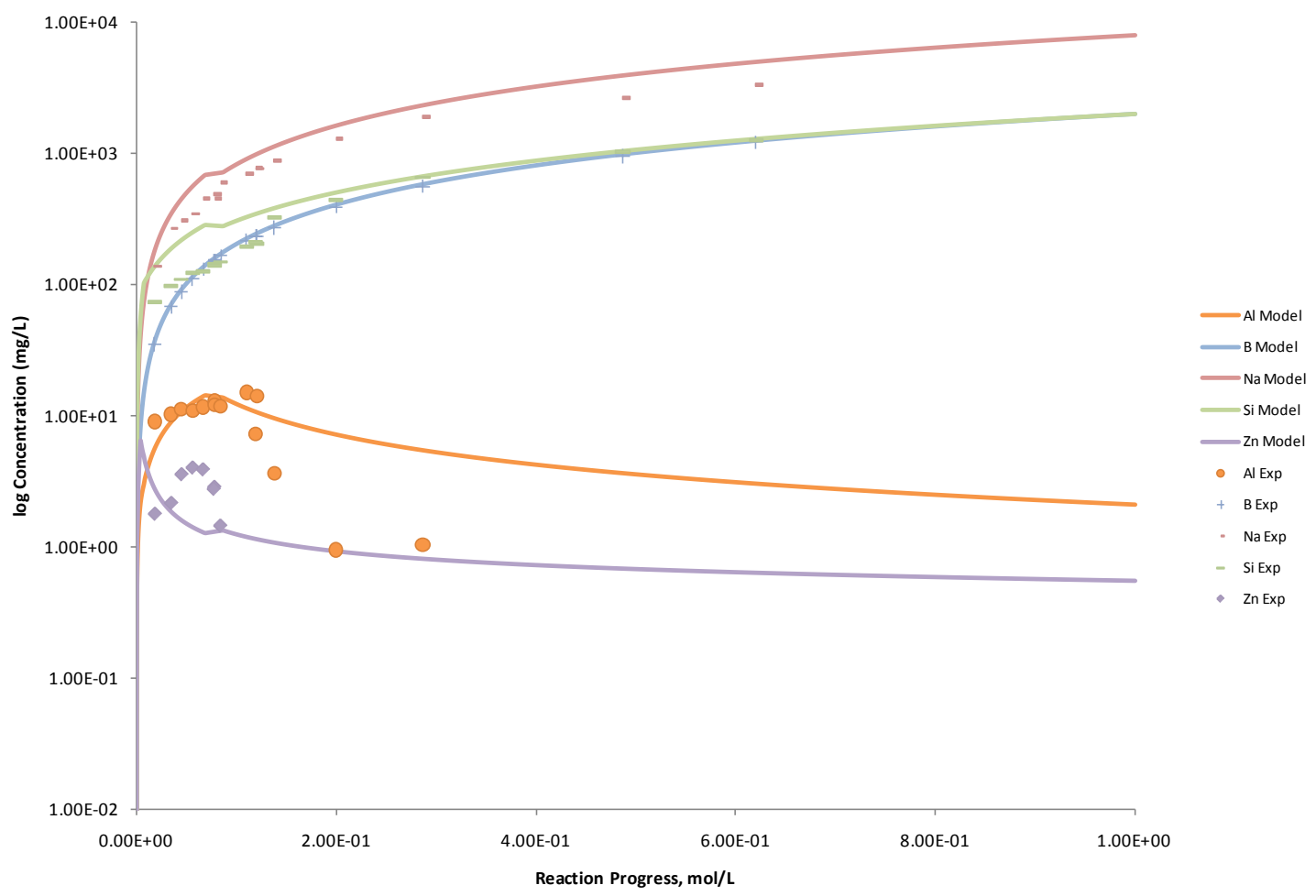

Figure C.176. Measured Solution Concentrations (mg/L) and Model Results for Al, B, Na, Si, and Zn, as a Function of Reaction Progress (mol-glass $/ \mathrm{kg}$ ) Determined for Glass Sample LAWA89 


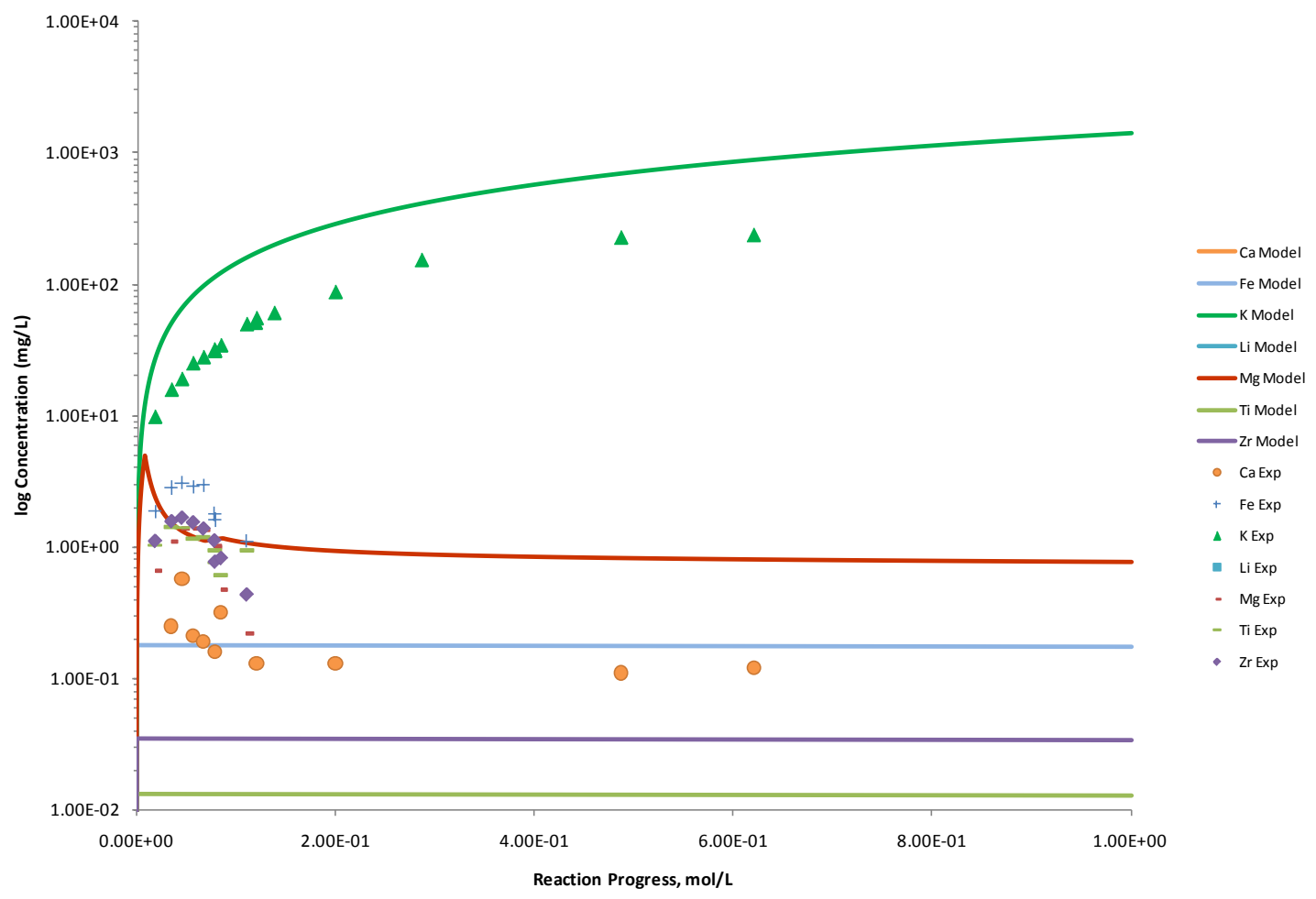

Figure C.177. Measured Solution Concentrations (mg/L) and Model Results for $\mathrm{Ca}, \mathrm{Fe}, \mathrm{K}, \mathrm{Li}, \mathrm{Mg}, \mathrm{Ti}$, and $\mathrm{Zr}$, as a Function of Reaction Progress (mol-glass/kg) Determined for Glass Sample LAWA89

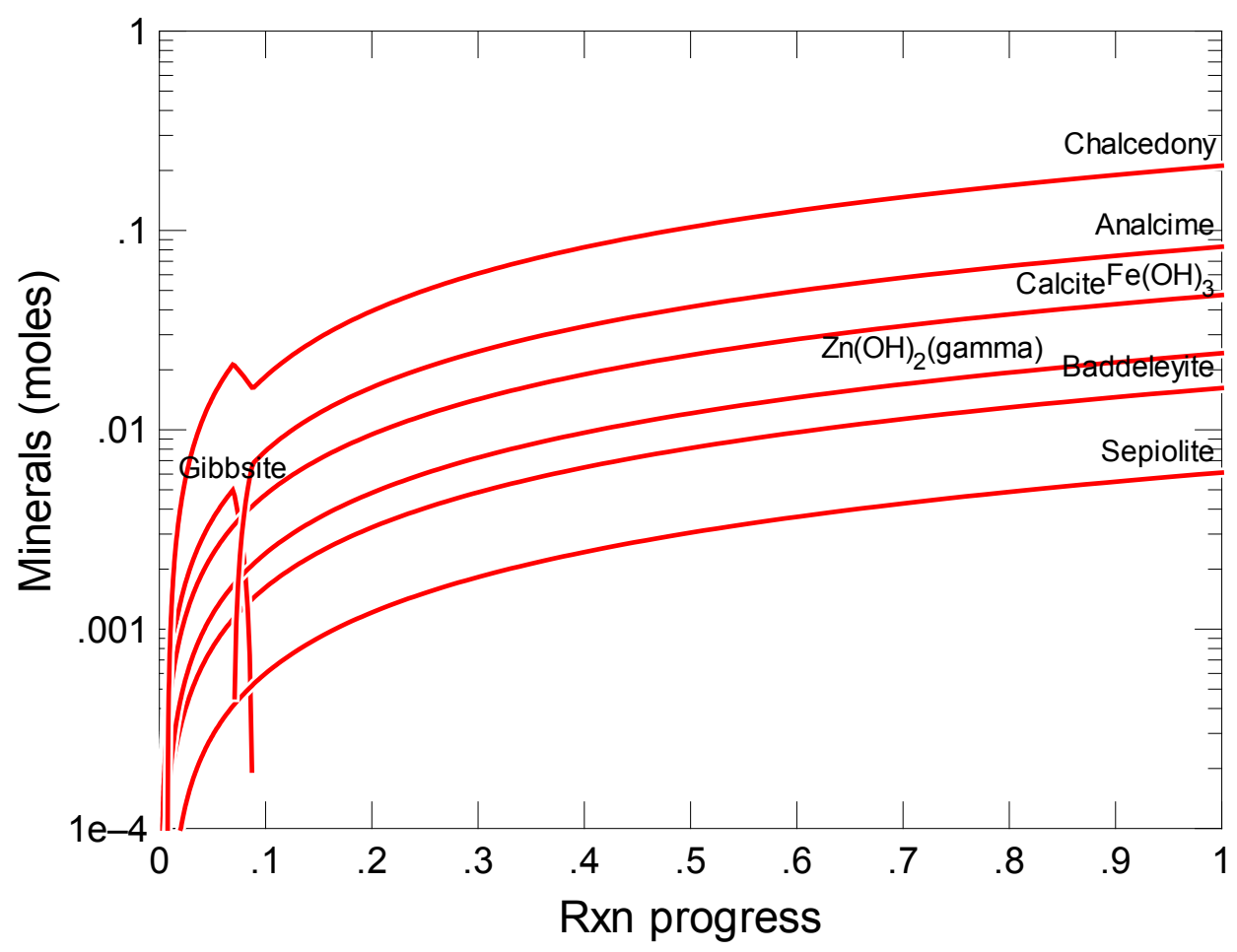

Figure C.178. Secondary Phases Calculated to Form as a Function of Reaction Progress (mol-glass/kg) Determined for Glass Sample LAWA90 


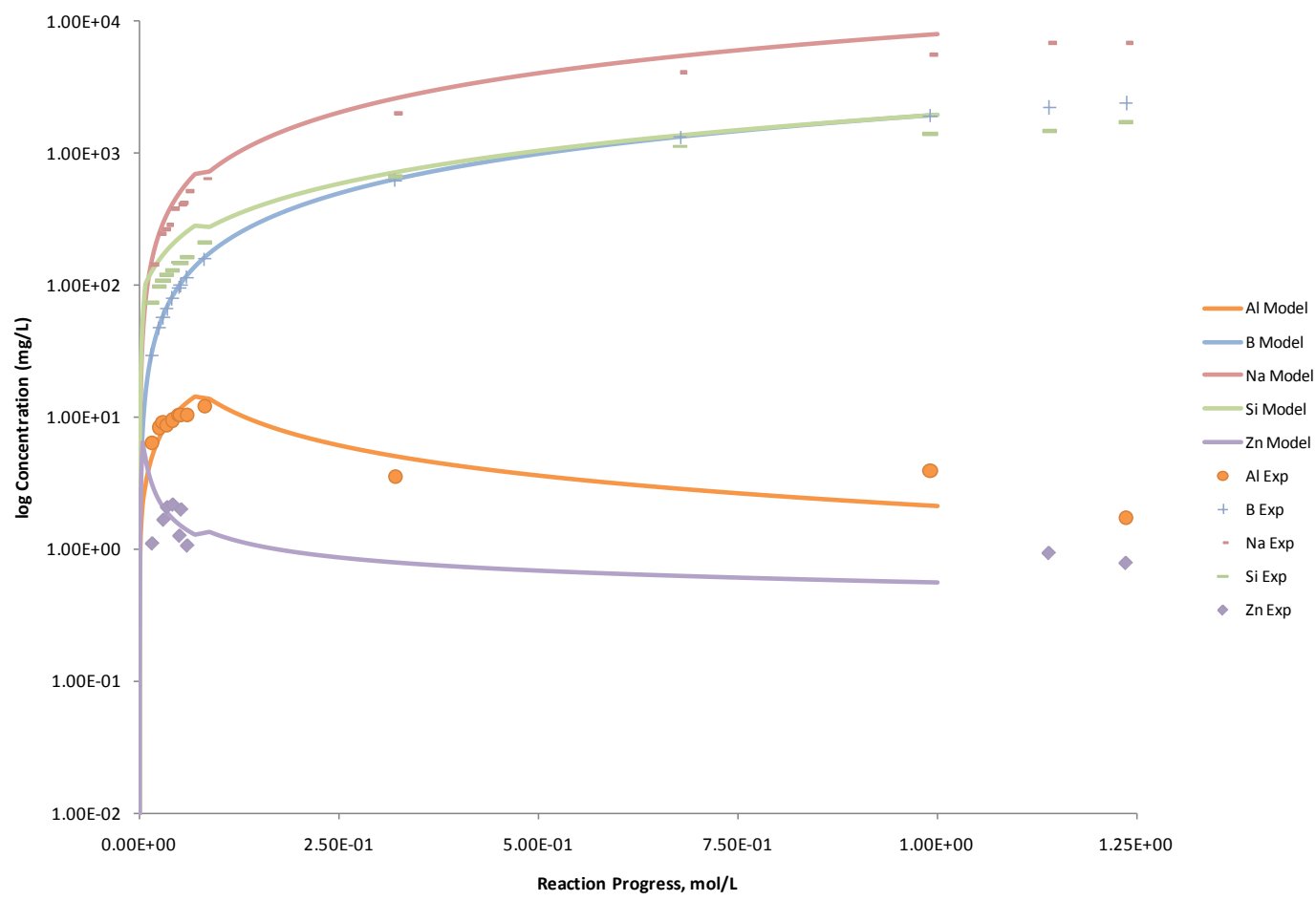

Figure C.179. Measured Solution Concentrations (mg/L) and Model Results for Al, B, Na, Si, and Zn, as a Function of Reaction Progress (mol-glass $/ \mathrm{kg}$ ) Determined for Glass Sample LAWA90

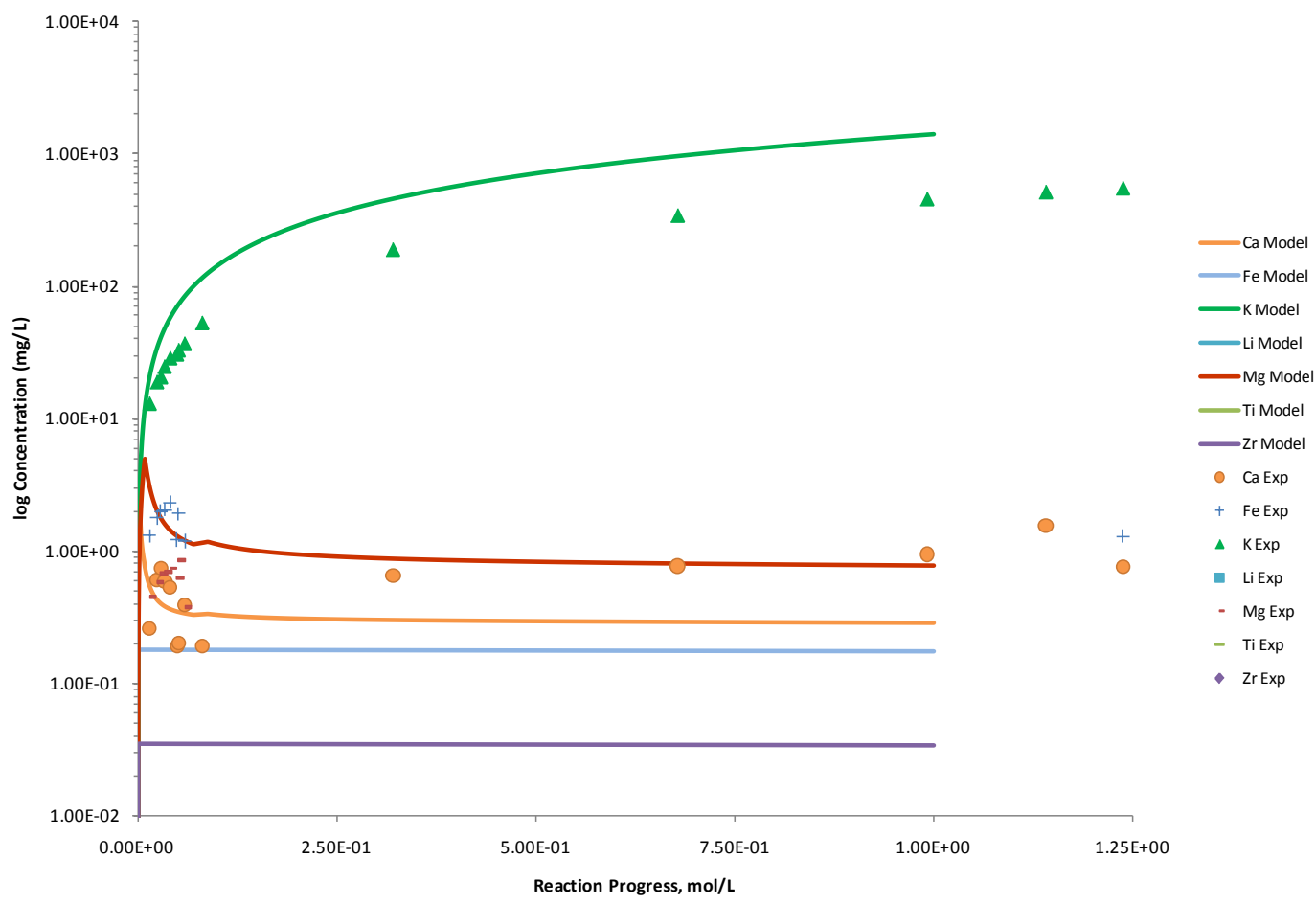

Figure C.180. Measured Solution Concentrations (mg/L) and Model Results for $\mathrm{Ca}, \mathrm{Fe}, \mathrm{K}, \mathrm{Li}, \mathrm{Mg}$, Ti, and $\mathrm{Zr}$, as a Function of Reaction Progress (mol-glass/kg) Determined for Glass Sample LAWA90 


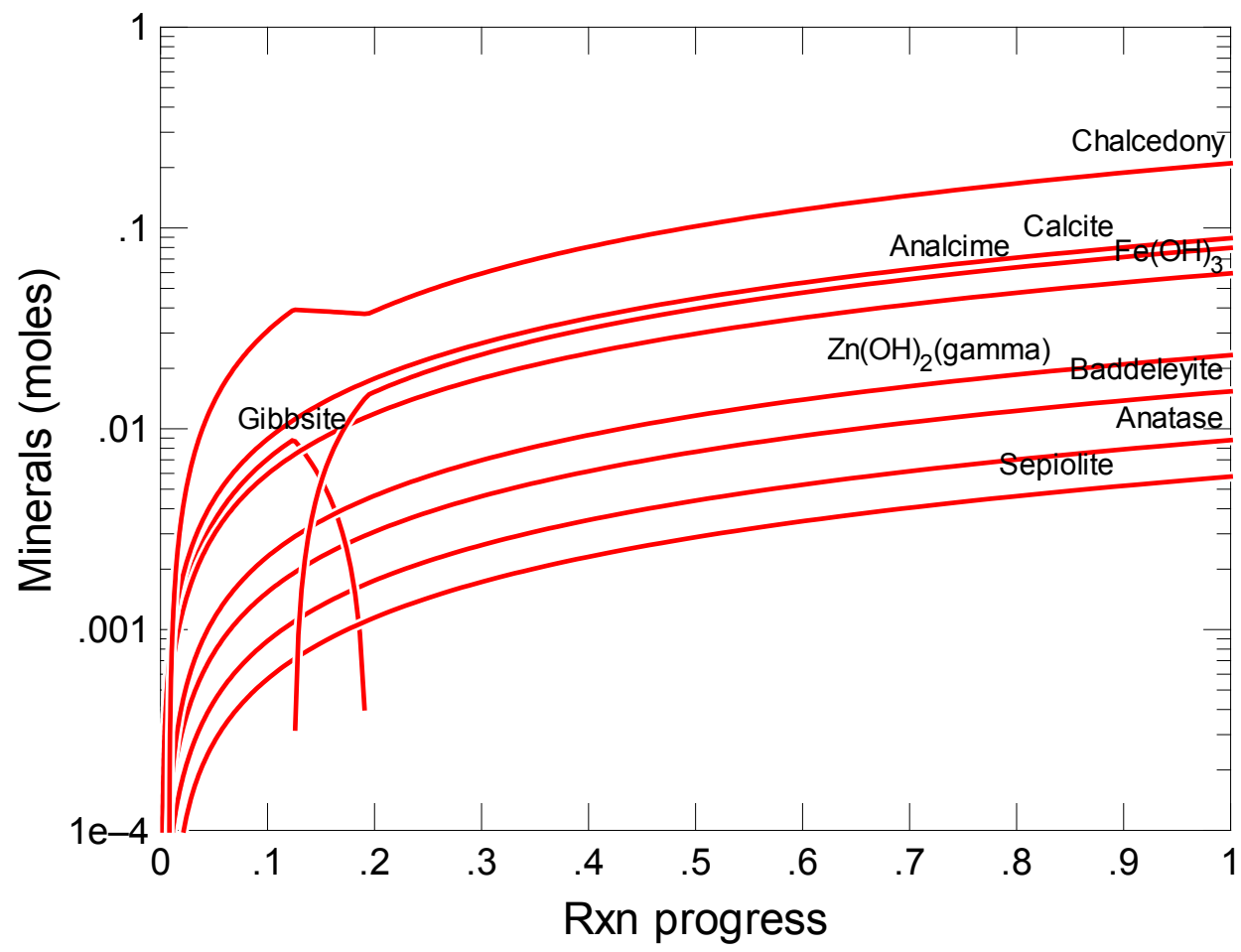

Figure C.181. Secondary Phases Calculated to Form as a Function of Reaction Progress (mol-glass $/ \mathrm{kg}$ ) Determined for Glass Sample LAWA93

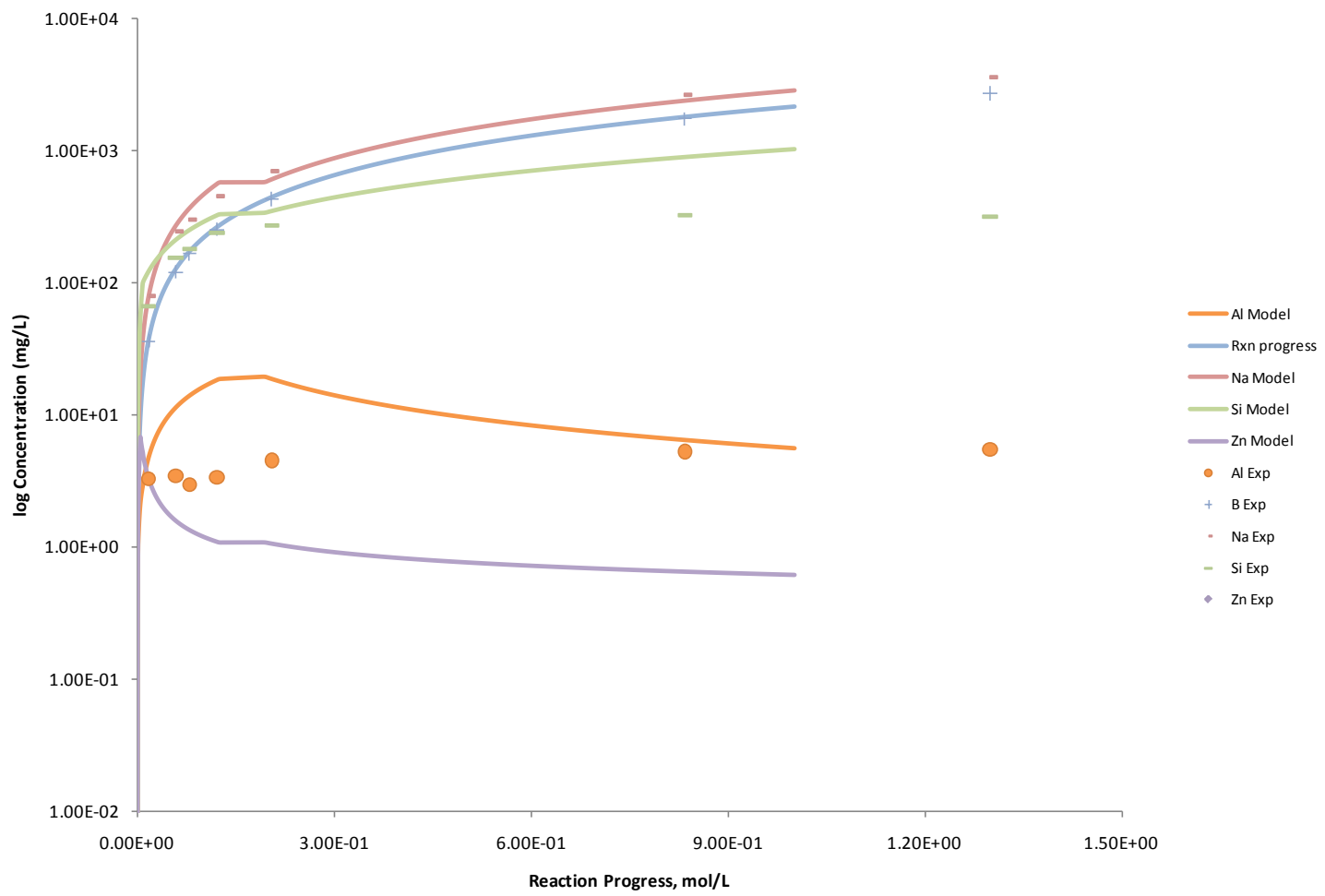

Figure C.182. Measured Solution Concentrations (mg/L) and Model Results for Al, B, Na, Si, and Zn, as a Function of Reaction Progress (mol-glass $/ \mathrm{kg}$ ) Determined for Glass Sample LAWA93 


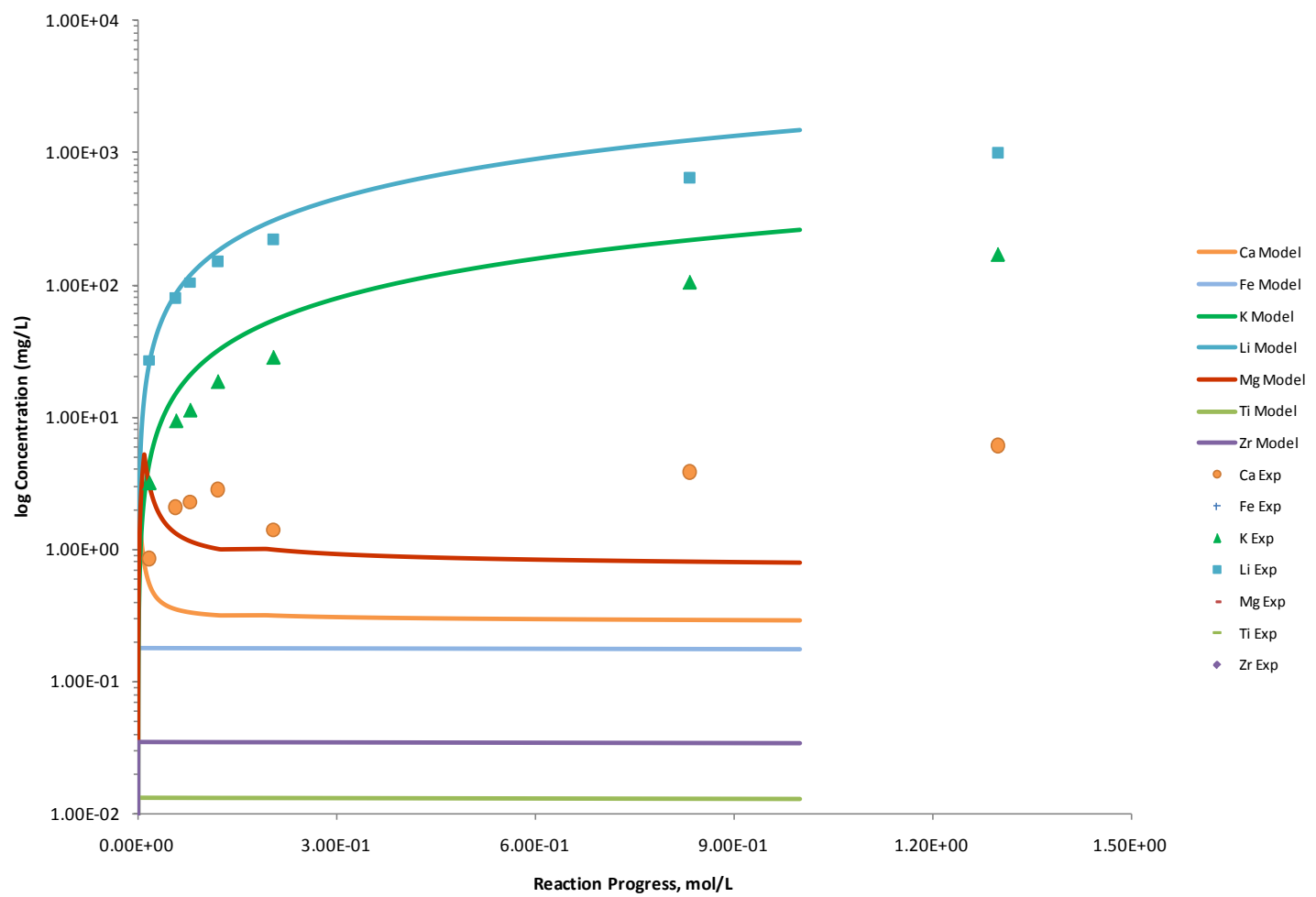

Figure C.183. Measured Solution Concentrations (mg/L) and Model Results for Ca, Fe, K, Li, Mg, Ti, and $\mathrm{Zr}$, as a Function of Reaction Progress (mol-glass/kg) Determined for Glass Sample LAWA93

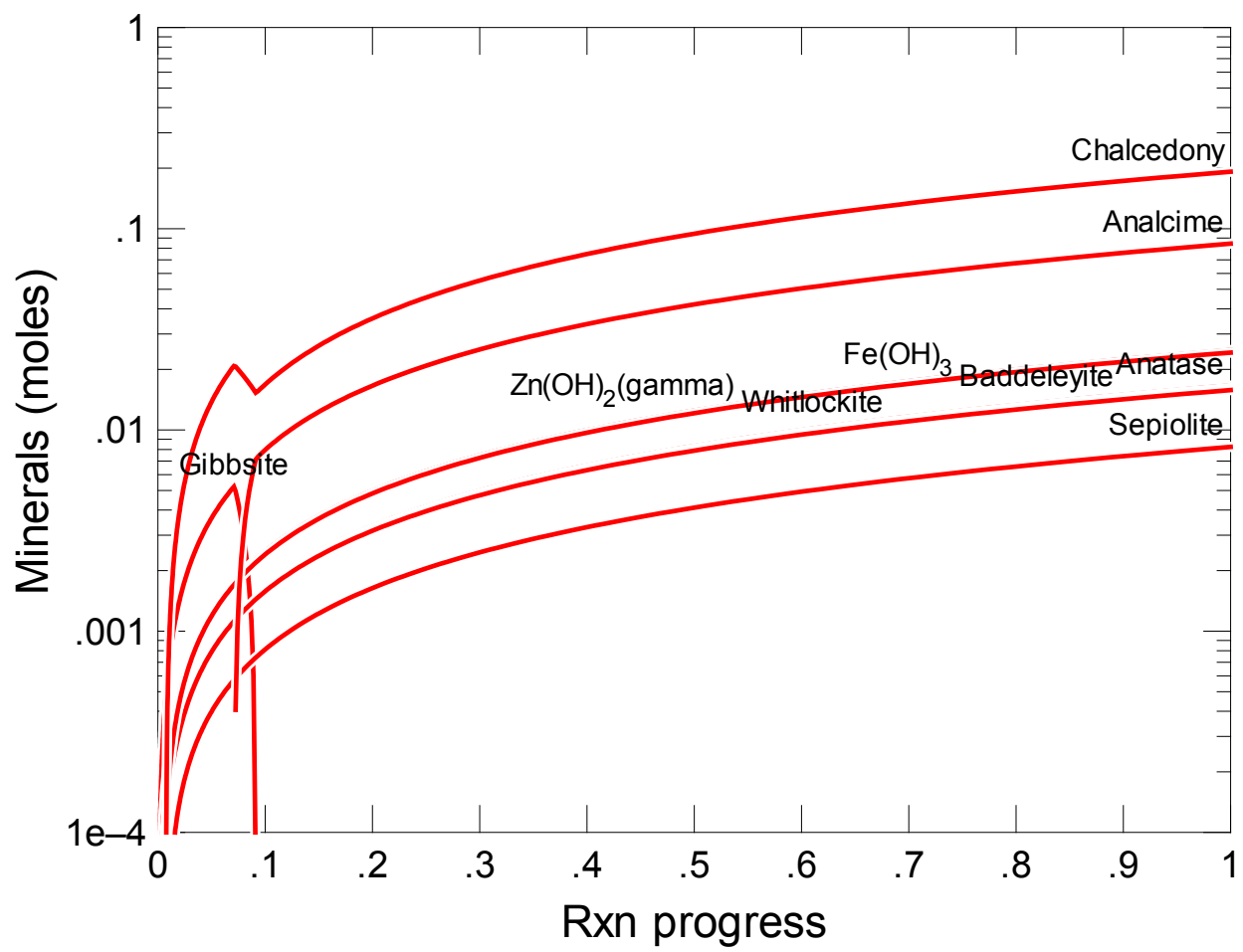

Figure C.184. Secondary Phases Calculated to Form as a Function of Reaction Progress (mol-glass/kg) Determined for Glass Sample LAWA96 


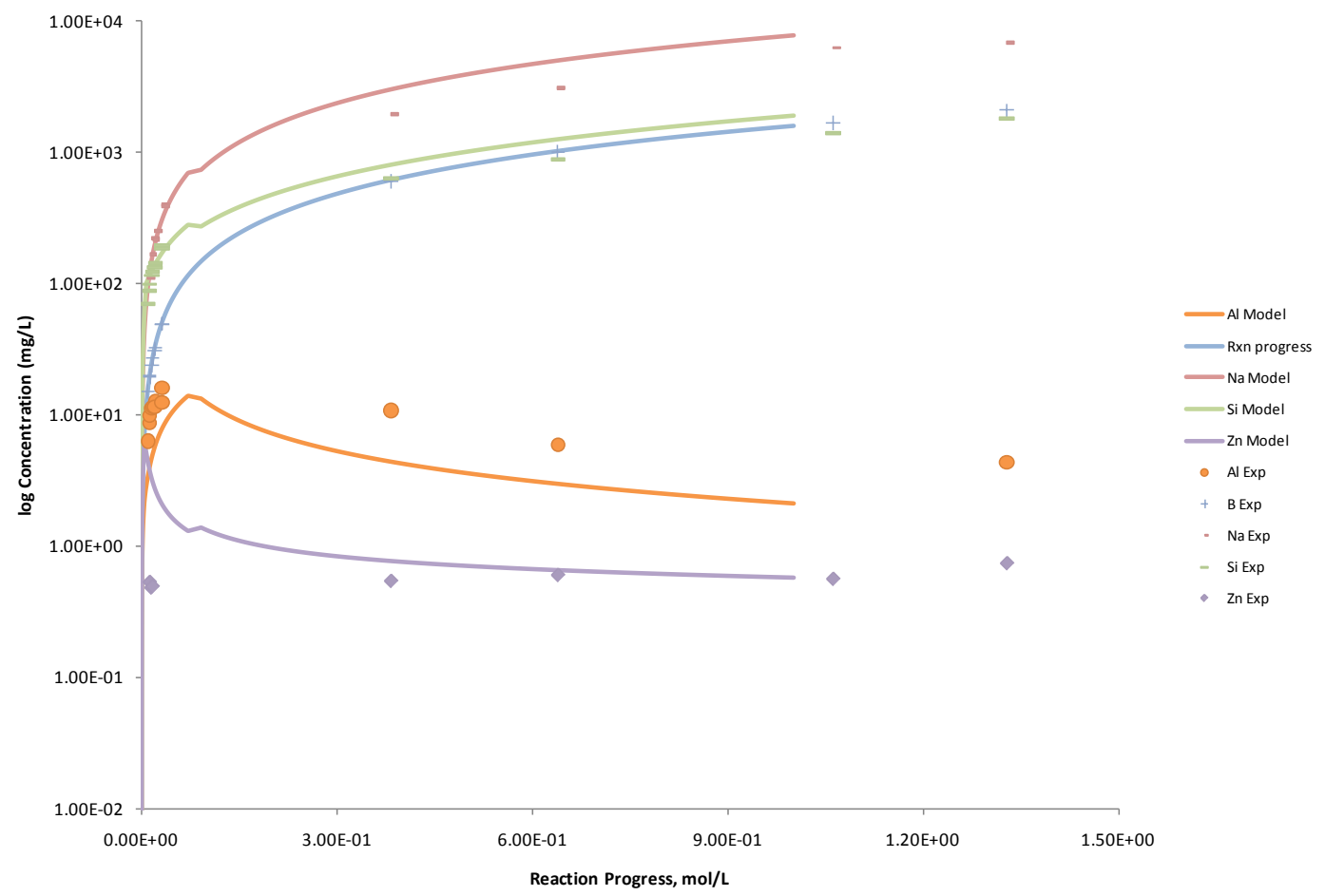

Figure C.185. Measured Solution Concentrations (mg/L) and Model Results for Al, B, Na, Si, and Zn, as a Function of Reaction Progress (mol-glass $/ \mathrm{kg}$ ) Determined for Glass Sample LAWA96

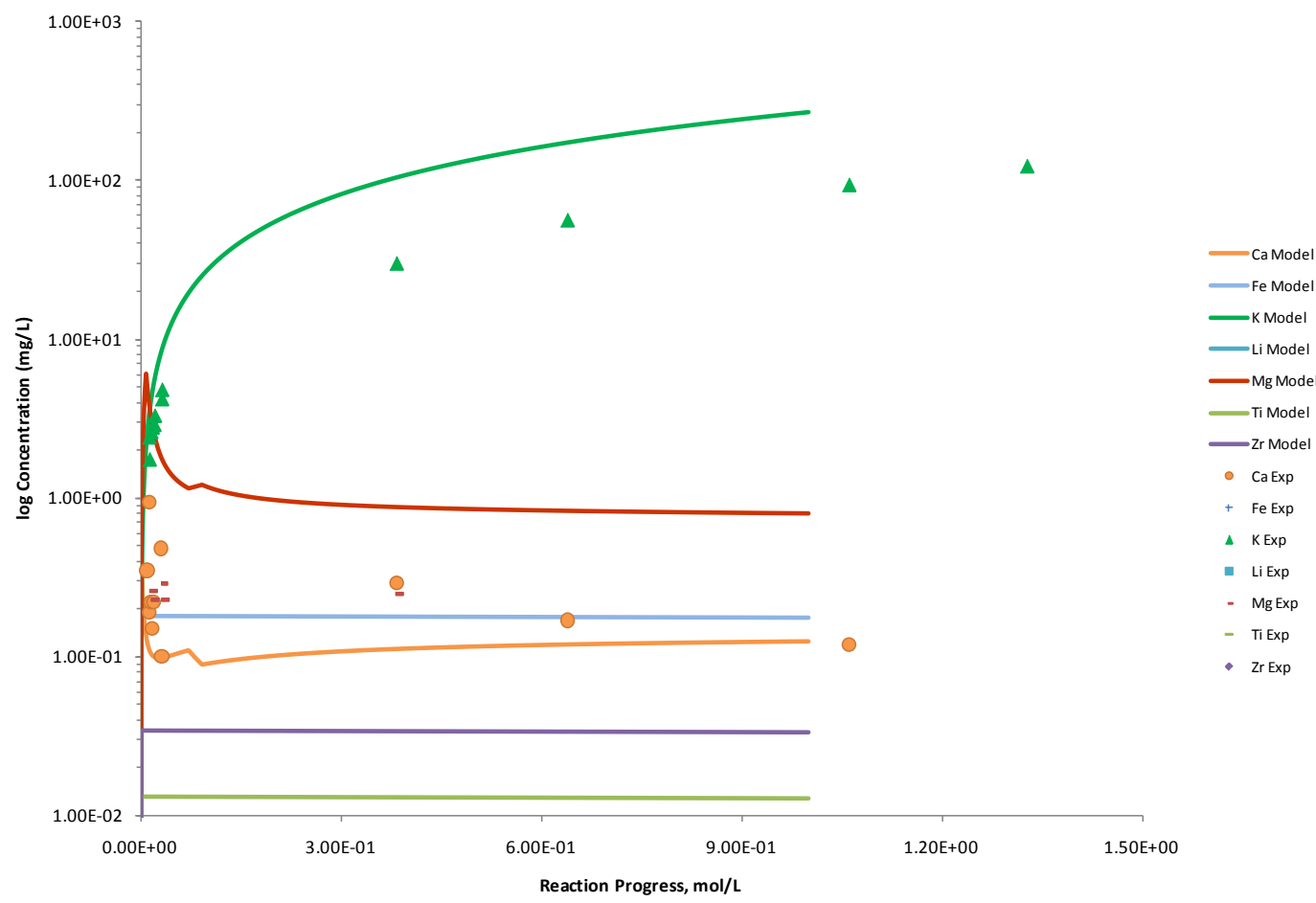

Figure C.186. Measured Solution Concentrations (mg/L) and Model Results for $\mathrm{Ca}, \mathrm{Fe}, \mathrm{K}, \mathrm{Li}, \mathrm{Mg}$, Ti, and $\mathrm{Zr}$, as a Function of Reaction Progress (mol-glass/kg) Determined for Glass Sample LAWA96 


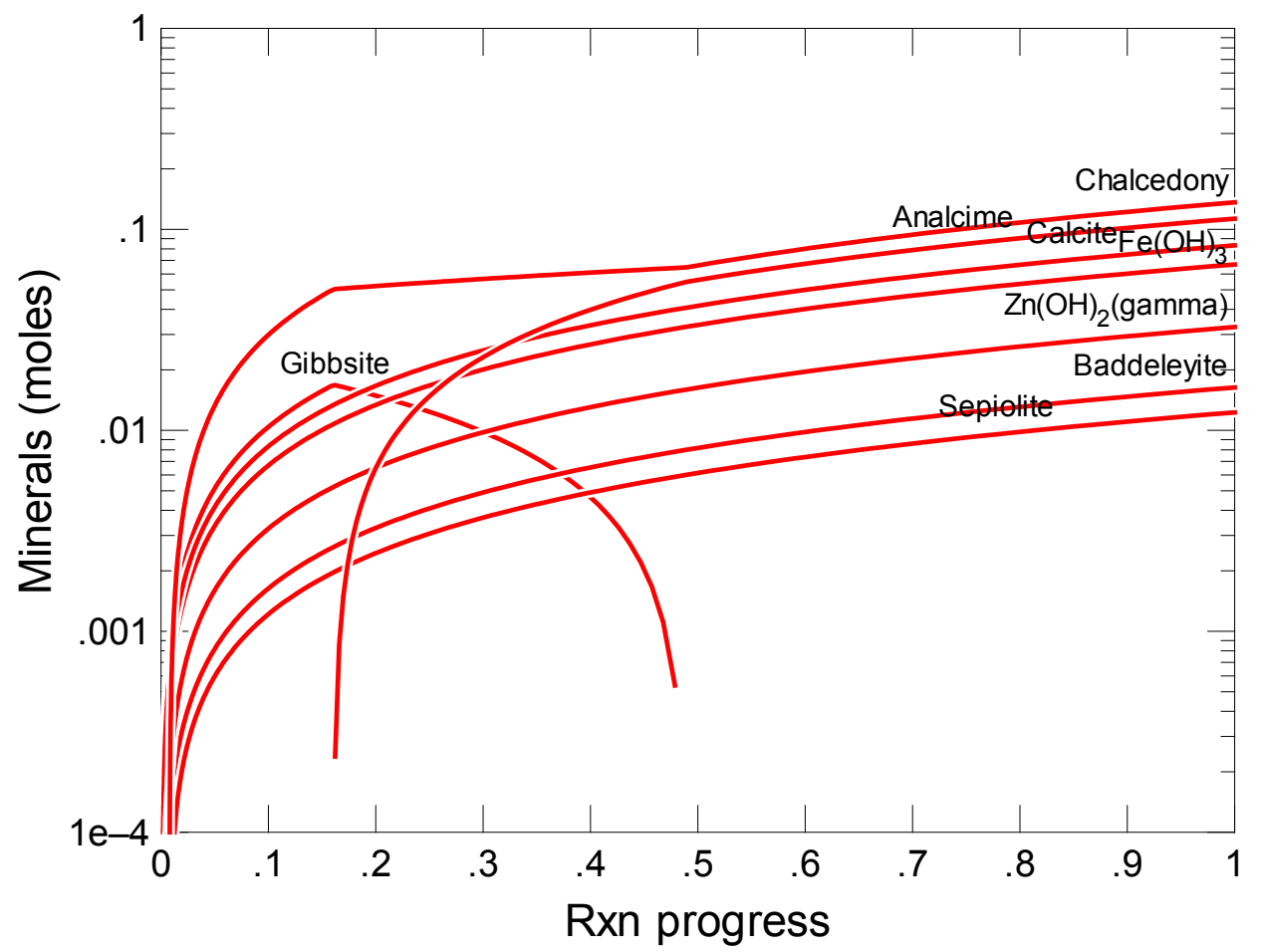

Figure C.187. Secondary Phases Calculated to Form as a Function of Reaction Progress (mol-glass $/ \mathrm{kg}$ ) Determined for Glass Sample LAWB30

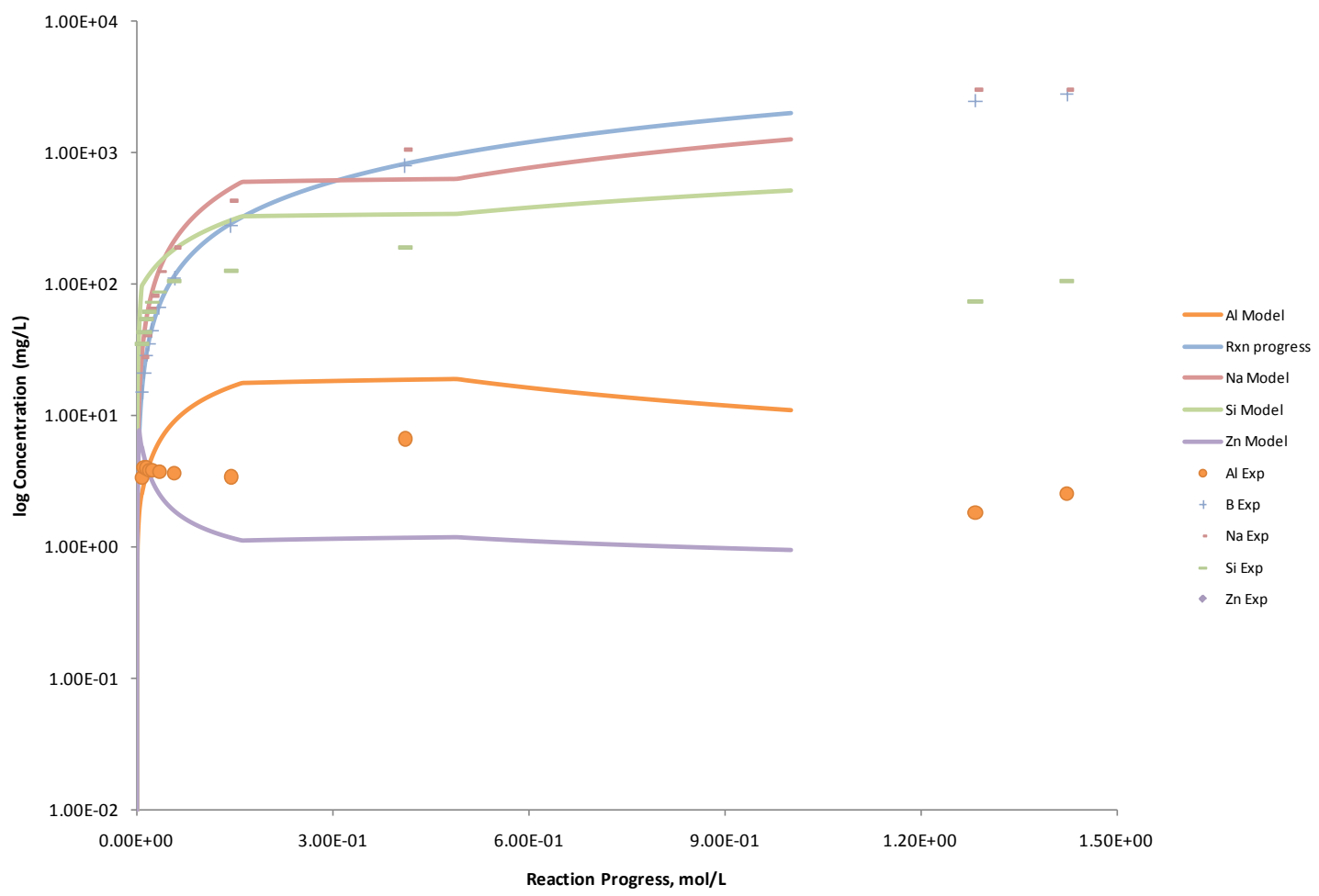

Figure C.188. Measured Solution Concentrations (mg/L) and Model Results for Al, B, Na, Si, and Zn, as a Function of Reaction Progress (mol-glass $/ \mathrm{kg}$ ) Determined for Glass Sample LAWB30 


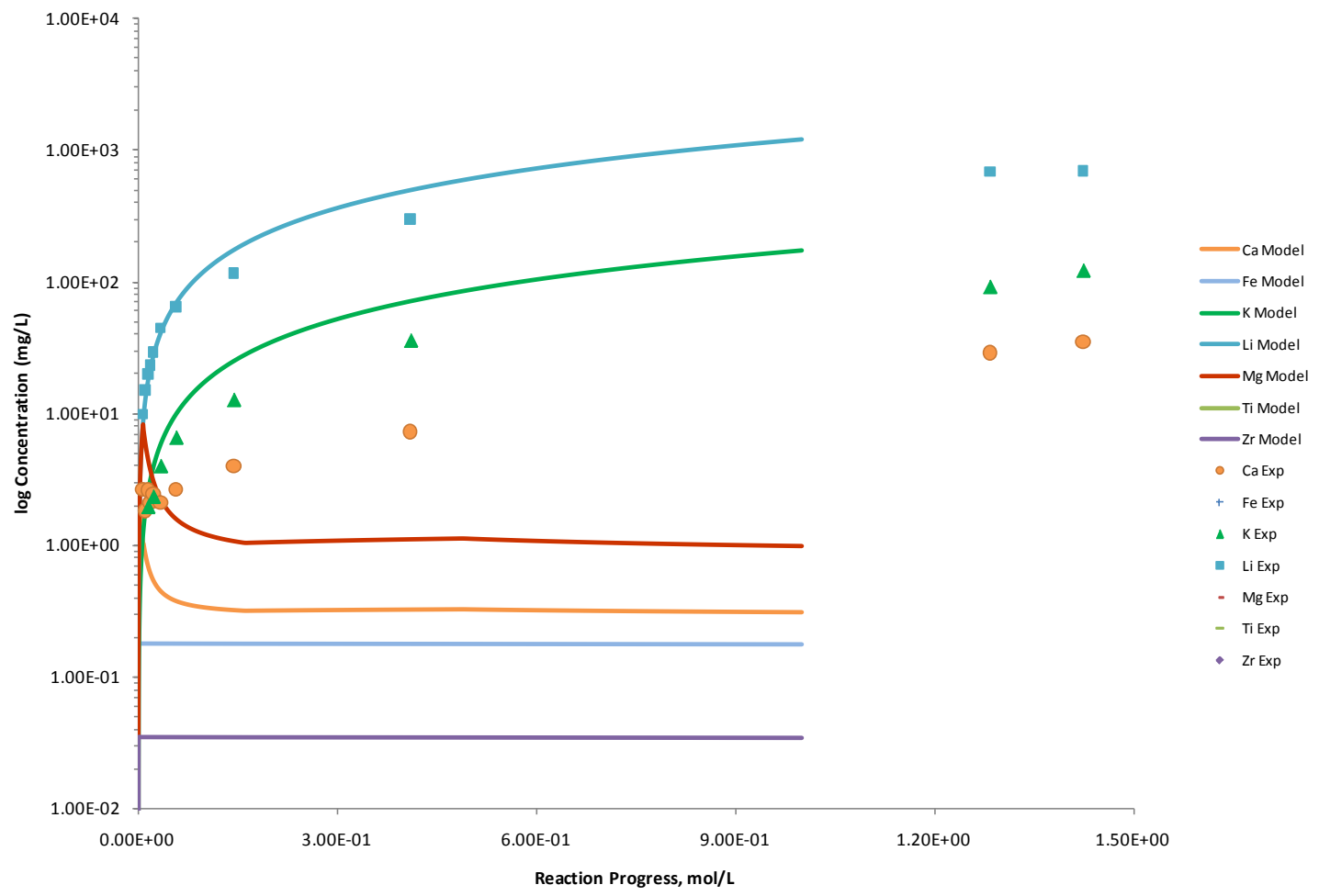

Figure C.189. Measured Solution Concentrations (mg/L) and Model Results for $\mathrm{Ca}, \mathrm{Fe}, \mathrm{K}, \mathrm{Li}, \mathrm{Mg}$, Ti, and $\mathrm{Zr}$, as a Function of Reaction Progress (mol-glass/kg) Determined for Glass Sample LAWB30

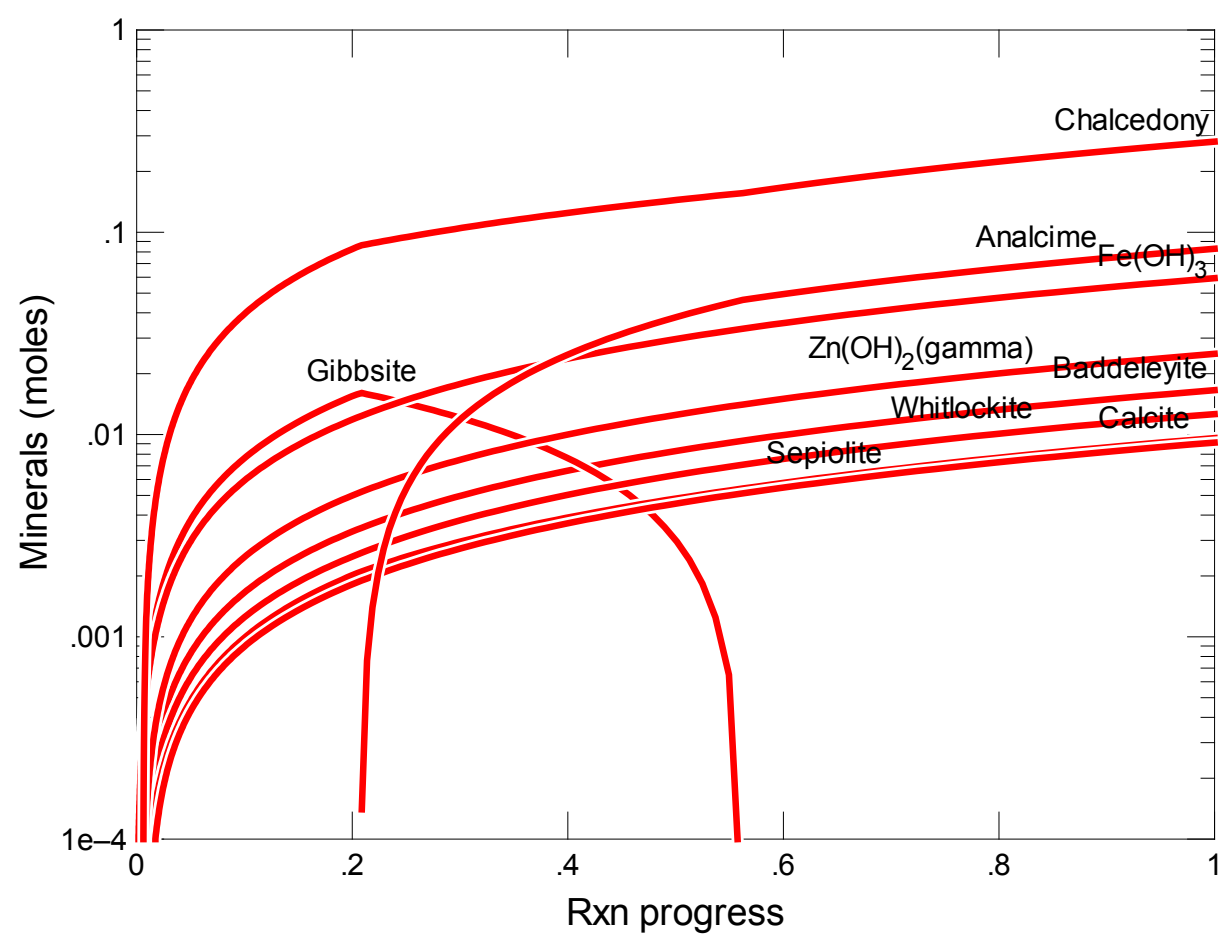

Figure C.190. Secondary Phases Calculated to Form as a Function of Reaction Progress (mol-glass/kg) Determined for Glass Sample LAWB31 


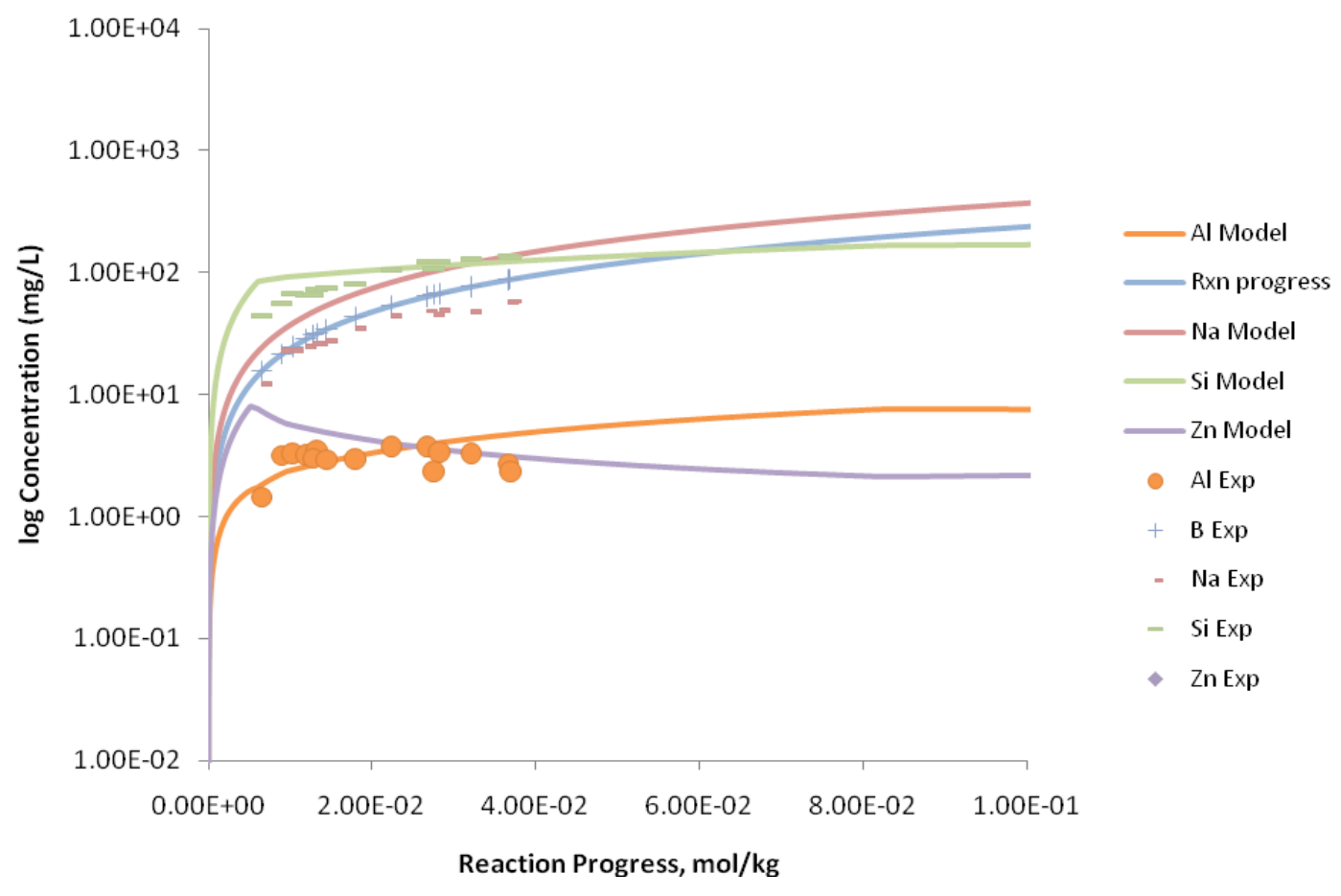

Figure C.191. Measured Solution Concentrations (mg/L) and Model Results for Al, B, Na, Si, and Zn, as a Function of Reaction Progress (mol-glass $/ \mathrm{kg}$ ) Determined for Glass Sample LAWB31

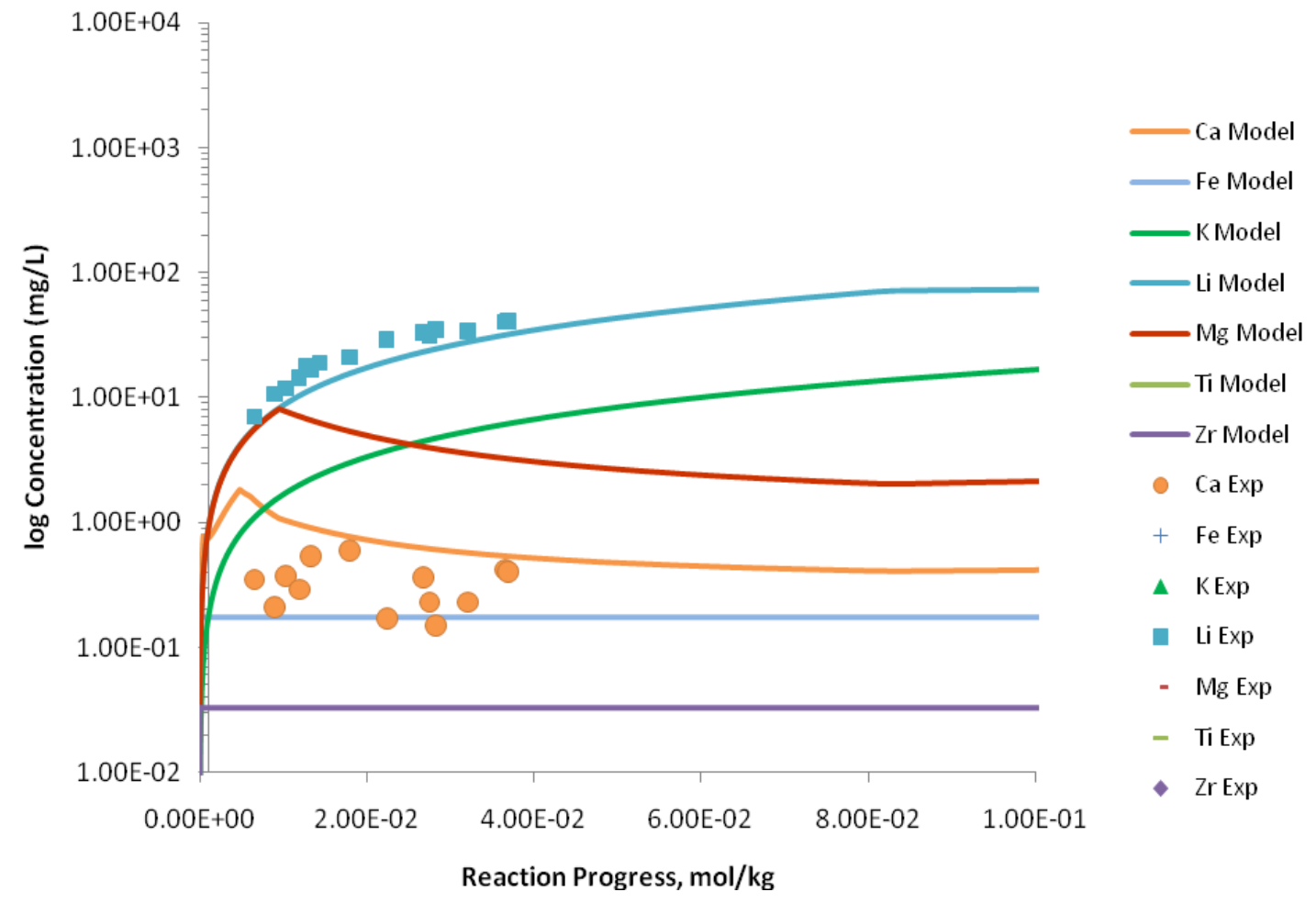

Figure C.192. Measured Solution Concentrations (mg/L) and Model Results for $\mathrm{Ca}, \mathrm{Fe}, \mathrm{K}, \mathrm{Li}, \mathrm{Mg}, \mathrm{Ti}$, and $\mathrm{Zr}$, as a Function of Reaction Progress (mol-glass $/ \mathrm{kg}$ ) Determined for Glass Sample LAWB31 


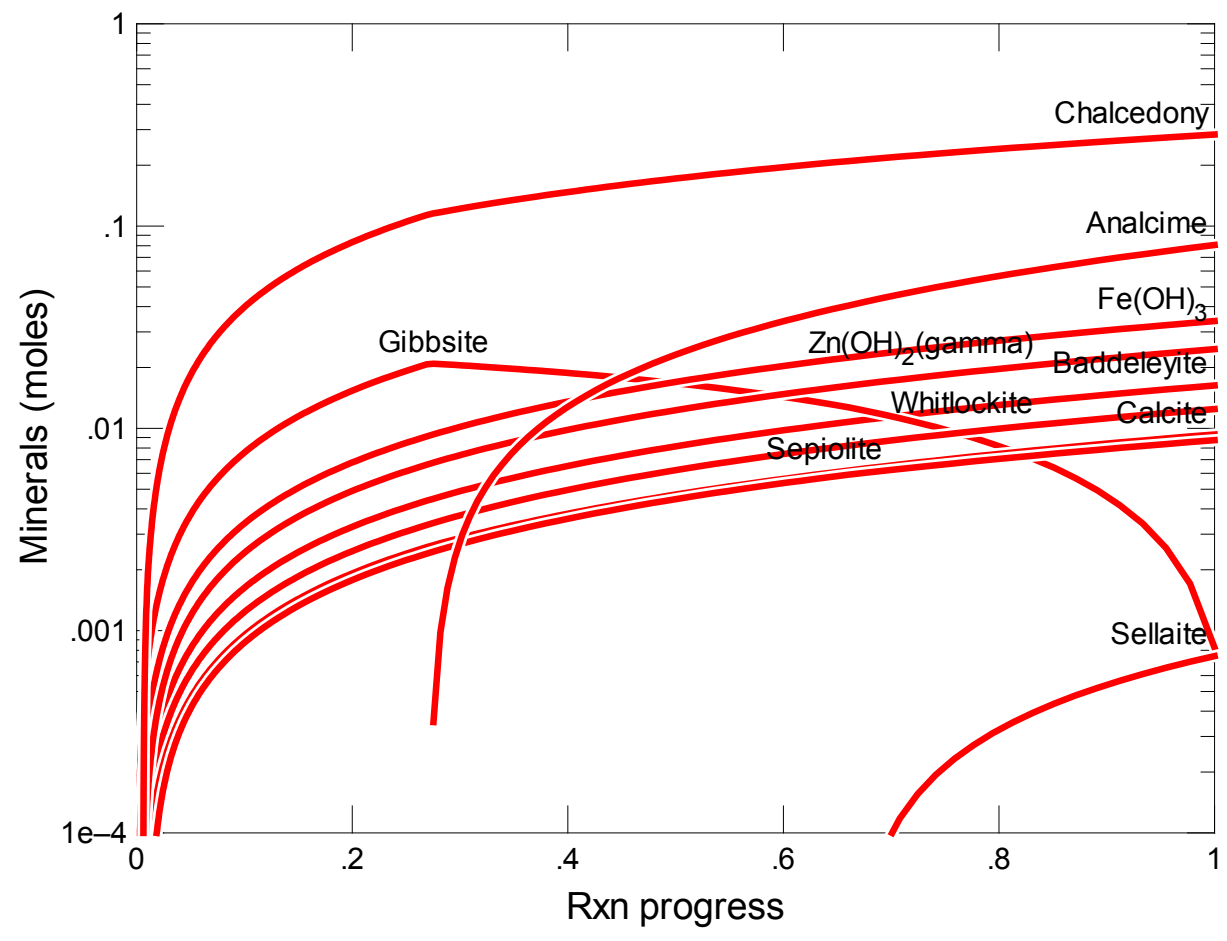

Figure C.193. Secondary Phases Calculated to Form as a Function of Reaction Progress (mol-glass $/ \mathrm{kg}$ ) Determined for Glass Sample LAWB32

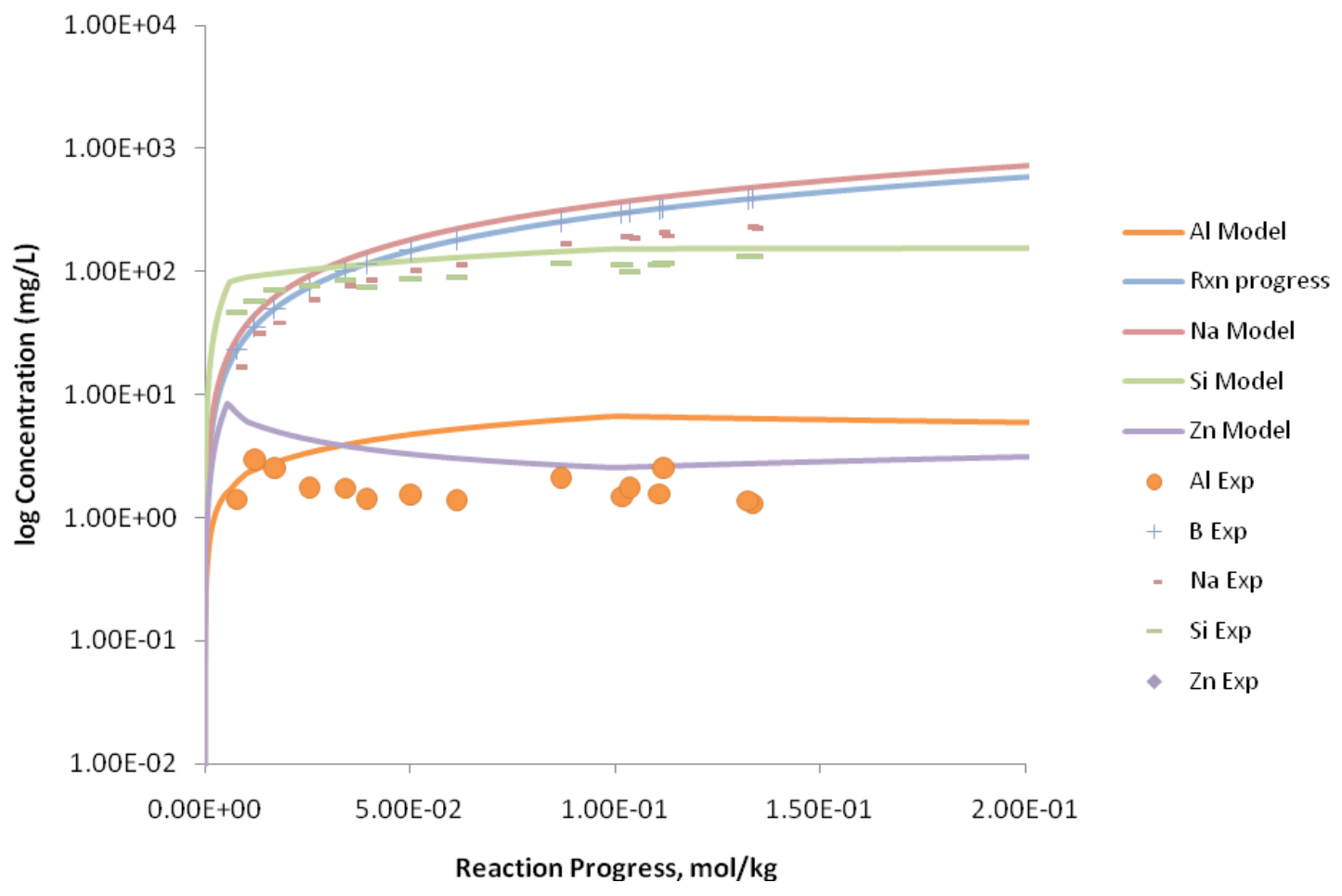

Figure C.194. Measured Solution Concentrations (mg/L) and Model Results for Al, B, Na, Si, and Zn, as a Function of Reaction Progress (mol-glass $/ \mathrm{kg}$ ) Determined for Glass Sample LAWB32 


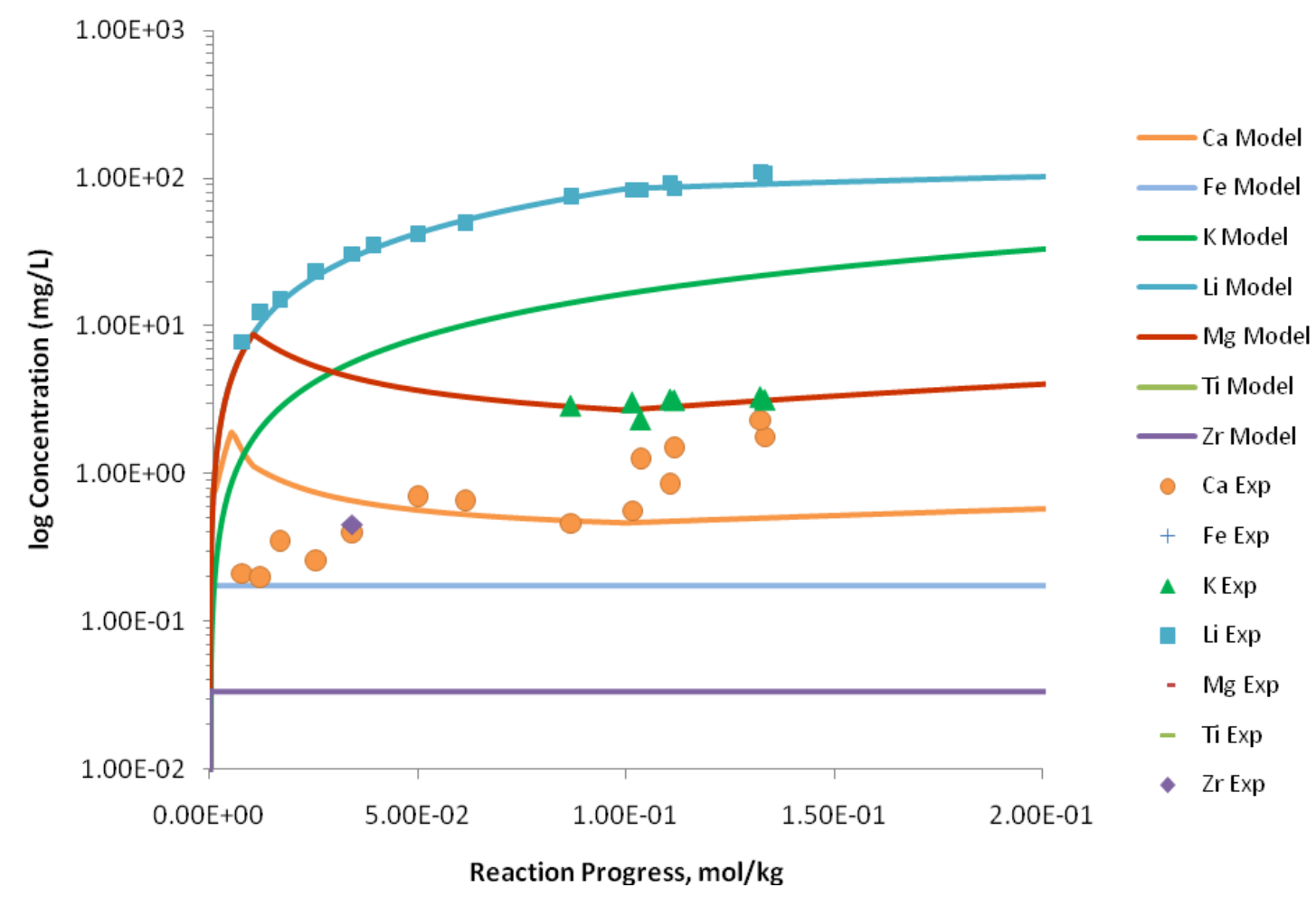

Figure C.195. Measured Solution Concentrations (mg/L) and Model Results for $\mathrm{Ca}, \mathrm{Fe}, \mathrm{K}, \mathrm{Li}, \mathrm{Mg}$, Ti, and $\mathrm{Zr}$, as a Function of Reaction Progress (mol-glass/kg) Determined for Glass Sample LAWB32

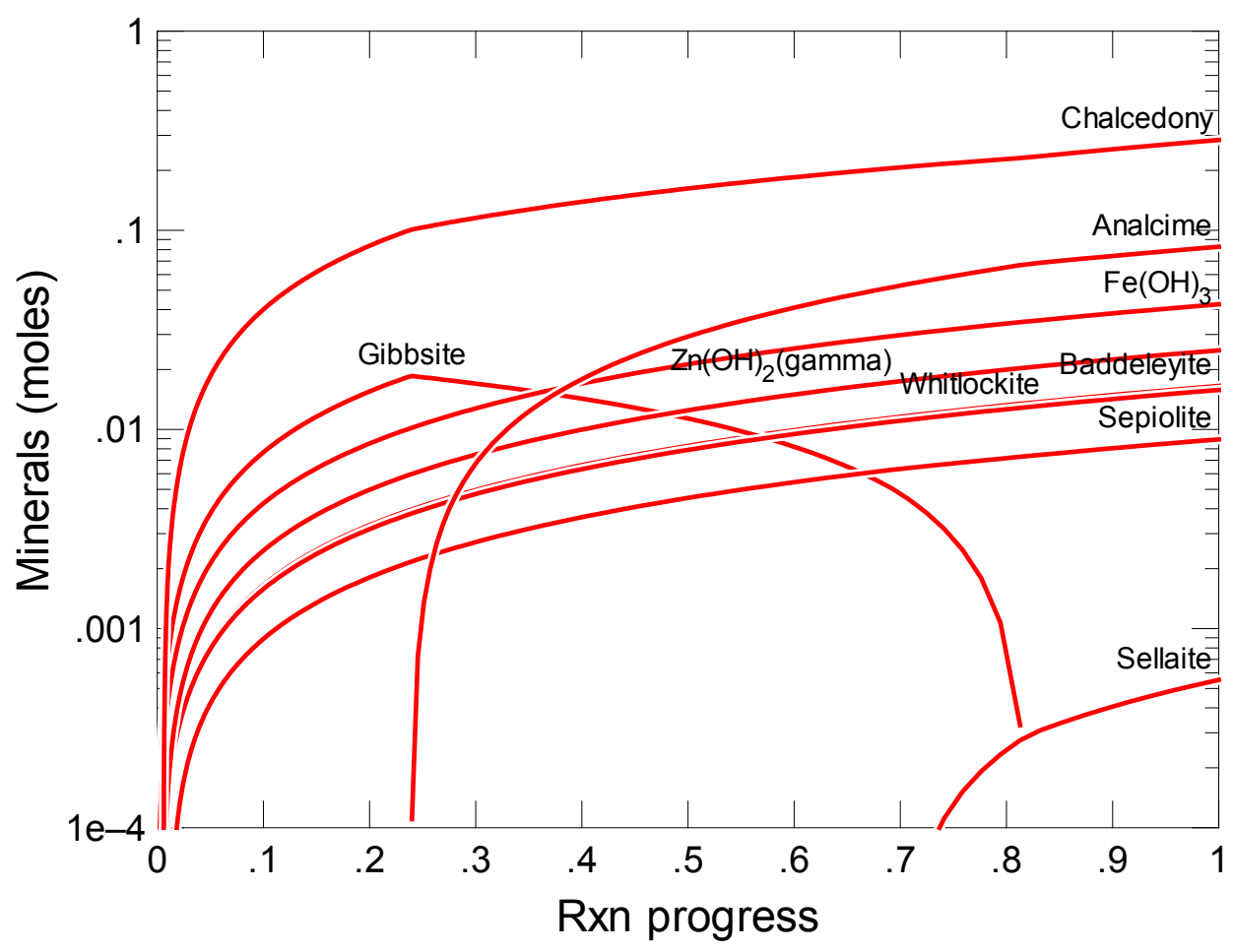

Figure C.196. Secondary Phases Calculated to Form as a Function of Reaction Progress (mol-glass $/ \mathrm{kg}$ ) Determined for Glass Sample LAWB33 


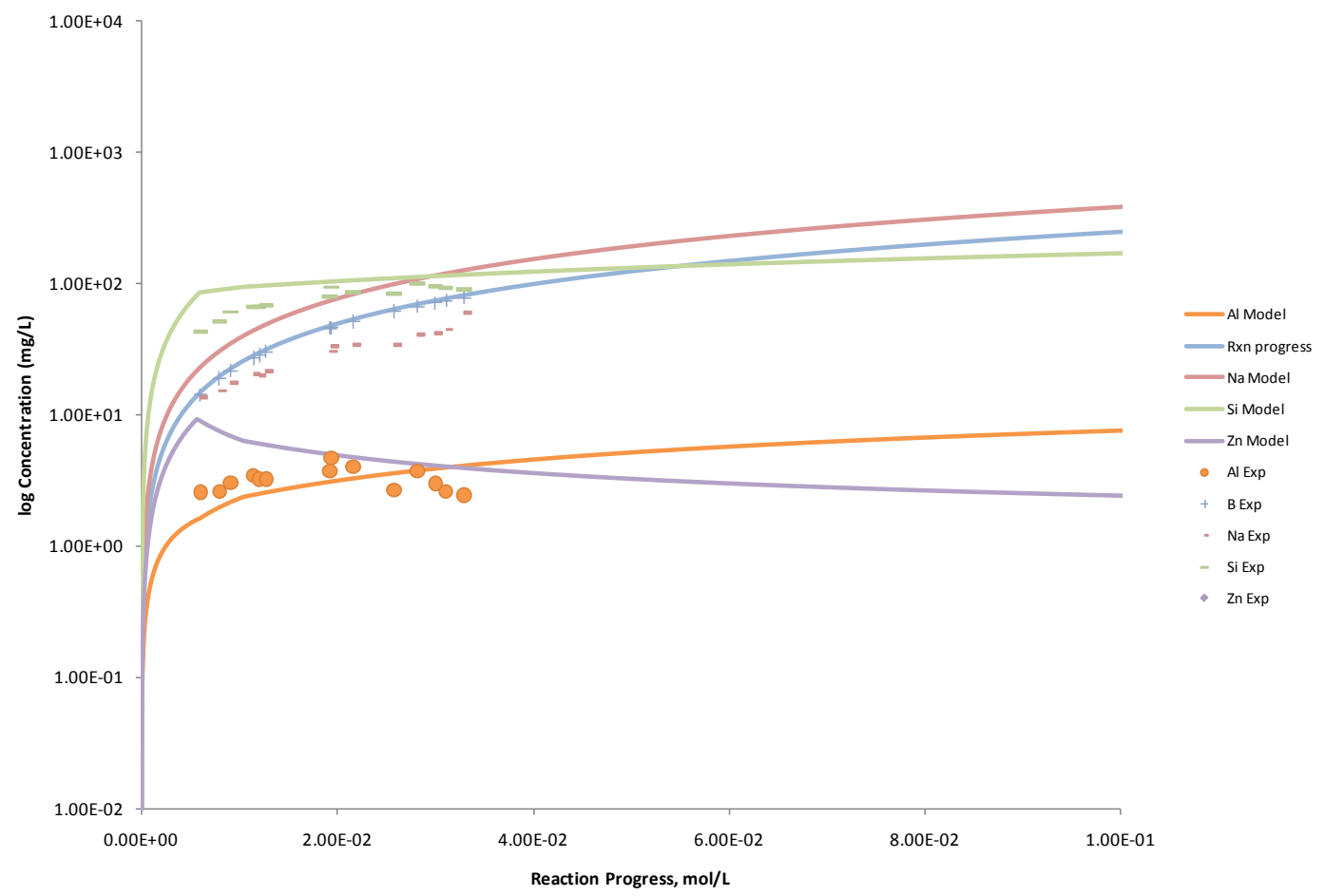

Figure C.197. Measured Solution Concentrations (mg/L) and Model Results for Al, B, Na, Si, and Zn, as a Function of Reaction Progress (mol-glass $/ \mathrm{kg}$ ) Determined for Glass Sample LAWB33

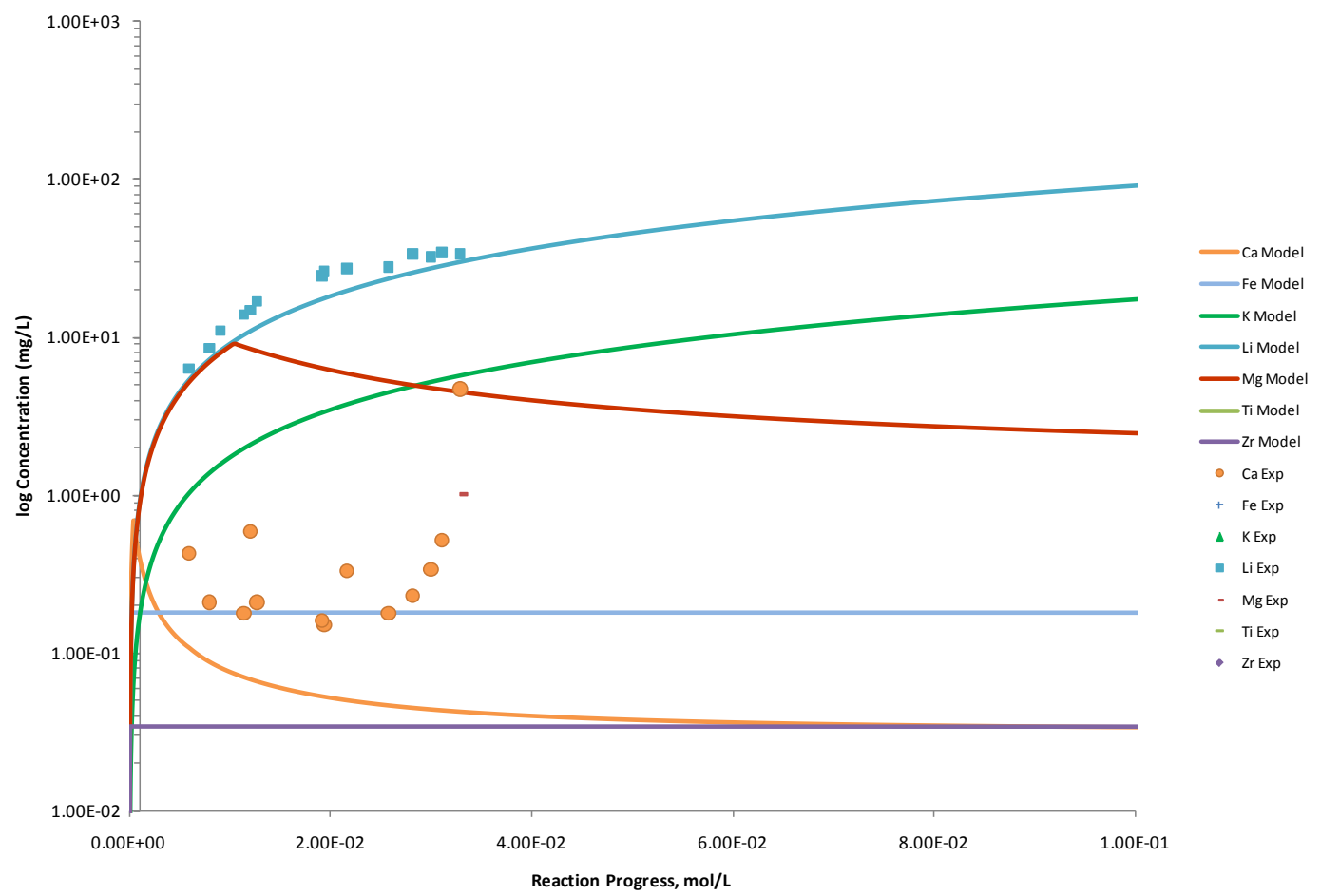

Figure C.198. Measured Solution Concentrations (mg/L) and Model Results for Ca, Fe, K, Li, Mg, Ti, and $\mathrm{Zr}$, as a Function of Reaction Progress (mol-glass/kg) Determined for Glass Sample LAWB33 


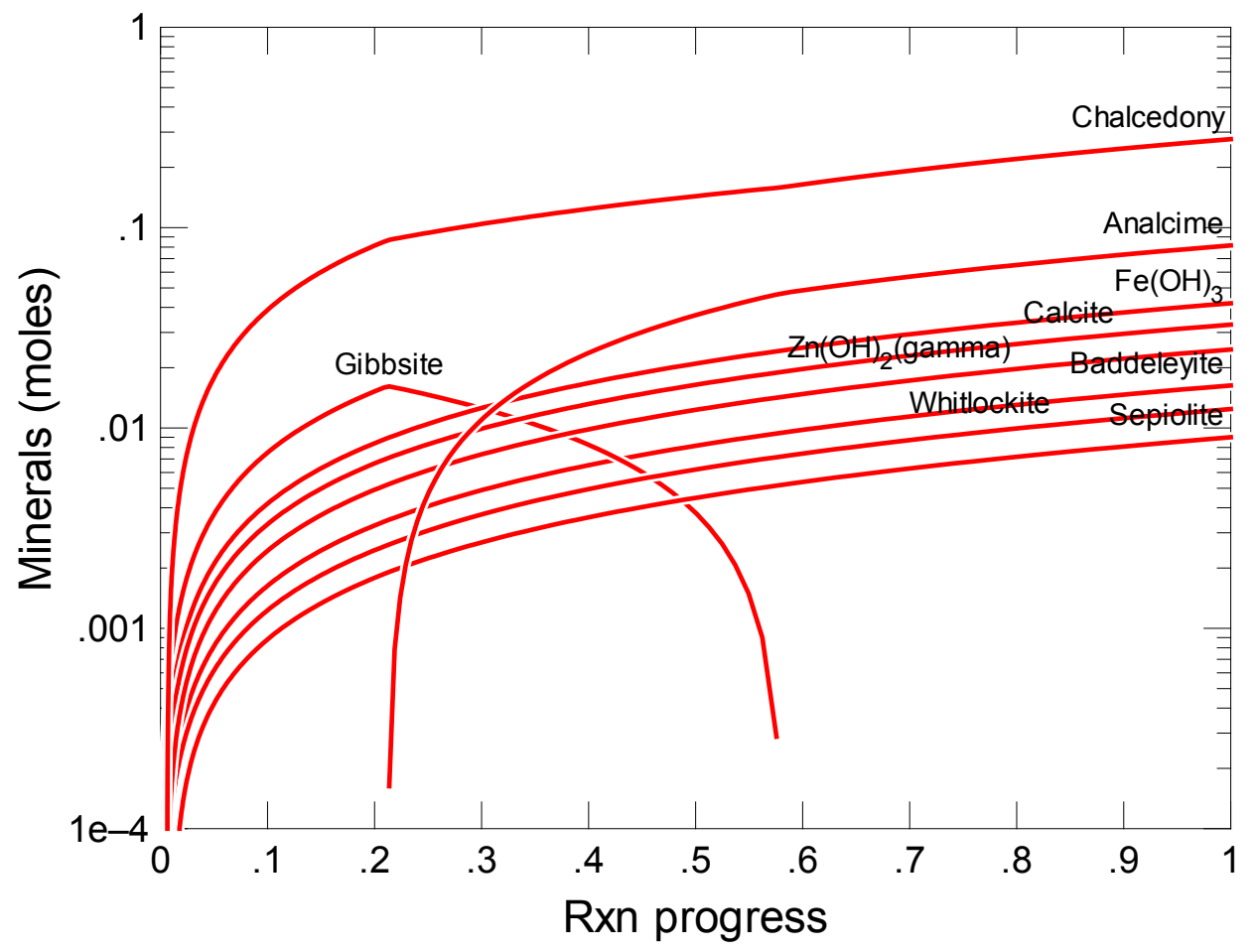

Figure C.199. Secondary Phases Calculated to Form as a Function of Reaction Progress (mol-glass $/ \mathrm{kg}$ ) Determined for Glass Sample LAWB34

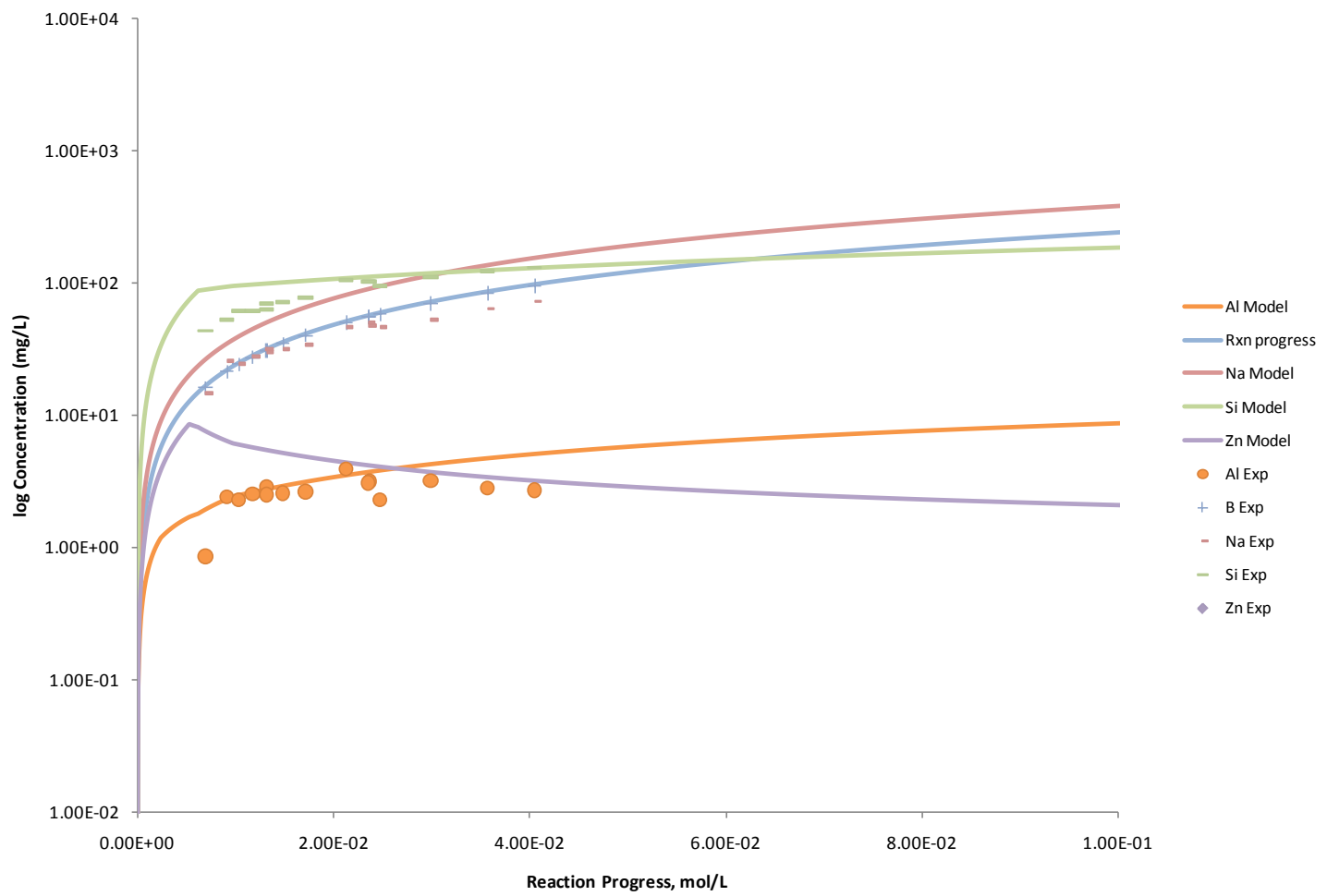

Figure C.200. Measured Solution Concentrations (mg/L) and Model Results for Al, B, Na, Si, and Zn, as a Function of Reaction Progress (mol-glass $/ \mathrm{kg}$ ) Determined for Glass Sample LAWB34 


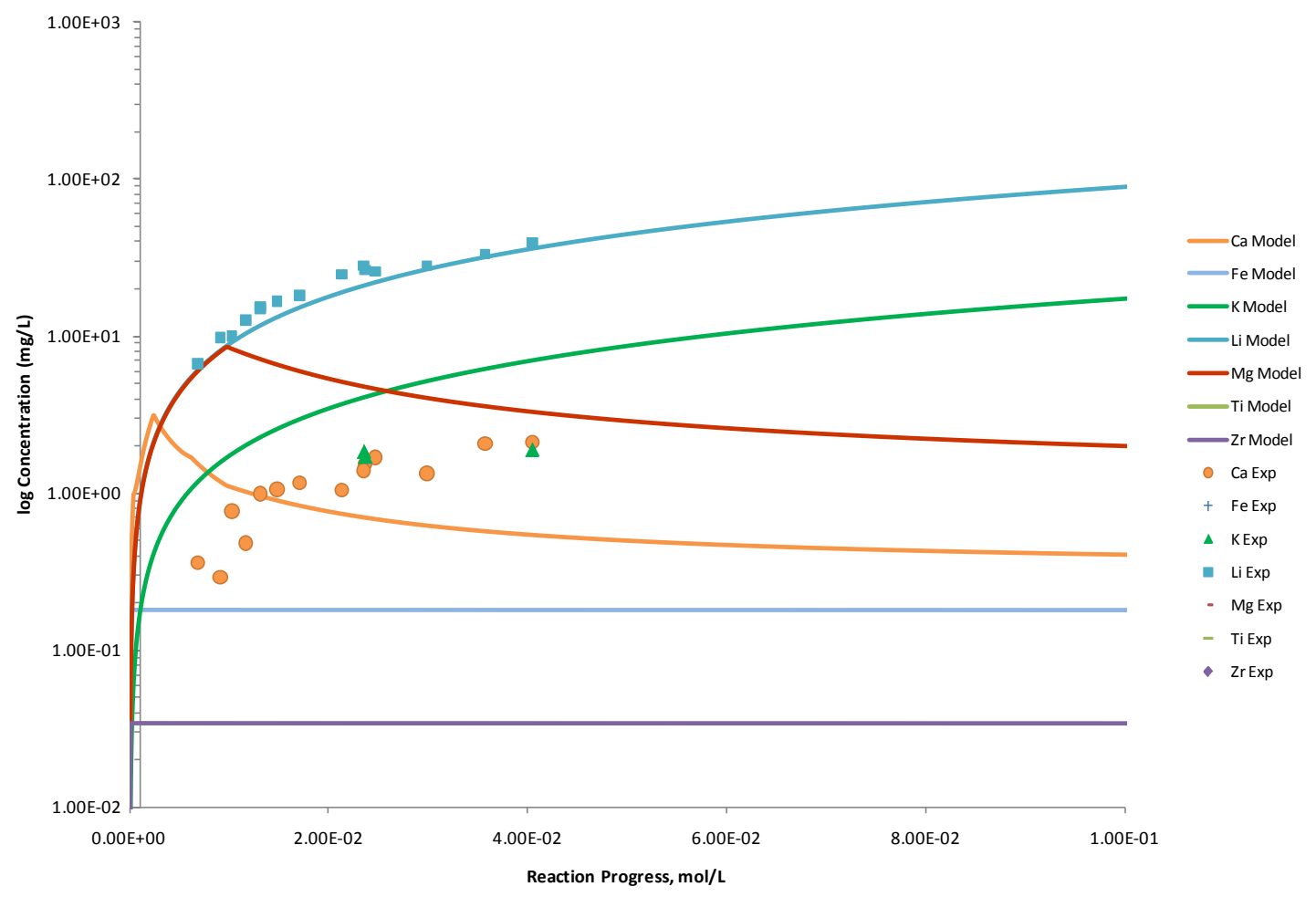

Figure C.201. Measured Solution Concentrations (mg/L) and Model Results for $\mathrm{Ca}, \mathrm{Fe}, \mathrm{K}, \mathrm{Li}, \mathrm{Mg}$, Ti, and $\mathrm{Zr}$, as a Function of Reaction Progress (mol-glass/kg) Determined for Glass Sample LAWB34

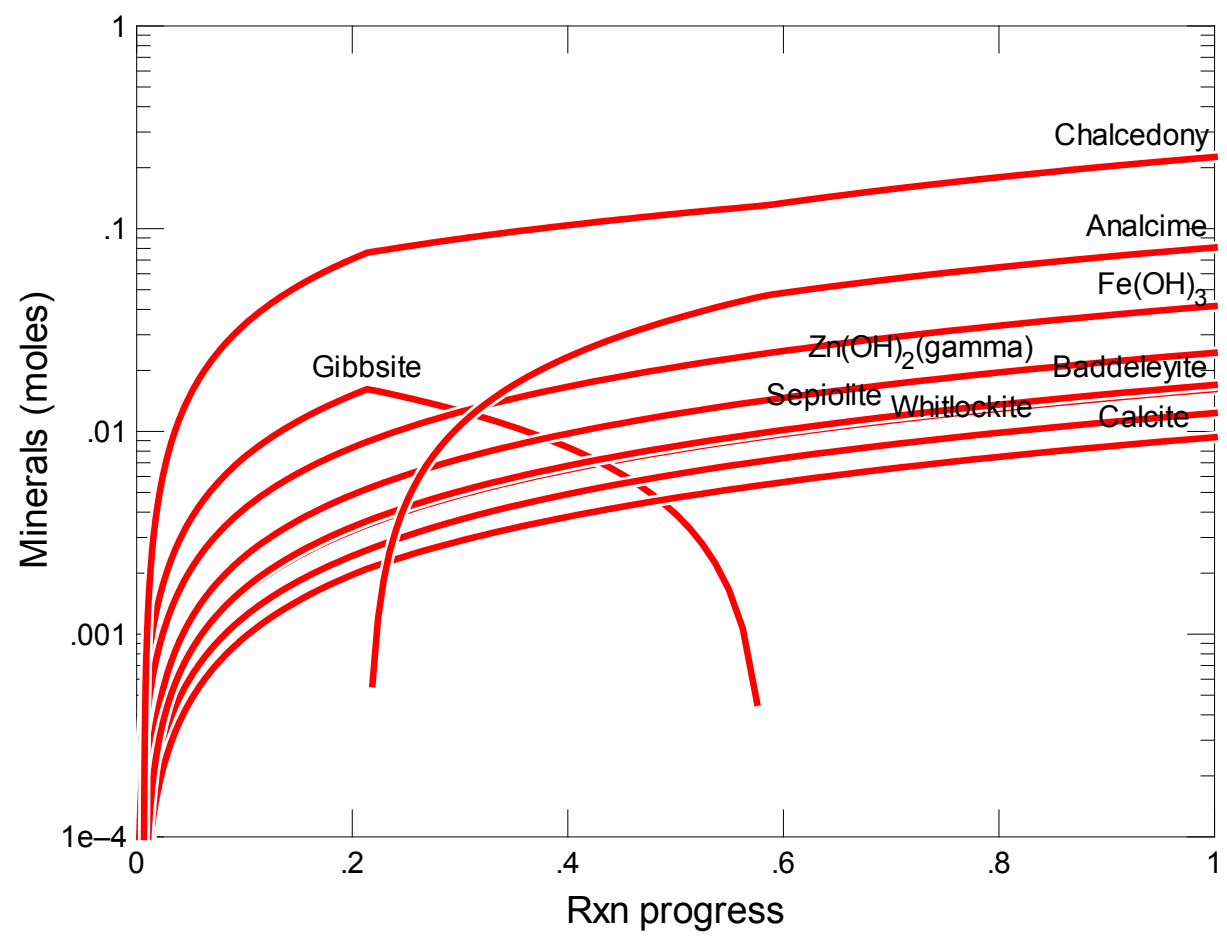

Figure C.202. Secondary Phases Calculated to Form as a Function of Reaction Progress (mol-glass/kg) Determined for Glass Sample LAWB35 


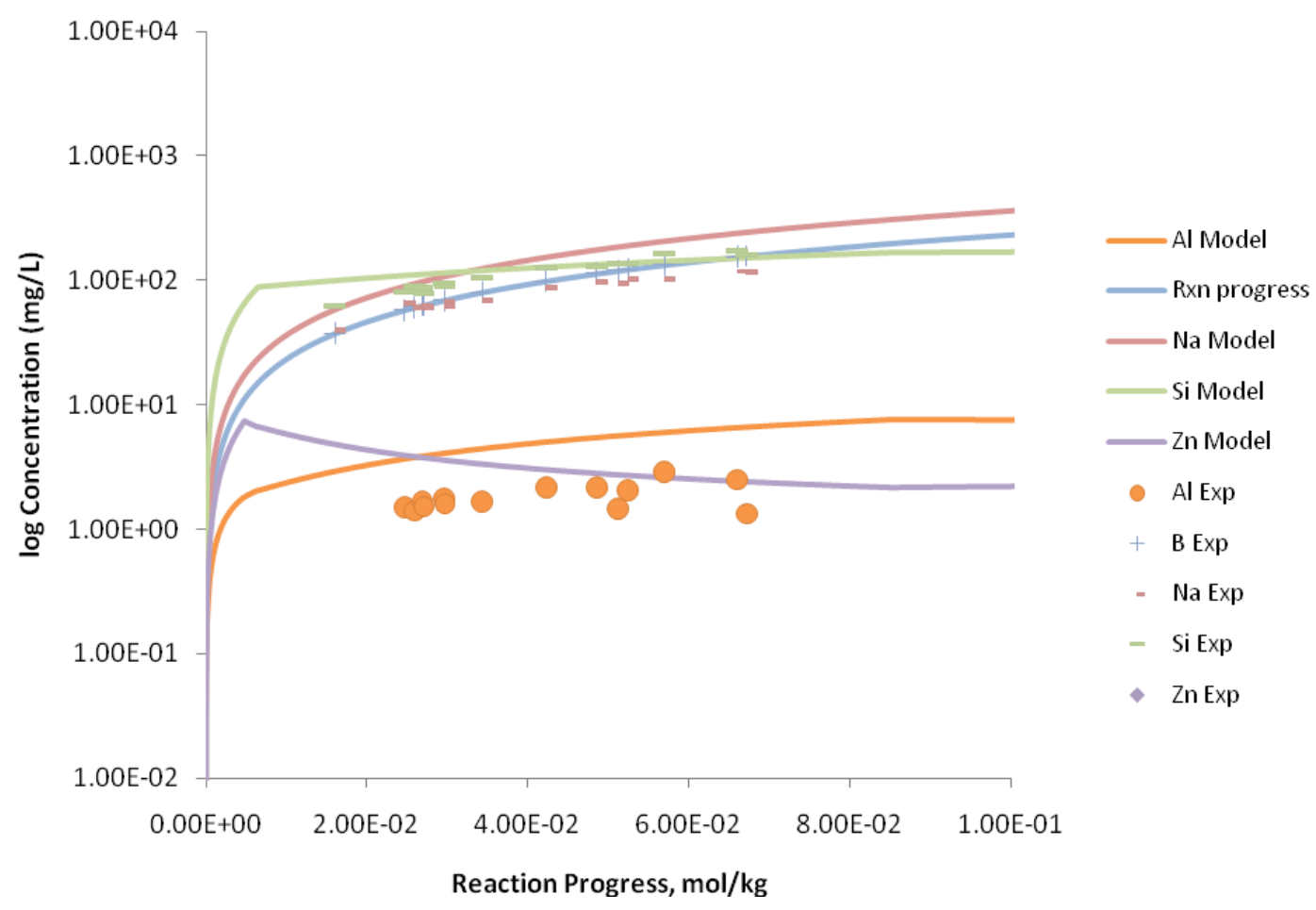

Figure C.203. Measured Solution Concentrations (mg/L) and Model Results for Al, B, Na, Si, and Zn, as a Function of Reaction Progress (mol-glass $/ \mathrm{kg}$ ) Determined for Glass Sample LAWB35
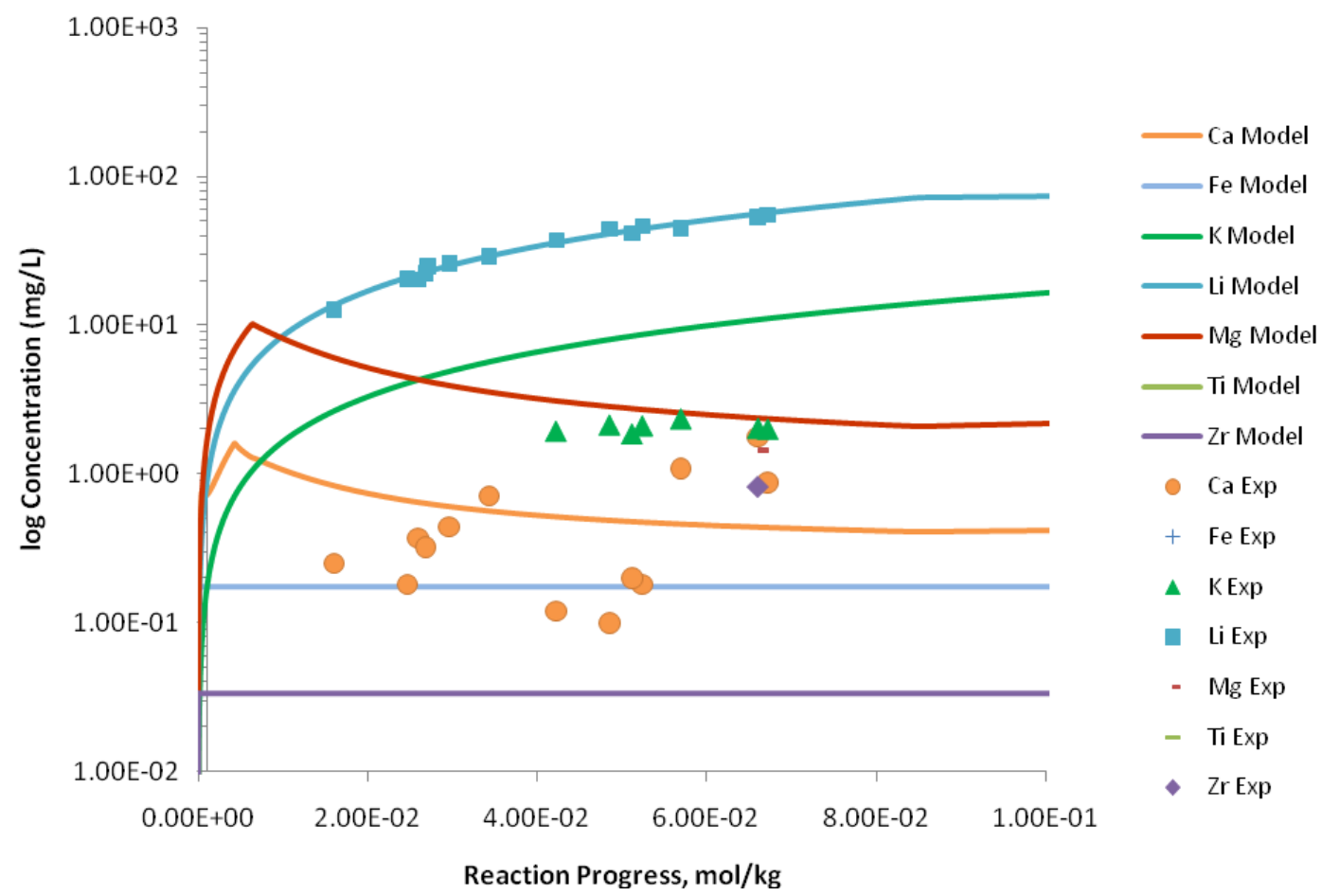

Figure C.204. Measured Solution Concentrations (mg/L) and Model Results for $\mathrm{Ca}, \mathrm{Fe}, \mathrm{K}, \mathrm{Li}, \mathrm{Mg}, \mathrm{Ti}$, and $\mathrm{Zr}$, as a Function of Reaction Progress (mol-glass/kg) Determined for Glass Sample LAWB35 


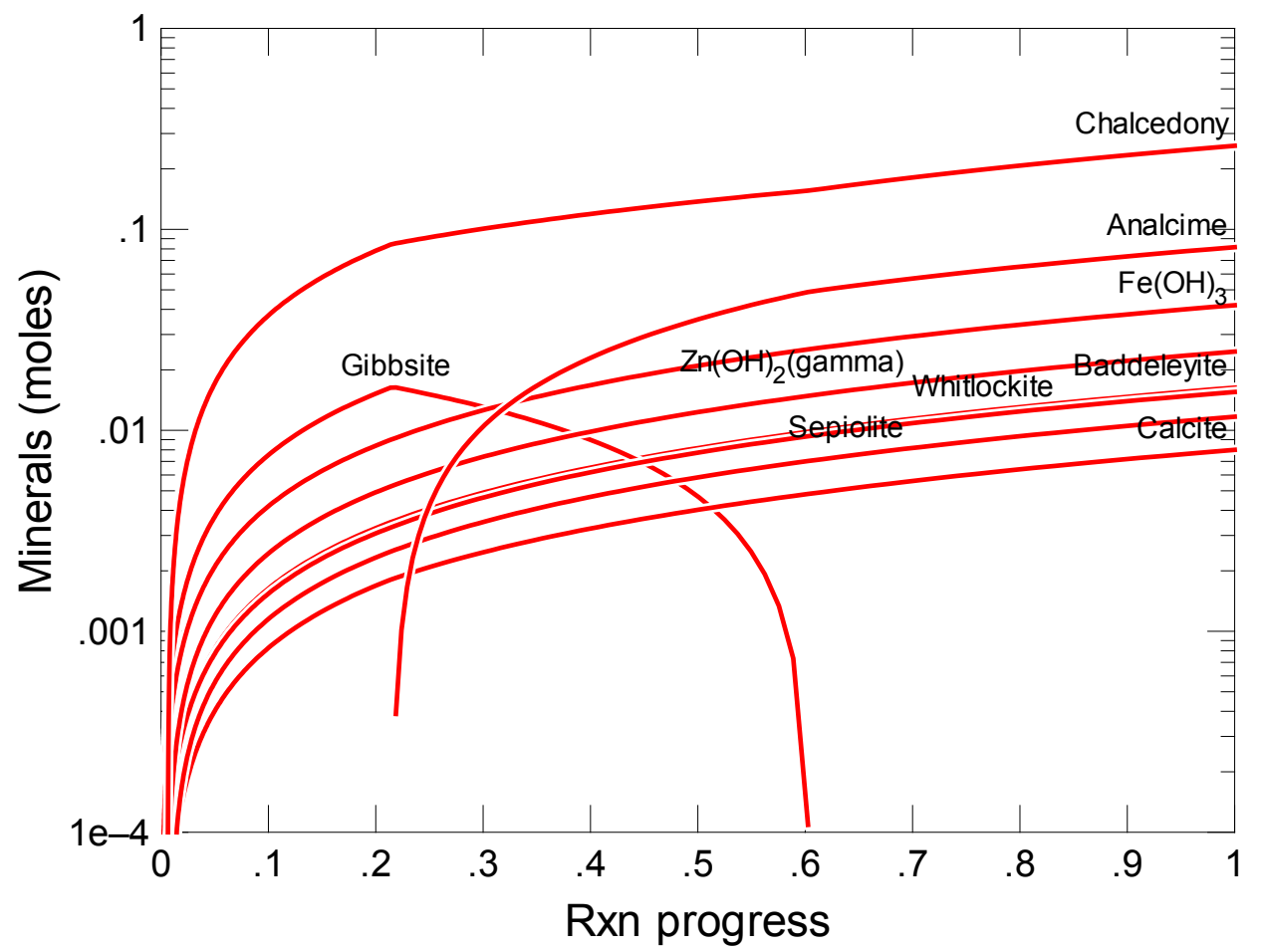

Figure C.205. Secondary Phases Calculated to Form as a Function of Reaction Progress (mol-glass $/ \mathrm{kg}$ ) Determined for Glass Sample LAWB37

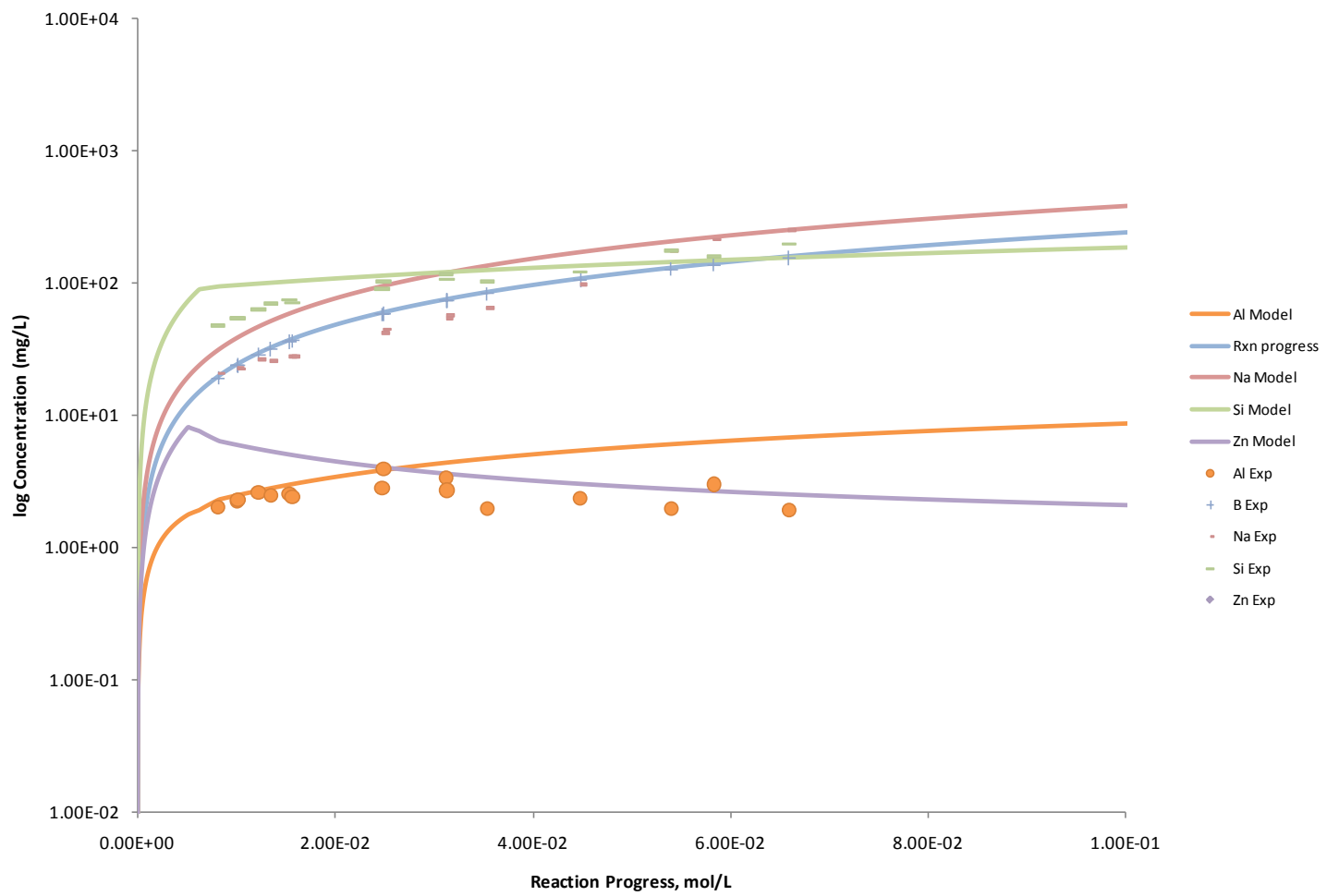

Figure C.206. Measured Solution Concentrations (mg/L) and Model Results for Al, B, Na, Si, and Zn, as a Function of Reaction Progress (mol-glass $/ \mathrm{kg}$ ) Determined for Glass Sample LAWB37 


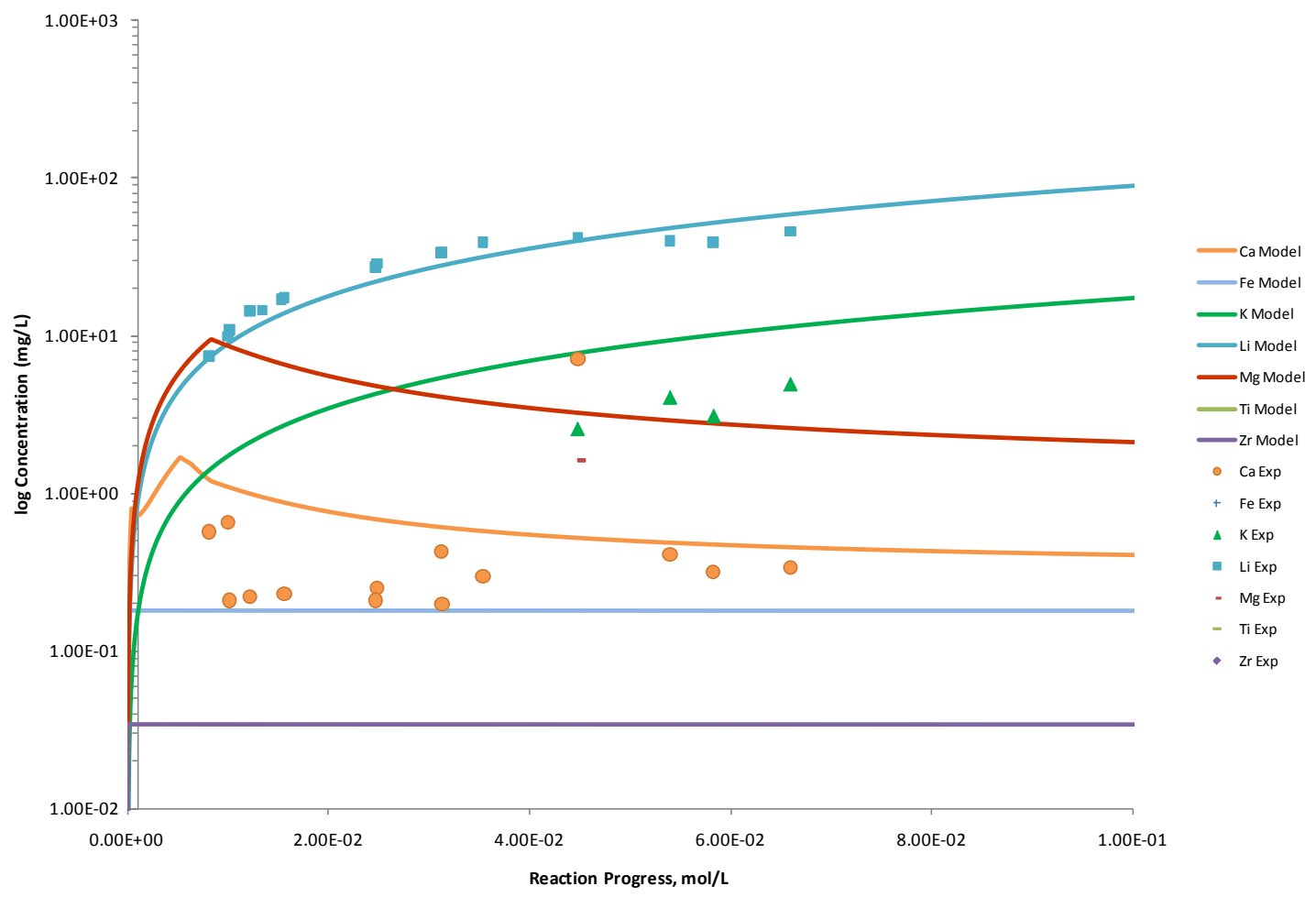

Figure C.207. Measured Solution Concentrations (mg/L) and Model Results for $\mathrm{Ca}, \mathrm{Fe}, \mathrm{K}, \mathrm{Li}, \mathrm{Mg}$, Ti, and $\mathrm{Zr}$, as a Function of Reaction Progress (mol-glass/kg) Determined for Glass Sample LAWB37

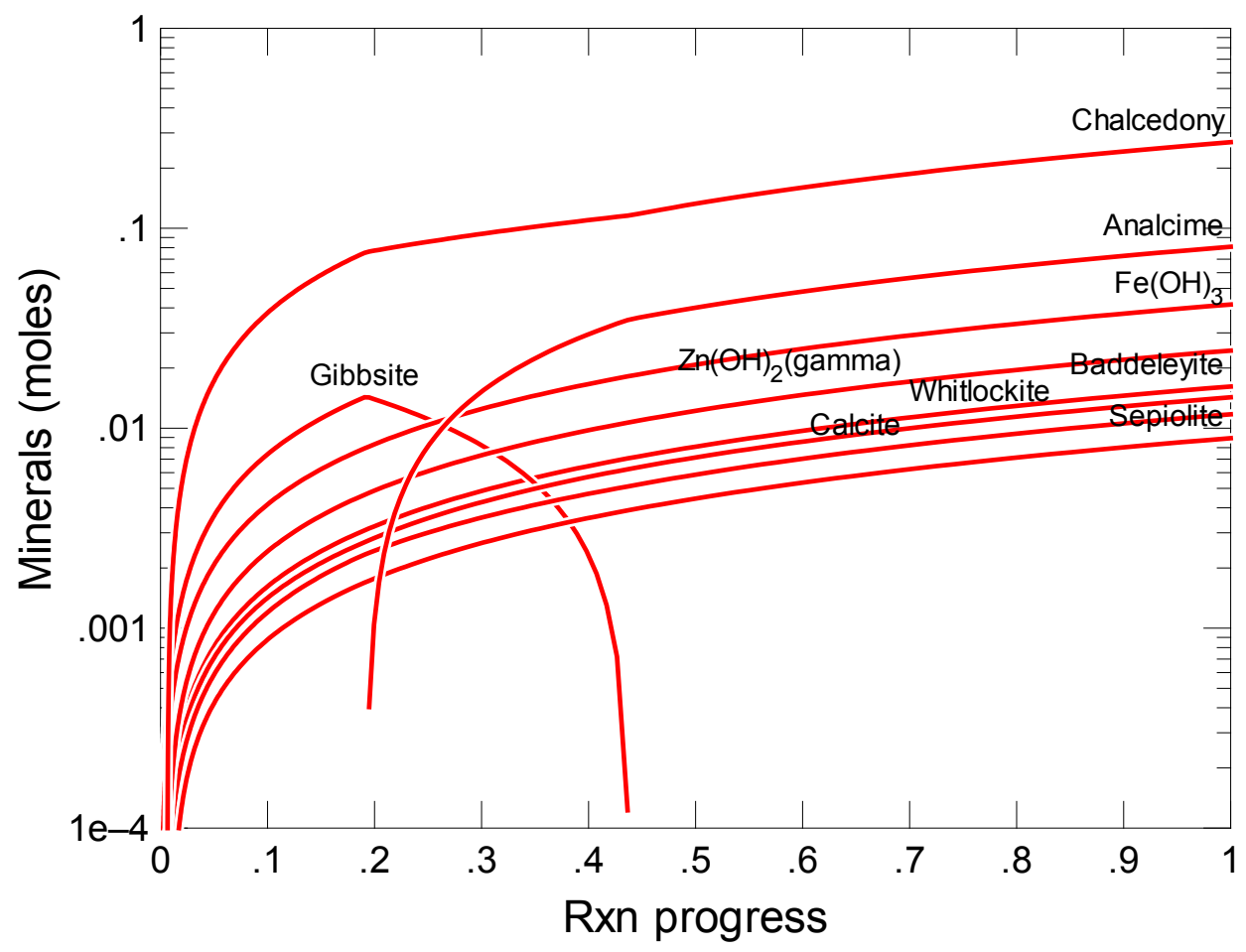

Figure C.208. Secondary Phases Calculated to Form as a Function of Reaction Progress (mol-glass $/ \mathrm{kg}$ ) Determined for Glass Sample LAWB38 


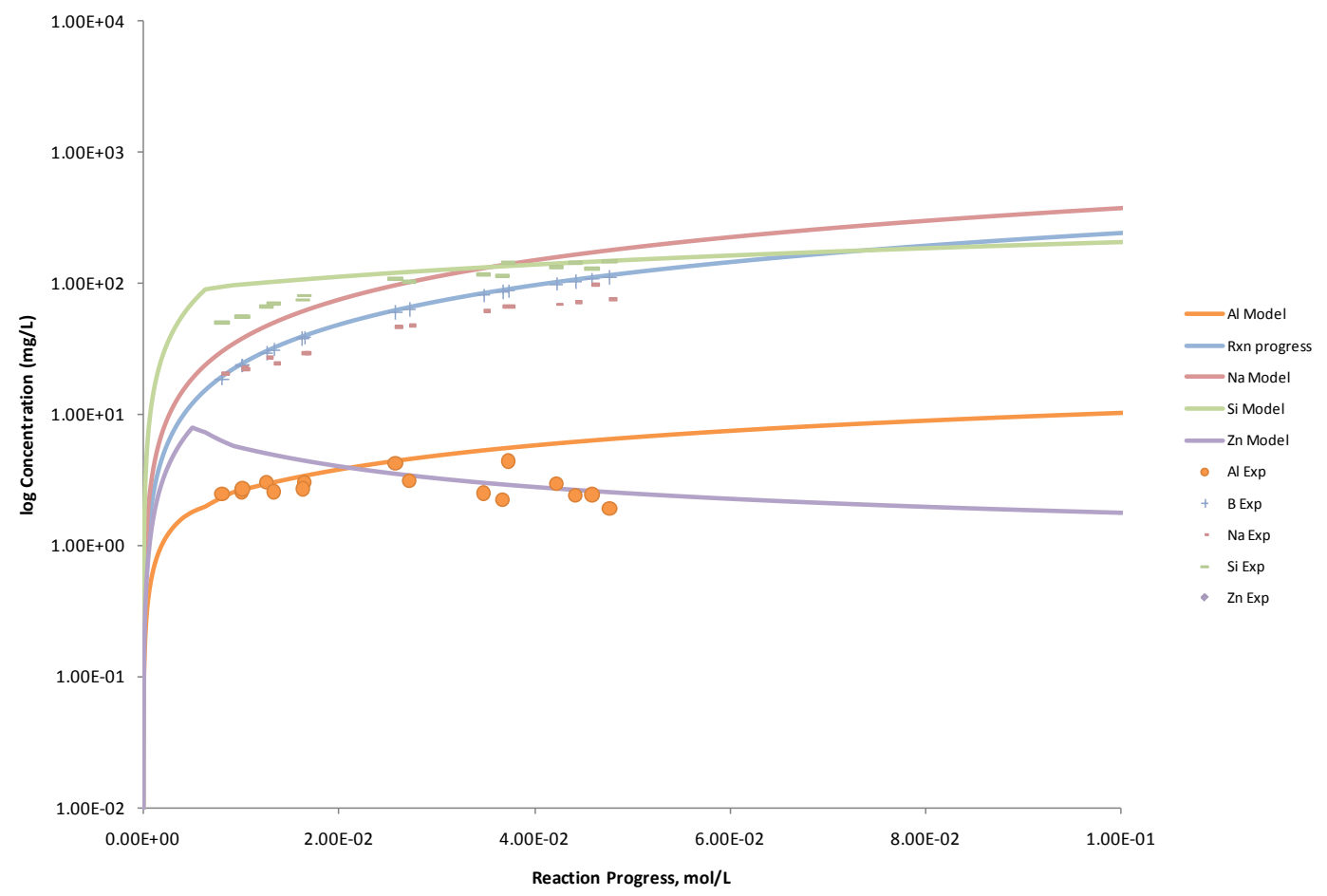

Figure C.209. Measured Solution Concentrations (mg/L) and Model Results for Al, B, Na, Si, and Zn, as a Function of Reaction Progress (mol-glass $/ \mathrm{kg}$ ) Determined for Glass Sample LAWB38

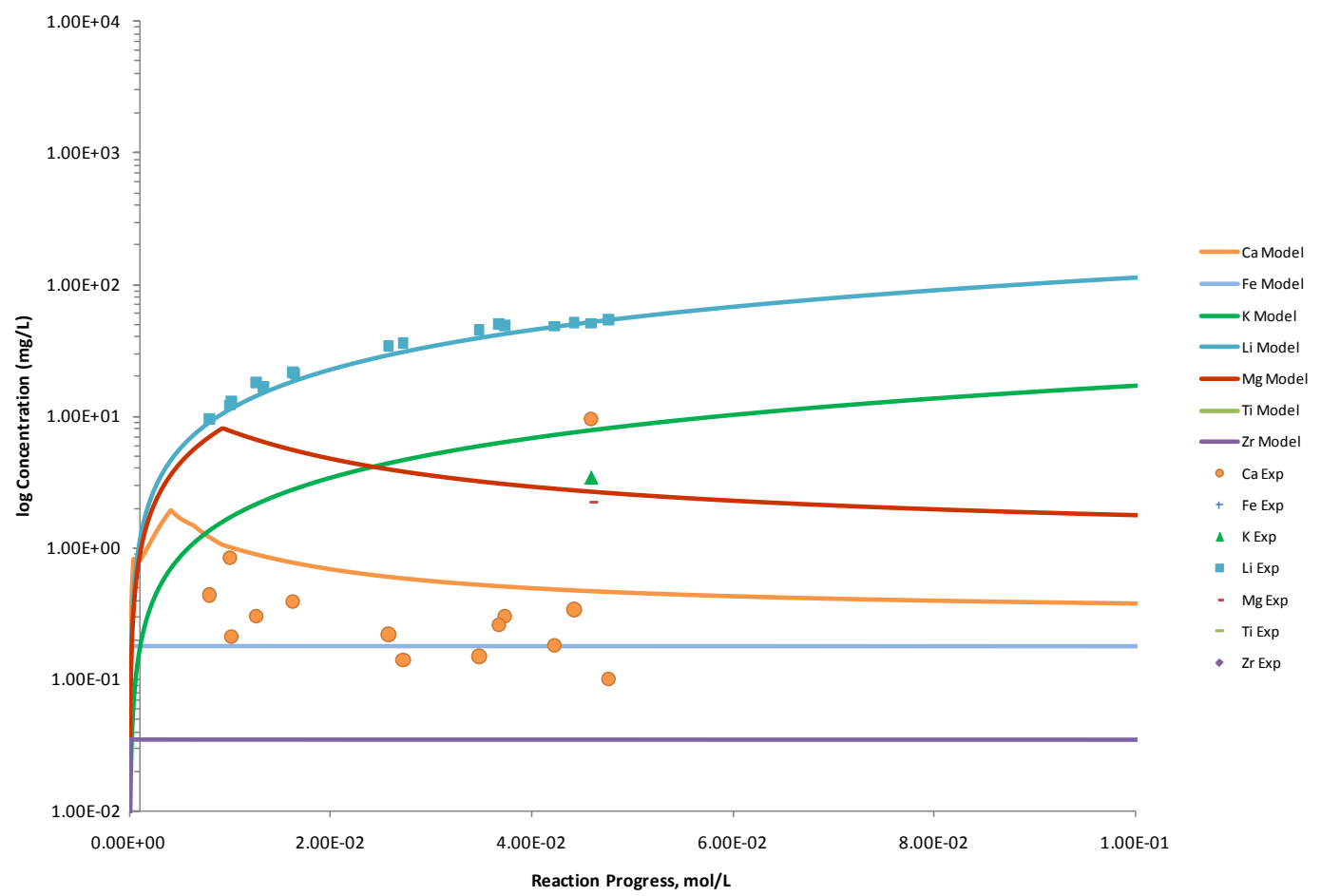

Figure C.210. Measured Solution Concentrations (mg/L) and Model Results for Ca, Fe, K, Li, Mg, Ti, and $\mathrm{Zr}$, as a Function of Reaction Progress (mol-glass/kg) Determined for Glass Sample LAWB38 


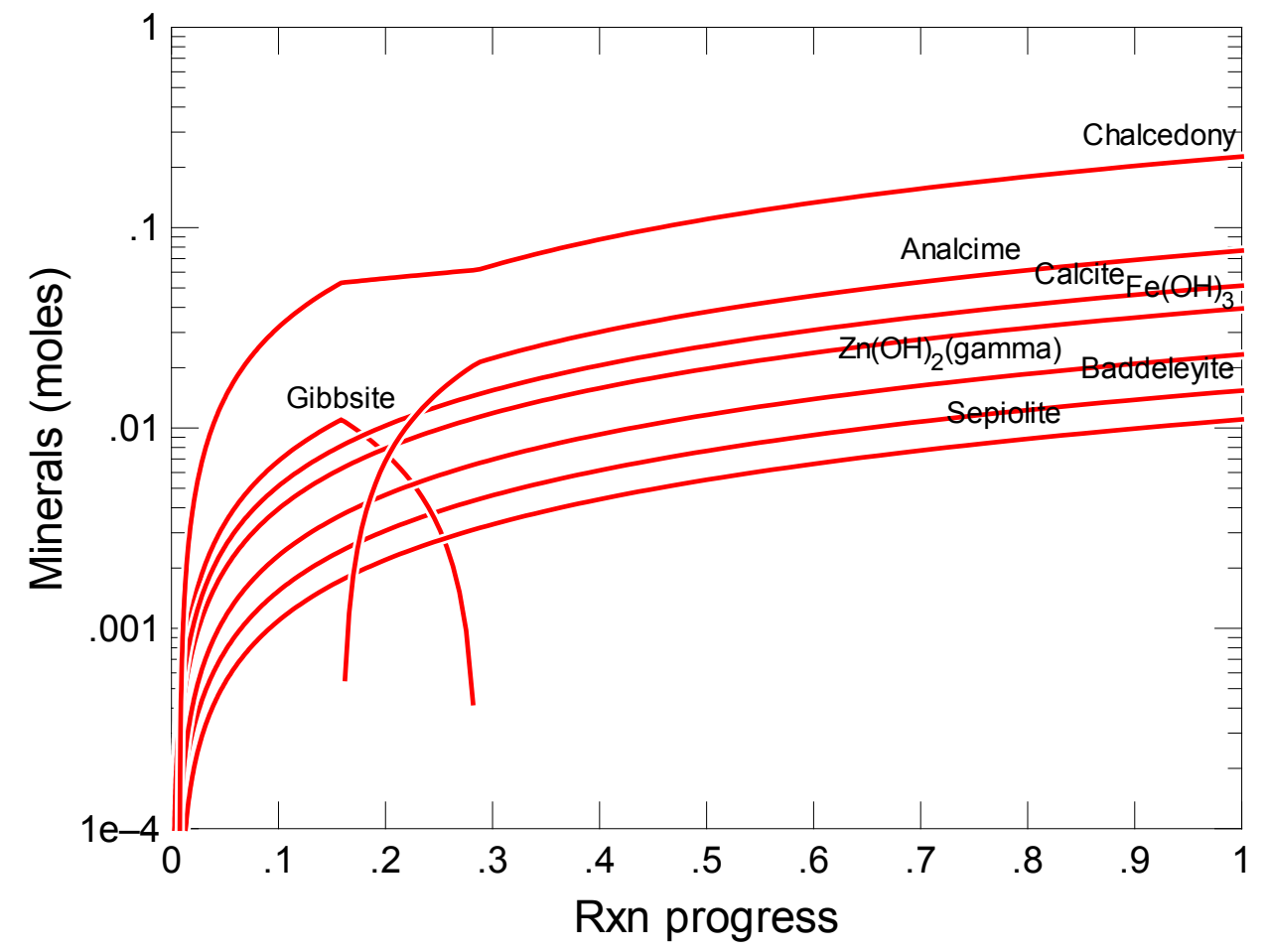

Figure C.211. Secondary Phases Calculated to Form as a Function of Reaction Progress (mol-glass $/ \mathrm{kg}$ ) Determined for Glass Sample LAWB40

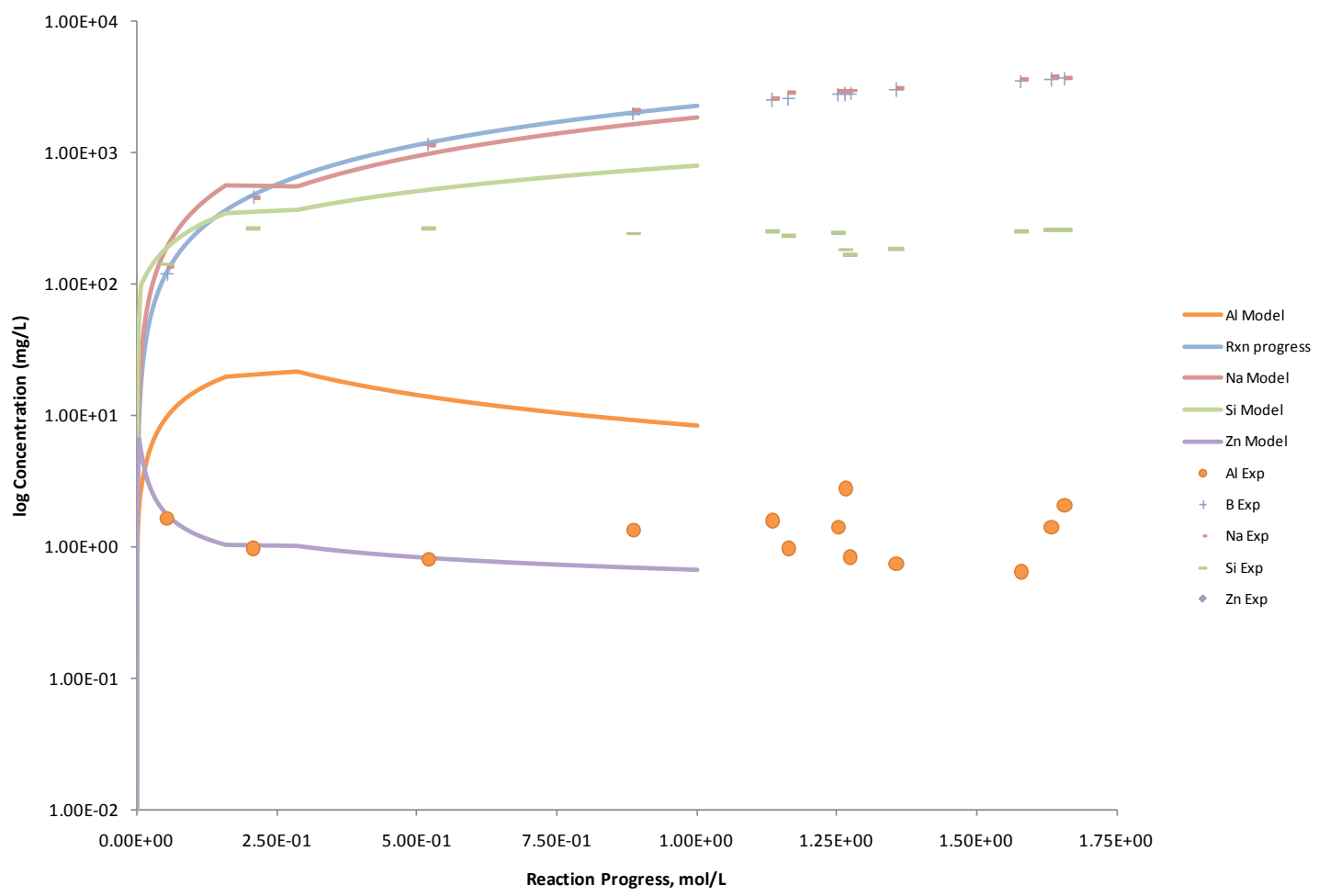

Figure C.212. Measured Solution Concentrations (mg/L) and Model Results for Al, B, Na, Si, and Zn, as a Function of Reaction Progress (mol-glass $/ \mathrm{kg}$ ) Determined for Glass Sample LAWB40 


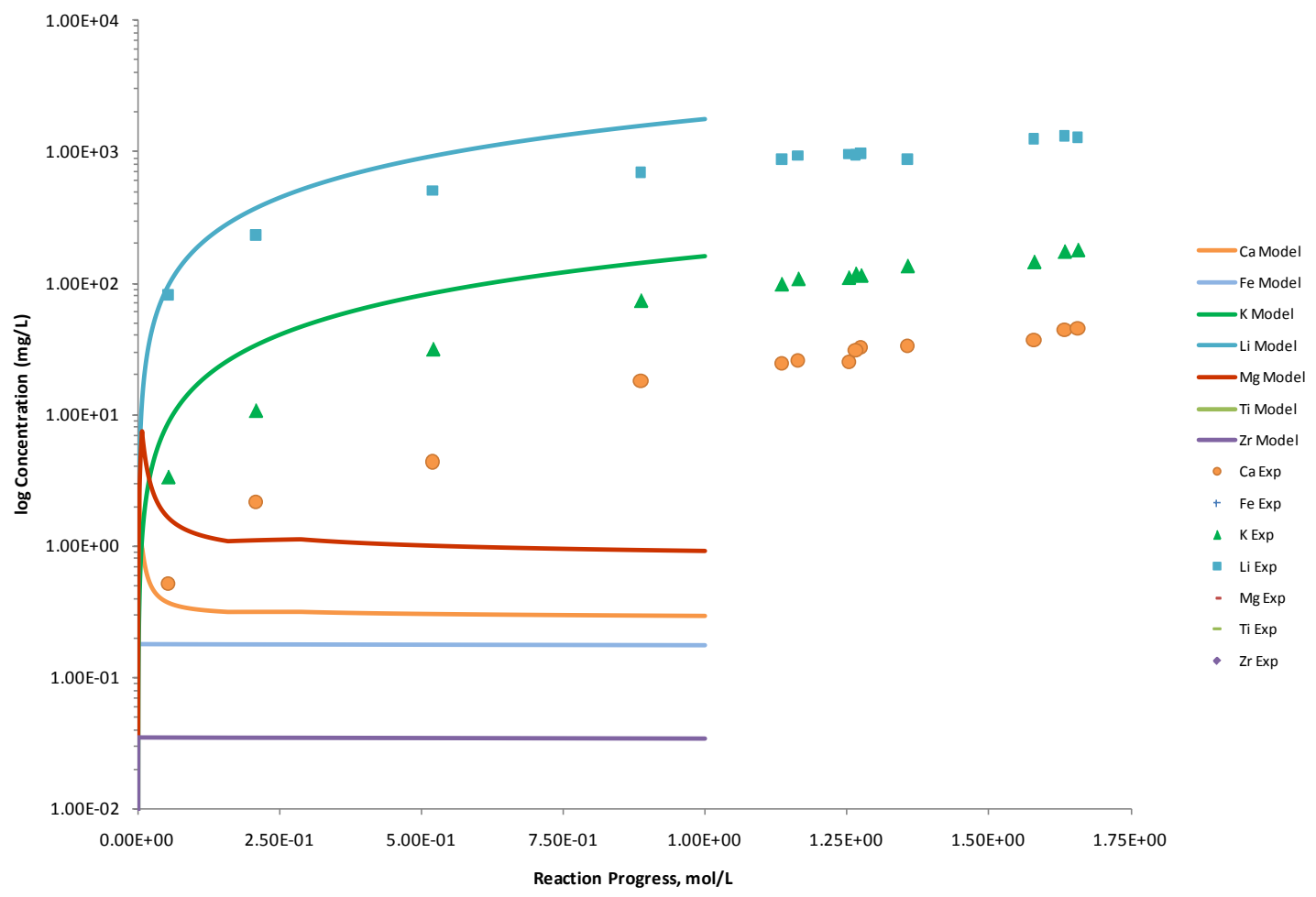

Figure C.213. Measured Solution Concentrations (mg/L) and Model Results for $\mathrm{Ca}, \mathrm{Fe}, \mathrm{K}, \mathrm{Li}, \mathrm{Mg}$, Ti, and $\mathrm{Zr}$, as a Function of Reaction Progress (mol-glass $/ \mathrm{kg}$ ) Determined for Glass Sample LAWB40

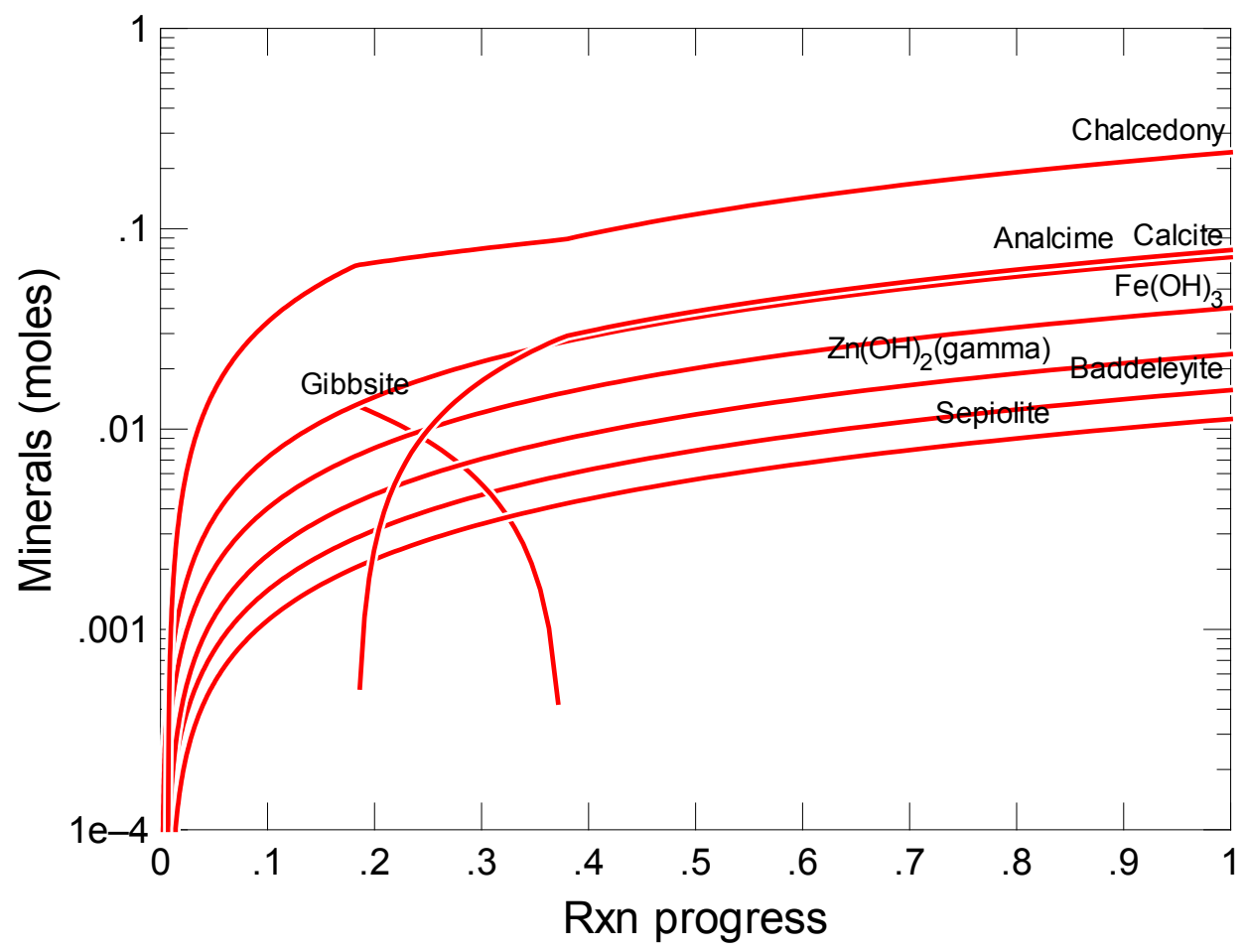

Figure C.214. Secondary Phases Calculated to Form as a Function of Reaction Progress (mol-glass $/ \mathrm{kg}$ ) Determined for Glass Sample LAWB41 


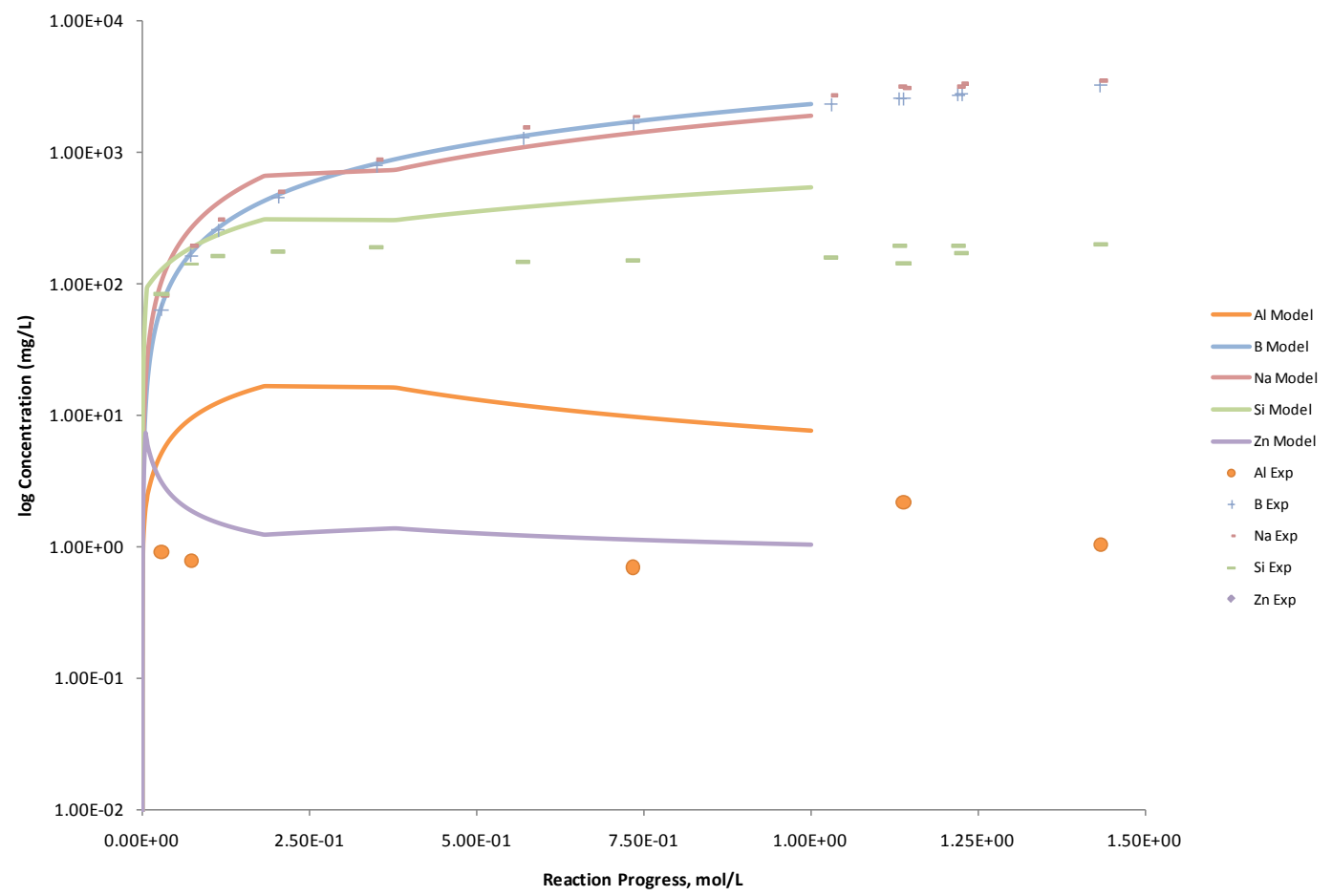

Figure C.215. Measured Solution Concentrations (mg/L) and Model Results for Al, B, Na, Si, and Zn, as a Function of Reaction Progress (mol-glass $/ \mathrm{kg}$ ) Determined for Glass Sample LAWB41

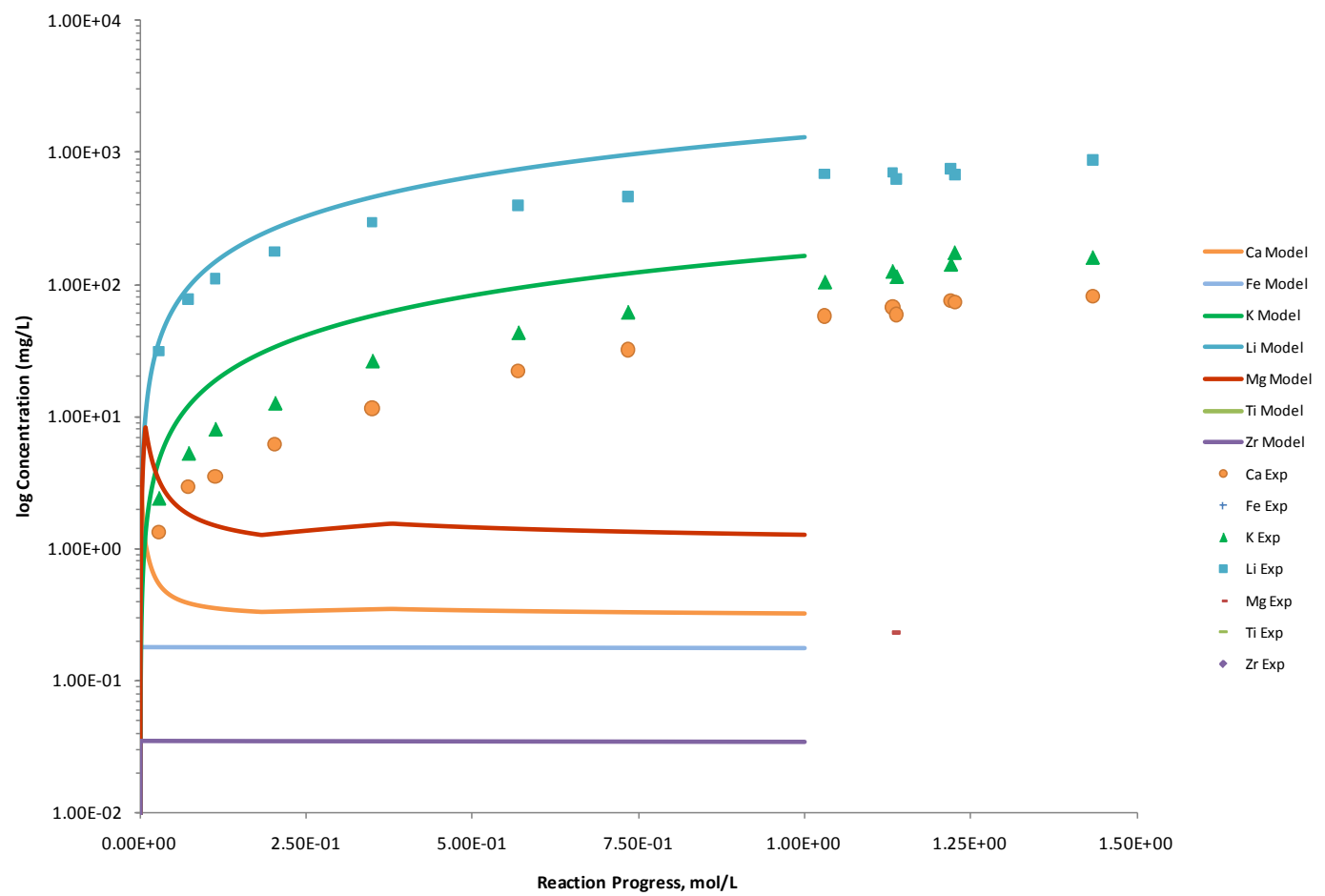

Figure C.216. Measured Solution Concentrations (mg/L) and Model Results for $\mathrm{Ca}, \mathrm{Fe}, \mathrm{K}, \mathrm{Li}, \mathrm{Mg}, \mathrm{Ti}$, and Zr, as a Function of Reaction Progress (mol-glass/kg) Determined for Glass Sample LAWB41 


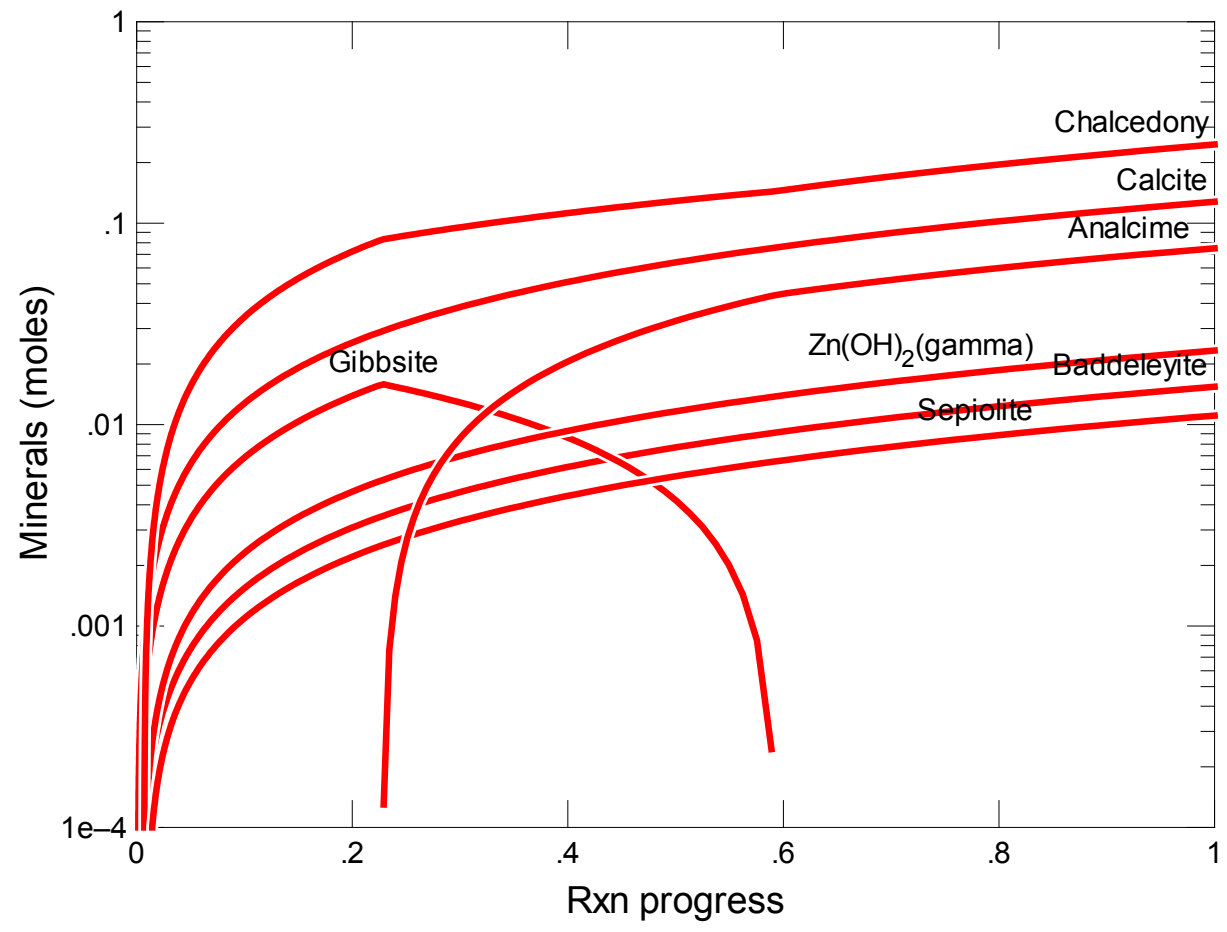

Figure C.217. Secondary Phases Calculated to Form as a Function of Reaction Progress (mol-glass $/ \mathrm{kg}$ ) Determined for Glass Sample LAWB60

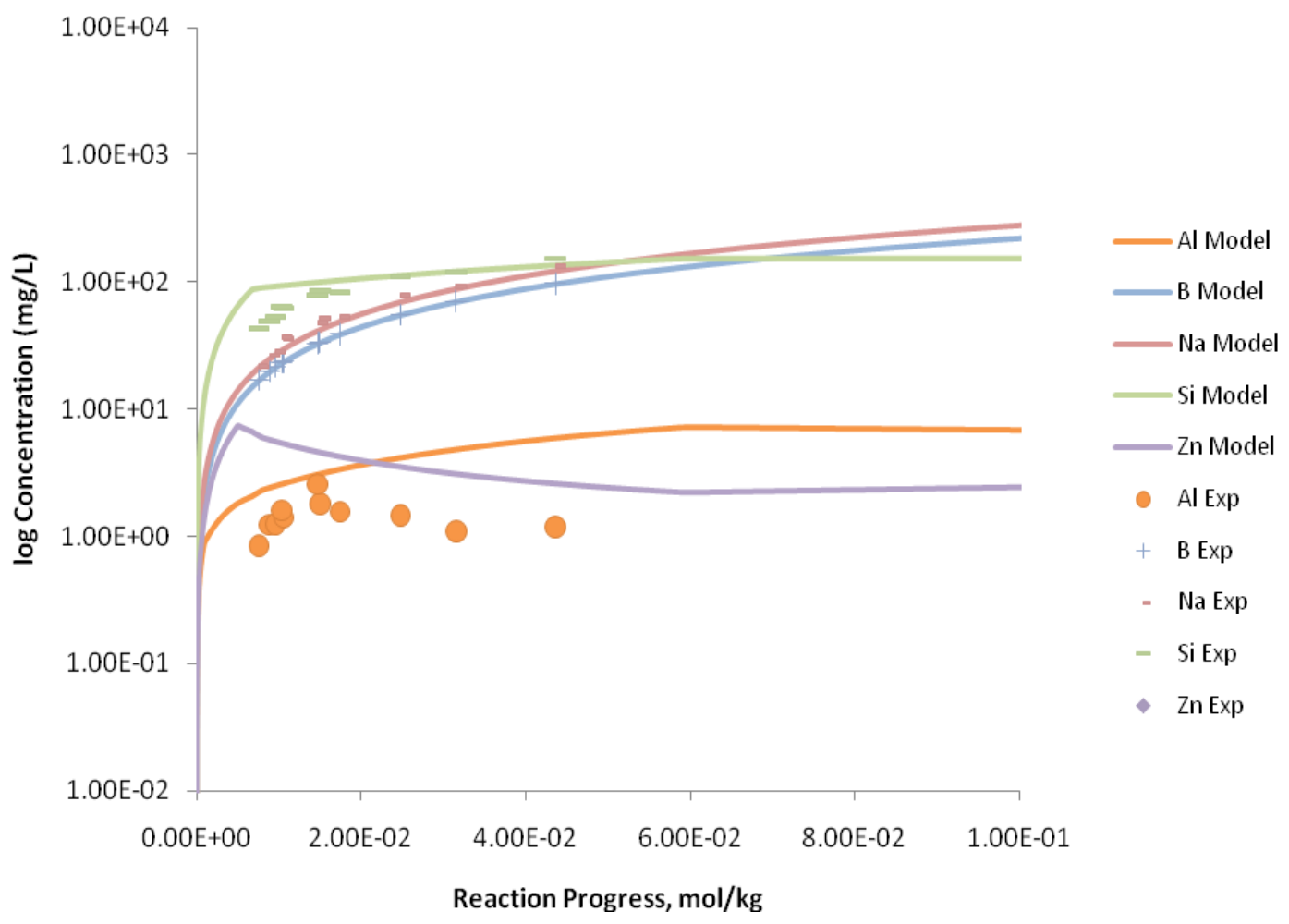

Figure C.218. Measured Solution Concentrations (mg/L) and Model Results for Al, B, Na, Si, and Zn, as a Function of Reaction Progress (mol-glass $/ \mathrm{kg}$ ) Determined for Glass Sample LAWB60 


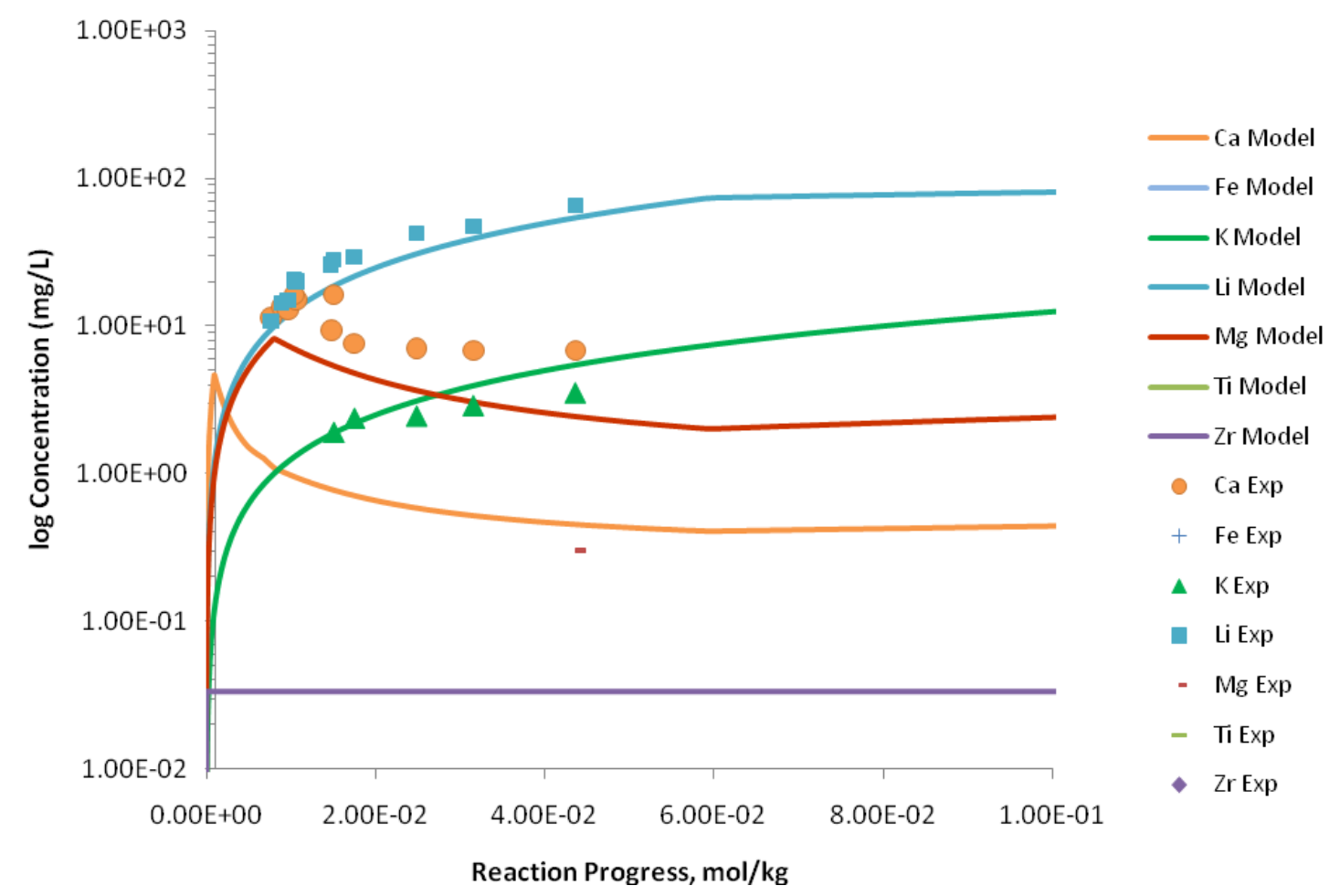

Figure C.219. Measured Solution Concentrations (mg/L) and Model Results for Ca, Fe, K, Li, Mg, Ti, and $\mathrm{Zr}$, as a Function of Reaction Progress (mol-glass/kg) Determined for Glass Sample LAWB60

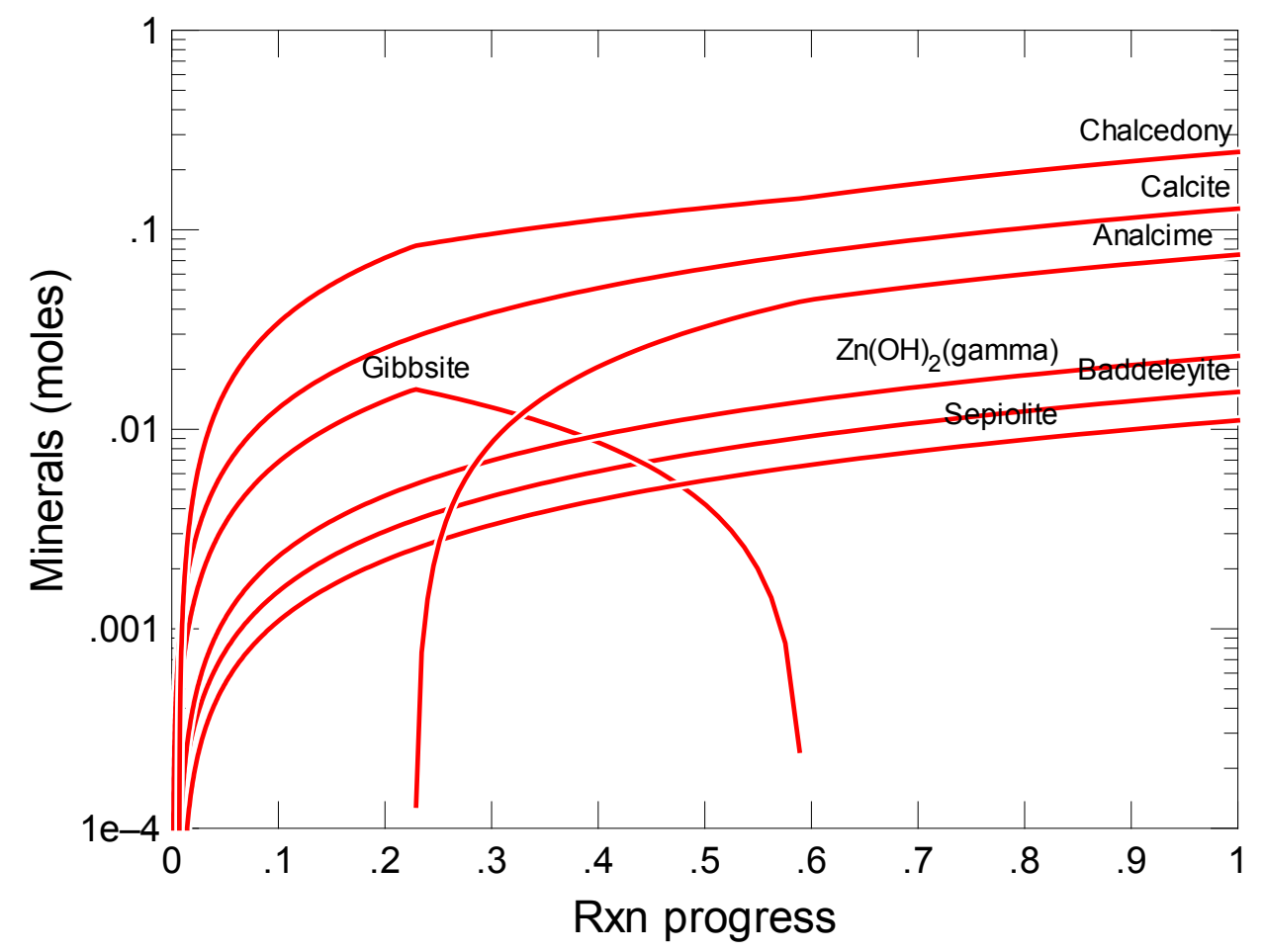

Figure C.220. Secondary Phases Calculated to Form as a Function of Reaction Progress (mol-glass/kg) Determined for Glass Sample LAWB61 


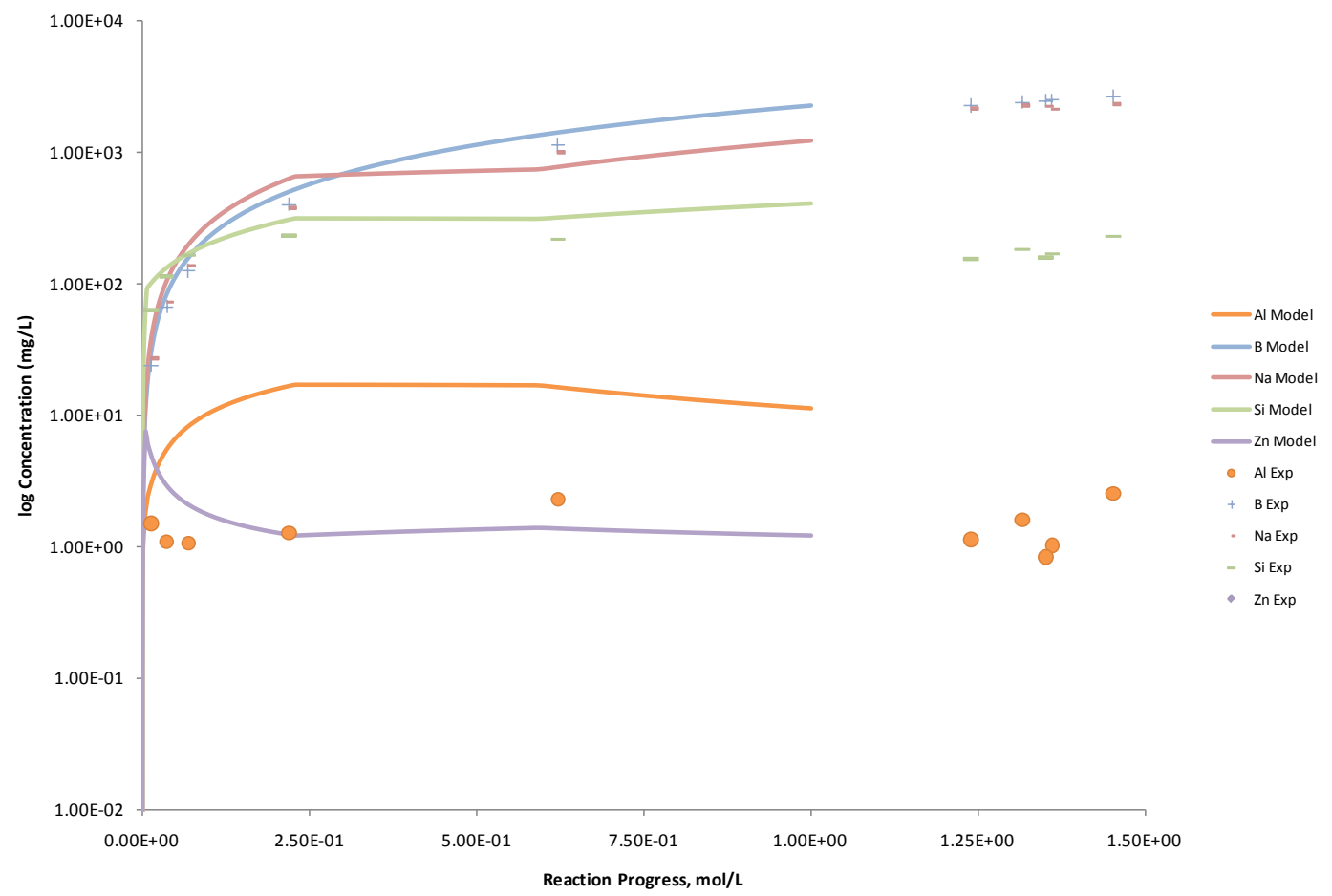

Figure C.221. Measured Solution Concentrations (mg/L) and Model Results for Al, B, Na, Si, and Zn, as a Function of Reaction Progress (mol-glass $/ \mathrm{kg}$ ) Determined for Glass Sample LAWB61

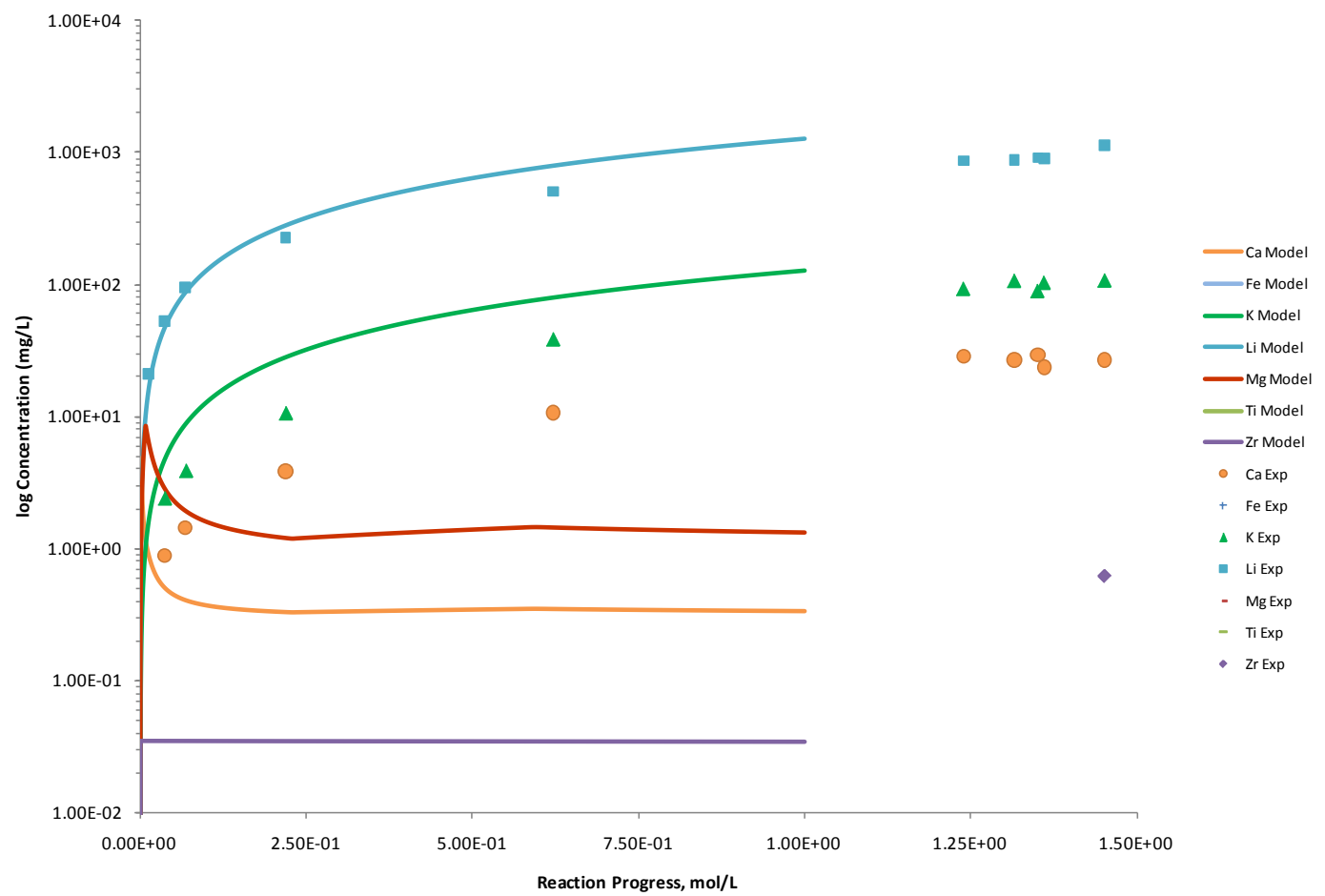

Figure C.222. Measured Solution Concentrations (mg/L) and Model Results for $\mathrm{Ca}, \mathrm{Fe}, \mathrm{K}, \mathrm{Li}, \mathrm{Mg}, \mathrm{Ti}$, and $\mathrm{Zr}$, as a Function of Reaction Progress (mol-glass/kg) Determined for Glass Sample LAWB61 


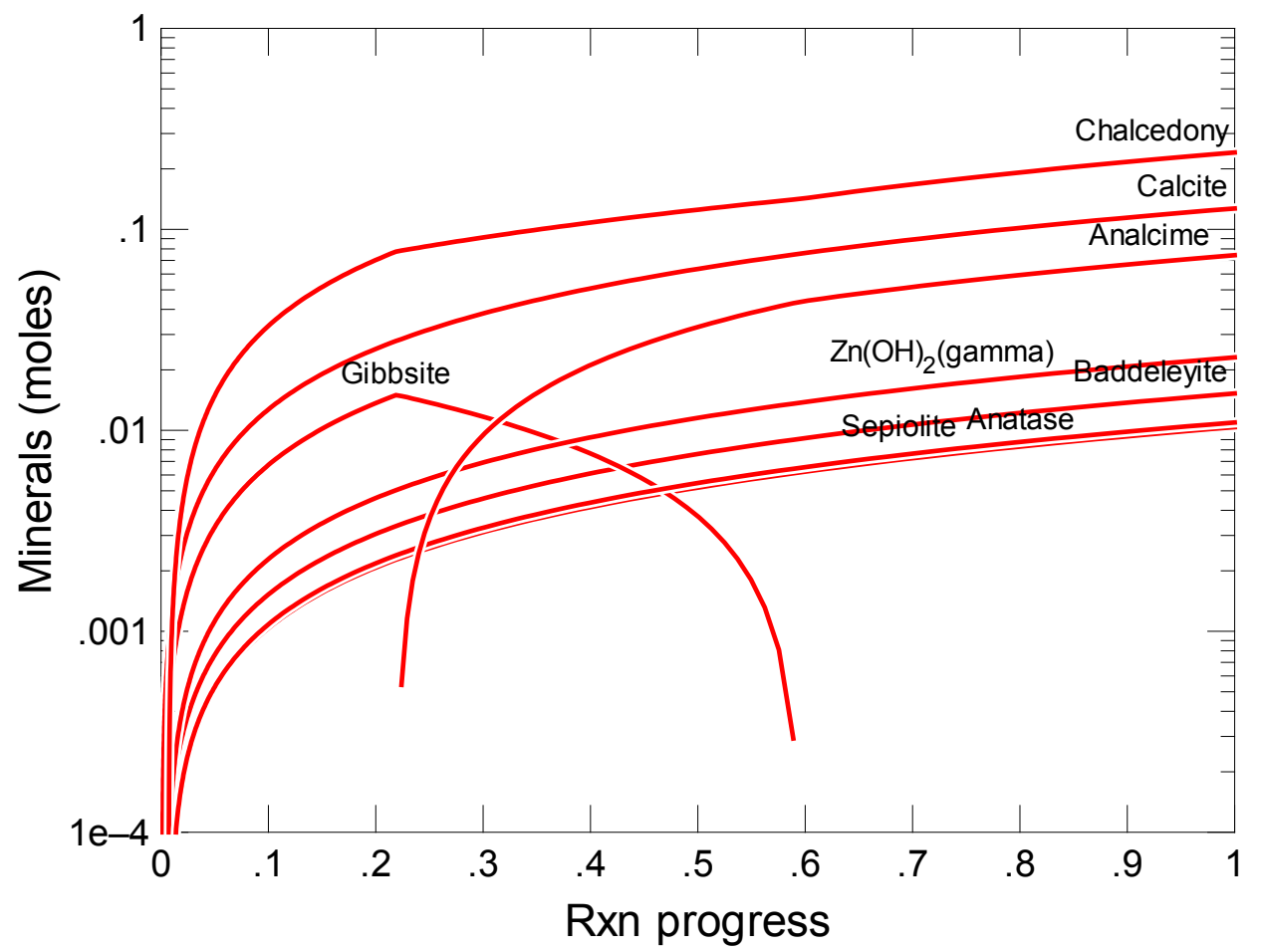

Figure C.223. Secondary Phases Calculated to Form as a Function of Reaction Progress (mol-glass $/ \mathrm{kg}$ ) Determined for Glass Sample LAWB62

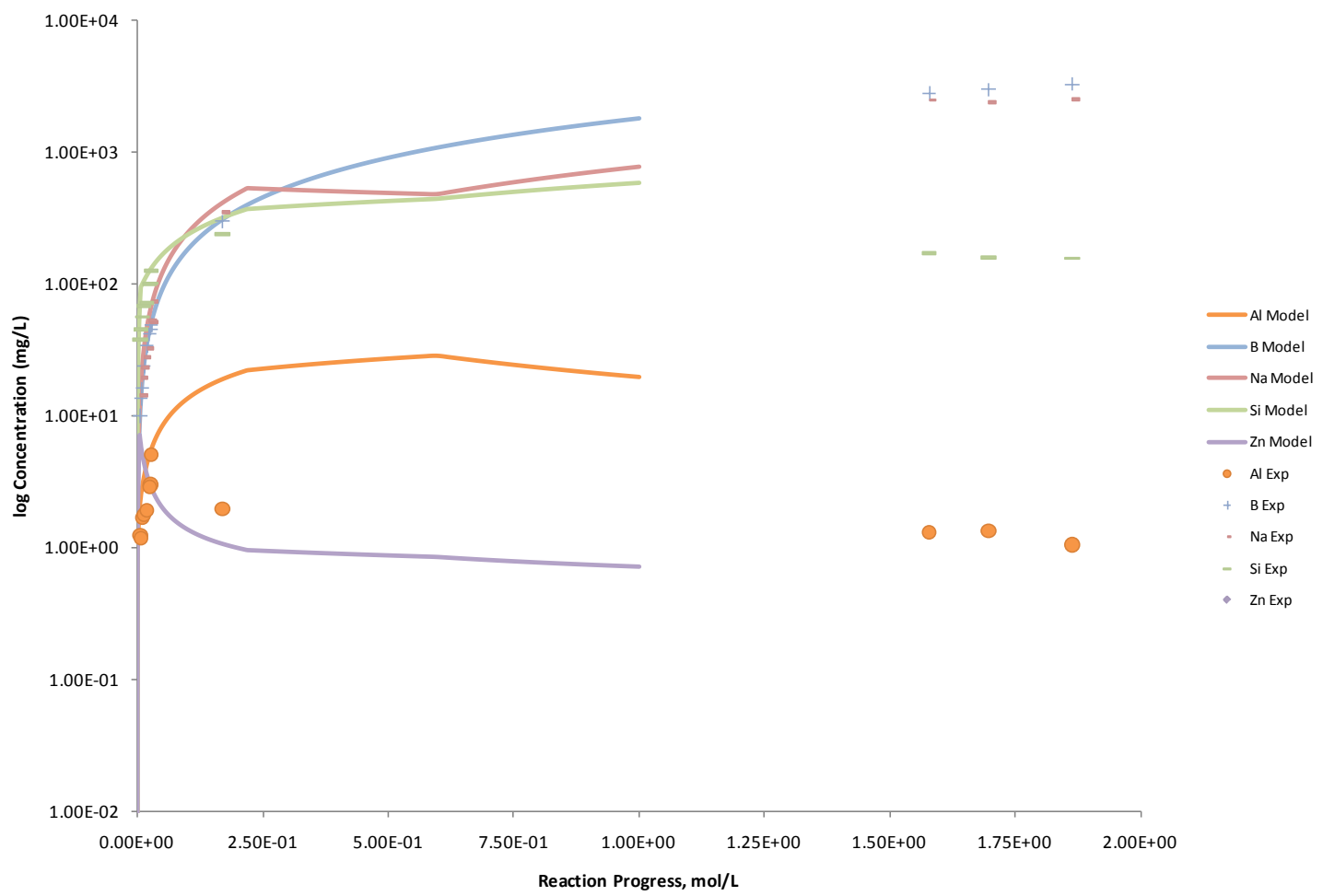

Figure C.224. Measured Solution Concentrations (mg/L) and Model Results for Al, B, Na, Si, and Zn, as a Function of Reaction Progress (mol-glass $/ \mathrm{kg}$ ) Determined for Glass Sample LAWB62 


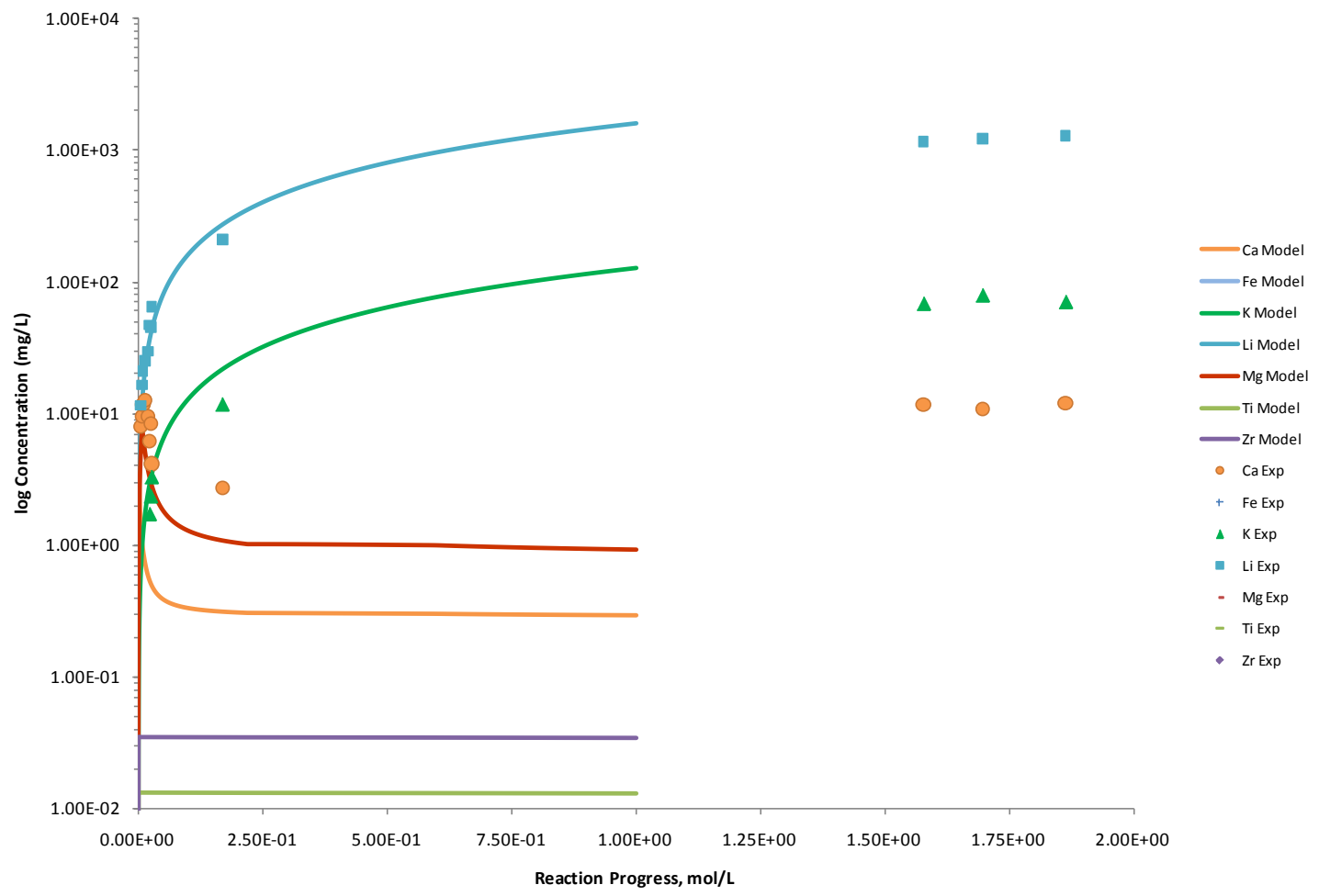

Figure C.225. Measured Solution Concentrations (mg/L) and Model Results for $\mathrm{Ca}, \mathrm{Fe}, \mathrm{K}, \mathrm{Li}, \mathrm{Mg}$, Ti, and $\mathrm{Zr}$, as a Function of Reaction Progress (mol-glass/kg) Determined for Glass Sample LAWB62

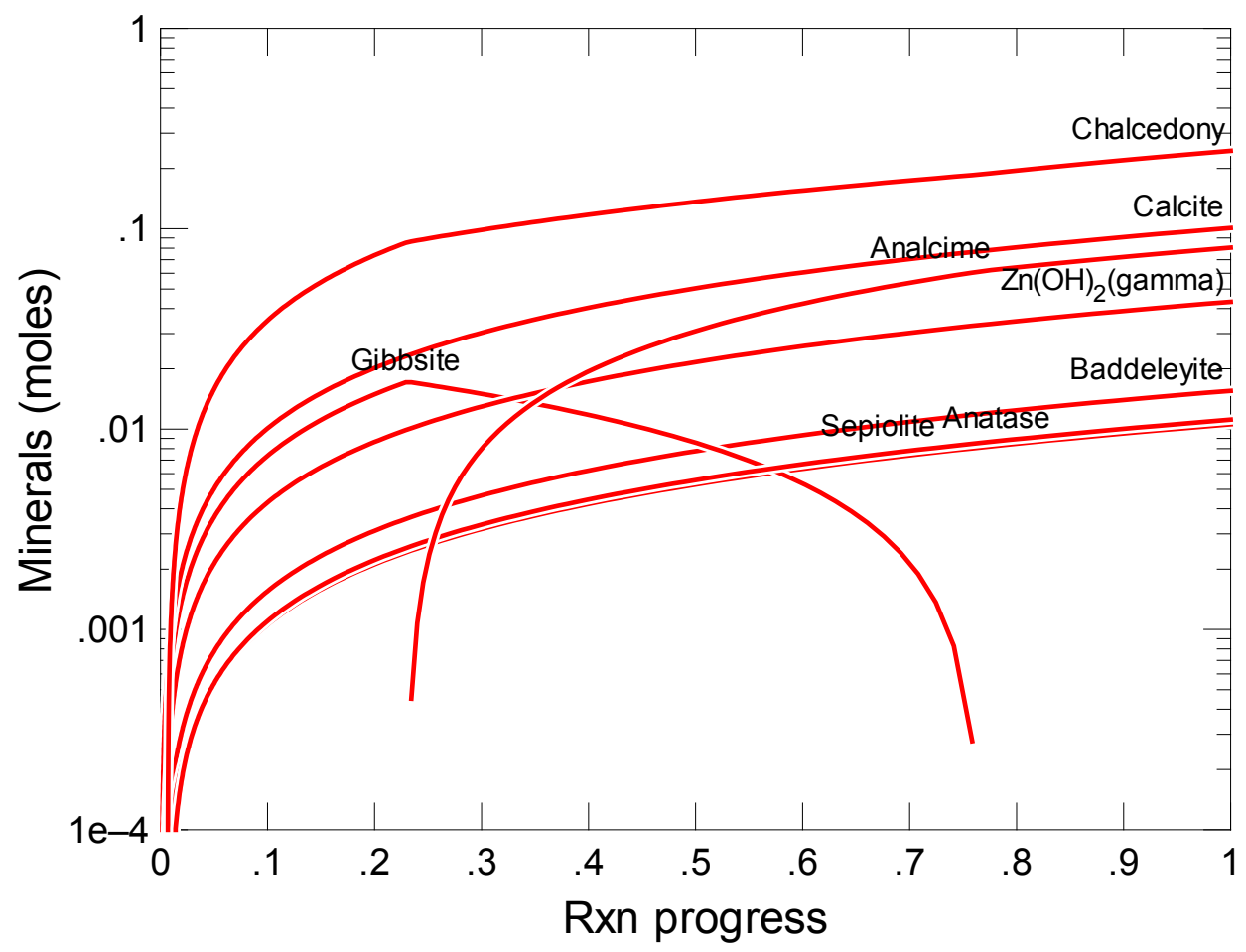

Figure C.226. Secondary Phases Calculated to Form as a Function of Reaction Progress (mol-glass $/ \mathrm{kg}$ ) Determined for Glass Sample LAWB63 


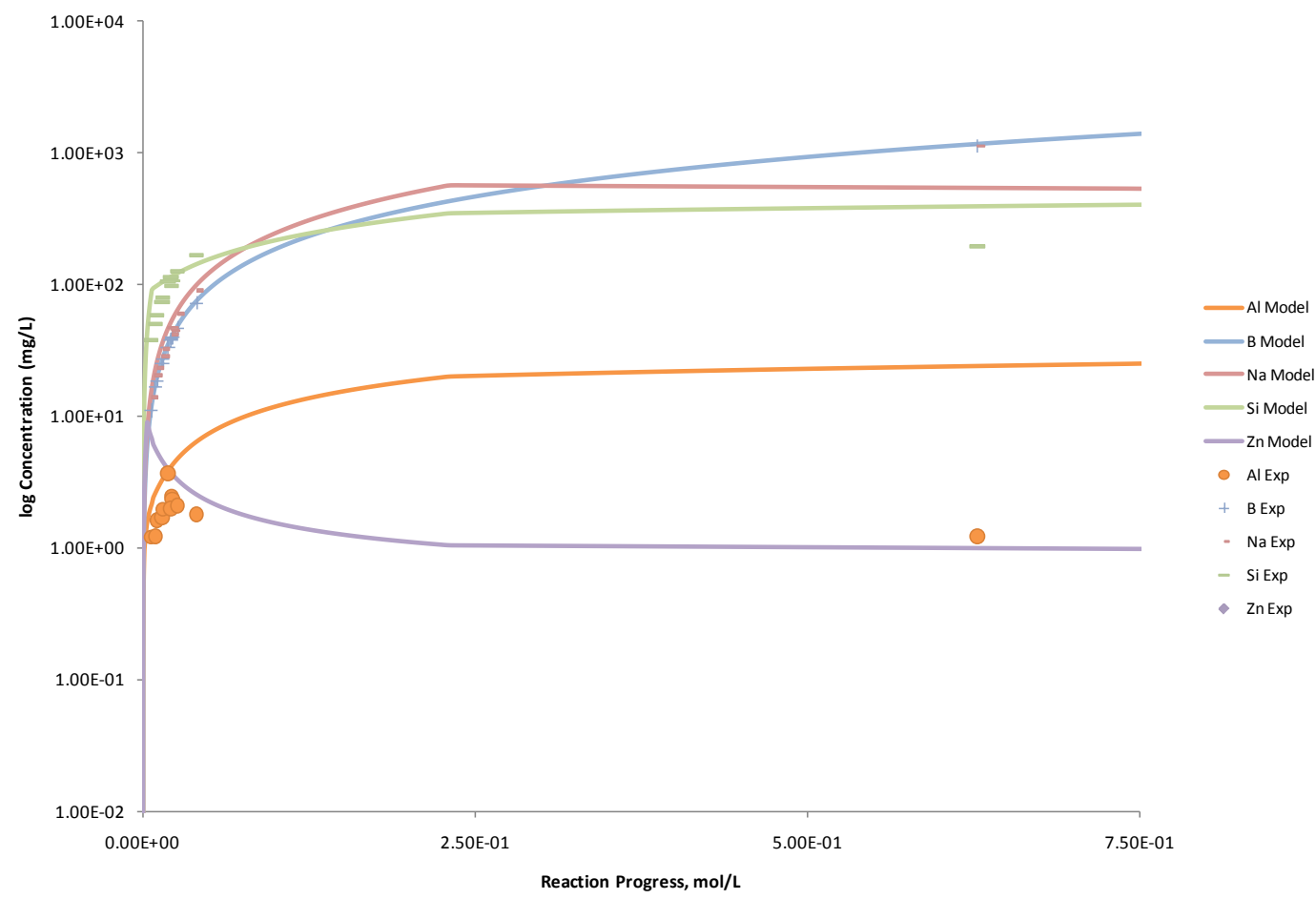

Figure C.227. Measured Solution Concentrations (mg/L) and Model Results for Al, B, Na, Si, and Zn, as a Function of Reaction Progress (mol-glass $/ \mathrm{kg}$ ) Determined for Glass Sample LAWB63

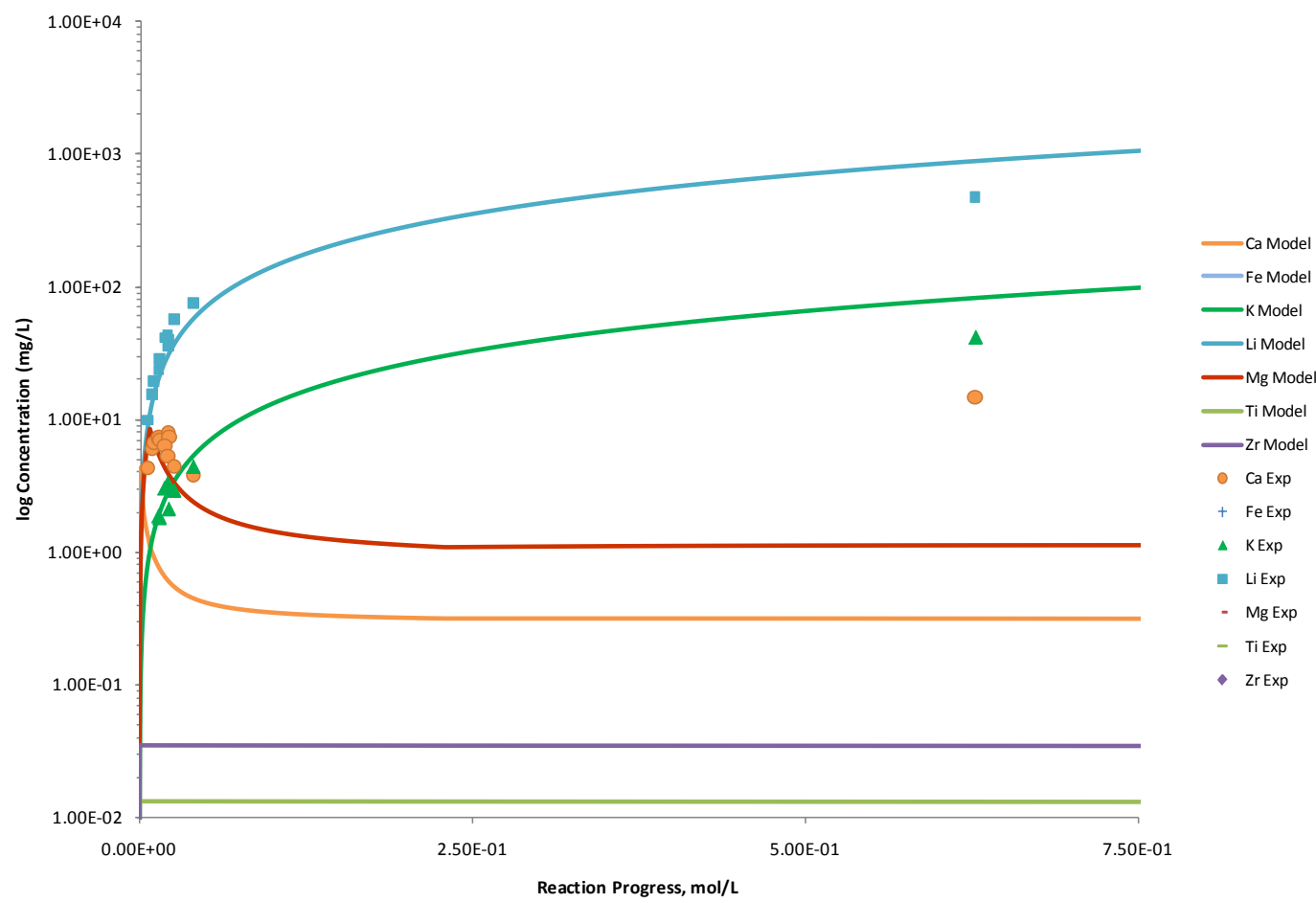

Figure C.228. Measured Solution Concentrations (mg/L) and Model Results for Ca, Fe, K, Li, Mg, Ti, and $\mathrm{Zr}$, as a Function of Reaction Progress (mol-glass/kg) Determined for Glass Sample LAWB63 


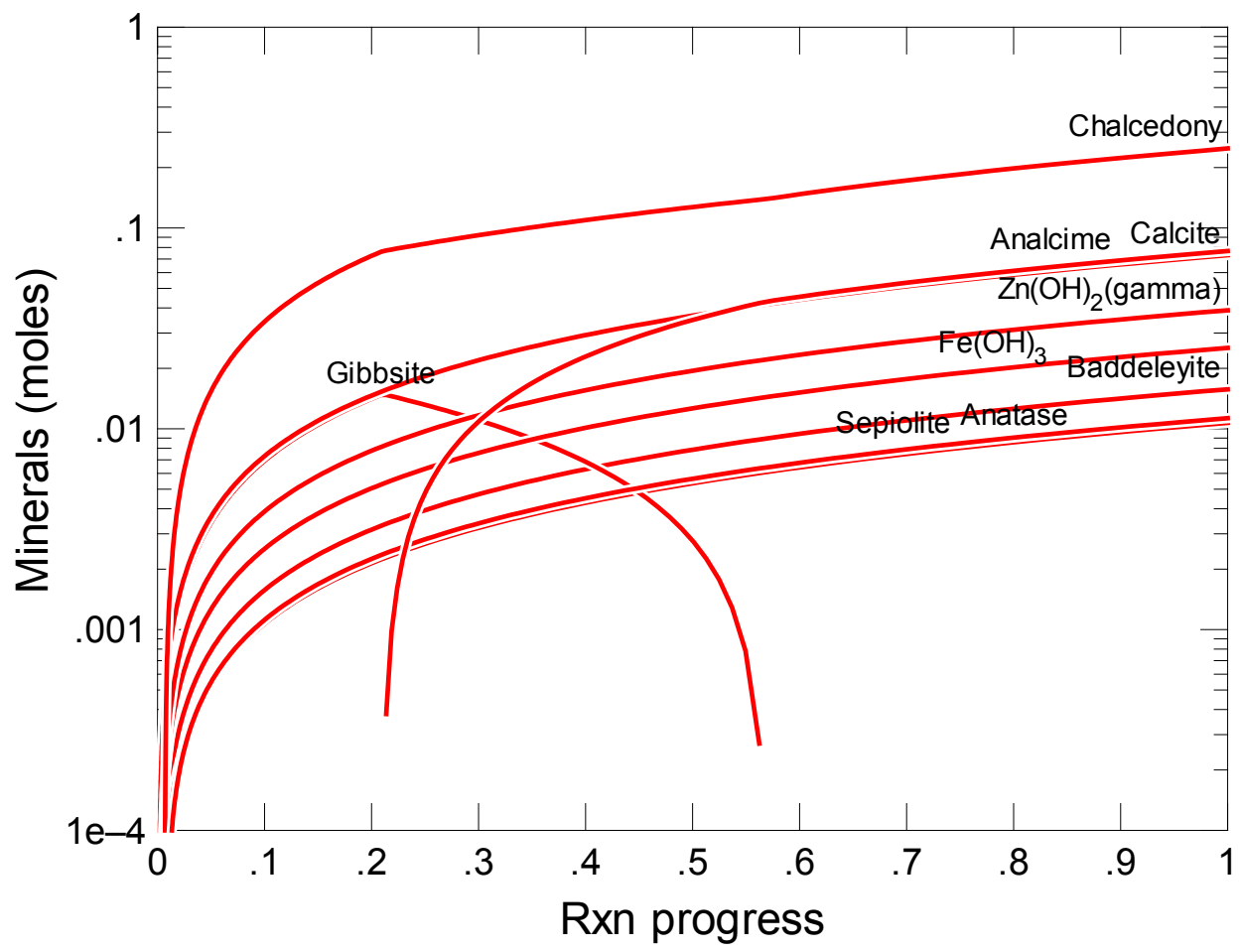

Figure C.229. Secondary Phases Calculated to Form as a Function of Reaction Progress (mol-glass $/ \mathrm{kg}$ ) Determined for Glass Sample LAWB64

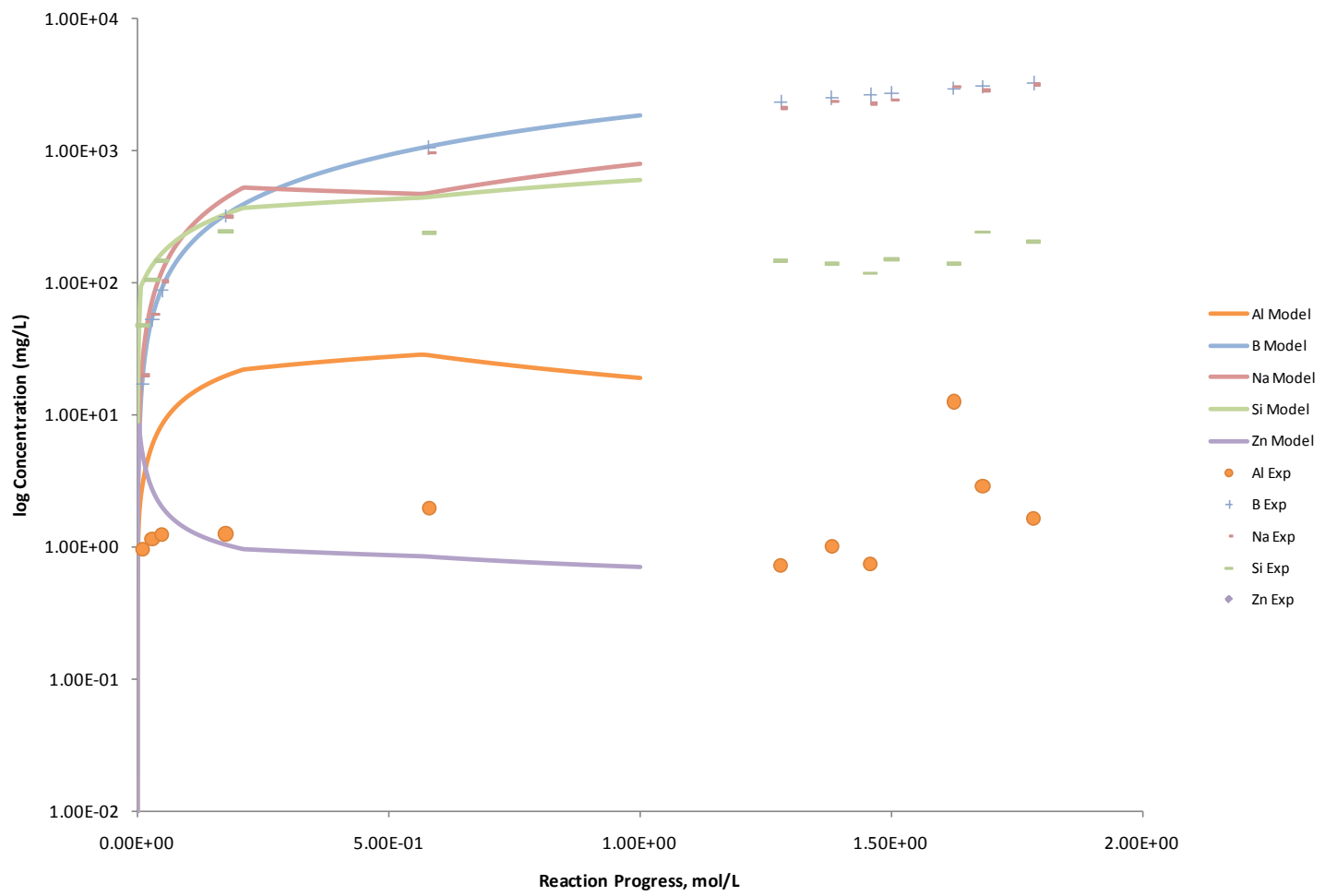

Figure C.230. Measured Solution Concentrations (mg/L) and Model Results for Al, B, Na, Si, and Zn, as a Function of Reaction Progress (mol-glass $/ \mathrm{kg}$ ) Determined for Glass Sample LAWB64 


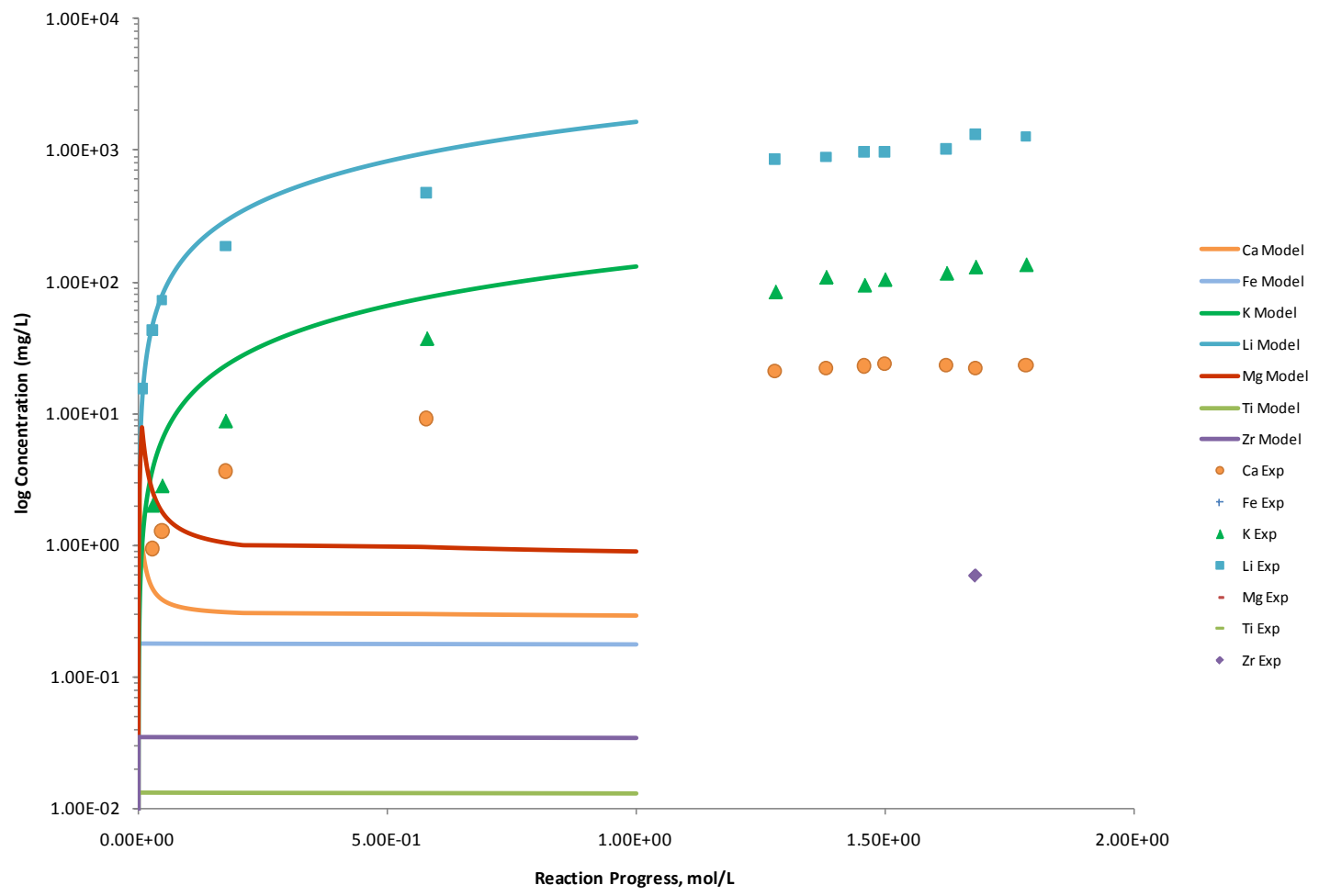

Figure C.231. Measured Solution Concentrations (mg/L) and Model Results for $\mathrm{Ca}, \mathrm{Fe}, \mathrm{K}, \mathrm{Li}, \mathrm{Mg}$, Ti, and $\mathrm{Zr}$, as a Function of Reaction Progress (mol-glass/kg) Determined for Glass Sample LAWB64

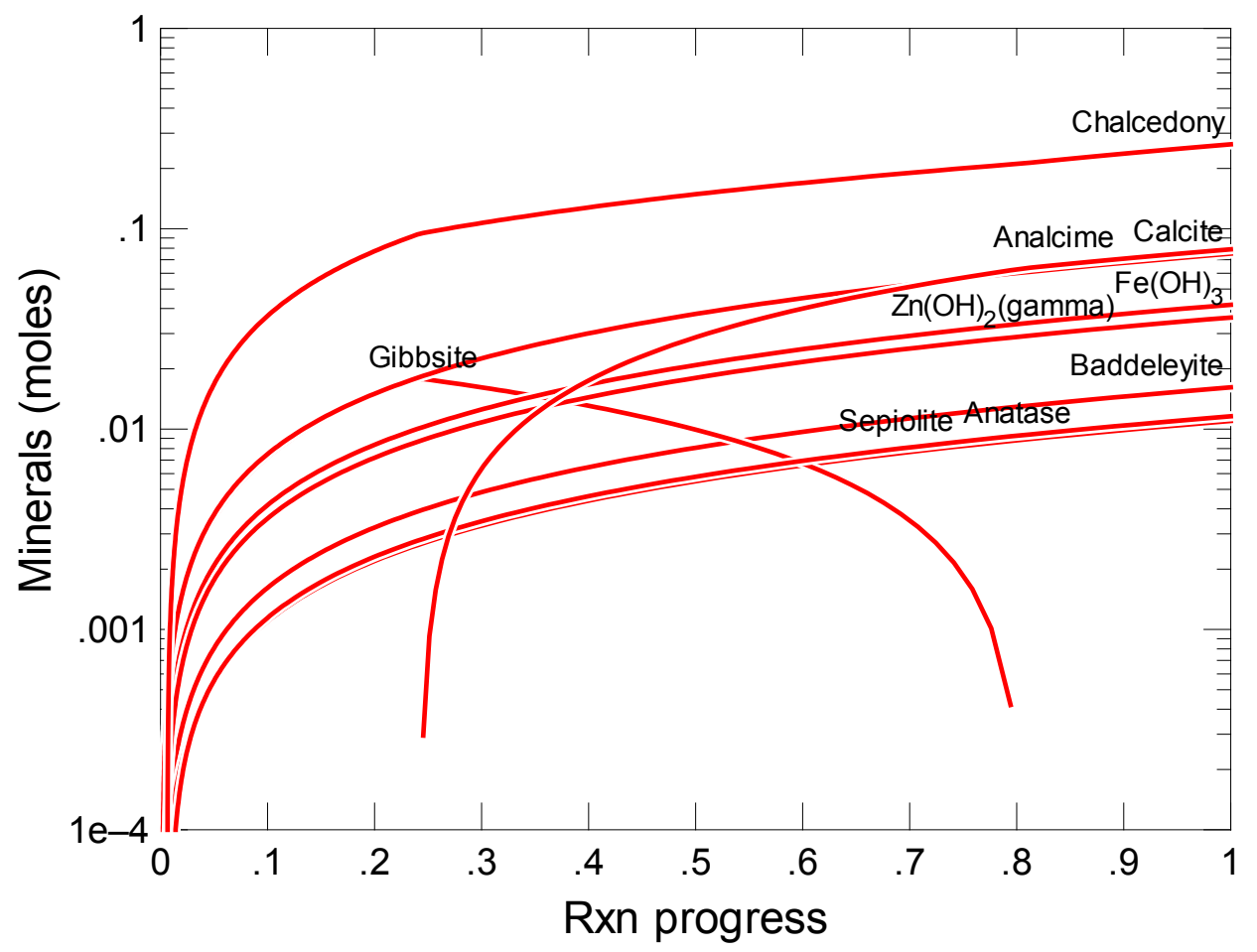

Figure C.232. Secondary Phases Calculated to Form as a Function of Reaction Progress (mol-glass $/ \mathrm{kg}$ ) Determined for Glass Sample LAWB65 


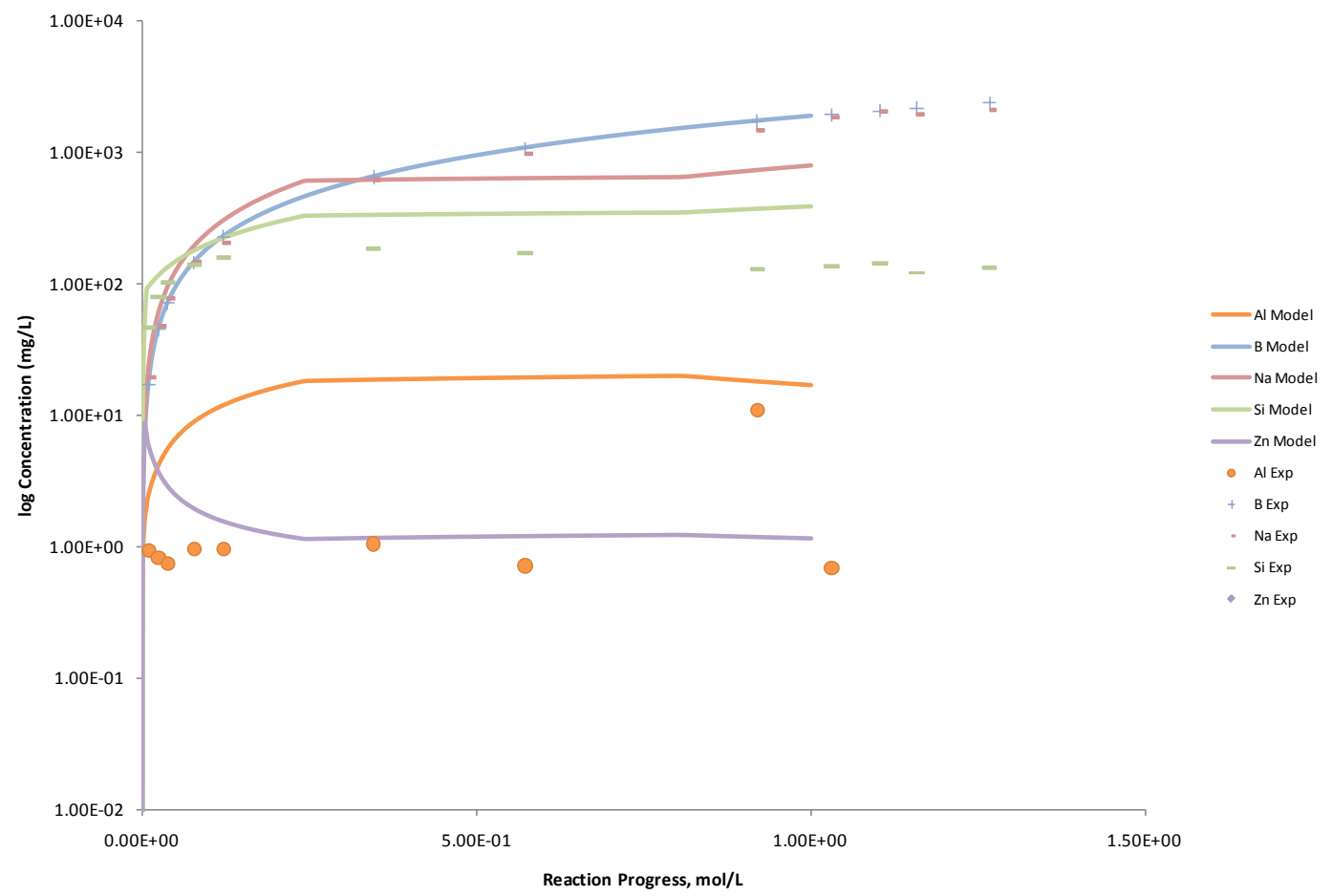

Figure C.233. Measured Solution Concentrations (mg/L) and Model Results for Al, B, Na, Si, and Zn, as a Function of Reaction Progress (mol-glass $/ \mathrm{kg}$ ) Determined for Glass Sample LAWB65

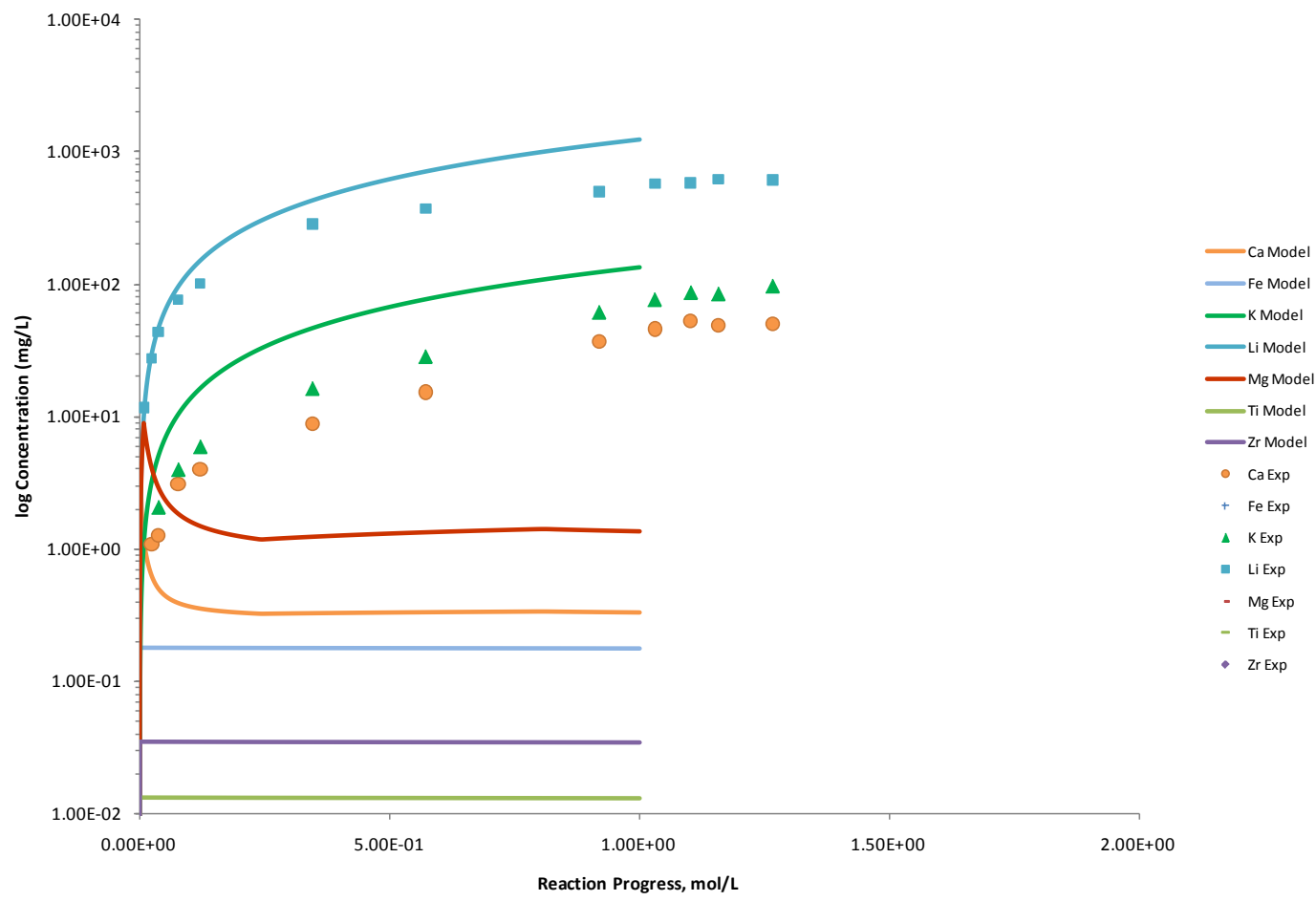

Figure C.234. Measured Solution Concentrations (mg/L) and Model Results for $\mathrm{Ca}, \mathrm{Fe}, \mathrm{K}, \mathrm{Li}, \mathrm{Mg}, \mathrm{Ti}$, and $\mathrm{Zr}$, as a Function of Reaction Progress (mol-glass/kg) Determined for Glass Sample LAWB65 


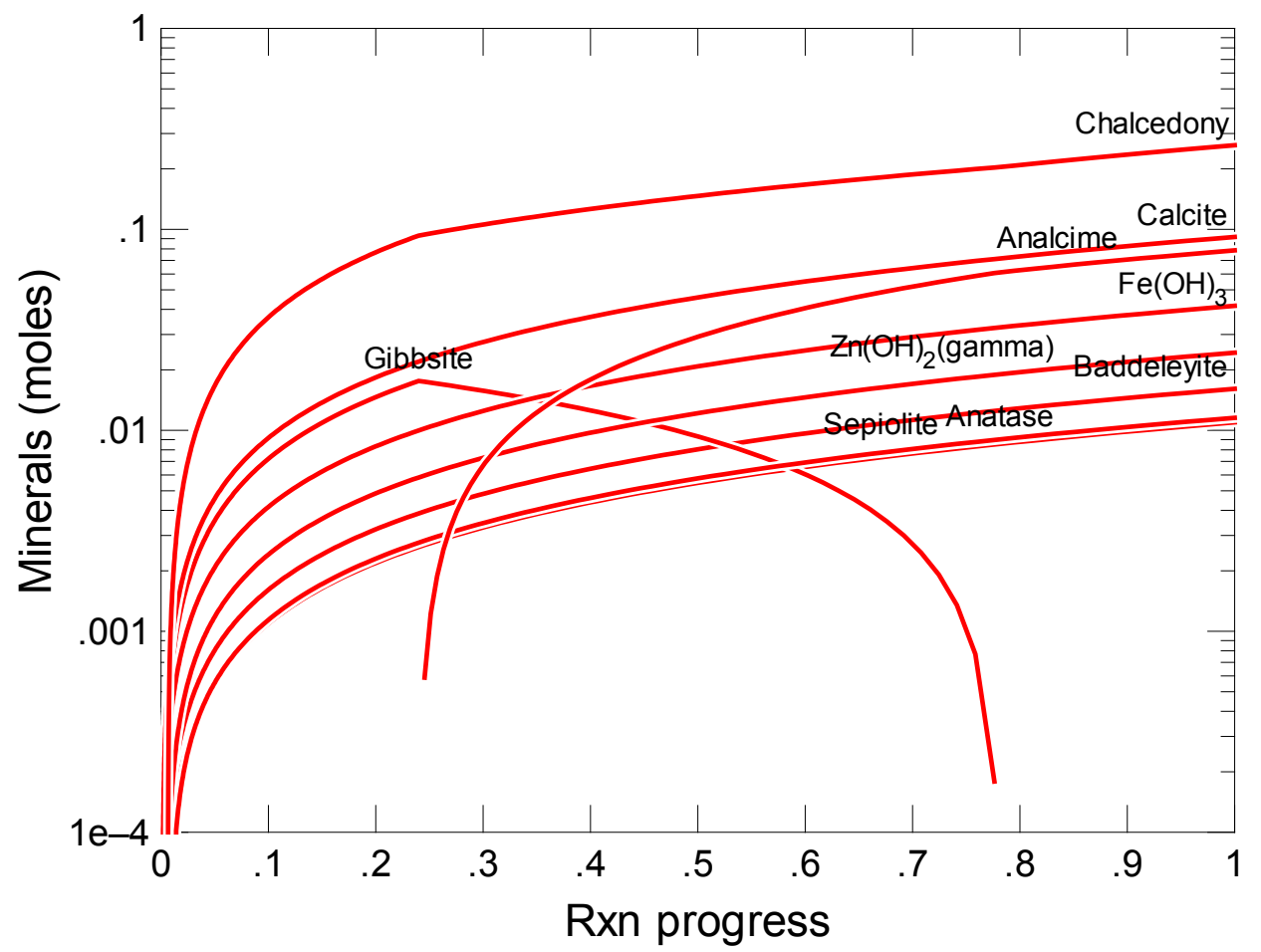

Figure C.235. Secondary Phases Calculated to Form as a Function of Reaction Progress (mol-glass $/ \mathrm{kg}$ ) Determined for Glass Sample LAWB66

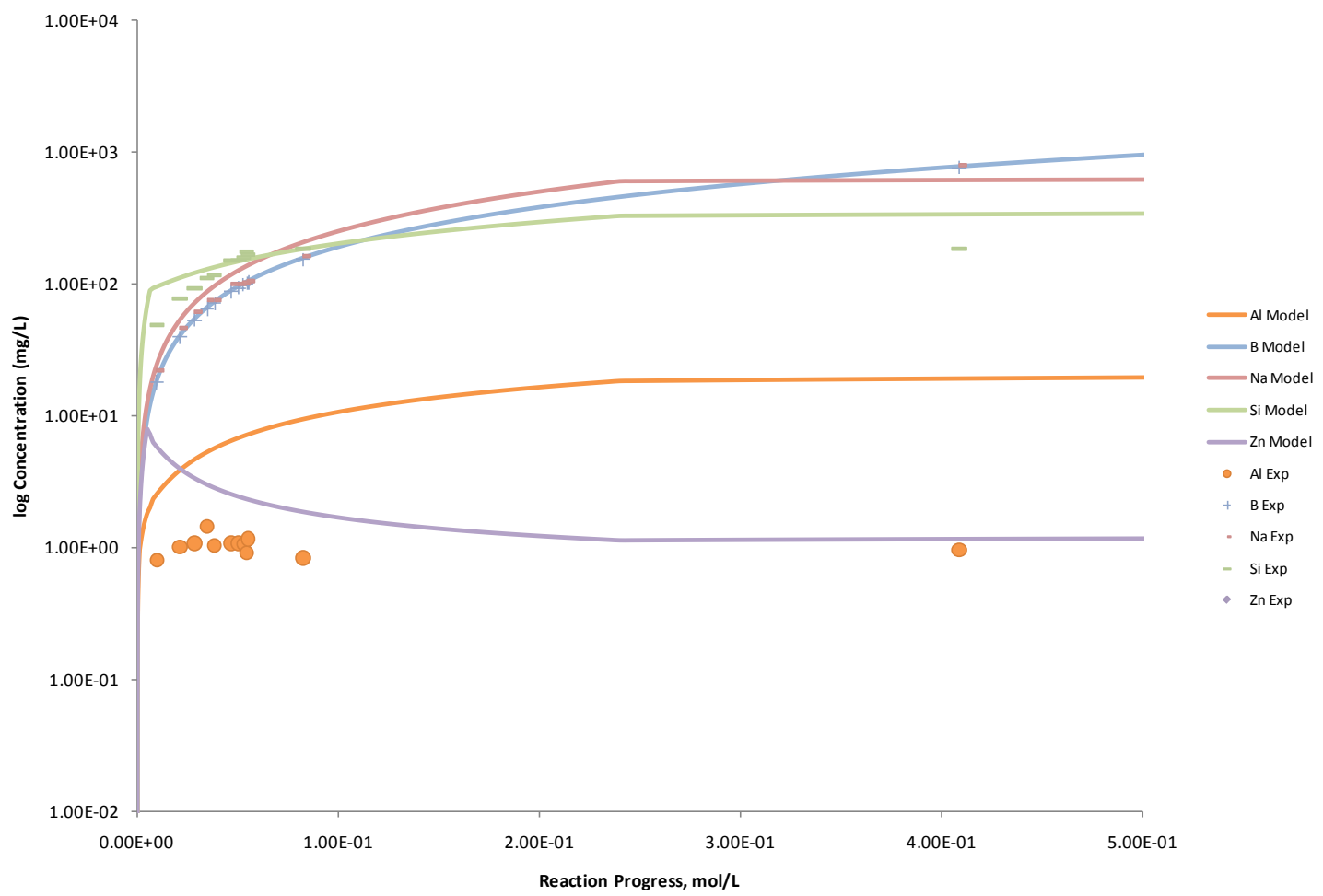

Figure C.236. Measured Solution Concentrations (mg/L) and Model Results for Al, B, Na, Si, and Zn, as a Function of Reaction Progress (mol-glass $/ \mathrm{kg}$ ) Determined for Glass Sample LAWB66 


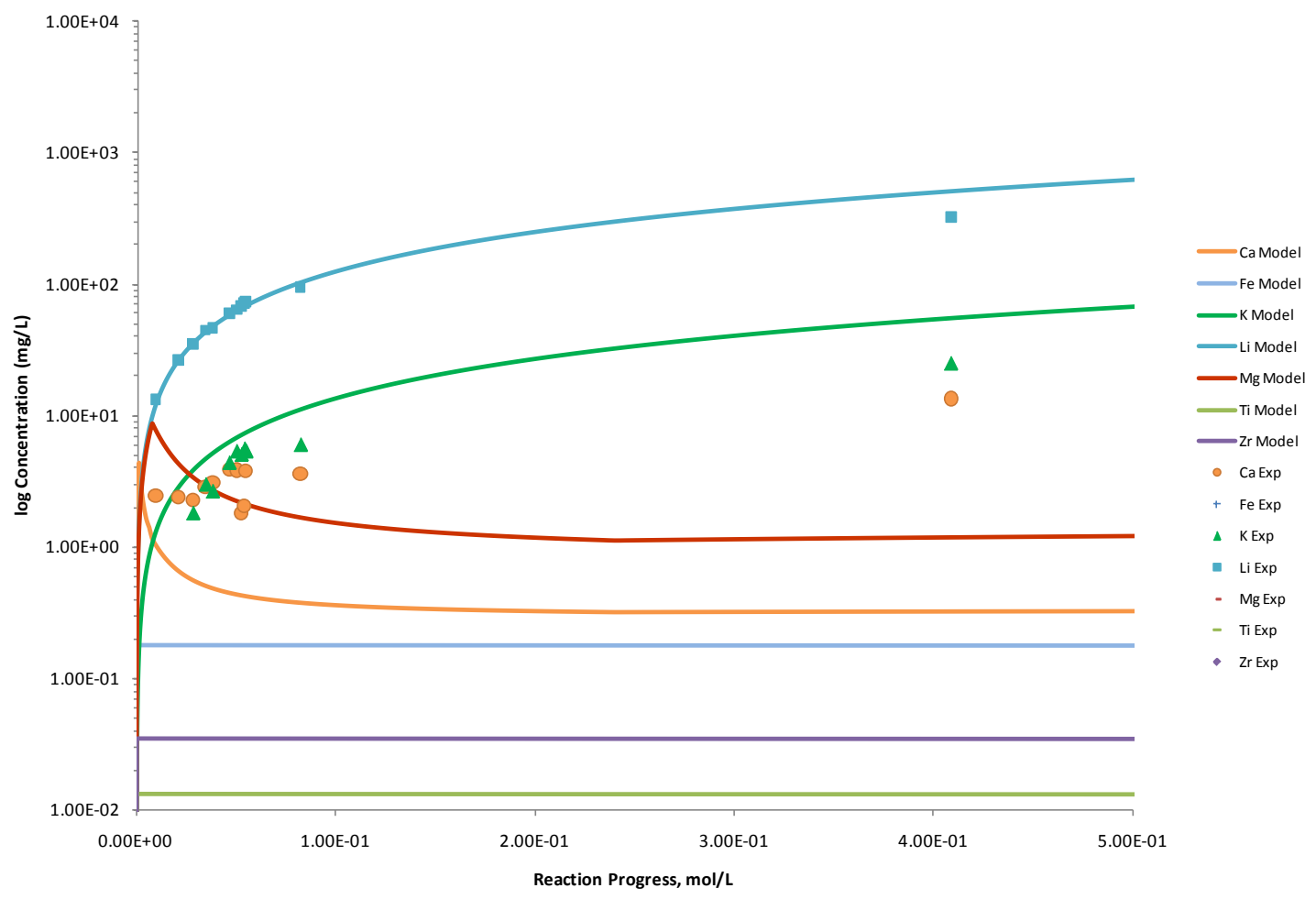

Figure C.237. Measured Solution Concentrations (mg/L) and Model Results for $\mathrm{Ca}, \mathrm{Fe}, \mathrm{K}, \mathrm{Li}, \mathrm{Mg}$, Ti, and $\mathrm{Zr}$, as a Function of Reaction Progress (mol-glass/kg) Determined for Glass Sample LAWB66

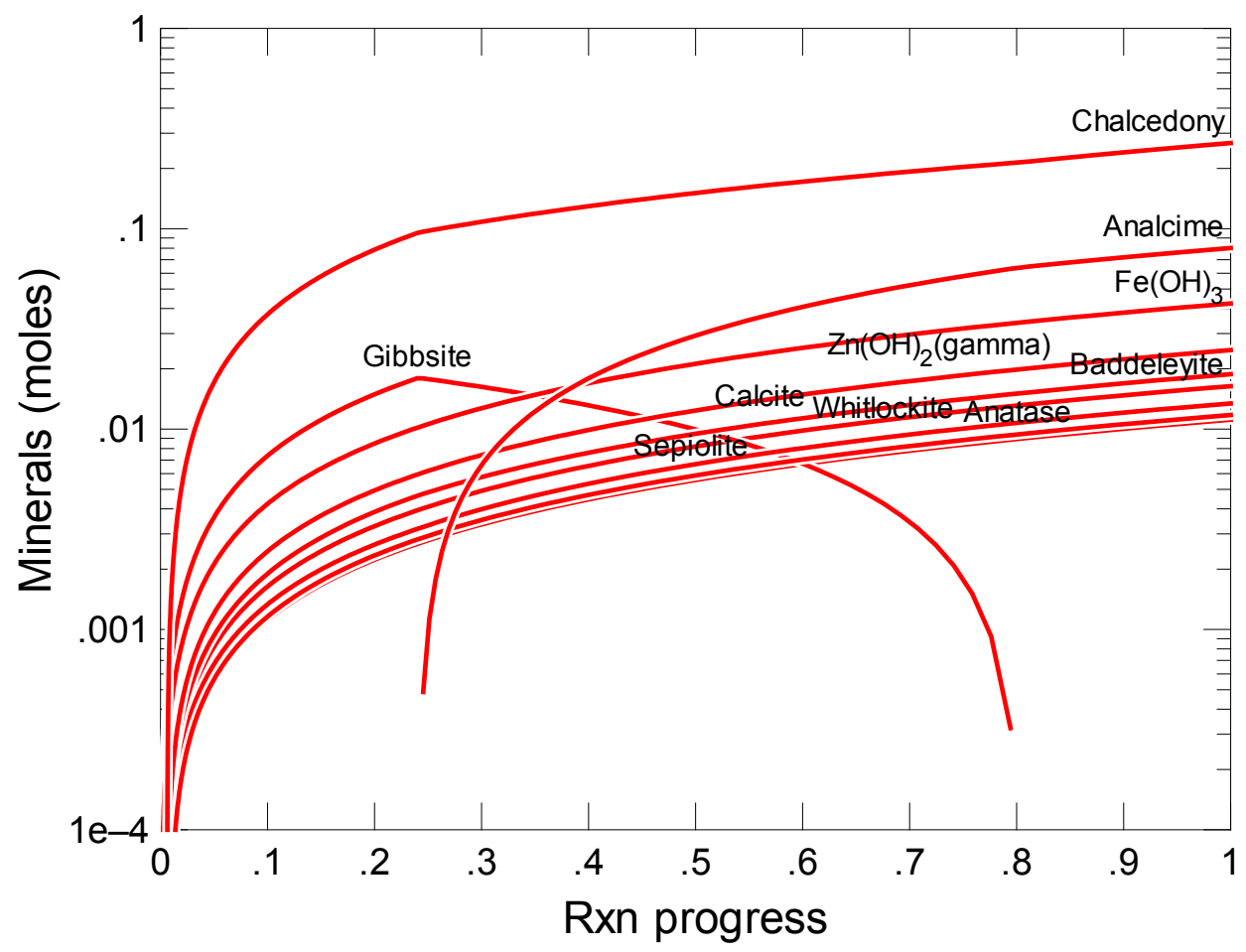

Figure C.238. Secondary Phases Calculated to Form as a Function of Reaction Progress (mol-glass $/ \mathrm{kg}$ ) Determined for Glass Sample LAWB67 


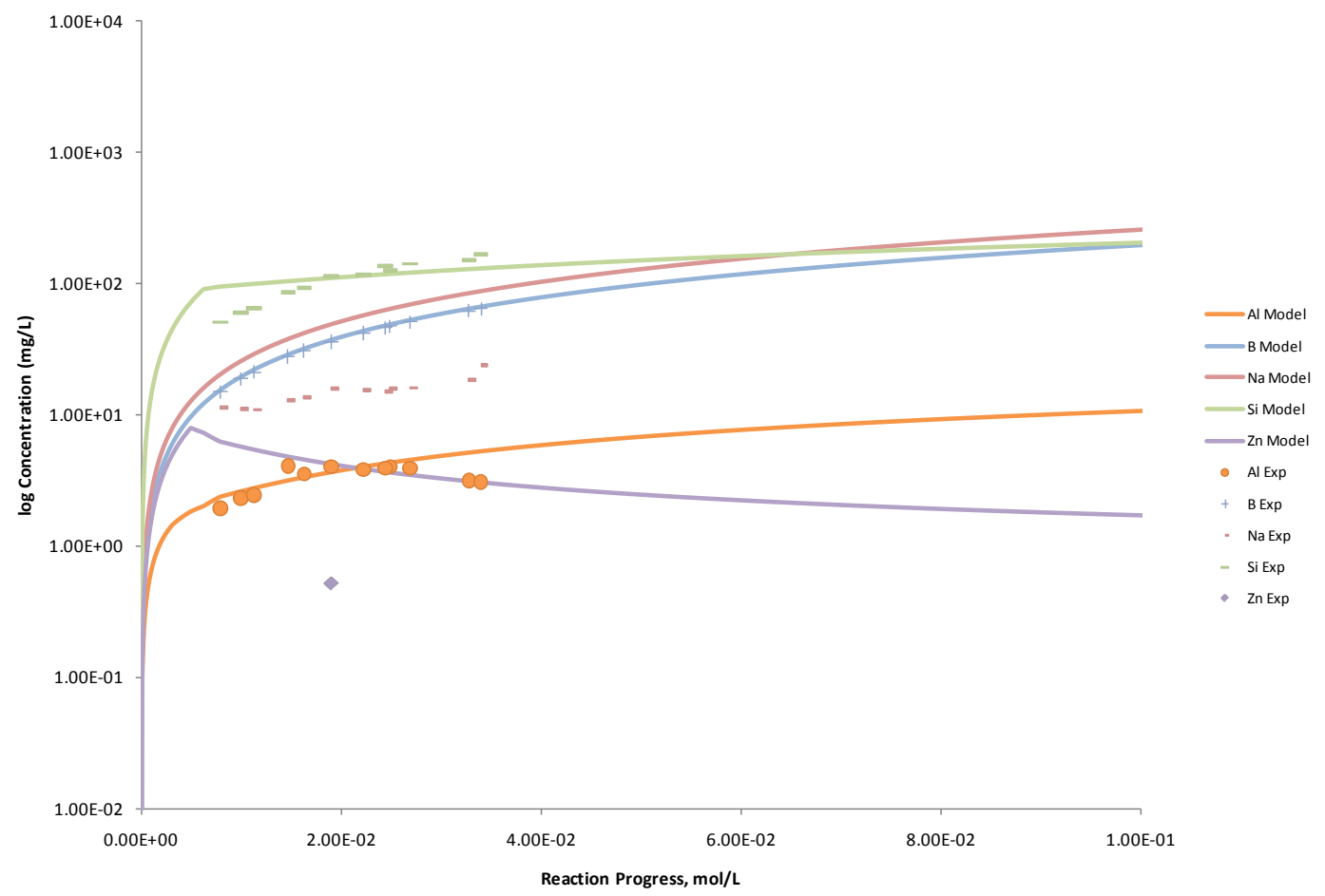

Figure C.239. Measured Solution Concentrations (mg/L) and Model Results for Al, B, Na, Si, and Zn, as a Function of Reaction Progress (mol-glass $/ \mathrm{kg}$ ) Determined for Glass Sample LAWB67

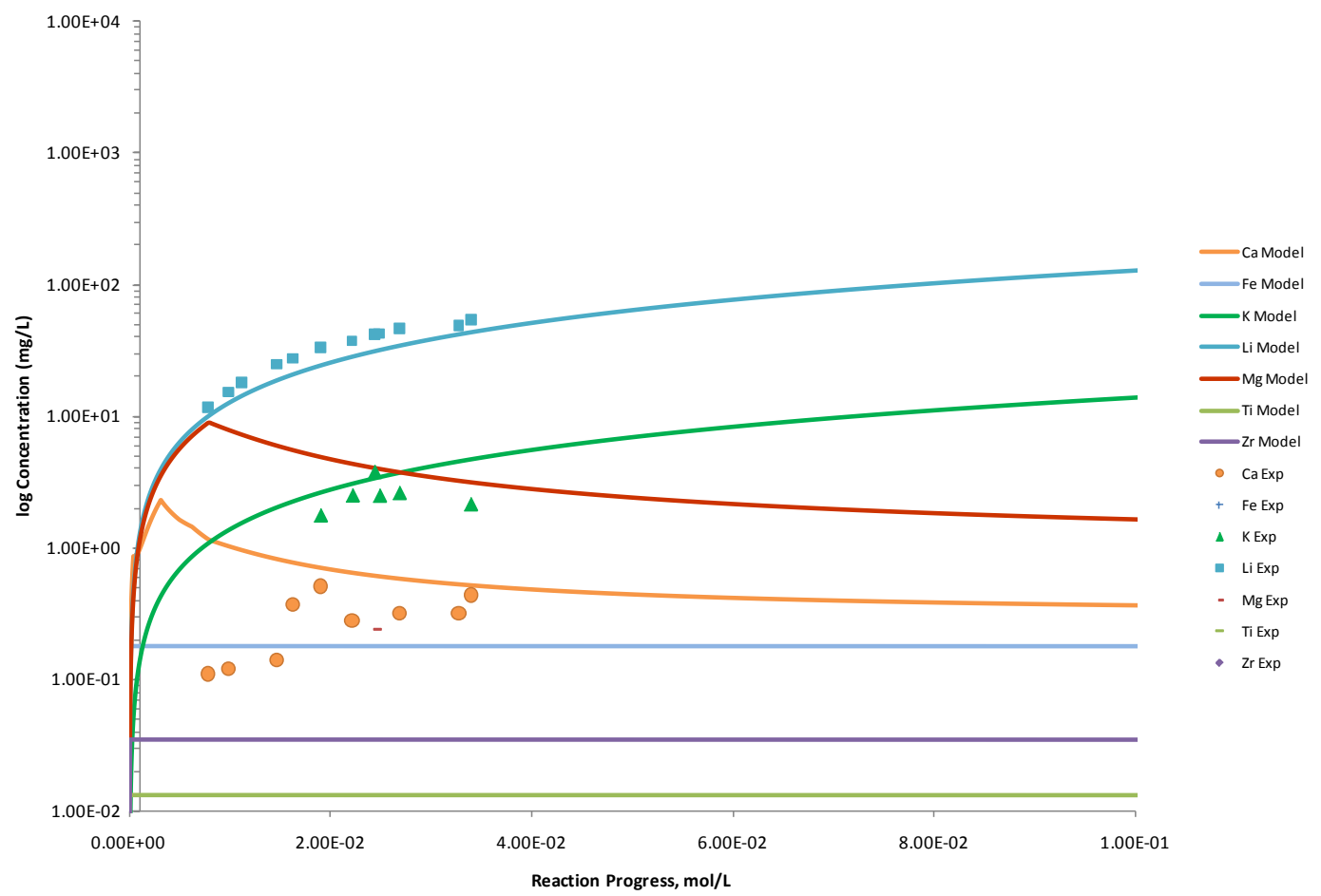

Figure C.240. Measured Solution Concentrations (mg/L) and Model Results for Ca, Fe, K, Li, Mg, Ti, and $\mathrm{Zr}$, as a Function of Reaction Progress (mol-glass/kg) Determined for Glass Sample LAWB67 


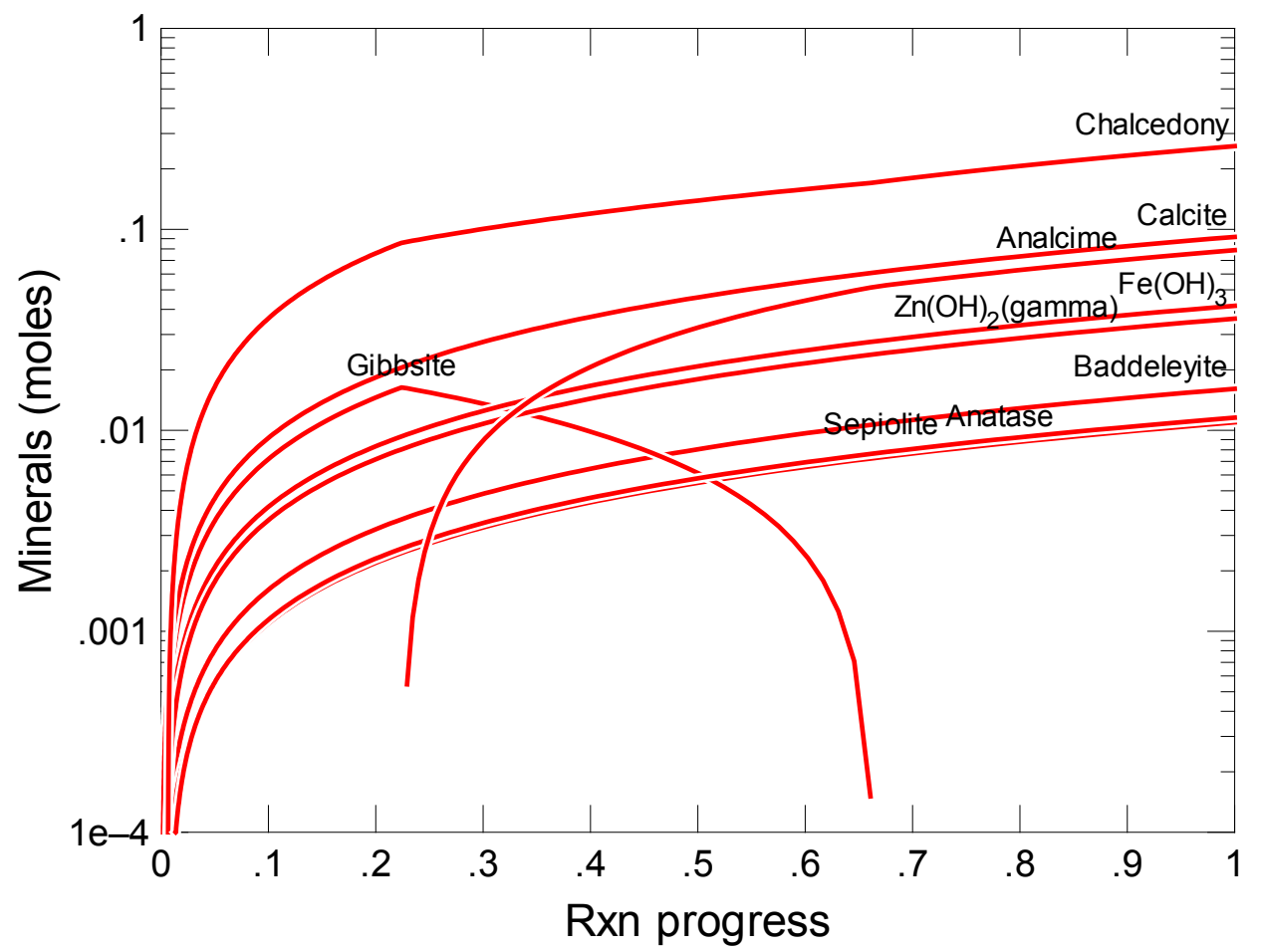

Figure C.241. Secondary Phases Calculated to Form as a Function of Reaction Progress (mol-glass $/ \mathrm{kg}$ ) Determined for Glass Sample LAWB68

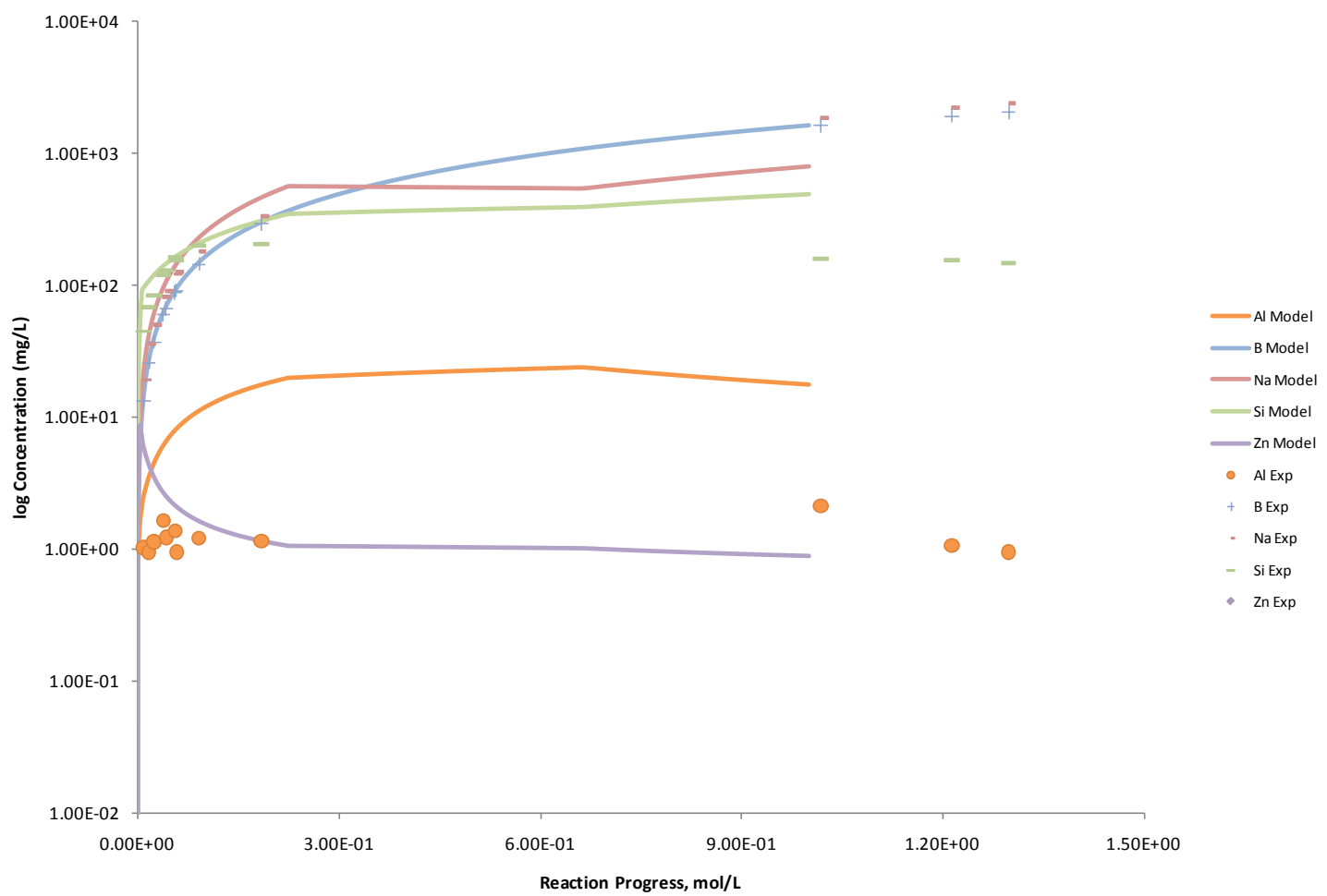

Figure C.242. Measured Solution Concentrations (mg/L) and Model Results for Al, B, Na, Si, and Zn, as a Function of Reaction Progress (mol-glass $/ \mathrm{kg}$ ) Determined for Glass Sample LAWB68 


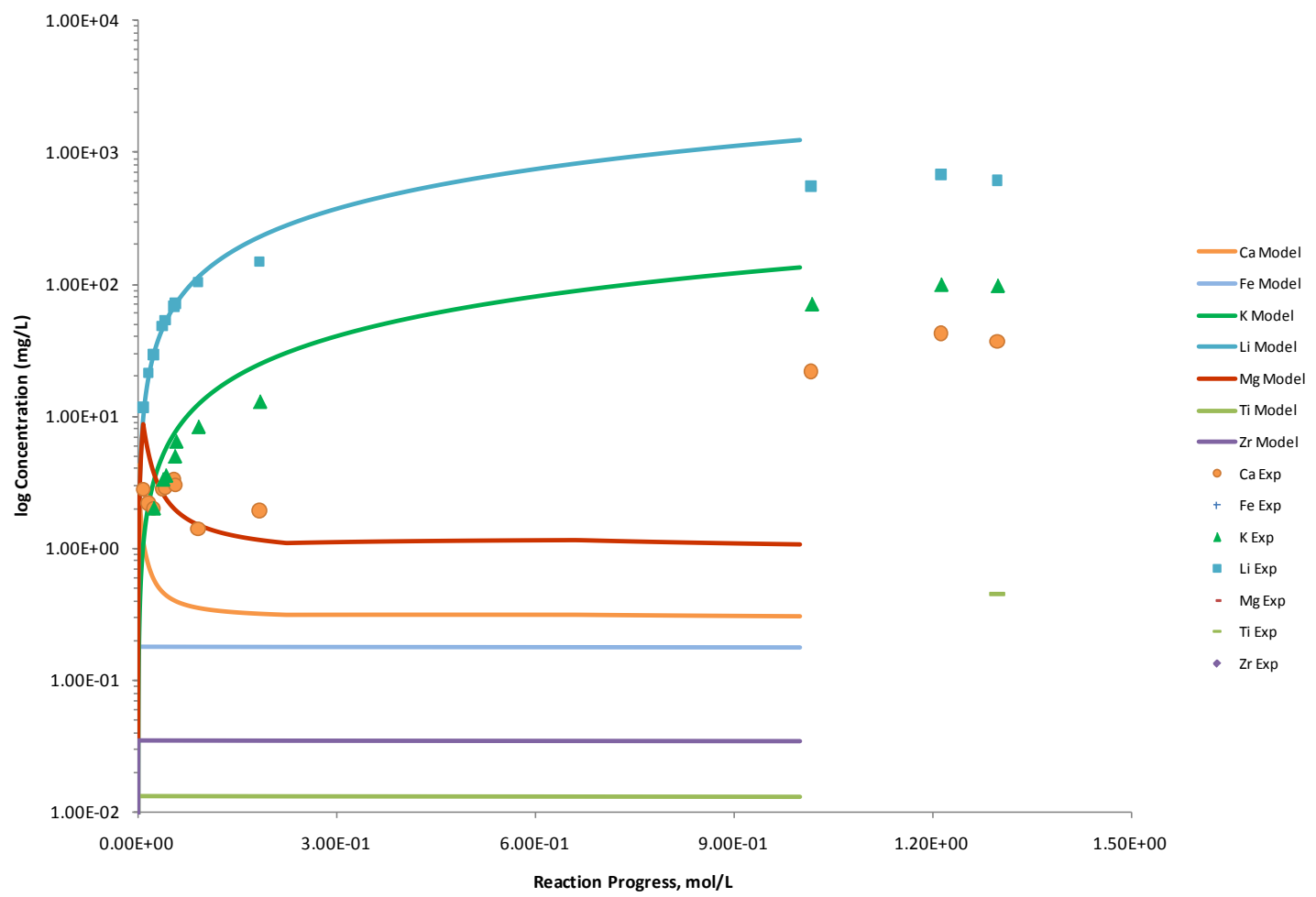

Figure C.243. Measured Solution Concentrations (mg/L) and Model Results for $\mathrm{Ca}, \mathrm{Fe}, \mathrm{K}, \mathrm{Li}, \mathrm{Mg}$, Ti, and $\mathrm{Zr}$, as a Function of Reaction Progress (mol-glass $/ \mathrm{kg}$ ) Determined for Glass Sample LAWB68

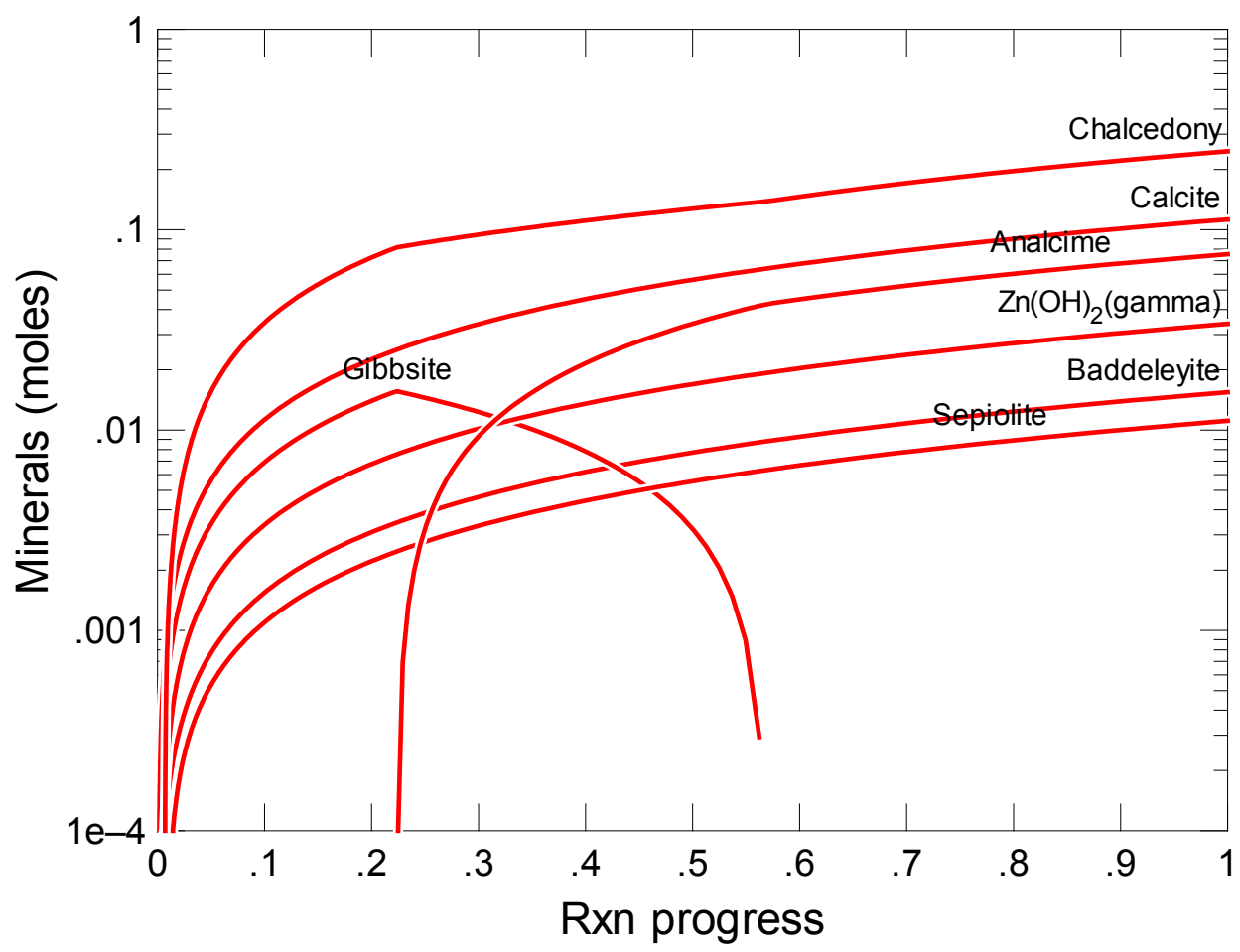

Figure C.244. Secondary Phases Calculated to Form as a Function of Reaction Progress (mol-glass $/ \mathrm{kg}$ ) Determined for Glass Sample LAWB69 


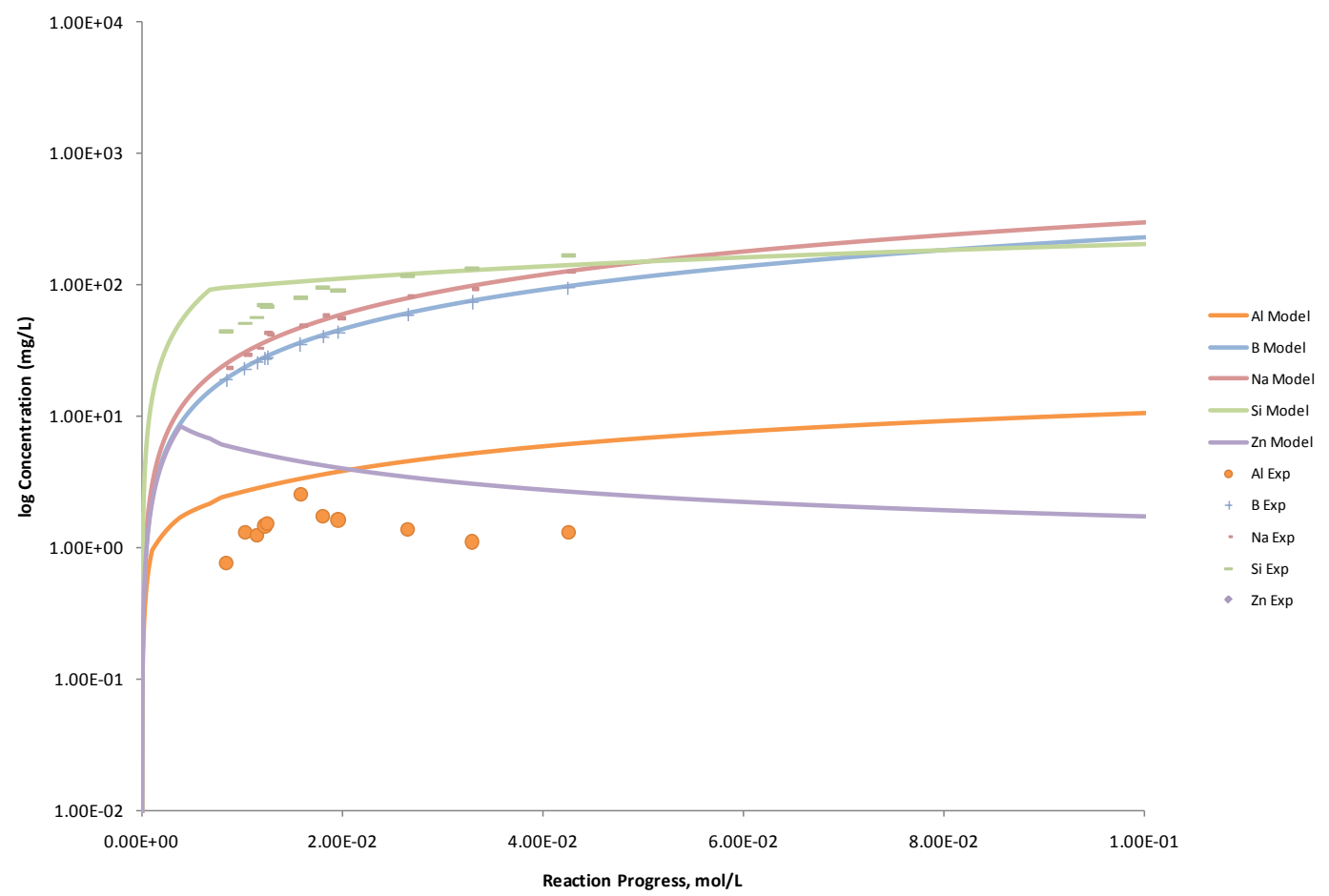

Figure C.245. Measured Solution Concentrations (mg/L) and Model Results for Al, B, Na, Si, and Zn, as a Function of Reaction Progress (mol-glass $/ \mathrm{kg}$ ) Determined for Glass Sample LAWB69

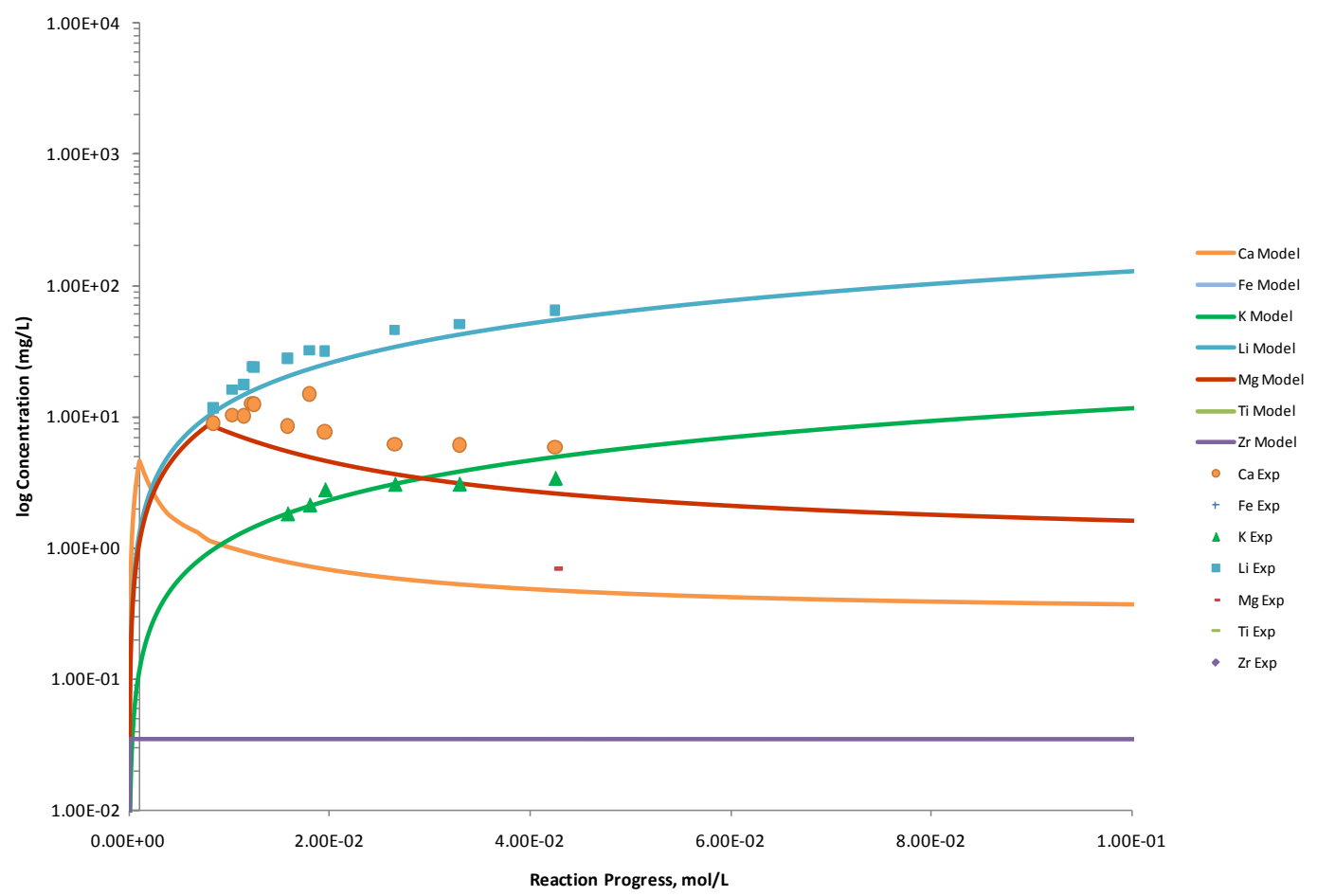

Figure C.246. Measured Solution Concentrations (mg/L) and Model Results for $\mathrm{Ca}, \mathrm{Fe}, \mathrm{K}, \mathrm{Li}, \mathrm{Mg}, \mathrm{Ti}$, and $\mathrm{Zr}$, as a Function of Reaction Progress (mol-glass/kg) Determined for Glass Sample LAWB69 


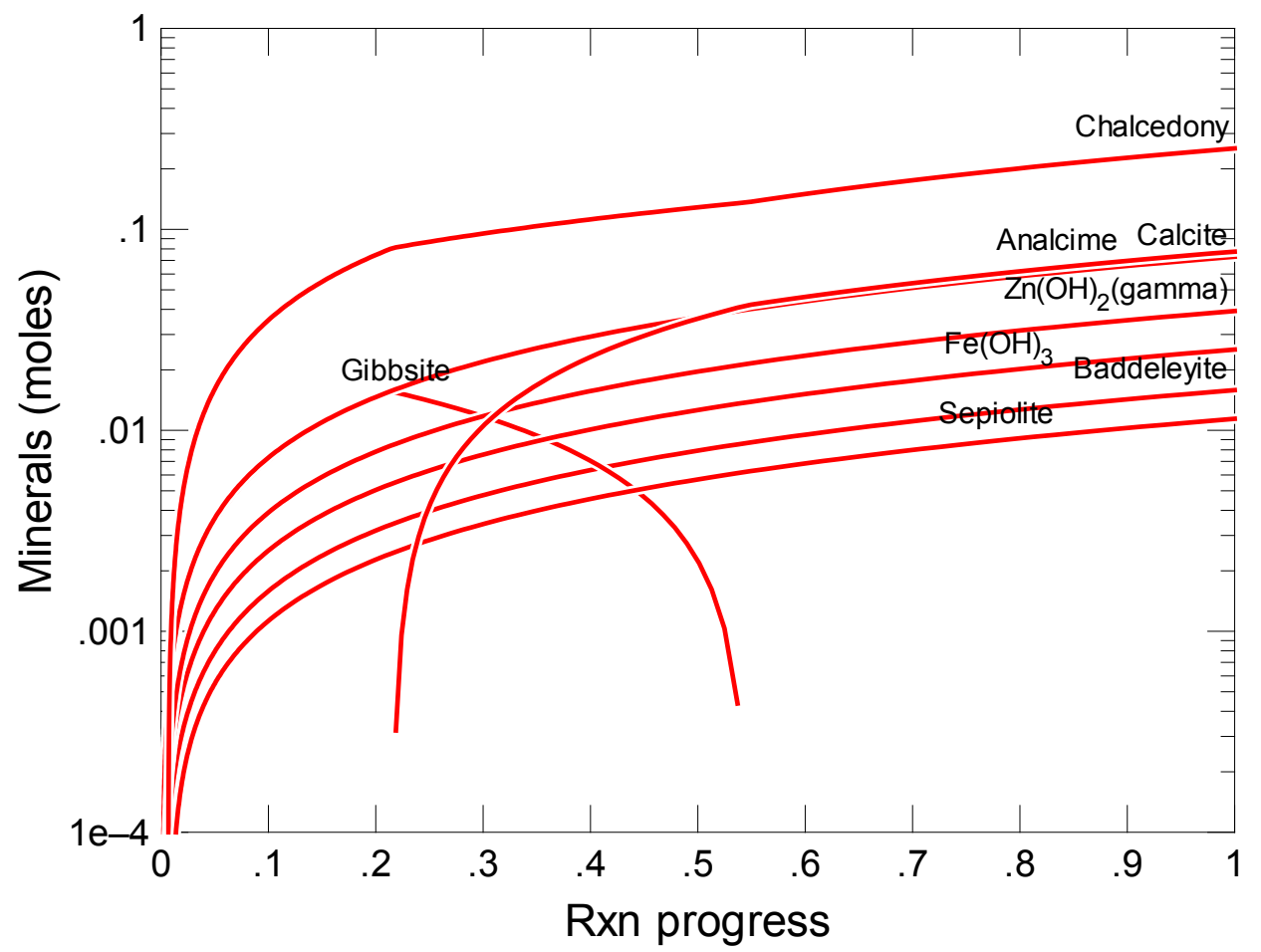

Figure C.247. Secondary Phases Calculated to Form as a Function of Reaction Progress (mol-glass $/ \mathrm{kg}$ ) Determined for Glass Sample LAWB70

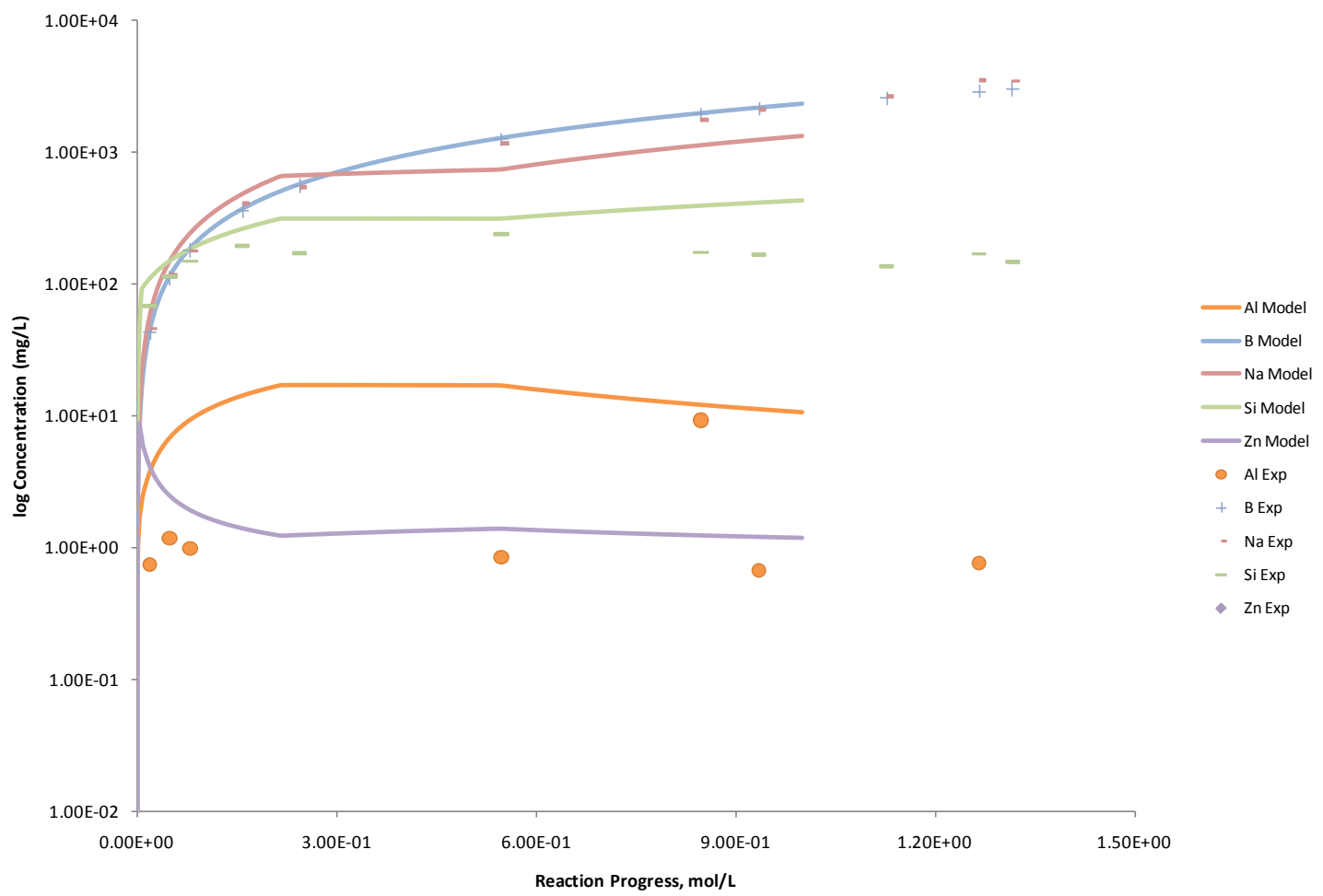

Figure C.248. Measured Solution Concentrations (mg/L) and Model Results for Al, B, Na, Si, and Zn, as a Function of Reaction Progress (mol-glass $/ \mathrm{kg}$ ) Determined for Glass Sample LAWB70 


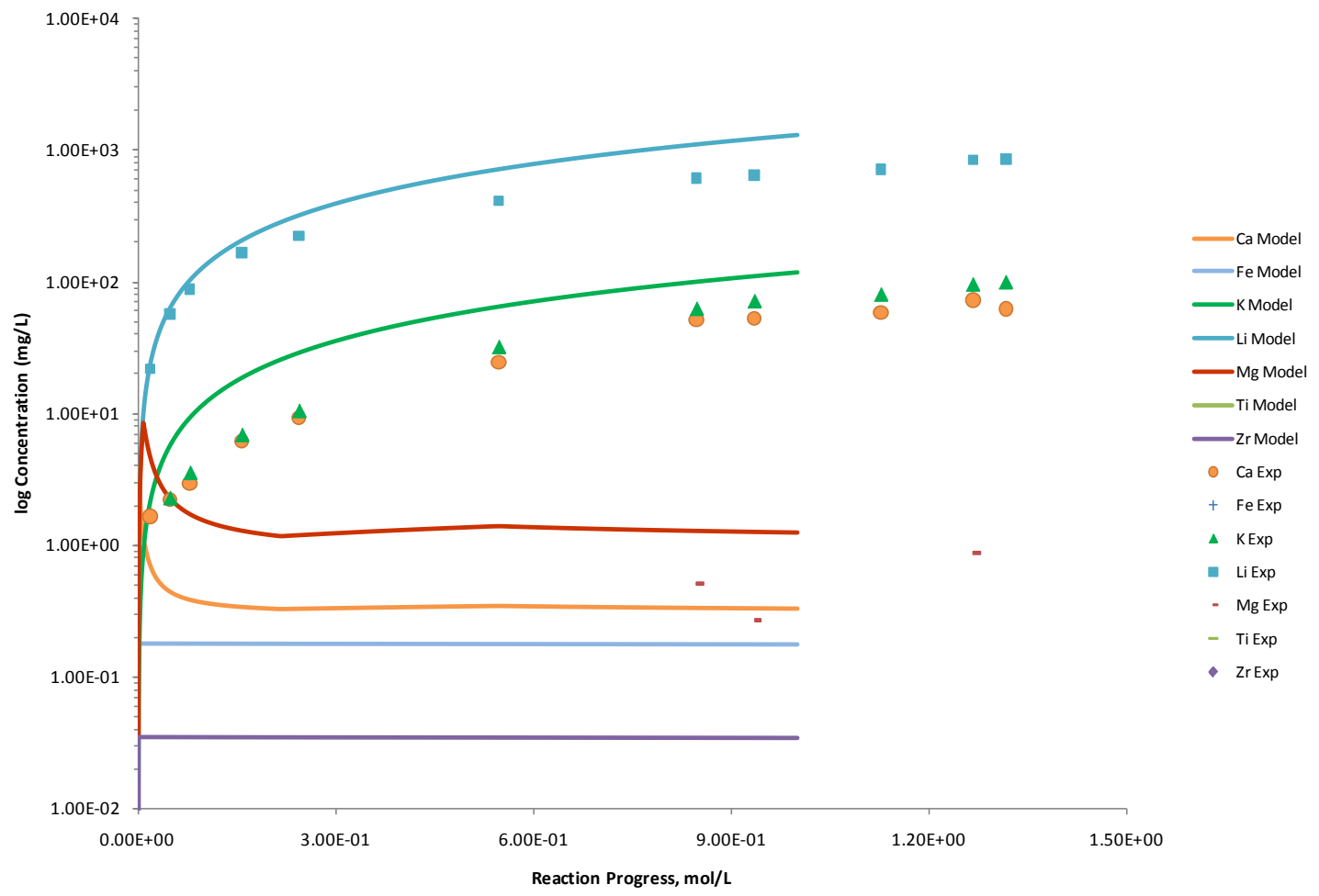

Figure C.249. Measured Solution Concentrations (mg/L) and Model Results for $\mathrm{Ca}, \mathrm{Fe}, \mathrm{K}, \mathrm{Li}, \mathrm{Mg}$, Ti, and $\mathrm{Zr}$, as a Function of Reaction Progress (mol-glass/kg) Determined for Glass Sample LAWB70

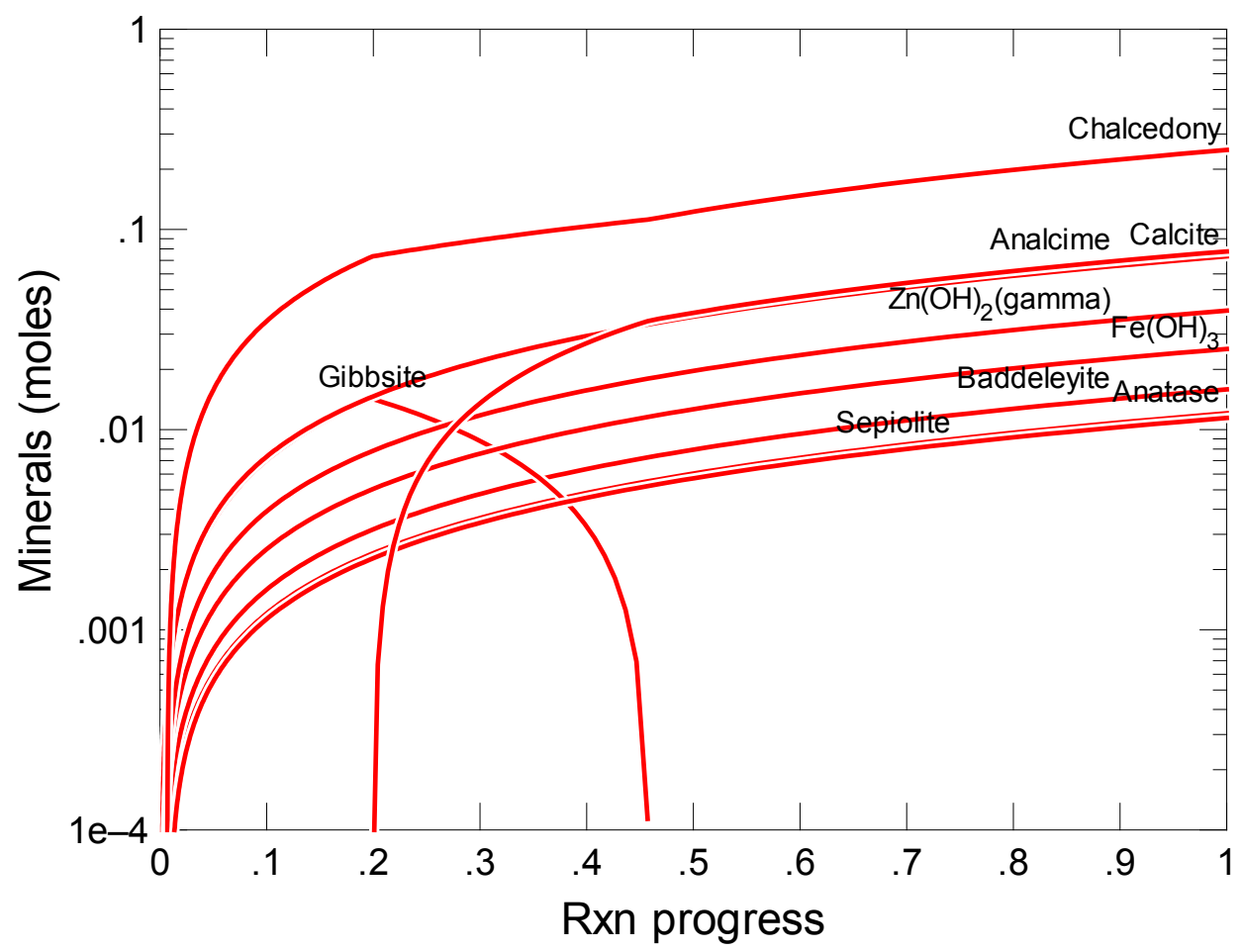

Figure C.250. Secondary Phases Calculated to Form as a Function of Reaction Progress (mol-glass/kg) Determined for Glass Sample LAWB71 


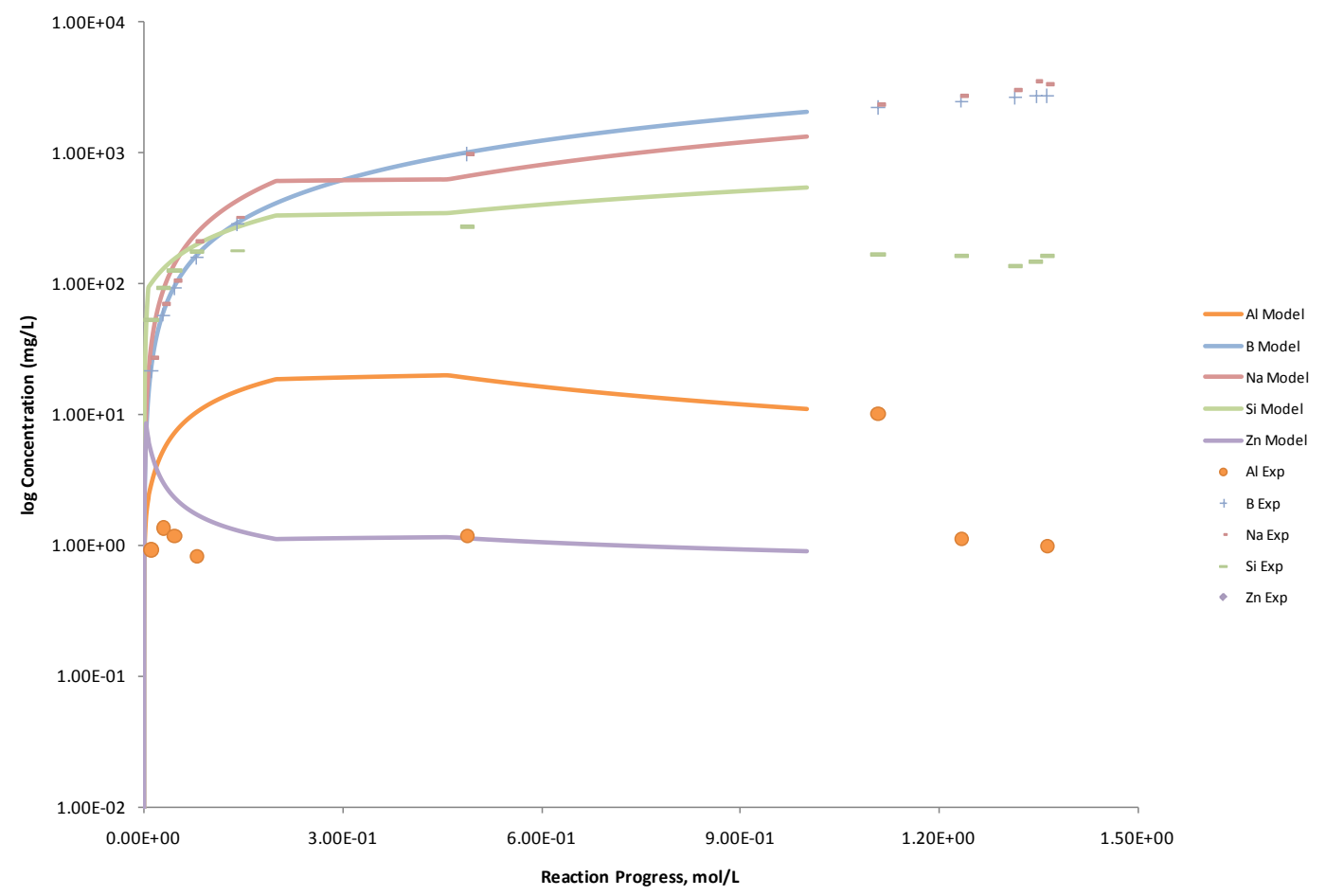

Figure C.251. Measured Solution Concentrations (mg/L) and Model Results for Al, B, Na, Si, and Zn, as a Function of Reaction Progress (mol-glass $/ \mathrm{kg}$ ) Determined for Glass Sample LAWB71

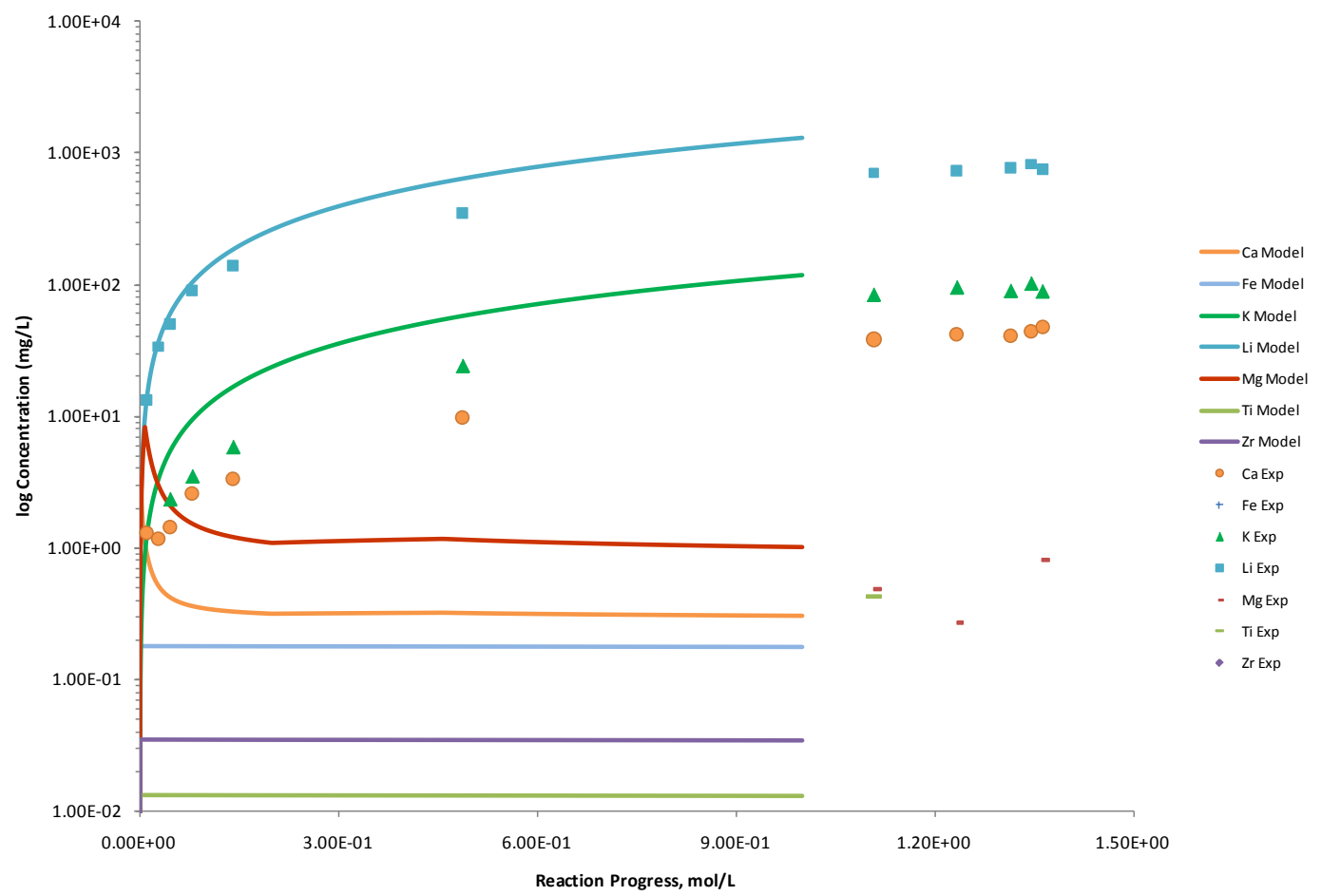

Figure C.252. Measured Solution Concentrations (mg/L) and Model Results for Ca, Fe, K, Li, Mg, Ti, and $\mathrm{Zr}$, as a Function of Reaction Progress (mol-glass/kg) Determined for Glass Sample LAWB71 


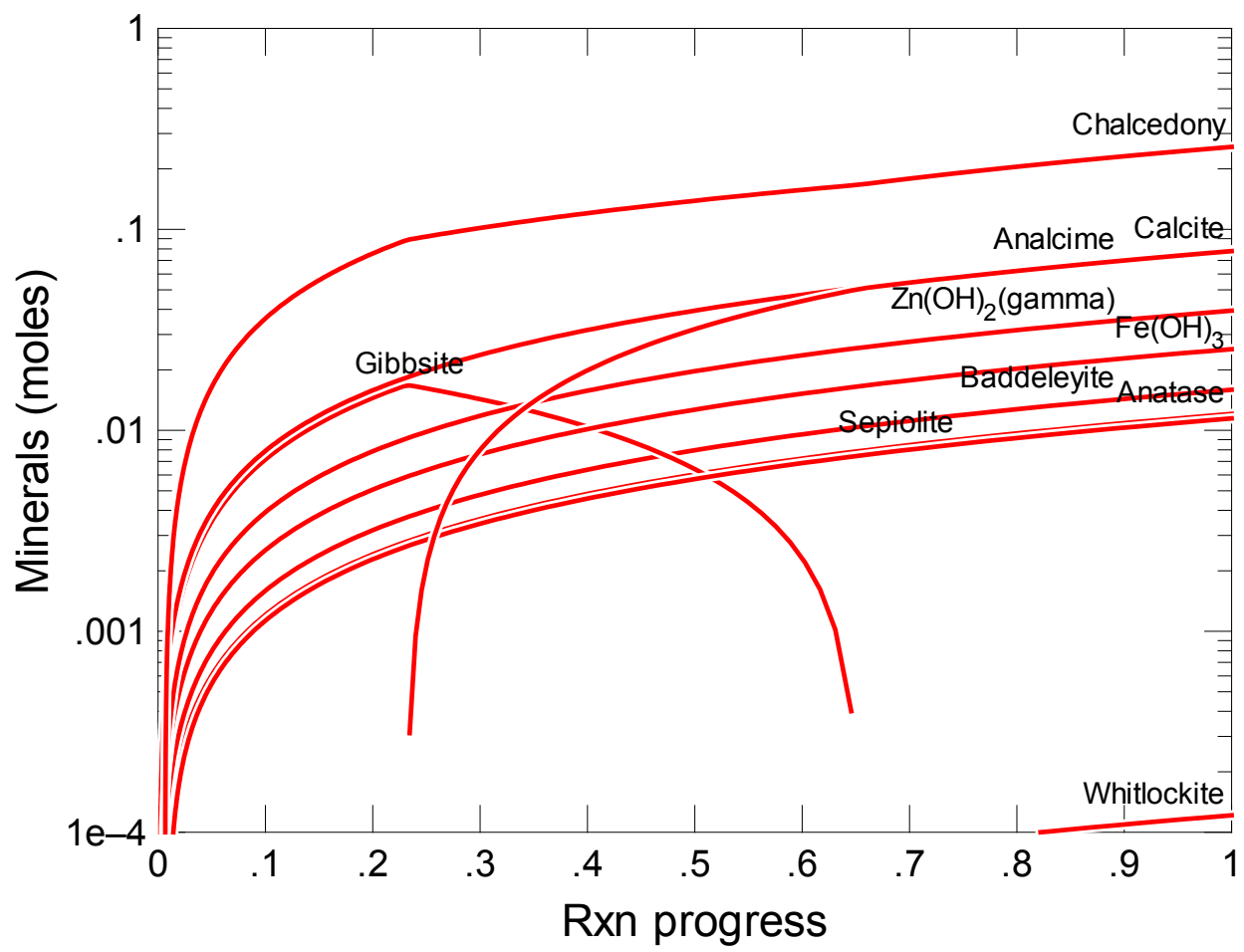

Figure C.253. Secondary Phases Calculated to Form as a Function of Reaction Progress (mol-glass $/ \mathrm{kg}$ ) Determined for Glass Sample LAWB72

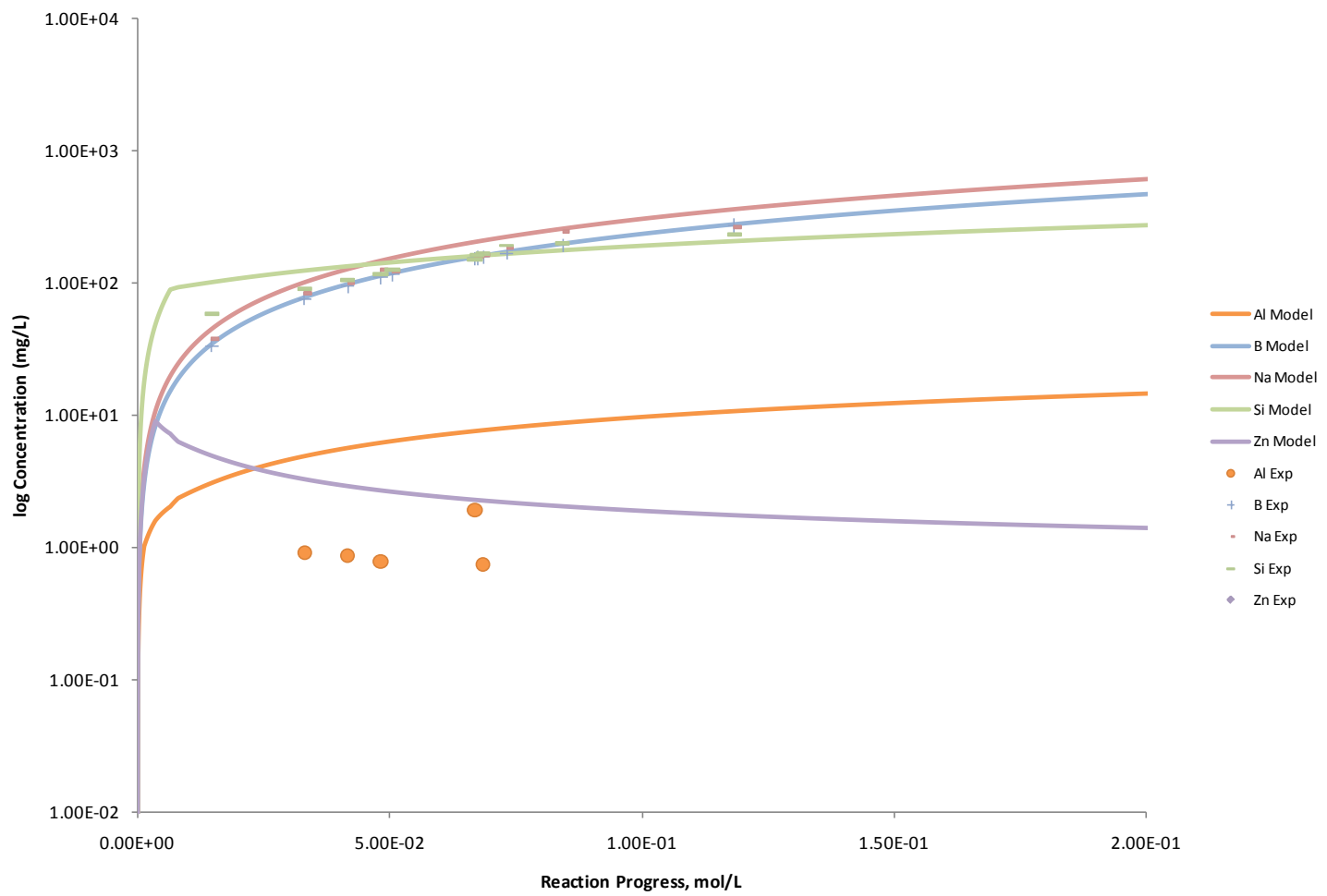

Figure C.254. Measured Solution Concentrations (mg/L) and Model Results for Al, B, Na, Si, and Zn, as a Function of Reaction Progress (mol-glass $/ \mathrm{kg}$ ) Determined for Glass Sample LAWB72 


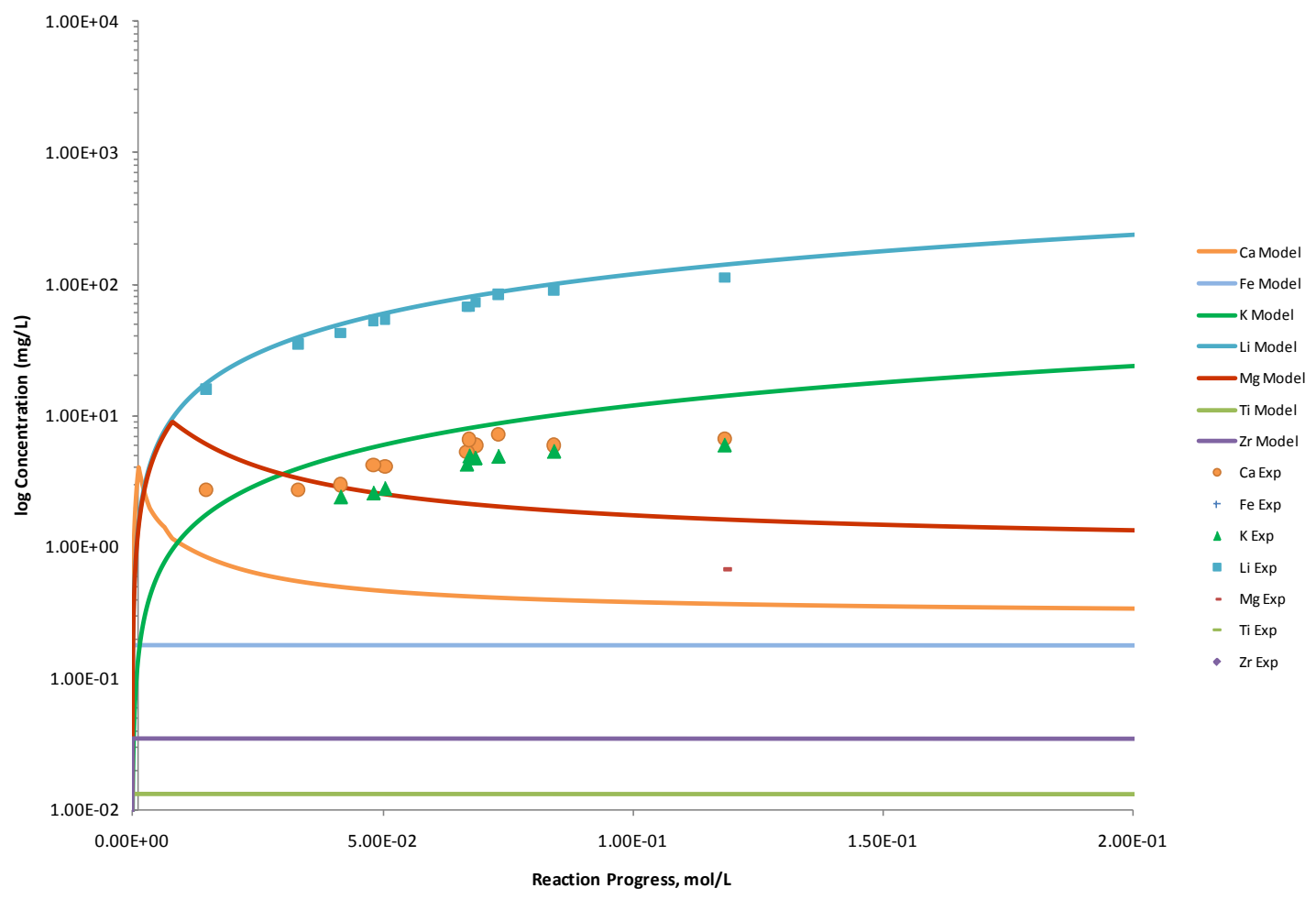

Figure C.255. Measured Solution Concentrations (mg/L) and Model Results for $\mathrm{Ca}, \mathrm{Fe}, \mathrm{K}, \mathrm{Li}, \mathrm{Mg}, \mathrm{Ti}$, and $\mathrm{Zr}$, as a Function of Reaction Progress (mol-glass/kg) Determined for Glass Sample LAWB72

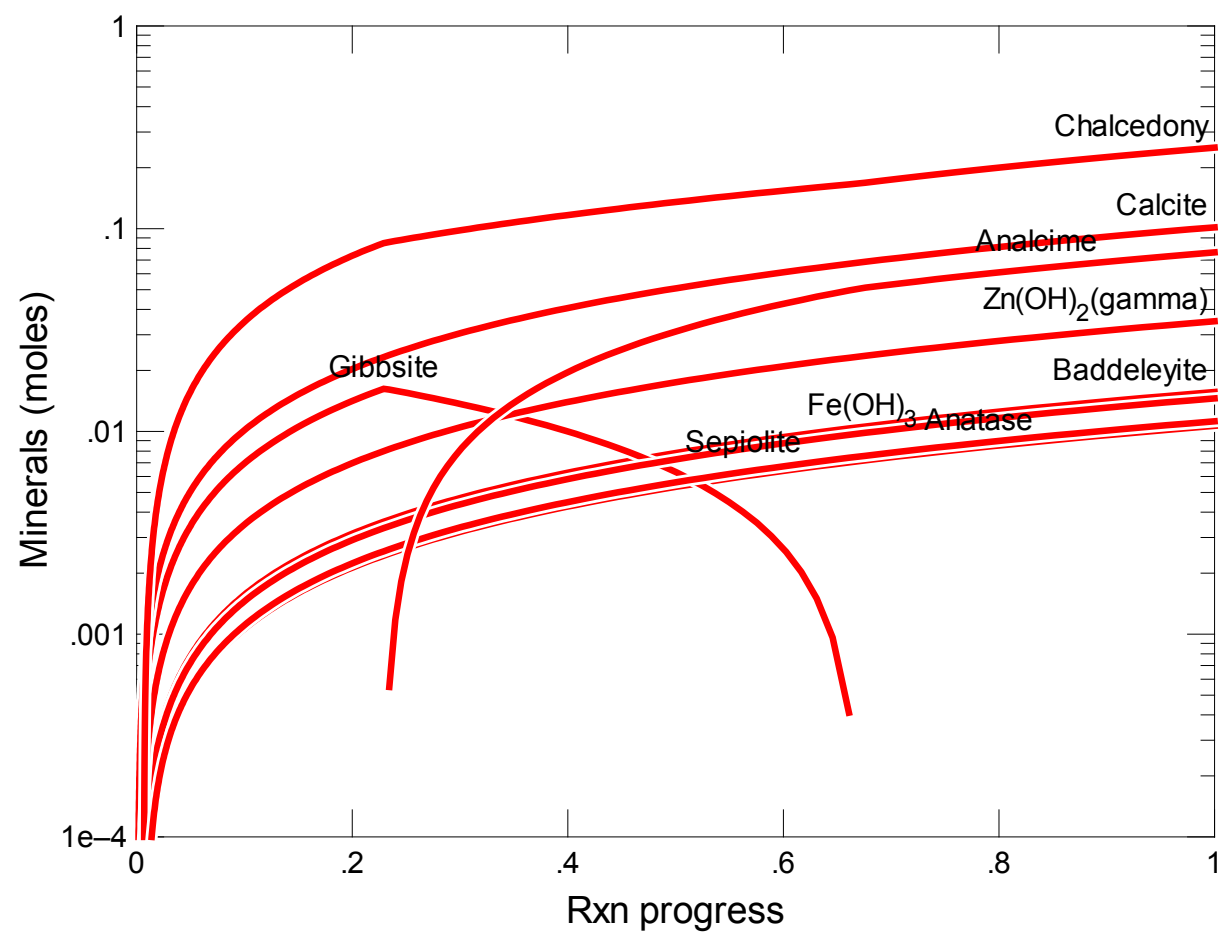

Figure C.256. Secondary Phases Calculated to Form as a Function of Reaction Progress (mol-glass $/ \mathrm{kg}$ ) Determined for Glass Sample LAWB73 


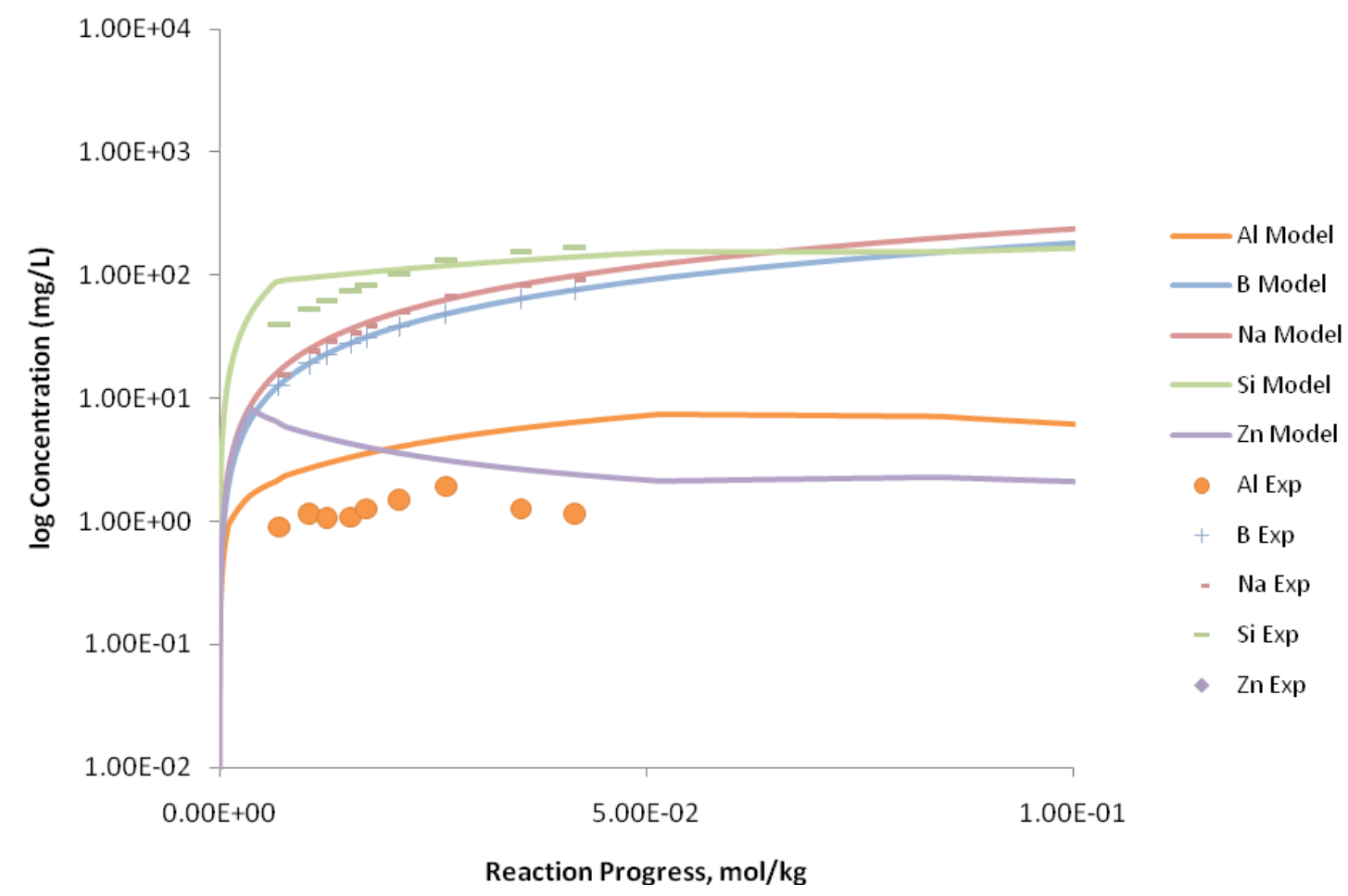

Figure C.257. Measured Solution Concentrations (mg/L) and Model Results for Al, B, Na, Si, and Zn, as a Function of Reaction Progress (mol-glass $/ \mathrm{kg}$ ) Determined for Glass Sample LAWB73
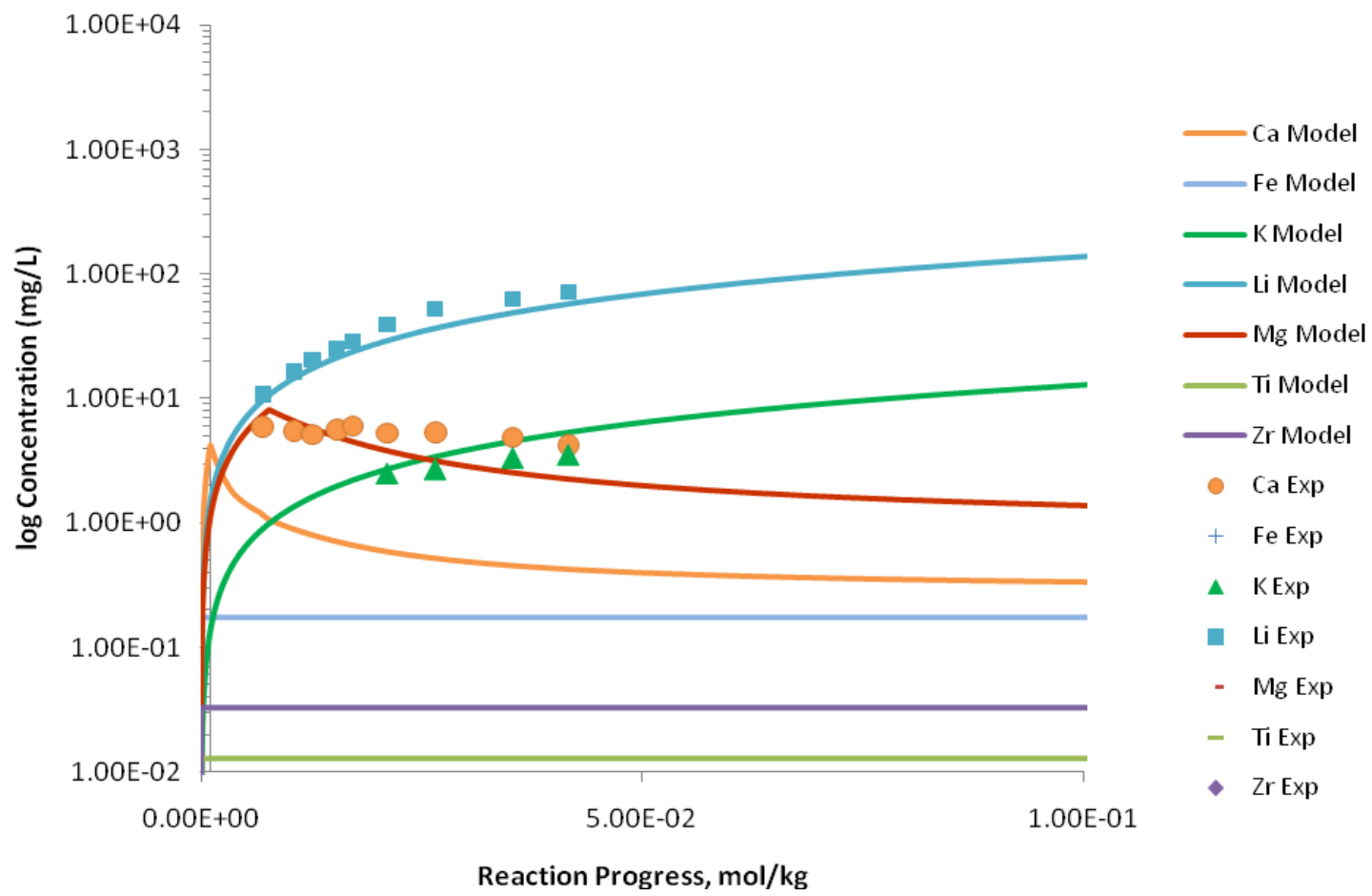

Figure C.258. Measured Solution Concentrations (mg/L) and Model Results for Ca, Fe, K, Li, Mg, Ti, and $\mathrm{Zr}$, as a Function of Reaction Progress (mol-glass/kg) Determined for Glass Sample LAWB73 


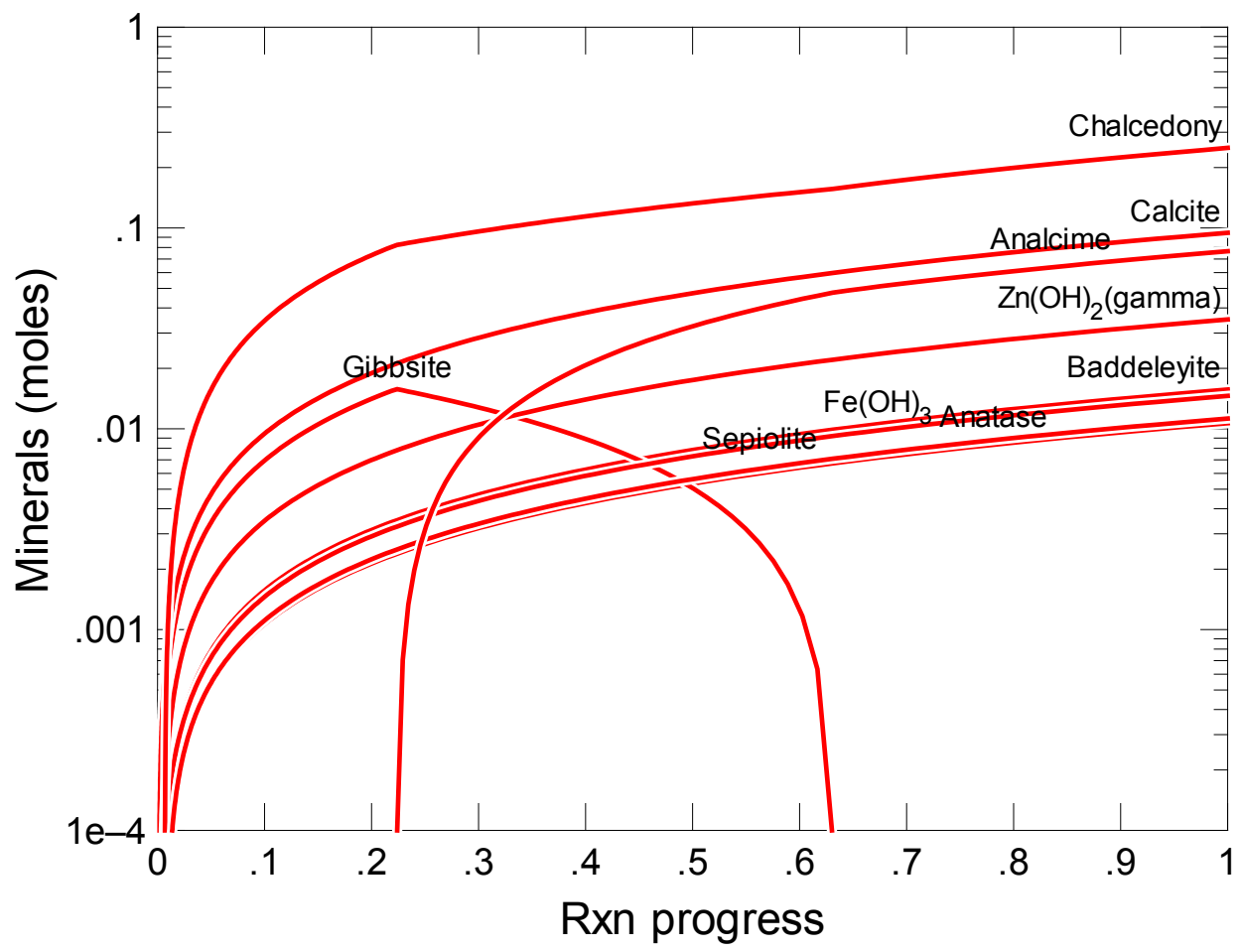

Figure C.259. Secondary Phases Calculated to Form as a Function of Reaction Progress (mol-glass $/ \mathrm{kg}$ ) Determined for Glass Sample LAWB74

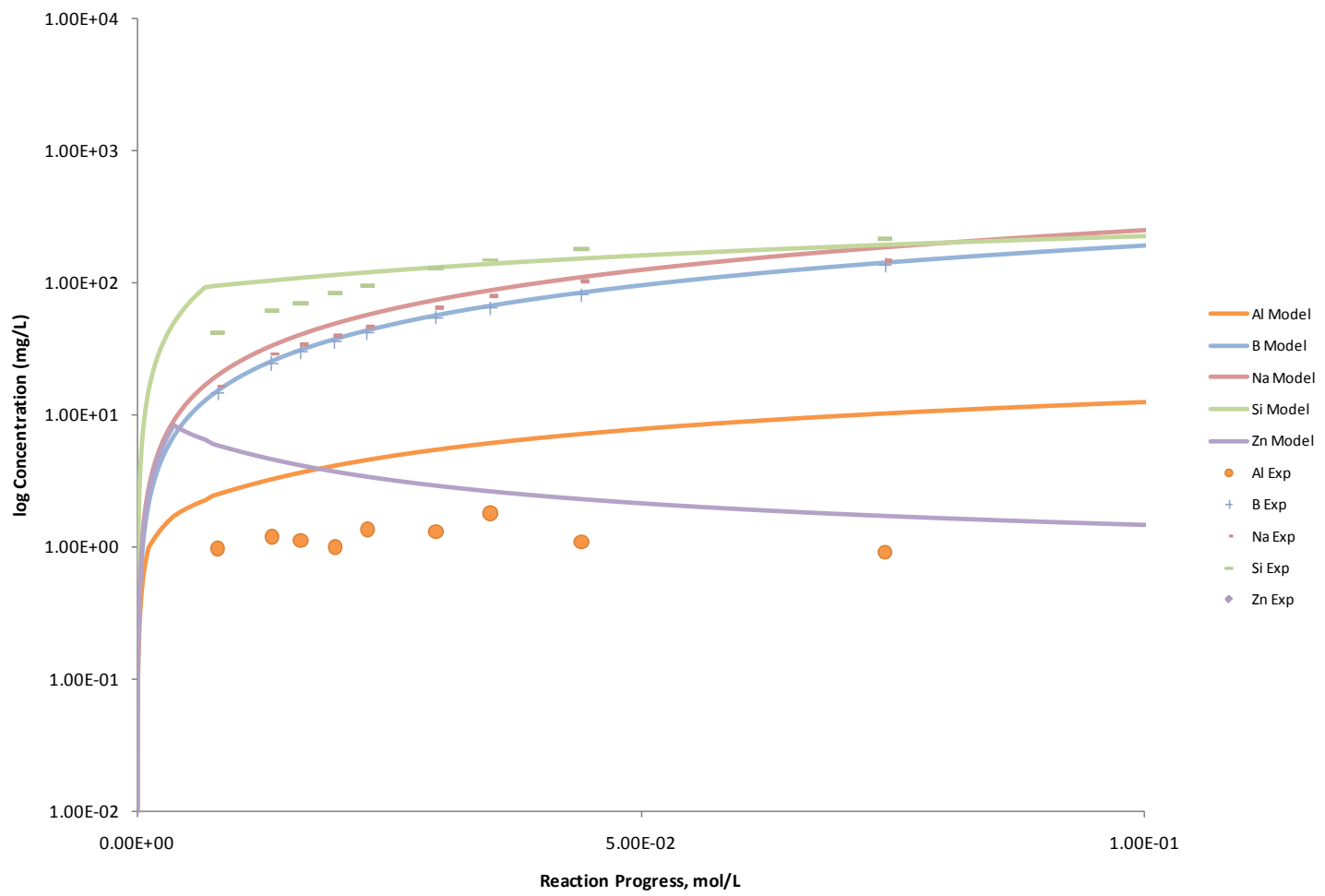

Figure C.260. Measured Solution Concentrations (mg/L) and Model Results for Al, B, Na, Si, and Zn, as a Function of Reaction Progress (mol-glass $/ \mathrm{kg}$ ) Determined for Glass Sample LAWB74 


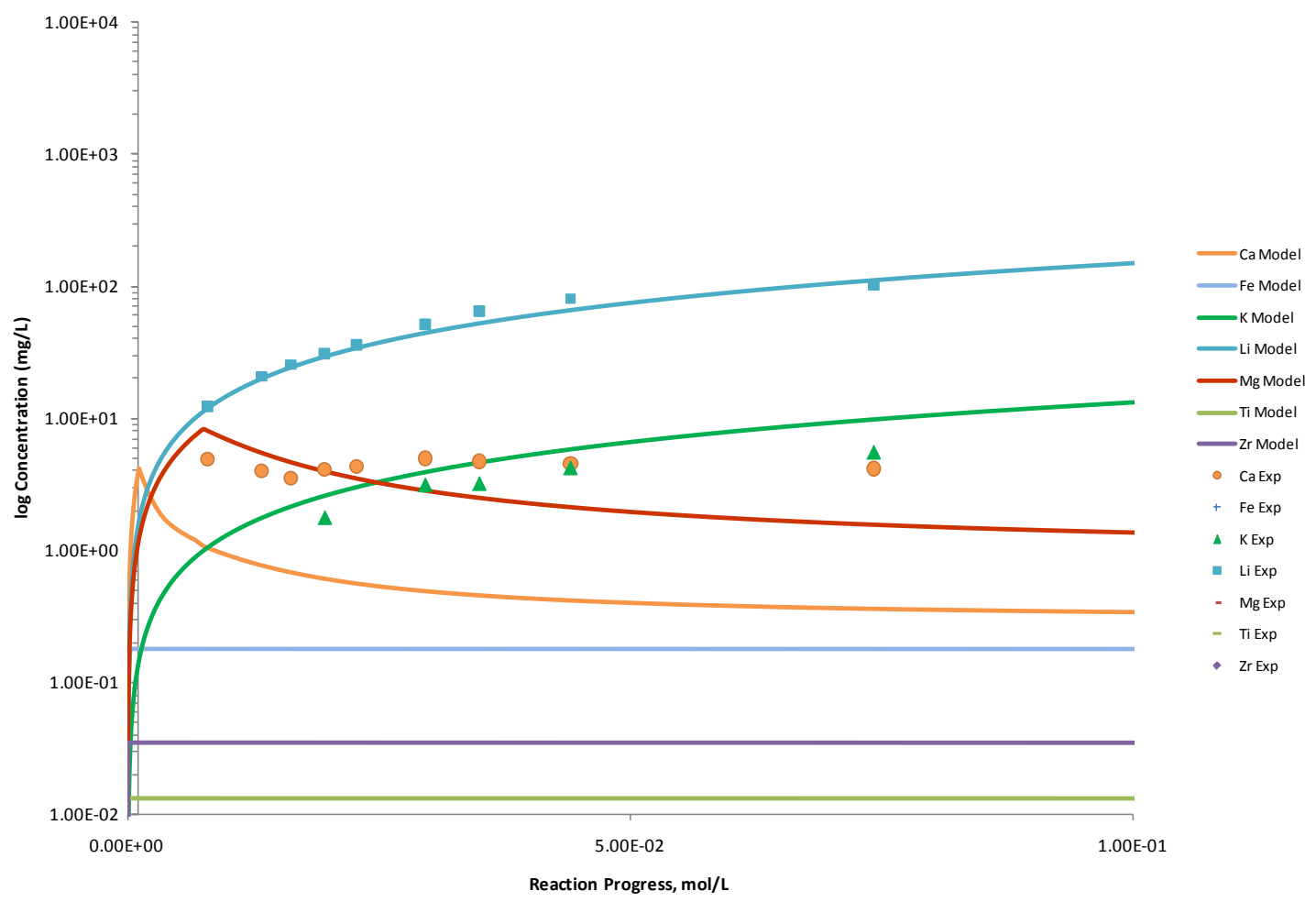

Figure C.261. Measured Solution Concentrations (mg/L) and Model Results for $\mathrm{Ca}, \mathrm{Fe}, \mathrm{K}, \mathrm{Li}, \mathrm{Mg}$, Ti, and $\mathrm{Zr}$, as a Function of Reaction Progress (mol-glass/kg) Determined for Glass Sample LAWB74

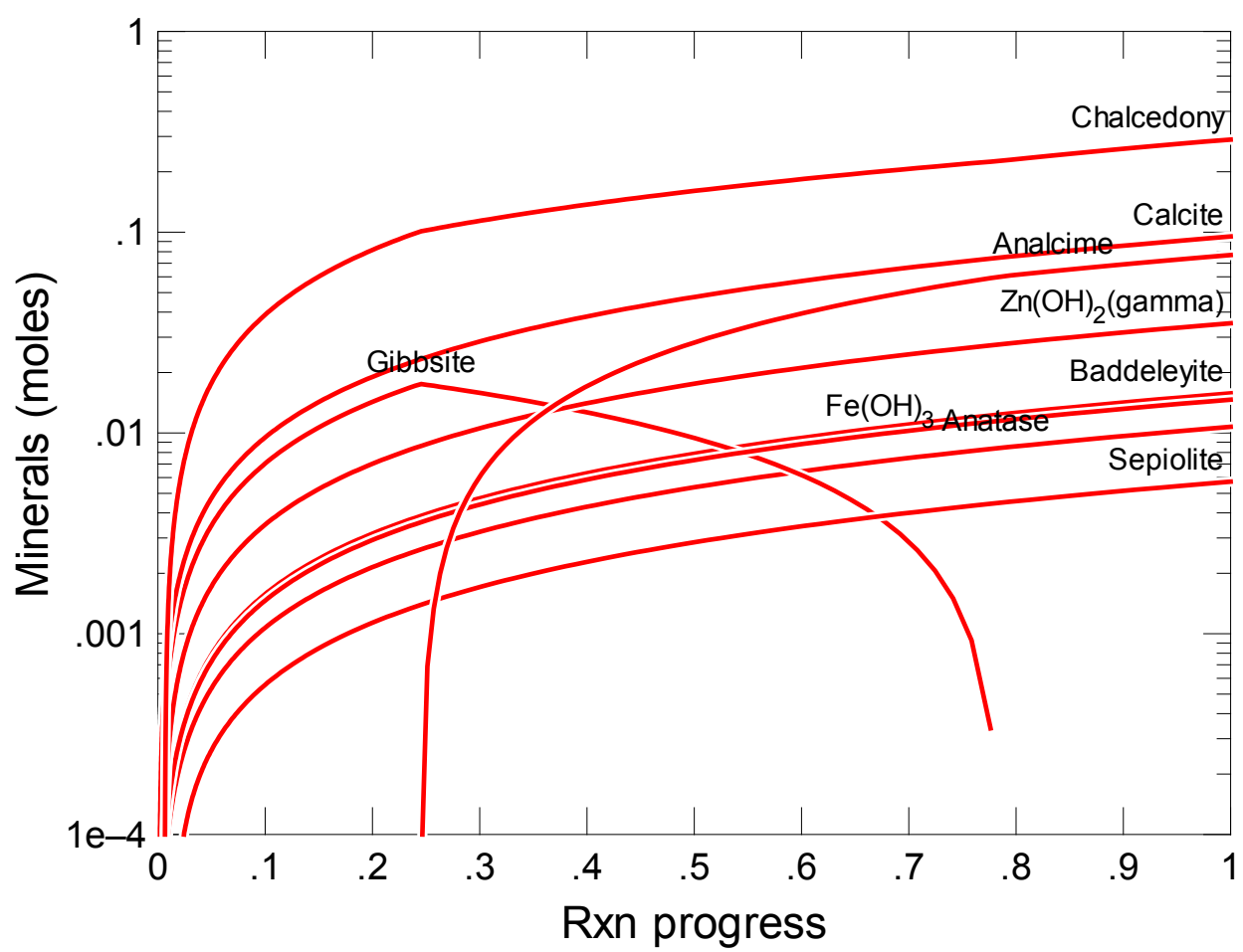

Figure C.262. Secondary Phases Calculated to Form as a Function of Reaction Progress (mol-glass/kg) Determined for Glass Sample LAWB75 


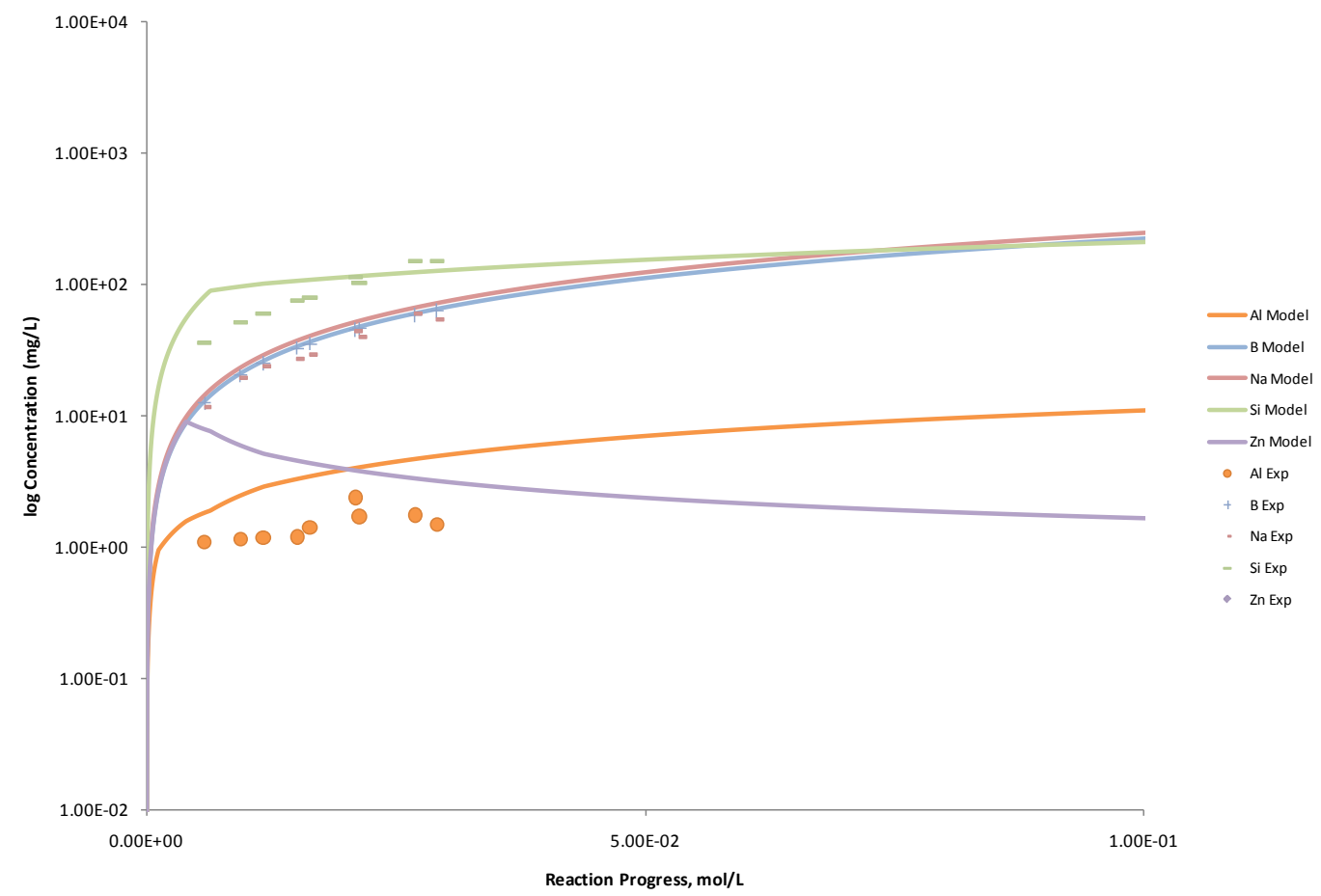

Figure C.263. Measured Solution Concentrations (mg/L) and Model Results for $\mathrm{Al}, \mathrm{B}, \mathrm{Na}, \mathrm{Si}$, and $\mathrm{Zn}$, as a Function of Reaction Progress (mol-glass $/ \mathrm{kg}$ ) Determined for Glass Sample LAWB75

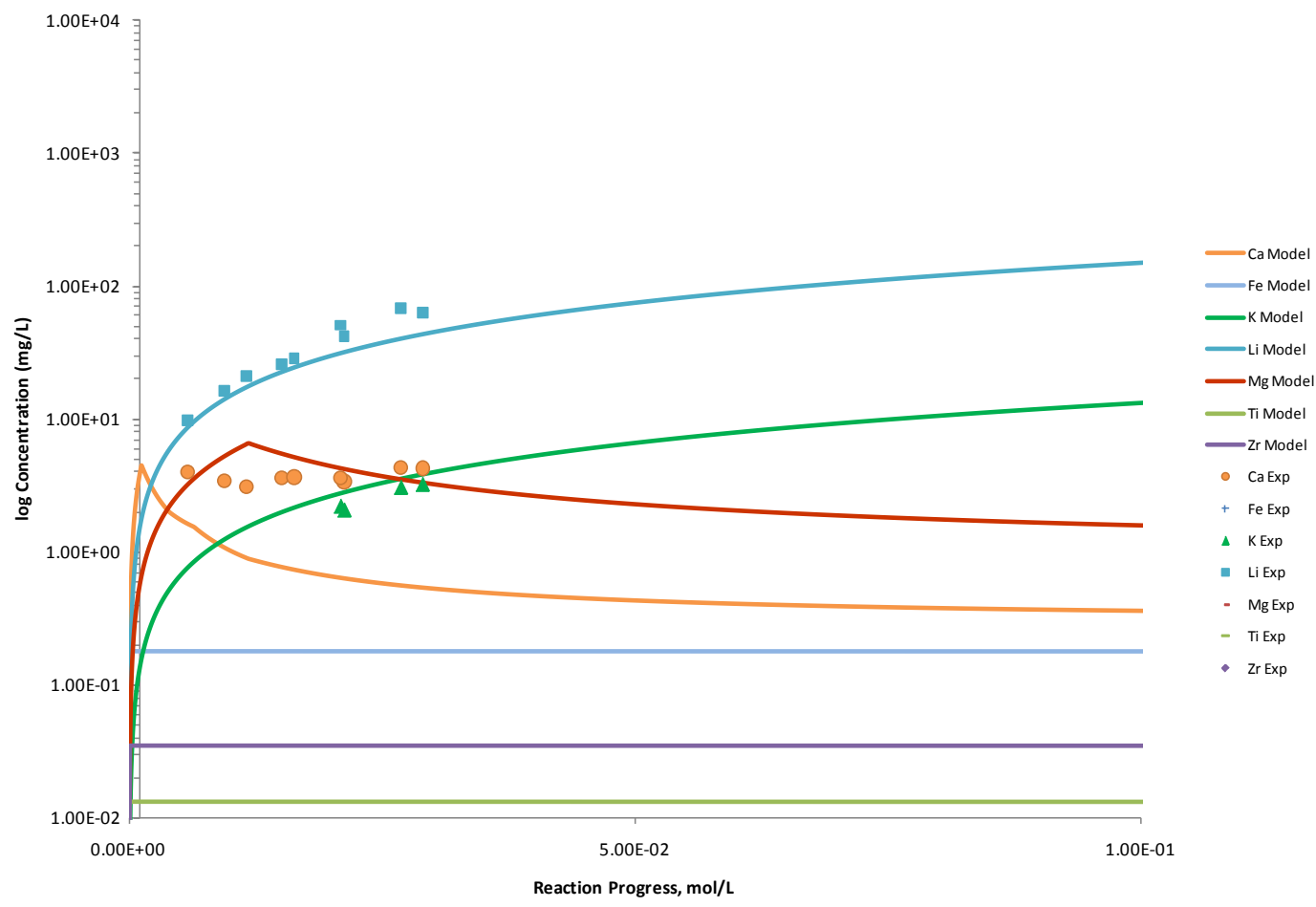

Figure C.264. Measured Solution Concentrations (mg/L) and Model Results for $\mathrm{Ca}, \mathrm{Fe}, \mathrm{K}, \mathrm{Li}, \mathrm{Mg}, \mathrm{Ti}$, and $\mathrm{Zr}$, as a Function of Reaction Progress (mol-glass/kg) Determined for Glass Sample LAWB75 


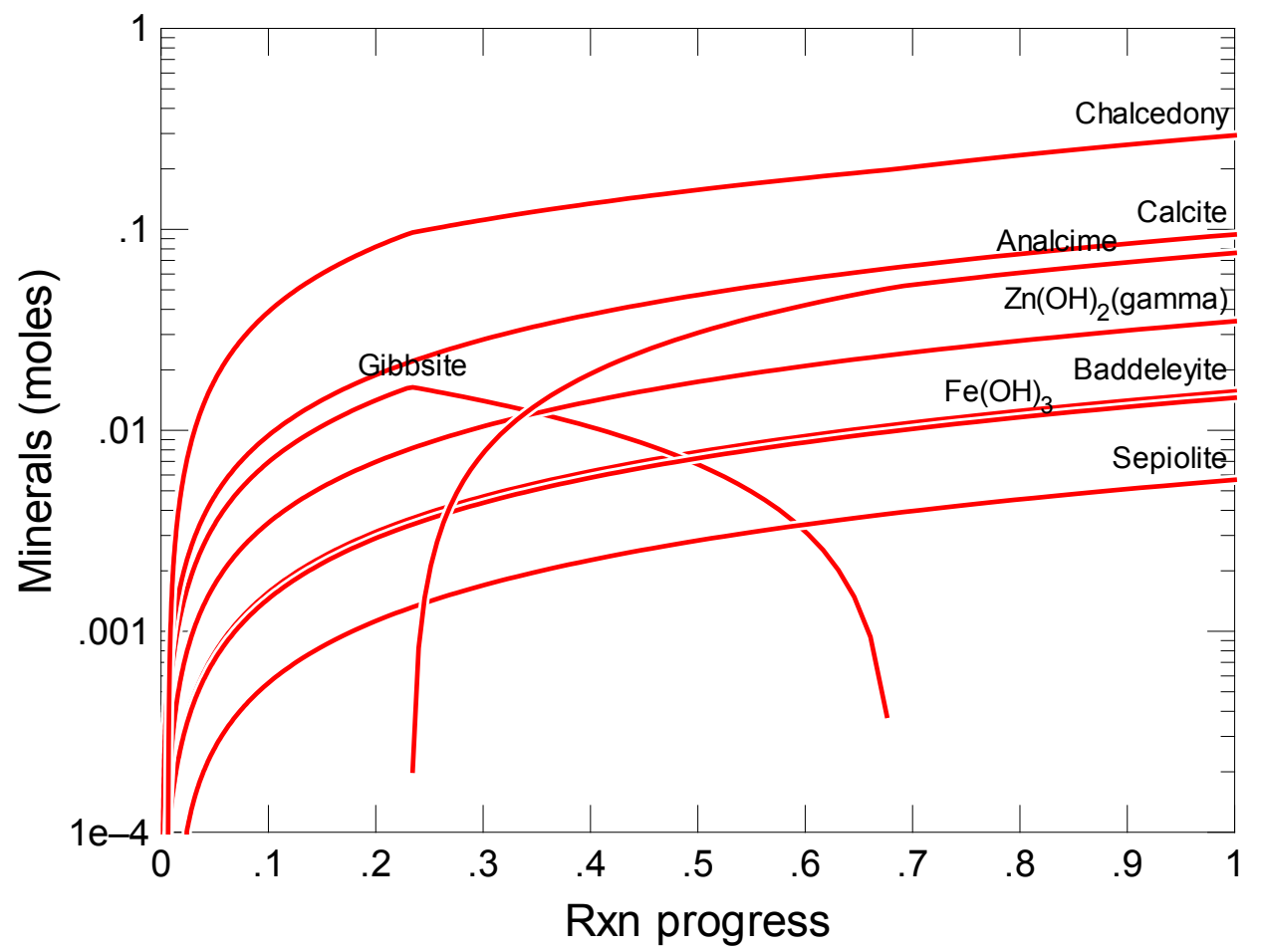

Figure C.265. Secondary Phases Calculated to Form as a Function of Reaction Progress (mol-glass $/ \mathrm{kg}$ ) Determined for Glass Sample LAWB76

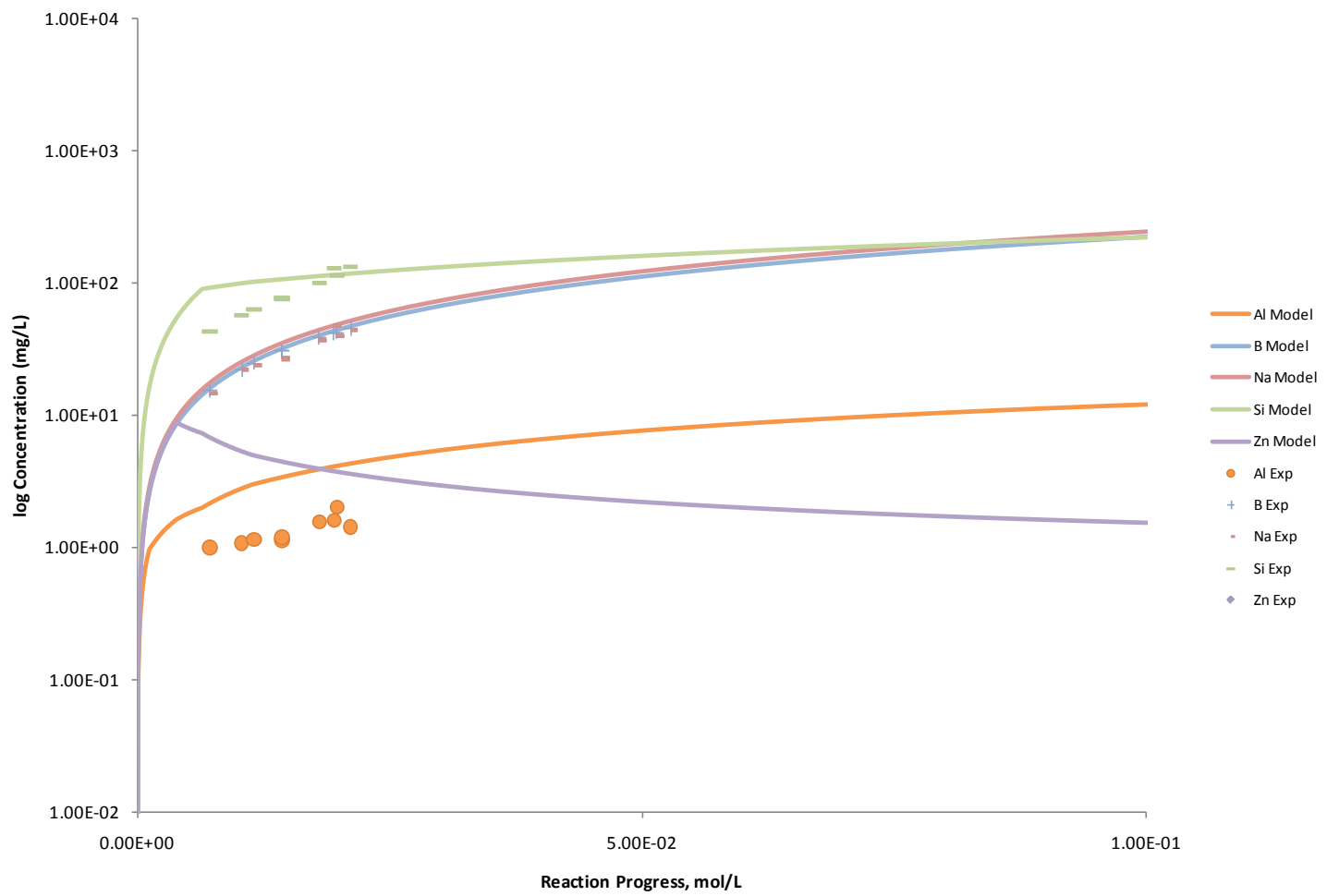

Figure C.266. Measured Solution Concentrations (mg/L) and Model Results for Al, B, Na, Si, and Zn, as a Function of Reaction Progress (mol-glass $/ \mathrm{kg}$ ) Determined for Glass Sample LAWB76 


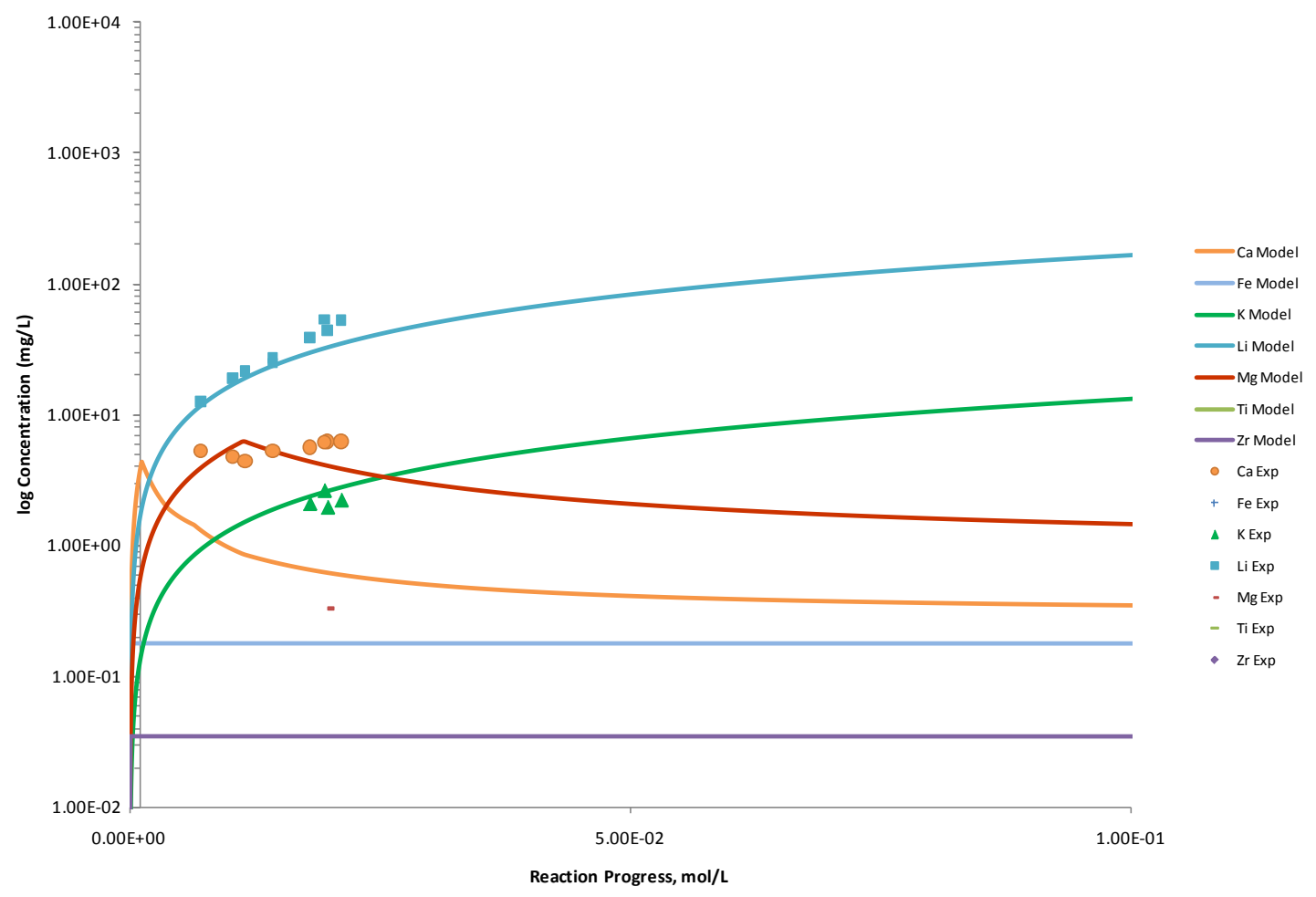

Figure C.267. Measured Solution Concentrations (mg/L) and Model Results for $\mathrm{Ca}, \mathrm{Fe}, \mathrm{K}, \mathrm{Li}, \mathrm{Mg}$, Ti, and $\mathrm{Zr}$, as a Function of Reaction Progress (mol-glass/kg) Determined for Glass Sample LAWB76

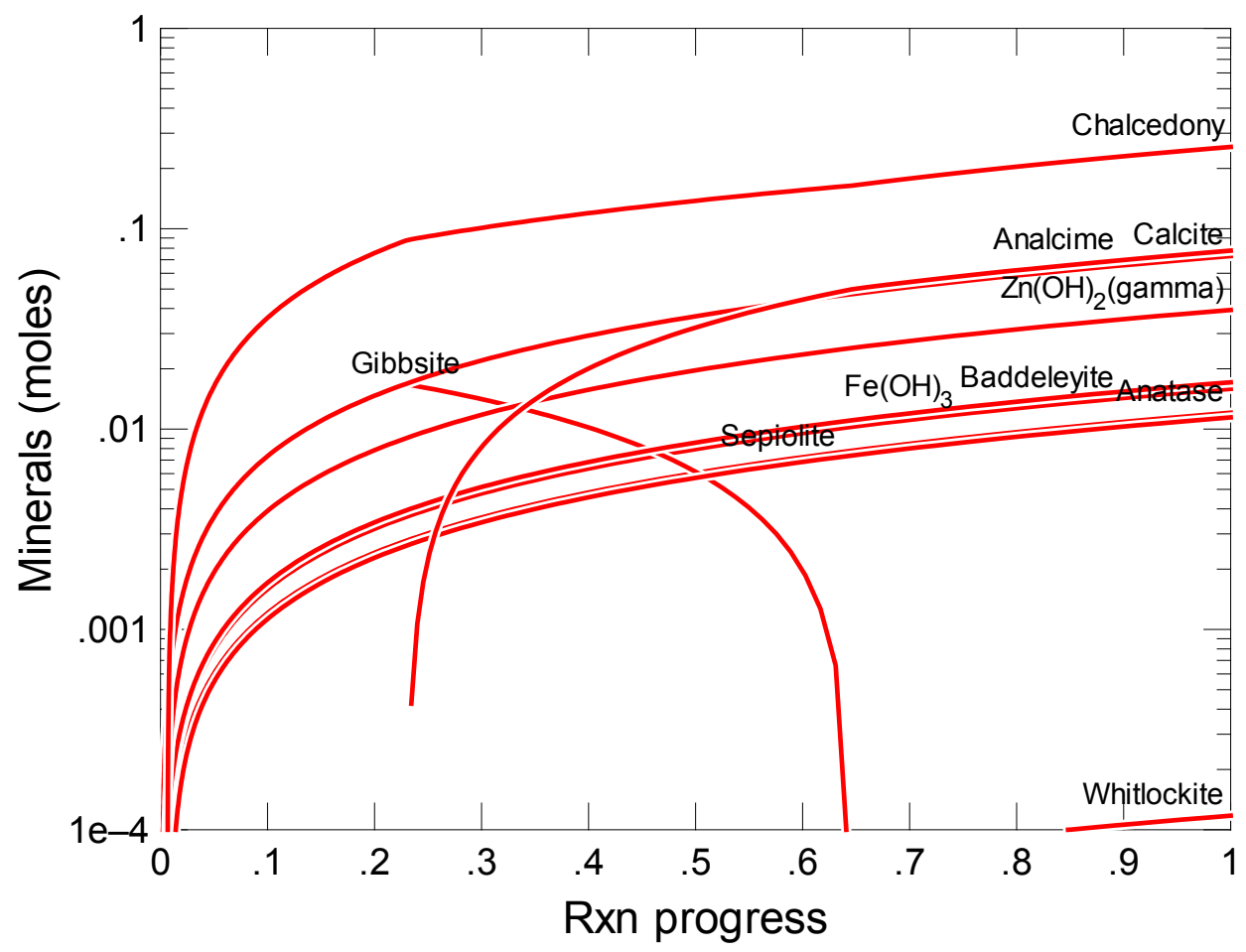

Figure C.268. Secondary Phases Calculated to Form as a Function of Reaction Progress (mol-glass $/ \mathrm{kg}$ ) Determined for Glass Sample LAWB77 


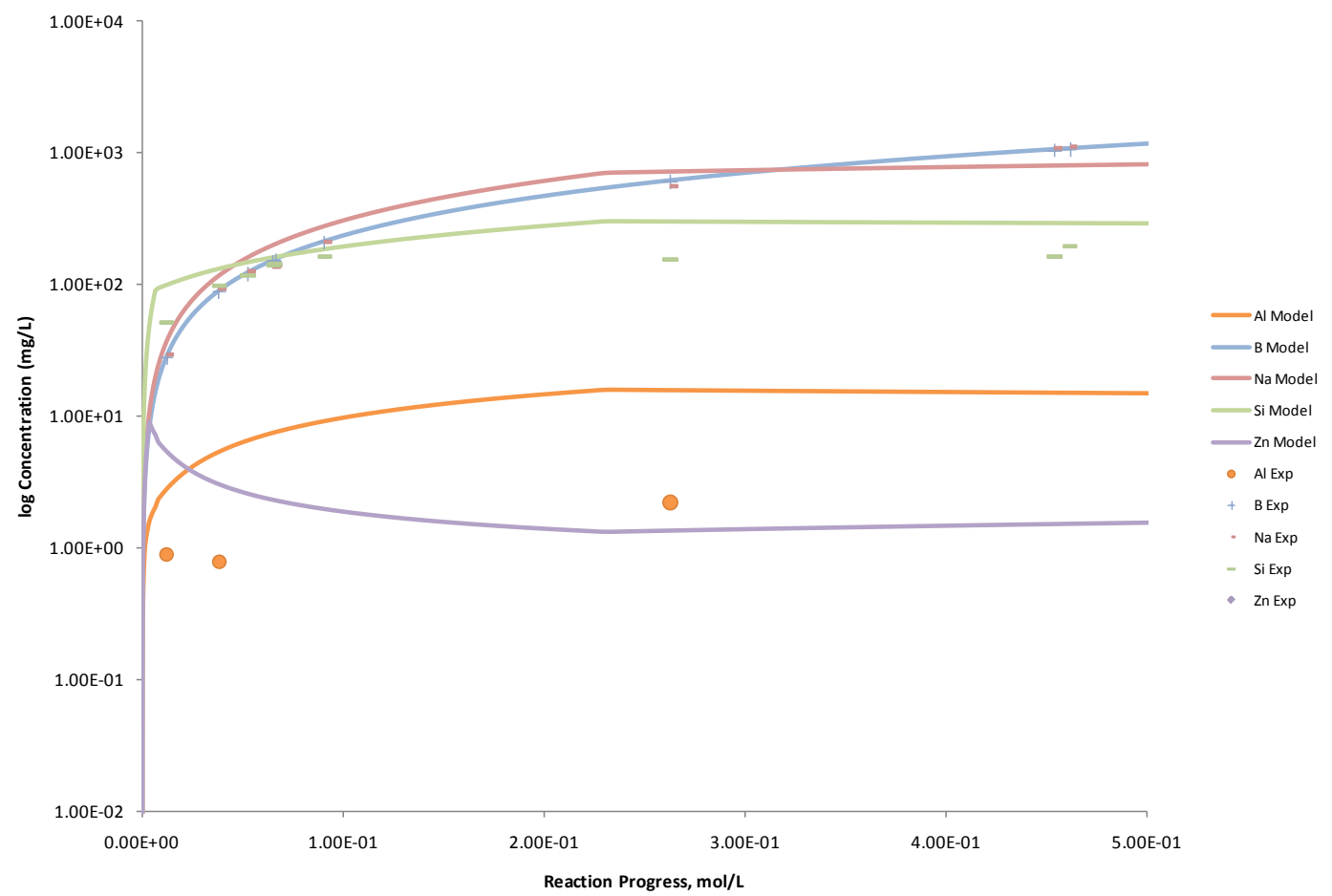

Figure C.269. Measured Solution Concentrations (mg/L) and Model Results for Al, B, Na, Si, and Zn, as a Function of Reaction Progress (mol-glass $/ \mathrm{kg}$ ) Determined for Glass Sample LAWB77

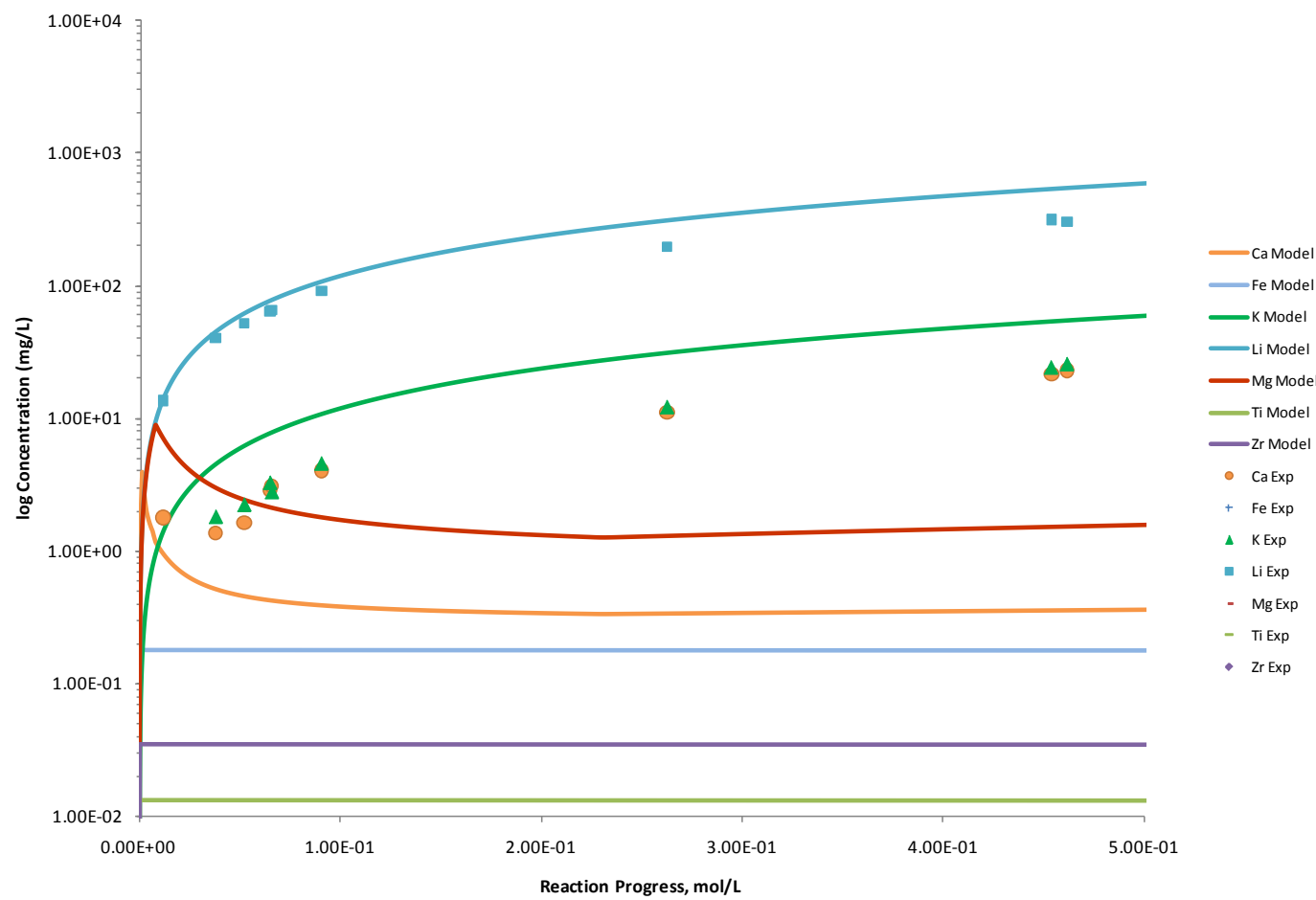

Figure C.270. Measured Solution Concentrations (mg/L) and Model Results for $\mathrm{Ca}, \mathrm{Fe}, \mathrm{K}, \mathrm{Li}, \mathrm{Mg}, \mathrm{Ti}$, and Zr, as a Function of Reaction Progress (mol-glass/kg) Determined for Glass Sample LAWB77 


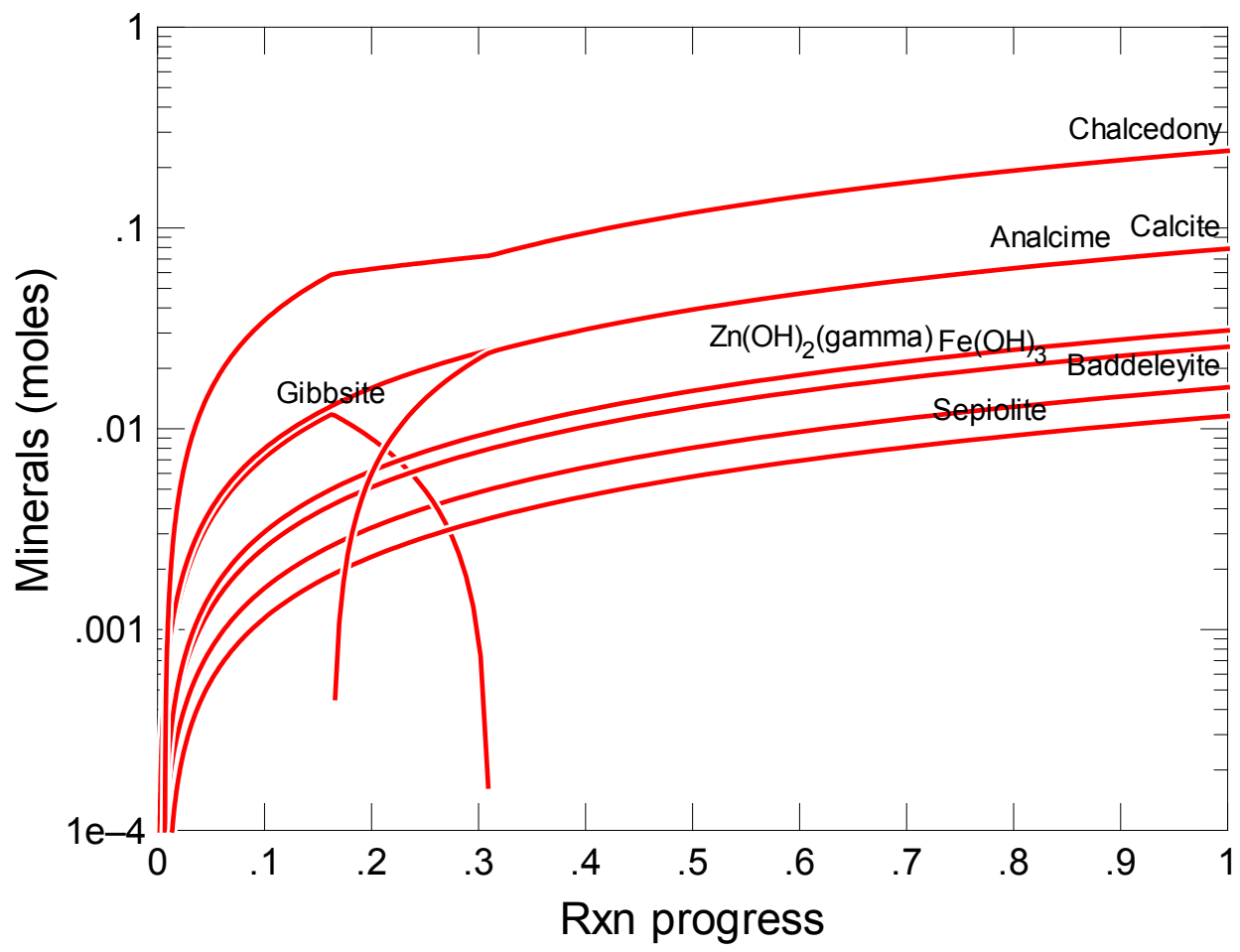

Figure C.271. Secondary Phases Calculated to Form as a Function of Reaction Progress (mol-glass $/ \mathrm{kg}$ ) Determined for Glass Sample LAWB78

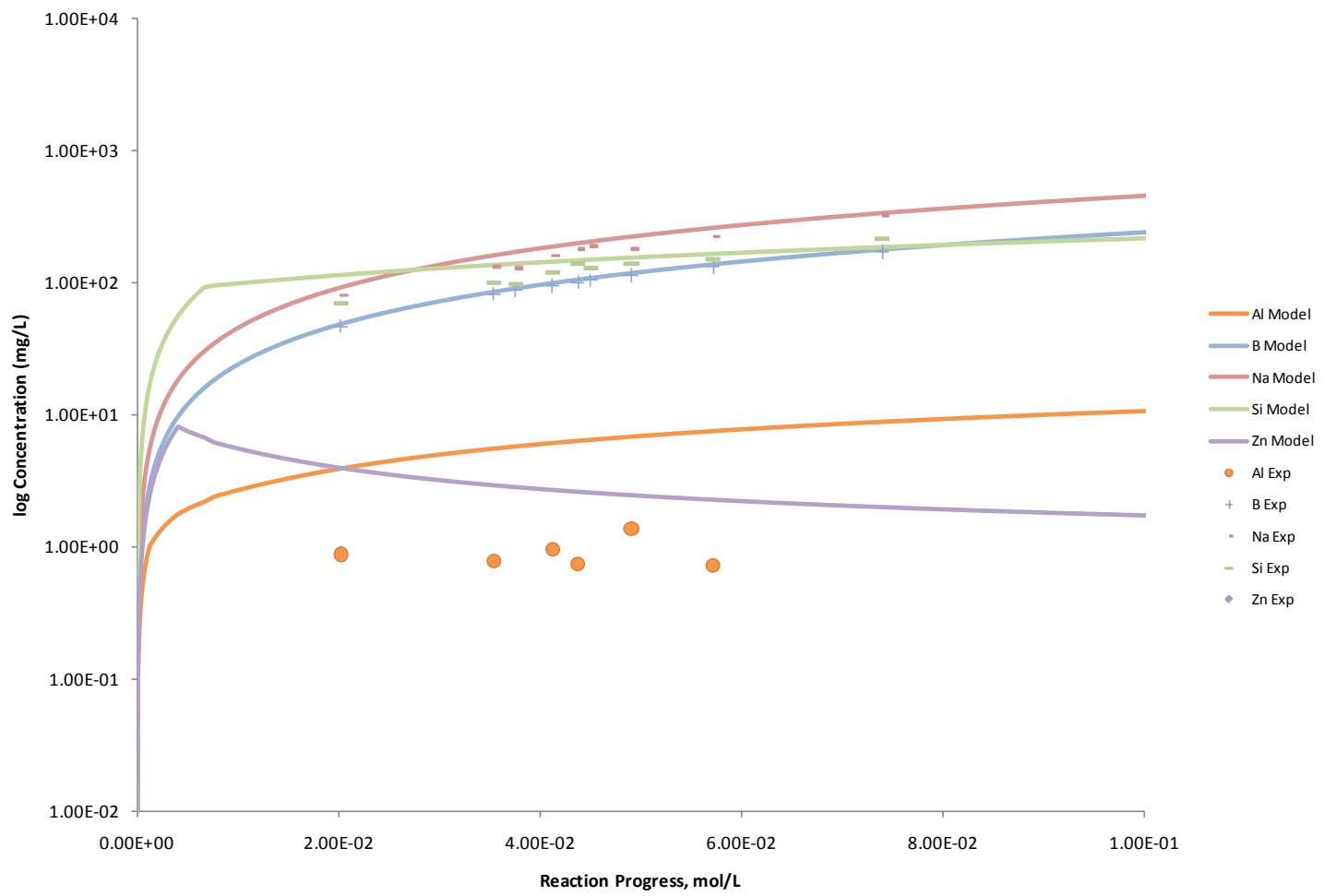

Figure C.272. Measured Solution Concentrations (mg/L) and Model Results for Al, B, Na, Si, and Zn, as a Function of Reaction Progress (mol-glass $/ \mathrm{kg}$ ) Determined for Glass Sample LAWB78 


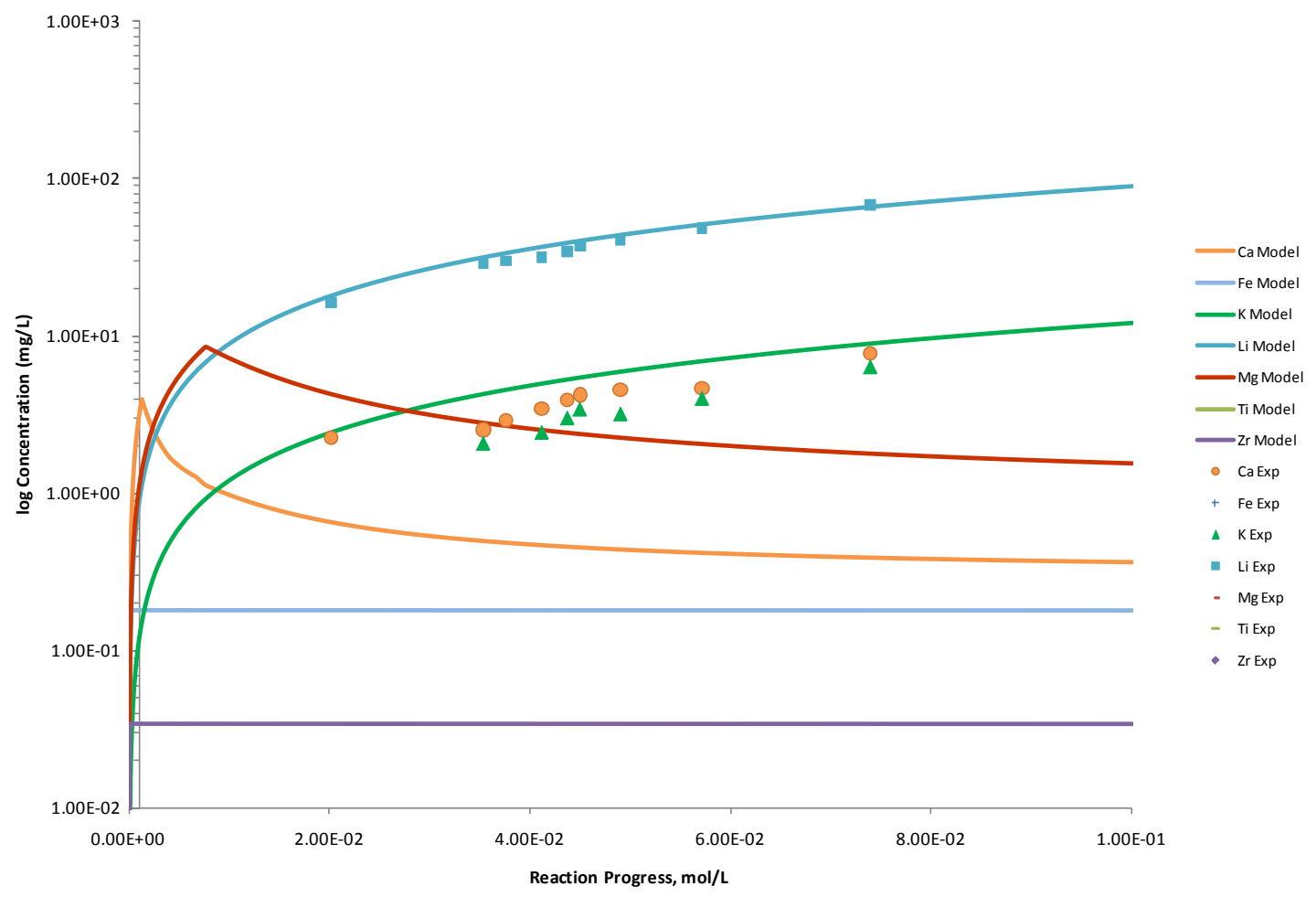

Figure C.273. Measured Solution Concentrations (mg/L) and Model Results for $\mathrm{Ca}, \mathrm{Fe}, \mathrm{K}, \mathrm{Li}, \mathrm{Mg}$, Ti, and $\mathrm{Zr}$, as a Function of Reaction Progress (mol-glass/kg) Determined for Glass Sample LAWB78

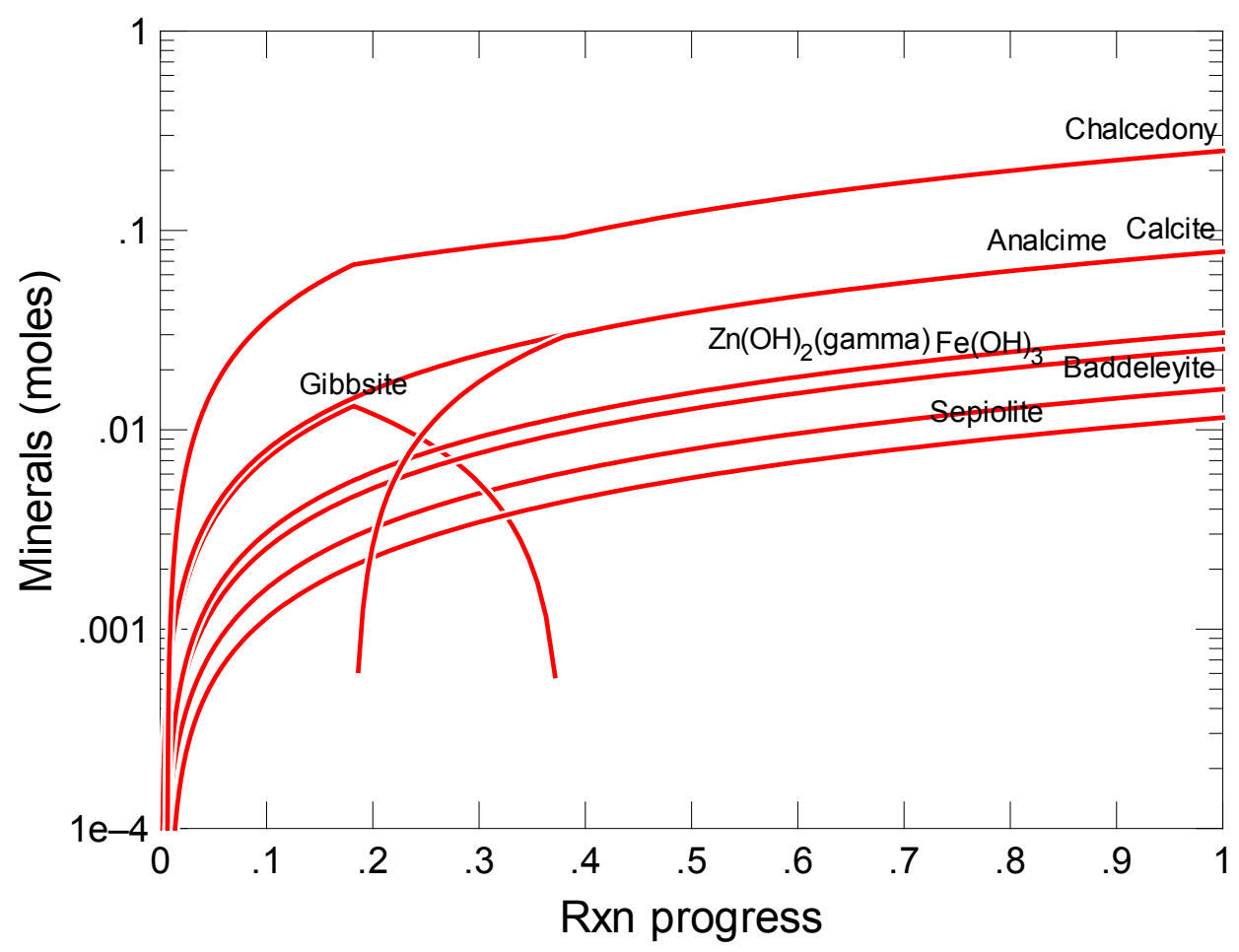

Figure C.274. Secondary Phases Calculated to Form as a Function of Reaction Progress (mol-glass/kg) Determined for Glass Sample LAWB79 


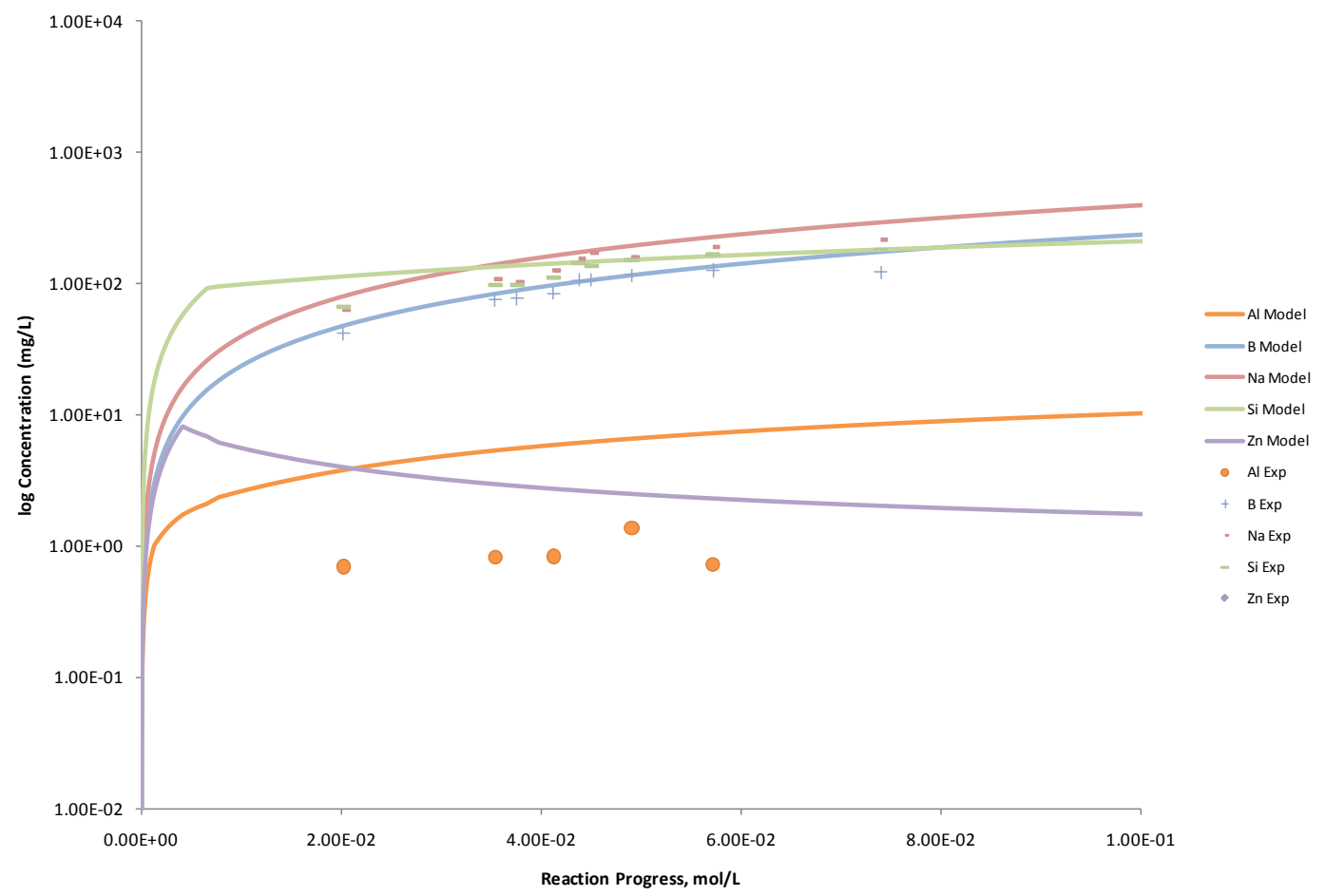

Figure C.275. Measured Solution Concentrations (mg/L) and Model Results for Al, B, Na, Si, and Zn, as a Function of Reaction Progress (mol-glass $/ \mathrm{kg}$ ) Determined for Glass Sample LAWB79

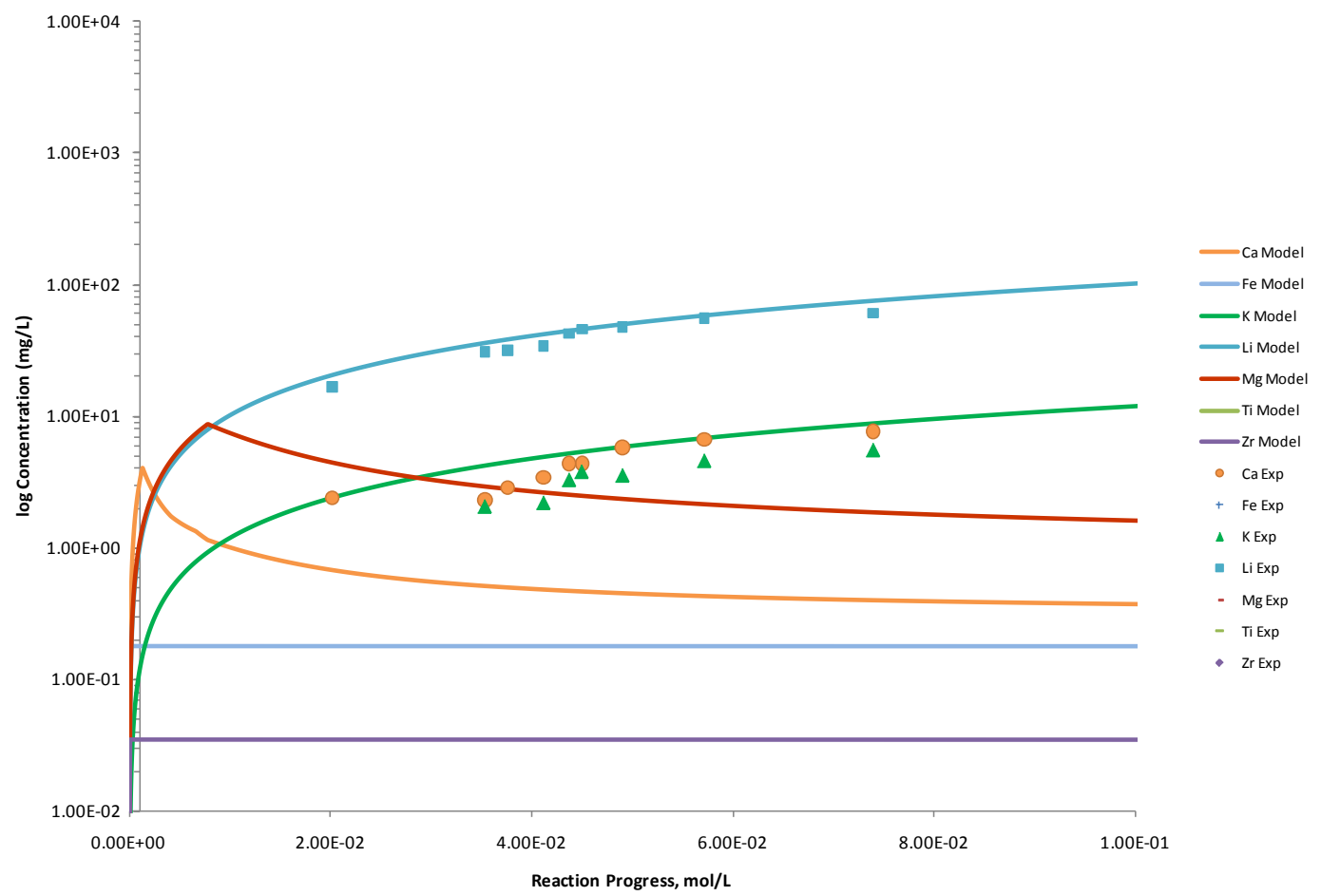

Figure C.276. Measured Solution Concentrations (mg/L) and Model Results for Ca, Fe, K, Li, Mg, Ti, and $\mathrm{Zr}$, as a Function of Reaction Progress (mol-glass/kg) Determined for Glass Sample LAWB79 


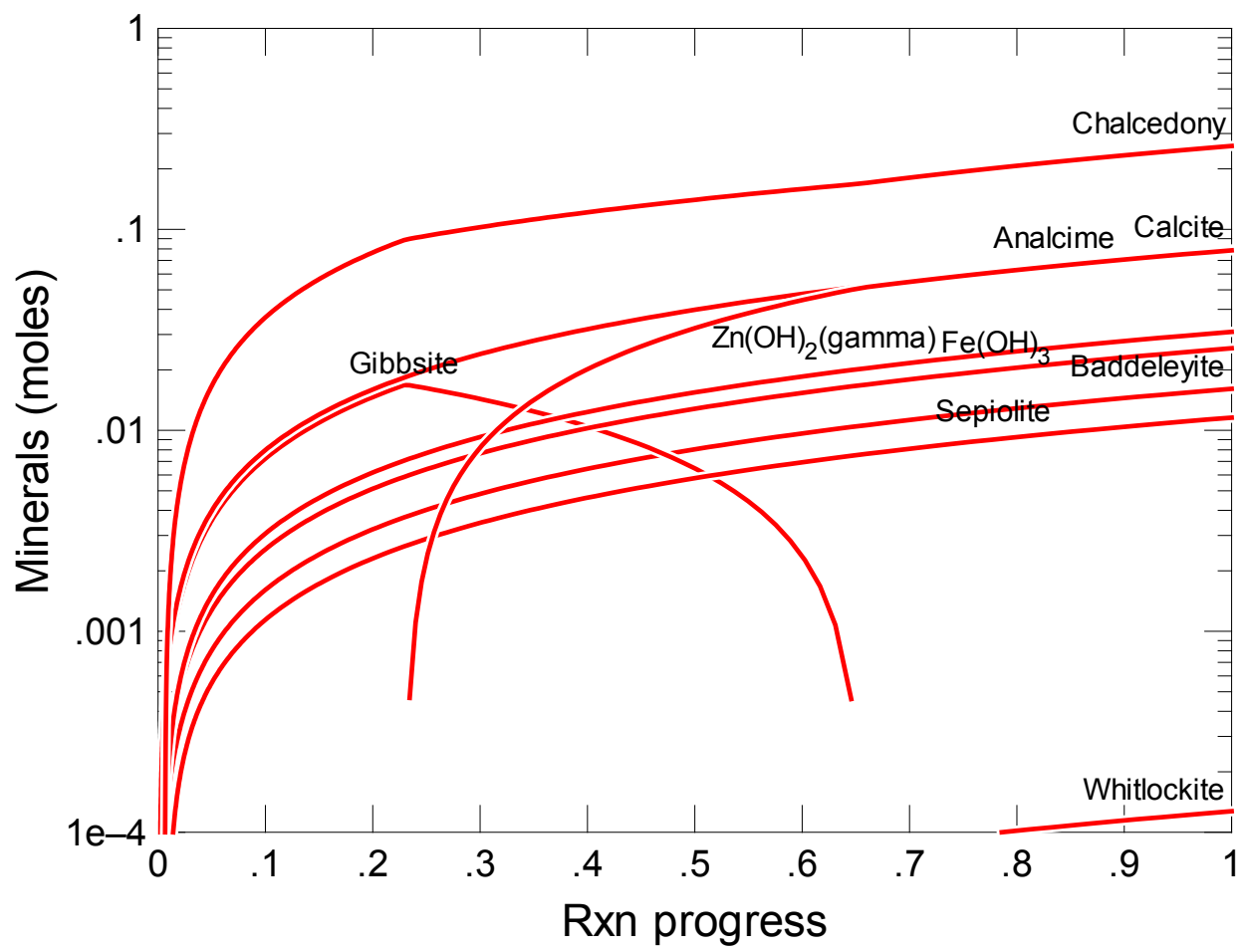

Figure C.277. Secondary Phases Calculated to Form as a Function of Reaction Progress (mol-glass $/ \mathrm{kg}$ ) Determined for Glass Sample LAWB80

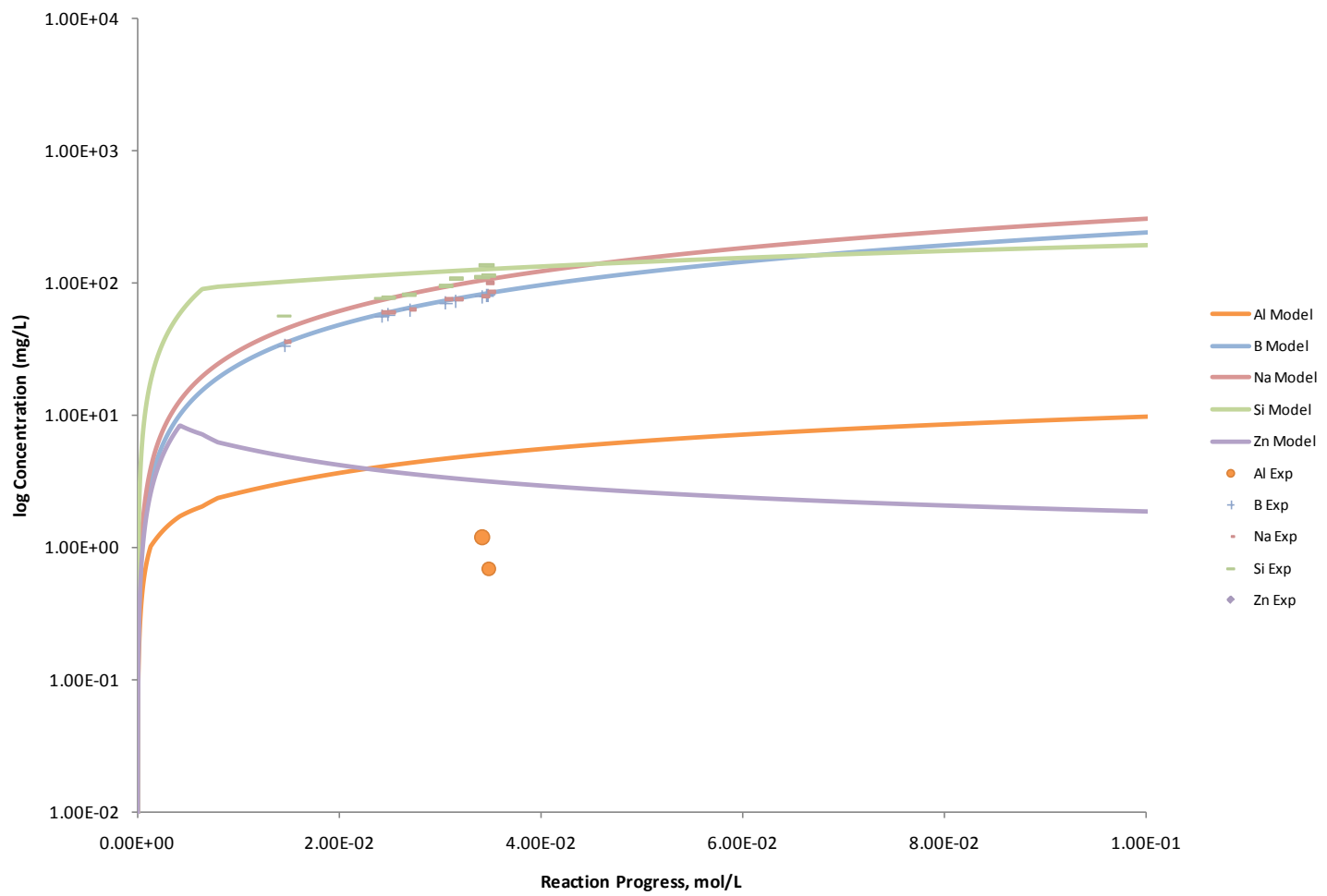

Figure C.278. Measured Solution Concentrations (mg/L) and Model Results for Al, B, Na, Si, and Zn, as a Function of Reaction Progress (mol-glass $/ \mathrm{kg}$ ) Determined for Glass Sample LAWB80 


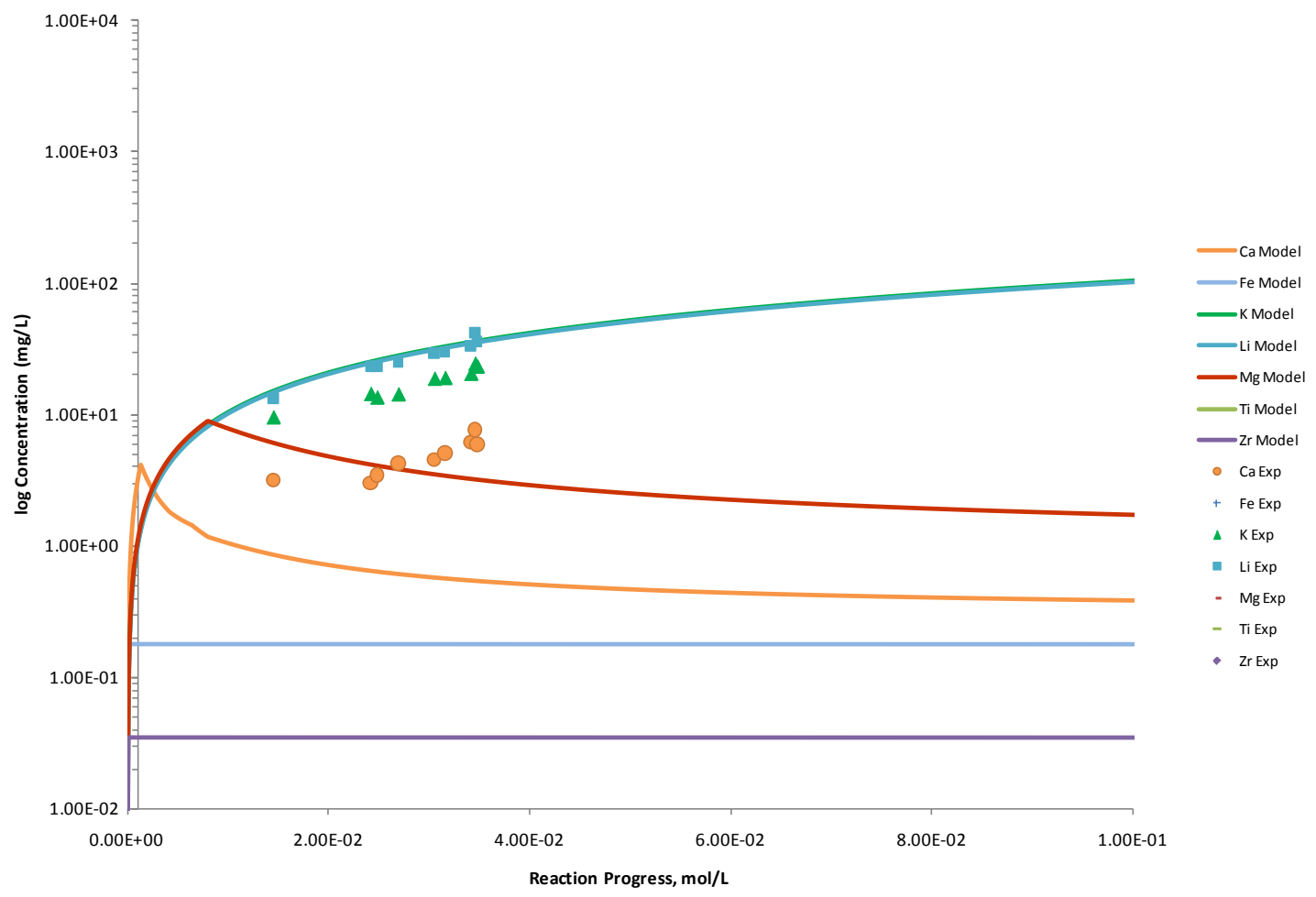

Figure C.279. Measured Solution Concentrations (mg/L) and Model Results for $\mathrm{Ca}, \mathrm{Fe}, \mathrm{K}, \mathrm{Li}, \mathrm{Mg}$, Ti, and $\mathrm{Zr}$, as a Function of Reaction Progress (mol-glass/kg) Determined for Glass Sample LAWB80

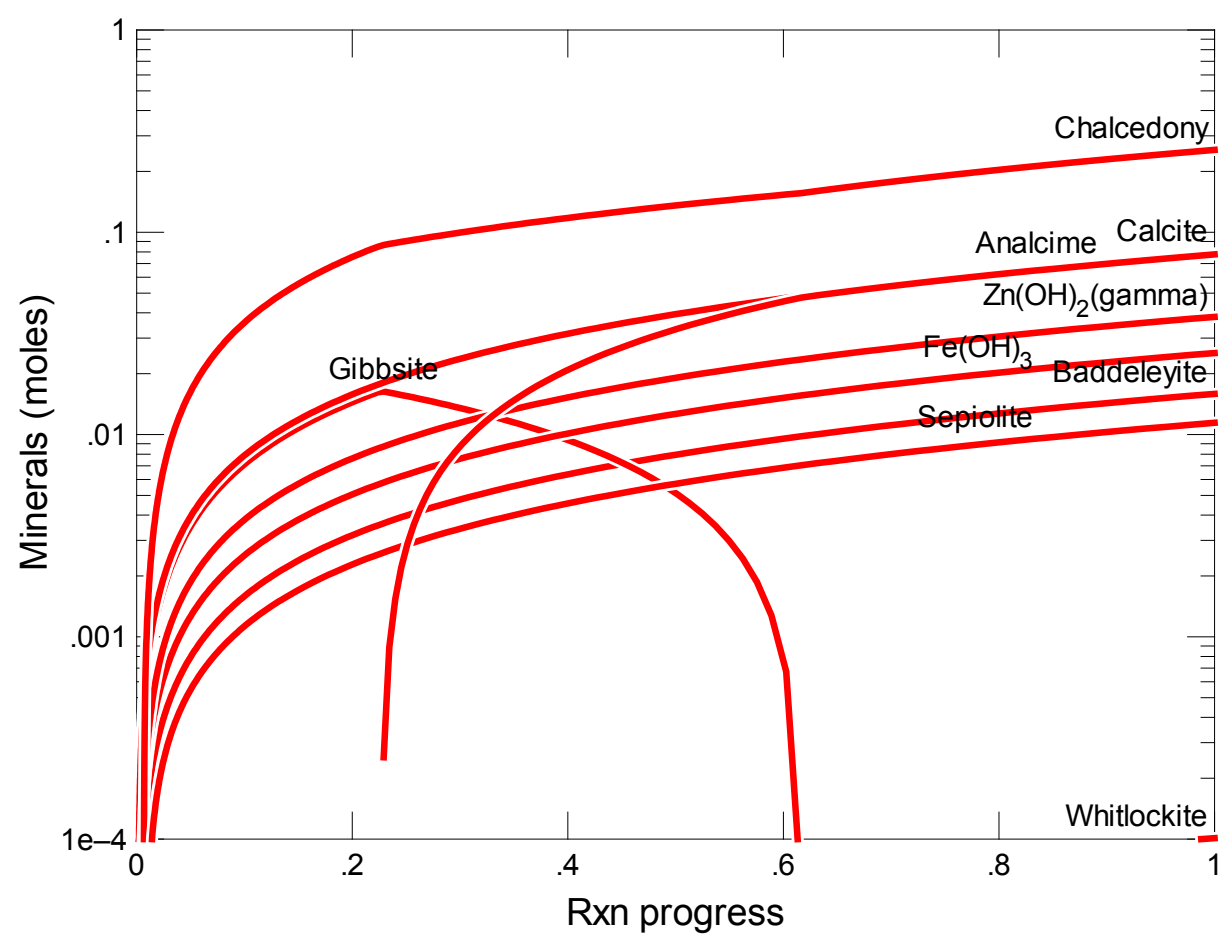

Figure C.280. Secondary Phases Calculated to Form as a Function of Reaction Progress (mol-glass/kg) Determined for Glass Sample LAWB81 


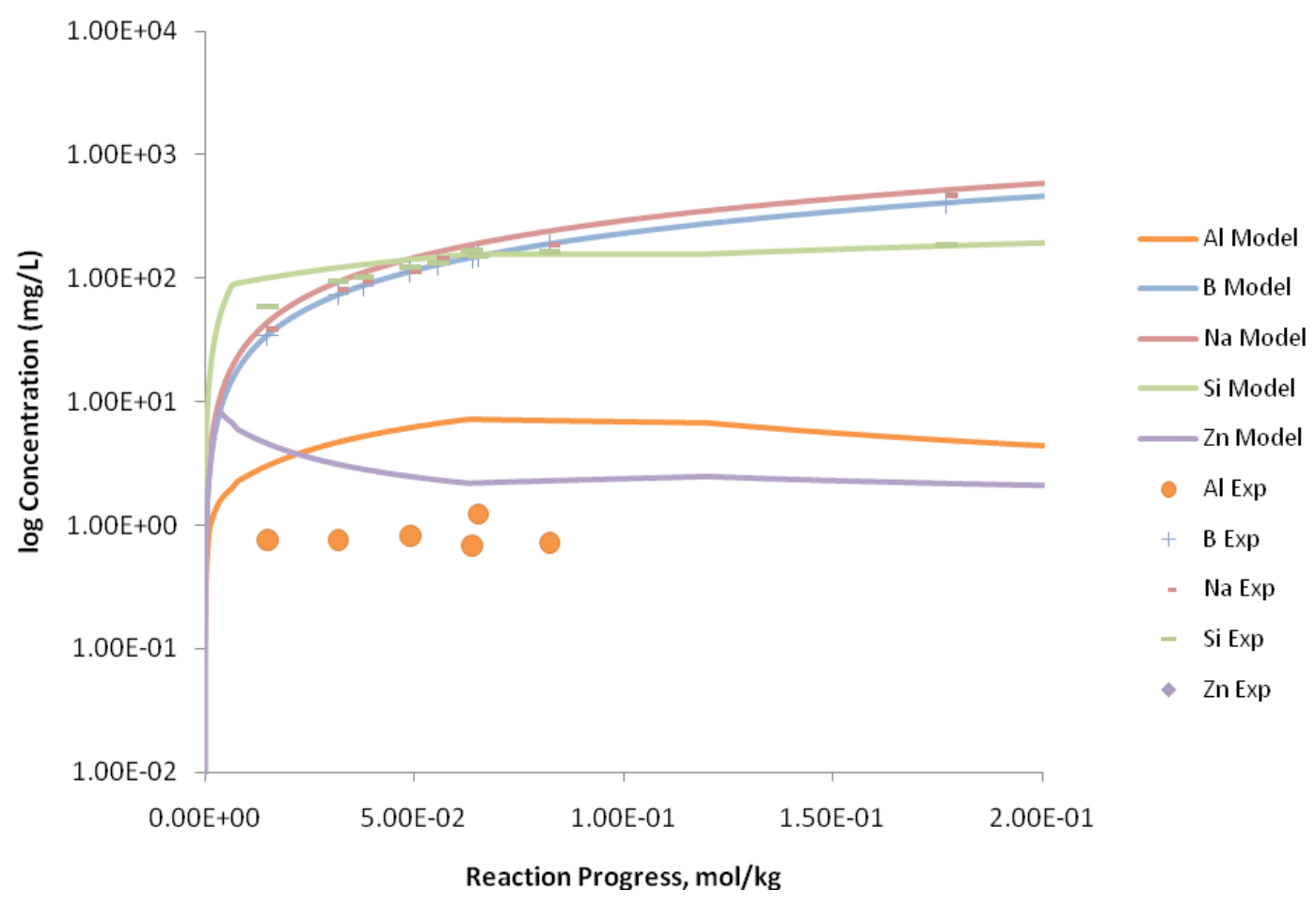

Figure C.281. Measured Solution Concentrations (mg/L) and Model Results for Al, B, Na, Si, and Zn, as a Function of Reaction Progress (mol-glass $/ \mathrm{kg}$ ) Determined for Glass Sample LAWB81

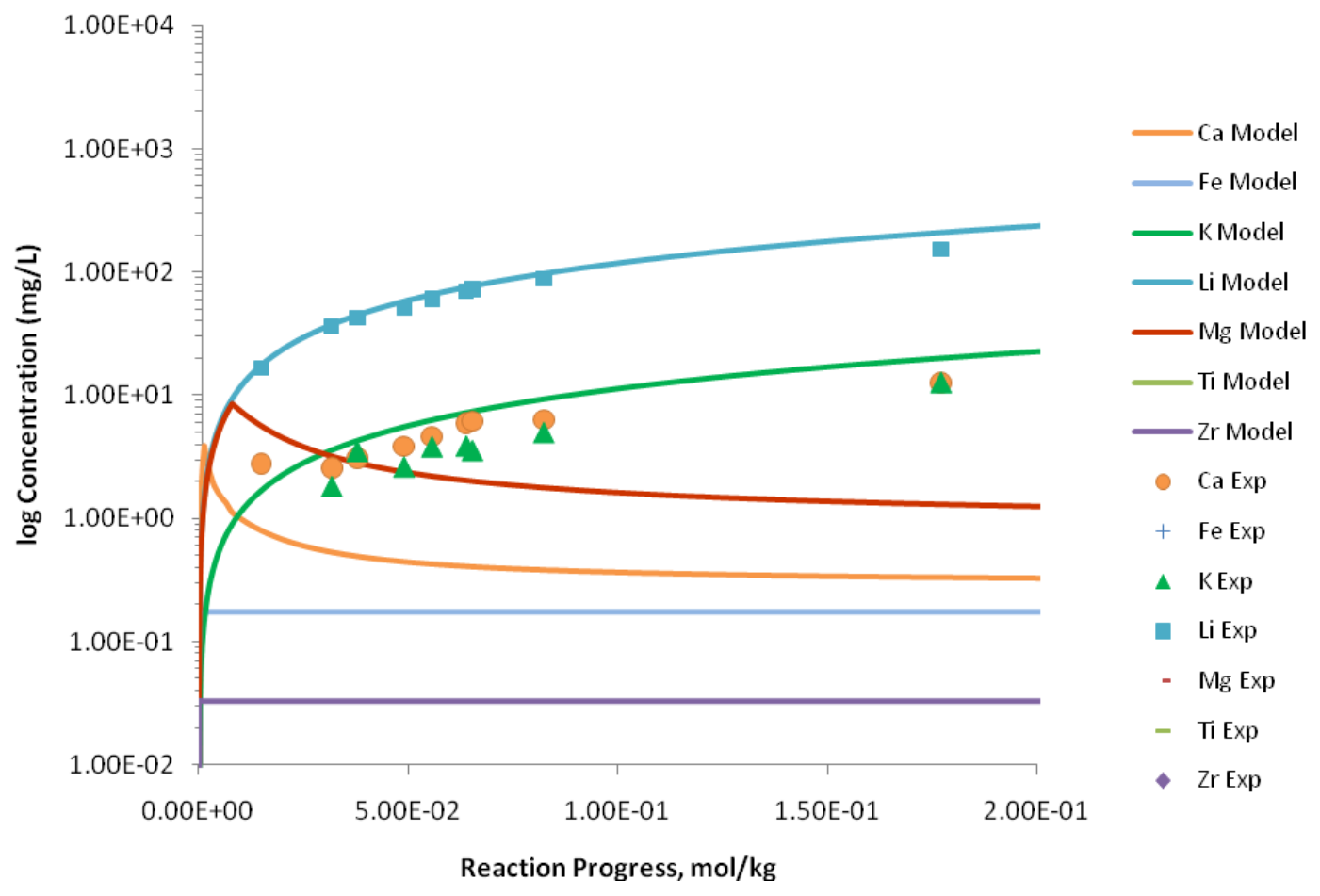

Figure C.282. Measured Solution Concentrations (mg/L) and Model Results for $\mathrm{Ca}, \mathrm{Fe}, \mathrm{K}, \mathrm{Li}, \mathrm{Mg}, \mathrm{Ti}$, and $\mathrm{Zr}$, as a Function of Reaction Progress (mol-glass/kg) Determined for Glass Sample LAWB81 


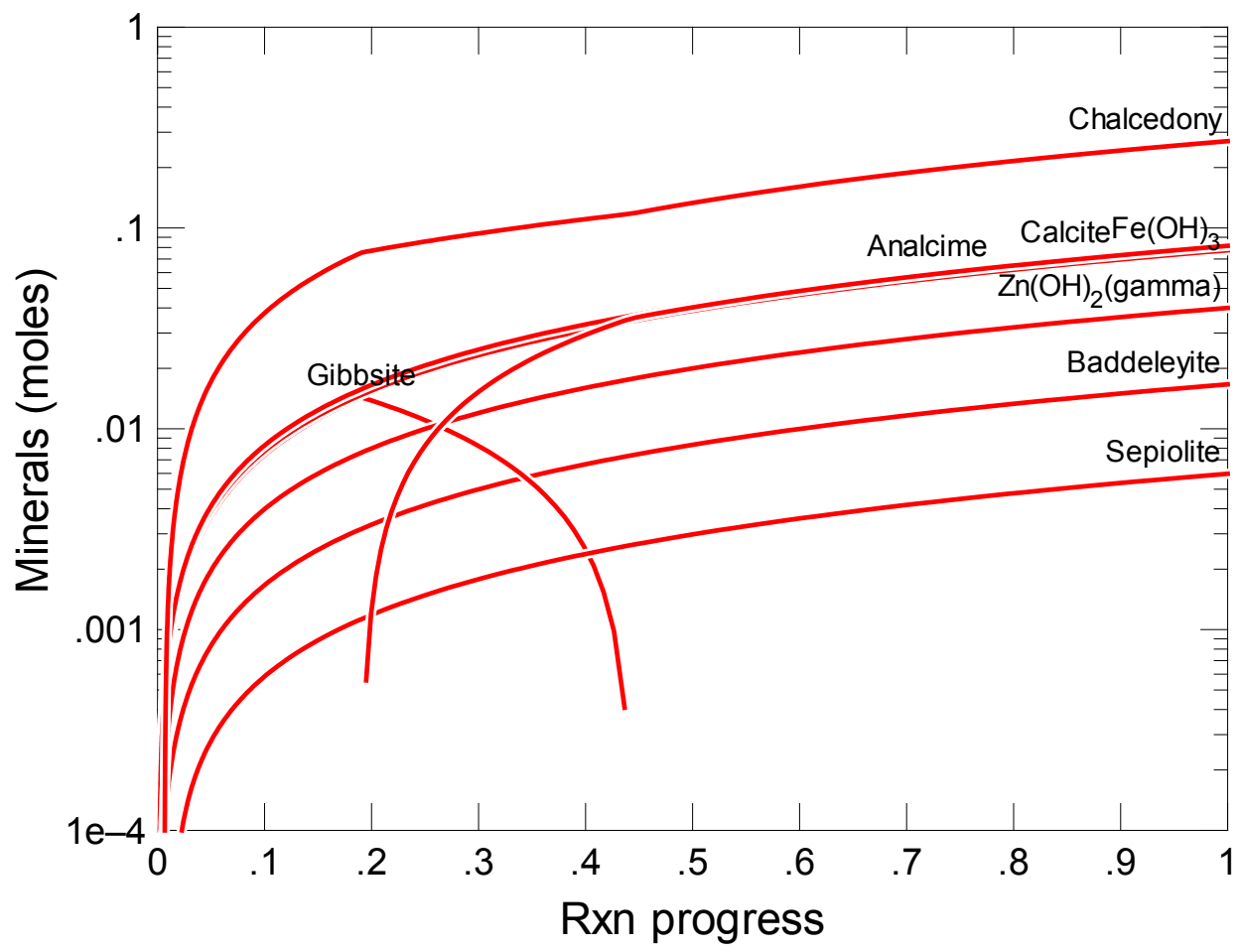

Figure C.283. Secondary Phases Calculated to Form as a Function of Reaction Progress (mol-glass $/ \mathrm{kg}$ ) Determined for Glass Sample LAWB82

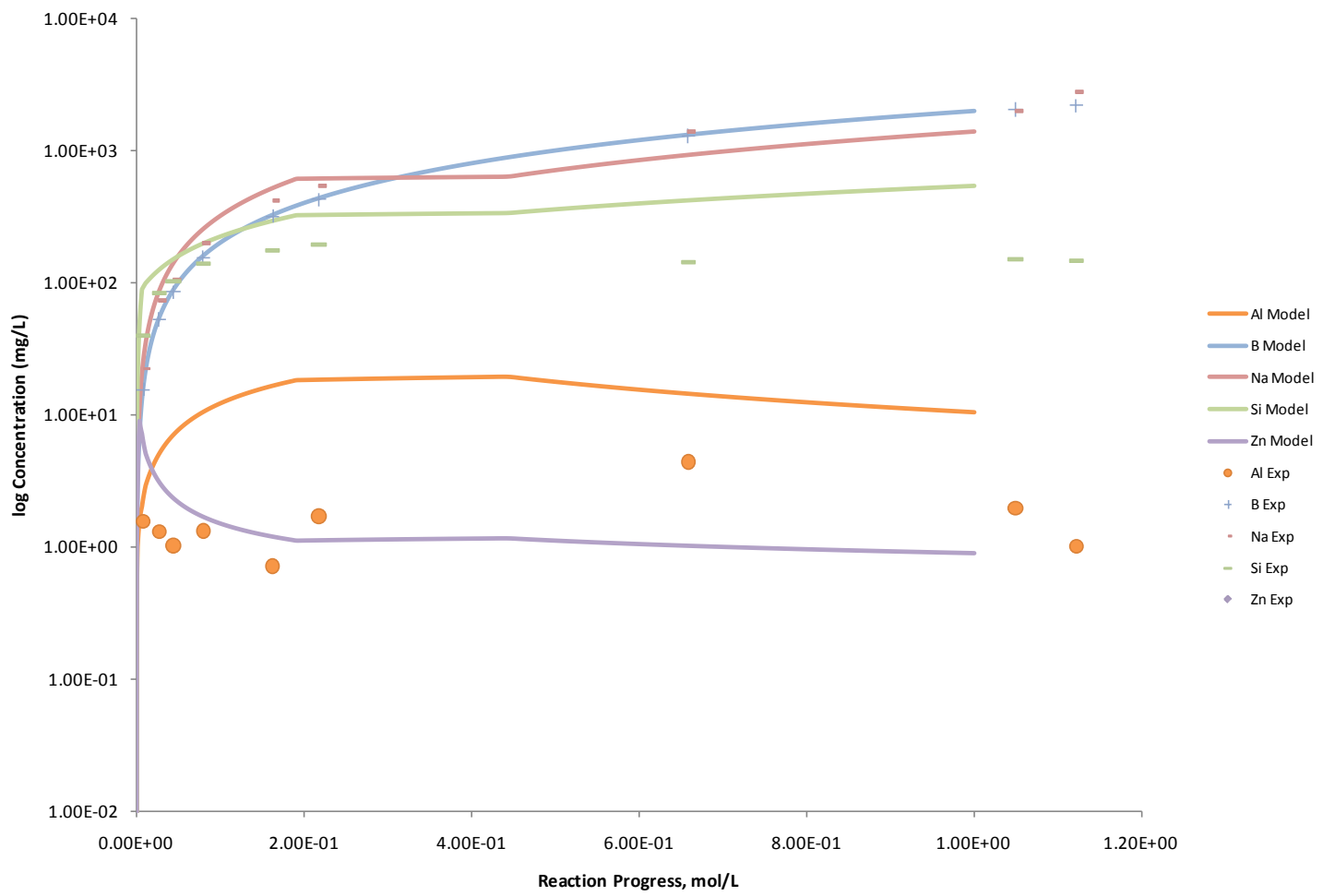

Figure C.284. Measured Solution Concentrations (mg/L) and Model Results for Al, B, Na, Si, and Zn, as a Function of Reaction Progress (mol-glass $/ \mathrm{kg}$ ) Determined for Glass Sample LAWB82 


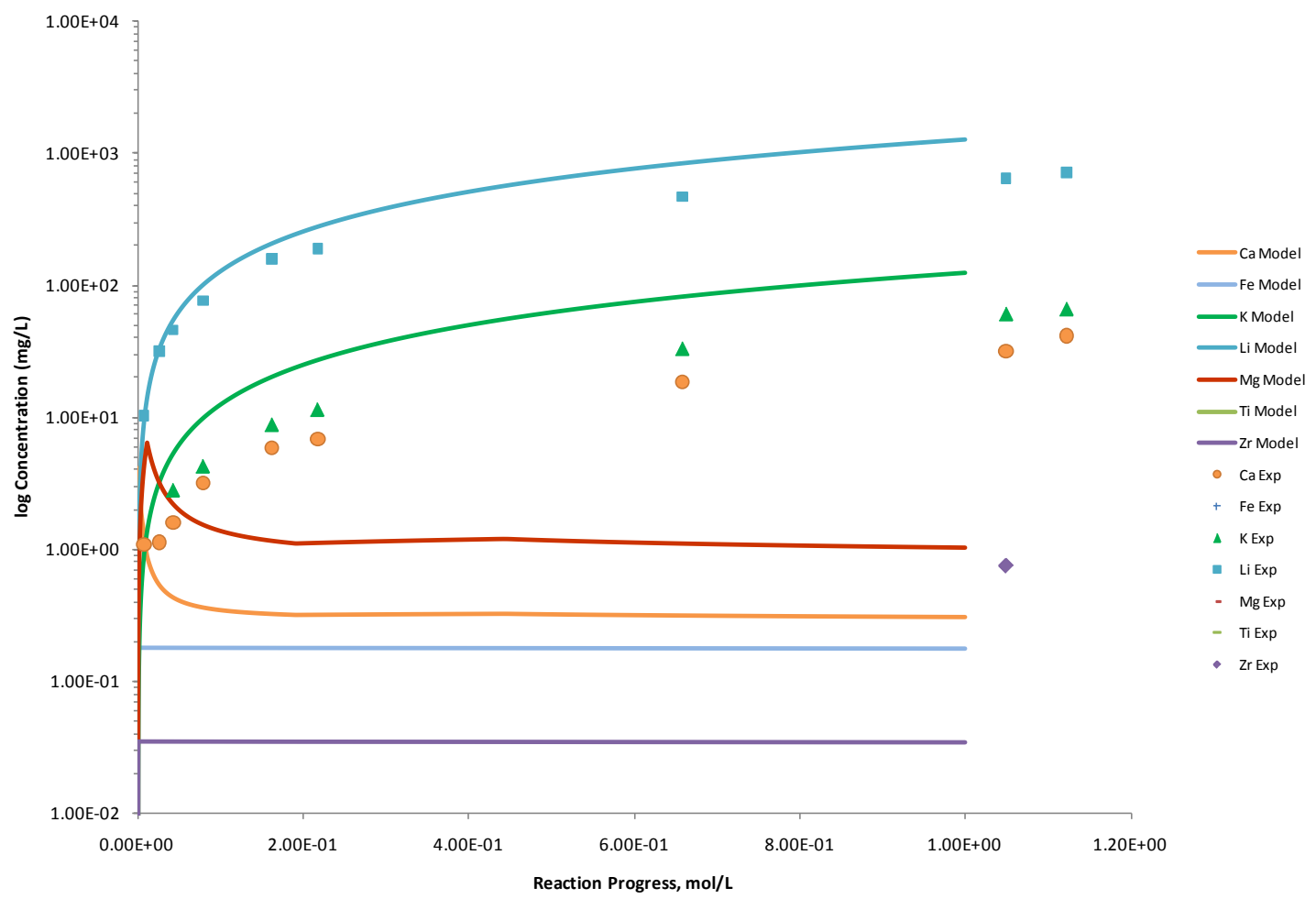

Figure C.285. Measured Solution Concentrations (mg/L) and Model Results for $\mathrm{Ca}, \mathrm{Fe}, \mathrm{K}, \mathrm{Li}, \mathrm{Mg}$, Ti, and $\mathrm{Zr}$, as a Function of Reaction Progress (mol-glass $/ \mathrm{kg}$ ) Determined for Glass Sample LAWB82

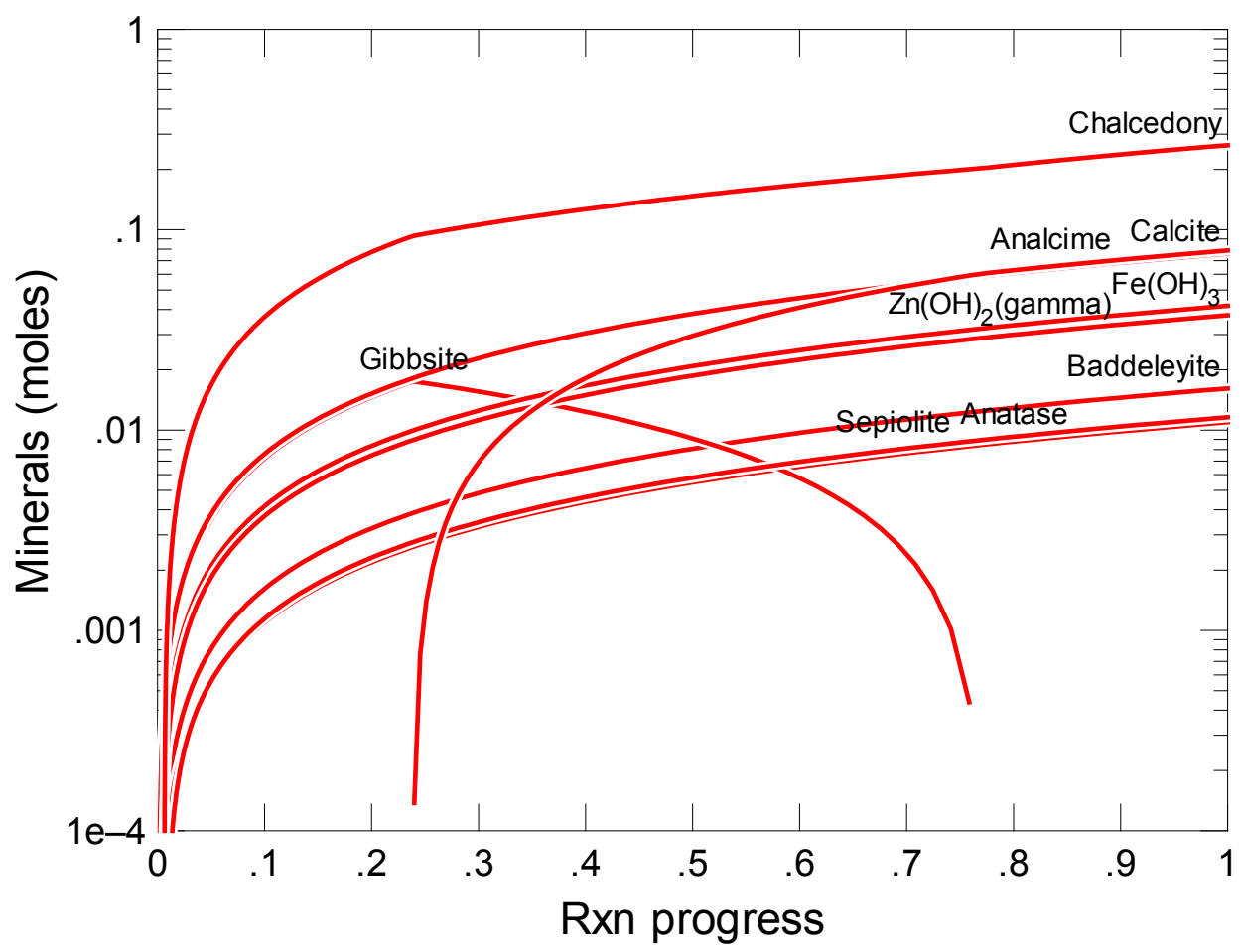

Figure C.286. Secondary Phases Calculated to Form as a Function of Reaction Progress (mol-glass $/ \mathrm{kg}$ ) Determined for Glass Sample LAWB83 


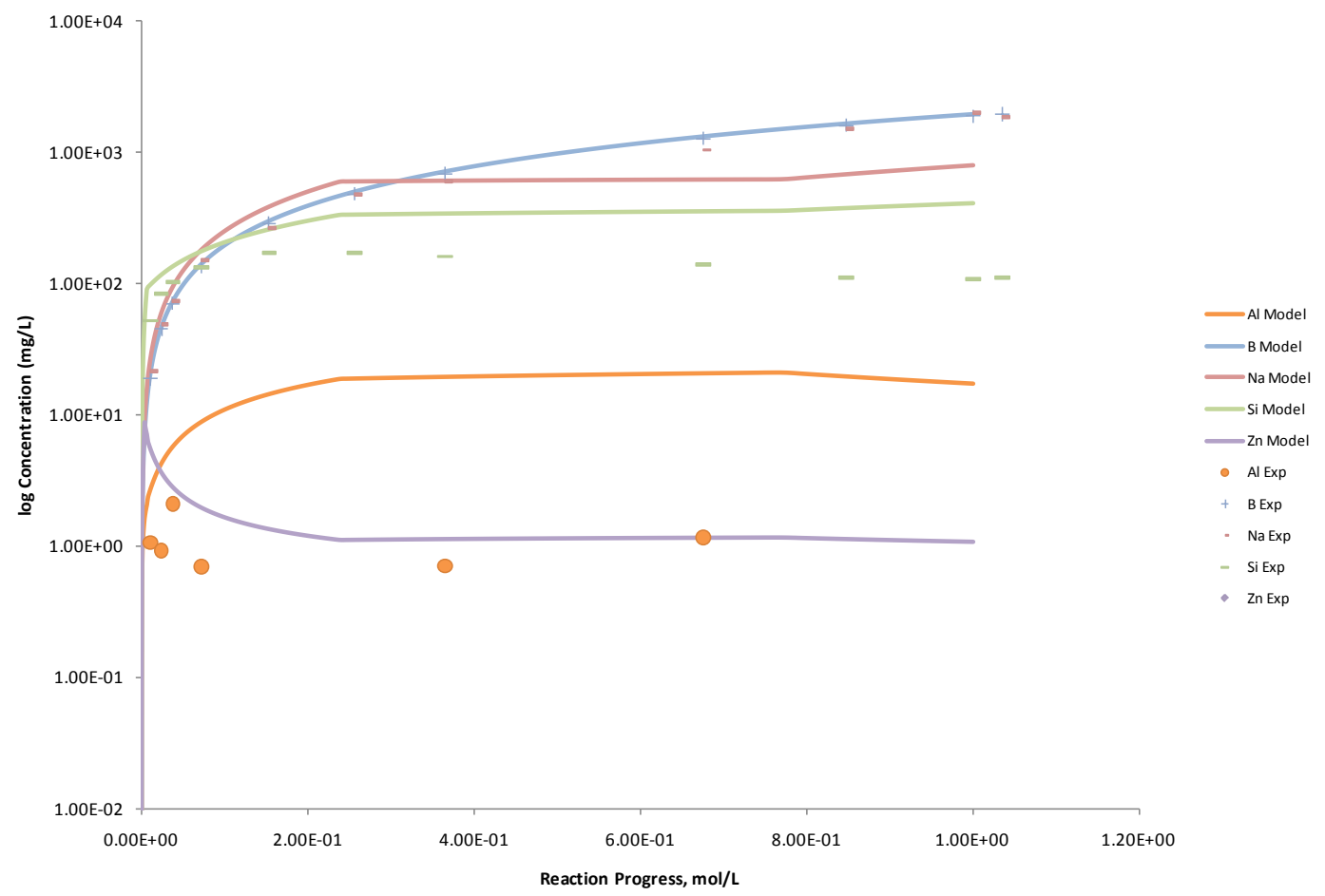

Figure C.287. Measured Solution Concentrations (mg/L) and Model Results for Al, B, Na, Si, and Zn, as a Function of Reaction Progress (mol-glass $/ \mathrm{kg}$ ) Determined for Glass Sample LAWB83

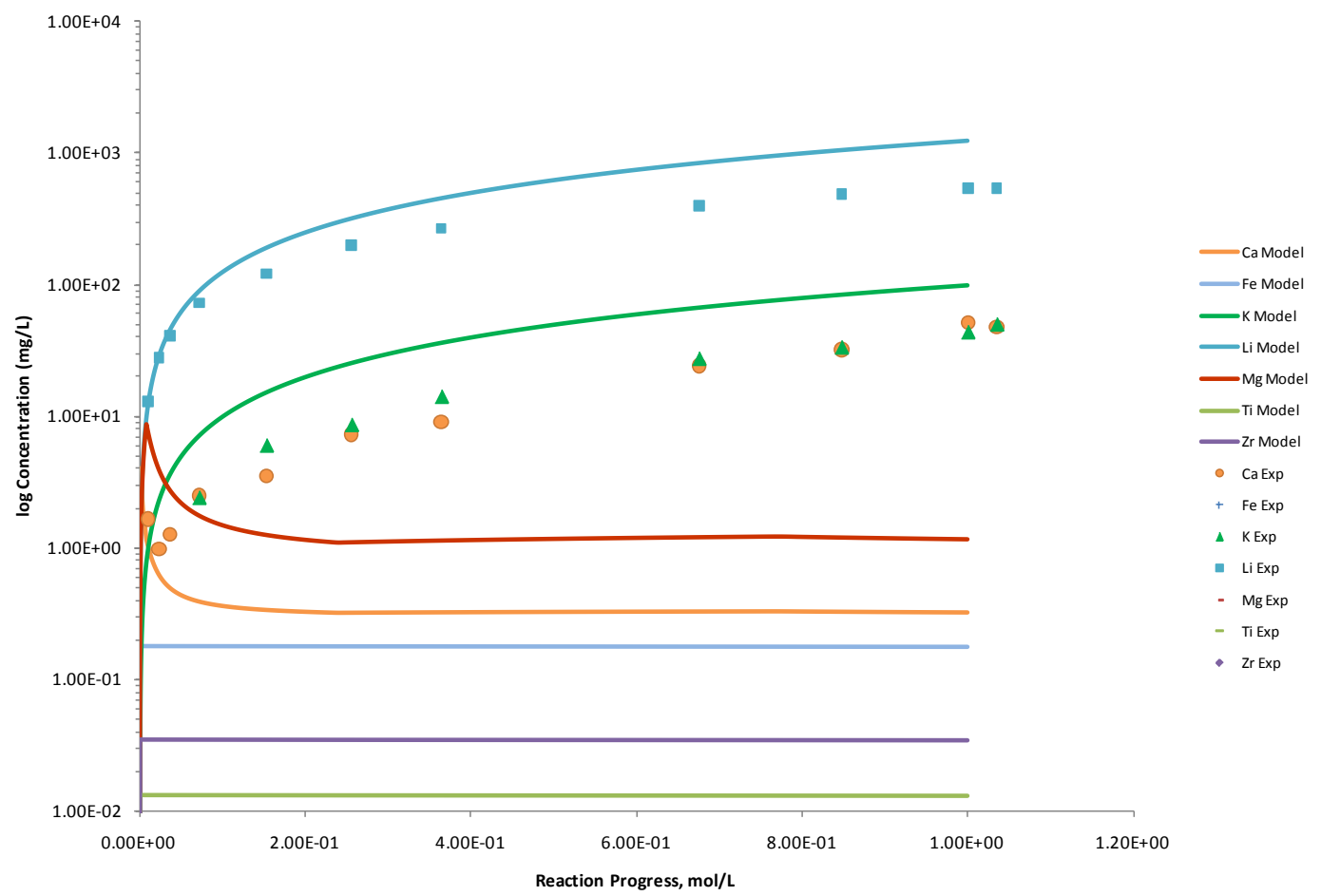

Figure C.288. Measured Solution Concentrations (mg/L) and Model Results for Ca, Fe, K, Li, Mg, Ti, and $\mathrm{Zr}$, as a Function of Reaction Progress (mol-glass/kg) Determined for Glass Sample LAWB83 


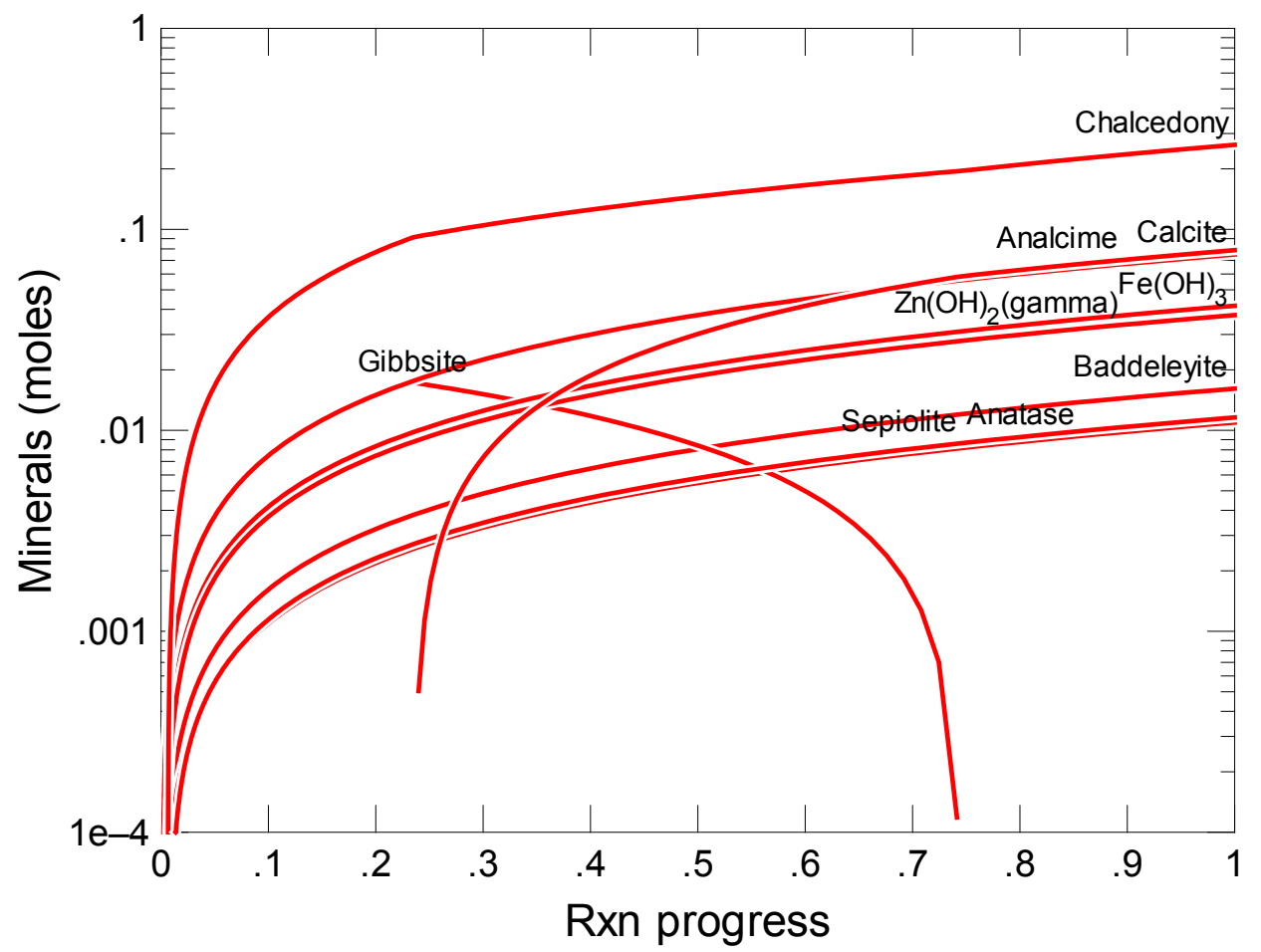

Figure C.289. Secondary Phases Calculated to Form as a Function of Reaction Progress (mol-glass $/ \mathrm{kg}$ ) Determined for Glass Sample LAWB84

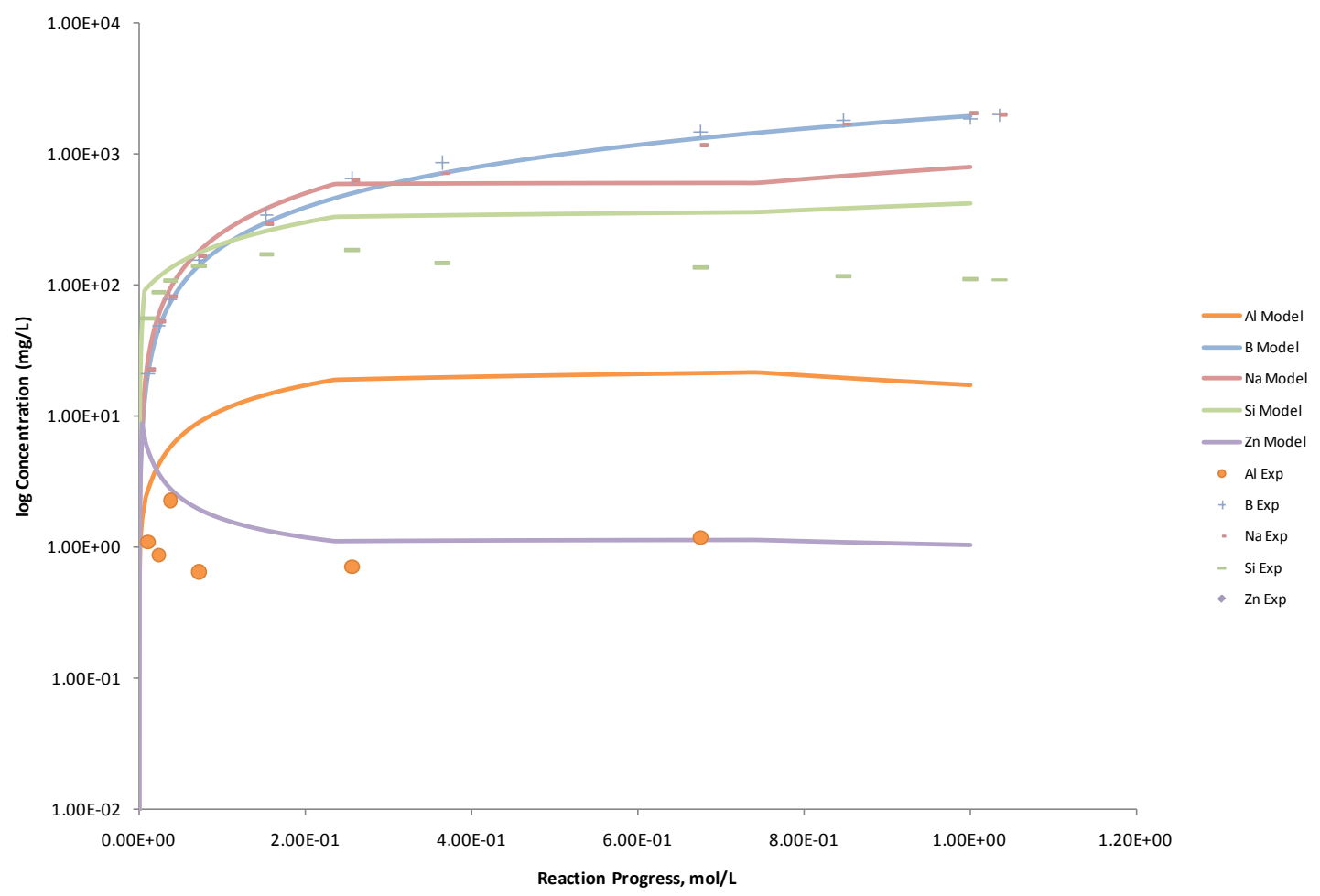

Figure C.290. Measured Solution Concentrations (mg/L) and Model Results for Al, B, Na, Si, and Zn, as a Function of Reaction Progress (mol-glass $/ \mathrm{kg}$ ) Determined for Glass Sample LAWB84 


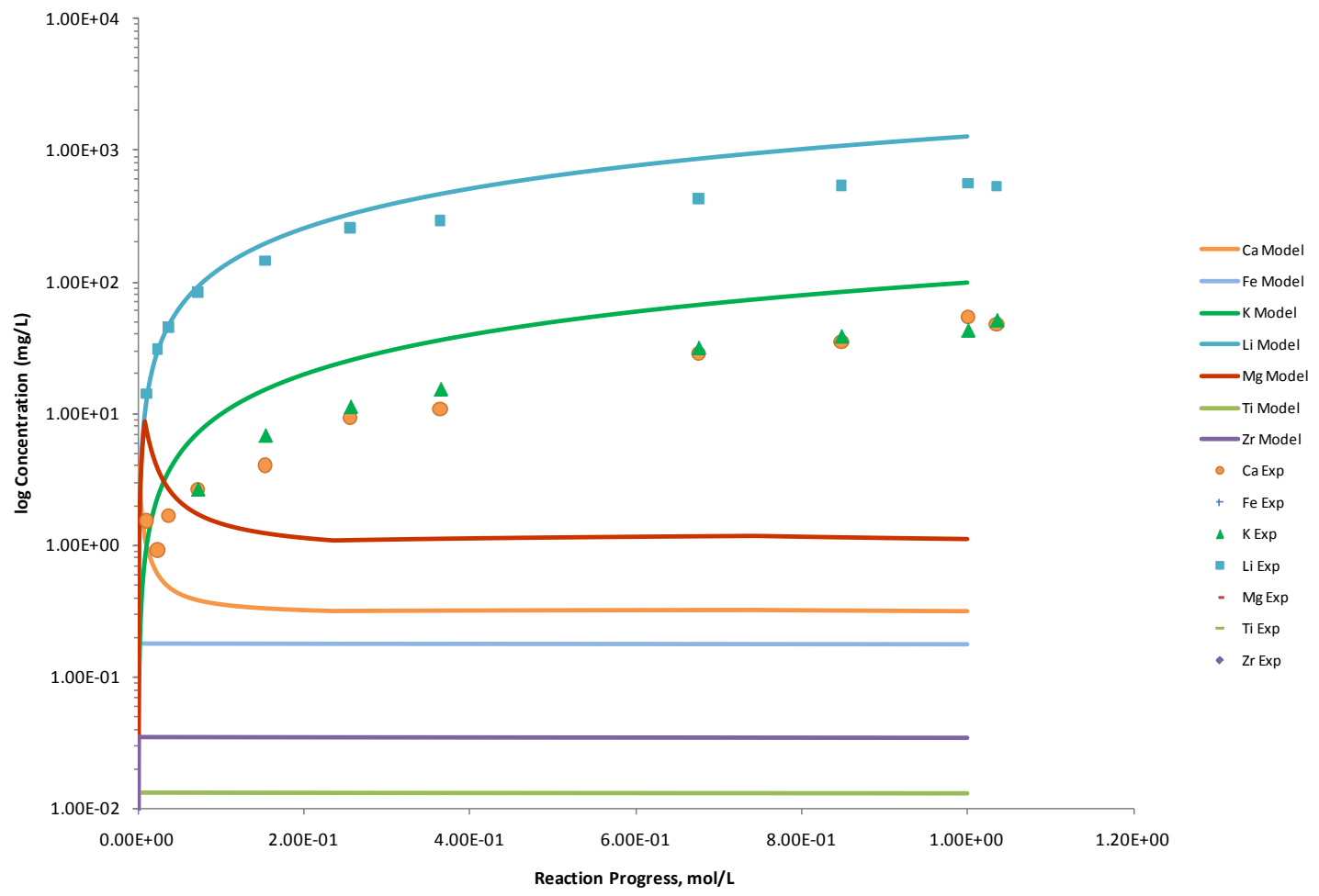

Figure C.291. Measured Solution Concentrations (mg/L) and Model Results for $\mathrm{Ca}, \mathrm{Fe}, \mathrm{K}, \mathrm{Li}, \mathrm{Mg}, \mathrm{Ti}$, and Zr, as a Function of Reaction Progress (mol-glass/kg) Determined for Glass Sample LAWB84

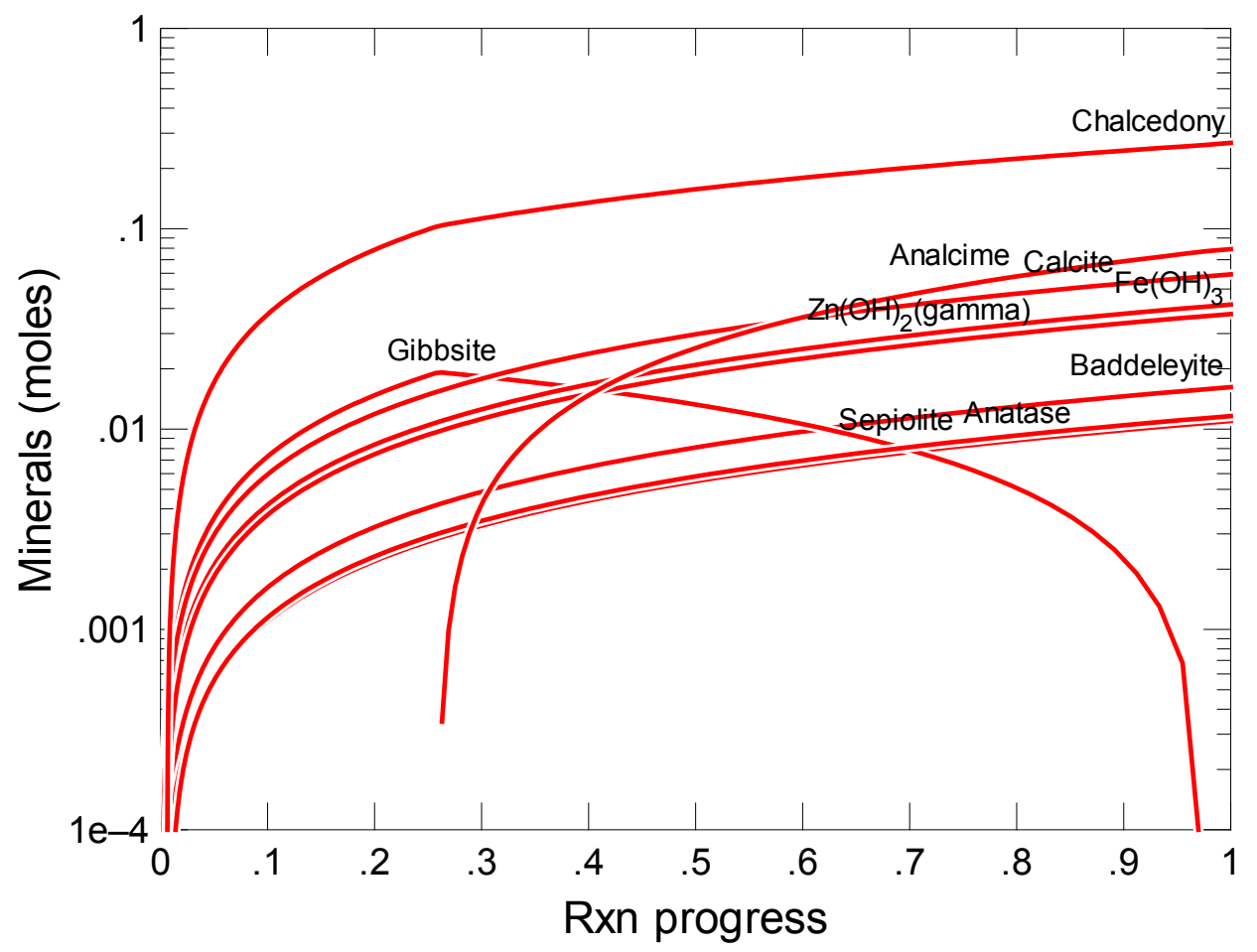

Figure C.292. Secondary Phases Calculated to Form as a Function of Reaction Progress (mol-glass $/ \mathrm{kg}$ ) Determined for Glass Sample LAWB85 


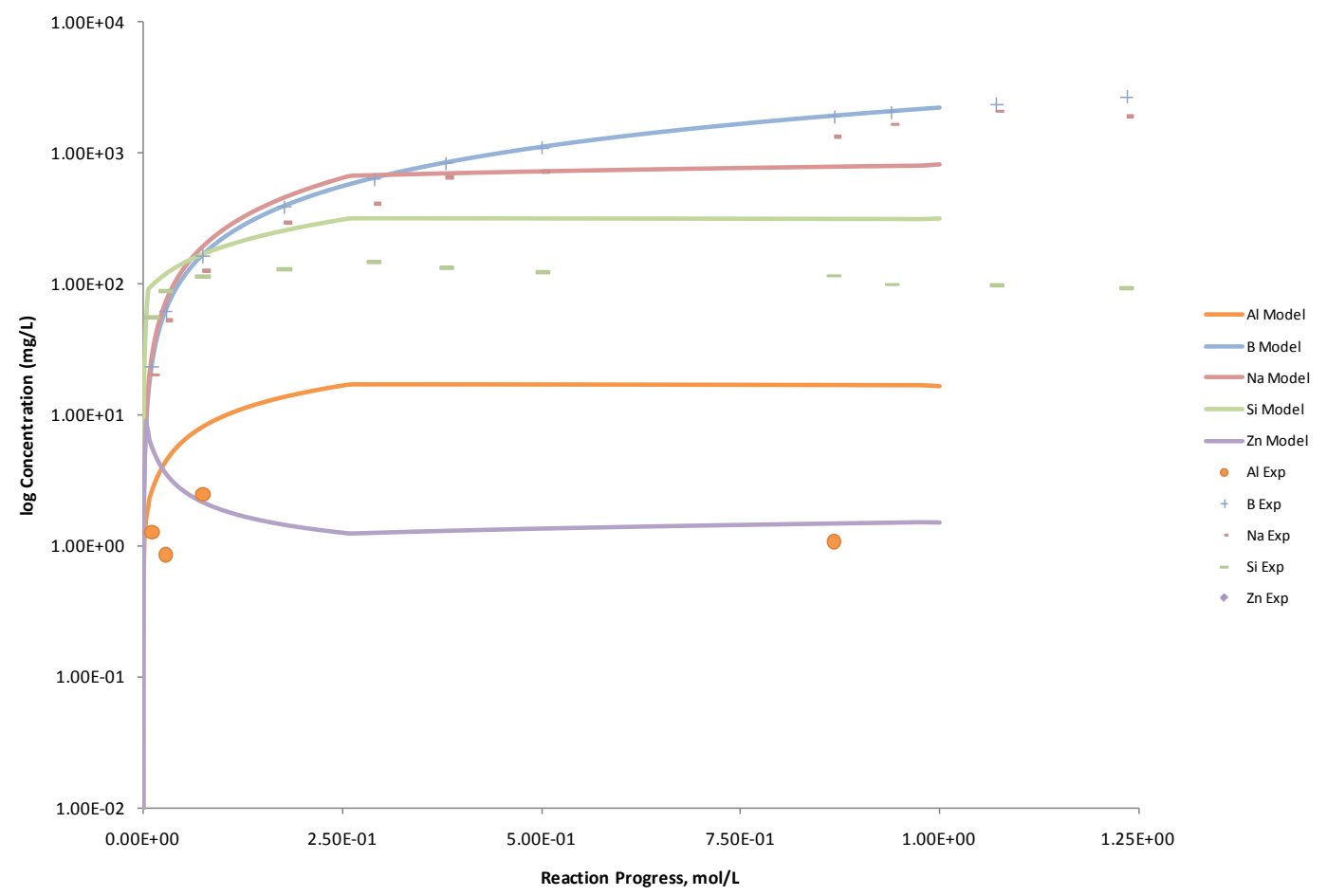

Figure C.293. Measured Solution Concentrations (mg/L) and Model Results for Al, B, Na, Si, and Zn, as a Function of Reaction Progress (mol-glass $/ \mathrm{kg}$ ) Determined for Glass Sample LAWB85

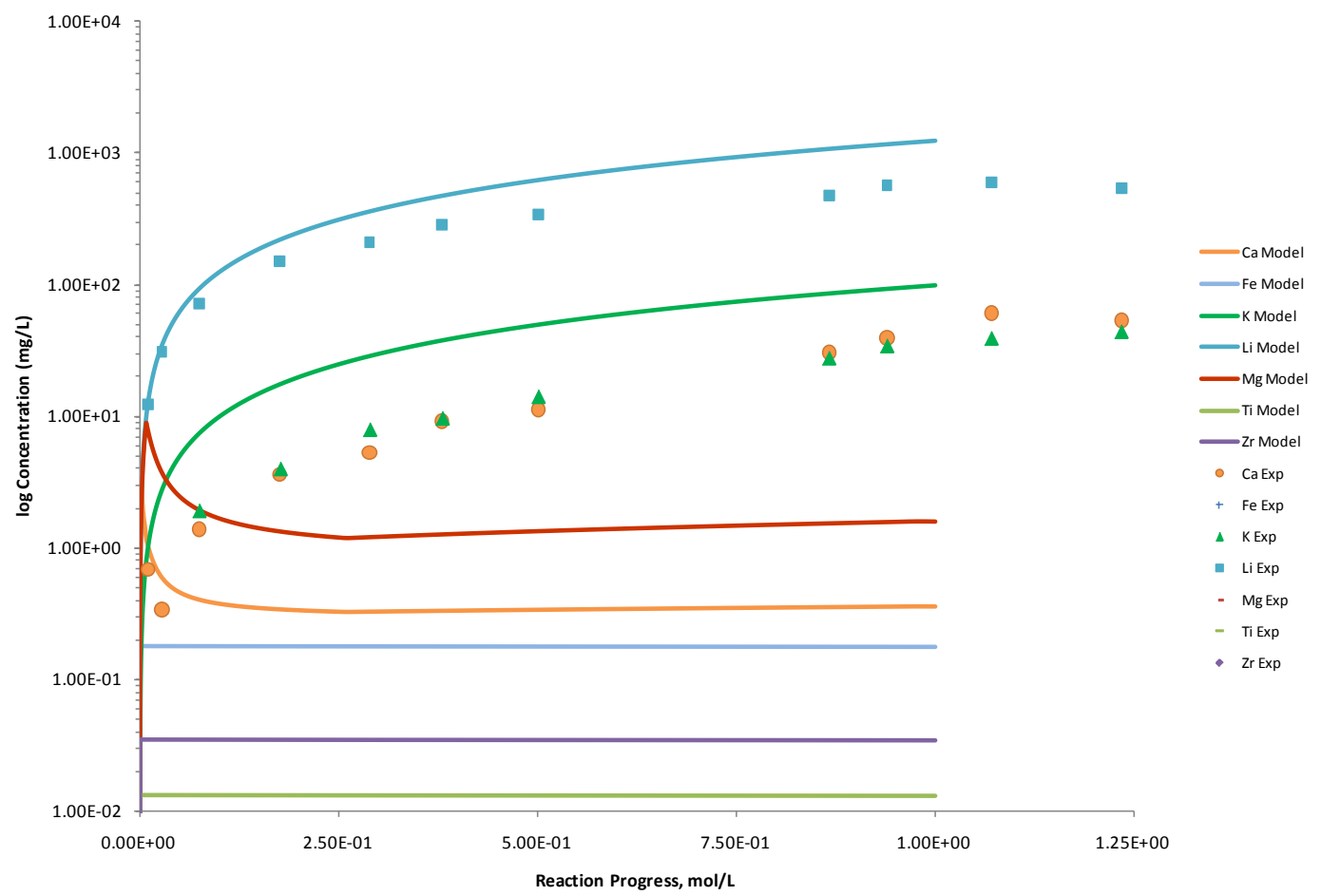

Figure C.294. Measured Solution Concentrations (mg/L) and Model Results for Ca, Fe, K, Li, Mg, Ti, and $\mathrm{Zr}$, as a Function of Reaction Progress (mol-glass/kg) Determined for Glass Sample LAWB85 


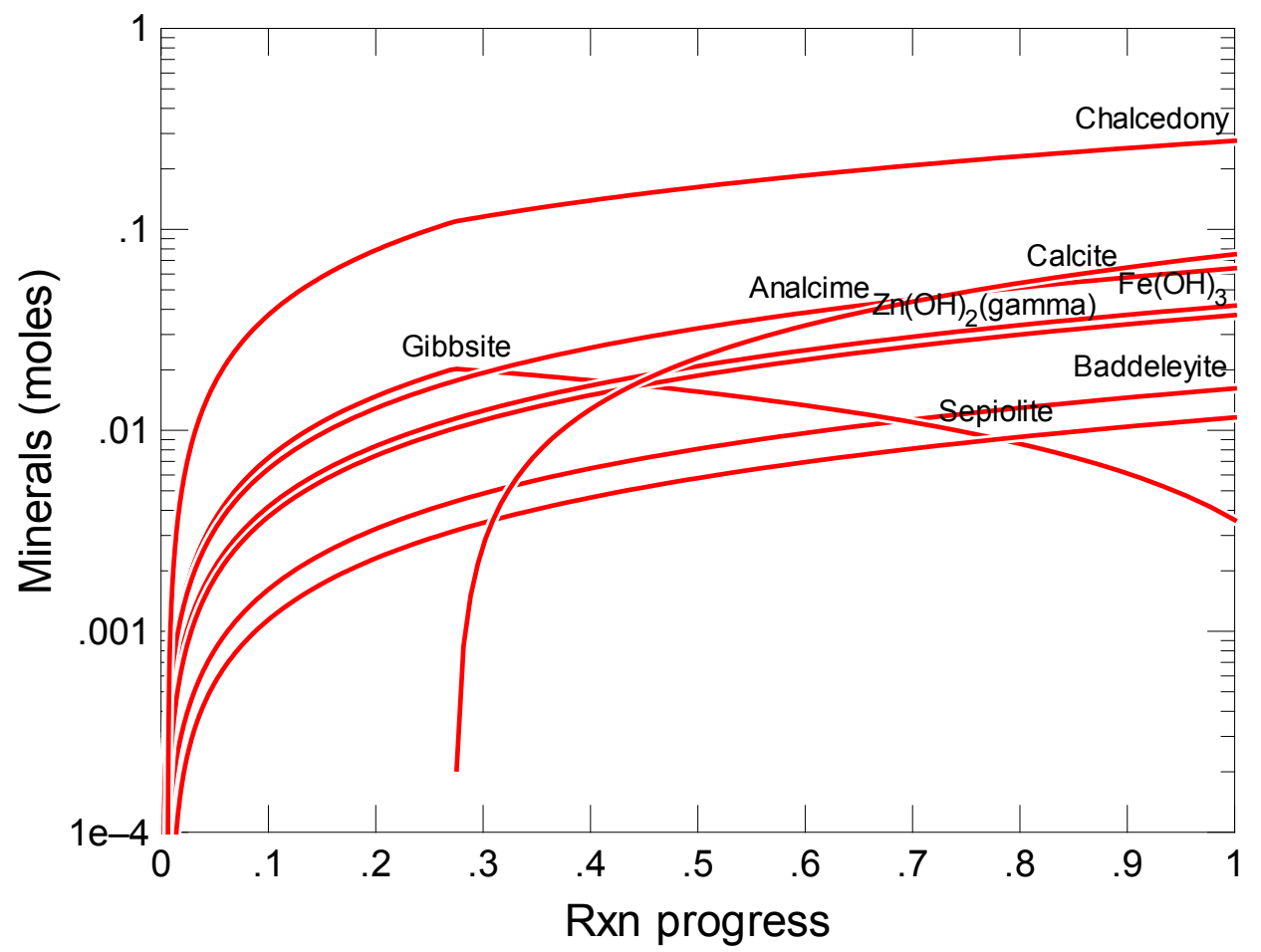

Figure C.295. Secondary Phases Calculated to Form as a Function of Reaction Progress (mol-glass $/ \mathrm{kg}$ ) Determined for Glass Sample LAWB86

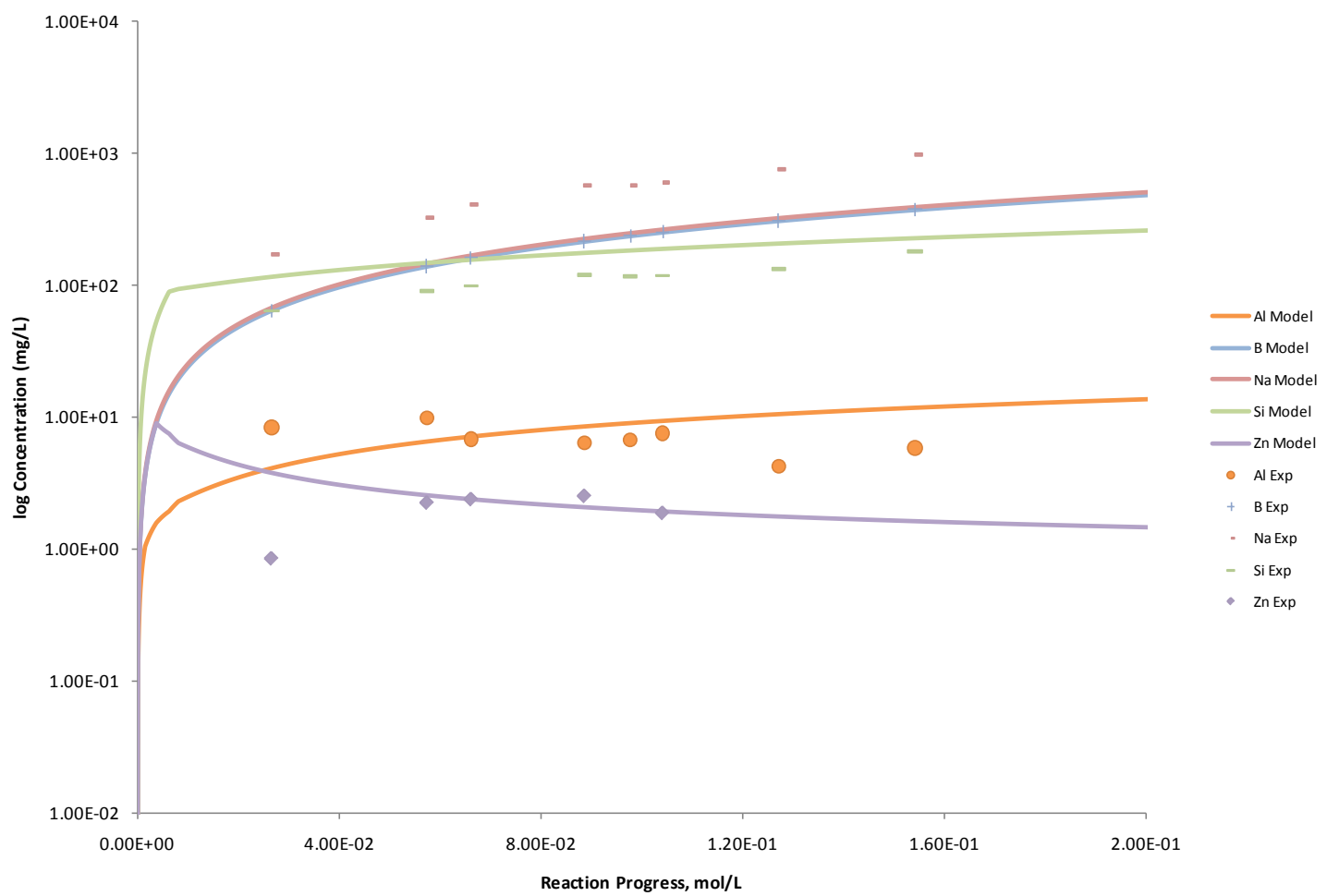

Figure C.296. Measured Solution Concentrations (mg/L) and Model Results for Al, B, Na, Si, and Zn, as a Function of Reaction Progress (mol-glass $/ \mathrm{kg}$ ) Determined for Glass Sample LAWB86 


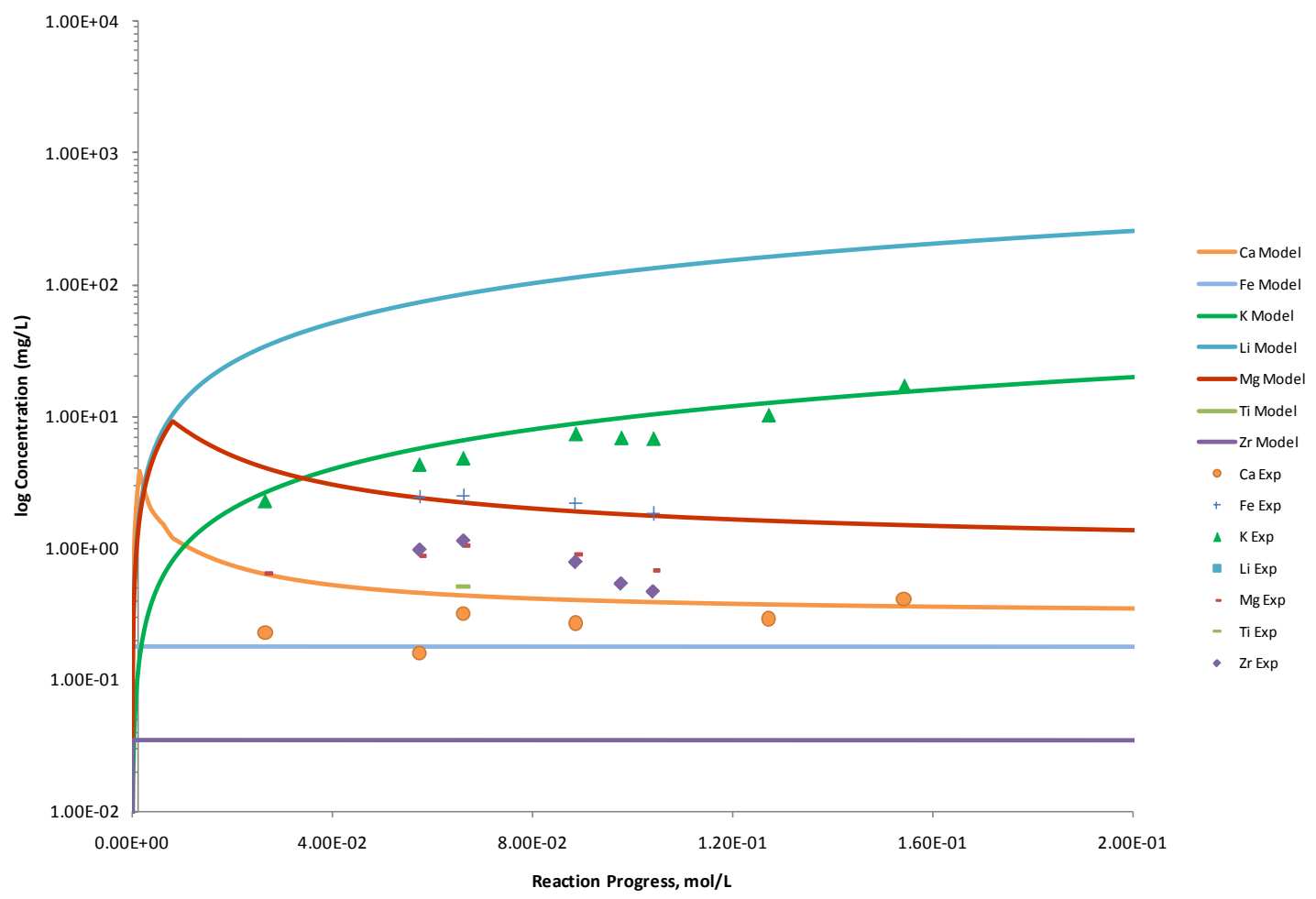

Figure C.297. Measured Solution Concentrations (mg/L) and Model Results for $\mathrm{Ca}, \mathrm{Fe}, \mathrm{K}, \mathrm{Li}, \mathrm{Mg}$, Ti, and $\mathrm{Zr}$, as a Function of Reaction Progress (mol-glass/kg) Determined for Glass Sample LAWB86

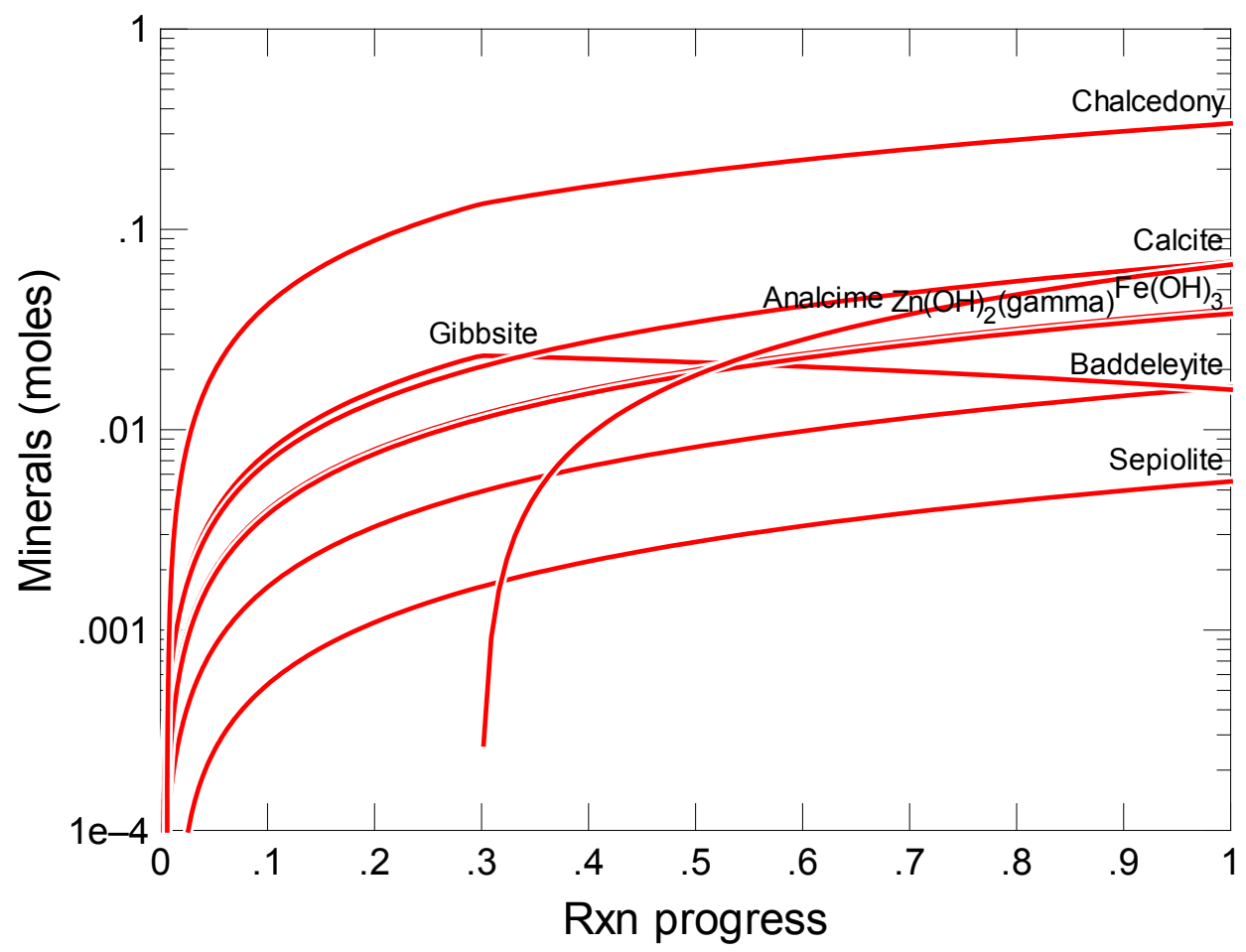

Figure C.298. Secondary Phases Calculated to Form as a Function of Reaction Progress (mol-glass/kg) Determined for Glass Sample LAWB87 


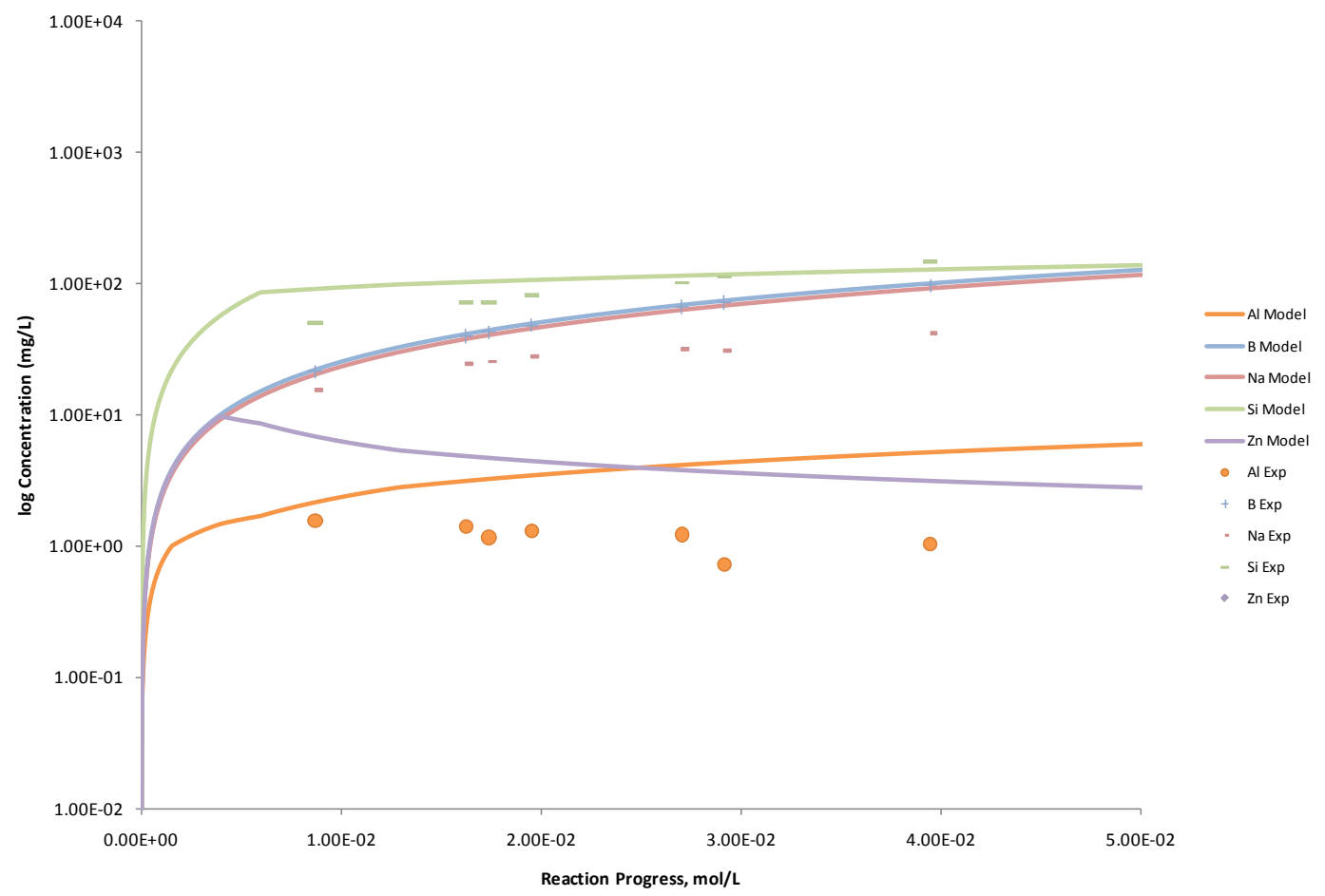

Figure C.299. Measured Solution Concentrations (mg/L) and Model Results for Al, B, Na, Si, and Zn, as a Function of Reaction Progress (mol-glass $/ \mathrm{kg}$ ) Determined for Glass Sample LAWB87

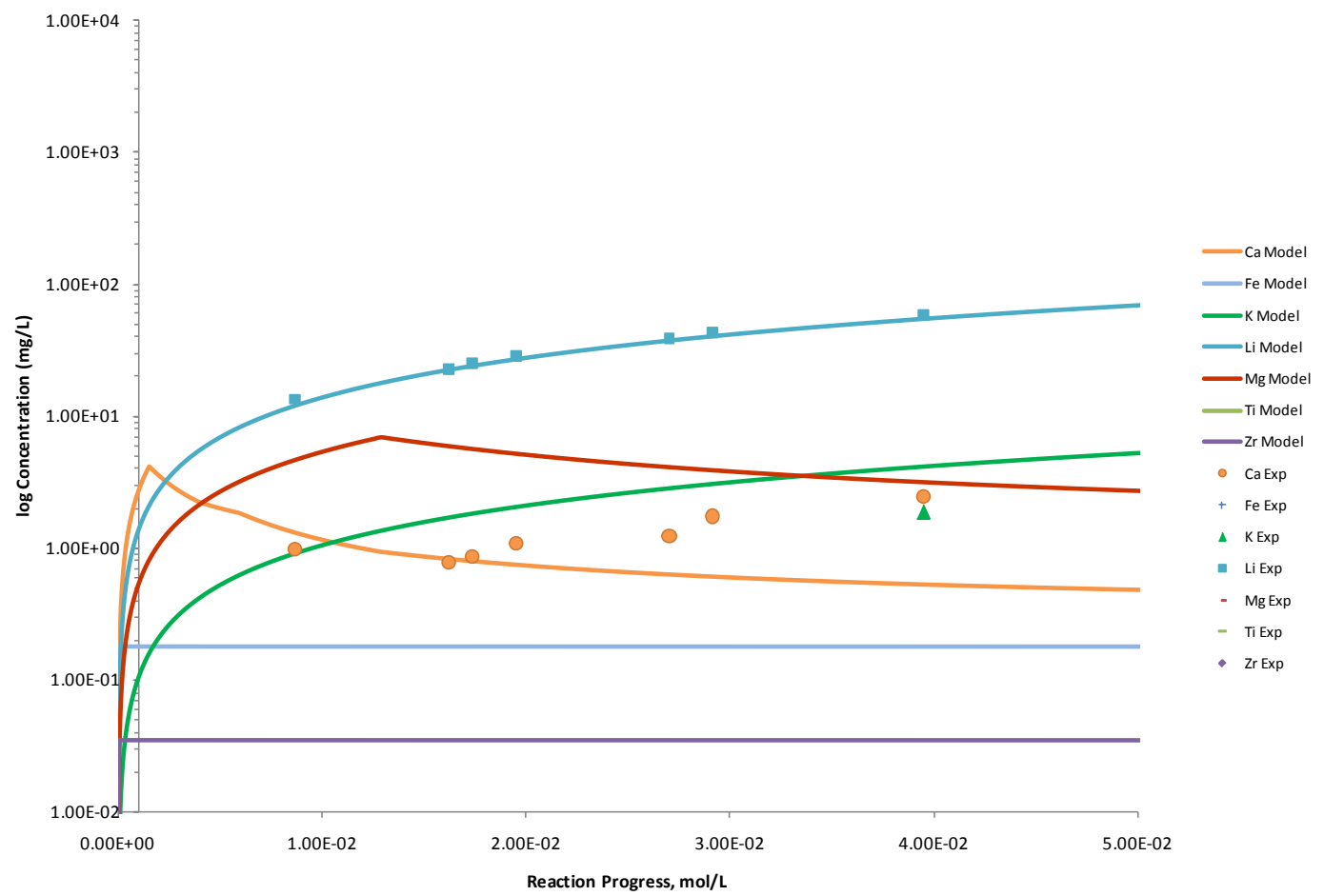

Figure C.300. Measured Solution Concentrations (mg/L) and Model Results for Ca, Fe, K, Li, Mg, Ti, and $\mathrm{Zr}$, as a Function of Reaction Progress (mol-glass/kg) Determined for Glass Sample LAWB87 


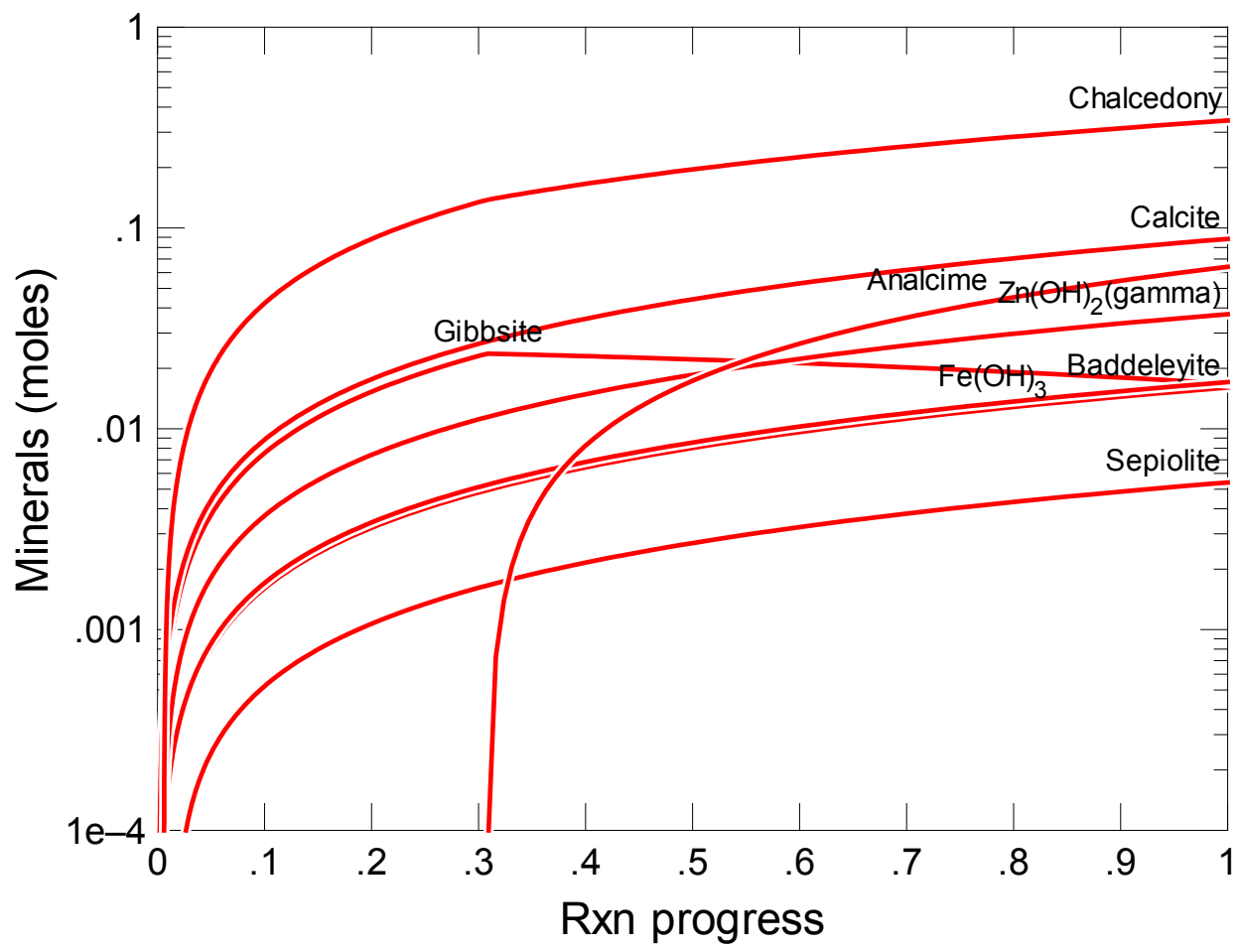

Figure C.301. Secondary Phases Calculated to Form as a Function of Reaction Progress (mol-glass $/ \mathrm{kg}$ ) Determined for Glass Sample LAWB88

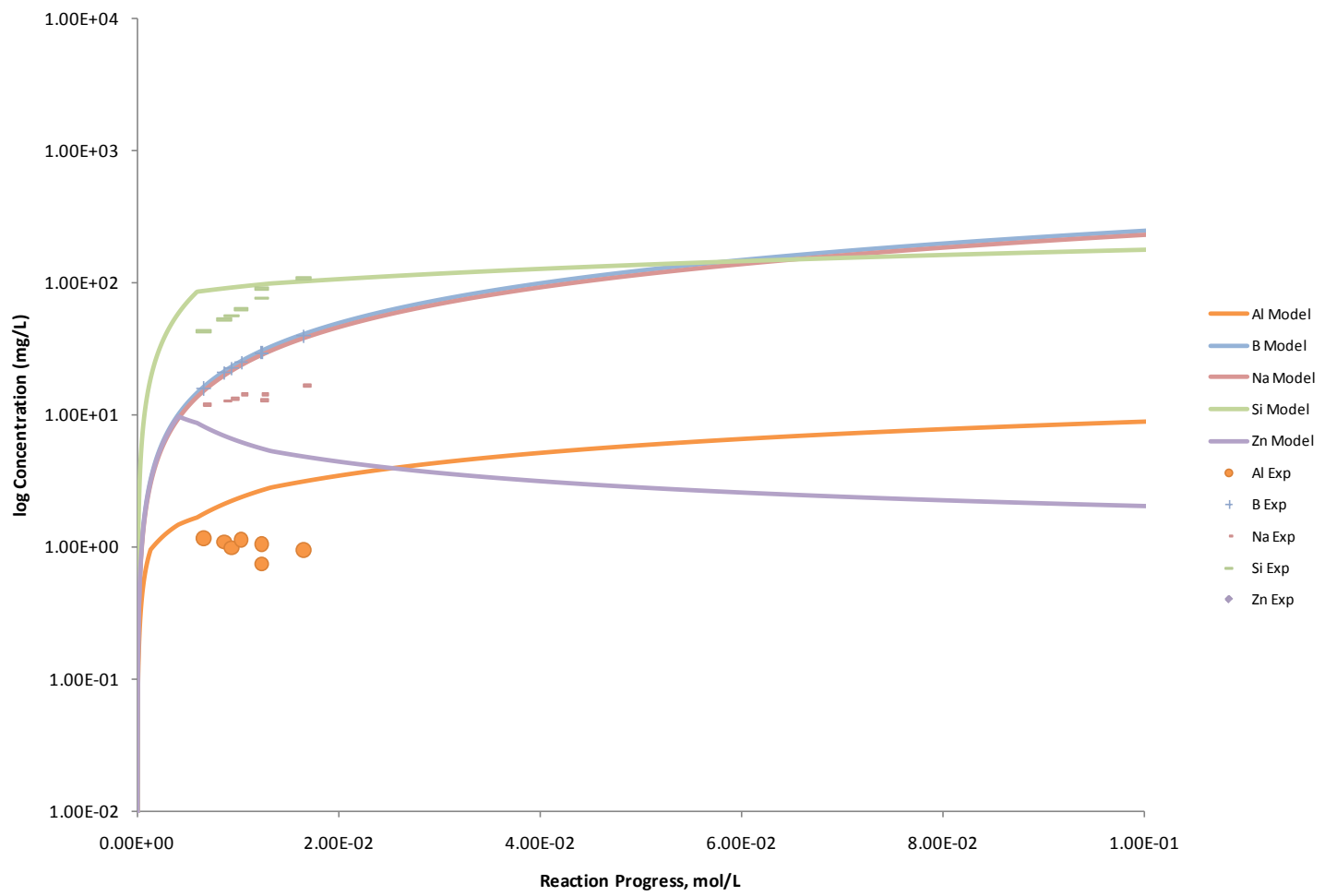

Figure C.302. Measured Solution Concentrations (mg/L) and Model Results for Al, B, Na, Si, and Zn, as a Function of Reaction Progress (mol-glass $/ \mathrm{kg}$ ) Determined for Glass Sample LAWB88 


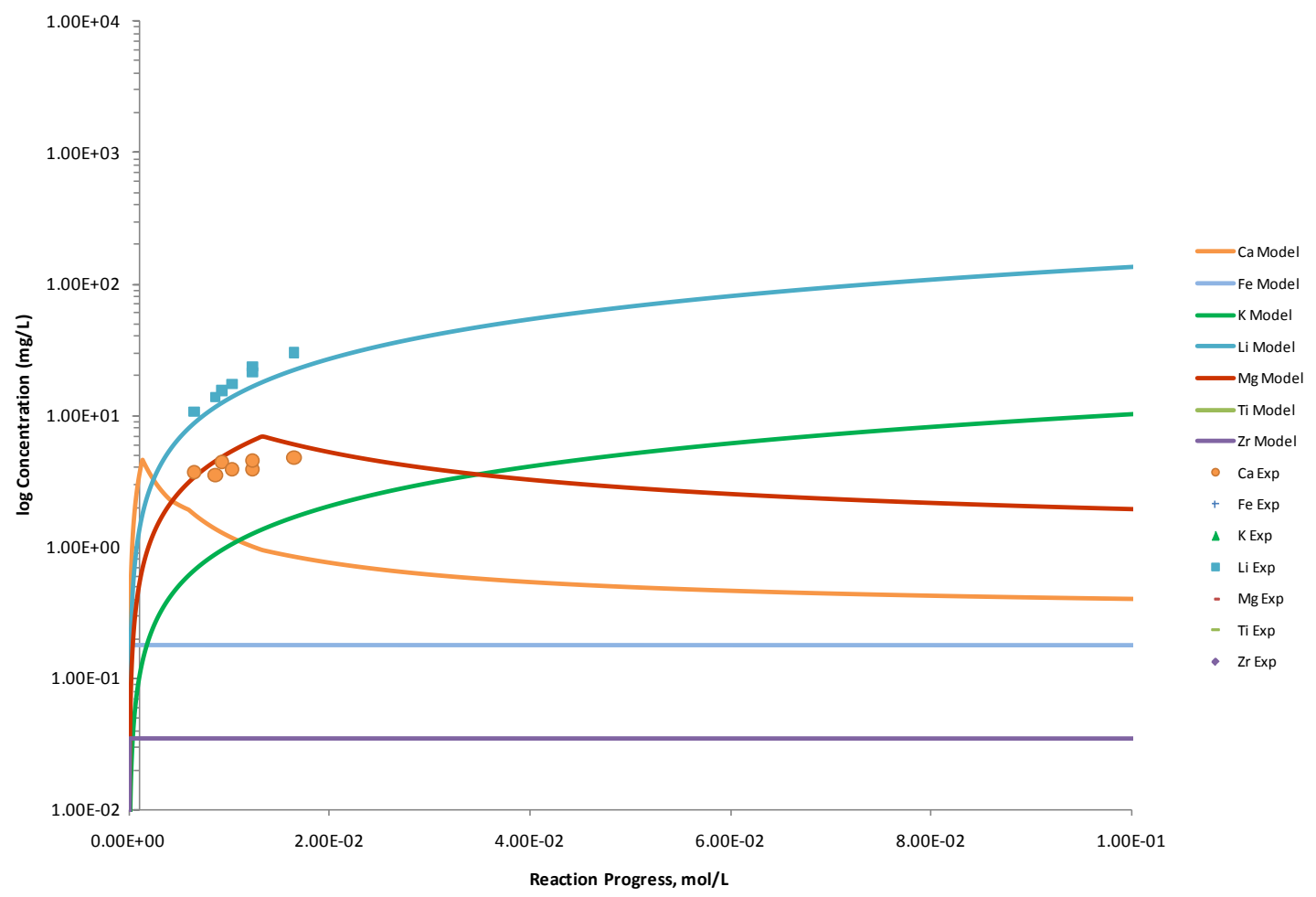

Figure C.303. Measured Solution Concentrations (mg/L) and Model Results for $\mathrm{Ca}, \mathrm{Fe}, \mathrm{K}, \mathrm{Li}, \mathrm{Mg}$, Ti, and $\mathrm{Zr}$, as a Function of Reaction Progress (mol-glass/kg) Determined for Glass Sample LAWB88

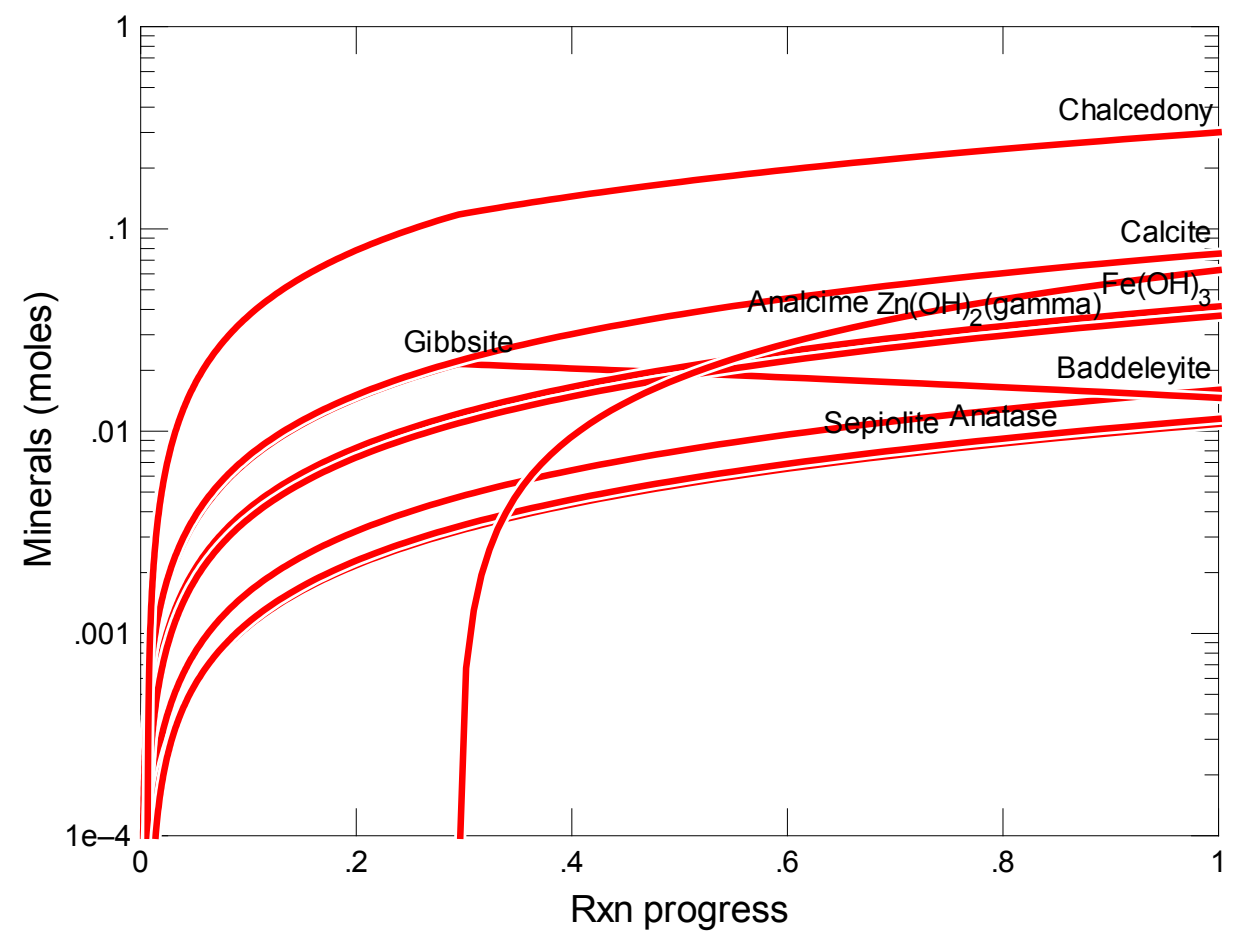

Figure C.304. Secondary Phases Calculated to Form as a Function of Reaction Progress (mol-glass $/ \mathrm{kg}$ ) Determined for Glass Sample LAWB89 


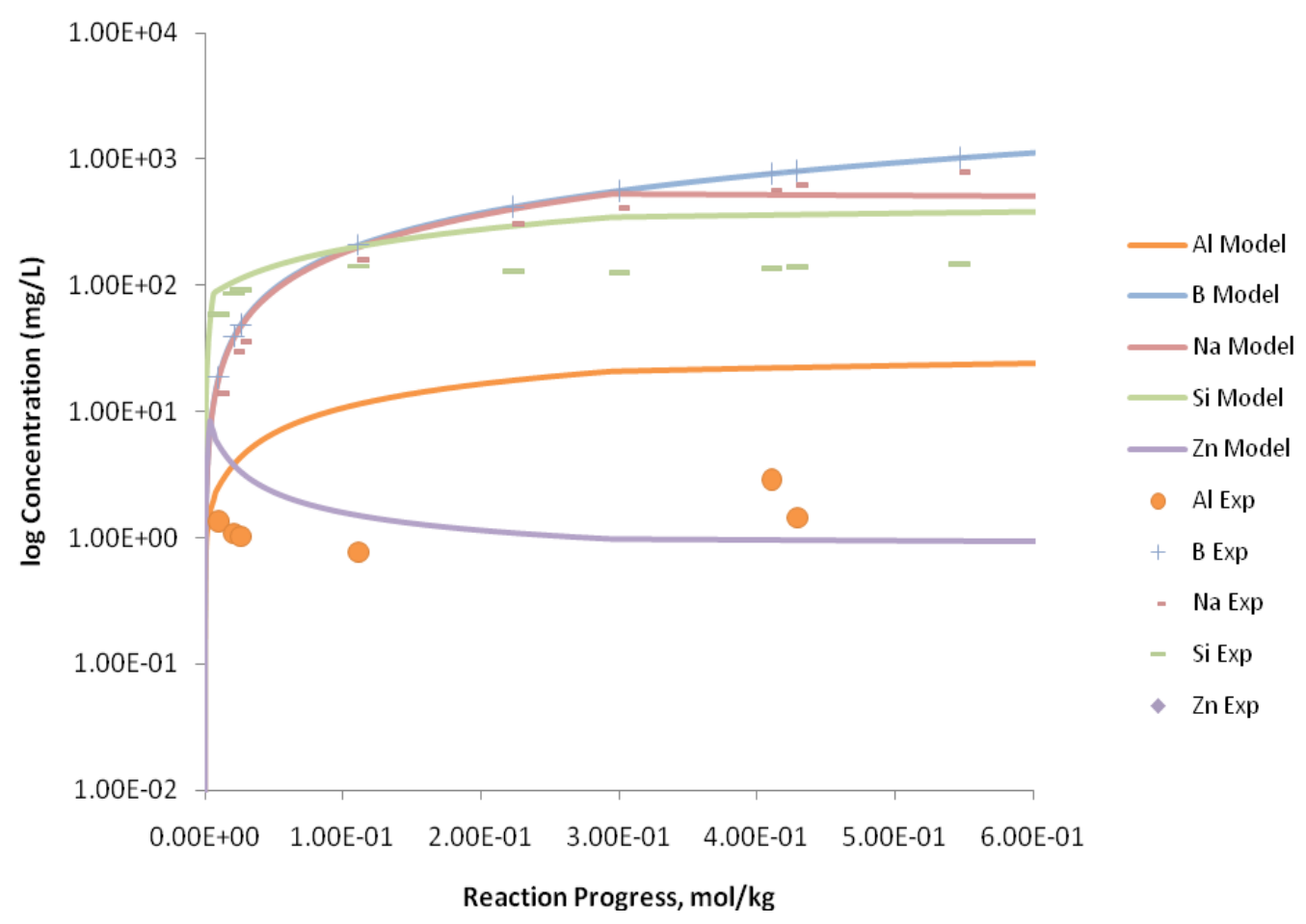

Figure C.305. Measured Solution Concentrations (mg/L) and Model Results for Al, B, Na, Si, and Zn, as a Function of Reaction Progress (mol-glass $/ \mathrm{kg}$ ) Determined for Glass Sample LAWB89

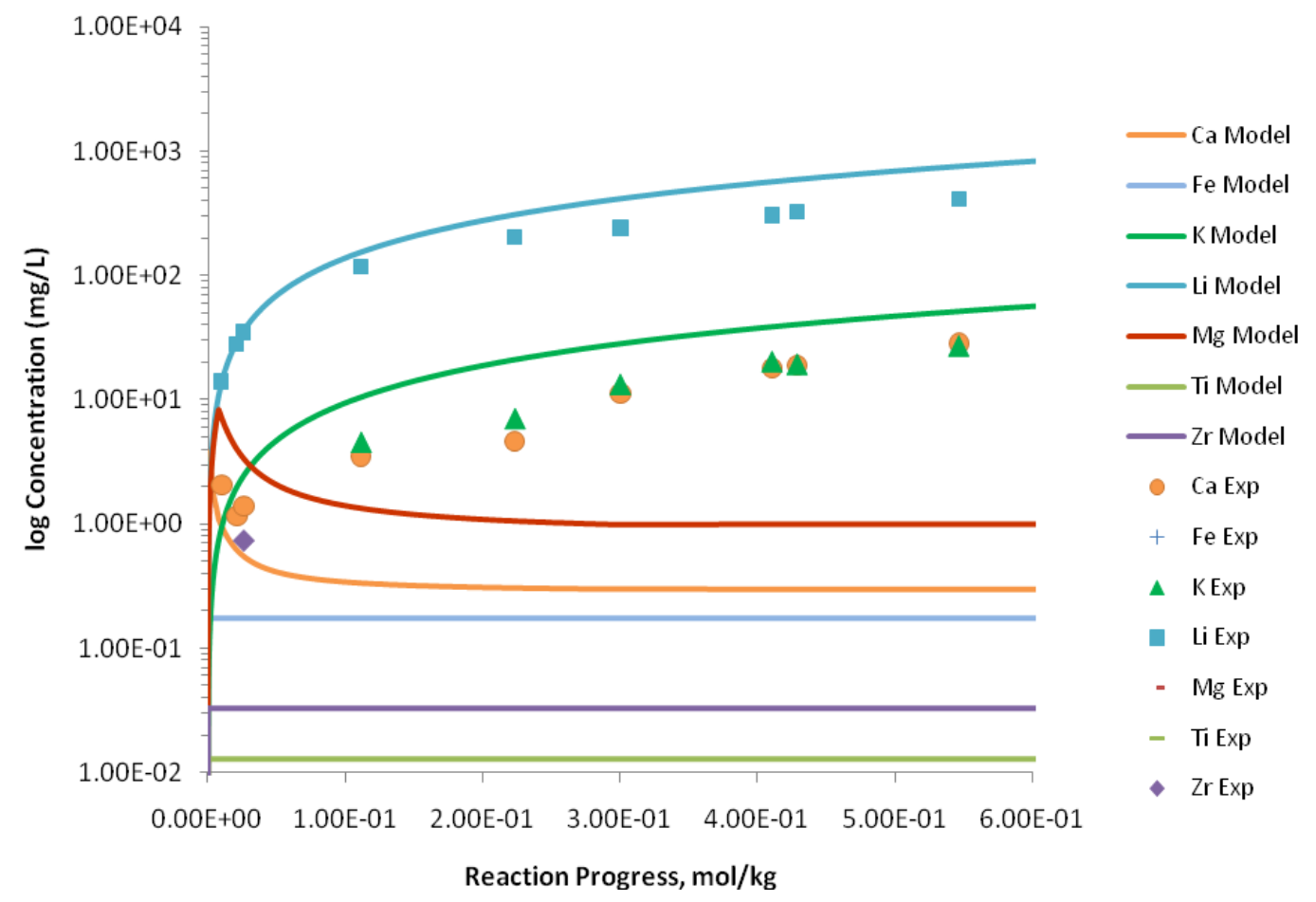

Figure C.306. Measured Solution Concentrations (mg/L) and Model Results for $\mathrm{Ca}, \mathrm{Fe}, \mathrm{K}, \mathrm{Li}, \mathrm{Mg}, \mathrm{Ti}$, and $\mathrm{Zr}$, as a Function of Reaction Progress (mol-glass $/ \mathrm{kg}$ ) Determined for Glass Sample LAWB89 


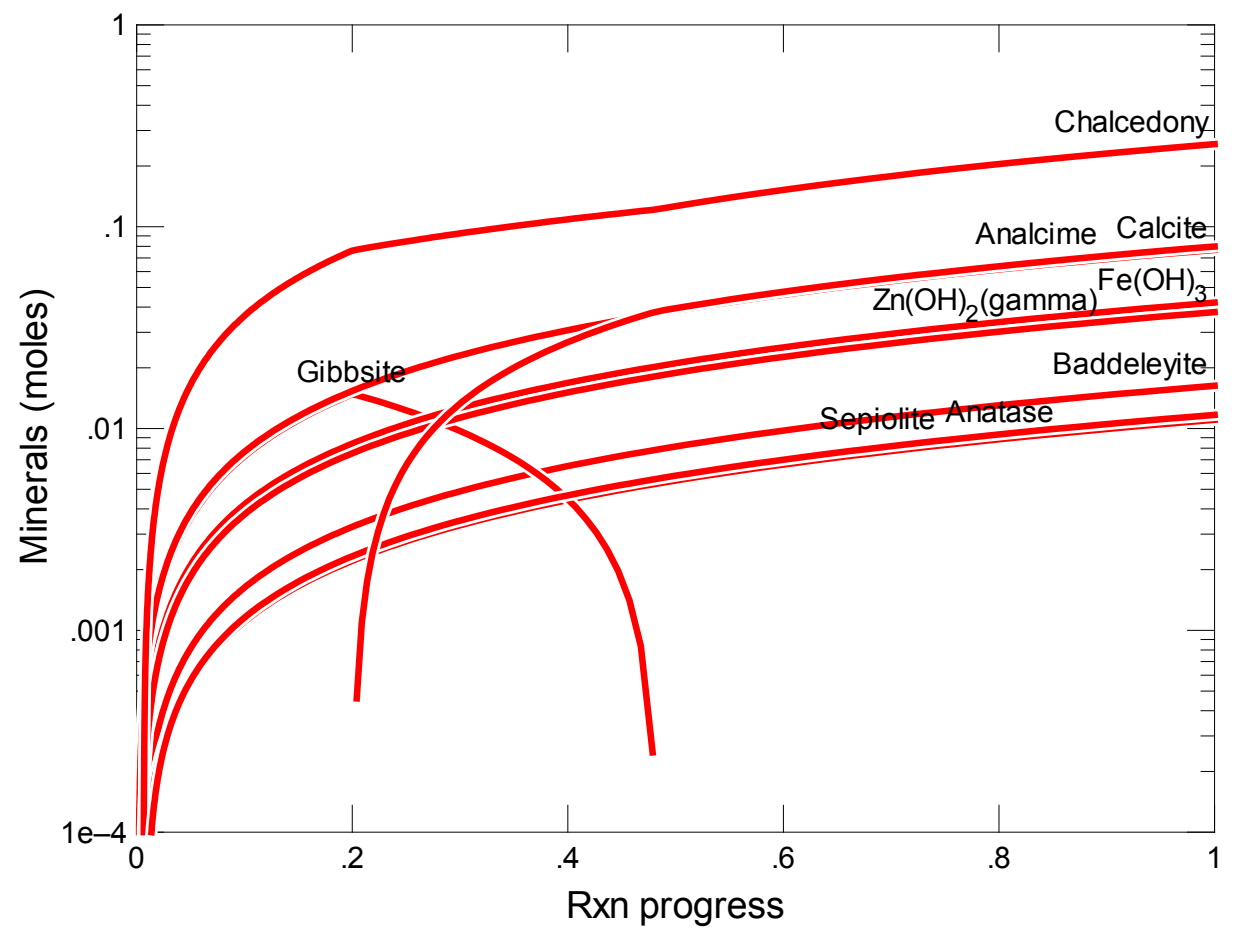

Figure C.307. Secondary Phases Calculated to Form as a Function of Reaction Progress (mol-glass $/ \mathrm{kg}$ ) Determined for Glass Sample LAWB90

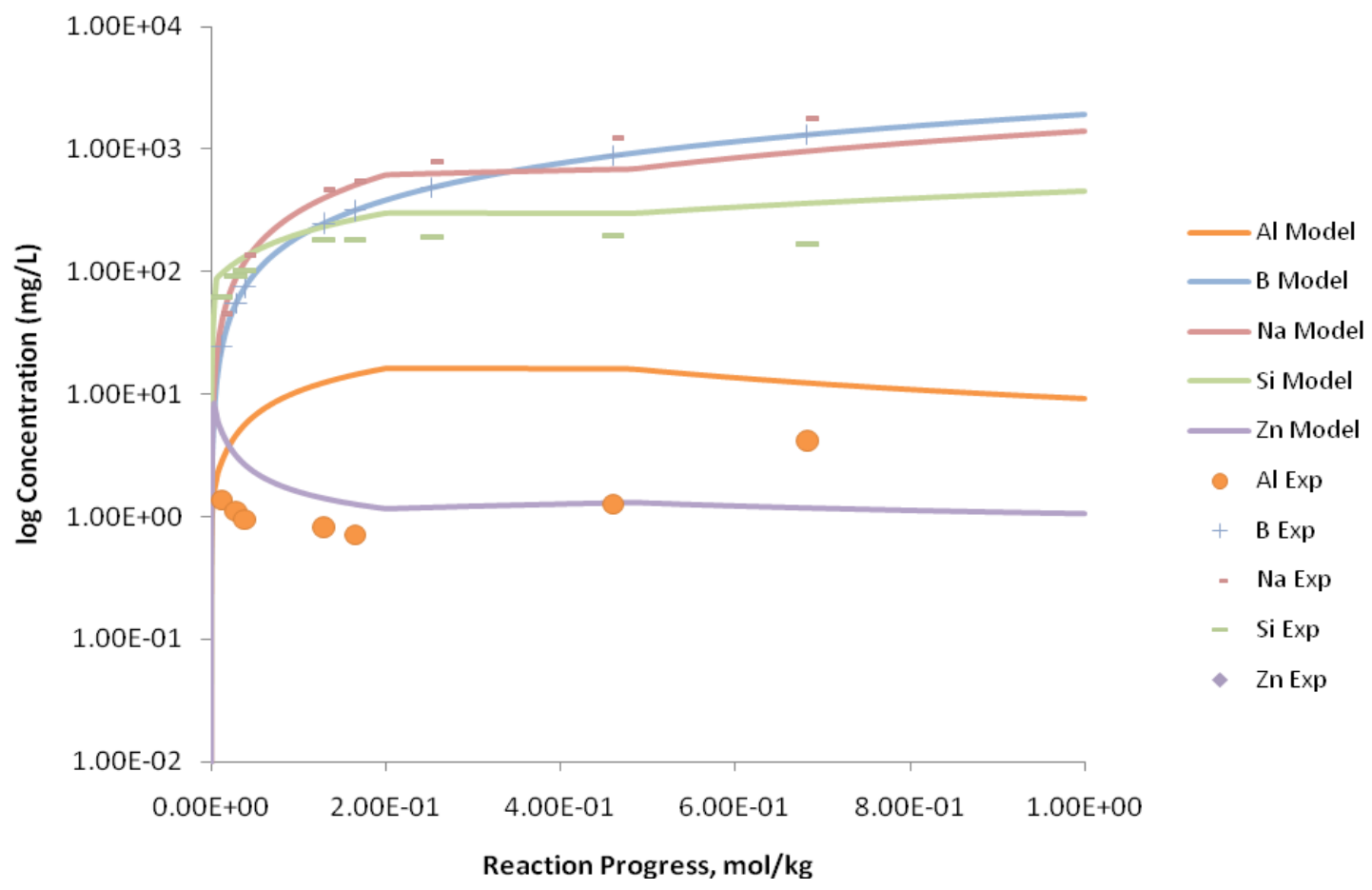

Figure C.308. Measured Solution Concentrations (mg/L) and Model Results for Al, B, Na, Si, and Zn, as a Function of Reaction Progress (mol-glass $/ \mathrm{kg}$ ) Determined for Glass Sample LAWB90 


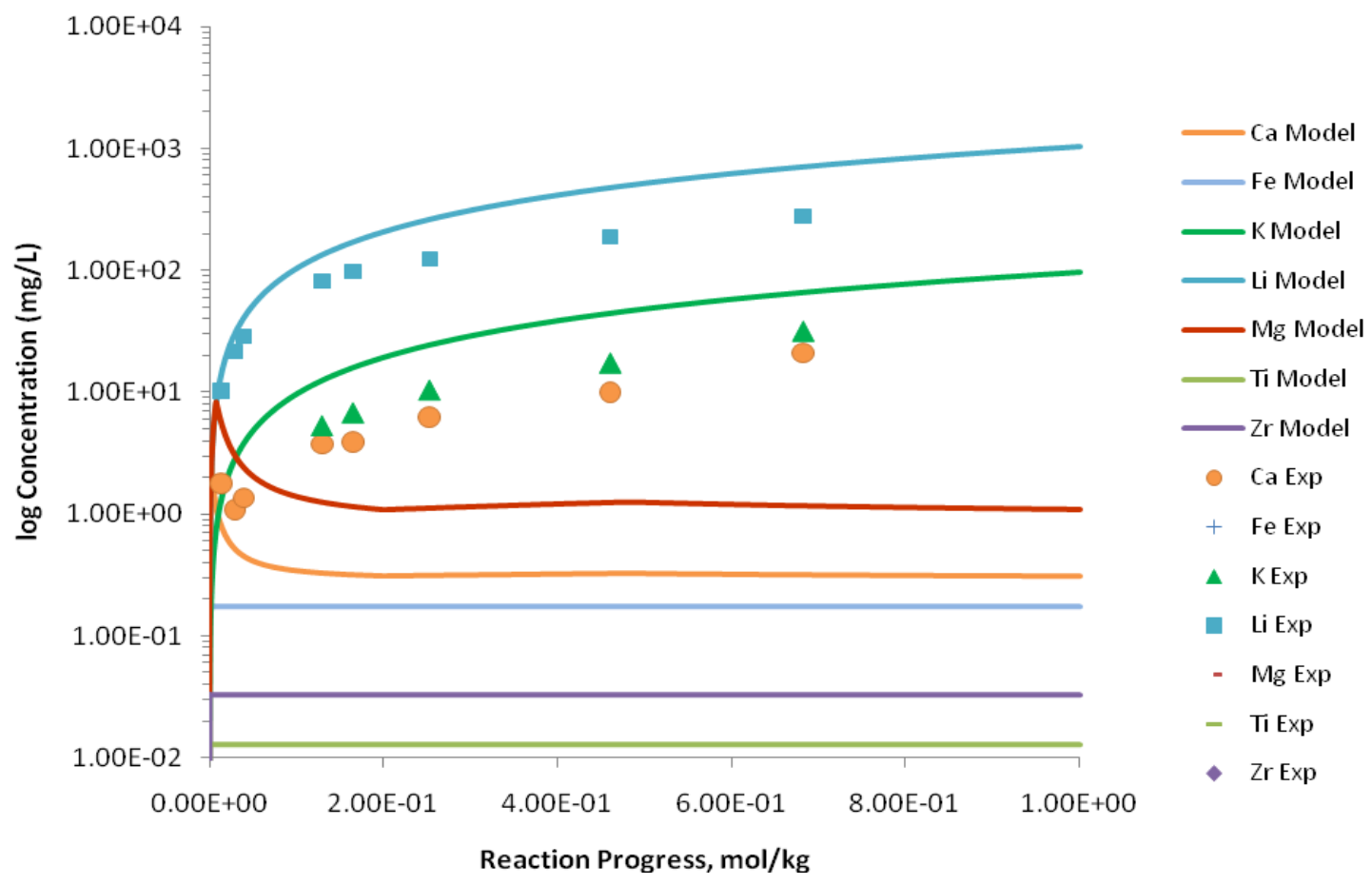

Figure C.309. Measured Solution Concentrations (mg/L) and Model Results for $\mathrm{Ca}, \mathrm{Fe}, \mathrm{K}, \mathrm{Li}, \mathrm{Mg}, \mathrm{Ti}$, and $\mathrm{Zr}$, as a Function of Reaction Progress (mol-glass/kg) Determined for Glass Sample LAWB90

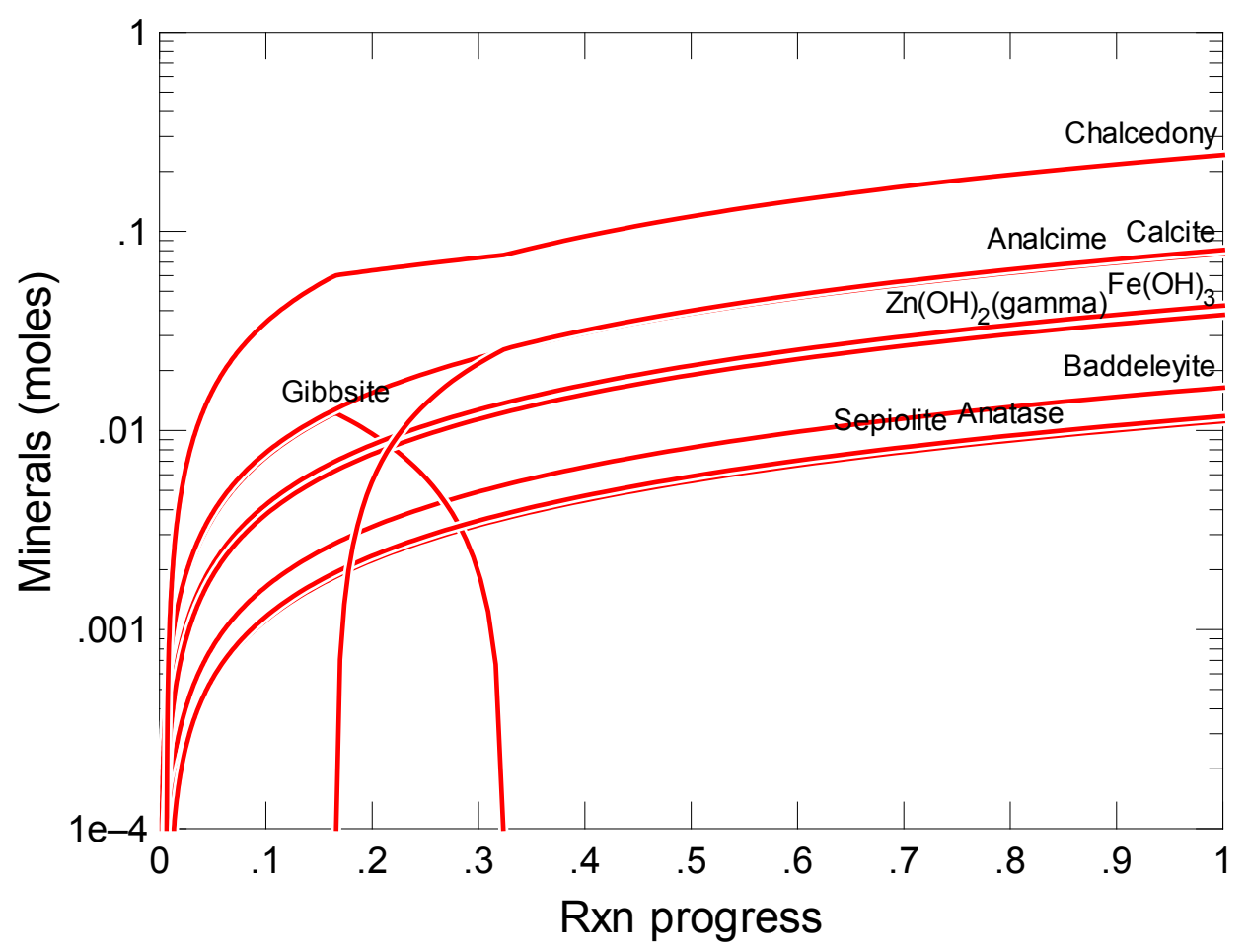

Figure C.310. Secondary Phases Calculated to Form as a Function of Reaction Progress (mol-glass $/ \mathrm{kg}$ ) Determined for Glass Sample LAWB91 


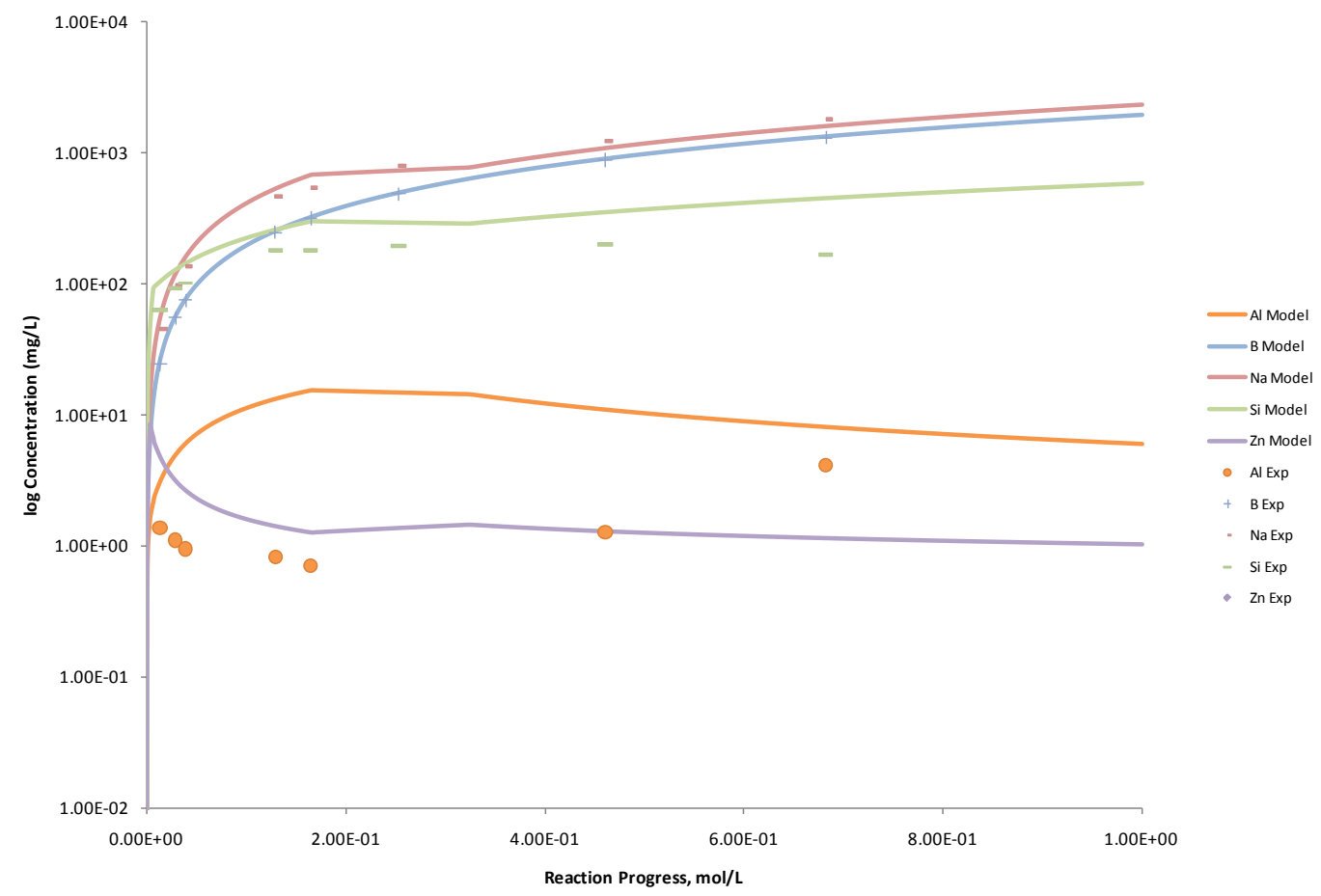

Figure C.311. Measured Solution Concentrations (mg/L) and Model Results for Al, B, Na, Si, and Zn, as a Function of Reaction Progress (mol-glass $/ \mathrm{kg}$ ) Determined for Glass Sample LAWB91

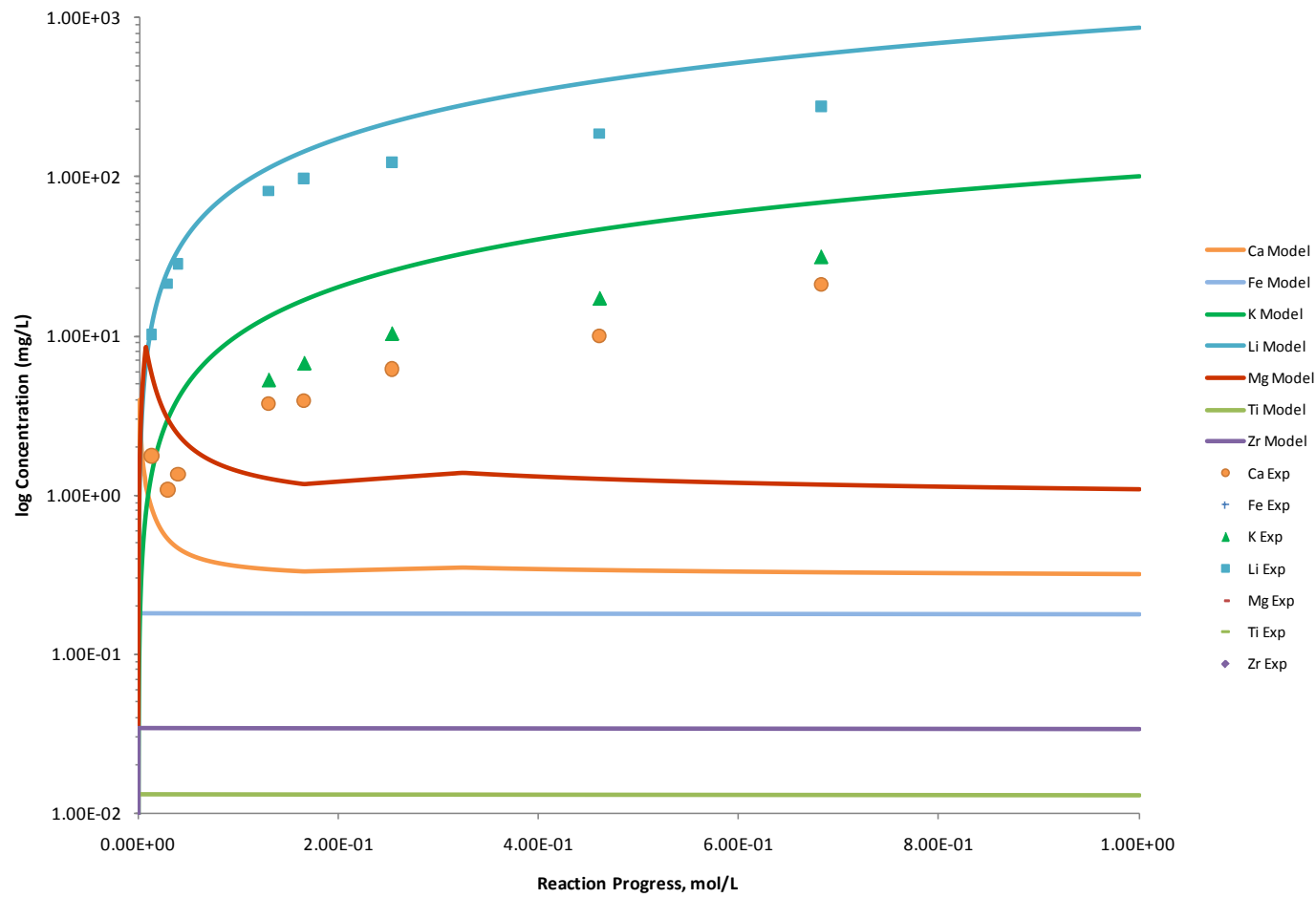

Figure C.312. Measured Solution Concentrations (mg/L) and Model Results for $\mathrm{Ca}, \mathrm{Fe}, \mathrm{K}, \mathrm{Li}, \mathrm{Mg}, \mathrm{Ti}$, and Zr, as a Function of Reaction Progress (mol-glass/kg) Determined for Glass Sample LAWB91 


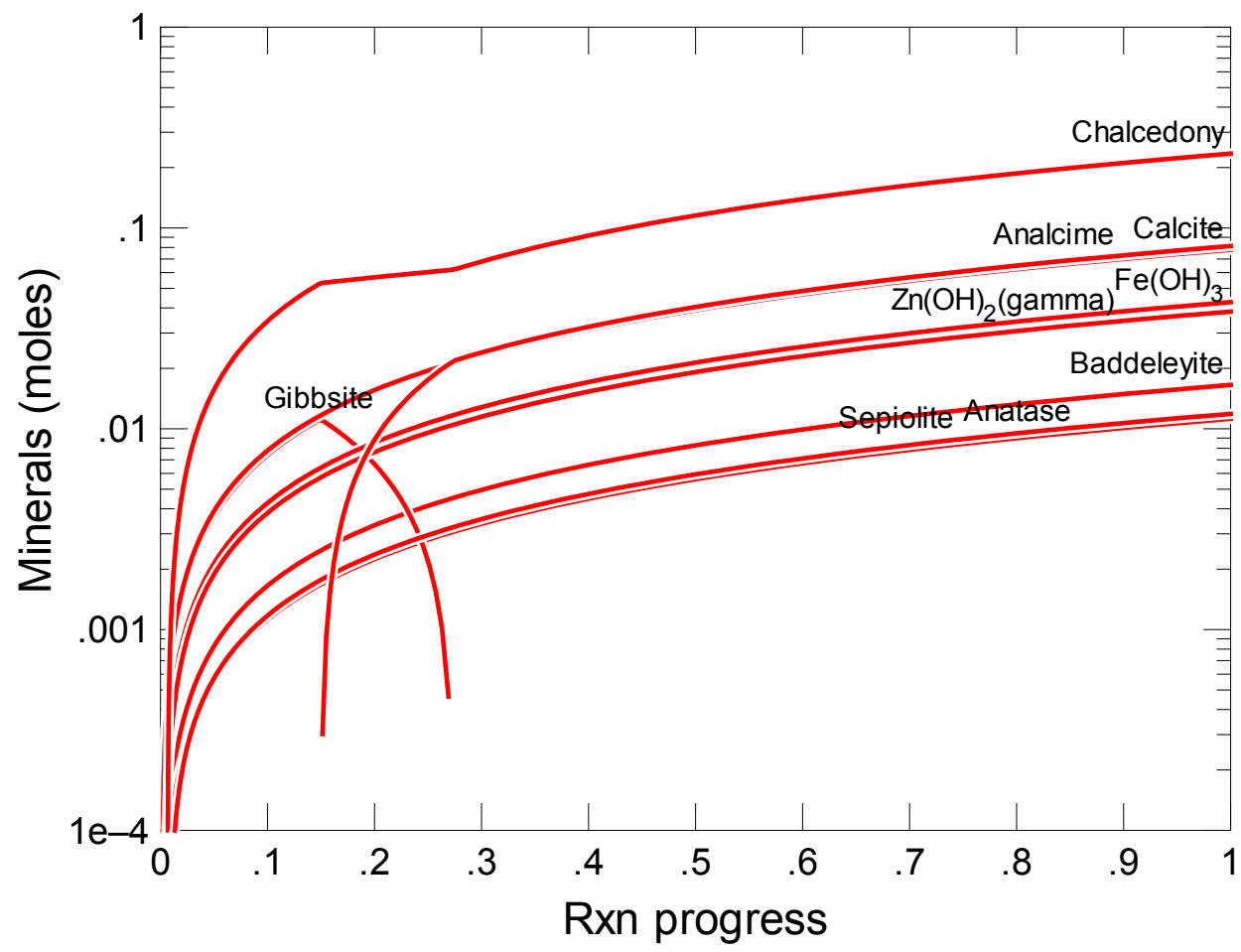

Figure C.313. Secondary Phases Calculated to Form as a Function of Reaction Progress (mol-glass $/ \mathrm{kg}$ ) Determined for Glass Sample LAWB92

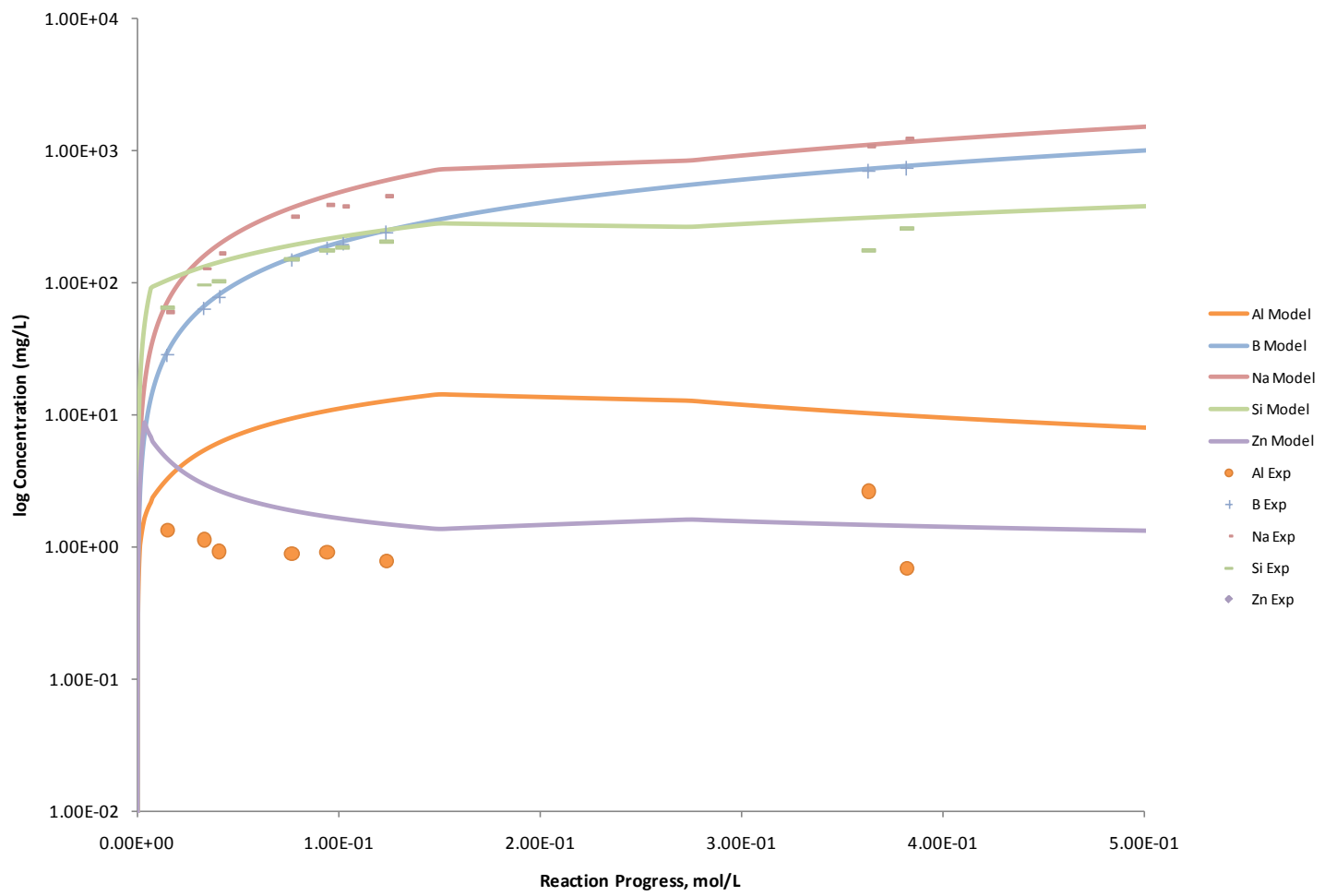

Figure C.314. Measured Solution Concentrations (mg/L) and Model Results for Al, B, Na, Si, and Zn, as a Function of Reaction Progress (mol-glass $/ \mathrm{kg}$ ) Determined for Glass Sample LAWB92 


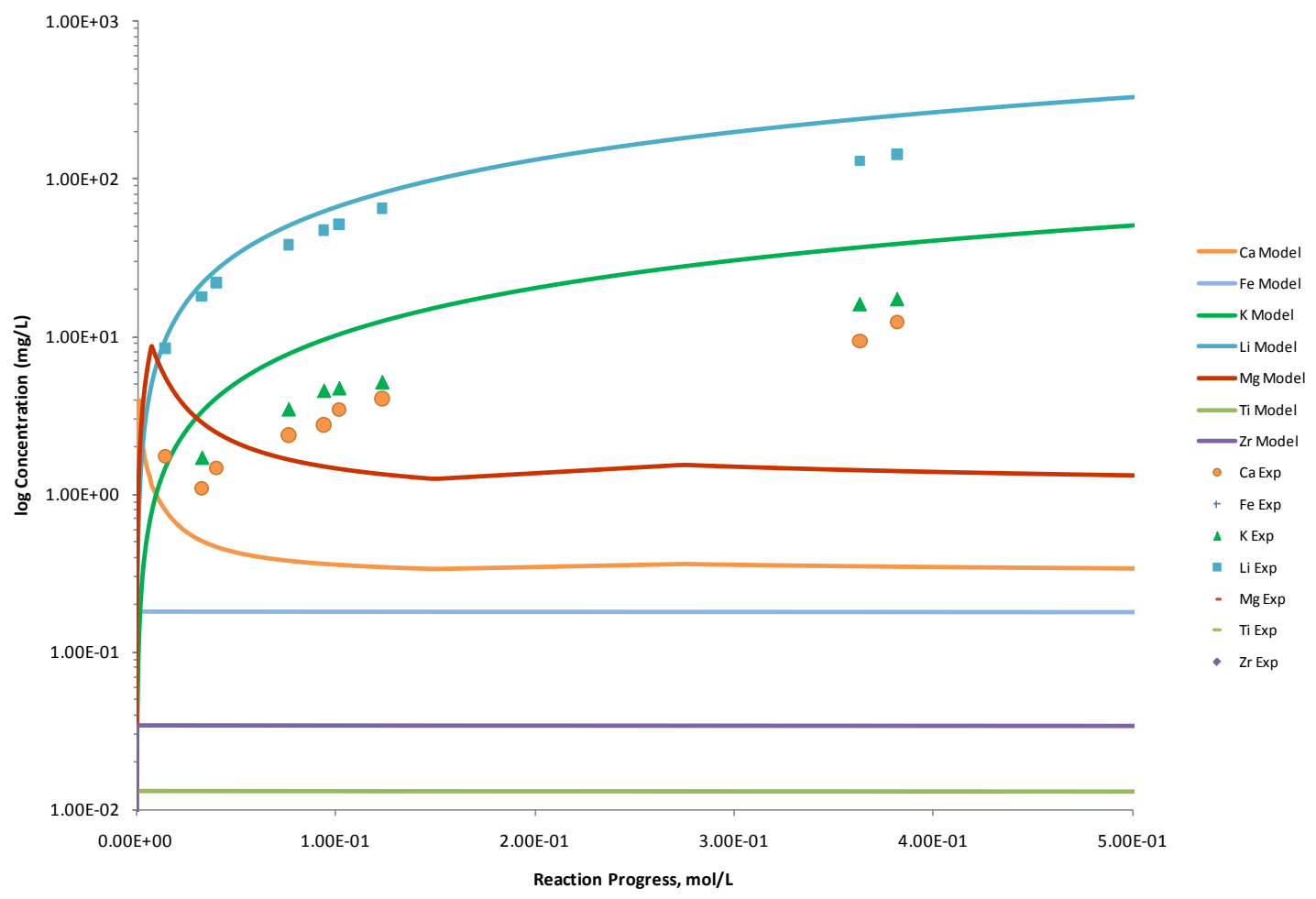

Figure C.315. Measured Solution Concentrations (mg/L) and Model Results for $\mathrm{Ca}, \mathrm{Fe}, \mathrm{K}, \mathrm{Li}, \mathrm{Mg}$, Ti, and $\mathrm{Zr}$, as a Function of Reaction Progress (mol-glass/kg) Determined for Glass Sample LAWB92

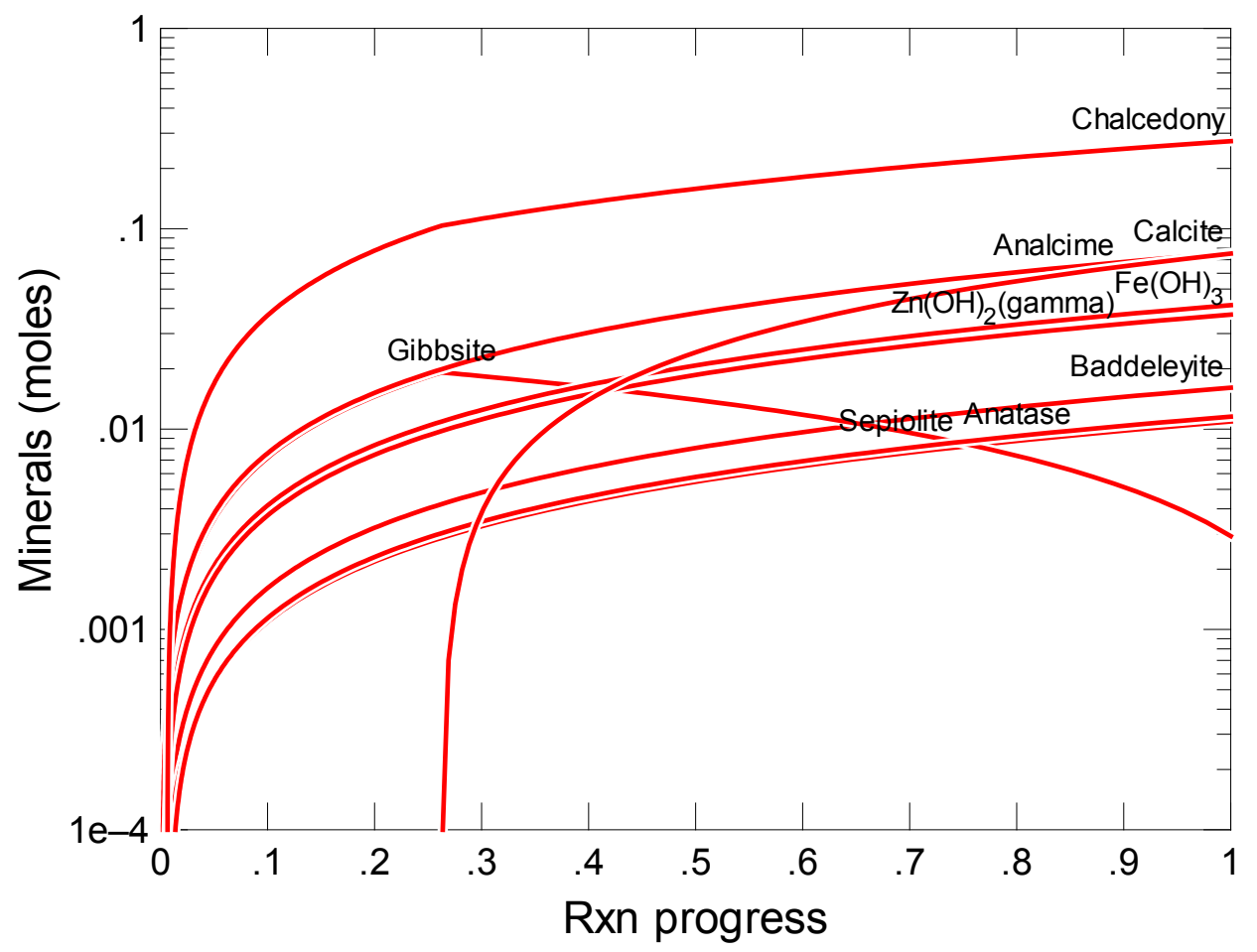

Figure C.316. Secondary Phases Calculated to Form as a Function of Reaction Progress (mol-glass $/ \mathrm{kg}$ ) Determined for Glass Sample LAWB93 


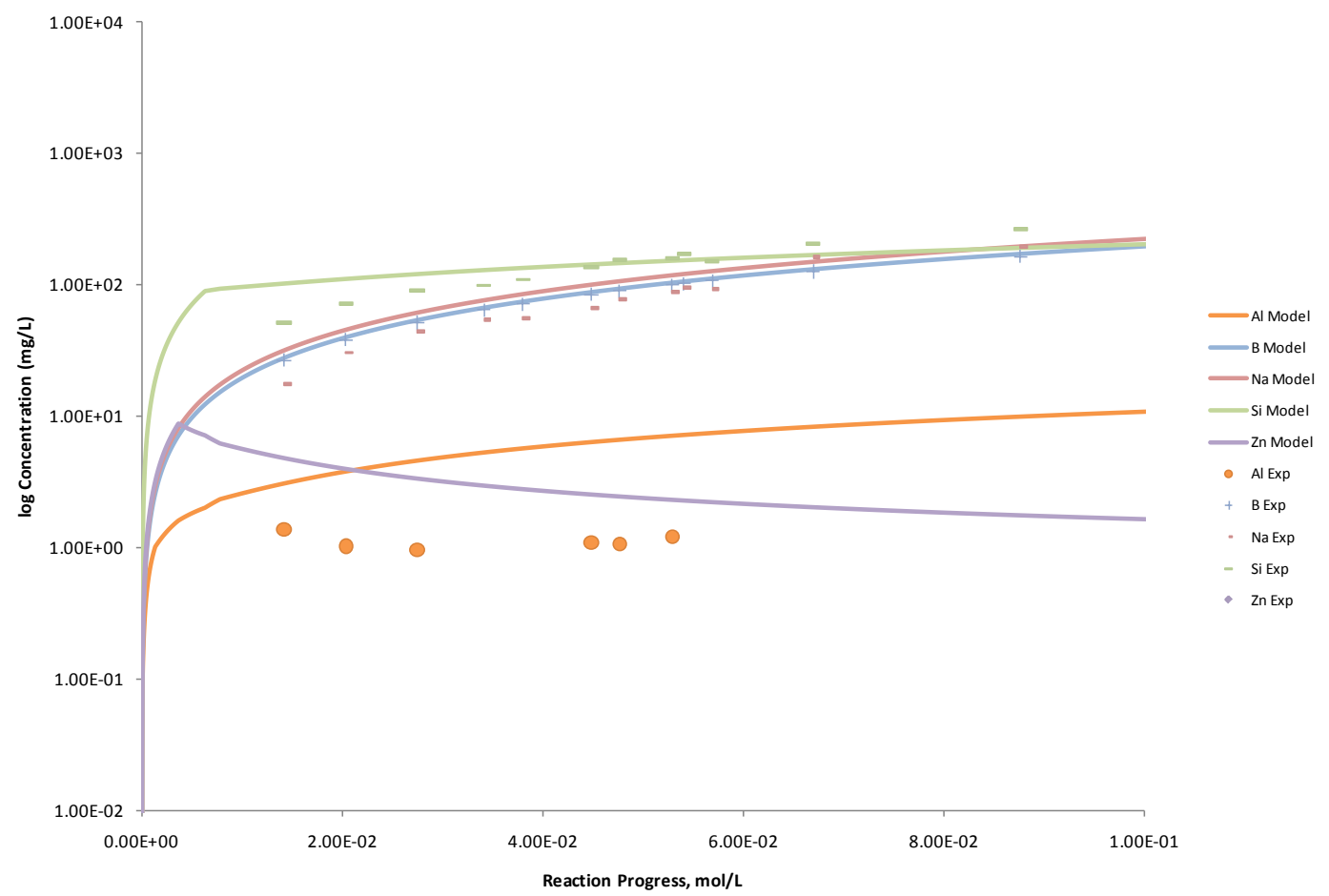

Figure C.317. Measured Solution Concentrations (mg/L) and Model Results for Al, B, Na, Si, and Zn, as a Function of Reaction Progress (mol-glass $/ \mathrm{kg}$ ) Determined for Glass Sample LAWB93

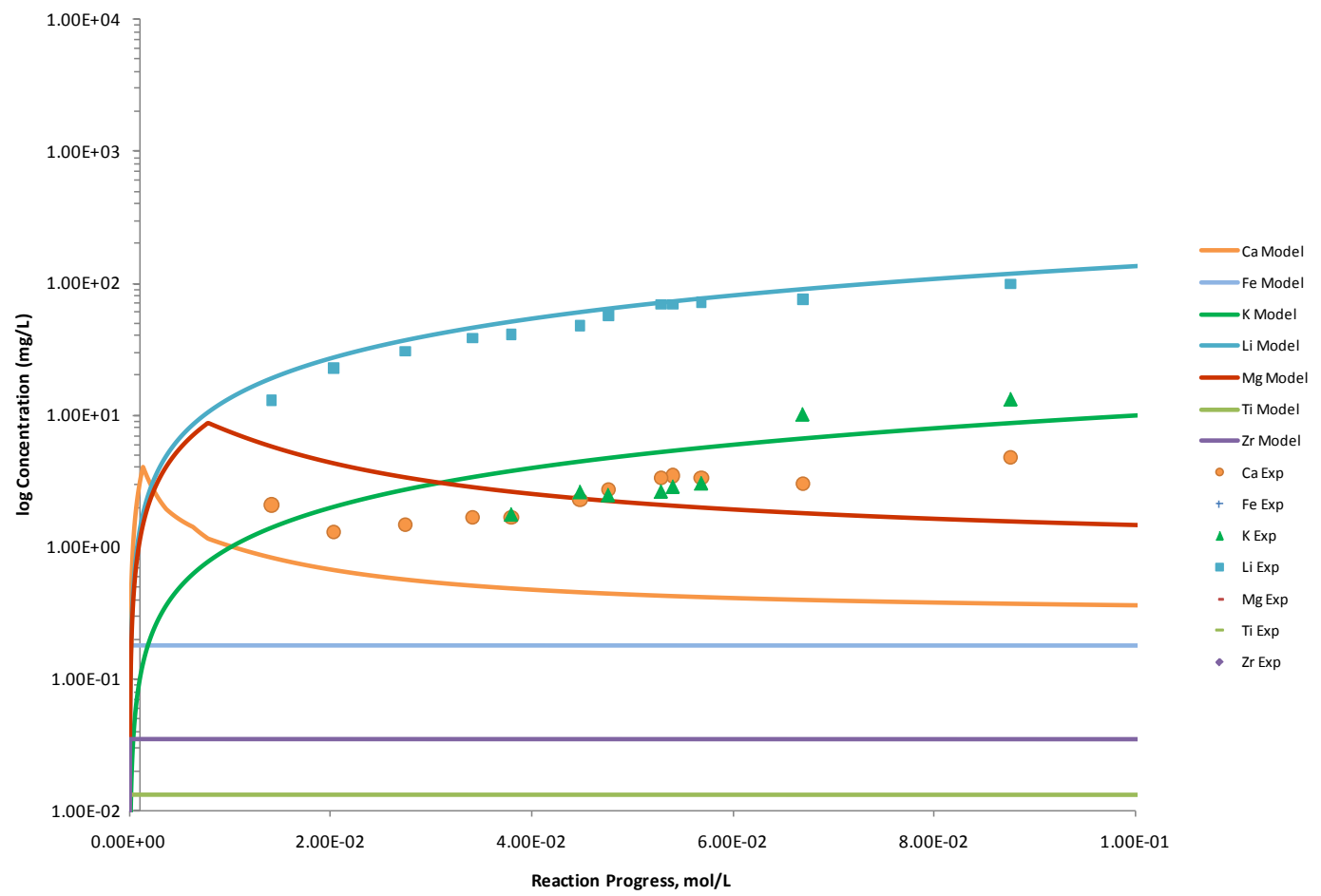

Figure C.318. Measured Solution Concentrations (mg/L) and Model Results for $\mathrm{Ca}, \mathrm{Fe}, \mathrm{K}, \mathrm{Li}, \mathrm{Mg}, \mathrm{Ti}$, and $\mathrm{Zr}$, as a Function of Reaction Progress (mol-glass/kg) Determined for Glass Sample LAWB93 


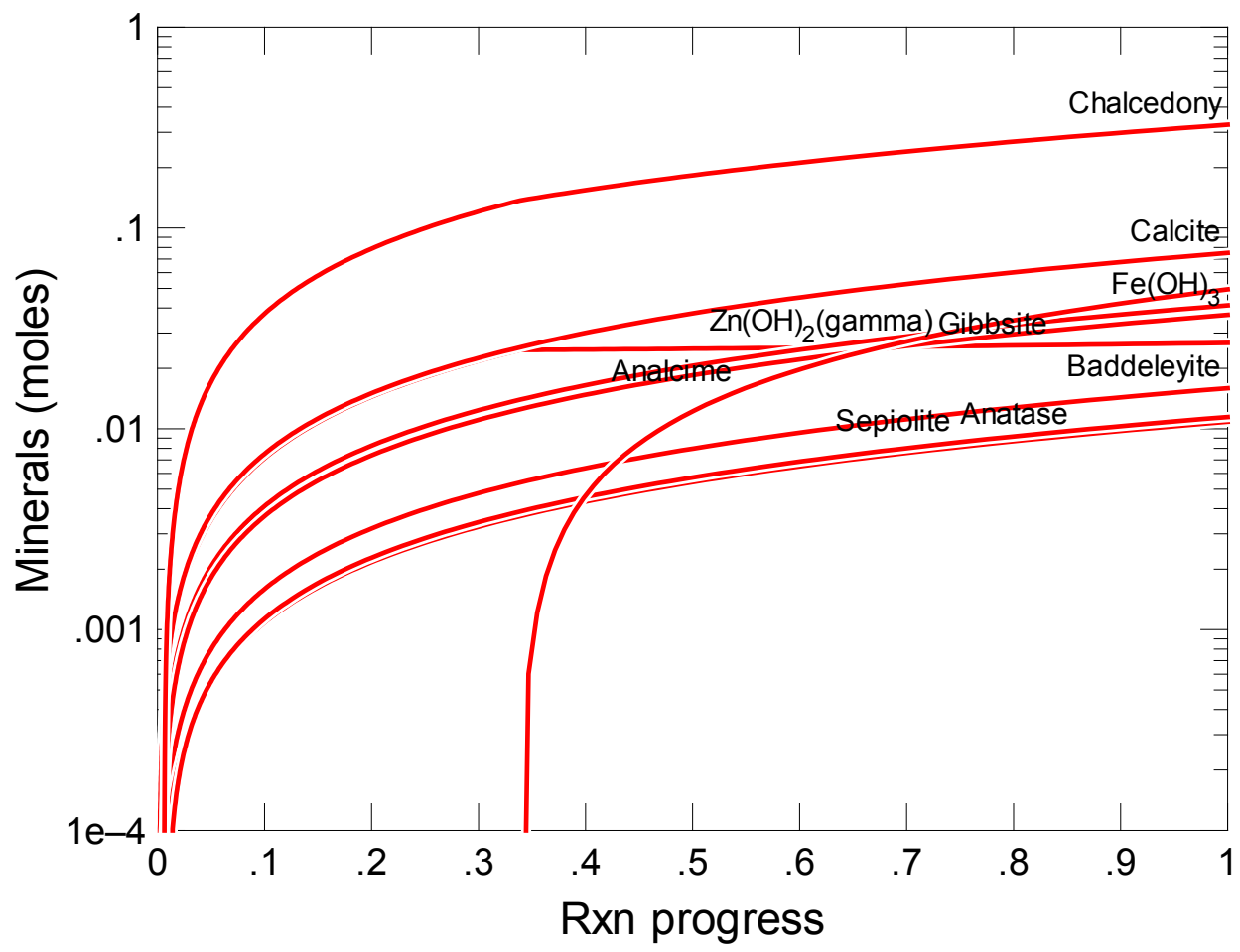

Figure C.319. Secondary Phases Calculated to Form as a Function of Reaction Progress (mol-glass $/ \mathrm{kg}$ ) Determined for Glass Sample LAWB94

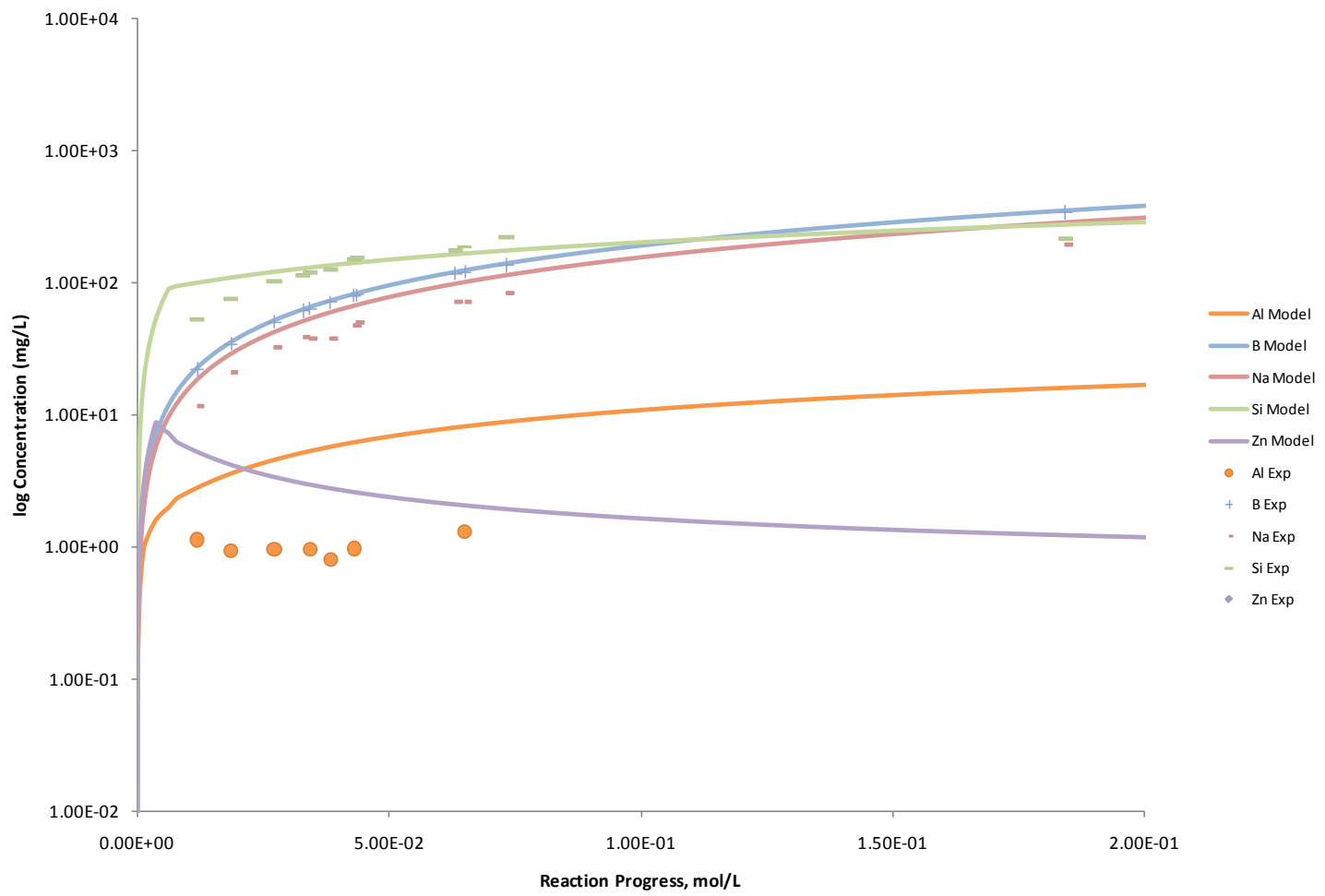

Figure C.320. Measured Solution Concentrations (mg/L) and Model Results for Al, B, Na, Si, and Zn, as a Function of Reaction Progress (mol-glass $/ \mathrm{kg}$ ) Determined for Glass Sample LAWB94 


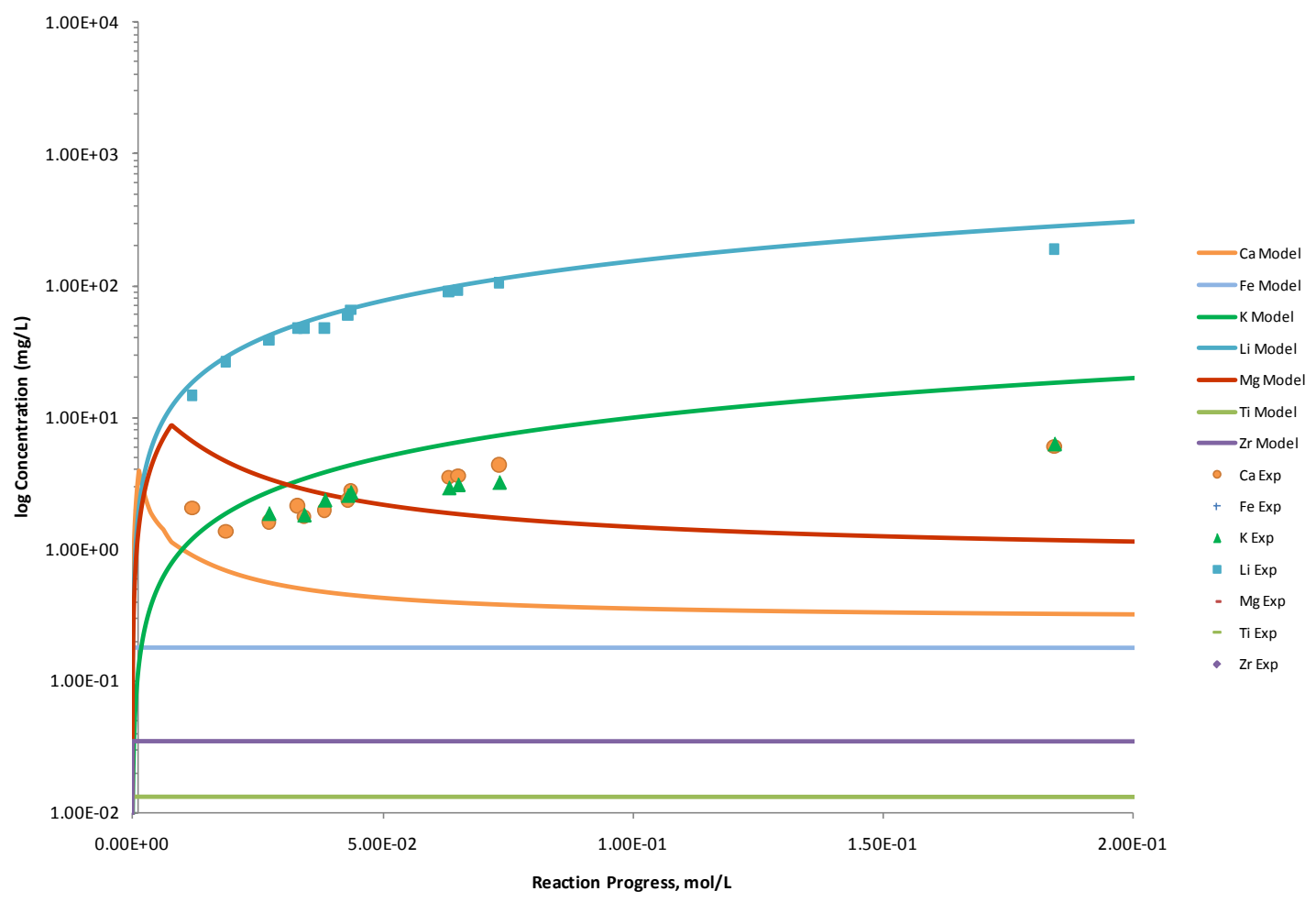

Figure C.321. Measured Solution Concentrations (mg/L) and Model Results for $\mathrm{Ca}, \mathrm{Fe}, \mathrm{K}, \mathrm{Li}, \mathrm{Mg}$, Ti, and $\mathrm{Zr}$, as a Function of Reaction Progress (mol-glass/kg) Determined for Glass Sample LAWB94

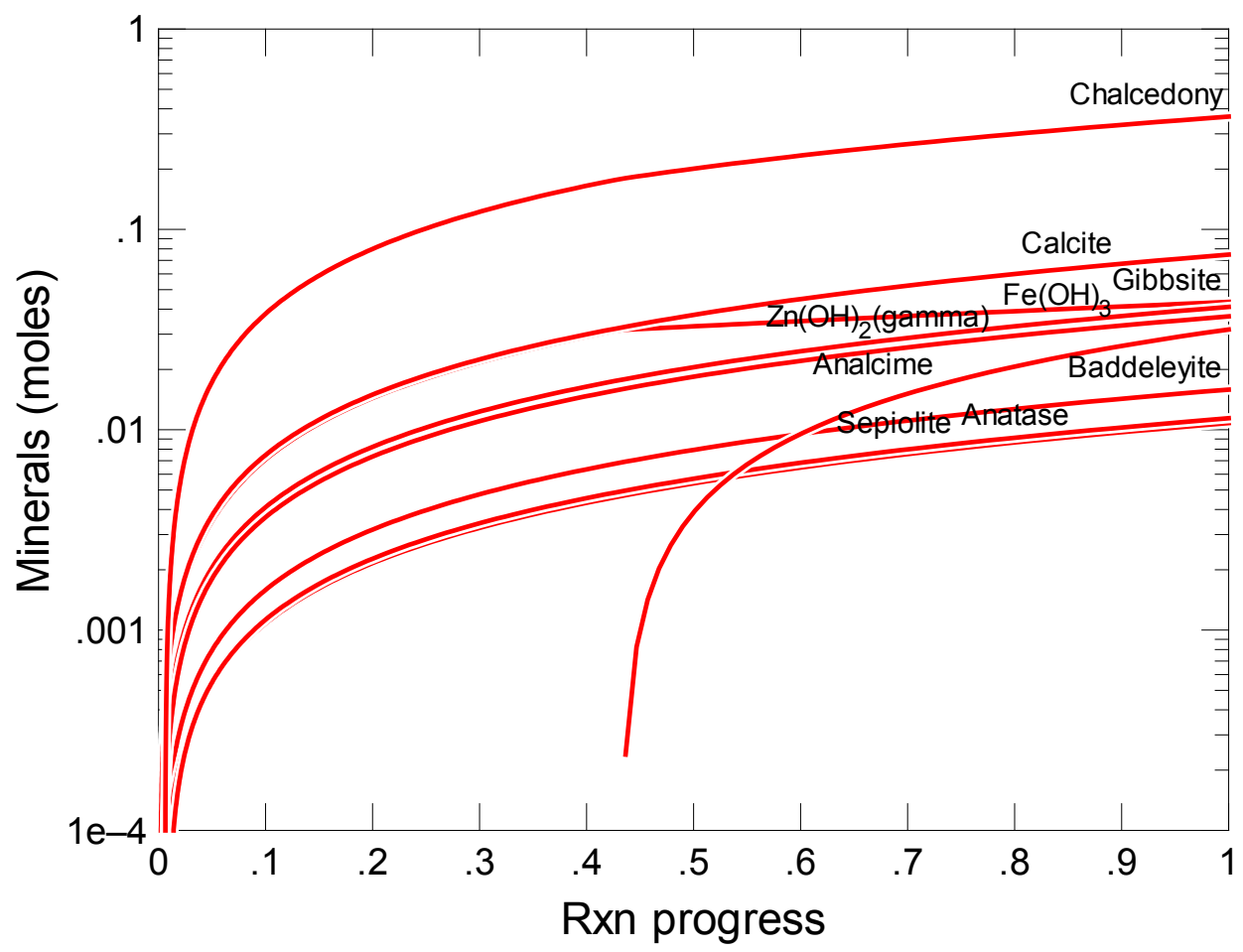

Figure C.322. Secondary Phases Calculated to Form as a Function of Reaction Progress (mol-glass $/ \mathrm{kg}$ ) Determined for Glass Sample LAWB95 


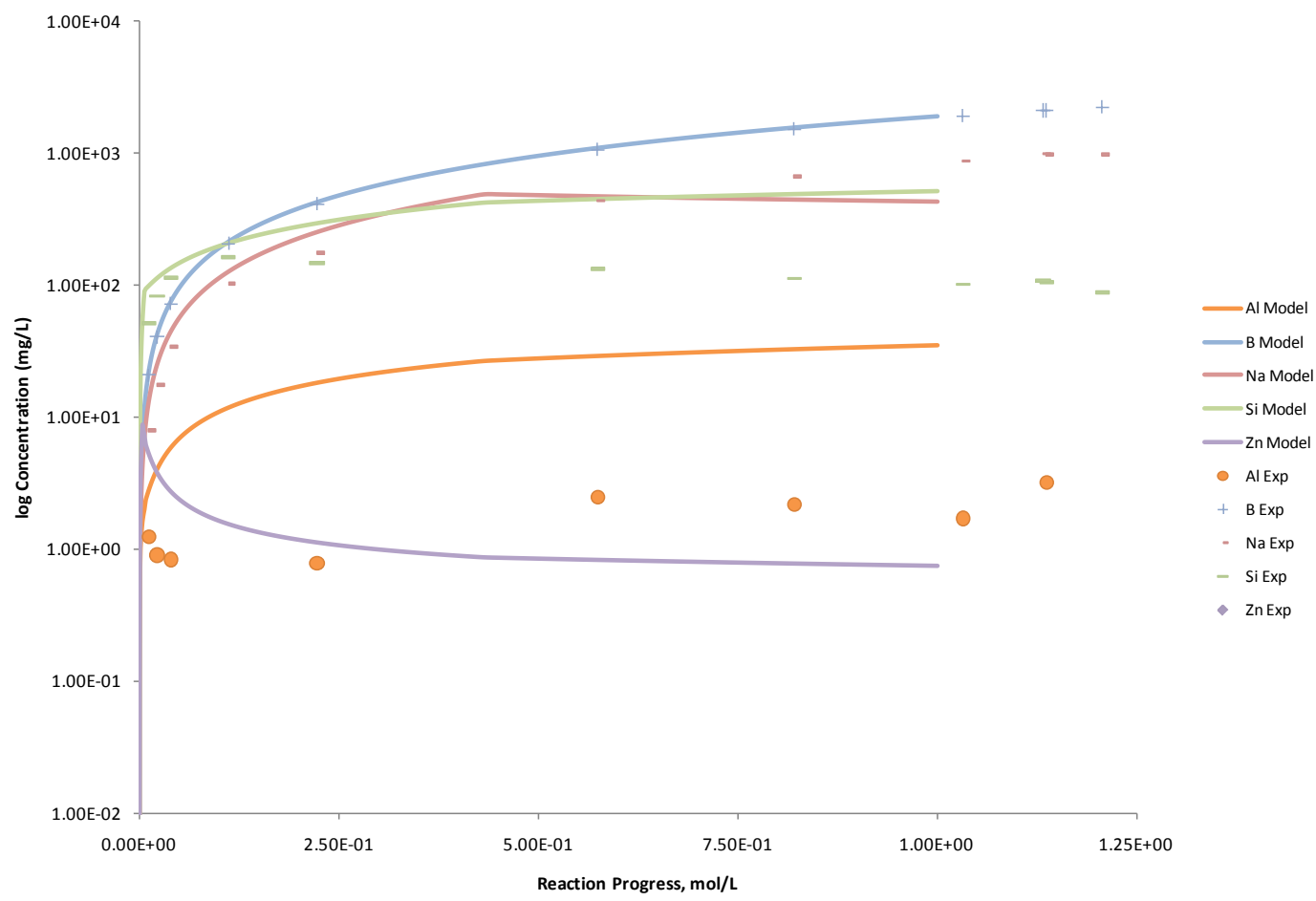

Figure C.323. Measured Solution Concentrations (mg/L) and Model Results for Al, B, Na, Si, and Zn, as a Function of Reaction Progress (mol-glass $/ \mathrm{kg}$ ) Determined for Glass Sample LAWB95

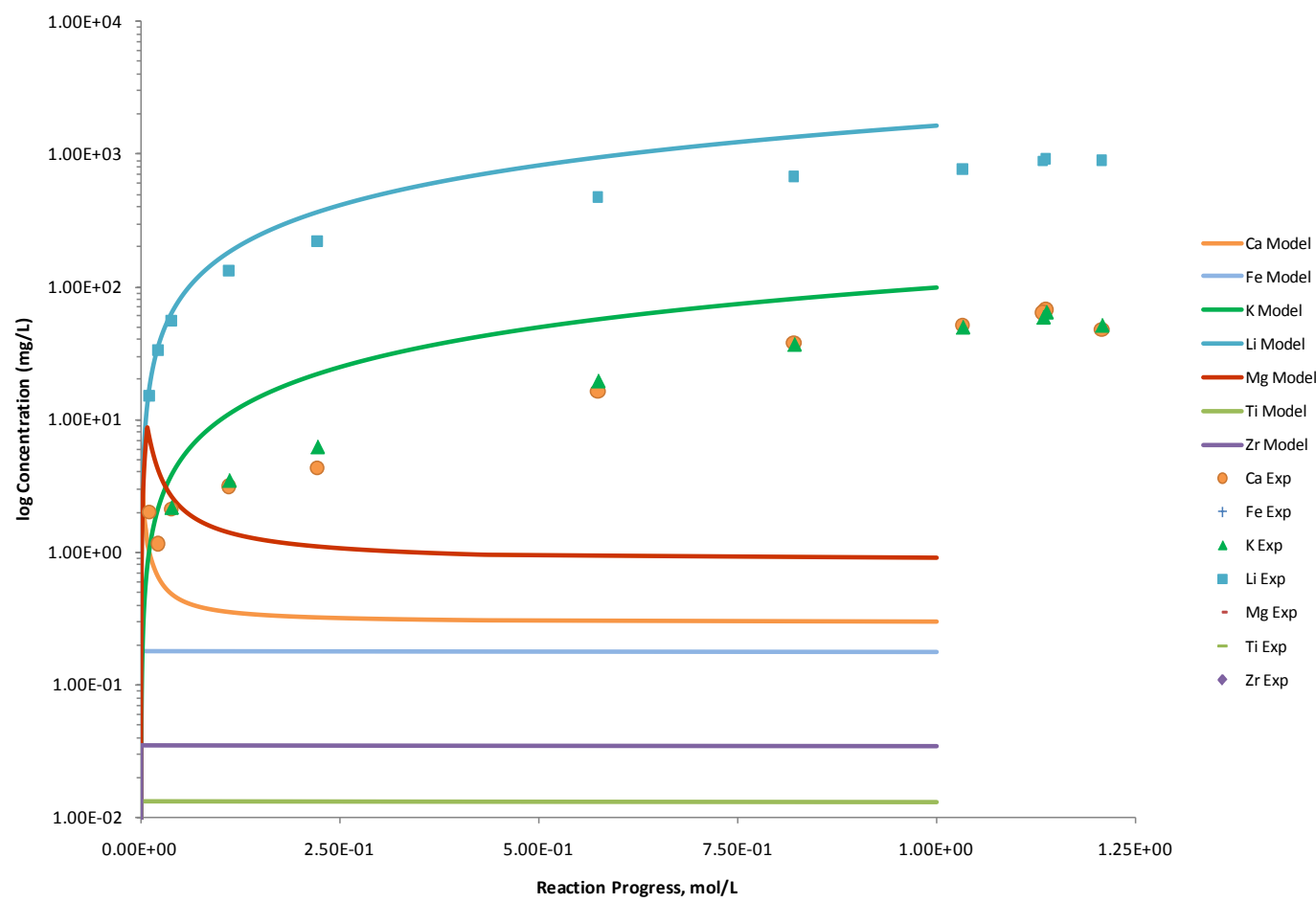

Figure C.324. Measured Solution Concentrations (mg/L) and Model Results for $\mathrm{Ca}, \mathrm{Fe}, \mathrm{K}, \mathrm{Li}, \mathrm{Mg}$, Ti, and $\mathrm{Zr}$, as a Function of Reaction Progress (mol-glass/kg) Determined for Glass Sample LAWB95 


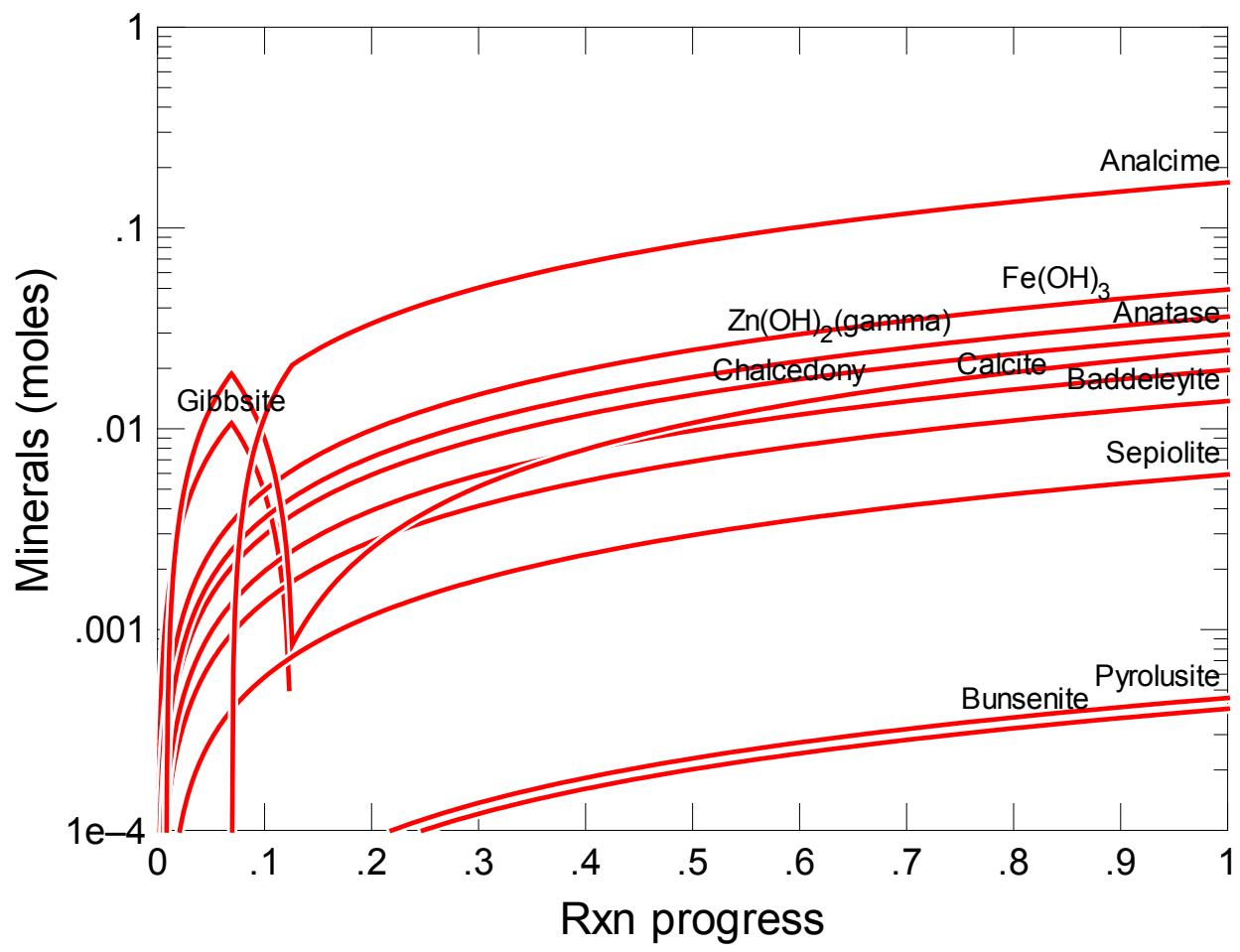

Figure C.325. Secondary Phases Calculated to Form as a Function of Reaction Progress (mol-glass $/ \mathrm{kg}$ ) Determined for Glass Sample LAWC12

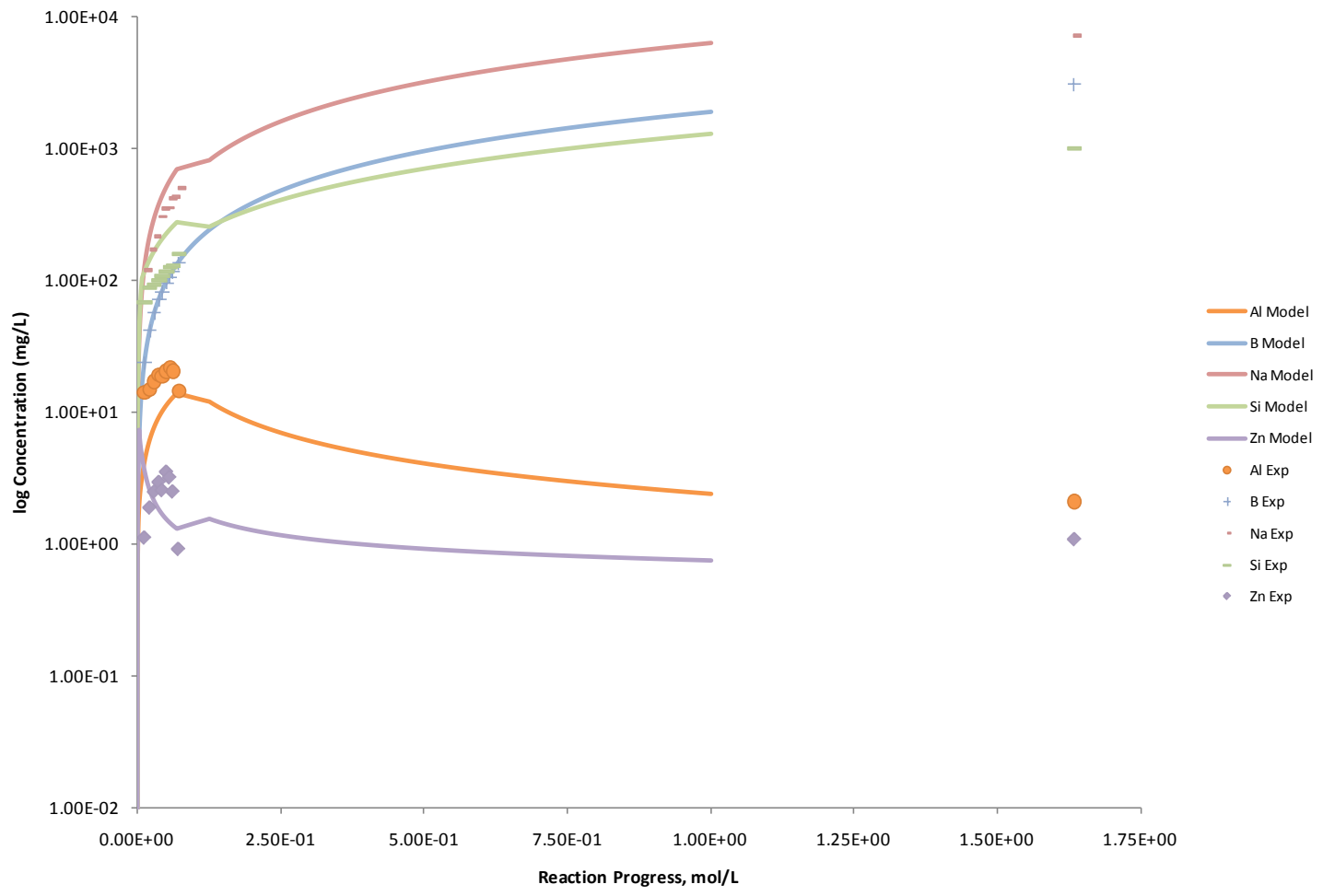

Figure C.326. Measured Solution Concentrations (mg/L) and Model Results for Al, B, Na, Si, and Zn, as a Function of Reaction Progress (mol-glass $/ \mathrm{kg}$ ) Determined for Glass Sample LAWC12 


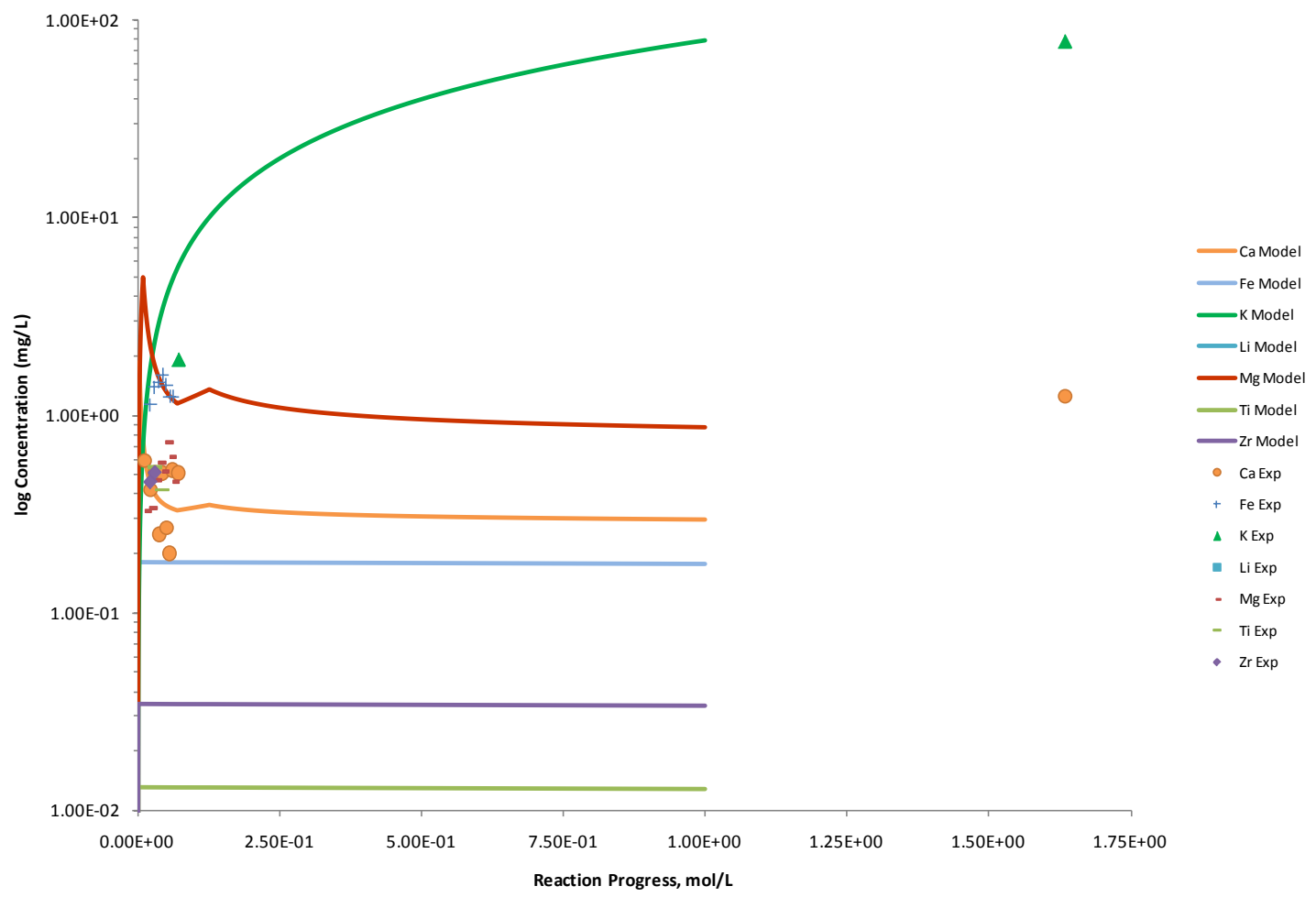

Figure C.327. Measured Solution Concentrations (mg/L) and Model Results for Ca, Fe, K, Li, Mg, Ti, and $\mathrm{Zr}$, as a Function of Reaction Progress (mol-glass/kg) Determined for Glass Sample LAWC12

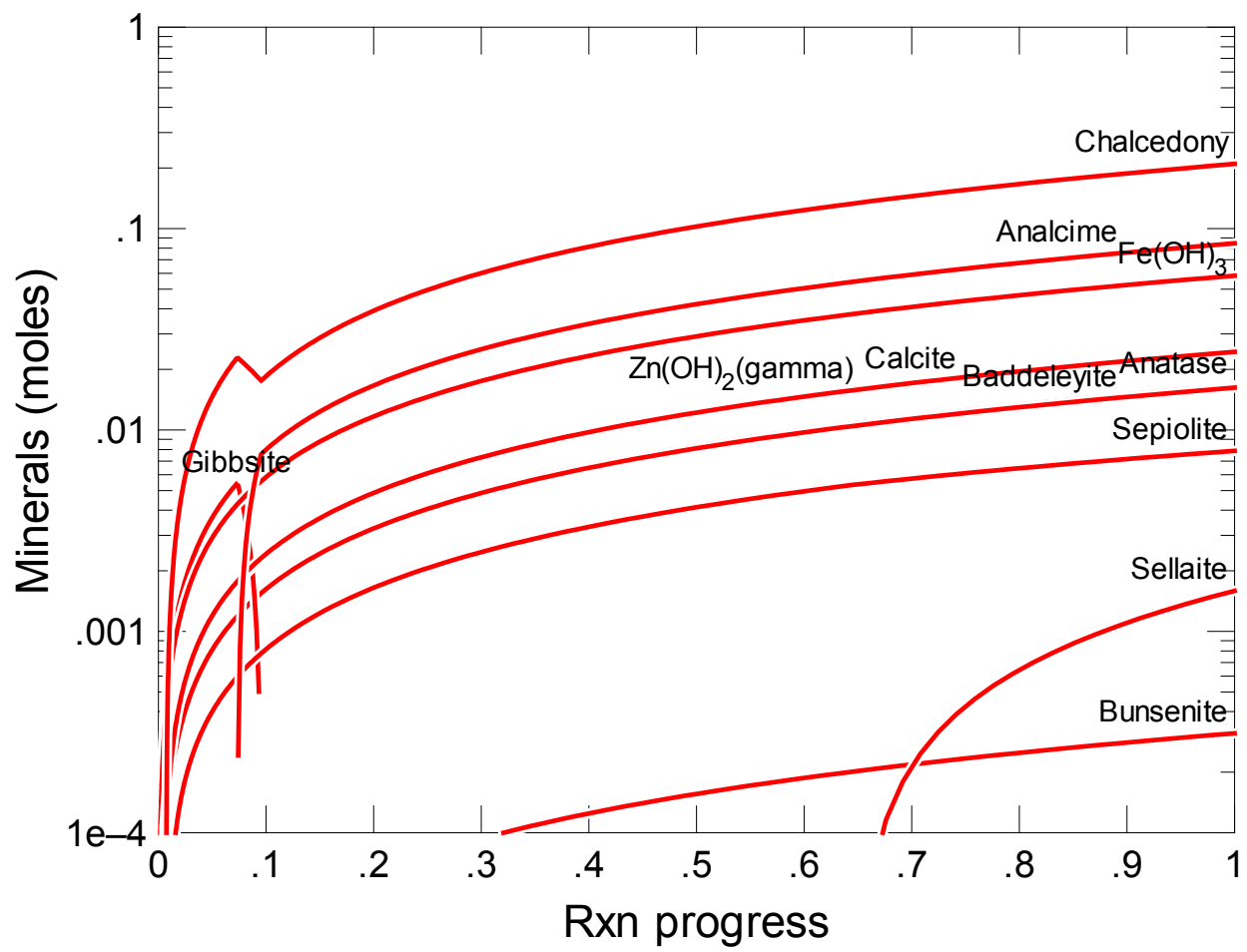

Figure C.328. Secondary Phases Calculated to Form as a Function of Reaction Progress (mol-glass $/ \mathrm{kg}$ ) Determined for Glass Sample LAWC15 


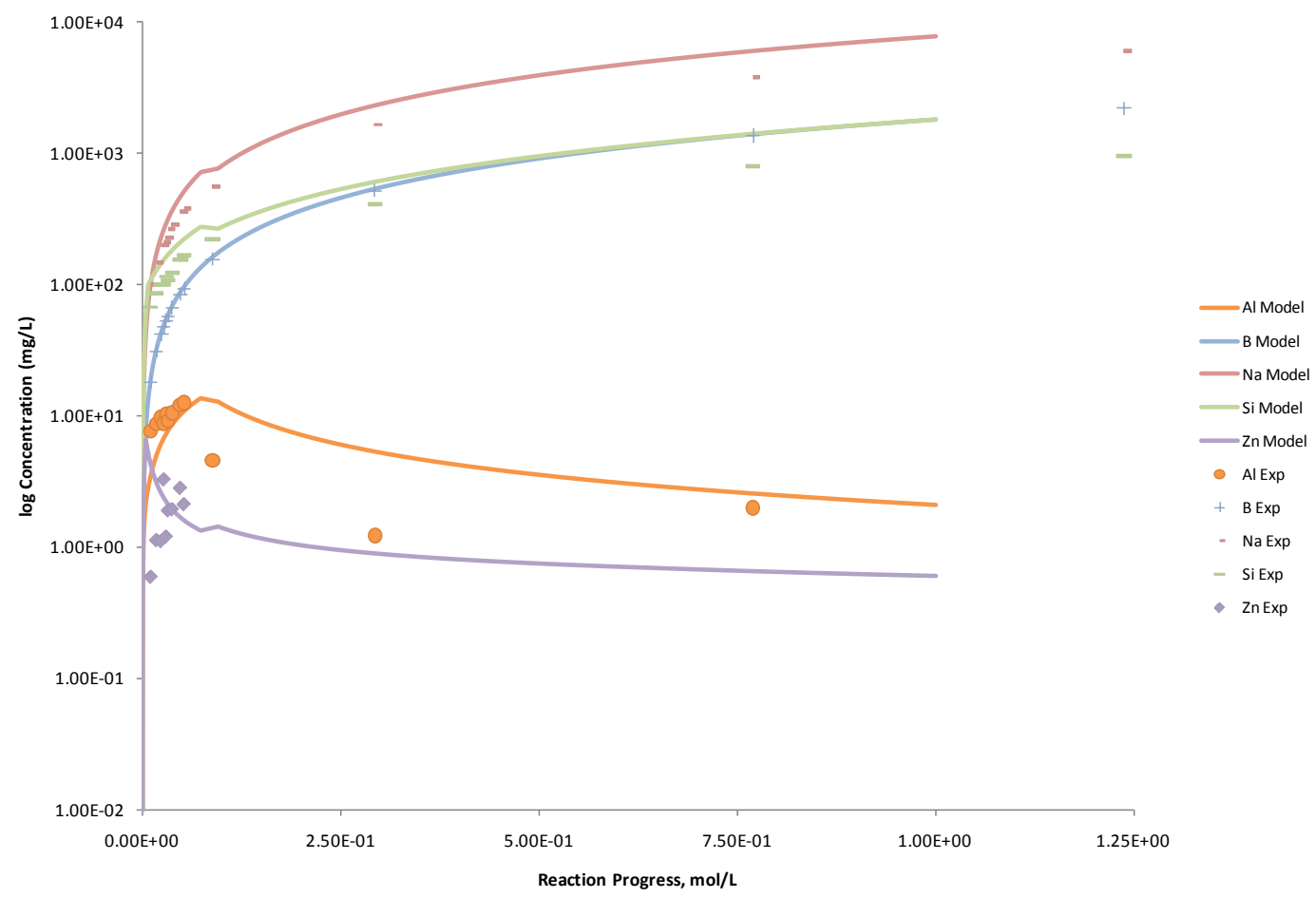

Figure C.329. Measured Solution Concentrations (mg/L) and Model Results for Al, B, Na, Si, and Zn, as a Function of Reaction Progress (mol-glass $/ \mathrm{kg}$ ) Determined for Glass Sample LAWC15

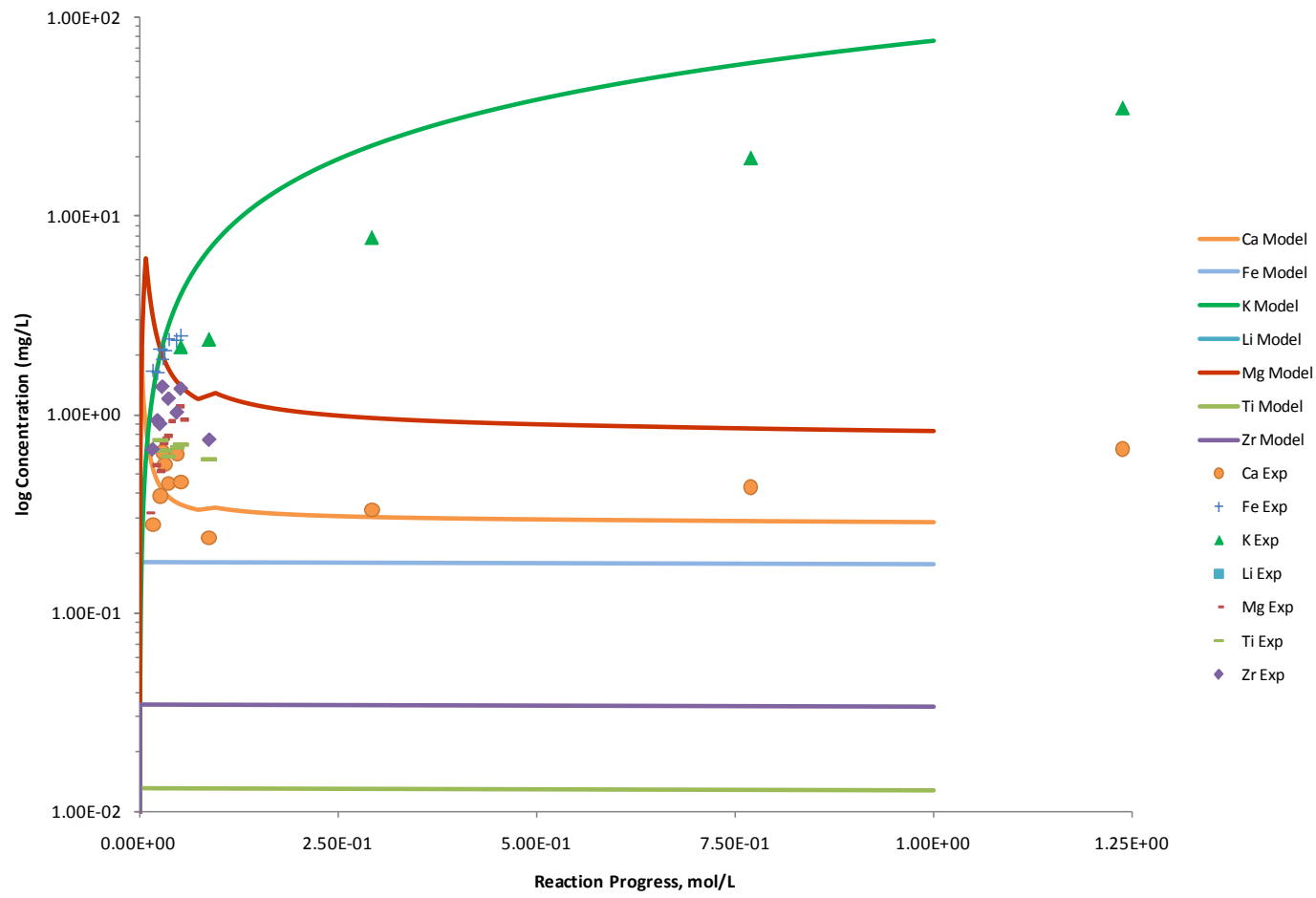

Figure C.330. Measured Solution Concentrations (mg/L) and Model Results for $\mathrm{Ca}, \mathrm{Fe}, \mathrm{K}, \mathrm{Li}, \mathrm{Mg}$, Ti, and $\mathrm{Zr}$, as a Function of Reaction Progress (mol-glass/kg) Determined for Glass Sample LAWC15 


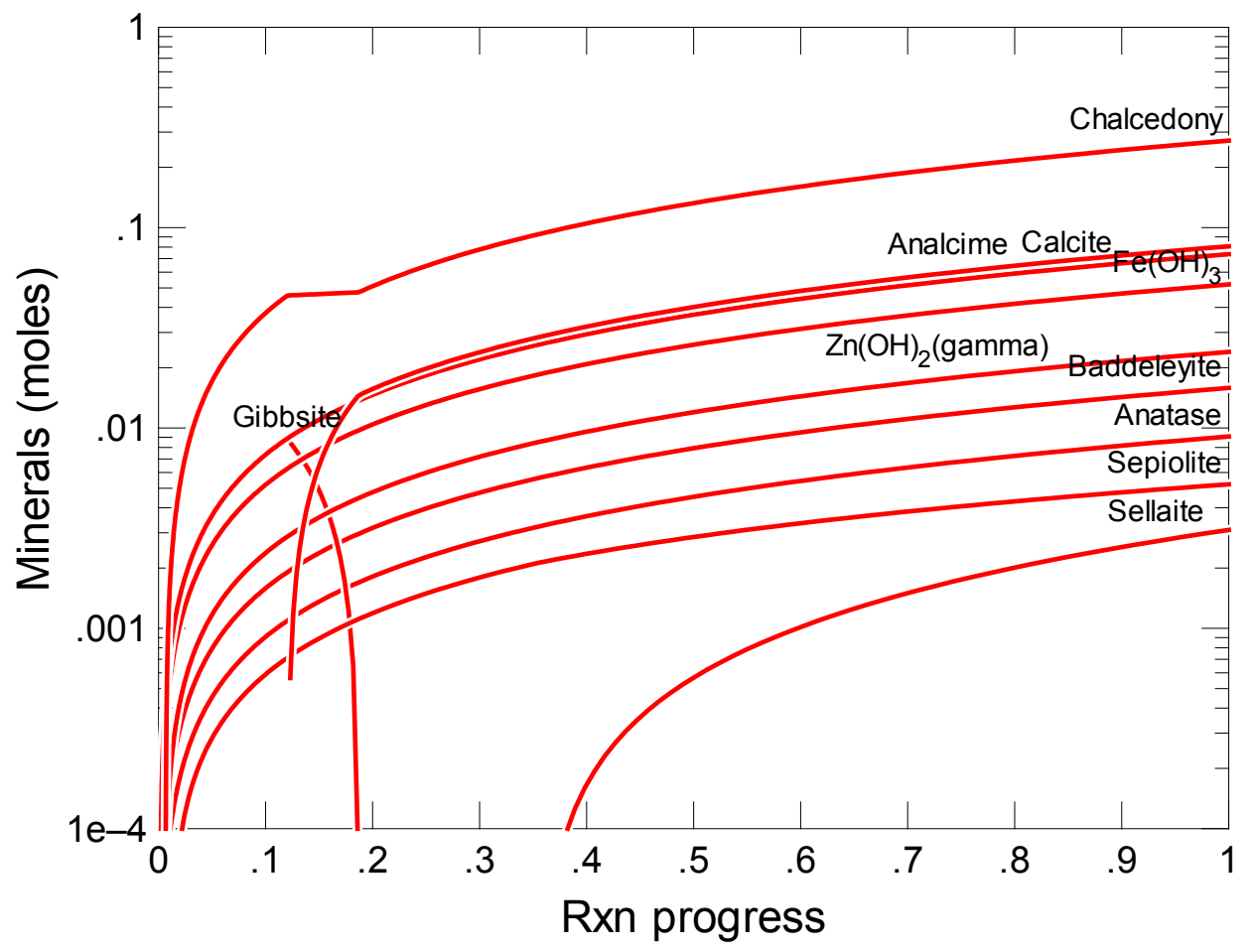

Figure C.331. Secondary Phases Calculated to Form as a Function of Reaction Progress (mol-glass $/ \mathrm{kg}$ ) Determined for Glass Sample LAWC21 rev2

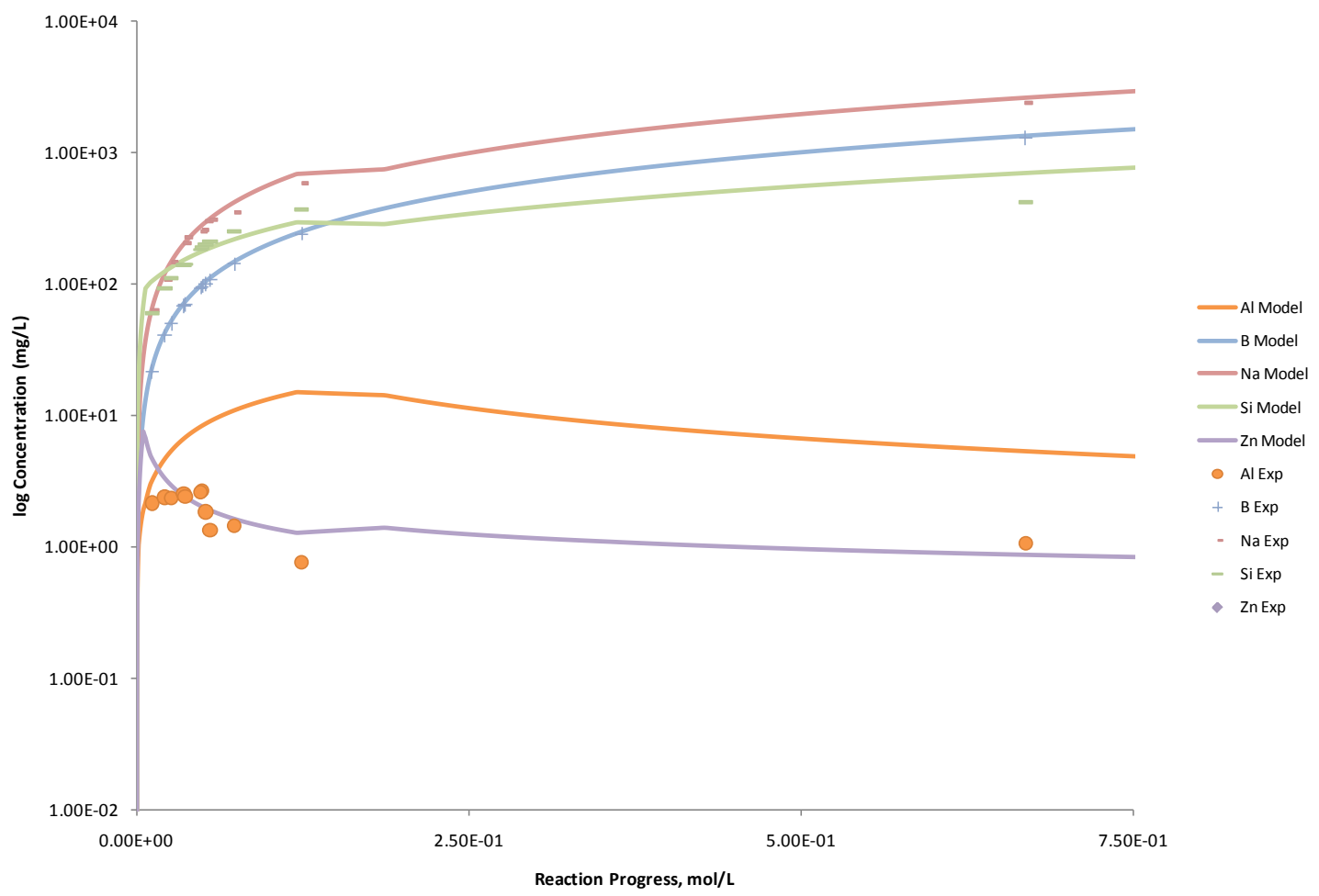

Figure C.332. Measured Solution Concentrations (mg/L) and Model Results for Al, B, Na, Si, and Zn, as a Function of Reaction Progress (mol-glass $/ \mathrm{kg}$ ) Determined for Glass Sample LAWC21rev2 


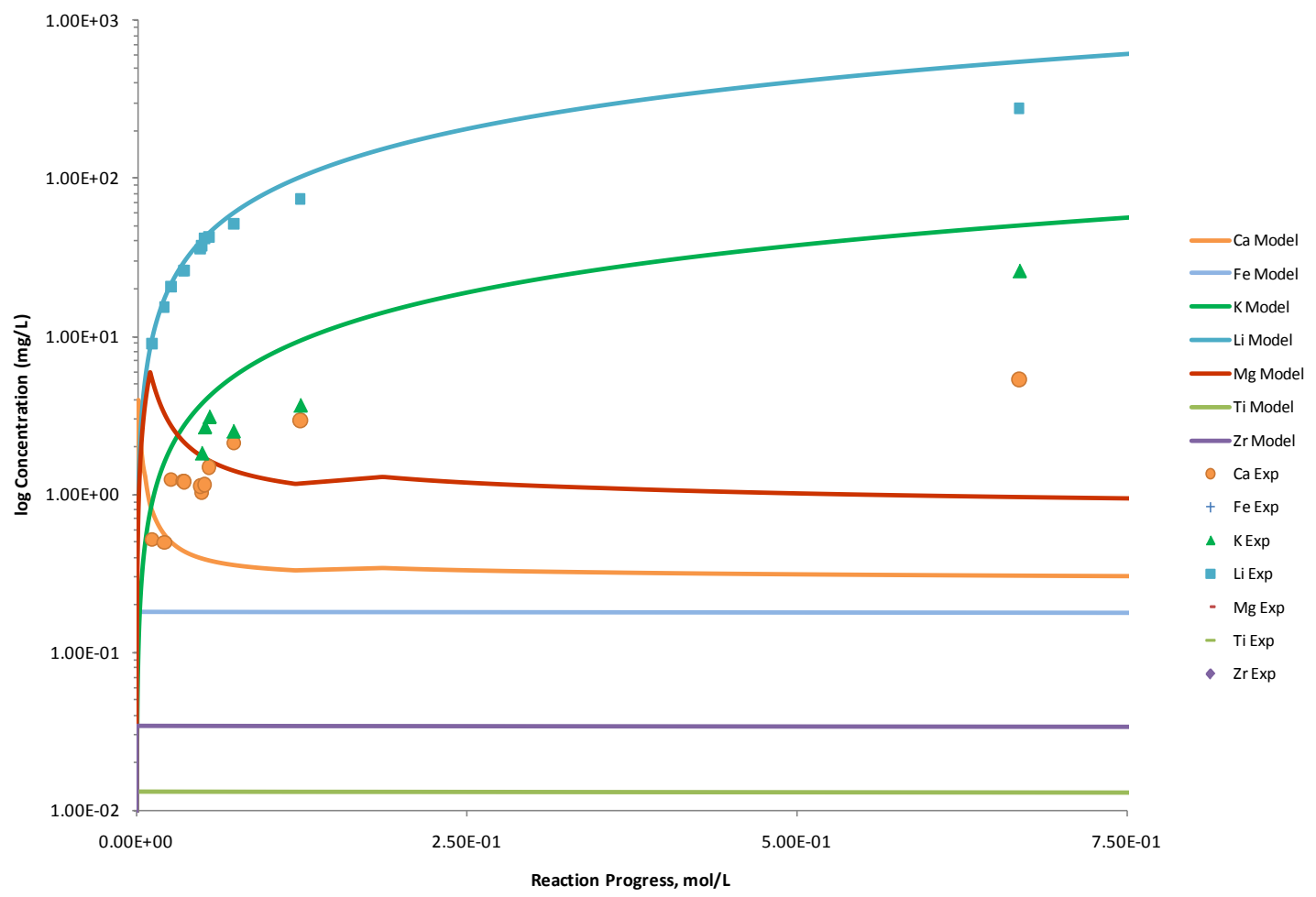

Figure C.333. Measured Solution Concentrations (mg/L) and Model Results for $\mathrm{Ca}, \mathrm{Fe}, \mathrm{K}, \mathrm{Li}, \mathrm{Mg}$, Ti, and $\mathrm{Zr}$, as a Function of Reaction Progress (mol-glass $/ \mathrm{kg}$ ) Determined for Glass Sample LAWC21rev2

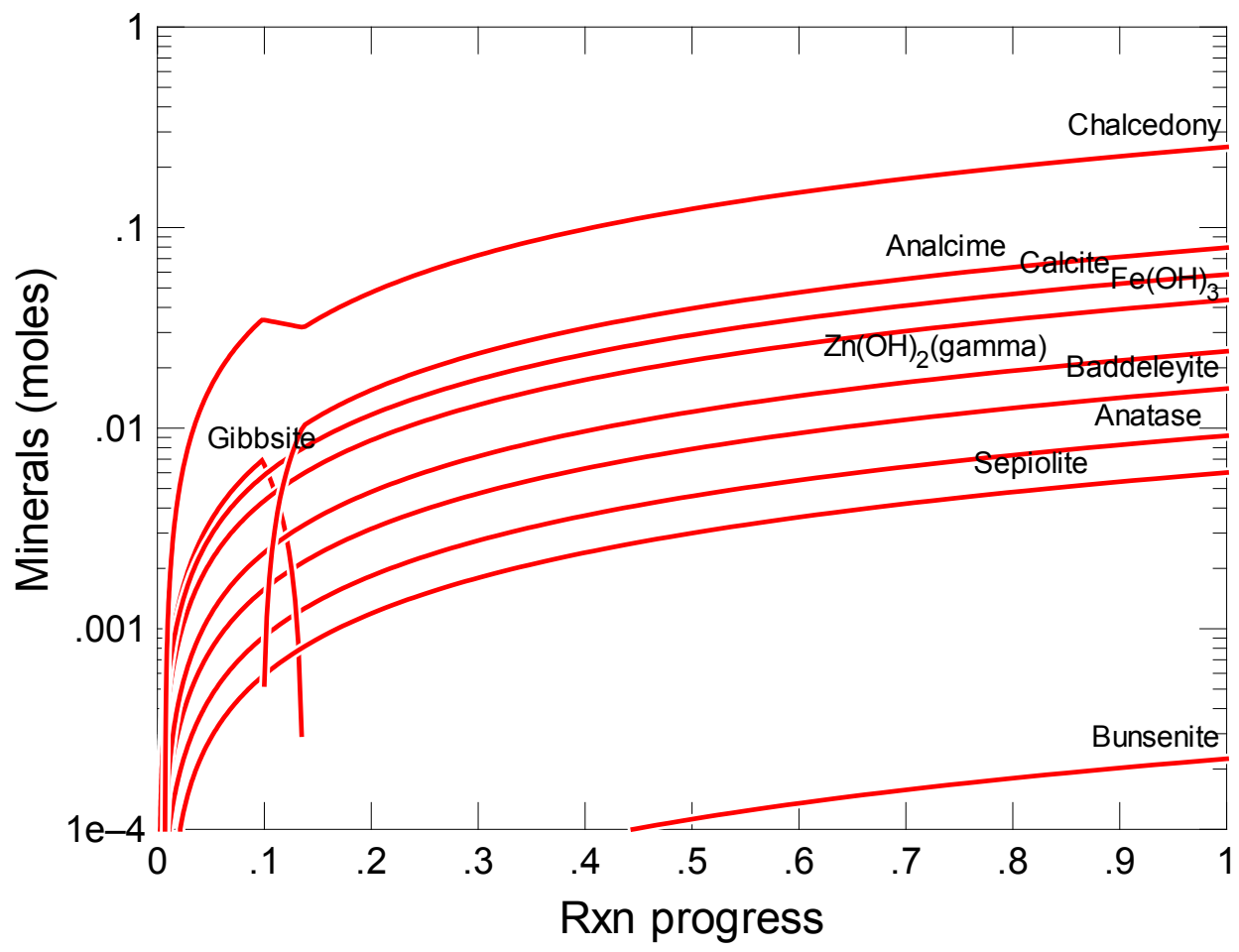

Figure C.334. Secondary Phases Calculated to Form as a Function of Reaction Progress (mol-glass $/ \mathrm{kg}$ ) Determined for Glass Sample LAWC22 


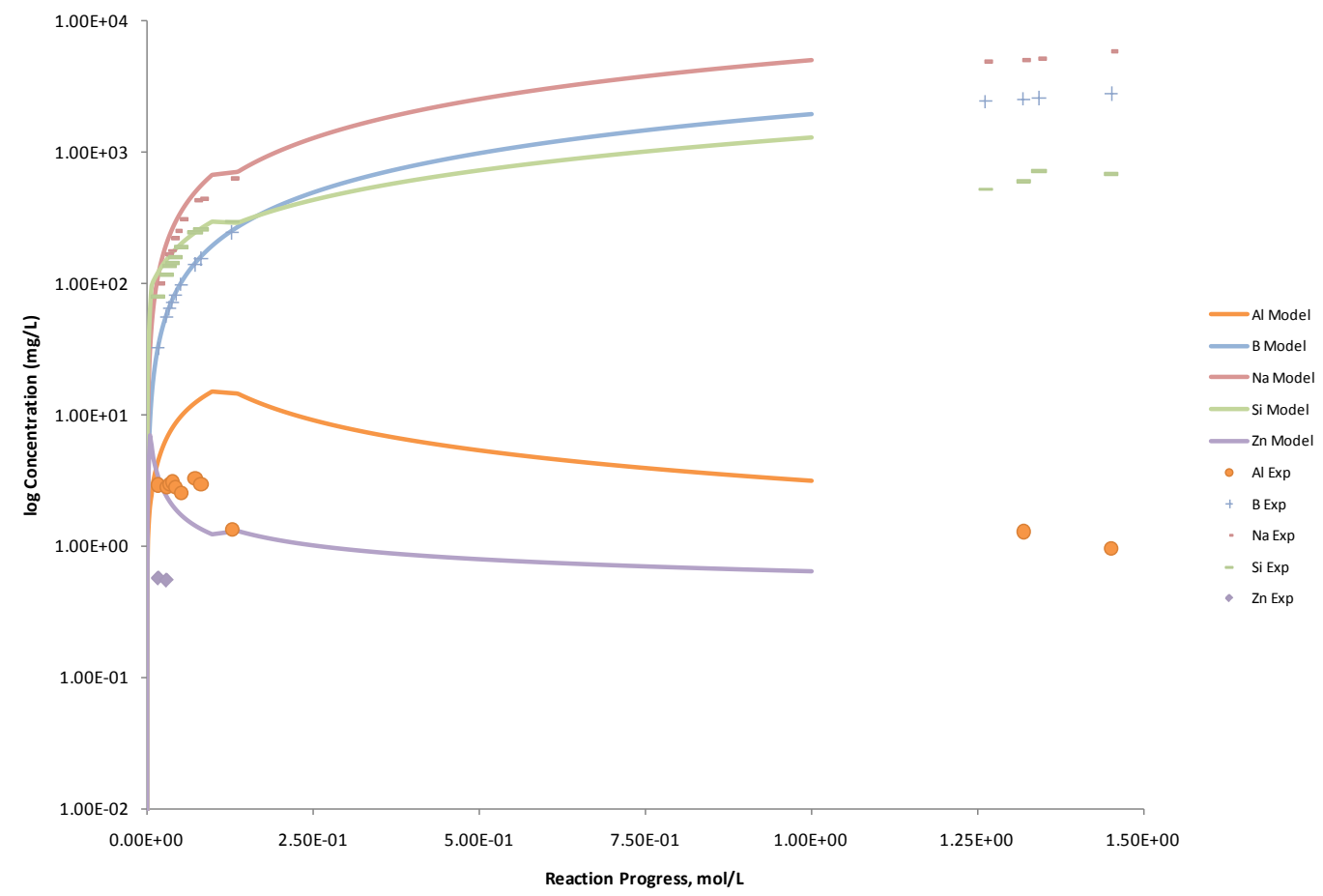

Figure C.335. Measured Solution Concentrations (mg/L) and Model Results for Al, B, Na, Si, and Zn, as a Function of Reaction Progress (mol-glass $/ \mathrm{kg}$ ) Determined for Glass Sample LAWC22

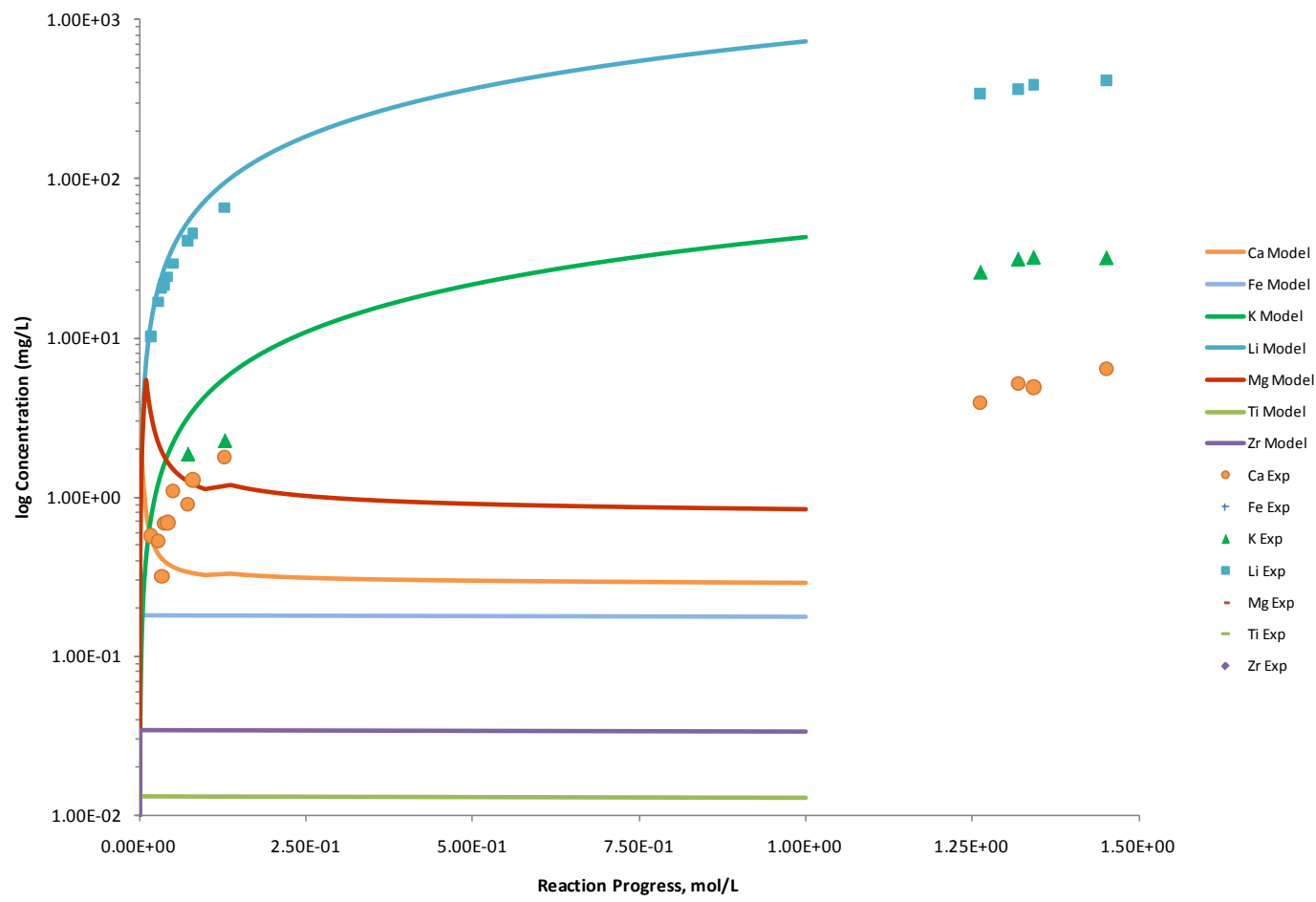

Figure C.336. Measured Solution Concentrations (mg/L) and Model Results for $\mathrm{Ca}, \mathrm{Fe}, \mathrm{K}, \mathrm{Li}, \mathrm{Mg}, \mathrm{Ti}$, and $\mathrm{Zr}$, as a Function of Reaction Progress (mol-glass/kg) Determined for Glass Sample LAWC22 


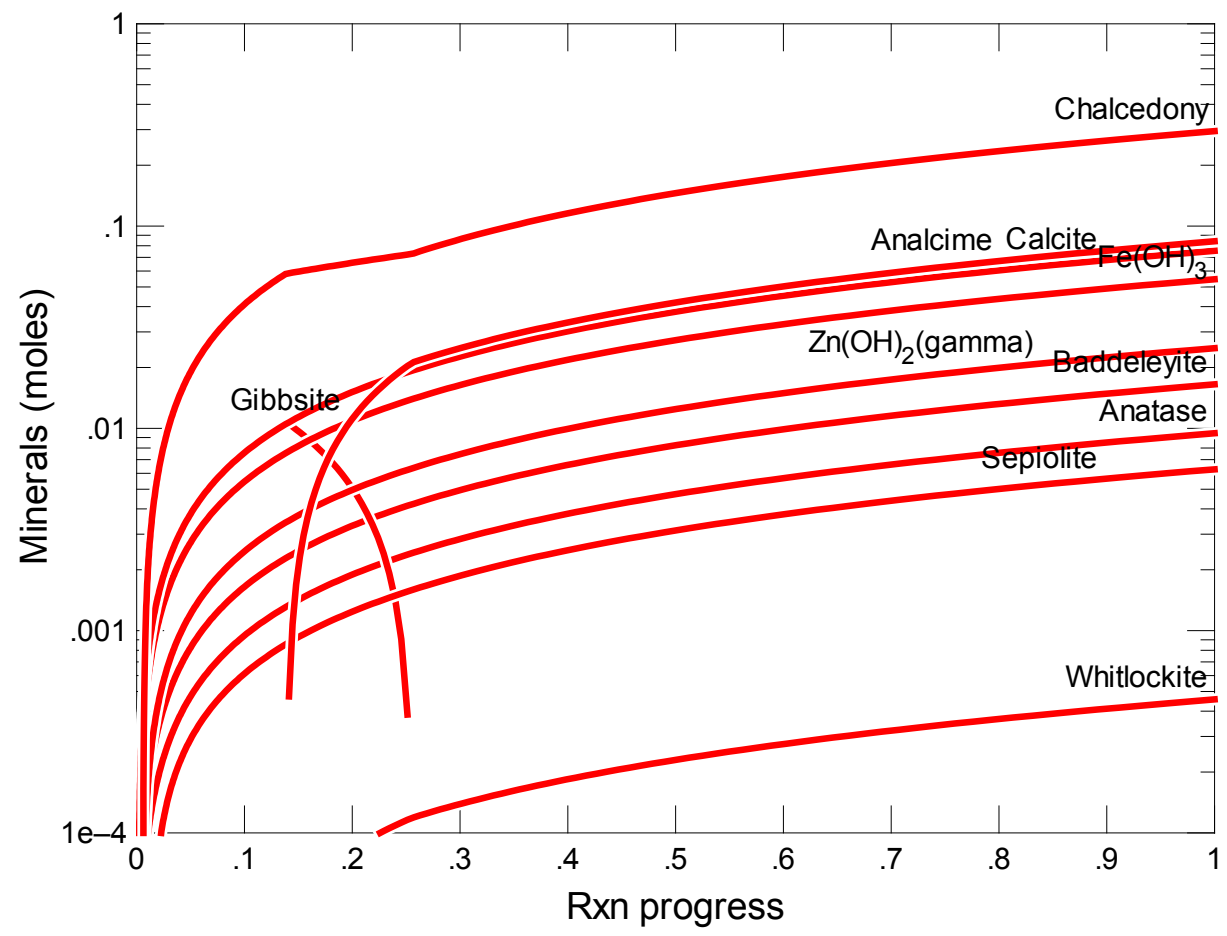

Figure C.337. Secondary Phases Calculated to Form as a Function of Reaction Progress (mol-glass $/ \mathrm{kg}$ ) Determined for Glass Sample LAWC23

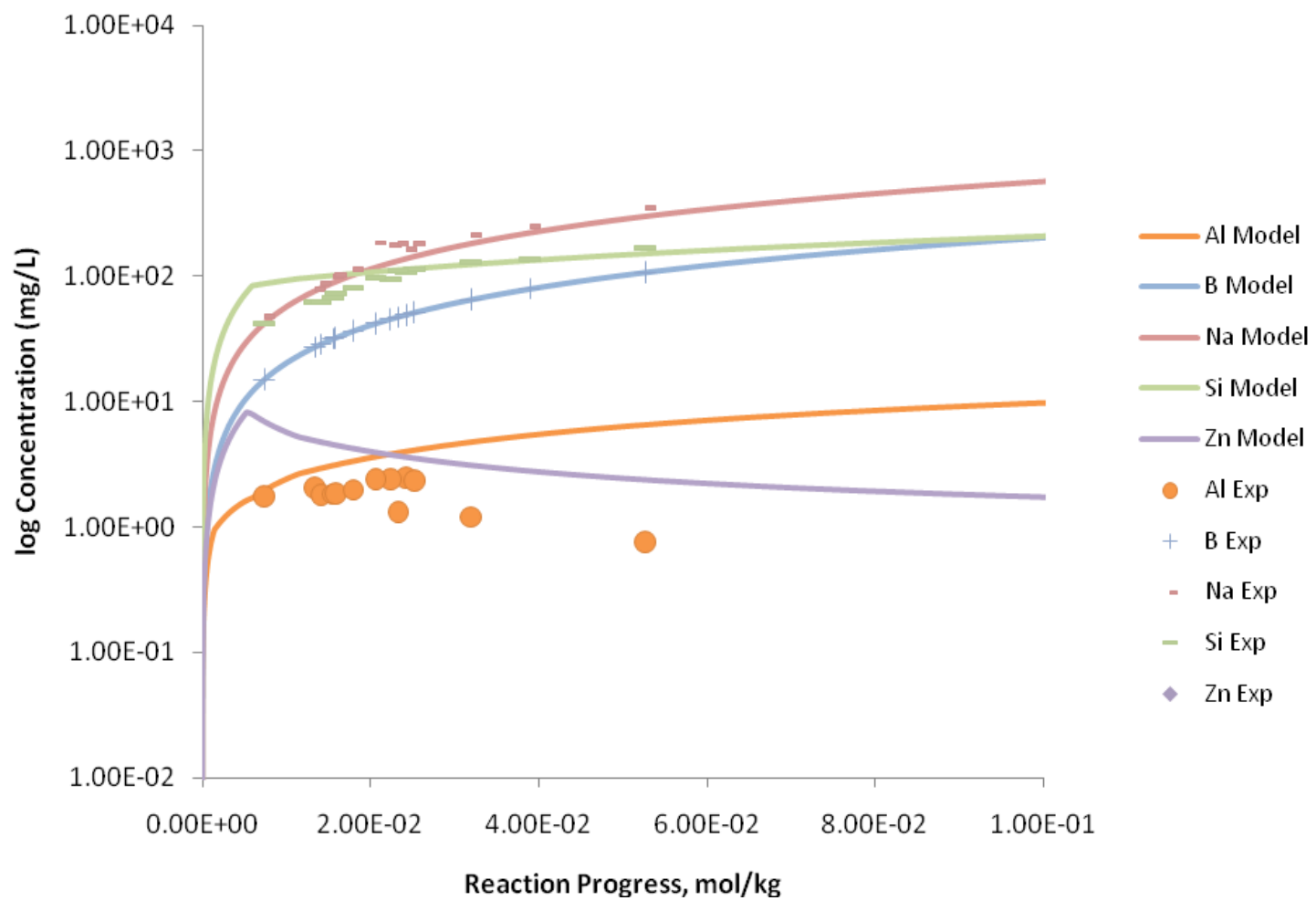

Figure C.338. Measured Solution Concentrations (mg/L) and Model Results for Al, B, Na, Si, and Zn, as a Function of Reaction Progress (mol-glass $/ \mathrm{kg}$ ) Determined for Glass Sample LAWC23 


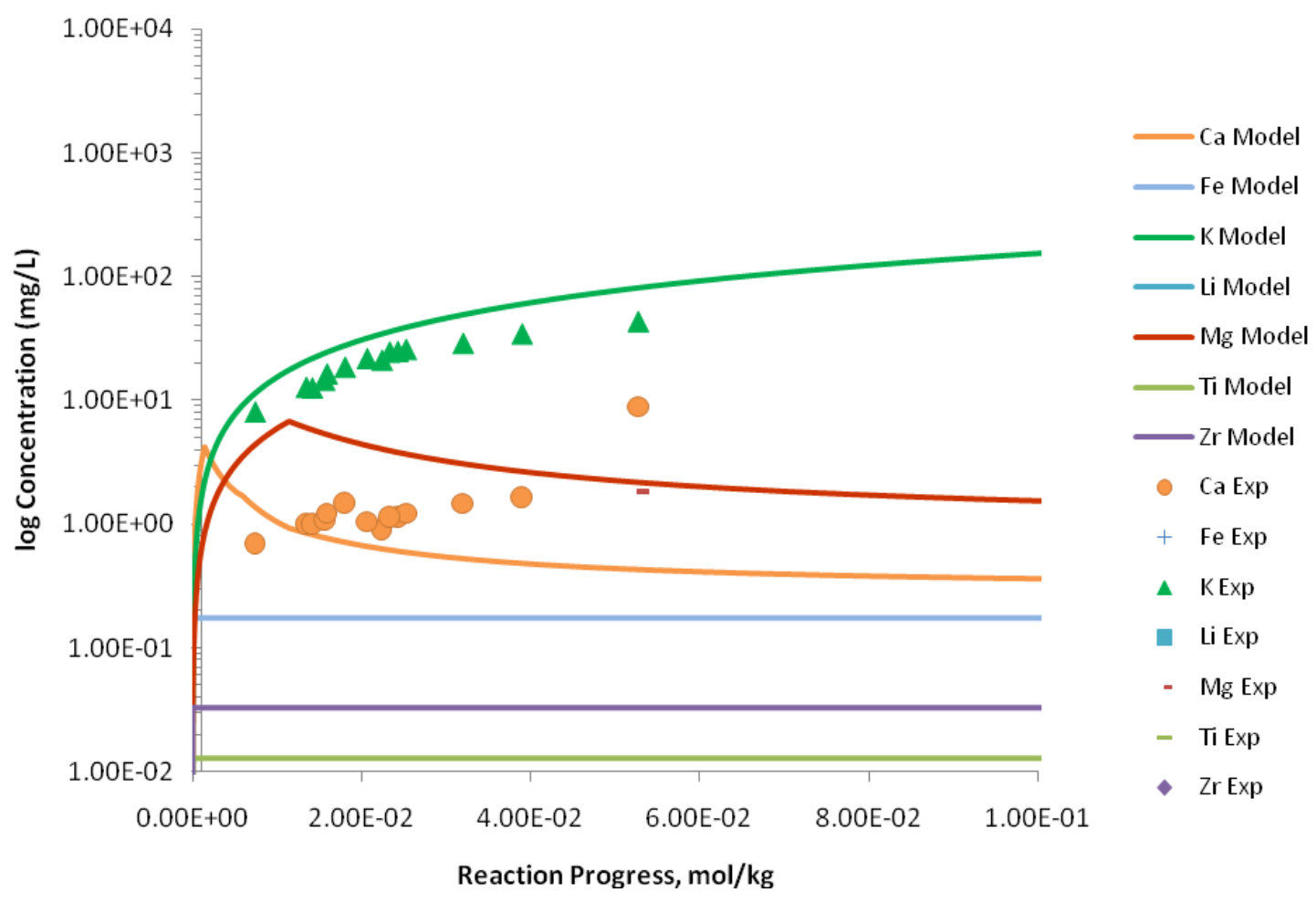

Figure C.339. Measured Solution Concentrations (mg/L) and Model Results for $\mathrm{Ca}, \mathrm{Fe}, \mathrm{K}, \mathrm{Li}, \mathrm{Mg}, \mathrm{Ti}$, and $\mathrm{Zr}$, as a Function of Reaction Progress (mol-glass/kg) Determined for Glass Sample LAWC23

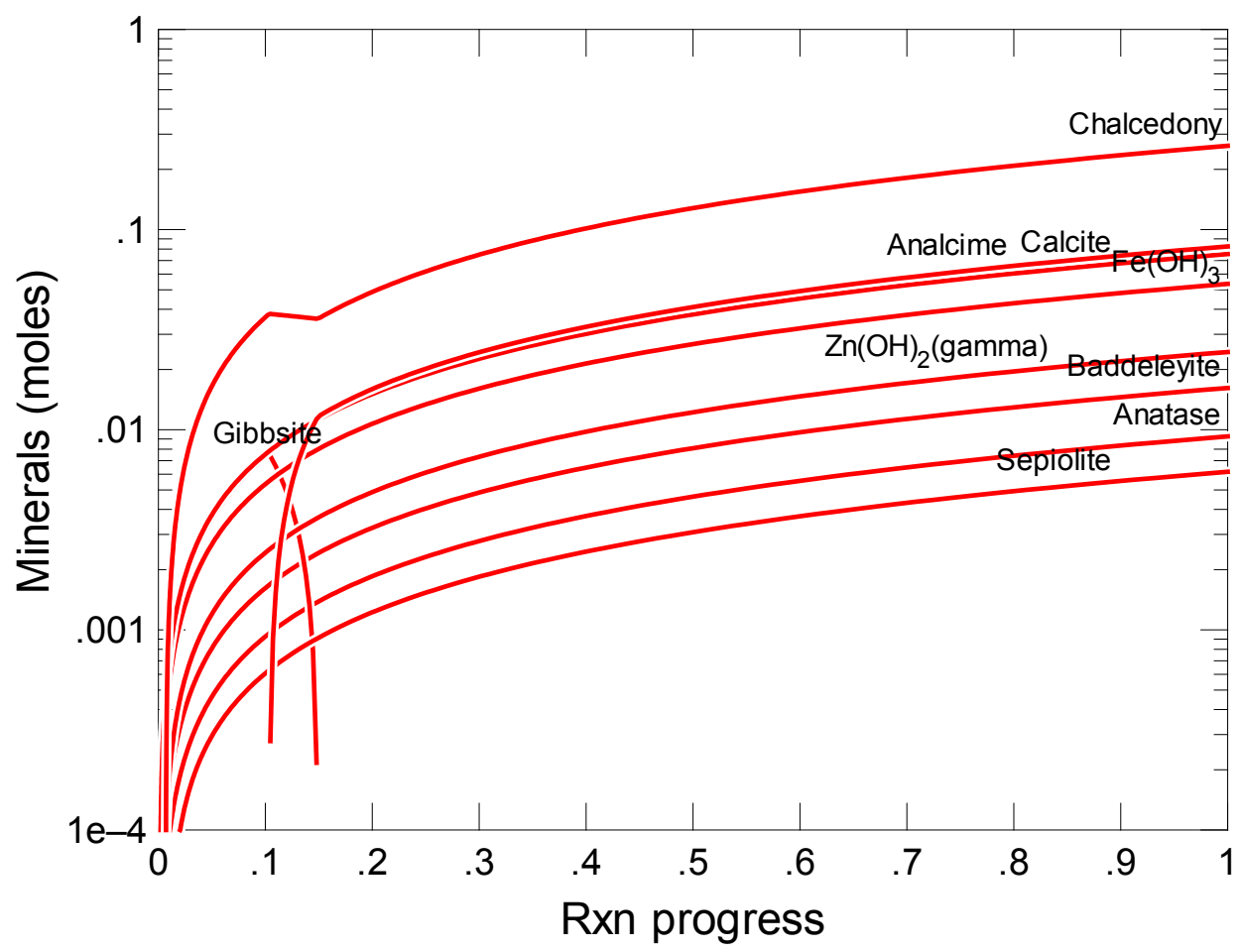

Figure C.340. Secondary Phases Calculated to Form as a Function of Reaction Progress (mol-glass/kg) Determined for Glass Sample LAWC24 


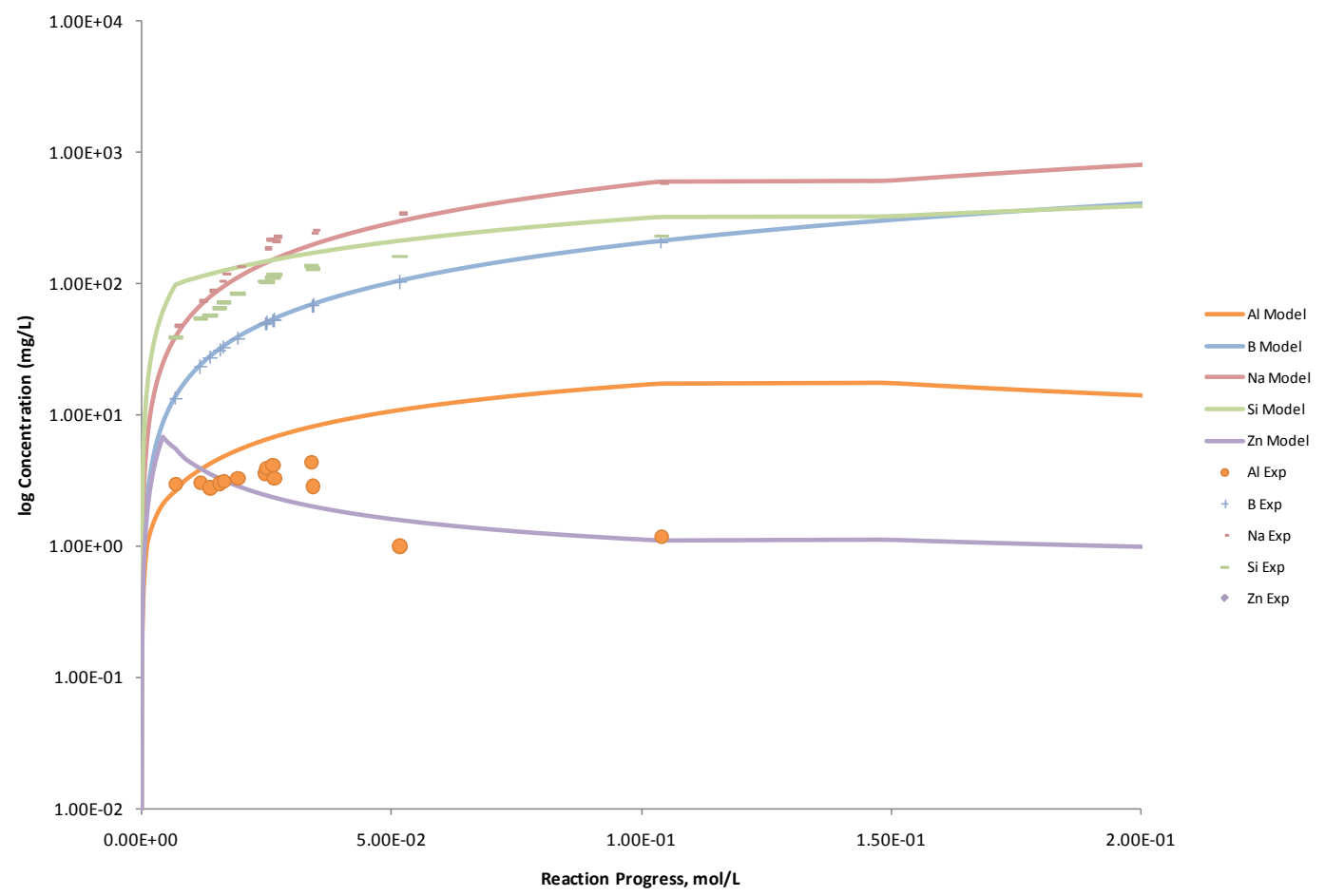

Figure C.341. Measured Solution Concentrations (mg/L) and Model Results for Al, B, Na, Si, and Zn, as a Function of Reaction Progress (mol-glass $/ \mathrm{kg}$ ) Determined for Glass Sample LAWC24

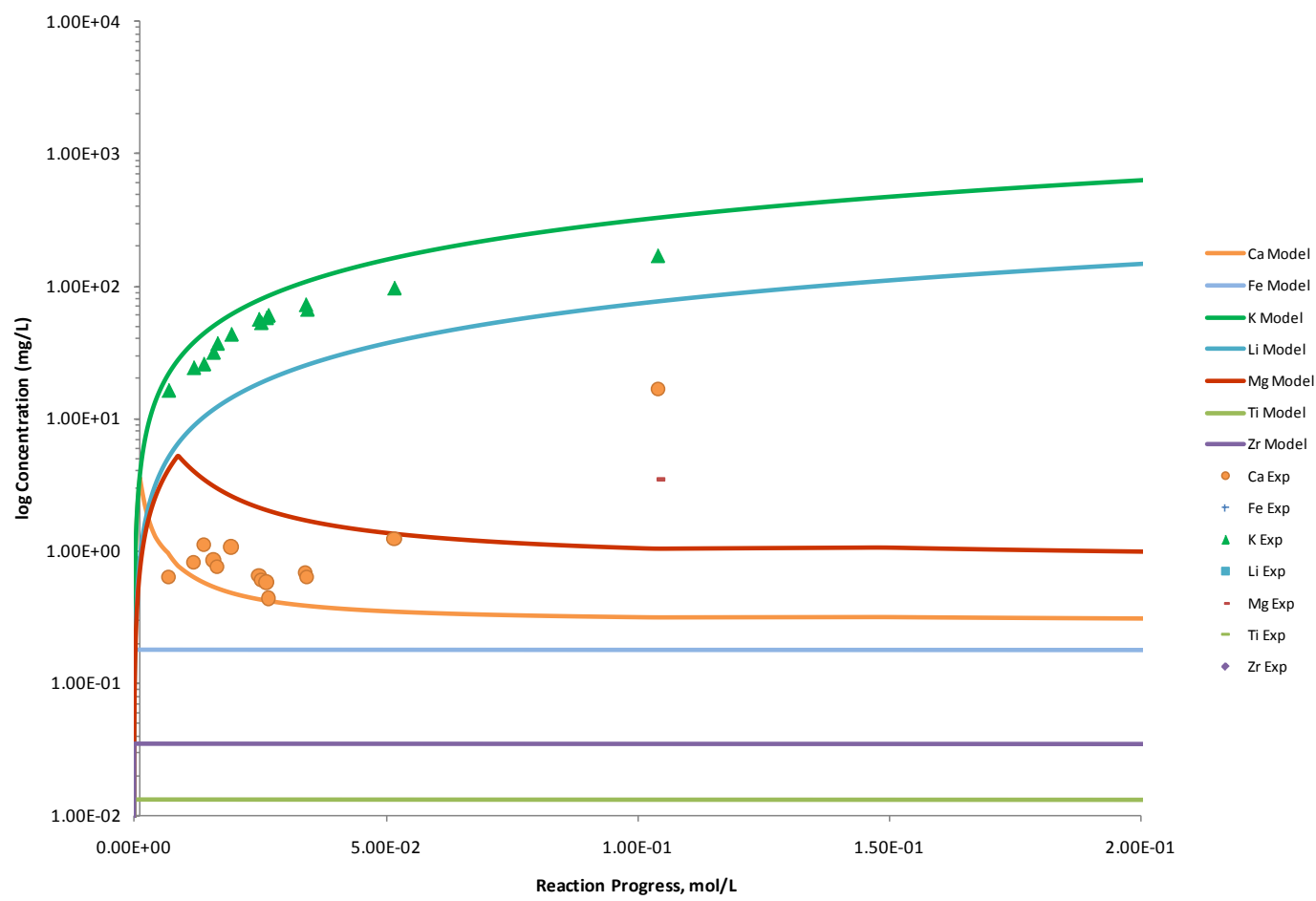

Figure C.342. Measured Solution Concentrations (mg/L) and Model Results for Ca, Fe, K, Li, Mg, Ti, and $\mathrm{Zr}$, as a Function of Reaction Progress (mol-glass/kg) Determined for Glass Sample LAWC24 


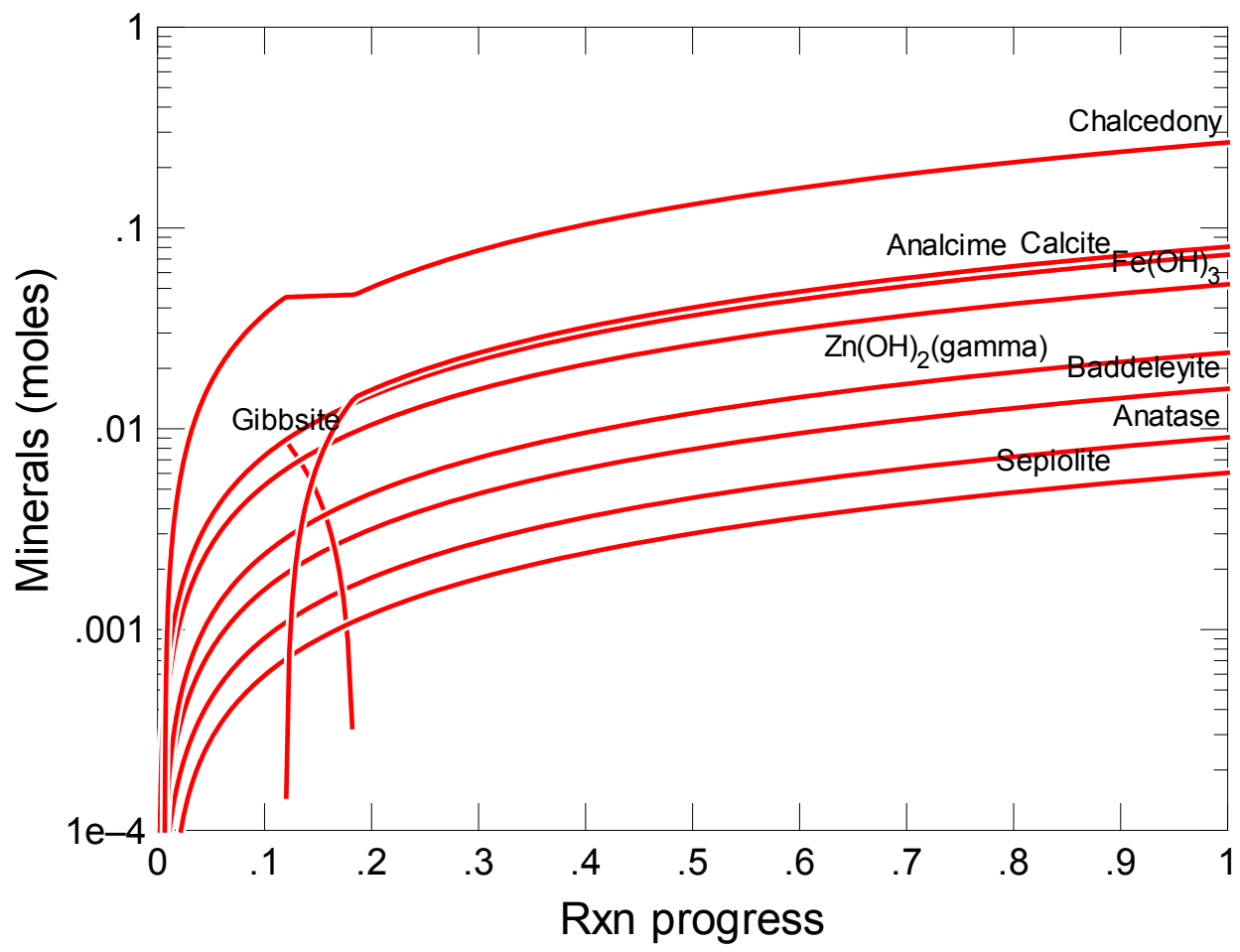

Figure C.343. Secondary Phases Calculated to Form as a Function of Reaction Progress (mol-glass $/ \mathrm{kg}$ ) Determined for Glass Sample LAWC25

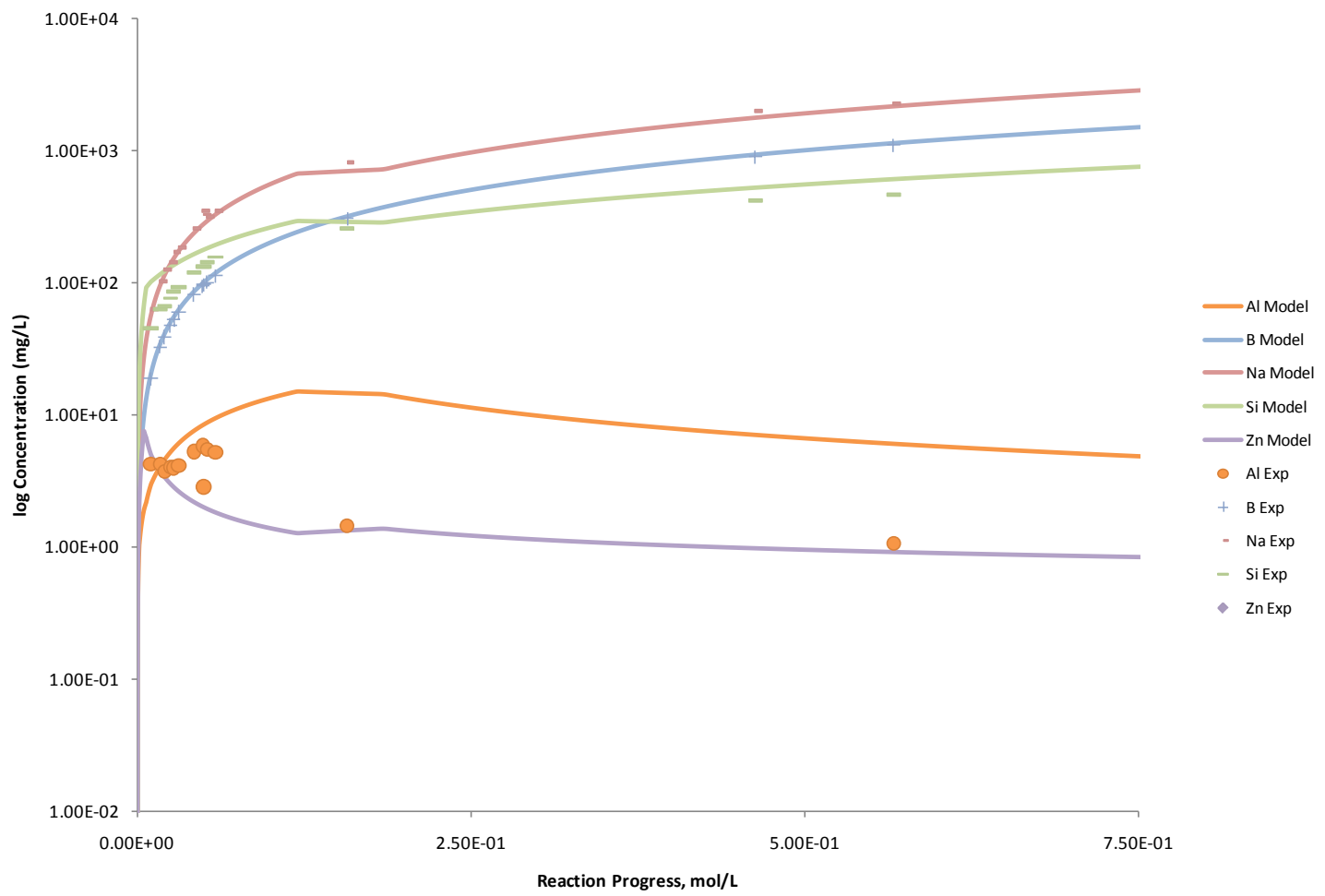

Figure C.344. Measured Solution Concentrations (mg/L) and Model Results for Al, B, Na, Si, and Zn, as a Function of Reaction Progress (mol-glass $/ \mathrm{kg}$ ) Determined for Glass Sample LAWC25 


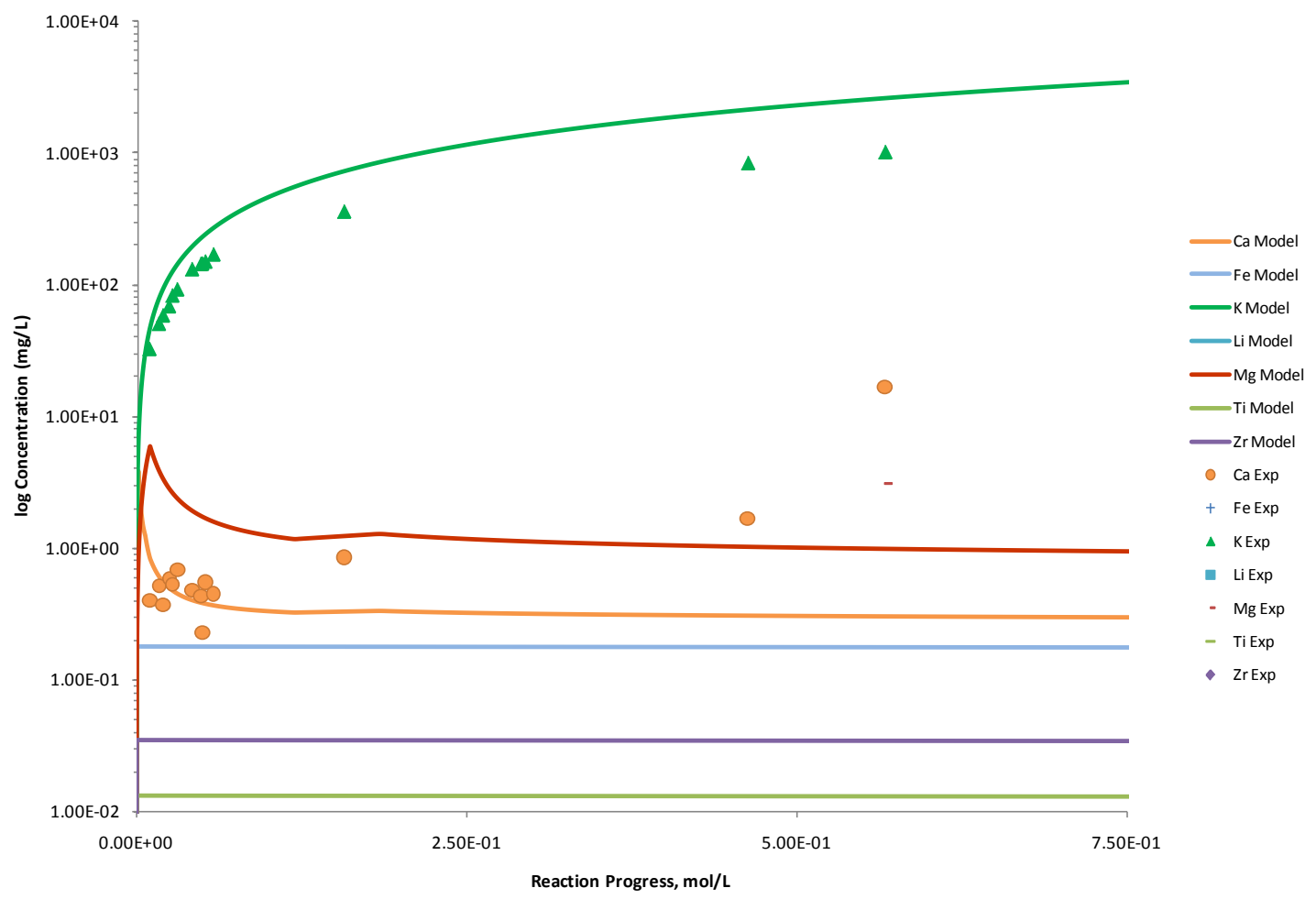

Figure C.345. Measured Solution Concentrations (mg/L) and Model Results for $\mathrm{Ca}, \mathrm{Fe}, \mathrm{K}, \mathrm{Li}, \mathrm{Mg}$, Ti, and $\mathrm{Zr}$, as a Function of Reaction Progress (mol-glass/kg) Determined for Glass Sample LAWC25

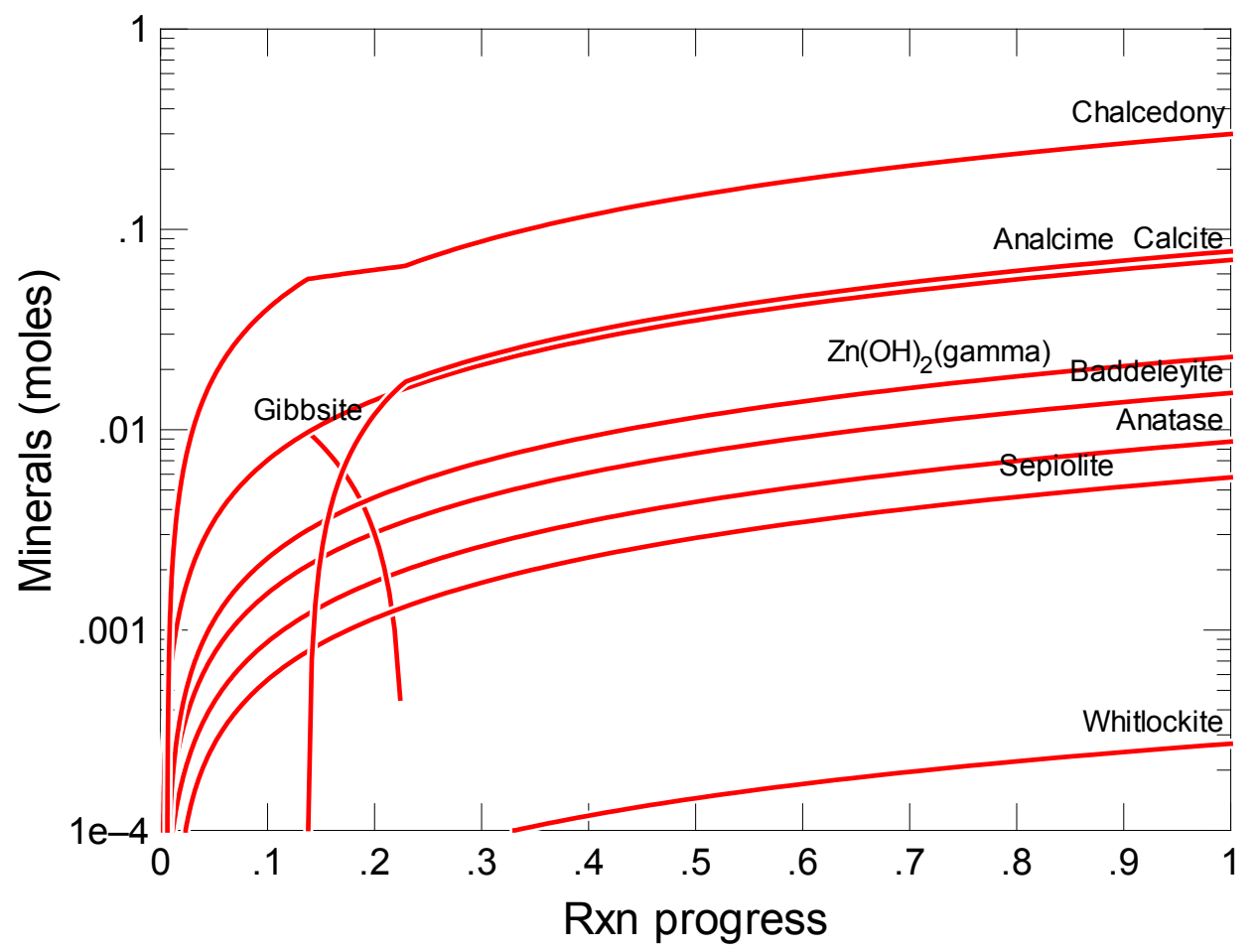

Figure C.346. Secondary Phases Calculated to Form as a Function of Reaction Progress (mol-glass/kg) Determined for Glass Sample LAWC26 


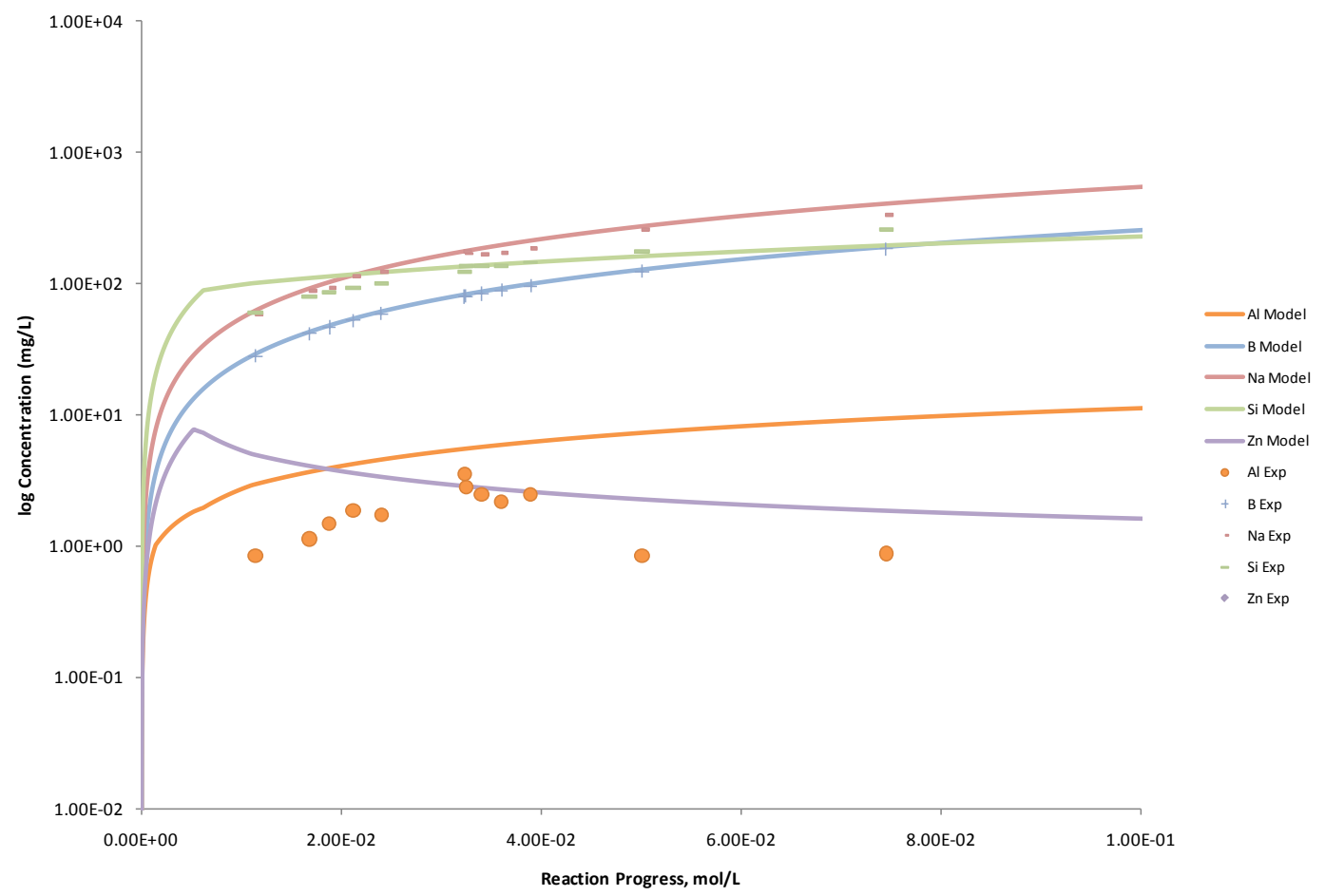

Figure C.347. Measured Solution Concentrations (mg/L) and Model Results for Al, B, Na, Si, and Zn, as a Function of Reaction Progress (mol-glass $/ \mathrm{kg}$ ) Determined for Glass Sample LAWC26

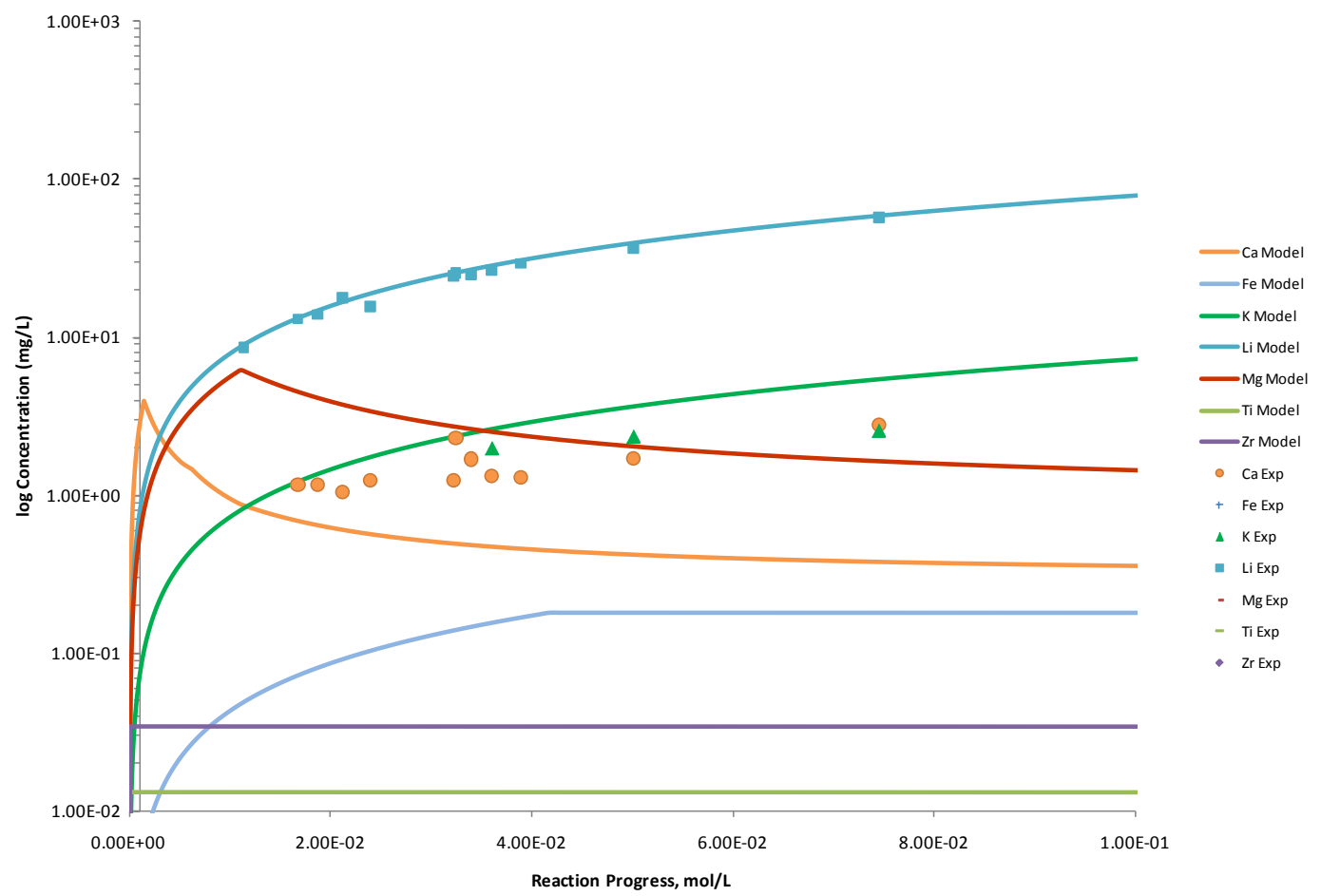

Figure C.348. Measured Solution Concentrations (mg/L) and Model Results for Ca, Fe, K, Li, Mg, Ti, and $\mathrm{Zr}$, as a Function of Reaction Progress (mol-glass/kg) Determined for Glass Sample LAWC26 


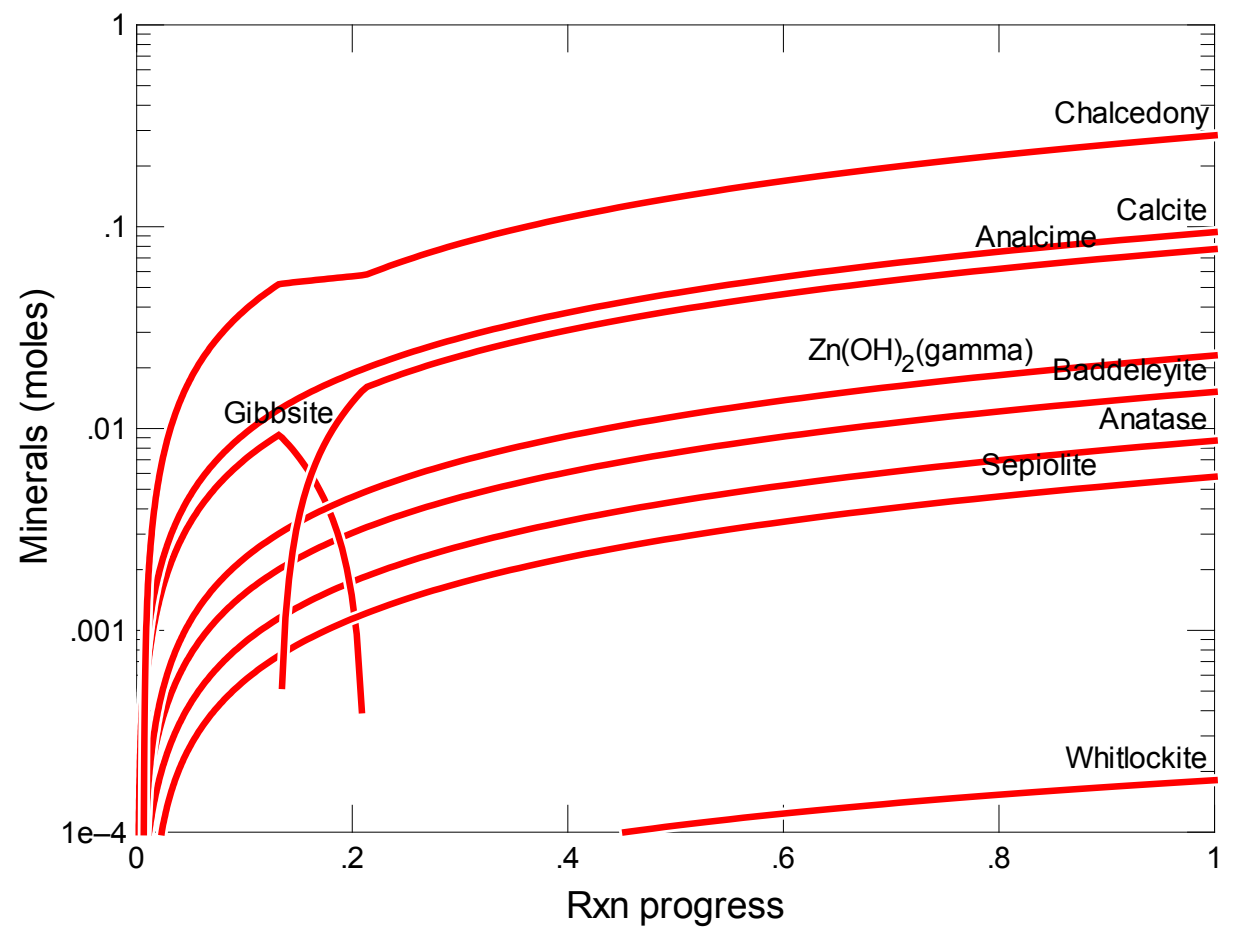

Figure C.349. Secondary Phases Calculated to Form as a Function of Reaction Progress (mol-glass $/ \mathrm{kg}$ ) Determined for Glass Sample LAWC27

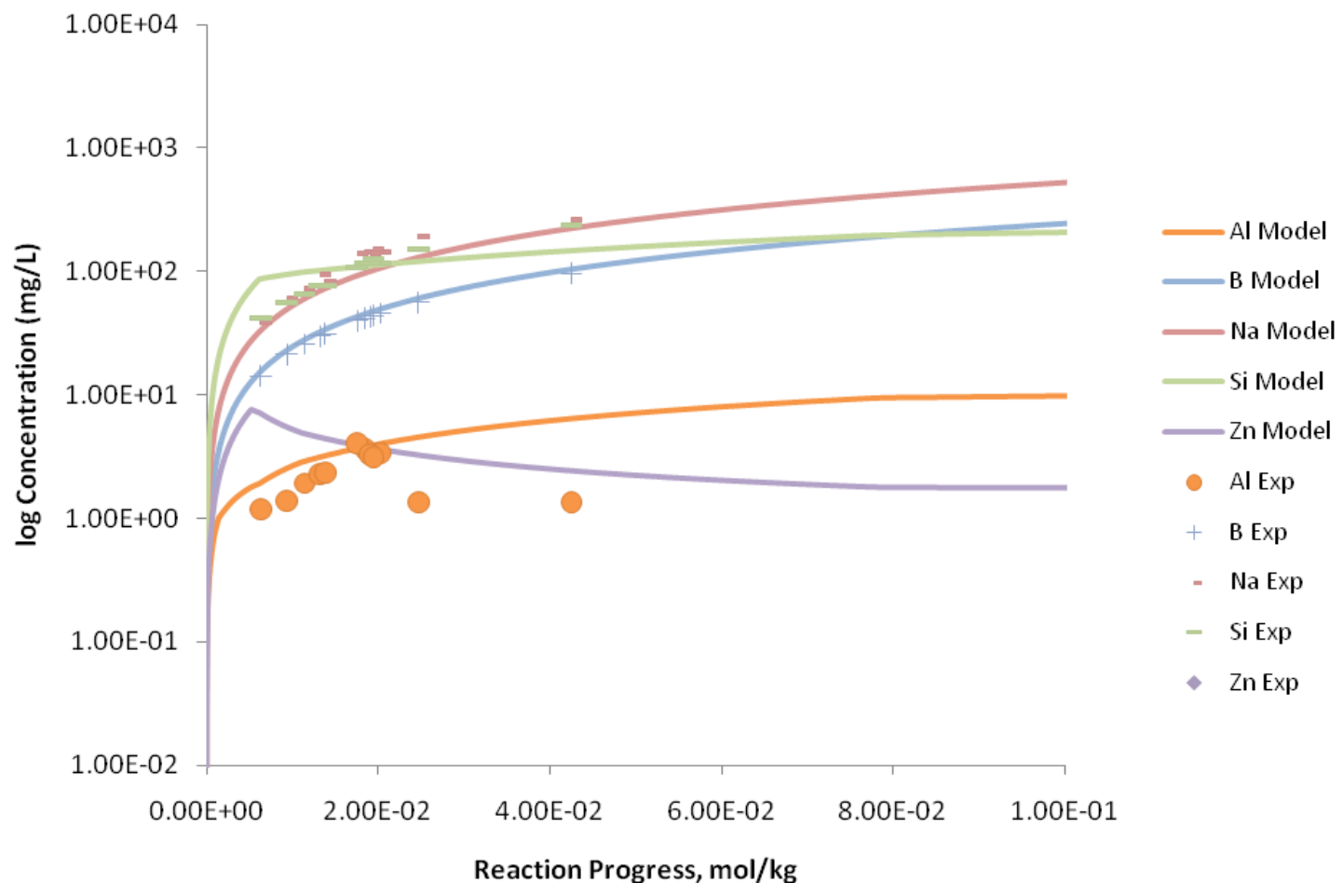

Figure C.350. Measured Solution Concentrations (mg/L) and Model Results for Al, B, Na, Si, and Zn, as a Function of Reaction Progress (mol-glass $/ \mathrm{kg}$ ) Determined for Glass Sample LAWC27 


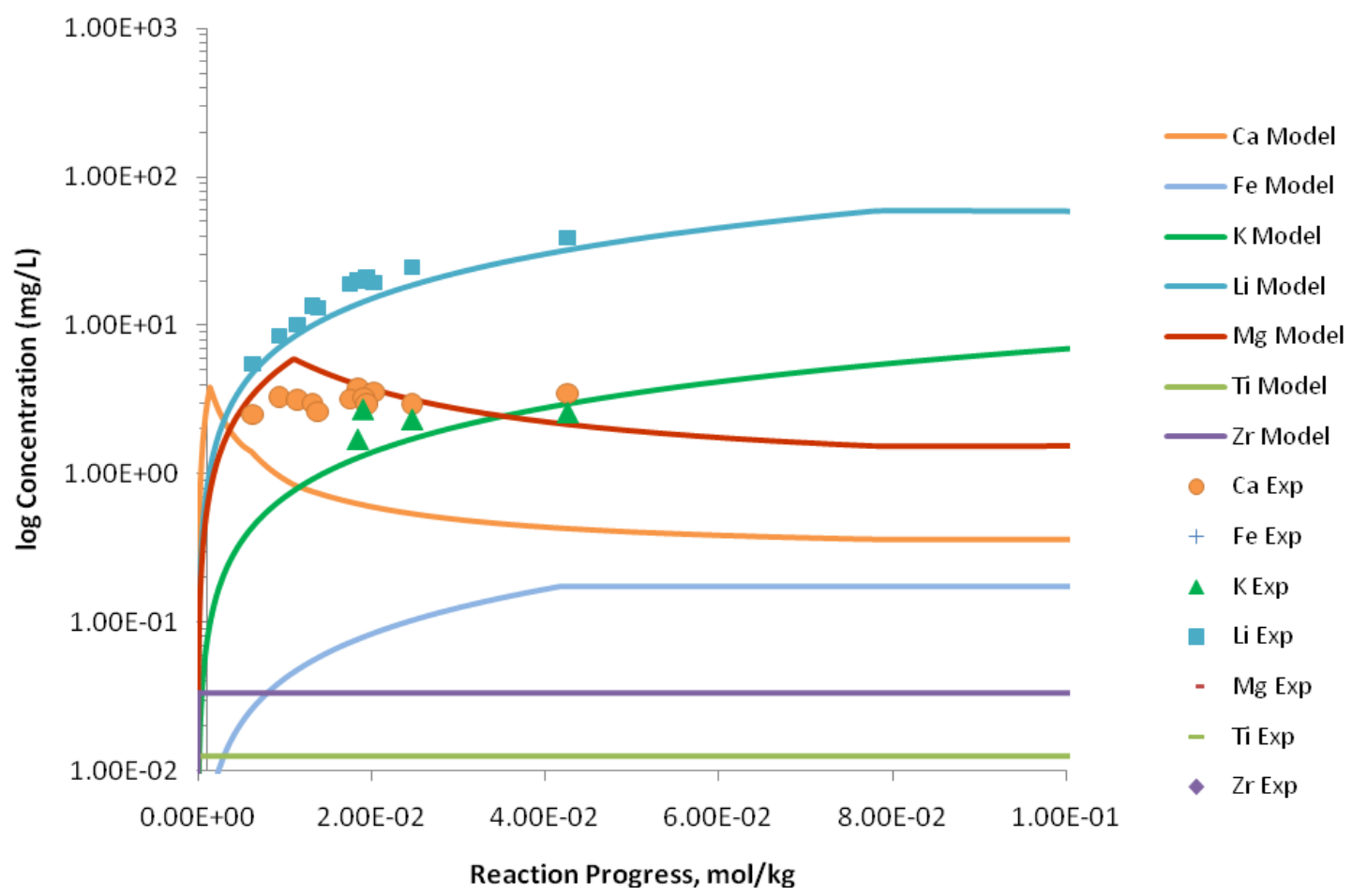

Figure C.351. Measured Solution Concentrations (mg/L) and Model Results for $\mathrm{Ca}, \mathrm{Fe}, \mathrm{K}, \mathrm{Li}, \mathrm{Mg}, \mathrm{Ti}$, and $\mathrm{Zr}$, as a Function of Reaction Progress (mol-glass/kg) Determined for Glass Sample LAWC27

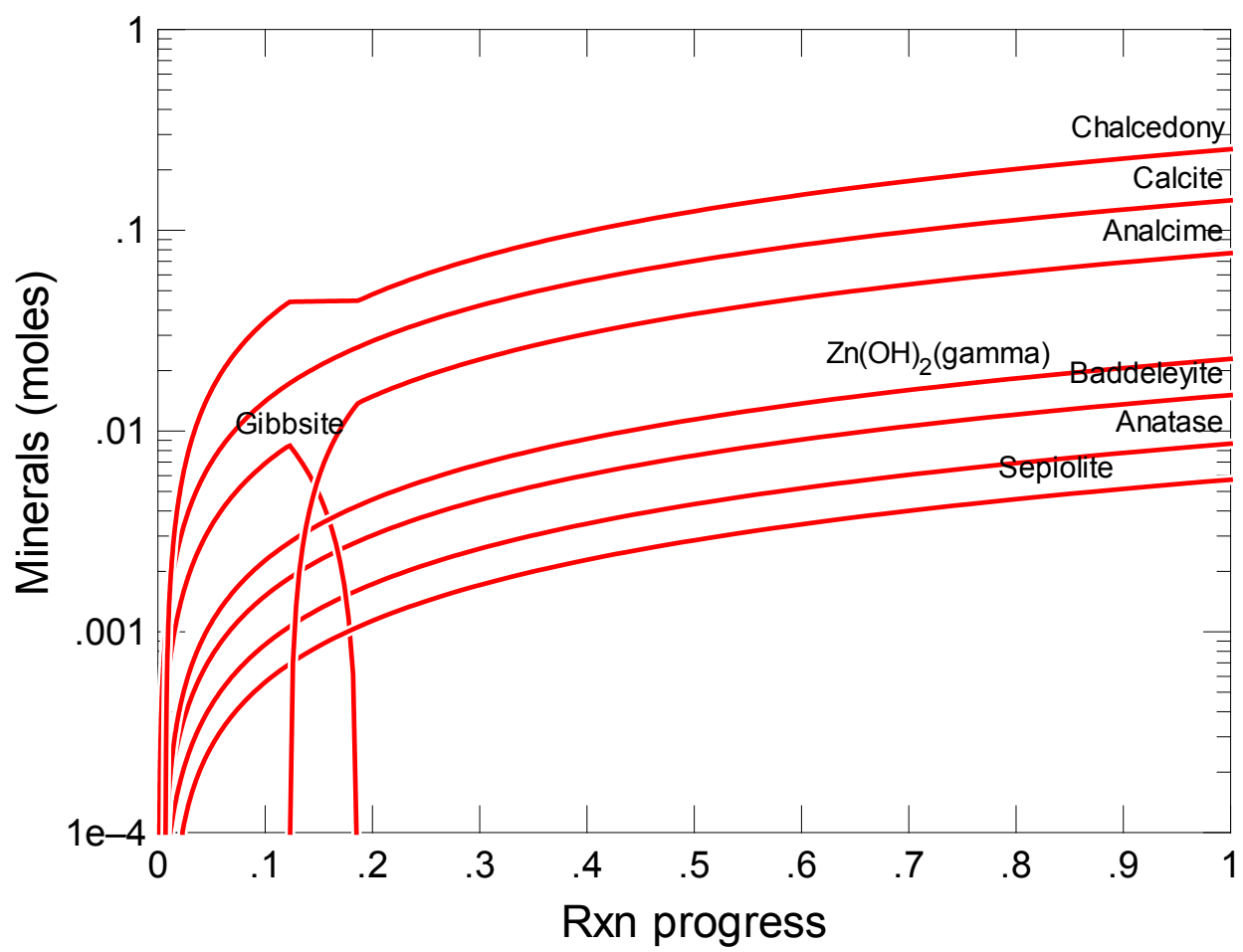

Figure C.352. Secondary Phases Calculated to Form as a Function of Reaction Progress (mol-glass/kg) Determined for Glass Sample LAWC28 


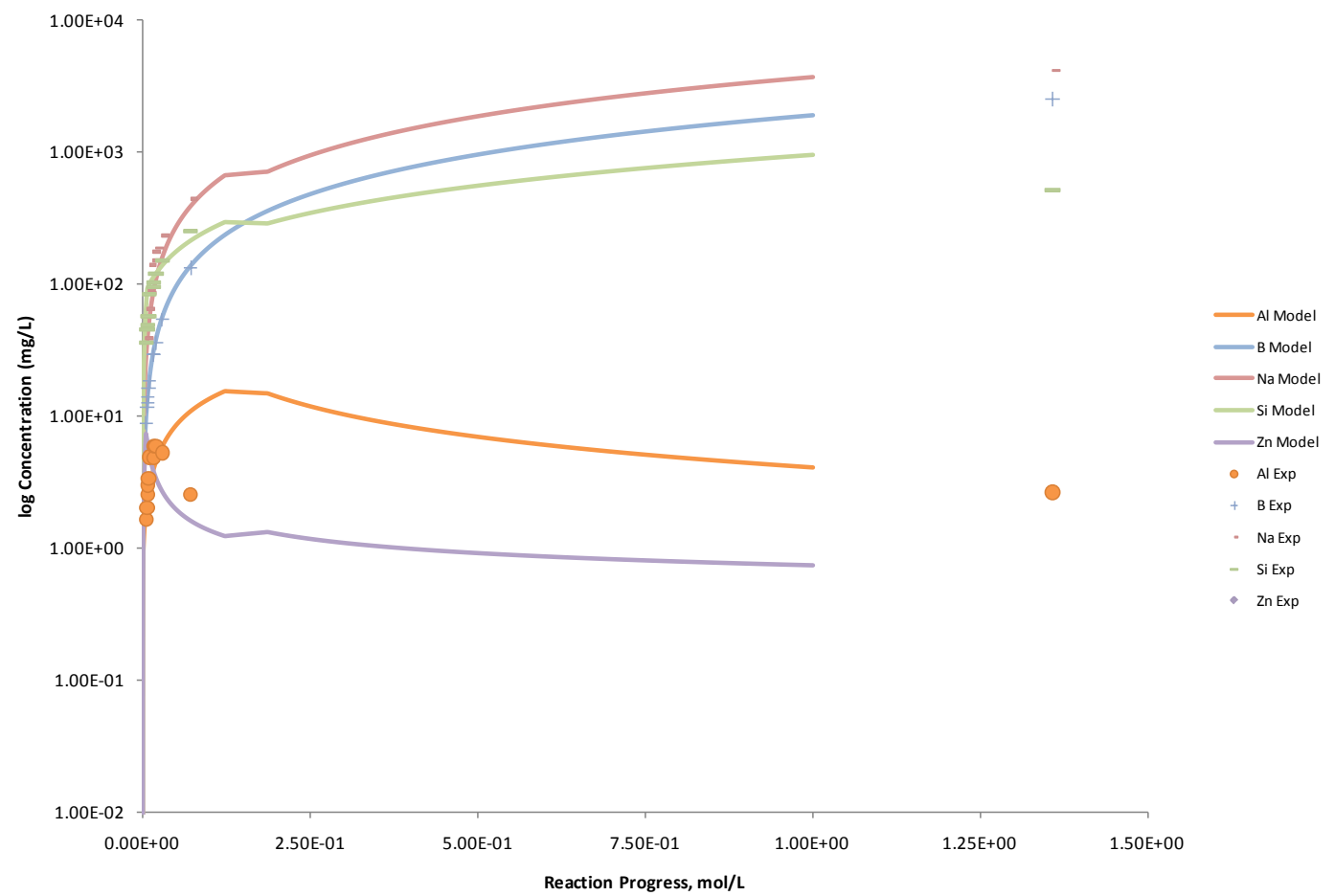

Figure C.353. Measured Solution Concentrations (mg/L) and Model Results for Al, B, Na, Si, and Zn, as a Function of Reaction Progress (mol-glass $/ \mathrm{kg}$ ) Determined for Glass Sample LAWC28

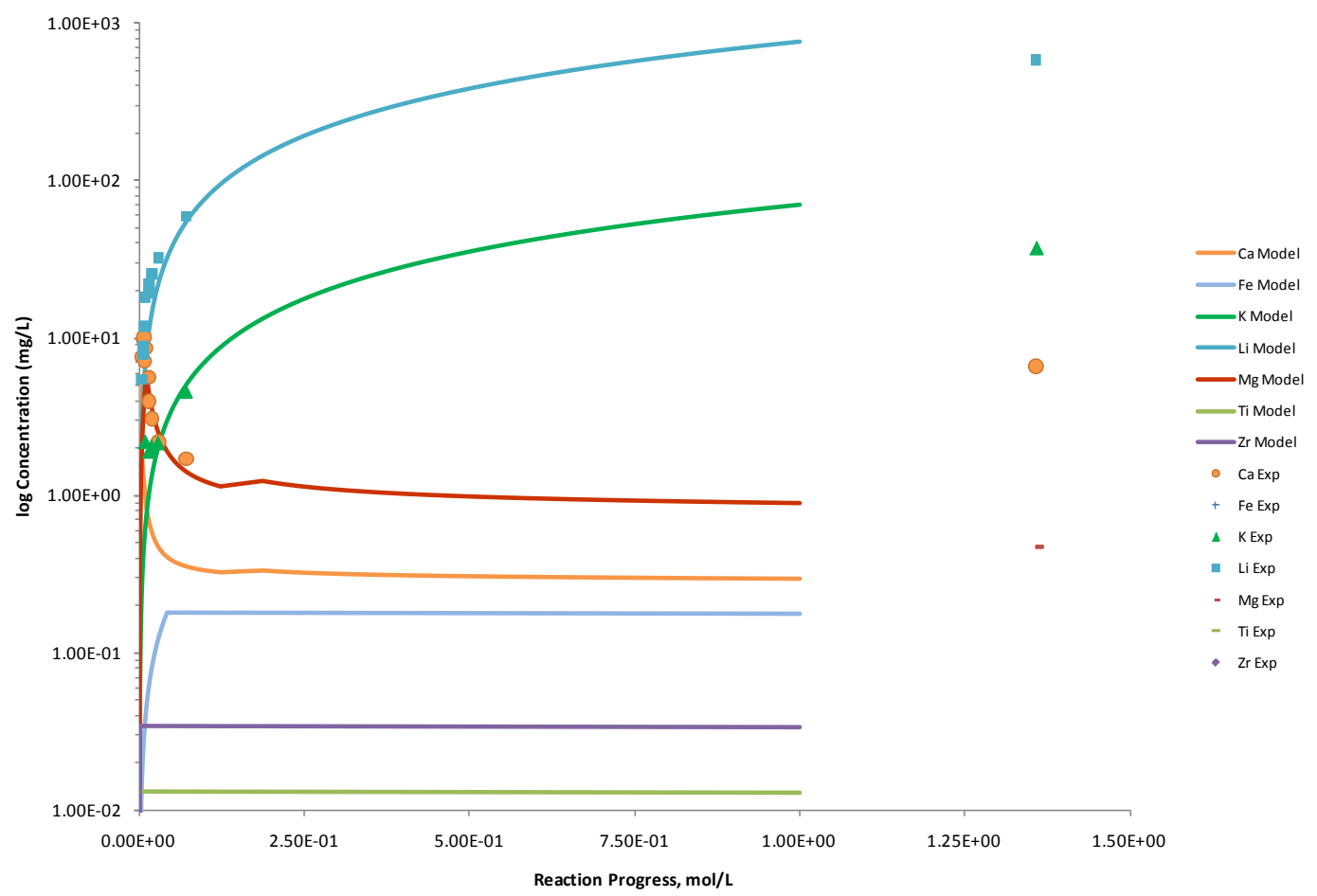

Figure C.354. Measured Solution Concentrations (mg/L) and Model Results for $\mathrm{Ca}, \mathrm{Fe}, \mathrm{K}, \mathrm{Li}, \mathrm{Mg}, \mathrm{Ti}$, and Zr, as a Function of Reaction Progress (mol-glass/kg) Determined for Glass Sample LAWC28 


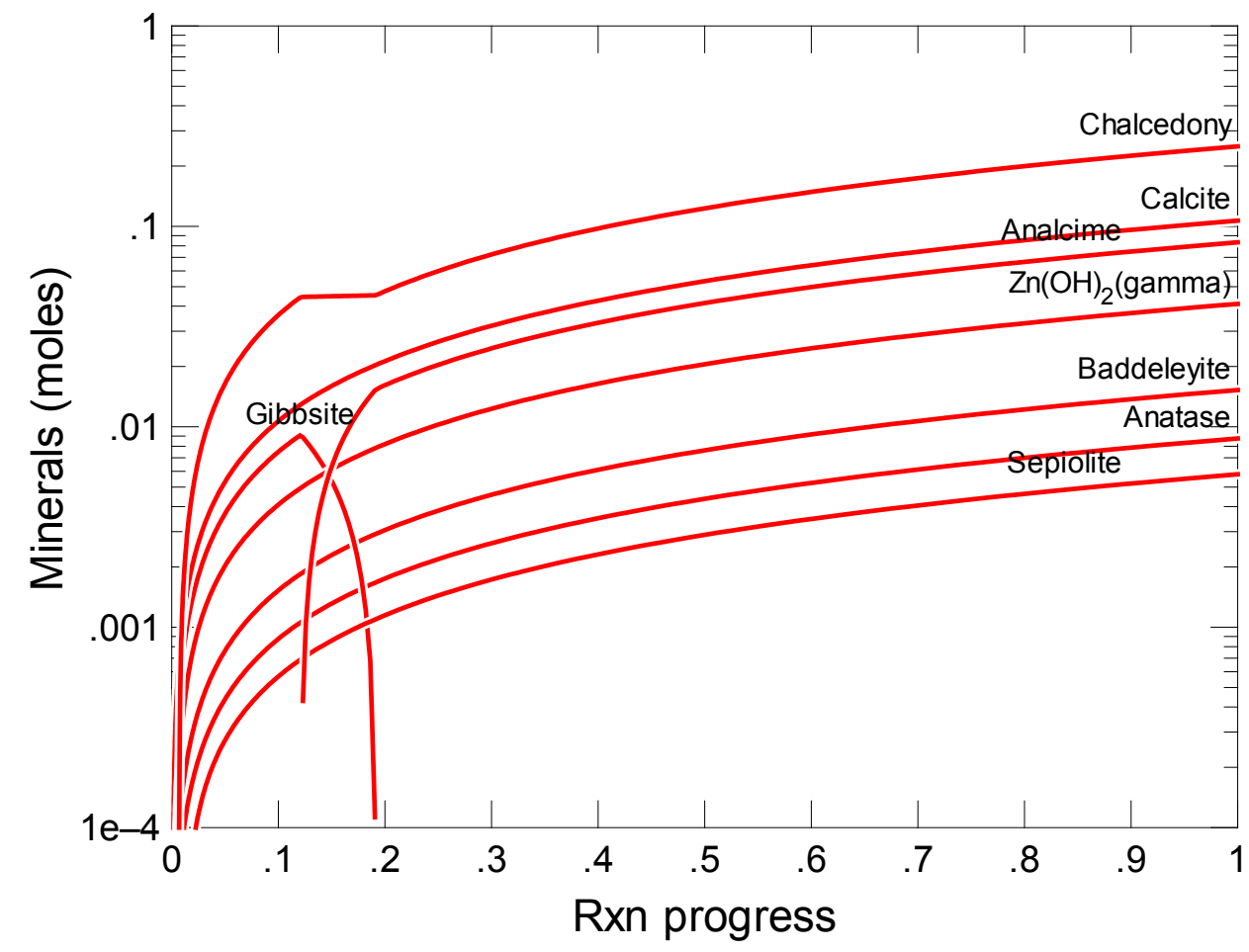

Figure C.355. Secondary Phases Calculated to Form as a Function of Reaction Progress (mol-glass $/ \mathrm{kg}$ ) Determined for Glass Sample LAWC29

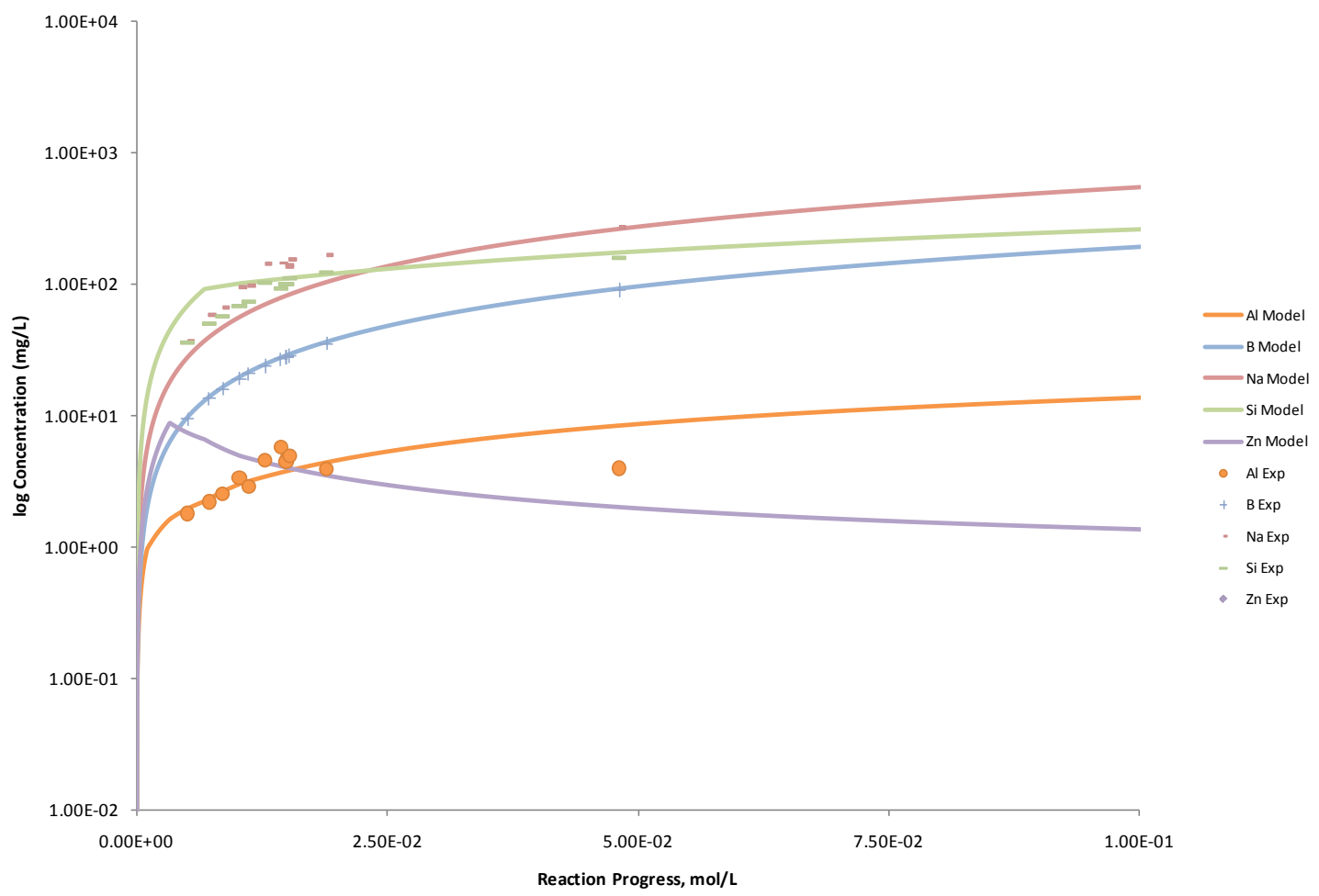

Figure C.356. Measured Solution Concentrations (mg/L) and Model Results for Al, B, Na, Si, and Zn, as a Function of Reaction Progress (mol-glass $/ \mathrm{kg}$ ) Determined for Glass Sample LAWC29 


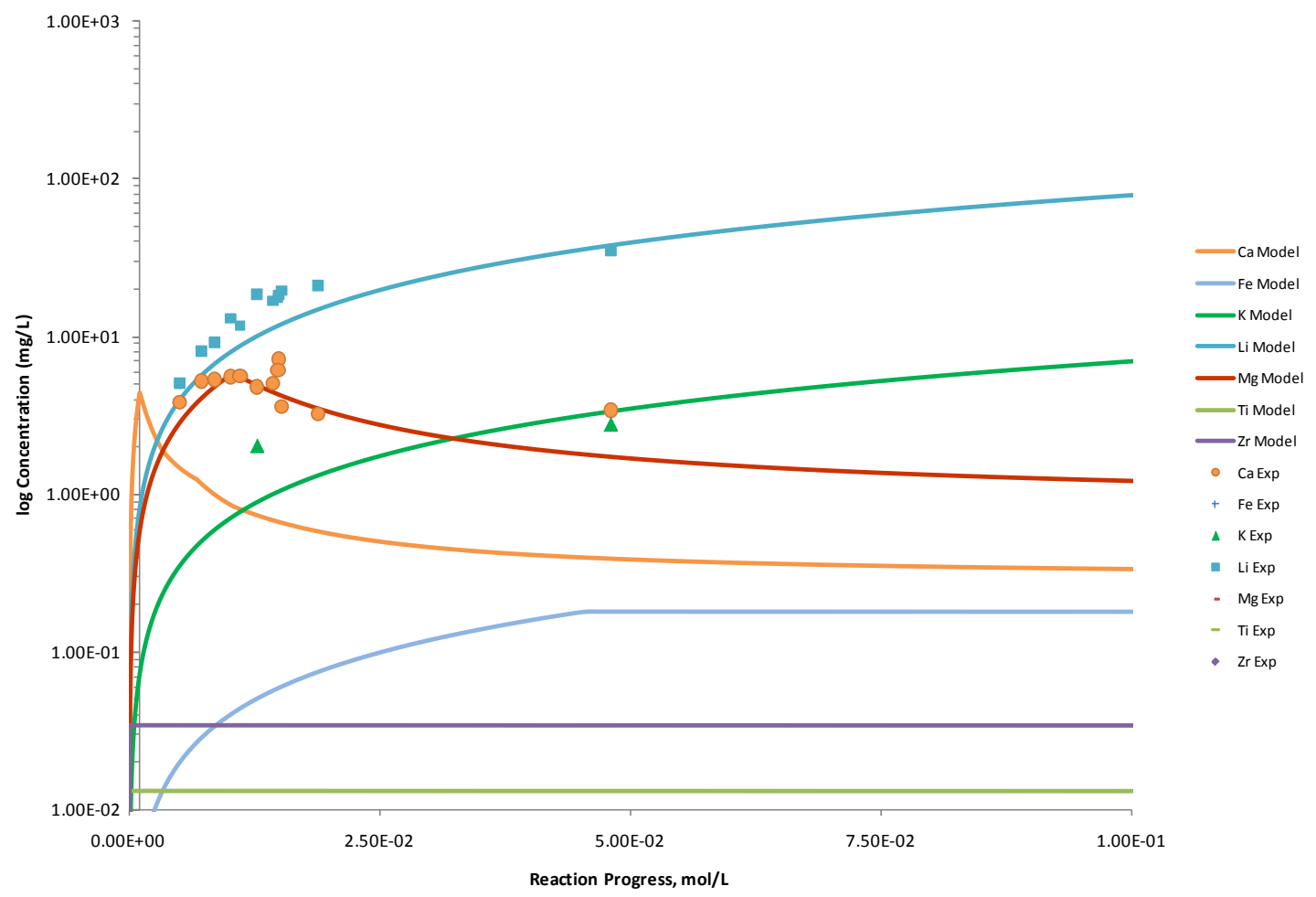

Figure C.357. Measured Solution Concentrations (mg/L) and Model Results for Ca, Fe, K, Li, Mg, Ti, and $\mathrm{Zr}$, as a Function of Reaction Progress (mol-glass/kg) Determined for Glass Sample LAWC29

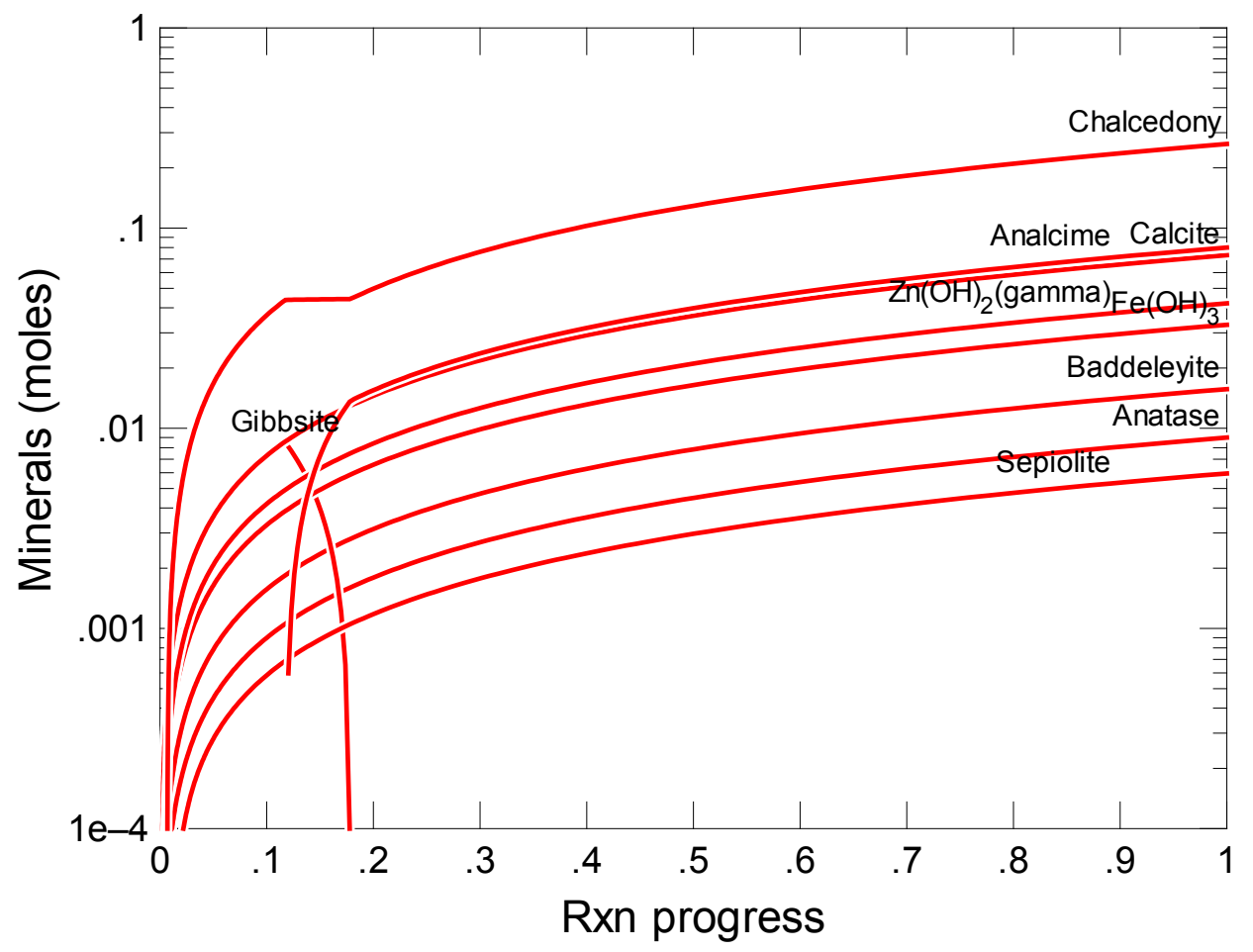

Figure C.358. Secondary Phases Calculated to Form as a Function of Reaction Progress (mol-glass $/ \mathrm{kg}$ ) Determined for Glass Sample LAWC30 


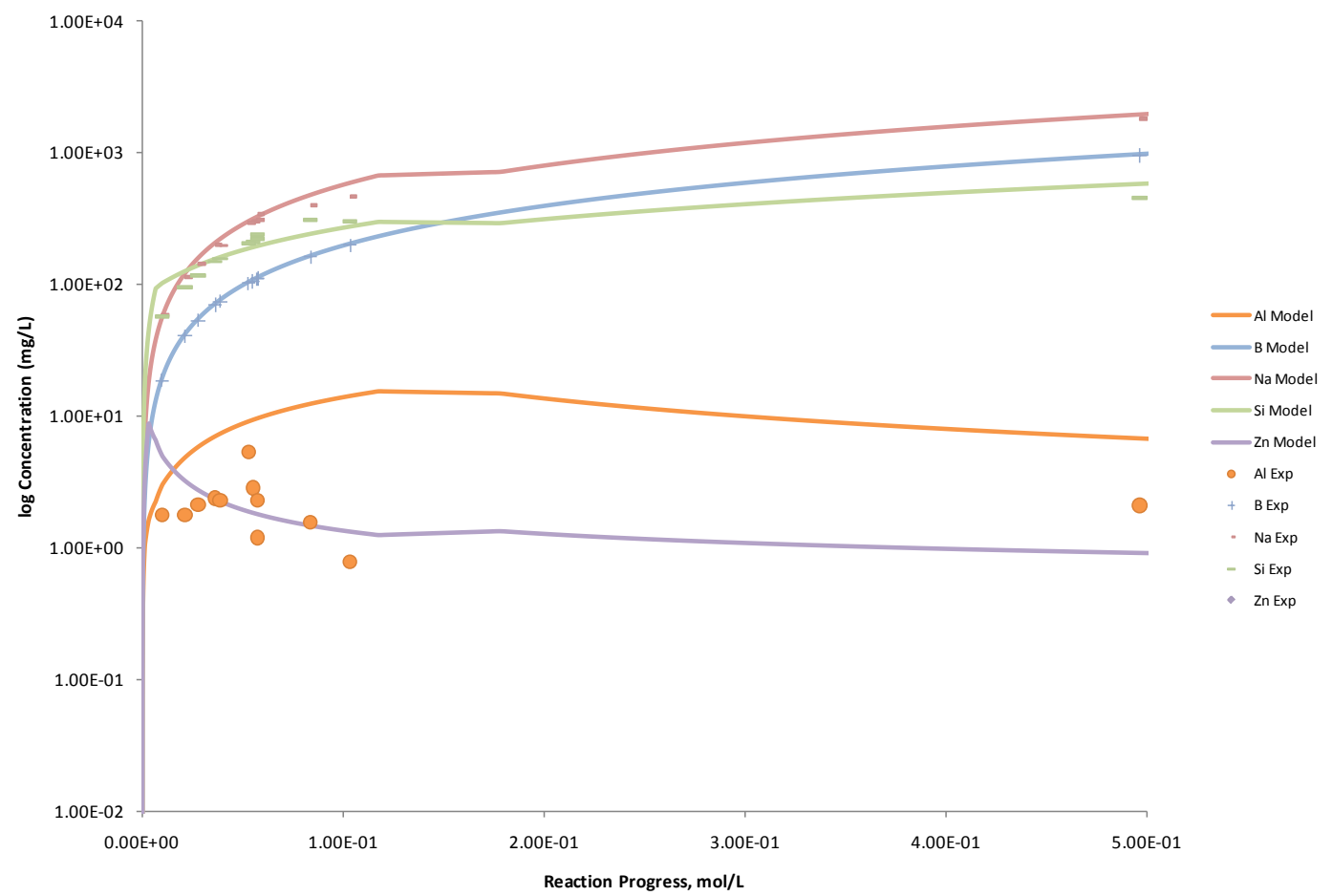

Figure C.359. Measured Solution Concentrations (mg/L) and Model Results for Al, B, Na, Si, and Zn, as a Function of Reaction Progress (mol-glass $/ \mathrm{kg}$ ) Determined for Glass Sample LAWC30

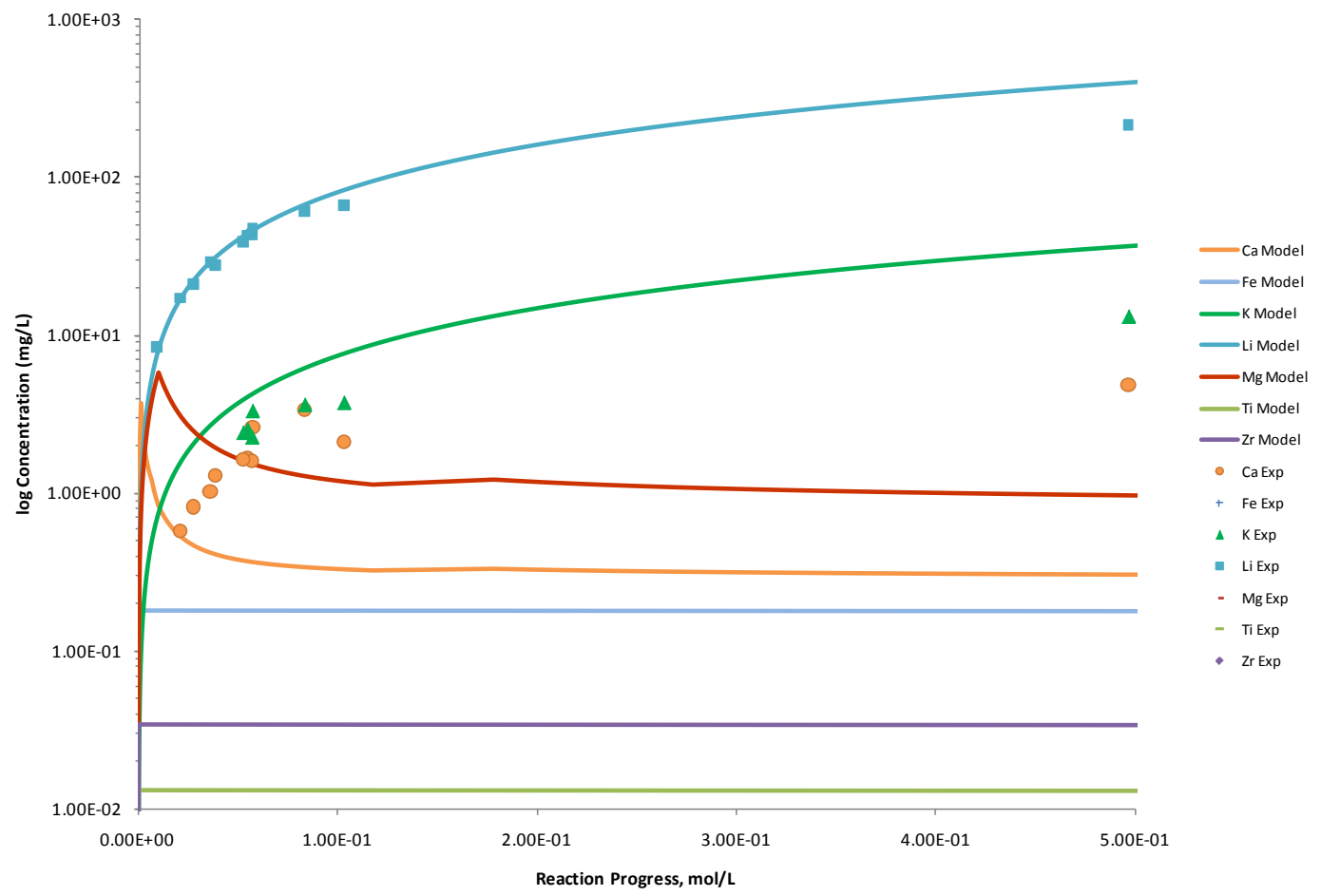

Figure C.360. Measured Solution Concentrations (mg/L) and Model Results for $\mathrm{Ca}, \mathrm{Fe}, \mathrm{K}, \mathrm{Li}, \mathrm{Mg}, \mathrm{Ti}$, and $\mathrm{Zr}$, as a Function of Reaction Progress (mol-glass/kg) Determined for Glass Sample LAWC30 


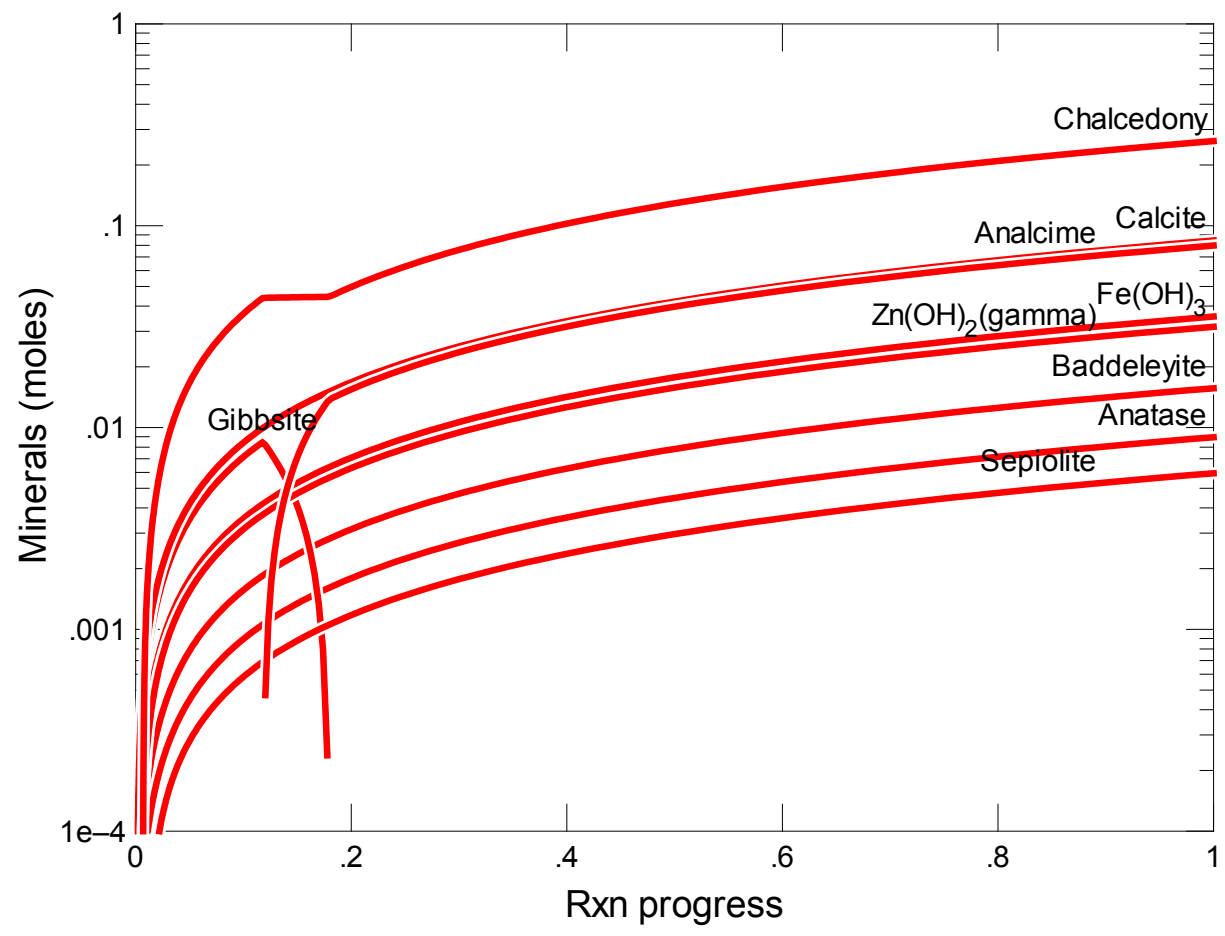

Figure C.361. Secondary Phases Calculated to Form as a Function of Reaction Progress (mol-glass $/ \mathrm{kg}$ ) Determined for Glass Sample LAWC31

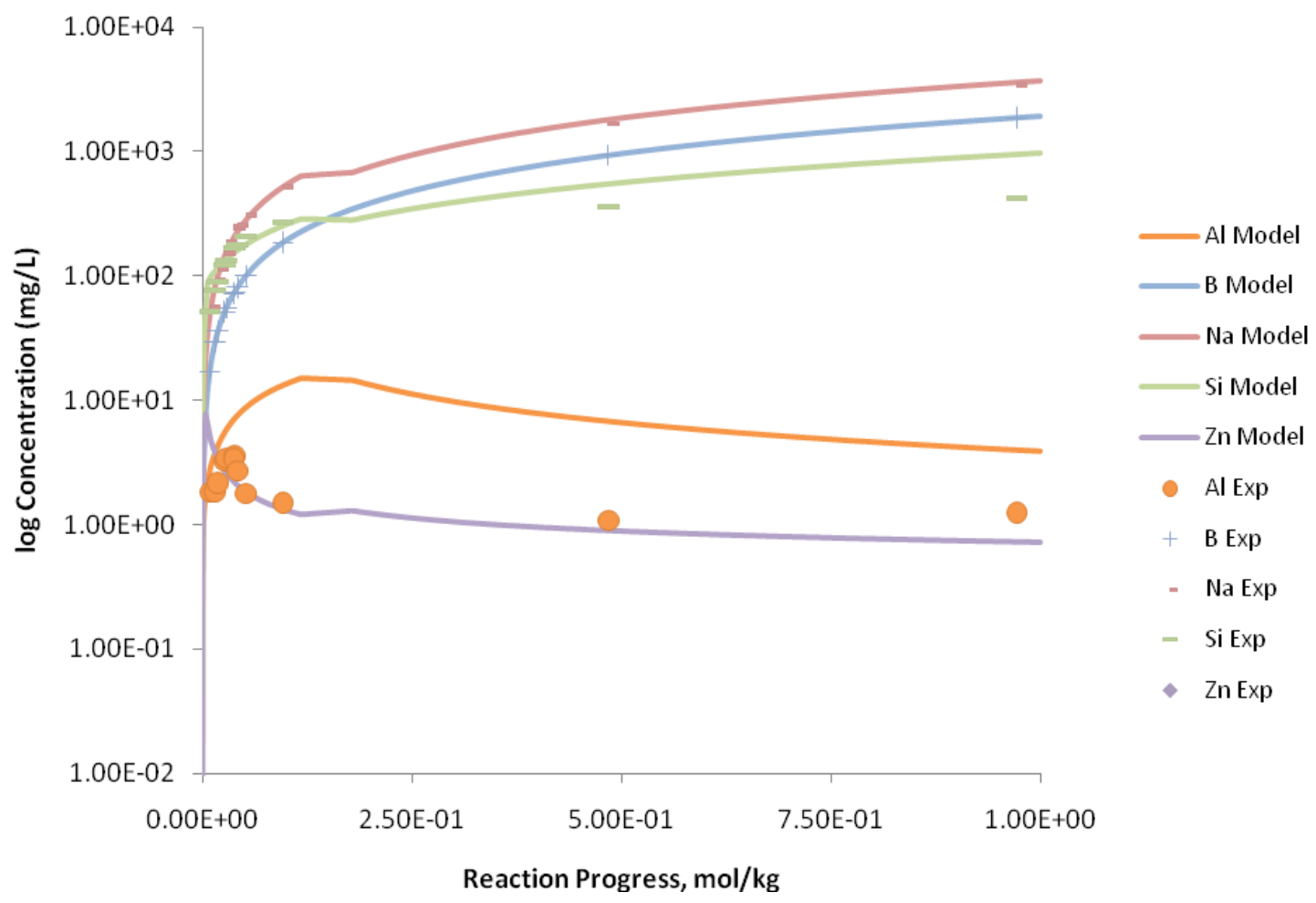

Figure C.362. Measured Solution Concentrations (mg/L) and Model Results for Al, B, Na, Si, and Zn, as a Function of Reaction Progress (mol-glass $/ \mathrm{kg}$ ) Determined for Glass Sample LAWC31 


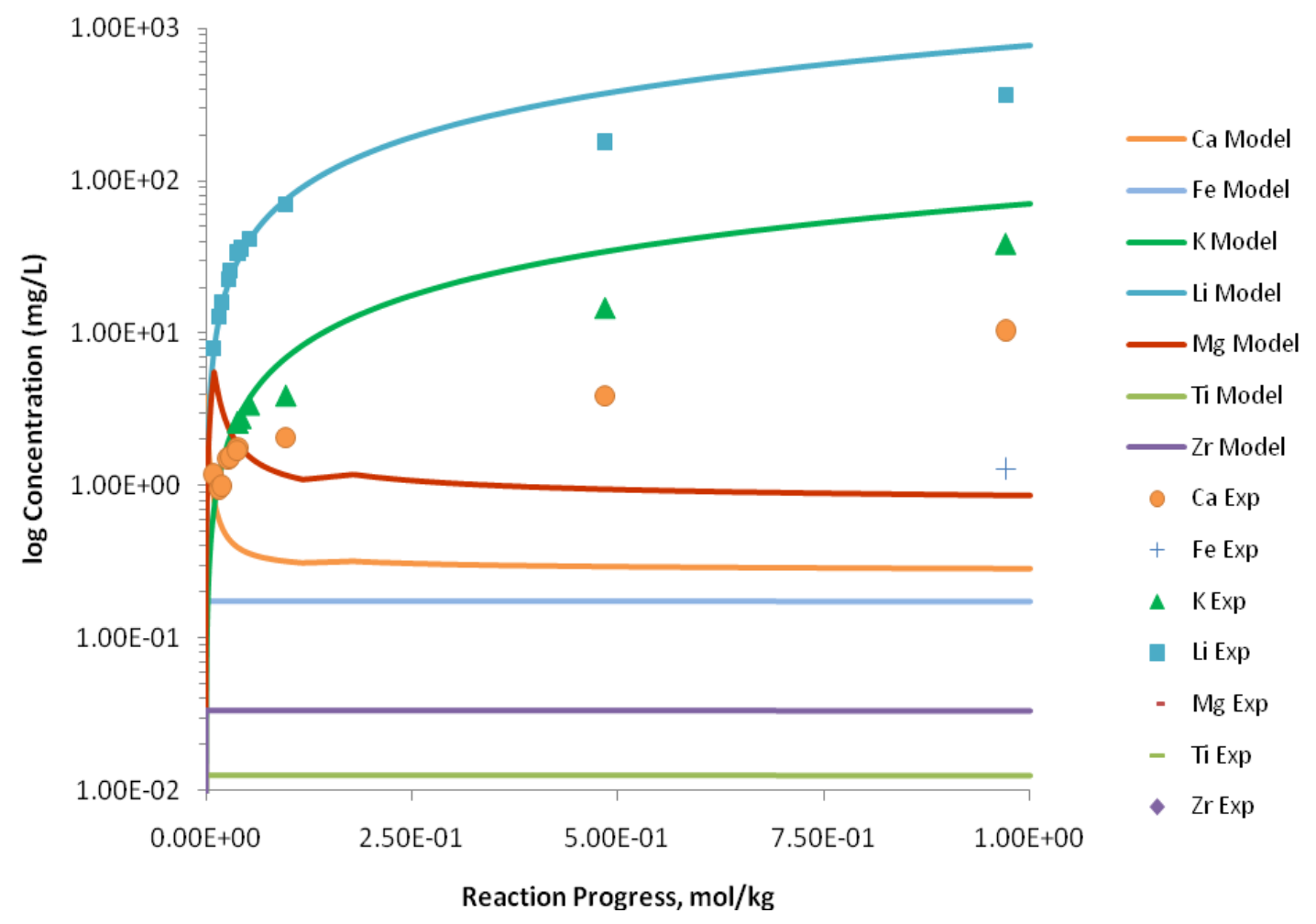

Figure C.363. Measured Solution Concentrations (mg/L) and Model Results for $\mathrm{Ca}, \mathrm{Fe}, \mathrm{K}, \mathrm{Li}, \mathrm{Mg}, \mathrm{Ti}$, and $\mathrm{Zr}$, as a Function of Reaction Progress (mol-glass/kg) Determined for Glass Sample LAWC31

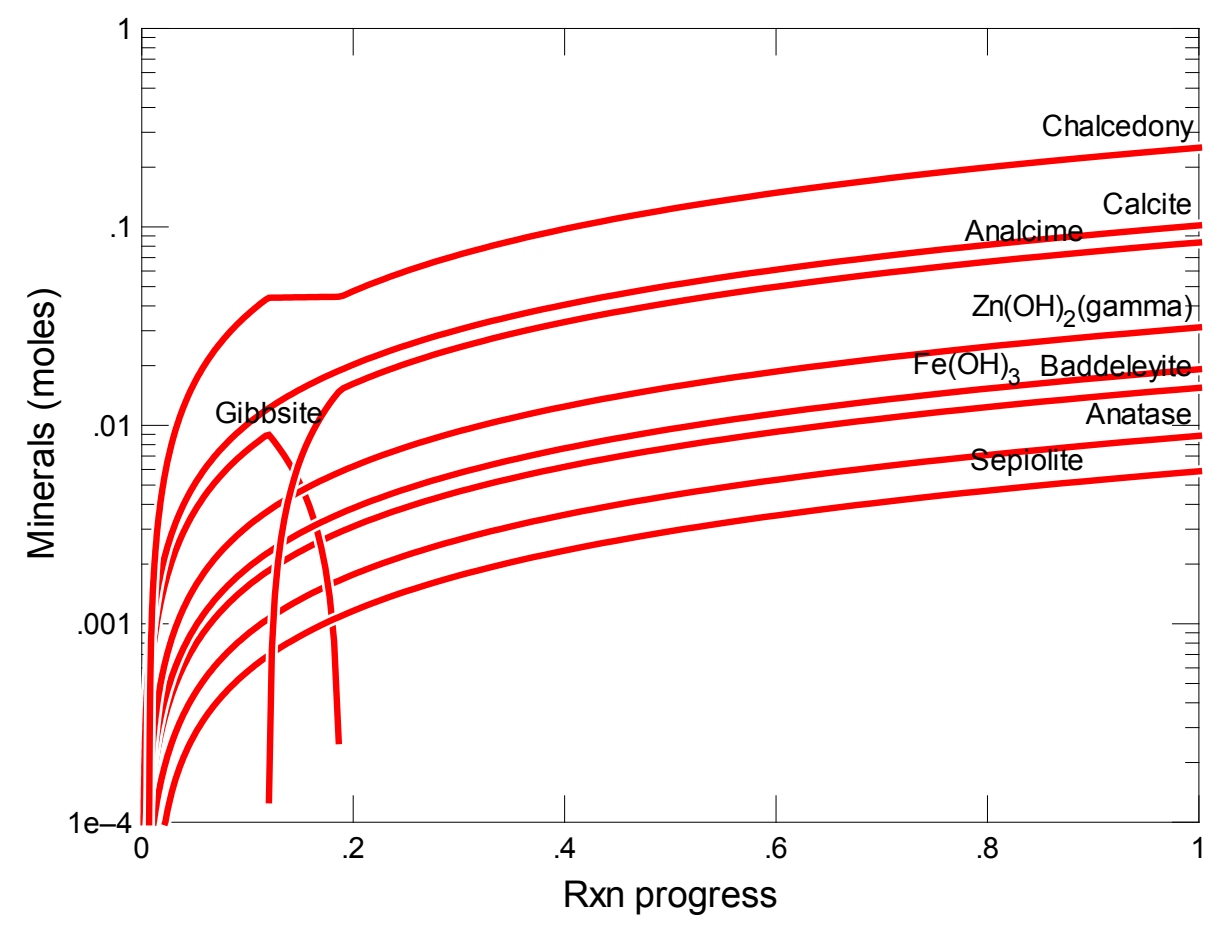

Figure C.364. Secondary Phases Calculated to Form as a Function of Reaction Progress (mol-glass $/ \mathrm{kg}$ ) Determined for Glass Sample LAWC32 


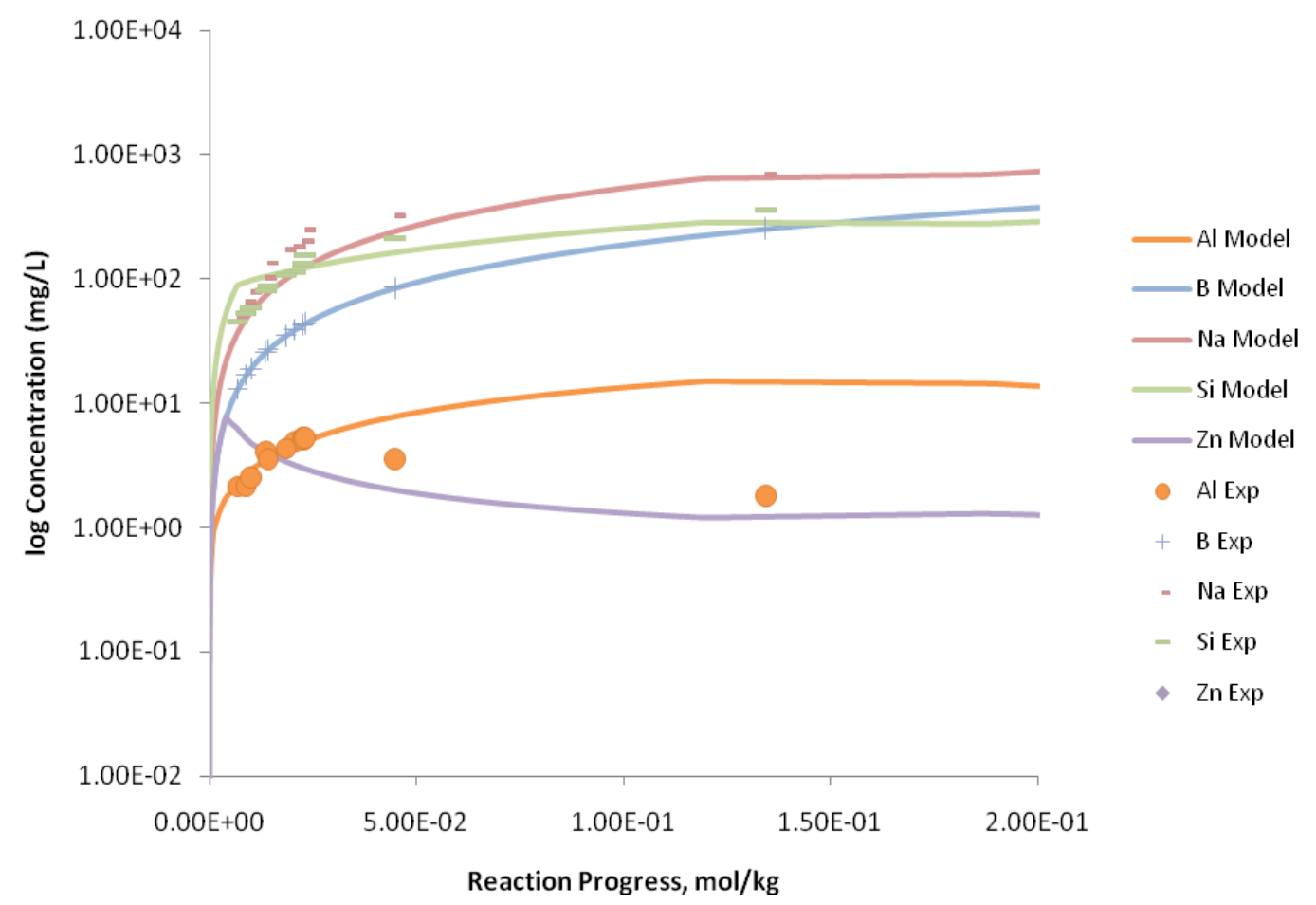

Figure C.365. Measured Solution Concentrations (mg/L) and Model Results for Al, B, Na, Si, and Zn, as a Function of Reaction Progress (mol-glass $/ \mathrm{kg}$ ) Determined for Glass Sample LAWC32

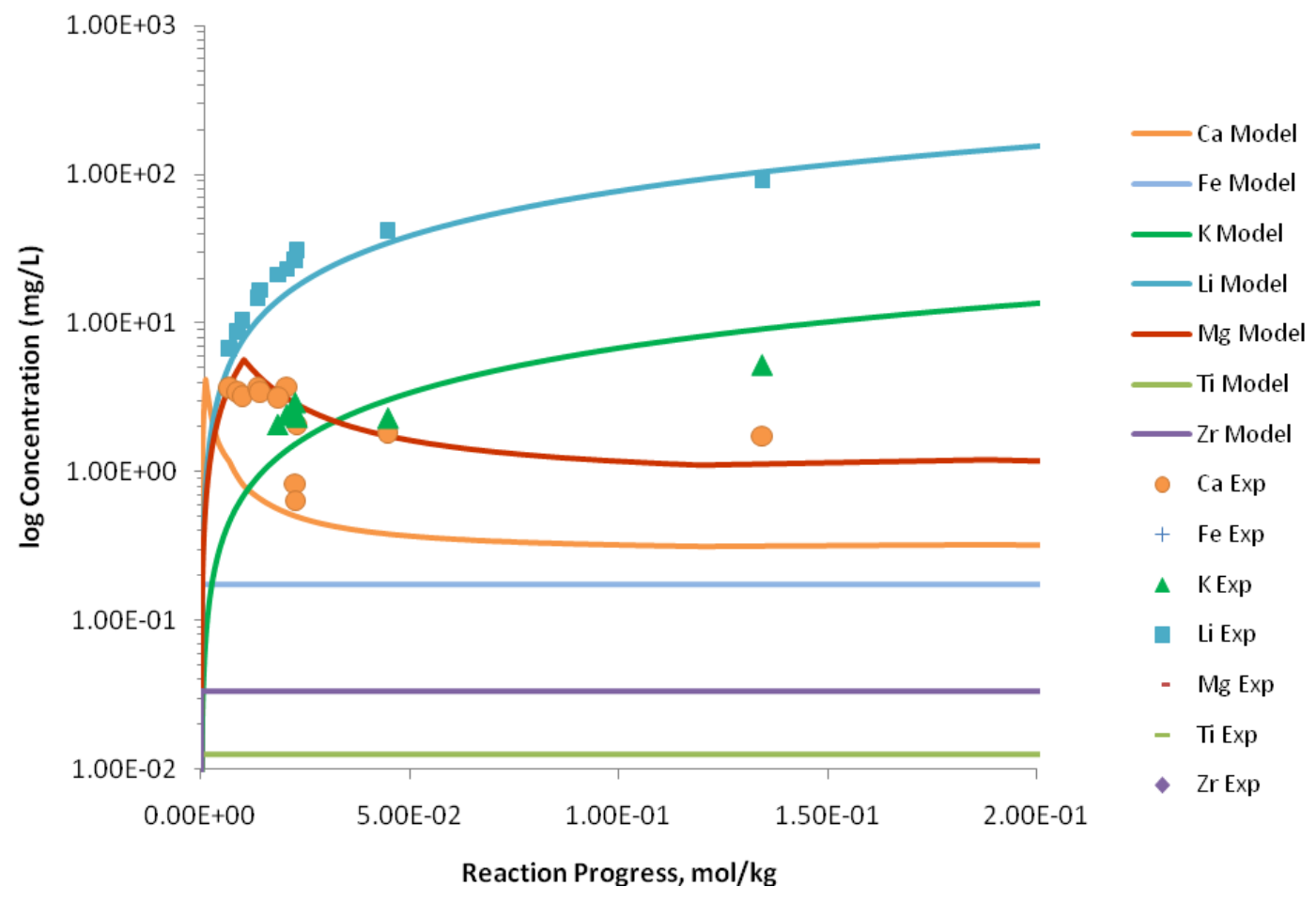

Figure C.366. Measured Solution Concentrations (mg/L) and Model Results for $\mathrm{Ca}, \mathrm{Fe}, \mathrm{K}, \mathrm{Li}, \mathrm{Mg}, \mathrm{Ti}$, and $\mathrm{Zr}$, as a Function of Reaction Progress (mol-glass/kg) Determined for Glass Sample LAWC32 


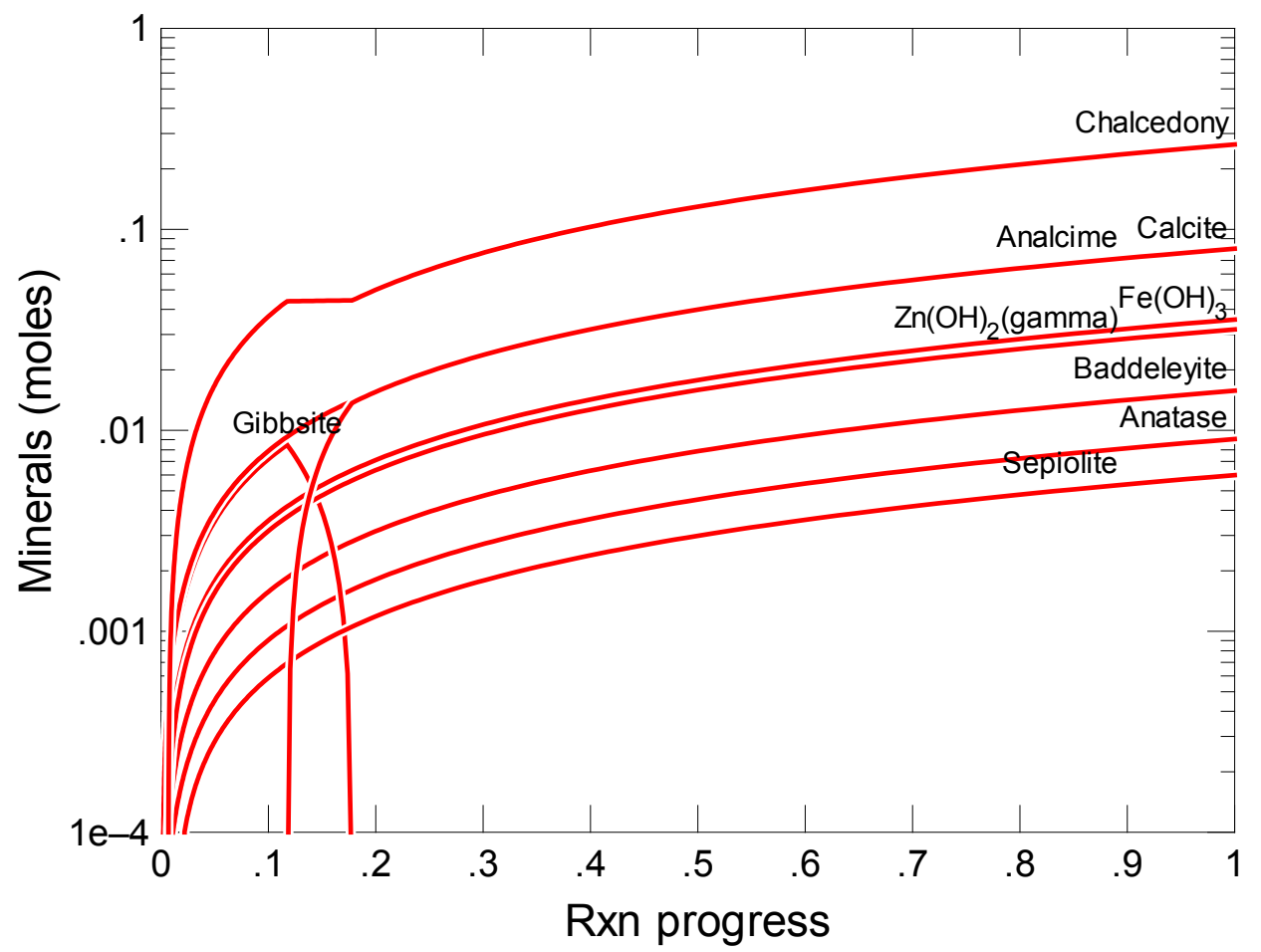

Figure C.367. Secondary Phases Calculated to Form as a Function of Reaction Progress (mol-glass $/ \mathrm{kg}$ ) Determined for Glass Sample LAWC33

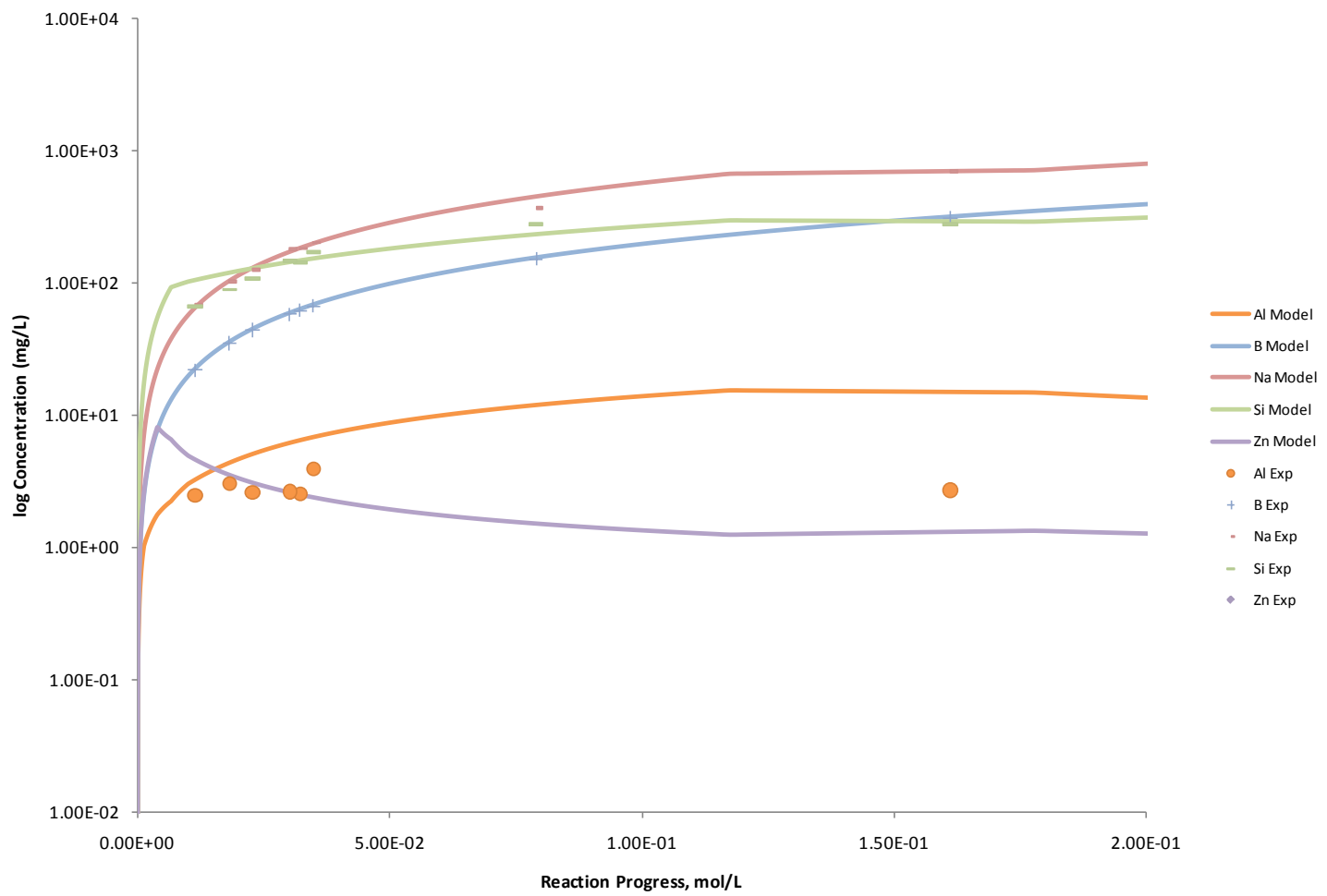

Figure C.368. Measured Solution Concentrations (mg/L) and Model Results for Al, B, Na, Si, and Zn, as a Function of Reaction Progress (mol-glass $/ \mathrm{kg}$ ) Determined for Glass Sample LAWC33 


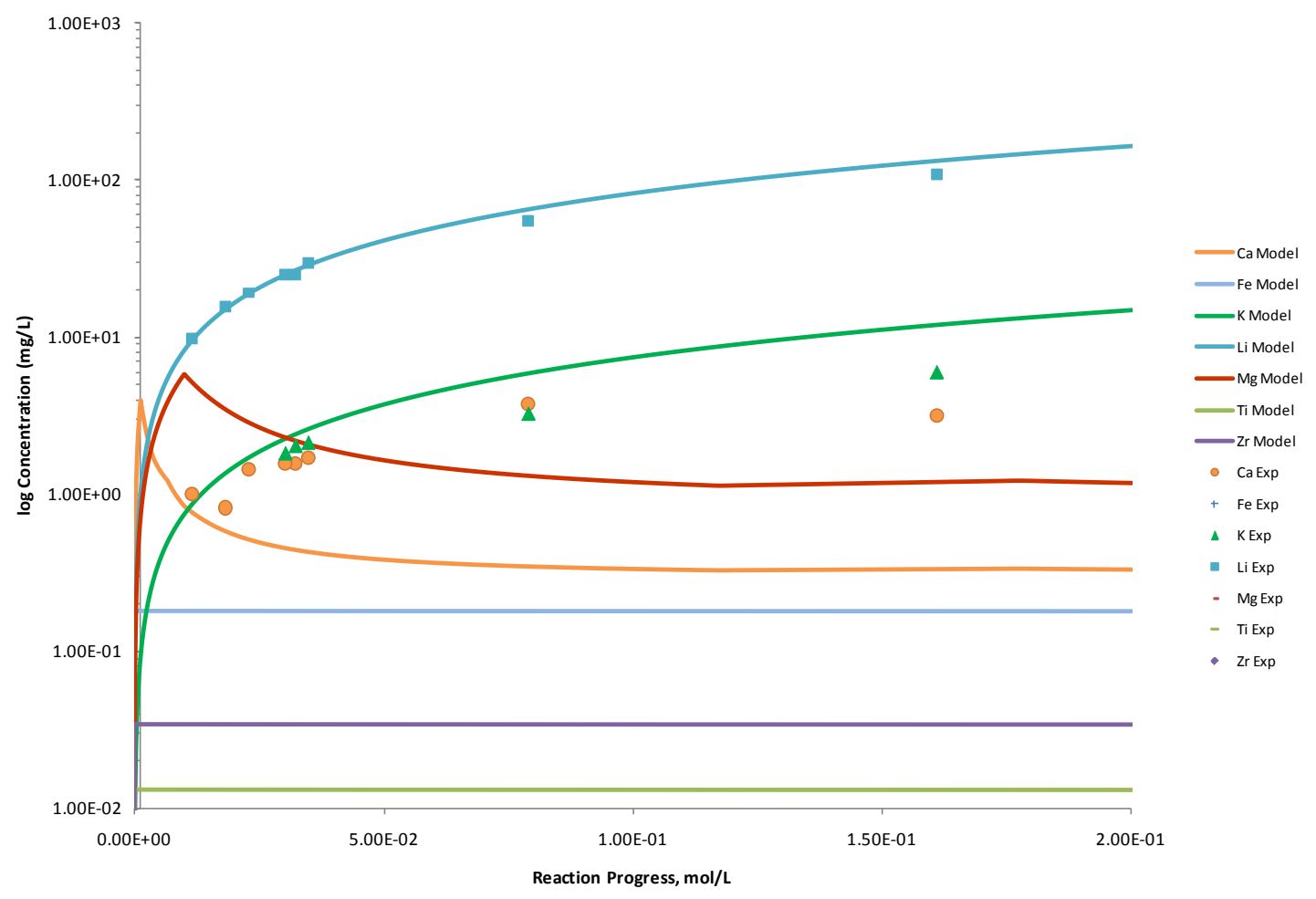

Figure C.369. Measured Solution Concentrations (mg/L) and Model Results for $\mathrm{Ca}, \mathrm{Fe}, \mathrm{K}, \mathrm{Li}, \mathrm{Mg}$, Ti, and $\mathrm{Zr}$, as a Function of Reaction Progress (mol-glass/kg) Determined for Glass Sample LAWC33

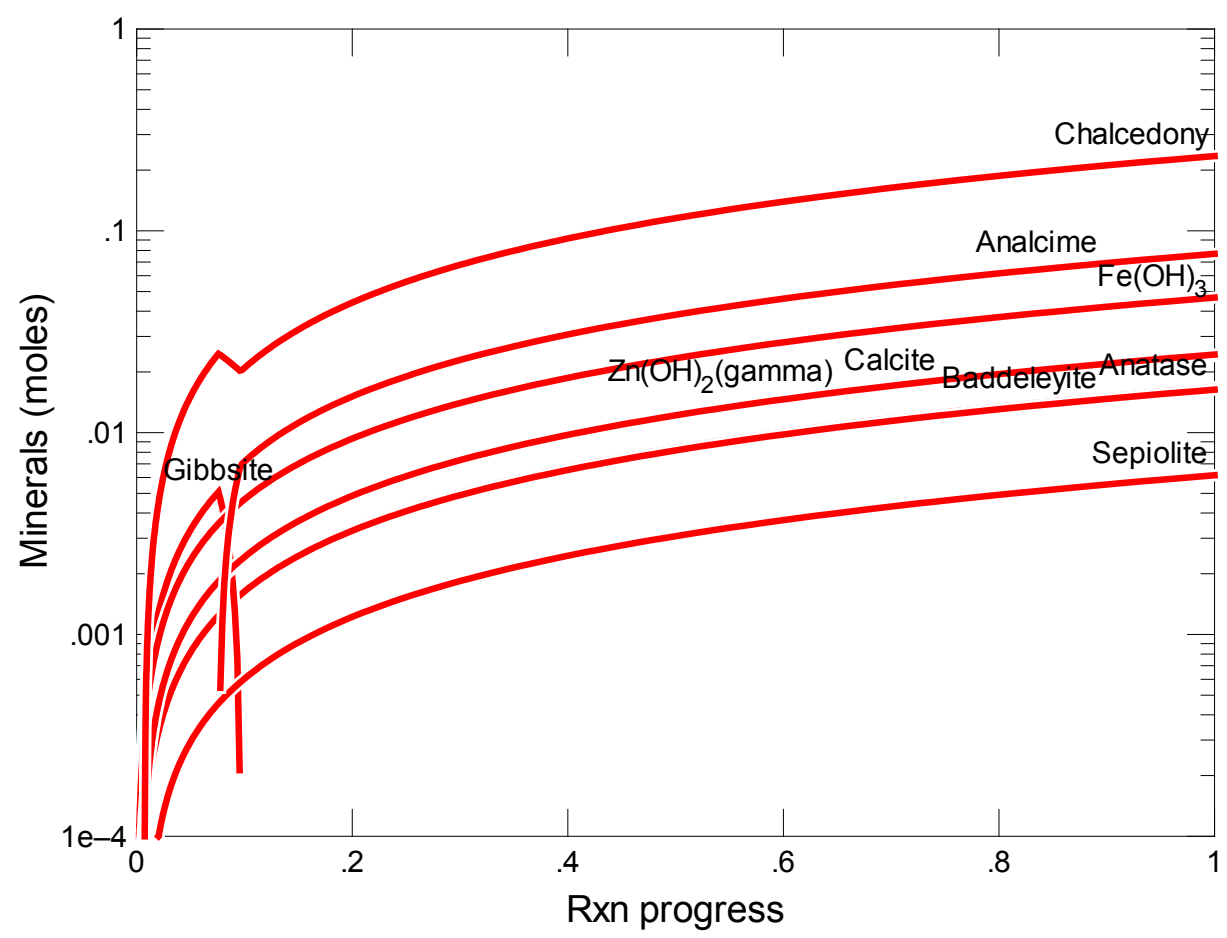

Figure C.370. Secondary Phases Calculated to Form as a Function of Reaction Progress (mol-glass $/ \mathrm{kg}$ ) Determined for Glass Sample PNLA126CC 


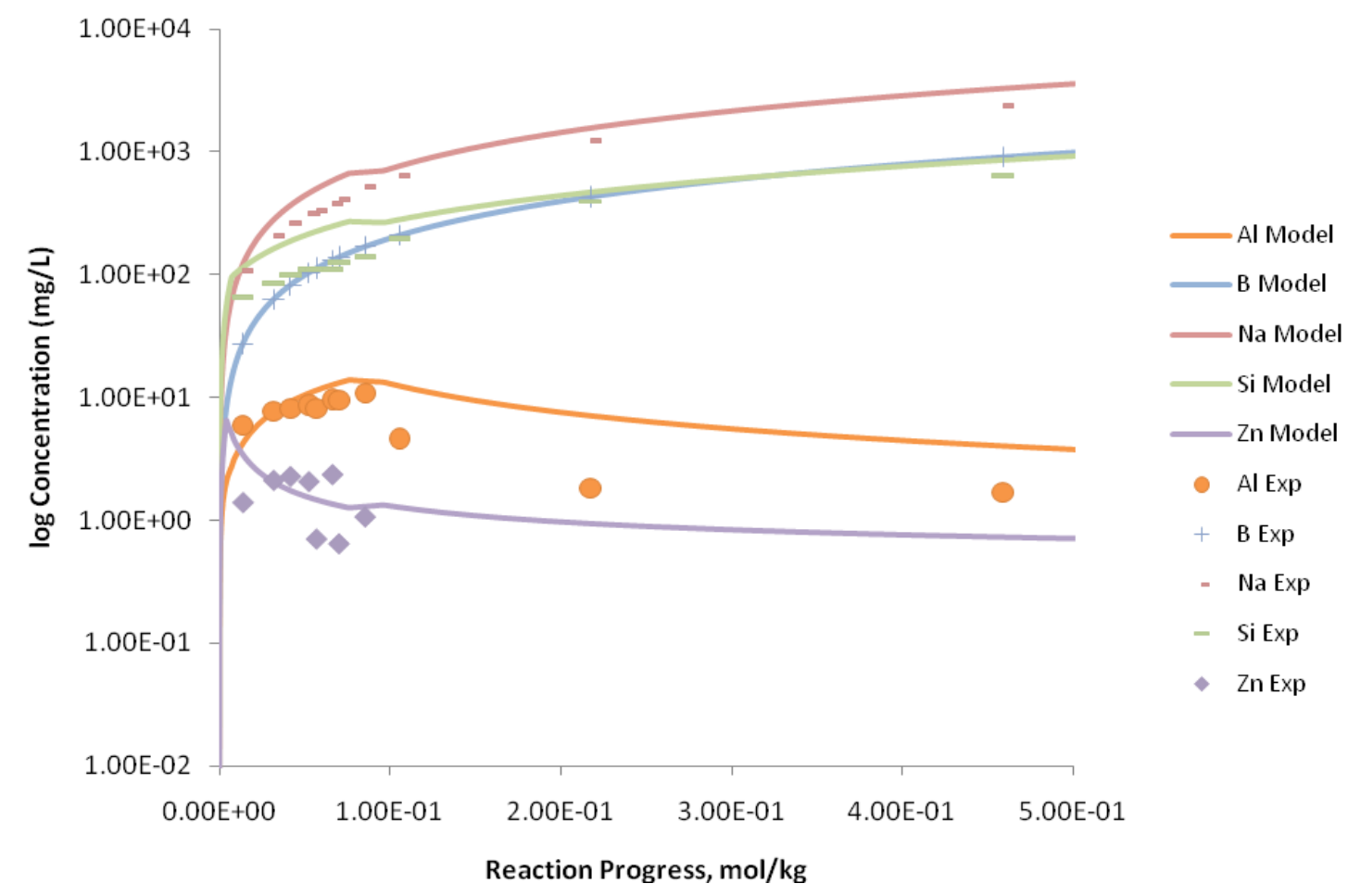

Figure C.371. Measured Solution Concentrations (mg/L) and Model Results for Al, B, Na, Si, and Zn, as a Function of Reaction Progress (mol-glass $/ \mathrm{kg}$ ) Determined for Glass Sample PNLA126CC

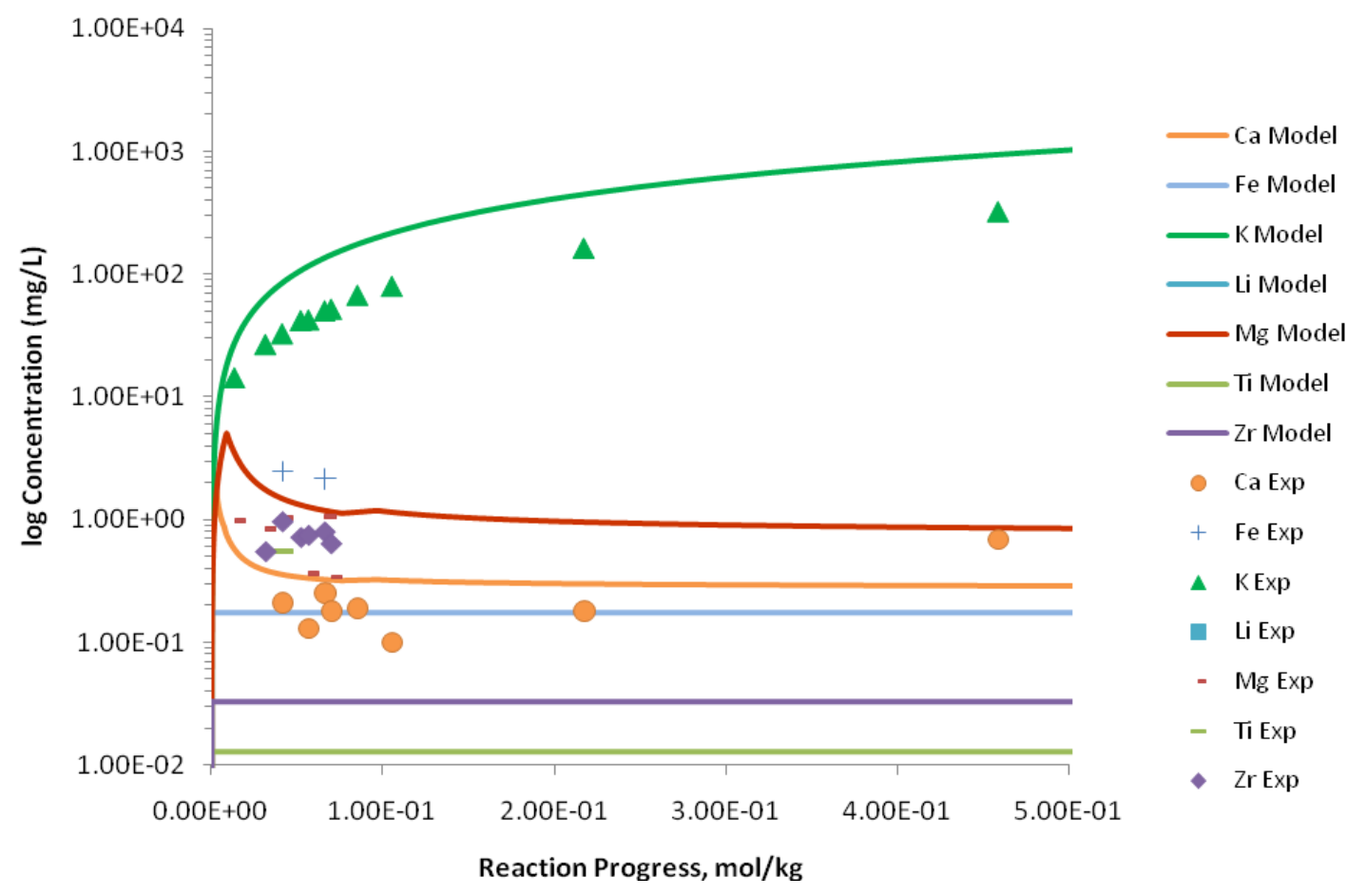

Figure C.372. Measured Solution Concentrations (mg/L) and Model Results for $\mathrm{Ca}, \mathrm{Fe}, \mathrm{K}, \mathrm{Li}, \mathrm{Mg}, \mathrm{Ti}$, and $\mathrm{Zr}$, as a Function of Reaction Progress (mol-glass/kg) Determined for Glass Sample PNLA126CC 


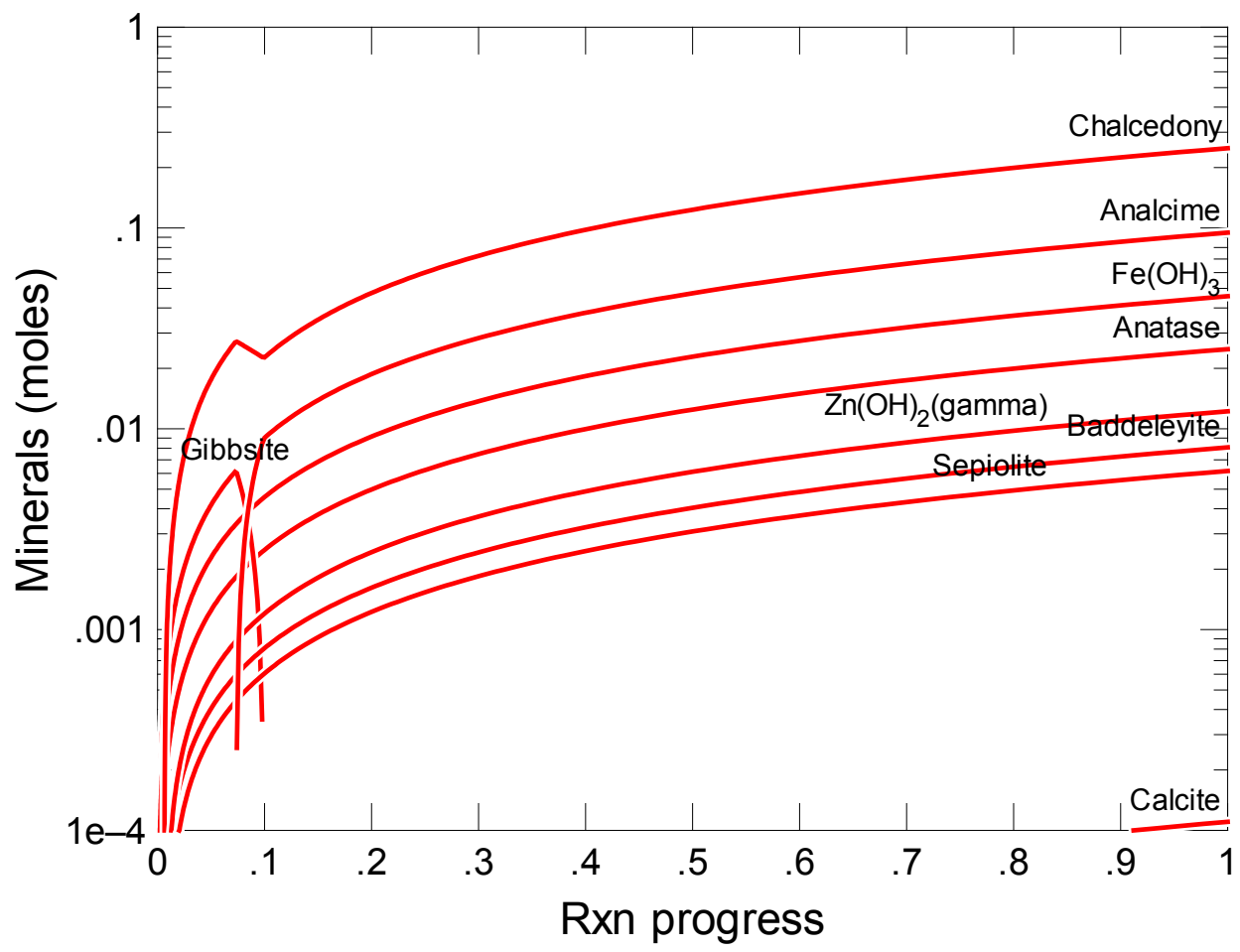

Figure C.373. Secondary Phases Calculated to Form as a Function of Reaction Progress (mol-glass $/ \mathrm{kg}$ ) Determined for Glass Sample TFA-BASE

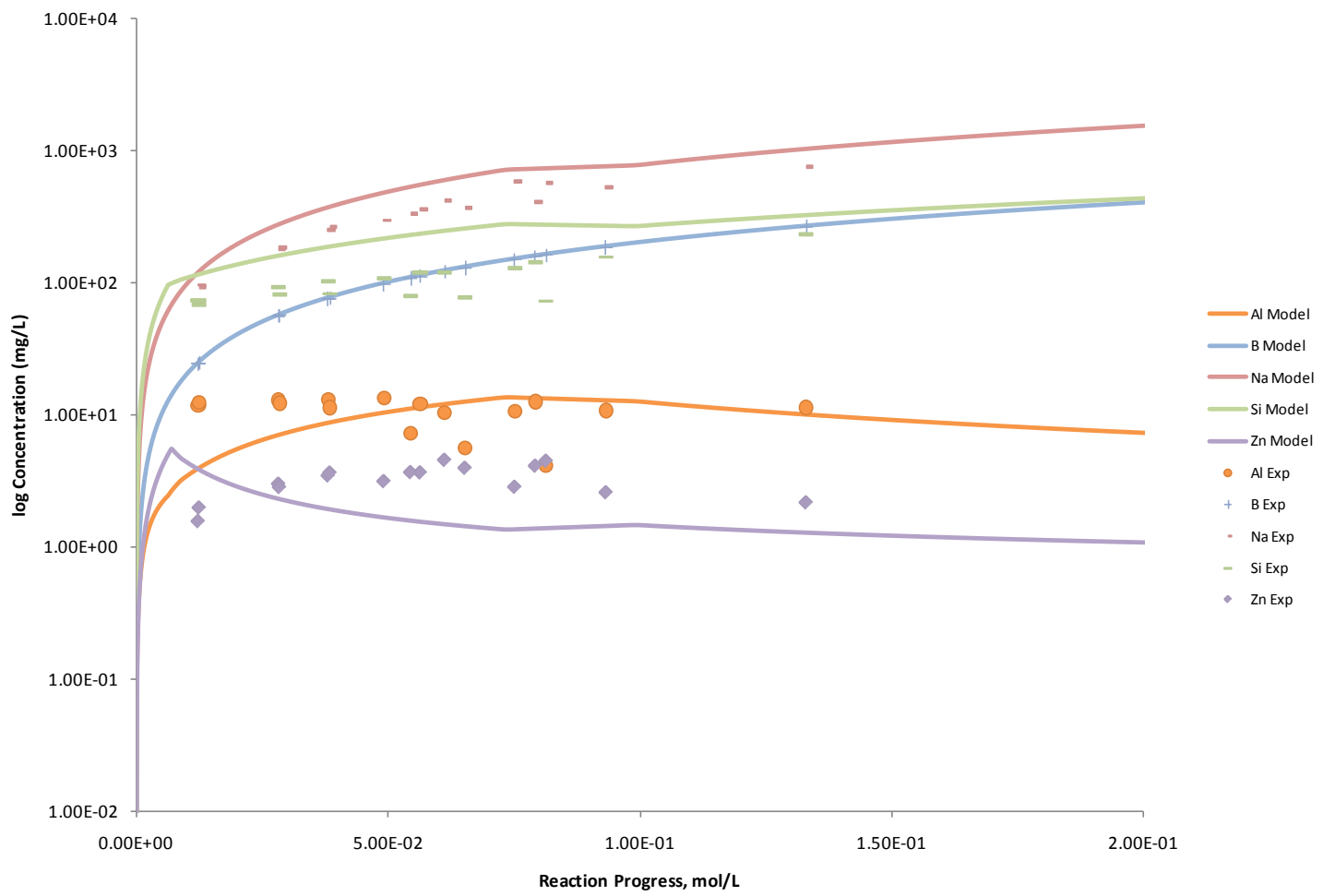

Figure C.374. Measured Solution Concentrations (mg/L) and Model Results for Al, B, Na, Si, and Zn, as a Function of Reaction Progress (mol-glass $/ \mathrm{kg}$ ) Determined for Glass Sample TFA-BASE 


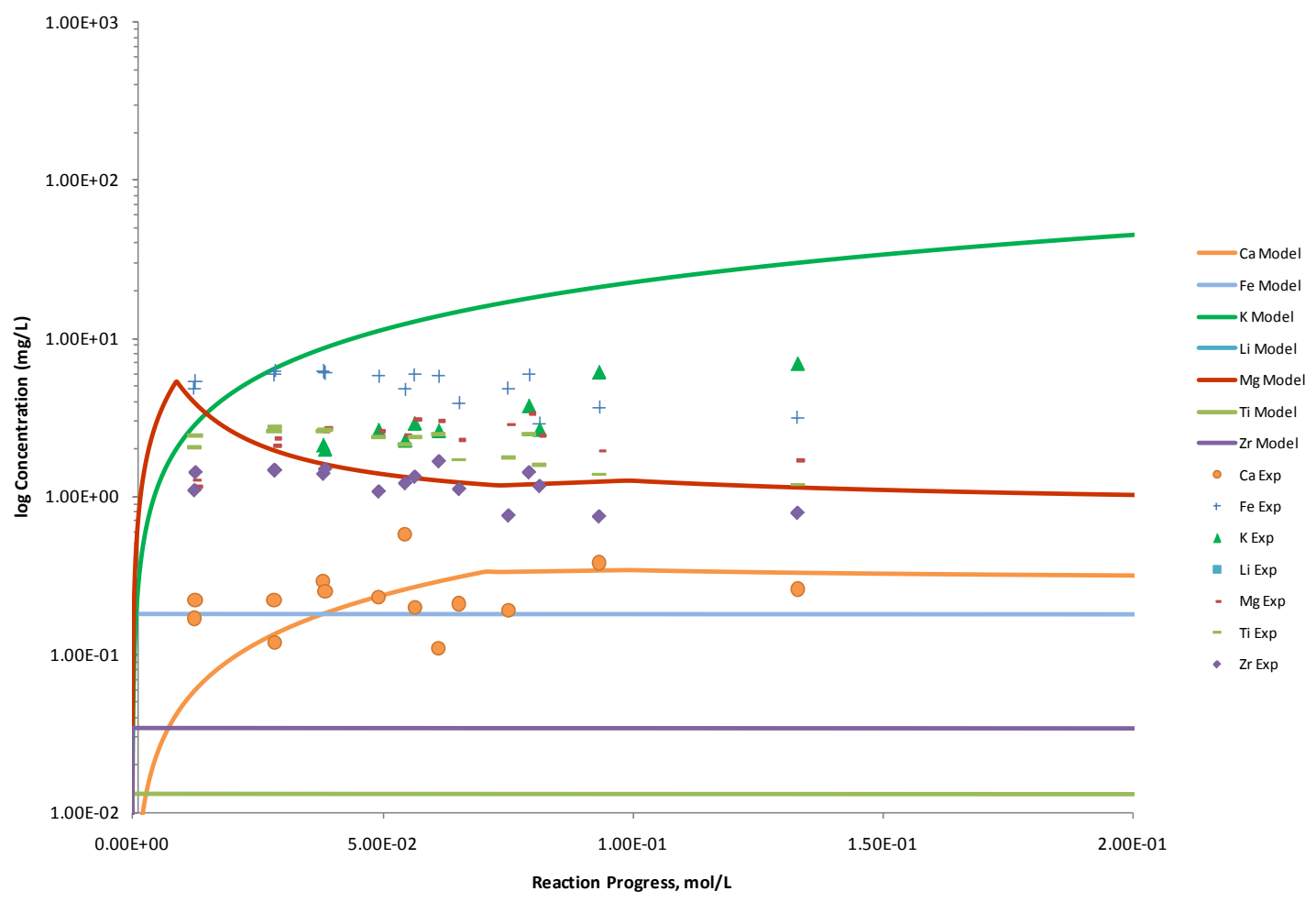

Figure C.375. Measured Solution Concentrations (mg/L) and Model Results for Ca, Fe, K, Li, Mg, Ti, and $\mathrm{Zr}$, as a Function of Reaction Progress (mol-glass/kg) Determined for Glass Sample TFA-BASE

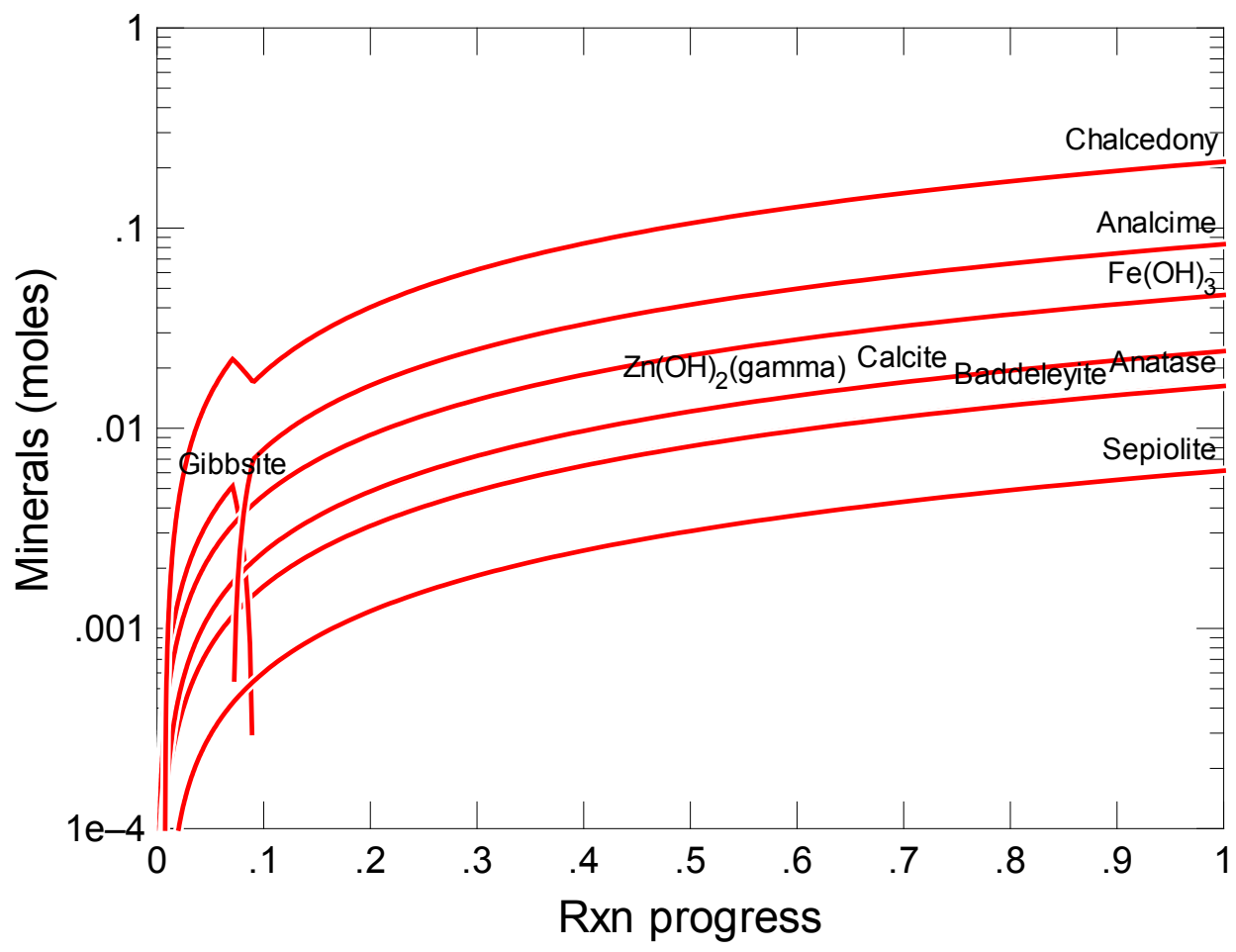

Figure C.376. Secondary Phases Calculated to Form as a Function of Reaction Progress (mol-glass $/ \mathrm{kg}$ ) Determined for Glass Sample WVF-G-21B 


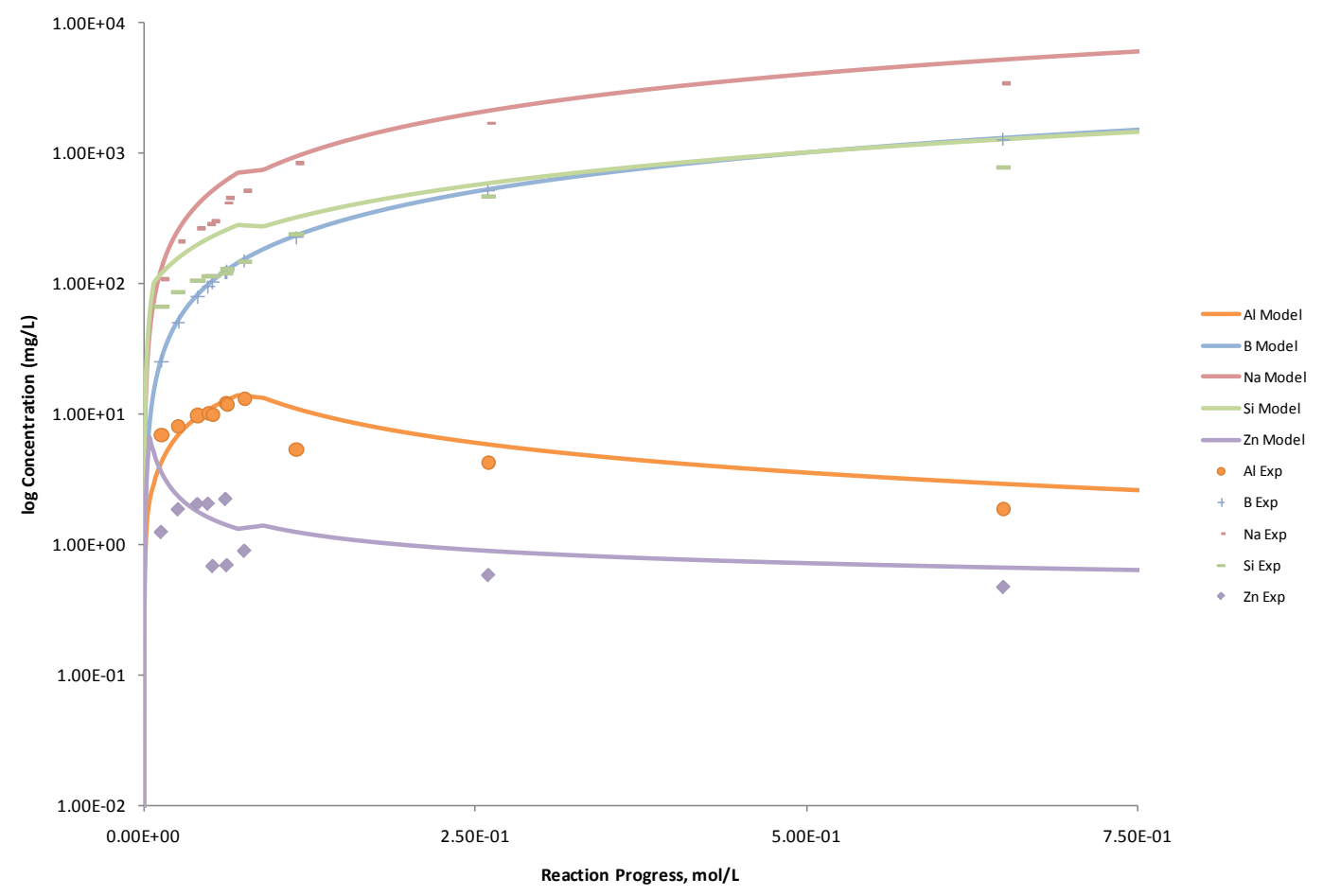

Figure C.377. Measured Solution Concentrations (mg/L) and Model Results for Al, B, Na, Si, and Zn, as a Function of Reaction Progress (mol-glass $/ \mathrm{kg}$ ) Determined for Glass Sample WVF-G-21B

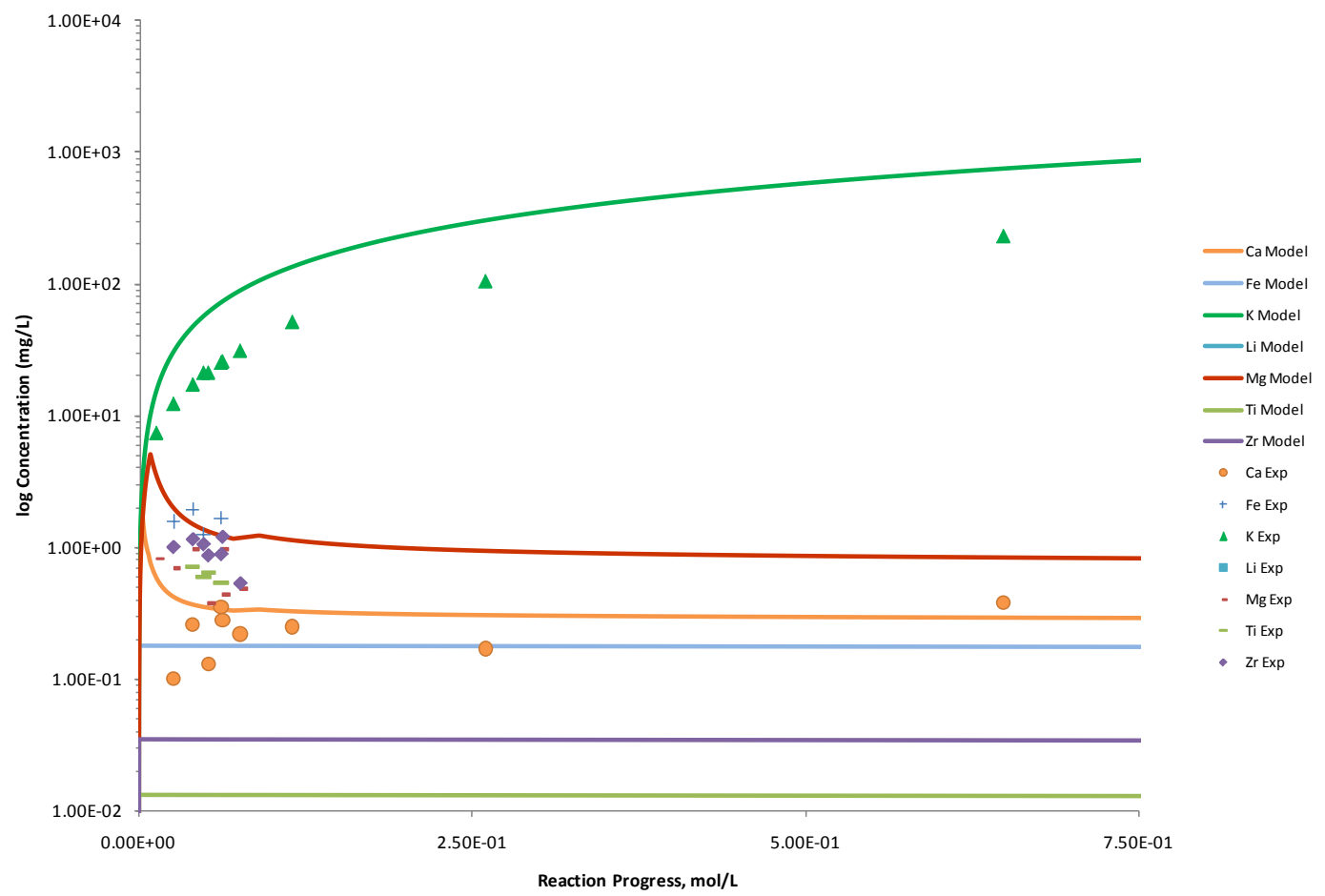

Figure C.378. Measured Solution Concentrations (mg/L) and Model Results for $\mathrm{Ca}, \mathrm{Fe}, \mathrm{K}, \mathrm{Li}, \mathrm{Mg}, \mathrm{Ti}$, and $\mathrm{Zr}$, as a Function of Reaction Progress (mol-glass/kg) Determined for Glass Sample WVF-G-21B 


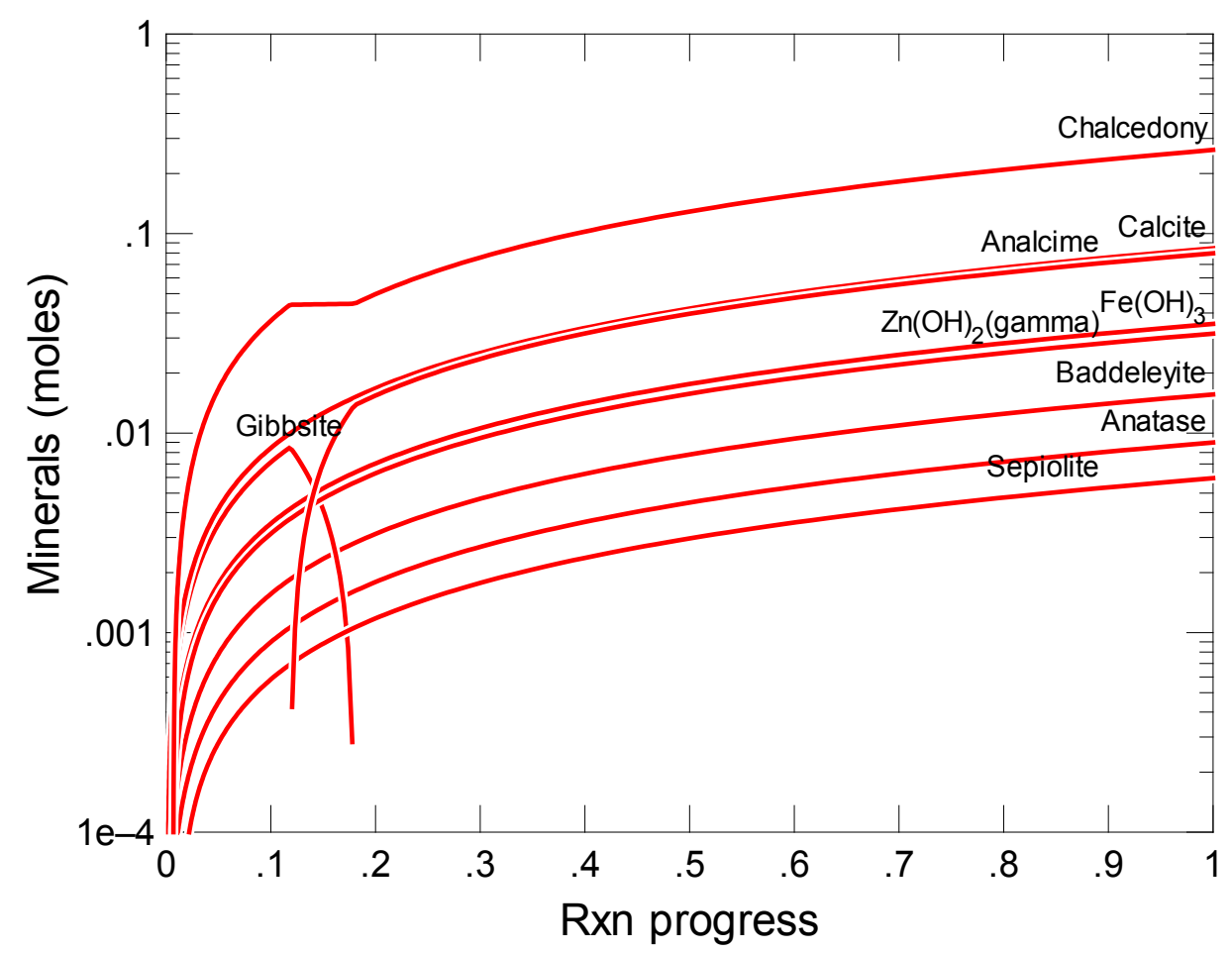

Figure C.379. Secondary Phases Calculated to Form as a Function of Reaction Progress (mol-glass $/ \mathrm{kg}$ ) Determined for Glass Sample WVH-G-57B

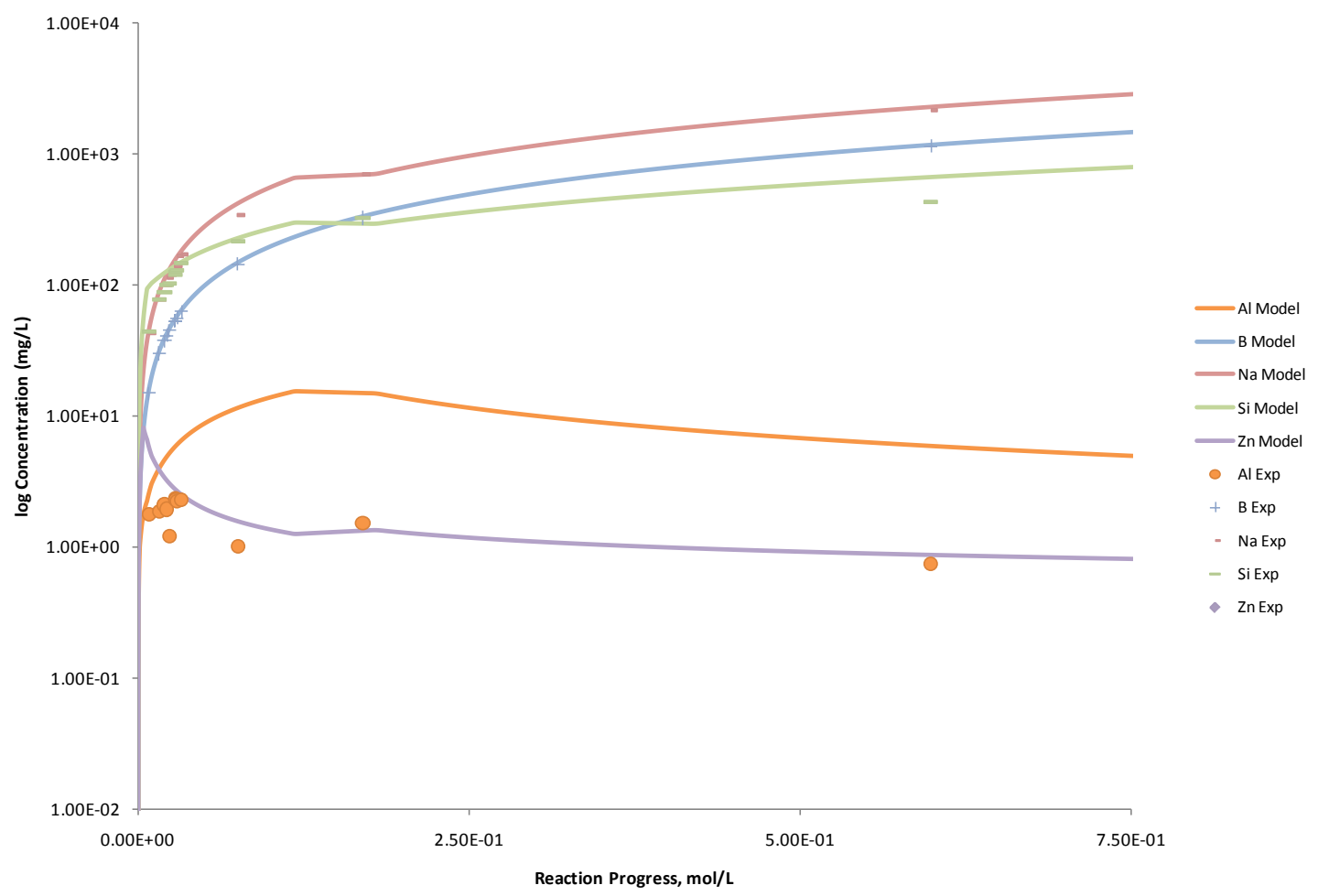

Figure C.380. Measured Solution Concentrations (mg/L) and Model Results for Al, B, Na, Si, and Zn, as a Function of Reaction Progress (mol-glass $/ \mathrm{kg}$ ) Determined for Glass Sample WVH-G-57B 


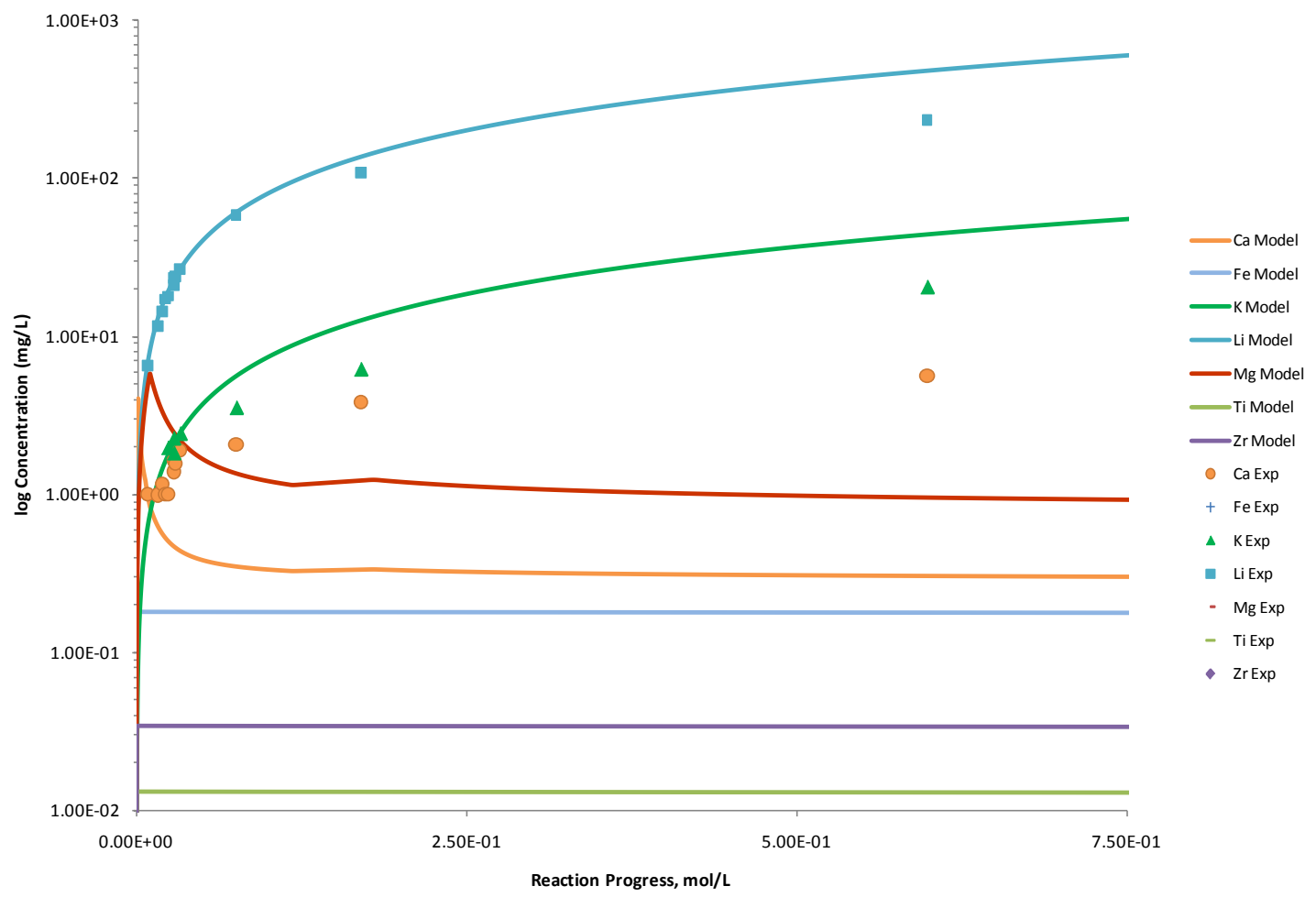

Figure C.381. Measured Solution Concentrations (mg/L) and Model Results for $\mathrm{Ca}, \mathrm{Fe}, \mathrm{K}, \mathrm{Li}, \mathrm{Mg}$, Ti, and $\mathrm{Zr}$, as a Function of Reaction Progress (mol-glass/kg) Determined for Glass Sample WVH-G-57B

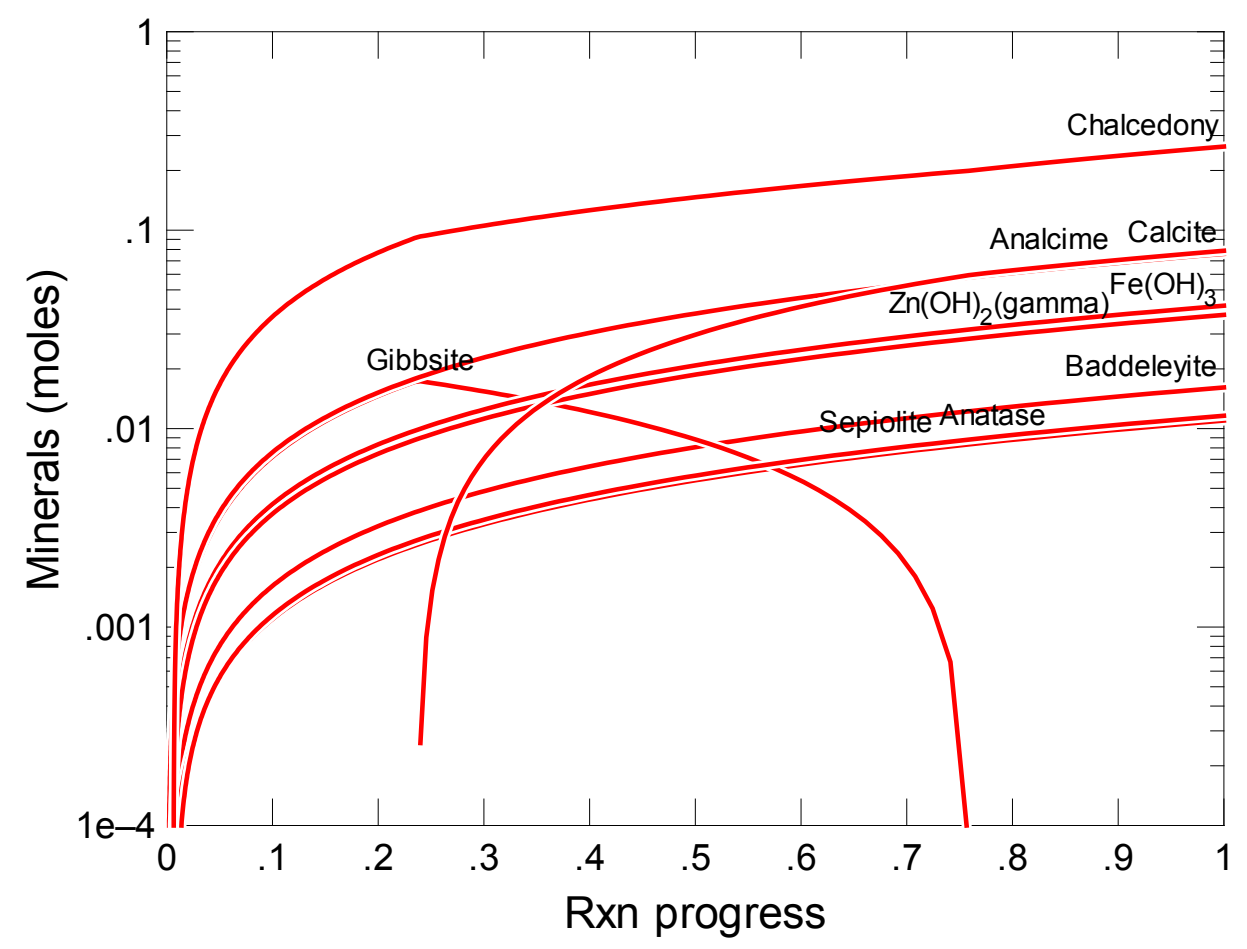

Figure C.382. Secondary Phases Calculated to Form as a Function of Reaction Progress (mol-glass/kg) Determined for Glass Sample WVJ-G-109D 


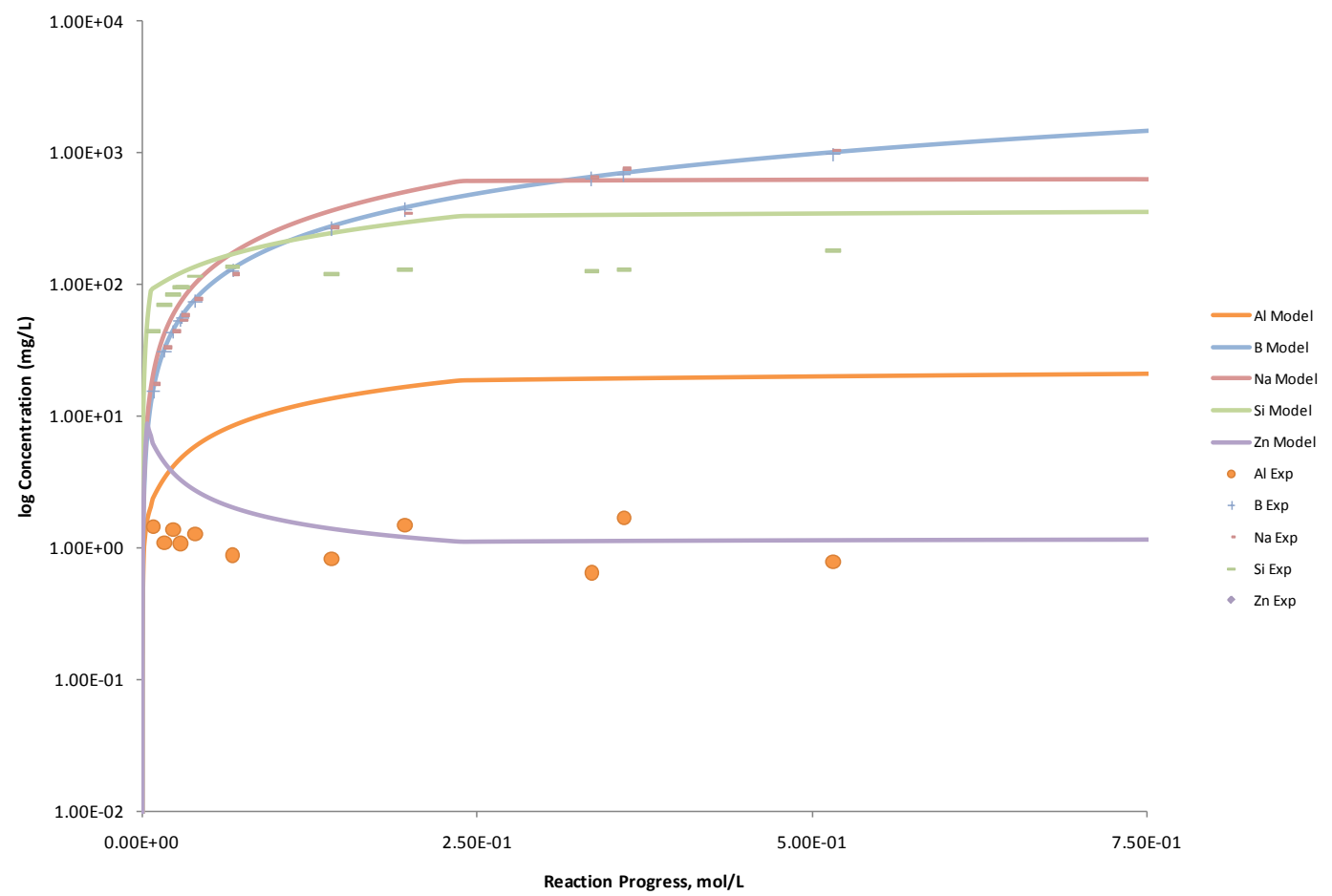

Figure C.383. Measured Solution Concentrations (mg/L) and Model Results for Al, B, Na, Si, and Zn, as a Function of Reaction Progress (mol-glass $/ \mathrm{kg}$ ) Determined for Glass Sample WVJ-G-109D

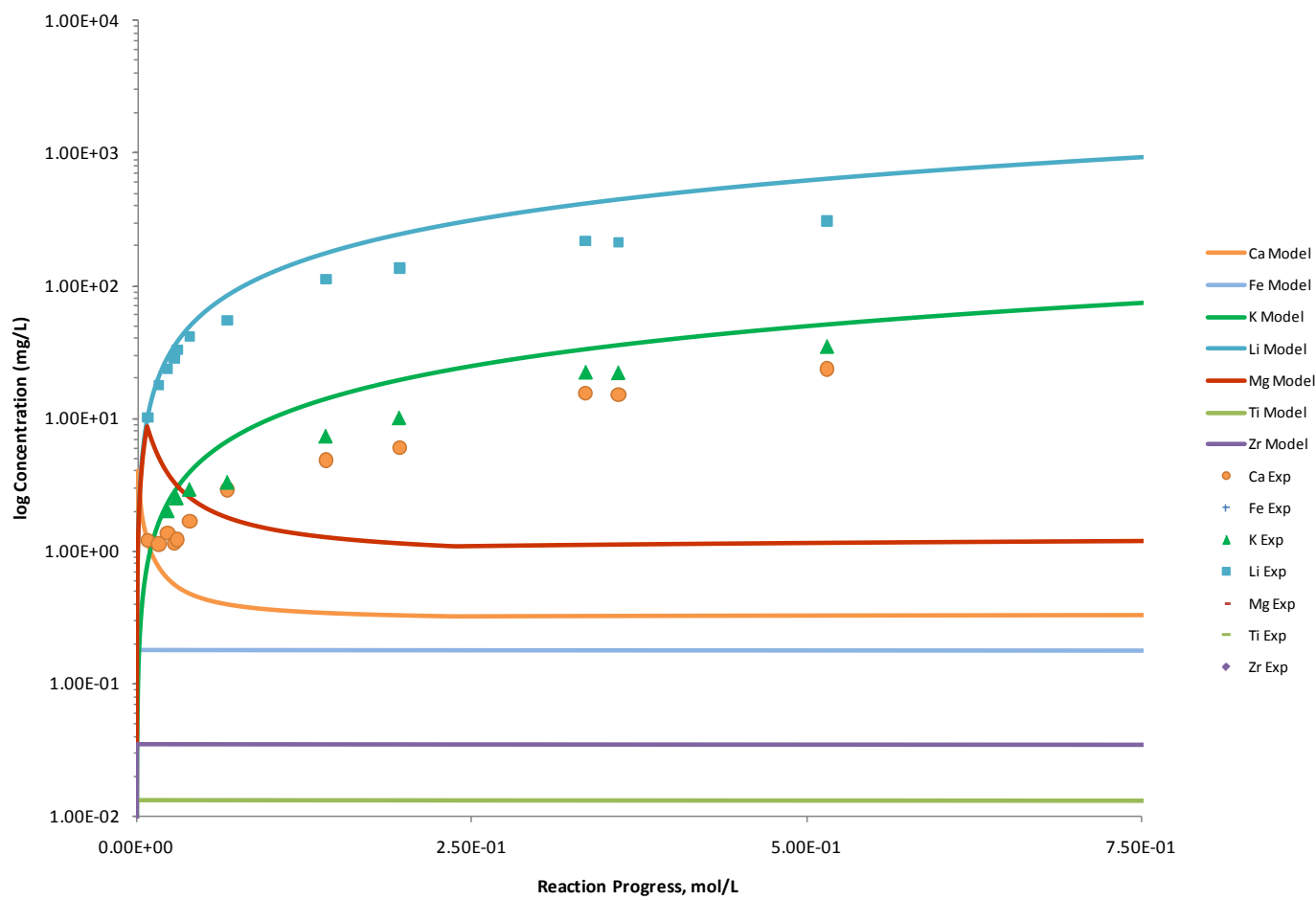

Figure C.384. Measured Solution Concentrations (mg/L) and Model Results for $\mathrm{Ca}, \mathrm{Fe}, \mathrm{K}, \mathrm{Li}, \mathrm{Mg}, \mathrm{Ti}$, and $\mathrm{Zr}$, as a Function of Reaction Progress (mol-glass $/ \mathrm{kg}$ ) Determined for Glass Sample WVJ-G-109D 


\section{Distribution}

No. of

Copies

\section{OFFSITE}

EM Pierce

Building 1505, MS 6038

Oak Ridge National Laboratory

P.O. Box 2008

Oak Ridge, TN 37831-6038

4 Washington River Protection Solutions

MA Melvin

E6-30

WG Ramsey

DJ Swanberg

KE Smith

LE Thompson

E6-30

E6-20
No. of

\section{Copies}

\section{ONSITE}

9 Pacific Northwest National Laboratory

DH Bacon

K9-33

SD Burton

K8-98

KJ Cantrell

K6-81

SN Kerisit

K8-96

SV Mattigod

$\mathrm{K} 3-62$

RJ Serne

K6-81

MM Valenta

K6-81

JH Westsik, Jr.

K7-15

CF Windisch

Distr. 1 



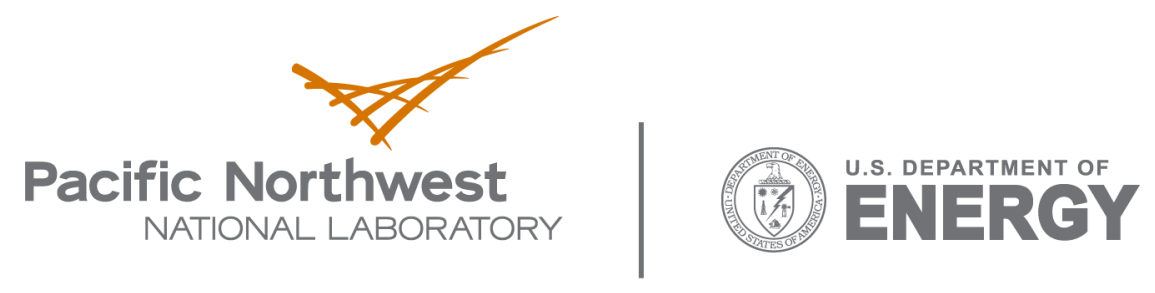

902 Battelle Boulevard

P.O. Box 999

Richland, WA 99352

1-888-375-PNNL (7665)

www.pnl.gov 